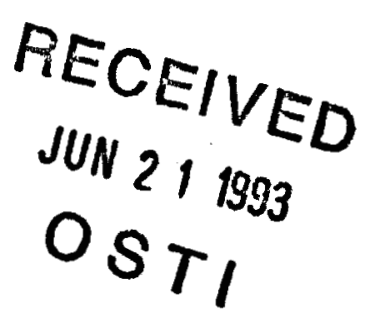

APPENDIX A

GLADYS MCCALL SITE (CAMERON PARISH, LA)

IGT REVIEW OF PAST PRODUCTION DATA AND

FINAL SITE REPORT 


\section{DISCLAIMER}

This report was prepared as an account of work sponsored by an agency of the United States Government. Neither the United States Government nor any agency Thereof, nor any of their employees, makes any warranty, express or implied, or assumes any legal liability or responsibility for the accuracy, completeness, or usefulness of any information, apparatus, product, or process disclosed, or represents that its use would not infringe privately owned rights. Reference herein to any specific commercial product, process, or service by trade name, trademark, manufacturer, or otherwise does not necessarily constitute or imply its endorsement, recommendation, or favoring by the United States Government or any agency thereof. The views and opinions of authors expressed herein do not necessarily state or reflect those of the United States Government or any agency thereof. 


\section{DISCLAIMER}

Portions of this document may be illegible in electronic image products. Images are produced from the best available original document. 


\author{
RESEARCH AND DEVELOPMENT FOR THE \\ GEOPRESSURED-GEOTHERMAL ENERGY PROGRAM
}

\title{
FLOW TESTS OF THE GLADYS MCCALL WELL
}

Final Report for the Period October 1985-October 1990

Prepared by

INSTITUTE OF GAS TECHNOLOGY

for

EATON OPERATING COMPANY

IGT/EOC Subcontract

IGT/EOC-85-4

DOE Prime Contract

DE-AC07-85ID12578

April 1992 
RESEARCH AND DEVELOPMENT FOR THE

GEOPRESSURED-GEOTHERMAL ENERGY PROGRAM

FLOW TESTS OF THE GLADYS MCCALL WELL

Final Report for the Period October 1985-October 1990

Prepared by
P. L. Randolph
C. G. Hayden
L. A. Rogers

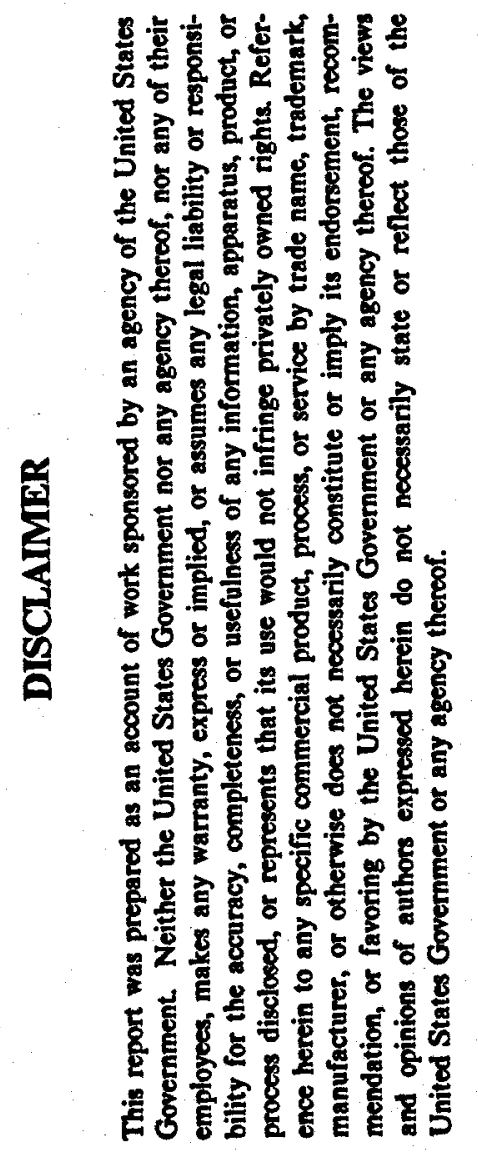

INSTITUTE OF GAS TECHNOLOGY

3424 South State Street

Chicago, Illinois 60616

IGT Project No. 65071

for

EATON OPERATING COMPANY

1240 Blalock

Suite 100

Houston, Texas 77055

IGT/EOC Subcontract

IGT/EOC-85-4

DOE Prime Contract

DE-AC07-85ID12578

April 1992 


\section{EXECUTTVE SUMMARY}

This report pulls together the data from all of the geopressured-geothermal field research conducted at the Gladys McCall well. It includes testing performed by the prior prime contractor, Technadril-Fenix \& Scisson, as well as work performed while the prime contractor was Eaton Operating Company (EOC) with the Institute of Gas Technology (IGT) as a subcontractor.

The U.S. Department of Energy (DOE) Gladys McCall well in Cameron Parish, Louisiana, was drilled in 1981 and subsequently tested as part of the DOE Geopressured-Geothermal Energy Program. The well produced geopressured brine containing dissolved natural gas from the Lower Miocene sands at a depth of 15,150 to 16,650 feet. More than 25 million barrels of brine and 727 million standard cubic feet of natural gas were produced in a series of flow tests between December 1982 and October 1987 at various brine flow rates up to 28,000 barrels per day. The well is now (1990) in a multiyear long-term pressure-buildup test.

Initial short-term flow tests for the Number 9 Sand found the permeability to be 67 to $85 \mathrm{md}$ (millidarcies) for a brine volume of $\mathbf{8 5}$ to $\mathbf{1 7 0}$ million barrels. Initial short-term flow tests for the Number 8 Sand found a permeability of 113 to $132 \mathrm{md}$ for a reservoir volume of 430 to 550 million barrels of brine. The long-term flow and buildup test of the Number 8 Sand found that the high-permeability reservoir connected to the wellbore (measured by the short-term flow test) was connected to a much larger, low-permeability reservoir. Numerical simulation of the flow and buildup tests required this large connected reservoir to have a volume of about 8 billion barrels (two cubic miles of reservoir rock) with effective permeabilities in the range of 0.2 to $20 \mathrm{md}$. Detailed chemical analysis of the brine and gas found the brine to be slightly undersaturated with gas at about 29 SCF/STB (standard cubic feet/stock tank barrel). The produced gas/brine ratio was invariant with production time and flow rate.

Calcium carbonate scale formation in the well tubing and separator equipment was a problem. During the first 2 years of production, scale formation was prevented in the surface equipment by injection of an inhibitor upstream of the choke. But scale had to be periodically removed from the production tubing with hydrochloric acid or prevented by limiting the flow rate to less than 15,000 barrels per day. Starting in 1985 , scale formation in the production tubing was successfully prevented by injecting inhibitor "pills" directly into the reservoir.

Corrosion and/or erosion of surface piping and equipment, as well as disposal well tubing, was also significant. The biggest problem was in high-turbulance areas immediately downstream of chokes or separator level control valves. Choke life was greatly extended by cladding the tailpiece with stainless steel. Piping in turbulent areas downstream of the separators was replaced. 


\section{TABLE OF CONTENTS}

Page

1.0. INTRODUCTION 1

2.0. SUMMARY OF GEOLOGY 1

3.0. SUMMARY OF DRILLING 6

4.0. SURFACE TEST EQUIPMENT AND FACILITIES $\quad 10$

5.0. SAND 9 TESTING 13

$\begin{array}{ll}\text { 5.1. Sand } 9 \text { Initial Production } & 13\end{array}$

5.2. Sand 9 Gas and Brine Recombination Study and Gas Saturation 14

5.3. Sand 9 Reservoir Limit Test 15

6.0. SAND 8 TESTING 19

6.1. Sand 8 Short-Term Reservoir Limit Tests 19

6.2. Sand 8 Long-Term Production 23

6.3. Sand 8 Long-Term Reservoir Test Data Interpretation 26

6.3.1. Reservoir Simulation 26

6.3.2. Use of Horner Plot to Estimate Reservoir Size 29

6.4. Change in Sand 8 Reservoir Transmissibility 33

6.4.1. Possible Reasons for Lower Transmissibility 35

6.4.2. August 27, 1987, Spinner Survey 37

7.0. CHARACTERISTICS OF HYDROCARBONS PRODUCED
FROM SAND 8

7.1. Produced Gas Composition 41

$\begin{array}{ll}\text { 7.1.1. Separator Studies } & 42\end{array}$

7.1.2. Correcting Gas Production Rates for Gas Remaining
in the Brine After the Separator

7.1.3. Field Measurements of Hydrogen Sulfide and Carbon Dioxide 49

7.1.4. Total Produced Gas Composition 51

7.2. Characteristics of Produced Liquid Hydrocarbons 51

8.0. GAS SATURATION OF RESERVOIR BRINE RELATIVE TO
THE BUBBLE POINT

8.1. Sand 8 Gas and Brine Recombination Studies $\quad 57$

$\mathbf{V}$

I N S T I T U T E OF G A S T E C H N O L O G Y 
TABLE OF CONTENTS, Cont.

Page

8.2. Changes in Composition of the Produced Gas 60

8.2.1. Variation in the Produced Gas/Brine Ratio Due to Bottomhole Pressure

8.2.2. "Bubble Test" for Free Gas Adjacent to the Wellbore 65

9.0. PRODUCED BRINE CHARACTERISTICS 67

9.1. Iron Concentration Change With Flow Rate 67

9.2. Questionable Change in Barium Concentration With Time 71

9.3. Other Changes in Concentrations 72

10.0. CHARACTERISTICS OF SUSPENDED SOLIDS 73

10.1. Filter Element Usage 73

10.2. Total Suspended Solids in the Brine 74

10.3. Relative Plugging Index 75

11.0. SCALE INHIBITION

12.0. CORROSION 82

12.1. Corrosion in the Production Well 82

12.2. Corrosion of Surface Piping 84

12.2.1. Corrosion Coupon Data 84

12.2.2. Direct Observations of Corrosion 85

13.0. CONCLUSIONS 87

14.0. RECOMMENDATIONS 88

15.0. ACKNOWLEDGMENTS 90

16.0. REFERENCES CITED $\quad 90$

APPENDIX A: Compositional Analysis of Core by Core Laboratories, Inc. A-1

APPENDIX B: PVT Analysis for Sand 9 by Weatherly Laboratories, Inc. B-1

APPENDIX C: Sand 8 Daily Production Data C-1

APPENDIX D: Sand 8 Graphical Production Data D-1

APPENDIX E: Sand 8 Gas Rate Measurements $\quad$ E-1

vi

$\begin{array}{lllllllllllllllllll}\text { I N S T I T U T E } & \text { O F } & \text { G A S } & \text { T E C H N } & \text { O L } & \text { O } & G & Y\end{array}$ 


\section{TABLE OF CONTENTS, Cont.}

Page

APPENDIX F: Long-Term Horner Plot

APPENDIX G: Gas Sampling and Analysis

G-1

APPENDIX H: Calculation of Total Produced Gas

H-1

APPENDIX I: Liquid Hydrocarbon Production

APPENDIX J: PVT Analysis for Sand 8 by Weatherly Laboratories, Inc.

APPENDIX K: Reservoir Bubble Tests

$\mathrm{K}-1$

APPENDIX L: Procedures Manual for Geopressured Fluids

APPENDIX M: Sand 8 Brine Analyses by Rice University

M-1

APPENDIX N: Corrosion Coupon Data

$\mathrm{N}-1$

vii 



\section{LIST OF EXHIBITS}

Exhibit No.

Page

1.0-1 Location of the DOE Gladys McCall Well in Cameron Parish, Louisiana

2.0-1 Structure Map Showing Major Growth Faults in the Area of the Gladys McCall Well

2.0-2 Schematic Diagram Showing the Mechanism for Formation of the Sand and Shale Sections in the Area of the Gladys McCall Well

2.0-3 Portion of Wireline Log for the Gladys McCall Well Showing Potential Production Zones

2.0-4 Subsurface Temperatures in the Area of the Gladys McCall Well 7

3.0-1 Schematic Diagram of Gladys McCall No. 1 Production Well Completion

3.0-2 Schematic Diagram of the Gladys McCall Salt Water Disposal Well No. 1 Completion

4.0-1 Schematic Diagram of the Gladys McCall Well Surface Gas/Brine Processing Facilities

5.1-1 Analysis of Brine From Gladys McCall No. 9 Sand 13

$\begin{array}{lll}\text { 5.1-2 Gas Chromatographic Analysis } & 14\end{array}$

5.2-1 Analysis of Gas Flashed From Separator Brine on March 23, 1983, Separator at 700 psia

5.3-1 Analysis of Sand 9 Draw-Down Test by Clark

5.3-2 Match of Data With Numerical Model by Dowdle, Fairchild \& Ancell, Inc.

5.3-3 Grid Structure of Numerical Model by Scientific SoftwareIntercomp

5.3-4 Layers in Numerical Model by Scientific Software-Intercomp

5.3-5 Match of Data to Numerical Model by Scientific SoftwareIntercomp

6.2-1 Sand 8 Long-Term Test Brine Production

6.2-2 Sand 8 Long-Term Test Gas Production

6.2-3 Sand 8 Gas/Brine Ratio From Production Data 27

6.2-4 Sand 8 Cumulative Gas Versus Brine Production 28 


\section{LIST OF EXHIBITS, Cont.}

Exhibit No.

Page

6.3.1-1 Schematic Diagram of the Grid for the Numerical Model Used by S-Cubed to Model Data

6.3.1-2 Simulated Sandface Pressures Compared to Values Estimated From Flowing Wellhead Pressures

6.3.1-3 Simulated Pressure Buildup Compared to Actual Buildup

6.3.2-1 Horner Plot of Sand 8 Long-Term Buildup Test 34

6.4-1 Change in Transmissibility 35

6.4.2-1 Spinner Logging Down Through the Packer at $65 \mathrm{ft} / \mathrm{min} \quad 38$

6.4.2-2 Spinner Logging Down Across Perforations at 140 and $200 \mathrm{ft} / \mathrm{min}$

7.1-1 Typical Gas Analyses, February 19, $1987 \quad 42$

7.1-2 Gas Analysis of McCall Sales Gas by GC/TCD/FID, October 21, 1987

7.1.1-1 Sales Gas Carbon Dioxide Concentration Versus Second-Stage Separator Pressure

7.1.1-2 Gas Remaining in Brine After the Separator 45

7.1.1-3 Heating Value of Gas Remaining in Brine Leaving the Separator 46

7.1.2-1 Gas Left in Brine Versus Separator Pressure 47

7.1.2-2 Methane Left in Brine Versus Methane Partial Pressure 47

7.1.2-3 Ethane Left in Brine Versus Ethane Partial Pressure 48

7.1.3-1 Field Measurements of Carbon Dioxide in Separators . 49

7.1.3-2 Field Measurements of Hydrogen Sulfide in Separators 50

7.1.3-3 Carbon Dioxide and Hydrogen Sulfide Concentrations in
Sales Gas

7.1.4-1 Gas/Brine Ratio From Recombination Study 52

7.1.4-2 Carbon Dioxide Content of Total Gas 52

7.1.4-3 Ethane Content of Total Gas 53

7.2-1 Cryocondensate Concentrations $\quad 54$ 


\section{LIST OF EXHIBITS, Cont.}

Exhibit No.

Page

7.2-2 Heavy Oil Production and Condensed Hydrocarbon Recovery Versus Cumulative Brine Production

7.2-3 Representative Chromatograms of Recovered Oils 56

8.1-1 Weatherly PVT Recombination Data 58

8.1-2 Graph of PVT Recombination Data and Calculated Methane Solubility

8.2-1 Sand 8 Gas Differential Liberation Data 61

8.2-2 Sand 9 Gas Differential Liberation Data 61

8.2-3 Ethane/Methane and Propane/Methane Ratios in Total Produced Gas

8.2-4 Ethane/Methane and Propane/Methane Ratios in First-Stage Separator Gas

8.2.1-1 Sand 8 Calculated Bottomhole Pressure 66

9.0-1 Sand 8 Brine Composition 68

9.1-1 Iron Concentration Versus Flow Rate 70

9.1-2 Iron Concentration Versus 1/Brine Rate 71

9.3-1 Water Loss From Brine Samples Due to Vaporization 72

10.0-1 Filter-Pot Usage Versus Produced Brine 74

10.2-1 Suspended-Solids Concentration After Separators 75

10.2-2 Suspended Solids at Outlet of Low-Pressure Separator,
October 20-21, 1987

10.3-1 Data From Brine-Filtering Test 76

10.3-2 Plot of Data for Relative Plugging Index (RPI) 77

11.0-1 Acid Treatments to Remove Wellbore Scale 78

11.0-2 Formation of Calcium Carbonate Scale in Wellbore
With Production

12.2.1-1 Overview of Corrosion Coupon Data 85 
FLow TESTS OF THE GLAdys MCCALL Well Through OCTOBER 1990

\section{FLOW TESTS OF THE GLADYS MCCALL WELL THROUGH OCTOBER 1990}

\subsection{INTRODUCTION}

The Gladys McCall well is one of the Design Wells tested in the Department of Energy's (DOE) Geopressured-Geothermal Energy Program. The objective of the program is to evaluate the geopressured-geothermal resource as a possible source of energy for the nation. The Gulf Coast geopressured-geothermal wells, such as the McCall well, produce hot brine and the hydrocarbons dissolved in the brine. The possible energy sources from these wells consist of the heat, pressure, and recoverable hydrocarbons. The McCall test focused on evaluating the reservoir response to production, mitigating operating problems such as scale formation, and determining the quantity and characteristics of the recoverable hydrocarbons.

This report focuses on the data obtained from the well-test program and the analysis of the data as performed by several organizations. The intent is to provide a summary of physical and chemical mechanisms involved in the testing of the Gladys McCall well and to provide information that may be useful for future production of other geopressured-geothermal wells. A report covering the test program from 1982 to 1985 was previously prepared by Technadril-Fenix \& Scisson when they were the site operator. 17,18 This previous report sets forth the program objectives and describes the well drilling and facilities installation in detail; therefore these items are only briefly summarized in this report.

Exhibit 1.0-1 shows the location of the Gladys McCall well in southwestern Louisiana. The site is in the coastal marsh about 3 miles southeast of Grand Chenier, Cameron Parish, Louisiana. Access to the location is via a gravel road on a levee that intersects Highway 82 just past mile marker 68. The site is about 2 miles south of Highway 82 at the end of a gravel road on a pad of approximately 4 acres. The pad is comprised of shell fill (more than 1000 yards) and boards to elevate the pad surface above the water level of the marsh.

\subsection{SUMMARY OF GEOLOGY}

The geology of the site and surrounding area was originally described in terms of the Geopressured-Geothermal Program by Bebout and others connected with the Louisiana Geologic Survey. 1,10 The most recent summary, which brings together the work of the previous authors and adds the latest information, was prepared by C. J. John. 8

Exhibit 2.0-1 shows a geologic structure map contoured at the top of the " $\mathrm{A}$ " sand in the prospect area. Exhibit 2.0-2 shows the figure presented by C. J. John that illustrates his interpretation that the reservoir was originally created from ancient rivers in meander channels. 
Flow Tests of the Gladys McCall Well Through October 1990

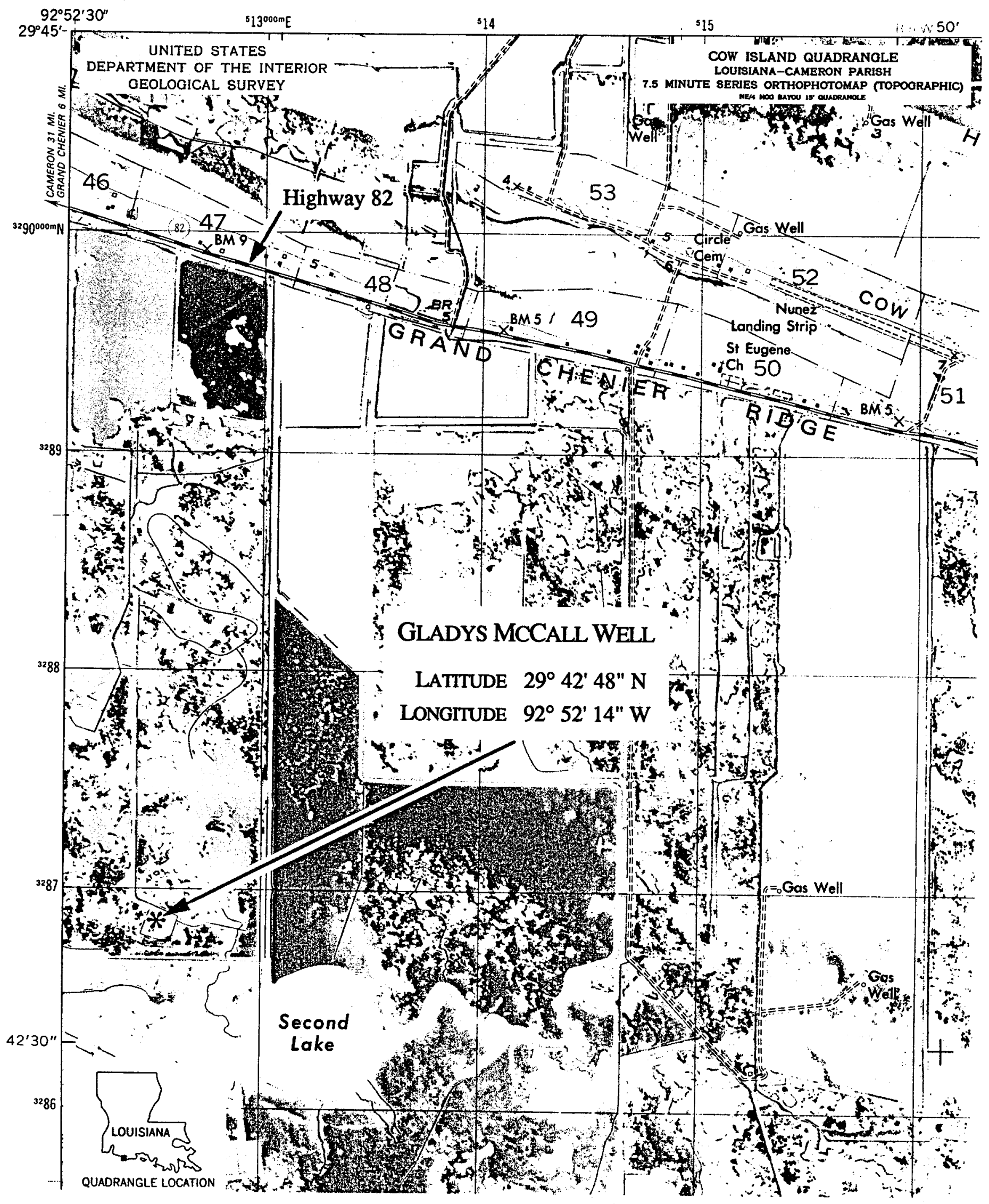

Exhibit 1.0-1. LOCATION OF THE DOE GLADYS McCALL WELL IN CAMERON PARISH, LOUISIANA 


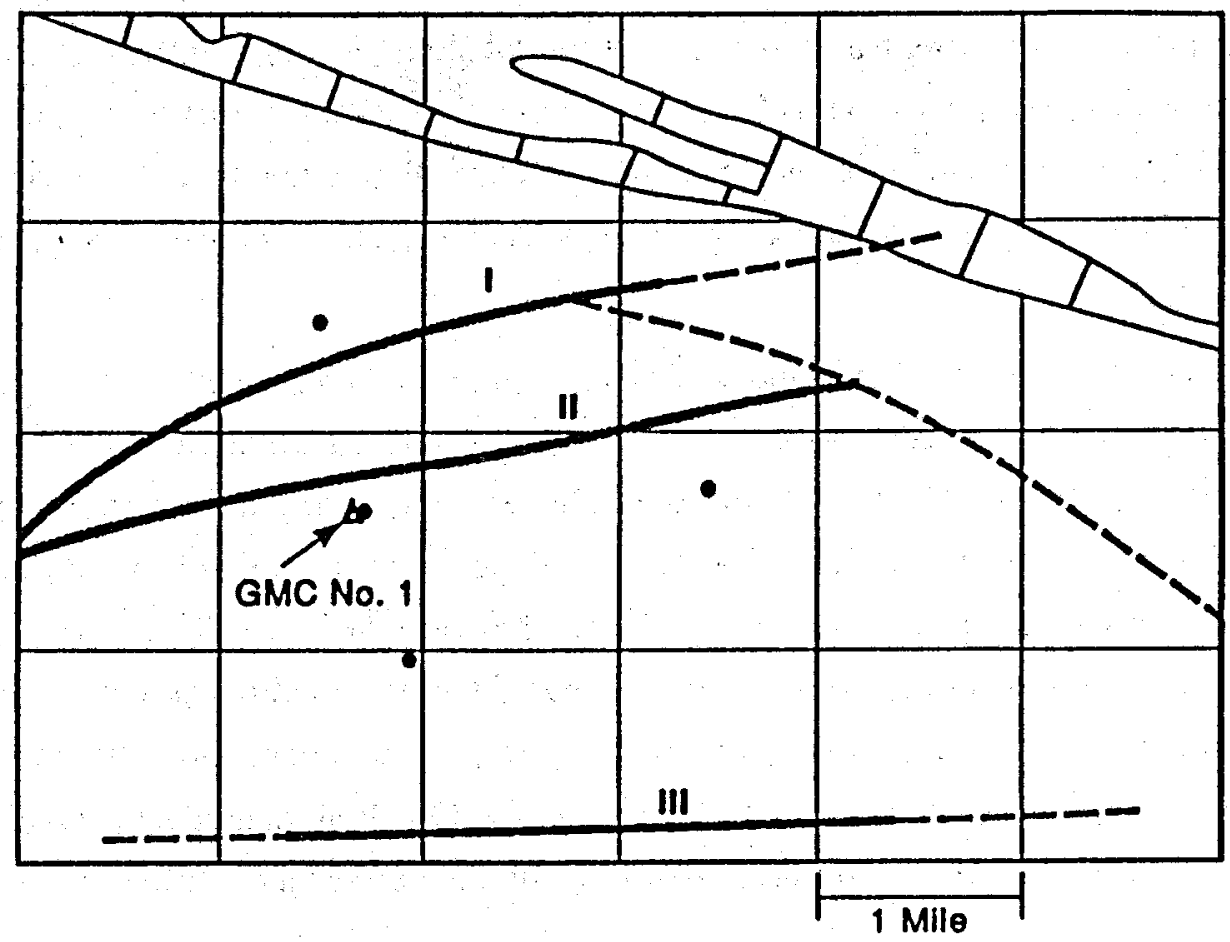

Exhibit 2.0-1. STRUCTURE MAP SHOWING MAJOR GROWTH FAULTS IN THE AREA OF THE GLADYS MCCALL WELL

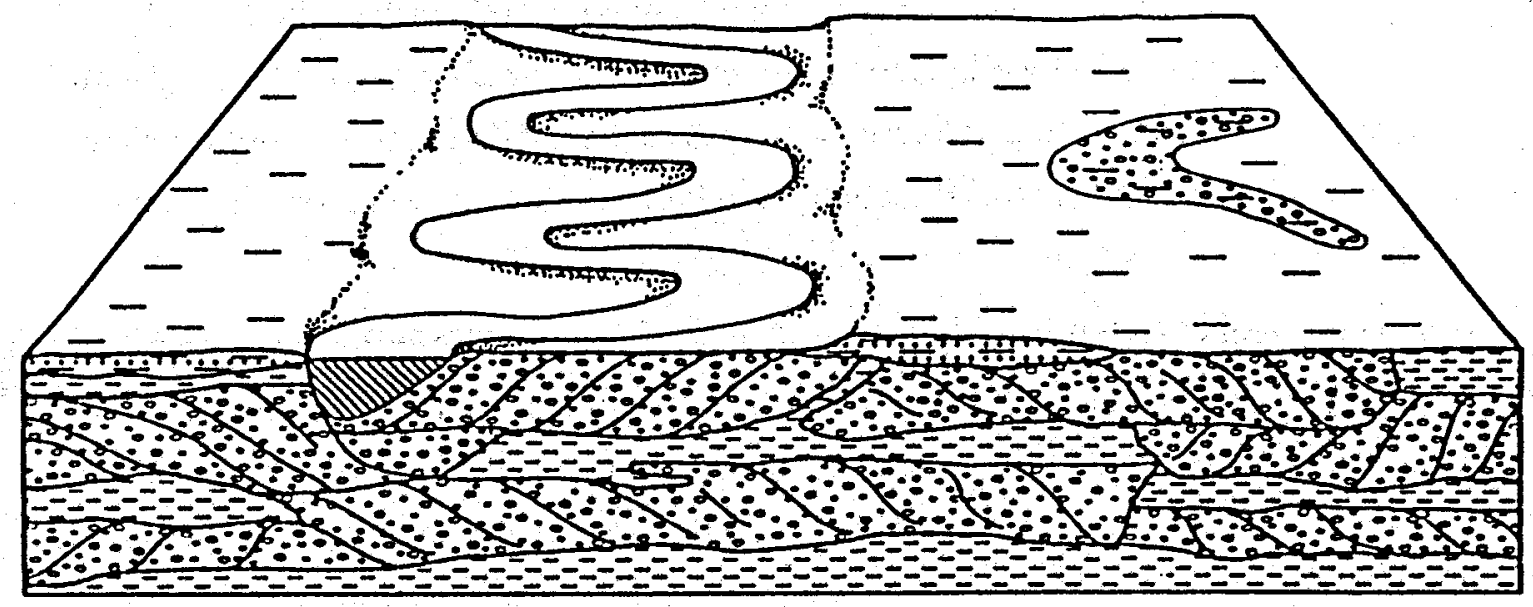

\section{$\because \because$ CHANNEL AND POINT BAR SANDS \\ E=:=-7 SHALES \\ \% \\ LEVEE AND SILTSTONES AND CLAY}

Exhibit 2.0-2. SCHEMATIC DIAGRAM SHOWING THE MECHANISM FOR FORMATION OF THE SAND AND SHALE SECTIONS IN THE AREA OF THE GLADYS MCCALL WELL 
The weight of the depositions over time causes the system to subside but continue to grow vertically as additional sediments are deposited over the subsiding layers. Because the reservoir rock consists of shales interspersed with channel and point bar sands, it is difficult to tell from the wireline logs which sands are interconnected. John speculates that, even though the wireline electric logs show the sands to be separate, they may behave as an interconnected single sand body for brine production.

Below 11,000 feet the shale and sand sections are quite massive. Exhibit 2.0-3 shows eleven potentially brine-productive zones below the top of geopressure at about 14,500 feet. The wireline log indicates almost 1100 feet of net sand. The reservoir is structurally controlled by major growth faults that are subparallel to the Gulf of Mexico. Starting inland and moving toward the Gulf, the fault blocks are successively down-dropped toward the coast. The growth faults are generally near-vertical at the surface, but then curve toward the coast and become sub-horizontal at great depths. The down-dropping of the fault block also rotates the block, and at the McCall site the target sands dip northward at angles of 10 to 30 degrees. One fault that cuts the Gladys McCall well at 16,350 feet may be a sealing or partial sealing fault that defines the northern boundary of the reservoir.

The exact geologic structure of the reservoir is not well defined because of the sparseness of other wells in the area drilled deep enough to correlate with the McCall well. One correlation in the approximate north-south direction, however, was done using one well north of the McCall well and two wells south of the McCall well. Good correlation of the sands was found, along with some missing sections due to faulting. Correlation in the east-west direction was not possible because of the lack of other wells in this direction. The faults in the area were located primarily by use of available seismic prospect data.

The available geological information is insufficient to accurately describe the reservoir size or shape. From the general structure of the area where the growth faults tend to be subparallel to the Gulf of Mexico, it is suspected that the reservoir would be comprised of the sandstone sections trapped between east-west trending faults. This would possibly render the reservoir shorter in the north-south direction and longer in the east-west direction, if the faults were sealing.

Whole cores were cut in the intervals from 15,167 to 15179 feet, 15,179 to 15,198 feet, and 15,348 to 15,375 feet. Twenty-eight sidewall core samples were obtained in the interval from 14,570 to 16,455 feet. The analysis of the core samples by Core Laboratories, Inc., 6 (shown in Appendix A) found the reservoir sandstones to be a very fine-grained composition of about $90 \%$ to 94\% quartz, $5 \%$ to $7 \%$ feldspar, with the remainder being minor amounts of clay, calcite, and other minerals. The studies were made using petrographic thin sections, X-ray diffraction, and 
PRODUCTION ZONE NUHBER

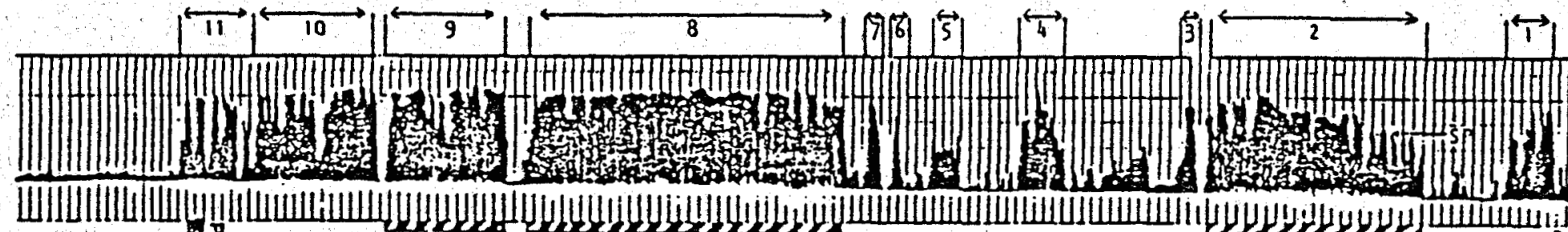

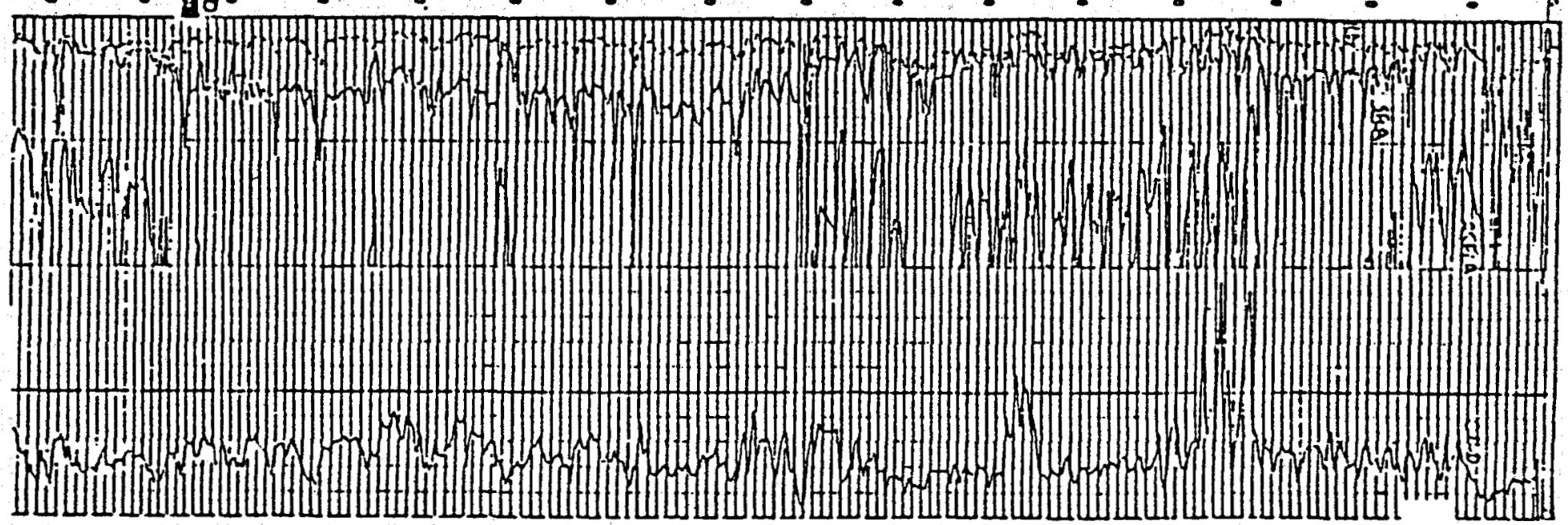

DIZITTO PRIMARY PRODUCTION ZONES

Exhibit 2.0-3. PORTION OF WIRELINE LOG FOR THE GLADYS MCCALL WELL SHOWING POTENTIAL PRODUCTION ZONES 
a scanning electron microscope. Oil content was found to range from $0 \%$ to $5.4 \%$ of the pore space. Conventional air permeability estimations on the sidewall samples ranged between 10 and $415 \mathrm{md}$. Conventional analysis of the cores found the average porosity to be $15.4 \%$ and the average permeability to range from 74 to $126 \mathrm{md}$ depending on the method used to do the averaging. 17 Additional core studies by Terra Tek found effective porosities in the range of $17 \%$ to $20 \%$.

Exhibit 2.0-4 shows the subsurface temperature as measured in five different wells in the area of the Gladys McCall well and the temperature measured in the McCall well just before perforation. In the hydropressured strata above 14,500 feet, the thermal gradient is $1.5^{\circ} \mathrm{F}$ per 100 feet. In the geopressured region below 14,500 feet, the thermal gradient is about $2.07^{\circ} \mathrm{F}$ per 100 feet.

\subsection{SUMMARY OF DRILLING}

DOE field activity at the Gladys McCall site began in March 1978 with the decision to attempt reentry of the Buttes Gas \& Oil/Getty Oil Company No. 1 Gladys McCall well. This well was selected from several alternatives in the area because of the thick Miocene sand ( 800 gross feet) in the geopressured interval between 15,050 and 16,600 feet. The access road and site were prepared during the summer, and reentry operations were started in September 1978. Attempts to reenter the old well were unsuccessful. When the well was previously plugged, explosives were used to remove some of the casing. Attempts to drill through these damaged points resulted in the bit sidetracking out of the old wellbore. The well was finally replugged in December 1978.6

After the failure to reenter the old well, the decision was made to drill a new well at the same site. A drilling contract was awarded and drilling of the new test well started in May 1981. The new Gladys McCall well was drilled to 16,510 feet, plugged back to 15,958 feet, and completed in September 1981. A 5-inch production-tubing string was installed to a depth of 13,933 feet through a polished-bore receptacle packer at 13,921 feet in January 1982. Exhibit 3.0-1 shows a schematic cross section of the well as it was completed. During drilling, a dozen wireline logging runs were made to obtain 30 logs, and whole cores were cut in the intervals from 15,167 to 15179 feet, 15,179 to 15,198 feet, and 15,348 to 15375 feet.

The original well, which had been unsuccessfully reentered as a production well, was again reentered in November 1981. The well was cleaned out to a depth of 3514 feet and recompleted as a disposal well in December 1981. Exhibit 3.0-2 shows a schematic cross section of the disposal well as it was completed. This well was then renamed as the T-F\&S/DOE Gladys McCall Salt Water Disposal Well No. 1. Four sands with a total thickness of 230 feet were perforated between 3050 and 3500 feet using a Schlumberger casing gun with four shots per foot of holes reported to be 0.91 inches in diameter. 
Flow Tests of the Gladys MCCall Well Through October 1990

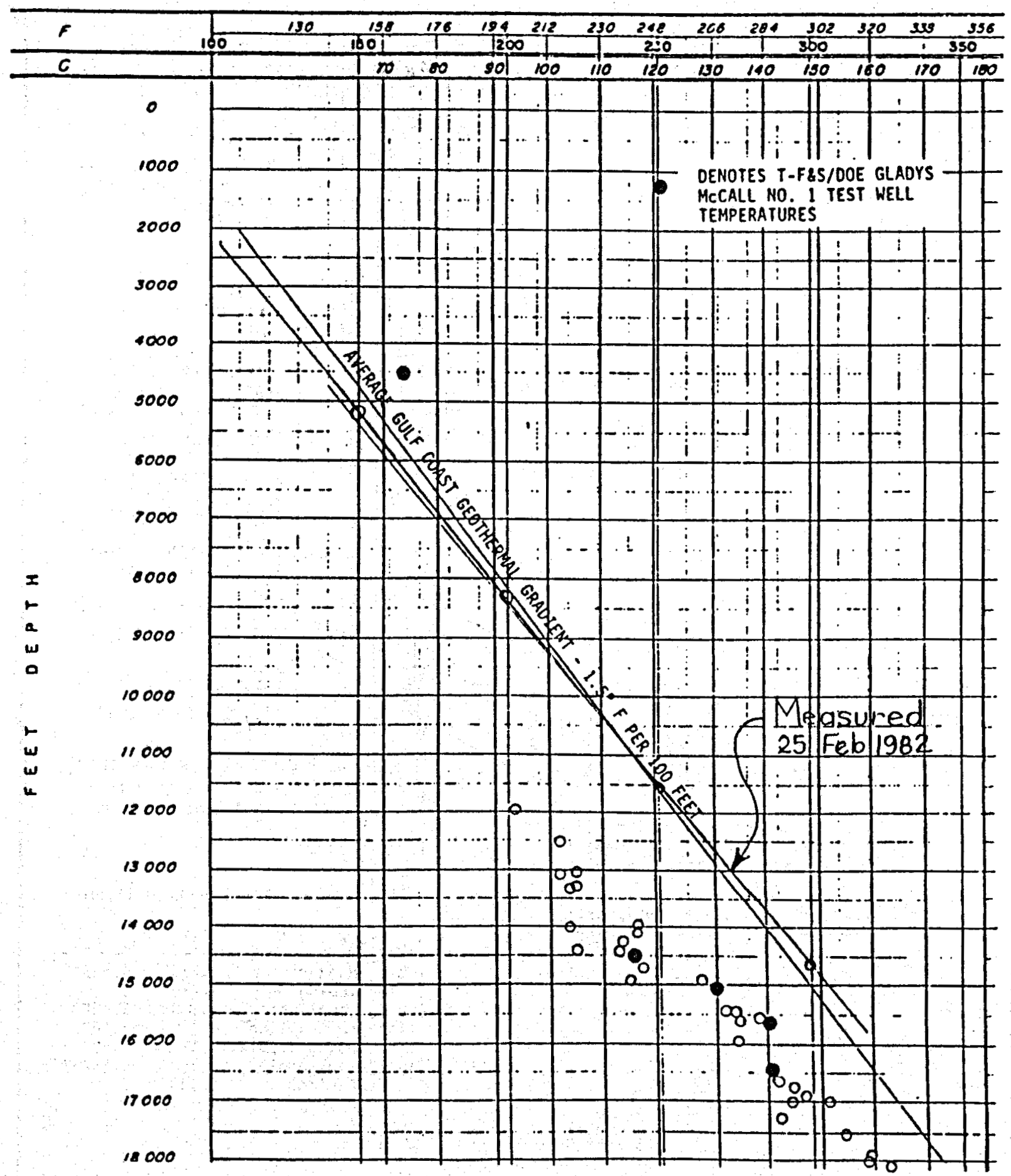

Exhibit 2.0-4. SUBSURFACE TEMPERATURES IN THE AREA OF THE GLADYS MCCALL WELL 


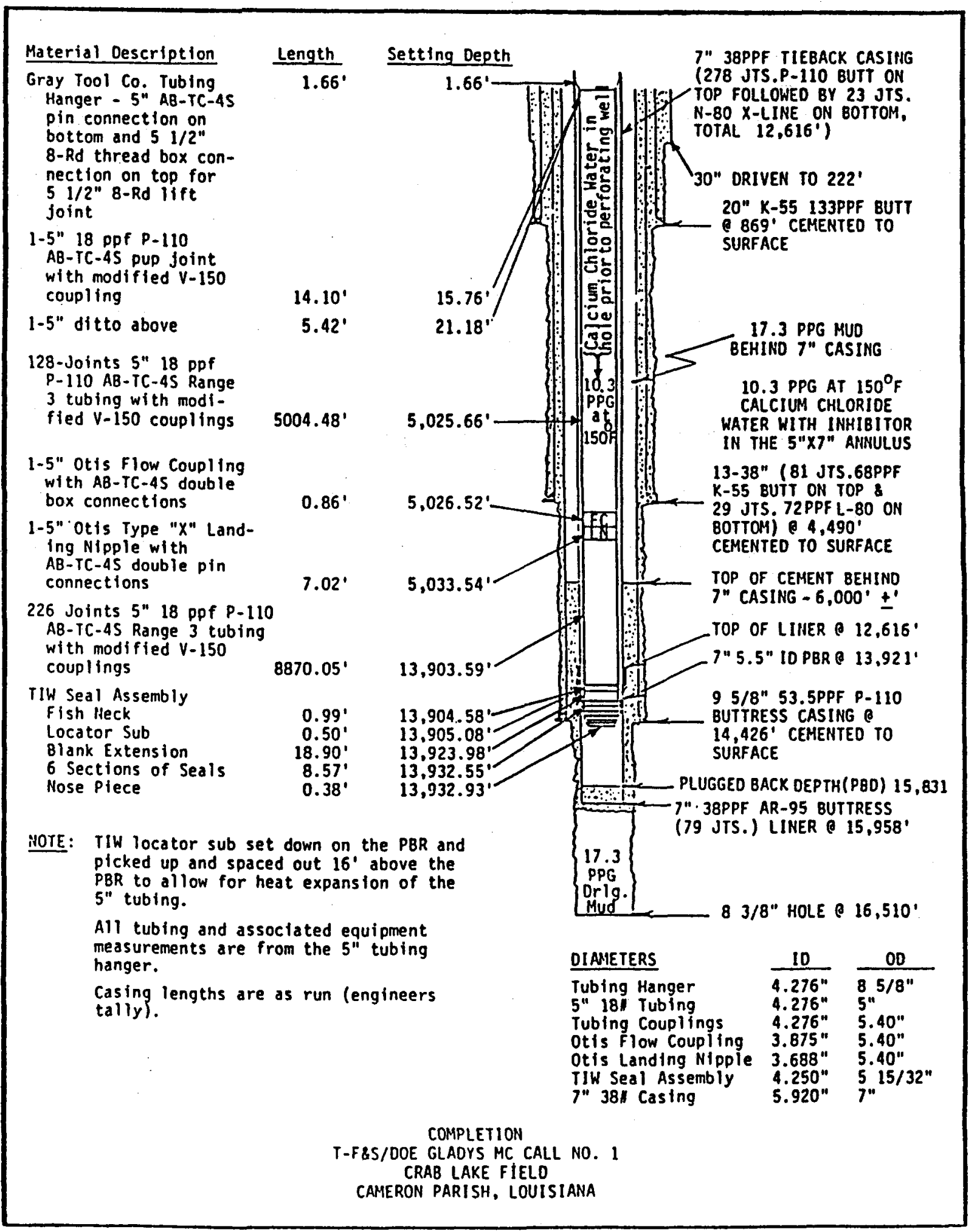

\section{Exhibit 3.0-1. SCHEMATIC DIAGRAM OF GLADYS MCCALL NO. 1 PRODUCTION WELL COMPLETION}




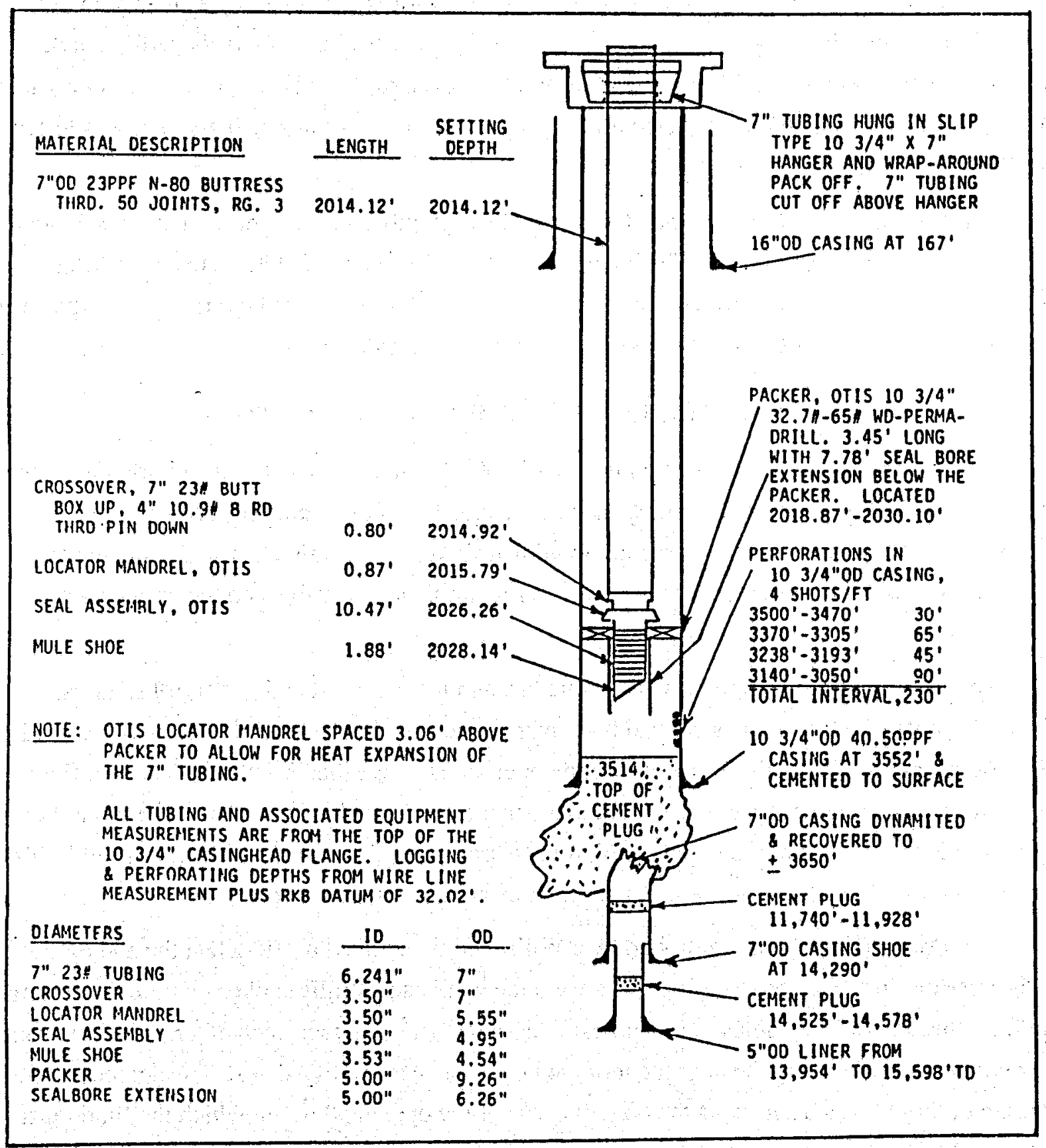

Exhibit 3.0-2. SCHEMATIC DIAGRAM OF THE GLADYS MCCALL SALT WATER DISPOSAL WELL NO. 1 COMPLETION 
The Number 9 Sand was initially perforated in the interval from 15,597 to 15,627 feet in February 1982 with four shots per foot using a 2-3/4 inch perforating gun and 11-gram charges. When a leak was found between the tubing and annulus, further perforation was delayed until workover activities were completed in December 1982. The additional intervals perforated in December 1982 were the 15,511 to 15,541 -foot interval and the 15,567 to 15,627 -foot interval in three runs using the same type of perforating gun as was previously used. This sand was tested and then plugged and abandoned.

Perforation of the Number 8 Sand was done in September 1983, after the Number 9 Sand had been tested and plugged off. The interval between 15,180 and 15,450 feet was perforated with eleven runs of the perforating gun. Welex 2-3/4 inch Sidewinder 11-gram SSB charges were used, with 1107 of the 1240 charges used in the gun successfully fired.

\subsection{SURFACE TEST EQUIPMENT AND FACILITIES}

Components of the wellhead are rated at $10,000 \mathrm{psi}$, while shut-in wellhead pressure was about 5500 psi. The wellhead assembly includes manually operated master valves above and below a hydraulically operated emergency shutdown valve. A kill valve ties a kill line into the wellhead between the hydraulically operated emergency shutdown valve and the upper master valve.

To accommodate the high brine flow rate through the wellhead and to control stresses, a block "Y" was installed on the wellhead that diverted the flow into two 45-degree heavy-walled flow loops. There is a swab valve for wireline operations above the "Y" block. The two flow loops made sweeping curves to the ground to another steel flow block that recombined the flow into a single stream before it entered the high-pressure horizontal pipe run. The produced fluids then passed through a block valve and a second emergency shutdown valve.

The brine flow rate was controlled by a Willis choke mounted in a block at the end of the high-pressure flow line about 50 feet away from the wellhead. Willis chokes operate by passing the fluid through off-axis holes in two tungsten-carbide disks that face each other. The upstream disk can be rotated to vary the alignment of the holes between the two disks. The degree of overlap of these holes determines the effective size of the opening through which the fluid must pass. Setting of the choke was accomplished manually using an external handle to rotate the internal yoke attached to the moveable disk. The carbide disks in the choke withstood the forces of the large pressure drop (several thousand psi) quite well. Immediately downstream of the choke, however, the intense turbulence of the fluid leaving the choke caused erosion of the interior pipe wall. This section of pipe was initially low-carbon steel but was subsequently clad with stainless 
steel. The stainless steel cladding had the metallurgical toughness to withstand the abrasive turbulence characteristic of the high-velocity brine exiting the choke.

Exhibit $4.0-1$ is a schematic diagram of the surface processing facilities. The piping and valves used to carry brine flow were generally 6-inch diameter or larger, to accommodate rates up to 40,000 barrels per day (BPD). Equipment downstream of the choke was initially designed to operate at a pressure of $1290 \mathrm{psi}$ and a temperature of $300^{\circ} \mathrm{F}$. Brine from the choke originally went to one separator, but a second separator was operating in series with the first starting in 1984 . The separators were of standard design -- with an oil weir, an internal diameter of 54 inches, and a length of 30 feet. The working-pressure rating of 1440 psi was downgraded to 1290 psi for operation at $300^{\circ} \mathrm{F}$. Brine from the separators was filtered prior to injection into the disposal well.

The gas from the separator was cooled, dehydrated, and sold. Carbon dioxide was not removed because a sales contract was obtained that allowed up to $10 \%$ carbon dioxide in the gas. Some gas was occasionally flared on location because of compressor malfunction or other reasons when the gas could not be sent to the sales line. Detailed engineering drawings of the equipment are given in the Technadril-Fenix \& Scisson report. 18

Initially, there was only one separator in the system, but in July 1984 the second separator was added. The two separators operated in series. Gas was separated from the brine in the first separator, called the high-pressure separator, at pressures high enough to enter the gas into the sales line without further compression. The high-pressure separator operating pressure was typically 1000 psig. The brine then passed to the second separator, called the low-pressure separator, which was operated at a pressure dictated by either the carbon dioxide content of the sales gas or the pressure needed to drive brine down the disposal well. The low-pressure separator was typically controlled in the range of 400 to $500 \mathrm{psi}$. The second separator recovered the gas that came out of solution between 1000 and 500 psi. Gas from this separator had to be compressed back up to the sales-line pressure. The dissolved gas remaining in the brine after passing through the low-pressure separator went through the filter and then into the disposal well. The sales gas carbon dioxide criterion that influenced the operating pressures of the separators was that the carbon dioxide content of the gas sent to sales had to be less than $10 \%$. The gas that came out of solution in the second separator contained roughly $15 \%$ carbon dioxide, whereas gas from the high-pressure separator contained only $8 \%$ carbon dioxide. The lower the low-pressure separator operating pressure, the higher the contribution of the high carbon dioxide fraction to the total gas. Lowering the pressure in the low-pressure separator recovers additional hydrocarbons -- but with a higher carbon dioxide content. Therefore the pressure in the second separator was maintained at a sufficient level to keep the commingled sales-gas carbon dioxide content below $10 \%$. 
Flow TeStS OF the Gladys MCCall Well Through OCtober 1990

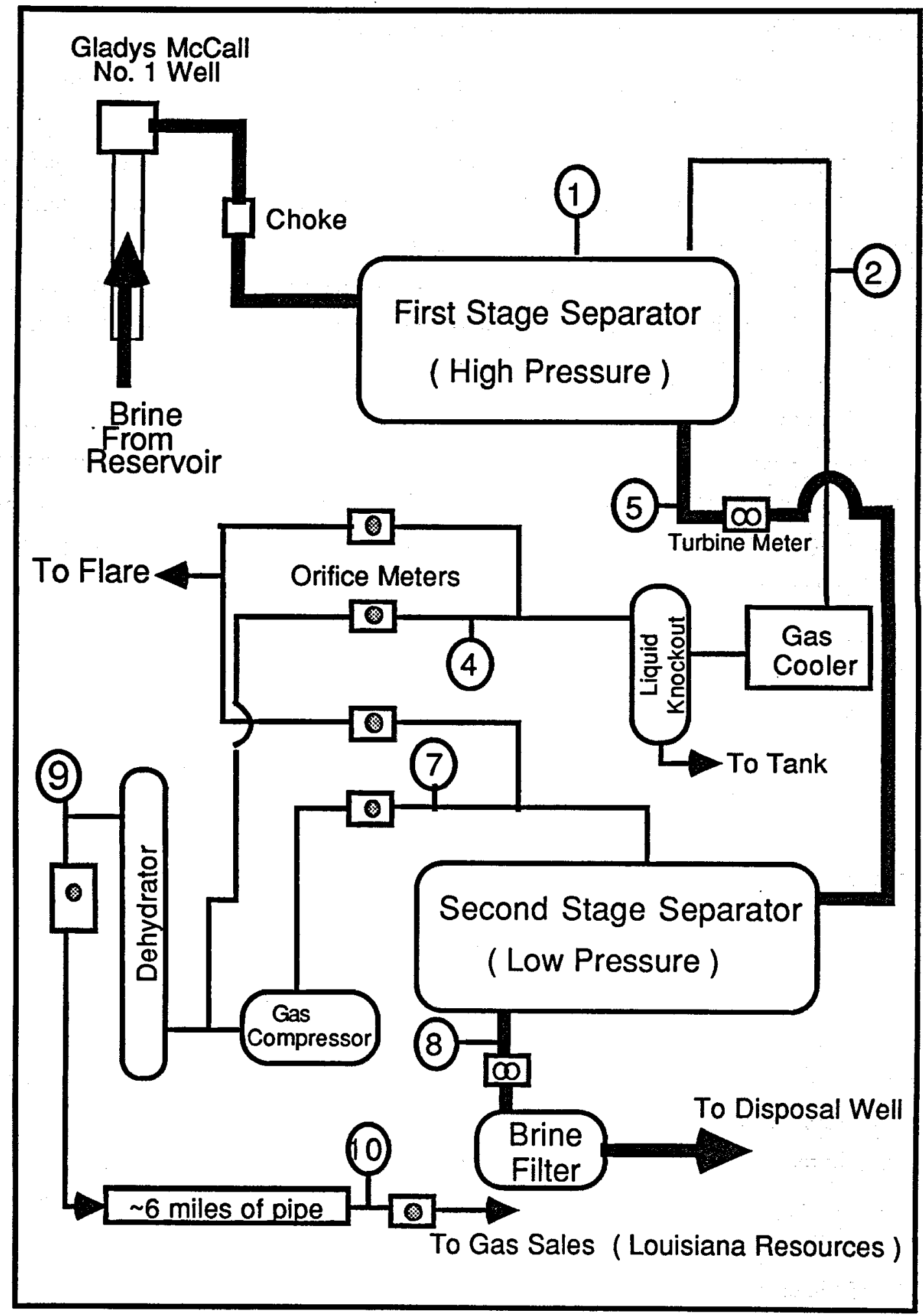

Exhibit 4.0-1. SCHEMATIC DIAGRAM OF THE GLADYS MCCALL WELL SURFACE GAS/BRINE PROCESSING FACILITIES 


\subsection{SAND 9 TESTING}

\subsection{Sand 9 Initial Production}

The first short-term Sand 9 flow test occurred in December 1982 for the purpose of well cleanup and sampling. The reported gas/brine ratio was $25.56 \mathrm{SCF} / \mathrm{STB}$ of gas recovered by the separator and an additional 5.35 SCF/STB of gas still dissolved in the brine injected into the disposal well, for a total produced gas/brine ratio of 30.91 SCF/STB. The second flow test was a short-term reservoir limit test performed in April and May 1983. A total of 100,000 barrels of brine were produced during the 23.8-day duration of this second test. Data analysis suggested the reservoir was too small for long-term production, so the Sand 9 was plugged and abandoned.

Several samples of brine were taken during these flow tests and analyzed by various parties. A summary of the results of brine analyses are presented in Exhibit 5.1-1.

\begin{tabular}{|c|c|c|c|}
\hline Date & $12 / 2 / 82$ & $3 / 22 / 83$ & $3 / 31 / 83$ \\
\hline $\begin{array}{l}\text { Alkalinity, as } \\
\mathrm{mg} \mathrm{HCO}_{3} / \mathrm{L}\end{array}$ & 547 & 571 & 532 \\
\hline Calcium, mg/L & 4,130 & 4,080 & 4,200 \\
\hline Chloride, $\mathrm{mg} / \mathrm{L}$ & 57,900 & 58,600 & 54,600 \\
\hline Dissolved Solids, mg/L & 96,300 & 95,500 & 97,600 \\
\hline $\begin{array}{c}\text { Hardness, as } \\
\mathrm{mg} \mathrm{CaCO}_{3} / \mathrm{L}\end{array}$ & 12,000 & 13,700 & 11,400 \\
\hline Iron, $\mathrm{mg} / \mathrm{L}$ & 35 & 34 & 34 \\
\hline Silica, $\mathrm{mg} \mathrm{SiO} / \mathrm{L}$ & 135 & 140 & 141 \\
\hline Specific Gravity & 1.062 & & 1.066 \\
\hline Sulfate, $\mathrm{mg} \mathrm{SO} 4 / \mathrm{L}$ & $<5$ & $<5$ & $\because<5$ \\
\hline Sulfide, $\mathrm{mg} \mathrm{S} / \mathrm{L}$ & $<1$ & $<1$ & \\
\hline
\end{tabular}

These analyses indicated the brine had a significant capacity to produce calcium carbonate scale during long-term production. The brine was salty, containing roughly three times the total dissolved solids of seawater.

Samples of gas were also collected and analyzed. The results of these analyses are presented in Exhibit 5.1-2. These analyses pointed to a problem with marketing gas from these wells. Normal sales contracts for natural gas have stringent carbon dioxide concentration limits, generally specifying $2 \%$ or less carbon dioxide. The operator was able to obtain a sales-gas contract that 
Flow TESTS OF THE GLAdys MCCALL Well Through OCtober 1990

Exhibit 5.1-2. GAS CHROMATOGRAPHIC ANALYSIS

$\begin{array}{llr}\begin{array}{l}\text { Sample Date } \\ \text { Mole Percent of: }\end{array} & 12 / 22 / 82^{\mathrm{a}} & 3 / 23 / 83^{\mathrm{b}} \\ \text { Carbon Dioxide } & 9.50 & 8.94 \\ \text { Nitrogen } & 0.28 & 0.26 \\ \text { Methane } & 86.91 & 86.93 \\ \text { Ethane } & 2.45 & 2.43 \\ \text { Propane } & 0.56 & 0.55 \\ \text { iso-Butane } & 0.09 & 0.08 \\ n \text {-Butane } & 0.09 & 0.08 \\ \text { iso-Pentane } & 0.02 & 0.04 \\ n \text {-Pentane } & 0.01 & 0.03 \\ \text { Hexanes } & 0.03 & 0.51 \\ \text { Heptanes+ } & 0.06 & 0.15 \\ \text { a Separator at } 500 \text { psig. } & & \\ \text { b Separator at } 700 \text { psig. } & & \end{array}$

specified the carbon dioxide concentration remain below 10\%. This is an exception to the norm, and such contracts must be in place to sell the gas at an economical price. Technology to remove carbon dioxide from the gas, such as amine plants or membranes, exist but will substantially detract from the economics of producing geopressured-geothermal gas.

\subsection{Sand 9 Gas and Brine Recombination Study and Gas Saturation}

A separator study was made to determine the produced gas/brine ratio. For this study, samples of brine taken at separator temperature and pressure were flashed to atmospheric pressure and room temperature. The amount of gas flashed from the sample was measured and the gas was analyzed. The results of analysis of the gas flashed from the separator brine sample are given in Exhibit 5.2-1. This gas contains a substantial amount of carbon dioxide and is of limited value.

From the flow rate of brine through the separator and the gas production it was determined that the gas/brine ratio for the produced gas was $25.56 \mathrm{SCF}$ separator gas per barrel of separator brine at stock tank conditions. The gas flashed from the separator brine sample provides an additional 5.35 SCF/STB, for a total gas/brine ratio of $30.91 \mathrm{SCF} / \mathrm{STB}$. This ratio is for dry gas at $15.025 \mathrm{psia}$ and $60^{\circ} \mathrm{F}$ and brine at stock tank conditions at atmospheric pressure and $60^{\circ} \mathrm{F}$. 
FLOW TESTS OF THE GLAdYS MCCALL WELL ThROUGH OCTOBER 1990

\section{Exhibit 5.2-1. ANALYSIS OF GAS FLASHED FROM SEPARATOR BRINE ON MARCH 23, 1983, SEPARATOR AT 700 psia}

$\begin{array}{lc}\text { Mole Percent of: } & \\ \text { Carbon Dioxide } & 41.00 \\ \text { Nitrogen } & 0.0 \\ \text { Methane } & 57.03 \\ \text { Ethane } & 1.38 \\ \text { Propane } & 0.24 \\ \text { iso-Butane } & 0.02 \\ n \text {-Butane } & 0.03 \\ \text { iso-Pentane } & 0.00 \\ n \text {-Pentane } & 0.00 \\ \text { Hexanes } & 0.07 \\ \text { Heptanest } & 0.23\end{array}$

A laboratory PVT (pressure-volume-temperature) recombination of Gladys McCall gas and brine was performed by Weatherly Laboratories, Inc. (Appendix B). Recombination of the measured 24.66 SCF of separator gas per barrel of separator brine had a bubble-point pressure of $10,030 \mathrm{psia}$ at $298^{\circ} \mathrm{F}$. It appears that the authors of the Technadril-Fenix \& Scisson Final Report (Page 130) ${ }^{17}$ performed an erroneous comparison to conclude that the reservoir brine was saturated with natural gas. They compared an extrapolated value of $30.4 \mathrm{SCF}$ separator gas at $15.025 \mathrm{psia}$ and $60^{\circ} \mathrm{F}$ per barrel and separator water at $700 \mathrm{psig}$ and $212^{\circ} \mathrm{F}$ for the bubble point at 12,936 psia with the sum of gas from the separator plus gas remaining in solution in brine leaving the separator. Unfortunately, such a comparison is in error by the amount of gas in solution in the separator brine, or about $5.35 \mathrm{SCF} / \mathrm{STB}$. In different terms, the gas remaining in brine leaving the separator is about the difference in gas content of brine for bubble points of 10,030 and 12,936 psia.

It is now clear that the brine in Sand 9 was not saturated with natural gas. The bubble point was about $2900 \mathrm{psi}$ less than the initial reservoir pressure.

\subsection{Sand 9 Reservoir Limit Test}

The well was produced from March 21, 1983, through April 14, 1983, for a reservoir limit test. A bottomhole pressure gauge was lowered into the well on March 20 and was operational most of the time to April 17. The buildup test was interrupted after only 3 days when the mast on the truck supporting the wire collapsed, causing the wireline to drop into the hole. A total of 
99,416 barrels of brine were produced in 23.8 days for an average rate of 4181 barrels per day. Exhibits 5.3-1 and 5.3-2 show plots of the flow rate and resulting bottomhole pressures for both the pressure draw-down and buildup tests.

The draw-down and buildup data were independently analyzed by four parties: 1) J. Donald Clark, Petroleum Consultant; 2) Dowdel, Fairchild and Ancell, Inc.; 3) S-Cubed; and 4) Scientific Software-Intercomp. Their results were as follows:

1. Clark ${ }^{17}$ noted five possible straight-line slopes on the semilog plot of bottomhole pressure ranging from 16.7 to 45.2 psi/cycle during the first 24 hours (Exhibit 5.3-1). None of the adjacent segments reached the 2:1 ratio indicative of a boundary, therefore he concluded that the changes were due to lenticularity of the formation rather than being caused by sealing geological faults. He calculated a hydraulic flow capacity of $10,153 \mathrm{md}-\mathrm{ft}$, a permeability to brine of $84.6 \mathrm{md}$, and a skin factor of +1.98 . He further calculated that the transient pressure wave explored the reservoir to a radial distance of 13,019 feet and that the in-place volume of brine was about 170 million barrels. These conclusions were all reached with generally accepted reservoir engineering methods based on various plots of the data.

2. Dowdle, Fairchild \& Ancell 17 used a single-phase, two-dimensional numerical reservoir simulator to match the experimental pressure data. The active grid blocks and properties of the grid blocks were adjusted until the calculated pressures were a good match to the experimental pressures. Exhibit 5.3-2 shows their final match. This match resulted for a model that assumed two separate reservoirs and parallel faults: one about 750 feet from the well, and the other about 1000 feet from the well. The resulting flow capacity was about $11,700 \mathrm{md}-\mathrm{ft}$, and the permeability was about $90 \mathrm{md}$. The transient pressure wave was calculated to have explored the reservoir to a distance of about 20,000 feet, and the in-place brine was calculated at about 184 million barrels. Predictive calculations for flow rates in the range of 15,000 to 35,000 barrels showed that this level of production would exhaust this size of a reservoir in about a year.

3. S-Cubed ${ }^{17}$ noted that the semilog plot of the draw-down data had slopes of 25,46 , and $92 \mathrm{psi} / \mathrm{cycle}$ in the first 100 hours of the test and that a doubling of the initial slope occurred at about 29 hours. From this they concluded that there was a boundary at a distance of about 960 feet from the well. From a Horner plot they derived a permeability of $67 \mathrm{md}$ and a skin factor of +0.54. Noting that the last 145 hours of the test gave an apparent constant slope of $0.332 \mathrm{psi} /$ hour, they calculated that the in-place brine was at least 85 million barrels. They cautioned, however, that this was a minimum value and that the reservoir could be larger.

4. Scientific Software-Intercomp ${ }^{15}$ first analyzed the data using the normal plots of the data and reservoir engineering methods to determine the reservoir properties. From the semilog 


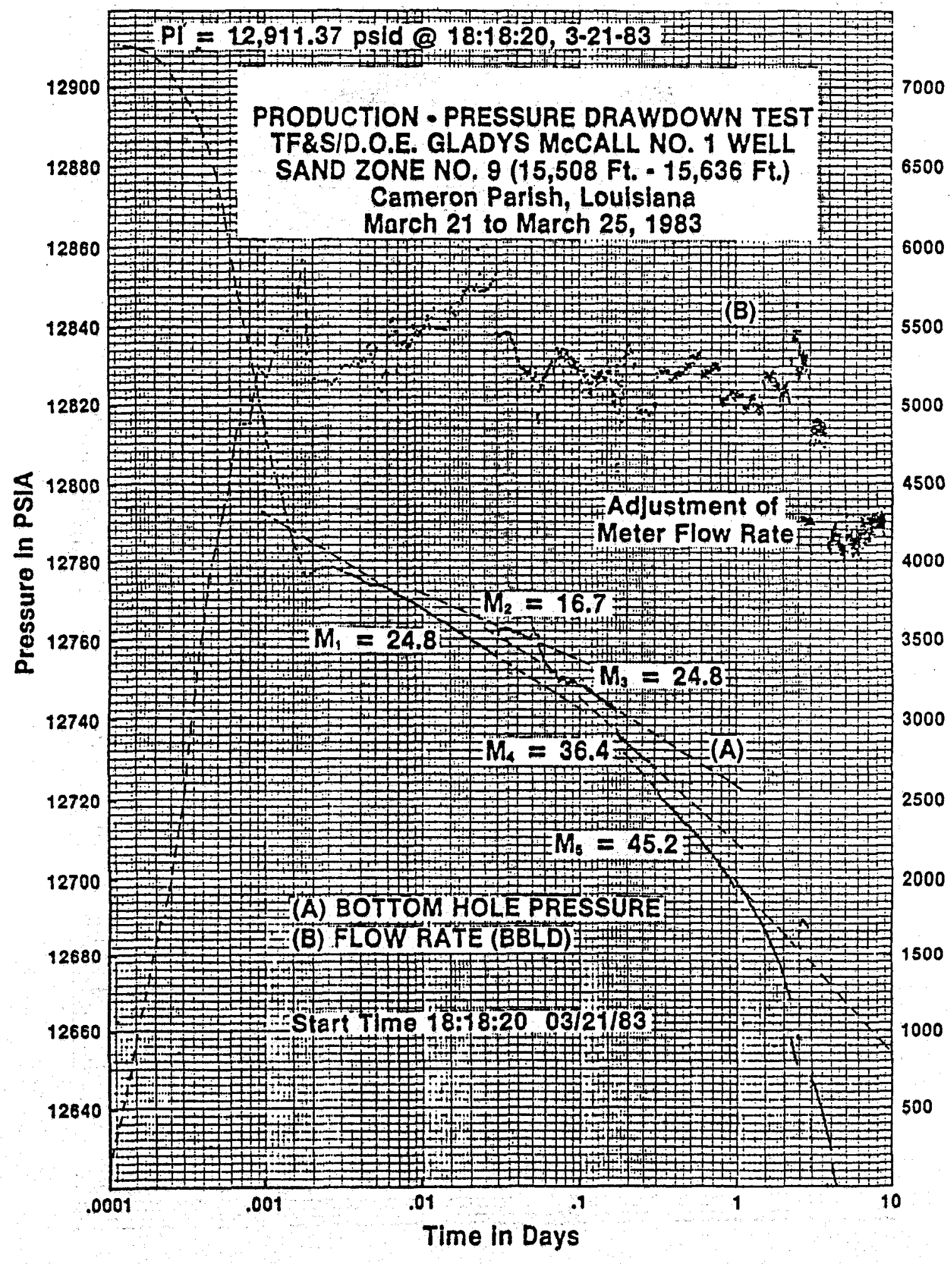

Exhibit 5.3-1. ANALYSIS OF SAND 9 DRAW-DOWN TEST BY CLARK ${ }^{17}$ 


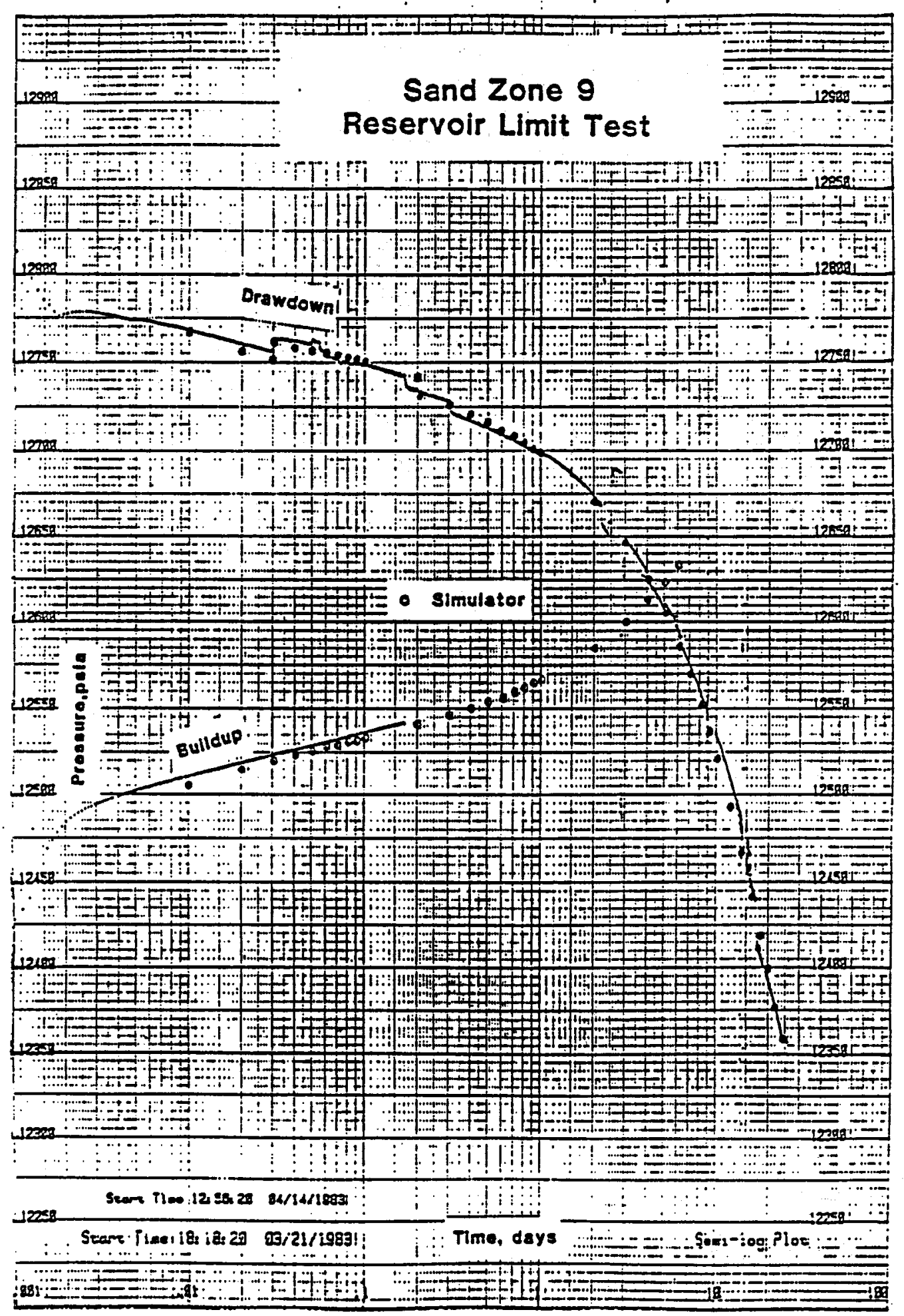

Exhibit 5.3-2. MATCH OF DATA WITH NUMERICAL MODEL BY DOWDLE, FAIRCHILD \& ANCELL, INC. 17 
pressure draw-down plot they derived a flow capacity of $9544 \mathrm{md}-\mathrm{ft}$, a permeability of $74.6 \mathrm{md}$, and a skin factor of -0.74 . From a Horner-type pressure-buildup plot they calculated the flow capacity to be $10,689 \mathrm{md}-\mathrm{ft}$, the permeability to be $83.5 \mathrm{md}$, and the skin factor to be +0.17 . Finally, they used a numerical reservoir simulator (BETA II) to model the test. Exhibits 5.3-3 and 5.3-4 show the grid block structure they used and the grid blocks that were zeroed out such that the active grid blocks modeled barriers some 3500 to 4000 feet from the well. The grid blocks and properties of the reservoir rock in the grid blocks were then adjusted as needed in repeated simulation runs until the calculated pressures matched the experimental pressures. Exhibit 5.3-5 shows their final match. To achieve this match, the permeability thickness in the outer blocks needed to be reduced. The final match model had an in-place brine volume of about 135 million barrels.

Although there are some differences in the exact values of the reservoir parameters as calculated by the four different groups, they are in general agreement that the reservoir was rather small and would not support long-term production. With this conclusion there was no need to test this sand further. Sand 9 was therefore plugged and attention was given to the next higher aquifer, Sand 8.

\subsection{SAND 8 TESTING}

Sand 8 testing consisted of relatively short reservoir limit tests, a 4-year period of production during which over 25 million barrels of brine and 0.7 billion SCF of gas were produced, and a multiyear buildup test that is still in progress. A short-term production test is planned prior to plugging and abandoning the well. Details of the tests are presented in subsections below.

\subsection{Sand 8 Short-Term Reservoir Limit Tests}

The first pressure transient test of Sand 8 was initiated on September 27, 1983. The flow rate started at 14,520 BPD and then was reduced to $13,703 \mathrm{BPD}$. This test lasted only 9 hours because of several equipment problems that required removing the bottomhole pressure tool from the hole and discontinuing production. This flow test provided adequate data for an interpretation of the reservoir properties relatively near the wellbore, as reported by J. D. Clark. ${ }^{3}$ He reported a productivity of $39,568 \mathrm{md}-\mathrm{ft}$ and a skin factor of +1.05 . Assuming 300 feet of net pay, the average permeability was $132 \mathrm{md}$.

After the equipment was repaired, the pressure transient test was restarted on October 7, 1983, with an initial flow rate of 13,407 BPD. Flow was continued for 21 days, until October 28 , with an average production rate of 12,985 BPD. The bottomhole pressure gauge was placed in the 


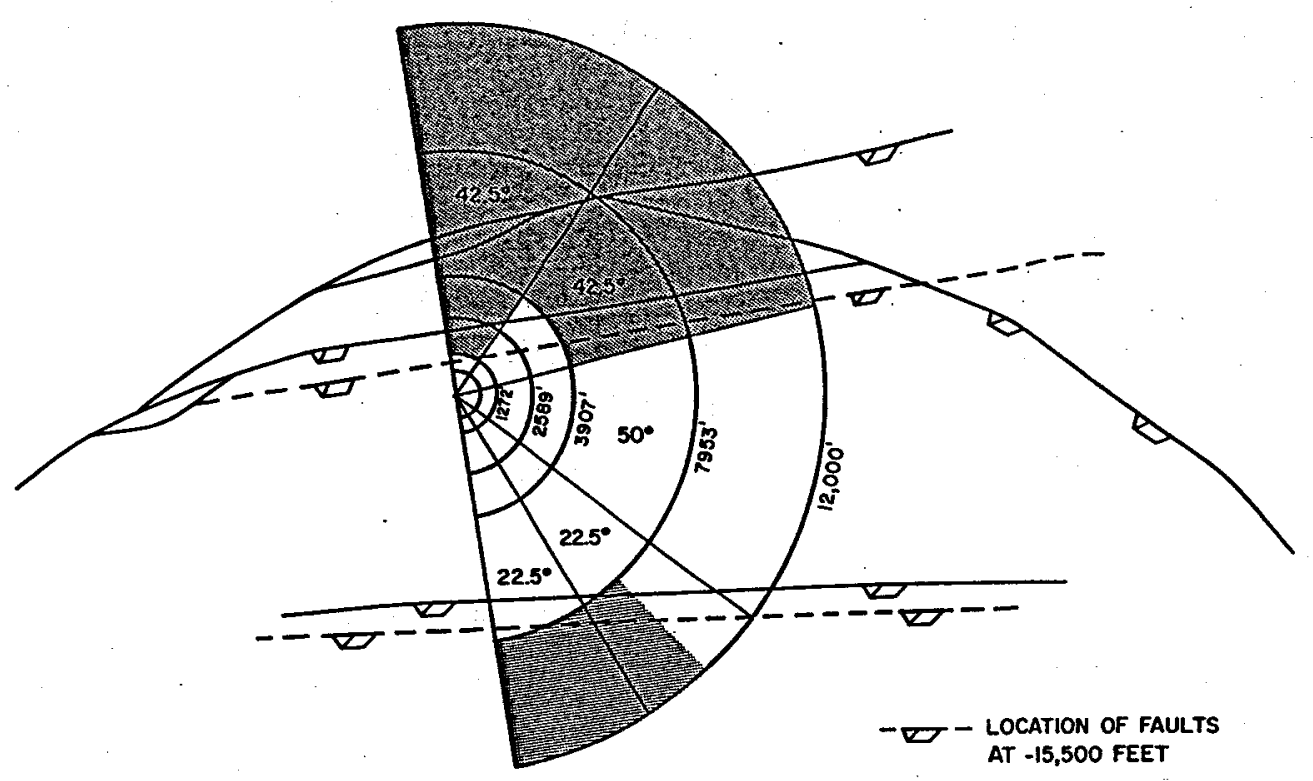

Exhibit 5.3-3. GRID STRUCTURE OF NUMERICAL MODEL BY SCIENTIFIC SOFTWARE-INTERCOMP15

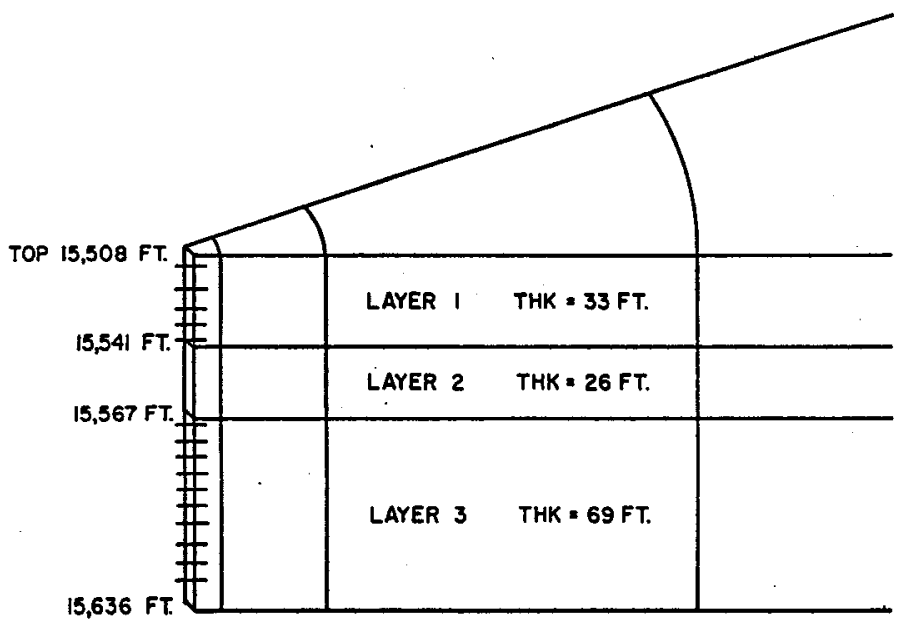

Exhibit 5.3-4. LAYERS IN NUMERICAL MODEL BY SCIENTIFIC SOFTWARE-INTERCOMP15 
FLOW TESTS OF THE GLADYS MCCALl Well THROUgh OCTOBER 1990

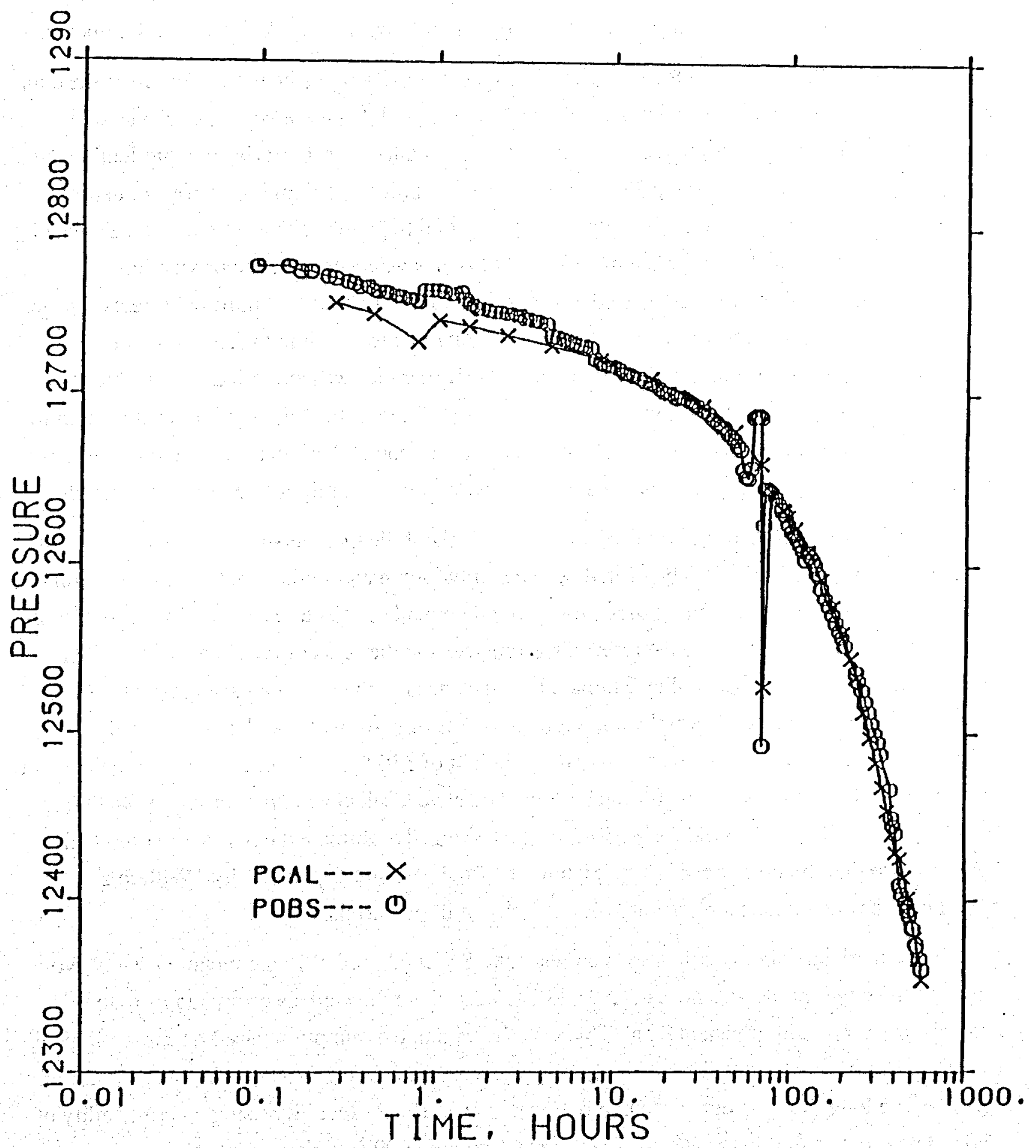

Exhibit 5.3-5. MATCH OF DATA TO NUMERICAL MODEL BY SCIENTIFIC SOFTWARE-INTERCOMP15 
hole on October 5 and removed on November 30, thus providing a continuous record for the drawdown and 32 days of buildup. The data were analyzed by both J. D. Clark and S-Cubed.

J. D. Clark $^{3}$ reported that the curved lines on the semilog graphs he used to interpret the data were an excellent example of lenticular-type sand deposits and that there was no evidence of a linear-type permeability barrier (such as a nearby sealing fault). For the early-time production data he calculated a productivity of $37,057 \mathrm{md}-\mathrm{ft}$ and a permeability of $123 \mathrm{md}$ for a 300 -foot sand. This compared well with previous results from the aborted September 27 test. He then calculated the reservoir volume with a graphical method that indicates when steady-state production apparently occurs. This graph suggested a reservoir volume of about 550 million barrels of brine. Similarly, graphical analysis of the pressure-buildup data yielded an initial productivity of $39,752 \mathrm{md}-\mathrm{ft}$. The line on the semilog time plot and Horner plot was straight only for times less than 1 day, therefore the reported value for productivity of approximately $39,000 \mathrm{md}-\mathrm{ft}$ is valid for only a relatively small volume of the reservoir near the wellbore. Clark made no attemp to interpret the data beyond the time that it deviated upwards, away from the straight-line portion of the plot.

S-Cubed did a similar, but more extensive, analysis of the October-through-November 1983 pressure transient test data. ${ }^{13}$ They fitted both the draw-down and buildup data to four straightline segments on the usual semilog time plot. They then made conjectures about how each of these straight-line segments related to the reservoir geometry. On the basis of the slopes of the plots doubling at 9.5 and 31.5 hours, they estimated the distances to the two nearest faults to be 780 and 1410 feet. Using the second straight-line segment on the draw-down plot, they calculated a reservoir permeability of $113 \mathrm{md}$ for an assumed height of 330 feet (124 md for an assumed height of 300 feet). Similar calculations for the buildup data gave a calculated productivity of $44,090 \mathrm{md}-$ $\mathrm{ft}$ and a permeability of $133 \mathrm{md}$ for a 330 -foot-thick sand. To estimate the reservoir volume, they hypothesized that the pressure was approaching the final pressure exponentially. With this hypothesis they calculated a reservoir volume of 433 million barrels.

To numerically simulate the reservoir test data, S-Cubed used a simple rectangular reservoir with parallel edges at the distances of 780 and 1410 feet from the well, as estimated from their analysis of the pressure transient data. This was a reasonable assumption based on the geological analysis of east-west growth faults through the reservoir area. With these widths and a height of 328 feet, the long distance out to the end boundaries was 10,827 feet. By using a permeability of $160 \mathrm{md}$ near the wellbore and $20 \mathrm{md}$ for distances beyond 3600 feet, they were able to calculate a pressure draw-down and buildup curve that closely matched the actual test data. 


\subsection{Sand 8 Long-Term Production}

The Number 8 Sand was completed in September 1983 with perforations in the interval between 15,180 and 15,450 feet. Long-term flow testing was initiated in December 1983 and concluded almost 4 years later in October 1987. This sand proved to be a very large reservoir and capable of sustaining long-term brine production.

Early production was curtailed by scale formation in the wellbore and surface facilities. Scale deposition in the surface facilities was controlled by injection of scale inhibitor prior to the chokes. Scale inhibition in the wellbore was eventually controlled after inhibitor "pills," consisting of many hundreds of pounds of scale inhibitor, were successfully displaced into the producing formation. Prior to these inhibitor pills, however, production rates were limited to below 15,000 barrels of brine per day so that the cooling of brine during transit up the wellbore and the higher wellhead pressures associated with the lower rates counteracted the tendency of the brine to form scale as pressure was reduced.

Once scale deposition in the wellbore was controlled with inhibitor pills, brine rates were increased. The limitation on the flow rates was the operation of the large separator at $1000 \mathrm{psig}$ pressure, which required a wellhead pressure of a little less than 1200 psig. The gradual decline in brine rate in 1986 through the first few months of 1987 reflected the drawdown of the reservoir pressure near the wellbore. The reduction of brine rates to just below 10,000 barrels per day in 1987 were to allow pressures to stabilize at a rate low enough for a bottomhole pressure sensor to be run into the well prior to shut-in for buildup testing.

A flow-test program was established where the flow rates and other production measurements were manually taken at 2-hour intervals and then manually summarized each day for daily reports. A computerized data acquisition system was installed in January 1986 to evaluate whether such a system could be used as the primary data collection system for the Pleasant Bayou well. The computer system was operated in parallel with the manual data acquisition, and the manually obtained data continued to be the reported data.

The initial daily reported data included the production and gas sales, but did not include the gas remaining in solution sent to the disposal well or account for the fact that the brine flow measurements were made at nonstandard conditions. Much of this field data has been previously reported. 17 For this current analysis, the reported daily volumes were adjusted to standard conditions and revised to include the gas remaining in solution after going through the separators. Plots of this revised data for brine production and gas production for Sand 8 are shown in Exhibits 6.2-1 and 6.2-2. Daily production data are provided in tabular form in Appendix $\mathrm{C}$ and in graphical form in Appendix D. 
Flow Tests of the Gladys McCall Well Through October 1990

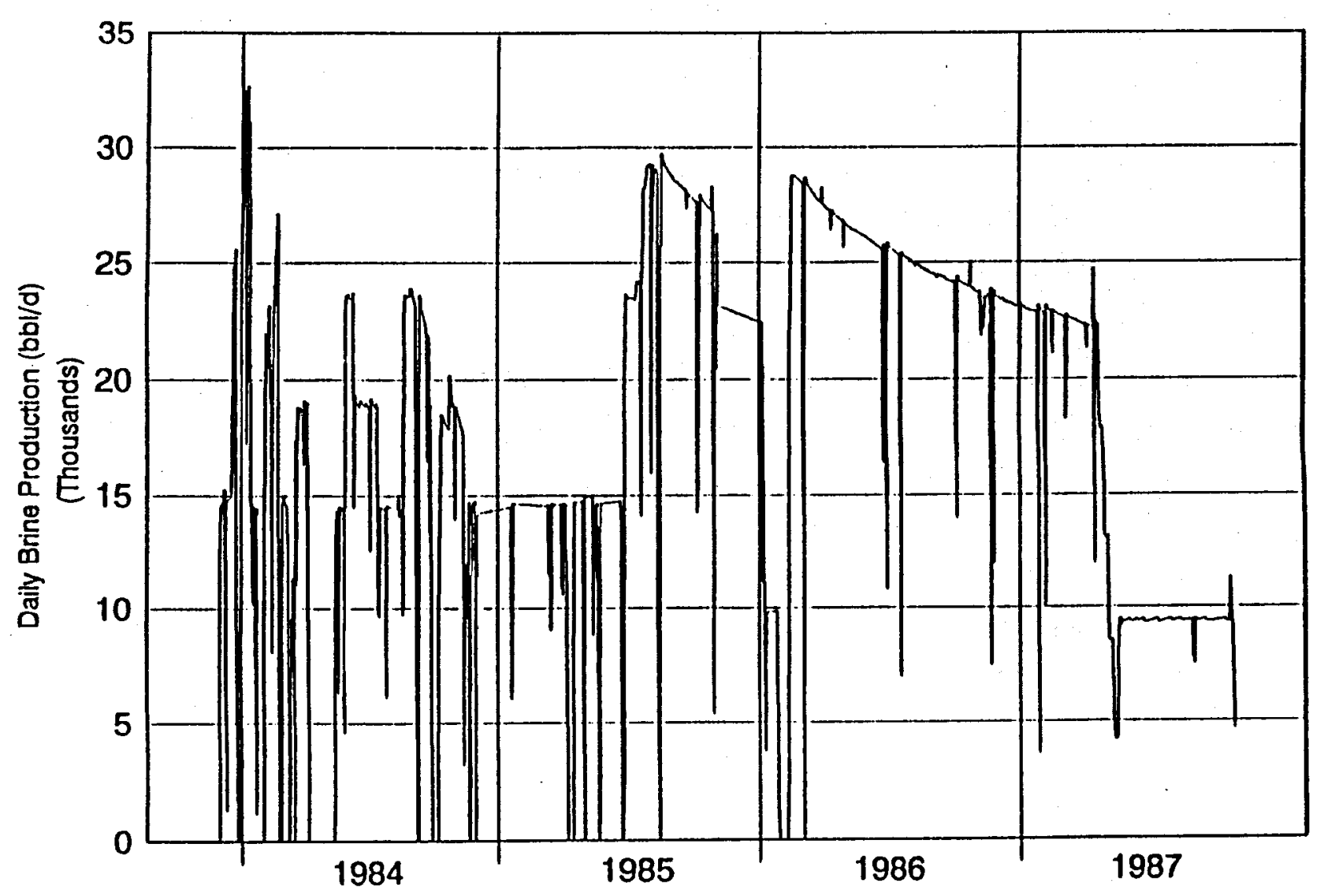

Exhibit 6.2-1. SAND 8 LONG-TERM TEST BRINE PRODUCTION 
Flow Tests of the Gladys MCCall Well Through OCtober 1990

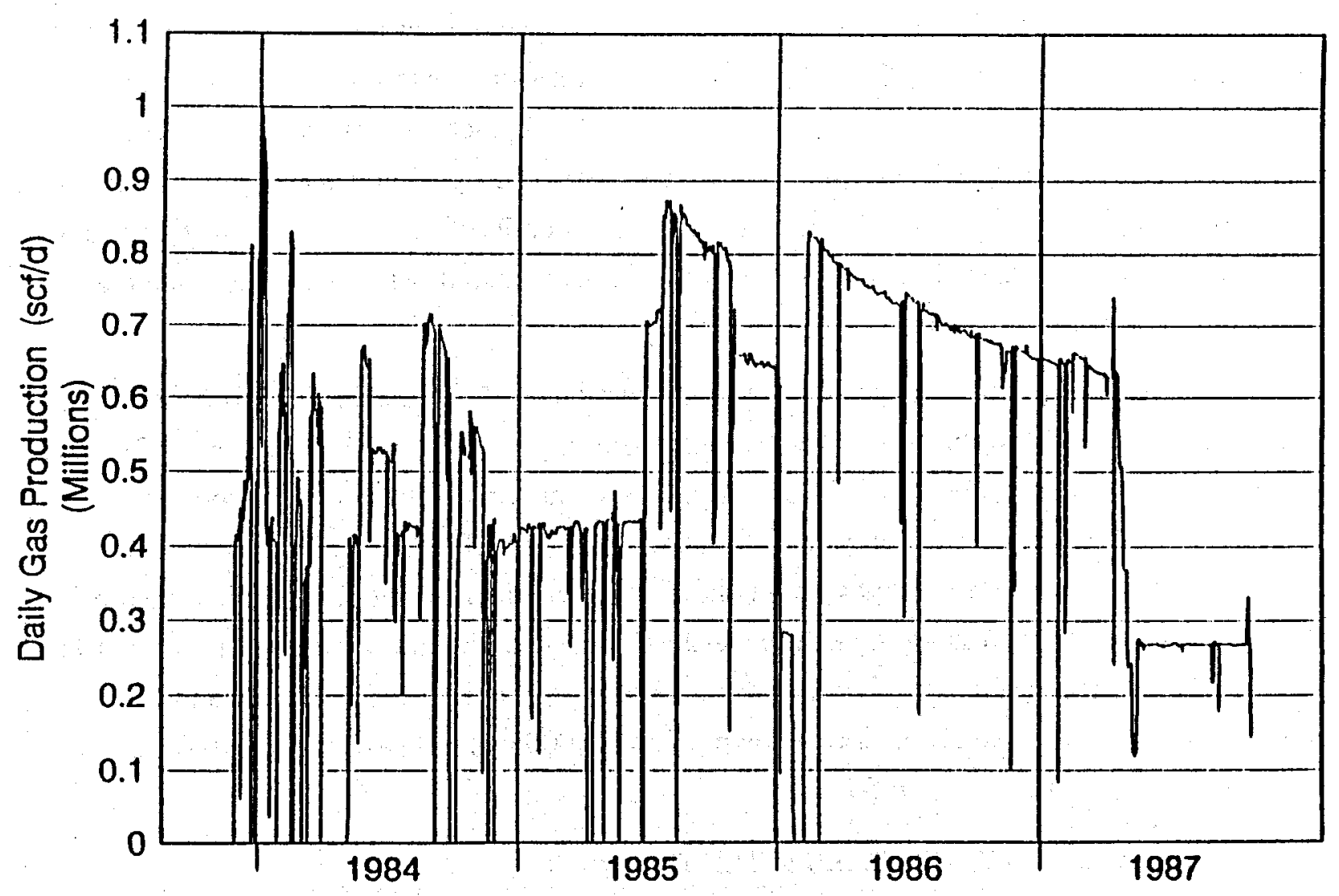

Exhibit 6.2-2. SAND 8 LONG-TERM TEST GAS PRODUCTION 
The revised brine volumes are $6 \%$ to $7 \%$ less than the field-reported volumes. The gas volumes were adjusted to include gas remaining in the brine after the separator with a computer algorithm developed at IGT, and they were typically $10 \%$ to $20 \%$ higher than the field-reported volumes. The plots of gas rate in Exhibit 6.2-2 and in Appendix D present the total amount of gas produced from the reservoir in the brine rather than the amount that was recovered or sold. The basis for these corrections is discussed in Appendix E.

The gas/brine ratio shown in Exhibit 6.2-3 plots the gas volumes in Exhibit 6.2-1 divided by the brine volumes in Exhibit 6.2-2. If the brine and gas measurements had been perfect, the gas/brine ratio plot should be very close to a straight line. In practice, however, there are spurious high or low values in the gas/brine ratio because there were some difficulties in the manual reading and reporting of the flow-rate data. During the first few months of production, the difficulties with meter calibrations and manual readings were more severe compared to the later time when the operations became more routine.

Cumulative perforation gas production versus cumulative brine production from these calculations is presented in Exhibit 6.2-4. The overall gas/brine ratio (the slope of the line) is $28.9 \mathrm{SCF} /$ STB for production up to about 10 million barrels. A slight bend in the curve then occurs, and subsequent production had an average gas/brine ratio of $28.6 \mathrm{SCF} / \mathrm{STB}$. This slight change in the ratio (slope) at 12 million barrels may reflect the point where the flowing bottomhole pressure fell below the bubble-point pressure of the brine. This change occurred during the latter half of 1985 , which is the time the sustained brine rate was increased to more than $20,000 \mathrm{STB} / \mathrm{d}$ and the flowing bottomhole pressure was drawn down below 10,000 psi. The overall average gas/brine ratio is calculated to be $28.7 \mathrm{SCF} / \mathrm{STB}$.

\subsection{Sand 8 Long-Term Reservoir Test Data Interpretation}

\subsubsection{Reservoir Simulation}

Reservoir simulation was updated as additional information was obtained. When S-Cubed prepared their report for the Sixth Geopressured-Geothermal Conference in 1985,13 they had a year's worth of production data from the long-term flow test discussed below. As this long-term test progressed, they found that the actual bottomhole pressures were higher than their simulated pressures. They regularly needed to increase the size of the reservoir used in their model to match the data from the ongoing long-term flow test. Because the model fit the early time well, they simply added the additional volume to the remote ends of the model. There was no accurate geological information about where the extra volume should be placed to match the actual reservoir. Several cases with different assumptions of volume were run, and a good fit to the data was found for a revised reservoir volume of 1.2 billion barrels. This revised volume was 
Flow Tests of the Gladys MCCall Well Through OCtober 1990

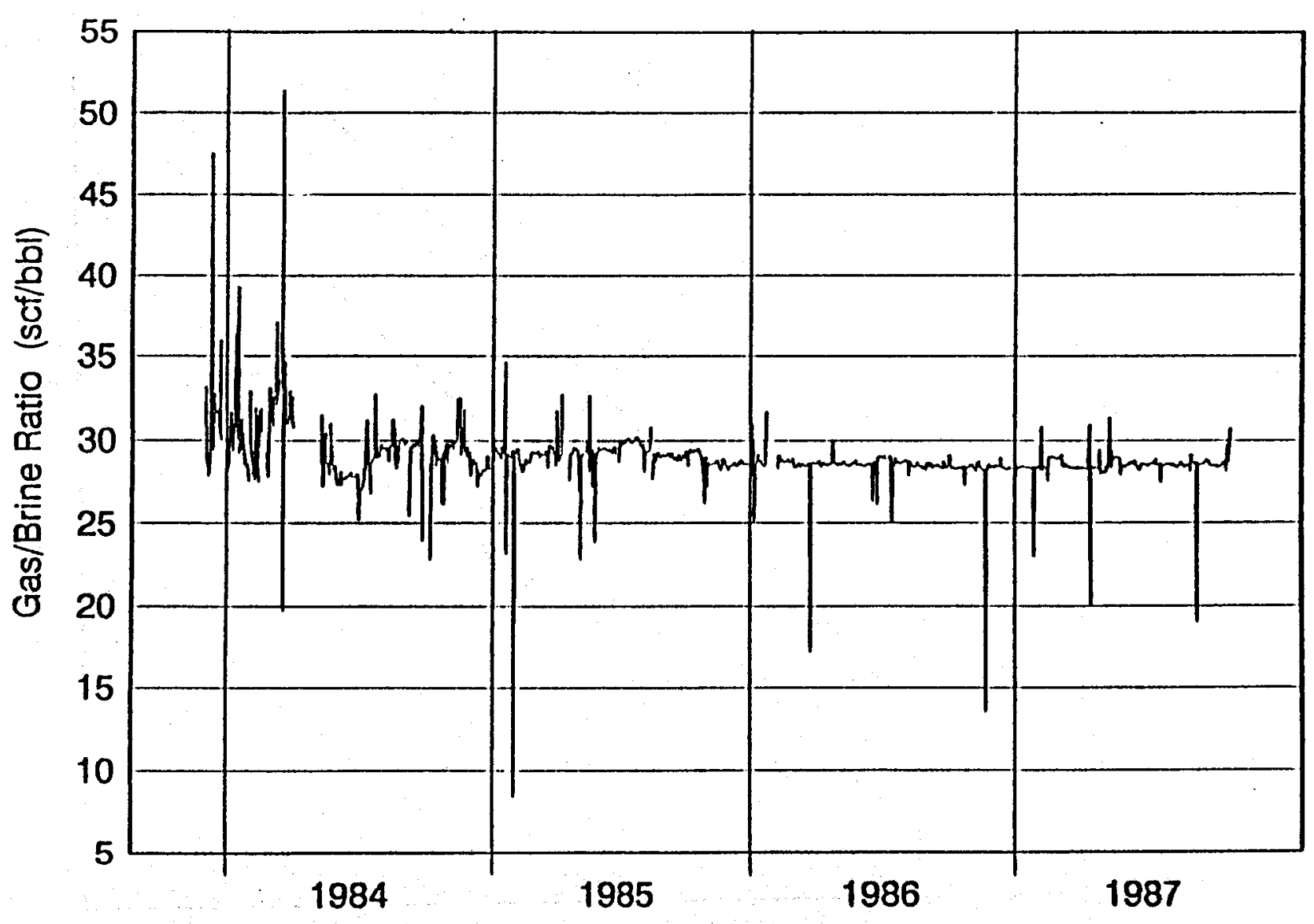

Exhibit 6.2-3. SAND 8 GAS/BRINE RATIO FROM PRODUCTION DATA 
FLOW TESTS OF THE GLAdys MCCALL Well Through OCtober 1990

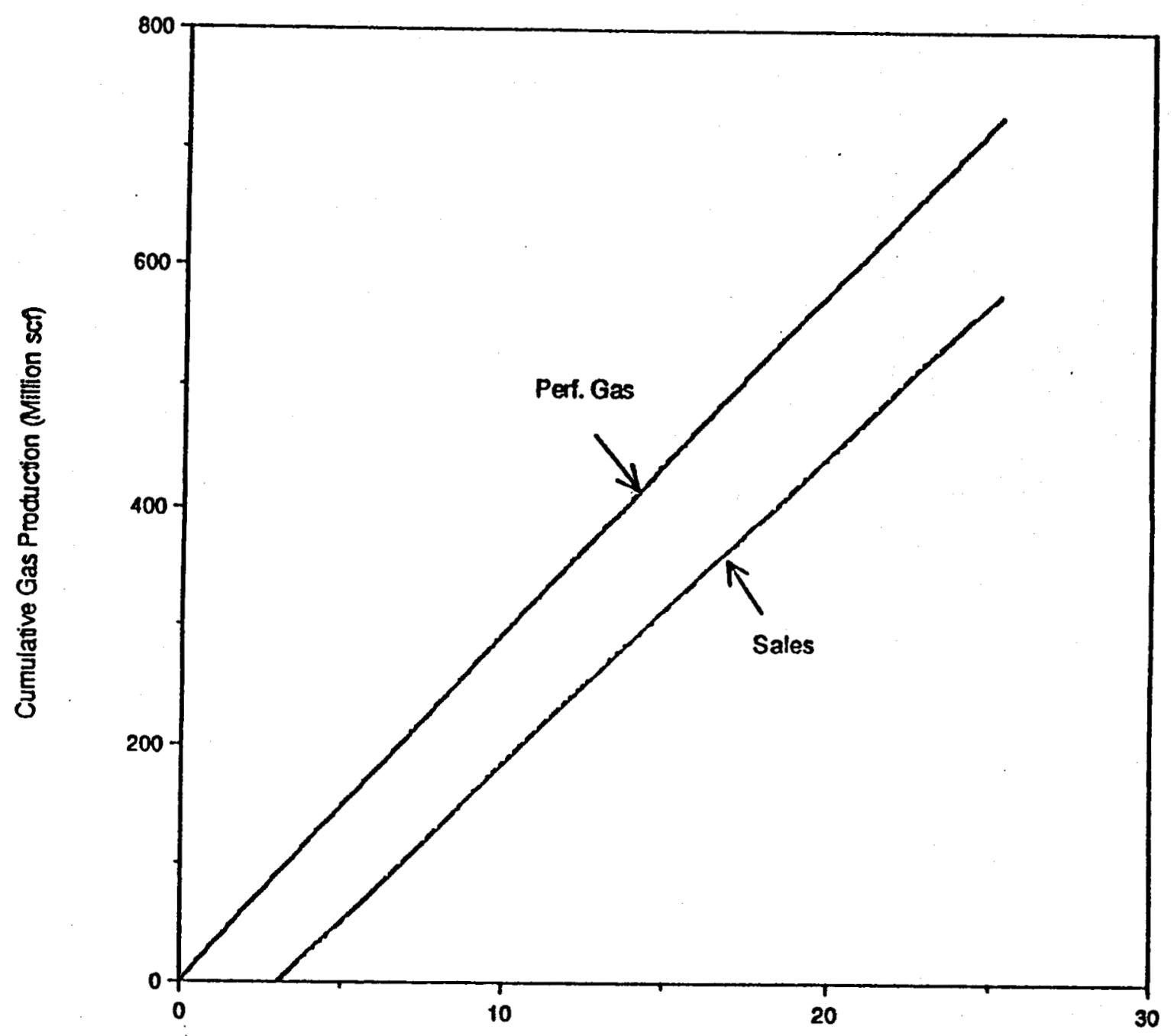

Cumulative Brine Production (Million bbls)

Exhibit 6.2-4. SAND 8 CUMULATIVE GAS VERSUS BRINE PRODUCTION 
approximately three times the volume initially deduced from the 21-day pressure transient test, although even this volume was eventually shown to be too small. During the 4 years of production, S-Cubed periodically updated the model in light of the most recent data.

In April 1985 and January 1986 there were short-term buildup tests from which the flow capacity could be recalculated. For both of these tests the flow capacity was calculated to be 28,340 md-ft rather than the previous $44,090 \mathrm{md}-\mathrm{ft}$. These tests were done after scale-inhibitor injection into the well, so S-Cubed interpreted this reduction to be caused by partial plugging of the perforations or formation below a shale stringer in the formation. The numerical model was therefore modified to include a stringer in the production interval that partially penetrated the formation. There were also increases in the skin factor attributed to the inhibitor injection (discussed below). To continue matching the pressure data through early 1986 with the model, the total reservoir volume in the model needed to be increased from 1.2 to 2.5 billion barrels.

In continuing to model the reservoir behavior during pressure buildup, S-Cubed found that the connected volume in the model needed to be increased even more. Exhibit 6.3.1-1 shows the dimensions of the model as it had evolved by 1990.14 By this time, the reservoir volume in the model that was needed to match the field data had been increased from the previous 2.5 billion barrels to a new volume of 7.8 billion barrels. This large increase in volume was needed to match the long-term bottomhole pressure buildup, which has continued to rise with no indication of reaching a plateau. Where the influx of fluid (presumed to be water) came from was unknown, but it was speculated to be either from shale de-watering or an influx from adjacent sands either above or below Sand 8. In the model, the extra volume was placed above the previous grid and partially isolated from the previous grid by a partial penetrating barrier. The permeability of this new volume was set low $(0.2 \mathrm{md})$. Both the horizontal and vertical permeability of this layer and the vertical permeability of the Sand 8 below it were set to this low value. Exhibit 6.3.1-2 shows the simulated pressure (sandface adjusted to 15,100 -foot datum level) compared to similar values calculated from the flowing wellhead pressure, and Exhibit 6.3.1-3 is the simulated pressure compared to the bottomhole pressures for the buildup test. There was no need to invoke any nonlinear mechanisms for the model, such as irreversible pore volume compaction. Their conclusion was that if there were any nonlinear effects, they would be close to the wellbore and would probably be masked by the skin factor.

\subsubsection{Use of Horner Plot to Estimate Reservoir Size}

The reservoir drained by the Gladys McCall well was so large that the reservoir had not clearly reached a pseudo-steady-state drawdown after years of production. The total reservoir volume could therefore not be accurately assessed by the computer model. Therefore, reservoir 
Flow Tests of the Gladys MCCall Well Through OCtober 1990
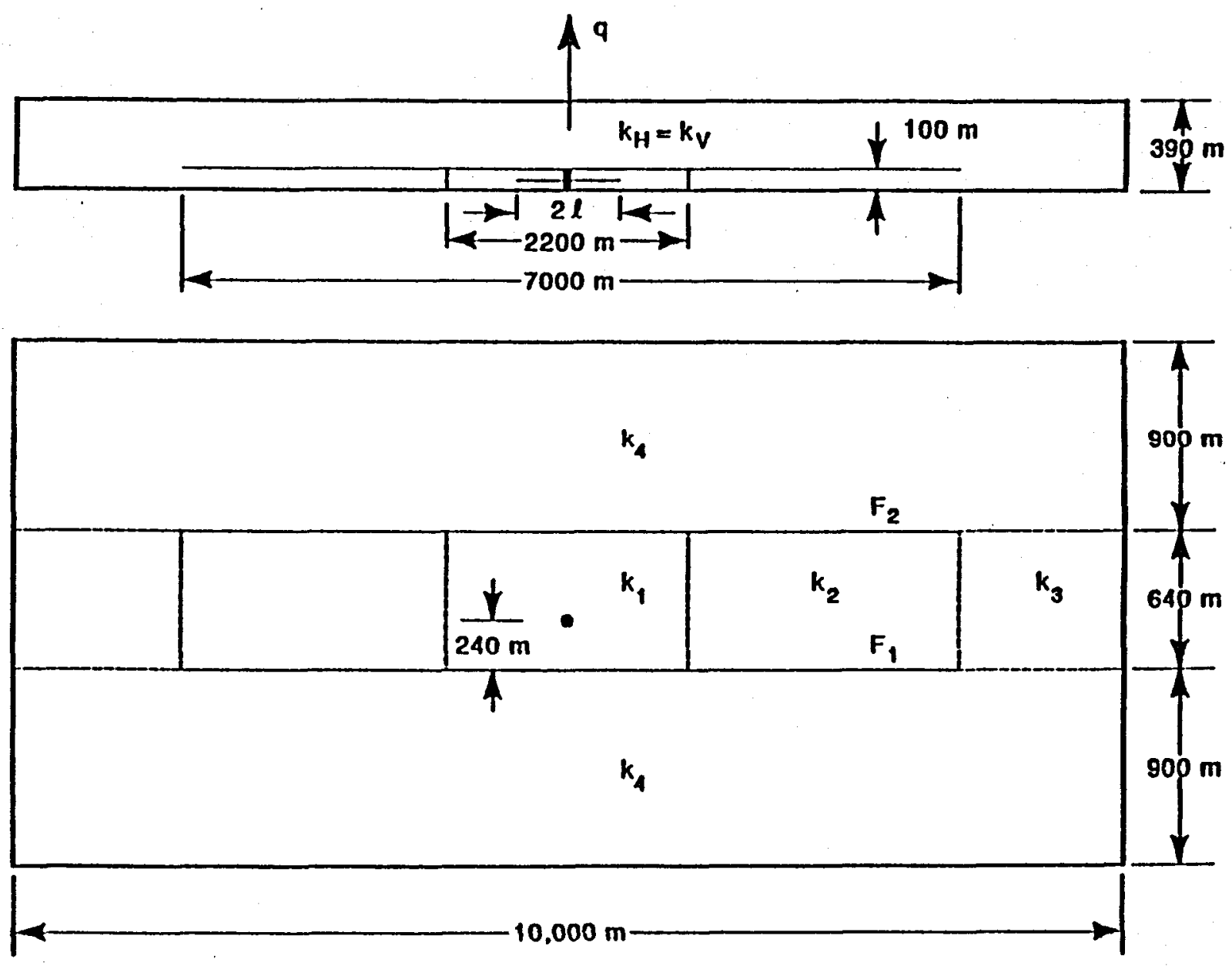

Exhibit 6.3.1-1. SCHEMATIC DIAGRAM OF THE GRID FOR THE NUMERICAL MODEL USED BY S-CUBED TO MODEL DATA 14 
Flow Tests of the Gladys MCCall Well Through OCtober 1990

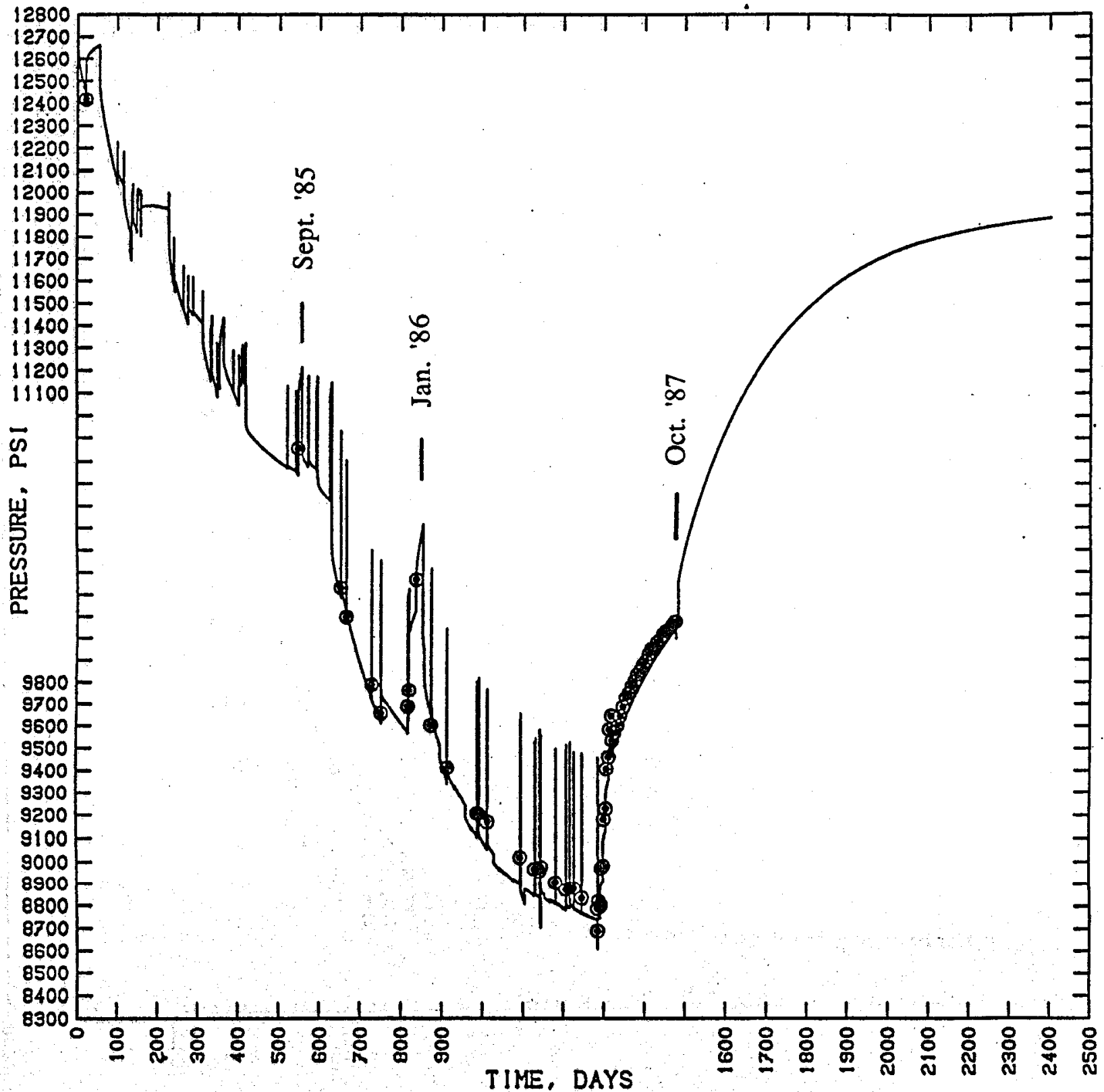

Exhibit 6.3.1-2. SIMULATED SANDFACE PRESSURES COMPARED TO VALUES ESTTMATED FROM FLOWING WELLHEAD PRESSURES 
Flow Tests of the Gladys MCCall Well Through OCtober 1990

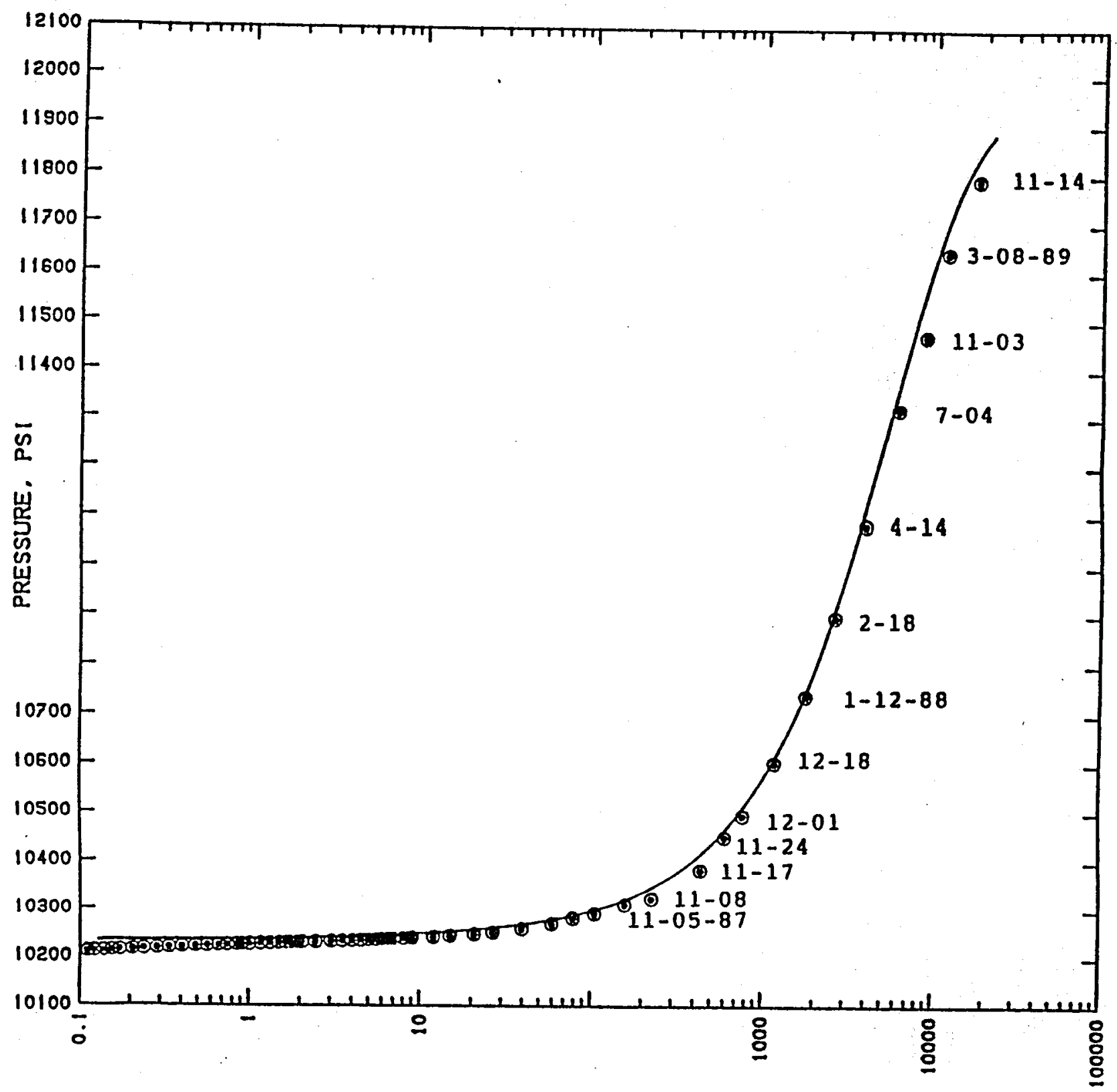

TIME MINUS 3.55988E+04, HOURS

Exhibit 6.3.1-3. SIMULATED PRESSURE BUILDUP COMPARED TO ACTUAL BUILDUP 
size was estimated with a Horner plot using long-term buildup data. The pressure-buildup data following the long-term production are plotted on a Horner plot in Exhibit 6.3.2-1. On the Horner plot, the final pressure to which the reservoir will recover after production is found where the extrapolation of the buildup curve intersects the $(T+\Delta t) / \Delta t=1$ axis. From this pressure and the material-balance equation, the reservoir volume can be estimated. A discussion of the engineering assumptions and input data that make up the basis of this graph is given in Appendix $F$.

For the McCall Horner plot, the pressure-buildup data curve is not expected to extrapolate as a straight line to the $(T+\Delta t) / \Delta t=1$ axis. The point marked $P_{f}$ is the end point that should be reached for the S-Cubed model with 7.8 billion barrels of reservoir volume. Whether the buildup would continue to build up to the value used by $S$-Cubed in the latest computer model is uncertain because the extrapolation requires a curved line that is not supported by the data. It may well be that the pressure, if left to build up indefinitely, would continue to rise to a value close to the original reservoir pressure. This would follow a more or less straight-line extrapolation that the data appears to be following. This hypothesized pressure response would require a much larger aquifer than the current model. It is anticipated that the well will be plugged and abandoned before definitive data can be obtained.

A possible conclusion from the Horner plot combined with the S-Cubed model is that there is a part of the reservoir intersected by the wellbore that contains 430,000 to 550,000 barrels of brine and has a high flow capacity $(39,000$ to $44,000 \mathrm{md}-\mathrm{ft})$ and that this high-flow-capacity part of the reservoir is in contact with a huge volume (at least as large as the 7.8 billion barrels used in the S-Cubed model) that has a very low flow capacity. The shape and orientation of the reservoir is not well-known because of the lack of other wells in the area that can be used to establish the geology and formation properties at the distances indicated by its size. The S-Cubed model takes all of the known geology into account even though the model describes the reservoir as being rectangular. The fact that the S-Cubed model matches the data so well is an indication that the volumes are approximately correct even if the exact shape is not known.

\subsection{Change in Sand 8 Reservoir Transmissibility}

Early determinations of the transmissibility (permeability times height, or kh) of the reservoir from short-term flow tests were presented in Section 6.1, and results of computer modeling were presented in Section 6.3. Additional draw-down or buildup testing with bottomhole pressure measurement was performed in 1985,1986 , and 1987. The results from the determinations of transmissibility for all of these tests are tabulated in Exhibit 6.4-1. 
Flow Tests of the Gladys MCCall Well through OCtober 1990

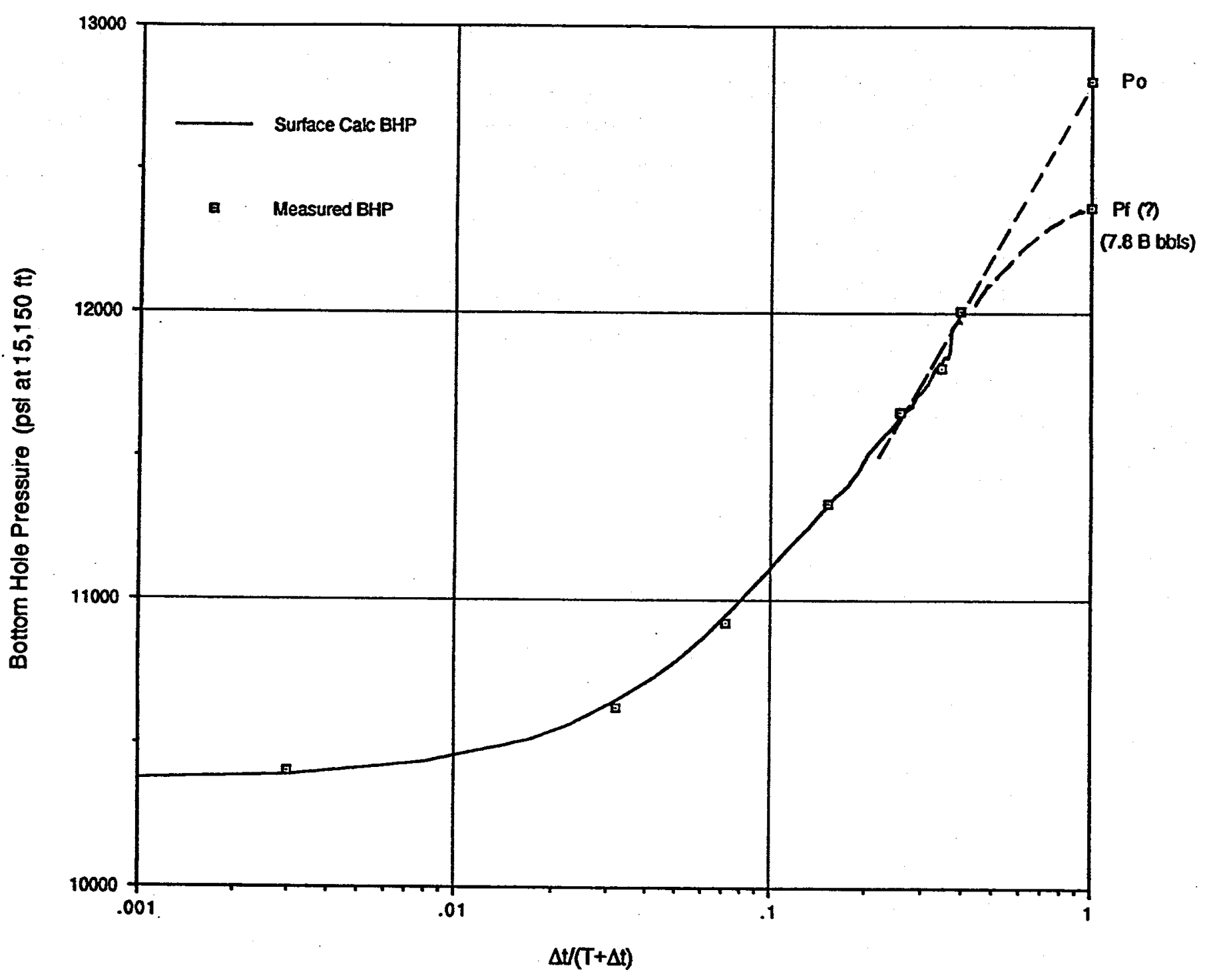

Exhibit 6.3.2-1. HORNER PLOT OF SAND 8 LONG-TERM BUILDUP TEST 


\section{Exhibit 6.4-1. CHANGE IN TRANSMISSIBILITY}

$\begin{array}{lcll}\text { Date of Test } & \text { Transmissibility, md-ft } & \text { Type of Test } & \text { Interpretation by } \\ \text { September 1983 } & 39,568 & \text { Draw-Down } & \text { J.D. Clark } \\ \text { October } 1983 & 37,057 & \text { Draw-Down } & \text { J.D. Clark } \\ \text { October } 1983 & 39,752 & \text { Buildup } & \text { J.D. Clark } \\ \text { October } 1983 & 44,090 & \text { Buildup } & \text { S-Cubed } \\ \text { April } 1985 & 28,340 & \text { Buildup } & \text { S-Cubed } \\ \text { January } 1986 & 28,340 & \text { Buildup } & \text { S-Cubed } \\ \text { January } 1986 & 28,770 & \text { Buildup } & \text { Eaton Oper. Co. } \\ \text { October } 1987 & 28,340 & \text { Draw-Down } & \text { S-Cubed } \\ \text { October } 1987 & 28,340 & \text { Buildup } & \text { S-Cubed }\end{array}$

\subsubsection{Possible Reasons for Lower Transmissibility}

The change from about 40,000 md-ft through October 1983 to about $28,000 \mathrm{md}-\mathrm{ft}$ subsequent to April 1985 is not understood. Four hypotheses have been that 1) the wellbore had become plugged such that the lower one-third of the perforated interval no longer contributed to production, 2) inhibitor-pill injection had reduced permeability in the vicinity of the wellbore, 3) drawdown of reservoir pressure to below the bubble point had reduced the relative permeability to brine, and 4) the increased compressive stress on the rock matrix due to drawdown of reservoir pressure had decreased the area available to flow between sand grains. Each of these is discussed below.

1. Plugging of the Wellbore: This possible reason for the decrease in transmissibility was triggered by the observation that the wireline trip into the well in April 1985 stopped at a depth of about 15,365 feet when resistance was encountered. Then, in response to a request from S-Cubed personnel, a University of Texas expert on interpretation of wireline logs observed that there was a shale stringer at that depth that could conceivably combine with a plug in the wellbore to preclude production from the lower one-third of the perforated sandstone.

S-Cubed modeling of production with the assumption that perforations below 15,365 feet could not contribute to production gave a nice fit to the data. However, in January 1986, the wireline was run to the depth of the bottom perforation. No obstruction was found in the perforated area. Additional doubt upon the viability of this hypothesis resulted from a spinner survey attempted in August 1987. The spinner data will be discussed later under a separate heading. 
2. Permeability Reduction by Inhibitor Pills: The April 1985 test was performed after the attempt to inject an inhibitor pill into the formation in November 1984. The reported skin factor for the April 1985 test was 8.5. This is considerably higher than the skin factor of 2.5 calculated for the 1983 tests. There was another unsuccessful attempt to inject an inhibitor pill during May 1985, and the first successful attempt was made in June 1985.

The January 1986 buildup test was performed after the successful attempt to inject an inhibitor pill into the reservoir. The skin factor value reported by S-Cubed was 5.1. One possible interpretation was that a portion of the reservoir remained plugged, and there was no efficient mechanism to flush precipitates from pores. However, following another successful inhibitor pill injection in February 1986 and the production of many millions of barrels of brine, the skin factor calculated for the October 1987 shut-in was down to 3.0. This is only slightly higher than the value of 2.5 for the 1983 reservoir limit test.

3. Lowering of Relative Permeability to Water by Free Gas: Drawdown of pore pressure to below the bubble-point pressure for gas in solution in the brine would result in gas coming out of solution and residing in pores as a free-gas phase. This gas would not become mobile until the amount was sufficient to exceed a critical gas saturation of at least $3 \%$ of the pore volume. At the same time, the fractional gas saturation of the pore space would decrease the relative permeability to brine.

The identical values of 28,340 md-ft for transmissibility in April 1985 and October 1987 make it unlikely that this lower value is caused by a partial gas saturation of pore space. The lowest flowing bottomhole pressure prior to April 1985 was above 10,500 psi and clearly above the bubble-point pressure of the reservoir brine. In contrast, the calculated flowing bottomhole pressure was almost down to 8600 psia in April 1987. Even after accounting for skin pressure drop, the pore pressure near the wellbore is believed to have been well below the bubble point.

4. Permeability Reduction Due to Stress on the Rock Matrix: Assuming an average overburden pressure gradient of $1.000 \mathrm{psi} / \mathrm{ft}$ of depth, the pressure due to the column of rock from ground level to the top perforation is about 15,145 psia. For the initial reservoir pressure of 12,821 psia measured at this depth, the net overburden compressive stress of the rock matrix was the difference between these values or about $2324 \mathrm{psi}$. The lowest flowing bottomhole pressure before completion of the 1983 measurements of transmissibility was about 12,400 psia, and the maximum net stress on the reservoir rock was about 2750 psi.

In contrast, bottomhole pressure had been drawn down to 10,500 psi for a net stress on the rock matrix of about 4650 psia in April 1985. At the maximum drawndown to almost 8600 psia in April 1987, the net stress on the rock matrix may have been as high as $6500 \mathrm{psi}$. But at the 
Flow TES TS OF THE GLadys MCCALL Well Through OCtober 1990

reduced flow rate of about 10,000 BPD at the times of shut-in in January 1986 and October 1987, the values of maximum net stress on the rock matrix adjacent to the wellbore were about 4850 and 5050 psi, respectively.

The above values suggest that compression of the rock matrix could be a reason for the change in transmissibility. The reduction in transmissibility from about 40,000 to about 24,000 md-ft correlates with doubling of net stress on rock adjacent to the wellbore from about 2500 to about 5000 psi.

\subsubsection{August 27. 1987. Spinner Survey}

To test whether a portion of the formation was plugged and not contributing to the total flow, a spinner survey across the perforated interval (15,160 to 15,470 feet) was attempted on August 27,1987 . The effort was partially successful, but interpretation of the data is complicated because of poor and decaying response of the tool. Brine production was constant at about 10,000 STB/d, but non-zero readings were obtained with the tool below the packer only when the logging tool was moving downward.

Exhibit 6.4.2-1 shows the response of the spinner while logging down through the packer at a rate of $65 \mathrm{ft} / \mathrm{min}$. Above $13,860 \mathrm{feet}$, the tool was moving through 4.276 -inch-ID tubing. The higher spinner rate between about 13,865 and 13,880 feet is caused by the 3.480 -inch ID of the seal assembly. The 12 feet of lower spinner rate and then the 8 feet of higher spinner rate are caused by the larger diameter inside the polished bore receptacle and the smaller diameter inside the packer, respectively. The low spinner rate below 13,910 feet reflects tool and fluid movement in the 7-inch, 38-pound-per-foot casing (5.920-inch ID).

The seal bore extension is above the packer and the distance from its top to the bottom of the packer is 34 feet. The spinner data in Exhibit 6.4.2-1 show 20 feet from the bottom of the packer to the bottom of the seal assembly. Thus, the seal assembly was found to extend 14 feet into the seal bore extension. This is in excellent agreement with the 12 feet reported at the time of well completion.

The logging pass through the packer shown in Exhibit 6.4.2-2 differs from subsequent logging passes in that the tool output was greater than zero in the casing for a tool velocity of only 1.1 foot per second. It is noted that the data in Exhibit 6.4.2-2 show that the tool response was a nonlinear function of fluid velocity relative to the logging tool. For a 10,000 -BPD production rate, fluid velocity in the tubing was $6.5 \mathrm{ft} / \mathrm{s}$ in the tubing and $3.4 \mathrm{ft} / \mathrm{s}$ in the casing. Adding the 1.1-ft/s downward velocity of the logging tool, the fluid velocities relative to the logging tool were $7.6 \mathrm{ft} / \mathrm{s}$ in the tubing and $4.5 \mathrm{ft} / \mathrm{s}$ in the casing. The ratio of these velocities was 1.7:1. But the ratio of tool responses was $7.3: 2.6$ or $2.8: 1$. 
Flow TeSts of the Gladys MCCall Well Through OCtober 1990

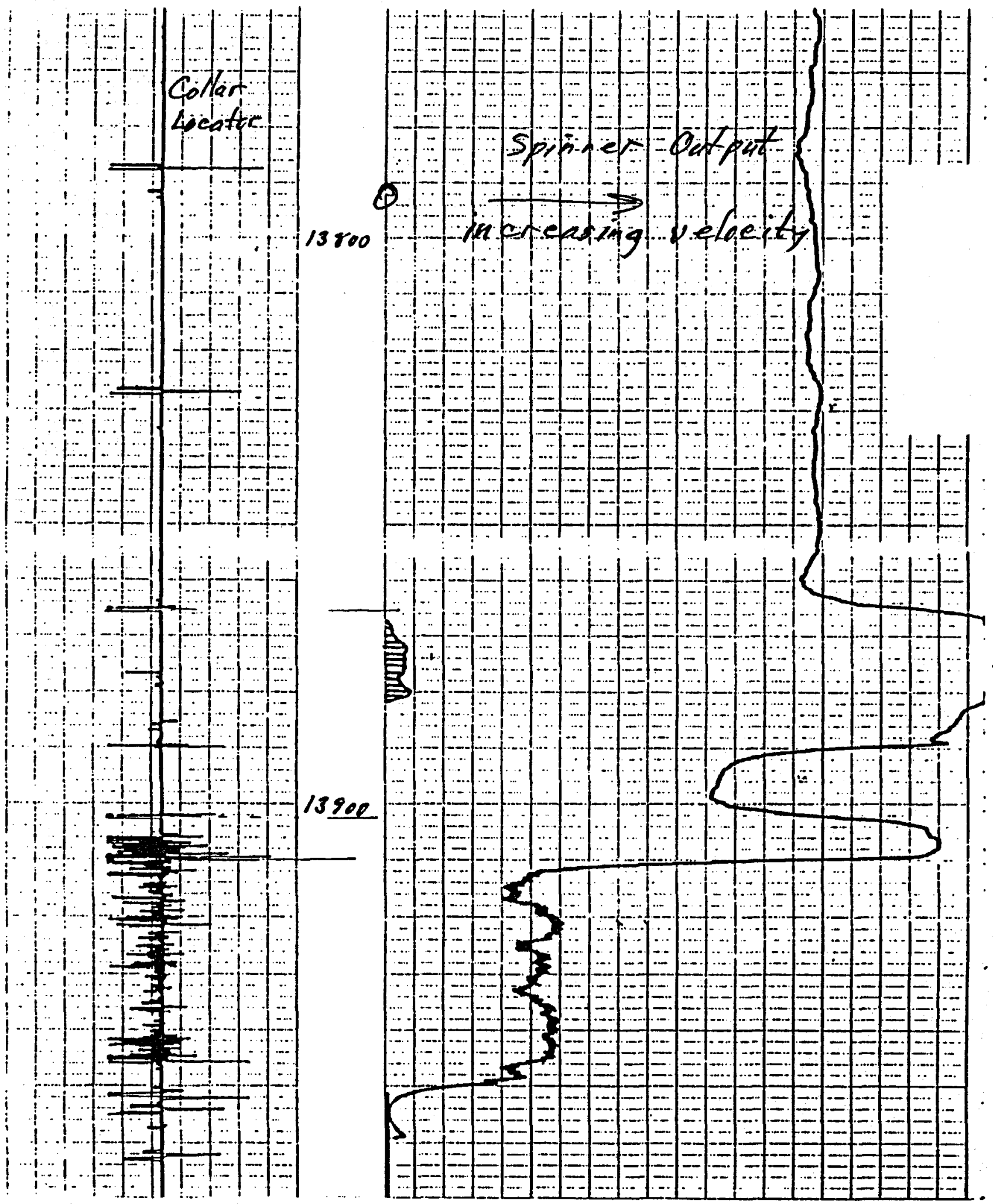

Exhibit 6.4.2-1. SPINNER LOGGING DOWN THROUGH THE PACKER AT $65 \mathrm{ft} / \mathrm{min}$ 
Flow Tests of the GLAdys MCCALL Well THROUgh OCTOBER 1990

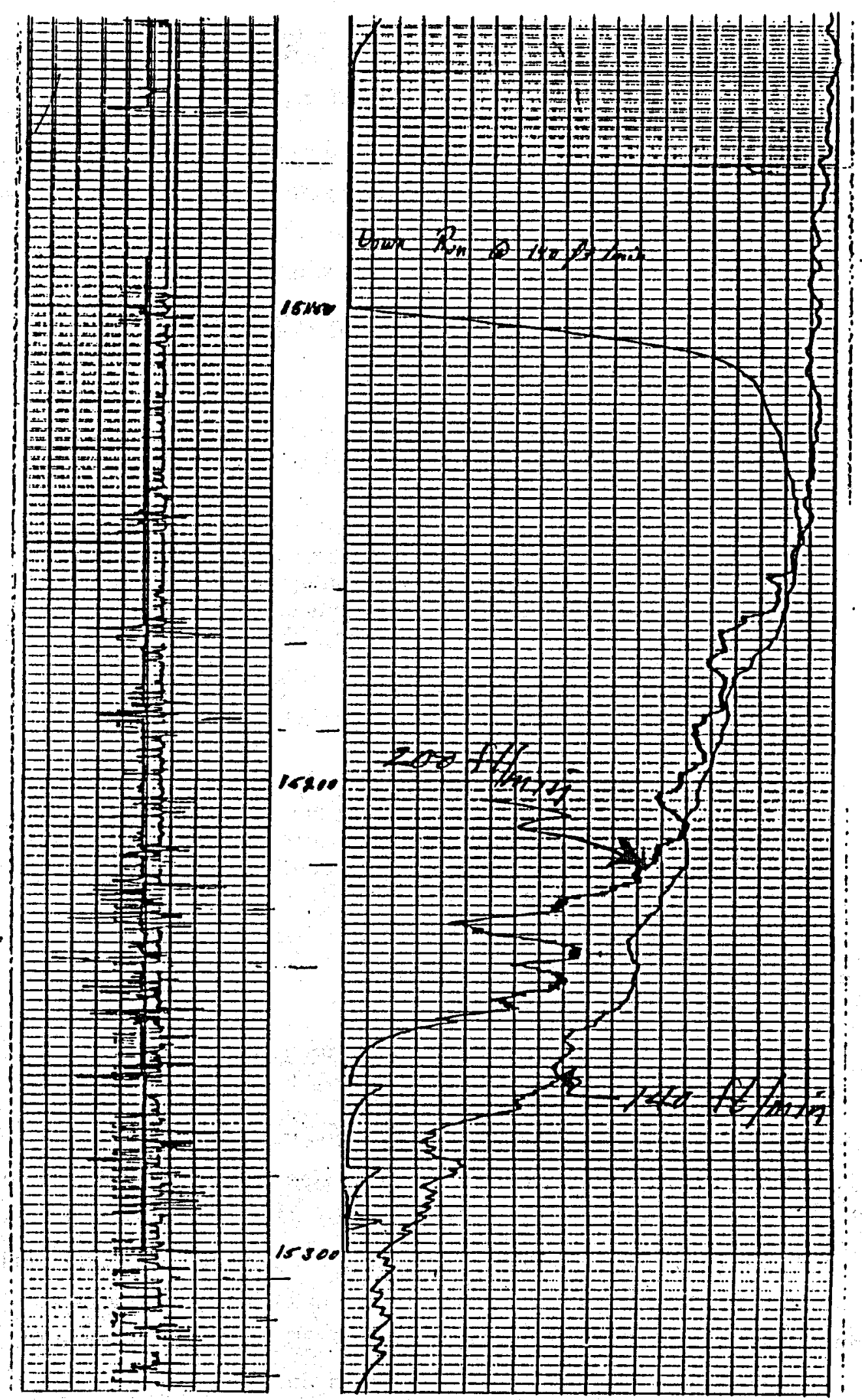

Exhibit 6.4.2-2. SPINNER LOGGING DOWN ACROSS PERFORATIONS AT 140 AND $200 \mathrm{ft} / \mathrm{min}$ 
Logging passes were recorded through portions of the perforated interval using logging speeds of $150,140,130$, and $200 \mathrm{ft} / \mathrm{min}$. However, the tool response was deteriorating with time.

Exhibit 6.4.2-2 is an overlay of spinner response for downward logging speeds of 140 and $200 \mathrm{ft} / \mathrm{min}$. The higher speed pass was later in time and suggests a cutoff in fluid entry at a shallower depth than the lower speed pass. This is the opposite of what would have been observed if the logging tool repsonse were not deteriorating with time.

Although the data are not adequate to profile fluid entry as a function of depth, it provides a basis for the following qualified conclusions:

1. Fluid entry is roughly a linear function of depth for the first 100 feet of perforations $(15,160$ to $15,260 \mathrm{feet})$. This was observed on a half dozen logging passes and the last, at $200 \mathrm{ft} / \mathrm{min}$, is the only exception.

2. About half of the produced brine enters the wellbore below the midpoint of the perforations at 15,315 feet. This is about the depth where spinner response went to zero for the majority of downward logging passes. But the zero output corresponded to a fluid velocity of 4.0 to $4.5 \mathrm{ft} / \mathrm{s}$ relative to the logging tool. Downward logging tool velocity was most often about $2.5 \mathrm{ft} / \mathrm{s}(150 \mathrm{ft} / \mathrm{min})$. Thus, tool output dropped to zero at the depth where fluid velocity dropped to about 1.5 to $2.0 \mathrm{ft} / \mathrm{s}$ relative to the casing. This corresponds to a brine rate in the range of 4400 to 5900 BPD. Thus, brine rate at the midpoint of perforations appears to be about one-half of the production rate of 10,000 BPD.

3. Some fluid is entering the wellbore from near the deepest perforations $(15,470 \mathrm{ft})$. The logging tool was lowered to this depth with a loss of only about 40 to 60 pounds of weight (much less than the weight of the tool and sinker bars). A pickup of that weight was observed at $14,466 \mathrm{ft}$. Thus, it is clear that any solids shallower than that depth are either carried out of the wellbore or fluidized by deeper fluid entry.

4. The entire reservoir thickness was shown to be contributing to the flow, thereby casting doubt on the interpretation that a large portion of the perforations below the shale stringer were plugged off.

\subsection{CHARACTERISTICS OF HYDROCARBONS PRODUCED FROM SAND 8}

Natural gas that was in solution in the brine in the reservoir constitutes the majority of produced hydrocarbons. The recovered gas has a relatively high content of carbon dioxide and aromatics (benzene, toluene, etc.). After gas sales began in 1984, separator pressures were kept high enough to limit the carbon dioxide content of gas to $10 \%$ because of specifications in the gas sales contract. The aromatic compounds have higher solubility in brine than alkanes with comparable molecular weight. At the temperature of about $280^{\circ} \mathrm{F}$ of natural gas leaving the separators, the aromatics constitute a major portion of $\mathrm{C} 6+$ hydrocarbons in the high-temperature gas stream. 
Initially, gas leaving the single separator was flared and the only constraint on separator pressure was the pressure required to drive brine into the disposal well. In 1984, a gas sales contract was agreed to. It provided for delivery of gas containing up to $10 \%$ carbon dioxide into a line with a normal operating pressure of about $1000 \mathrm{psig}$. At this pressure, about one-fourth of the produced gas remains in the brine. After a separator study revealed that lower pressure operation of a second separator and purchase of a gas compressor would pay out in terms of increased gas sales, a second large separator, previously used at the Sweet Lake Design Well test, was installed for low-pressure operation.

When the gas from the separators was cooled prior to dehydration, both hydrocarbons and water vapor condensed from the gas stream. The condensing hydrocarbons had a high aromatic content. In addition, a small amount of paraffinic oil collected in the high-pressure separator. This was periodically flowed over the oil weir and manually bled off from the oil outlet of the threephase separator.

Details of the collection and.analysis of samples of the produced gas are presented in Section 7.1 below. Similar details for the recovered liquid hydrocarbons are in Section 7.2.

\subsection{Produced Gas Composition}

Numerous gas samples were collected from several different points in the process stream and were analyzed by various parties during the course of this project. Sample points include the highpressure (HP) and low-pressure (LP) separator meter runs, sample points located directly on the separators, cooled and dehydrated gas commingled from the separators, and gas flashed from brine from the separators while lowering the pressure to atmospheric. The sample points were shown in the schematic diagram in Exhibit 4.0-1. The composition of the gas at a sample point depended on the pressure and temperature at the point and upon whether gas separation had preceded it. Appendix $G$ gives the results of all gas analyses available. Some of these were previously reported. 17

Typical analyses of a first-stage separator gas, a second-stage separator gas, and of gas flashed off brine after the second separator are shown in Exhibit 7.1-1. Also included is a computational recombination of these gases to estimate the composition of the total gas. A more detailed analysis of a sales-gas sample (LP separator gas compressed and commingled with HP separator gas), collected on October 21, 1987, is shown in Exhibit 7.1-2. This analysis gives a breakdown of the heavy hydrocarbons that constitute the $\mathrm{C} 6$ fraction of the gas. The gas contains a little less than $10 \%$ carbon dioxide and the $\mathrm{C} 6+$ fraction contains more than twice as much aromatics as alkanes. 
Flow Tests of The GLadys MCCALL Well Through OCtober 1990

Exhibit 7.1-1. TYPICAL GAS ANALYSES, FEBRUARY 19, 1987

Sample Source

Pressure, psia

GWR, SCF/STB

Mole Percent of:

Carbon Dioxide

Nitrogen

Methane

Ethane

Propane

iso-Butane

$n$-Butane

iso-Pentane

$n$-Pentane

C6+

Gas Grav (air $=1$ )

Heating Value,

Btu/SCF

Liquids
HP Sep Gas

1015

22.86

7.91

0.25

88.57

2.40

0.53

0.08

0.07

0.02

0.02

0.15

0.656

968

0.93
Gas in Brine

LP Sep Gas Leaving LP Sep

285

4.44

285

1.75

29.05
Total Gas,

Calculated

20.52

0.16

77.22

1.64

0.24

0.02

0.02

0.01

0.00

0.17

0.769

828

0.60
37.39

0.81

60.25

1.05

0.10

0.01

0.00

0.00

0.00

0.08

0.927

637

0.35
11.61

0.27

85.13

2.20

0.46

0.07

0.06

0.02

0.02

0.15

0.690

927

0.85

\subsubsection{Separator Studies}

Early flow tests on this well were performed using only one separator. The long-term production test plan included selling the produced gas. The sales-gas line operating pressure was about 1000 psig. It had been shown on previous wells that about 7 cubic feet of gas remain in the brine at a separator pressure of 1000 psig. This is almost one-fourth of the total produced gas, although the concentration of carbon dioxide in this gas is generally above $20 \%$.

An early priority was to determine whether two-stage separation, with the costs associated with installing a second separator and a compressor, could be justified based on incremental recovery of the low-pressure separator. Relevant constraints in gas sales contracts were that the gas contain less than $10 \%$ carbon dioxide and less than 35 ppmv hydrogen sulfide. Lowering separator pressure increases the carbon dioxide and hydrogen sulfide content of the gas. Singlestage separator pressure below about 700 psig caused the carbon dioxide concentration to exceed the $10 \%$ limitation.

A series of tests were performed with a small separator borrowed from another location in series with the original separator. The separator study involved collecting gas samples from the separator and collecting brine from the brine outlet of the separator at a variety of separator pressures. The gas samples were analyzed. The brine was then flashed to atmospheric pressure 
FLOW TESTS OF THE GLADYS MCCALL WELL THROUGH OCTOBER 1990

\section{Exhibit 7.1-2. GAS ANALYSIS OF McCALL SALES GAS \\ BY GC/TCD/FID, OCTOBER 21, 1987}

\section{Mole Percent of:}

Helium

$\mathrm{BDL}^{\mathrm{a}}$

Hydrogen

Oxygen/Argon

Nitrogen

0.07

Carbon Dioxide

0.33

Methane

9.38

Ethane

87.1

Propane

2.40

iso-Butane

0.51

n-Butane

0.08

neo-Pentane

0.07

iso-Pentane

BDL

n-Pentane

0.03

0.01

Sum of Hexanes $\quad 0.007$

Sum of Heptanes $\quad 0.005$

Sum of Octanes $\quad 0.003$

Sum of Nonanes $\quad 0.001$

Sum of Decanes $\quad 0.001$

Sum of Undecanes $\quad 0.001$

Sum of Dodecanes \& Heavier $\quad 0.001$

Benzene $\quad 0.029$

Toluene $\quad 0.014$

$o, m, p$-Xylene \& Ethylbenzene $\quad 0.009$

C3 Benzenes

0.001

Calculated Heating Values,

Btu/SCF $\left(60^{\circ} \mathrm{F}, 15.025 \mathrm{psia}, \mathrm{dry}\right) \quad 960$

Calculated Gravity (air $=1$ )

a $\mathrm{BDL}=$ Component concentration below detection limit $(0.01 \%)$.

and the gas that exsolved was measured and analyzed. Separator pressure was varied, and the effect of separator pressure on both the quantity of gas remaining in the disposal well brine and the quality of the separator gas was determined. These tests showed that for a two-stage separation, second-stage pressures well below 400 psig were achievable while keeping the carbon dioxide content of the combined gas below the contractual gas-sales maximum of less than $10 \%$.

A second large DOE-owned separator became available early in 1984 after production testing of the Sweet Lake Design Well was completed. This separator, which was identical to the highpressure separator, was installed in series after the first separator. The first separator was operated 
at the gas sales pressure of about 1000 psig so that the majority of the produced gas could be sold without compression. The second separator was operated at the lowest practicable pressure, which was dictated either by the carbon dioxide ceiling in the sales gas contract or by the pressure required to inject brine down the disposal well.

The carbon dioxide content of the commingled sales gas is plotted versus the second-stage separator pressure in Exhibit 7.1.1-1. The scatter in this graph reflects the effects of brine temperature. The effect of temperature on carbon dioxide solubility is very pronounced. At brine rates above $20,000 \mathrm{STB} / \mathrm{d}$, the brine temperature remained within a few degrees of $280^{\circ} \mathrm{F}$. However, during the reduced flow rate of 9300 STB/d in October 1987, the brine temperature at the separator was $268^{\circ} \mathrm{F}$. At the lower brine temperature, the carbon dioxide has a stronger tendency to remain with the brine. The two points on the lower left-hand corner of the graph reflect data obtained at this lower temperature and are obviously outside the trend of the data obtained at higher temperatures. A similar variation of carbon dioxide content with temperature was observed in the IGT separator studies on the HO\&M Prairie Canal Well. 7

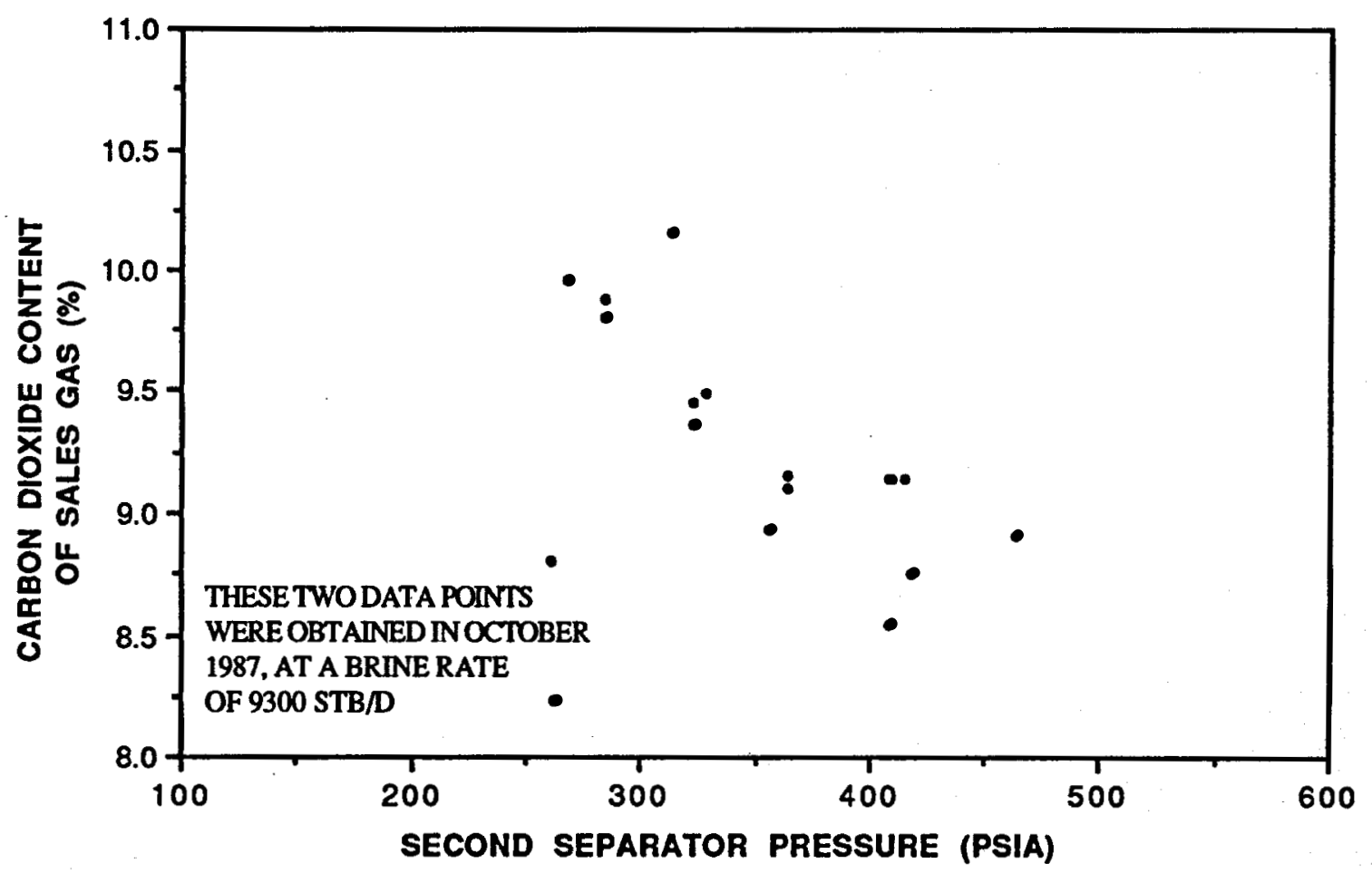

Exhibit 7.1.1-1. SALES GAS CARBON DIOXIDE CONCENTRATION VERSUS SECOND-STAGE SEPARATOR PRESSURE 
The relationship between the separator operating pressure and the gas contained in the brine after the separator is shown in Exhibit 7.1.1-2. At the first-stage separator pressures, generally near 1000 psig, about 7 SCF gas/STB brine would not be recovered by the separator. This is roughly $25 \%$ of the total gas produced. The hydrocarbon fraction of this gas is about 5 cubic feet. Exhibit 7.1.1-3 shows the gross heating value of the gas remaining in each stock tank barrel of brine leaving separator versus the separator pressure.

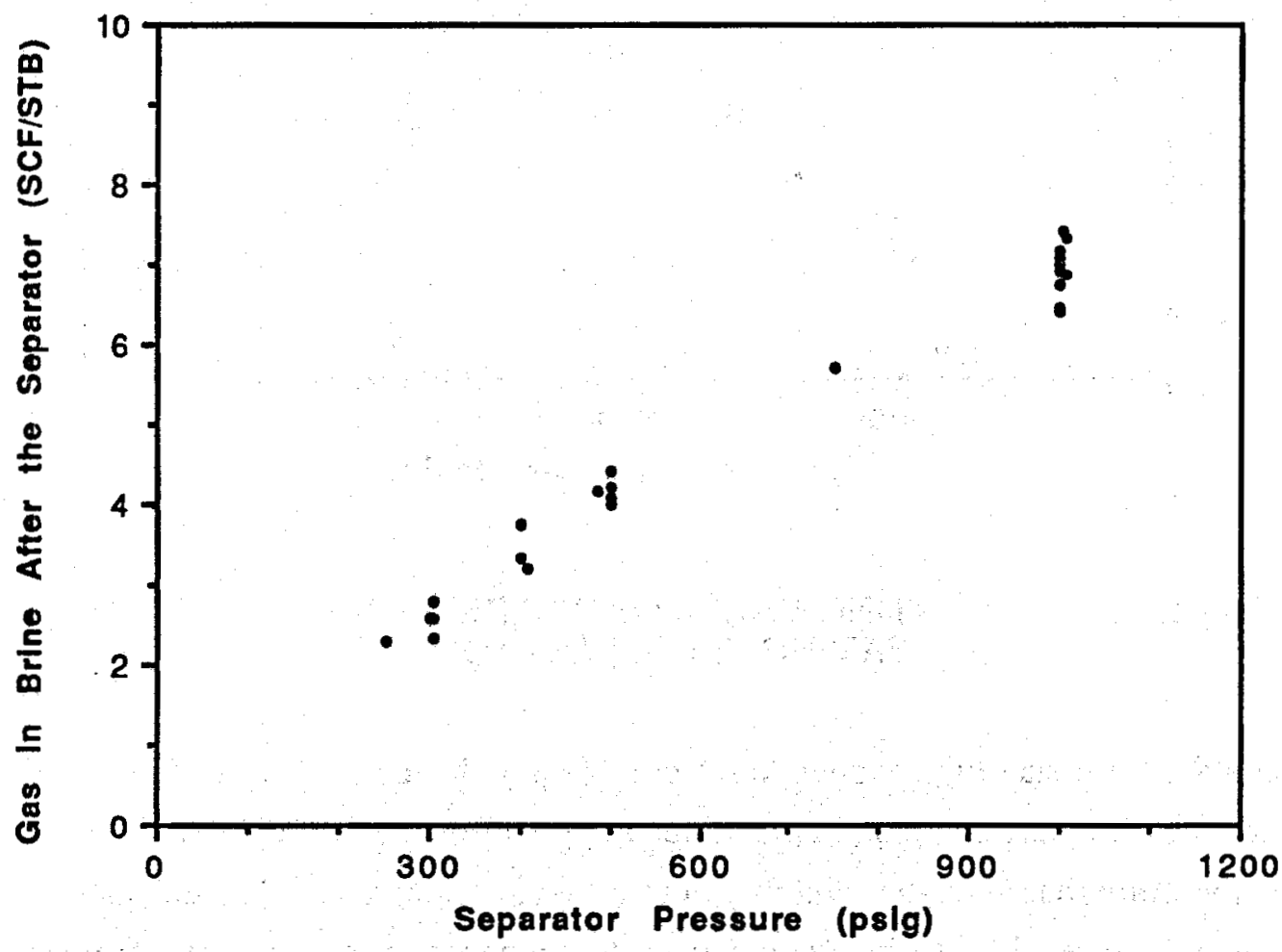

\section{Exhibit 7.1.1-2. GAS REMAINING IN BRINE AFTER THE SEPARATOR}

An additional 2 to 5 cubic feet of gas per barrel of brine could be recovered by the secondstage separator, depending on the second separator operating pressure. Operating the second-stage separator at 400 psig pressure recovered roughly 4 SCF of gas containing about 3000 Btu's of combustion energy that would otherwise be injected into the disposal well with the injected brine.

\subsection{Correcting Gas Production Rates for Gas Remaining in the Brine After the Separator}

The high-pressure separator was kept at the sales-line gas pressure of about $1000 \mathrm{psig}$ pressure during the long-term test of Sand 8. The low-pressure separator pressure was kept high enough to limit the carbon dioxide content of the commingled gas from the two separators to below 


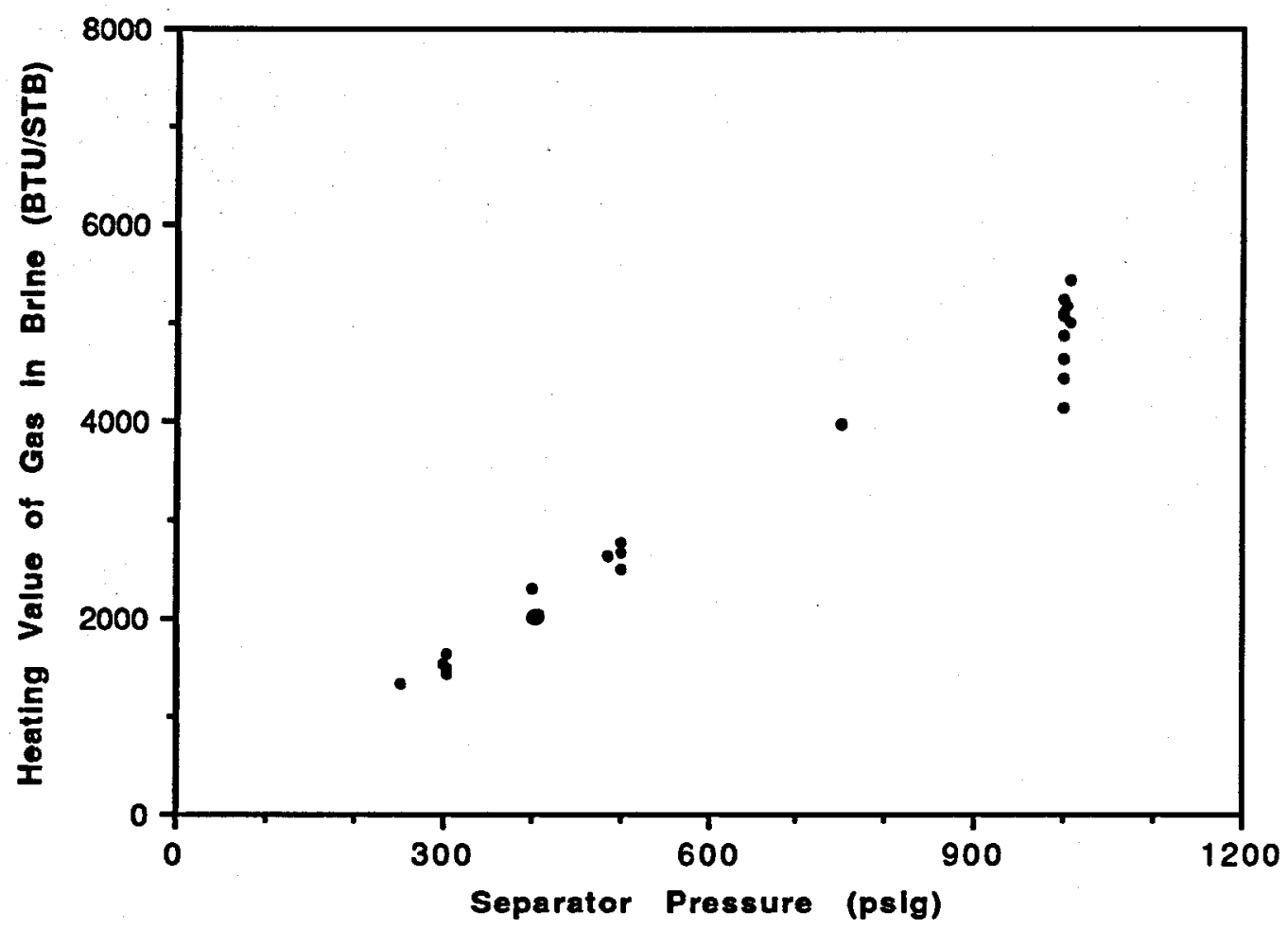

Exhibit 7.1.1-3. HEATING VALUE OF GAS REMAINING IN BRINE LEAVING THE SEPARATOR

$10 \%$ or to maintain a pressure high enough to inject brine into the disposal well. There was still a considerable quantity of gas remaining in the brine after the low-pressure separator. IGT had developed an algorithm (based on the solubility of methane in brine) to estimate the quantity of this gas, and this quantity was added to the recovered gas to obtain a total produced gas from this well.

The diamonds in Exhibit 7.1.2-1 are the amounts of gas obtained by flashing separator brine to atmospheric pressure (performed by IGT and Weatherly). The squares with the dots in the middle represent calculated values using the IGT algorithm. The calculated value is lower than the measured flashed gas by about $20 \%$ to $30 \%$. The algorithm is based only on methane solubility in brine, not natural gas containing carbon dioxide and heavier hydrocarbons. Exhibit 7.1.2-2 is a plot of the methane content of the brine against the methane partial pressure rather than the total gas pressure. The IGT algorithm is reproduced on this graph. With this adjustment there is excellent agreement between the field data and the algorithm derived from laboratory data. Nevertheless, the reported gas production and gas/brine ratio are low. The amount of the error is roughly $1 / 2$ cubic foot per barrel of brine. The justification for continuing use of this algorithm is that it accurately reflects the hydrocarbon content of the dissolved gas, which is most important to end users. 
FLOW TESTS OF THE GLADYS MCCALL WELL THROUGH OCTOBER 1990

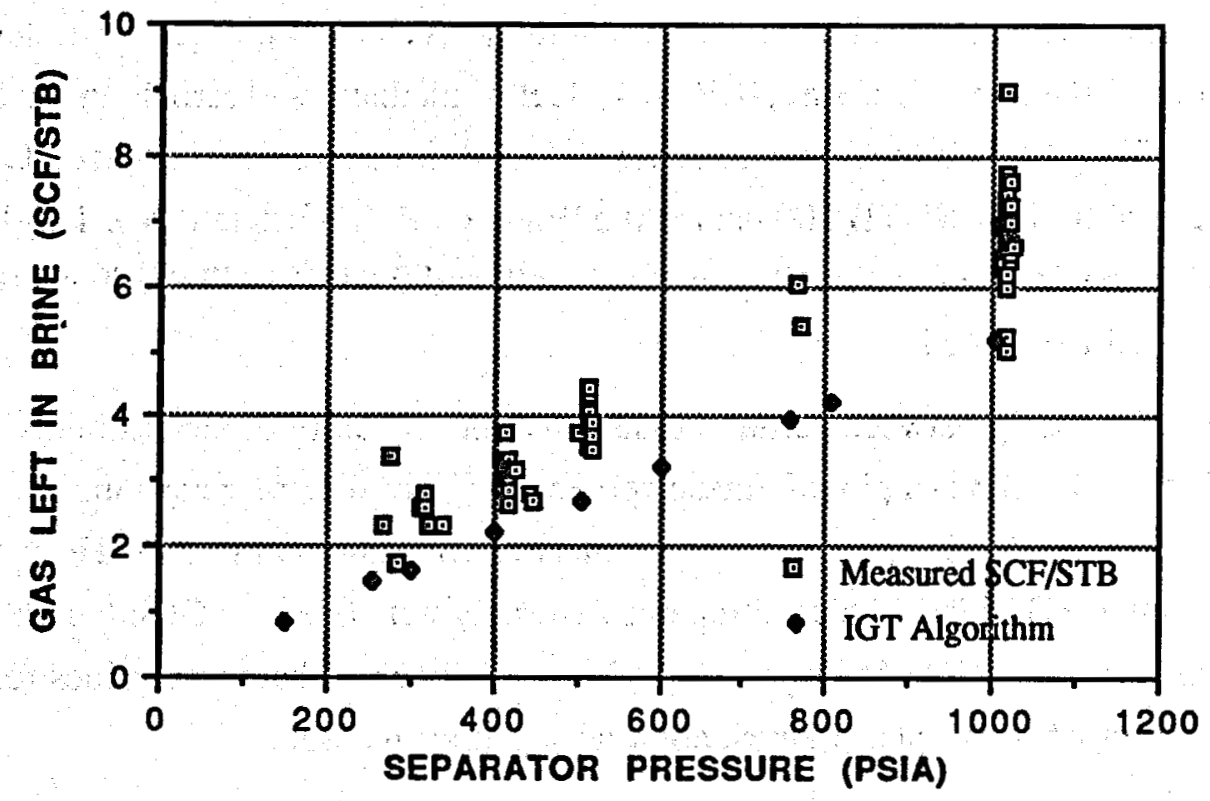

Exhibit 7.1.2-1. GAS LEFT IN BRINE VERSUS SEPARATOR PRESSURE

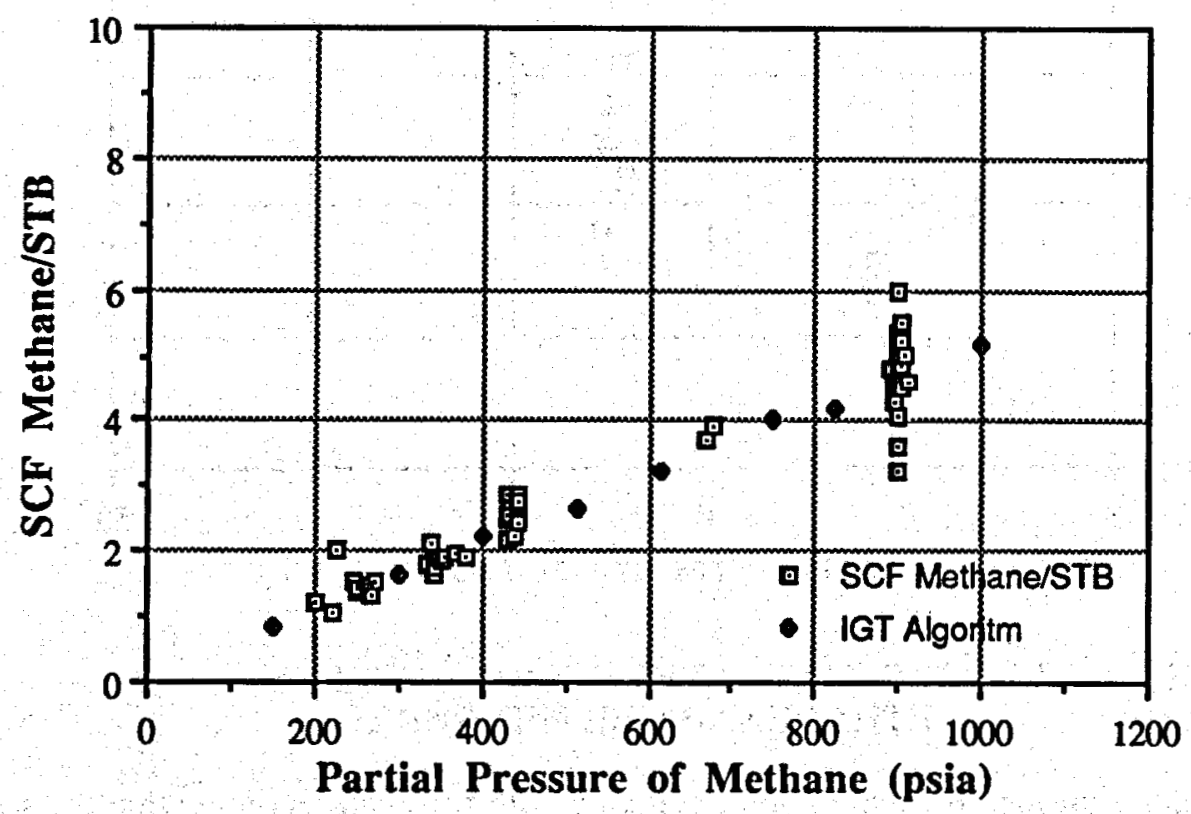

Exhibit 7.1.2-2. METHANE LEFT IN BRINE VERSUS METHANE PARTIAL PRESSURE 
It is clear from Exhibit 7.1.2-2 that the methane content remaining in the brine after the separator is consistent with Henry's Law in that its solubility is close to a linear dependence. For every 100 psi of methane partial pressure, 0.56 SCF/STB of methane will remain in the brine. This value for the Gladys McCall well can be compared with similar values for other DOE projects. IGT found a value of 0.62 SCF/STB/100 psi for the Wainoco P. R. Girouard No. 1 well, $0.60 \mathrm{SCF} / \mathrm{STB} / 100$ psi for the Pleasant Bayou No. 2 well, and $0.53 \mathrm{SCF} / \mathrm{STB} / 100$ psi for the HO\&M Prairie Canal No. 1 well.

This linear relationship between partial pressure and the solubility of the gas holds for ethane and propane. Exhibit 7.1.2-3 is a plot of ethane content of disposal brine versus the ethane partial pressure in the separator. Again, there is a simple linear relationship that follows Henry's Law, with $0.0040 \mathrm{SCF}$ ethane/STB/psi, which compares favorably with $0.0038 \mathrm{SCF}$ ethane/STB/psi ethane partial pressure at the HO\&M Prairie Canal No. 1 Well. Note that these values for solubility are valid only for partial pressures, not total separator pressure.

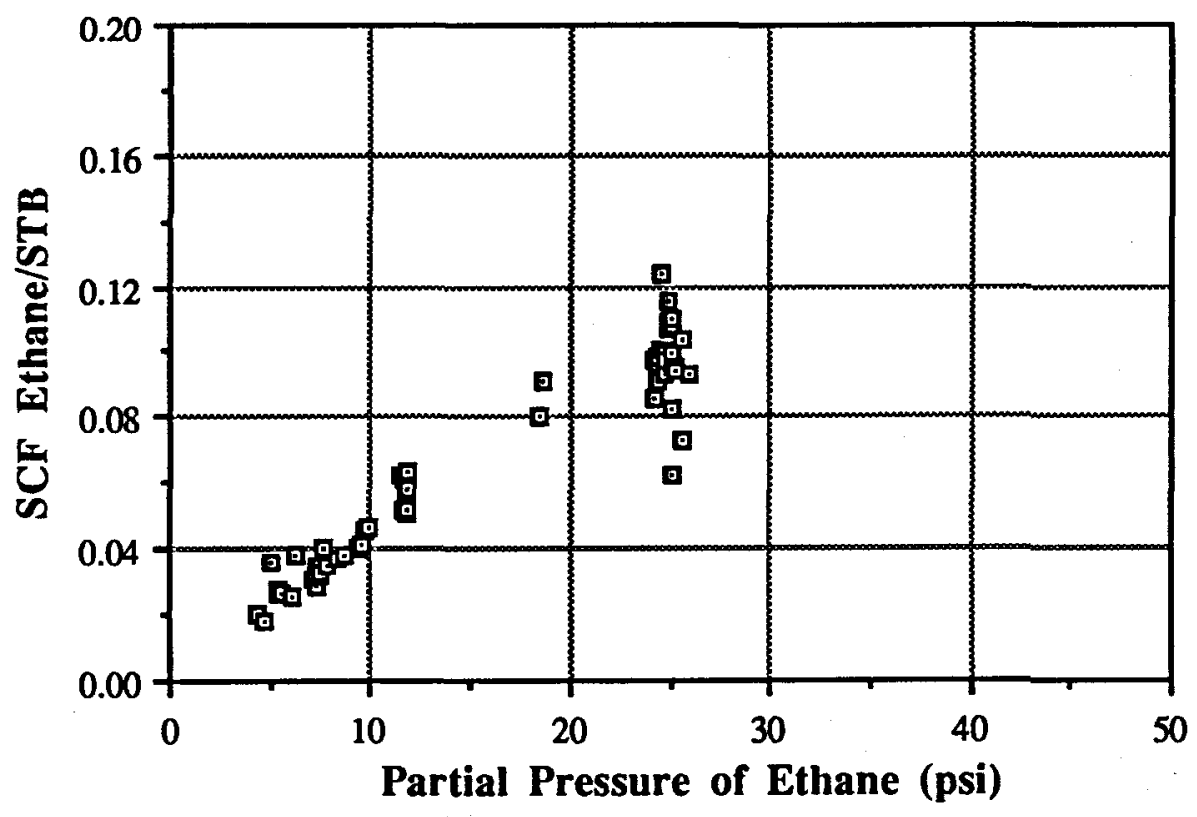

\section{Exhibit 7.1.2-3. ETHANE LEFT IN BRINE VERSUS ETHANE PARTIAL PRESSURE}

These simple relationships, which do not change with flow rate, indicate that the separators are at equilibrium and the only way to recover more methane would be to lower the separator pressure. 


\subsection{Field Measurements of Hydrogen Sulfide and Carbon Dioxide}

Throughout most of the long-term flow test of Sand 8, measurements of the carbon dioxide and hydrogen sulfide content in the gas were made on a routine, daily basis. The tests were made with a hand-held apparatus where a sample of gas is aspirated by a calibrated squeeze bulb through a small glass tube, which is pre-charged with an indicating medium that changes color depending on the amount of $\mathrm{CO}_{2}$ or $\mathrm{H}_{2} \mathrm{~S}$ in the gas (Draeger Tubes). Exhibit 7.1.3-1 shows the reported carbon dioxide content in the first separator (high-pressure) and second separator (low-pressure) for the entire 4-year test period. Exhibit 7:1.3-2 is a similar plot for the hydrogen sulfide content of gas from the two separators. Exhibit 7.1.3-3 plots both the carbon dioxide and hydrogen sulfide measurements for the combined gas sent to sales. The hydrogen sulfide content of the combined gas stream was comfortably below the sales-gas contract specification of $35 \mathrm{ppm}$.

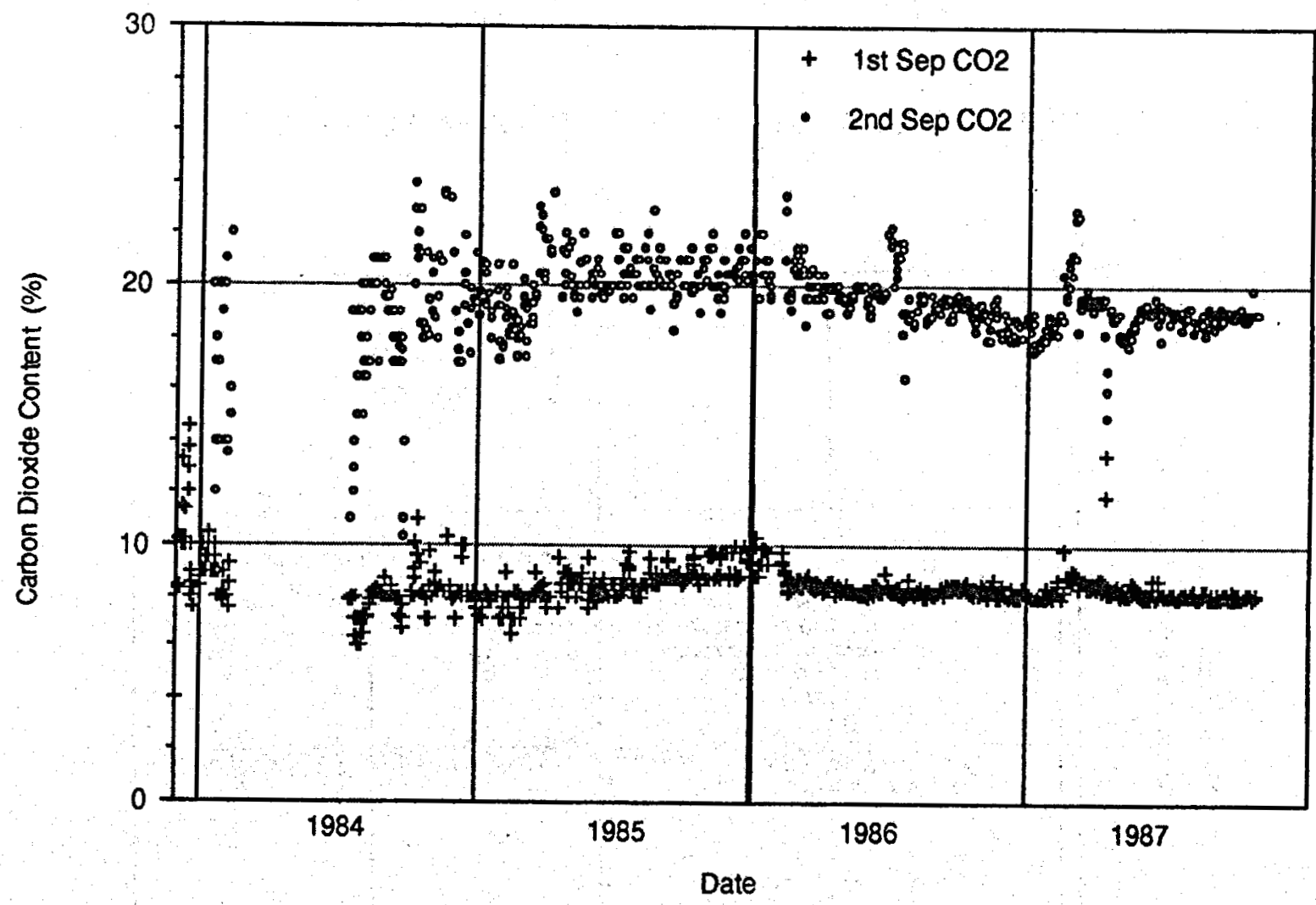

Exhibit 7.1.3-1. FIELD MEASUREMENTS OF CARBON DIOXIDE IN SEPARATORS

There is considerable scatter in the data. Nevertheless, the lack of a trend or significant change is apparent. The change in character of the carbon dioxide data between 1985 and 1986 is 
Flow TESTS OF THE GLAdys MCCALl Well THROUgh OCTOBER 1990

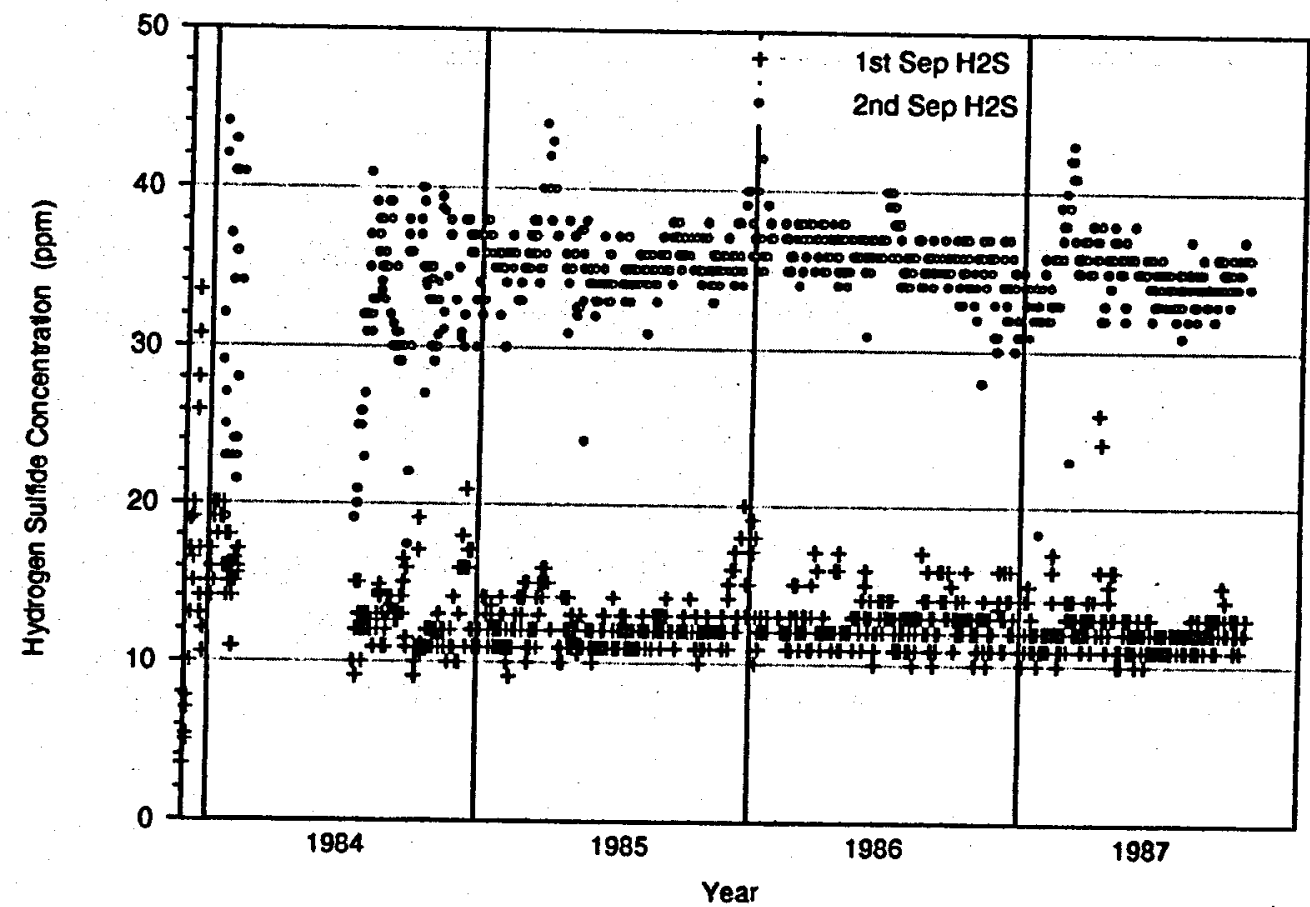

Exhibit 7.1.3-2. FIELD MEASUREMENTS OF HYDROGEN SULFIDE IN SEPARATORS

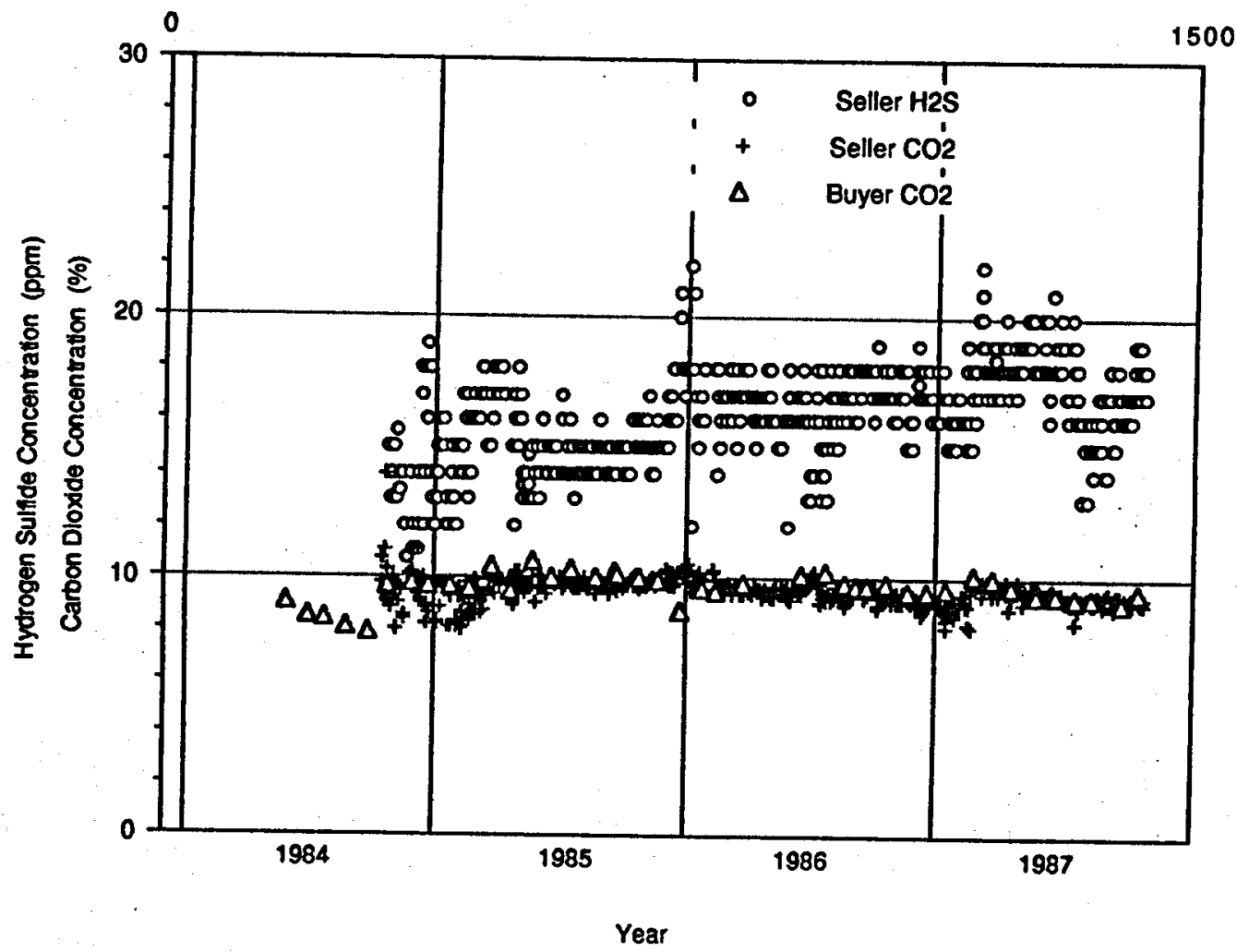

Exhibit 7.1.3-3. CARBON DIOXIDE AND HYDROGEN SULFIDE CONCENTRATIONS IN SALES GAS 
believed to be caused by a technique change after the change in contractors, rather than a change in the produced gas. Much of the scatter is caused by the inherent inaccuracy of the measurement method. Variations result from differences in how the aspirator bulb was squeezed, how the tube was located in the sample gas stream, or how well the different operators could interpret the colorchange points on the indicator. The readings were taken each day primarily for quality control, to ensure that the gas being sent to sales was within the contract limits for carbon dioxide and hydrogen sulfide. The carbon dioxide measurements were the most accurate because they were taken multiple times a day and averaged. The gas buyer was also making gas composition measurements for the purpose of custody transfer. The close agreement between the seller and buyer measurements can be seen in Exhibit 7.1.3-3.

\subsubsection{Total Produced Gas Composition}

The gas partitioning between free gas and gas dissolved in the brine depends upon separator pressure. Thus, deducing the total gas content and composition of each barrel of brine passing through the perforations into the wellbore requires the summation of gas volume and composition measurements for the gas streams from the separators and accounting for the gas remaining in brine leaving the low-pressure separator. The gas analyses are combined by weighting each of the measured compositional percentages by the gas/brine ratio at each sample point. Appendix $H$ gives the details of the computational recombinations. Exhibit 7.1.4-1 plots the resulting gas/brine ratios for total gas through the perforations, Exhibit 7.1.4-2 plots the fraction of carbon dioxide in the total gas, and Exhibit 7.1.4-3 presents the fraction of ethane in the total gas.

The gas that is separated and recovered in the first-stage separator generally comprises about 23 SCF/STB out of a total of about 29 SCF/STB, so the composition of the first-stage gas greatly affects the composition of the total gas. In contrast, the gas flashed from the second-stage separator brine generally provides less than 3 SCF/STB. Although the composition of this flashed gas is very different from that of the first-stage gas, it has only a modest effect upon the calculated composition of the total gas. In cases where the first-stage separator brine was flashed, the second-stage separator gas was not needed to calculate the composition of the total gas.

There was considerable variability in the resulting gas compositions and gas/brine ratios. Nevertheless, small trends are discernable in the data. The quantity of ethane and propane declined slightly. The significance of this is discussed in a subsequent section.

\section{Characteristics of Produced Liquid Hydrocarbons}

Three categories of liquid hydrocarbons were collected and measured during this test. These are 1) "cryocondensates," 2) gas knockout-pot liquids, and 3) heavy separator oil. The total 
Flow Tests of the Gladys McCall Well Through OCtober 1990

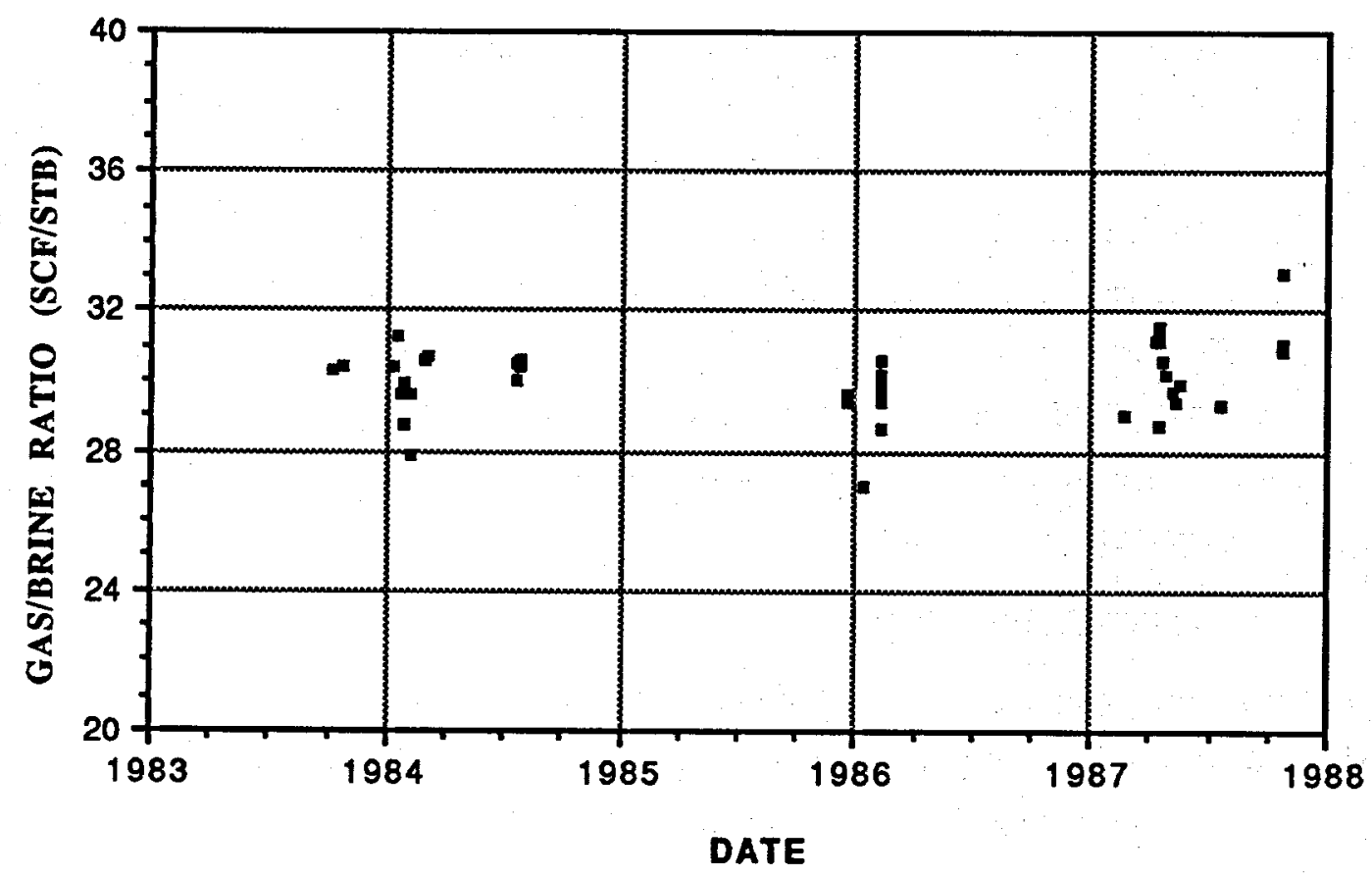

Exhibit 7.1.4-1. GAS/BRINE RATIO FROM RECOMBINATION STUDY

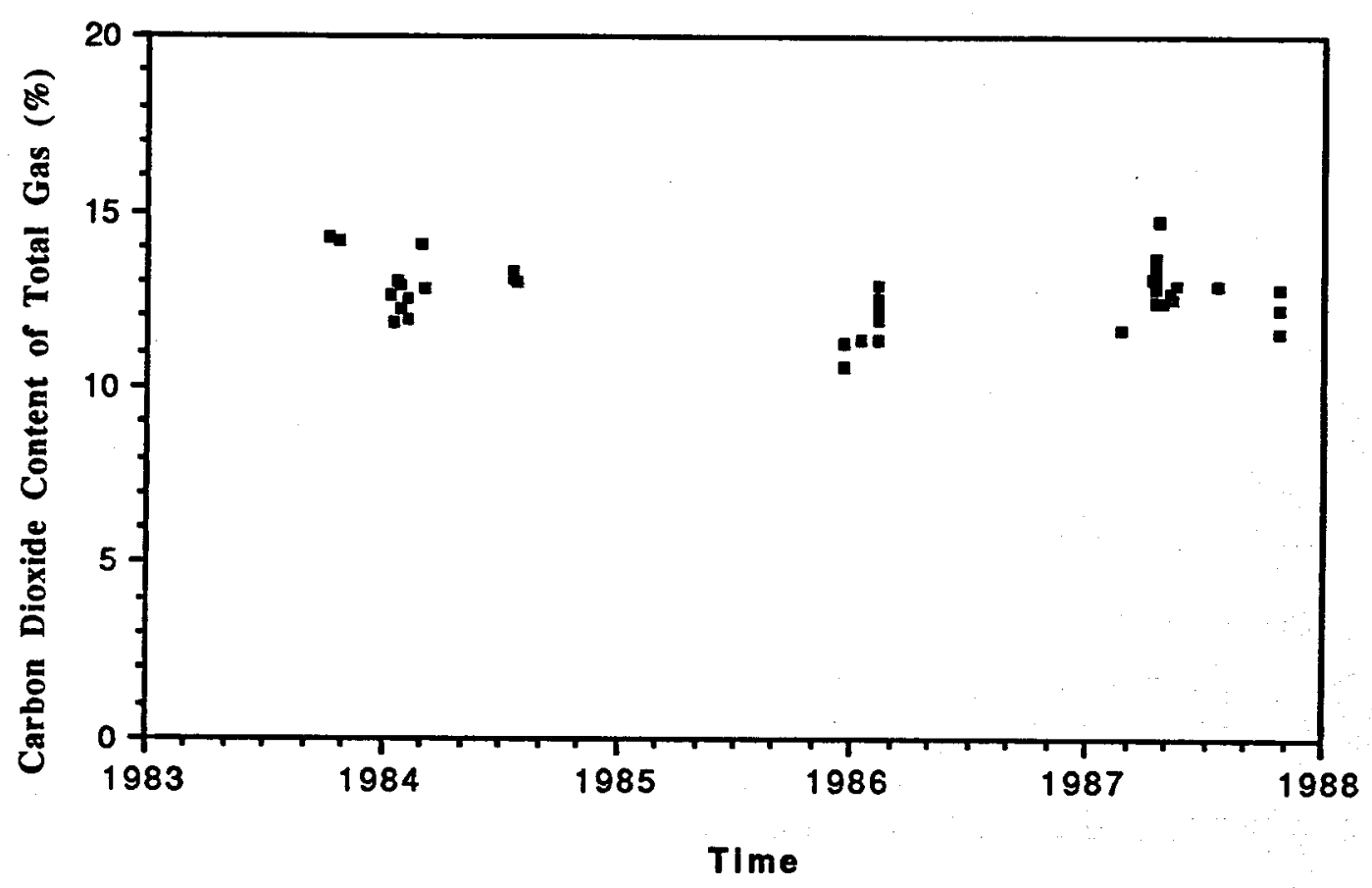

Exhibit 7.1.4-2. CARBON DIOXIDE CONTENT OF TOTAL GAS 


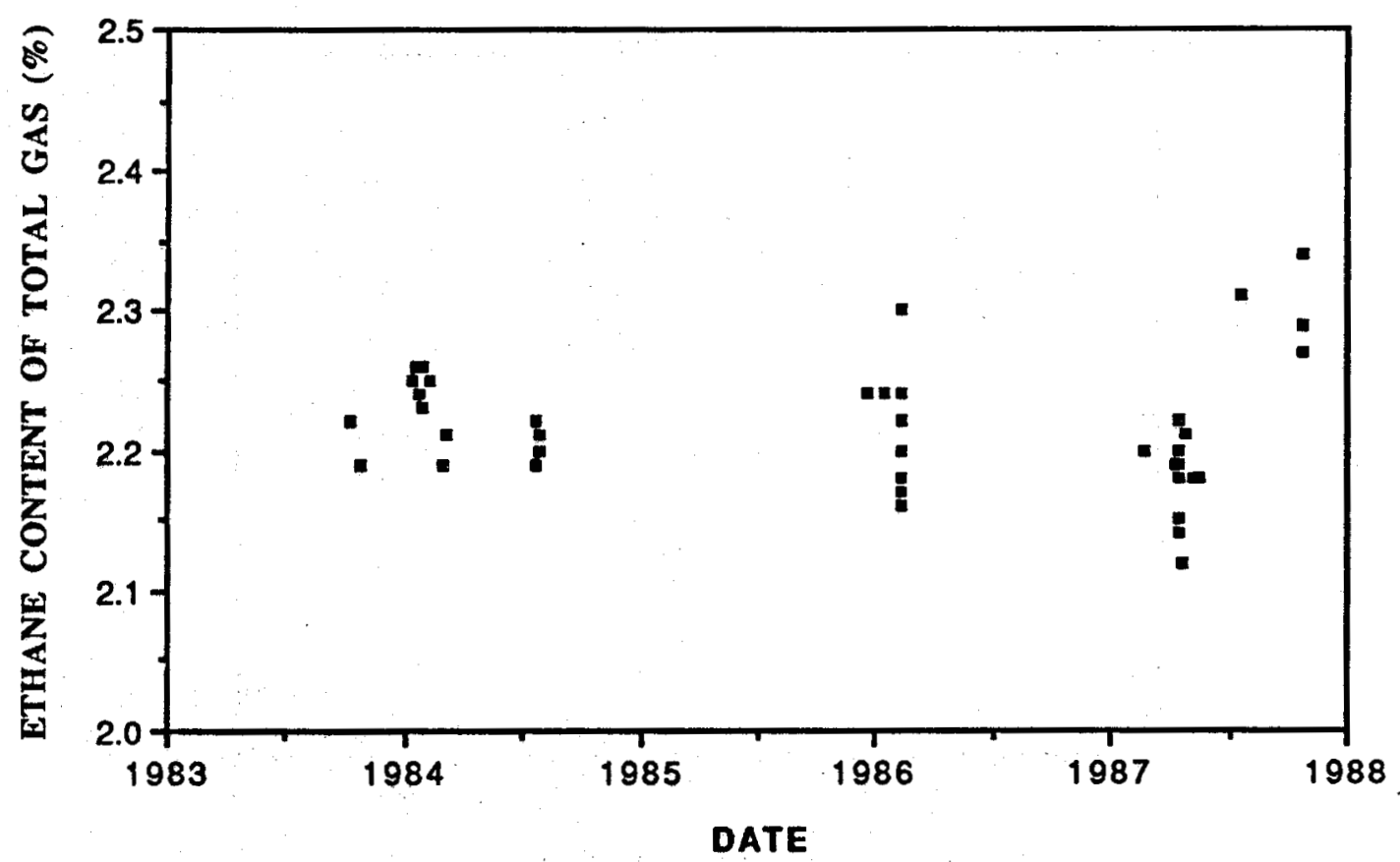

Exhibit 7.1.4-3. ETHANE CONTENT OF TOTAL GAS

quantity of liquid hydrocarbons produced was only a very small fraction of the produced brine. Recovered liquid hydrocarbons had no positive effect on project economics. Total liquid hydrocarbon recovery was less than 300 hundred barrels, or about 1 barrel per week, averaged over the entire flow test.

The "cryocondensates" are named after the method of collecting samples. Gas is passed through dry ice/acetone baths to cool the gas to almost $-60^{\circ} \mathrm{F}$. An apparatus is in-line to trap liquid hydrocarbons that condense out of a measured volume of gas. In addition, brine is cooled, collected in bottles, and then extracted for hydrocarbons in the laboratory. These samples were collected, quantified, and analyzed by Drs. Keeley and Meriwether of the University of Southwestern Louisiana. These cryocondensates are predominantly aromatic in nature.

The concentrations of cryocondensates, reported herein as parts per million in the brine phase, are shown in Exhibit 7.2-1. The cryocondensate concentration has averaged somewhat below $35 \mathrm{ppm}$, and there was no real trend in the concentration over time. Cumulative production of these cryocondensates has totaled just under 1000 barrels. Almost none of the cryocondensates are separated and recovered - a portion remains with the brine that is injected into the disposal well and a portion is sold with the gas. Separation and recovery of the cryocondensate from both the gas phase and the brine phase are not economically feasible. 


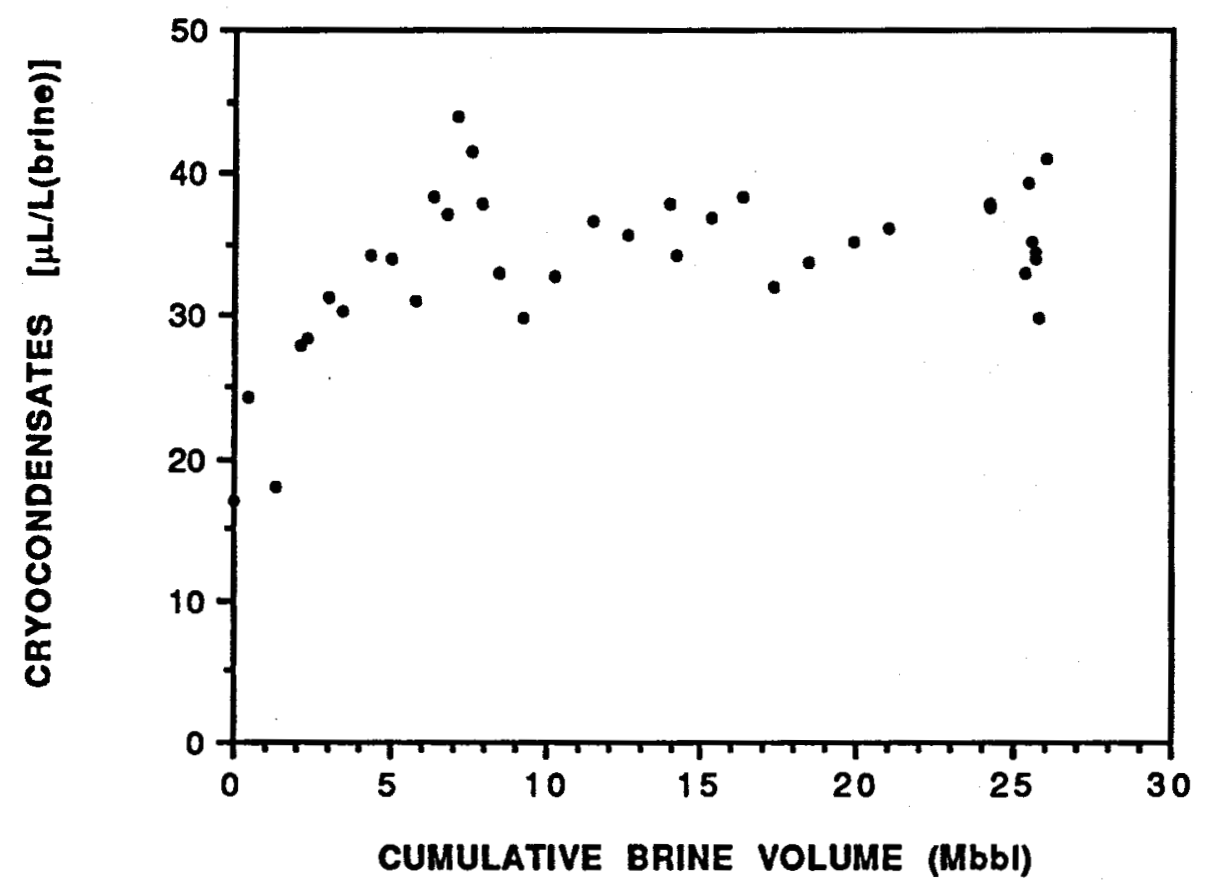

Exhibit 7.2-1. CRYOCONDENSATE CONCENTRATIONS

Cryocondensates are primarily composed of aromatic hydrocarbons that are much more water soluble than are aliphatic hydrocarbons of similar molecular weight. These include benzene, biphenyl, indene, naphthalene, fluorene, phenantrene, and their derivatives. ${ }^{9}$ The cryocondensate is believed to be soluble in the brine at reservoir conditions.

The second oil fraction is those hydrocarbons that drop out of the gas phase as it cools and is compressed prior to entering the sales line. This liquid is rich in the very high-boiling-point fraction of the cryocondensates, but does not contain an appreciable fraction of the heavy aliphatics found in the heavy oil that was recovered from the separator. The composition of numerous samples of gas knockout liquids is presented in Appendix I. The sample from the gas-cooler knockout contains hydrocarbons that leave the high-pressure separator as gas but condense as the gas temperature is reduced to near ambient. Until the liquids from the cooler knockout were collected in a tank beginning in 1986, the liquids went unmeasured down the disposal well. Liquid hydrocarbons are also flowed to the tank from the glycol dehydration unit. This liquid was not quantified but was in the range of a gallon or less per day. This liquid was lighter than the gas knockout sample and is very highly aromatic.

Cumulative measurement of liquid collected after the tank was installed is shown in Exhibit 7.2-2. Brine production during the time that 79 barrels of liquid accumulated in the tank 


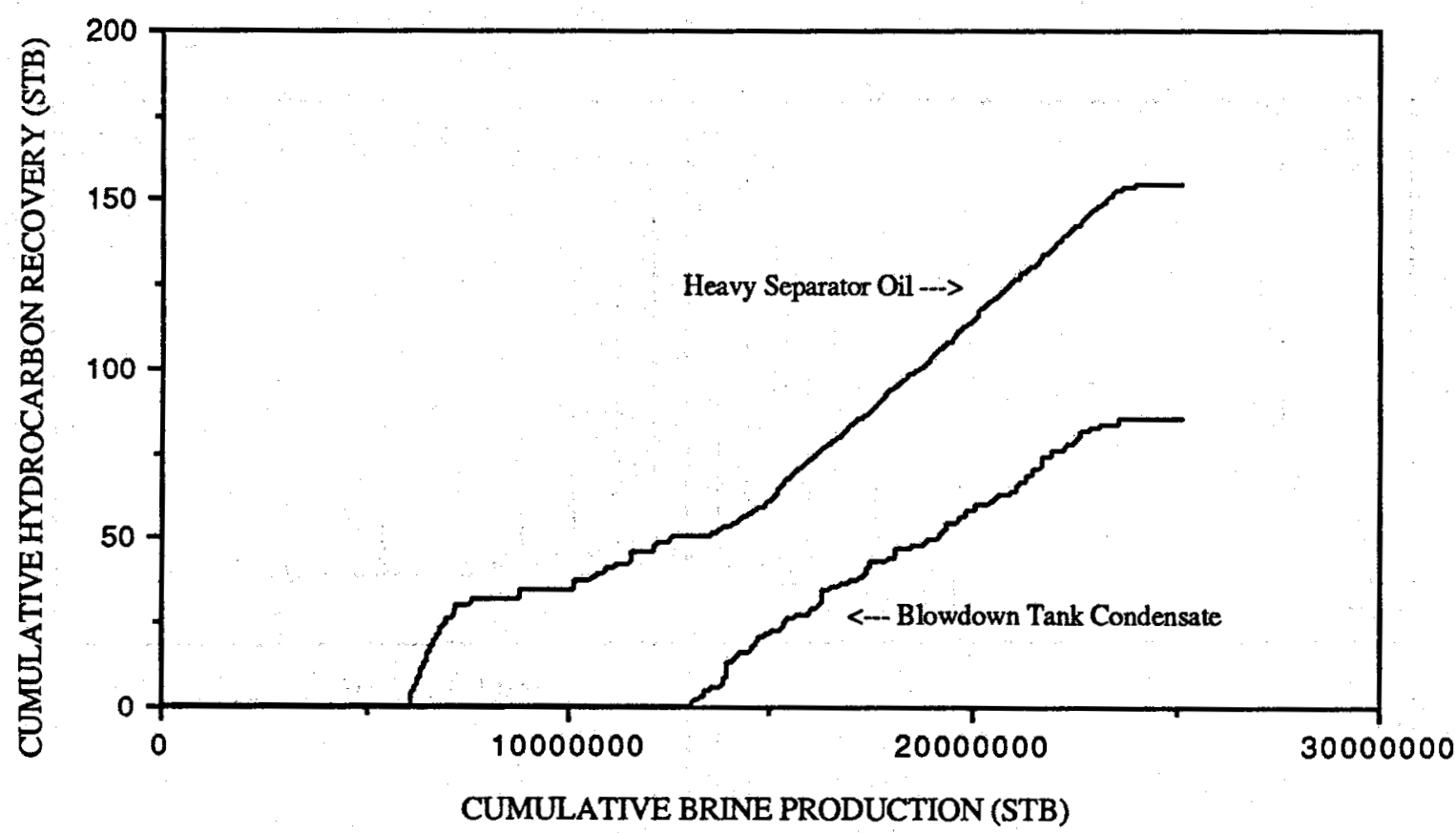

\section{Exhibit 7.2-2. HEAVY OIL PRODUCTION AND CONDENSED HYDROCARBON RECOVERY VERSUS CUMULATIVE BRINE PRODUCTION}

was about 10.4 million barrels. These values indicate that recovery of liquid hydrocarbons from the knockout is about 7.6 parts per million of produced brine by volume.

The heavy separator oil was found in the separators at the gas/brine interface. This oil was first observed in January 1985. It has the appearance of a very heavy, aliphatic fraction of a crude oil and does not contain the high percentage of aromatics present in the cryocondensate. Only a few percent of the heavy oil is comprised of light hydrocarbons that are volatile at $300^{\circ} \mathrm{F}$.

Exhibit 7.2-2 shows heavy oil production versus cumulative brine production. Whereas the amount of oil produced varied with time, the heavy oil production averaged about $6 \mathrm{ppm}$ by volume in the brine, or $5 \mathrm{ppm}$ by weight. The heavy oil recovery changed with time but was similar in volume to the knockout-pot condensate recovery. This heavy oil was analyzed by gas chromatography. Representative chromatograms of the heavy oil recovered from both separators and of a gas knockout oil are provided in Exhibit 7.2-3. The normal alkane backbone is apparent in these chromatograms. Breakdowns either by carbon number or by boiling point (the simulated distillation technique) are provided in Appendix I.

It is not known whether the oil flowing into the wellbore is transported through a continuous hydrocarbon phase or dissolved in the brine. Summaries of the proposed methods of oil transport 
Flow Tests of the Gladys McCall Well Through OCtober 1990

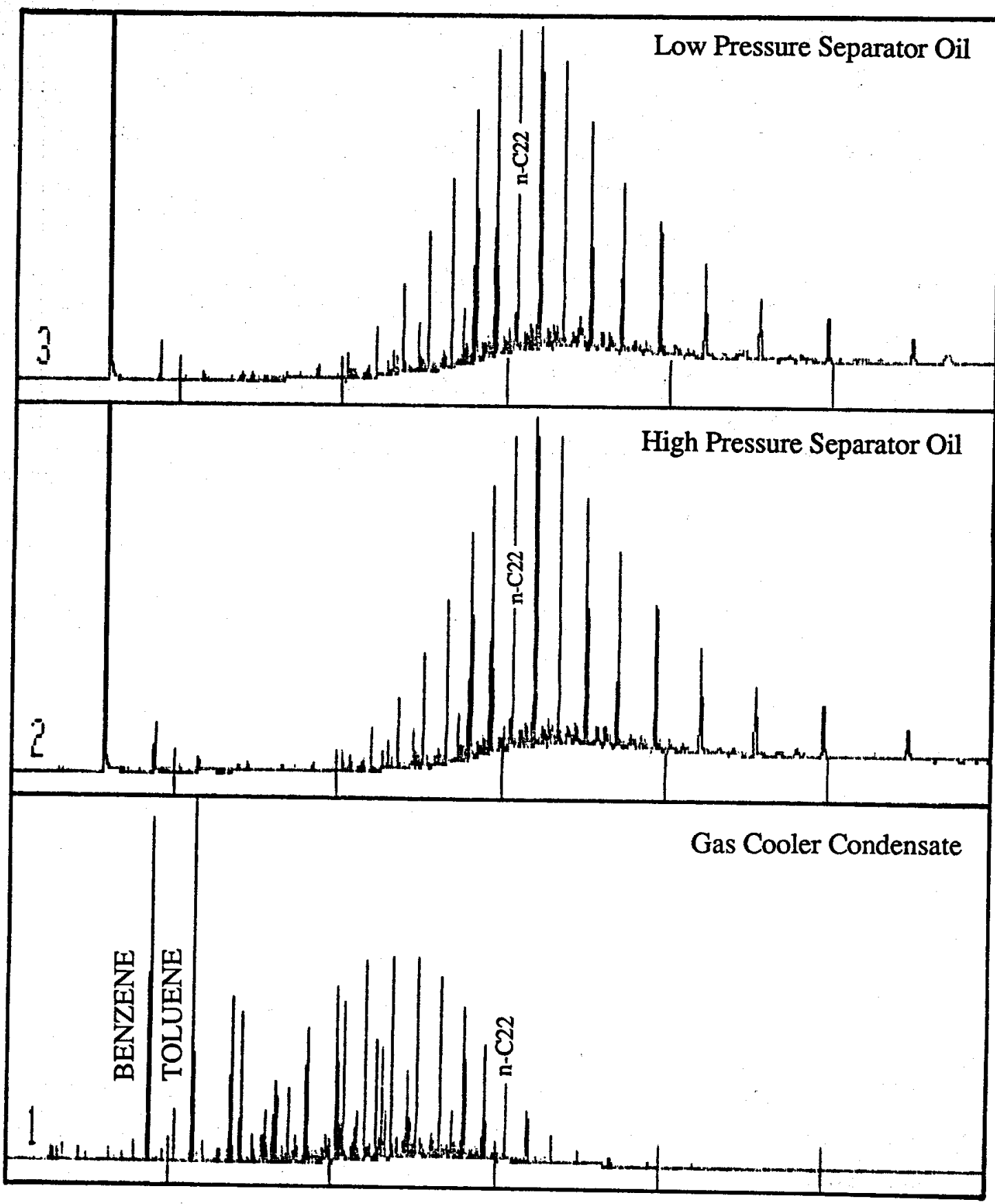

Exhibit 7.2-3. REPRESENTATIVE CHROMATOGRAMS OF RECOVERED OILS 
in the reservoir are presented in Appendix I. It is unlikely that the quantity of oil produced will become economical with continued production. Oil production from the Gladys McCall Sand 8 would be expected to remain only at a nuisance level of a few parts per million in the brine.

\subsection{GAS SATURATION OF RESERVOIR BRINE RELATIVE TO THE BUBBLE POINT}

The Gladys McCall well Sand 8 was initially undersaturated with natural gas at reservoir pressure. During the long-term production phase, however, the flowing bottomhole pressure was drawn down below the 9200 psia believed to be the reservoir bubble-point pressure. The flowing bottomhole pressure reached a low of about 500 psi below this bubble-point pressure in 1986. Evidence -- including the decline in the produced gas/brine ratio, changes in the produced gas composition, and special short-term transient tests developed by IGT -- suggests the reservoir pressure was drawn down below the bubble-point pressure. Observed changes were very small, however, as would be expected if the flowing bottomhole pressure was within a few hundred psi of the reservoir bubble-point pressure.

The laboratory data on bubble-point pressure for the reservoir brine is discused below in Section 8.1. Then, changes in the produced gas/brine ratio and transient testing to determine whether the reservoir has been drawn down to below the bubble-point pressure are discussed in Sections 8.2 and 8.3 .

\subsection{Sand 8 Gas and Brine Recombination Studies}

On October 8, 1983, after 24 hours of production at 13,400 STB/d, separator gas and brine samples were collected at a pressure of 500 psi for laboratory PVT analyses. This 1983 PVT study (Appendix J) was performed by the same personnel and laboratory facility as similar prior studies of samples from the Wells of Opportunity Program. Their experience from this prior work was in good agreement with other laboratories studying solubility of natural gas in brine. The laboratory recombined at the ratio of produced fluids measured from the separator, 25.01 SCF of gas per barrel of separator brine. The bubble-point pressure of this mixture was 9200 psia, whereas the initial reservoir pressure had been reported to be $12,783 \mathrm{psia}$. This laboratory result was the basis for reporting that the reservoir was undersaturated with respect to natural gas. 2,3 Gas content below saturation was unexpected because the brine in Sand 9 was erroneously believed to be saturated with natural gas. We now recognize that the bubble point in Sand 9 was about 2900 psi below the reservoir pressure and the bubble point in Sand 8 was about 3600 psi below the reservoir pressure. 
Exhibit 8.1-1 presents the gas/brine ratios from laboratory recombination studies (Appendix J in terms of SCF/separator barrel, SCF/STB, and the resulting bubble-point pressures. Because of equipment pressure limitations, the bubble-point pressure could not be measured at the actual reservoir pressure of 12,783 psia. Five bubble-point pressures were measured at separator gas/brine ratios of 25 and lower SCF of separator gas/barrel of separator brine. The results tabulated in Exhibit 8.1-1 were extrapolated out to the reservoir pressure (pages 12 and 20 of Appendix J). The plot of the bubble-point curve indicated that the reservoir brine is only about $80 \%$ saturated and the ratio of separator gas to separator brine would have been about 31.9 SCF of separator gas per barrel of separator brine if the reservoir brine had been saturated with natural gas. The right-hand column of Exhibit 8.1-1 is methane solubility calculated from equations developed for DOE by C. W. Blount and his students. 12

\section{Exhibit 8.1-1. WEATHERLY PVT RECOMBINATION DATA}

\begin{tabular}{|c|c|c|c|}
\hline \multicolumn{2}{|c|}{---Gas To Brine Ratios---- } & \multirow{2}{*}{$\begin{array}{l}\text { Bubble Point, } \\
\text { psia }\end{array}$} & \multirow{2}{*}{$\begin{array}{l}\text { Blount Solubility, } \\
\text { SCF/STB }\end{array}$} \\
\hline SCF/Sep Barrel & ${\underline{S C F} / \text { STB }^{a}}^{a}$ & & \\
\hline 10.01 & 14.36 & 2855 & 15.85 \\
\hline 15.00 & 19.64 & 4550 & 20.68 \\
\hline 18.00 & 22.82 & 5785 & 23.64 \\
\hline 20.00 & 24.94 & 6730 & 25.67 \\
\hline 25.01 & 30.25 & 9200 & 30.30 \\
\hline $31.9+$ & 37.5 & 12783 & 35.84 \\
\hline
\end{tabular}

${ }^{a}$ Gas at 15.025 psia and $60^{\circ} \mathrm{F}$.

b Calculated for $294^{\circ} \mathrm{F}$ and $95,000 \mathrm{ppm} \mathrm{NaCl}$.

Only the highest laboratory pressure, 9200 psia, is near reservoir conditions, and the only entries in Exhibit 8.1-1 near the actual well conditions are the three highest pressures. The agreement between recombination gas content and laboratory solubility of pure methane in pure $\mathrm{NaCl}$ brine is close at bubble-point pressures of 6780 and 9200 psia. Unfortunately, page 12 of the PVT report (and the fifth line of Exhibit 8.1-1) reflects the author's questionable extrapolation to 31.9 SCF of separator gas per barrel of separator water at 500 psig and $268^{\circ} \mathrm{F}$ for the initial reservoir pressure of 12,783 psia. Correcting the water volume to atmospheric pressure and $60^{\circ} \mathrm{F}$ and adding the $3.75 \mathrm{SCF} / \mathrm{STB}$ of gas flashed from the separator brine results in the high value of 37.5 SCF/STB for gas solubility in reservoir brine. The author's extrapolation on page 23 of the same report (to $35.8 \mathrm{SCF} / \mathrm{STB}$ ) is in much better agreement with expectations based on pure 
components. As shown in Exhibit 8.1-2, a simple least-squares polynomial fit to the data provides excellent agreement with the measured data and suggests the gas solubility at a pressure of 12,783 psia would be 35.3 SCF/STB.

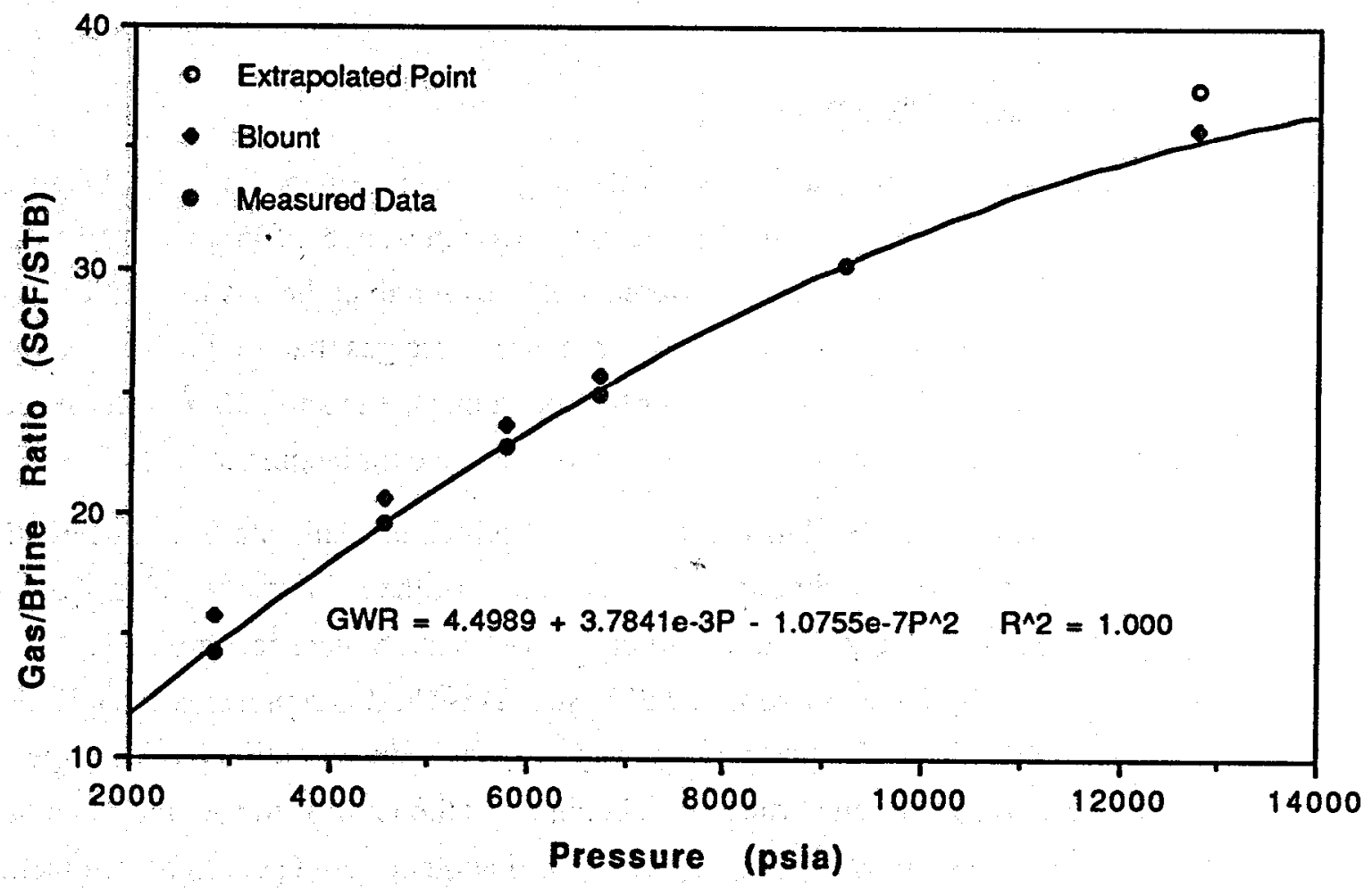
Exhibit 8.1-2. GRAPH OF PVT RECOMBINATION DATA AND CALCULATED
METHANE SOLUBILITY

Nevertheless, it was clear the recombination of separator fluids at the rates that were measured resulted in a system with a bubble-point pressure several thousands of psi below the measured reservoir pressure. One concern regarding the 1983 PVT work is whether an incorrect ratio of separator gas and brine was recombined because of problems or errors in flow-rate measurement. The primary uncertainty was whether rate-measurement problems had resulted in laboratory recombination of the wrong gas/brine ratio. This concern has been put to rest. The gas/brine ratio derived from the adjusted data from long-term testing (Exhibits 6.2-1 and 6.2-2) is in agreement with the laboratory recombination PVT data and supports the conclusion that Sand 8 was not saturated with gas.

The oil accumulation in the separators that became apparent more than a year after the start of production provides another concern. It is virtually impossible to collect and recombine samples of 
three fluid phases (gas, oil, and water) in the correct proportions. Also, careful work in the same laboratory had previously revealed that trace amounts of oil precluded reproducible measurement of the gas/brine bubble point for samples from the Lear G.M. Koelemay well, and in all cases raised the apparent bubble-point. Whether these early measurements were affected by traces of oil that were not seen is conjectural.

\subsection{Changes in Composition of the Produced Gas}

The natural gas in this reservoir is a mixture containing methane, ethane, propane, butanes, carbon dioxide, and other gases. Because the individual components have different solubilities, a gas phase in equilibrium with brine will have a different composition than the gas in solution in the brine. The heavier hydrocarbon/methane ratios are higher in the free gas than in the dissolved gas. The effect becomes more pronounced as still heavier hydrocarbons are examined. For instance, the propane/methane ratio contrast is greater than the ethane/methane ratio contrast.

This effect is demonstrated in Exhibits 8.2-1 and 8.2-2, which present data from differential liberation studies performed by Weatherly Laboratories as a part of the PVT studies of samples from Sands 8 and 9 (Appendixes $J$ and B). Gas and brine from Sand 8 were recombined at $30.19 \mathrm{SCF} / \mathrm{STB}$. The bubble-point pressure was $9200 \mathrm{psia}$. This fluid is representative of the reservoir brine prior to production. The pressure on the brine was reduced until a bubble large enough to sample had exsolved from the brine. This bubble was then removed for analysis in a gas chromatograph and the pressure was lowered further until another bubble could be sampled. Each column of the table gives the composition of gas liberated by the pressure step at the top of the column. The total volume of gas liberated was 31.6 SCF/STB. The difference from the amount recombined is in part caused by the necessity of cooling the brine before dropping pressure to atmospheric and the associated shift in carbonate/bicarbonate equilibrium in the brine.

It is noted that there is an apparent problem with the carbon dioxide concentrations for the differential liberation steps in Exhibit 8.2-1. The values should monotonically increase as the pressure decreases. As shown in Exhibit 8.2-2, the carbon dioxide concentrations reported for differential liberation steps to the same pressures for the sample from Sand 9 exhibited the normal trend. For Sand 9, differential liberation steps ending at pressures of $6000,4000,2000$, and 15 psia resulted in reported carbon dioxide concentrations in the ascending order $2.82 \%, 3.37 \%$, $9.00 \%$, and $23.58 \%$, respectively.

Both of the differential liberation studies show the normal lower concentration of heavier hydrocarbons with successive pressure drops. It is clear from these tables that, if bubbles of gas formed in the reservoir as the pressure was drawn down below the bubble-point pressure, the gas would be richer in the heavy hydrocarbons than the original solution gas. At the same time, the 
Flow Tests of the gladys McCall Well Through OCtober 1990

Exhibit 8.2-1. SAND 8 GAS DIFFERENTIAL LIBERATION DATA

Pressure, psia

Gas Remaining in

Brine, SCF/STB

Mole Percent of:

Carbon Dioxide

Methane

Ethane

Propane

Butanes

Pentanes

C6+

$\begin{array}{ccccc} & 9200- & 6000 & 4000 & 2000 \\ \text { Total Gas } & 6000 & 4000 & 2000 & 15\end{array}$

$\begin{array}{lllll}31.60 & 27.53 & 22.89 & 15.80 & 0\end{array}$

14.26

82.62

2.22

0.54

0.14

0.03

0.19

3.10

3.87

$89.03 \quad 91.74$

92.34

4.34

3.50

2.75

1.53

0.99

0.63

0.40

0.32

0.18

0.12

0.06

0.03

0.38

0.29

0.20

24.79

73.93

1.06

0.11

0.00

0.00

0.11

Exhibit 8.2-2. SAND 9 GAS DIFFERENTIAL LIBERATION DATA

Pressure, psia

\begin{tabular}{|c|c|}
\hline Total & 6000 \\
\hline
\end{tabular}

Gas Remaining in

Brine, SCF/STB

Mole Percent of:

Carbon Dioxide

Methane

Ethane

Propane

Butanes

Pentanes

C6+
$31.14 \quad 26.76$

22.30

15.30

0

14.67

81.88

2.22

0.48

0.14

0.05

0.58
3.37

9.00

23.58

89.56

91.25

3.18

0.84

0.28

0.10

0.98

86.51

75.08

$3.16 \quad 1.06$

1.37

0.56

0.10

0.51

0.10

0.03

0.17

1.57

0.05

0.00

0.62

0.18 
gas remaining in solution in the brine and produced up the wellbore would become slightly depleted in ethane and heavier hydrocarbons. Exhibit 8.2-3 presents the ethane/methane and propane/methane ratios from the calculated composition of the total produced gas tabulated in Appendix H. These plots suggest that the reservoir may have been below the bubble point by December 1985. At that time, the hydrocarbon ratios were clearly below those at the start of the long-term flow test.

We can estimate the change in solution-gas composition as the pressure drops below the bubble point. For a 500-psi drop from a bubble point of 9200 psi, the difference of solutions of the equation in Exhibit 8.1-2 reveals that approximately 0.93 SCF/STB of gas should have been exsolved and trapped in the reservoir. Using the gas compositions in the first two columns of Exhibit 8.2-1 and assuming that all of the exsolved gas is trapped in the reservoir, we can calculate that the ethane content of the produced (solution) gas should drop from $2.22 \%$ to $2.15 \%$. The propane content should drop from $0.48 \%$ to $0.45 \%$. The ethane/methane ratio should drop from 0.0269 to 0.0262 , and the propane/methane ratio should drop from 0.0058 to 0.0054 . These changes, both in the produced gas/brine ratio and in the hydrocarbon ratios, are about what was observed between the 1984 samples and the 1986-to-1987 samples.

The gaps of more than a year between total gas measurements preclude interpretation of Exhibit 8.2-3 to determine when the reservoir pressure fell below the bubble-point pressure. Some of the gaps in time were examined by making a similar plot (Exhibit 8.2-4) from analyses of samples from the first-stage separator at times when the pressure was near 1000 psi. Overall trends of the two plots are similar, but they do not resolve the question of whether the change during 1985 was caused by dropping below the bubble point or caused by some other phenomena such as changes in the source of brine. The latter possibility cannot be ignored. Oil accumulation in the separators began early in 1985. Changes in the concentration of some species in solution in the produced brine were reported for samples collected in February and May 1985. The most notable was a reported, but questionable, increase in barium concentration from about 100 to about $500 \mathrm{mg} / \mathrm{L}$.

\subsubsection{Variation in the Produced Gas/Brine Ratio Due to Bottomhole Pressure}

The curve fit to Weatherly's PVT data in Exhibit 8.1-2 suggests that, for every psi the brine is below the bubble point, 0.018 SCF/STB of gas will come out of solution. If the well were produced at a high rate, and long enough to lower the pressure around the well to below the bubble pressure, then gas would come out of solution and form a free-gas phase in the formation. This gas would be trapped in the reservoir rock pores until the critical gas saturation (about $3 \%$ of the pore volume) is reached. The volume of this portion of the cone of depression would increase 
Flow tests of the Gladys MCCall Well Through OCtober 1990

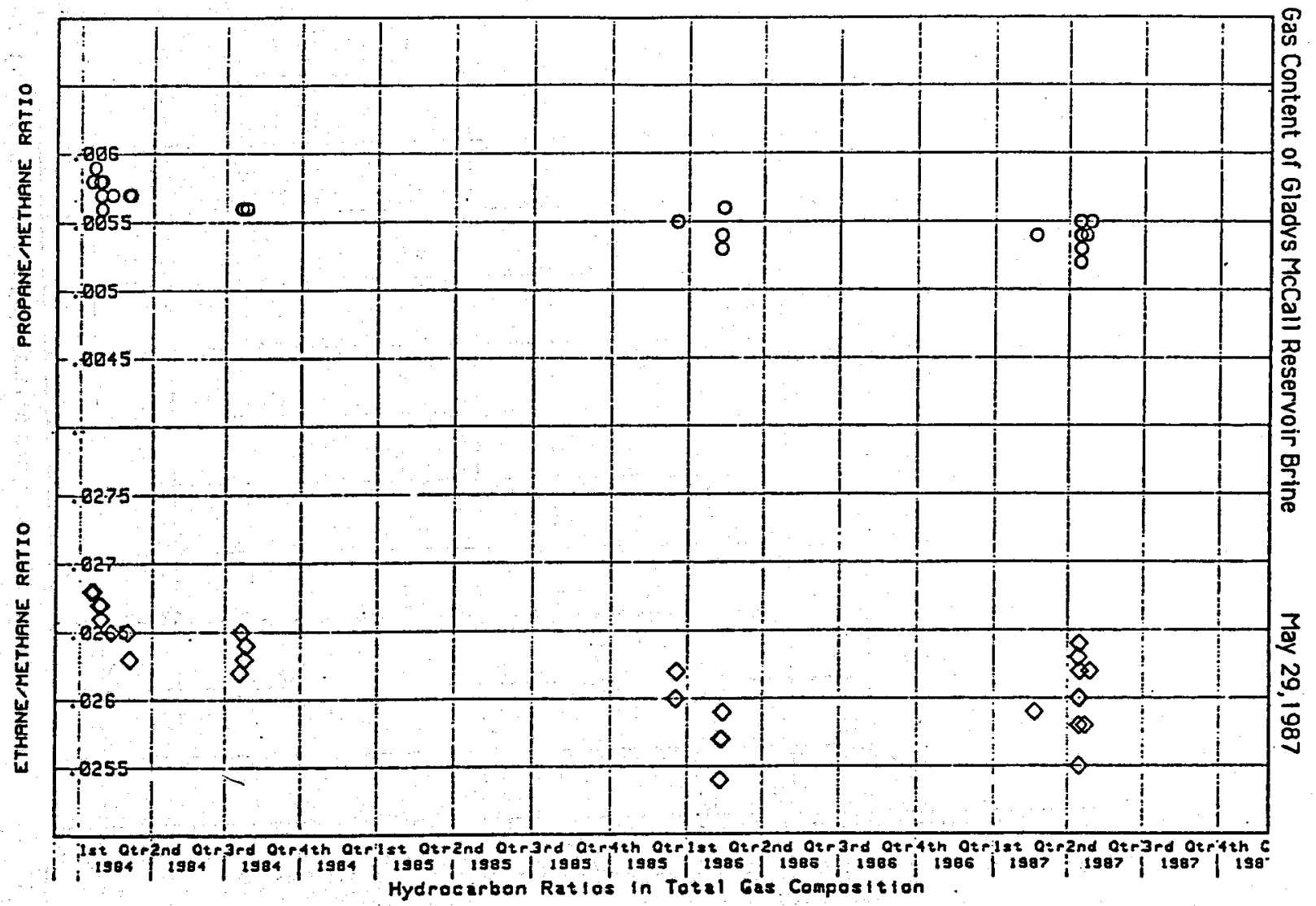

Exhibit 8.2-3. ETHANE/METHANE AND PROPANE/METHANE RATIOS IN TOTAL PRODUCED GAS 


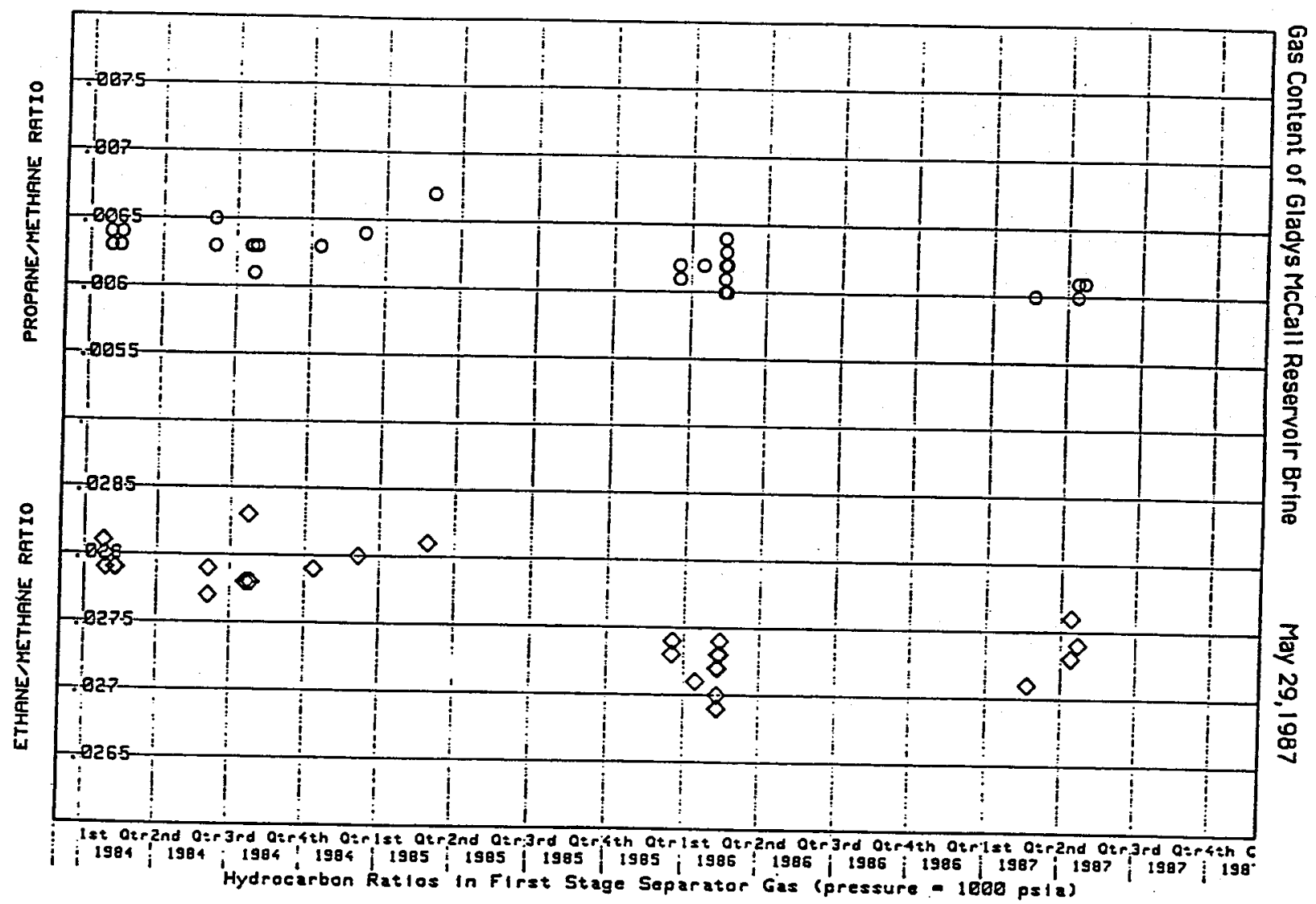

Exhibit 8.2-4. ETHANE/METHANE AND PROPANE/METHANE RATIOS IN FIRST-STAGE SEPARATOR GAS 
with time, and only a small portion of the gas being trapped would flow. This gas remaining behind in the cone of depression would detract from the amount of gas that would otherwise be produced. The produced gas/brine ratio is expected to reflect some value between the solubility of gas at the pressure that exists within a few feet of the wellbore and the gas content of original reservoir brine.

The difficulty in measuring the gas rates during the first portion of the test is apparent in the scatter of values for the gas/brine ratio (Exhibit 6.2-3). By late 1984 the operational problems had been largely overcome and the data accuracy was improved. Whether the drop in the gas/brine ratio during the third and fourth quarters of 1985 are caused by the bottomhole pressure falling below the bubble-point pressure is conjectural, but it is within the realm of possibility. Since the first successful scale-inhibitor pill had been pumped, sustained brine rates were higher than had previously been practicable and flowing bottomhole pressure was correspondingly lower than had previously been experienced (roughly 9500 psi).

The slight decline in the slope of the cumulative gas versus cumulative brine plot (Exhibit 6.2-4) at about 10 million barrels of brine is hypothesized to have been caused by the near-wellbore pressure falling below the bubble-point pressure. The change in the gas/brine ratio is very slight and occurred gradually in the third quarter of 1985 . There was less than 1 SCF/STB decline throughout the test. This is consistent with the bottomhole pressure falling less than 500 psi below the bubble-point pressure. Calculated flowing bottomhole pressure is shown in Exhibit 8.2.1-1. During the third quarter of 1985 the flowing bottomhole pressure ranged from 9700 to about 9400 psia. This suggests that the bubble-point pressure is in the same range. That range is in reasonable agreement with the 9200 psia deduced from the PVT studies.

On the other hand, if the reservoir brine had been saturated with natural gas at original reservoir pressure of 12,783 psia, the trapping of exsolved gas in the reservoir would have been expected to reduce the gas/brine ratio through the perforations by about 4 to 5 SCF/STB over the time span shown in Exhibit 8.2.1-1. Such a change would have been clearly apparent. This strongly supports the notion that the reservoir brine was not initially saturated with gas.

\subsection{2. "Bubble Test" for Free Gas Adjacent to the Wellbore}

IGT developed a "bubble test" to determine whether there was free gas at critical saturation in the formation near the wellbore. As the flowing bottomhole pressure falls below the bubble-point pressure of the brine, gas is exsolved. This gas remains trapped in the reservoir until the gas saturation reaches the critical gas saturation. A small amount of the free gas then flows into the wellbore and the gas saturation near the wellbore is maintained at the critical gas saturation. The "bubble test" involves increasing the rate in a stepwise manner. This stepwise increase in flow rate 
Flow Tests of the Gladys MCCall Well Through OCtober 1990

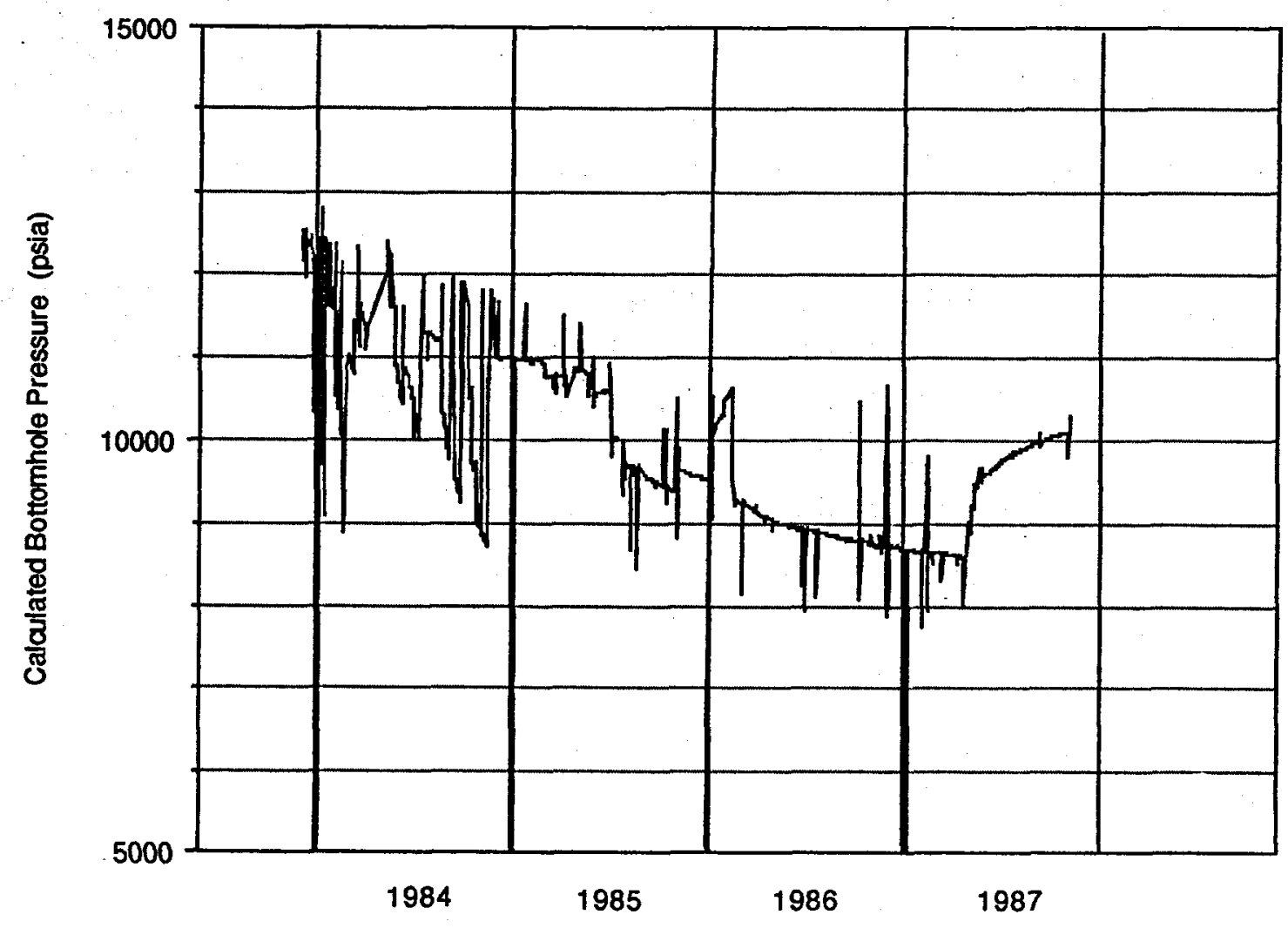

Exhibit 8.2.1-1. SAND 8 CALCULATED BOTTOMHOLE PRESSURE

creates an instantaneous drop in the bottomhole pressure, which in turn causes gas caught in the reservoir to expand slightly. As the gas expands, the gas saturation exceeds the critical gas saturation, so the free gas flows. The amount of gas produced is dependent on the pressure decline, which is small for these high-permeability reservoirs. The excess gas is produced for a short period, and then the produced gas/brine ratio should drop to a level slightly lower than its level before the rate increase because more gas exsolves from the brine further out in the reservoir.

IGT monitored gas rates and composition following a step increase in drawdown on two occasions as a "bubble test" to determine whether the flowing bottomhole pressure was below the bubble-point pressure of reservoir brine -- or, in other words, to determine whether free gas was in pores of the reservoir rock near the wellbore. Excess gas production is generally hard to spot because of transients in the surface facilities caused by the flow rate change. Changes in gas composition, caused by the addition of a small amount of rich gas in equilibrium with the brine at reservoir conditions, are generally easier to determine. 
The first test was on February 12,1986, and the second was on April 14, 1987. Both suggested that the bottomhole pressure was below the bubble-point pressure. But the amount of free gas in pores at near the critical gas saturation was very small. Details of the procedure, the test results, and interpretation are given in Appendix $\mathrm{K}$.

\subsection{PRODUCED BRINE CHARACTERISTICS}

In the 17-month period between November 1983 and May 1985, seven suites of brine samples were collected and analyzed using the Standard Sampling and Analytical Methods for Geopressured Fluids prepared by McNeese State University in 1980 (Appendix L). After the change in prime contractors, budget restrictions resulted in suites of samples being collected for comprehensive analyses only in December 1985, September 1986, and June 1987. Inductively coupled plasma (ICP) arc spectroscopy was used to determine the concentrations of most of the species in the latter three suites of samples. Results of all the comprehensive analyses are presented in Exhibit 9.0-1, Parts 1 and 2.

Weekly, or often daily, samples were collected by site personnel for chloride and/or alkalinity measurements in relation to scale control. In 1987 IGT subcontracted for Rice University to do a detailed study of the brine chemistry at various flow rates. Between April and June 1987 Rice took samples almost daily and analyzed the data to better understand the constitutive nature of the produced brine and how it related to the production rate. Rice also performed chloride analyses of a portion of the daily samples that had been previously collected by site personnel. Appendix $\mathbf{M}$ includes the report submitted by Rice.

Most of the elements/compounds in the brine showed no significant change with either time or flow rate. The noteworthy exception is flow-rate dependence of iron concentration. There were minor changes that may correlate with accuracy or procedure differences between the different laboratories that analyzed the samples. There were some unexplained differences in the compositions for the 1985 and early 1986 samples. Relevant aspects of these topics are discussed under subheadings below.

\subsection{Iron Concentration Change With Flow Rate}

The concentration of iron in the brine was inversely related to the flow rate. This is shown in Exhibit 9.1-1. At an iron concentration of $30 \mathrm{mg} / \mathrm{L}$ and a flow rate of $10,000 \mathrm{STB} / \mathrm{d}$, about 105 pounds of iron is produced each day. The Rice researchers interpreted the variable concentration as the effect of a mass-transport controlled rate without discussing the mechanism. A reasonable mechanistic model to explain the iron concentration variation is to postulate that the concentration of iron in the produced brine is the sum of the iron in the native brine plus the iron 
Exhibit 9.0-1, Part 1. SAND 8 BRINE COMPOSITION

\begin{tabular}{|c|c|c|c|c|c|c|}
\hline $\begin{array}{l}\text { Sample Date } \\
\text { Analysis for: }\end{array}$ & Units & $11 / 83$ & $2 \pi / 84$ & $8 \pi / 84$ & $10 / 12 / 84$ & $12 / 1 / 84$ \\
\hline Alkalinity $\left(\mathrm{HCO}_{3}^{-}\right)$ & $\mathrm{mgl}$ & - & 232 & 288 & 285 & 288 \\
\hline Alpha (Gross) & pCin & 40 & & 72 & 68 & 60 \\
\hline $\begin{array}{l}\text { Ammonia } \\
\text { Arsenic }\end{array}$ & $\begin{array}{l}\mathrm{mg} / \mathrm{L} \\
\mathrm{mg} / \mathrm{L}\end{array}$ & 0.013 & $\begin{array}{l}280 \\
0.004\end{array}$ & $\begin{array}{l}135 \\
<0.005\end{array}$ & $\begin{array}{l}50 \\
<0.005\end{array}$ & $\begin{array}{l}100 \\
<0.005\end{array}$ \\
\hline Barium & $\mathrm{mg} / \mathrm{L}$ & 420 & $\begin{array}{l}.004 \\
60\end{array}$ & 80 & 44 & 125 \\
\hline Beta (Gross) & pCir & 340 & 1870 & 380 & & 310 \\
\hline Boron & $\mathrm{mg} / \mathrm{L}$ & & 38.5 & 40.8 & 41.5 & 41.5 \\
\hline Cadmium & $\mathrm{mg} / \mathrm{L}$ & 0.015 & 0.022 & 0.005 & 0.02 & 0.03 \\
\hline Calcium & $\mathrm{mg} / \mathrm{L}$ & 4,040 & 3,643 & 4,330 & 3,840 & 3,830 \\
\hline $\begin{array}{l}\text { Chloride } \\
\text { Chromium }\end{array}$ & $\mathrm{mg} / \mathrm{L}$ & $\begin{array}{l}59,290 \\
0.04\end{array}$ & 58,700 & 57,750 & 56,300 & 55,200 \\
\hline $\begin{array}{l}\text { Chromium } \\
\text { Conductivity }\end{array}$ & $\begin{array}{l}\mathrm{mg} / \mathrm{L} \\
\mu \mathrm{mho} / \mathrm{cm}\end{array}$ & $\begin{array}{l}0.04 \\
-\end{array}$ & $\begin{array}{l}<0.02 \\
111,800\end{array}$ & $\begin{array}{l}<0.02 \\
117,800\end{array}$ & $\begin{array}{l}<0.02 \\
109,000\end{array}$ & $\begin{array}{l}0.11 \\
111,400\end{array}$ \\
\hline Copper & $\mathrm{mg} / \mathrm{L}$ & 0.015 & 0.075 & 0.035 & 0.020 & 0.020 \\
\hline Dissolved Solids & $\mathrm{mg} / \mathrm{L}$ & 97,800 & 94,900 & 95,100 & 93,600 & 91,700 \\
\hline Fluoride & $\mathrm{mg} / \mathrm{L}$ & 0.14 & 0.40 & 0.17 & 0.27 & 0.16 \\
\hline Gamma (Gross) & pCi/L & 1530 & 1290 & 180 & 150 & 230 \\
\hline Hardness $\left(\mathrm{CaCO}_{3}\right)$ & $\mathrm{mg} / \mathrm{L}$ & - & - & - & - & 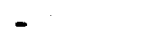 \\
\hline Iodide & $\mathrm{mg} / \mathrm{L}$ & - & & & & \\
\hline Iron & $\mathrm{mg} / \mathrm{L}$ & 14.0 & 18.6 & 23.6 & 22.0 & 89.3 \\
\hline Lead & $\mathrm{mg} / \mathrm{L}$ & $<0.05$ & $<0.05$ & $<0.05$ & $<0.05$ & 0.16 \\
\hline Lithium & $\mathrm{mg} / \mathrm{L}$ & - & - & - & - & \\
\hline Magnesium & $\mathrm{mg} / \mathrm{L}$ & 354 & 318 & 370 & 348 & 300 \\
\hline Manganese & $\mathrm{mg} / \mathrm{L}$ & 2.1 & 1.4 & 1.6 & 1.73 & 3.05 \\
\hline Mercury & $\mathrm{mg} / \mathrm{L}$ & 0.001 & $<0.001$ & $<0.001$ & $<0.001$ & $<0.001$ \\
\hline pH & $-\overline{m a n}(1)$ & & & 6.9 & 6.18 & 6.34 \\
\hline $\begin{array}{l}\text { Potassium } \\
\text { Radium }\end{array}$ & $\mathrm{mg} / \mathrm{L}$ & 430 & 780 & 833 & 825 & 807 \\
\hline Radium & $\mathrm{pCi} / \mathrm{L}$ & 17 & 33 & 72 & 41 & \\
\hline Radon (Gas) & pCi/L & & 49.3 & 26 & 20 & 30 \\
\hline Silica $\left(\mathrm{SiO}_{2}\right)$ & $\mathrm{mg} / \mathrm{L}$ & 100 & 127 & 129 & 130 & 128 \\
\hline Sodium & $\mathrm{mg} / \mathrm{L}$ & 29,750 & 30,200 & 38,400 & 33,900 & 32,150 \\
\hline $\begin{array}{l}\text { Specific Gravity } \\
\text { Strontium }\end{array}$ & $\begin{array}{l}\mathrm{g} / \mathrm{ml} \\
\mathrm{m} / \mathrm{L}\end{array}$ & $\begin{array}{l}1.0639 \\
540\end{array}$ & $\begin{array}{l}1.0637 \\
473\end{array}$ & $\begin{array}{l}1.0626 \\
420\end{array}$ & $\begin{array}{l}1.0610 \\
440\end{array}$ & $\begin{array}{l}1.0632 \\
427\end{array}$ \\
\hline $\begin{array}{l}\text { Strontium } \\
\text { Sulfate }\end{array}$ & $\mathrm{mg} / \mathrm{L}$ & $<1$ & $<1$ & $<1$ & $<1$ & 2.0 \\
\hline Sulfide & $\mathrm{mg} / \mathrm{L}$ & - & $<0.5$ & $<0.5$ & $<0.5$ & $<0.5$ \\
\hline Suspended Solids & $\mathrm{mg} / \mathrm{L}$ & & 0.40 & 3.3 & 1.1 & 0.6 \\
\hline Zinc & $\mathrm{mg} / \mathrm{L}$ & 0.29 & 0.26 & 0.28 & 0.24 & 0.21 \\
\hline Laboratory a & & SCAI & SCAI & SCAI & SCAI & SCAI \\
\hline
\end{tabular}

a SCAI = Scientific Consulting and Analysis, Inc., Lake Charles, LA. 
Exhibit 9.0-1, Part 2. SAND 8 BRINE COMPOSITION

\begin{tabular}{|c|c|c|c|c|c|c|}
\hline $\begin{array}{l}\text { Sample Date } \\
\text { Analysis for: }\end{array}$ & Units & $2 / 28 / 85$ & $5 / 1 / 85$ & $12 / 17 / 85$ & 2/4/86 & $6 / 5 / 87$ \\
\hline Alkalinity $\left(\mathrm{HCO}_{3}^{-}\right)$ & $\overline{\mathrm{mg} / \mathrm{L}}$ & 337 & 281 & 488 & 306 & 477 \\
\hline Alpha (Gross) & $\mathrm{pCi} / \mathrm{L}$ & 56 & 35 & - & - & - \\
\hline Ammonia & $\mathrm{mg} / \mathrm{L}$ & 60 & 81 & 71 & - & - \\
\hline Arsenic & $\mathrm{mg} / \mathrm{L}$ & $<0.005$ & $<0.005$ & & $<2.5$ & \\
\hline Barium & $\operatorname{mg} \Lambda$ & 95 & 470 & 576 & 536 & 468 \\
\hline Beta (Gross) & $\mathrm{pCi} / \mathrm{L}$ & 470 & 510 & - & & \\
\hline Boron & $\mathrm{mg} / \mathrm{L}$ & 40.3 & 40.4 & & 33 & 39 \\
\hline Cadmium & $\mathrm{mg} / \mathrm{L}$ & 0.015 & 0.015 & 0.11 & $<0.5$ & 0.12 \\
\hline Calcium & $\mathrm{mg} / \mathrm{L}$ & 3,730 & 3,690 & 3,900 & 3,760 & 3,574 \\
\hline Chloride & $\mathrm{mg} / \bar{L}$ & 56,600 & 56,100 & 55,200 & 55,770 & 55,000 \\
\hline Chromium & $\mathrm{mg} / \mathrm{L}$ & 0.04 & 0.03 & 0.06 & $<0.5$ & 0.03 \\
\hline Conductivity & $\mu \mathrm{mho} / \mathrm{cm}$ & 107,200 & 110,000 & & & \\
\hline Copper & $\mathrm{mg} / \mathrm{L}$ & 0.035 & 0.035 & 0.14 & $<0.5$ & 0.02 \\
\hline Dissolved Solids & $\mathrm{mg} / \mathrm{L}$ & 93,500 & 91,600 & 96,500 & & - \\
\hline Fluoride & $\mathrm{mg} / \mathrm{L}$ & 0.20 & 0.19 & - & 0.5 & - \\
\hline Gamma (Gross) & $\mathrm{pCi} / \mathrm{L}$ & 180 & 250 & & - & - \\
\hline Hardness $\left(\mathrm{CaCO}_{3}\right)$ & $\mathrm{mg} / \mathrm{L}$ & - & - & 11,200 & - & - \\
\hline Iodide & $\mathrm{mg} / \mathrm{L}$ & - & - & 44 & - & - \\
\hline Iron & $\mathrm{mg} / \mathrm{L}$ & 25.6 & 26.5 & 26.6 & 28 & 31 \\
\hline Lead & $\mathrm{mg} / \mathrm{L}$ & $<0.05$ & 0.08 & $<0.2$ & 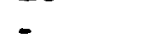 & $<1$ \\
\hline Lithium & $\mathrm{mg} / \mathrm{L}$ & - & & 24.8 & 25 & 29 \\
\hline Magnesium & $\mathrm{mg} / \mathrm{L}$ & 305 & 306 & 280 & 300 & 256 \\
\hline Manganese & $\mathrm{mg} / \mathrm{L}$ & 2.36 & 2.09 & 1.88 & 2.0 & 2.1 \\
\hline Mercury & $\mathrm{mg} / \mathrm{L}$ & $<0.001$ & $<0.001$ & $<0.005$ & - & - \\
\hline & -- & 6.56 & 6.3 & 6.8 & - & \\
\hline Potassium & $\mathrm{mg} / \mathrm{L}$ & 810 & 817 & 788 & 862 & 749 \\
\hline Radium & $\mathrm{pCi} / \mathrm{L}$ & 47 & 53 & $-a$ & - & \\
\hline Radon (Gas) & $\mathrm{pCi} / \mathrm{L}$ & 33 & 36 & - & - & - \\
\hline Silica $\left(\mathrm{SiO}_{2}\right)$ & $\mathrm{mg} / \mathrm{L}$ & 128 & 132 & 149 & 101 & 151 \\
\hline Sodium & $\mathrm{mg} / \mathrm{L}$ & 31,700 & 32,550 & 34,000 & 31,930 & 29,560 \\
\hline Specific Gravity & $\mathrm{g} / \mathrm{ml}$ & 1.0666 & 1.0627 & & & \\
\hline Strontium & $\mathrm{mg} / \mathrm{L}$ & 400 & 433 & 324 & 336 & 381 \\
\hline Sulfate & $\mathrm{mg} / \mathrm{L}$ & 1.1 & & $<2.0$ & $<10$ & \\
\hline Sulfide & $\mathrm{mg} / \mathrm{L}$ & $<0.5$ & $<0.5$ & - & - & - \\
\hline Suspended Solids & $\mathrm{mg} / \mathrm{L}$ & 0.5 & 2.5 & & & \\
\hline Zinc & $\mathrm{mg} / \mathrm{L}$ & 0.28 & 0.37 & 0.11 & $<0.5$ & 0.16 \\
\hline Laboratory a & & SCAI & SCAI & IGT & MSL & Rice \\
\hline
\end{tabular}

a SCAI = Scientific Consulting and Analysis, Inc., Lake Charles, LA.

IGT = Institute of Gas Technology.

MSL $=$ Mineral Studies Laboratory, $U$ of Texas B.E.G. Average of two analyses of 9/4/86 sample.

Rice = Rice University (Dr. M. Tomson). Average of analyses of five 6/5/87 samples. 


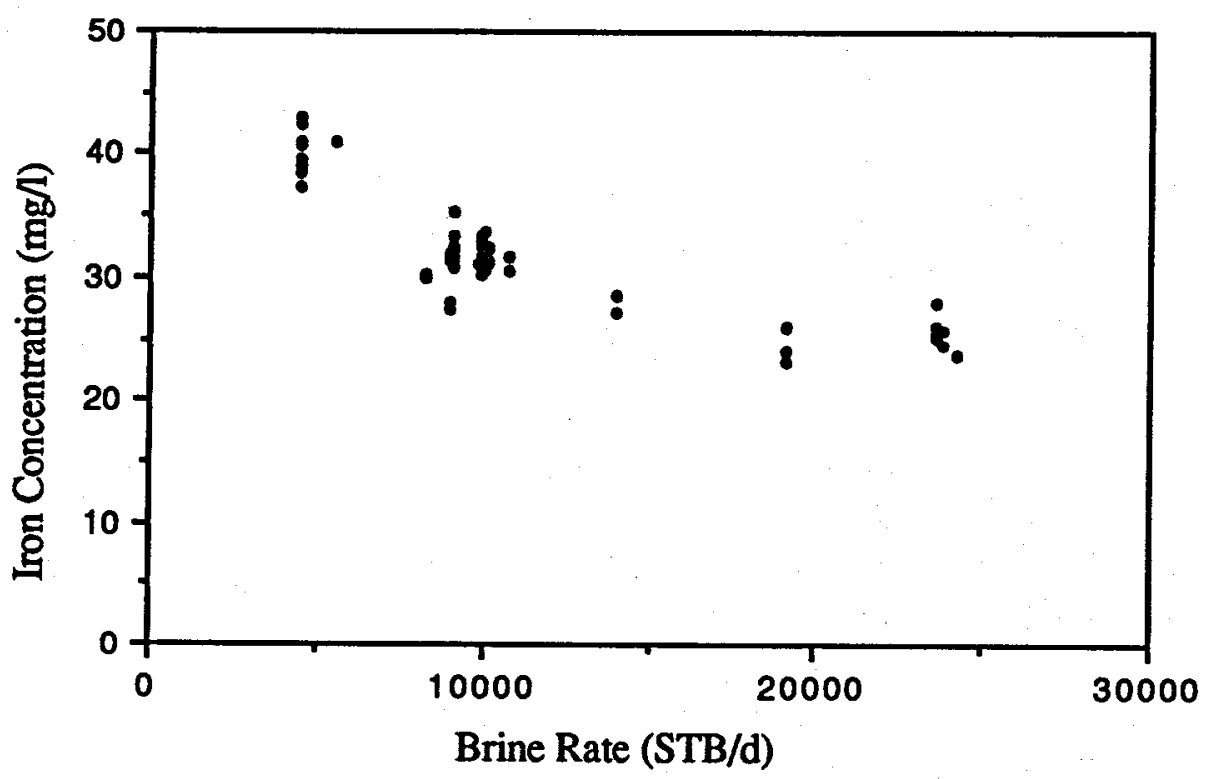

Exhibit 9.1-1. IRON CONCENTRATION VERSUS FLOW RATE

that corrodes off the well tubing as the brine flows up the well. The rate of corrosion is assumed to be independent of flow rate. For this model the data can be fit with the equation --

$$
\mathrm{Fe}=\mathrm{C}_{0}+\mathrm{C}_{1} / \mathrm{Flow}
$$

where -- $\quad \mathrm{C}_{0}=22.6 \mathrm{mg} / \mathrm{L}$ (Natural concentration of iron in formation water)

$$
\mathrm{C}_{1}=83033 \mathrm{mg} / \mathrm{L} / \mathrm{STB} / \mathrm{d} \text { (Rate of iron dissolution in tubing/casing). }
$$

The values for $\mathrm{C}_{0}$ and $\mathrm{C}_{1}$ were found by plotting the measured iron concentrations against the reciprocal of flow rate and fitting the data with a straight line (Exhibit 9.1-2).

The validity of this model was cross-checked with a measurement of the hydrogen concentration in the produced gas. Hydrogen content is a measure of the iron dissolved because, in an acidic brine environment, each atom of metallic iron that dissolves into the brine liberates one molecule of hydrogen gas. A hydrogen content of $0.07 \%$ was measured in the produced gas on October 21,1987 , when the brine flow rate was $9375 \mathrm{STB} / \mathrm{d}$. This corresponds to $8 \mathrm{mg} / \mathrm{L}$ of iron from corrosion. Adding this amount of iron to the natural iron concentration of $23 \mathrm{mg} / \mathrm{L}$ gives a total iron concentration of about $31 \mathrm{mg} / \mathrm{L}$. This value falls on the line in Exhibit 9.1-2, indicating excellent correlation with the model. 


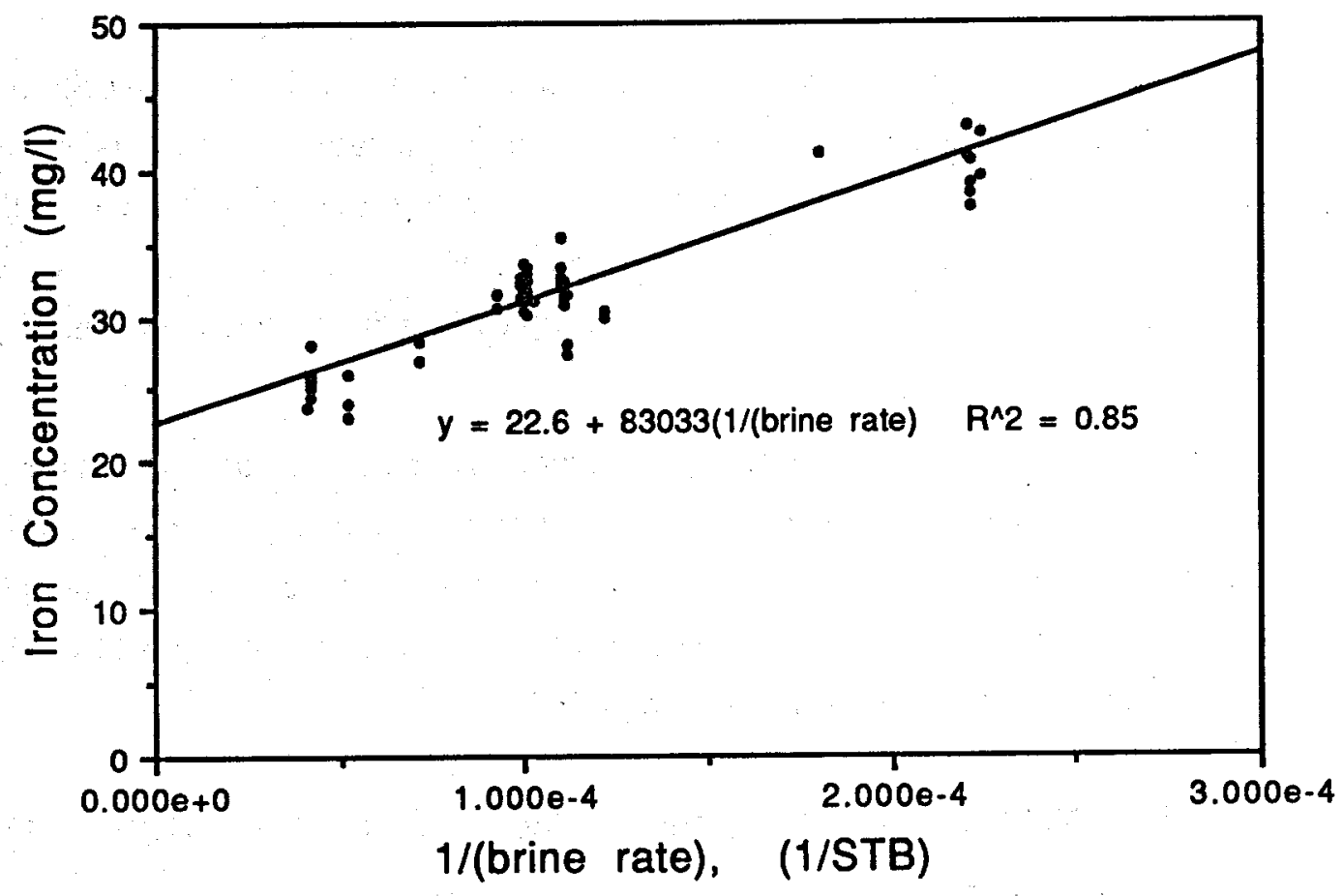

Exhibit 9.1-2. IRON CONCENTRATION VERSUS 1/BRINE RATE

\subsection{Ouestionable Change in Barium Concentration With Time}

The largest reported change in concentration was the increase in the barium concentration that occurred between October 1984 and May 1985. The concentration of barium was reported to have dropped from $420 \mathrm{mg} / \mathrm{L}$ in 1983 (very early into the flow test) to the range of 44 to $125 \mathrm{mg} / \mathrm{L}$ between February 1984 and February 1985. Then, inexplicably, the last analysis performed by SCAI showed the concentration had increased to $470 \mathrm{mg} / \mathrm{L}$. Subsequent analyses by IGT, MSL and Rice averaged $500 \mathrm{mg} / \mathrm{L}$. There is reason to suspect the lower values reported in 1984 and 1985. Rice University analyzed archived Gladys McCall brine samples collected during that time and found they contained about $500 \mathrm{mg} / \mathrm{L}$ barium. 19

The source of this barium is not residual drilling mud being flushed from the reservoir. If the barium concentration of the original reservoir brine is assumed to be $60 \mathrm{ppm}$, then the excess production of barium since March 1985 would exceed 2000 tons. This is many times more barium than could be accounted for by a wellbore full of drilling mud. 


\subsection{Other Changes in Concentrations}

Some deviations from the averages, such as reported calcium and chloride concentrations of 4330 and $38,400 \mathrm{mg} / \mathrm{L}$, respectively in an August 1984 sample, remain a mystery and are assumed to reflect sampling or analytical error. Both the Gross Beta and Gross Gamma values for the SCAI sample for February 7, 1984, as well as the Gross Gamma value for the November 1983 sample, are an order of magnitude different from all the other samples. Again, analytical or transcription error is suspected.

Concentration changes, on the order of a few percent, may be caused by sampling technique. It is known that if geothermal brines are collected without prior cooling, a portion of the brine flashes at atmospheric pressure. Assuming that the sample bottle is capped when the sample cools to $203^{\circ} \mathrm{F}$, the calculated percent of brine that would vaporize from a sample collected from high pressure lines without pre-cooling is shown in Exhibit 9.3-1.

\section{Exhibit 9.3-1. WATER LOSS FROM BRINE SAMPLES DUE TO VAPORIZATION}

Temperature at Sample Point. ${ }^{\circ} \mathrm{F}$

284

266

248

230

212
\% Water Vaporized

7.2

5.6

4.1

2.5

0.8

The site personnel historically collected daily samples in 500-ml Nalgene bottles without cooling. A portion of the archived daily brine samples that had been collected by site personnel (every 6 days) was analyzed by Rice University. The concentration of chloride appeared to have decreased by about $4 \%$ between 1984 and 1987 . Most of this change occurred in the first 12 months of flow. The decline between 1985 and 1987 was $1 \%$ or less. The sensitivity of salinity to brine handling was brought to the operator's attention in 1985, and this may have affected sample-handling procedures. The chloride also showed a cyclic variation with a period of between 30 and 60 days and an amplitude between 1500 and $4000 \mathrm{mg} / \mathrm{L}$ (2.5\% and 7.5\%). The amplitude of the cycles increased with time. These changes raised the question about whether fresher water was being introduced into the produced brine either through shale de-watering or flow from an adjacent zone that is less saline. The data is not considered to be definitive because 1) the salinity can be strongly affected by sample-collection procedures and 2) no correlation with the reported periodicity has been found. 


\subsection{CHARACTERISTICS OF SUSPENDED SOLIDS}

The Gladys McCall-produced brine contained a very low concentration of suspended solids. The disposal well injection pressure did not increase with cumulative flow as would be expected with an increasing skin factor caused by particulate plugging. Solids did not accumulate in volumes large enough to cause operational problems in the surface facilities. The brine from the Gladys McCall well was successfully injected into disposal formations without use of advanced filtration methodologies such as deep-bed filtration.

The flow rate through the large separators (54-inch ID X 30 feet long) was low enough that particles with the density of sand and a diameter in excess of $\mathbf{4 0}$ microns would settle out therein. Brine was occasionally blown from the bottom of the separators to "blowdown tanks" on the location. The amount of solids in those tanks from production of more than 20 million barrels of brine is estimated to be less than 200 cubic feet, or 20 tons. This corresponds to an upper limit of 1000 pounds of solids per million barrels of brine.

Additional data on the amount and character of produced solids are discussed under subheadings below.

\subsection{Filter Element Usage}

The brine was filtered using cartridge-type polishing filters prior to injecting it into the disposal well. Produced brine was put through three parallel filter pots (pressure vessels), each of which contained either eleven or twelve tubular elements that were 40 inches long and about 2.5 inches in diameter. The elements were cotton wound around a stainless steel core and had a nominal rating of 50 microns. The filter pots were located just upstream of the disposal well.

A detailed study of the filter usage was not made, but an indication of the need for filters can be seen in Exhibit 10.1-1, which plots the number of changes of the filter pots as a function of produced brine for part of the flowing time in 1986 and 1987. During the first 1 million barrels after the flow rate was raised to about 22,000 barrels per day, the rate of changing filter pots was about 15 pots per million barrels of brine. At the end of the high flow-rate period, the rate of pot changes had decreased to about 6 pots per million barrels of brine. This decreasing rate of filter usage suggests that the high flow rate initially conveyed an increased amount of solids from the formation, but as flow continued, the solids production decreased. During the final flow period at a rate of about 9000 barrels per day, the rate of filter-pot changes remained at about 6 pots per million barrels of brine. 


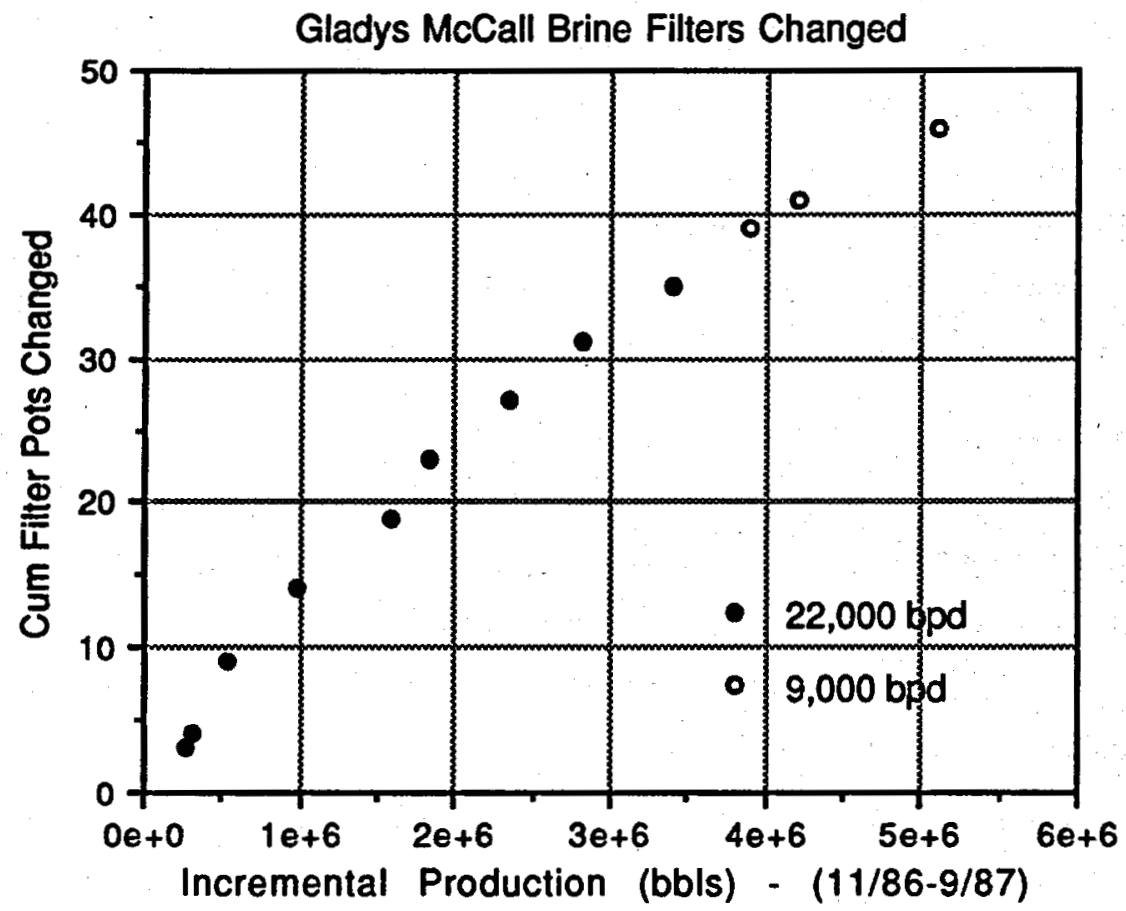

Exhibit 10.0-1. FILTER-POT USAGE VERSUS PRODUCED BRINE

The filters were located after the separators. Stokes Law on the settling velocity for sand particles suggests that most grains with a size larger than 40 microns should have settled out in the separators. Because the separator should have caught the majority of the solids as large as the 50-micron rating of the filter elements, filter loading is only a general indication of solids production. Work at Pleasant Bayou has shown that each filter pot can trap between 0.5 and 1 pound of solids before the filters are plugged. At 15 pots per million barrels of brine, the solids loading of the 50 -micron filters averaged 11 pounds per million barrels of brine or $0.03 \mathrm{mg} / \mathrm{L}$. At 6 pots per million barrels of brine, the solids loading on the 50 -micron filters is only 5 pounds per million barrels of brine, or $0.01 \mathrm{mg} / \mathrm{L}$.

\subsection{Total Suspended Solids in the Brine}

The suspended-solids concentration in the brine was measured six times between February 1984 and May 1985 by Scientific Consulting and Testing, Inc., and once by IGT in October 1987. The suspended-solids samples were caught on 0.3 to 0.45 -micron filters from sample-collection points located after the separators. The measured values are presented in Exhibit 10.2-1. The average value was $1.2 \mathrm{mg} / \mathrm{L}$ ( $430 \mathrm{lbs} /$ million barrels), although there was considerable scatter in the data. 
FLOW TESTS OF THE GLADYS MCCALL WELl ThROUGH OCTOBER 1990

Exhibit 10.2-1. SUSPENDED-SOLIDS CONCENTRATION AFTER SEPARATORS

$\begin{array}{ccc}\text { Date } & \mathrm{mg} \Omega & \text { Concentration- } \\ \text { 2 Feb 1984 } & 0.4 & 140 \\ 7 \text { Aug } 1974 & 3.3 & 1150 \\ \text { 12 Oct } 1984 & 1.1 & 380 \\ 1 \text { Dec } 1984 & 0.6 & 210 \\ 28 \text { Feb } 1985 & 0.5 & 170 \\ 1 \text { May } 1985 & 2.5 & 870 \\ 20 \text { Oct } 1987 & 0.6 & 230\end{array}$

These values are more than an order of magnitude higher than the 5 to 11 pounds per million barrels of brine caught by the 50-micron polishing filters. This suggests that most of the suspended solids in brine leaving the separators are smaller than 50 microns. These observations are consistent with the calculation using Stokes Law on settling velocity, which suggests that most particles with a size larger than $\mathbf{4 0}$ microns should settle out in the separators.

Additional suspended-solids tests were run on October 20 through 21, 1987, using 5 and 10-micron filters. These data are summarized in Exhibit 10.2-2. Half of the suspended solids are smaller than 5 microns and half are larger than 5 microns in diameter.

\section{Exhibit 10.2-2. SUSPENDED SOLIDS AT OUTLET OF LOW- PRESSURE SEPARATOR, OCTOBER 20-21, 1987}

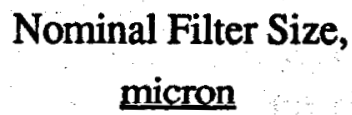

10

5

0.3

\begin{tabular}{cc}
$\mathrm{mg} / \mathrm{L}$ & lbs/million STB \\
\hline 0.27 & 90 \\
0.31 & 110 \\
0.60 & 230
\end{tabular}

An X-ray diffraction of an October 21 suspended-solids sample indicated the solids were primarily sand and clays. Iron, presumably from corrosion of tubulars or from the iron-rich chlorite clays present in the reservoir, was only a small fraction of the collected solids.

\subsection{Relative Plugging Index}

Filtration data from tests performed on October 1987, while the well was flowing at the reduced rate of $10,000 \mathrm{STB} / \mathrm{d}$, indicate high quality for the water leaving the separators. For 
example, a correlation of the cumulative volume through the filter as a function of time, developed by Amoco, is called the Relative Plugging Index (RPI). The Gladys McCall RPI is about 0.8 , which is rated as excellent. The data and interpretation leading to this conclusion are discussed below.

The Relative Plugging Index is an empirical method to estimate the quality of water. It involves passing a sample of water through a filter apparatus and determining the quality of the water as it relates to plugging of the filter. The data is plotted on a semilog plot of flow rate versus cumulative volume throughput. The slope, which is the rate of change of flow, is the indicator of the "quality" or the degree of plugging that has occurred. Exhibit 10.3-1 gives the data for a sample of McCall brine and Exhibit 10.3-2 shows a plot of the data.

\section{Exhibit 10.3-1. DATA FROM BRINE-FILTERING TEST}

\begin{tabular}{|c|c|c|c|}
\hline$\Delta \mathrm{t}, \mathrm{s}$ & $\mathrm{V} \cdot \mathrm{ml}$ & $\Delta \mathrm{V}, \mathrm{ml}$ & $\Delta \mathrm{V} / \Delta \mathrm{t}, \mathrm{ml} / \mathrm{s}$ \\
\hline 60 & 0.25 & 250 & 4.17 \\
\hline 90 & 0.50 & 250 & 2.78 \\
\hline 100 & 0.75 & 250 & 2.50 \\
\hline 93 & 1.00 & 250 & 2.69 \\
\hline 92 & 1.25 & 250 & 2.72 \\
\hline 105 & 1.50 & 250 & 2.38 \\
\hline 105 & 1.75 & 250 & 2.38 \\
\hline 115 & 2.00 & 250 & 2.17 \\
\hline 115 & 2.25 & 250 & 2.17 \\
\hline 130 & 2.50 & 250 & 1.92 \\
\hline 132 & 2.75 & 250 & 1.89 \\
\hline 133 & 3.00 & 250 & 1.88 \\
\hline
\end{tabular}

The Relative Plugging Index is defined as follows:

$$
\text { RPI = TSS }- \text { MTSN }
$$

where -- RPI = Relative Plugging Index

TSS $=$ Total Suspended Solids, ppm

MTSN $=$ Millipore Test Slope Number . 
FLOW TESTS OF THE GLAdYS MCCALL WELL THROUGH OCTOBER 1990

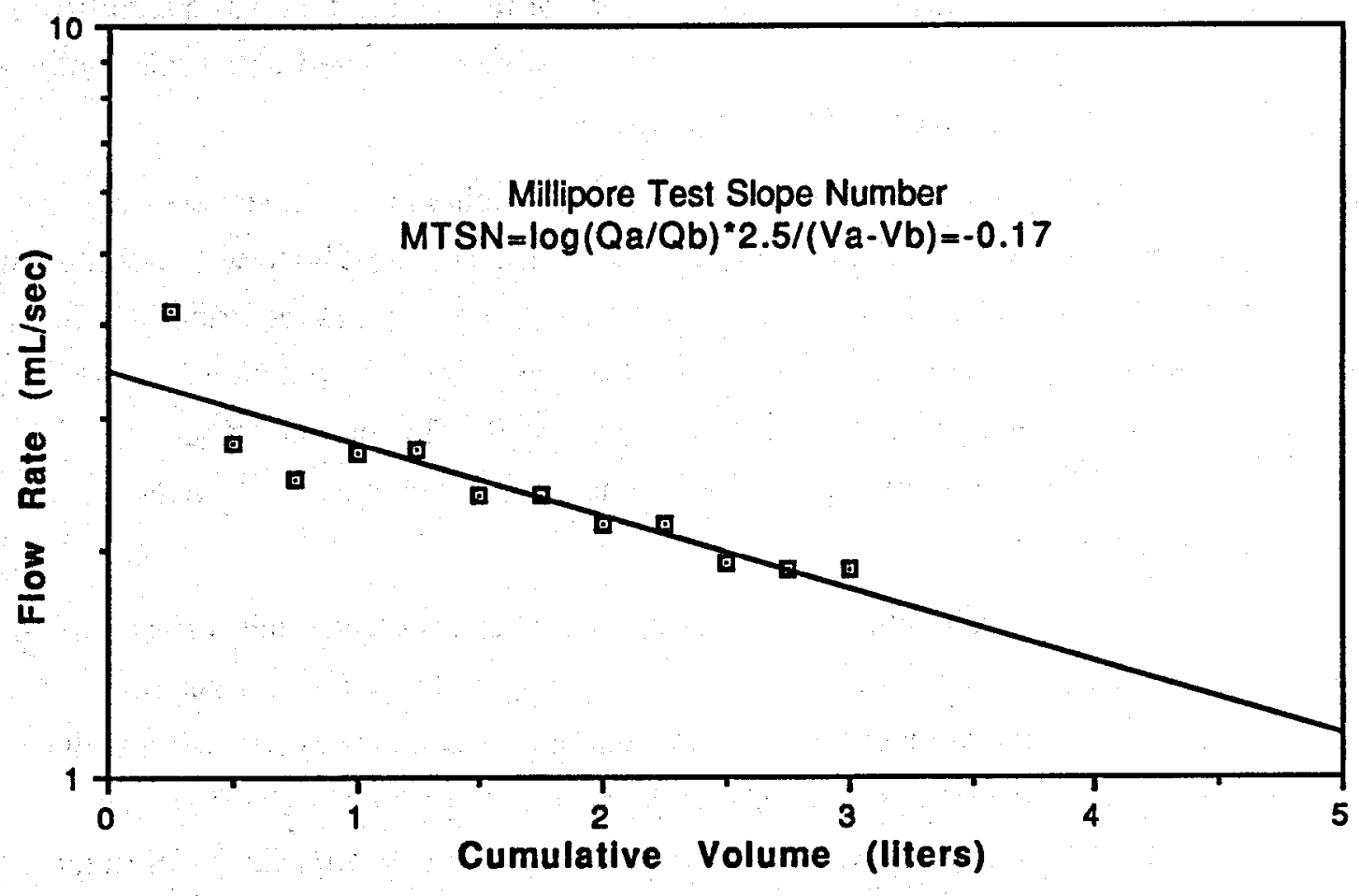

Exhibit 10.3-2. PLOT OF DATA FOR RELATIVE PLUGGING INDEX (RPI)

For the brine from the low-pressure separator in October 1987, Exhibit 10.2-2 reveals a value of $0.60 \mathrm{mg} / \mathrm{L}$ for the amount of solids that were caught on a 0.3 -micron millipore filter (TSS) and the slope of Exhibit 10.3-2 gives a value of -0.17 for MTSN. Thus, the value of RPI is --

$$
\mathrm{RPI}=0.60-(-0.17)=0.77
$$

Amoco gives a water quality rating guide --

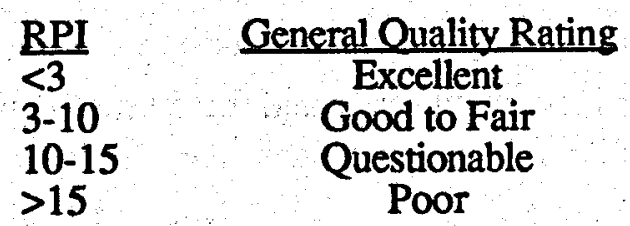

The RPI of 0.77 calculated above corresponds to a general quality rating of excellent.

\subsection{SCALE INHIBITION}

Analysis of the initial brine samples from the McCall well revealed that calcium carbonate scale formation in the brine flow lines would be a problem unless measures were taken to counteract it. Therefore, scale inhibitor was set up to inject into the surface flow lines from the 
beginning of the flow tests. But scale deposition in the production-well tubing was a significant problem during the first 2 years of flow. This problem was eventually solved with scale-inhibitor squeezes, or pills, that were injected directly into the reservoir.

The inhibitor used for most of the flow test was a polyphosphonate (Dequest 2000) manufactured by Monsanto Chemical Company. The pure chemical was diluted with water to an active strength of about $2 \%$ to $3 \%$ and then injected by a chemical pump into the brine flow line upstream of the choke so that the concentration in the brine was about $0.5 \mathrm{ppm}$ phosphonate by weight. Initially, the acid form of the polyphosphonate was used. This proved to be excessively corrosive to the injection piping and equipment, so a switch was made to the neutralized form of the chemical.

Although the injection of scale inhibitor upstream of the choke protected the surface piping and equipment from scale formation, it did not protect the tubing in the well or the surface hardware upstream of the inhibitor-injection point. Formation of scale in the production well tubing soon became apparent from degraded well performance. Inspection of the flow lines revealed calcium carbonate scale. Acid was used to remove the scale. From March 7 through 14, 1984, the first of several series of acid treatments and intervening evaluations was performed. Although this treatment removed the scale, it was only a temporary measure.

With resumption of brine production, scale immediately began reforming. To monitor the scale buildup, the flow line between the wellhead and the surface inhibitor-injection point was periodically inspected. The increased friction pressure in the flowing well was also monitored. When the scale buildup became a problem -- with its weight on the tubing, too much pressure drop, or problems with the equipment, such as seizing of the valves -- another acid treatment was performed. A typical acid treatment was about 150 barrels of $15 \% \mathrm{HCl}$ pumped into the well with spacer pads of brine to spot the acid at the desired points in the tubing. Each treatment was allowed to soak for about an hour before back-flowing it out of the well. Exhibit 11.0-1 tabulates the total amount of acid used for each treatment series and the estimated amount of calcium carbonate scale removed.

\section{Exhibit 11.0-1. ACID TREATMENTS TO REMOVE WELLBORE SCALE}

\begin{tabular}{lcc} 
Dates & 15\% HCl Acid. Bbls & Scale Removed, lbs \\
\cline { 2 - 3 } Mar. 7-14, 1984 & 360 & 33,700 \\
Jul. 10-12, 1984 & 410 & 24,800 \\
Nov. 12-16,1984 & 754 & 49,900 \\
May 16, 1985 & 150 & 3,000
\end{tabular}


The rate of calcium carbonate scale buildup was calculated by plotting the cumulative amount of scale removed by the acid treatments as a function of the cumulative amount of brine produced. This is shown in Exhibit 11.0-2 for the treatments up through November 1984. Each of these treatments removed all of the wellbore scale. Flow rates during this period were generally $20,000 \mathrm{STB} / \mathrm{d}$ and higher. A linear relationship was found for the buildup rate (slope of the line) of 19.4 pounds of scale formation per 1000 barrels of brine produced. This amount of scaling should have reduced the alkalinity in the brine by $55 \mathrm{mg} \mathrm{CaCO} / \mathrm{L}$. After the November 19, 1984, acid treatment of the Gladys McCall production string, the strength of the returned acid indicated that the string was completely free of scale.

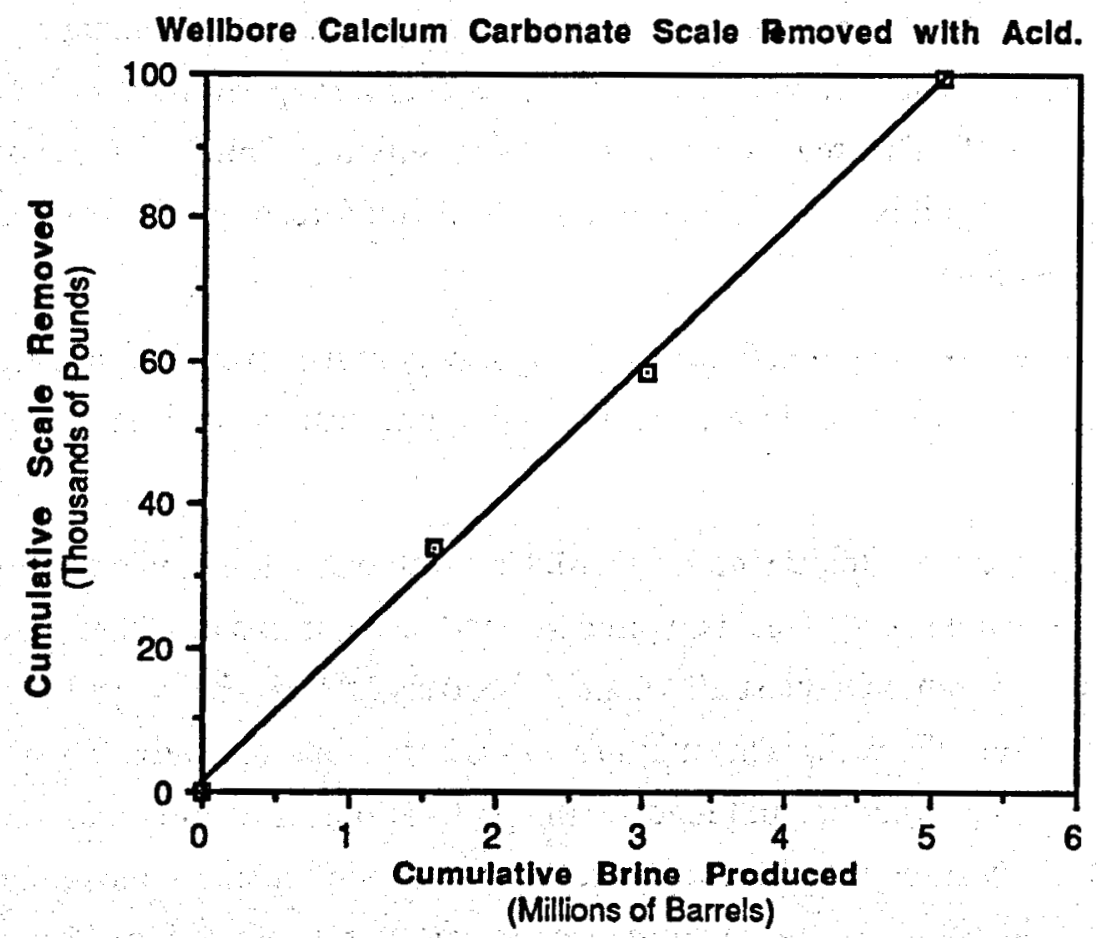

\section{Exhibit 11.0-2. FORMATION OF CALCIUM CARBONATE SCALE IN WELLBORE WITH PRODUCTION}

Flow was then limited to below 15,000 STB/d to keep the wellhead pressure high enough to minimize scale formation in the wellbore. On May 17, 1985, another acid job was done. From the amount of acid spent, it was calculated that 3018 pounds of scale were removed and that the string was again scale-free. Between the acid jobs, about $2,300,000$ barrels of brine were produced at a fairly constant rate of about 14,500 BPD. Assuming a constant scale-formation rate, the scaling would reduce the alkalinity by $4 \mathrm{mg} \mathrm{CaCO} / \mathrm{L}$. This is considerably less scale deposition than had 
been experienced at the higher rates. It is not known whether the reduced rate or perhaps a small quantity of inhibitor injected during the unsuccessful pill, or both, were responsible for the reduced rate of scale deposition.

There was an unsuccessful attempt to inject an inhibitor pill in November 1984 and another in May 1985. Inhibitor pills were successfully injected in June 1985 and February 1986.

Inhibitor pills are composed of what would be many months supply of a scale inhibitor that is stable at the reservoir temperature. The intent is to inject, or "squeeze," this inhibitor into the reservoir. In the reservoir matrix, a portion of this inhibitor would either adsorb to sand grains or form a pseudoscale. This portion of the injected inhibitor then leaches out of the rock slowly as brine is produced. This inhibitor residual should be at a concentration high enough to prevent scale formation in the wellbore. The "inhibitor squeeze" treatments were performed with consultation from Rice University. 11,16 The treatments consist of first mixing a "pill" of a few percent phosphonate in brine. The pill is then pumped into the well and forced out into the reservoir formation with a brine chaser.

When brine production is resumed, the inhibitor slowly redissolves into the brine that passes through the treatment zone next to the wellbore, thus inhibiting scale formation in the brine before it enters the wellbore.

The first inhibitor squeeze treatment for the McCall well was attempted on November 28, 1984. This attempt was not successful. The pill consisted of 23 drums of Champion Chemical $\mathrm{T}-120$ (Equivalent to Monsanto Dequest 2000) and 20 barrels of $15 \% \mathrm{HCl}$ mixed with 450 barrels of hot brine produced from the well. This mixture was pumped into the well. The pumping pressure abruptly increased when the pill reached the perforations. Plugging was occurring, so the job was aborted. Back-flushing the pill revealed a large amount of calcium phosphonate and iron phosphonate solids. The source of the calcium was the 450 barrels of produced brine, which contains 280 kilograms (600 pounds) of dissolved calcium. The iron source was steel dissolved from the mixing tanks and well tubulars by the acid. The dissolved calcium and iron then reacted with the phosphonate to precipitate insoluble calcium and iron phosphonate solids. Production was resumed and the treatment was redesigned to use a neutralized form of the chemical.

A second inhibitor squeeze was attempted on May 28, 1985. As before, this treatment was also not successful. A 300 -barrel slug of $15 \%$ synthetic sodium chloride brine was injected into the well. A small 27-barrel slug of 3\% neutralized phosphonate inhibitor (Champion Chemical $\mathrm{T}-132)$ diluted in $15 \%$ synthetic sodium chloride brine was then displaced down the well with the synthetic sodium chloride brine. Injected fluids were preheated and filtered. The resistance to pumping suddenly increased as the pill reached the perforations which again stopped further 
injection. Back-flushing of the pill still in the wellbore produced some solids consisting of calcium-inhibitor salts and/or iron oxides. A second small inhibitor pill was blended and injected, with the same results. The source of the problem was believed to be sodium chloride salt used to make the synthetic brine. Although a sample of the solid salt used to make the synthetic brine was analyzed and found free of calcium, it turned out that the supplier had provided salt from two different sources, and only one of the sources was sampled. The chemists were unaware that two sources had been used. The unsampled salt from the second source turned out to be contaminated with calcium chloride, and the brine had about $250 \mathrm{mg} / \mathrm{L}$ of calcium. The pill and synthetic brine had been mixed and stored in several different tanks on location so that the problem with the calcium-contaminated brine was not known until they were mixed during pumping into the well.

Following these two unsuccessful inhibitor squeeze treatments, the procedure was replanned and successfully accomplished on June 25,1985 . Stringent quality control was exercised to ensure that the fluids were not contaminated and that precipitate would not form in the wellbore. This included stringent quality-control specifications that essentially required the use of reagentgrade sodium chloride for preparation of the $15 \%$ synthetic sodium chloride brine. A $10 \%$ calcium chloride brine was prepared as an overflush. Iron concentration of the delivered brine was less than $1 \mathrm{mg} / \mathrm{L}$. EDTA was added to the brine to tie up what little iron was present. Plastic-lined or fiberglass trucks and mixing vessels were used to the greatest extent possible.

The precautions were only marginally successful. The injection rate was decreased by a factor of three and the injection pressure jumped 1000 psi while the pill was being displaced into the formation. Rates decreased even further as a calcium chloride brine chaser reached the perforations. Nevertheless, the inhibitor pill and 120 barrels of brine chaser were displaced into the formation.

This pill consisted of 550 gallons of Champion T-132 dissolved in 87 barrels of $15 \%$ sodium chloride brine. The pill was pumped into the formation with a 300-barrel spearhead of $15 \%$ sodium chloride brine ahead of the pill, followed by two 100 -barrel overflushes of $15 \%$ sodium chloride brine and 10 pounds per gallon (10\%) calcium chloride brine behind the pill. The purpose of the calcium chloride was to enhance precipitation of the phosphonate inhibitor in the formation. The well was then shut in for 24 hours to enhance the absorption/precipitation of the inhibitor before resumption of production. Sampling of the initial production (flow-back of the injected fluids) revealed that only $30 \%$ of the inhibitor was retained in the formation rock and that $70 \%$ of the inhibitor was flushed back out within a few days.

A caliper run before another pill job (on February 4, 1986) indicated that the June 25, 1985, pill job was completely effective in preventing scale formation. This inhibitor squeeze effectively 
stopped the formation of scale in the wellbore. The concentration of phosphonate in the produced brine was in the range of about 1 ppm shortly after the inhibitor squeeze and decreased to levels near the detection limit of the analysis procedure (a tenth of a part per million) while effective scale inhibition was continuing to occur. Inhibition was occurring at inhibitor concentration levels lower than were expected to be effective.

The last inhibitor squeeze was performed on February 5, 1986. For this squeeze, the pill consisted of 100 barrels of $3 \%$ phosphonate (Champion T-132) in 10\% synthetic sodium chloride brine. It was pumped in with a 100-barrel spearhead of synthetic brine and an overflush of 1200 barrels of synthetic brine. There was no calcium chloride overflush included in this pill. This treatment successfully controlled scale formation in the wellbore until the termination of the flow test in October 1987.

During the time of the Rice study (April through June 1987) the phosphonate concentration in the produced brine from the previous inhibitor squeeze operations remained at about $0.15 \mathrm{mg} / \mathrm{L}$ and was sufficient to prevent scale formation in the wellbore.

\subsection{CORROSION}

Corrosion was less severe at the Gladys McCall well than had been observed during prior testing of the Pleasant Bayou well. Corrosion inhibitor was not used at Gladys McCall. Prior to successful down-hole treatment with scale inhibitor, calcite scale probably had a significant role in preventing corrosion of the tubing in the production well. The extent to which scale provided protection of surface facilities is not apparent. But it is clear that corrosion/erosion at turbulent areas in the surface piping resulted in penetration of the pipe wall by pits and the necessity for repair.

Production-well and surface-facility corrosion are discussed under separate headings below.

\subsection{Corrosion in the Production Well}

Corrosion rates in the production wellbore were monitored periodically through iron analyses of the brine, molecular hydrogen analysis of the gas, and caliper surveys. As discussed in Section 9.2, analysis of the iron concentration in brine suggested that the rate of corrosion was a very weak function of brine rate (that is, the concentration of iron in the brine was inversly proportional to the brine rate). In other words, for rates in excess of 10,000 barrels per day, down-hole corrosion was occurring at the constant rate of about 25 to 29 pounds per day and was independent of the flow rate.

A handle on the absolute corrosion rate was provided by the detailed gas analysis of a salesgas sample collected on October 21, 1987. This sample was analyzed at IGT for gases other than 
those normally reported in a natural gas analysis. The gas sample was found to contain 0.07 mole percent molecular hydrogen. Molecular hydrogen is not normally found in the produced gas but is produced during the corrosion of iron in an acidic brine as follows:

$$
\left(\mathrm{Fe}^{0}\right)_{\text {solid }}+2\left(\mathrm{H}^{+}\right) \text {aqueous }->\left(\mathrm{Fe}^{+2}\right)_{\text {aqueous }}+\left(\mathrm{H}_{2}\right)_{\text {gas }}
$$

Hydrogen content is a direct measure of the iron dissolved because, in an acidic brine environment, each atom of metallic iron that dissolves into the brine liberates one molecule of hydrogen gas. The hydrogen content of $0.07 \%$ was measured in the produced gas on October 21 , 1987, when the brine flow rate was 9375 STB/d. This corresponds to an iron loss of 25 pounds per day from the wellbore, wellhead, and plumbing through the separators. This value is consistent with the value of 29 pounds per day estimated from brine analysis data. This iron loss would add $8 \mathrm{mg} / \mathrm{L}$ of iron from corrosion. Adding this amount of iron to the natural iron concentration gives a total iron concentration of about $31 \mathrm{mg} / \mathrm{L}$. This equals the average iron concentration value reported by Rice University for that flow rate (Appendix M).

For the approximately 1200 days of production, an iron loss rate of 25 pounds per day corresponds to a total of 30,000 pounds, or about $12 \%$ of the weight of the 13,933 feet of 18-pound-per-foot tubing that is in the well. If all of the corrosion was uniform from the tubing, the metal loss would correspond to $12 \%$ of the thickness. In practice, we would expect a substantial portion of the down-hole corrosion to occur in the perforated interval. The reason is the higher velocity and turbulance associated with the brine flowing through the perforations and then making a 90-degree change in direction to move up the wellbore. Indeed, on some GRI coproduction wells, caliper logging has revealed that the casing has completely eroded away in the perforated interval.

An amount of down-hole corrosion that is consistent with the above discussion was detected by a multi-feeler caliper logging tool run down the tubing. A Kinley Caliper Survey run in July 1988 found only one large pit. This pit was 0.16 inches in depth, which is $44 \%$ of the tubing wall thickness. This pit was found in Joint 73, which is at a depth of approximately 2720 feet. The pit was found in the middle of the joint, rather than near the threaded connections. There was also "minor," but detectable, corrosion reported for 217 of the 372 tubing joints inspected during the survey. Minor corrosion is defined in the report as less than $20 \%$ of the total wall thickness and may be only a few percent of the wall thickness (on the order of 0.01 inch). This minor corrosion extended the entire length of the tubing, although it seemed more pervasive between 7500 and 11200 feet. Minor corrosion includes shallow pits, shallow general corrosion, roughness, and irregular interior diameters. The number of joints with "minor" corrosion is summarized below. 


$\begin{array}{ccc}\text { Depth, ft } & \begin{array}{c}\text { Number of } \\ \text { Tubing Joints }\end{array} & \begin{array}{c}\text { Number of Joints in Interval } \\ \text { With Minor Comosion }\end{array} \\ 0-1870 & 1-50 & 27 \\ 1870-3740 & 51-100 & 27 \\ 3740-5600 & 101-150 & 19 \\ 5600-7470 & 151-200 & 28 \\ 7470-9340 & 201-250 & 38 \\ 9340-11210 & 251-300 & 39 \\ 11210-13080 & 301-350 & 25 \\ 13080-13900 & 351-372 & 14\end{array}$

\subsection{Corrosion of Surface Piping}

Two types of data were obtained on corrosion of surface piping. The first was from the use of corrosion coupons and is discussed in Section 12.2.1. Additional data have come from direct observation of corrosion, including the occurance of leaks due to corrosion pits penetrating the pipe. The direct observations are described in Section 12.2.2.

\subsubsection{Corrosion Coupon Data}

Corrosion coupons were in place at one or more locations in the surface facilities throughout the flow-testing of both Sands 9 and 8. The coupons used downstream of the chokes were cut from 1/8-inch-thick "mild steel" by a local machine shop. Details of composition are not known.

An overview of the corrosion coupon data is in Exhibit 12.2.1-1, and comprehensive data on the coupons is in Appendix N. The locations at the heads of the columns in Exhibit 12.2.1-1 relate to the pressure. The "Before Sep" column refers to a location between the choke and the first separator. Pressure at that point is the same as the first separator. There are entries in the "Btw Seps" column only when two separators were in operation in the brine flowpath. The pressure at the coupons is the pressure of the second, or low-pressure, separator. The "Disp Line" coupon point was downstream of the dump valve on the lowest pressure separator and upstream of the filter skid. Pressure exceeded disposal well injection pressure by up to a few tens of psi because of the flowing pressure drop in the surface piping and across the filters.

The rows in Exhibit 12.2.1-1 are in chronological order for the sequence of tests of the Gladys McCall well. Each entry in the exhibit is an average for all coupons used during that flow period. In some cases, the tabulated value reflects results from as many as three separate coupon 


\section{EXHIBIT 12.2.1-1. OVERVIEW OF CORROSION COUPON DATA}

\begin{tabular}{|c|c|c|c|}
\hline & -------Metal & ss Rate, mi & r year-- \\
\hline & Before Sep & Btw Seps & Disp Line \\
\hline Sand 9 - 24 -Day Test & -10.4 & & -8.4 \\
\hline Sand 8 - 21-Day Test & -0.7 & & 92.9 \\
\hline Sand 8 - 1 Separator & 1.7 & & 247.3 \\
\hline Sand 8 - 2 Separators & & 8.6 & 553.5 \\
\hline Sand 8 - 1 Separator & & & 202.1 \\
\hline Sand 8 - 2 Separator & & & \\
\hline $7 / 17 / 84>12 / 30 / 84$ & & 374.5 & 138.7 \\
\hline $12 / 30 / 84>12 / 30 / 85$ & & 161.0 & 2.3 \\
\hline $12 / 30 / 85>1 / 1 / 87$ & & -1.2 & 61.8 \\
\hline $1 / 1 / 87>10 / 26 / 87$ & & -0.1 & 388.9 \\
\hline
\end{tabular}

holders that were examined daily, weekly, and monthly. The tabulated average involved weighing each coupon by the number of days that it was in service. Negative values represent gaining weight. This was most often caused by scale formation on the coupon.

There are a large number of reservations and qualifications regarding the coupon data. Nevertheless, the overall observation that corrosion severity increased with removal of gas from the flowstream and the associated lowering of pressure is consistent with the direct observations of corroded piping.

In addition to the reservations and qualifications regarding the coupon data that are set forth in Appendix $\mathrm{N}$, the balance between scaling and corrosion must be borne in mind when evaluating the coupon data. Both scale and pseudoscale (precipitation caused by an excessive amount of inhibitor) form an impervious coating on steel and thereby retard or prevent corrosion. During 1986 and 1987, the surface scale-inhibitor-injection rate was adjusted on the basis of examining the coupon from between the separators every few days. The same coupon was used for 2 years. A thin layer of scale was usually present, but the coupon was ocassionally cleaned with acid.

\subsubsection{Direct Observations of Corrosion}

Fortunately the corrosion of the pipe was less extensive than the coupon data would suggest. If the piping had uniformly lost between 200 and 500 mils per year, as suggested by the coupon data, the majority of piping would require replacement.

In practice, the onset of leaks and replacement of portions of the piping was after less than 2 years of production. But after the end of almost 4 years of testing, the majority of the long runs of piping exhibited little, if any, corrosion. To the extent that corrosion was a problem, it was 
concentrated in regions characterized by high velocity (such as downstream of chokes) or areas where turbulence was induced by changes in direction, weld penetration into the pipe, or other sources of internal roughness.

The leaks that were experienced were in the form of pits penetrating the pipe wall. Onset of leakage was characterized by either 1 ) growth of crystaline salt or 2) visible water vapor from condensing of water vapor that had evaporated in conjunction with passage through the hole at the temperature of $270^{\circ}$ to $290^{\circ} \mathrm{F}$. Growth of observed leaks was slow. Leaks were observed for as long as a week while parts needed to repair it were being procured. Then the repairs were made with a down time of only a few hours.

The first leaks occurred in elbows or changes of diameter near the level-control valves just upstream of the coupon located between the separators. This area continued to intermittently spring leaks. Leaks also appeared at similar points in the brine line between the low-pressure separator and the disposal well, although at a lower frequency than the piping after the large separator.

The other location where leaks formed was at the Willis chokes. After a few months of flow, the chokes were opened; one choke had enough corrosion to warrant immediate replacement whereas corrosion was also noted on the other choke. The second choke was removed later that month and both were repaired. Repair consisted of 1) building up the corroded area, 2) machining out $1 / 4$ inch of the total interior diameter, 3) welding in a layer of $309 \mathrm{~L}$ stainless steel, 4) welding in a layer of $316 \mathrm{~L}$ stainless steel, and 5) stress relieving the body at $1200^{\circ} \mathrm{F}$ for 2 hours. This stainless steel overlay was found to be very effective at preventing corrosion in the choke body. Subsequent to this, stainless steel overlays were found to be needed also in the spool pieces, on flange faces and near ring gaskets in the turbulent region downstream of the chokes.

In summary, corrosion in the surface facilities was extensive where 1) brine velocity was in excess of 15 feet per second or 2) there was turbulence induced by restrictions in the flow line or elbows. Internal corrosion along with leaks immediately after control valves and chokes were common, whereas corrosion in the separators -- where flow is essentially laminar -- was minimal. Leaks that eventually did form in the pipe started small and grew slowly, over a period of hours or days. Catastrophic failure of piping, wherein leaks develop quickly and become very large in a short time, was not observed. The onsite personnel became adept at repairing or replacing pipe that had sprung leaks with a minimum of down time. 


\subsection{CONCLUSIONS}

The Gladys McCall well was a successful test as part of the DOE Geopressured-Geothermal Energy Program. The well produced geopressured brine containing dissolved natural gas from the Lower Miocene sands at a depth of 15,150 to 16,650 feet. More than 25 million barrels of brine were produced in a series of flow tests between December 1982 and October 1987 at various flow rates up to about 30,000 barrels per day.

More than 727 million SCF of gas were produced. Of this, 577 million SCF were sold, 90 million SCF were flared, and 60 million SCF remained with the brine injected down the disposal well.

The well is now (1990) in a multiyear long-term pressure-buildup test. Initial short-term flow tests for the Number 9 Sand found the permeability to be 67 to $85 \mathrm{md}$ for a brine volume of 85 to 170 million barrels. Initial short-term flow tests for the Number 8 Sand found a permeability of 113 to $132 \mathrm{md}$ for a reservoir volume of 430 to 550 million barrels of brine. The long-term flow and buildup test of the Number 8 Sand found that the volume of the reservoir as measured by the short-term flow test was connected to a much larger, low-permeability reservoir. Numerical simulation of the flow and buildup tests required this large, connected reservoir to have a pore volume of about 8 billion barrels (two cubic miles of reservoir rock) with an effective permeability in the range of 0.2 to $20 \mathrm{md}$.

Detailed analyses of the brine and gas found the brine to be undersaturated with gas. The gas content of about $30 \mathrm{SCF} / \mathrm{STB}$ was at about $85 \%$ of saturation at reservoir pressure and temperature. The corresponding bubble-point presure is about 9200 psi, or about 3700 psi below the initial reservoir pressure. The produced gas/brine ratio was largely invariant with production, time, and flow rate. This is consistent with expectations when it is recognized that the lowest flowing bottomhole pressure inside the wellbore was in the range of 8600 to $8700 \mathrm{psi}$. This was during the first 4-1/2 months of 1987.

Very small, non-economical quantities of liquid hydrocarbons were also produced. The only data during the first year was from "cryocondensate" analyses. Over the lifetime of the production, the average concentration of hydrocarbons with high aromatic content in the produced brine was found to be about 35 ppmv (parts per million by volume). After accumulation of a heavy aliphatic fraction of crude oil was observed in the high-pressure separator in January 1985 , it was found to accumulate at a rate corresponding to a concentration of about $6 \mathrm{ppmv}$ of brine. Measurement of the rate of hydrocarbon recovery by condensation of liquid with high aromatic content from the gas began in January 1986. Recovery rate was found to average $7.6 \mathrm{ppmv}$. 
Substantial inprovements were made in procedures for inhibiting calcium carbonate scale formation in the well tubing and separator equipment. Initially, scale inhibitor was injected into the brine stream upstream of the separator. But scale formed in the production tubing and had to be periodically removed with hydrochloric acid during 1984 and the first half of 1985 . For the last half of 1985 , brine rate was limited to 15,000 BPD to avoid scale formation in the tubing. Successful injection of inhibitor "pills" into the formation made possible production with the choke wide open for a substantial portion of the last 2 years of production.

Corrosion and/or erosion of surface piping was significant. The problem was most severe in the high-turbulence region immediately downstream of the choke aperture. Use of stainless steel components, or cladding of the inpacted surfaces with stainless steel, was found to remove the problem. The lifetime of A-53 or A-106 carbon steel was found to be only 1 to 3 years downstream of the separators in regions of turbulence due to control valves, elbows, or weld penetrations. Leaks developed because of pitting and grew slowly over a period of hours to days. There was no indication of sudden onset of large or catostrophic leak rates.

\subsection{RECOMMENDATIONS}

The main objectives of the McCall well-test program have been achieved. The question now is to define the remaining few things to be completed before abandoning the location.

Several recommendations have been made by the involved DOE contractors in recent planning meetings. IGT"s positions in relation to these various proposals are as follows:

1. Periodic measurement of bottomhole pressure should continue as long as possible. This is because the pressure-buildup data for the long-term flow test has provided surprising evidence that the geopressured reservoir is very large and that the concept of a sealed reservoir to provide the geopressure may not be as simple as previously thought.

2. The proposal to drill a sidetrack hole to core through the producing zone near the wellbore is a good technical idea on how to obtain direct information on the reservoir rock and how it responded to the production and inhibitor squeezes. Although the procedure to do the coring is a straight-forward drilling practice, the core analysis procedures are not. It would be a mistake to simply cut a core and send it to a commercial core-analysis laboratory for either their routine or special core analysis. Before cutting core, a program needs to be established to identify the experts who are going to do the analysis and to define and initiate the analysis program. It would take a year to assemble the required equipment and verify the special test procedures that will be needed. An important part of such a program would be to make comparisons between the new core and the old core taken when the well was originally drilled. The coring program should not be undertaken until adequate baseline data from the original core is in hand. 
3. A brief flow test of the previously produced Number 8 Sand will be useful in comparing the flow capacity $(\mathrm{kh})$ of the well now to what it was when it was shut in 3 years ago. It may not be possible to compare this proposed test to the initial well completion, however, because the down-hole conditions changed with the inhibitor-squeeze operations. This proposed test needs to be done with a bottomhole pressure gauge in the well. The test has been proposed to be 4 to 5 days days of flow time followed by 3 weeks of pressure buildup. This proposed flow time may be longer than necessary. A flow period of 1 day at a low flow rate, followed by 3 to 4 days of pressure buildup, should be adequate to determine the flow characteristics near the wellbore. The longer programmed time allows for detection of the first reservoir boundaries and evaluation of whether the compressibility has changed. If the disposal well is not in a condition to accept the produced brine, the flow time and rate should be down-sized so that it is practical to haul the produced brine to a commercial disposal well rather than perform an expensive workover of the McCall disposal well.

4. Perforating two or three zones above the Number 8 Sand, but still in the geopressured region, and measuring their pressure, will be useful in helping to determine which zones are hydraulically connected to the Number 8 Sand and contribute to the large volume determined from the pressure-buildup data and numerical modeling. Testing of zones above the geopressured horizon will not contribute to analysis of the geopressured energy and should not be undertaken with the limited program funds. Solicitation of bids for companies to perform the test at their own expense could concievably lead to discovering conventional hydrocarbons that will give the well commercial value for sale rather than abandonment.

In addition to the recommendations for which a consensus has been reached in the recent program meetings, IGT recommends the following actions on the Gladys McCall location.

5. Utilize the full suite of production logging technologies in seeking resolution of the confusion regarding the apparent change of a factor of two in formation kh after the first reservoir limit test. This would include nuclear logging to look for changes below the "shale break" near the mid-point of the perforations. Gamma-ray logging would provide insight into whether precipitation of radioactive species was greater for the perforations above or below the "shale break." This result could be further resolved by use of the photoelectric effect and gamma spectrum-analysis logging.

6. Evaluate the effects of disposal of tens of millions of barrels of high-temperature brine. This brine has created a region in the disposal well (presumed to be circular) whose temperature is about $150^{\circ} \mathrm{F}$. above the normal temperature. The circular region has a diameter of roughly half a mile at a depth of about half a mile. Also, the density of the injected brine is probably lower than the density of the native brine. Whether this perturbation of the normal geothermal gradient or pore-pressure relationship to depth will have significant effects, either positive or negative, needs to be evaluated.

7. Document the corrosion of surface hardware and wellbore tubulars. Substantial amounts of corrosion of surface hardware was observed during the test of the Gladys McCall well, but documentation thereof has been minimal. Also, corrosion of disposal well tubulars was observed but not documented. While dismantling the surface equipment and plugging and 
abandoning the two wells, it is important that there be rigorous documentation of the corrosion and any other effects on the equipment from the production. Understanding the corrosion mechanisms and means to minimize costs related thereto is an important element of the cost of future energy supply, whether from geothermal wells or from production of hydrocarbons with a high water cut.

\subsection{ACKNOWLEDGMENTS}

This report was prepared under DOE Contract DE-AC07-85ID12578 with Eaton Operating Company and Subcontract IGT/EOC 85-4 with the Institute of Gas Technology.

\subsection{REFERENCES CITED}

1. Bebout, D. G., "Regional and Local Geologic Setting of the Tecnadril-Fenix and ScissonDepartment of Energy Gladys McCall No. 1 Well Site," in Geopressured-Geothermal Energy Resource Appraisal, Guidebook Series \#2. Baton Rouge: Louisiana Geological Survey, 1982.

2. CK GeoEnergy Corporation, "Minutes From DOE/Industry Geopressure-Geothermal Resource Development Program Working Group Meetings," DOE/H\&N/CKG/3-84.

3. Clark, J. D., "Engineering Interpretation of Exploration Drawdown Tests, Lower Miocene Geopressured-Brine Reservoirs, TF\&S/DOE Gladys McCall No. 1 Well, Cameron Parish, Louisiana," Proceedings of the Sixth U.S. Gulf Coast Geopressured-Geothermal Energy Conference, Austin, Texas, February 4-6, 1985.

4. Dake, L. P., Fundamentals of Reservoir Engineering. New York: Elsevier Science Publishers, 1978.

5. Durrett, L., "Results of Long-Term Testing of a Geopressured-Geothermal Design Well, TF\&S/DOE Gladys McCall No. 1," Proceedings of the Sixth U.S. Gulf Coast GeopressuredGeothermal Energy Conference, Austin, Texas, February 4-6, 1985.

6. Gruy Federal, Inc, "Investigation and Evaluation of Geopressured-Geothermal Wells, Final Report, Gladys McCall No. 1 Well, Cameron Parish, Louisiana," January 1979.

7. Hayden, C. G. and Randolph, P. L., "Parametric Study of Separator Performance," Proceedings of the Fifth U.S. Gulf Coast Geopressured-Geothermal Energy Conference, Louisiana State University, 1981.

8. John, C. J., "Geology of the Gladys McCall Geopressured-Geothermal Project, Cameron Parish, Louisiana." Paper presented at the Geothermal Energy Symposium, Eleventh Annual Energy-Source Technical Conference and Exhibit, New Orleans, Louisiana, January 10-13, 1988. 
9. Keeley, D. F. and Meriwether, J. R., "Aromatic Hydrocarbons Associated With Brines From Geopressured Wells" Proceedings of the Sixth U.S. Gulf Coast GeopressuredGeothermal Energy Conference, Austin, Texas, February 4-6, 1985.

10. Louisiana State University, "Geopressured-Geothermal Resource in Texas and Louisiana -Geological Constraints." Paper presented at the Fifth U.S. Gulf Coast GeopressuredGeothermal Energy Conference, 1981.

11. Matty, J. M. et al., "Control of Scale Associated with Geopressured-Geothermal Brine Production," Proceedings of the Sixth U.S. Gulf Coast Geopressured-Geothermal Energy Conference, Austin, Texas, February 4-6, 1985.

12. Price, C. et al., "Methane Solubility in Brines with Application to the Geopressured Resource," Proceedings of the Fifth Conference on Geopressured-Geothermal Energy, Bebout, D. G. and Buchman, A. L., Eds., sponsored by the Louisiana Geological Survey, Louisiana State Univ., and the U.S. Dept. of Energy at Louisiana State Univ., Baton Rouge, Louisiana, October 13-15, 1981.

13. Pritchett, J. W. and Riney, T. D., "Analysis of the T-F\&S Gladys McCall No. 1 Well Test Results and History Matching Simulations for Sand No. 8," Proceedings of the Sixth U.S. Gulf Coast Geopressured-Geothermal Energy Conference, Austin, Texas, February 4-6, 1985.

14. Riney, T. D., "Depleting and Recovery Behavior of the Gladys McCall Geopressured Geothermal Reservoir," Topical Report, S-Cubed, W/O 31071, SSS-TR-90-11474, June 1990.

15. Scientific Software-Intercomp, "Single Well Study, Gladys McCall Well No. 1, Cameron Parish, Louisiana, Final Report," August 1983.

16. Sundareswaren, P. C. et al., "Brine Chemistry and Control of Adverse Chemical Reactions with Natural Gas Production," Gas Research Institute Annual Report GRI/86-0073, January 1986.

17. Technadril-Fenix \& Scisson, "Geopressured-Geothermal Well Report Volume I - Drilling and Completion," DOE/ET/27217-2, Vol. 1 (DE83005095), January 1982.

18. Technadril-Fenix \& Scisson, "Geopressured-Geothermal Well Report Volume II - Well Workover and Production Testing for the Period February 1982 - October 1985," DOE/ET/27217, Vol. 2.

19. Tomson, M., personal communication, 1987.

20. Weatherly Laboratories, Inc., "Reservoir Fluid Analysis for Technadril-Fenix \& Scission, Inc., Gladys McCall Well No. 1, Sand 8, East Crab Lake Field, Cameron Parish, Louisiana," October 1983. 

Flow tests of the Gladys MCCall Well Through OCtober 1990

\section{APPENDIX A}

Compositional Analysis of Core by Core Laboratories, Inc.

A-1 

Flow Tests of the Gladys MCCALl Well Through OCtober 1990

\author{
Special Core Analys is Study \\ for \\ TECHNIDRIL-FENIX \& SCISSON \\ Gladys McCall Hell No. 1 \\ Petrographic Analys is
}

A-3 


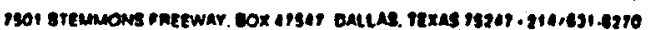

December 28, 1981

CORE LABORATORIES, INC.

Speclal Core Analvsis

Technadril-Fenix \& Scisson

3 Horthpoint Orive

Sulte 200

Houston, Texas 77060

Attention: Mr. Art Pyron

Subject: Combination Petrology Study

Gladys McCall :Vell Mo. 1

Grand Chenier Field

Cameron Parish, Louisiana

File Number: SCAL-308-81328

fentlemen:

On August 24, 1981, eighteen core samples from the subject well were submitted to the Special Core Analys is Department of Core Laboratories, Inc. at Dallas, Texas, by Charles Chiasson, Core Lahoratorles, Inc. Lafayette, Louisiana, with a request on behalf of Technadril-Fenix \& Scisson for a Combination Petrographic Study to be performed on each sample. This combination study consisted of Petrographic Thin Section Analyses, Mineral Content Determinations by X-Ray Diffraction and Scanning Electron Microscope (SEM) Study. The results of these analyses are presented herein, and the original set of SEM photomicrographs appears as an appendix to one copy of the report.

A thin section slide was prepared from each submitted sample and described in detail with the aid of a polarizing microscope. The results of these analyses appear on Pages 1 through 18.

An additional portion of each sample was prepared for mineral content determinations. The total sample and clay-sized (less than 4 microns in diameter) fractions were analyzed separately using an $x$-ray diffraction technique with monochromatic Cuka radiation. The results of these tests appear on Pages 19 through 28. 
FLOW TESTS OF THE GLADYS MCCALL Well THROUGH OCTOBER 1990

Technadril-Fenix \& Scisson

File Number: SCAL-308-81328

Page Two

A third portion of each submitted sample was prepared for SEM study by creating freshly broken surfaces and coating these surfaces with a thin (750A) film of gold-palladium. A discussion of the features revealed in the SEM photomicrographs appears on Pages 23 through 32.

It has been a pleasure performing this study on behalf of TechnadrilFenix \& Scisson. Should any questions arise concerning the results of this study, or if we can be of further assistance, please do not hesitate to contact us.

Very truily yours.

Core Laboratories, Inc.

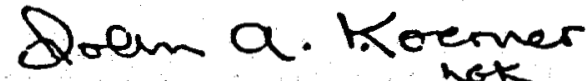

John A. Koerner, Lahoratory Supervisor

Special Core Analysis

JAK : SRO : sd

7 cC. - Addressee 
CORE LABORATORIES, INC.

Abroleun Reservoir Engineering

Dallas, texas 78247

PETROGRAPHIC ANAL YSIS

Technidril-Fenix \& Scisson

Gladys HcCall Well No. 1

Grand Chenier Field

Cameron Parish, Louisiana

Depth, feet: $15,182.7-84$

Fine Sandstone: Suharkose

This sample is a moderately sorted, moderately packed fine sandstone consisting of gn percent quartz, 5 percent feldspar, 3 percent rock fragments, 1 percent calcite and 1 percent clay. Also present are traces of organic matter, pyrite, muscovite and tourmallne. Framework grains averaging $0.16 \mathrm{~mm}$ are subangular to subrounded and subelongate to equant. Contacts between grains are planar, concavo-convex and occasionally sutured.

Monocrystalline quartz predominates, exhibiting straight or undulose extinction. Less common are ploycrystalline quartz grains displaying undulatory ext inction. Vacuoles, some forming linear "bubble trains", are present in these quartz grains in addition to microlite inclusions of zircon, tourmaline, rutile and muscovite. The feldspar present is mostly potasslum-rich orthoclase and less commonly albite-twinned plagioclase. Most of these gralns show partial to extensive alteration marked by significant dissolution creating secondary porosity. Vacuolization, sericitization and minor replacement by calcite are also noted. Especially common representing the lithic portion of the sample is detrital chert, which is composed of microcrystalline quartz and megaquartz. Minor aiteration is evident in these chert grains, resulting in clayey overlays, sericitization and replacement by calcite. In addition to these framework grains, organic matter, tourma-line and muscovite are scattered throughout the section.

An early to intermediate stage of quartz overgrowth development is the primary source of cementation. Characterized by euhedral grain terminations, "dust rim" inclusions and concavo-convex contacts, these overgrowths significantly reduce primary intergranular porosity. Additional porosity loss is enhanced by calcite replacement in feldspars and replacement of organic matter by pyrite concentrated within the pore space. Minor clays are also evident coating grains, suggesting a possible authigenic origin

Remnant primary and secondary porosittes account for 15 percent of this sample.

A11 percentages were obtained by point count. 
FLOW TESTS OF THE GLADYS MCCALL WELL THROUGH OCTOBER 1990

CORE LABORATORIES, INC.

Atolemen Reservoir Engineering

DALLAS, TEXAS TERAT

Page $\frac{2}{2}$ of $\frac{31}{\text { SCAL-308-81328 }}$

PETROGRAPHIC ANALYSIS

Technadril-Fentx \& Sctsson

Gladys MeCall Well No. 1

Grand Chenter Fleld

Cameron Parish, Loulsiana

Depth, feet: $15,184.8-86.0$

Fine Sandstone: quartz arenite

This sample is a moderately sorted, moderately packed fine sandstone consisting of 92 percent quartz, 3 percent feldspar, 3 percent clay and 2 percent rock fragments. Traces of tourmaline, zircon, pyrite and organic matter are also present. Framework grains are angular to subrounded and subelongate to equant. Averaging $0.20 \mathrm{~mm}$, grain size ranges from silt to medium sand. Grain contacts are tangential, planar and occastonally concavo-convex.

The predominant framework grain is monocrystalline quartz displaying strafght or undulose extinction. Less common is polycrystalline quartz showing undulose extinction. These quartz grains occasionaliy conta in vacuoles and microlite inclusions of acfcular rutile, muscovite, zircon and tourmaline. The feldspar present consists of potasslum-rich orthoclase and plagloclase marked by alblte twinning. Most of the feldspar grains have undergone partial to extensive alteration resulting in vacuolization, replacement by serficite or calcite and dissolution creating secondary porosity. The lithic portion of the sample is mostly detrital chert composed of microcrystalline quartz. These chert grains are characterized by clayey overlays, replacement by serfcite and minor ofssolution created as a result of alteration. Organic matter, tourmaline and zircon occur as accessories scattered throughout the section.

The primary source of cementation is an early stage of quartz overgrowth development. These overgrowths are characterized by "dust rim" inclusions, euhedral gra in terminations and minor concavo-convex contacts. As a result of overgrowth cementation, primary intergranular porosity is considerabiy reduced. Secondary calcite occuring as pore-filiting cement and as a minor replacement of feldspars also contributes to porosity loss. Pore-flliling authigenic koolinite forms stacked booklets of pseudohexagonal platelets which create some microporosity. Additional clay, possibly chlorite, appears to coat some grains. Organic matter is dispersed throughout the section.

Remnant primary and secondary porosities account for 21 percent of the san.ple.

All percentages were obtalned by point count. 
CORE LABORATORIES, INC.

Atoleur Reservoir Engineering

DAllas, TEXas TBEAT

Page $\frac{3 \text { of } \frac{31}{\text { SCAL-308-81328 }}}{\text { File }}$

PETROGRAPHIC ANALYSIS

Technadril-Fenix \&ctsson

Gladys McCall Hell No. 1

Grand Chenter Field

Cameron Parish, Loutsiana

Depth, feet: $15,186.0-87.0$

Fine Sandstone: quartz arenite

This sample is a loosely to moderately packed, moderately sorted.fine sandstone consisting of 92 percent quartz, 3 percent clay, 3 percent feldspar, 1 percent rock fragments and 1 percent caicite. Traces of organic matter, pyrite and tourmaline are also present. Framework grains are angular to subrounded and subelongate to equant, averaging $0.18 \mathrm{~mm}$. Grain to grain contacts are planar or concavo-convex.

Monocrystalline quartz is the predominant framework element. It exhibits straight or undulatory extinction, and occasionally contains vacuoles and microlite inclusions of rutile, zircon and tourma ine. Polycrystalline quartz containing planar or crenulate subcrystals and showing undulose extinction is much less common. The feldspar present includes plagloclase and the potassium feldspars, orthoclase and microcline. Plagioclase is marked by albite twinning. and grid-iron twinning characterizes microcline. Although some feldspars appear fresh, most grains show partial to extensive alteration resulting in clayey overlays, replacement by sericite or calcite and minor dissolution creating secondary porosity. The lithic portion of the sample is mostly detrital chert. Composed of microcrystalline quartz and megaquartz, these chert grains show minor alteration resulting in clayey overlays and some replacement by serfcite. In addition to these framework grains, organic matter and tourmaline are scattered throughout the section.

Secondary quartz overgrowths are the predominant cementing agent in this sample. Euhedral grain terminations, concavo-convex contacts and "dust rim" inclusions characterize these quartz overgrowths, and an early to intermediate stage of overgrowth development substantially reduces primary intergranular porosity. Secondary calcite plays a minor role in cementation, replacing feldspar grains and occurring as a minor pore-filling cement. Pyrite is also evident partially replacing organic matter finely dispersed throughout the pore space. Patches of pore-filling authigenic kaolinite occur as stacked booklets of pseudohexagonal platelets creating significant microporosity. Additional clay, rich in chlorite. appears to coat some framework grains.

Remnant primary and secondary porosities account for 21 percent of the sample. A11 percentages were obtained by point count. 
CORE LABORATORIES, INC.

Atolewer Reservoir Engineering

DALlas, TEXAS 78247

Page $\frac{4}{\text { SCAL }}$ of $\frac{31}{308-81328}$

PETROGRAPHIC ANALYSIS

Technadril-Fenix \& Scisson

Gladys MeCall Well No. 1

Grand Chenter Fleld

Cameron Parish, Loutsiana

Depth, feet: $15,187.5-89.0$

Fine sandstone: quartz arenite

This sample is a moderately packed, moderately sorted fine sandstone consisting of 90 percent quartz, 3 percent feidspar, 2 percent rock fragments, 2 percent clay, 2 percent organic residue and 1 percent calcite. Also present are traces of pyrite, zircon and tourmaline. Framework grains are subangular to subrounded, subelongate to equant and average $0.19 \mathrm{~mm}$ in size. Grain contacts are planar, concavo-convex and occasfonally sutured.

The major framework constituent is monocrystalline quartz showing straight or undulose extinction. Polycrystalline quartz occurs much less frequently and displays undulose extinction. Vacuoles, "bubble trains" and inclustons of muscovite, zircon and tourmaline are evident in these quartz grains. Or thoclase, grid-iron twinned microcline and plagioclase marked by albite twinning represent the feldspathic fraction of the sample. Most of the feldspars have undergone partial to extensive alteration resulting in clayey overlays, sericitization, replacement by calcite and minor dissolution. The lithic portion of the sample is almost entirely detrital chert. Minor alteration in these chert grains shows clayey overlays, replacement by sericite or calcite and some dissolution. Organic residue is concentrated within the pore space, and additional trace accessories of zircon and tourmaline are dispersed throughout the section.

The major cementing agent is an early to intermediate stage of secondary quartz overgrowths characterized by euhedral grain terminations, "dust rim" Inclusions and concavo-convex or sutured contacts. As a result of this overgrowth cementation, primary intergranular porosity is significantly reduced. Calclte occurring as a pore-filling cement and partially replacing feldspar grains also contributes to cementation. Some pore-ilning clays are present, suggesting a possible authigenic origin. Rare patches of authigenlc kaolinite form stacked booklets of pseudohexagonal platelets creating microporosity. In addition, organic residue scattered throughout the section has been replaced by pyrite.

Remnant primary and secondary porosities account for 15 percent of the sample.

All percentages were obtained by point count. 
CORE LABORATORIES, INC.

Atrolewer Reservoir Engineering

DALLAS, TEXAS 7BRAT

PF.TROGRAPHIC ANALYSIS

Technadril-Fenix \& Scisson

Gladys McCall Well No. 1

Grand Chenter Fleld

Cameron Parish, Loutsiana

Depth, feet: $15,189.0-91.0$

Fine sandstone: subarkose

This sample is a loosely packed, moderately sorted fine sandstone consisting of 90 percent quartz, 5 percent feldspar, 3 percent clay and 2 percent rock

fragments. Traces of organic residue, tourmaline, pyrite and calcite are also present. Subangular to subrounded framework grains are subelongate to equant, averaging $0.17 \mathrm{~mm}$. Contacts between grains are tangential, planar or concavoconvex.

Quartz, the major framework element, is predominantly monocrystalline and shows straight or undulose extinction. Less common is polycrystali ine quartz exhibiting undulose extinction. Vacuoles, some as linear "bubble trains," and inclusions of muscovite, zircon and rutile are occasionally evident in these quartz grains. The feldspar present includes orthoclase and plagioclase marked by albite twinning. Most of these feldspars show partlal to extensive alteration along cleavage traces and twinning planes, resulting in clayey overlays. replacement by sericite or calcite and dissolution. The lithic fraction of the sample is mostly detrital chert. Minor aiteration of these chert fragments reveals clayey overlays and replacement by sericite. In addition to these framework grains, traces of tourmaline and organic residue are scattered throughout the section.

The primary source of cementation is an early stage of secondary quartz overgrowth development. Delineated by "dust rim" inclusions, concavo-convex contacts and euhedral grain terminations, these overgrowths considerably reduce primary intergranular porosity. A trace of secondary calcite occurs as a porefilling cement and occasionaliy replaces feldspar grains. Minor patches of authigenic kaolinite also contribute to porosity reduction. In addition, organic residue is partially replaced by pyrite scattered throughout the oore systeni.

Remnant primary and secondary porosities account for 24 percent of the sample.

All percentages were obtained by point count. 
CORE LAEORATORIES, INC.

Atolown Reservoir Engineering

DALLAS, TEXAS TB247

Page $\frac{6}{6 \text { of }} \frac{31}{S C A L-308-81328}$

PETROGRAPHIC ANALYSIS

Technadril-Fenix \& Scisson

Gladys McCall Well No. 1

Grand Chenter Fleld

Cameron Parish, Louisiana

Depth, feet: $15,348.0-50.0$

Fine sandstone: subarkose

This sample is a moderately sorted, loosely to moderately packed fine sandstone composed of 87 percent quartz, 7 percent feldspar, 3 percent rock fragments and 3 percent clay. Traces of organic residue, pyrite, zircon, tourmaline and calcite are also present. Framework grains are subangular to subrounded and subelongate to equant, averaging $0.19 \mathrm{~mm}$. Contacts between grains are planar or concavo-convex.

The predominant framework element is monocrystalline quartz exhibiting straight or undulose extinction. Less common are polycrystalline quartz grains showing undulatory extinction. Occastonally, vacuoles and inclusions of muscovite, zircon, tourmaline and rutile are present in these quartz grains. The feldspathic portion of the sample is comprised of plagloclase and the potassium feldspars, orthoclase and microcline. Hicrocline shows characteristic gridiron twinning. and plagioclase is marked by albite or pericline twinning. Most of the feldspars appear relatively fresh with only minor alterations resulting in clayey overlays, replacement by sericite and leaching creating secondary porosity. Litlic fragments present include detrital chert and less comon claystone clasts. Composed of microcrystalline quartz and megaquartz, these chert grains reveal clayey overlays and replacement by calcte, sericite and pyrite created as a result of alteration. Trace accessories of zircon, tourmaline and organic residue are scattered throughout the section.

An intermediate to advanced stage of secondary quartz overgrowths and concavoconvex contacts is the major cementing agent. As a result of this interlocking texture, primary intergranular porosity is substantially reduced. Rare patches of authigenic kaolinite occur as stacked booklets of pseudohexagonal platelets which create significant microporosity. In addition, possible grain-coating authigenic clay contributes to cementation. Organic residue partially replaced by pyrite is also dispersed throughout the section.

Remnant primary and secondary porosittes account for 16 percent of the sample.

All percentages were obtained by point count. 
CORE LABORATORIES, INC.

Atolean Reservoir Engineering

DALLAS, TEXAS TB247

Page $\frac{7}{\text { SIIe }}$ of $\frac{31}{30 \text { - } 308-81328}$

PETROGRAPHIC ANALYSIS

Technadril-Fenix \& Scisson

Gladys MCCall Well No. 1

Grand Chenteir Field

Cameron Parish, Louistana

Depth, feet: $15,350.0-52.0$

Fine sandstone: subarkose

This sample is a moderately sorted, loosely to moderately packed fine sandstone composed of 89 percent quartz, 6 percent feldspar, 3 percent rock fragnents and 2 percent clay. Also present are traces of organic residue, muscovite, tourmaline and zircon. Framework grains are subangular to subrounded, subelongate to equant and average $0.16 \mathrm{~mm}$. Contacts between grains are pianar, concavo-convex and sutured.

Monocrystalline quartz exhibiting straight or undulatory extinction is the predominant framework element. Poiycrystalline quartz displaying undulose extinction is much less common. Vacuoles, some as linear "bubble trains," and inclusions of zircon, muscovite, tourmaline and rutlie are evident in these quartz grains. Orthoclase, grid-iron twinned microcline and plagloclase marked by albite and pericline twinning represent the feldspathic fraction of the sample. Although some of the feldspars appear fresh, most of the grains show alteration resulting in clayey overlays, replacement by sericte and minor dissolution. The lithic portion of the sample is mostly detrital chert and minor claystone clasts. Minor alteration of these rock fragments results in clayey overlays, sericitization and dissolution creating secondary porosity. In addition, traces of muscovite, organic residue, tourmaline and zircon are scattered throughout the section.

Overgrowths of secondary quartz are the primary cementing agent and are characterized by "dust rim" inclusions, euhedral grain terminations and concavo-convex or sutured contacts. As a result of an early to intermediate stage of overgrowth cementation, primary intergranular porosity is signifi. cantly reduced. In addition, patches of authigenic kaolinite occur as stacked booklets of pseudohexagonal platelets which create substantial microporosity.

Remnant primary and secondary porosities account for 14 percent of the sample.

All percentages were obtained by point count. 
CORE LABORATORIES, INC.

Atoleun Reservoir Engineering

DALLAS, TEXAS 78247

Page $\frac{8}{8}$ of $\frac{31}{\text { SCAL-308-81328 }}$

PETROGRAPHIC ANALYSIS

Technadril-Fenix \& Scisson

Gladys McCall Well No. 1

Grand Chenter Fleld

Cameron Parish, Loutsiana

Depth, feet: $15,352.0-54.0$

Fine sandstone: subarkose

This sample is a moderately sorted, moderately packed fine sandstone consisting of 90 percent quartz, 6 percent feldspar, 3 percent rock fragments and 1 percent clay. Also present are traces of organic residue, pyrite, tourmaline and zircon. Subangular to subrounded framework grains are subelonga te to equant and average $0.18 \mathrm{~mm}$. Contacts between grains are planar or concavo-convex.

Quartz, the predominant framework element, is generally monocrystalline and exhibits straight or undulatory extinction. Polycrystalline quartz displaying undulose extinction is much less common. Vacuoles, "bubble trains" and inclusion of rutile, tourmaline and zircon occasionally are present in these quartz grains. The feldspar present consists of plagloclase and the potassium feldspars, orthoclase and microcline. Plagfoclase is marked by albite or percline twinning, and microcline is characterized by grid-jron twinning. Most of the feldspars appear to have undergone partial to extensive alteration resulting in clayey overlays, replacement by serfcite and dissolution. The lithic portion of the sample includes detrital chert and minor claystone clasts. As a result of alteration, clayey overlays and sericitization are evident in these chert fragments. In addition. zircon, tourmaline, and organtc residue are scattered throughout the section.

The primary source of cementation is an early stage of secondary quartz overgrowths. Delineated by concavo-covex contacts, euhedral grain terminations and "dust rim" inclusions, the development of overgrowth cement has substantially reduced primary intergranular porosity. Additional porosity loss is attributed to rare patches of pore-filling authigenic kaolinite. Organic residue is partially replaced by pyrite and finely dispersed throughout the pore space.

Remnant primary and secondary porosities account for 24 percent of the sample.

All percentages were obtained by point count. 
CORE LABORATORIES, INC.

Atroleur Reservoir Engincering

DALLAS, TEXAS TBEAT

Page $\frac{9}{\text { File } \text { SCAL }-308-81328}$

\section{PETROGRAPHIC ANALYSIS}

Technadril-Fenix \& Scisson

Gladys McCall Well No. 1

Grand Chenier Field

Cameron Parish, Louisiana

Depth, feet: $15,354.0-56 . n$

Fine sandstone: subarkose

This sample is a moderately sorted, loosely to moderately packed fine sandstone composed of 85 percent quartz, 9 percent feldspar, 4 percent rock fragments, and 2 percent clay. Traces of organic residue, pyrite, zircon and muscovite are also present. Framework grains are subangular to subrounded, subelongate to equant and average $0.20 \mathrm{~mm}$. Contacts between grains are planar or concavoconvex.

The predominant framework element is monocrystalline quartz displaying straight or undulose extinction. Less common are polycrystalline quartz grains exhibiting undulose extinction. Vacuoles, some as linear "bubble trains," and inclusions of zircon, muscovite, tourmaline and rutfle are evident in these quartz grains. Orthoclase, grid-iron twinned microcline and plagloclase marked by albite or pericline twinning represent the feldspathic fraction of the sample. Although some grains appear relatively fresh, most of the feldspars show minor to extensive alteration resulting in clayey overlays, replacement by sericite and dissolution. The lithic portion of the sample is mostly detrital chert. The chert fragments are composed of microcrystalline quartz and show minor alteration to clay and sericite. Traces of organic residue, zircon and muscovite are scattered throughout the section.

An early to intermediate stage of secondary quartz overgrowth development is the major cementing agent. The se overgrowths are delineated by "dust rim" inclusions, concavo-convex contacts and euhedral grain terminations. As a result of overgrowth cementation, primary intergranular porosity is considerably reduced. Minor patches of pore-filling authigenic kaolinite also contribute to porosity reduction. In addition, organic residue finely dispersed throughout the section is partially replaced by pyrite.

Remnant primary and secondary porosities account for 19 percent of the sample. All percentages were obtained by point count. 
CORE LABORATORIES, INC.

Atoleum Reservoir Engineering

DALLAS, TEXAS 7E2AT

Page $\frac{10}{\text { SCAL-303-81328 }}$

PETROGRAPHIC ANALYSIS

Technadril-Fenix \& Scisson

Gladys McCall Kell No. 1

Grand Chenier Field

Cameron Parish, Loulsiana

Depth, feet: $15,356.0-58.0$

Fine șandstone: subarkose

This sample is a moderately sorted, loosely to moderately packed fine sandstone composed of 88 percent quartz, 6 percent feldspar, 4 percent clay and 2 percent rock fragments. Traces of zircon, tourmaline, organic residue, pyrite and muscovite are also present. Framework grains are subangular to subrounded, subelongate to equant and average $0.17 \mathrm{~mm}$. Grain to grain contacts are either planar or concavo-convex.

Monocrystalline quartz showing straight or undulose extinction is the major framework constituent and occastonally contains vacuoles and microlite inclusions of rutlle, zircon, tourmaline and muscovite. Polycrystalline quartz exhibiting undulose extinction is much less common. The feldspar present consists of plagioclase and the potassium feldspars, orthoclase and microcline. Hicrocline shows characteristic grid-iron twinning, and albite or pericline twinning is evident in the plagloclase feldspars. Minor to extensive alteration of these feldspars has resulted in clayey overlays and replacement by sericite. Leaching has further created apprecfable secondary porosity. The lithic portion of the sample is mostly detrital chert. Pronounced alteration of these chert grains to clay and sericite is noted. Traces of organic residue, zircon, tourmaline and muscovite are scattered throughout the section.

Secondary quartz overgrowths, as characterized by euhedral grain terminations, "dust rim" inclusions and concavo-convex contacts, are the primary source of cementation. This early to intermediate stage of overgrowth development has resulted in a reduced primary intergranular porosity. Patches of authigenic kaolinite occur as stacked booklets of pseudohexagonal platelets which create significant microporosity. In addition, possible authigenic clay appears to coat grains. Organic matter partialiy altered to pyrite is dispersed throughout the pore space.

Remnant primary and secondary porosities account for 18 percent of the sample. All percentages were obtained by point count. 
CORE LABORATORIES, INC.

Atroleur Reservoir Engineering

OALLAS, TEXAS TB2AT

Page $\frac{11}{\text { Flle } \text { SCAL-308-81328 }}$

PETROGRAPHIC ANALYSIS

Technadril-Fentx \& Scisson

Gladys McCall Well No. 1

Grand Chenter Fleld

Cameron Parish, Loulsiana

Depth, feet: $15,358.0-60.0$

Fine sandstone: subarkose

This sample is a moderately sorted, moderately packed fine sandstone consisting of 85 percent quartz, 8 percent feidspar, 5 percent clay and 2 percent rock fragments. Also present are traces of organic residue, pyrite, muscovite. tourmaline and zircon. Framework grains are subangular to subrounded and subelongate to equant, averaging $0.16 \mathrm{~mm}$. Contacts between grains are planar, concavo-convex and occasionaliy sutured.

The predominate framework element is monocrystalline quartz exhiblting stralght or undulose extinction and containing vacuoles and inclusions of muscovite, rutile, tourmaline and zircon. Less common is polyerystalline quartz displaying undulatory extinction. Orthoclase and plagioclase marked by albite or pericline twinning are the most abundant feldspars present. Pronounced alteration to clay and sericite is evident in most of these feidspars along with dissolution creating apprectable secondary porosity. Microcline characterized by grid-iron twinning is much less comon, and only silight alteration to clay and sericite is noted in these grains. The ifthic portion of the sample is mostly detrital chert composed of microcrystalline quartz and megaquartz. Minor alteration is evident in these chert grains, resulting in clayey overlays, replacement by sericite and dissolution. In addition, traces of organic residue, zircon, tourmaline and muscovite are scattered throughout the section.

An early stage of secondary quartz overgrowth development characterized by euhedral grain terminations, "dust rim" inclusions and concavo-convex or sutured contacts is the primary cementing agent. As a result of this interlocking texture, primary intergranular porosity is significantly reduced. Patchy interstitial clay appears sericitized and further contributes to porosity reduction. Rare patches of authigenic kaolinite occur as stacked booklets of pseudohexagonal platelets creating significant microporosity. In addition. orqantc residue is finely dispersed throughout the section, partially replaced by pyrite.

Remnant primary and secondary porosities account for 11 percent of the sample.

All percentages were obtained by point count. 
CORE LABORATORIES, INC.

Aboleum Reservoir Engineering

DALLAS, TEXAS TBRAT

Page $\frac{12}{\text { SCAL }}$ of $\frac{31}{08-81328}$

PETROGRAPHIC ANALYSIS

Technadril-Fenix \& Scisson

Gladys McCali Well No. 1

Grand Chenier Fleld

Cameron Parlsh, Loulsiana

Depth, feet: $15,360.0-62.0$

Fine sandstone: subarkose

This sample is a moderately sorted, loosely packed fine sandstone consisting of 88 percent quartz, 6 percent feldspar, 4 percent rock fragments and 2 percent clay. Also present are traces of organic matter, pyrite, muscovite, tourmaline and zircon. Framework grains averaging $0.18 \mathrm{~mm}$ are subangular to subrounded and subelongate to equant. Contacts between grains are planar or concavo-convex.

The predominant framework element is monocrystalline quartz displaying straight or undulose extinction. Less common is polycrystalline quartz exhibiting undulose extinction. Vacuoles, some as linear "bubble trains," and microlite inclusions of rutile, zircon, tourmaline and muscovite are evident in these quartz grains. Orthoclase, grid-iron twinned microcline and plagloclase marked by albite or pericline twinning represent the feldspathic fraction of the sample. Al though some feldspars appear fresh, most grains show minor to extensive alteration resulting in clayey overlays, replacement by sericite and dissolution along cleavage traces and twinning planes. The lithic portion of the sample consists of detrital chert and less common claystone clasts. Clayey overlays, sericitization and minor dissolution are evident forms of alteration in these chert grains. Traces of organic matter, tourmaline, muscovite and $z$ ircon are scattered throughout the section in addition to the above framework elenents.

Overgrowths of secondary quartz are the primary source of cementation and are delineated by euhedral grain terminations, "dust rim" inclusions and concavoconvex contacts. As a result of this early to intermediate stage of overgrowth development, primary intergranular porosity has been reduced significantly.

Rare patches of authigenic kaol inite occur as stacked booklets of pseudohexagonal platelets which create some microporosity. Traces of possible authigenic clays are noted as grain coatings. Organic matter has been partially replaced by pyrite and is scattered throughout the section.

Remnant primary and secondary porositles account for 20 percent of the sample.

All percentages were obtained by point count. 
CORE LABORATORIES, INC.

$$
\begin{aligned}
& \text { Abolewn Reservoir Engineering } \\
& \text { DALLAS, TEXas } 78247
\end{aligned}
$$

Page 13 of $\frac{31}{\text { File SCAL-308-81328 }}$
Fis

PETROGRAPHIC ANAL YSIS

Technadril-Fenix \& Scisson Gladys MeCall Well No. 1 Grand Chenter Fleld Cameron Parish, Louisiana

Depth, feet: $15,362.0-64.0$

Fine sandstone: sublithic subarkose

This sample is a moderately sorted, loosely packed fine sandstone consisting of 88 percent quartz, 5 percent feldspar, 5 percent rock fragments and 2 percent clay. Also present are traces of zircon, tourmaline, organtc matter, muscovite and pyrite. Framework grains are subangular to subrounded and subelongate to equant. Averaging $0.20 \mathrm{~mm}$, grains range from silt to medium sand-size. Contacts between grains are planar or concavo-convex.

The predominant framework element is monocrystalline quartz exhibiting straight or undulose extinction. Polycrystalline quartz displaying undulose extinction is much less common. Vacuoles, some as linear "bubble trains," and inclusions of tourmaline, apatite, zircon, rutile and muscovite occasionally occur in these quartz grains. The feldspar present consists of plagioclase and the potassium feldspars, orthoclase and microcline. Relativelv fresh. microcline shows typical grid-iron twinning. Plagioclase is marked by albite or pericline twinning. Alteration to clay and sericite is quite pronounced in most of the plagioclase and orthoclase grains. In addition, extensive leaching in some of these grains has created appreciable secondary porosity. The lithic portion of the sample includes detrital chert and lesser amounts of claystone clasts. Alteration resulting in clayey overlays, sericitization, replacement by pyrite and minor dissolution is evident in these rock fragments. Organic matter. zircon, tourmaline and muscovite are scattered throughout the section as trace accessories.

Framework elements are cemented primarily by an early stage of secondary quartz overgrowths. Delineated by concavo-convex contacts, "dust rim" inclusions and euhedral grain terminations, these overgrowths have considerably reduced primary intergranular porosity. Authigenic kaolinite occurs as a pore-filling cement further contributing to porosity loss. Additional clay appears to coat grains, suggesting an authigenic origin. Finely dispersed throuohout the section is organic matter which has been partially replaced by nyrite.

Remnant primary and secondary porosities account for 2 percent of the sample.

All percentages were obtained by point count. 
CORE LABORATORIES, INC.

Atgoleum Reservoi Engineering

DALLAB, TEXAS 78247

Page $\frac{14}{\text { FCAL }}$ of $\frac{31}{308-81328}$

PETROGRAPHIC ANALYSIS

Technadril-Fenix \& Scisson

Gladys HcCall Hell No. 1

Grand Chenter Field

Cameron Parish, Loulsiana

Depth, feet: $15,364.0-66.0$

Fine sandstone: subarkose

This sample is a moderately packed, moderately sorted fine sandstone composed of 87 percent quartz, 7 percent feldspar, 4 percent rock fragments and 2 percent clay, Also present are traces of organic matter, pyrite, zircon and muscovite. Framework grains are subangular to subrounded, subelongate to equant and average $0.18 \mathrm{~mm}$. Grain contacts are planar, concavo-convex and occastonally sutured.

Monocrystalline quartz displaying straight or undulose extinction is the major framework constituent and occasionally contains vacuoles and inclusions of zircon, muscovite, tourmaline and rutile. Less comon is polycrystalline quartz exhibiting undulatory extinction. Orthoclase, plagioclase and minor amounts of microcline represent the feldspathic fraction of the sample. Plagioclase is marked by albite or pericline twinning and grid-iron twinning characterizes microcline. Microcline grains appear relatively fresh; however the remaining feldspars show appreciable alteration to clay and sericite along cleavage traces and twinning planes. Extensive leaching creating secondary porosity is evident in some of the feldspar grains. The lithic fragments present are mostly detrital chert and minor claystone clasts. Minor alteration resulting. In clayey overlays, sericitization and replacement by pyrite are common in these chert fragments. In addition, traces of muscovite, zircon and organic matter are scattered throughout the section.

The primary source of cementation is an early stage of secondary quartz overgrowth development. These overgrowths are characterized by "dust rim" inclusion, euhedral grain terminations and concavo-convex or sutured contacts. Patches of authigenic kaolinite and rare grain-coating clays further contribute to cementation. In addition, organic matter partialiy replaced by pyrite is finely dispersed throughout the sample.

Remnant primary and secondary porosities account for 15 percent of the sample.

All percentages were obtained by point count. 
CORE LABORATORIES, INC.

Atolewen Reservoir Engineering

DALLAS, TEXAS TE247

Page 15 of 31

File SCAL-308-81328

PETROGRAPHIC ANALYSIS

Technadril-Fenix \& Sclsson

Gladys McCall Well No. 1

Grand Chenler Fleld

Cameron Parish, Louisiana

Depth, feet: $15,366.0-68.0$

FIne sandstone: subarkose

This sample is a loosely to moderately packed, moderately sorted fine sandstone consisting of 88 percent quartz, 5 percent feldspar, 4 percent rock fragments and 3 percent clay. Also present are traces of organic matter, pyrite, muscovite and tourmaline. Subangular to subrounded framework grains are subelongate to equant and average $0.21 \mathrm{~mm}$. Grain contacts are planar or concavo-convex.

Quartz, the major framework constituent, is generally monocrystalline showing straight or undulose extinction. Scattered polycrystalline quartz grains display undulatory extinction. Vacuoles and occasional inclusions of rutile, zircon, muscovite and tourmaline are evident in these quartz grains. The feldspar present consists of orthoclase, grid-iron twinned microcline and plagioclase showing albite or pericline twinning. Although some of the grains appear fresh, most feldspars show minor to extensive alteration resulting in clayey overlays, replacement by sericite and dissolution along cleavage traces and twinning planes. The lithic portion of the sample is mostly detrital chert. These chert grains reveal clayey overlays, sericitization, replacement by pyrite and minor dissolution created as a result of alteration. In addition to these framework grains, accessories of muscovite, tourmaline and organic matter are scattered throughout the section.

The development of secondary quartz overgrowths marked by concavo-convex contacts, euhedral grain terminations and "dust rim" inclustons is the major source of cementation. An early to intermediate stage of overgrowth cementation has considerably reduced primary intergranular porosity. Minor patches of authigenic kaolinite occur as stacked booklets of pseudohexagonal platelets creating significant microporosity. Additional clay appears to be pore-lining further reducing porosity. Organic matter dispersed throughout the section has been partially replaced by pyrite.

Remnant primary and secondary porosities account for 20 percent of the sample. All percentages were obtained by point count. 
CORE LABORATORIES, INC.

Atrolemen Reservoir Engincering

OALLAB, TEXAS 782A7

Page $\frac{16 \text { of } \frac{31}{\text { SCAL-308-81328 }}}{}$

PETROGRAPHIC ANALYSIS

Technadril-Fenix \& Scisson

- Gladys McCall Well No. 1

Grand Chenfer Fleld

Cameron Parish, Loulsiana

Depth, feet: $15,368.0-70.0$

Fine sandstone: sublithic subarkose

This sample is a moderately sorted, loosely to moderately packed fine sandstone composed of 86 percent quartz, 6 percent feldspar, 5 percent rock fragments and 3 percent clay. Also present are traces of organic matter, pyrite and muscovite. Framework grains are subangular to subrounded and subelongate to equant. Ranging from silt to medium sand, grains average $0.20 \mathrm{~mm}$. Contacts between grains are planar or concavo-convex.

The predominant framework element is monocrystalline quartz exhibiting straight or undulose extinction and occasionally containing vacuoles and inclusions of tourmaline, muscovite, apatite, rutile and zircon. Polycrystalline quartz is much less abundant, displaying undulatory extinction. The feldspar present includes orthoclase, albite or pericline-twinned plagloclase and less prevalent microcline marked by grid-iron twinning. Al though some feldspars appear fresh, most grains show alteration resulting in clayey overlays, replacement by sericite and dissolution. The lithic portion of the sample is mostly detrital chert composed of microcrystalline quartz and megaquartz. Minor alteration to clay and sericite is evident. In addition, traces of organic matter and muscovite are scattered throughout the section.

Framework grains are primarlly cemented by an early to intermediate stage of secondary quartz overgrowth development. Characterized by euhedral grain terminations, "dust rim" inclusions and concavo-convex contacts, these overgrowths substantially reduce primary intergranular porosity. Patches of auth1genic kaolinfte occur as stacked booklets of pseudohexagonal platelets which creats significant microporosity. Additional pore-lining clays are indistinguishable; however, their high birefringence sungests an authigenic origin. Trace amounts of pyrite partially replace organic debris finely dispersed throughout the section.

Remnant primary and secondary porosities account for 17 percent of the sample.

All percentages were obtained by point count. 
CORE LABORATORIES, INC.

Atroleum Reservoir Engincering

DALLAS, TEXAS 78247

Page $\frac{17 \text { of } \frac{31}{\text { SCAL }-308-81328}}{}$

PEIRODRAPHIC ANALYSIS

Technadrit-Fenix \& Scisson

Gladys McCall Well No. 1

Grand Chenier Field

Cameron Parish, Loulsiana

Depth, feet: $15,370.0-72.0$

Fine sandstone: subarkose

This sample is a moderately sorted, moderately packed fine sandstone consisting of 86 percent quartz, 8 percent feidspar, 3 percent rock fragments and 3 percent clay. Traces of calcite, organic matter, pyrite, zircon, tourmaline and muscovite are also present. Framework grains are subangular to subrounded and subelongate to equant. Averaging $0.23 \mathrm{~mm}$, grains range in size from silt to coarse sand. Contacts between grains are planar, concavo-convex and sutured.

Monocrystalline quartz exhibiting straight or undulose extinction is the predominant framework element, occasionally containing vacuoles and microlite inclusions. Less common is polycrystalline quartz displaying undulatory extinction. Orthoclase, grid-iron twinned microcline and plagioclase marked by albite or pericline twinning represent the feldspathic fraction of the sample. Most of the feldspars show pronounced alteration to clay and sericite. Leaching of these grains is also noted, creating secondary porosity. The ifthic portion of the sample is mostly detrital chert and minor claystone clasts. These rock fragments show alteration resulting in clayey overlays, sericitization and replacement by pyrite. Traces of zircon, tourmaline, muscovite and organic matter are scattered throughout the section.

The primary source of cementation is an early stage of secondary quartz overgrowth development. Euhedral grain terminations, "dust rim" inclusions and concavoconvex or sutured contacts characterize these overgrowths. As a result of this interlocking texture, primary intergranular porosity is appreciably reduced. Sericitized clay appears to form stringers as a result of pressure solution, and accessory minerals in addition to organic matter partially replaced by pyrite are closely associated with these stringers of clay. Minor patches of authigenic kaolinite are present. filling some pore spaces. These stacked, pseudohexagonal platelets create significant microporosity.

Remnant primary and secondary porosities account for 10 percent of the sample.

All percentages were obtained by point count. 
CORE LABORATORIES, INC.

Abolewer Reservoir Engineering

DALLAS, TEXAS TERAT

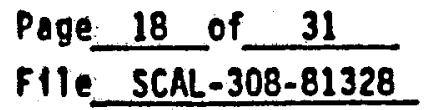

PETROGRAPHIC ANALYSIS

Technadril-Fenix Scisson

Gladys McCall Well No. 1

Grand Chenter Field

Cameron Parish, Loulsiana

Depth, feet: $15,372.0-74.0$

Fine sandstone: sublithic subarkose

This sample is a moderately sorted, moderately packed fine sandstone consisting of 82 percent quartz, 11 percent feldspar, 5 percent rock fragment and 2 percent clay. Traces of calcite, organic matter, pyrite, tourmaline and muscovite are also present. Framework elements are subangular to subrounded and subelongate to equant, averaging $0.17 \mathrm{~mm}$. Grain to grain contacts are planar, concavoconvex and occasionally sutured.

Monocrystalline quartz displaying straight or undulatory extinction is the major framework constituent. Less comon is, polycrystalline quartz displaying undulose extinction. Vacuoles, some as ilinear "bubble trains," and incluslons of tourmaline, zircon, muscovite and rutlle occaslonally are evident in these quartz grains. The feldspar present includes plagloclase and the potassium feldspars, orthoclase and microcline. Grid-iron twinning is characteristic of microcline, and the plagioclase shows albite or pericline twinning. Many feldspars show pronounced alteration to clay and sericite. Leaching creating secondary porosity is also noted. The ifthic portion of the sample is mostly detrital chert in which minor alteration has resulted in clayey overlays, sericitization and replacement by calcite or pyrite. Accessories of muscovite, tourmaline and organic matter are scattered throughout the section.

The primary source of cementation is an intermediate stage of secondary quartz overgrowth development. These overgrowths are characterized by "dust $\mathrm{rim}^{\prime}$ ". inclusions, euhedral grain terminations and concavo-convex or sutured contacts. As a result of the interlocking texture, primary intergranular porosity is substantially reduced. Scattered patches of calcite occur as a replacement for feldspars, quartz and chert grains. Authigenic pyrite also replaces organic matter dispersed throughout the section. Pore-filling authigenic kaolinite and indistinguishable pore-1ining clays further contribute to cementation.

Remnant primary and secondary porositles account for 18 percent of the sample.

All percentages were obtained by point count. 
CORE LABORATORIES, INC.

Ptrolewe Reservoir Esgineering

DALLAS, TEXAS 7E247

MINERAL CONTENT OETERMINATION

(by X-ray Diffraction)

Technadril-Fenix \& Scisson

Gladys McCall Well No. 1

Grand Chenier Field

Cameron Parish, Louisiana

Sample Identification:

Sample Depth, feet:

Particle Size

of Sample Fraction:

Estimate of Net Percent Clay Minerals:

Mineral

Quartz

Feldspars

Barite

Kaolinite

Chlorite (Fe-Rich)

Inlite/Mica

$\frac{1}{15,182.7-84.0}$
$\begin{aligned} & \text { Whole } \\ & \text { Rock Clay }\end{aligned}$
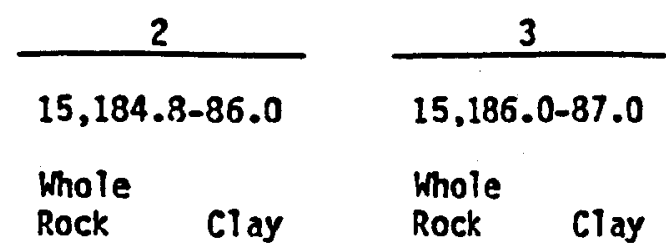

3.3

3.1

Trace

Trace

2. 48

2

1

Trace 3

Trace

44

1

Trace
1.9

94

4

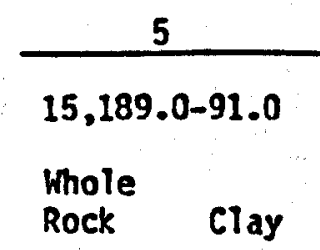

2.7

91

6

Trace

Trace

\& 42

2

66

$1 \quad 46$

$<1$

24

Trace

12

Trace

10


CARE LABOR.:TORIES, INC.

Atroleum Reservoir Engineering

Dallas, texas 7azat

MINERAL CONTENT DETERMINATION

(by X-ray Diffraction)
Page 20 of 31

File SCAL-308-81328

Technadril-Fenix \& Scisson

Glarlys McCall Well No. 1

firand Chenier Field

Cameron Parish, Louisiana

Sample Identification:

Sample Depth, feet:

$15,348.0-5 n .0$
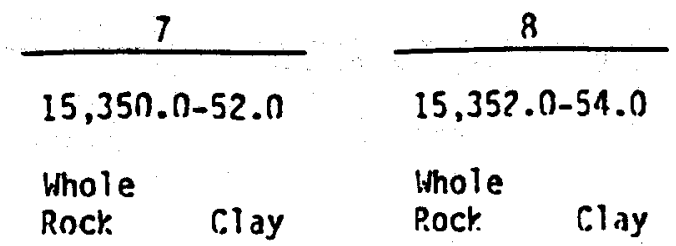

$\frac{9}{15,354.0-56.0}$
$\begin{aligned} & \text { Whole } \\ & \text { Rock Clay }\end{aligned}$

2.1

1.8

1.8

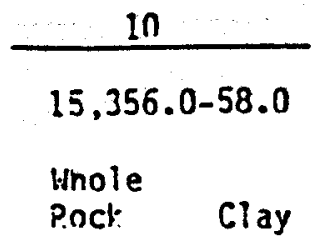

Estimate of $\mathrm{Net}$

Percent Clay Hinerals:

$3 . n$

Mineral

ṇuartz

Feldspars

Barite

Kaolinite

Chlorite (Fs-PiCh)

Illite/Mica

Mixed Layer Clay*

-lilice/Chlorite

Fraction of Sample Analyzed

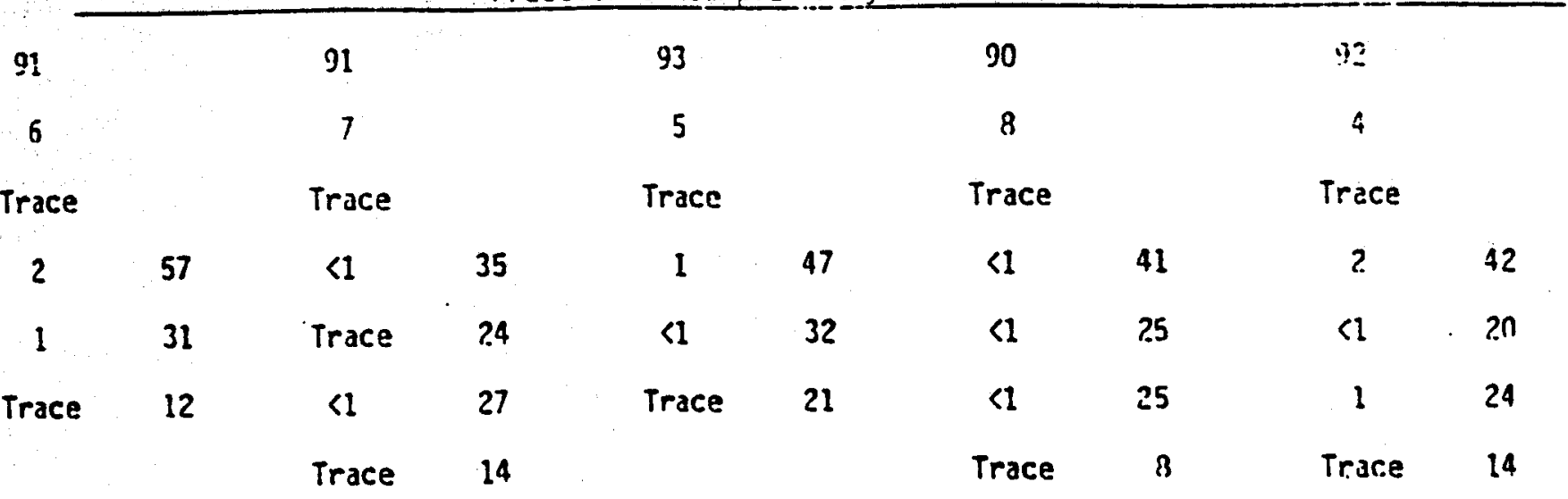


CORE LABORATORIES, IMC.

Potrolewn Reservoir Engineering

oAlLAs, TEXAS 76247

\section{MINERAL CONTENT DETERMINATION}

(by X-ray Oiffraction)
Technadril-Fenix \& Scisson

Gladys McCall Well No. I

Grand Chenier Field

Cameron Parish, Loulisiana

Sample Identification:

Sample Depth, feet:
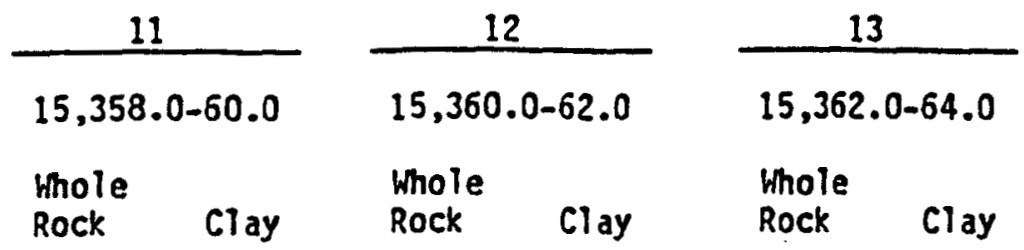

1.9

2.1
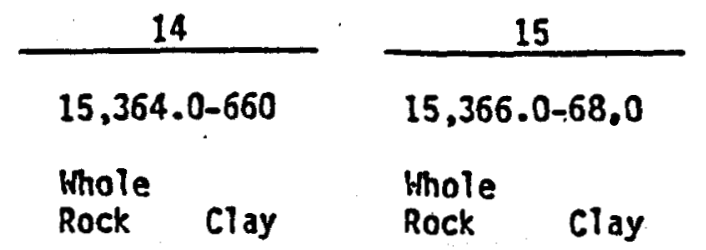

stimate of Net Percent Clay Minerals:

Mineral

Quartz

Feldspars

Barite

Kaolinite

Chlorite (Fe-Rich)

Illite/Mica

Mixed Layer Clay*

- Illite/Chlorite

Fraction of Sample Analyzed

\begin{tabular}{cc}
\hline 87 & \\
8 & \\
Trace & \\
1 & 25 \\
$<1$ & 18 \\
2 & 45 \\
41 & 12 \\
&
\end{tabular}

94

4

Trace

152

$<1$

$<1$
2.6

2.5

$\begin{array}{cccc}91 & & 93 \\ 6 & & 4 & \\ \text { Trace } & & \text { Trace } & \\ \text { Trace } & 12 & <1 & 27 \\ < & 19 & <1 & 25 \\ 1 & 50 & 1 & 32 \\ \Lambda & 19 & \text { Trace } & 16\end{array}$

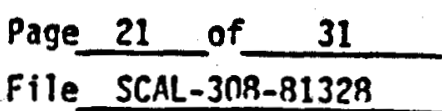

1
5
0
3
$n$
$n$
$n$
$n$
0

0

孚

Q

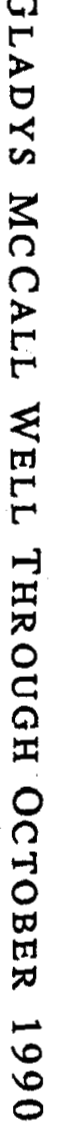


CORE LABORATORIES, INC.

Abolem Resennoir Engineering

DALLAS, TEXAS 78247

MINERAL CONTENT DETERMINATION

(by $X$-ray Diffraction)
Technadril-Fenix \& Scisson

Gladys McCall Well No. 1

Grand Chenier Field

Cameron Parish, Louisiana

Page 22 of 31

File SCAL-308-81328

n

Sample Identification:

Sample Depth, feet:

Particle Size

of Sample Fraction:

Estimate of Net

Percent Clay Minerals:

Mineral

\section{Quartz}

Feldspars

Barite

Kaolinite

Chlorite (Fe-Rich)

I11ite/Mica
16

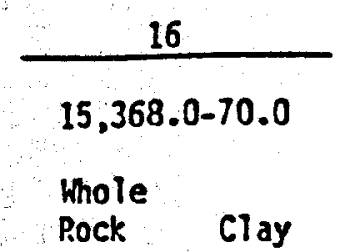

3.5

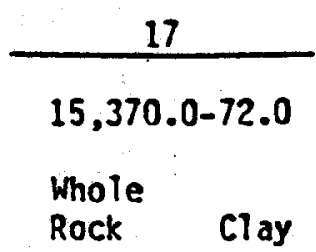

2.7
Fraction of Sample Analyzed

\section{8}

9

Trace

243

126

131
$<1$

1

1
18

$15,372.0-74.0$

Whole

Rock Clay

2.4

89

9

Trace

148

<1 27

Trace 25 
CORE LABORATORIES, INC.

Abrolewen Reservoir Engineering

DALLAS, TEXAS 78247

\begin{tabular}{l} 
Page $\frac{23}{\text { File of }} \frac{31}{S C A L-308-81328}$ \\
\hline
\end{tabular}

SCANNING ELECTRON MICROSCOPE STUDY

Technadril-Fenix \& Scisson

Gladys McCall Well No. 1

Grand Chenier Fleld

Cameron Parish, Loulsiana

Depth, feet: $15,182.7-84.0$

Sample 1 is a light gray, moderately sorted, moderately consolidated, finegrain sandstone. Photomicrograph Al (50X) shows a moderately packed aggregate of subangular to subrounded fine sand grains cemented by an early to intermediate state of secondary quartz overgrowths and authigenic clay. Primary intergranular porosity has been greatiy reduced by the cements; however, photomicrographs $B 1(300 X)$ and $C 1$ (400X) indicate significant remnant porosity. In addition, microporosity has been created by the crystalline morphologies of authigenic clays. A more detailed examination, provided by photomicrograph C2 (2000X), reveals idiomorphic plates of pore-lining authigenic chlorite. Idiomorphic plates of authigenic chlorite occur with morphologies resembling pyrite in photomicrograph B2 (1500X).

Depth, feet: $15,184.8-86.0$

Sample 2 is a light gray, moderately sorted, moderately consolidated, finegrain sandstone. Photomicrograph Al (50X) shows a moderately packed aggregate of subangular to subrounded fine sand and silt grains cemented by an early stage of quartz overgrowths and pore-filling authigenic clays. Although primary intergranular porosity has been substantially reduced by the cements, photomicrograph $B 1(300 X)$ indicates significant porosity remains. In addition, microporosity occurs in association with the delicate crystalline morphologies of authigenic clays. Photomicrograph B2 (1500X) provides a more detailed examination of these morphologies and reveals 1diomorphic plates of authigenic chlorite. The presence of poorly defined clay material in association with authigenic chlorite in this photomicrograph suggests recrystallization of detrital clays. Stacked pseudohexagonal plates of authigenic kaolinite are shown by photomicrograph B1 (300X). 
Flow TeStS OF THE GLADYS MCCALl Well THROUgh OCTOBER 1990

CORE LABORATORIES, INC.

Atroleun Reservoir Engineering

DALLAS, TEXAS T8247

\begin{tabular}{l} 
Page $\frac{24}{\text { FCAL }}$ of $\frac{31}{308-81328}$ \\
\hline
\end{tabular}

SCANNING ELECTRON MICROSCOPE STUDY

Technadril-Fenix \& Scisson

Gladys McCall Well No. 1

Grand Chenter Fleld

Cameron Parish, Louisiana

Depth, feet: $15,186.0-87.0$

Sample 3 is a llght gray, moderately sorted, moderately consolldated, finegrain sandstone. Photomicrograph A1 (50X) shows a moderately packed aggregate of subangular to subrounded fine and silt grains cemented hy an early stage of secondary quartz overgrowths and pore-filling authlgentc clay. Primary intergranular porosity has been substantlally reduced by the cements; however, photomicrographs $B 1$ (300X) and C1 (400X) Indicate significant interparticle porosity remains. Additional porosity in the form of microporosity occurs as a result of the crystalline morphology of authigenic clay. A more detalled view, provided by photomicrograph $C 2$ (2000X), reveals idiomorphic plates of pore-lining authigenic chlorite occurring with delicate lath-like terminations of authigenic llite. In addition, photomicrograph B2 (1500X) examines stacked, pseudohexagonal plates of pore-flling auth1genic kaolinite.

Depth, feet: $15,187.5-89.0$

Sample 4 is a light gray, moderately sorted, moderately consolldated, finegrain sandstone. Photomicrograph $\mathrm{Al}(50 \mathrm{X})$ shows a moderately packed aggregate of subangular to subrounded fine sand and silt grains cemented by an early stage of secondary quartz overgrowths and authigentc clay. Although primary intergranular porosity has been substantlally reduced by the cements photomicrographs B1 (300X) and C1 (600X) suggest significant remnant porosity. In addition, microporosity occurs as a result of the crystalilne morphologies of authigenic clays. A more detalled view, provided by photomicrograph B2 $(1500 x)$, reveals idiomorphic plates of authigenlc chlorite and delfate lath-like terminations of authigenic fllite. The occurrence of these authlgenic clays with poorly defined clay material suggests recrystallization of detrital clays. Photomicrograph C1 (600X) shows authigentc chlorite and stacked, pseudohexagonal plates of authigenic kaolinite. 
Flow tests of the Gladys MCCall Well Through OCtober 1990

CORE LABORATORIES, INC.

Atroleum Reservoir Engineering

oAllas, TEXAs 78247

Page 25 of $\frac{31}{5 C A}$

File SCAL-308-81328

SCANNING ELECTRON MICROSCOPE STUDY

Technadril-Fenix \& Scisson

Gladys McCall Well No. 1

Grand Chenier Field

Cameron Parish, Louisiana

Depth, feet: $15,189.0-91.0$

Sample 5 is a light gray, moderately sorted, moderately consolidated, finegrain sandstone. Photomicrograph Al (50X) shows a moderately packed aggregate of subangular to subrounded fine sand and silt grains cemented by an early stage of quartz overgrowths and authigenic clay. Primary intergranular porosity has been greatly reduced by the cements; however, photomicrograph B1 (300X) suggests significant interparticle porosity remains. In addition, microporosity has been created by the crystalline morphologies of authigenic clays. Photomicrograph B2 (1500X) provides a more detalled examination of these morphologies and reveals booklets of pore-filling authigenic kaolinite and delicate lath-like terminations resembling authigente 111 ite. Pore-lining authigenic chlorite is shown by photomicrograph B1 (300X).

Depth, feet: $15,348.0-50.0$

Sample 6 is a light gray, moderately sorted, moderately consolidated, finegrain sandstone. Photomicrograph Al (50X) shows a moderately packed aggregate of subangular to subrounded fine sand grains cemented by an early stage of quartz overgrowths and pore-filling authigenic clay. Although primary intergranular porosity has been reduced by the cements, photomicrograph R1 (300X) indicates substantial remnant porosity. In addition, significant microporosity has been created by the crystalline structures of authigenic clays. A more detalled examination of these structures, provided by photomicrograph B2 (1500X), reveals stacked pseudohexagonal plates of authigenic kaolinite and delicate projections resembling authigenic fllite. 
CORE LABORATORIES, INC.

Atoleum Reservoir Engineering

oAllas, texas 75247

\begin{tabular}{|c|c|c|}
\hline Page & 26 of & 31 \\
\hline Flle & $\overline{S C A L}-3 C$ & $108-81328$ \\
\hline
\end{tabular}

SCANHING ELECTRON MICROSCOPE STUDY

Technadril-Fenix \& Scisson

Gladys McCall Well No. 1

Grand Chenier Fleld

Cameron Parish, Louisiana

Depth, feet: $15,350.0-52.0$

Sample 7 is a light gray, moderately sorted, moderately consolldated, finegrain sandstone. Photcmicrograph Al (50X) shows a moderately packed aggregate of subangular to subrounded fine sand grains cement by an early stage of secondary quartz overgrowths and authigenic clay. Primary intergranular porossity has been substantially reduced by the cements; however, photomicrographs BI (300X) and $\mathrm{Cl}(300 \mathrm{X})$ indicate significant porosfty remains. In addition, microporosity occurs in association with crystalline morphologies of authigenic clays. Photomicrograph B2 (1500X) provides a more detalled view of these clays, revealing delicate lath-like projectlons of authigenic llilte and fllustrating the pore-bridging habit of this clay. In addition, stacked pseudohexagonal plates of authigenic kaolinite and dellcate projections of authigenic fllite are shown in photomicrograph C2 (1500X).

Depth, feet: $15,352.0-54.0$

Sample $B$ is a light gray, moderately sorted, moderately consolldated, finegrain sandstone. Photomicrograph Al (50X) shows a moderately packed aggregate of subangular to subrounded fine sand grains cemented by an early stage of quartz overgrowths and pore-filling authigenic clay. Primary intergranular porosity has heen substantially reduced by the cements; however, photomicrograph B1 (300X) suggests signiffcant remnant porosity. Addit lonal microporosity occurs as a result of the dellcate crystalline morphology of authigenfc clay. Photomicrograph B2 (1500X) examines this morphology in greater detall and reveals stacked pseudohexagonal plates of authigenic kaolinite. 
CORE LABORATORIES, INC.

Atroleum Reservoir Engineering

DALLAS, TEXAS 78247

Page 27 of $\quad 31$

Flle SCAL-308-81328

SCANNING ELECTRON MICROSCOPE STUMY

Technadril-Fenix \& Scisson

Gladys McCall Well No. 1

Grand Chenier Fleld

Cameron Parish, Louisiana

Depth, feet: $15,354.0-56.0$

Sample 9 is a light gray, moderately sorted, moderately consolldated, finegrain sandstone. Photomicrograph Al (50X) shows a moderately packed aggregate of subangular to subrounded fine sand grains cemented by an early stage of quartz overgrowths and pore-filling authigenic clay. The cements in this sample have substantially reduced primary intergranular porosity; however, photomicrograph Bl (300X) suggests significant interparticle porosity remsins. In addition, microporosity occurs in association with the crystalline structures of authigentc clays. Photomicrograph B2 (1500X) provides a more detalled view of these structures revealing delicate lath-like projections of authigenic illite. Photomicrograph 81 (300X) shows morphologies resembling authigenic kaolinfte hooklets.

Depth, feet: $15,356.0-58.0$

Sample 10 is a light gray, moderately sorted, moderately consolidated, finegrain sandstone. Photomicrograph $\mathrm{Al}(50 \mathrm{X})$ shows a moderately packed aggregate of fine sand grains cemented by an early stage of quartz overgrowths and porefilling authigenic clay. Although primary intergranular porosity, vlewed in photomicrograph $B I$ ( $300 X)$, has been significantly reduced by the cements, substantial interparticle porosity remains. In addition, microporosity occurs in association with crystalline morphologies of authigenic clays. A more detalled examination, provided by photomicrograph B2 (1500X), reveals delicate laths of authigenic illite. Book.lets of authigenic kaolinite are shown in photomicrograph 81 (300X). 
CORE LABORATORIES, INC.

Pebolewn Reservoir Engineering

DALLAS, TEXAS 752AT

\begin{tabular}{l} 
Page $\frac{28}{\text { File of }} \frac{31}{\text { SCAL-308-81328 }}$ \\
\hline
\end{tabular}

SCANNING ELECTRON MICROISCOPE STUDY

Technadril-Fenix \& Scisson

Gladys McCall Well No. i

Grand Chenter Fleld

Cameron Parish, Louistana

Depth, feet: $15,358.0-60.0$

Sample 11 is a light gray, moderately sorted, moderately consolidated, finegrain sandstone. Photomicrograph Al (50X) shows a moderately packed aggregate of subangular to subrounded fine sand grains cemented by an early stage of secondary quartz overgrowths and pore-filling authigenic clay. Primary intergranular porosity has been substantially reduced; however, significant remnant porosity is indicated by photomicrographs $B 1$ (400X) and $C 1$ (300X). In addition, microporosity has been created by the crystalline morphologles of authigenic clays. A more detalled view, provided by photomicrograph 82 (2000X), reveals delicate lath-like terminations of authigenic fllite and fllustrates the porebridging habit of this authigenic clay. Photomicrograph C2 (1500X) examines stacked, pseudohexagonal plates of pore-fililng authigenic kaolinite occurring with wisps of authigenic filite.

Depth, feet: $115,360.0-62.0$

Sample 12 is a light gray, moderately sorted, moderately consolldated, finegrain sandstone. Photomicrograph Al (50X) shows moderately packed aggregate of subangular to subrounded fine sand grafns cemented by an early stage of quartz overgrowths and authigentc clay. Although primary intergranular porosity, vlewed in photomicrograph B1 $(300 x)$, has been slgnificantly reduced by the cements, substantial interparticle porosity remains. In addition, microporosity occurs in association with the crystalline morphologies in greater detail and reveals dellcate lath-like terminations of authigenic flllte occurring with fdiomorphic plates resembling authigenic chlorite. 
CORE LABORATORIES, INC.

Atroleum Reservoir Engineering

DALLAS, TEXAS 7B247

Page 29 of 31

Flle SCAL-308-81328

SCAMNING ELECTRON MICROSCOPE STUDY

Technadril-Fenix \& Scisson

Gladys McCall Well No. 1

Grand Chenfer Fleld

Cameron Parish, Loutsiana

Depth, feet: $15,362.0-64.0$

Sample 13 is a light gray, moderately sorted, moderately consolidated, finegrain sandstone. Photomicrograph Al (50X) shows a moderately packed aggregate of subangular to subrounded fine sand grains cemented by an early stage of quartz overgrowths and pore-filling authigenic clay. Primary intergranular porosity, viewed in photomicrographs $\mathrm{B1}$ (300X) and $\mathrm{Cl}$ (300X) has been substantialiy reduced by the cements; however, significant interparticle porosity remains. In addition, microporosity has been created by the crystalline morphologies of authigenic clays. Photomicrograph B2 (1500X) provides a more detailed view of these morphologies, revealing delicate laths of authigenic illite. Stacked pseudohexagonal plates of pore-filling authigenic kaolinite are shown by photomicrograph C2 (1500X).

Depth, feet: $15,364.0-66.0$

Sample 14 is a light gray, moderately sorted, moderately consolfdated, finegrain sandstone. Photomicrograph Al (50X) shows a moderately packed aggregate of subangular to subrounded fine sand and silt grains cemented by an early stage of secondary quartz overgrowths and pore-filling authigenle clay. Although primary intergranular porosity has been substantially reduced hy the cements, photomfcrograph B1 (300X) suggests significant remnant porosity. In addition, microporosity occurs as a result of the crystalline morphologles of authigenic clays. A more detalled examination of these morphologles, provided by photomicrograph $82(500 x)$, reveals delicate laths of authigentc fllite. 
CORE LABORATORIES, INC.

Atrolewor Reservoir Engineering

DALLAS, TEXAS 782A7

\begin{tabular}{|c|c|c|}
\hline & 30 & 31 \\
\hline & SCAL & 8132 \\
\hline
\end{tabular}

SCANHING ELECTRON MICROSCOPE STUDY

Technadril-Fenix \& Scisson

Gladys McCall Well No. 1

Grand Chenier Field

Cameron Parish, Loulsiana

Depth, feet: $15,366.0-68.0$

Sample 15 is a light gray, moderately sorted, moderately consolidated, finegrain sandstone. Photomicrograph Al (50X) shows a moderately packed aggregate of subangular to subrounded fine sand grains cemented by an early stage of secondary quartz overgrowths. Primary intergranular porosity has been somewhat reduced hy the cements; however, photomicrograph ?1 $_{1}$ (300X) indicates substantial porosity remains. A more detalled view of the clay material in this sample, provided by photomicrograph B2 (1500X), reveals a poorly defined structure suggesting a primarily detrital origin.

Depth, feet: $15,368.0-70.0$

Sample 16 is a light gray, moderately sorted, moderately consolldated, finegrain sandstone. Photomlcrograph $A 1(50 X)$ shows a moderately packed aggregate of subangular to subrounded fine sand grains cemented by an early stage of secondary quartz overgrowths and pore-fliling authigenic clay. Although primary intergranular porosity, examined by photomicrograph B1 (300X), has been significantly reduced by the cements, substantial interparticle porosity remains. In addition, microporosity has been created by the dellcate structure of authigenic clays. Photomicrograph B2 (1500X) provides a more detalled view of these structures, revealing stacked pseudohexagonal plates of pore-filling authigentc kaolinite and morphologies resembling authigenlc llilte. 
CORE LABORATORIES, INC.

$\begin{aligned} & \text { Atroleum Reservoir Engineering } \\ & \text { DALLAS, TEXAs } 78247\end{aligned}$
$\begin{aligned} & \text { Page } \frac{31}{\text { SCAL }} \text { of } \frac{31}{308-81328} \\ & \text { Flle }\end{aligned}$

SCANNING ELECTRON MICROSCOPE STUDY

Technadril-Fenix \& Scisson

Gladys Mcr.all Well No. 1

Grand Chenier Field

Cameron Parish, Louisiana

Depth, feet: $15,370.0-72.0$

Sample 17 is a light gray, moderately sorted, moderately consolidated, finegrain sandstone. Photomicrograph Al (50X) shows a moderately packed aggregate. of angular to subrounded fine sand and silt grains cemented by an early stage of quartz overgrowths. Primary intergranular porosity, vlewed in photomicrographs $B 1$ (300X) and $\mathrm{Cl}(400 \mathrm{X})$, has been reduced by the cement and a sflty matrix such that only microporosity associated with the matrix particles remains. A more detailed view of these particles, provided by photomicrographs B2 (1500X) and C2 (2000X), reveals a poorly defined structure suggesting a primarily detrital origin.

Depth, feet: $15,372.0-74.0$

Sample 18 is a light gray, moderately sorted, moderately consolidated, fine grain sandstone. Photomicrograph Al (50X) shows a moderately packed aggregate of subangular to subrounded fine sand and silt grains cemented by an early to intermediate stage of quartz overgrowths and pore-filling authigenic clay. Although primary intergranular porosity has been substantially reduced by the cements and a silty matrix, photomicrographs $\mathrm{Bl}$ (300X) and $\mathrm{Cl}$ (400X) indicate significant porosity remains. In addition, microporosity occurs in association with the particles of the matrix and the morphologies of authigenic clays. A more detalled view, provided by photomicrograph B2 (1500X), reveals the poorly defined structure of detrital clay; however, photomicrograph C2 (2000X) shows delicate lath-like projections of pore-lining authigenic fllite. 
FLOW TESTS OF THE GLADYS MCCALL WELL THROUgh OCTOBER 1990

\section{APPENDIX B}

PVT Analysis for Sand 9 by Weatherly Laboratories, Inc.

B-1 

FLOW TESTS OF THE GLAdys MCCALL WELL THROUGH OCTOBER 1990

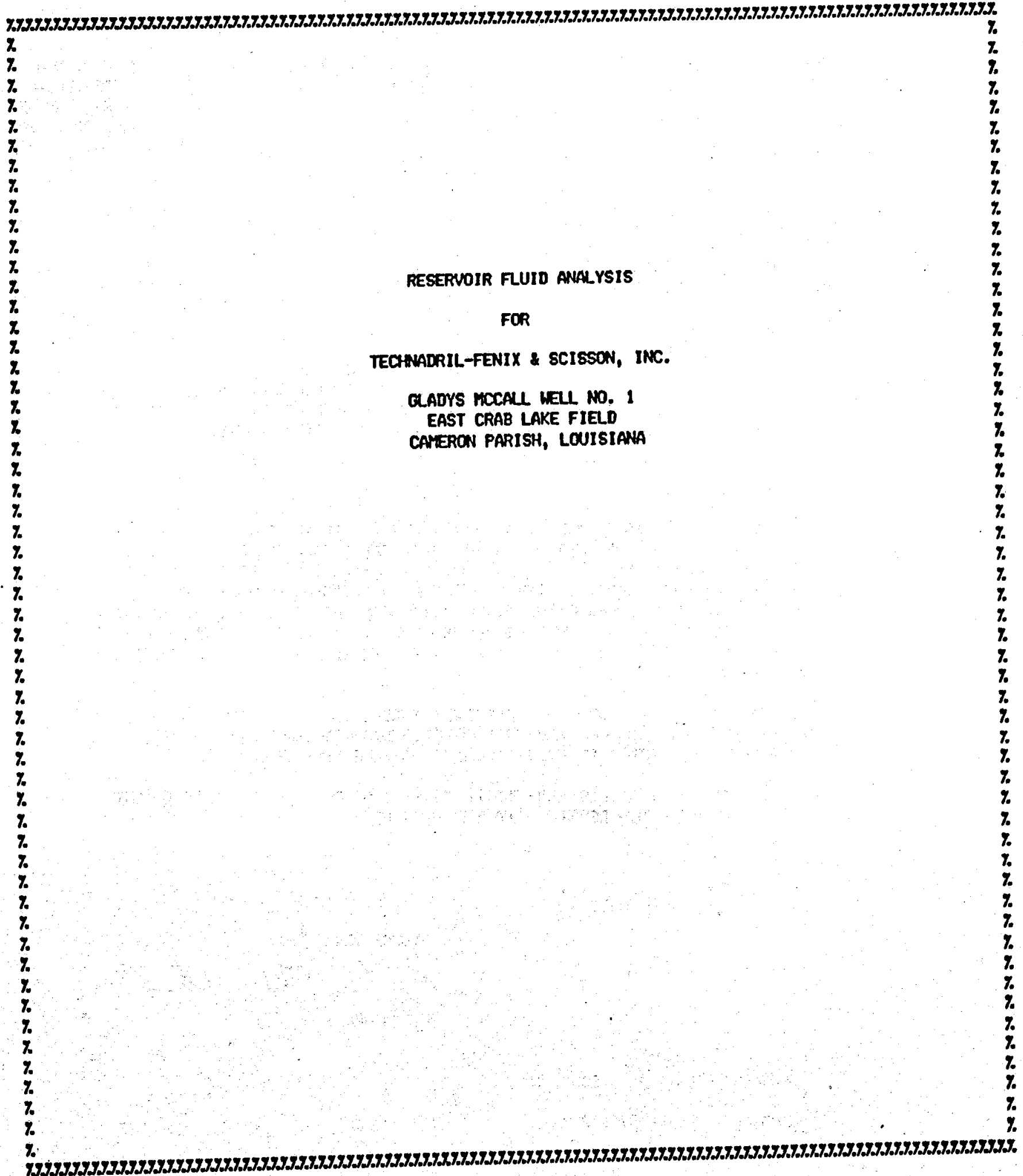

MEATHERLY LABORATORIES, INC.

B-3
IN S T I T U TE
O F
G A S
T E C H N O L O G Y 
MEATHERLY LABORATORIES, INC.

J. E. WEATHERLY, JR. CHAIRMAN
223 GEORGETTE LAFAYETTE, LA 70506

PHONE (318) 232-4877
JOAN D. NEAL

PRESIDENT

BRYAN SONWIER

VICE PRESIDENT

APRIL 30,1983

TECHNAIRIL-FENIX \& SCISSON, INC.

3 NORTHPOINT DRIVE

SUITE 209

HOUSTON, TEXAS 77060

ATTENTION: MR. LARRY DURRETT

\author{
RE: RESERVOIR FLUID STUDY \\ OLAOYS MCCALL WELL NO. 1 \\ EAST CRAB LAKE FIELD \\ CAMERON PARISH, LOUISIANA
}

GENTLEMEN:

ATTACHED ARE THE RESLRTS OF THE ANALYSES OF THE CHEMICAL AND FHYSICAL

CHARACTERISTICS OF A RECOMBINER RESERUOIR FLUID SAMPLE FROM THE SUBUECT WELL. SIIRFACE SEPARATOR SAMPLES WERE COLLECTED FROH THIS WELL BY A REPRESENTATIVE OF WEATIERLY LABORATCRIES, INC. ON MARCH 23, 1983. THE GAS-WATER RATIO (GWR) MEASURED ON THIS TEST, 24.66 CUBIC FEET OF SEPARATOR GAS FER BARREL OF SEPARATOR LIQUID, WAS USED AS THE BASIS FOR ONE RECOMBINATION. THE RESULTANT RESERVDIR FLUID EXHIBITED A BUBELE POINT OF 10,030 PSIA AT THE RESERVOIR TEMPERATURE 298 DEGREES FAHRENEIT.

OTHER RECOMBINATIONS WERE DONE TO DETERMINE A BUBBLE POINT -VS- GUR RELATIONSHIP. A DIFFERENTIAL LIBERATION AND VISCOSITY MEASUREMENTS WERE FERFORMED USINO RESERVOIR FLUID RECOMBINED TO THE PRODUCED GWR AT THE TIME OF SAMFLING.

WE WISH TO THANK YOU FOR THIS OPPORTUNITY OF SERVIMG YOIJ. SHOLLD THERE BE ANY QUESTIONS CONCERNING THIS REPORT, PLEASE CONTACT US.

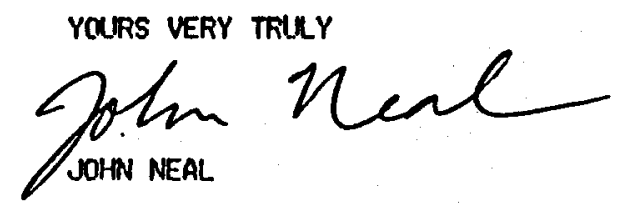

CCI MR. JOMNE BERNING

TECHNADRIL-FENIX \& SCISSON, INC.

P. 0. BOX 231

GRAND CHENIER, LA 70643

LAR. NO. N1901-10224

B-4

I NST ITUTE OF G A S T TCH NOL O G Y 
TECHNADRIL-FENIX \&CISSON, INC. BLADYS MCCALL WELL ND. I

EAST CRAB LAKE FIELD

GEOPRESSURE/GEOTHERMAL PROUECT SAMPLING AND LABORATORY PROCEDURE

1) WATER VAPOR CONTENT OF SEPARATOR GAS WAS DETERMINED BY FLOWINO GAS FROM A METERING VALVE ON THE SEPARATOR GAS METER RUN THROUGH A WEIGHING TUBE IINDICATOR DRIERITE (CaS04) WEIGHED TO 0.1 MILLIGRAM) TO A G.C.A. /FRECISION SCIENTIFIC WET TEST METER. SEPARATOR GAS SAMPLES WERE TAKEN FROM THE SAME PLACE INTO EVACUATED 1 GALLON STAIMLESS STEEL (S.S.) CYLINDERS AFTER THOROUGH FURGING DF TRANSFER LINE AT SEPARATOR PRESSLRE. SEPAFATOR LIQUID SATFLE CYLINDERS $1590 \mathrm{ML}$. S.S.) WERE FIRST CHARGED WITH SEPARATOR GAS TO FULL SEPARATOR PRESSLRE. THE LIQUID CYLINDERS WERE THEN CONNECTED TO THE SEPARATOR HATER SAMFLING POINT BY A S.S. TUBE LONG ENOUGH TO LOOP THROUGH A COOLING BATH. THE WATER TRANSFER LINE WAS THEN SLOWLY AND THOROUGFI Y PURGED AT THE CYLINDER. SEPARATOR NATER WAS LET INTO THE CYL INDER BY SLOWLY ELEEDING GAS FROM THE TOP VALVE. AT NO TIME WAS THE WATER CAUNHT IN THE CYLINDER ALLOWED TO DROP BELOW SEPARATOR PRESSURE.

2) FLASH LIRERATION OF GAS FROM SEPARATOR WATER WAS ACCOMPLISHED BY USING A WEIGHED SEPARATOR FLASK. THIS SEPARATOR FLASK WAS CONNECTED TO THE OUTLET OF A SEPARATOR WATER CYLINDER BY A SHORT CAPILLARY LINE. GAS FROM THE SEPARATOR FLASK PASSED THROUOH A WEIGHED DRYING TUBE THROUGH A GLASS CYLINDER ( n 300 ML.) I TO A RUSKKA GASOMETER. A VACUUM VALVE AND A MERCURY MANOMETER WAS CONNECTED TO THE GAS MANIFOLD BETWEEN THE DRYING TURE AND THE GASOMETER, BEFORE COMMENCING THE FLASH, THE ENTIRE FLASH GAS MANIFOLD WAS EVACUATED AND THEN FILLED WITH HELIUIT TO ATMOSFHERIC FRESSLRE. A KNOWN VOLUME OF SEPARATOR WATER HAS FUSHED OUT OF THE SAMFLE CYLINDER AT A PRESSURE SLIGHTLY ABOVE FIELD SEPARATOR PRESSLRE EY USE OF A CALIBRATED MERCURY PLMP. THE VOLUME OF STOCK TANK HATER PRODUCED WAS OETERMINED BY ITS WEIOHT AND DENSITY. THE VOLLME OF DRY GAS EVDLVED WAS DETERMINED WITH THE GASOMETER. THIS GAS VOCLME WAS SUB.ECT TO \& 2 \% ERROR DUE TO THE VERY SMALL AMOUNTS MEASLIRED. THE GAS NAS CHARGED TO A CIROMOTOGRAFH FOR ANALYSIS FROM THE GLASS CYLINDER.

3) PHYSICAL RECOMBINATION OF SEPARATOR EFFLUENTS: SEPARATOR GAS WAS CHARGED INTO A TEMPERATURE CONTROLLED CELL. THE VOUUME OF THIS HINDOWED CELL IS KNOWN FOR ANY PRESSURE AND TEMPERATURE. THE FRESSIURE OF THE GAS IN THE CELL WAS MEASURED HITH A MERCURY MANOMETER AND A BAROMETER. THIS CALCULATED GAS VOLLMTE WAS SUBJECT TO A $\pm 1 \%$ ERROR DUE TO THE SMALL AMOUNT CHARGED TO THE CELL. A VOLUME OF SEPARATCR WATER WAS CHARGED INTO TIE WINDOWED CELL BY USE OF A CALIERATED MERCLRY PUMP. THE NATER NAS METERED AND MEASURED AT A PRESSURE SLIGHTLY ABOVE FIELD SEPARATOR PRESSLURE. FOUR RECOMBINATIONS WERE DONE IN ORDER TO FRODUCE A SATURATION PRESSURE-US-GAS NATER RATIO CURVE. RESERVOIR FLUID RESURTING FROH RECOMBINATION OF THE FRODUCED GWR (FIFTH RECOMBINATION) NAS USED TO PERFCRM A DIFFERENTIAL LIBERATION AND VISCOSITY MEASUREMENT. 
TECHNADRIL-FENIX \& SCISSON, INC. GLADYS MCCALL WELL NO. I

EAST CRAB LAKE FIELD

4) FRESSURE-VOUUTE RELATIONS OF RECOMBINED RESERVOIR FLUID AT RESERVOIR TEMPERATURE: EACH DATUM OF PRESSURE-VOLUME RELATIONS HAS CORRECTED FOR MERCURY PUMP CALIBRATION, MANIFOLD EXPANSION, CELL EXPANSION, MERCURY COMFRESSIBILITY AND MERCLRY THERMAL EXPANSION. LIOUID VOLUME PERCENT WAS DETERMINED BY CALJBRATED CATHETOMETER AND BY DATA INTERPRETATION.

5) DIFFERENTIAL LIBERATION OF RESERVOIR FLUID AT RESERUOIR TEMPERATURE: GAS FROM EACH PRESSURE DECREMENT OF THE DIFFERENTIAL LIRERATION WAS ANALYZEO IN THE SAME MANNER AS DESCRIBED IN 2), (FLASH LIBERATION). DIFFERENTIAL LIQUID CHANGES WERE NOTED.

6) VISCOSITY OF RESERVOIR FLUID WAS MEASURED BY MR. J. R. COMEAU OF MEATHERLY LABORATORIES. A DESCRIPTION OF MR. COMEAU'S EXPERIMENTAL PROCEDURES IS GIVEN BELOW: GEOTHERMAL WATER VISCOSITIES WERE MEASURED USING AN E.L.1. ROLLING BALL VISCOHETER HITH AN ELECTRONIC DETECTION SYSTEM TO FREVENT ELECTROLYSIS. THE DETECTION SYSTEM CONSISTS OF A SENSITIVE AUDIO AMPLIFIER WITH POSITIVE FEEDBACK ADUJSTED UUST BELOH OSCILLATION. FEEDBACK WAS TURNED ON BY AN AUTOMATIC SWITCH AS THE VISCOMETER WAS INVERTED AT THE BEGINNING OF THE CYCLE AND TURNED OFF WHEN THE BALL MADE CONTACT. PART OF THE SIGNAL WAS USED TO TURN THE DIGITAI. TIMER ON AND OFF. TIMES WERE MEASURED TO 1/190TH OF A SECOND AND AVERAGED. THE VISCOMETER WAS CAL.IBRATED AT EACH OF THREE ANGES USING SEVERAL KNOWN VISCOSITY STANDARDS WHICH WERE CHECKED AGAINST CANNON-FENSKE VISCOMETERS AND THE RESUTS (t $\triangle \mathrm{p}$ vs. $\mu$ ) PLOTTED. THE VISCOMETER WAS RECALIBRATED USINO DISTILLED WATER AT SEVERAL TEMPERATLRES. THESE RESULTS WERE USED ALONO WITH PREVIOUS RESURTS TO OBTAIN NEW CALIBRATION CURVES.

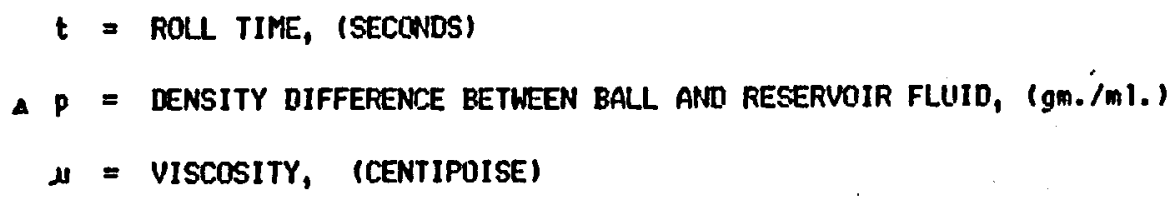

THE VISCOMETER WAS CHARGED HITH RESERWOIR FLUID AND RUN AT 298'F AT 100 LB. INTERVALS. THE VISCOSITIES HAD A PROBABLE ERROR OF \pm 0.007 CENTIPOISE.

NOTE: ALL DATA FOR PRESSURES GREATER THAN 11, 00 PSI WERE OBTAINED BY EXTRAPOLATION. 
FLOW TESTS OF THE GLADYS MCCALL WELL THROUGH OCTOBER 1990

FIELD DATA FOR WEATHERLY LABORATORY IWESTIOATION

WEL RECORD

COMPANY

WELL

FIELD

PARISH AND STATE
TECHNADRIL-FENIX \& SCISSON, INC.

GLADYS MCCALL NO. 1

EAST CRAB LAKE

CAMERON, LOUISIANA

\section{FIELD CHARACTERISTICS}

FORMATION NAME

SAND NAME AND DESIGNATION

DATE COMPLETED

ORIGINAL RESERVOIR PRESSURE

WEL CHARACTERISTICS

ORIOINAL PRODUCED GAS-LIQUID RATIO

PERFORATIONS

ELEVATIONS

TOTAL DEPTH

LAST RESERVOIR PRESSURE

RESERVOIR TEMPERATUPE

12,936 PSIA

298 DEGREES $F$

SARPLING CONDITIONS

DATE SAMPLED

TUBING PRESSURE, FLOWING

PRIMARY SEPARATOR TEMPERATURE

PRIMARY SEPARATCR PRESSLRE

PRIMARY SEPARATOR GAS RATE

SEPARATOR LIQUID RATE

GAS-LIQUID RATIO (SEPARATOR)

1000 TO 1523 HOURS, 3-23-83

5835

(METER R(N)

72

(WET GAS)

SHRINKAGE FACTOR (VOL, 5.T.WATER OQ 'F/VOL. SEP. WATER)

700

102.1

4149

PSIG

DECREES F, (SEP.) 212'F

PSIG

MCF/DAY

24.66 : SCF/BQL.SEP.WATER

GAS-LIQUID RATIO (STOCK TANK)

0.9637

25.59 SCF/BBL.S.T.WATER

PRESSUIRE BASE

15.025 PSIA 60 DEGREES F

NOTE, FOR DRY GAS, 24.63 SCF/BBL. SEP. WATER SEP. COWDITIONS.

25.5B SCF/BEL. S.T. WATER GO'F.

LAB. NO. N1901-10224

PAOE 4 OF 25

B-7
I N S T I T U T E
o $F$
G A S
T E C H NO
L $O$ G $Y$ 
TECHNADRIL-FENIX \& SCISSON, INC. GLADYS MCCALL WELL NO. 1

EAST CRAB LAKE FIELD

CALCULATION OF GAS RATE, 3-23-63 TEST

(Factors frow GPA Engineering Data Book)

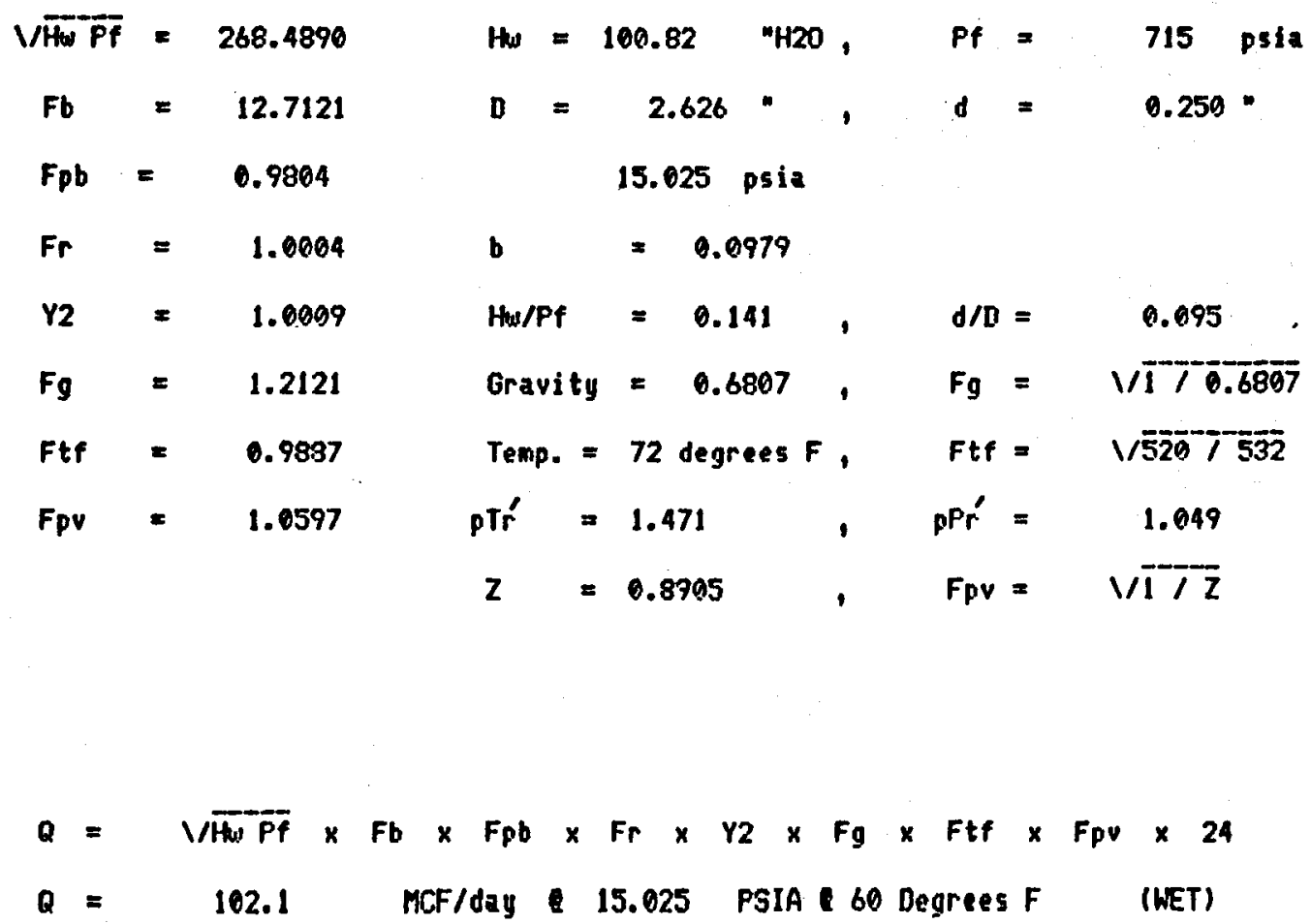


TECHNADRIL-FENIX \& SCISSON, INC. GLADYS MCCALL WELL NO. 1

EAST CRAB LAKE FIELD

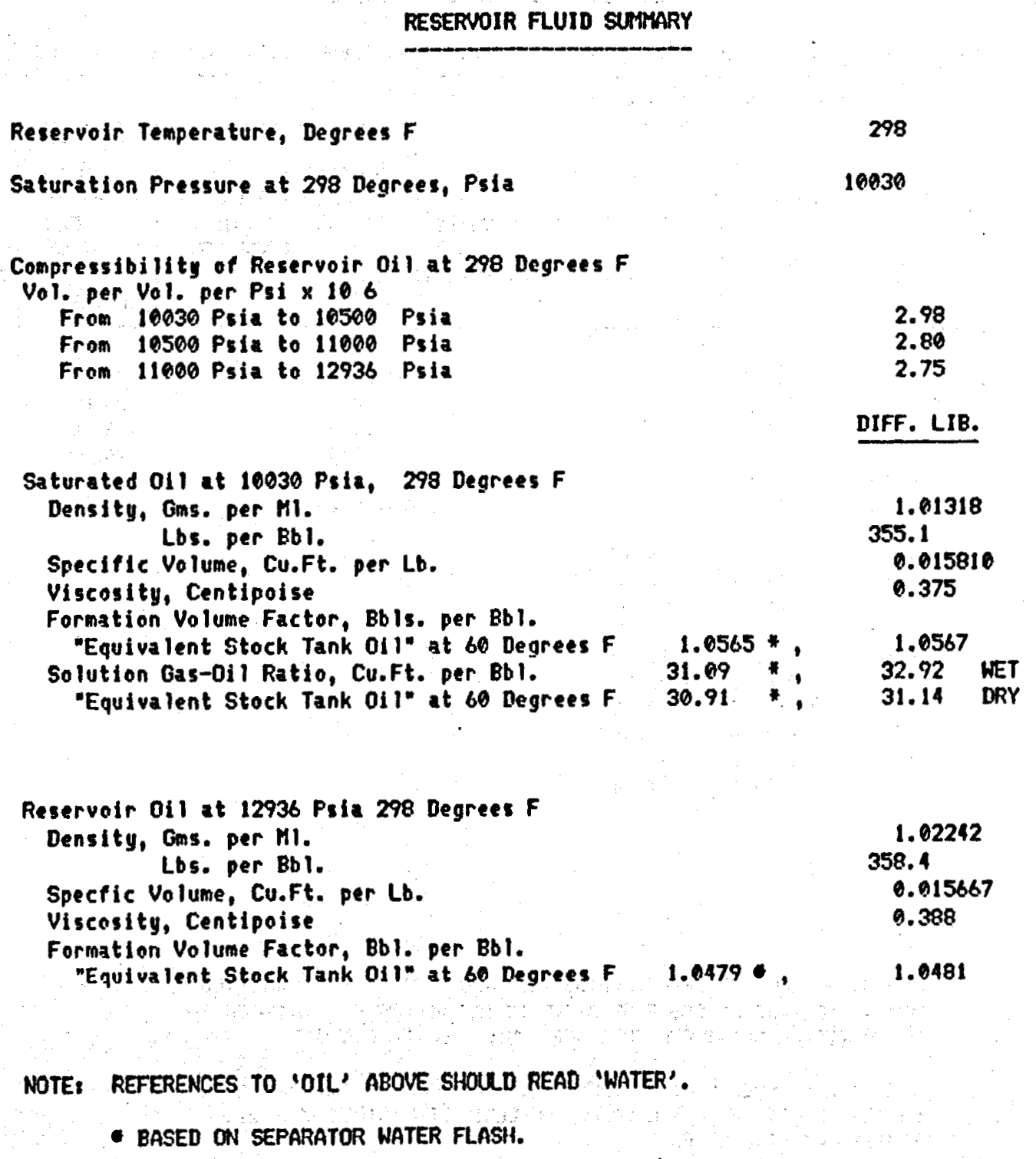

LAB No. N1901-10224 
TECHNADRIL-FENIX \& SCISSON, INC.

GLADYS MCCALL WELL NO. I

EAST CRAB LAKE FIELD

COMPOSITE LABDRATORY DATA 298 DEGREES F

RECONBINATION (1) 20.00 SCF SEP. CAS 15.025 PSIA \& 60 F/BBL. SEP. WATER E SEP. CONDITIONS.

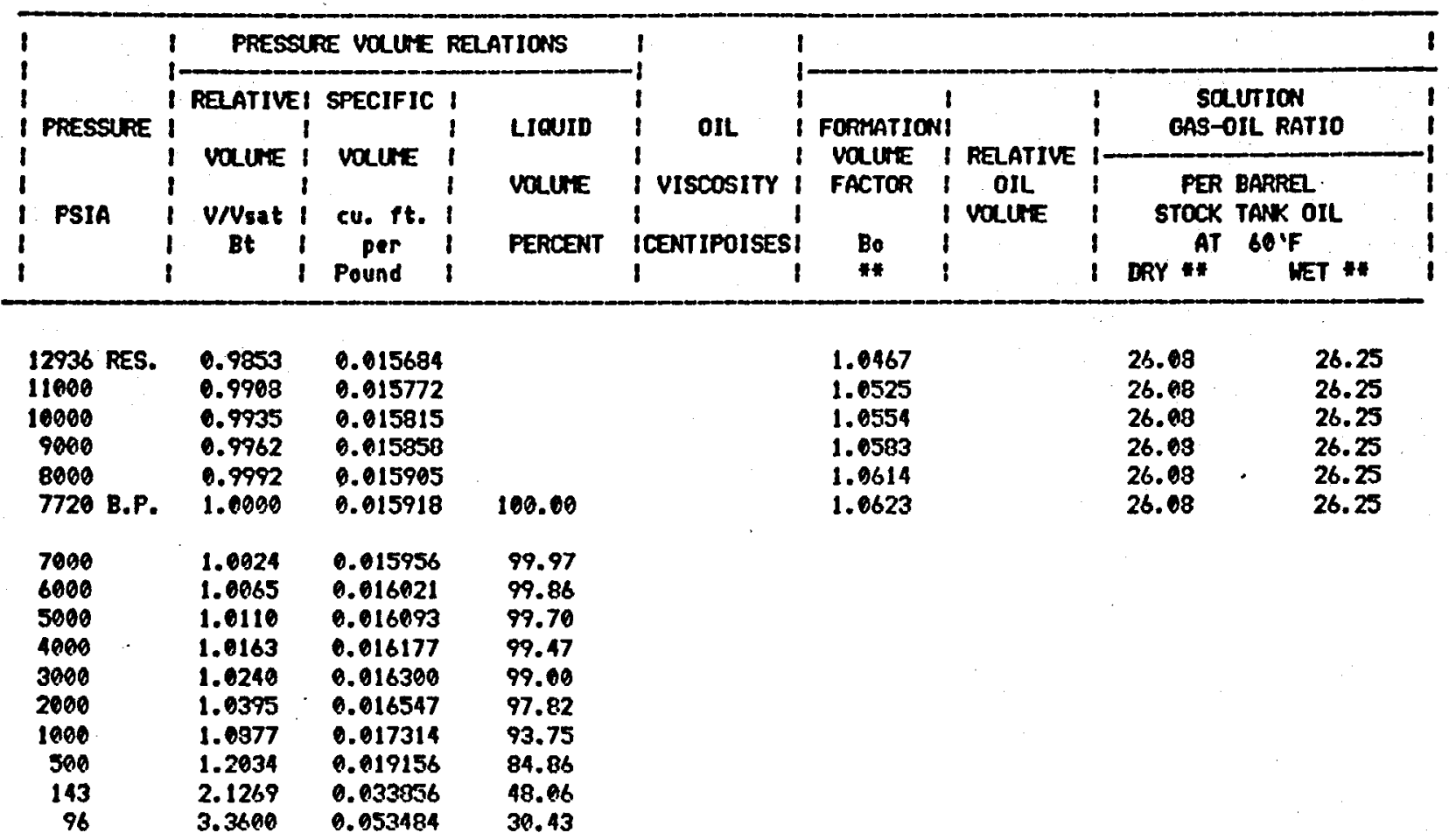

\section{NORENCLATURE:}

V/USAT. IS THE VOLUME OF FLUIDS (OIL AND GAS) AT THE INDICATED TEMTERATURE AND PRESSURE RELATIVE TO THE VOLUME OF SATLRATED OIL AT BUBBLE-POINT FRESSURE AND INDICATED TEMPERATURE.

Bo IS THE VOLUME OF OIL AT RESERVOIR TEMPERATURE AND INDICATED PRESSURE RELATIVE TO THE VOLLME OF EQUIVALENT STOCK TANK OIL. MEASLRED AT 60 DECREES F.

GAS-OIL RATIO, IS CUPIC FEET OF CAS AT 15.025 PSIA AND 60 DEGRES $F$, PER BARREL OF STOCK TANK OIL AT 60 OEGREES $F$.

NOTE: * BASED ON SEPARATOR WATER FLASH. REF. TO 'OIL' ABOVE SHOULD READ 'WATER'. 
TECHNADRIL-FENIX \& SCISSON, INC.

GLADYS MCCALL WELL NO. 1

EAST CRAB LAKE FIELD

COMPOSITE LABCRATORY DATA 298 DEGREES F

RECOMBINATION (2) 18.00 SCF SEP. GAS 2 15.025 PSIA \& 60 'F/BBL. SEP. WATER Q SEP. CONDITIONS.

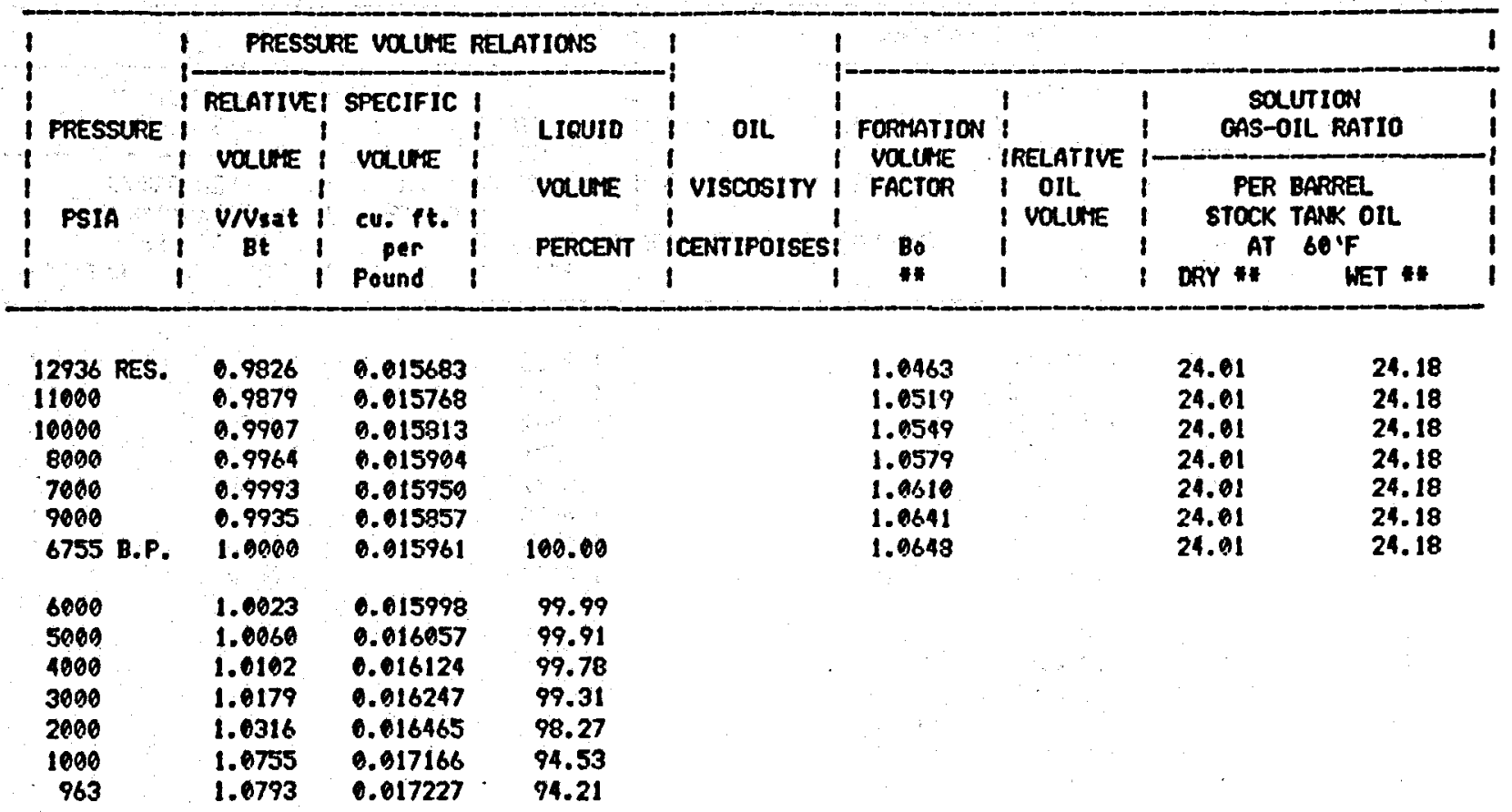

NOHENCLATURE:

V/VSAT. IS THE VOLUHE OF FLUIDS (OIL AND GASI AT THE INDICATED TEMPERATURE AND PRESSLIRE RELATIVE TO THE VOLLME OF SATLRATED OIL AT BUBBLE-POINT PRESSURE AND INOICATED TEMTERATURE.

Bo IS THE VOUUTE OF OLL AT RESERVOIR TEMPERATURE AND INDICATED PRESSLRE RELATIVE TO THE VOLUME OF EQUIVALENT STOCK TANK OIL. MEASURED AT 60 DEGREES F.

GAS-OIL RATIO, IS CUBIC FEET OF CAS AT 15.025 PSIA ANID 60 DEGREES F, PER BARREL OF STOCK TANK OIL AT 60 DEGREES $F$.

NOTE, * BASED ON SEPARATOR WATER FLASH. REF. TO 'OIL' ABOVE SHOULD READ 'WATER'. 
TECHNADRIL-FENIX \& SCISSON, INC.

GLADYS MCCALL WELL NO. I

- eAST CRAB LAKE fIELd

COMPOSITE LABORATORY DATA 298 DECREES F

RECONBINATION (3) 15.00 SCF SEP. GAS 15.025 PSIA \& 60'F/BBL. SEP. WATER Q SEP. CONDITIONS.

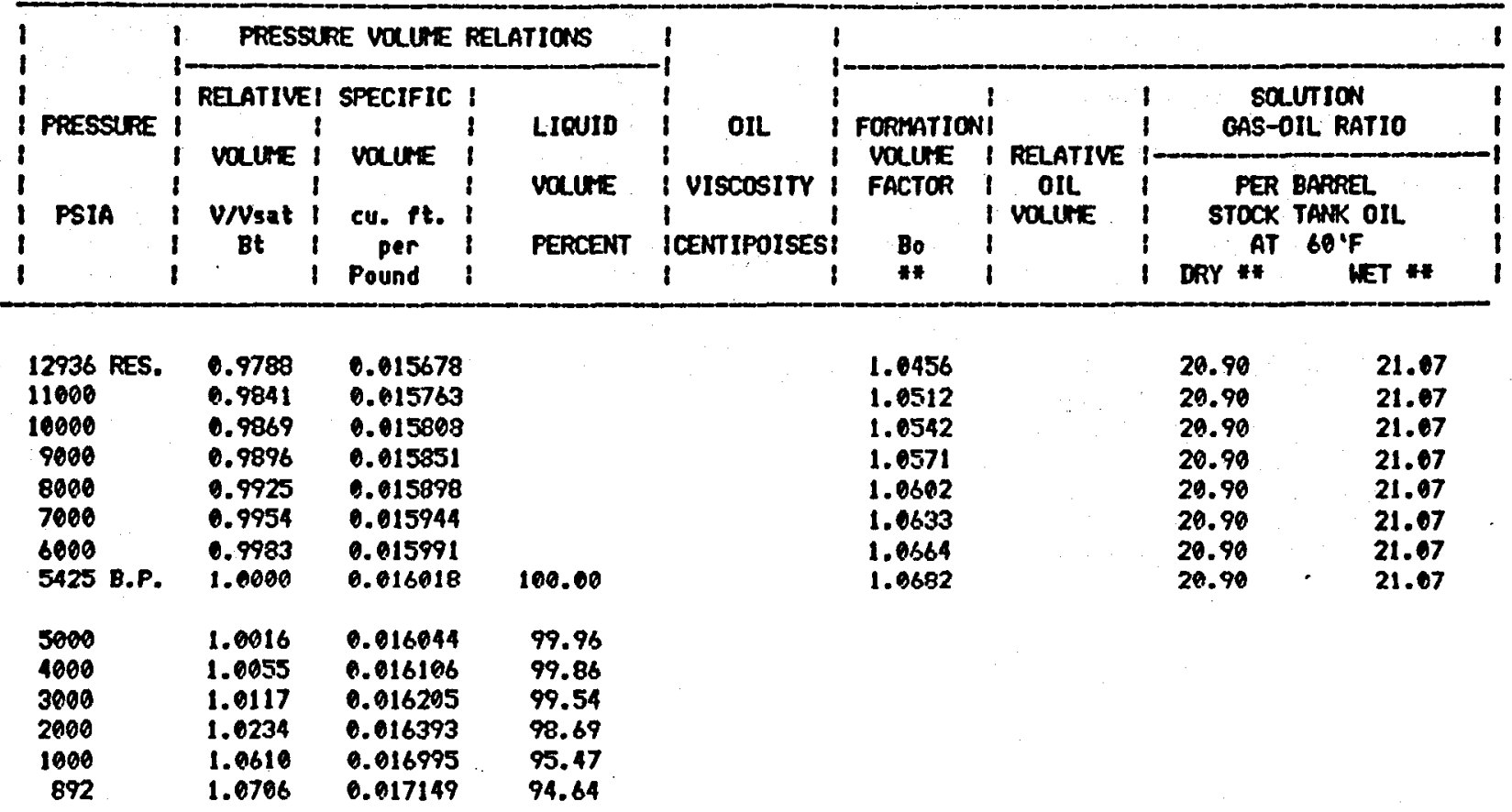

NOHENCLATURE:

V/VSAT. IS THE VOLUME OF FLUIDS (OIL AND GAS) AT THE INDICATED TEMPERATURE AND PRESSURE RELATIVE TO THE VDLUME OF SATURATED OIL AT BURBLE-POINT FRESSLRE AND INDICATED TEMPERATURE.

Bo IS THE VOLUIE OF OIL AT RESERVOIR TEMPERATURE AND INDICATED PRESSURE RELATIVE TO THE VOLUHE OF EQUIVALENT STOCK TANM OIL MEASTIRED AT 60 DEGREES F.

GAS-OIL RATIO, IS CUBIC FEET OF GAS AT 15.025 PSIA AND 60 DECREES $F$, PER RARREL OF STCCK TANK OIL AT 60 DECREES F.

NOTE: * BASED ON SEPARATOR WATER FLASH. REF. TO 'OIL' ABOVE SHOULD READ 'WATER'. 
TECHNARRIL-FENIX \& SCISSON, INC.

CAADYS MCCALL WELL NO. 1

EAST CRAB LAKE FIELD

COHPOSITE LABORATORY DATA 298 DECREES F

RECONBINATION (4) 10.00 SCF SEP. CAS 15.025 PSIA \& 60'F/BBL. SEP. WATER E SEP. CONDITIONS.

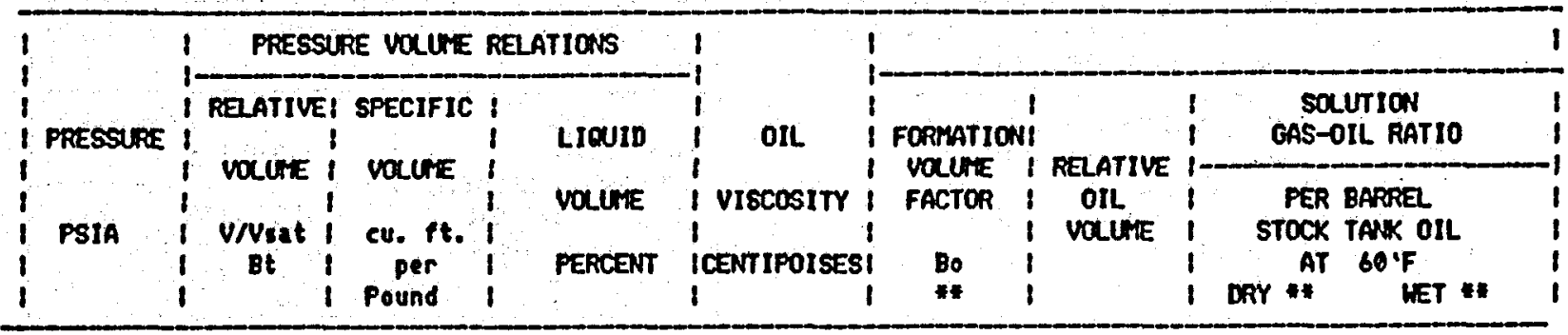

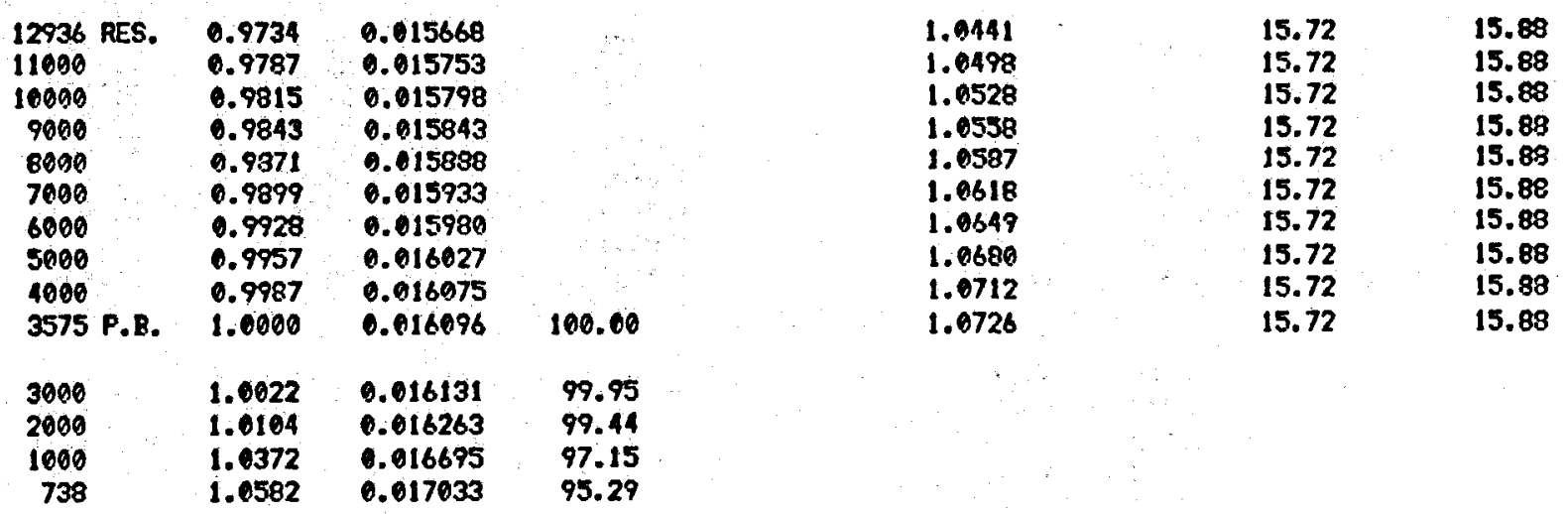

\section{NOTENCLATLRE:}

V/USAT. IS THE VOLUNE OF FLUIDS (OIL AND GAS) AT THE INDICATED TEMPERATURE AND PRESSURE RELATIVE TO THE VOLUTE OF SATURATED OIL AT BUBBLE-POINT PRESSURE AND INDICATED TEMPERATLRE.

Bo IS THE VOLLME OF OIL AT RESERVDIR TEMPERATURE AND INDICATED PRESSURE RELATIVE TO THE VOLLUE OF EQUTVALENT STOCK TANK OIL MEASURED AT 60 DEGREES F.

GAS-OLL RATIO, IS CUBIC FEET OF GAS AT I5.025 PSIA AND 60 DECREES F, PER BARREL OF STOCK TANK OIL AT 60 DEGREES F.

NOTE: BASED ON SEPARATOR WATER FLASH.

REF. TO 'OIL' ABOVE SHWULD READ 'WATER'.

LAB. NO. N1901-10224

PAISE 10 of 25 
TECHNADRIL-FENIX \& SCISSON, INC.

GLADYS MCCALL WELL NO. 1

- east cRaB Lake field

COAPOSITE LABORATORY DATA 298 DEOREES F

RECONBINATION (3) 15.00 SCF SEP. CAS 15.025 PSIA \& 60 'F/BBL. SEP. WATER Q SEP. CONDITIONS.

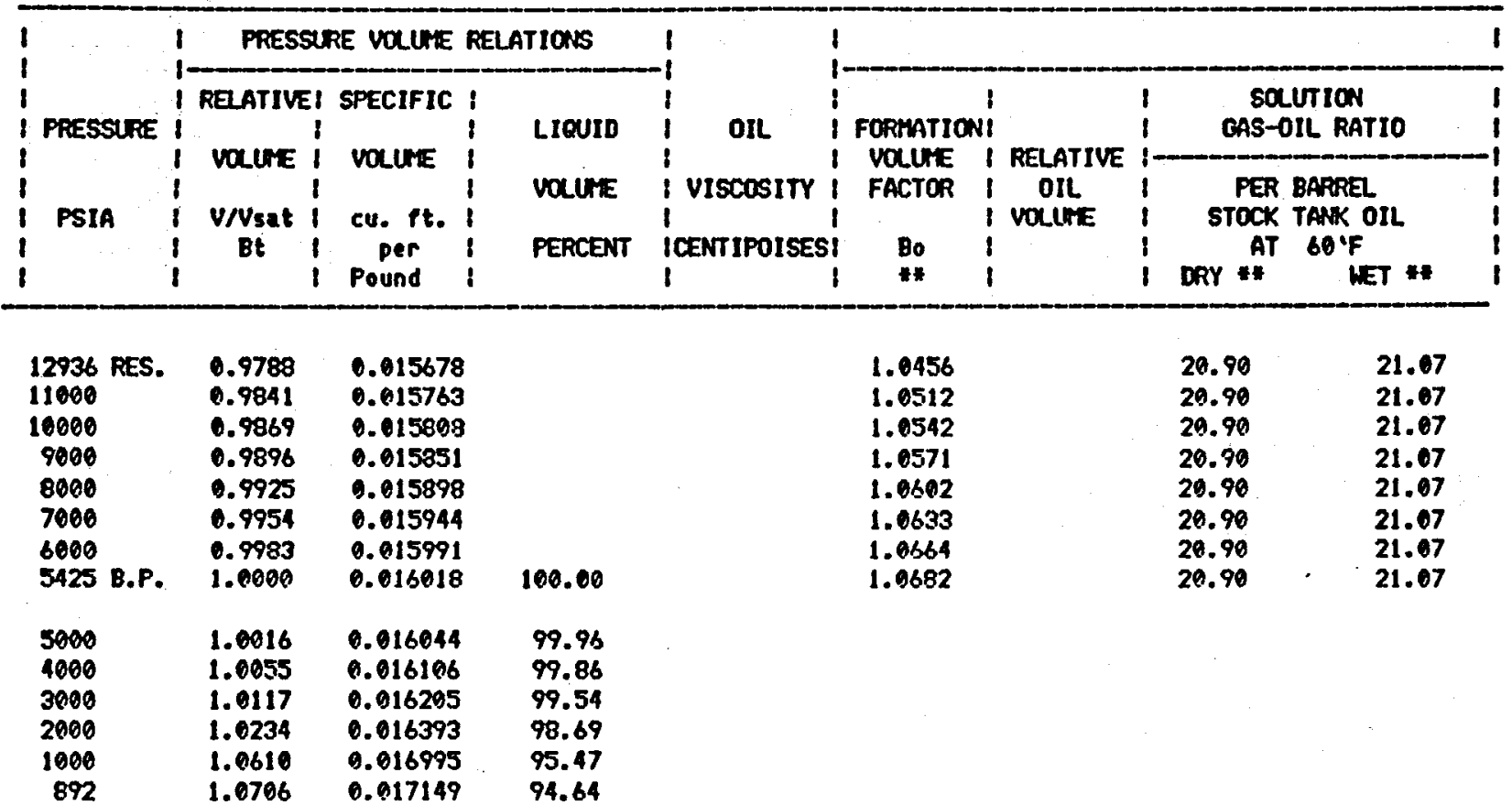

NOHENCLATURE:

VIUSAT. IS THE VOLLRE OF FLUIDS (OIL AND GAS) AT THE INDICATED TEMPERATURE AND PRESSURE RELATIVE TO THE VOUURE OF SATURATED OIL AT BUBBLE-POINT FRESSLRE AND INDICATED TERPERATLRE.

Bo IS THE VOLUME OF OIL AT RESERNOIR TEMFERATURE AND INDICATED PRESSURE RELATIVE TO THE VOLLATE OF EQUIVALENT STOCK TANK OIL reAsLIRED AT 60 DEGREES F.

GAS-OIL RATIO, IS CUBIC FEET OF GAS AT 15.025 PSIA AND 60 DECREES F, PER BARREL OF STCCK TANK OIL AT 60 DECREES F.

NOTE: * BASED ON SEPARATOR WATER FLASH.

REF. TO 'OIL' ABOVE SHOMLD READ 'WATER'. 
FLOW TESTS OF THE GLADYS MCCALL WELL THROUGH OCTOBER 1990

TECHWADRIL-FENIX \& SCISSON, INC. GLADYS MCCALL HELL NO. 1 EAST CRAB LAKE FIELD

EFFECT OF GAS HATER RATIO UPON BUBBLE POINT PRESSURES 2 298'F

GAS-WATER RATIO

(SCF SEP. GAS 2 15.025 PSIA 7 60'F)

(BBL. SEP. HATER \& 700 PSIO \& 212)

* 30.4 extrapolated

24.66 (PRODUCED)

20.00

18.00

15.00

10.00
RUBRLE POINT

(PSIA)

12936 RES. PRESSURE

10030

7720

6755

5425

3575 
TECINADRIL-FENIX \& SCISSON, INC. GLADYS MCCALL WELL ND. 1 EAST CRAB LAKE FIELD

SOLUTION GAS-WATER RATIO, DRY $=5.35$

$$
\text { , WET }=5.50 \text { SCF GAS 15.025 PSIA \& 60'F }
$$

SHRINKAGE

$$
\begin{aligned}
& =0.9637 \text { VOL. 3.T. WATER Q 60'F } \\
& \text { VOL. SEP. H2O } 709 \text { PSIG \& 212'F }
\end{aligned}
$$

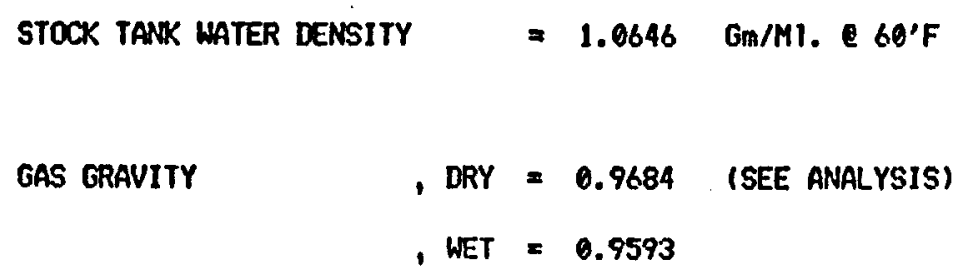

GAS GRAVITY

$$
\begin{aligned}
& \text { DRY }=0.9684 \quad \text { (SEE ANALYSIS) } \\
& \text { WET }=0.9593
\end{aligned}
$$

PRODUCED MARCH 23, 1983:

$$
\begin{aligned}
& \text { GWR }=25.56+5.35=30.91 \quad \frac{\text { SCF TOTAL DRY GAS } 15.025 \text { PSIA \& 60'F }}{\text { BBL. STOCK TAIK WATER G9'F }} \\
& \text { GRR }=25.59+5.50=31.09 \quad \frac{\text { SCF TOTAL WET GAS } 15.025 \text { PSIA \& 60'F }}{\text { BBL. STOCK TANK WATER 60'F }}
\end{aligned}
$$


TECHNADRIL-FENIX \& SCISSON, INC. CLADYS MCCALL WELL NO. 1 EAST CRAB LAKE FIELD

\section{SEPARATOR GAS SATLED: \\ MARCH 23, 1983 \\ 700 PSIO \& 724 \\ CHROMATOCRAPHIC ANALYSIS}

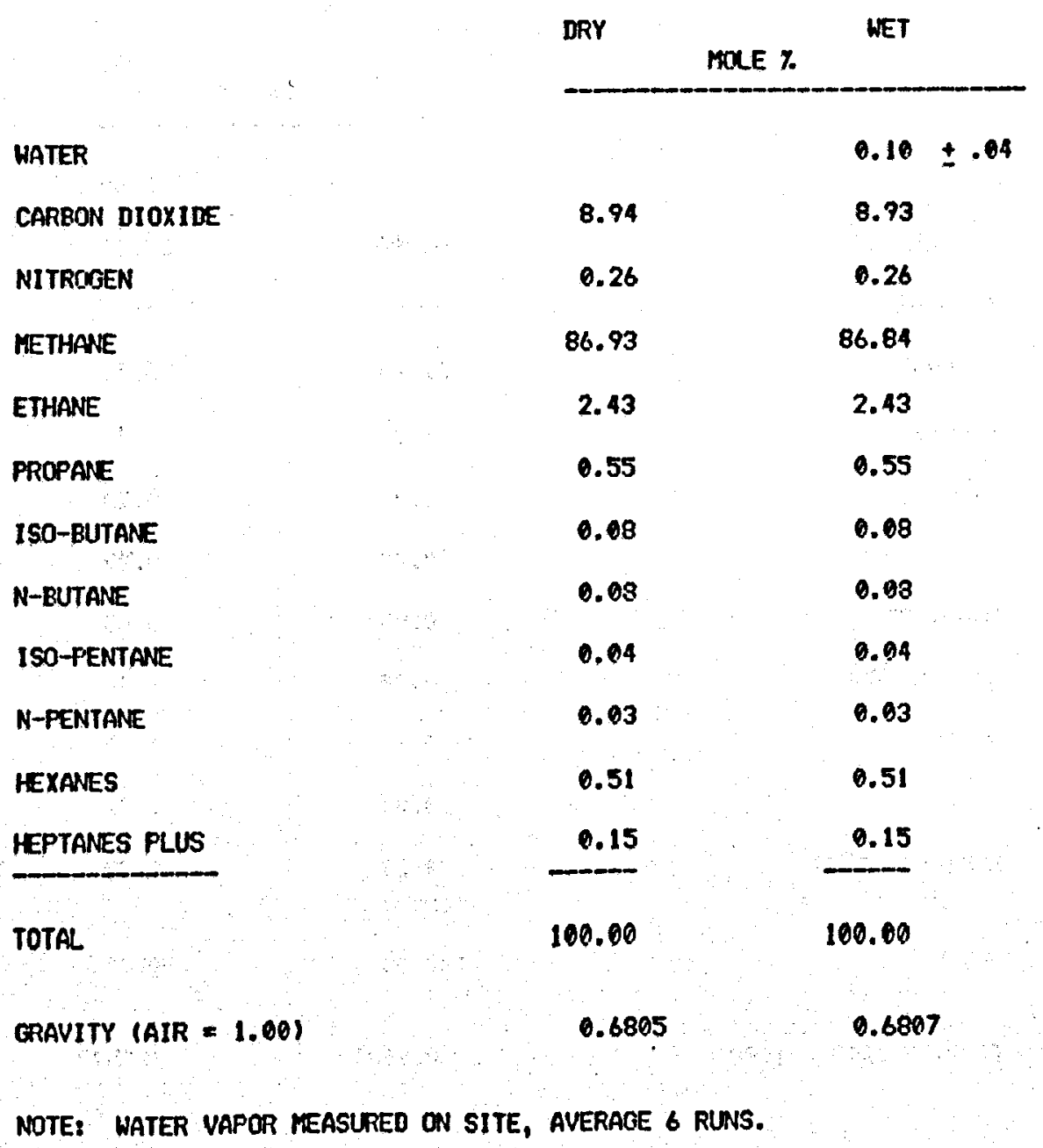

LAB. NO, N1901-10224

PAGE 14 OF 25 
TECHNARRIL-FENIX * SCISSON, INC. GLADYS MCCALL HELL NO. 1 EAST CRAB LAKE FIELD

SOUUTION GAS FROM

SEPARATOR WATER FLASH

C PSIG \& 72'F

(CALCLLATED NITROOEN FREE)

CHROMATOCRAPHIC ANALYSIS

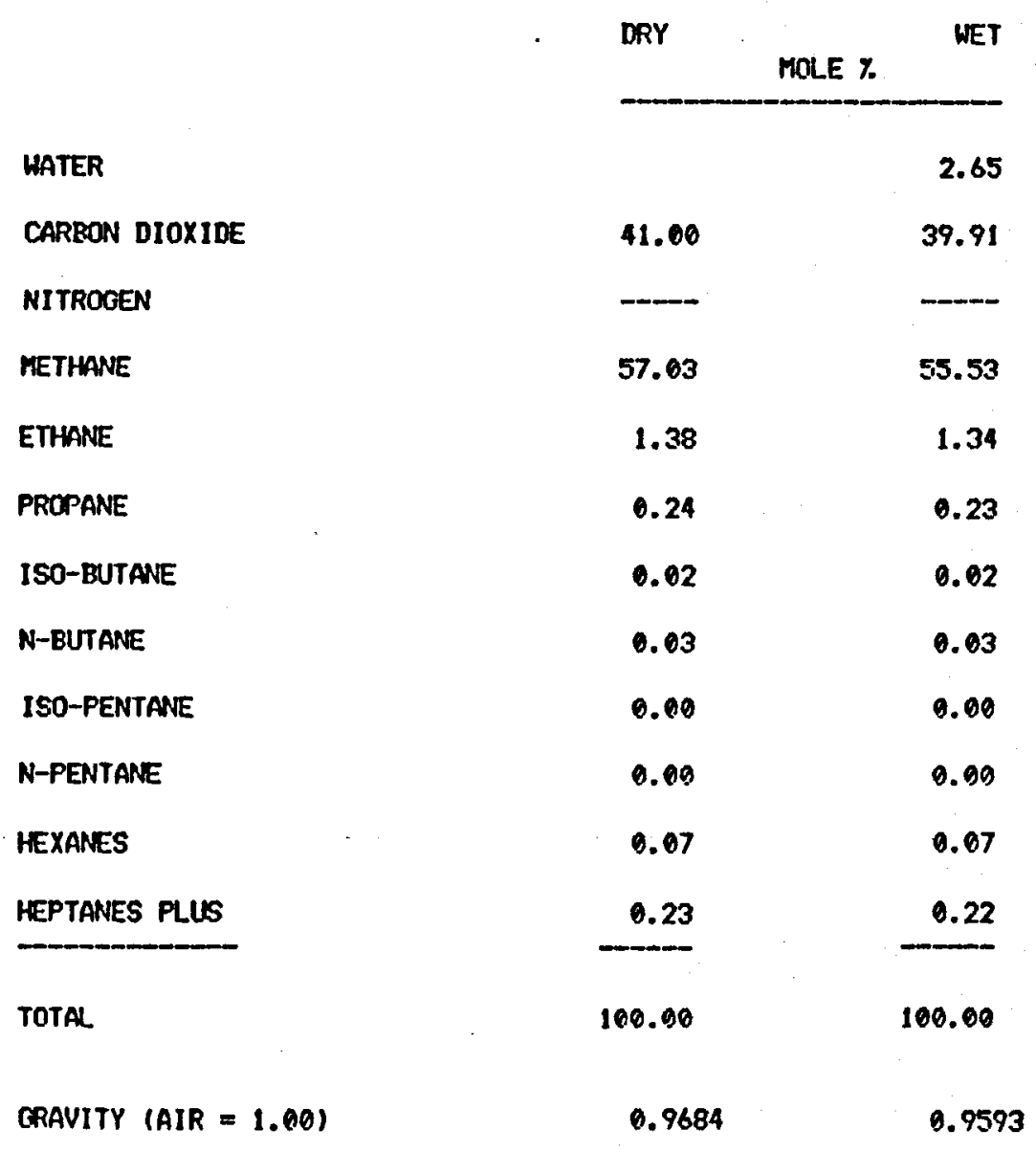

LAB. ND. N1991-19224

PAGE 15 OF 24

B-1 8 
Flow TESTS OF THE GLADYS MCCALL WeLl THROUgh OCTOBER 1990

TECHNADRIL-FENIX SCISSON, INC. GLADYS MCCALL WELL MO. I EAST CRAB LAKE FIELD

\section{SOLUTION CAS FROH 6000 PSIA SAMPLE - DIFFERENITAL LIBERATION (CALCULATED NITROGEN FREE) \\ CHROMATOGRAPHIC ANALYSIS}

\begin{tabular}{|c|c|c|}
\hline & DRY & WET \\
\hline WATER & & 2.00 \\
\hline CARBON DIOXIDE & 2.82 & 2.76 \\
\hline NITROGEN & $\cdots$ & $\cdots$ \\
\hline METHAME & 89.56 & 87.77 \\
\hline ETHANE & 4.00 & 3.92 \\
\hline PROPANE & 1.37 & 1.34 \\
\hline 150-BUTANE & 0.26 & 0.25 \\
\hline N-Dutane & 0.25 & 0.25 \\
\hline 150-PENTANE & 0.10 & 0.10 \\
\hline N-PENTANE & 0.97 & 9.07 \\
\hline HEXANES & 1.24 & 1.22 \\
\hline HEPTANES PLUS & 0.33 & 0.32 \\
\hline TOTAL & 100.00 & 100.00 \\
\hline GRAVITY LAIR $=1.001$ & 0.6648 & 0.6640 \\
\hline
\end{tabular}

LAB, NO. N1901-10224

FAGE 16 OF 25

B-19 
TECHNADRIL-FENIX \& SCISSON, INC. GLADYS MCCALL WELL NO. I EAST CRAB LAKE FIELD

SQUUTION GAS FROH 4000 PSIA SAMPLE DIFFERENITAL LIBERATION (CALCURATED NITROGEN FREE)

ChrOMATDORAPHIC aNALYSIS

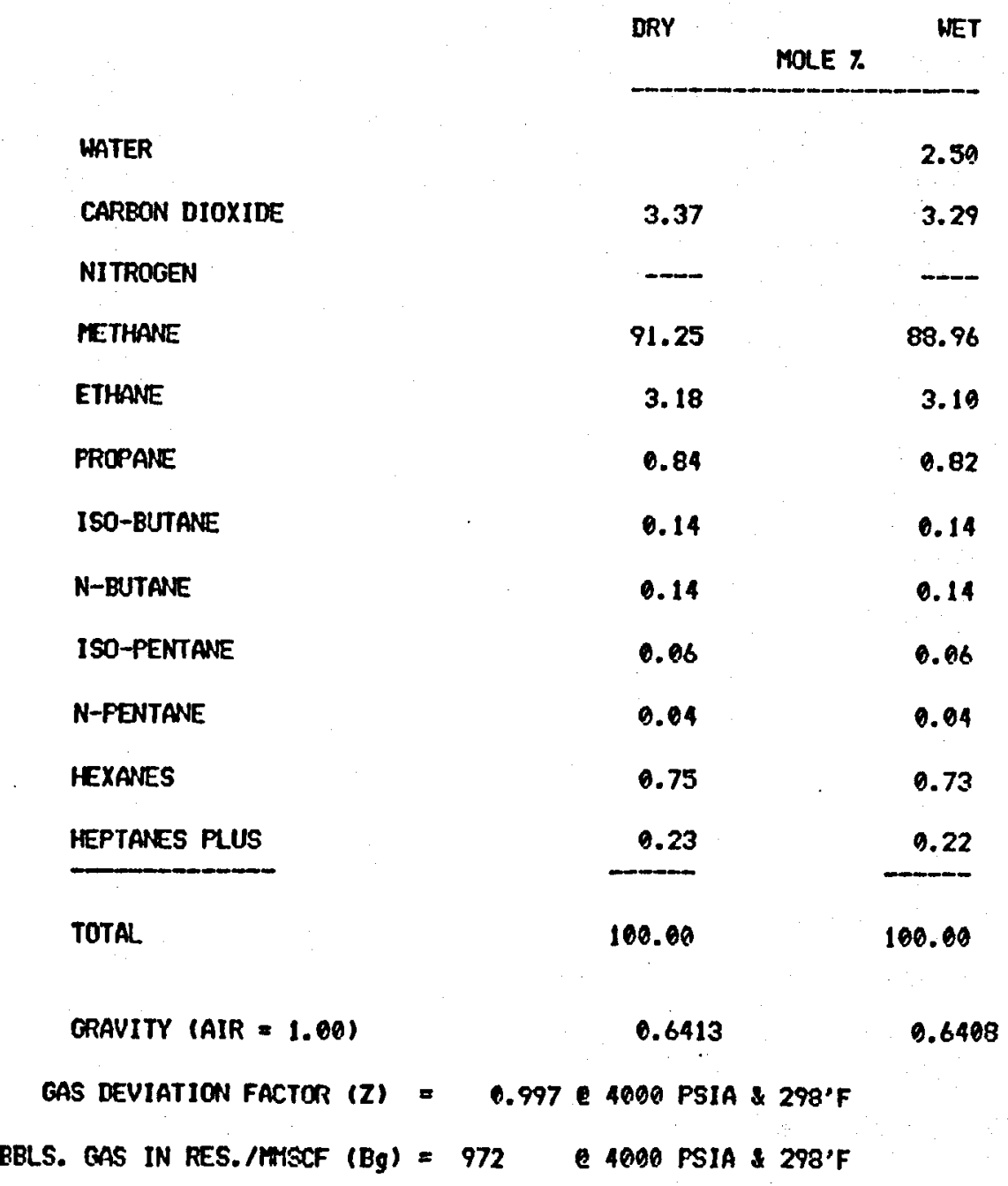

LAB. NO. N1901-19224

PAGE 17 OF 25

B-20 
FLOW TESTS OF THE GLADYS MCCALL Well THROUGH OCTOBER 1990

TECINAORIL-FENIX \& SC.ISSON, INC.

GLADYS MCCALL WELL NO. 1

EAST CRAB LAKE FIELD

SOUUTION GAS FROM

2000 PSIA SATPLE -

DIFFERENITAL LIBERATION

(CALCULATED NITROCEN FREE)

CHROHATOGRAPHIC ANALYSIS

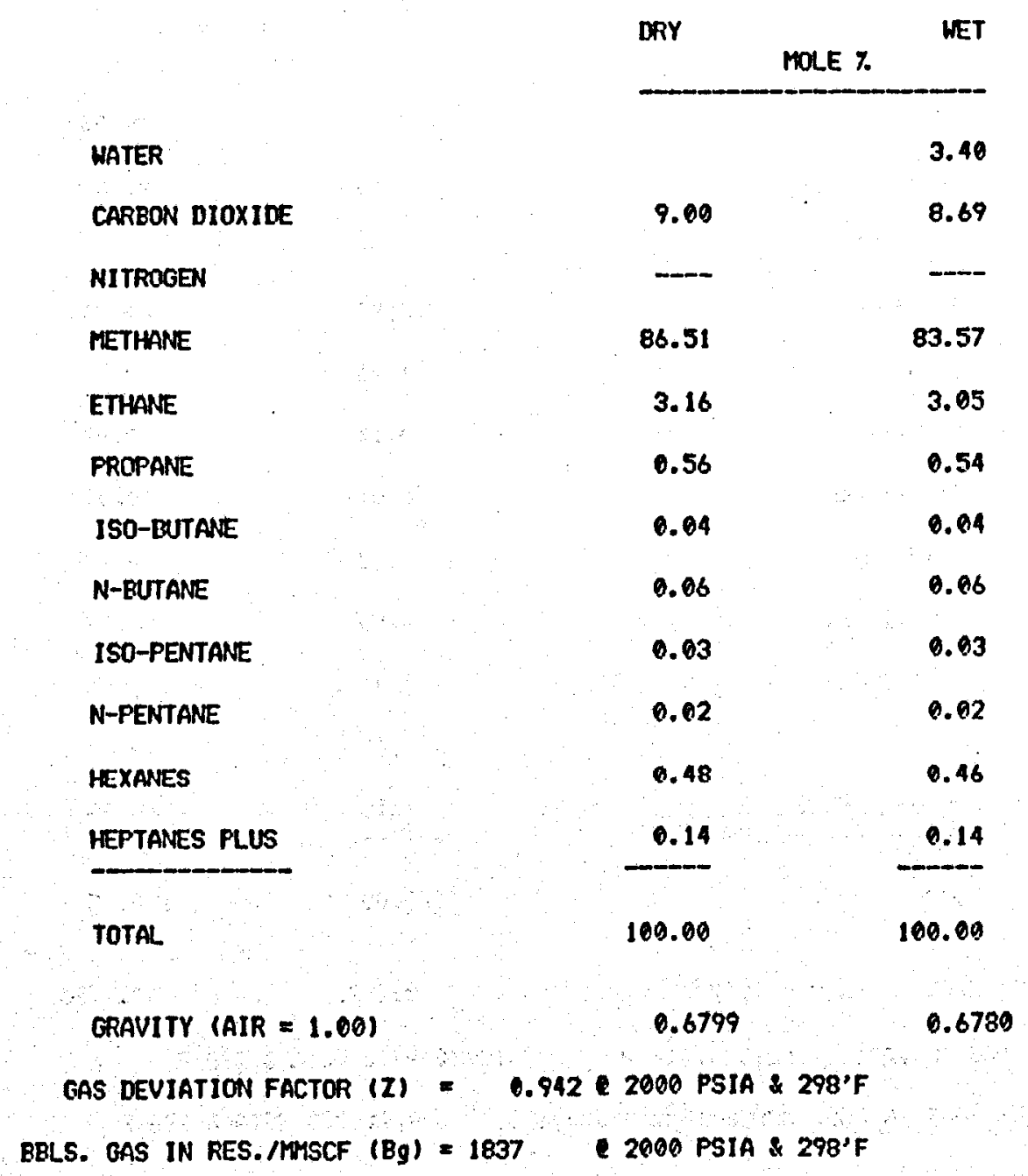

LAB. NO. N1901-10224

PAGE 18 of 25

B-2 1 
TECHMARIL-FENIX \& SCISSON, INC. GLADYS MCCALL NELL MO. I EAST CRAB LARE FIELD

SOUUTION GAS FROH

15 PSIA SAMPLE -

DIFFERENITAL LIBERATION

(CALCULATED NITROGEN FREE)

ChromatographIC ANALYSIS

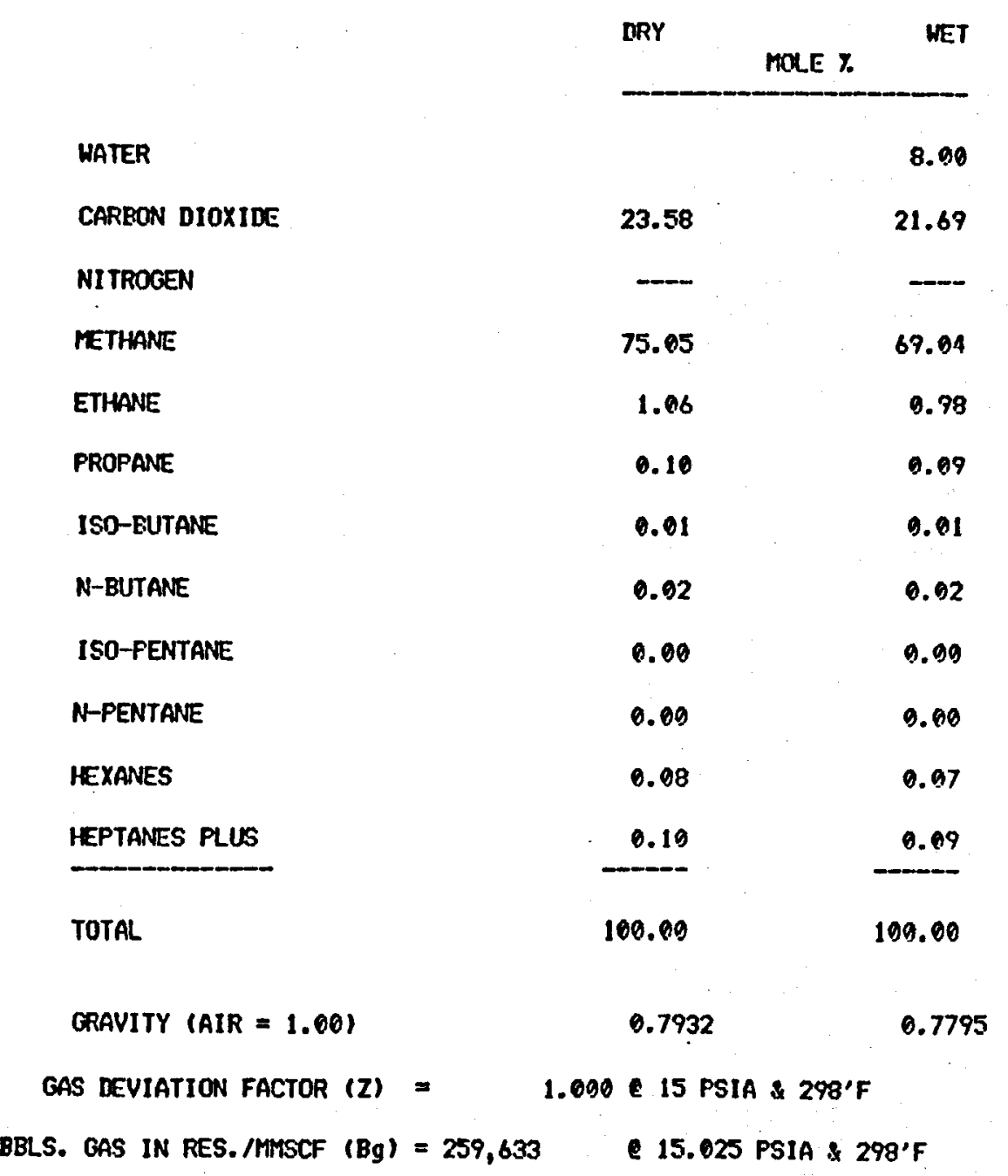

LAB. NO. N1901-10224

PAGE 19 of 25

B-22
I N S T I T U T E
O F
G A S
T E C H N O L O 
FLOW TESTS OF THE GLAdys MCCall Well ThROUgh OCTOBER 1990

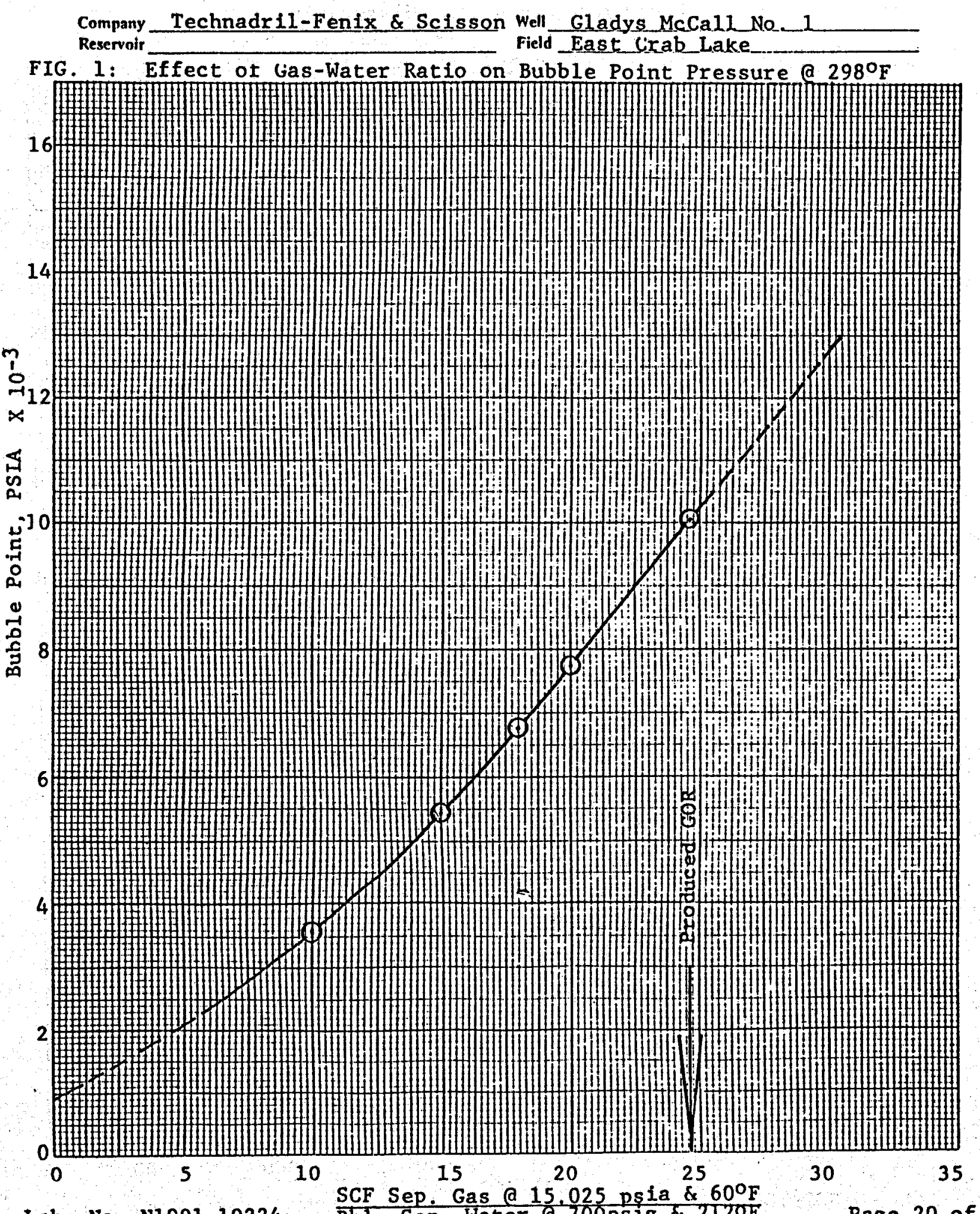

Lab. No. N1901-10224 $\frac{\text { SCF Sep. Gas a } 15.025 \text { psia \& } 60^{\circ} \mathrm{F}}{\text { Bb1. Sep. Water C.700psig \& } 2120 \mathrm{~F}}$

Page 20 of 25 
FLOW TESTS OF the Gladys MCCALL WeLl THROUgh OCTOBER

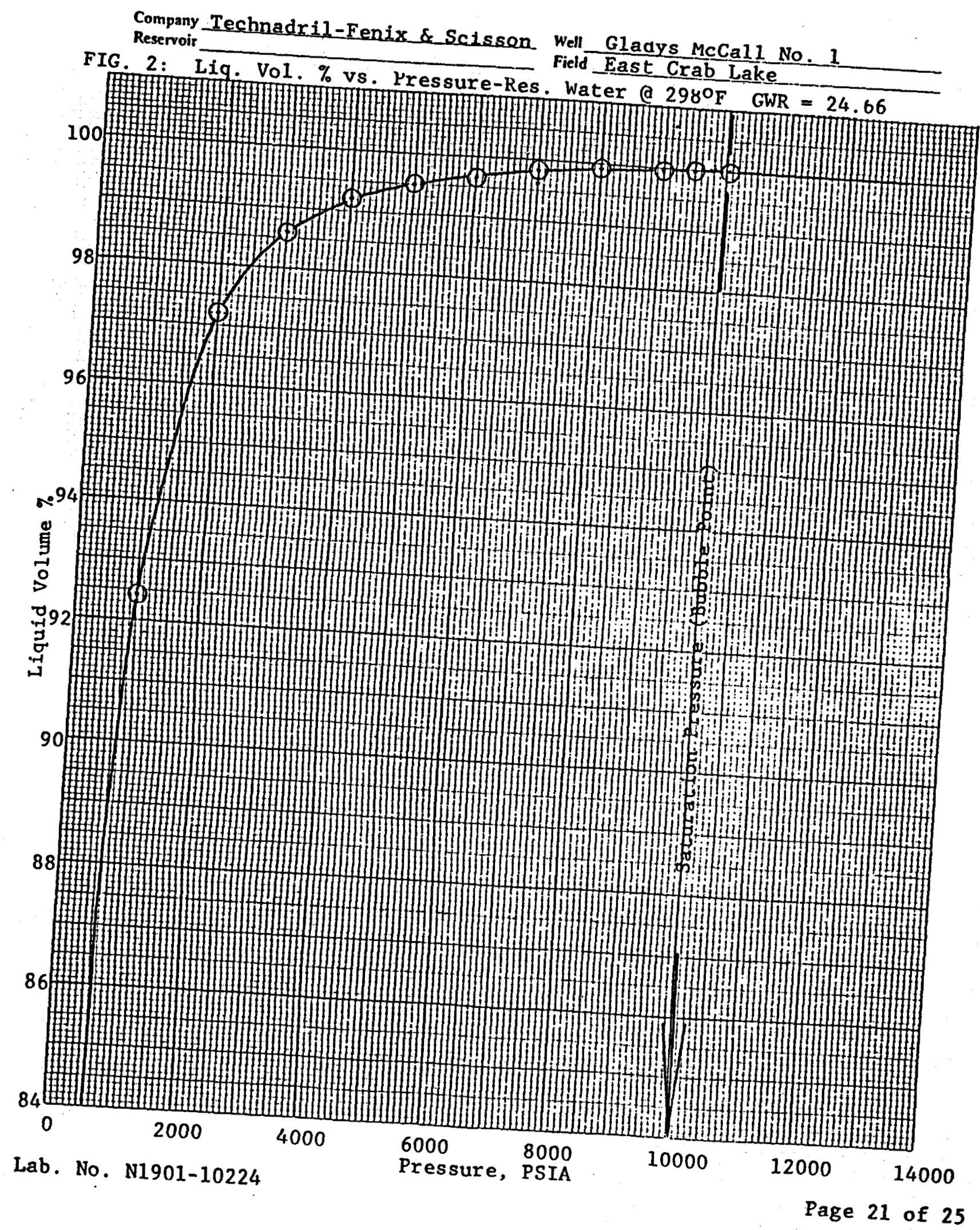

B-24

I N S T I T U T

O F G A S

TE C H NOL O O G Y 


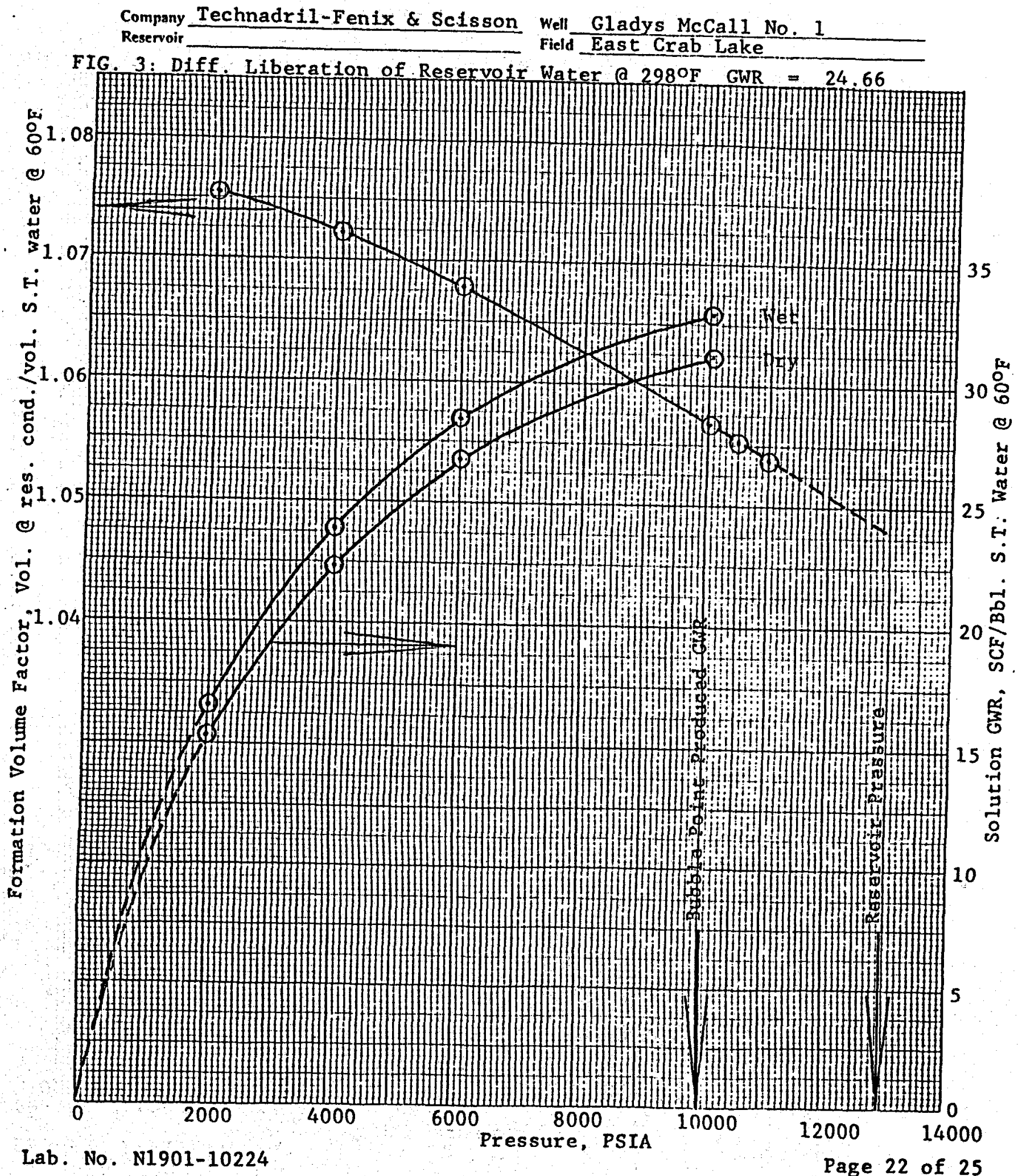


Flow Tests of the Gladys MCCall Well Through OCtober 1990

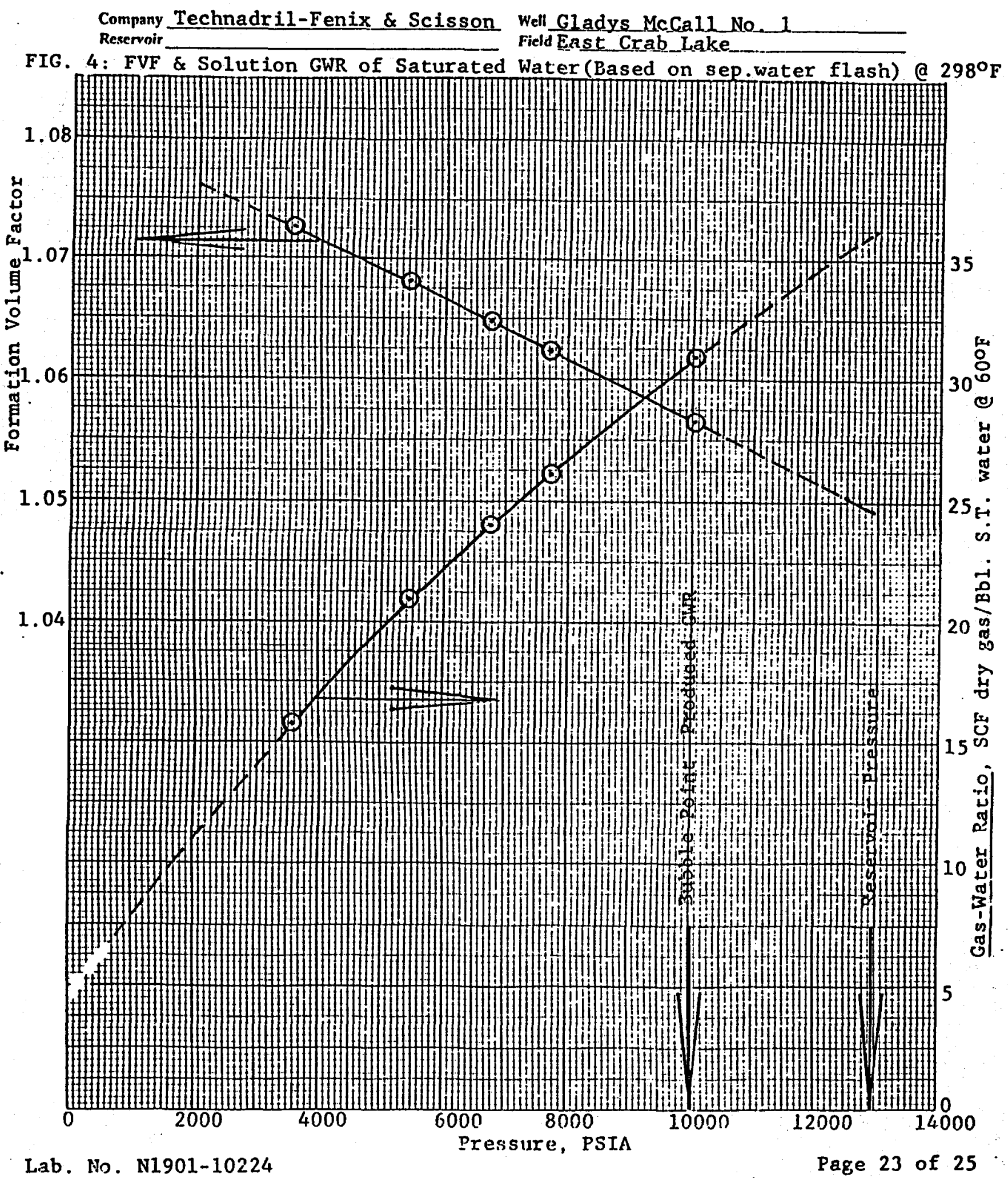


FLOW TESTS OF THE GLADYS MCCALL WELL THROUGH OCTOBER 1990

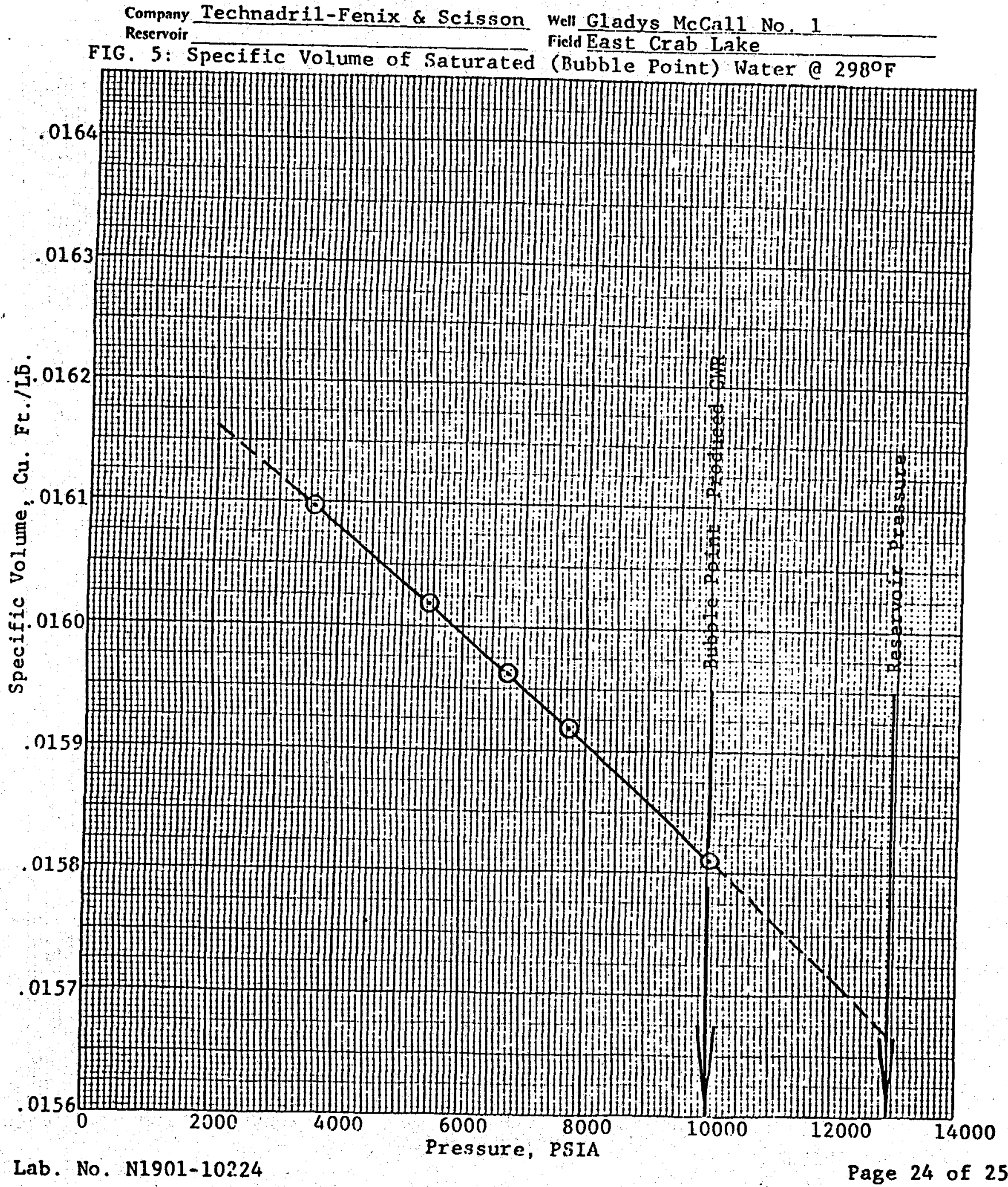


Flow tests of the Gladys MCCALl Well Through OCtober 1990

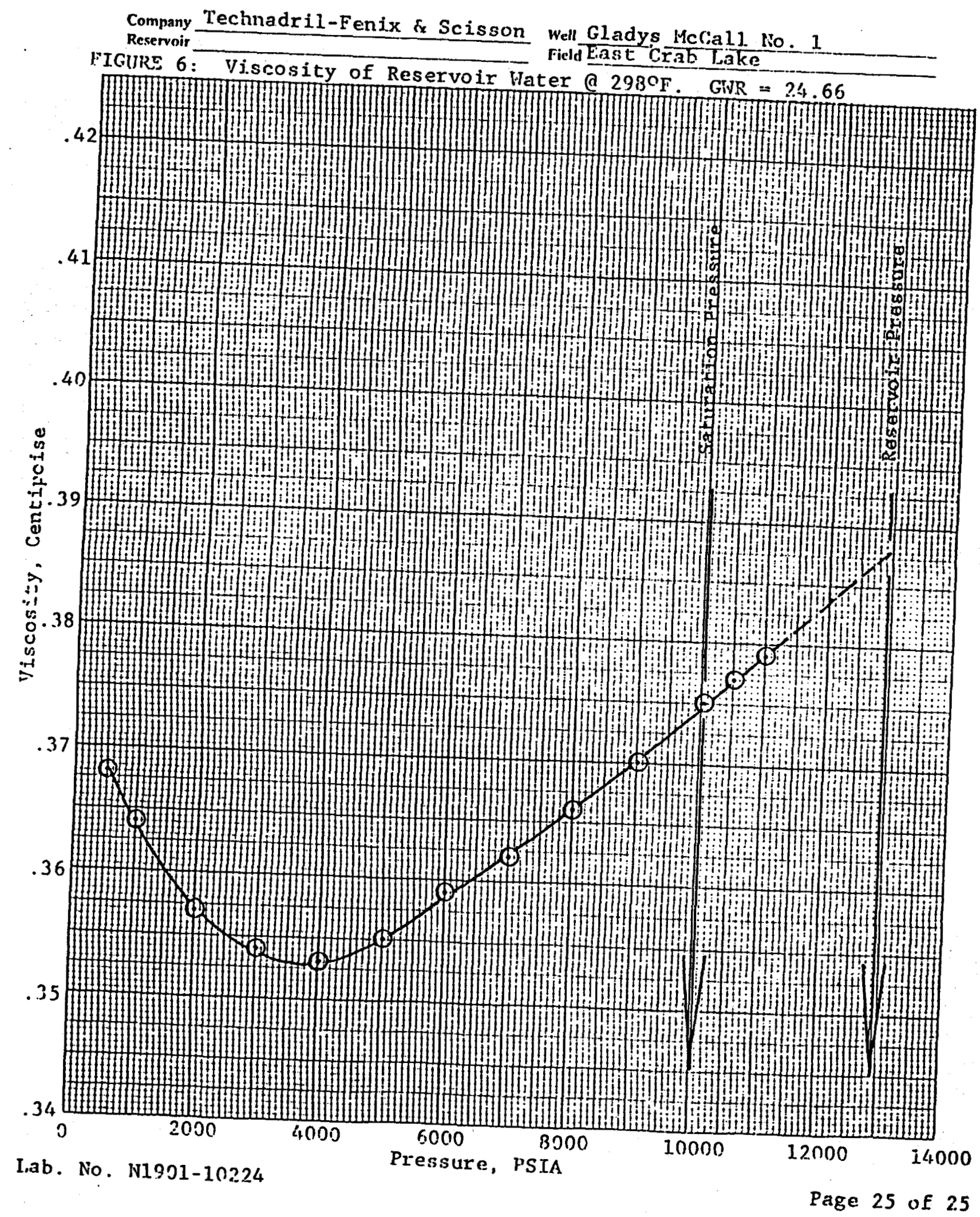

B-28 
FLOW TESTS OF THE GLADYS MCCALL WELL THROUGH OCTOBER 1990

\section{APPENDIX C}

Sand 8 Daily Production Data

\section{C-1}




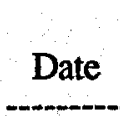

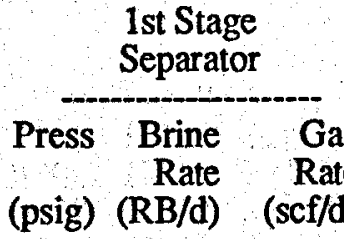

1-Dec-83

$1007 \quad 15491335317$

4-Dec-83 $1013 \quad 15421339631$

$\begin{array}{llll}5-\text { Dec-83 } & 1017 & 15455 & 339631\end{array}$

6-Dec-83 $\quad 770 \quad 15646 \quad 348769$

$\begin{array}{lllll}7-\text { Dec-83 } & 772 & 15659 & 355228\end{array}$

$\begin{array}{llll}8-D e c-83 & 754 & 15742 & 355228\end{array}$

$\begin{array}{lllll}\text { 9-Dec-83 } & 750 & 16231 & 389482\end{array}$

$\begin{array}{llll}10-D e c-83 & 500 & 1358 & 56861\end{array}$

11-Dec-83 $501 \quad 13902 \quad 399868$

12-Dec-83 $502 \quad 15849396195$.

13-Dec-83 $501 \quad 15837399868$

14-Dec-83 $504 \quad 15819394675$

15-Dec-83 $\quad 502 \quad 15884 \quad 446651$

16-Dec-83 $\quad 254 \quad 15918 \quad 449233$

17-Dec-83 - $254 \quad 15899 \quad 449233$

18-Dec-83 $254 \quad 15851 \quad 448533$

19-Dec-83 $1018 \quad 18024 \quad 448533$

20-Dec-83 $1018 \quad 22284 \quad 538300$

21-Dec-83 100826482620980

22-Dec-83 100124826595074

23-Dec-83 $1011 \quad 24055 \quad 693329$

24-Dec-83 $1008 \quad 27244634296$

25-Dec-83 $990 \quad 3634 \quad 0$

26-Dec-83

27-Dec-83

28-Dec-83

29-Dec-83

$\begin{array}{rrrr}30-\text { Dec-83 } & 0 & 0 & 0 \\ 31-\text { Dec-83 } & 1002 & 10595 & 434624\end{array}$

\section{2nd Stage \\ Sales Max Surface Brine \\ Gas \\ Pressure \\ Prod Disp \\ Rate}

Press Rate

(psig) (scf/d)

Well Well

1st 2nd Disp
Stage Stg Well

(scf/d) (psig) (psig) (stb/d) (sc//stb)(scf/stb)(sc//stb) (psia) (scf/d)

0
0
0
0
0
0
0
0
0
0
0
0
0
0
0
0
0
0
0
0
0
0
0
0
0
0
0
0
0
0
0

5800
5200
5200
5200
5200
5423
5424
5386
5370
5274
5270
526
5253
5226
5225
521
5209
5192
5218
4968
434
4620
3905
3645

0

$\begin{array}{lllll}0.00 & 0.00 & 0 & 0 & 0\end{array}$

\begin{tabular}{lll}
177 & 12014 \\
\hline & 2 &
\end{tabular}

\begin{tabular}{lll}
183 & 14525 \\
\hline
\end{tabular}

$\begin{array}{lllll}27.91 & 27.91 & 33.17 & 12177 & 398504\end{array}$

$\begin{array}{lllll}23.38 & 23.38 & 28.58 & 12300 & 415125\end{array}$

$\begin{array}{llllll}23.49 & 23.49 & 28.72 & 12297 & 415291\end{array}$

$\begin{array}{lllll}23.44 & 23.44 & 28.69 & 12299 & 415775\end{array}$

$\begin{array}{llllll}23.79 & 23.79 & 27.85 & 12535 & 408253\end{array}$

196

19614659

19514671

$205 \quad 14748$

$\begin{array}{lllll}24.21 & 24.21 & 28.28 & 12537 & 414896\end{array}$

$\begin{array}{lllll}24.09 & 24.09 & 28.07 & 12502 & 413976\end{array}$

$\begin{array}{lllll}25.61 & 25.61 & 29.57 & 12508 & 449641\end{array}$

$\begin{array}{rrrrrrrr}5274 & 128 & 1271 & 44.73 & 44.73 & 47.44 & 11956 & 60296\end{array}$

$\begin{array}{lll}5270 & 128 & 13012\end{array}$

$\begin{array}{lllll}30.73 & 30.73 & 33.44 & 12293 & 435121\end{array}$

$\begin{array}{llllll}26.71 & 26.71 & 29.43 & 12381 & 436594\end{array}$

$\begin{array}{ll}133 & 14824 \\ 136 & 14807\end{array}$

\begin{tabular}{lllll}
26.98 & 26.98 & 29.69 & 12368 & 440125 \\
\hline
\end{tabular}

$\begin{array}{lllll}26.65 & 26.65 & 29.38 & 12340 & 435030\end{array}$

31614868

$\begin{array}{lllll}30.04 & 30.04 & 32.76 & 12338 \quad 487076\end{array}$

13514886

$\begin{array}{llllll}30.18 & 30.18 & 31.61 & 12334 & 470546\end{array}$

$\begin{array}{lllll}30.21 & 30.21 & 31.65 & 12323 & 470604\end{array}$

$146 \quad 14824$

$\begin{array}{lllll}30.26 & 30.26 & 31.69 & 12303 & 469773\end{array}$

19216901

$\begin{array}{lllll}26.54 & 26.54 & 31.79 & 12444 & 537283\end{array}$

$\begin{array}{lllllllll}4968 & 218 & 20895 & 25.76 & 25.76 & 31.02 & 12449 & 648163\end{array}$

\begin{tabular}{lllll}
4544 & 251 & 24831 \\
\hline & 25 & &
\end{tabular}

$\begin{array}{lllll}25.01 & 25.01 & 30.21 & 12324 & 750145\end{array}$

25023278

$\begin{array}{lllll}25.56 & 25.56 & 30.74 & 12008 & 715566\end{array}$

$\begin{array}{llllll}30.74 & 30.74 & 35.96 & 12209 & 811078\end{array}$

$3905 \quad 250-25545$

$\begin{array}{llllll}24.83 & 24.83 & 30.04 & 11733 & 767372\end{array}$

$\begin{array}{llll}3645 & 250 & 3407\end{array}$

$\begin{array}{llrrr}0.00 & 0.00 & 5.12 & 10354\end{array}$

7444

0
0
0
0
0

$0.00 \quad 0.00$

0

$0.00 \quad 0.00$

$0.00 \quad 0.00$

$\begin{array}{rrrrrr}0 & 0.00 & 0.00 & 0 & 0 & 0 \\ 34 & 43.75 & 43.75 & 48.93 & 12501 & 486071\end{array}$

00

9934 
$$
\text { 11-Jan-84 }
$$

12-Jan-84

ค ? 13-Jan-84

$>\quad$ 14-Jan-84

16-Jan-84

17-Jan-84

18-Jan-84

19-Jan-84

20-Jan-84

21-Jan-84

22-Jan-84

23-Jan-84

24-Jan-84

25-Jan-84

26-Jan-84

27-Jan-84

28-Jan-84

29-Jan-84

30-Jan-8
31-Jan-84

\begin{tabular}{cc}
\multicolumn{1}{c}{$\begin{array}{c}\text { 1st Stage } \\
\text { Separator }\end{array}$} \\
\hdashline Press & $\begin{array}{c}\text { Brine } \\
\text { Rate }\end{array}$ \\
(psig) & $\begin{array}{c}\text { Gas } \\
\text { Rate }\end{array}$ \\
(RB/d) & (sc/d)
\end{tabular}

2nd Stage Separato Gas

Press Rate

$\begin{array}{lll}1005 & 28175 & 653256\end{array}$

$\begin{array}{lll}1009 & 29830 & 647273\end{array}$

$1005 \quad 29532 \quad 642720$

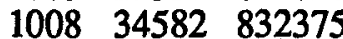

$1004 \quad 34153 \quad 798543$

$\begin{array}{lll}760 & 30862 & 799515\end{array}$

$\begin{array}{llll}756 & 18363 & 462563\end{array}$

$\begin{array}{llll}763 & 34804 & 826165\end{array}$

$\begin{array}{ll}760 & 34235 \\ 816488\end{array}$

$\begin{array}{lll}768 & 32362 \quad 805183\end{array}$

$\begin{array}{lll}760 & 33217 & 791612\end{array}$

$\begin{array}{lll}763 & 26331 & 787089\end{array}$

$\begin{array}{llll}756 & 16098 & 488538\end{array}$

$\begin{array}{llll}776 & 15229 & 370673\end{array}$

$\begin{array}{llll}757 & 12606 & 361687\end{array}$

$\begin{array}{llll}799 & 10895 & 358108\end{array}$

$\begin{array}{llll}778 & 15487 & 364390\end{array}$

$\begin{array}{llll}805 & 15356 & 364390\end{array}$

$\begin{array}{lll}787 & 15403 & 364390\end{array}$

$\begin{array}{llll}502 & 1245 & 31498\end{array}$

$\begin{array}{lll}757 & 12885 & 329211\end{array}$

$\begin{array}{lll}761 & 15405 & 369393\end{array}$

$\begin{array}{lll}769 & 15379 & 380097\end{array}$

$\begin{array}{lll}1001 & 15180 & 332987\end{array}$

$1004 \quad 15151 \quad 335940$

100415164335940

$1007 \quad 15117.329328$

$1006 \quad 15149 \quad 331591$

$\begin{array}{llll}1008 & 15124 & 331591\end{array}$

$\begin{array}{rrrr}15118 & 316688 \\ 0 & 0 & 0\end{array}$ (psig) (scf/d)

0
0
0
0
0
0
0
0
0
0
0
0
0
0
0
0
0
0
0
0
0
0
0
0
0
0
0
0
0
0
0

Sales Max Surface Brine

Pressure Rate

Prod Disp

Well Well

$\begin{array}{rrr}1 \text { st } & \text { 2nd Disp } \\ \text { Stage } & \text { Stg Well }\end{array}$

$\begin{array}{llll}\text { Calc } & \text { Perf } & \text { Cum } & \text { Cum } \\ \text { BHP } & \text { Gas } & \text { Gas } & \text { Brine }\end{array}$

(psig) (psig) (stb/d) (scf/stb)(scf/stb)(scf/stb) (psia) (scf/d)

(scf)

(stb)

12560173

$\begin{array}{llllllll}4509 & 297 & 26418 & 24.73 & 24.73 & 29.92 & 12426 & 790427\end{array}$

$\begin{array}{lllllllll}3382 & 316 & 27970 & 23.14 & 23.14 & 28.35 & 11421 & 792950\end{array}$

$\begin{array}{lllllllll}3379 & 321 & 27691 & 23.21 & 23.21 & 28.4 & 11392 & 786424\end{array}$

$\begin{array}{llllllll}3367 & 383 & 32426 & 25.67 & 25.67 & 30.88 & 11862 & 1001315\end{array}$

$\begin{array}{lllllllll}2103 & 381 & 32023 & 24.94 & 24.94 & 30.12 & 10527 & 964533\end{array}$

$\begin{array}{llllllll}2880 & 384 & 28913 & 27.65 & 27.65 & 31.66 & 10996 & 915386\end{array}$

$\begin{array}{lllllllll}5543 & 314 & 17203 & 26.89 & 26.89 & 30.88 & 12795 & 531229\end{array}$

$\begin{array}{lllllllll}1570 & 328 & 32607 & 25.34 & 25.34 & 29.36 & 10046 & 957342\end{array}$

$\begin{array}{lllllllll}1532 & 340 & 32073 & 25.46 & 25.46 & 29.47 & 9947 & 945191\end{array}$

$\begin{array}{lllllllll}1504 & 349 & 30319 & 26.56 & 26.56 & 30.6 & 9727 & 927761\end{array}$

$\begin{array}{lllllllll}1464 & 356 & 31119 & 25.44 & 25.44 & 29.45 & 9773 & 916455\end{array}$

$\begin{array}{lllllllll}1434 & 363 & 24669 & 31.91 & 31.91 & 35.93 & 9095 & 886357\end{array}$

$\begin{array}{lllllllll}4688 & 227 & 15081 & 32.39 & 32.39 & 36.38 & 11790 & 548647\end{array}$

$\begin{array}{llllllllll}4688 & 186 & 14268 & 25.98 & 25.98 & 30.07 & 11762 & 429039\end{array}$

$\begin{array}{llllllllll}5457 & 194 & 11810 & 30.63 & 30.63 & 34.62 & 12429 & 408862\end{array}$

$\begin{array}{lllllllll}5435 & 136 & 10208 & 35.08 & 35.08 & 39.28 & 12332 & 400970\end{array}$

$\begin{array}{lllllllll}4519 & 143 & 14510 & 25.11 & 25.11 & 29.21 & 11603 & 423837\end{array}$

$\begin{array}{llllllll}4511 & 150 & 14389 & 25.32 & 25.32 & 29.55 & 11588 & 425195\end{array}$

$\begin{array}{lllllllll}4509 & 151 & 14432 & 25.25 & 25.25 & 29.39 & 11588 & 424156\end{array}$

$\begin{array}{lllllllll}5425 & 146 & 1165 & 27.03 & 27.03 & 29.75 & 12154 & 34659\end{array}$

$\begin{array}{llllllll}5370 & 158 & 12071 & 27.27 & 27.27 & 31.27 & 12357 & 377460\end{array}$

$\begin{array}{llllllll}4506 & 159 & 14432 & 25.59 & 25.59 & 29.61 & 11585 & 427332\end{array}$

$\begin{array}{lllllllll}4511 & 154 & 14408 & 26.38 & 26.38 & 30.43 & 11587 & 438435\end{array}$

$\begin{array}{lllllllll}4586 & 159 & 14233 & 23.40 & 23.40 & 28.57 & 11658 & 406637\end{array}$

$\begin{array}{lllllllll}4526 & 161 & 14206 & 23.65 & 23.65 & 28.84 & 11595 & 409701\end{array}$

$\begin{array}{lllllllll}4511 & 165 & 14218 & 23.63 & 23.63 & 28.81 & 11581 & 409621\end{array}$

$\begin{array}{lllllllll}4512 & 173 & 14174 & 23.23 & 23.23 & 28.44 & 11580 & 403109\end{array}$

$\begin{array}{lllllllll}4500 & 175 & 14204 & 23.34 & 23.34 & 28.54 & 11569 & 405382\end{array}$

$\begin{array}{llllllll}4490 & 186 & 14181 & 23.38 & 23.38 & 28.59 & 11558 & 405435\end{array}$

$\begin{array}{llllllll}4489 & 190 & 14175 & 22.34 & 22.34 & 27.54 & 11558 & 390380\end{array}$

13353123

14139547

15140862

16105395

17020780

17552009

18509351

19454542

20382303

21298758

22185115

22733762

23162801

23571663

23972633

24396470

24821665

25245821

25280480

25657940

26085272

26523707

26930344

27340045

27749666

28152774

28558157

28963591

29353971

29353971 
\begin{tabular}{cccc}
$\begin{array}{c}\text { 2nd Stage } \\
\text { Separator }\end{array}$ & $\begin{array}{c}\text { Sales } \\
\text { Gas }\end{array}$ & $\begin{array}{c}\text { Max Surface } \\
\text { Pressure }\end{array}$ & $\begin{array}{c}\text { Brine } \\
\text { Rate }\end{array}$ \\
\hdashline Gas & & $\begin{array}{c}\text { Prod Disp } \\
\text { Press Rate }\end{array}$ & Well Well
\end{tabular} Cum Gas/Brine
Ratios 1st 2nd Disp Stage Stg Well

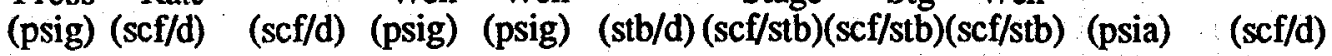
(psig) (RB/d) (scf/d)

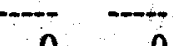

$1-$ Feb-84

2-Feb-84

3-Feb-84

$1004 \quad 13614 \quad 353691$

$\begin{array}{llll}1005 & 18701 & 435615\end{array}$

$1005 \quad 23435 \quad 519336$

$\begin{array}{lll}1014 & 22810 & 516831\end{array}$

$\begin{array}{llll}5-F e b-84 & 1001 & 21999 & 468839\end{array}$

6-Feb-84:1002 $21904 \quad 475696$

$\begin{array}{llll}7-F e b-84 & 1003 & 24520 & 526924\end{array}$

8-Feb-84 $\quad 1003 \quad 24681 \quad 520522$

9-Feb-84 $1005 \quad 20646516831$

10-Feb-84 $1005 \quad 20169428231$

11-Feb-84 $503 \quad 8595 \quad 230775$

12-Feb-84 $504 \quad 20588 \quad 512408$

13-Feb-84 $505 \quad 20539 \quad 476552$

14-Feb-84 $505 \quad 24131 \quad 654804$

15-Feb-84 $506 \quad 24867 \quad 643891$

16-Feb-84 $505 \quad 24965 \quad 643891$

17-Feb-84 $\quad 518 \quad 27806 \quad 756046$

18-Feb-84 50628936751456

19-Feb-84 $506 \quad 28466 \quad 741556$

20-Feb-84 $507 \quad 28000 \quad 731563$

21-Feb-84

$507 \quad 28000731563$

22-Feb-84

23-Feb-84

24-Feb-84

25-Feb-84 $1007 \quad 9109 \quad 205499$

26-Feb-84 $1006 \quad 15654 \quad 332248$

27-Feb-84 $998 \quad 15657 \quad 332248$

28-Feb-84 $991 \quad 15931 \quad 415448$

29-Feb-84 $511 \quad 15773 \quad 447827$

0
0
0
0
0
0
0
0
0
0
0
0
0
0
0
0
0
0
0
0
0
0
0
0
0
0
0
0
0

$200 \quad \overline{12765}$

$220 \quad 17535$

26421974

26421388

25020627

25420538

25422991

$247 \quad 23142$

$\begin{array}{lll}247 & 19359\end{array}$

$228 \quad 18911$

$\begin{array}{llll}5298 & 153 & 8045\end{array}$

$\begin{array}{llll}3458 & 156 & 19271\end{array}$

$\begin{array}{llll}3440 & 161 & 19225\end{array}$

$3424 \quad 193 \cdot 22587$

$\begin{array}{lll}2488 & 198 & 23276\end{array}$

$\begin{array}{lll}2455 & 205 & 23368\end{array}$

$\begin{array}{lll}2345 & 239 & 26028\end{array}$

$\begin{array}{lll}1151 & 239 & 27085\end{array}$

$\begin{array}{lll}1125 & 237 & 26645\end{array}$

1096

$240 \quad 26209$

$\begin{array}{ll}0 & 0 \\ 0 & 0 \\ 0 & 0\end{array}$

0

4052

0

3956

1728541

17914678

18114680

$\begin{array}{ll}182 & 14937 \\ 173 & 14764\end{array}$ $\begin{array}{llllllll}3935 & 173 & 14764 & 30.33 & 30.33 & 33.1 & 11008 & 488688\end{array}$

$\begin{array}{llllll}27.71 & 27.71 & 32.9 & 12350 & 419969\end{array}$

$\begin{array}{llllll}24.84 & 24.84 & 30.04 & 11511 & 526751\end{array}$

$\begin{array}{lllll}23.63 & 23.63 & 28.83 & 10532 & 633510\end{array}$

$\begin{array}{llllll}24.16 & 24.16 & 29.4 & 10876 & 628807\end{array}$

$\begin{array}{llllll}22.73 & 22.73 & 27.9 & 10809 & 575493\end{array}$

$\begin{array}{lllll}23.16 & 23.16 & 28.34 & 10785 & 582047\end{array}$

$\begin{array}{llllll}22.92 & 22.92 & 28.1 & 10942 & 646047\end{array}$

$\begin{array}{llllll}22.49 & 22.49 & 27.68 & 10364 & 640571\end{array}$

$\begin{array}{lllll}26.70 & 26.70 & 31.89 & 10901 & 617359\end{array}$

$\begin{array}{llllll}22.64 & 22.64 & 27.84 & 10868 & 526482\end{array}$

$\begin{array}{lllll}28.69 & 28.69 & 31.41 & 12140 & 252693\end{array}$

$\begin{array}{lllllll}26.59 & 26.59 & 29.32 & 10794 & 565026\end{array}$

$\begin{array}{llllll}24.79 & 24.79 & 27.52 & 10775 & 529072\end{array}$

$\begin{array}{llllll}28.99 & 28.99 & 31.72 & 10994 & 716460\end{array}$

$\begin{array}{lllll}27.66 & 27.66 & 30.4 & 10088 & 707590\end{array}$

$\begin{array}{llllll}27.55 & 27.55 & 30.29 & 10062 & 707817\end{array}$

$\begin{array}{llllll}29.05 & 29.05 & 31.85 & 10173 & 828992\end{array}$

$\begin{array}{llllll}27.74 & 27.74 & 30.48 & 9035 & 825551\end{array}$

$\begin{array}{lllllll}27.83 & 27.83 & 30.57 & 8966 & 814538\end{array}$

$\begin{array}{llllll}27.91 & 27.91 & 30.66 & 8895 & 803568\end{array}$

$0.00 \quad 0.00$

$0.00 \quad 0.00$

$0.00 \quad 0.00$

$\begin{array}{lll}0.00 & 0.00\end{array}$

$\begin{array}{lllll}24.06 & 24.06 & 29.26 & 10882 & 249910\end{array}$

$\begin{array}{llllll}22.64 & 22.64 & 27.83 & 11037 & 408489\end{array}$

$\begin{array}{lllll}22.63 & 22.63 & 27.79 & 11027 & 407957\end{array}$

$\begin{array}{llllll}27.81 & 27.81 & 32.94 & 11007 & 492025\end{array}$ 
Date

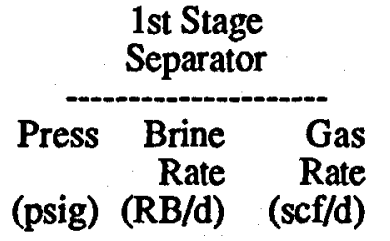

\begin{tabular}{cc} 
2nd Stage & Sales \\
Separator & Gas \\
\hdashline- & -
\end{tabular} Press Rate (psig) (scf/d)

1-Mar-84 $\begin{array}{lll}309 & 15599 \quad 433929\end{array}$ 2-Mar-84 $311 \quad 15584 \quad 431148$ 3-Mar-84 $405 \quad 15522 \quad 429456$ 4-Mar-84 $406 \quad 15570 \quad 417796$ 5-Mar-84 $406 \quad 12912 \quad 366829$

6-Mar-84

7-Mar-84

$\begin{array}{llll}8 \text {-Mar-84 } & 422 & 3748 & 104306\end{array}$

9-Mar-84 $518 \quad 10165 \quad 325686$

10-Mar-84 $400 \quad 10219 \quad 294102$

11-Mar-84 $414 \quad 7871 \quad 219522$

12-Mar-84 $403 \quad 12087 \quad 347501$

13-Mar-84 $397 \quad 10498 \quad 308431$

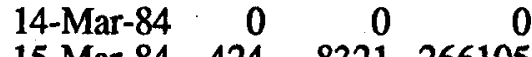

15-Mar-84 424

$\begin{array}{llrl}16-M a r-84 & 410 & 18508 & 534148\end{array}$

17-Mar-84 $409 \quad 11686 \quad 537405$

18-Mar-84 $411 \quad 20156 \quad 330246$

19-Mar-84 $410 \quad 20104 \quad 537405$

20-Mar-84 $40920058 \quad 535805$

21-Mar-84 $999 \quad 19476537777$

22-Mar-84 $403 \quad 20109542379$

23-Mar-84 $403 \quad 20063 \quad 542379$

24-Mar-84 $403 \quad 20043 \quad 540662$

25-Mar-84 $403 \quad 20008 \quad 540662$

26-Mar-84 $402 \quad 19990537405$

27-Mar-84 $401 \quad 17411500218$

28-Mar-84 $412 \quad 20408 \quad 561654$

29-Mar-84 $406 \quad 20371548954$

30-Mar-84 $407 \quad 20343 \quad 550433$

31-Mar-84 $406 \quad 15354 \quad 436207$

$\begin{array}{llll}3928 & 151 & 14577\end{array}$
Max Surface Brine Pressure Rate

\section{Prod Disp \\ Well Well}

Gas/Brine Ratios

1st 2nd Disp
Stg Well

$\begin{array}{llllll} & & \\ & \end{array}$

3927

$\begin{array}{lll}3929 & 159 & 14524\end{array}$

$\begin{array}{lll}3930 & 165 & 14569\end{array}$

3917

17012082

4109

$$
4109
$$

$\begin{array}{llllllll}4109 & 136 & 3507 & 29.74 & 29.74 & 32.05 & 10821 & 112399\end{array}$

$\begin{array}{lllllllll}4244 & 146 & 9515 & 34.23 & 34.23 & 37.03 & 11089 & 352340\end{array}$

$\begin{array}{lllllllll}4552 & 160 & 9562 & 30.76 & 30.76 & 32.95 & 11419 & 315068\end{array}$

$\begin{array}{lllllllll}4634 & 157 & 7365 & 29.81 & 29.81 & 32.07 & 11439 & 236196\end{array}$

$\begin{array}{lllllllll}4373 & 208 & 11310 & 30.73 & 30.73 & 32.94 & 11300 & 372551\end{array}$

$\begin{array}{lllllllll}5404 & 187 & 9823 & 31.40 & 31.40 & 33.58 & 12301 & 329856\end{array}$

$\begin{array}{rrrrrrrr}0 & 0 & 0 & 0.00 & 0.00 & 0 & 0 & 0 \\ 5492 & 207 & 7786 & 34.18 & 34.18 & 36.49 & 12320 & 284111\end{array}$

$\begin{array}{lllllllll}4336 & 211 & 17318 & 30.84 & 30.84 & 33.09 & 11564 & 573053\end{array}$

$\begin{array}{llllllll}4290 & 222 & 10935 & 49.15 & 49.15 & 51.39 & 11148 & 561950\end{array}$

$\begin{array}{lllllllll}4288 & 235 & 18860 & 17.51 & 17.51 & 19.76 & 11622 & 372674\end{array}$

$\begin{array}{lllllllll}4265 & 243 & 18812 & 28.57 & 28.57 & 30.82 & 11588 & 579786\end{array}$

$\begin{array}{lllllllll}4251 & 244 & 18768 & 28.55 & 28.55 & 30.79 & 11571 & 577867\end{array}$

$\begin{array}{llllllllll}4217 & 258 & 18261 & 29.45 & 29.45 & 34.61 & 11496 & 632013\end{array}$

$\begin{array}{llllllll}4203 & 249 & 18816 & 28.83 & 28.83 & 31.04 & 11524 & 584049\end{array}$

$\begin{array}{llllllll}4190 & 245 & 18773 & 28.89 & 28.89 & 31.1 & 11508 & 583840\end{array}$

$\begin{array}{lllllllll}4178 & 232 & 18754 & 28.83 & 28.83 & 31.04 & 11495 & 582124\end{array}$

$\begin{array}{llllllll}4178 & 232 & 18721 & 28.88 & 28.88 & 31.09 & 11493 & 582036\end{array}$

$\begin{array}{lllllllll}4150 & 236 & 18704 & 28.73 & 28.73 & 30.94 & 11463 & 578702\end{array}$

$\begin{array}{lllllllll}4136 & 236 & 16291 & 30.70 & 30.70 & 32.91 & 11298 & 536137\end{array}$

$\begin{array}{lllllllll}4079 & 240 & 19096 & 29.41 & 29.41 & 31.67 & 11415 & 604770\end{array}$

$\begin{array}{lllllllll}4063 & 246 & 19061 & 28.80 & 28.80 & 31.03 & 11397 & 591463\end{array}$

$\begin{array}{llllllll}4052 & 253 & 19035 & 28.92 & 28.92 & 31.15 & 11384 & 592940\end{array}$

$\begin{array}{lllllllll}4047 & 252 & 14367 & 30.36 & 30.36 & 32.59 & 11105 & 468221\end{array}$ 


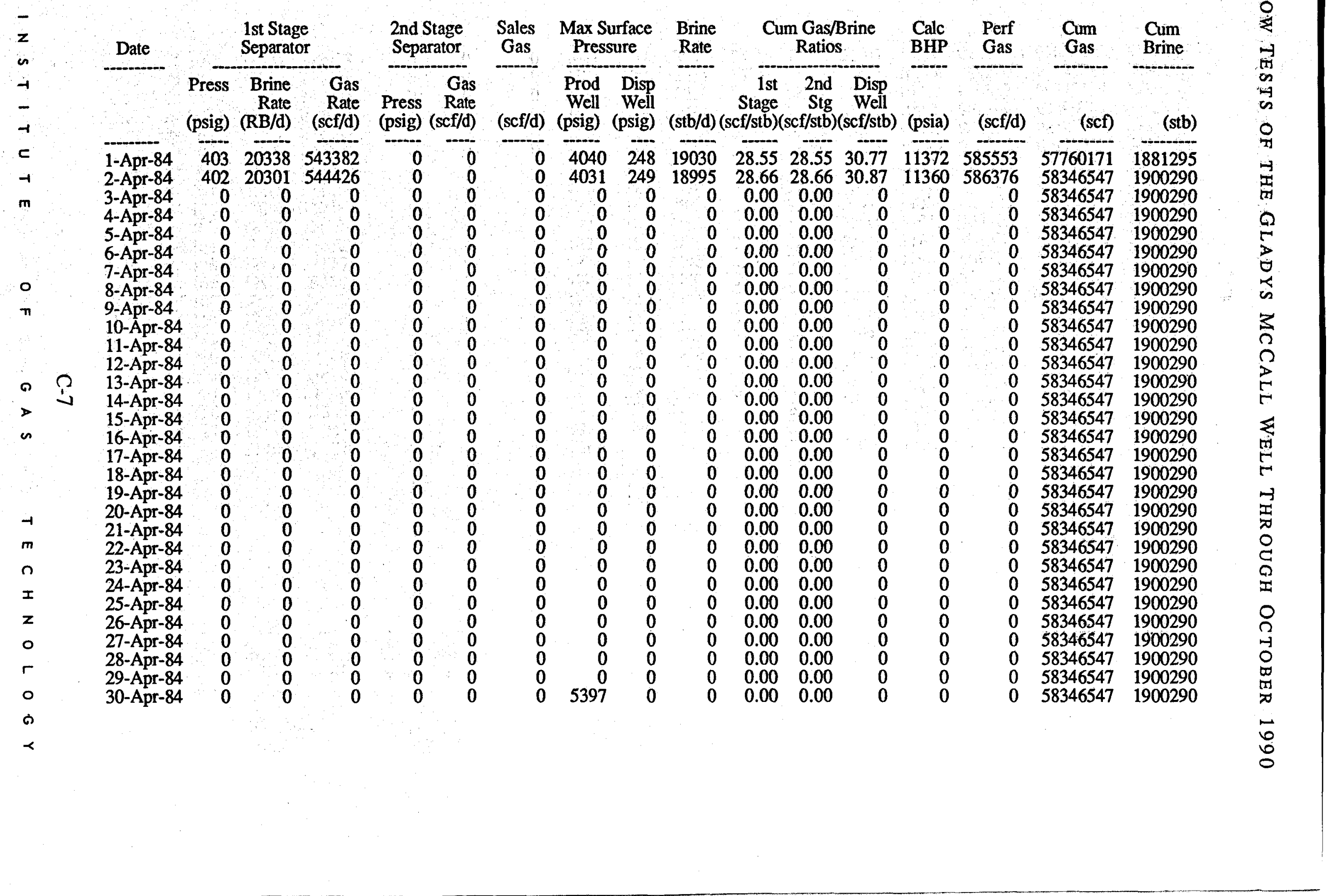




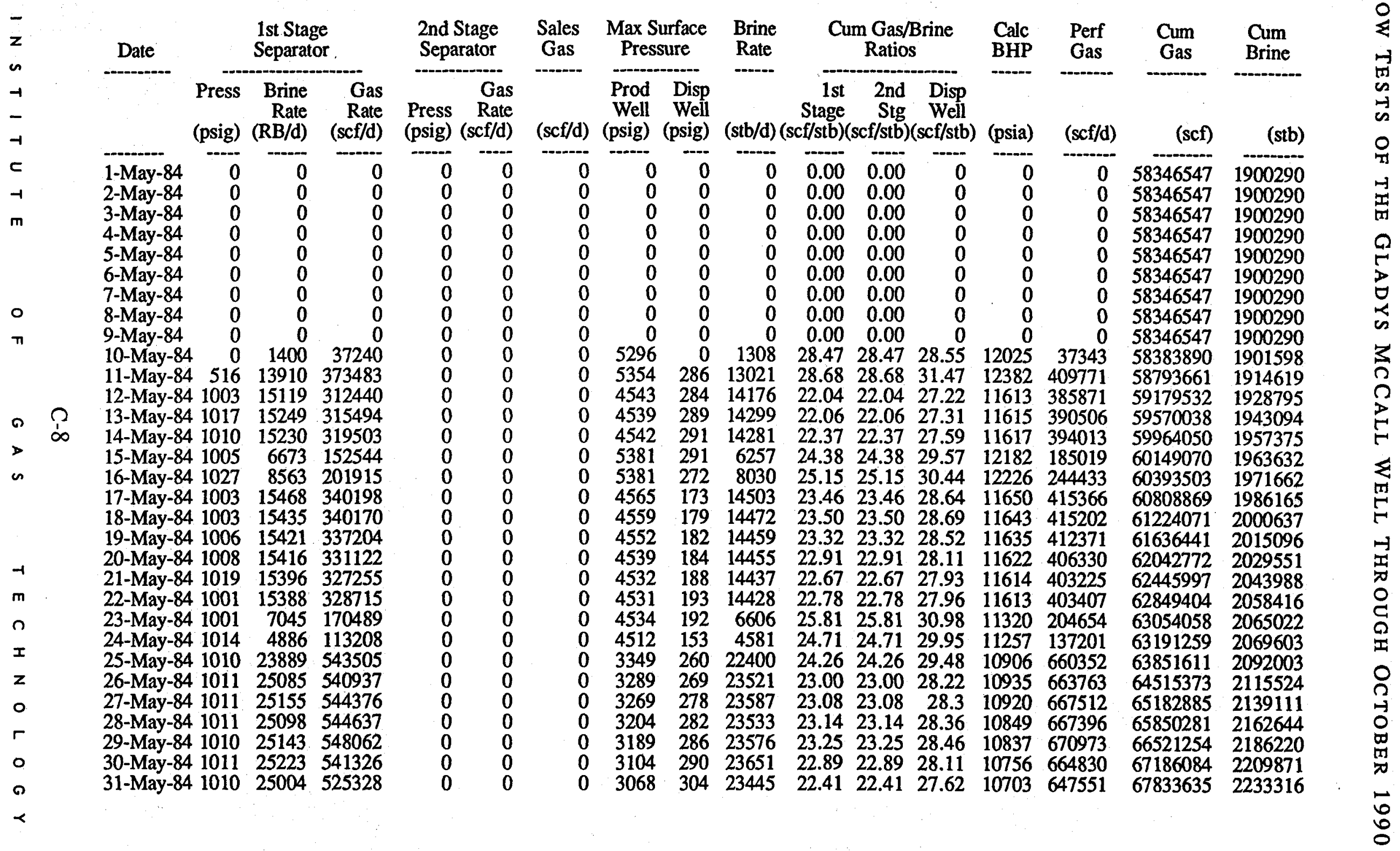


Date

1st Stage
Separator
Press
Brime
(psig)

Sales Max Surface Brine Separator Gas Pressure Rate

1-Jun-84 $1005 \quad 25004 \quad 519677$ 2-Jun-84 $1023 \quad 25017 \quad 517114$

$\begin{array}{llllll}3-J u n-84 & 1028 & 24992 & 516352\end{array}$

4-Jun-84 $\quad 1014 \quad 24970 \quad 517524$

5-Jun-84 $\quad 1004 \quad 25164 \quad 530196$

6-Jun-84 $1011 \quad 25248 \quad 521976$

7-Jun-84 $\quad 1015 \quad 15449 \quad 330680$

8-Jun-84 $1008 \quad 20631 \quad 427416$

9-Jun-84 $\quad 1008 \quad 20386 \quad 426738$

10-Jun-84 $1008 \quad 20351 \quad 430633$

11-Jun-84 $1009 \quad 20310 \quad 427404$

12-Jun-84 $100420263 \quad 425506$

13-Jun-84 $1017 \quad 20198 \quad 427017$

14-Jun-84 $1006 \quad 20137 \quad 423811$

15-Jun-84 $1008 \quad 20082 \quad 425868$

16-Jun-84 $1005 \quad 20225 \quad 427353$

17-Jun-84 $1003 \quad 20400 \quad 433115$

18-Jun-84 $1003 \quad 20348 \quad 432809$

19-Jun-84 $1009 \quad 20292 \quad 432070$

20-Jun-84 $1003 \quad 20242 \quad 433901$

21-Jun-84 $1007 \quad 20190 \quad 430777$

22-Jun-84 $1005 \quad 20128 \quad 426904$

23-Jun-84 $1007 \quad 20062 \quad 424565$

24-Jun-84 $1007 \quad 20223 \quad 427373$

25-Jun-84 $1006 \quad 20289 \quad 430215$

26-Jun-84 $1008 \quad 20215 \quad 427061$

27-Jun-84 $1005 \quad 20159 \quad 427674$

28-Jun-84 $1005 \quad 20085 \quad 428311$

29-Jun-84 100520025426258

30-Jun-84 $1005 \quad 13402 \quad 283809$

Gas
Press Rate
(psig) (scf/d)

\section{Well Well}

$-\frac{-}{0}$

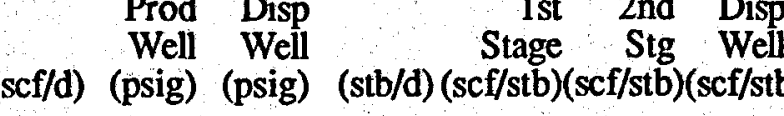

$\begin{array}{lllllllll}0 & 3068 & 304 & 23445 & 22.17 & 22.17 & 27.36 & 10704 & 641455 \\ 0 & 3046 & 309 & 23458 & 22.04 & 22.04 & 27.32 & 10682 & 640873 \\ 0 & 3006 & 281 & 23435 & 22.03 & 22.03 & 27.33 & 10639 & 640479 \\ 0 & 2982 & 293 & 23414 & 22.10 & 22.10 & 27.34 & 10613 & 640139 \\ 0 & 2912 & 283 & 23595 & 22.47 & 22.47 & 27.66 & 10555 & 652638 \\ 0 & 2814 & 287 & 23674 & 22.05 & 22.05 & 27.27 & 10462 & 645590 \\ 0 & 4235 & 288 & 14486 & 22.83 & 22.83 & 28.07 & 11313 & 406622 \\ 0 & 4236 & 207 & 19345 & 22.09 & 22.09 & 27.3 & 11598 & 528119 \\ 0 & 3551 & 215 & 19115 & 22.32 & 22.32 & 27.53 & 10882 & 526236 \\ 0 & 3549 & 220 & 19082 & 22.57 & 22.57 & 27.77 & 10877 & 529907 \\ 0 & 3543 & 224 & 19044 & 22.44 & 22.44 & 27.65 & 10869 & 526567 \\ 0 & 3523 & 228 & 18999 & 22.40 & 22.40 & 27.58 & 10845 & 523992 \\ 0 & 3519 & 233 & 18939 & 22.55 & 22.55 & 27.8 & 10837 & 526504 \\ 0 & 3500 & 236 & 18881 & 22.45 & 22.45 & 27.64 & 10814 & 521871 \\ 0 & 3486 & 238 & 18830 & 22.62 & 22.62 & 27.82 & 10796 & 523851 \\ 0 & 3466 & 240 & 18964 & 22.54 & 22.54 & 27.73 & 10784 & 525872 \\ 0 & 3377 & 243 & 19128 & 22.64 & 22.64 & 27.83 & 10704 & 532332 \\ 0 & 3366 & 245 & 19079 & 22.69 & 22.69 & 27.87 & 10689 & 531732 \\ 0 & 3356 & 247 & 19027 & 22.71 & 22.71 & 27.92 & 10675 & 531234 \\ 0 & 3339 & 248 & 18980 & 22.86 & 22.86 & 28.04 & 10654 & 532199 \\ 0 & 3327 & 249 & 18931 & 22.75 & 22.75 & 27.96 & 10639 & 529311 \\ 0 & 3311 & 250 & 18873 & 22.62 & 22.62 & 27.81 & 10619 & 524858 \\ 0 & 3288 & 251 & 18811 & 22.57 & 22.57 & 27.77 & 10592 & 522381 \\ 0 & 3275 & 253 & 18962 & 22.54 & 22.54 & 27.74 & 10588 & 526006 \\ 0 & 3197 & 251 & 19024 & 22.61 & 22.61 & 27.81 & 10512 & 529057 \\ 0 & 3188 & 252 & 18955 & 22.53 & 22.53 & 27.74 & 10498 & 525812 \\ 0 & 3178 & 252 & 18902 & 22.63 & 22.63 & 27.82 & 10484 & 525854 \\ 0 & 3151 & 229 & 18833 & 22.74 & 22.74 & 27.94 & 10452 & 526194 \\ 0 & 3138 & 235 & 18776 & 22.70 & 22.70 & 27.89 & 10435 & 523663 \\ 0 & 3093 & 207 & 12566 & 22.58 & 22.58 & 27.78 & 10049 & 349083\end{array}$

68475090

$\begin{array}{ll}69756441 & 2303654\end{array}$

$70396580 \quad 2327068$

$71049217 \quad 2350663$

$\begin{array}{lll}71694807 & 2374337\end{array}$

$72101429 \quad 2388823$

$72629548 \quad 2408168$

$\begin{array}{lll}73155784 & 2427283\end{array}$

$73685691 \quad 2446365$

$74212258 \quad 2465409$

$74736250 \quad 2484408$

$\begin{array}{lll}75262754 & 2503347\end{array}$

$75784625 \quad 2522228$

$\begin{array}{lll}76308476 & 2541058\end{array}$

$76834347 \quad 2560022$

$77366680 \quad 2579150$

$77898411 \quad 2598229$

$78429645 \quad 2617256$

$78961844 \quad 2636236$

$79491155 \quad 2655167$

800160132674040

$80538395 \quad 2692851$

$81064401 \quad 2711813$

$81593458 \quad 2730837$

$82119270 \quad 2749792$

$82645123 \cdot 2768694$

$83171317 \quad 2787527$

$83694980 \quad 2806303$

$84044064 \quad 2818869$ 
Date

\begin{tabular}{ccc}
\multicolumn{3}{c}{ 1st Stage } \\
Separator \\
Press \\
$\begin{array}{rlr}\text { Brine } \\
\text { Rate }\end{array}$ & $\begin{array}{r}\text { Gas } \\
\text { Rate } \\
\text { (psfig) }\end{array}$ \\
$\begin{aligned} \text { (RB/d) } \\
\text { (sc/d) }\end{aligned}$
\end{tabular}

1-Jul-84

2-Jul-84

3-Jul-84

4-Jul-84

5-Jul-84

6-Jul-84

7-Jul-84

8-Jul-84

9-Jul-84

10-Jul-84

11-Jul-84

12-Jul-84

13-Jul-84

$14-\mathrm{Jul}-84$

15-Jul-84

17-Jul-84

18-Jul-84

19-Jul-84

20-Jul-84

22-Jul-84

23-Jul-84

24-Jul-84

25-Jul-84

26-Jul-84

27-Jul-84

29-Jul-84

30-Jul-84

31-Jul-84 $\begin{array}{lll}1005 & 20223 \quad 380652\end{array}$

$1005 \quad 20454 \quad 419924$

$\begin{array}{lll}1005 & 20376 \quad 415042\end{array}$

$1005 \quad 20302 \quad 415095$

100520227414796

$1007 \quad 20155414537$

$1006 \quad 20071413319$

$1006 \quad 20135 \quad 424720$

100520262437810

$\begin{array}{llll}1005 & 20195 & 436264\end{array}$

$\begin{array}{llll}1008 & 12712301782\end{array}$

$\begin{array}{lll}1006 & 10562 & 256867\end{array}$

$\begin{array}{lll}1009 & 10269 & 248099\end{array}$

100515460337606

100715457338359

100415431319563

$\begin{array}{lll}1003 \quad 15417 & 332974\end{array}$

$\begin{array}{lll}1003 & 15410 & 329512 \\ 1005 & 15402 & 331436\end{array}$

$1003 \quad 15400331004$

$\begin{array}{lll}1003 & 15399 & 331483\end{array}$

$\begin{array}{lll}1002 & 9471207303\end{array}$

$\begin{array}{llll}1003 & 6526 \quad 157840\end{array}$

100615500330463

$\begin{array}{lll}1005 & 15492 \quad 333797\end{array}$

$1005 \quad 15484 \quad 336540$

100415471330515

$1005 \quad 15461335102$

100515448331508

$\begin{array}{lll}1004 & 15441 & 337446\end{array}$ 2nd Stage Sales Max Surface Brine

Separator Gas Pressure Rate

Press $\begin{array}{r}\text { Gas } \\ \text { Rate }\end{array}$

Prod Disp

Well Well

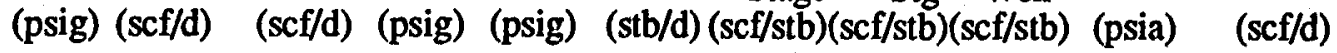

\begin{tabular}{ll} 
Calc & Perf \\
BHP & Gas \\
\hdashline- &
\end{tabular}

Cum

Cum

Brine

$\begin{array}{ll}0 & 0 \\ 0 & 0 \\ 0 & 0 \\ 0 & 0 \\ 0 & 0 \\ 0 & 0 \\ 0 & 0 \\ 0 & 0 \\ 0 & 0 \\ 0 & 0 \\ 0 & 0 \\ 0 & 0 \\ 0 & 0 \\ 0 & 0 \\ 0 & 0 \\ 0 & 0\end{array}$

$50028857 \quad 348420$

50039442372416

50045214374726

$50046098 \quad 377534$

40052641383645

40056447387930

30038352245655

30031985189825

30065887396350

30073397467194

25068880405420

25168468398983

25168777403879

25068559400067

$$
\begin{aligned}
& 3018 \\
& 29 \\
& 29 \\
& 29 \\
& 29 \\
& 29 \\
& 28 \\
& 28 \\
& 27 \\
& 27 \\
& 50 \\
& 5024 \\
& 5024 \\
& 42 \\
& 42 \\
& 42 \\
& 42 \\
& 42 \\
& 42 \\
& 4231 \\
& 42 \\
& 42 \\
& 42 \\
& 42 \\
& 42 \\
& 42 \\
& 42 \\
& 42 \\
& 42 \\
& 4195 \\
& 4191
\end{aligned}
$$$$
\begin{array}{llllllll}
3018 & 200 & 18962 & 20.07 & 20.07 & 25.27 & 10328 & 479170
\end{array}
$$$$
\begin{array}{llllllllll}
2968 & 207 & 19179 & 21.90 & 21.90 & 27.09 & 10288 & 519559
\end{array}
$$$$
\begin{array}{lllllllll}
2951 & 212 & 19105 & 21.72 & 21.72 & 26.92 & 10266 & 514307
\end{array}
$$$$
\begin{array}{lllllllll}
2932 & 216 & 19036 & 21.81 & 21.81 & 27 & 10242 & 513972
\end{array}
$$$$
\begin{array}{lllllllll}
2918 & 221 & 18966 & 21.87 & 21.87 & 27.06 & 10223 & 513220
\end{array}
$$$$
\begin{array}{lllllllll}
2902 & 221 & 18898 & 21.94 & 21.94 & 27.14 & 10202 & 512892
\end{array}
$$$$
\begin{array}{llllllll}
2898 & 225 & 18820 & 21.96 & 21.96 & 27.16 & 10192 & 511151
\end{array}
$$$$
\begin{array}{lllllllll}
2872 & 229 & 18880 & 22.50 & 2250 & 27.69 & 10169 & 522787
\end{array}
$$$$
\begin{array}{llllllll}
2785 & 232 & 18999 & 23.04 & 23.04 & 28.24 & 10086 & 536532
\end{array}
$$$$
\begin{array}{llllllll}
2759 & 234 & 18936 & 23.04 & 23.04 & 28.23 & 10055 & 534563
\end{array}
$$$$
\begin{array}{llllllll}
5002 & 191 & 11919 & 25.32 & 25.32 & 30.53 & 11976 & 363887
\end{array}
$$$$
\begin{array}{lllllllll}
5024 & 173 & 9903 & 25.94 & 25.94 & 31.13 & 11919 & 308280
\end{array}
$$$$
\begin{array}{llllllll}
5024 & 173 & 9903 & 25.94 & 25.94 & 31.13 & 11919 & 308280 \\
0 & 143 & 9629 & 25.77 & 25.77 & 30.98 & 11910 & 298306
\end{array}
$$$$
\begin{array}{lllllllll}
4238 & 144 & 14486 & 23.62 & 23.62 & 28.81 & 11314 & 417342
\end{array}
$$$$
\begin{array}{llllllll}
4238 & 147 & 14496 & 23.29 & 23.29 & 28.48 & 11315 & 412846
\end{array}
$$

$\begin{array}{llllllll}4235 & 149 & 14493 & 23.35 & 23.35 & 28.55 & 11312 & 413775\end{array}$

$\begin{array}{lllllllll}4229 & 132 & 14469 & 22.09 & 24.08 & 26.79 & 11307 & 387625\end{array}$

$\begin{array}{lllllllll}4225 & 132 & 14456 & 23.03 & 25.76 & 28.47 & 11300 & 411562\end{array}$

$\begin{array}{llllllll}4231 & 135 & 14449 & 22.81 & 25.93 & 28.64 & 11306 & 413819\end{array}$

$\begin{array}{llllllll}4231 & 137 & 14442 & 22.95 & 26.14 & 28.85 & 11305 & 416652\end{array}$

$\begin{array}{llllllll}4225 & 133 & 14440 & 22.92 & 26.57 & 28.76 & 11299 & 415294\end{array}$

$\begin{array}{lllllllll}4219 & 133 & 14439 & 22.96 & 26.87 & 29.06 & 11292 & 419597\end{array}$

$\begin{array}{lllllllll}4229 & 131 & 8880 & 23.34 & 27.66 & 29.34 & 11074 & 260539\end{array}$

$\begin{array}{llllllll}4228 & 117 & 6119 & 25.79 & 31.02 & 32.7 & 10989 & 200091\end{array}$

$\begin{array}{lllllllll}4223 & 120 & 14534 & 22.74 & 27.27 & 28.95 & 11301 & 420759\end{array}$

$\begin{array}{lllllllll}4220 & 121 & 14526 & 22.98 & 28.03 & 29.71 & 11296 & 431567\end{array}$

$\begin{array}{lllllllll}4215 & 122 & 14518 & 23.18 & 27.92 & 29.34 & 11292 & 425958\end{array}$

$\begin{array}{lllllllll}4209 & 123 & 14506 & 22.78 & 27.50 & 28.92 & 11286 & 419514\end{array}$

$\begin{array}{lllllllll}4205 & 124 & 14497 & 23.12 & 27.86 & 29.28 & 11280 & 424472\end{array}$

$\begin{array}{llllllll}4190 & 124 & 14485 & 22.89 & 27.62 & 29.03 & 11265 & 420500 \\ 4191 & 127 & 14478 & 23.31 & 28.04 & 29.46 & 11265 & 426522\end{array}$ 
2nd Stage Sales Max Surface Brine Separator Gas Pressure Rate

1-Aug-84 $1008 \quad 15432 \quad 341199$ 2-Aug-84 $1007 \quad 15424 \quad 337950$ $\begin{array}{llll}3-\text { Aug-84 } & 1007 & 15421 & 338833\end{array}$ 4-Aug-84 $1006 \quad 15415 \quad 337080$ $\begin{array}{lllll}5-A u g-84 & 1006 & 15407 & 336954\end{array}$ 6-Aug-84 $1007 \quad 15398 \quad 333069$ $\begin{array}{llll}7-A u g-84 & 1007 & 15394 & 336225\end{array}$ 8-Aug-84 $1007 \quad 15384 \quad 334771$ $\begin{array}{llll}9 \text {-Aug-84 } & 1006 \quad 15381 \quad 333972\end{array}$ 10-Aug-84 $1005 \quad 15374 \quad 334573$ 11-Aug-84 $1005 \quad 15826 \quad 335592$ 12-Aug-84 $1005 \quad 14972 \quad 324752$

$\therefore \quad 13$-Aug-84 $100715263 \quad 334589$ $\circ \quad=\quad 14$-Aug-84 $1004 \quad 15152 \quad 332222$

$>\quad$ 15-Aug-84 1007 15142 333395 is $\quad$ 16-Aug-84 1008 15135333580 17-Aug-84 $1005 \quad 10402 \quad 247567$ 18-Aug-84 $1006 \quad 15560 \quad 341554$ 19-Aug-84 $1005 \quad 24166 \quad 546343$ 20-Aug-84 $1005 \quad 25207 \quad 553053$ 21-Aug-84 $1007 \quad 25100 \quad 549827$ 22-Aug-84 $1006 \quad 25152550337$ 23-Aug-84 $1006 \quad 25176 \quad 553306$ 24-Aug-84 100625076551735 25-Aug-84 $1006 \quad 25138 \quad 553983$ 26-Aug-84 1006 $25145 \quad 550785$ 27-Aug-84 100825059548786 28-Aug-84 $1006 \quad 25437 \quad 556028$ 29-Aug-84 $1004 \quad 25436 \quad 556647$ 30-Aug-84 $1012 \quad 25311560086$ 31-Aug-84 $1005 \quad 25193 \quad 551051$

$\begin{aligned} \text { Gas } & \text { Prod Disp } \\ \text { Press Rate } & \text { Well Well }\end{aligned}$

Press Rate

(scf/d)

$\begin{array}{llll}313 & 64240 & 406360\end{array}$

$\begin{array}{llll}313 & 64240 & 406360 \\ 310 & 63218 & 401551\end{array}$

$315 \quad 63465 \cdot 402300$

30065319402587

$300 \quad 66630 \quad 403349$

$30067026 \quad 400525$

$30066281 \quad 402180$

$300 \quad 66166 \quad 402840$

30565481399000

30666085400689

29866385402206

$30165086 \quad 392192$

$29865788 \quad 400141$

$306 \quad 64979 \quad 397562$

$30265021 \cdot 398215$

30365451398633

$303 \quad 40255 \quad 287822$

$30255097 \quad 396651$

$306110213 \quad 665699$

303110044663297

$\begin{array}{lll}0 & 0 & 549827\end{array}$

$30477544 \quad 627881$

$306106783 \cdot 660316$

$\begin{array}{lll}0 & 0 & 551735 \\ 0 & 0 & 553983\end{array}$

309116299666714

308117415666100

323116600672663

322116451672418

$324111943 \quad 672883$

352106063657861 (psig) (psig) (stb/d) (sct/s

$\begin{array}{lll}4191 & 133 & 14470\end{array}$

$\begin{array}{llll}4184 & 133 & 14462\end{array}$

$\begin{array}{llll}4178 & 135 & 14460\end{array}$

$\begin{array}{lll}4180 & 131 & 14454\end{array}$

$\begin{array}{lll}4158 \quad 134 & 14446\end{array}$

$\begin{array}{llll}4152 & 137 & 14438\end{array}$

$\begin{array}{lll}4151 & 138 & 14434\end{array}$

$\begin{array}{lll}4146 & 139 & 14425\end{array}$

$\begin{array}{llll}4140 & 140 & 14422\end{array}$

$\begin{array}{llll}4135 & 141 & 14415\end{array}$

$\begin{array}{lll}4132 & 142 & 14839\end{array}$

$\begin{array}{llll}4168 & 141 & 14038\end{array}$

$\begin{array}{lll}4144 & 143 & 14311\end{array}$

$\begin{array}{lll}4137 & 139 & 14207\end{array}$

$\begin{array}{llll}4138 & 141 & 14198\end{array}$

$\begin{array}{llll}4126 & 142 & 14191\end{array}$

$\begin{array}{lll}4962 & 129 & 9753\end{array}$

$\begin{array}{llll}4072 & 130 & 14590\end{array}$

$\begin{array}{llll}4059 & 200 & 22659\end{array}$

$\begin{array}{lll}2718 & 208 & 23635\end{array}$

$\begin{array}{lll}2696 & 234 & 23535\end{array}$

$\begin{array}{lll}2611 & 235 & 23606\end{array}$

$\begin{array}{lll}2588 & 242 & 23512\end{array}$

$\begin{array}{lll}2570 & 245 & 23571\end{array}$

$\begin{array}{lll}2497 & 232 & 23577\end{array}$

$\begin{array}{lll}2456 & 239 & 23851\end{array}$

$\begin{array}{lll}2324 & 241 & 23850\end{array}$

$\begin{array}{lll}2301 & 243 & 23733\end{array}$

$\begin{array}{lll}2290 & 243 & 23622\end{array}$ $\begin{array}{lll}2684 & 218 & 23584\end{array}$

$\begin{array}{lll}2478 & 236 & 23497\end{array}$

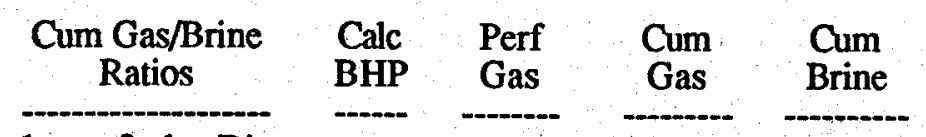

1st 2nd Disp

Stage Stg Well

(scf)

(stb)

$23.58 \quad 28.02 \quad 29.76 \quad 11264 \quad 430627$

$\begin{array}{llllll}23.37 & 27.74 & 29.47 & 11257 & 426195\end{array}$

$\begin{array}{llllll}23.43 & 27.82 & 29.58 & 11250 & 427727\end{array}$

$\begin{array}{lllll}23.32 & 27.84 & 29.52 & 11252 & 426682\end{array}$

$\begin{array}{lllllll}23.32 & 27.94 & 29.61 & 11229 & 427746\end{array}$

$\begin{array}{llllll}23.07 & 27.71 & 29.39 & 11223 & 424333\end{array}$

$\begin{array}{lllllll}23.29 & 27.89 & 29.56 & 11221 & 426669 & 100301104\end{array}$

$\begin{array}{lllllll}23.21 & 27.79 & 29.47 & 11216 & 425105 & 100726209\end{array}$

$\begin{array}{llllllll}23.16 & 27.70 & 29.4 & 11210 & 424007 & 101150216\end{array}$

$\begin{array}{lllllll}23.21 & 27.79 & 29.5 & 11204 & 425243 & 101575458\end{array}$

$\begin{array}{lllllll}22.62 & 27.09 & 28.76 & 11224 & 426770 & 102002228\end{array}$

$\begin{array}{lllllll}23.13 & 27.77 & 29.45 & 11219 & 413419 & 102415647\end{array}$

$\begin{array}{lllllll}23.38 & 27.98 & 29.64 & 11208 & 424178 & 102839825\end{array}$

$\begin{array}{lllllll}23.38 & 27.96 & 29.67 & 11195 & 421522 & 103261347\end{array}$

$\begin{array}{lllllll}23.48 & 28.06 & 29.75 & 11196 & 422391 & 103683737\end{array}$

$\begin{array}{llllll}23.51 & 28.12 & 29.81 & 11183 & 423034 & 104106771\end{array}$

$\begin{array}{lllllll}25.38 & 29.51 & 31.2 & 11851 & 304294 & 104411065\end{array}$

$\begin{array}{lllllll}23.41 & 27.19 & 28.87 & 11149 & 421213 & 104832278\end{array}$

$\begin{array}{llllll}24.11 & 28.98 & 30.68 & 11652 & 695178 & 105527456\end{array}$

$\begin{array}{lllllll}23.40 & 28.06 & 29.75 & 10356 & 703141 & 106230597\end{array}$

$\begin{array}{lllllll}23.36 & 23.36 & 28.56 & 10327 & 672160 & 106902757\end{array}$

$\begin{array}{lllllll}23.34 & 26.62 & 28.32 & 10319 & 667899 & 107570656\end{array}$

$\begin{array}{lllllll}23.44 & 27.96 & 29.67 & 10243 & 700390 & 108271046\end{array}$

$\begin{array}{lllllll}23.47 & 23.47 & 28.66 & 10214 & 673854 & 108944900\end{array}$

$\begin{array}{llllll}23.50 & 23.50 & 28.7 & 10200 & 676488 & 109621387\end{array}$

$\begin{array}{lllllll}23.36 & 28.29 & 30.02 & 10123 & 707782 & 110329169\end{array}$

$\begin{array}{lllllll}23.36 & 28.35 & 30.07 & 10097 & 706555 & 111035724\end{array}$

$\begin{array}{lllllll}23.31 & 28.20 & 30 & 10103 & 715530 & 111751254\end{array}$

$9967 \quad 715739112466992$

$\begin{array}{llll}-1 & 0 \\ 23.34 & 28.22 & 30.01\end{array}$

9933714838113181830

$23.6028 .32 \quad 30.12$

$9914703227 \quad 113885057$ 


\begin{tabular}{ccc} 
Date & \multicolumn{2}{c}{$\begin{array}{c}\text { 1st Stage } \\
\text { Separator }\end{array}$} \\
\hdashline & $\begin{array}{c}\text { Press } \\
\text { Brine } \\
\text { Rate }\end{array}$ & $\begin{array}{r}\text { Gas } \\
\text { Rate }\end{array}$ \\
(psig) & $(\mathrm{RB} / \mathrm{d})$ & (scf/d)
\end{tabular}

$\begin{array}{llll}1-S e p-84 & 1006 & 25058 & 545875\end{array}$ 2-Sep-84 $1006 \quad 24928 \quad 545671$ 3-Sep-84 $1007 \quad 24800542105$ 4-Sep-84 $1009 \quad 24666 \quad 541839$ 5-Sep-84 $\quad 1009 \quad 15119 \quad 339696$ 6-Sep-84 $1009 \quad 9386 \quad 206451$ 7-Sep-84

9-Sep-84 $1008 \quad 18176 \quad 338094$ 10-Sep-84 $1009 \quad 25158 \quad 547842$ 11-Sep-84 $100924982 \quad 546667$ 12-Sep-84 100924809542516 13-Sep-84 $1009 \quad 24639 \quad 536585$ 14-Sep-84 $100924472 \quad 537327$ 15-Sep-84 $100924346 \quad 534345$ 16-Sep-84 $100824213 \quad 532392$ 17-Sep-84 $1009 \quad 24037 \quad 526846$ 18-Sep-84 $1007 \quad 23872524816$ 19-Sep-84 $100823706 \quad 524918$ 20-Sep-84 $1008 \quad 23547 \quad 517208$ 21-Sep-84 $1008 \quad 17549 \quad 385683$ 22-Sep-84 $1010 \quad 23376 \quad 514719$ 23-Sep-84 $1008 \quad 23205 \quad 511703$ 24-Sep-84 100923039510731 25-Sep-84 $1008 \quad 14215 \quad 332488$ 26-Sep-84 $1008 \quad 20194 \quad 478193$ 27-Sep-84 101017185290639 28-Sep-84 29-Sep-84 30-Sep-84

$\begin{array}{lll}0 & 0 & 0 \\ 0 & 0 & 0 \\ 0 & 0 & 0\end{array}$

\begin{tabular}{|c|c|c|c|c|c|c|c|c|c|c|c|c|}
\hline \multicolumn{2}{|c|}{$\begin{array}{l}\text { 2nd Stage } \\
\text { Separator }\end{array}$} & $\begin{array}{l}\text { Sales } \\
\text { Gas }\end{array}$ & \multicolumn{2}{|c|}{$\begin{array}{c}\text { Max Surface } \\
\text { Pressure }\end{array}$} & \multirow{2}{*}{$\begin{array}{l}\text { Brine } \\
\text { Rate } \\
- \\
\text { (stb/d) }\end{array}$} & \multicolumn{3}{|c|}{$\begin{array}{c}\text { Cum Gas/Brine } \\
\text { Ratios }\end{array}$} & $\begin{array}{l}\text { Calc } \\
\text { BHP }\end{array}$ & $\begin{array}{l}\text { Perf } \\
\text { Gas }\end{array}$ & $\begin{array}{l}\text { Cum } \\
\text { Gas }\end{array}$ & $\begin{array}{l}\text { Cum } \\
\text { Brine }\end{array}$ \\
\hline $\begin{array}{l}\text { ess } \\
\text { sig) }\end{array}$ & $\begin{array}{r}\text { Gas } \\
\text { Rate } \\
\text { (scf/d) }\end{array}$ & $(\operatorname{scf} / d)$ & $\begin{array}{r}\text { Prod } \\
\text { Well } \\
\text { (psig) }\end{array}$ & $\begin{array}{l}\text { Disp } \\
\text { Well } \\
\text { (psig) }\end{array}$ & & $\begin{array}{r}\text { 1st } \\
\text { Stage } \\
(\mathrm{scf} / \mathrm{stb})(\end{array}$ & $\begin{array}{r}\text { 2nd } \\
\text { Stg } \\
\text { scf/stb) }\end{array}$ & $\begin{array}{c}\text { Disp } \\
\text { Well } \\
\text { (scf/stb) }\end{array}$ & (psia) & (scf/d) & (scf) & (stb) \\
\hline & & & & 24 & 496 & 5.2 & & & & & & \\
\hline & & & & 24 & 23374 & 35 & & & & & & \\
\hline & & 6 & & & $\begin{array}{l}23254 \\
72128\end{array}$ & .31 & & 29 & & 72 & 115 & 917723 \\
\hline & & 3 & & & $\begin{array}{l}2312 \\
1417\end{array}$ & & & 29 & $\begin{array}{l}91 \\
362\end{array}$ & & & \\
\hline & & 5194 & 4 & 05 & & 23.46 & 27. & & & & & \\
\hline 0 & & 0 & & 1 & 0 & 0.00 & & 0 & 0 & 0 & & \\
\hline & & & & & & 0.00 & & & & & & \\
\hline 407 & 58328 & 211127 & 4745 & 288 & 17043 & 19.84 & 23. & 25.49 & 11975 & 434426 & & \\
\hline & & 3007 & & 288 & 2 & 23.22 & & & 9658 & & & \\
\hline & & 640847 & & 283 & 2. & 23.34 & & 29. & & & & \\
\hline & & 63825 & & & 262 & 23.32 & & & 9594 & & & \\
\hline & & 63281 & & 28 & 23 & 23. & & & & & & \\
\hline & & & & & & 23.42 & & & & & & \\
\hline & & & & 28 & 828 & 23.41 & & & & & & \\
\hline & & & $19 ?$ & & 2 & & & & & & & \\
\hline & & & & & & 23. & 27 & & 94 & & & \\
\hline & & & & 27 & 2 & & & & & & & \\
\hline & & & & & 222 & & & & & & & \\
\hline & & & & 27 & 22079 & 23.43 & & & 93 & & & \\
\hline & & & & 22 & 164 & 23.4 & & & & & & \\
\hline & & & & 22 & & 23.48 & & & & & & \\
\hline & & & & & & & & & & & & 2089 \\
\hline & & & & & & & & & & & & \\
\hline & & 382243 & & 40 & 133 & 24.95 & 27. & 30.4 & 1112 & & & 7021 \\
\hline & & & & & & & & & & & & \\
\hline & & & & & & & & & & & & \\
\hline 0 & & 0 & & & & & & 0 & & 0 & & \\
\hline 0 & & & & & & & & & & & & \\
\hline 0 & U & 0 & & 0 & 0 & 0.00 & & 0 & & 0 & 334 & \\
\hline
\end{tabular}




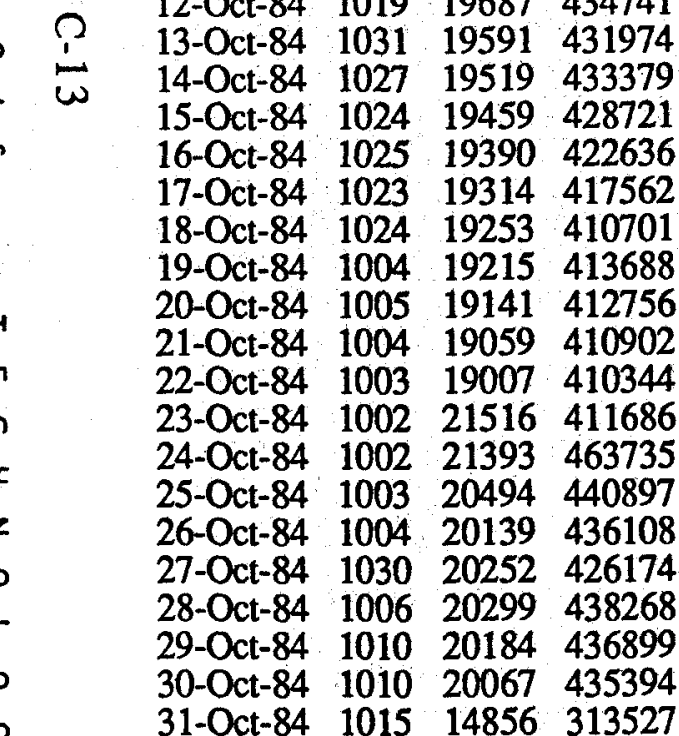

\begin{tabular}{cccc}
$\begin{array}{c}\text { 2nd Stage } \\
\text { Separator }\end{array}$ & $\begin{array}{c}\text { Sales } \\
\text { Gas }\end{array}$ & $\begin{array}{c}\text { Max Surface } \\
\text { Pressure }\end{array}$ & $\begin{array}{l}\text { Brine } \\
\text { Rate }\end{array}$ \\
\hdashline Gas & & $\begin{array}{c}\text { Prod Disp } \\
\text { Press Rate }\end{array}$ & Well Well
\end{tabular}

(psig) (scf/d)

(scf/d)

0
0
0
0
0
0

$$
\begin{aligned}
& 0 \\
& 0 \\
& 0 \\
& 0 \\
& 0 \\
& 0
\end{aligned}
$$

(psig) (psig) (stb/d)

$31026562 \quad 169501$

$\begin{array}{llll}320 & 64574 \quad 377790\end{array}$

$320 \quad 67748 \quad 390374$

$32080393 \quad 478067$

$\begin{array}{lll}325 & 81081 \quad 507255\end{array}$

$32681893 \quad 495468$

$\begin{array}{lll}329 & 80909 \quad 478117\end{array}$

31277782484500

$31058001 \quad 479540$

$\begin{array}{lll}313 & 80229 & 493037\end{array}$

$\begin{array}{llll}389 & 70740 & 475629\end{array}$

$\begin{array}{lll}399 & 68820 & 453872\end{array}$

$40266384 \quad 409370$

$407 \quad 66250 \quad 468262$

$403 \quad 66250 \quad 472544$

$395 \quad 66303 \quad 468739$

$40272728 \quad 460242$

$40272728 \quad 460242$

$349 \quad 84532 \quad 536226$

36020139502739

$\begin{array}{lll}358 & 86270 & 482704\end{array}$

$36483742 \quad 508807$

35784637507933

$33989965 \quad 504226$

35456961360861

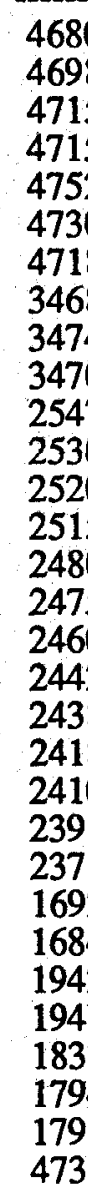

4680

4698

4715

4715

4752

4718

3468

3474

2547

0

0

0
0

0

0
80

$80 \quad 9336$

$0.00 \quad 0.00$

$88 \quad 1426$

10114271

10216602

10318534

$104 \quad 18460$

$107 \quad 18371$

$107 \cdot 18303$

$\begin{array}{ll}106 & 18247\end{array}$

$\begin{array}{lll}106 & 18182\end{array}$

$110 \quad 18111$

11018054

11118017

$111 \quad 17947$

$110 \quad 17871$

$110 \cdot 17822$

11020174

10920059

10519216

10818883

10818991

10919033

10918926

$\begin{array}{lll}1791 & 107 & 18816\end{array}$

$4731 \quad 105 \quad 1393$
Cum Gas/Brine Ratios

1st 2nd Disp Stage Stg Well

$\begin{array}{llll}\text { Calc } & \text { Perf } & \text { Cum } & \text { Cum } \\ \text { BHP } & \text { Gas } & \text { Gas } & \text { Brine }\end{array}$

$0.00 \quad 0.00$

$0.00 \quad 0.00$

$0.00 \quad 0.00$

$0.00 \quad 0.00$

$\begin{array}{ll}0.00 & 0.00\end{array}$

scf/stb
-0
0
0
0
0
0

$\begin{array}{lll}18.27 & 21.12 & 22.85\end{array}$

$21.9526 .48 \quad 28.26$

$\begin{array}{lll}22.62 & 27.36 & 29.15 \\ 23.68 & 28.53 & 30.31\end{array}$

$\begin{array}{lll}23.68 & 28.53 & 30.31\end{array}$

$\begin{array}{rrr}23.63 & 28.01 & 29.81 \\ 23.55 & 27.99 & 29.8\end{array}$

$\begin{array}{lll}23.51 & 27.92 & 29.75\end{array}$

$\begin{array}{llll}23.68 & 27.93 & 29.67\end{array}$

$\begin{array}{llll}23.50 & 26.67 & 28.4\end{array}$

$\begin{array}{lll}23.24 & 27.66 & 29.4\end{array}$

$\begin{array}{llll}23.06 & 26.96 & 29.1\end{array}$

$22.7526 .56 \quad 28.75$

$22.96 \quad 26.65 \quad 28.85$

$23.00 \quad 26.69 \quad 28.92$

$22.99 \quad 26.7028 .91$

$23.02 \quad 26.75 \quad 28.92$

$\begin{array}{lll}20.41 & 24.01 & 26.22\end{array}$

23.1226 .7428 .95

$22.94 \quad 27.34 \quad 29.28$

$23.10 \quad 24.16 \quad 26.15$

$22.4426 .98 \quad 28.96$

$\begin{array}{lll}23.03 & 27.43 & 29.44\end{array}$

$\begin{array}{lll}23.08 & 27.56 & 29.53\end{array}$

$\begin{array}{lll}23.14 & 27.92 & 29.8\end{array}$

$\begin{array}{lll}22.51 & 26.60 & 28.55\end{array}$ (psia) (scf/d)

(scf)

$\begin{array}{ll}0 & 129086334\end{array}$

$\begin{array}{lll}0 & 129086334 & 4362070\end{array}$

$\begin{array}{llll}0 & 129086334 & 4362070\end{array}$

$\begin{array}{llll}0 & 129086334 & 4362070\end{array}$

$\begin{array}{rrrr}0 & 0 & 129086334 & 4362070 \\ 1596 & 213328 & 129299662, & 4371406\end{array}$

$\begin{array}{lllll}10514 & 403101 & 129702762 & 4385670\end{array}$

$10519416000 \quad 130118762 \quad 4399941$

$\begin{array}{lllll}10638 & 503207 & 130621969 & 4416543\end{array}$

$\begin{array}{llll}9806 & 552499 & 131174467 & 4435077\end{array}$

$\begin{array}{lllll}9783 & 550108 & 131724575 & 4453537\end{array}$

$\begin{array}{llll}9767 & 546537 & 132271112 & 4471908\end{array}$

$\begin{array}{llll}9758 & 543050 & 132814162 & 4490211\end{array}$

$\begin{array}{lllll}9722 & 518215 & 133332377 & 4508458\end{array}$

$\begin{array}{llllll}9710 & 534551 & 133866928 & 4526640\end{array}$

$\begin{array}{lllll}9691 & 527030 & 134393958 & 4544751\end{array}$

$\begin{array}{lllll}9669 & 519053 & 134913011 & 4562805\end{array}$

$\begin{array}{lllll}9662 & 519790 & 135432801 & 4580822\end{array}$

$9637 \quad 519027 \quad 135951828 \quad 4598769$

$9624516651 \quad 136468479$ " 4616640

$\begin{array}{llll}9601 & 515412 & 136983891 & 4634462\end{array}$

$9750 \quad 528962 \quad 137512853 \quad 4654636$

$9023 \quad 580708 \quad 138093561 \quad 4674695$

$\begin{array}{llll}8955 & 562644 & 138656206 & 4693911\end{array}$

$\begin{array}{lllll}9212 & 493790 & 139149996 & 4712794\end{array}$

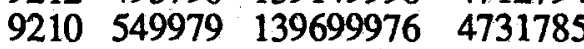

$\begin{array}{lllll}9098 & 560332 & 140260307 & 4750818\end{array}$

$\begin{array}{lllll}9050 & 558885 & 140819192 & 4769744\end{array}$

$\begin{array}{llll}9039 & 560717 & 141379909 & 4788560\end{array}$

$\begin{array}{lllll}11792 & 397702 & 141777610 & 4802490\end{array}$ 


\begin{tabular}{|c|c|c|c|c|c|c|c|c|c|c|c|c|c|c|c|c|c|c|}
\hline \multirow{2}{*}{\multicolumn{2}{|c|}{$\begin{array}{l}z \\
n \\
-1\end{array}$}} & \multirow[t]{2}{*}{ Date } & \multicolumn{3}{|c|}{$\begin{array}{l}\text { 1st Stage } \\
\text { Separator }\end{array}$} & \multicolumn{2}{|c|}{$\begin{array}{l}\text { 2nd Stage } \\
\text { Separator }\end{array}$} & $\begin{array}{c}\text { Sales } \\
\text { Gas }\end{array}$ & \multicolumn{2}{|c|}{$\begin{array}{l}\text { Max Surface } \\
\text { Pressure }\end{array}$} & $\begin{array}{l}\text { Brine } \\
\text { Rate }\end{array}$ & \multicolumn{3}{|c|}{$\begin{array}{c}\text { Cum Gas/Brine } \\
\text { Ratios }\end{array}$} & $\begin{array}{l}\text { Calc } \\
\text { BHP }\end{array}$ & $\begin{array}{l}\text { Perf } \\
\text { Gas }\end{array}$ & $\begin{array}{l}\text { Cum } \\
\text { Gas }\end{array}$ & $\begin{array}{l}\text { Cum } \\
\text { Brine }\end{array}$ \\
\hline & & & $\begin{array}{l}\text { Press } \\
\text { (psig) }\end{array}$ & $\begin{array}{r}\text { Brine } \\
\text { Rate } \\
\text { (RB/d) }\end{array}$ & $\begin{array}{r}\text { Gas } \\
\text { Rate } \\
\text { (scf/d) }\end{array}$ & $\begin{array}{l}\text { Press } \\
\text { (psig) }\end{array}$ & $\begin{array}{r}\text { Gas } \\
\text { Rate } \\
\text { (scf/d) }\end{array}$ & (scf/d) & $\begin{array}{r}\text { Prod } \\
\text { Well } \\
\text { (psig) }\end{array}$ & $\begin{array}{r}\text { Disp } \\
\text { Well } \\
\text { (psig) }\end{array}$ & (stb/d) & $\begin{array}{r}1 s t \\
\text { Stage } \\
(\mathrm{scf} / \mathrm{stb})\end{array}$ & $\begin{array}{r}\text { 2nd } \\
\text { Stg } \\
\text { scf/stb }\end{array}$ & $\begin{array}{c}\text { Disp } \\
\text { Well } \\
\text { (scf/stb) }\end{array}$ & (psia) & (scf/d) & (scf) & (stb) \\
\hline$c$ & & 1-Nov-84 & 016 & & 134130 & 354 & 5014 & 07018 & 167 & ins & & & 70 & 20 & 2025 & 5712 & 224745 & \\
\hline & & 1-Nov-84 & 1016 & & & $\begin{array}{l}354 \\
355\end{array}$ & 85944 & 07018 & & 105 & [891 & 22.95 & 27.49 & & 8925 & $25 / 135$ & $344 / 42$ & 18 \\
\hline & & $\begin{array}{l}\text { Nov-84 } \\
\text { Noy-84 }\end{array}$ & $\begin{array}{l}1015 \\
1015\end{array}$ & $\begin{array}{l}20047 \\
19933\end{array}$ & $\begin{array}{l}433661 \\
428938\end{array}$ & $\begin{array}{l}355 \\
354\end{array}$ & $\begin{array}{l}89663 \\
87133\end{array}$ & $\begin{array}{l}501627 \\
497119\end{array}$ & & 105 & 18798 & 23.07 & 27.84 & & 8895 & 560180 & 94926 & 0206 \\
\hline & & 4-Nov-84 & 1010 & 19808 & 423978 & 352 & 91724 & 493615 & 1625 & 105 & $\begin{array}{l}10091 \\
18573\end{array}$ & 22.83 & $\begin{array}{l}21.01 \\
27.77\end{array}$ & 29.71 & $\begin{array}{l}8009 \\
8849\end{array}$ & $\begin{array}{l}552693 \\
551804\end{array}$ & $\begin{array}{l}143447619 \\
143999423\end{array}$ & $\begin{array}{l}4858897 \\
4877470\end{array}$ \\
\hline & & 5-Nov-84 & 1010 & 19668 & 418830 & 351 & 93705 & 493990 & 1623 & 104 & 18442 & 22.71 & 27.79 & 29.7 & 8838 & 548281 & 144547703 & 4895912 \\
\hline & & $v-84$ & 1012 & 19530 & 416710 & 350 & 92207 & 488798 & 1609 & 104 & 18313 & 22.76 & 27.79 & 29.73 & 8815 & 544445 & 145092149 & 4914225 \\
\hline & & 7-Nov-84 & 1019 & 19391 & 415295 & 353 & 93870 & 486134 & 1605 & 102 & 1818 & 22.84 & 28.00 & 29.96 & 8802 & 544763 & 145636911 & 4932408 \\
\hline 0 & & 8-Nov-84 & 1021 & 19233 & 403504 & 353 & 92565 & 477797 & 1608 & 102 & 18035 & 22.37 & 27.5 & 29.46 & 8797 & 531311 & 146168222 & 4950443 \\
\hline$\pi$ & & $9-\mathrm{N}$ & 1021 & 19104 & 407867 & 355 & 91675 & 475226 & 1595 & 100 & 17914 & 22.77 & 27.89 & 29.85 & 8774 & 733 & 146702955 & 8357 \\
\hline & & .84 & $\begin{array}{l}41020 \\
41019\end{array}$ & $\begin{array}{l}18974 \\
18840\end{array}$ & $\begin{array}{l}405989 \\
404143\end{array}$ & 351 & $\begin{array}{l}91414 \\
90272\end{array}$ & $\begin{array}{l}4 \\
4 \\
2 \\
2 \\
47272780\end{array}$ & $\begin{array}{l}1089 \\
1582\end{array}$ & 101 & $\begin{array}{l}17 / 92 \\
17666\end{array}$ & $\begin{array}{l}22.82 \\
22.88\end{array}$ & $\begin{array}{l}27.96 \\
27.99\end{array}$ & $\begin{array}{r}29.9 \\
2903\end{array}$ & 8760 & 531981 & 147234936 & 36149 \\
\hline & & $12-\mathrm{N}$ & 41019 & 18704 & 398549 & 358 & 91609 & 9468973 & 158 & 91 & 17539 & 22.72 & 27.95 & $\begin{array}{l}29.93 \\
29.93\end{array}$ & $\begin{array}{l}8 / 45 \\
8739\end{array}$ & $\begin{array}{l}528743 \\
524942\end{array}$ & $\begin{array}{l}147763680 \\
148288622\end{array}$ & $\begin{array}{l}5003815 \\
5021354\end{array}$ \\
\hline & & $v-84$ & 41008 & 3396 & 78787 & 0 & 0 & 0 & 4000 & 118 & 3184 & 24.74 & 24.74 & 29.95 & 10711 & 95361 & 148383983 & \\
\hline & & 14-Nov-84 & 41020 & 10790 & 251838 & 356 & 56539 & 390578 & 428 & 83 & 1011 & 24.89 & 30 & 32.45 & 11169 & 328 & 2312 & 50 \\
\hline & & $15-$ & 41010 & 11402 & 266692 & 35 & 54615 & 254378 & 487 & 94 & 10691 & 24.94 & 30.6 & 31.99 & 11789 & 342005 & 54317 & \\
\hline & & $16-N$ & 41011 & 12729 & 298368 & 349 & 59699 & 286275 & 4303 & 94 & 11936 & 25.00 & 30.00 & 31.93 & 11257 & 381116 & 149435433 & 5057283 \\
\hline & & $17-\mathrm{N}$ & 41015 & 10243 & 242246 & 35 & 39333 & 232618 & 47 & 85 & 9605 & 25.22 & 29.32 & 31.26 & 11640 & 300252 & 5686 & \\
\hline & & $18-$ & 41018 & 10588 & 247335 & 350 & 55798 & 303133 & 48 & 83 & 992 & 24.91 & 30 & 32.4 & 11726 & 322362 & 048 & \\
\hline & & $19-\Lambda$ & 41015 & 15690 & 326437 & 352 & 73693 & 377198 & 414 & 84 & 14712 & 22.19 & 27.20 & 29.14 & 11229 & 428708 & & \\
\hline & & $20-\mathrm{N}$ & & & & 0 & & 0 & 0 & 0 & 0 & 0.00 & 0.00 & 0 & 0 & 0 & 6755 & \\
\hline & & $21-1$ & & & & 0 & & & 0 & 0 & 0 & 0.00 & & 0 & 0 & 0 & 86755 & 1528 \\
\hline $\mathbf{m}$ & & 22-Nov-84 & & & & 0 & c & & & 0 & & 0.00 & 0.00 & & & & 150486755 & 5091528 \\
\hline$\Omega$ & & $\begin{array}{l}23-1 \\
24-1\end{array}$ & $\begin{array}{l}41023 \\
41017\end{array}$ & $\begin{array}{r}9014 \\
15505\end{array}$ & $\begin{array}{l}214643 \\
336092\end{array}$ & $\begin{array}{l}355 \\
354\end{array}$ & $\begin{array}{l}37408 \\
6436\end{array}$ & $\begin{array}{ll}8 & 245723 \\
2 & 385546\end{array}$ & $\begin{array}{l}4873 \\
3940\end{array}$ & $\begin{array}{l}84 \\
89\end{array}$ & $\begin{array}{r}8452 \\
14539\end{array}$ & $\begin{array}{l}25.39 \\
23.12\end{array}$ & $\begin{array}{l}29.82 \\
27.54\end{array}$ & $\begin{array}{r}31.78 \\
205\end{array}$ & 11716 & 268605 & 5360 & \\
\hline & & & 41019 & 15544 & 334460 & 352 & 64511 & 382862 & 39 & 90 & 14575 & 22.95 & 27.37 & 29.32 & $\begin{array}{l}11000 \\
11035\end{array}$ & 427339 & $\begin{array}{l}4200 \\
1599\end{array}$ & \\
\hline $\mathbf{z}$ & & $26-1$ & 41019 & 15540 & 335266 & 359 & 64499 & 384223 & 39 & 91 & 14572 & 23.01 & & 29.42 & 11036 & 428708 & 0308 & \\
\hline 0 & & $27-1$ & 41019 & 15693 & 336647 & 354 & 61411 & 382706 & 39 & 91 & 14715 & 22.88 & 27. & 29.01 & 11046 & 426882 & 7190 & \\
\hline$\Gamma$ & & & & 15708 & 346716 & 342 & 61568 & 388574 & 3965 & 67 & 14729 & 23.54 & 27.72 & 29.61 & 11045 & 436126 & 152903316 & 5173110 \\
\hline 1 & & 29 & & & 0 & 0 & c & & 0 & 0 & & 0.00 & 0.00 & 0 & & 0 & & \\
\hline 0 & & & 4 & 1800 & 0 & 0 & c & 0 & 0 & 0 & 1682 & 0.00 & 0.00 & 0.08 & 6615 & 135 & 152903450 & 5174792 \\
\hline & & & & & & & & & & & & & & & & & & \\
\hline & & & & & & & & & & & & & & & & & & \\
\hline
\end{tabular}




\begin{tabular}{cc} 
Date & $\begin{array}{c}\text { 1st Stage } \\
\text { Separator }\end{array}$ \\
\hline (psig) $(\mathrm{RB} / \mathrm{d}) \quad$ (scf/d)
\end{tabular}

$\begin{array}{llll}1-D e c-84 & 1000 & 9311 & 207542\end{array}$ $\begin{array}{llll}2-D e c-84 & 1010 & 15052 & 306767\end{array}$ 3-Dec-84 $1010 \quad 15066 \quad 308814$ 4-Dec-84 $\quad 1010 \quad 15097 \quad 312278$ 5-Dec-84 $1013 \quad 15096 \quad 321096$ 6-Dec-84 $1013 \quad 15152 \quad 322016$ 7-Dec-84 $\quad 1012 \quad 15186 \quad 319789$ 8-Dec-84 $1014 \quad 15217 \quad 320093$ 9-Dec-84 $1015 \quad 15200 \quad 319512$ 10-Dec-84 $1014 \quad 15201 \quad 320781$ 11-Dec-84 $1030 \quad 15203 \quad 318826$ 12-Dec-84 $1012 \quad 15196 \quad 300625$ 13-Dec-84 $1010 \quad 15219 \quad 314165$ 14-Dec-84 $1014 \quad 15213 \quad 311358$ 15-Dec-84 $1014 \quad 15222 \quad 311019$ 16-Dec-84 $1014 \quad 15236 \quad 311019$ 17-Dec-84 $1012 \quad 15235 \quad 310608$ 18-Dec-84 $1012 \quad 15219 \quad 311581$ 19-Dec-84 $1013 \quad 15228 \quad 312533$ 20-Dec-84 $1014 \quad 15241 \quad 314281$ 21-Dec-84 $1014 \quad 15328 \quad 315901$ 22-Dec-84 $1013 \quad 15258 \quad 314956$ 23-Dec-84 $1014 \quad 15264 \quad 316908$ 24-Dec-84 $1013 \quad 15269 \quad 317884$ 25-Dec-84 $1014 \quad 15276 \quad 317340$ 26-Dec-84 $1014 \quad 15294 \quad 329275$ 27-Dec-84 $1014 \quad 15300 \quad 327787$ 28-Dec-84 $1014 \quad 15315318387$ 29-Dec-84 $1013 \quad 15328 \quad 319137$ 30-Dec-84 $1013 \quad 15332 \quad 318892$ 31-Dec-84 $1012 \quad 15331319049$ \begin{tabular}{cccc}
$\begin{array}{c}\text { 2nd Stage } \\
\text { Separator }\end{array}$ & $\begin{array}{c}\text { Sales } \\
\text { Gas }\end{array}$ & $\begin{array}{c}\text { Max Surface } \\
\text { Pressure }\end{array}$ & $\begin{array}{c}\text { Brine } \\
\text { Rate }\end{array}$ \\
\hline Gas & & $\begin{array}{c}\text { Prod Disp } \\
\text { Press Rate }\end{array}$ & $\begin{array}{l}\text { Well Well } \\
\text { Pres }\end{array}$
\end{tabular}

(psig) (scf/d) (scf/d) (psig) (psig) (stb/d) (scf/stb)(scf/stb)(scf/stb) (psia)

$\begin{array}{llllllllll}347 & 31564 & 190298 & 4816 & 90 & 8730 & 23.77 & 27.39 & 29.31 & 11671\end{array}$

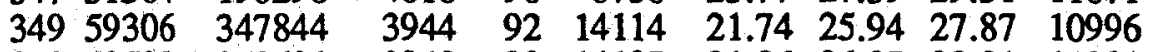

$\begin{array}{llllllllll}350 & 59532 & 350631 & 3948 & 92 & 14127 & 21.86 & 26.07 & 28.01 & 11001\end{array}$

$\begin{array}{lllllllll}346.59062 & 352048 & 3937 & 92 & 14156 & 22.06 & 26.23 & 28.15 & 10991\end{array}$

$\begin{array}{llllllllll}3499 & 58954 & 315329 & 3934 & 93 & 14155 & 22.68 & 26.85 & 28.78 & 10986\end{array}$

$\begin{array}{llllllllll}358 & 59446 & 336121 & 3927 & 93 & 14208 & 22.67 & 26.85 & 28.83 & 10982\end{array}$

$\begin{array}{llllllllll}368 & 59352 & 357375 & 3940 & 95 & 14239 & 22.46 & 26.63 & 28.66 & 10997\end{array}$

$\begin{array}{llllllllll}357 & 59954 & 357634 & 3940 & 97 & 14269 & 22.43 & 26.64 & 28.61 & 10998\end{array}$

$\begin{array}{llllllllll}358 & 60764 & 360162 & 3940 & 97 & 14253 & 22.42 & 26.68 & 28.66 & 10998\end{array}$

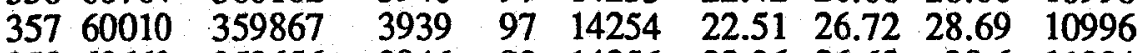

$\begin{array}{llllllllll}358 & 60663 & 359656 & 3946 & 93 & 14256 & 22.36 & 26.62 & 28.6 & 11004\end{array}$

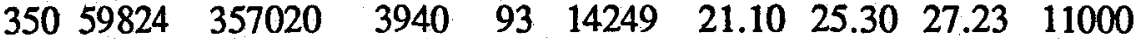

$\begin{array}{llllllllll}348 & 58487 & 360240 & 3941 & 93 & 14270 & 22.02 & 26.11 & 28.04 & 11001\end{array}$

$\begin{array}{llllllllll}351 & 59029 & 359728 & 3940 & 93 & 14265 & 21.83 & 25.97 & 27.91 & 10999\end{array}$

$\begin{array}{llllllllll}347 & 59683 & 357899 & 3940 & 93 & 14273 & 21.79 & 25.97 & 27.89 & 11000\end{array}$

$\begin{array}{llllllllll}351 & 58874 & 356196 & 3938 & 94 & 14286 & 21.77 & 25.89 & 27.83 & 10999\end{array}$

$\begin{array}{llllllllll}353 & 59055 & 358396 & 3939 & 94 & 14285 & 21.74 & 25.88 & 27.83 & 11000\end{array}$

$\begin{array}{llllllllll}352 & 60021 & 358720 & 3940 & 94 & 14270 & 21.83 & 26.04 & 27.99 & 11000\end{array}$

$\begin{array}{llllllllll}353 & 61119 & 358398 & 3942 & 95 & 14279 & 21.89 & 26.17 & 28.12 & 11002\end{array}$

$\begin{array}{llllllllll}352 & 61209 & 362252 & 3943 & 95 & 14291 & 21.99 & 26.27 & 28.22 & 11003\end{array}$

$\begin{array}{llllllllll}350 & 60212 & 364377 & 3940 & 95 & 14373 & 21.98 & 26.17 & 28.11 & 11004\end{array}$

$\begin{array}{llllllllll}356 & 60291 & 365426 & 3940 & 94 & 14307 & 22.01 & 26.23 & 28.2 & 11001\end{array}$

$\begin{array}{llllllllll}352 & 58276 & 362511 & 3937 & 94 & 14313 & 22.14 & 26.21 & 28.16 & 10998\end{array}$

$\begin{array}{llllllllll}353 & 59165 & 365392 & 3939 & 96 & 14317 & 22.20 & 26.34 & 28.29 & 11000\end{array}$

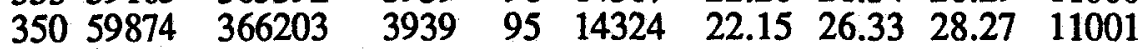

$\begin{array}{llllllllll}352 & 58924 & 370428 & 3940 & 94 & 14341 & 22.96 & 27.07 & 29.02 & 11001\end{array}$

$\begin{array}{llllllllll}347 & 60276 & 367745 & 3936 & 95 & 14346 & 22.85 & 27.05 & 28.97 & 10998\end{array}$

$\begin{array}{llllllllll}350 & 59733 & 367790 & 3935 & 94 & 14360 & 22.17 & 26.33 & 28.27 & 10998\end{array}$

$35059733 \quad 367790$

35259331369748

$34959884 \quad 369272$ $\begin{array}{lllllll}3931 & 95 & 14373 & 22.20 & 26.36 & 28.3 & 10995\end{array}$

$\begin{array}{lllllll}3931 & 95 & 14376 & 22.18 & 26.31 & 28.26 & 10995\end{array}$

$\begin{array}{lllllll}3929 & 95 & 14375 & 22.19 & 26.36 & 28.29 & 10993\end{array}$ $(\mathrm{scf} / \mathrm{d}) \quad(\mathrm{scf}) \quad(\mathrm{stb})$

$255876153159326 \quad 5183522$

$393357153552684 \quad 5197636$

$395697153948381 \quad 5211763$

$398491154346872 \quad 5225919$

$407381 \quad 154754253 \quad 5240074$

$409617155163870 \quad 5254282$

$\begin{array}{llll}408090 & 155571960 & 5268521\end{array}$

$408236155980196 \quad 5282790$

$408491156388687 \quad 5297043$

$40777156797634 \quad 5311297$

$\begin{array}{llll}388000 & 157593356 & 5339802\end{array}$

$400131 \quad 157993487 \quad 5354072$

$\begin{array}{lll}398136 & 158391623 & 5368337\end{array}$

$398074158789697 \quad 5382610$

$397579159187276 \quad 5396896$

$397552159584828 \quad 5411181$

$399417159984245 \quad 5425451$

$401525160385770 \quad 5439730$

$403292160789062 \quad 5454021$

$404025161193087 \quad 5468394$

$403457161596545 \quad 5482701$

$403054161999599 \quad 5497014$

$405028162404627 \quad 5511331$

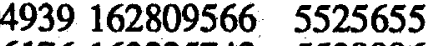

(163225742 5539996

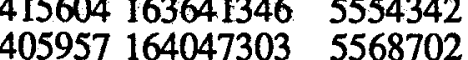

$406756164454059 \quad 5583075$

$406266164860325 \quad 5597451$

4066691652669935611826 


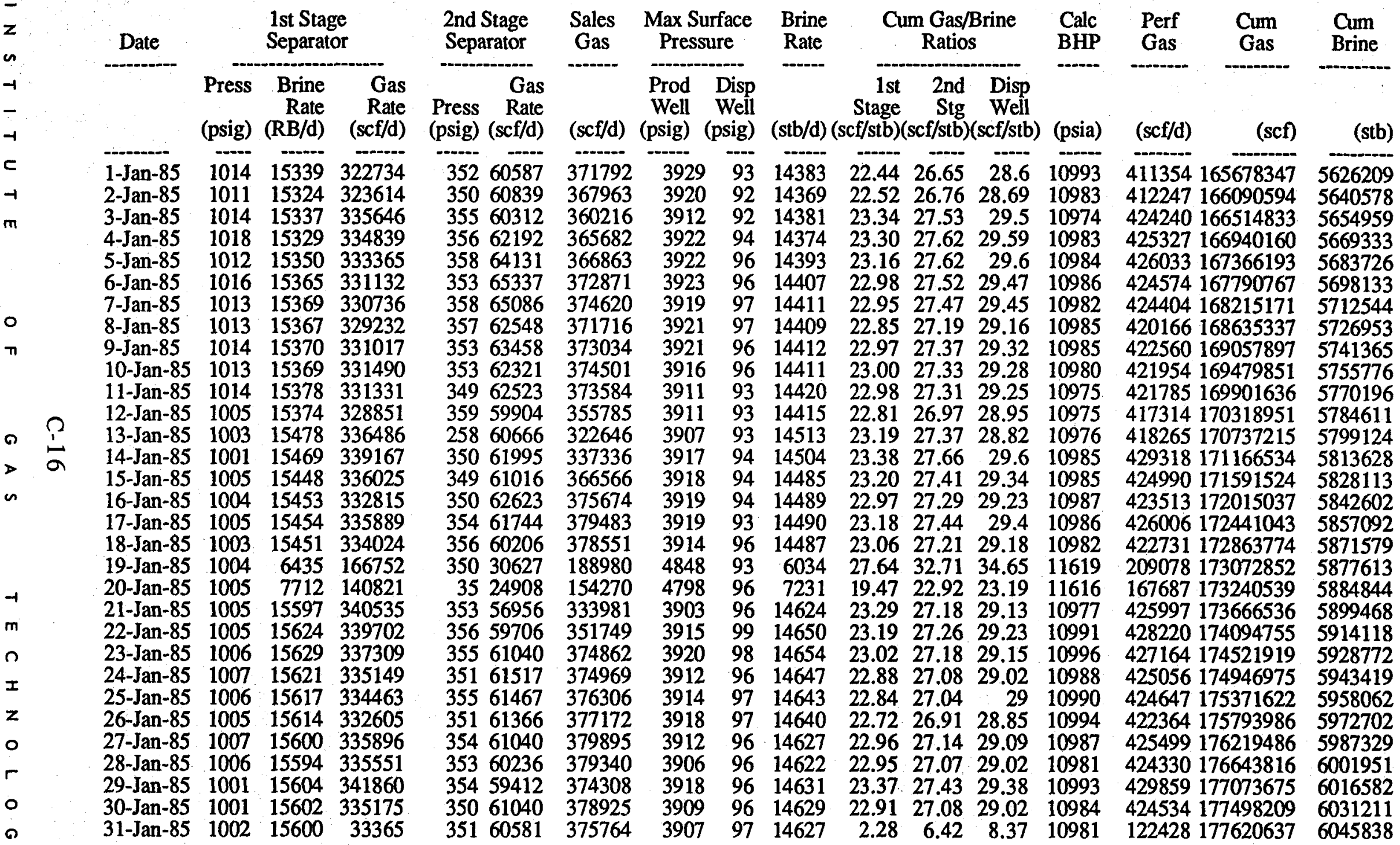




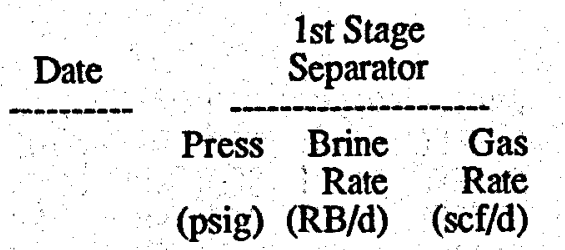

1-Feb-85

15582342331

3-Feb-85 $1002 \quad 15590 \quad 343643$

4-Feb-85 $\quad 1000 \quad 15585 \quad 344914$

$\begin{array}{lllll}5-\mathrm{Feb}-85 & 1003 & 15590 & 343167\end{array}$

6-Feb-85 $\quad 1002 \quad 15597 \quad 335757$

7-Feb-85 $\quad 1003 \quad 15596 \quad 334047$

8-Feb-85 $1003 \quad 15559 \quad 334586$

9-Feb-85 $1007 \quad 15576 \quad 330210$

10-Feb-85 $1007 \quad 15577 \quad 327927$

11-Feb-85 $1007 \quad 15576 \quad 326750$

12-Feb-85 $1005 \quad 15567 \quad 334248$

13-Feb-85 $1007 \quad 15573 \quad 327540$

14-Feb-85 $1008 \quad 15573 \quad 325256$

15-Feb-85 $1008 \quad 15565 \quad 331790$

16-Feb-85 $1008 \quad 15561336857$

17-Feb-85 $1008 \quad 15559 \quad 335557$

18-Feb-85 $1008 \quad 15560 \quad 330660$

19-Feb-85 1008 15557 332007

20-Feb-85 $1009 \quad 15555 \quad 332097$

21-Feb-85 $1009 \quad 15550 \quad 334405$

22-Feb-85 $1008 \quad 15535 \quad 332827$

23-Feb-85 $1003 \quad 15558 \quad 335751$

24-Feb-85 $1006 \quad 15549338332$

25-Feb-85 $1006 \quad 15516 \quad 340682$

26-Feb-85 $1006 \quad 15520 \quad 339469$

27-Feb-85 $1007 \quad 15518 \quad 338567$

28-Feb-85 $1008 \quad 15517 \quad 338887$

\begin{tabular}{|c|c|c|c|c|c|c|c|c|c|c|}
\hline \multicolumn{2}{|c|}{$\begin{array}{l}\text { 2nd Stage } \\
\text { Separator }\end{array}$} & $\begin{array}{l}\text { Sales } \\
\text { Gas }\end{array}$ & \multicolumn{2}{|c|}{$\begin{array}{l}\text { Max Surface } \\
\text { Pressure }\end{array}$} & & \multicolumn{3}{|c|}{$\begin{array}{c}\text { Cum Gas/Brine } \\
\text { Ratios }\end{array}$} & $\begin{array}{l}\text { Calc } \\
\text { BHP }\end{array}$ \\
\hline $\begin{array}{l}\text { Press } \\
\text { psig) }\end{array}$ & $\begin{array}{r}\text { Gas } \\
\text { Rate } \\
\text { (scf/d) }\end{array}$ & (scf/d) & $\begin{array}{c}\text { Prod } \\
\text { Well } \\
\text { (psig) }\end{array}$ & $\begin{array}{r}\mathrm{Di} \\
\mathrm{W} \\
(\mathrm{psi}\end{array}$ & & & $\begin{array}{r}1 \text { st } \\
\text { Stage } \\
\text { cf/stb) }\end{array}$ & $\begin{array}{r}2 \text { nd } \\
\text { Stg } \\
\text { scf/stb) }\end{array}$ & $\begin{array}{c}\text { Disp } \\
\text { Well } \\
\text { (scf/stb) }\end{array}$ & (psia) \\
\hline & 6990 & 3 & & & & 14610 & & & & \\
\hline & & & & & & & & & & \\
\hline & & 3 & 389 & & & & & & & 10966 \\
\hline & & 3873 & 387 & & & 14613 & 3.60 & 27.53 & & \\
\hline & & 6585 & 389 & & & 14618 & 23.48 & 27.55 & & \\
\hline & & 7739 & 389 & & & 14624 & & & & 10969 \\
\hline & & 1738 & 389 & & & 14623 & & & 28.8 & 10967 \\
\hline & & 4017 & & & & & & & & 10968 \\
\hline & & 7178 & 3 & & & 05 & & & & 10971 \\
\hline & & & 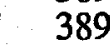 & & & 146 & & & & \\
\hline & & & & & & & & & & \\
\hline & & 32 & & & & & & & & 10959 \\
\hline & & & & & & & & & & \\
\hline & & & & & & & & & & \\
\hline & & 37 & & & & & & & & \\
\hline & & 37 & & & & & & & & \\
\hline & & & & & & & & & & 10962 \\
\hline & & & & & & 14590 & & & & 10960 \\
\hline & & & & & & & & & & 10962 \\
\hline & & & & & & & & & & \\
\hline & & & & & & & & & & \\
\hline & & 37 & & & & & & & & 10952 \\
\hline & & & & & & & & & & 10951 \\
\hline & & & & & & 145 & & & & 10955 \\
\hline & & & & & & & & & & \\
\hline & & & & & & & & & & \\
\hline & & 375847 & & & & 14550 & & & & 10787 \\
\hline & & 4968 & & & & & & & & \\
\hline
\end{tabular}

Perf
Gas

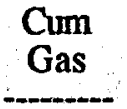

Cum

Brine

(scf/d) (scf)

(stb)

$427927178048563 \quad 6060448$

$426874178475437 \quad 6075032$

$430646178906083 \quad 6089650$

$430499179336582 \quad 6104263$

$\begin{array}{lll}431231 & 179767813 & 6118881\end{array}$

$423804180191617 \quad 6133505$

$421142180612759 \quad 6148128$

$\begin{array}{ll}417245181030005 & 6162717\end{array}$

$413322181443326 \quad 6177322$

$411597181854923 \quad 6191928$

$409962182264886 \quad 6206533$

$416716182681601 \quad 6221129$

$412360183093962 \quad 6235731$

$410462183504424 \quad 6250333$

4166871839211116264928

$420804184341916 \quad 6279519$

4201631847620796294108

$\begin{array}{lll}415961 & 185178040 & 6308698\end{array}$

$417772185595812 \quad 6323285$

$417569186013380 \quad 6337870$

$418912186432292 \quad 6352451$

$\begin{array}{lll}416733186849026 & 6367017\end{array}$

$\begin{array}{lll}421156187270181 & 6381605\end{array}$

$423957187694138 \quad 6396184$

$425995188120133 \quad 6410733$

$426228188546361 \quad 6425285$

$426170188972531 \quad 6439835$

$426752189399282 \quad 6454385$ 
12-Mar-85 $1004 \quad 15513 \quad 335760$

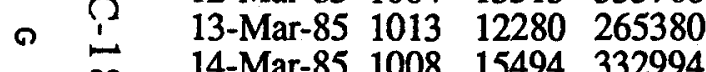

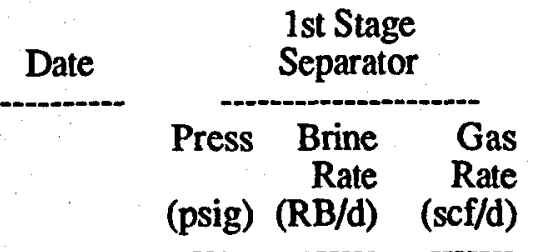

1-Mar-85 $1006 \quad 15532 \quad 338079$

2-Mar-85 $1009 \quad 15540 \quad 336995$

3-Mar-85 $1008 \quad 15540 \quad 336165$

4-Mar-85 $1013 \quad 15519337201$

5-Mar-85 $1013 \quad 15515 \quad 338656$

6-Mar-85 $1012 \quad 15504 \quad 337300$

7-Mar-85 $1012 \quad 15501333827$

8-Mar-85 $1015 \quad 15494 \quad 330332$

9-Mar-85 $1003 \quad 15499 \quad 335485$

10-Mar-85 $1003 \quad 15532 \quad 337547$

$\begin{array}{llll}11-M a r-85 & 1003 & 15540 & 336744\end{array}$

15-Mar-85 $1011 \quad 15528 \quad 335891$

16-Mar-85 $100915506 \quad 337545$ 17-Mar-85 $1025 \quad 9611 \quad 209417$

18-Mar-85 $1009 \quad 15592 \quad 334082$ 19-Mar-85 $1017 \quad 14993 \quad 314938$ 20-Mar-85 $1019 \quad 15588 \quad 333006$ 21-Mar-85 $1015 \quad 15541332863$ 22-Mar-85 $1009 \quad 15556 \quad 334530$ 23-Mar-85 $1005 \quad 15589334447$ 24-Mar-85 $1001 \quad 15603 \quad 333717$ 25-Mar-85 $1009 \quad 15582 \quad 333604$ 26-Mar-85 $1013 \quad 15559 \quad 332318$ 27-Mar-85 $1011 \quad 15557 \quad 330610$ 28-Mar-85 $1008 \quad 15574 \quad 333341$ 29-Mar-85 $1008 \quad 15571333190$

30-Mar-85 $1009 \quad 15561 \quad 332238$

31-Mar-85 $1008 \quad 15560 \quad 333589$ 2nd Stage Sales Max Surface Brine Separator Gas Pressure Rate

Press Rate

(psig) (scf/d)

35359405

35459890

34961831

34961100

35459820

35359173

35460319

35062439

35160630

35259691

35259458

35159404

34948233

35162386

35060412

35060814

35237931

35660560

35455814

35660685

32370788

32072643

31973687

32072363

32073858

32174295

33069740

33069071

32562542

32057855

31158589

Prod Disp

Well Well

380062

378024

235691

372010

351589

376872

378861

384329

382469

385013

381533

379614

377770

374318

377324

333589 (scf/d) (psig) (psig) (stb/d) (scf/stb)(scf/stb)(scf/stb) (psia)

$\begin{array}{llllllll}373384 & 3720 & 91 & 14564 & 23.21 & 27.29 & 29.25 & 10786\end{array}$

$\begin{array}{llllllll}374984 & 3718 & 92 & 14571 & 23.13 & 27.24 & 29.2 & 10785\end{array}$

$\begin{array}{lllllllll}380531 & 3715 & 92 & 14571 & 23.07 & 27.31 & 29.25 & 10781\end{array}$

$\begin{array}{llllllll}381167 & 3717 & 91 & 14552 & 23.17 & 27.37 & 29.3 & 10782\end{array}$

$\begin{array}{llllllll}382656 & 3718 & 91 & 14548 & 23.28 & 27.39 & 29.35 & 10783\end{array}$

$\begin{array}{llllllll}380439 & 3715 & 90 & 14538 & 23.20 & 27.27 & 29.23 & 10780\end{array}$

$\begin{array}{lllllllll}374416 & 3716 & 94 & 14535 & 22.97 & 27.12 & 29.08 & 10781\end{array}$

$\begin{array}{llllllll}378542 & 3710 & 93 & 14528 & 22.74 & 27.03 & 28.97 & 10775\end{array}$

$\begin{array}{llllllll}382535 & 3711 & 93 & 14532 & 23.09 & 27.26 & 29.2 & 10775\end{array}$

$\begin{array}{lllllllll}382939 & 3711 & 94 & 14563 & 23.18 & 27.28 & 29.22 & 10777\end{array}$

$\begin{array}{lllllllll}381558 & 3709 & 93 & 14571 & 23.11 & 27.19 & 29.14 & 10775\end{array}$

$\begin{array}{lllllllll}344646 & 3709 & 93 & 14546 & 23.08 & 27.17 & 29.11 & 10774\end{array}$

$\begin{array}{llllllll}280145 & 3721 & 91 & 11515 & 23.05 & 27.24 & 29.17 & 10648\end{array}$

$\begin{array}{llllllll}382782 & 3716 & 92 & 14528 & 22.92 & 27.22 & 29.16 & 10780\end{array}$ $\begin{array}{lllllll}3716 & 89 & 14560 & 23.07 & 27.22 & 29.16 & 10782\end{array}$

$\begin{array}{lllllll}3727 & 91 & 9012 & 23.24 & 27.45 & 29.39 & 10562\end{array}$

$\begin{array}{llllllll}3723 & 95 & 14620 & 22.85 & 26.99 & 28.96 & 10793\end{array}$

$\begin{array}{llllllll}3724 & 97 & 14059 & 22.40 & 26.37 & 28.33 & 10767\end{array}$

$\begin{array}{llllllll}3721 & 96 & 14617 & 22.78 & 26.93 & 28.9 & 10791\end{array}$

$\begin{array}{lllllll}3719 & 93 & 14572 & 22.84 & 27.70 & 29.5 & 10785\end{array}$

$\begin{array}{llllllll}3719 & 93 & 14586 & 22.93 & 27.91 & 29.7 & 10785\end{array}$

$\begin{array}{lllllll}3718 & 94 & 14617 & 22.88 & 27.92 & 29.7 & 10786\end{array}$

$\begin{array}{lllllll}3721 & 94 & 14630 & 22.81 & 27.76 & 29.54 & 10790\end{array}$

$\begin{array}{llllllll}3716 & 95 & 14611 & 22.83 & 27.89 & 29.67 & 10784\end{array}$

$\begin{array}{llllllll}3716 & 95 & 14589 & 22.78 & 27.87 & 29.66 & 10783\end{array}$

$\begin{array}{lllllll}3712 & 93 & 14587 & 22.66 & 27.45 & 29.28 & 10779\end{array}$

$\begin{array}{lllllll}3710 & 94 & 14603 & 22.83 & 27.56 & 29.39 & 10778\end{array}$

$\begin{array}{llllllll}3709 & 101 & 14600 & 22.82 & 27.10 & 28.91 & 10777\end{array}$

$\begin{array}{llllllll}3709 & 101 & 14591 & 22.77 & 26.74 & 28.52 & 10778\end{array}$

$\begin{array}{lllllll}3711 & 101 & 14590 & 22.86 & 26.88 & 28.61 & 10780\end{array}$ $\begin{array}{lllllll}3717 & 90 & 14539 & 23.22 & 27.40 & 29.34 & 10782\end{array}$

\begin{tabular}{lrr}
$(\mathrm{scf} / \mathrm{d})$ & $(\mathrm{scf})$ & $(\mathrm{stb})$ \\
\hdashline$-(\mathrm{n})$ &
\end{tabular}

$425997189825279 \quad 6468949$

$425473190250752 \quad 6483520$

$426202190676954 \quad 6498091$

(191530312 652719

424946191955257 6541729

$422678192377935 \quad 6556264$

420876 $192798811 \quad 6570792$

$424334193223146 \quad 6585324$

$425531193648677 \quad 6599887$

$424599194073275 \quad 6614458$

(2)

3358931948326026640519

$423636195256239 \quad 6655047$

$424570195680808 \quad 6669607$

$426574196107382 \quad 6684146$

264863 $196372245 \quad 6693158$

$\begin{array}{lll}23395 & 196795640 \quad 6707778\end{array}$

622431
$197616363 \quad 6736454$

429874 $198046237 \quad 675102$

\begin{tabular}{l}
$434125198913566 \quad 6780229$ \\
\hline
\end{tabular}

$432170199345736 \quad 6794859$

$432710200211955 \quad 6824059$

$427107200639062 \quad 6838646$

$429182201068244 \quad 6853249$

$422086201490330 \quad 6867849$

$416135201906465 \quad 6882440$

$417420202323885 \quad 6897030$ 


\begin{tabular}{|c|c|c|}
\hline Date & & $\begin{array}{l}\text { 1st Sta } \\
\text { Separa }\end{array}$ \\
\hline & $\begin{array}{l}\text { Press } \\
\text { (psig) }\end{array}$ & $\begin{array}{r}\text { Brine } \\
\text { Rate } \\
\text { (RB/d) }\end{array}$ \\
\hline
\end{tabular}

$\begin{array}{llll}1-A p r-85 & 1008 & 11672 & 277604\end{array}$ $\begin{array}{lllll}2-A p r-85 & 998 & 12760 & 275914\end{array}$ 3-Apr-85 $1005 \quad 11288 \quad 260188$ 4-Apr-85 $\quad 1007 \quad 15586 \quad 334150$ $\begin{array}{llll}5-A p r-85 & 1008 & 15572 & 334304\end{array}$ $\begin{array}{lllll}6-A p r-85 & 1003 & 15539 & 336854\end{array}$ $\begin{array}{lllll}7-A p r-85 & 1003 & 15514 & 337240\end{array}$ $\begin{array}{llll}8-A p r-85 & 1003 & 15510 & 337371\end{array}$ $\begin{array}{lllll}9-A p r-85 & 1003 & 10300 & 239305\end{array}$ 10-Apr-85

11-Apr-85 12-Apr-85 13-Apr-85 14-Apr-85 15-Apr-85 16-Apr-85

17-Apr-85 18-Apr-85 19-Apr-85 $1010 \quad 12451 \quad 256365$ $\begin{array}{lllll}20 \text {-Apr-85 } & 1009 & 15689 & 340723\end{array}$ 21-Apr-85 $1009 \quad 15681 \quad 342456$ 22-Apr-85 $1009 \quad 15700 \quad 342504$ 23-Apr-85 $1010 \quad 15697 \quad 343236$ 24-Apr-85 $1009 \quad 15699 \quad 343848$ 25-Apr-85 $1009 \quad 15689 \quad 343704$ 26-Apr-85 $1009 \quad 15694 \quad 347535$ $\begin{array}{lllll}27-A p r-85 & 1010 & 15699 & 346068\end{array}$ 28-Apr-85 $1010 \quad 15696 \quad 347170$ 29-Apr-85 $1010 \quad 15699 \quad 347170$ 30-Apr-85 $1010 \quad 15656 \quad 346814$ 2nd Stage Sales Max Surface Brine Separator Gas Pressure Rate Prod Disp Well Well Cum Brine Ratios

BHP Perf

Gas $\begin{array}{ll}\text { Cum } & \text { Cum } \\ \text { Gas } & \text { Brine }\end{array}$ 1st 2nd Disp Press Rate (psig) (scf/d)

(scf/d) (psig) (psig) (stb/d) (scf/stb)(scf/stb)(scf/stb) (psia)

31350534 31350534 32046393 30461315 30262042 30262870 32060125

31659530

31659530

$\begin{array}{ll}0 & 0 \\ 0 & 0 \\ 0 & 0 \\ 0 & 0 \\ 0 & 0 \\ 0 & 0 \\ 0 & 0 \\ 0 & 0 \\ 0 & 0\end{array}$

31445641

31561309

31561122

30761976

31061667

31561983

31562456

30962660

31561595

31861085

33059664

33059786

316999

$\begin{array}{llllllllll}316999 & 3735 & 105 & 11964 & 23.06 & 27.29 & 29.03 & 10681\end{array}$

$\begin{array}{llllllllll}248490 & 4588 & 103 & 10584 & 24.58 & 28.97 & 30.75 & 11498\end{array}$

$\begin{array}{lllllllll}389848 & 3725 & 104 & 14614 & 22.86 & 27.06 & 28.76 & 10795\end{array}$

$\begin{array}{lllllllllll}390925 & 3721 & 105 & 14601 & 22.90 & 27.14 & 28.83 & 10790\end{array}$

$\begin{array}{llllllllll}391580 & 3724 & 107 & 14570 & 23.12 & 27.43 & 29.12 & 10791\end{array}$

$\begin{array}{lllllllll}387448 & 3723 & 109 & 14547 & 23.18 & 27.32 & 29.1 & 10789\end{array}$

389115

295270

393734

394849

396261

399199

399159

397550

394277

394822

397455

398089 $\begin{array}{lll}4581 & 103 & 10944\end{array}$

$\begin{array}{llll}25.37 & 29.98 & 31.73 & 11503\end{array}$

$3720 \quad 108 \quad 145$

$\begin{array}{llll}23.20 & 27.29 & 29.05 & 10786\end{array}$

$\begin{array}{llllllll}3698 & 109 & 9658 & 24.78 & 30.94 & 32.7 & 10544\end{array}$

$\begin{array}{llll}0 & 0.00 & 0.00\end{array}$

$0.00 \quad 0.00$

$0.00 \quad 0.00$

$0.00 \quad 0.00$

$0.00 \div 0.00$

$0.00 \quad 0.00$

$0.00 \quad 0.00$

$0.00 \quad 0.00$

$0.00 \quad 0.00$

(scf/d) (scf) (stb)

$\begin{array}{lll}347253 & 202671138 & 6907974\end{array}$ $\begin{array}{lll}347315 & 203018453 & 6919938\end{array}$ $325458203343911 \quad 6930522$ $420299203764210 \quad 6945136$ 420947204185157 6959737 $424278204609435 \quad 6974307$ $423318205032753 \quad 6988854$ $422474205455227 \quad 7003397$ $0205771044 \quad 7013055$ 02057710447013055 02057710447013055 $0205771044 \quad 7013055$ 0 $205771044 \quad 7013055$ $0205771044 \quad 7013055$ $0205771044 \quad 7013055$ 02057710447013055 02057710447013055 $\begin{array}{llllllllll}3806 & 117 & 11675 & 21.96 & 25.87 & 27.62 & 10745 & 322464 & 206093507 & 7024730\end{array}$ $\begin{array}{llllllll}3800 & 118 & 14711 & 23.16 & 27.33 & 29.08 & 10876\end{array}$ $\begin{array}{lllllll}3793 & 118 & 14703 & 23.29 & 27.45 & 29.2 & 10868\end{array}$ $\begin{array}{lllllll}3788 & 119 & 14721 & 23.27 & 27.48 & 29.19 & 10864\end{array}$ $\begin{array}{lllllll}3786 & 121 & 14718 & 23.32 & 27.51 & 29.24 & 10862\end{array}$ $\begin{array}{lllllll}3783 & 122 & 14720 & 23.36 & 27.57 & 29.32 & 10859\end{array}$ $\begin{array}{lllllll}3790 & 124 & 14711 & 23.36 & 27.61 & 29.36 & 10865\end{array}$ $\begin{array}{lllllll}3772 & 123 & 14716 & 23.62 & 27.87 & 29.6 & 10847\end{array}$ $\begin{array}{llllllll}3773 & 123 & 14720 & 23.51 & 27.69 & 29.45 & 10848\end{array}$ $\begin{array}{lllllll}3780 & 124 & 14718 & 23.59 & 27.74 & 29.51 & 10855\end{array}$ $\begin{array}{lllllll}3773 & 128 & 14720 & 23.58 & 27.64 & 29.47 & 10848\end{array}$ $\begin{array}{lllllll}3771 & 113 & 14680 & 23.62 & 27.70 & 29.53 & 10844\end{array}$ $315817205771044 \quad 7013055$ 


\begin{tabular}{|c|c|c|c|}
\hline Date & & $\begin{array}{l}\text { 1st Sta } \\
\text { Separa }\end{array}$ & \\
\hline & $\begin{array}{l}\text { Press } \\
\text { (psig) }\end{array}$ & $\begin{array}{r}\text { Brine } \\
\text { Rate } \\
\text { (RB/d) }\end{array}$ & $\begin{array}{r}\text { Gas } \\
\text { Rate } \\
\text { (scf/d) }\end{array}$ \\
\hline
\end{tabular}

1-May-85 $1010 \quad 15733 \quad 347080$

2-May-85 $1008 \quad 15644335680$

$\begin{array}{llrl}3-M a y-85 & 0 & 7823 & 167480\end{array}$

$\begin{array}{rrrr}\text { 4-May-85 } & 0 & 0 & 0 \\ \text { 5-May-85 } & 1014 & 15953 & 277735\end{array}$

$\begin{array}{lrrr}\text { 5-May-85 } & 1014 & 15953 & 277735 \\ \text { 6-May-85 } & 1010 & 15920 & 343732\end{array}$

7-May-85 $1010 \quad 15925 \quad 347533$

8-May-85 $1011 \quad 15922348153$

9-May-85 $1011 \quad 15917349006$

10-May-85 101015912349556

11-May-85 $100915903 \quad 349566$

12-May-85 100915901351027

13-May-85 101015900349374

14-May-85 101015894350697

15-May-85 $101015903 \quad 359150$

16-May-85 $1010 \quad 15896 \quad 352856$

17-May-85 $1010 \quad 9360 \quad 196245$

18-May-85 $1002 \quad 15482 \quad 389520$

19-May-85 $1003 \quad 15492 \quad 337850$

20-May-85 $1002 \quad 15512 \quad 333820$

21-May-85 $1001 \quad 15534339163$

22-May-85 $1003 \quad 12098249535$

23-May-85 99815587344414

24-May-85

4698

25-May-85

26-May-85 1011

27-May-85 $1010 \quad 13464 \quad 303279$

28-May-85 $1010 \quad 15623 \quad 341861$

29-May-85 $1012 \quad 15617 \quad 342230$

30-May-85 $100915610 \quad 341990$

31-May-85 $1010 \quad 15633 \quad 347929$

\begin{tabular}{|c|c|c|c|c|c|c|c|c|c|c|c|c|}
\hline \multicolumn{2}{|c|}{$\begin{array}{l}\text { 2nd Stage } \\
\text { Separator }\end{array}$} & \multirow{2}{*}{\begin{tabular}{l} 
Sales \\
Gas \\
\hdashline$(s c f / d)$
\end{tabular}} & \multicolumn{2}{|c|}{$\begin{array}{c}\text { Max Surface } \\
\text { Pressure }\end{array}$} & \multirow{2}{*}{$\begin{array}{l}\text { Brine } \\
\text { Rate } \\
-\cdots \\
\text { (stb/d) }\end{array}$} & \multicolumn{3}{|c|}{$\begin{array}{c}\text { Cum Gas/Brine } \\
\text { Ratios }\end{array}$} & \multirow{2}{*}{\begin{tabular}{c} 
Calc \\
BHP \\
\hdashline \\
\hdashline (psia)
\end{tabular}} & \multirow{2}{*}{\begin{tabular}{c}
$\begin{array}{c}\text { Perf } \\
\text { Gas }\end{array}$ \\
\hdashline (scf/d)
\end{tabular}} & \multirow{2}{*}{ 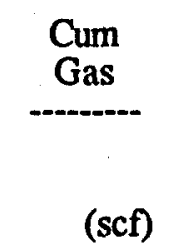 } & \multirow{2}{*}{$\begin{array}{r}\begin{array}{c}\text { Cum } \\
\text { Brine }\end{array} \\
\text { (stb) }\end{array}$} \\
\hline $\begin{array}{l}\text { Press } \\
\text { (psig) }\end{array}$ & $\begin{array}{r}\text { Gas } \\
\text { Rate } \\
\text { (scf/d) }\end{array}$ & & $\begin{array}{l}\text { Prod } \\
\text { Well } \\
\text { (psig) }\end{array}$ & $\begin{array}{r}\text { Disp } \\
\text { Well } \\
\text { (psig) }\end{array}$ & & $\begin{array}{r}\text { 1st } \\
\text { Stage } \\
\text { scf/stb) }\end{array}$ & $\begin{array}{r}2 n d \\
\text { Stg } \\
\text { (scf/stb) }\end{array}$ & $\begin{array}{c}\text { Disp } \\
\text { Well } \\
\text { (scf/stb) }\end{array}$ & & & & \\
\hline $\begin{array}{r}326 \\
320 \\
0 \\
0 \\
149 \\
320 \\
318 \\
320 \\
320 \\
319 \\
321 \\
321 \\
320 \\
320 \\
320 \\
321 \\
320 \\
316 \\
318 \\
316 \\
315 \\
332 \\
311 \\
0 \\
0 \\
0 \\
338 \\
338 \\
325 \\
319 \\
319\end{array}$ & $\begin{array}{r}59425 \\
58998 \\
29117 \\
0 \\
51012 \\
61096 \\
61418 \\
60878 \\
60730 \\
61476 \\
60727 \\
60259 \\
59587 \\
59991 \\
60427 \\
61252 \\
34235 \\
58406 \\
57588 \\
63475 \\
63628 \\
38494 \\
60616 \\
0 \\
0 \\
0 \\
42494 \\
42494 \\
60606 \\
59759 \\
59506\end{array}$ & $\begin{array}{r}395693 \\
399296 \\
196401 \\
0 \\
016525 \\
402149 \\
400942 \\
400635 \\
400278 \\
399209 \\
398583 \\
400093 \\
385066 \\
400021 \\
400441 \\
401516 \\
225016 \\
389520 \\
380542 \\
392550 \\
397797 \\
288487 \\
407958 \\
0 \\
0 \\
55563 \\
339206 \\
339206 \\
398344 \\
386929 \\
404041\end{array}$ & $\begin{array}{l}3770 \\
3776 \\
4604 \\
4600 \\
3772 \\
3764 \\
3762 \\
3748 \\
3749 \\
3750 \\
3738 \\
3735 \\
3741 \\
3729 \\
3731 \\
3739 \\
3703 \\
3715 \\
3720 \\
3728 \\
3715 \\
3736 \\
3746 \\
3936 \\
4280 \\
4287 \\
3440 \\
3492 \\
3486 \\
3488 \\
3491\end{array}$ & $\begin{array}{r}112 \\
113 \\
0 \\
19 \\
149 \\
148 \\
146 \\
145 \\
146 \\
150 \\
151 \\
153 \\
155 \\
153 \\
156 \\
151 \\
144 \\
147 \\
144 \\
143 \\
135 \\
172 \\
164 \\
0 \\
0 \\
138 \\
186 \\
182 \\
168 \\
174 \\
174\end{array}$ & $\begin{array}{r}14752 \\
14669 \\
7309 \\
0 \\
14959 \\
14928 \\
14932 \\
14929 \\
14925 \\
14920 \\
14912 \\
14910 \\
14909 \\
14903 \\
14912 \\
14905 \\
8777 \\
14516 \\
14526 \\
14545 \\
14565 \\
11344 \\
14615 \\
4390 \\
0 \\
2979 \\
12625 \\
14649 \\
14644 \\
14637 \\
14658\end{array}$ & $\begin{array}{r}23.53 \\
22.88 \\
22.91 \\
0.00 \\
18.57 \\
23.03 \\
23.27 \\
23.32 \\
23.38 \\
23.43 \\
23.44 \\
23.54 \\
23.43 \\
23.53 \\
24.09 \\
23.67 \\
22.36 \\
26.83 \\
23.26 \\
22.95 \\
23.29 \\
22.00 \\
23.57 \\
0.00 \\
0.00 \\
18.65 \\
24.02 \\
23.34 \\
23.37 \\
23.37 \\
23.74\end{array}$ & $\begin{array}{r}27.56 \\
26.91 \\
26.90 \\
0.00 \\
21.98 \\
27.12 \\
27.39 \\
27.40 \\
27.45 \\
27.55 \\
27.52 \\
27.59 \\
27.43 \\
27.56 \\
28.14 \\
27.78 \\
26.26 \\
30.86 \\
27.22 \\
27.32 \\
27.65 \\
25.39 \\
27.71 \\
0.00 \\
0.00 \\
18.65 \\
27.39 \\
26.24 \\
27.51 \\
27.45 \\
27.80\end{array}$ & $\begin{array}{r}29.37 \\
28.69 \\
26.98 \\
0 \\
22.86 \\
28.9 \\
29.16 \\
29.18 \\
29.23 \\
29.33 \\
29.3 \\
29.37 \\
29.21 \\
29.34 \\
29.92 \\
29.57 \\
28.04 \\
32.62 \\
28.99 \\
29.08 \\
29.41 \\
27.24 \\
29.45 \\
0.08 \\
0 \\
23.87 \\
29.26 \\
28.11 \\
29.32 \\
29.22 \\
29.57\end{array}$ & $\begin{array}{r}10847 \\
10850 \\
11416 \\
0 \\
10869 \\
10851 \\
10848 \\
10834 \\
10835 \\
10835 \\
10822 \\
10819 \\
10826 \\
10813 \\
10814 \\
10823 \\
10533 \\
10771 \\
10785 \\
10794 \\
10781 \\
10660 \\
10815 \\
10660 \\
0 \\
11013 \\
10406 \\
10559 \\
10550 \\
10552 \\
10555\end{array}$ & $\begin{array}{r}433266 \\
420854 \\
197197 \\
0 \\
341963 \\
431419 \\
435417 \\
435628 \\
436258 \\
437604 \\
436922 \\
437907 \\
435492 \\
437254 \\
446167 \\
440741 \\
246107 \\
473512 \\
421109 \\
422969 \\
428357 \\
309011 \\
430412 \\
351 \\
0 \\
71109 \\
369408 \\
411783 \\
429362 \\
427693 \\
433437\end{array}$ & $\begin{array}{l}11278187 \\
11699041 \\
11896238 \\
11896238 \\
12238200 \\
12669619 \\
13105037 \\
13540665 \\
13976923 \\
14414526 \\
14851448 \\
15289354 \\
15724846 \\
16162100 \\
16608267 \\
17049008 \\
17295115 \\
17768627 \\
18189736 \\
18612705 \\
19041061 \\
19350072 \\
19780484 \\
19780835 \\
19851943 \\
20221351 \\
20633134 \\
21062496 \\
21490190 \\
21923627\end{array}$ & $\begin{array}{l}7201320 \\
7215989 \\
7223298 \\
7223298 \\
7238257 \\
7253185 \\
7268117 \\
7283046 \\
7297971 \\
7312891 \\
7327803 \\
7342713 \\
7357622 \\
7372525 \\
7387437 \\
7402342 \\
7411119 \\
7425635 \\
7440161 \\
7454706 \\
7469271 \\
7480615 \\
7495230 \\
7499620 \\
7499620 \\
7502599 \\
7515224 \\
7529873 \\
7544517 \\
7559154 \\
7573812\end{array}$ \\
\hline
\end{tabular}




\begin{tabular}{|c|c|c|c|c|c|}
\hline Date & \multicolumn{3}{|c|}{$\begin{array}{l}\text { 1st Stage } \\
\text { Separator }\end{array}$} & \multicolumn{2}{|c|}{$\begin{array}{l}\text { 2nd Stage } \\
\text { Separator }\end{array}$} \\
\hline & $\begin{array}{l}\text { Press } \\
\text { (psig) }\end{array}$ & $\begin{array}{l}\text { Brine } \\
\text { Rate } \\
\text { (RB/d) }\end{array}$ & $\begin{array}{r}\text { Gas } \\
\text { Rate } \\
\text { (scf/d) }\end{array}$ & $\begin{array}{l}\text { Press } \\
\text { (psig) }\end{array}$ & $\begin{array}{r}\text { Gas } \\
\text { Rate } \\
\text { (scf/d) }\end{array}$ \\
\hline
\end{tabular}

$\begin{array}{llll}1-J u n-85 & 1014 & 15644 & 346422\end{array}$ 2-Jun-85 $\quad 1020 \quad 15642 \quad 344194$ 3-Jun-85 $1020 \quad 15654 \quad 343944$ $\begin{array}{llll}4-J u n-85 & 1020 & 15672 & 345385\end{array}$ $\begin{array}{llll}5-J u n-85 & 1018 \quad 15692 & 346078\end{array}$ 6-Jun-85 $\quad 1018 \quad 15711 \quad 346540$ $\begin{array}{lllll}7-J u n-85 & 1015 & 15648 & 345958\end{array}$ 8-Jun-85 $1019 \quad 15639 \quad 346279$ 9-Jun-85 $1007 \quad 15663 \quad 347373$ $\begin{array}{llll}10-J u n-85 & 1012 & 15664 & 347043\end{array}$ 11-Jun-85 $1012 \quad 15664 \quad 345573$ 12-Jun-85 $1009 \quad 15663 \quad 344652$ 13-Jun-85 $1000 \quad 15661344065$ 14-Jun-85 $1000 \quad 15715 \quad 345544$ $\begin{array}{llll}15-J u n-85 & 1001 & 15720 & 347088\end{array}$ 16-Jun-85 $1000 \quad 15688 \quad 346551$ $\begin{array}{llllll}17-J u n-85 & 1010 & 15672 & 345238\end{array}$ 18-Jun-85 $1003 \quad 15706 \quad 344120$ 19-Jun-85 $1001 \quad 15723 \quad 344835$ 20-Jun-85 $1002 \quad 15746 \quad 345038$ 21-Jun-85 $990 \quad 15746 \quad 349722$ 22-Jun-85 $\quad 1001 \quad 15754 \quad 349652$ 23-Jun-85 $\quad 1002 \quad 15753 \quad 349897$ 24-Jun-85 $1005 \quad 15757 \quad 349643$ 25-Jun-85 $1003 \quad 14665 \quad 320629$ 26-Jun-85 27-Jun-85 28-Jun-85 30-Jun-85 $1010 \quad 21330 \quad 458353$
31959872 32161705 32161705

32161817. 32061698 32061694 32061895 32061200

32160874 32161026 32161048

32161286

31862200

31961309

31861092

31960880

31960388

32060533

32160207

32260054

32059800

31960308

32161058

32361537

32056288

0

00

$0 \quad 0$

31679817553331

403154

403838

402838

404805

405944

406769

406609

406240

404682

402170

405031

406193

405455

406111

405309

405224

402675

405374

406292

374165 \begin{tabular}{cc}
$\begin{array}{c}\text { Max Surface } \\
\text { Pressure }\end{array}$ & $\begin{array}{c}\text { Brine } \\
\text { Rate }\end{array}$ \\
\hline Prod Disp & - \\
Well Well &
\end{tabular}

(scf/d) (psig) (psig) (stb/d) (scf/stb)(scf/stb)(scf/stb) (psia)

$\begin{array}{lll}3496 & 176 & 14669 \\ 3499 & 177 & 14667\end{array}$

$3504 \quad 178 \quad 14679$

$\begin{array}{llll}3510 & 171 & 14696\end{array}$

$\begin{array}{llll}3509 & 174 & 14714\end{array}$

$\begin{array}{lll}3513 & 178 & 14732\end{array}$

$\begin{array}{lll}3519 & 179 & 14673\end{array}$

$\begin{array}{llll}3519 & 178 & 14665\end{array}$

$\begin{array}{lll}3515 & 179 & 14686\end{array}$

$\begin{array}{lll}3518 & 180 & 14688\end{array}$

$\begin{array}{llll}3518 & 179 & 14688\end{array}$

$\begin{array}{lll}3525 & 181 & 14687\end{array}$

$\begin{array}{llll}3528 & 181 & 14684\end{array}$

$\begin{array}{lll}3527 & 180 & 14735\end{array}$

$\begin{array}{lll}3529 & 182 & 14740\end{array}$

$\begin{array}{lll}3538 & 184 & 14710\end{array}$

$\begin{array}{lll}3527 & 182 & 14695\end{array}$

$\begin{array}{lll}3527 & 179 & 14727\end{array}$

$\begin{array}{llll}3533 & 181 & 14742\end{array}$

$\begin{array}{lll}3533 & 183 & 14764\end{array}$

$\begin{array}{lll}3529 & 181 & 14763\end{array}$

$\begin{array}{llll}3532 & 182 & 14771\end{array}$

$\begin{array}{lll}3549 & 184 & 14771\end{array}$

$\begin{array}{lll}3543 & 182 & 14774\end{array}$

$\begin{array}{lll}3541 & 184 & 13750\end{array}$

$\begin{array}{rrr}4604 & 0 & 0\end{array}$

$\begin{array}{rrr}4174 & 40 & 0 \\ 4190 & 81 & 2343\end{array}$

2343
2413

$\begin{array}{llr}2467 & 176 & 20000\end{array}$

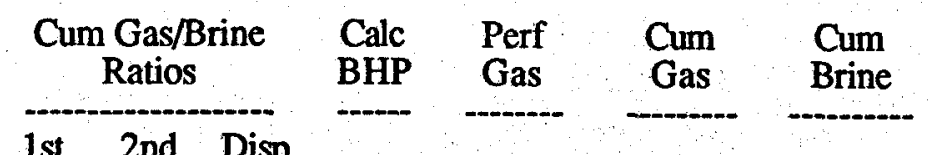

(scf/d)

(scf)

(stb)

$432295222355922 \quad 7588481$

$\begin{array}{llll}432090222788012 & 7603148\end{array}$

$431856223219868 \quad 7617827$

$433532223653400 \quad 7632523$

$\begin{array}{llll}433916 & 224087316 & 7647237\end{array}$

$\begin{array}{llll}434447224521763 & 7661969\end{array}$

$434027224955790 \quad 7676642$

$433644225389434 \quad 7691307$

$434412225823846 \quad 7705993$

$434324226258170 \quad 7720681$

$\begin{array}{lll}432855226691025 & 7735369\end{array}$

$432238227123264 \quad 7750056$

$432297227555561 \quad 7764740$

$433062227988622 \quad 7779475$

$434240228422863 \quad 7794215$

$433504228856367 \quad 7808925$

$431739229288106 \quad 7823620$

$430912229719018 \quad 7838347$

$\begin{array}{llll}431351230150369 & 7853089\end{array}$

$\begin{array}{lll}431552230581920 & 7867853\end{array}$

$435804231017724 \quad 7882616$

$\begin{array}{lll}436188 & 231453912 \quad 7897387\end{array}$

$437369231891281 \quad 7912158$

$437754232329035 \quad 7926932$

$401363232730397 \quad 7940682$

$\begin{array}{lll}0232730397 & 7940682\end{array}$

$0232730397 \quad 7940682$

$187232730585 \quad 7943025$

$12644232743229 \quad 7945438$ $\begin{array}{lll}573400 & 233316629 & 7965438\end{array}$ 


\begin{tabular}{ccc}
\multicolumn{3}{c}{ 1st Stage } \\
Separator \\
Press & $\begin{array}{c}\text { Brine } \\
\text { Rate }\end{array}$ & $\begin{array}{c}\text { Gas } \\
\text { Rate }\end{array}$ \\
(psig) & $(\mathrm{RB} / \mathrm{d})$ & $(\mathrm{scf} / \mathrm{d})$
\end{tabular}

\begin{tabular}{llll}
\hline 1-Jul-85 & 1010 & 25179 & 559894
\end{tabular} 2-Jul-85 $\quad 988 \quad 25136 \quad 560214$

3-Jul-85 $1004 \quad 25128 \quad 559619$

4-Jul-85 $\quad 1005 \quad 25064555238$

5-Jul-85 $1004 \quad 25083 \quad 559751$

6-Jul-85 $1004 \quad 25051555917$

7-Jul-85 $1004 \quad 25029 \quad 556577$

8-Jul-85 $\quad 1005 \quad 25012 \quad 555358$

9-Jul-85 100425066557200

10-Jul-85 $100625055 \quad 558676$

11-Jul-85 $1004 \quad 25024 \quad 565499$

12-Jul-85 $1003 \quad 25005 \quad 563636$

13-Jul-85 $1002 \quad 24976 \quad 563822$

14-Jul-85 $1011 \quad 24949 \quad 561977$

15-Jul-85 $1012 \quad 24917 \quad 560977$

16-Jul-85 $1020 \quad 25499 \quad 572147$

$\begin{array}{lllll} & 17-J u l-85 & 1022 & 25746 & 575837\end{array}$

18-Jul-85 $1022 \quad 25803 \quad 575509$

19-Jul-85 $1020 \cdot 25784 \quad 574855$

20-Jul-85 $1022 \quad 25771 \quad 574406$

21-Jul-85 $1019 \quad 25778 \quad 578020$

22-Jul-85 $1021 \quad 25748 \quad 578514$

23-Jul-85 $1020 \quad 15042 \quad 337570$

24-Jul-85 $1020 \quad 25686 \quad 579629$

25-Jul-85 $1004 \quad 27782 \quad 626375$

26-Jul-85 $1005 \quad 30089 \quad 682636$

27-Jul-85 $\quad 1005 \quad 30126 \quad 682249$

28-Jul-85 $1002 \quad 30090 \quad 683129$

29-Jul-85 $\quad 1002 \quad 30076 \quad 681231$

30-Jul-85 $1003 \quad 31060 \quad 694929$

$\begin{array}{lllll}31-J u l-85 & 1003 & 31078 & 692908\end{array}$

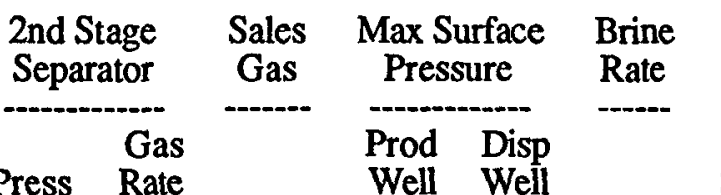

Cum Gas/Brine Ratios

1st 2nd Disp

$\begin{array}{llll}\text { Calc } & \text { Perf } & \text { Cum } & \text { Cum } \\ \text { BHP } & \text { Gas } & \text { Gas } & \text { Brine }\end{array}$ Well Well Stage Stg Well

(psig) (scf/d) (scf/d) (psig) (psig) (stb/d) (scf/stb)(scf/stb)(scf/stb) (psia)

$\begin{array}{llllllllll}320104481 & 651266 & 2455 & 179 & 23609 & 23.71 & 28.14 & 29.92 & 10082\end{array}$

$\begin{array}{llllllllll}319101995 & 657361 & 2441 & 180 & 23567 & 23.77 & 28.10 & 29.87 & 10065\end{array}$

$\begin{array}{llllllllll}321101852 & 653829 & 2442 & 181 & 23561 & 23.75 & 28.07 & 29.86 & 10065\end{array}$

$\begin{array}{lllllllll}321101482 & 651914 & 2442 & 183 & 23501 & 23.63 & 27.94 & 29.73 & 10061\end{array}$

$\begin{array}{llllllllll}320102111 & 657152 & 2441 & 181 & 23519 & 23.80 & 28.14 & 29.92 & 10061\end{array}$

$\begin{array}{lllllllll}323101292 & 651337 & 2438 & 183 & 23489 & 23.67 & 27.98 & 29.78 & 10055\end{array}$

$\begin{array}{llllllllll}321102918 & 652735 & 2442 & 183 & 23468 & 23.72 & 28.10 & 29.89 & 10058\end{array}$

$\begin{array}{llllllllll}322103273 & 654850 & 2442 & 183 & 23452 & 23.68 & 28.08 & 29.88 & 10056\end{array}$

$\begin{array}{llllllllll}320104138 & 654747 & 2415 & 183 & 23503 & 23.71 & 28.14 & 29.92 & 10033\end{array}$

$\begin{array}{llllllllll}322100647 & 654456 & 2418 & 182 & 23493 & 23.78 & 28.06 & 29.86 & 10035\end{array}$

$\begin{array}{lllllllllll}318 & 99367 & 652211 & 2415 & 182 & 23464 & 24.10 & 28.34 & 30.11 & 10029\end{array}$

$\begin{array}{lllllllll}318100315 & 650369 & 2415 & 183 & 23446 & 24.04 & 28.32 & 30.09 & 10027\end{array}$

$\begin{array}{llllllllll}320100154 & 646333 & 2410 & 183 & 23418 & 24.08 & 28.35 & 30.13 & 10020\end{array}$

$\begin{array}{llllllllll}318100655 & 653572 & 2409 & 184 & 23394 & 24.02 & 28.33 & 30.1 & 10017\end{array}$

319100757651963

$332101601 \quad 661768$

$342100136 \quad 657063$

$341101393 \quad 670843$

$341101732 \quad 668198$

$340101647 \quad 676053$

$339101000 \quad 671438$

340101212668636

34258619390160

$341101855 \quad 664956$

$340108573 \quad 764293$

$344115999 \quad 785715$

345115279784539

$342114512 \quad 785567$

$343113716 \quad 781106$

$343122042 \quad 804218$

$\begin{array}{lllllll}2406 & 183 & 23364 & 24.01 & 28.32 & 30.1 & 10012\end{array}$

$\begin{array}{lllllll}2355 & 188 & 23910 & 23.93 & 28.18 & 30.02 & 10004\end{array}$

$\begin{array}{lll}2346 & 188 & 24142\end{array}$

$\begin{array}{llll}23.85 & 28.00 & 29.9 & 10014\end{array}$

$\begin{array}{lllllll}2346 & 188 & 24195 & 23.79 & 27.98 & 29.87 & 10019\end{array}$

$\begin{array}{lll}2340 & 188 & 24177\end{array}$

$\begin{array}{llll}23.78 & 27.98 & 29.87 & 10011\end{array}$

$2340-18924165$

$\begin{array}{lll}23.77 & 27.98 & 29.86\end{array}$

10010

$2333188 \quad 24144$

$\begin{array}{llll}23.91 & 28.09 & 29.97 & 10011 \\ 23.96 & 28.15 & 30.04 & 10001\end{array}$

$2373 \quad 175 \quad 14105$

$23.93 \quad 28.09 \quad 29.98$

9370

$\begin{array}{lll}2363 & 177 & 24086\end{array}$

$\begin{array}{llll}24.07 & 28.29 & 30.18 & 10026\end{array}$

17442052605

$\begin{array}{llll}24.05 & 28.21 & 30.1\end{array}$

$\begin{array}{lll}1739 & 206 & 28213\end{array}$

$\begin{array}{lll}24.15 & 28.23 & 30.14\end{array}$

$\begin{array}{llll}24.21 & 28.27 & 30.17\end{array}$

$\begin{array}{lllllll}1570 & 212 & 29123 & 23.86 & 28.05 & 29.95\end{array}$

$\begin{array}{llll}1583 & 211 & 29140\end{array}$

$23.78 \quad 27.99 \quad 29.83$ (scf/d) (scf) (stb)

$706381234023010 \quad 7989047$

$703946234726956 \quad 8012614$

$703531235430488 \quad 8036175$

$698685236129172 \quad 8059676$

7036882368328618083195

699502237532363
8106684

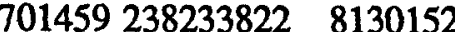

$700746238934568 \quad 8153604$

$703210239637777 \quad 8177107$
7015011240339278

$701501240339278 \quad 8200600$

$706501241045779 \quad 8224064$

$705490241751270 \quad 8247510$

$705584242456854 \quad 8270928$

$704159243161013 \quad 8294322$

$703256243864270 \quad 8317686$

$717778244582048 \quad 8341596$

$721846245303894 \quad 8365738$

\begin{tabular}{l}
$722705246026598 \quad 8389933$ \\
\hline
\end{tabular}

$722167246748765 \quad 8414110$

\begin{tabular}{l}
$721567247470332 \quad 8438275$ \\
\hline
\end{tabular}

$724435248194767 \quad 8462447$

$725286248920053 \quad 8486591$

$422868249342921 \quad 8500696$

$726915250069836 \quad 8524782$

7841052508539418550832

$9762852315251706256 \quad 8579045$

$\begin{array}{llll}9762 & 851365 & 252557620 & 8607292\end{array}$

$9757 \quad 851186253408807 \quad 8635505$

$\begin{array}{llll}9747 \quad 848538 & 254257345 \quad 8663705\end{array}$

96738722342551295798692828

$\begin{array}{ll}9688 \quad 869246 & 255998825 \quad 8721968\end{array}$ 

19-Aug-85 $999 \quad 31682 \quad 691782$ 20-Aug-85 $999 \quad 31556 \quad 691541$ 21-Aug-85 $999 \quad 31453 \quad 685158$ 22-Aug-85 $997 \quad 31394.683414$ 23-Aug-85 $1000 \quad 31318 \quad 685109$ 24-Aug-85 $1000 \quad 31226 \quad 682163$ 25-Aug-85 $1006 \quad 31146 \quad 680547$ 26-Aug-85 $1009 \quad 31082 \quad 678391$ 27-Aug-85 $1009 \quad 31017 \quad 674483$ 28-Aug-85 $1012 \quad 30939 \quad 671167$ 29-Aug-85 $1008 \quad 30885 \quad 666612$ 30-Aug-85 1015 $30828 \quad 666943$ 31-Aug-85 $1013 \cdot 30827 \quad 667997$ 2nd Stage Sales Max Surface Brine

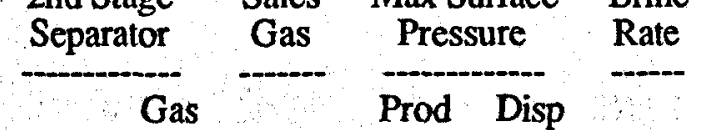

Well Well

Ratios

1st 2nd Disp

Stage $\quad$ Stg Wisp

(psig) (scf/d)

(scf/d) (psig) (psig) (stb/d)

(cf/stb)(scf/stb)(scf/stb)

$801708 \quad \begin{array}{llll}1585 & 213 \quad 29193\end{array}$

$\begin{array}{llllllll}330121809 & 804819 & 1593 & 211 & 29277 & 23.79 & 27.95 & 29.78 \\ 328122376 & 796375 & 1590 & 212 & 29285 & 23.79 & 27.97 & 29.79\end{array}$

$\begin{array}{lllllllll}330121809 & 804819 & 1593 & 211 & 29277 & 23.79 & 27.95 & 29.78 \\ 328122376 & 796375 & 1590 & 212 & 29285 & 23.79 & 27.97 & 29.79 \\ 338123139 & 797562 & 1608 & 213 & 29192 & 23.49 & 27.71 & 29.58\end{array}$

$23.68 \quad 27.87 \quad 29.71$

$23.7927 .95 \quad 29.78$

$\begin{array}{lllllll}330124094 & 796035 & 1596 & 214 & 29100\end{array}$

$\begin{array}{llllll}32459339 & 418762 & 1618 & 208 & 15909\end{array}$

$23.4927 .71 \quad 29.58$

$23.45 \quad 27.7129 .54$

$\begin{array}{llllll}328120676 & 799771 & 1611 & 211 & 29228\end{array}$

$\begin{array}{llllll}328123574 & 790209 & 1616 & 212 & 29102\end{array}$

$\begin{array}{llllll}329117192 & 748331 & 1607 & 211 & 27880\end{array}$

$\begin{array}{llllll}328122555 & 794726 & 1603 & 212 & 29088\end{array}$

$\begin{array}{llllll}328121614 & 792441 & 1602 & 212 & 29069\end{array}$

$\begin{array}{llllll}326122023 & 794176 & 1602 & 211 & 29020\end{array}$

$\begin{array}{llllll}331120995 & 792802 & 1602 & 212 & 28949\end{array}$

$\begin{array}{llllll}333120487 & 790560 & 1602 & 212 & 28913\end{array}$

33352557

343728

0

34449195

341119299

338116024

335110785

332108237

330107058

342118816

342118452

340117901

339118072

338117481

345116608

345117036

345116802 $\begin{array}{llll}22.59 & 26.32 & 28.12\end{array}$

$\begin{array}{llll}23.26 & 27.39 & 29.22\end{array}$

$\begin{array}{llll}23.22 & 27.47 & 29.29\end{array}$

$23.25 \quad 27.46 \quad 29.29$

$\begin{array}{lll}23.36 & 27.58 & 29.4\end{array}$

$\begin{array}{lll}23.35 & 27.53 & 29.35\end{array}$

$\begin{array}{llll}23.32 & 27.52 & 29.34\end{array}$

$23.3927 .57 \quad 29.41$

$\begin{array}{lll}23.42 & 27.58 & 29.43\end{array}$

$\begin{array}{lllllll}1592 & 213 & 12035 & 24.56 & 28.92 & 30.77\end{array}$

$\begin{array}{llllll}0 & 0 & 0 & 0.00 & 0.00 & 0 \\ 0 & 0 & 0 & 0.00 & 0.00 & 0\end{array}$

$\begin{array}{lllllll}1566 & 246 & 13461 & 22.12 & 25.78 & 27.68\end{array}$

$\begin{array}{llllll}1559 & 247 & 29706 & 23.29 & 27.30 & 29.19\end{array}$

$\begin{array}{llllll}1554 & 246 & 29588 & 23.37 & 27.29 & 29.17\end{array}$

$\begin{array}{lllllll}1551 & 245 & 29491 & 23.23 & 26.99 & 28.85\end{array}$

$\begin{array}{llllll}1552 & 244 & 29436 & 23.22 & 26.89 & 28.74\end{array}$

$\begin{array}{lllllll}1550 & 242 & 29365 & 23.33 & 26.98 & 28.81\end{array}$

$\begin{array}{lllllll}1543 & 240 & 29278 & 23.30 & 27.36 & 29.25\end{array}$

$\begin{array}{llllll}1543 & 239 & 29204 & 23.30 & 27.36 & 29.25\end{array}$

$\begin{array}{llllll}1548 & 238 & 29144 & 23.28 & 27.32 & 29.21\end{array}$

$\begin{array}{lllllll}1549 & 233 & 29083 & 23.19 & 27.25 & 29.13\end{array}$

$\begin{array}{llllll}1546 & 232 & 29010 & 23.14 & 27.18 & 29.06\end{array}$

$\begin{array}{llllll}1544 & 233 & 28959 & 23.02 & 27.05 & 28.96\end{array}$

$\begin{array}{llllll}1541 & 232 & 28907 & 23.07 & 27.12 & 29.03\end{array}$

$\begin{array}{llllll}1537 & 231 & 28906 & 23.11 & 27.15 & 29.06\end{array}$
Calc Perf Cum Cum

BHP Gas Gas Brine

(psia)

(scf/d)

(scf)

(stb)

$\begin{array}{llll}9696 \quad 867324256866149 & 8751161\end{array}$

$9713 \quad 871869257738018 \quad 8780438$

$\begin{array}{llll}9710 & 872400 & 258610418 \quad 8809723\end{array}$

$\begin{array}{llllll}9720 & 863499 & 259473917 & 8838915\end{array}$

$9698 \quad 859614260333531 \quad 8868015$

$8685 \quad 447361260780892 \quad 8883924$

$\begin{array}{lllll}9727 & 854042 & 261634935 & 8913152\end{array}$

$\begin{array}{lllll}9719 & 852398 & 262487332 \quad 8942254\end{array}$

$\begin{array}{llllll}9589 & 816605 & 263303937 & 8970134\end{array}$

$\begin{array}{lllll}9704 & 855187 & 264159125 \quad 8999222\end{array}$

$9702 \quad 853175265012300 \quad 9028291$

$9697 \quad 851447265863747 \quad 9057311$

$\begin{array}{llll}9689 & 851390266715137 \quad 9086260\end{array}$

9686 . $850910267566046 \quad 9115173$

$8451 \quad 370317267936363 \quad 9127208$

02679363639127208

$0267936363 \quad 9127208$

$8503 \quad 372600268308964 \quad 9140669$

$\begin{array}{llll}9722 & 867118 & 269176082 & 9170375\end{array}$

$9705863082270039164 \quad 9199963$

$\begin{array}{llll}9693 & 850815 & 270889979 & 9229454\end{array}$

$\begin{array}{llll}9688 & 845991271735970 \quad 9258890\end{array}$

$9679846006272581975 \quad 9288255$

$\begin{array}{llll}9662 & 856382 & 273438357 & 9317533\end{array}$

$\begin{array}{llll}9654 & 854217 & 274292574 & 9346737\end{array}$

$9654 \quad 851296275143870 \quad 9375881$

$9649847188275991058 \quad 9404964$

$\begin{array}{llll}9638 & 843031276834089 & 9433974\end{array}$

$9631838653277672741 \quad 9462933$

$\begin{array}{llll}9623839170278511911 & 9491840\end{array}$

$9618 \quad 840008279351920 \quad 9520746$ 


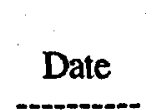

\begin{tabular}{ccc}
\multicolumn{3}{c}{ 1st Stage } \\
Separator \\
Press & $\begin{array}{c}\text { Brine } \\
\text { Rate }\end{array}$ & $\begin{array}{c}\text { Gas } \\
\text { Rate }\end{array}$ \\
(psig) & $(\mathrm{RB} / \mathrm{d})$ & $(\mathrm{scf} / \mathrm{d})$
\end{tabular}

1-Sep-85

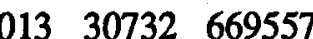
$\begin{array}{llll}2 \text {-Sep-85 } & 1012 \quad 30684 \quad 667019\end{array}$ 3-Sep-85 $1013 \quad 30631 \quad 664688$ 4-Sep-85 $\quad 1013 \quad 30580 \quad 663572$ 5-Sep-85 $1014 \quad 30534 \quad 664936$ 6-Sep-85 $1014 \quad 30476 \quad 661932$ 7-Sep-85 $1007 \quad 30435 \quad 660547$ 8-Sep-85 $\quad 1005 \quad 30417 \quad 664318$ $\begin{array}{llll}\text { 9-Sep-85 } & 1007 & 30402 & 663871\end{array}$ 10-Sep-85 $1005 \quad 30382 \quad 661443$ 11-Sep-85 101130312656391 12-Sep-85 $100930284 \quad 658212$ 13-Sep-85 $1013 \quad 30246 \quad 659892$ 14-Sep-85 $1013 \quad 30230 \quad 657630$ 15-Sep-85 $101130217 \quad 656309$ 16-Sep-85 $101030186 \quad 651320$ 17-Sep-85 $1010 \quad 30173653817$ 18-Sep-85 $1013 \quad 30130653094$ 19-Sep-85 101030097652977 20-Sep-85 $1010 \quad 30063 \quad 652037$ 21-Sep-85 101429998643896 22-Sep-85 $1012 \quad 29941641782$ 23-Sep-85 $1012 \quad 29133 \quad 627822$ 24-Sep-85 101229881644453 25-Sep-85 $101129828 \quad 638279$ 26-Sep-85 $101029793 \quad 638528$ 27-Sep-85 101129750633087 28-Sep-85 $1011 \quad 29721 \quad 631389$ 29-Sep-85 101129689631914 30-Sep-85 $101129654 \quad 634464$

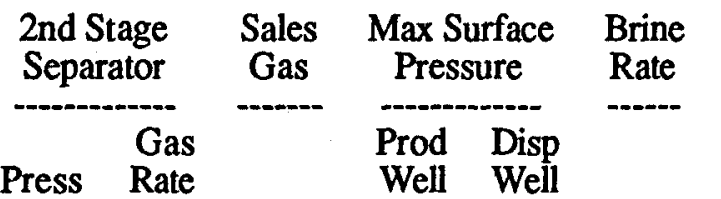
\begin{tabular}{cc}
$\begin{array}{c}\text { Cum Gas/Brine } \\
\text { Ratios }\end{array}$ \\
\hline 1st & 2nd Disp \\
Stage & Stg Well
\end{tabular}

$\begin{array}{llll}\text { Calc } & \text { Perf } & \text { Cum } & \text { Cum } \\ \text { BHP } & \text { Gas } & \text { Gas } & \text { Brin }\end{array}$ (psig) (scf/d) (scf/d) (psig) (psig) (stb/d) (scf/stb)(scf/stb)(scf/stb) (psia) 345115852 778863 $\begin{array}{lll}1534 & 231 & 28816\end{array}$ $\begin{array}{llll}23.24 & 27.26 & 29.17\end{array}$ 346115522 $\begin{array}{lllll}775018 & 1533 & 231 & 28771\end{array}$ $\begin{array}{lll}1532 & 230 & 28722\end{array}$ $\begin{array}{llllllll}343114210 & 771260 & 1531 & 231 & 28674 & 23.14 & 27.13 & 29.03\end{array}$ $23.18 \quad 27.20 \quad 29.12$ $\begin{array}{llll}342114368 & 772092 & 1532 & 230\end{array}$ $\begin{array}{lllllllll}345114454 & 770195 & 1530 & 231 & 28631 & 23.22 & 27.22 & 29.13\end{array}$ $\begin{array}{llllllll}345114288 & 768108 & 1528 & 231 & 28577 & 23.16 & 27.16 & 29.07\end{array}$ $\begin{array}{lllllllll}346114336 & 763649 & 1524 & 231 & 28537 & 23.15 & 27.15 & 29.07\end{array}$ $\begin{array}{llllllll}343114719 & 765169 & 1526 & 232 & 28520 & 23.29 & 27.32 & 29.22\end{array}$ $\begin{array}{llllllll}346114000 & 763620 & 1529 & 231 & 28506 & 23.29 & 27.29 & 29.2\end{array}$ $\begin{array}{llllllll}341114219 & 763202 & 1522 & 232 & 28488 & 23.22 & 27.23 & 29.12\end{array}$ 341114052760399 $345114728 \quad 772940$ 346114492765666 $353110569 \quad 758042$ $353110327 \quad 753282$ 353110155755230 $357109745 \quad 752237$ $351109960 \quad 763054$ 356110099753041 353109911751110 $356110068 \quad 739390$ $356111207 \quad 737689$ $360111312 \quad 724474$ $357116280 \quad 742500$ $356116193 \quad 737018$ $355114810 \quad 739136$ $\begin{array}{lll}352114833 & 730868\end{array}$ 360120089733393 $354120834 \quad 732554$ $358121330 \quad 734065$ $\begin{array}{lll}1522 & 231 & 28422\end{array}$

152023128396

$\begin{array}{lll}1528 & 229 & 28361\end{array}$

$\begin{array}{lll}1518 & 229 & 28346\end{array}$

$\begin{array}{lll}1517 & 228 & 28333\end{array}$

$\begin{array}{lll}1516 & 229 & 28304\end{array}$

$\begin{array}{lll}515 & 230 & 28292\end{array}$

$\begin{array}{lll}1519 & 229 & 28252\end{array}$

$\begin{array}{llll}1513 & 229 & 28221\end{array}$

$\begin{array}{lll}1511 & 229 & 28189\end{array}$

$\begin{array}{lll}1526 & 230 & 28128\end{array}$

$\begin{array}{lll}1530 & 229 & 28075\end{array}$

$\begin{array}{lll}1520 & 229 & 27317\end{array}$

$\begin{array}{lll}1519 & 224 & 28018\end{array}$

$\begin{array}{lll}1521 & 226 & 27969\end{array}$

$\begin{array}{lll}1517 & 226 & 27936\end{array}$

$\begin{array}{lll}1516 & 227 & 27868\end{array}$

$\begin{array}{lll}1516 & 227 & 27838\end{array}$

$\begin{array}{lll}1514 & 227 & 27805\end{array}$ $\begin{array}{lll}1516 & 227 & 27895\end{array}$ $\begin{array}{llll} & 29 & 9555\end{array}$

$\begin{array}{lll}23.18 & 27.22 & 29.13\end{array}$ $\begin{array}{lll}23.27 & 27.30 & 29.22\end{array}$ $\begin{array}{llll}23.20 & 27.10 & 29.05\end{array}$ $23.1627 .06 \quad 29.01$ 23.0126 .9028 .86 $\begin{array}{lll}23.11 & 26.99 & 28.96\end{array}$ $23.12 \quad 27.01 \quad 28.95$ $\begin{array}{llll}23.14 & 27.04 & 29.01\end{array}$ $\begin{array}{lll}23.13 & 27.03 & 28.98\end{array}$ $\begin{array}{lll}22.89 & 26.80 & 28.77\end{array}$ $\begin{array}{lll}22.86 & 26.82 & 28.79\end{array}$ $22.98 \quad 27.06 \quad 29.05$ $23.00 \quad 27.15 \quad 29.12$ $22.82 \quad 26.98 \quad 28.94$ $\begin{array}{lll}22.86 & 26.97 & 28.93\end{array}$ 22.6926 .8128 .76 $\begin{array}{lll}22.66 & 26.97 & 28.95\end{array}$ $\begin{array}{lll}22.70 & 27.04 & 29\end{array}$ $\begin{array}{lll}22.82 & 27.18 & 29.16\end{array}$ 


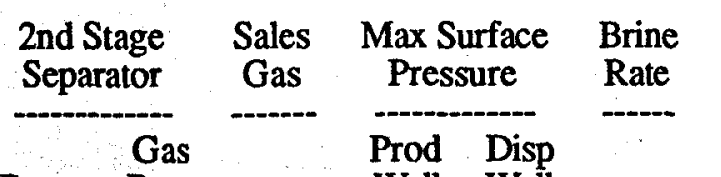

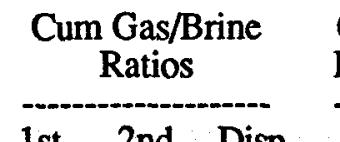

$\begin{array}{llll}\text { Calc } & \text { Perf } & \text { Cum } & \text { Cum } \\ \text { BHP } & \text { Gas } & \text { Gas } & \text { Brine }\end{array}$

Well Well

1st 2nd Disp

Press Rate

(scf/d) (psig) (psig) (stb/d) (scf/stb)(scf/stb)(scf/stb) (psia)

1-Oct-85 $101129611 \quad 625860$

2-Oct-85 $\quad 1012 \quad 29567 \quad 625190$

$\begin{array}{lllll}3-O c t-85 & 1014 & 29534 & 622240\end{array}$

$\begin{array}{lllll}4-\text { Oct-85 } & 1015 & 29506 & 629583\end{array}$

$\begin{array}{lllll}5-O c t-85 & 1012 & 29464 & 636974\end{array}$

$\begin{array}{lllll}6-O c t-85 & 1013 & 29424 & 628038\end{array}$

$\begin{array}{llllll}7-\text { Oct-85 } & 1009 & 15175 & 322234\end{array}$

8-Oct-85 $\quad 1006 \quad 16376 \quad 361171$

$\begin{array}{lllll}9-O c t-85 & 1008 & 16401 & 360515\end{array}$

$\begin{array}{lllll}10-O c t-85 & 1004 & 26833 & 587956\end{array}$

$\begin{array}{lllll}11-O c t-85 & 1015 & 29758 & 645019\end{array}$

$\begin{array}{llll}12-O c t-85 & 1012 & 29676 & 645343\end{array}$

13-Oct-85 $1011 \quad 29581 \quad 642366$

14-Oct-85 $1007 \quad 29561 \quad 648016$

$\begin{array}{lllll}15-O c t-85 & 1018 & 29513 & 650249\end{array}$

16-Oct-85 $1001 \quad 29451 \quad 646132$

$17-$ Oct-85 $\quad 1000 \quad 29400 \quad 646293$

$\begin{array}{lllll}18-O c t-85 & 1010 & 29351 & 645860\end{array}$

$\begin{array}{lllll}19-O c t-85 & 1002 & 29301 & 644573\end{array}$

$\begin{array}{lllll}20-O c t-85 & 1000 & 29258 & 646622\end{array}$

21-Oct-85 $1000 \quad 29210 \quad 644394$

22-Oct-85 $1026 \quad 29171 \quad 643170$

23-Oct-85 $100129130 \quad 641866$

24-Oct-85 $1001 \quad 29082 \quad 638929$

25-Oct-85 $1002 \quad 29034 \quad 638820$

26-Oct-85 $1001 \quad 28990 \quad 638863$

27-Oct-85 $1002 \quad 30155 \quad 637866$ 28-Oct-85 $1001 \quad 28894 \quad 631615$ $\begin{array}{lllll}29-O c t-85 & 0 & 5754 & 131917\end{array}$

$30-$-ct-85 1005 15088 301040

31-Oct-85 $100525105 \quad 552166$ $\begin{array}{llllllll}353123033 & 729033 & 1516 & 226 & 27765 & 22.54 & 26.97 & 28.93\end{array}$

$\begin{array}{lllllllll}359125629 & 729322 & 1516 & 227 & 27724 & 22.55 & 27.08 & 29.07\end{array}$

$\begin{array}{llllllllll}364122481 & 721648 & 1516 & 228 & 27693 & 22.47 & 26.89 & 28.9\end{array}$

$\begin{array}{lllllllll}364126611 & 732419 & 1510 & 228 & 27667 & 22.76 & 27.33 & 29.34\end{array}$

$\begin{array}{lllllllll}352120003 & 744152 & 1509 & 226 & 27627 & 23.06 & 27.40 & 29.35\end{array}$

349119649742408

$35554474 \quad 368665$

$33960152 \quad 420770$

$34560678 \quad 416955$

$348104743 \quad 672950$

$355115528 \quad 747251$

$355115972 \quad 745906$

$356115172 \quad 746833$

$357112534 \quad 744247$

$361109451 \quad 745121$

$360107978 \quad 743060$

$367107120 \quad 744482$

362106582742490

$362106768 \quad 739809$

$365106585 \quad 738572$

$365109297 \quad 739272$

$362105874 \quad 737252$

$367102502 \quad 740080$

$36998909 \quad 732208$

$35896336 \quad 731744$

$36096699 \quad 728413$

$36093981 \quad 724397$

$\begin{array}{lll}0 & 19632 \quad 139302\end{array}$

$\begin{array}{lll}388 & 39886 & 340840\end{array}$

$\begin{array}{llll}385 & 73726 & 625892\end{array}$

$\begin{array}{lll}1486 & 221 & 27474\end{array}$

$\begin{array}{lll}2058 & 321 & 14147\end{array}$

$\begin{array}{lll}23.46 & 27.35 & 29.35\end{array}$ $\begin{array}{lll}36096667 & 734323\end{array}$ $\begin{array}{llll}1509 & 226 & 27590\end{array}$

$\begin{array}{lll}3049 & 152 & 14229\end{array}$

$\begin{array}{lll}3059 & 155 & 15355\end{array}$

$\begin{array}{lll}3070 & 154 & 15378\end{array}$

$\begin{array}{lll}1525 & 225 & 25160\end{array}$

$\begin{array}{lll}1526 & 224 & 27903\end{array}$

$\begin{array}{lll}1508 \quad 221 & 27826\end{array}$

$\begin{array}{lll}1508 & 221 & 27737\end{array}$

$\begin{array}{lll}1494 & 223 & 27718\end{array}$

$\begin{array}{lll}490 & 222 & 27674\end{array}$

$\begin{array}{lll}1488 & 222 & 27614\end{array}$

$\begin{array}{lll}1492 & 222 & 27566\end{array}$

$\begin{array}{llll}1487 & 222 & 27521\end{array}$

$\begin{array}{lll}1488 & 222 & 27433\end{array}$

$\begin{array}{lll}1481 & 221 & 27388\end{array}$

$\begin{array}{lll}1484 & 222 & 27354\end{array}$

$\begin{array}{lll}1476 & 225 & 27313\end{array}$

$\begin{array}{lll}1479 & 225 & 27268\end{array}$

$\begin{array}{lll}1471 & 225 & 27223\end{array}$

$\begin{array}{lll}1473 & 224 & 27182\end{array}$

$\begin{array}{llll}1478 & 222 & 28274\end{array}$

$\begin{array}{lll}1476 & 219 & 27092\end{array}$

$\begin{array}{lll}3774 & 0 & 5376\end{array}$

$\begin{array}{lll}2 & \\ 26 & 27.10 \quad 29.03\end{array}$

$\begin{array}{llll}22.65 & 26.47 & 28.44 & 10081\end{array}$

$\begin{array}{llll}23.52 & 27.44 & 29.32 & 10147\end{array}$

$\begin{array}{llll}23.44 & 27.39 & 29.3 & 10160\end{array}$

$\begin{array}{llll}23.37 & 27.53 & 29.46 & 9252\end{array}$

$\begin{array}{llll}23.12 & 27.26 & 29.22 & 9508\end{array}$

$\begin{array}{lll}23.19 & 27.36 & 29.32\end{array}$

$\begin{array}{lll}23.16 & 27.31 & 29.28\end{array}$

$\begin{array}{lll}23.38 & 27.44 & 29.41\end{array}$

$23.50 \quad 27.45 \quad 29.45$

$\begin{array}{lll}23.40 & 27.31 & 29.3\end{array}$

$\begin{array}{lll}23.45 & 27.33 & 29.36\end{array}$

$\begin{array}{lll}23.47 & 27.34 & 29.34\end{array}$

$\begin{array}{lll}23.57 & 27.46 & 29.47\end{array}$

$\begin{array}{lll}23.53 & 27.52 & 29.53\end{array}$

$\begin{array}{lll}23.51 & 27.38 & 29.38\end{array}$

$\begin{array}{lll}23.50 & 27.25 & 29.28\end{array}$

$23.4327 .06 \quad 29.09$

$23.4727 .02 \quad 29.01$

$23.5027 .05 \quad 29.03$

$\begin{array}{lll}22.56 & 25.98 & 27.97\end{array}$

$\begin{array}{lll}23.31 & 26.78 & 28.77\end{array}$

$24.54 \quad 28.19 \quad 28.27$

$\begin{array}{llllll}2052 & 302 & 23540 & 23.46 & 26.59 & 28.71\end{array}$ (scf/d)

(scf)

(stb)

80324130477599710396718 80593730558193410424442 80032830638226110452135 81175030719401110479802 81085230800486410507429 $800938308805801 \quad 10535019$ 40467330921047410549248 45020930966068310564603 $450575310111258 \quad 10579981$ $741214310852472 \cdot 10605141$ $815326311667797 \quad 10633044$ 81585831248365610660870 81213931329579510688607 81518631411098210716325 $814999314925981 \quad 10743999$ 80909031573507110771613 80933831654440910799179 80746631735187510826700 80636231815823710854174 80845131896668710881607 $808768319775455 \quad 10908995$ 80366132057911510936349 79972532137884010963662 79322632217206610990930 78973932296180511018153 $789093323750899 \quad 11045335$ 79082432454172311073609 77943732532116011100701 15198032547313911106077 37107632584421511120224 67583332652004811143764 


\begin{tabular}{ccc} 
Date & \multicolumn{2}{c}{ 1st Stage } \\
Separator
\end{tabular}

1-Nov-85 $1007 \quad 25076 \quad 556512$ 2-Nov-85 $1000 \quad 21849 \quad 450014$ 3-Nov-85 100327936588346 4-Nov-85 $1000 \quad 24691 \quad 536767$ 5-Nov-85 $1000 \quad 24695 \quad 538659$ 6-Nov-85 $1003 \quad 24688 \quad 529919$ 7-Nov-85 $1008 \quad 24652 \quad 534040$ 8-Nov-85 $1007 \quad 24631 \quad 533111$ 9-Nov-85 $100624620 \quad 533446$ 10-Nov-85 100824612534962 11-Nov-85 100724599532264 12-Nov-85 100724587531507 13-Nov-85 $100924575 \quad 532663$ 14-Nov-85 $100824565 \quad 533526$ 15-Nov-85 $1008 \quad 24550 \quad 533872$ 16-Nov-85 100824539535485 17-Nov-85 $1002 \quad 24530 \quad 533564$ 18-Nov-85 $100924514 \quad 533783$ 19-Nov-85 $1008 \quad 24497524626$ 20-Nov-85 $100824485 \quad 525174$ 21-Nov-85 $100924465 \quad 520686$ 22-Nov-85 $1008 \quad 24459 \quad 520588$ 23-Nov-85 $100524448 \quad 529097$ 24-Nov-85 $100824432 \quad 534661$ 25-Nov-85 $100624418 \quad 534640$ 26-Nov-85 $100624405 \quad 528956$ 27-Nov-85 100724389.530820 28-Nov-85 $1004 \quad 24370.527072$ 29-Nov-85 $1006 \quad 24351 \quad 525482$ 30-Nov-85 $100524342 \quad 521956$

\begin{tabular}{ccc} 
2nd Stage & Sales \\
Separator & Gas \\
\hdashline & Gas & - \\
\hline Press & Rate & \\
(psig) & (scf/d) & (scf/d) \\
\hdashline 375 & 75865 & 626137 \\
\hline 406 & 61398 & 497193 \\
356 & 82907 & 664515 \\
365 & 79474 & 610366 \\
366 & 78800 & 611692 \\
390 & 80313 & 598118 \\
383 & 76442 & 592125 \\
390 & 75802 & 591652 \\
390 & 75731 & 583128 \\
390 & 76151 & 593381 \\
403 & 74941 & 591060 \\
412 & 74249 & 589321 \\
408 & 74434 & 588486 \\
409 & 74688 & 592640 \\
408 & 74597 & 592100 \\
411 & 74597 & 594820 \\
408 & 74513 & 591753 \\
409 & 74340 & 590334 \\
402 & 74157 & 590942 \\
402 & 74228 & 590669 \\
420 & 73549 & 591305 \\
408 & 74986 & 591312 \\
406 & 74642 & 590092 \\
409 & 74736 & 587857 \\
413 & 74451 & 587928 \\
407 & 74299 & 587600 \\
414 & 73916 & 586517 \\
413 & 73652 & 587143 \\
409 & 73831 & 587149 \\
411 & 73875 & 586477 \\
& &
\end{tabular}

Max Surface Brine $\begin{array}{cc}\text { Pressure } & \text { Rate } \\ -\cdots\end{array}$

Well Wisp

\section{2}

$1483 \quad 325$

208729826194

$\begin{array}{lll}2086 & 305 & 23151\end{array}$

$\begin{array}{lll}2079 & 318 & 23155\end{array}$

$\begin{array}{lll}2080 & 325 & 23148\end{array}$

$\begin{array}{lll}2079 & 328 & 23115\end{array}$

$\begin{array}{lll}2075 & 329 & 23095\end{array}$

$2073 \quad 336 \quad 23085$

$\begin{array}{lll}2072 & 340 & 23078\end{array}$

$\begin{array}{lll}2070 & 343 & 23065\end{array}$

$\begin{array}{lll}2073 & 344 & 23054\end{array}$

$\begin{array}{llll}2073 & 345 & 23043\end{array}$

$\begin{array}{lll}2065 & 345 & 23033\end{array}$

$2065348 \quad 23019$

$\begin{array}{lll}2061 & 350 & 23009\end{array}$

$\begin{array}{lll}2062 & 350 & 23000\end{array}$

$2060352 \quad 22986$

$\begin{array}{lll}2057 & 351 \quad 22970\end{array}$

$\begin{array}{lll}2058 & 349 & 22958\end{array}$

206435322940

206135422934

$\begin{array}{lll}2054 & 352 & 22924\end{array}$

$\begin{array}{lll}2056 & 353 & 22909\end{array}$

$\begin{array}{lll}2051 & 352 & 22895\end{array}$

$\begin{array}{lll}2047 & 354 & 22883\end{array}$

$2044356 \quad 22868$

$\begin{array}{lll}2045 & 357 & 22850\end{array}$

$\begin{array}{lll}2048 & 357 & 22833\end{array}$

$2046 \quad 357 \quad 22824$

\section{Cum Gas/Brine Ratios \\ 1st 2nd Disp Stage Stg Well}

$\begin{array}{llll}23.67 & 26.90 & 28.96\end{array}$ $\begin{array}{lll}21.97 & 24.96 & 27.19\end{array}$ $22.46 \quad 25.63 \quad 27.59$ $\begin{array}{lll}23.19 & 26.62 & 28.63\end{array}$ 23.2626 .6728 .69 $22.8926 .36 \quad 28.51$ $\begin{array}{lll}23.10 & 26.41 & 28.52\end{array}$ $\begin{array}{lll}23.08 & 26.37 & 28.51\end{array}$ $\begin{array}{llll}23.11 & 26.39 & 28.53\end{array}$ $\begin{array}{lll}23.18 & 26.48 & 28.63\end{array}$ $\begin{array}{lll}23.08 & 26.33 & 28.54\end{array}$ $23.05 \quad 26.28 \quad 28.53$ $23.12 \cdot 26.35 \quad 28.58$ $23.16 \quad 26.41 \quad 28.65$ $\begin{array}{llll}23.19 & 26.43 & 28.67\end{array}$ $\begin{array}{lll}23.27 & 26.51 & 28.77\end{array}$ $23.2026 .44 \quad 28.68$ $\begin{array}{llll}23.22 & 26.46 & 28.7\end{array}$ $\begin{array}{llll}22.84 & 26.07 & 28.27\end{array}$ $22.87 \quad 26.11 \quad 28.31$ $\begin{array}{lll}22.70 & 25.90 & 28.2\end{array}$ $\begin{array}{lll}22.70 & 25.97 & 28.21\end{array}$ $23.08 \quad 26.34 \quad 28.56$ $\begin{array}{lll}23.34 & 26.60 & 28.84\end{array}$ $\begin{array}{lll}23.35 & 26.60 & 28.87\end{array}$ $\begin{array}{lll}23.12 & 26.36 & 28.59\end{array}$ $23.21 \quad 26.44 \quad 28.71$ $\begin{array}{lll}23.07 & 26.29 & 28.55\end{array}$ $\begin{array}{llll}23.01 & 26.25 & 28.49\end{array}$ $\begin{array}{llll}22.87 & 26.11 & 28.36\end{array}$ \begin{tabular}{llll} 
Calc & Perf & Cum & Cum \\
BHP & Gas & Gas & Brine \\
\hline
\end{tabular}

$\begin{array}{llll}(\mathrm{psia}) & (\mathrm{scf} / \mathrm{d}) \quad(\mathrm{scf}) & (\mathrm{stb})\end{array}$

$9664 \quad 68093632720098511167277$

$8841 \quad 557014327757999 \quad 11187763$

993072269232848069211213957

$9667 \quad 66281332914350511237108$

$9660 \quad 664317329807822 \quad 11260263$

$9661659949330467771 \quad 11283411$

$9657 \quad 659240331127011 \quad 11306526$

$9652 \quad 65843833178544911329621$

964965861533244406411352706

$9647 \quad 660723333104788 \quad 11375784$

$9644 \quad 658275333763063 \quad 11398849$

$9646 \quad 65773133442079311421903$

$9645 \quad 658569335079362 \quad 11444946$

$9636 \quad 65989533573925811467979$

$9635 \quad 65995533639921211490998$

$9630 \quad 66196933706118111514007$

$9630 \quad 65964033772082111537007$

962765969833838052011559993

962364936233902988111582963

962464994133967982211605921

$9628 \quad 64690834032673011628861$

962564696834097369911651795

$9616 \quad 654709341628408 \quad 11674719$

$9616 \quad 66069634228910411697628$

961066097934295008211720523

$9605 \quad 65422534360430711743406$

$9601 \quad 656540344260847 \quad 11766274$

$9601 \quad 65236834491321511789124$

$9603 \quad 650512345563727 \quad 11811957$

$9600 \quad 64728934621101611834781$ 


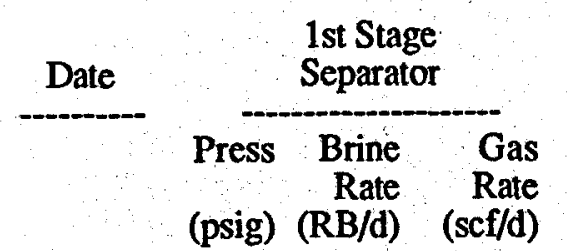

\begin{tabular}{lllll}
\hline $1-D e c-85$ & 1009 & 24331 & 522888
\end{tabular} 2-Dec-85 $\quad 1009 \quad 24312 \quad 519986$ 3-Dec-85 $\quad 1003 \quad 24311 \quad 523857$ 4-Dec-85 $\quad 1003 \quad 24304 \quad 521553$ 5-Dec-85 $\quad 1006 \quad 24289 \quad 523569$ $\begin{array}{lllll}6-\text { Dec-85 } & 1006 & 24272 & 522613\end{array}$ 7-Dec-85 $1004 \quad 24263 \quad 520939$ 8-Dec-85 $1007 \quad 24251 \quad 521189$ 9-Dec-85 $1005 \quad 24240 \quad 521641$ 10-Dec-85 $1008 \quad 24229 \quad 524947$ 11-Dec-85 $100924218 \quad 523497$ 12-Dec-85 $1008 \quad 24205 \quad 524050$ 13-Dec-85 $1009 \quad 24185 \quad 522498$ 14-Dec-85 $1006 \quad 24154 \quad 519491$ 15-Dec-85 $1003 \quad 24158 \quad 522691$ 16-Dec-85 $1005 \quad 24152519794$ 17-Dec-85 100624131522539 18-Dec-85 $1005 \quad 24080 \quad 516046$ 19-Dec-85 $1004 \quad 24074 \quad 521597$ 20-Dec-85 $1009 \quad 24060 \quad 521020$ 21-Dec-85 $1008 \quad 24066 \quad 517054$ 22-Dec-85 100724058516096 23-Dec-85 100624041517739 24-Dec-85 1008 24041 517256 25-Dec-85 100624017517065 26-Dec-85 100623996519653 27-Dec-85 $100623996 \quad 517632$ 28-Dec-85 $101023978 \quad 515394$ 29-Dec-85 $1003 \cdot 23968514968$ 30-Dec-85 $1008 \quad 23959 \quad 516429$ 31-Dec-85 $1000 \quad 23941 \quad 516717$

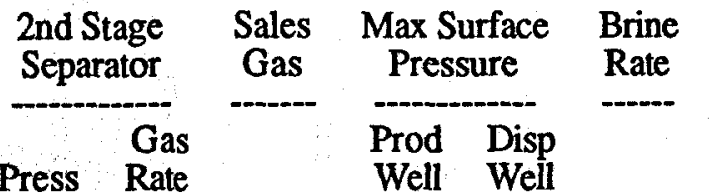

\begin{tabular}{l} 
Cum Gas/Brine \\
Ratios \\
\hdashline 1st $\quad$ 2nd \\
Stage $\quad$ Disp \\
Stg
\end{tabular}

(psig) (scf/d)

40973425

(scf/d) (psig) (psig) (stb/d) (scf/stb)(scf/stb)(scf/stb) (psia)

\begin{tabular}{lllllllll}
\hline 587458 & 2043 & $\overline{357}$ & 22814 & 22.92 & 26.14 & 28.38
\end{tabular}

$\begin{array}{llllllllll}584296 & 2048 & 343 & 22796 & 22.81 & 26.00 & 28.21\end{array}$

$\begin{array}{lllllllll}403 & 72774 & 584296 & 2048 & 343 & 22796 & 22.81 & 26.00 & 28.21 \\ 415 & 72407 & 586575 & 2045 & 353 & 22795 & 22.98 & 26.16 & 28.43\end{array}$

$\begin{array}{lllllllll}419 & 73964 & 586274 & 2040 & 361 & 22788 & 22.89 & 26.13 & 28.43\end{array}$

$\begin{array}{lllllllll}421 & 71630 & 580540 & 2043 & 362 & 22775 & 22.99 & 26.13 & 28.44\end{array}$

$\begin{array}{llllllllll}387 & 77044 & 581881 & 2042 & 330 & 22759 & 22.96 & 26.35 & 28.48\end{array}$

$\begin{array}{llllllllll}398 & 77399 & 582616 & 2036 & 340 & 22750 & 22.90 & 26.30 & 28.49\end{array}$

$\begin{array}{lllllllll}408 & 75646 & 583403 & 2033 & 345 & 22739 & 22.92 & 26.25 & 28.48\end{array}$

$\begin{array}{lllllllll}407 & 75036 & 577255 & 2031 & 348 & 22728 & 22.95 & 26.25 & 28.48\end{array}$

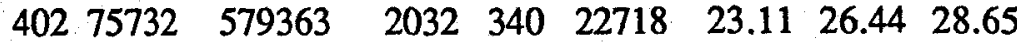

40974637

41673188

41572565

41671306

41372492

41873593

41574613

42076083

41875187

42576384

42576384

42475815

42575975

41973648

42474632

42270915

41774608

41174193

43574784

42074571

579292

$\begin{array}{lllllll}2029 & 349 & 22708 & 23.05 & 26.34 & 28.58 \\ 2033 & 356 & 22696 & 23.09 & 26.31 & 28.59\end{array}$

$\begin{array}{llllll}2033 & 356 & 22696 & 23.09 & 26.31 & 28.59 \\ 2032 & 354 & 22677 & 23.04 & 26.24 & 28.51\end{array}$

$\begin{array}{lllllll}2032 & 354 & 22677 & 23.04 & 26.24 & 28.51 \\ 2030 & 346 & 22648 & 22.94 & 26.09 & 28.36\end{array}$

$\begin{array}{llllllll}582462 & 2030 & 346 & 22648 & 22.94 & 26.09 & 28.36 \\ 581321 & 2026 & 349 & 22651 & 23.08 & 26.28 & 28.54\end{array}$

$\begin{array}{lllllllll}581321 & 2026 & 349 & 22651 & 23.08 & 26.28 & 28.54 \\ 577799 & 2024 & 357 & 22646 & 22.95 & 26.20 & 28.49\end{array}$

$\begin{array}{llllllll}579756 & 2030 & 355 & 22626 & 23.09 & 26.39 & 28.67\end{array}$

$\begin{array}{llllllll}575037 & 2025 & 361 & 22578 & 22.86 & 26.23 & 28.52\end{array}$

$\begin{array}{llllllll}577390 & 2024 & 347 & 22573 & 23.11 & 26.44 & 28.73\end{array}$

$\begin{array}{lllllll}584820 & 2028 & 359 & 22560 & 23.09 & 26.48 & 28.81\end{array}$

$\begin{array}{lllllll}584820 & 2021 & 357 & 22566 & 22.91 & 26.30 & 28.62\end{array}$

$\begin{array}{llllllll}580239 & 2016 & 363 & 22558 & 22.88 & 26.24 & 28.56\end{array}$

$\begin{array}{llllllll}584865 & 2018 & 363 & 22542 & 22.97 & 26.34 & 28.66\end{array}$

$\begin{array}{llllllll}582852 & 2020 & 358 & 22542 & 22.95 & 26.21 & 28.51\end{array}$

$\begin{array}{llllllll}583305 & 2016 & 355 & 22519 & 22.96 & 26.27 & 28.59\end{array}$

$\begin{array}{llllllll}585271 & 2019 & 360 & 22500 & 23.10 & 26.25 & 28.56\end{array}$

$\begin{array}{lllllll}583310 & 2013 & 356 & 22500 & 23.01 & 26.32 & 28.61\end{array}$

$\begin{array}{lllllll}585005 & 2016 & 350 & 22483 & 22.92 & 26.22 & 28.48\end{array}$

$\begin{array}{llllllll}579556 & 2014 & 366 & 22473 & 22.91 & 26.24 & 28.62\end{array}$

$\begin{array}{lllllll}2014 & 366 & 22473 & 22.91 & 26.24 & 28.62 \\ 2007 & 363 & 22465 & 22.99 & 26.31 & 28.61\end{array}$

$\begin{array}{llllll}2006 & 361 & 22448 & 23.02 & 26.33 & 28.61\end{array}$ $\begin{array}{llll}\text { Calc } & \text { Perf } & \text { Cum } & \text { Cum } \\ \text { BHP } & \text { Gas } & \text { Gas } & \text { Brine }\end{array}$

(scf/d)

(scf)

(stb)

$9596 \quad 647461346858477 \quad 11857595$

$9601 \quad 64307534750155211880391$

959764806234814961411903186

$9591 \quad 64786334879747711925974$

$9593 \quad 647721349445198 \quad 11948749$

959164817635009337411971508

$9584 \quad 648148350741522 \quad 11994258$

$\begin{array}{lll}9580 & 647607351389128 & 12016997\end{array}$

$9577 \quad 647293352036422 \quad 12039725$

$9577 \quad 650871352687293 \quad 12062443$

$\begin{array}{llll}9573 & 648995 & 353336287 & 12085151\end{array}$

$9576 \quad 648879353985166 \quad 12107847$

$9574 \quad 646521354631687 \quad 12130524$

$9570 \quad 642297355273984 \quad 12153172$

$9566 \quad 64646035592044412175823$

$9563 \quad 645185.356565629 \quad 12198469$

$\begin{array}{lll}9567 & 648687357214316 \quad 12221095\end{array}$

955964392535785824012243673

$9557 \quad 648522358506763 \quad 12266246$

956064995435915671612288806

$9553 \quad 645839359802555 \quad 12311372$

$9548 \quad 644256360446812 \quad 12333930$

$9548 \quad 64605436109286612356472$

$9551 \quad 64267236173553812379014$

$9545 \quad 64381836237935612401533$

$9546 \quad 64260036302195612424033$

$9540 \quad 64372536366568112446533$

$9542 \quad 640316364305997 \quad 12469016$

953964317736494917412491489

$9531 \quad 64272436559189812513954$

$9529 \quad 64223736623413512536402$ 
Date

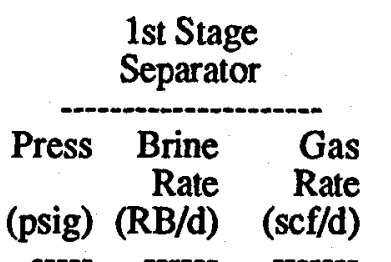

1-Jan-86

2-Jan-86

3-Jan-86

4-Jan-86

5-Jan-86

6-Jan-86

7-Jan-86

8-Jan-86

9-Jan-86

10418222189

11-Jan-86 100010458227582

12-Jan-86 $1000 \quad 10507231969$

$\begin{array}{llllll}1 & 13-J a n-86 & 1000 & 10534 & 229066\end{array}$

$\rightarrow \quad \infty \quad 14-J a n-86 \quad 999 \quad 10531230355$

$\rightarrow \quad \infty \quad 15-J a n-86 \quad 1000 \quad 10540 \quad 230686$

16-Jan-86 $1002 \quad 10523 \quad 230095$

17-Jan-86 $1002 \quad 10492 \quad 227820$

18-Jan-86 $1003 \quad 10492 \quad 227646$

19-Jan-86 $1001 \quad 10514 \quad 227329$

20-Jan-86 $1002 \quad 10512 \quad 227558$

21-Jan-86 $1002 \quad 10520 \quad 227452$

22-Jan-86 $1002 \quad 10516 \quad 228568$

23-Jan-86 $1001 \quad 10492 \quad 227751$

24-Jan-86

25-Jan-86

26-Jan-86

27-Jan-86

28-Jan-86

29-Jan-86

30-Jan-86

31-Jan-86 2nd Stage

Separator

Gas

Press Rate

(psig) (scf/d)

42072155

42372199

042990

42536676

42769199

15033942

30311891

32636217
330
35596

32837167

33236699

33936194

33836404

34234451

34032134

34934994

34834622

34834622

35034547

35733371

34833715

34833753

34033808

$0 \quad 6659$

$\begin{array}{ll}0 & 0 \\ 0 & 0 \\ 0 & 0 \\ 0 & 0 \\ 0 & 0 \\ 0 & 0 \\ 0 & 0\end{array}$

\section{Sales Max Surface Brine Pressure Rate \\ Prod Disp \\ Well Well}

(scf/d) (psig) (psig) (stb/d) (scf/stb)(scf/stb)(scf/stb) (psia)

582688

581914

338573

299553

569541

278100

85751

258206

222913

256651

257735

259217

259272

260340

258243

254992

255580

252666

252483

251962

252488

252711

49810

2007342

22445

$\begin{array}{llll}23.14 & 26.35 & 28.65 & 9529\end{array}$

$\begin{array}{lllllll}2006 & 358 & 22431 & 23.04 & 26.26 & 28.58 & 9527\end{array}$

$\begin{array}{lllllll}3645 & 31 & 11178 & 27.08 & 30.92 & 31 & 10551\end{array}$

$\begin{array}{llllllll}2159 & 374 & 12072 & 22.57 & 25.61 & 27.94 & 9060\end{array}$

$\begin{array}{lllllll}2161 & 372 & 20562 & 24.33 & 27.70 & 30.03 & 9544\end{array}$

$\begin{array}{llllllll}3651 & 51 & 10675 & 23.67 & 26.85 & 27.74 & 10546\end{array}$

$\begin{array}{llllllll}3335 & 224 & 3751 & 20.17 & 23.34 & 25.03 & 10045\end{array}$

$\begin{array}{lllllll}3340 & 241 & 9734 & 22.97 & 26.69 & 28.5 & 10190\end{array}$

3350250

3358252

$3367 \quad 56$

3374261

3381259

3387261

3418266

3419266

3431264

3439265

3448265

3453267

3457268

3458270

3457266

38100

3810

3812

3817

3817 $\begin{array}{lllll}9768 & 22.75 & 26.39 & 28.22 & 10202\end{array}$

$\begin{array}{llllll}9767 & 23.18 & 26.99 & 28.81 & 10209\end{array}$

$\begin{array}{llllll}9806 & 23.21 & 26.95 & 28.8 & 10220\end{array}$

$\begin{array}{llllll}9852 & 23.55 & 27.22 & 29.1 & 10228\end{array}$

$\begin{array}{llllll}9877 & 23.19 & 26.88 & 28.75 & 10237\end{array}$

$\begin{array}{llllll}9874 & 23.33 & 26.82 & 28.71 & 10243\end{array}$

$\begin{array}{llllll}9883 & 23.34 & 26.59 & 28.48 & 10276\end{array}$

$\begin{array}{llllll}9867 & 23.32 & 26.87 & 28.8 & 10275\end{array}$

$\begin{array}{lllll}9838 & 23.16 & 26.68 & 28.6 & 10287\end{array}$

$\begin{array}{lllll}9838 & 23.14 & 26.66 & 28.59 & 10295\end{array}$

$\begin{array}{lllll}9858 & 23.06 & 26.56 & 28.5 & 10306\end{array}$

$\begin{array}{lllll}9856 & 23.09 & 26.47 & 28.45 & 10311\end{array}$

$\begin{array}{lllll}9864 & 23.06 & 26.48 & 28.4 & 10315\end{array}$

$\begin{array}{llllll}9860 & 23.18 & 26.60 & 28.53 & 10316\end{array}$

$\begin{array}{llllll}9838 & 23.15 & 26.59 & 28.47 & 10314\end{array}$

$\begin{array}{llllll}1634 & 27.51 & 31.58 & 31.66 & 10495\end{array}$

$0.00 \quad 0.00$

$0.00 \quad 0.00$

$\begin{array}{lll}0 & 0.00 & 0.00\end{array}$

$\begin{array}{lll}0 & 0.00 & 0.00\end{array}$

$\begin{array}{lll}0 & 0.00 & 0.00\end{array}$

$\begin{array}{lll}0 & 0.00 & 0.00\end{array}$

$0.00 \quad 0.00$

0
0
0
0
0
0
0

(scf/d) (scf) (stb)

$643049366877184 \quad 12558847$ 64107836751826212581278 34651836786478012592456 33729236820207212604528 61747736881954912625090 29612536911567312635765

9388836920956112639516 $277419369486980 \quad 12649250$ 27565336976263312659018 28138737004402012668785 28241337032643312678591 286693370613126 12688443 28396437089709012698320 $283483371180572 \quad 12708194$ 28146837146204012718077 28417037174621012727944 $281367372027577 \quad 12737782$ 28126837230884512747620 $280953372589798 \quad 12757478$ 28040337287020112767334 28013837315033912777198 28130637343164512787058 28008837371173312796896

5173237376346512798530 037376346512798530 037376346512798530 $0373763465 \quad 12798530$ 037376346512798530 037376346512798530 037376346512798530 037376346512798530 


\begin{tabular}{ccc} 
Date & $\begin{array}{c}\text { 1st Stage } \\
\text { Separator }\end{array}$ \\
\hline & $\begin{array}{c}\text { Press } \\
\text { Brine } \\
\text { Rate }\end{array}$ & $\begin{array}{c}\text { Gas } \\
\text { Rate }\end{array}$ \\
(psig) & $(\mathrm{RB} / \mathrm{d})$ & (scf/d)
\end{tabular}

2nd Stage Separator

1-Feb-86

2-Feb-86

3-Feb-86

4-Feb-86

5-Feb-86

6-Feb-86

7-Feb-86

8-Feb-86

0
0
0
0
0

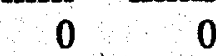

9-Feb-86

10-Feb-86 1008

11-Feb-86 1000

12-Feb-86 1032

13-Feb-86 1004

14-Feb-86 1005

15-Feb-86 1006

30691654918

17-Feb-86 $1006 \quad 30664 \quad 651803$

18-Feb-86 $1006 \quad 30623 \quad 651747$

19-Feb-86 $1006 \quad 30582 \quad 650931$

20-Feb-86 $1006 \quad 30558 \quad 651408$

21-Feb-86 $1007 \quad 30544 \quad 651218$

22-Feb-86 $1001 \quad 30526 \quad 654964$

23-Feb-86 $1001 \quad 30476 \quad 653664$

24-Feb-86 $1000 \quad 30441 \quad 652252$

25-Feb-86 $1001 \quad 30398 \quad 648249$

26-Feb-86 $1002 \quad 30369 \quad 646986$

27-Feb-86 $1012 \quad 30324 \quad 647882$

28-Feb-86 $1005 \quad 30259646984$

0
0
0
0
0
0
0
0

316119598

316119017
Pressure Rate

Prod Disp

Well Well

Ratios

$\begin{array}{ll}\text { Calc } & \text { Perf } \\ \text { BHP } & \text { Gas }\end{array}$

Cum
Gas

Cum

1st 2nd Disp

Press Rate

(psig) (scf/d)

(scf/d) (psig) (psig) (stb/d)

$$
\text { Stage Stg Well }
$$

23493163

259111364

299105151

336116376

324123300

323122329

328120989

324121244

324120418

325120780

326121603

326120221

327118773

313118285

315118810

316120339

318119036

310119560

(1)

$\begin{array}{rrrrrr}0 & 0 & 0 & 0.00 & 0.00 & 0 \\ 0 & 0 & 0 & 0.00 & 0.00 & 0 \\ 0 & 0 & 0 & 0.00 & 0.00 & 0 \\ 0 & 0 & 0 & 0.00 & 0.00 & 0 \\ 0 & 0 & 0 & 0.00 & 0.00 & 0 \\ 0 & 0 & 0 & 0.00 & 0.00 & 0 \\ 3928 & 82 & 2316 & 0.00 & 0.00 & 2.71 \\ 3954 & 119 & 2288 & 0.00 & 0.00 & 4.51 \\ 2632 & 94 & 21193 & 22.55 & 26.95 & 28.28 \\ 2045 & 111 & 22862 & 22.72 & 27.59 & 29.05 \\ 2042 & 112 & 22955 & 22.82 & 27.40 & 29.07 \\ 1248 & 140 & 27887 & 22.75 & 26.92 & 28.78 \\ 1233 & 141 & 28767 & 22.78 & 27.06 & 28.87 \\ 1225 & 141 & 28771 & 22.82 & 27.08 & 28.87 \\ 1235 & 142 & 28771 & 22.80 & 27.00 & 28.83 \\ 1228 & 144 & 28777 & 22.76 & 26.97 & 28.77 \\ 1227 & 144 & 28752 & 22.67 & 26.86 & 28.66 \\ 1227 & 145 & 28714 & 22.70 & 26.90 & 28.71 \\ 1225 & 146 & 28675 & 22.70 & 26.94 & 28.75 \\ 1227 & 146 & 28653 & 22.73 & 26.93 & 28.74 \\ 1228 & 147 & 28640 & 22.74 & 26.89 & 28.7 \\ 1226 & 145 & 28622 & 22.88 & 27.02 & 28.76 \\ 1231 & 146 & 28575 & 22.88 & 27.03 & 28.79 \\ 1225 & 147 & 28542 & 22.85 & 27.07 & 28.83 \\ 1230 & 147 & 28502 & 22.74 & 26.94 & 28.7 \\ 1222 & 147 & 28475 & 22.72 & 26.90 & 28.66 \\ 1231 & 148 & 28434 & 22.79 & 26.97 & 28.74 \\ 1225 & 147 & 28372 & 22.80 & 27.02 & 28.75\end{array}$

(psia) (scf/d) (scf) (stb)

037376346512798530

037376346512798530

037376346512798530

037376346512798530

037376346512798530

037376346512798530

$6276373769741 \quad 12800846$

$10319373780060 \quad 12803134$

$599338374379398 \quad 12824327$

$664141375043539 \cdot 12847189$

$667302375710841 \quad 12870144$

80258837651342912898031

83050337734393212926798

$830619378174551 \quad 12955569$

82946837900401912984340

82791437983193313013117

82403238065596613041869

82437938148034513070583

82440638230475113099258

82348738312823813127911

82196838395020613156551

82316938477337513185173

82267438559604913213748

82286638641891513242290

81800738723692213270792

81609438805301613299267

81719338887020913327701

81569538968590413356073 


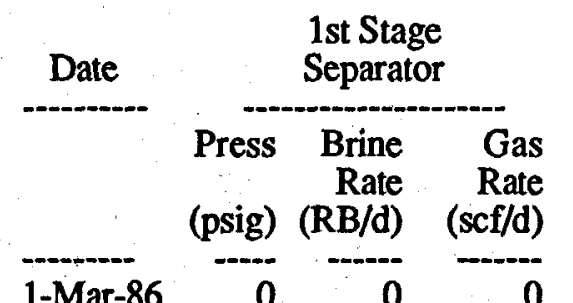

2-Mar-86 $\quad 1005 \quad 15089 \quad 327500$

3-Mar-86 $\quad 1000 \quad 30573 \quad 657315$

4-Mar-86 $1001 \quad 30531 \quad 648915$

$\begin{array}{llll}5-M a r-86 & 1002 & 30423 & 645873\end{array}$

6-Mar-86 $1020 \cdot 30344 \quad 646971$

$\begin{array}{llll}7-M a r-86 & 1003 \quad 30279 & 643161\end{array}$

$\begin{array}{lllll}8-M a r-86 & 1003 & 30231 & 646620\end{array}$

$\begin{array}{lllll}9-M a r-86 & 1003 & 30168 & 645168\end{array}$

10-Mar-86 $1003 \quad 30108 \quad 645881$

11-Mar-86 100430059645603

12-Mar-86 $1003 \quad 30007 \quad 640431$

? 13-Mar-86 100329924636215

๑ $\quad \omega \quad 14-$ Mar-86 100329890638433

$>\quad$ 15-Mar-86 100329840638701

en

16-Mar-86 $1003 \quad 29794 \quad 636952$

17-Mar-86 $100329746 \quad 636566$

18-Mar-86 $1004 \quad 29689 \quad 635326$

19-Mar-86 $100429638 \quad 631805$

20-Mar-86 $100429596 \quad 630384$

21-Mar-86 100329571631272

22-Mar-86 $1004 \quad 29521 \quad 630350$

23-Mar-86 $102429466 \quad 630161$

24-Mar-86 $100029406 \quad 628002$

25-Mar-86 $100129426 \quad 627910$

26-Mar-86 100629367629981

27-Mar-86 100430089367967

28-Mar-86 $1004 \quad 29383 \quad 631418$

29-Mar-86 $1003 \quad 29329631379$

30-Mar-86 $100429284 \quad 628994$

31-Mar-86 $1003 \quad 29234 \quad 629328$

\section{2nd Stage \\ Separator \\ Gas \\ Sales
Gas
$-\cdots--$ \\ Max Surface Brine \\ Pressure \\ Well Well \\ Rate \\ Stage Stg Wel}

(psig) (scf/d)

00

0

$40549557 \quad 372110$

$401100672 \quad 745107$

$401100054 \quad 742469$

404100085737451

$39599274 \quad 735972$

$39999408 \quad 732655$

$39699548 \quad 739881$

$\begin{array}{lll}399 & 99198 & 741722\end{array}$

$39498952 \quad 741220$

$39999114 \quad 742317$

$39198659 \quad 736769$

$39899455 \quad 733074$

$40299431 \quad 730878$

$39899465 \quad 733382$

$40299506 \quad 731456$

$40399124 \quad 729571$

$39698283 \quad 727318$

$39498420 \quad 725372$

$39498420 \quad 725372$

$\begin{array}{lll}393 & 97253 \quad 723124\end{array}$

40596981721702

40397956723067

$39398014 \quad 722314$

40096759720088

40396440719960

$39656273 \quad 419741$

$39096713 \quad 722152$

39795466721876

$39497143 \quad 720848$

39795956720461 (psig) (psig) (stb/d) (scf/stb)(scf/stb)(scf/stb) (psia)

$0 \quad 0$

$\begin{array}{llll}0 & 0.00 & 0.00 & 0\end{array}$

$\begin{array}{llllll}1234 & 315 & 14148 & 23.15 & 26.65 & 28.87 \\ 1237 & 306 & 28666 & 22.93 & 26.44 & 28.64\end{array}$

$\begin{array}{lllllll}1237 & 306 & 28666 & 22.93 & 26.44 & 28.64\end{array}$

$\begin{array}{lllllll}1225 & 304 & 28627 & 22.67 & 26.16 & 28.36\end{array}$

$\begin{array}{llllll}1231 & 303 & 28526 & 22.64 & 26.15 & 28.37\end{array}$

$\begin{array}{llllll}1240 & 301 & 28453 & 22.74 & 26.23 & 28.4\end{array}$

$\begin{array}{llllll}1226 & 302 & 28391 & 22.65 & 26.16 & 28.35\end{array}$

$\begin{array}{llllll}1225 & 302 & 28346 & 22.81 & 26.32 & 28.5\end{array}$

$\begin{array}{lllllll}1218 & 302 & 28287 & 22.81 & 26.32 & 28.51\end{array}$

$\begin{array}{lllllll}1218 & 303 & 28230 & 22.88 & 26.38 & 28.55\end{array}$

$\begin{array}{lllllll}1221 & 304 & 28185 & 22.91 & 26.42 & 28.61\end{array}$

$\begin{array}{llllll}1218 & 302 & 28136 & 22.76 & 26.27 & 28.42\end{array}$

$\begin{array}{lllllll}1221 & 303 & 28058 & 22.68 & 26.22 & 28.41\end{array}$

$\begin{array}{llllll}1223 & 302 & 28026 & 22.78 & 26.33 & 28.53\end{array}$

$\begin{array}{lllllll}1225 & 301 & 27979 & 22.83 & 26.38 & 28.57\end{array}$

$\begin{array}{lllllll}1217 & 301 & 27936 & 22.80 & 26.36 & 28.57\end{array}$

$\begin{array}{llllll}1224 & 301 & 27891 & 22.82 & 26.38 & 28.59\end{array}$

$\begin{array}{llllll}1212 & 302 & 27838 & 22.82 & 26.35 & 28.53\end{array}$

$\begin{array}{lllllll}1217 & 302 & 27790 & 22.74 & 26.28 & 28.44\end{array}$

$\begin{array}{lllllll}1216 & 301 & 27750 & 22.72 & 26.26 & 28.43\end{array}$

$\begin{array}{lllllll}1218 & 302 & 27727 & 22.77 & 26.28 & 28.43\end{array}$

$\begin{array}{llllll}1220 & 300 & 27680 & 22.77 & 26.28 & 28.5\end{array}$

$\begin{array}{llllll}1227 & 299 & 27630 & 22.81 & 26.35 & 28.56\end{array}$

$\begin{array}{llllll}1213 & 302 & 27572 & 22.78 & 26.33 & 28.49\end{array}$

$\begin{array}{lllllll}1213 & 304 & 27591 & 22.76 & 26.26 & 28.46\end{array}$

$\begin{array}{lllllll}1215 & 302 & 27536 & 22.88 & 26.38 & 28.59\end{array}$

$\begin{array}{lllllll}1208 & 305 & 27551 & 22.92 & 26.43 & 28.57\end{array}$

$\begin{array}{lllllll}1207 & 304 & 27500 & 22.96 & 26.43 & 28.61\end{array}$

$\begin{array}{lllllll}1206 & 305 & 27458 & 22.91 & 26.45 & 28.61\end{array}$

$\begin{array}{llllll}1201 & 303 & 27411 & 22.96 & 26.46 & 28.64\end{array}$ $\begin{array}{lllllll}1209 & 305 & 28213 & 13.04 & 15.04 & 17.21\end{array}$ \begin{tabular}{llll}
$\begin{array}{c}\text { Calc } \\
\text { BHP }\end{array}$ & $\begin{array}{c}\text { Perf } \\
\text { Gas }\end{array}$ & $\begin{array}{l}\text { Cum } \\
\text { Gas }\end{array}$ & $\begin{array}{l}\text { Cum } \\
\text { Brine }\end{array}$ \\
\hdashline & - &
\end{tabular}

(scf/d) (scf) (stb)

o 38968590413356073 40845339009435713370221 82099439091535113398887 81186239172721313427514 80928339253649513456040 80806539334456113484493 80488539414944513512884 80786139495730613541230 80646239576376913569517 80596739656973513597747 80637339737610813625932 79962539817573313654068 $797128398972861 \quad 13682126$ 79958239977244313710152 79936040057180313738131 79813240136993413766067 79740440216733813793958 79421840296155613821796 79034840375190413849586 78893340454083613877336 78827940532911513905063 78888040611799513932743

917278911340690710813960373

$9152 \quad 78552640769263413987945$

$9154 \quad 78524040847787414015536$

$9150 \quad 78725440926512814043072$

$9228 \quad 485546409750674 \quad 14071285$

$9145 \quad 78713241053780614098836$

$9139 \quad 786775411324581 \quad 14126336$

913478557341211015414153794

912478505141289520514181205 
Date

$-$ $\begin{array}{llll}12-A p r-86 & 1003 & 28911 & 616109 \\ 13-A p r-86 & 1004 & 28867 & 616226\end{array}$

1-Apr-86 $\quad 1004 \quad 29189 \quad 627720$ 2-Apr-86 $\quad 1003 \quad 29152 \quad 626985$ $\begin{array}{lllll}3-A p r-86 & 1005 & 29094 & 625780\end{array}$ $\begin{array}{llll}4-A p r-86 & 999 & 29084 & 625996\end{array}$ 5-Apr-86 $1000 \quad 29057 \quad 626361$ $\begin{array}{lllll}6-A p r-86 & 1000 & 29025 & 625002\end{array}$ $\begin{array}{llll}7-A p r-86 & 999 & 28998 & 627605\end{array}$ 8-Apr-86 $999 \quad 28951 \quad 625567$ 9-Apr-86 $\quad 999 \quad 28099 \quad 604146$ $\begin{array}{lllll}9-A p r-86 & 999 & 28099 & 604146\end{array}$ $11-A p r-86 \quad 1003$. 28954 * 614675 $\begin{array}{llll}13-A p r-86 & 1004 & 28867 & 616226 \\ 14-A p r-86 & 1003 & 28837 & 617463\end{array}$ $\begin{array}{lllll}15-A p r-86 & 1003 & 28793 & 616498\end{array}$ 16-Apr-86 $1003 \quad 28758 \quad 612801$ 17-Apr-86 $1003 \quad 28729 \quad 613312$ 18-Apr-86 $1003 \quad 28714 \quad 613627$ 19-Apr-86 $1003 \quad 28703 \quad 615750$ 20-Apr-86 $1002 \quad 28588 \quad 611377$ 21-Apr-86 $1004 \quad 28671 \quad 612282$ 22-Apr-86 $1001 \quad 28624 \quad 612132$ 23-Apr-86 $1000 \quad 28602 \quad 610647$ 24-Apr-86 $100028586 \quad 610429$ 25-Apr-86 $1002 \quad 28548 \quad 609696$ 26-Apr-86 $1001 \cdot 28501 \cdot 611239$ 27-Apr-86 $1000 \quad 27308 \quad 612046$ 28-Apr-86 $1101 \quad 28448 \quad 612825$ 29-Apr-86 $1001 \quad 28422 \quad 612610$ 30-Apr-86 $1001 \quad 28389 \quad 608658$

\section{2nd Stage Sales Max Surface Brine Separator Gas Pressure Rate} Press Ras (psig) (scf/d) Well Well

39895833 39395622 39695618 39194604 39394113 39894349 39394607 39995357 39889420 40196691 40296574 39997348 40497964 40396944 39995589 39996244 39996560 39395931 $386 \quad 96128$ 38496390 36998572 37999138 38199588 38198769 38398750 38298134 38797665 38396737 38297167 38197327 $\begin{array}{llll}718378 & 1198 & 304 & 27369\end{array}$

$\begin{array}{lllll}716109 & 1200 & 304 & 27334\end{array}$

$\begin{array}{lllll}712863 & 1196 & 302 & 27280\end{array}$

$\begin{array}{lllll}715348 & 1191 & 302 & 27270\end{array}$

$\begin{array}{lllll}711568 & 1192 & 300 & 27245\end{array}$

$\begin{array}{llll}710120 & 1194 & 299 & 27215\end{array}$

$\begin{array}{lllll}712062 & 1194 & 297 & 27189\end{array}$

$\begin{array}{lllll}707874 & 1190 & 293 & 27145\end{array}$

$\begin{array}{lllll}689155 & 1190 & 296 & 26346\end{array}$

$\begin{array}{llllll}708798 & 1193 & 292 & 27200\end{array}$

$\begin{array}{lllll}704340 & 1198 & 287 & 27148\end{array}$

$\begin{array}{lllll}701469 & 1191 & 284 & 27108\end{array}$

$\begin{array}{llllll}701273 & 1196 & 281 & 27067\end{array}$

$\begin{array}{lllll}702199 & 1190 & 279 & 27039\end{array}$

$\begin{array}{lllll}701178 & 1193 & 275 & 26997\end{array}$

$\begin{array}{lllll}698848 & 1193 \quad 274 & 26965\end{array}$

$\begin{array}{lllll}702721 & 1194 & 271 & 26937\end{array}$

$\begin{array}{llll}702710 & 1190 & 269 & 26923\end{array}$

$\begin{array}{lllll}701132 & 1190 & 268 & 26913\end{array}$

$\begin{array}{llllll}683763 & 1187 & 269 & 26805\end{array}$

$\begin{array}{lllll}698126 & 1188 & 262 & 2688\end{array}$

$\begin{array}{llllll}704878 & 1188 & 265 & 26839\end{array}$

$\begin{array}{lllll}703863 & 1186 & 265 & 26818\end{array}$

$\begin{array}{llllll}701926 & 1190 & 264 & 26803\end{array}$

$\begin{array}{lllll}701970 & 1185 & 266 & 26768\end{array}$

$\begin{array}{llll}701844 & 1182 & 267 & 26723\end{array}$

$\begin{array}{lllll}700929 & 1183 & 264 & 25605\end{array}$

$\begin{array}{lllll}698836 & 1183 & 265 & 26683\end{array}$

698818

698543
$1189262 \quad 26649$

118326426618

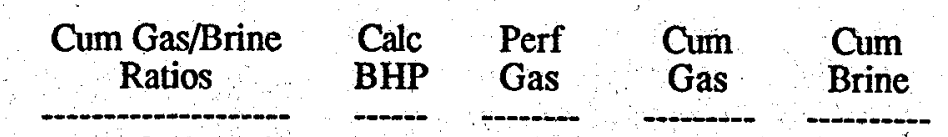

1st 2nd Disp Stage Stg Well (scf/stb)(scf/stb) (psia) $22.94 \quad 26.44 \quad 28.62$ $\begin{array}{lll}22.94 & 26.44 & 28.6\end{array}$ $22.9426 .44 \quad 28.62$ $22.96 \quad 26.42 \quad 28.57$ $\begin{array}{lll}22.99 & 26.44 & 28.6\end{array}$ $22.97 \quad 26.43 \quad 28.62$ $23.08 \quad 26.56 \quad 28.72$ $23.05 \quad 26.56 \quad 28.75$ $\begin{array}{lll}22.93 & 26.32 & 28.51\end{array}$ $22.77 \quad 26.32 \quad 28.53$ $22.64 \quad 26.20 \quad 28.4$ $22.73 \quad 26.32 \quad 28.51$ $\begin{array}{llll}22.77 & 26.39 & 28.6\end{array}$ $22.8426 .42 \quad 28.63$ $22.84 \quad 26.38 \quad 28.57$ $22.73 \quad 26.30 \quad 28.49$ $22.77 \quad 26.3528 .54$ $22.7926 .35 \quad 28.51$ $22.88 \quad 26.45 \quad 28.57$ $22.81 \quad 26.40 \quad 28.52$ $22.78 \quad 26.44 \quad 28.48$ $\begin{array}{llll}22.81 & 26.50 & 28.59\end{array}$ $22.77 \quad 26.48 \quad 28.58$ 22.7726 .4628 .56 $\begin{array}{llll}22.78 & 26.47 & 28.57\end{array}$ $22.87 \quad 26.54 \quad 28.65$ $23.90 \quad 27.72 \quad 29.85$ $\begin{array}{lll}22.97 & 26.59 & 28.7\end{array}$ $22.9926 .63 \quad 28.74$ $22.8726 .52 \quad 28.62$ $(\operatorname{scf} / d) \quad(s c f) \quad(s t b)$ $783301413678506 \quad 14208574$ $\begin{array}{llll}781752 & 414460258 \quad 14235908\end{array}$ $780754: 415241012 \quad 14263188$ 77910441602011614290458 77920741679932314317703 77889341757821614344918 78086841835908414372107 $780419419139503 \quad 14399252$ $751124419890628 \quad 14425598$ 77601642066664414452798 $771003421437647 \quad 14479946$ 77284942221049614507054 $774116422984612 \quad 14534121$ 77412742375873914561160 77130442453004314588157 $768233425298276 \quad 14615122$ $768782426067058 \quad 14642059$ 76757542683463214668982 76890442760353714695895 76447942836801514722700 $765628429133643 \quad 14749583$ 76732742990097014776422 $766458430667429 \quad 14803240$ 76549443143292214830043 76476243219768414856811 $765614432963298 \quad 14883534$ 76430943372760714909139 76580243449341014935822 $765892435259302 \quad 14962471$ 76180743602110914989089 


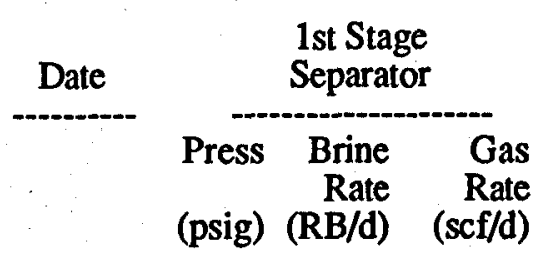

$\begin{array}{llll}-1-M a y-86 & 1001 & 28355 & 606859\end{array}$ 2-May-86 $100128328 \quad 606606$ 3-May-86 $1000 \quad 28291603621$ 4-May-86 $100128265 \quad 603851$ 5-May-86 $1000 \quad 28238 \quad 605523$ 6-May-86 100128210605435 7-May-86 100128187604166 8-May-86 $1001 \quad 28165 \quad 602735$ 9-May-86 $1002 \quad 28137 \quad 603976$ 10-May-86 $100028123 \quad 603569$ 11-May-86 $1001 \quad 28116 \quad 603558$ 12-May-86 $1000 \quad 28120604192$ 13-May-86 100128093605550 14-May-86 100128074601645 15-May-86 $100128042 \quad 599505$ 16-May-86 100128021599122 17-May-86 100028002598411 18-May-86 $1001 \quad 27978 \quad 597047$ 19-May-86 100027961594871 20-May-86 100127944593436 21-May-86 $1000 \quad 27933 \quad 595724$ 22-May-86 100127908595800 23-May-86 100127895596289 24-May-86 100027871597591 25-May-86 100127849597712 26-May-86 $1001 \quad 27830 \quad 596645$ 27-May-86 $1000 \quad 27814 \quad 597515$ 28-May-86 $1000 \quad 27794597031$ 29-May-86 100027767598593 30-May-86 $1002 \quad 27743 \quad 594236$ 31-May-86 $100027708 \quad 589984$

\section{2nd Stage Sales Max Surface Brine \begin{tabular}{cccc} 
2nd Stage & Sales & Max Surface & Brine \\
Separator & Gas & Pressure & Rate \\
\hdashline-- & - & --o-n & -
\end{tabular}} Press Rate (psig) (scf/d)

38397627 37497598 37097390 37397438 37097702 37497238 37096952 37096477 36996481 37796719 37297269 37297128 37496800 35199584 35499027 35299538 34899144 34899477 348100094 35399876 358100053 35499204 35298788 35499024 35299117 35099751 35399526 353100009 35599682 35695588 35898735

$\begin{array}{llll}696273 & 1182 & 265 & 26587\end{array}$ $\begin{array}{llll}695182 & 1185 & 264 & 26561\end{array}$

$\begin{array}{llll}697142 & 1184 & 263 & 26526\end{array}$

$\begin{array}{llll}696322 & 1185 & 263 & 26502\end{array}$

$\begin{array}{llll}694600 & 1180 & 263 & 26477\end{array}$

692520

689979

690556

691323

691139

692190

685894

684935

686005

691565

690343

691196

690096

690000

690361

690710

689451

688401

687715

688088

687407

686731

686199

685321

683825

$\begin{array}{lll}1180 & 263 & 26451\end{array}$

$\begin{array}{lll}1178 & 263 & 26429\end{array}$

$\begin{array}{lll}1180 & 262 & 26408\end{array}$

$\begin{array}{lll}1182 & 262 & 26382\end{array}$

$\begin{array}{lll}1180 & 262 & 26369\end{array}$

$\begin{array}{lll}1186 & 263 & 26362\end{array}$

$\begin{array}{lll}1180 & 262 & 26366\end{array}$

$\begin{array}{lll}1181 & 263 & 26341\end{array}$

$\begin{array}{lll}1177 & 263 & 26323\end{array}$

$\begin{array}{lll}1183 & 258 & 26293\end{array}$

$\begin{array}{lll}1178 & 260 & 26273\end{array}$

$\begin{array}{lll}1177 & 258 \quad 26255\end{array}$

117826026233

$\begin{array}{lll}1178 & 260 & 26217\end{array}$

$\begin{array}{lll}1180 & 261 & 26201\end{array}$

$\begin{array}{lll}1184 & 261 & 26191\end{array}$

$\begin{array}{lll}1175 & 263 & 26167\end{array}$

$\begin{array}{lll}1175 & 258 & 26155\end{array}$

$1176260 \quad 26133$

$\begin{array}{lll}1178 & 261 & 26112\end{array}$

$1174 \quad 258 \quad 26094$

$\begin{array}{lll}1180 & 260 & 26079\end{array}$

$\begin{array}{lll}1175 & 260 & 26060\end{array}$

118425926035

$\begin{array}{lll}1181 & 258 & 26013\end{array}$ 684286

$\begin{array}{lll}1186 & 259 & 25980\end{array}$

\section{Stage Stg Well} (scf/d) (psig) (psig) (stb/d) (scf/stb)(scf/stb)(scf/stb) (psia) $\begin{array}{llll}22.83 & 26.50 & 28.61\end{array}$ $22.84 \quad 26.5128 .57$ $22.7626 .43 \quad 28.47$ 22.7826 .4628 .52 $22.87 \quad 26.56 \quad 28.6$ $22.8926 .57 \quad 28.63$ $22.86 \quad 26.53 \quad 28.57$ $\begin{array}{lll}22.82 & 26.48 & 28.52\end{array}$ $\begin{array}{lll}22.89 & 26.55 & 28.59\end{array}$ $22.8926 .56 \quad 28.63$ $\begin{array}{lll}22.89 & 26.58 & 28.64\end{array}$ $22.92 \quad 26.6028 .65$ $22.9926 .66 \quad 28.73$ 22.8626 .6428 .58 $22.8026 .57 \quad 28.53$ $22.80 \quad 26.59 \quad 28.54$ $\begin{array}{lll}22.79 & 26.57 & 28.49\end{array}$ $22.76 \quad 26.55 \quad 28.48$ $\begin{array}{lll}22.69 & 26.51 & 28.44\end{array}$ $22.65 \quad 26.46 \quad 28.41$ $\begin{array}{llll}22.75 & 26.57 & 28.54\end{array}$ $22.77 \quad 26.56 \quad 28.52$ $\begin{array}{lll}22.80 & 26.58 & 28.52\end{array}$ 22.87. 26.6628 .61 $\begin{array}{lll}22.89 & 26.69 & 28.63\end{array}$ 22.8626 .6928 .62 $\begin{array}{lll}22.91 & 26.73 & 28.68\end{array}$ $\begin{array}{lll}22.91 & 26.75 & 28.7\end{array}$ $\begin{array}{lll}22.99 & 26.82 & 28.78\end{array}$ $\begin{array}{lll}22.84 & 26.52 & 28.49\end{array}$ $\begin{array}{lll}22.71 & 26.51 & 28.49\end{array}$ $\begin{array}{llll}\text { Calc } & \text { Perf } & \text { Cum } & \text { Cum } \\ \text { BHP } & \text { Gas } & \text { Gas } & \text { Brine }\end{array}$

(scf/d) (scf) $\quad(s t b)$ $760654436781763 \quad 15015676$ $758848437540611 \quad 15042237$ 75519543829580615068763 75583743905164315095265 75724243980888515121742 75729244056617715148193 75507744132125415174622 75315644207441015201030 75426144282867115227412 75494444358361615253781 75500844433862415280143 75538644509400915306509 75677744585078615332850 75231144660309815359173 75013944735323715385466 74983144810306815411739 74800544885107315437994 74711644959818915464227 74561145034380115490444 74437045108817115516645 74749145183566215542836 74628345258194515569003 74594145332788615595158 $747665454075551 \quad 15621291$ 74758745482313715647403 74681045556994815673497 74794645631789315699576 $8970 \quad 747922457065815 \quad 15725636$ $8977 \quad 749287457815103 \quad 15751671$ $8972 \quad 741110458556213 \quad 15777684$ $8974 \quad 74017045929638315803664$ 


\begin{tabular}{ccc} 
Date & \multicolumn{1}{c}{$\begin{array}{l}\text { Sst Stage } \\
\text { Separator }\end{array}$} \\
\hline & $\begin{array}{c}\text { Press } \\
\text { Brine }\end{array}$ & $\begin{array}{c}\text { Gas } \\
\text { Rate }\end{array}$ \\
(psig) & $(\mathrm{RB} / \mathrm{d})$ & (scf/d)
\end{tabular}

1-Jun-86

27690589560

3-Jun-86 $1000 \quad 27665 \quad 591391$

4-Jun-86 $1002 \quad 27609 \quad 591054$

5-Jun-86 $1002 \quad 27586 \quad 587795$

6-Jun-86 99927571588845

7-Jun-86 $1001 \quad 27553 \quad 588633$

$\begin{array}{llllll}8 \text {-Jun-86 } & 1001 & 27523 & 586787\end{array}$

$\begin{array}{llll}9-J u n-86 & 1002 & 27488 & 585001\end{array}$

10-Jun-86 $1001 \quad 27471 \quad 585909$

11-Jun-86 $1002 \quad 27452 \quad 585002$

12-Jun-86 $1002 \quad 27425 \quad 584712$

$\begin{array}{llllll}13-J u n-86 & 1002 & 27406 & 585345\end{array}$

14-Jun-86 $1002 \quad 27383 \quad 584401$

15-Jun-86 $1010 \quad 27352 \quad 583660$ 16-Jun-86 $1002 \quad 27321 \quad 583578$

$\begin{array}{llllll}17-J u n-86 & 1003 & 27305 & 581454\end{array}$ 18-Jun-86 $1003 \quad 27292 \quad 581877$ $\begin{array}{lllll}19-J u n-86 & 1003 & 27289 & 579165\end{array}$ 20-Jun-86 $1004 \quad 27278 \quad 579770$ 21-Jun-86 $1001 \quad 17434 \quad 339566$ 22-Jun-86 $1001 \quad 27449 \quad 583358$ 23-Jun-86 $1000 \quad 27388 \quad 585394$ 24-Jun-86 $1000 \quad 27351 \quad 584528$ 25-Jun-86 $999 \quad 27321 \quad 583664$ 26-Jun-86 $995 \quad 11520 \quad 243095$ 27-Jun-86 $1009 \quad 20172 \quad 385504$ 28-Jun-86 $999 \quad 27512 \quad 587338$ 29-Jun-86 $\quad 999 \quad 27447 \quad 588633$ 30-Jun-86 $1002 \quad 27388 \quad 587369$ \begin{tabular}{cccc}
$\begin{array}{ccc}\text { 2nd Stage } \\
\text { Separator }\end{array}$ & $\begin{array}{c}\text { Sales } \\
\text { Gas }\end{array}$ & $\begin{array}{c}\text { Max Surface } \\
\text { Pressure }\end{array}$ & $\begin{array}{c}\text { Brine } \\
\text { Rate }\end{array}$ \\
\hline Gas & & $\begin{array}{c}\text { Prod Disp } \\
\text { Well }\end{array}$ \\
Press & Wall & & Wall
\end{tabular}

Cum Gas/Brine Ratios

(psig) (scf/d)

35898185 (scf/d) (psig) (psig) (stb/d) (scf/stb)(scf/stb)(scf/stb) (psia)

$\begin{array}{llllllll}682538 & 1185 & 259 & 25963 & 22.71 & 26.49 & 28.47\end{array}$ $\begin{array}{llllllll}681919 & 1186 & 259 & 25942 & 22.76 & 26.53 & 28.52\end{array}$ $\begin{array}{llllllll}679960 & 1182 & 256 & 25939 & 22.80 & 26.57 & 28.55\end{array}$ $\begin{array}{llllllll}680639 & 1176 & 257 & 25887 & 22.83 & 26.58 & 28.56\end{array}$ $\begin{array}{lllllllll}678735 & 1175 & 255 & 25866 & 22.72 & 26.49 & 28.48\end{array}$ $\begin{array}{lllllllll}681333 & 1174 & 254 & 25851 & 22.78 & 26.54 & 28.51\end{array}$ $\begin{array}{llllllll}679763 & 1173 & 252 & 25835 & 22.78 & 26.54 & 28.5\end{array}$ $\begin{array}{llllllll}678591 & 1173 & 251 & 25806 & 22.74 & 26.50 & 28.48\end{array}$ $\begin{array}{llllllll}677649 & 1178 & 249 & 25774 & 22.70 & 26.44 & 28.41\end{array}$ $\begin{array}{lllllll}677352 & 1173 & 249 & 25758 & 22.75 & 26.51 & 28.44\end{array}$ $\begin{array}{llllllll}677522 & 1174 & 249 & 25740 & 22.73 & 26.51 & 28.45\end{array}$ $\begin{array}{llllllll}678262 & 1177 & 248 & 25715 & 22.74 & 26.54 & 28.48\end{array}$ $\begin{array}{llllllll}675759 & 1174 & 243 & 25697 & 22.78 & 26.60 & 28.55\end{array}$ $\begin{array}{llllllllll}676061 & 1179 & 241 & 25675 & 22.76 & 26.62 & 28.56\end{array}$ $\begin{array}{lllllllll}674760 & 1193 & 241 & 25647 & 22.76 & 26.63 & 28.58\end{array}$ $\begin{array}{llllllll}676181 & 1183 & 242 & 25617 & 22.78 & 26.68 & 28.6\end{array}$ $\begin{array}{lllllllll}676827 & 1172 & 228 & 25602 & 22.71 & 26.57 & 28.51\end{array}$ $\begin{array}{lllllll}677978 & 1186 & 243 & 25590 & 22.74 & 26.61 & 28.55\end{array}$ $\begin{array}{llllllll}673492 & 1182 & 243 & 25587 & 22.63 & 26.50 & 28.45\end{array}$ $\begin{array}{lllllll}673691 & 1177 & 242 & 25577 & 22.67 & 26.64 & 28.54\end{array}$ $\begin{array}{llllllll}393645 & 1190 & 286 & 16347 & 20.77 & 24.38 & 26.32\end{array}$ $\begin{array}{llllllll}677104 & 1183 & 282 & 25737 & 22.67 & 26.59 & 28.54\end{array}$ $\begin{array}{lllllll}676543 & 1182 & 283 & 25680 & 22.80 & 26.72 & 28.63\end{array}$ $\begin{array}{lllllll}677201 & 1181 & 288 & 25645 & 22.79 & 26.75 & 28.67\end{array}$ $\begin{array}{lllllllll}675961 & 1177 & 292 & 25617 & 22.78 & 26.74 & 28.65\end{array}$ $\begin{array}{llllllll}279590 & 1170 & 290 & 10801 & 22.51 & 26.32 & 28.25\end{array}$ $\begin{array}{llllllll}457211 & 1184 & 179 & 18914 & 20.38 & 24.56 & 26.2\end{array}$ $\begin{array}{llllllll}694454 & 1176 & 178 & 25796 & 22.77 & 27.30 & 28.96\end{array}$ 692102

$\begin{array}{lll}1174 \quad 179 & 25735 \\ 1144 & 179 & 25680\end{array}$ $1174 \quad 17925680$

22.8727 .34 29 $\begin{array}{ll}298114862 & 692102 \\ 298115070 & 689848\end{array}$

\begin{tabular}{|l} 
Calc \\
BHP \\
\hline \\
\hline \\
\hline psia) \\
\hline 8972 \\
8971 \\
8966 \\
8955 \\
8953 \\
8950 \\
8948 \\
8945 \\
8948 \\
8941 \\
8940 \\
8941 \\
8936 \\
8939 \\
8951 \\
8938 \\
8926 \\
8939 \\
8935 \\
8928 \\
8265 \\
8949 \\
8943 \\
8938 \\
8932 \\
7962 \\
8420 \\
8946 \\
8938 \\
8933 \\
\hline
\end{tabular}

(scf/d) (stb)

$739167460035550 \quad 15829627$ 73986646077541615855569 74055846151597415881508 $739333462255307 \quad 15907395$ 73666446299197115933261 73701246372898315959112 736298464465280.15984947 73495546520023516010753 $732239465932474 \quad 16036527$ 73255846666503216062285 73230346739733516088025 73236346812969816113740 $733649468863347 \quad 16139437$ 73327846959662516165112 73299147032961716190759 73264647106226316216376 72991347179217616241978 73059547252277016267568 72795047325072116293155 72996847398068816318732 43025347441094116335079 73453447514547516360816 73521847588069416386496 73524247661593616412141 73392747734986316437758 30512847765499116448559 49554747815053816467473 74705247889759016493269 74631547964390516519004 74523448038913916544684 

26-Jul-86 28-Jul-86

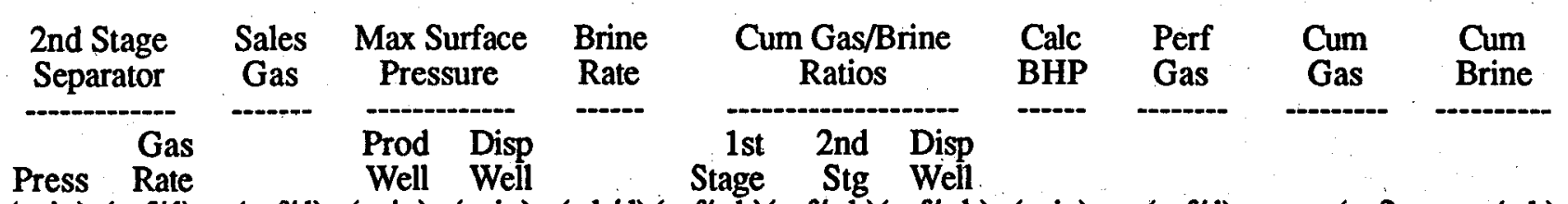
(psig) (scf/d) (scf/d) (psig) (psig) (stb/d) (scf/stb)(scf/stb)(scf/stb) (psia)
650632 653005 653173 647850

$$
\begin{array}{lll}
1178 & 178 & 25643
\end{array}
$$

$\begin{array}{lll}1178 & 177 & 25602\end{array}$

$\begin{array}{lll}1172 & 177 & 25578\end{array}$

$\begin{array}{lll}1190 & 177 & 25528\end{array}$

$\begin{array}{lll}1179 & 176 & 25532\end{array}$

$\begin{array}{lll}1186 & 177 & 25498\end{array}$

$\begin{array}{lll}1193 & 176 & 2546\end{array}$

$\begin{array}{lll}1184 & 179 & 25450\end{array}$

$\begin{array}{lll}1187 & 178 & 25417\end{array}$

$\begin{array}{lll}1171 & 179 & 25399\end{array}$

$\begin{array}{lll}1176 & 178 & 25380\end{array}$

$\begin{array}{lll}1175 & 179 & 25361\end{array}$

$\begin{array}{lll}1178 & 182 & 25363\end{array}$

$\begin{array}{lll}1186 & 182 & 25329\end{array}$

$\begin{array}{llll}1185 & 181 & 25288\end{array}$

$\begin{array}{lll}1180 & 181 & 25269\end{array}$

$\begin{array}{llll}1427 & 334 & 6976\end{array}$

$\begin{array}{lll}1193 & 348 & 25260\end{array}$

$\begin{array}{lll}1187 & 340 & 25409\end{array}$

$\begin{array}{lll}1184 & 337 & 25352\end{array}$

$\begin{array}{lll}1183 & 336 & 25312\end{array}$

$\begin{array}{lll}1186 & 334 & 25284\end{array}$

$\begin{array}{llll}1183 & 333 & 25256\end{array}$

$\begin{array}{lll}1181 & 331 & 25225\end{array}$

$\begin{array}{lll}1182 & 330 & 25189\end{array}$

$\begin{array}{lll}1181 & 330 & 25171\end{array}$

$\begin{array}{lll}1177 & 328 & 25163\end{array}$

$\begin{array}{lll}1177 & 327 & 25120\end{array}$

$\begin{array}{lll}1180 & 327 & 25117\end{array}$

118132725101 $\begin{array}{lll}1176 & 328 & 25145\end{array}$ $\begin{array}{lll}22.84 & 27.34 & 29\end{array}$

$\begin{array}{lll}22.91 & 27.38 & 29.05 \\ 22.87 & 27.34 & 29.01\end{array}$

$22.8627 .31 \cdot 28.97$

$\begin{array}{llll}22.87 & 27.29 & 28.96\end{array}$

$\begin{array}{lll}22.84 & 27.23 & 28.92\end{array}$

$\begin{array}{lll}22.92 & 27.38 & 29.07\end{array}$

$\begin{array}{lll}22.87 & 27.20 & 28.87\end{array}$

$\begin{array}{lll}22.87 & 27.20 & 28.87\end{array}$

$\begin{array}{lll}22.85 & 27.21 & 28.89\end{array}$

$\begin{array}{lll}22.86 & 27.23 & 28.91\end{array}$

$\begin{array}{lll}22.86 & 27.28 & 28.95\end{array}$

$\begin{array}{llll}22.97 & 27.35 & 29.02\end{array}$

$\begin{array}{lll}22.85 & 27.28 & 28.96\end{array}$

$\begin{array}{lll}22.82 & 27.20 & 28.87\end{array}$

$\begin{array}{llll}19.91 & 22.77 & 25\end{array}$

$\begin{array}{llll}22.72 & 26.05 & 28.34\end{array}$

$22.8126 .14 \quad 28.46$

$\begin{array}{llll}22.82 & 26.17 & 28.49\end{array}$

$\begin{array}{lll}22.85 & 26.25 & 28.51\end{array}$

$\begin{array}{lll}22.85 & 26.70 & 28.93\end{array}$

$\begin{array}{llll}22.87 & 26.42 & 28.63\end{array}$

$\begin{array}{lll}22.89 & 26.49 & 28.68\end{array}$

$\begin{array}{llll}22.78 & 26.34 & 28.57\end{array}$

$\begin{array}{lllll}22.93 & 26.51 & 28.72\end{array}$

$\begin{array}{lll}22.87 & 26.43 & 28.62\end{array}$

$\begin{array}{llll}22.89 & 26.44 & 28.64\end{array}$

$\begin{array}{lll}22.90 & 26.42 & 28.6\end{array}$

$\begin{array}{llll}22.79 & 26.37 & 28.56\end{array}$

$\begin{array}{llll}22.84 & 26.42 & 28.63\end{array}$ $\begin{array}{lll}22.91 & 27.21 & 28.89\end{array}$
8934

8930
8922
8936

8936

8925

8933

8923

8924

8909
8906

8909

8914

8910

8903

8127

8924

8916

8911

8911

8906

8901

8899

8896

8891

8889

8887

8891

8890 (scf/d) (scf) (stb)

$743647481132786 \quad 16570327$ 74373848187652416595929 74201848261854116621507 73954648335808816647035 73740248483489616698065 74015148557504816723526 73474248630978916748976 73378948704357816774393 73377748777735516799792 $733228488510583 \quad 16825172$ $733187489243770 \cdot 16850533$ $734259489978029 \quad 16875896$ 73504849071307616901225 $732340491445417 \quad 16926513$ 72951649217493316951782 17440049234933316958758 $715868493065201 \quad 16984018$ $723140493788341 \quad 17009427$ 72227849451062017034779 72164549523226517060091 $731466495963731 \quad 17085375$ 72307949668681017110631 72345349741026317135856 $719650498129913 \quad 17161045$ 72291149885282417186216 72016549957298917211379 $720153500293142 \quad 17236524$ 71843250101157417261644 71734250172891617286761 $718642502447557 \quad 17311862$ 73940748409749416672567

\section{8} 298114660 298114252 297113560 299112795 302111853 302113560 298110082 298110117 299109308 302110455 300110961

300111903 299110764 301111919 300110584 40719956 41984168 42484543 42484875 41385968 40897256 40289878 39990729 40789711 40290288 39989767 40289207 39888289 39989706 40389804

688572 689334 688996 687464 684619 681390 687464 683362 682742 682000 682679 681816 683315 688463 686696 686522 153486 655144 664185 663453 650819 650789 650994 650476 650662 655593 655167 29-Jul-86 31-Jul-86 


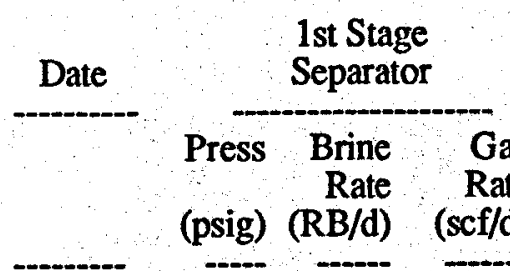

\begin{tabular}{llll}
\hline 1-Aug-86 & 1002 & 26722 & 573886
\end{tabular} 2-Aug-86 $1005 \quad 26690 \quad 573328$ $\begin{array}{lllll}3 \text {-Aug-86 } & 1022 & 26625 & 568468\end{array}$ 4-Aug-86 $1022 \quad 26593 \quad 569631$ 5-Aug-86 $1006 \quad 26613 \quad 571916$ 6-Aug-86 $1010 \quad 26606 \quad 569114$ 7-Aug-86 $1024 \quad 26431 \quad 563863$ 8-Aug-86 $\quad 998 \quad 26584 \quad 567752$ $\begin{array}{lllll}9-A u g-86 & 1001 & 26601 & 568557\end{array}$ 10-Aug-86 1001 $26559 \quad 547037$ 11-Aug-86 1001 26554 566351 12-Aug-86 $1002 \quad 26510 \quad 566305$ ? 13-Aug-86 1001 $26509 \quad 567312$ 14-Aug-86 $1002 \quad 26490 \quad 566105$ 15-Aug-86 $1006 \quad 26423 \quad 563540$ 16-Aug-86 $1004 \quad 26395 \quad 561851$ 17-Aug-86 $1002 \quad 26351 \quad 561569$ 18-Aug-86 $1002 \quad 26402 \quad 562939$ 19-Aug-86 $999 \quad 26377 \quad 562572$ 20-Aug-86 $1006 \quad 26349 \quad 563174$ 21-Aug-86 $1002 \quad 26348 \quad 564055$ 22-Aug-86 $1013 \quad 26240 \quad 561996$ 23-Aug-86 $1001 \quad 26238 \quad 562267$. 24-Aug-86 $1002 \quad 26295 \quad 564226$ 25-Aug-86 $1001 \quad 26286 \quad 561808$ 26-Aug-86 $1001 \quad 26261 \quad 560598$ 27-Aug-86 $1000 \quad 26251 \quad 560416$ 28-Aug-86 $1010 \quad 26203 \quad 556343$ 29-Aug-86 $100126176 \quad 555524$ 30-Aug-86 $1000 \quad 26184 \quad 559364$ 31-Aug-86 $100126180 \quad 557902$

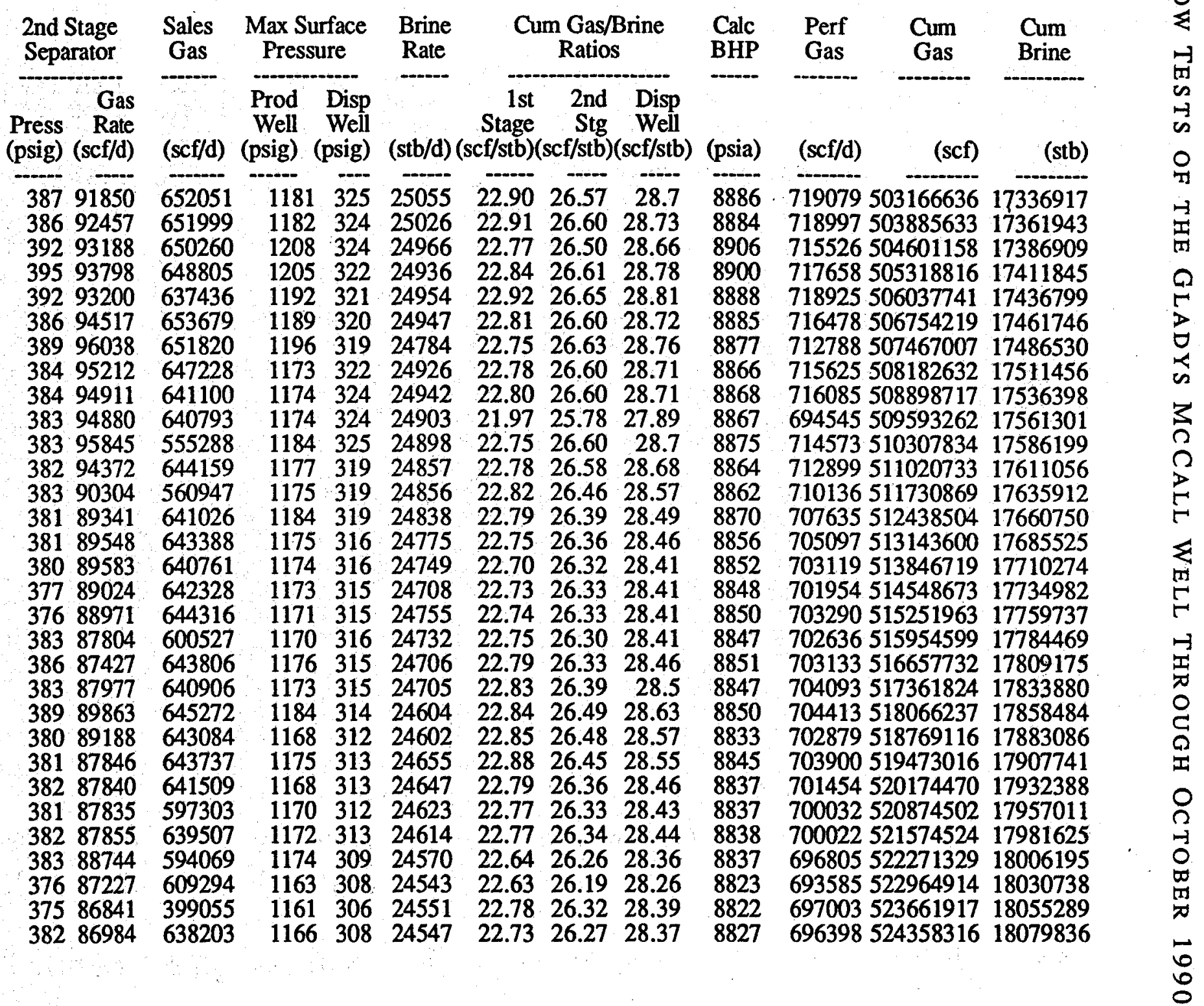




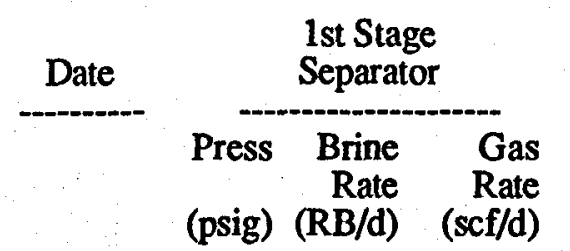

$\begin{array}{llll}7-S e p-86 & 1013 & 26135 & 557460\end{array}$ 2-Sep-86 $1007 \quad 26105 \quad 556268$ 3-Sep-86 $1010 \quad 26115 \quad 550818$ 4-Sep-86 $\quad 1000 \quad 26148 \quad 563606$ 5-Sep-86 $1001 \quad 26121 \quad 559390$ 6-Sep-86 $1003 \quad 26058 \quad 558510$ 7-Sep-86 $1014 \quad 26025 \quad 560313$ 8-Sep-86 $1021 \quad 25917 \quad 554695$ 9-Sep-86 $1005 \quad 26066 \quad 562670$ 10-Sep-86 101026062558932 11-Sep-86 $1000 \quad 26063 \quad 556666$ 12-Sep-86 $1004 \quad 26063 \quad 557745$ 13-Sep-86 $1004 \quad 26029 \quad 555040$ 14-Sep-86 $1001 \quad 26053 \quad 560018$ 15-Sep-86 100426004557567 16-Sep-86 $1003 \quad 26016557987$ 17-Sep-86 $100126011 \quad 560364$ 18-Sep-86 $1001 \quad 25994 \quad 558456$ 19-Sep-86 $1032 \quad 25933 \quad 557337$ 20-Sep-86 $1003 \quad 25916 \quad 557446$ 21-Sep-86 $1007 \quad 25896554351$ 22-Sep-86 $1005 \quad 25890 \quad 553592$ 23-Sep-86 $101625806 \quad 551498$ 24-Sep-86 $1014 \quad 25819550995$ 25-Sep-86 $1010 \quad 25828 \cdot 549724$ 26-Sep-86 $1012 \quad 25787 \quad 549670$ 27-Sep-86 $101025765 \quad 556562$ 28-Sep-86 $1021 \quad 25744 \quad 550273$ 29-Sep-86 $1010 \quad 25730 \quad 550573$ 30-Sep-86 $1000 \quad 25758 \quad 548591$ 2nd Stage Separator Separator Press Rate (psig) (scf/d)

38787138

38287457

38188360

40383682

40082943

40083771

40683565

40183621

40083105

39983377

39382458

39781649

39682302

39582328

39982426

39882302

39582355

39782022

40582304

39583488

39882395

39682308

39882548

39782737

39182384

39482011

39684464

39584992

39784692

40081756 \begin{tabular}{ccc}
$\begin{array}{c}\text { Sales } \\
\text { Gas }\end{array}$ & $\begin{array}{c}\text { Max Surface } \\
\text { Pressure }\end{array}$ & $\begin{array}{c}\text { Brine } \\
\text { Rate }\end{array}$ \\
\hdashline & $\begin{array}{cc}\text { Prod Disp } \\
\text { Well Well }\end{array}$ &
\end{tabular}

Cum Gas/Brine Ratios

1st 2nd Disp (pst) (scf/stb)(scf/stb)(scf/stb) (psia) $\begin{array}{llllllll}636942 & 1179 & 307 & 24506 & 22.75 & 26.30 & 28.43 & 8836\end{array}$ $\begin{array}{llllllll}633510 & 1174 & 307 & 24477 & 22.73 & 26.30 & 28.4\end{array}$ $\begin{array}{llllllll}631413 & 1176 & 308 & 24487 & 22.49 & 26.10 & 28.2\end{array}$ $\begin{array}{llllllll}619657 & 1162 & 303 & 24517 & 22.99 & 26.40 & 28.61\end{array}$ $\begin{array}{llllllll}634127 & 1169 & 303 & 24492 & 22.84 & 26.23 & 28.42\end{array}$ $\begin{array}{llllllll}630567 & 1170 & 304 & 24433 & 22.86 & 26.29 & 28.48\end{array}$ $\begin{array}{llllllll}633413 & 1174 & 303 & 24403 & 22.96 & 26.39 & 28.61\end{array}$ $\begin{array}{llllllll}634154 & 1180 & 304 & 24302 & 22.82 & 26.27 & 28.47\end{array}$ $\begin{array}{lllllll}636108 & 1169 & 310 & 24441 & 23.02 & 26.42 & 28.62\end{array}$ $\begin{array}{llllllll}628419 & 1173 & 311 & 24437 & 22.87 & 26.28 & 28.47\end{array}$ $\begin{array}{lllllllll}629966 & 1158 & 310 & 24437 & 22.78 & 26.15 & 28.31\end{array}$ $\begin{array}{llllllll}632362 & 1163 & 312 & 24438 & 22.82 & 26.16 & 28.34\end{array}$ $\begin{array}{lllllllll}632164 & 1162 & 311 & 24406 & 22.74 & 26.11 & 28.29\end{array}$ $\begin{array}{llllllll}636730 & 1161 & 310 & 24428 & 22.93 & 26.30 & 28.47\end{array}$ $\begin{array}{lllllll}634473 & 1164 & 312 & 24382 & 22.87 & 26.25 & 28.44\end{array}$ $\begin{array}{llllllll}633819 & 1166 & 311 & 24394 & 22.87 & 26.25 & 28.43\end{array}$ $\begin{array}{llllllll}636218 & 1164 & 313 & 24389 & 22.98 & 26.35 & 28.52\end{array}$ $\begin{array}{llllllll}633062 & 1162 & 313 & 24373 & 22.91 & 26.28 & 28.46\end{array}$ $\begin{array}{llllllll}633885 & 1189 & 309 & 24318 & 22.92 & 26.30 & 28.52\end{array}$ $\begin{array}{llllllll}635187 & 1164 & 311 & 24300 & 22.94 & 26.38 & 28.55\end{array}$ $\begin{array}{llllllll}632602 & 1167 & 311 & 24281 & 22.83 & 26.22 & 28.41\end{array}$ $\begin{array}{llllllll}633783 & 1165 & 311 & 24276 & 22.80 & 26.20 & 28.37\end{array}$ $\begin{array}{llllllll}618473 & 1173 & 310 & 24198 & 22.79 & 26.20 & 28.39\end{array}$ $\begin{array}{llllllll}629387 & 1167 & 310 & 24210 & 22.76 & 26.18 & 28.36\end{array}$ 629366 628458 628066 627490 627585 622186
$1164 \quad 310 \quad 24218$

$1167310 \quad 24180$

$\begin{array}{lllllll}1176 & 312 & 24140 & 22.80 & 26.32 & 28.49\end{array}$ $\begin{array}{llllll}1167 & 314 & 24126 & 22.82 & 26.33 & 28.51\end{array}$ $\begin{array}{llllll}1154 & 315 & 24151 & 22.71 & 26.10 & 28.3\end{array}$ \begin{tabular}{cccc}
$\begin{array}{c}\text { Calc } \\
\text { BHP }\end{array}$ & $\begin{array}{l}\text { Perf } \\
\text { Gas }\end{array}$ & $\begin{array}{c}\text { Cum } \\
\text { Gas }\end{array}$ & $\begin{array}{l}\text { Cum } \\
\text { Brine }\end{array}$ \\
\hdashline- & - & &
\end{tabular} (scf/d)

(scf)

(stb)

69670652505502118104342 69514752575016818128819 69053352644070118153306 70143152714213318177823 69606352783819518202315 69585252853404718226748 69817052923221718251151 69187852992409518275453 69950153062359618299894 69572153131931818324331 69181153201112918348768 69257353270370218373206 $690446533394148 \quad 18397612$ $695465534089613 \quad 18422040$ 69342453478303718446422 69352153547655918470816 69557453617213318495205 69365653686578818519578 $693549537559338 \quad 18543896$ 69376553825310318568196 68982353894292618592477 68871053963163618616753 68698154031861718640951 68659654100521318665161 $684159541689371 \quad 18689379$ 68405254237342418713559 69360554306702918737718 68774954375477718761858 68783254444260918785984 68347354512608318810135 
2nd Stage Sales Max Surface Brine Separator Gas Pressure Rate Press Brine Gas
Rate Rate (psig) (RB/d) (scf/d) Press Rate (psig) (scf/d)

$\begin{array}{llll}1-O c t-86 & 999 & 25814 & 551052\end{array}$ $\begin{array}{llll}2-O c t-86 & 999 & 25751 & 550762\end{array}$ $\begin{array}{lllll}3-O c t-86 & 1012 & 25764 & 552233\end{array}$ $\begin{array}{lllll}4-O c t-86 & 1020 & 25657 & 548679\end{array}$ $\begin{array}{lllll}5-\text { Oct-86 } & 1000 & 21338 & 466330\end{array}$ $\begin{array}{lllll}6-O c t-86 & 1003 & 14872 & 324744\end{array}$ 7-Oct-86 $1010 \quad 26006 \quad 557700$ 8-Oct-86 $1000 \quad 25966 \quad 555090$ $\begin{array}{lllll}9-\text { Oct-86 } & 1021 & 25891 & 551751\end{array}$ 10-Oct-86 $1009 \quad 25776 \quad 548886$ $\begin{array}{lllll}11-O c t-86 & 1013 & 25748 & 549170\end{array}$ 12-Oct-86 $1022 \quad 25760 \quad 548230$ 13-Oct-86 $1006 \quad 25723 \quad 549245$ $\begin{array}{lllll}14-O c t-86 & 1015 & 25724 & 548850\end{array}$ 15-Oct-86 $1015 \quad 25692 \quad 546849$ $\begin{array}{lllll}16-O c t-86 & 999 & 25671 & 547431\end{array}$ $\begin{array}{lllll}17-\text { Oct-86 } & 1001 & 25675 & 549147\end{array}$ $\begin{array}{llll}18-O c t-86 & 1002 & 25654 & 549283\end{array}$ 19-Oct-86 $1002 \quad 25653 \quad 548477$ $\begin{array}{llll}20-O c t-86 & 1002 & 25631 & 548386\end{array}$ 21-Oct-86 $1002 \quad 25594 \quad 545802$ 22-Oct-86 $1002 \quad 25563 \quad 546760$ 23-Oct-86 $1008 \quad 25537 \quad 544081$ 24-Oct-86 $1000 \quad 25540 \quad 545243$ $\begin{array}{lllll}25-O c t-86 & 1002 & 25539 & 545490\end{array}$ 26-Oct-86 $1002 \quad 26586 \quad 544013$ 27-Oct-86 $1002 \quad 25504 \quad 543902$ 28-Oct-86 $1002 \quad 25483 \quad 542793$ 29-Oct-86 $1000 \quad 25464 \quad 542856$ 30-Oct-86 $1001 \quad 25462 \quad 544698$ 31-Oct-86 $999 \quad 25440 \quad 544496$ $\begin{array}{lllllll}1153 & 315 & 24204 & 22.77 & 26.11 & 28.31\end{array}$ $40083478 \quad 625313$ $40682641 \quad 622740$ $400 \quad 71210 \quad 528943$ $\begin{array}{llll}450 & 43100 \quad 367844\end{array}$ $443 \quad 73426 \quad 621002$ 44874253 45175386 44175837 44676258 44476933 4277728

43176248 43776058 43076640 42875838 43276425 41576297 41876408 42677367 42578413

41478951 42378435 41777706 42478214 42278467 42078358

41978156 41878044 41878327 $\begin{array}{llllllll}609653 & 1176 & 341 & 24278 & 22.73 & 25.83 & 28.29\end{array}$ $\begin{array}{lllllllll}603156 & 1167 & 341 & 24169 & 22.71 & 25.85 & 28.25\end{array}$ $\begin{array}{lllllllll}604472 & 1175 & 342 & 24143 & 22.75 & 25.91 & 28.34\end{array}$ $\begin{array}{llllllll}603542 & 1177 & 341 & 24155 & 22.70 & 25.88 & 28.3\end{array}$ $\begin{array}{llllllll}605248 & 1163 & 340 & 24119 & 22.77 & 25.98 & 28.31\end{array}$ $\begin{array}{llllllll}606259 & 1176 & 341 & 24121 & 22.75 & 25.92 & 28.27\end{array}$ $\begin{array}{lllllllll}605356 & 1175 & 342 & 24091 & 22.70 & 25.86 & 28.24\end{array}$ $\begin{array}{llllllll}603453 & 1161 & 343 & 24070 & 22.74 & 25.93 & 28.28\end{array}$ $\begin{array}{llllllll}603693 & 1162 & 341 & 24074 & 22.81 & 25.96 & 28.3\end{array}$ $\begin{array}{lllllllll}604299 & 1160 & 341 & 24054 & 22.84 & 26.01 & 28.37\end{array}$ $\begin{array}{llllllll}604372 & 1157 & 340 & 24053 & 22.80 & 25.97 & 28.25\end{array}$ $\begin{array}{lllllllll}603700 & 1157 & 340 & 24033 & 22.82 & 26.00 & 28.29\end{array}$ $\begin{array}{lllllllll}602041 & 1157 & 340 & 23998 & 22.74 & 25.97 & 28.3\end{array}$ $\begin{array}{llllllll}601624 & 1155 & 339 & 23969 & 22.81 & 26.08 & 28.41\end{array}$ $\begin{array}{llllllll}602153 & 1157 & 339 & 23945 & 22.72 & 26.02 & 28.29\end{array}$ $\begin{array}{llllllll}602729 & 1151 & 336 & 23947 & 22.77 & 26.04 & 28.36\end{array}$ $\begin{array}{llllllll}602848 & 1155 & 338 & 23946 & 22.78 & 26.02 & 28.31\end{array}$ $\begin{array}{llllllll}602155 & 1154 & 339 & 24928 & 21.82 & 24.96 & 27.28\end{array}$ $\begin{array}{llllllll}601385 & 1156 & 339 & 23913 & 22.74 & 26.03 & 28.34\end{array}$ $\begin{array}{llllllll}601285 & 1156 & 338 & 23894 & 22.72 & 26.00 & 28.3\end{array}$ $\begin{array}{lllllllll}600282 & 1152 & 336 & 23876 & 22.74 & 26.01 & 28.3\end{array}$ $\begin{array}{lllllll}601176 & 1154 & 336 & 23874 & 22.82 & 26.08 & 28.37\end{array}$ 605283 


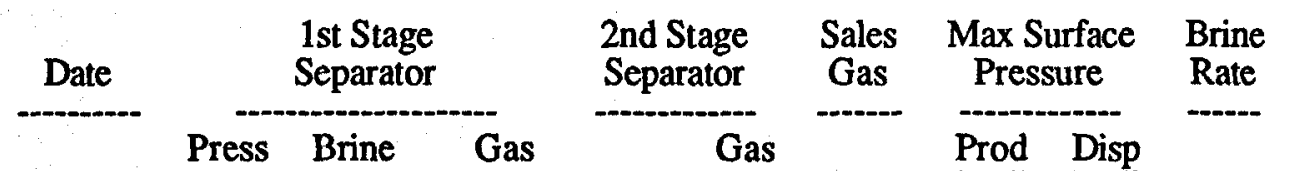

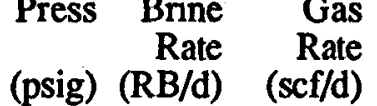

$\begin{array}{llll}\text { 1-Nov-86 } & 1020 & 25341 & 540798\end{array}$

2-Nov-86 $1000 \quad 25312 \quad 543321$

3-Nov-86 $1018 \quad 25311543351$

4-Nov-86 $1016 \quad 25299 \quad 542653$

5-Nov-86 $1013 \quad 25275 \quad 546165$

6-Nov-86 $1001 \quad 25305 \quad 541416$

7-Nov-86 $1001 \quad 25320 \quad 541264$

8-Nov-86 $1002 \quad 25314.541698$

9-Nov-86 $1002 \quad 25294 \quad 541586$

10-Nov-86 $1002 \quad 23313 \quad 498312$

11-Nov-86 102323768510319

12-Nov-86 $1025 \quad 23829511816$

? 13-Nov-86 $1002 \quad 23902 \quad 515634$

ه $\quad \omega \quad$ 14-Nov-86 $102723590 \quad 512921$

$>\quad \infty \quad 15-$ Nov-86 $103625049 \quad 536719$

16-Nov-86 103924996534350

17-Nov-86 102225060535913

18-Nov-86 102125073536695

19-Nov-86 $1002 \quad 25144 \quad 538213$

20-Nov-86 100225180539390

21-Nov-86 $101125061 \quad 536324$

22-Nov-86 $1008 \quad 23564 \quad 502827$

23-Nov-86 $1003 \quad 793966460$

24-Nov-86 $1003 \quad 25399543489$

25-Nov-86 100425386542510

26-Nov-86 1000 24675529743

27-Nov-86 $1001 \quad 12717274527$

28-Nov-86 $1013 \quad 25288 \quad 542280$

29-Nov-86 $1013 \quad 25167539102$

30-Nov-86 $101725162 \quad 537727$
Press Rate

(psig) (scf/d)

42278974

41578644

42178935

42276819

42679446

42474215

42374107

42974170

38670050

38879424

38879222

37978847

44567417

43673386

42975799

42574846

43372855

43072154

43270837

43570817

43566573

43016615

43072070

43073085

44070730

44036949

44571778

44272751

44772907
41975608
Well Well

$\begin{array}{llllllll}(\mathrm{scf} / \mathrm{d}) & (\mathrm{psig}) & (\mathrm{psig}) & (\mathrm{stb} / \mathrm{d})(\mathrm{scf} / \mathrm{stb})(\mathrm{scf} / \mathrm{stb})(\mathrm{scf} / \mathrm{stb}) & (\mathrm{psia}) & (\mathrm{scf} / \mathrm{d}) & (\mathrm{scf}) & (\mathrm{stb})\end{array}$

$\begin{array}{lllllll}603128 & 1170 & 332 & 23762 & 22.76 & 26.08 & 28.39\end{array}$

$\begin{array}{llllllll}606755 & 1150 & 333 & 23733 & 22.89 & 26.21 & 28.48\end{array}$

$\begin{array}{llllllll}605646 & 1164 & 332 & 23734 & 22.89 & 26.22 & 28.52\end{array}$

$\begin{array}{llllllll}600384 & 1164 & 331 & 23722 & 22.88 & 26.11 & 28.42\end{array}$

$\begin{array}{llllllll}607394 & 1162 & 332 & 23700 & 23.05 & 26.24 & 28.53\end{array}$

$\begin{array}{lllllll}609212 & 1154 & 335 & 23727 & 22.82 & 26.17 & 28.5\end{array}$

$\begin{array}{llllllll}609245 & 1151 & 332 & 23741 & 22.80 & 25.92 & 28.24\end{array}$

$\begin{array}{llllllll}605347 & 1149 & 332 & 23735 & 22.82 & 25.94 & 28.26\end{array}$

$\begin{array}{llllllll}605053 & 1152 & 333 & 23717 & 22.84 & 25.96 & 28.31\end{array}$

$\begin{array}{llllllll}558847 & 1348 & 316 & 21859 & 22.80 & 26.00 & 28.12\end{array}$

$\begin{array}{llllllll}581684 & 1362 & 314 & 22287 & 22.90 & 26.46 & 28.59\end{array}$

$\begin{array}{llllllll}583527 & 1354 & 316 & 22345 & 22.91 & 26.45 & 28.58\end{array}$

$\begin{array}{llllllll}586158 & 1334 & 317 & 22411 & 23.01 & 26.53 & 28.61\end{array}$

$\begin{array}{llllllll}550203 & 1196 & 360 & 22121 & 23.19 & 26.24 & 28.66\end{array}$

$\begin{array}{llllllll}602602 & 1200 & 352 & 23490 & 22.85 & 25.97 & 28.35\end{array}$

$\begin{array}{llllllll}602708 & 1196 & 351 & 23440 & 22.80 & 26.03 & 28.38\end{array}$

$\begin{array}{lllllllll}604231 & 1178 & 351 & 23499 & 22.81 & 25.99 & 28.32\end{array}$

$\begin{array}{lllllllll}604684 & 1176 & 350 & 23511 & 22.83 & 25.93 & 28.29\end{array}$

$\begin{array}{llllllll}601901 & 1162 & 351 & 23576 & 22.83 & 25.89 & 28.24\end{array}$

$\begin{array}{lllllll}603155 & 1158 & 350 & 23610 & 22.85 & 25.85 & 28.21\end{array}$

$\begin{array}{llllllll}601273 & 1171 & 348 & 23499 & 22.82 & 25.84 & 28.21\end{array}$

601892

152002

610184

608596

607053

604010

607367

604027 $\begin{array}{lll}3052 & 340 & 22095\end{array}$

$\begin{array}{lll}1161 & 340 & 7444\end{array}$

$\begin{array}{lll}1160 & 343 & 23815\end{array}$

$\begin{array}{llll}1160 & 341 & 23803\end{array}$

306835023136

$\begin{array}{lll}1166 & 364 & 11924\end{array}$

$\begin{array}{lll}1176 & 363 & 23712\end{array}$

$\begin{array}{llll}1176 & 362 & 23598\end{array}$

$\begin{array}{lll}1178 & 362 & 23594\end{array}$ $\begin{array}{llll}8.92 & 25.85 & 28.2 & 8758\end{array}$

$\begin{array}{llll}22.79 & 25.86 & 28.21\end{array}$

$\begin{array}{llll}22.90 & 25.95 & 28.36 & 10678\end{array}$

$\begin{array}{llll}23.02 & 26.12 & 28.52 & 8003\end{array}$

$\begin{array}{llll}22.87 & 25.90 & 28.32 & 8766\end{array}$

$\begin{array}{llll}22.84 & 25.93 & 28.34 & 8757\end{array}$

$\begin{array}{lllll}22.79 & 25.88 & 28.32 & 8758\end{array}$
67460356655223419566648 67591656722815019590381 67689456790504419614115 67417956857922319637837 67616156925538419661537 67622056993160419685264 67044657060205019709005 67075157127280119732740 67142857194422919756457 61467557255890419778316 63718557319608919800603 63862057383470919822948 64117957447588819845359 63398857510987619867480 66594257577581719890970 66522757644104519914410 66549257710653619937909 66512657777166319961420 66578657843744919984996 66603857910348720008606 66290757976639420032105 62197458038836820054200 10056858048893620061644 67158358116051920085459 67148358183200220109262 65613758248813920132398 34007258282821120144322 67152458349973520168034 66876758416850320191632 66818258483668520215226 


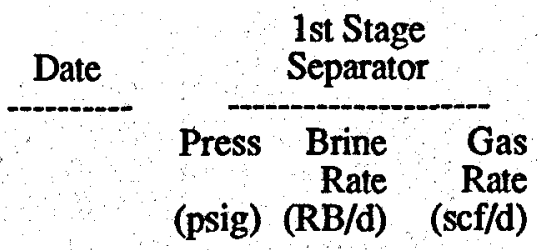

$\begin{array}{llll}1-\text { Dec-86 } & 1004 & 25118 & 538070\end{array}$ 2-Dec-86 $\quad 1030 \quad 25078 \quad 535166$ 3-Dec-86 $1001 \quad 24975 \quad 534522$ 4-Dec-86 $1003 \quad 25072 \quad 537344$ 5-Dec-86 $1012 \quad 25046 \quad 537023$ 6-Dec-86 $1005 \quad 24971 \quad 535070$ 7-Dec-86 $1019 \quad 24954 \quad 535700$ 8-Dec-86 $1000 \quad 24971 \quad 534629$ $\begin{array}{llll}9-D e c-86 & 998 & 24988 & 535041\end{array}$ 10-Dec-86 $1001 \quad 24987 \quad 536568$ 11-Dec-86 $1001 \quad 24951 \quad 538105$ 12-Dec-86 $1035 \quad 24837 \quad 532170$ 13-Dec-86 $1006 \quad 24821 \quad 542684$ 14-Dec-86 $999 \quad 24898 \quad 533462$ 15-Dec-86 $1008 \quad 24887 \quad 532378$ 16-Dec-86 $1012 \quad 24840 \quad 533083$ 17-Dec-86 $1022 \quad 24750 \quad 531000$ 18-Dec-86 $1008 \quad 24762 \quad 528139$ 19-Dec-86 $1001 \quad 24821 \quad 532254$ 20-Dec-86 $1002 \quad 24801 \quad 532846$ 21-Dec-86 $1000 \quad 24778 \quad 530375$ 22-Dec-86 $1013 \quad 24774 \quad 530651$ 23-Dec-86 $1003 \quad 24710 \quad 530457$ 24-Dec-86 $1006 \quad 24712 \quad 529858$ 25-Dec-86 $1006 \quad 24679 \quad 528491$ 26-Dec-86 $1005 \quad 24650 \quad 526661$ 27-Dec-86 $1000 \quad 24679 \quad 527425$ 28-Dec-86 $1017 \quad 24595 \quad 526554$ 29-Dec-86 $999 \quad 24640 \quad 527166$ 30-Dec-86 $999 \quad 24666 \quad 527322$ 31-Dec-86 $1000 \quad 24639 \quad 527585$

\section{2nd Stage Sales Max Surface Brine Separator Gas Pressure Rate Press Rate \\ Prod Disp Well Well} (psig) (scf/d) 44974476 44972832 45673754 45871392 44272123 44273167 44773767 44573150 44273017 44371509 45070272 43972877 44174426 43973273 43872884 44270501 44072262 43873003 44468860 44369114 43869245 43869064 44467549 44769035 44072180 43672558 43971011 43870326 43572379 43472137 43172253 $\begin{array}{llll}603499 & 1162 & 364 & 23552\end{array}$ 605070 599664 595138 598488 596241 5.98089 600007 599025 598314 596476 591557 598167 595997 597491

596761

596138 595875 592743 596786 595852 595968 594550 595348 596221

596841 598464 599747 597972 598293 595019 $\begin{array}{lll}1189 & 359 & 23516\end{array}$

$\begin{array}{lll}1169 & 364 & 23417\end{array}$

$\begin{array}{lll}1168 & 361 & 23508\end{array}$

$\begin{array}{lll}1176 & 362 & 23485\end{array}$

$\begin{array}{lll}1166 & 361 & 23414\end{array}$

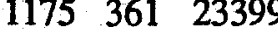

$\begin{array}{llll}1157 & 365 & 23414\end{array}$

$1154364 \quad 23429$

$\begin{array}{lll}1162 & 359 & 23429\end{array}$

$\begin{array}{lll}1164 & 350 & 23395\end{array}$

119435423291

$\begin{array}{lll}1166 & 357 & 23273\end{array}$

$\begin{array}{lll}1155 & 358 & 23345\end{array}$

$\begin{array}{lll}1161 & 353 & 23335\end{array}$

$\begin{array}{lll}1169 & 356 \quad 23292\end{array}$

$\begin{array}{lll}1175 & 356 & 23208\end{array}$

$\begin{array}{llll}1163 & 357 & 23218\end{array}$

$\begin{array}{llll}1160 & 350 & 23273\end{array}$

$\begin{array}{lll}1161 & 352 & 23254\end{array}$

$\begin{array}{llll}1158 & 352 & 23233\end{array}$

$\begin{array}{lll}1168 & 350 & 23230\end{array}$

$\begin{array}{lll}1159 & 356 & 23169\end{array}$

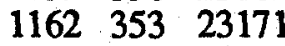

$1165 \quad 355 \quad 23140$

$\begin{array}{lll}1162 & 358 & 23113\end{array}$

$\begin{array}{lll}1158 & 350 & 23140\end{array}$

$\begin{array}{lll}1173 & 347 & 23062\end{array}$

$\begin{array}{lll}1158 & 347 & 23103\end{array}$

$\begin{array}{lll}1156 & 353 & 23127\end{array}$

$1152 \quad 344 \quad 23102$ (scf/d) (psig) (psig) (stb/d) (scf/stb)(scf/stb)(scf/stb) (psia)
Cum Gas/Brine Ratios

1st 2nd Disp 1st 2nd Well $\begin{array}{llll}22.85 & 26.01 & 28.46\end{array}$ $\begin{array}{llll}22.76 & 25.85 & 28.3\end{array}$ $22.83 \quad 25.98 \quad 28.46$ $22.86 \quad 25.89 \quad 28.39$ $22.8725 .94 \quad 28.35$ $\begin{array}{lll}22.85 & 25.98 & 28.39\end{array}$ $22.8926 .05 \quad 28.48$ $22.83 \quad 25.9628 .39$ $22.84 \quad 25.95 \quad 28.36$ $22.90 \quad 25.95 \quad 28.37$ $23.00 \quad 26.00 \quad 28.46$ $\begin{array}{llll}22.85 & 25.98 & 28.37\end{array}$ $\begin{array}{llll}23.32 & 26.52 & 28.92\end{array}$ 22.8525 .9928 .39 $\begin{array}{lll}22.81 & 25.94 & 28.33\end{array}$ $22.8925 .91 \quad 28.33$ $\begin{array}{llll}22.88 & 25.99 & 28.4\end{array}$ $\begin{array}{llll}22.75 & 25.89 & 28.28\end{array}$ $\begin{array}{llll}22.87 & 25.83 & 28.25\end{array}$ $\begin{array}{lllll}22.91 & 25.89 & 28.3\end{array}$ $\begin{array}{lll}22.83 & 25.81 & 28.2\end{array}$ $\begin{array}{lll}22.84 & 25.82 & 28.21\end{array}$ $\begin{array}{lll}22.90 & 25.81 & 28.23\end{array}$ $\begin{array}{llll}22.87 & 25.85 & 28.28\end{array}$ $22.8425 .96 \quad 28.36$ $\begin{array}{llll}22.79 & 25.86 & 28.26\end{array}$ $\begin{array}{llll}22.83 & 25.88 & 28.27\end{array}$ $\begin{array}{lll}22.82 & 25.95 & 28.33\end{array}$ $\begin{array}{lll}22.80 & 25.92 & 28.29\end{array}$ $\begin{array}{lll}22.84 & 25.96 & 28.32\end{array}$ $\begin{array}{lll}22.79 & 25.93 & 28.31\end{array}$
Calc Perf Cum Cum BHP Gas Gas Brine (scf/d) (scf) (stb) 67029058550697520238778 66550358617247720262294 66644858683892520285711 66739258750631720309219 66580058817211720332704 66472358883684120356118 66640458950324420379517 6647235901679682040293 66444659083241420426360 66468159149709520449789 66582259216291620473184 66076659282368220496475 67305559349673720519748 66276559415950220543093 66108159482058220566428 65986259548044520589720 65910759613955220612928 65660559679615720636146 65746259745361920659419 65808859811170720682673 65517159876687820705906 65531859942219620729136 65406160007625720752305 65527660073153320775476 65625060138778320798616 65432960204211220821729 65393660269604920844869 65196360334801220867931 65450860400252020891034 65426360465678220914161 65424960531103120937263 
Q $\quad$ 12-Jan-87 $1002 \quad 24508 \quad 525992$ ค $\quad \begin{array}{lllll}A & 13-J a n-87 & 1006 & 24497 & 524272\end{array}$ 2-Jan-87 $1000 \quad 21684 \quad 452307$ 3-Jan-87 $1000 \quad 24712 \quad 528885$ 4-Jan-87 $1001 \quad 24675 \quad 529496$ $\begin{array}{llll}5-J a n-87 & 1000 & 24652 & 528049\end{array}$ 6-Jan-87 $\quad 1000 \quad 24631 \quad 526668$ 7-Jan-87 $1004 \quad 24611 \quad 526706$ 8-Jan-87 $\quad 998 \quad 24579 \quad 526135$ 9-Jan-87 $1001 \quad 24575 \quad 527690$ $\begin{array}{llll}10-J a n-87 & 1019 & 24512 & 525078\end{array}$ 11-Jan-87 $1002 \quad 24464 \quad 524452$ $\begin{array}{lllll} & \text { 14-Jan-87 } & 1002 & 24451 & 522672\end{array}$ 16-Jan-87 $1004 \quad 24408 \quad 522560$ 17-Jan-87 $1001 \quad 24444 \quad 524197$ 18-Jan-87 $1001 \quad 24436 \quad 524071$ 19-Jan-87 $1001 \quad 24404 \quad 523250$ 20-Jan-87 $1000 \quad 24395 \quad 522454$ 21-Jan-87 $1000 \quad 24388 \quad 523606$ 22-Jan-87 $1001 \quad 24413 \quad 522955$ 23-Jan-87 $1001 \quad 24382 \quad 521286$ 24-Jan-87 $1000 \quad 24375 \quad 520778$ 25-Jan-87 $100124335 \quad 521653$ 26-Jan-87 $1001 \quad 24336 \quad 520075$ 27-Jan-87 100123801509704 28-Jan-87 $1009 \quad 3868 \quad 65295$ 29-Jan-87 $1000 \quad 24624 \quad 525786$ 30-Jan-87 $100124536 \quad 525504$ 31-Jan-87 $1002 \quad 24490 \quad 523723$

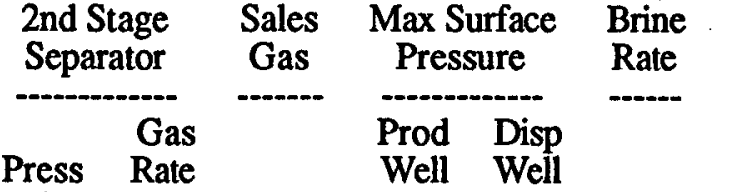

Cum Gas/Brine Ratios

1st 2nd Disp Stage Stg Well (scf/d) (psig) (psig) (stb/d) (scf/stb)(scf/stb)(scf/stb) (psia)

1-Jan-87 $\quad 1018 \quad 24550 \quad 524196$ 15-Jan-87 $1002 \quad 24481 \quad 524420$ (psig) (scf/d)

44373079 44463755 44172380 44170058 44570145 44371825 43872194 44070974 44771008 44671988 44671960 44671979 44272842 44072204 43871760 43471011 43171230 44570615 44071223 44070798 43071380 43471502 43371310 43371270 43171423 43069244 $416 \quad 9871$ 41474837589475 $42074104 \quad 585812$ 44472193

$\begin{array}{rrrrrr}1173 & 344 & 23020 & 22.77 & 25.95 & 28.36 \\ 1160 & 361 & 20332 & 22.25 & 25.38 & 27.8 \\ 1153 & 360 & 23171 & 22.83 & 25.95 & 28.36 \\ 1157 & 360 & 23136 & 22.89 & 25.91 & 28.32 \\ 1159 & 359 & 23114 & 22.85 & 25.88 & 28.31 \\ 1152 & 358 & 23095 & 22.80 & 25.91 & 28.33 \\ 1154 & 357 & 23076 & 22.82 & 25.95 & 28.38 \\ 1150 & 355 & 23046 & 22.83 & 25.96 & 28.35 \\ 1150 & 353 & 23042 & 22.90 & 25.98 & 28.38 \\ 1173 & 352 & 22985 & 22.84 & 25.93 & 28.37 \\ 1157 & 352 & 22938 & 22.86 & 26.00 & 28.43 \\ 1160 & 353 & 22980 & 22.89 & 26.02 & 28.45 \\ 1160 & 352 & 22970 & 22.82 & 25.96 & 28.39 \\ 1152 & 349 & 22926 & 22.80 & 25.98 & 28.39 \\ 1152 & 349 & 22954 & 22.85 & 25.99 & 28.39 \\ 1154 & 344 & 22886 & 22.83 & 25.97 & 28.36 \\ 1147 & 346 & 22919 & 22.87 & 25.97 & 28.34 \\ 1148 & 346 & 22912 & 22.87 & 25.98 & 28.34 \\ 1154 & 341 & 22882 & 22.87 & 25.95 & 28.38 \\ 1155 & 345 & 22873 & 22.84 & 25.95 & 28.36 \\ 1153 & 331 & 22867 & 22.90 & 25.99 & 28.4 \\ 1154 & 338 & 22890 & 22.85 & 25.96 & 28.31 \\ 1158 & 343 & 22861 & 22.80 & 25.93 & 28.3 \\ 1151 & 343 & 22855 & 22.79 & 25.91 & 28.27 \\ 1153 & 341 & 22817 & 22.86 & 25.99 & 28.35 \\ 1154 & 343 & 22818 & 22.79 & 25.92 & 28.28 \\ 1152 & 343 & 22317 & 22.84 & 25.94 & 28.29 \\ 1163 & 311 & 3627 & 18.00 & 20.72 & 23 \\ 1151 & 322 & 23088 & 22.77 & 26.07 & 28.32 \\ 1152 & 322 & 23006 & 22.84 & 26.10 & 28.36 \\ 1151 & 324 & 22963 & 22.81 & 26.03 & 28.33\end{array}$

\begin{tabular}{llll}
$\begin{array}{c}\text { Calc } \\
\text { BHP }\end{array}$ & $\begin{array}{l}\text { Perf } \\
\text { Gas }\end{array}$ & $\begin{array}{c}\text { Cum } \\
\text { Gas }\end{array}$ & $\begin{array}{c}\text { Cum } \\
\text { Brine }\end{array}$ \\
\hdashline & - &
\end{tabular}

(scf/d) (scf) (stb)

$8706 \quad 652847605963878 \quad 20960283$

848856523060652910820980615

8697 . 65713060718623721003786

869965521260784144921026922

869965435760849580621050036

$8690 \quad 65428160915008821073131$

$8690 \quad 65489760980498521096207$

$8684 \quad 65335461045833921119253$

868365393261111227121142295

$8703 \quad 65208461176435521165280$

$8682 \quad 65212761241648221188218$

$\begin{array}{lllll}8689 & 653781613070263 & 21211198\end{array}$

$8688 \quad 652118613722382 \quad 21234168$

$8676 \quad 65086961437325121257094$

867865166461502491521280048

$8675 \quad 64904761567396221302934$

867064952461632348621325853

$8671 \quad 64932661697281221348765$

867564939161762220421371647

$8675 \quad 64867861827088221394520$

867264942361892030521417387

$8675 \quad 64801661956832121440277$

$8677 \quad 64696662021528721463138$

$8670 \quad 64611162086139821485993$

$8668 \quad 64686262150826021508810$

$8670 \quad 64529362215355321531628$

$8627 \quad 63134862278490121553945$

$\begin{array}{llll}7788 & 83421622868322 & 21557572\end{array}$

$8688 \quad 65385262352217421580660$

$8682 \quad 65245062417462421603666$

867865054262482516621626629 
2nd Stage Sales Max Surface Brine \begin{tabular}{cccc} 
Separator & Gas & Pressure & Rate \\
\hline & & Prod & Disp
\end{tabular} Ratios Well Well Stage Stg Well

1st 2nd Disp Press Rate (psig) (scf/d) (scf/d) (psig) (psig) (stb/d)

\begin{tabular}{llll}
\hline 1-Feb-87 & $1000 \quad 24448 \quad 522617$
\end{tabular} 2-Feb-87 $\quad 1019 \quad 24392 \quad 522048$ 3-Feb-87 $1000 \quad 24383 \quad 521335$ 4-Feb-87 $1019 \quad 24302 \quad 521229$ $\begin{array}{lllll}5-F e b-87 & 1000 & 24334 & 520158\end{array}$ 6-Feb-87 $\quad 1000 \quad 10738 \quad 228905$ 7-Feb-87 $\quad 1000 \quad 12368 \quad 291506$ 8-Feb-87 $\quad 999 \quad 24645 \quad 527903$ 9-Feb-87 $1000 \quad 24574 \quad 526625$ 10-Feb-87 $1000 \quad 24523 \quad 526106$ 11-Feb-87 $1005 \quad 24439 \quad 523264$ 12-Feb-87 $100124475 \quad 523135$ 13-Feb-87 $1002 \quad 24421 \quad 521810$ 14-Feb-87 $1002 \quad 24420 \quad 522414$ 15-Feb-87 $1002.24388 \quad 522113$ 16-Feb-87 $1000 \quad 22473 \quad 474523$ $\begin{array}{lllll}17-F e b-87 & 1002 & 24447 & 524378\end{array}$ 18-Feb-87 $1000 \quad 24385 \quad 523282$ 19-Feb-87 $1000 \quad 24373 \quad 523684$ 20-Feb-87 $1000 \quad 24343 \quad 523513$ 21-Feb-87 $1005 \quad 24294522406$ 22-Feb-87 $1001 \% 24303 \quad 523028$ 23-Feb-87 $1000 \quad 24280 \quad 522065$ 24-Feb-87 $1000 \quad 24268519830$ 25-Feb-87 $1001 \quad 24234 \quad 521102$ 26-Feb-87 $1001 \quad 24225 \quad 520226$ 27-Feb-87 $1000 \quad 24220 \quad 518409$ 28-Feb-87 100124204517644
41574059 41573336 41175638 41176355 40274781 402. 32460 40340350 41172418 40970306 41775407 41276374 40976158 41275778 41675496 40874361 35165021 285100256 286102913 287102099

286101556

286101315

285101597

286101593

285102309

287101451

285101549

284101700

282100854 $\begin{array}{lllll}585533 & 1147 & 324 & 22923\end{array}$

$\begin{array}{lllll}587696 & 1167 & 321 & 22872\end{array}$

$\begin{array}{lllll}586438 & 1148 & 323 & 22862\end{array}$

$\begin{array}{llll}586443 & 1162 & 320 & 22788\end{array}$

580610

257349

329257

592686

589794

591374

889047

588490

588750

589193

589258

538661

614276

616112

613758

615465

614563

615721

614960

613780

610425

606081

602268 $\begin{array}{lll}1149 & 321 & 22816\end{array}$

$\begin{array}{llll}2953 & 321 & 10068\end{array}$

$\begin{array}{lll}1156 & 327 & 11597\end{array}$

$\begin{array}{lll}1154 & 330 & 23108\end{array}$

$\begin{array}{lll}1155 & 329 & 23041\end{array}$

$\begin{array}{lll}1149 & 330 & 22993\end{array}$

$\begin{array}{lll}1151 & 329 & 22915\end{array}$

$\begin{array}{lll}1149 & 329 & 22949\end{array}$

$\begin{array}{lll}1149 & 328 & 22898\end{array}$

$\begin{array}{lll}1149 & 327 & 22897\end{array}$

$\begin{array}{lll}1146 & 323 & 22867\end{array}$

$\begin{array}{lll}1152 & 138 & 21071\end{array}$

$\begin{array}{lll}1155 & 140 & 22922\end{array}$

$\begin{array}{lll}1153 & 143 \quad 22864\end{array}$

$\begin{array}{lll}1154 & 144 & 22853\end{array}$

$\begin{array}{lll}1146 \quad 144 & 22825\end{array}$

$\begin{array}{llll}1154 & 144 & 22779\end{array}$

$\begin{array}{lll}1151 & 146 & 22787\end{array}$

$\begin{array}{lll}1150 & 144 & 22766\end{array}$

$\begin{array}{lll}1150 & 145 & 22754\end{array}$

$\begin{array}{lll}1144 & 147 & 22723\end{array}$

$\begin{array}{lll}1149 & 146 & 22714\end{array}$

$\begin{array}{lll}1146 & 147 & 22709\end{array}$

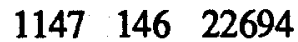

$\begin{array}{lll}22.80 & 26.03 & 28.3\end{array}$

$\begin{array}{llll}22.82 & 26.03 & 28.3\end{array}$

$\begin{array}{lll}22.80 & 26.11 & 28.36\end{array}$

$\begin{array}{lll}22.87 & 26.22 & 28.48\end{array}$

$\begin{array}{lll}22.80 & 26.08 & 28.28\end{array}$

$\begin{array}{lll}22.74 & 25.96 & 28.17\end{array}$

$\begin{array}{llll}22.85 & 25.98 & 28.23\end{array}$

$\begin{array}{llll}22.86 & 25.91 & 28.15\end{array}$

$\begin{array}{lll}22.88 & 26.16 & 28.44\end{array}$

$\begin{array}{llll}22.83 & 26.17 & 28.43\end{array}$

22.8026 .1128 .36

$\begin{array}{lll}22.79 & 26.10 & 28.36\end{array}$

$\begin{array}{lll}22.82 & 26.11 & 28.39\end{array}$

$\begin{array}{llll}22.52 & 25.61 & 27.55\end{array}$

$\begin{array}{llll}22.88 & 27.25 & 28.85\end{array}$

$\begin{array}{llll}22.89 & 27.39 & 28.99\end{array}$

$\begin{array}{lll}22.94 & 27.39 & 28.99\end{array}$

$\begin{array}{llll}22.95 & 27.41 & 29.01\end{array}$

$\begin{array}{lll}22.93 & 27.39 & 29\end{array}$

$\begin{array}{lll}22.93 & 27.40 & 29.01\end{array}$

$\begin{array}{lll}22.90 & 27.37 & 28.97\end{array}$

$\begin{array}{lll}22.83 & 27.31 & 28.9\end{array}$

$\begin{array}{llll}22.81 & 27.25 & 28.84\end{array}$
$25.14 \quad 28.62 \quad 30.83$

$\begin{array}{llll}22.83 & 26.08 & 28.32\end{array}$

$\begin{array}{llll}22.92 & 27.38 & 28.99\end{array}$

$\begin{array}{lll}22.93 & 27.3828 .98\end{array}$

$\begin{array}{llll}22.85 & 27.34 & 28.94\end{array}$

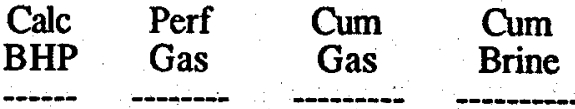

(scf/d)

(scf)

(stb)

8671

8688

8667

8675

8664

9804

7967

8678

8674

8675

8671

8665
8534

8677

8670

8670

8664

8661

8659

8658

8649

8654

8650

8650
64872162547388721649552 64727862612116421672424 64836662676953121695286 64900262741853321718074 64523662806376921740890 28361662834738521750958 35753662870492021762555 65233962935725921785663 64860463000586321808704 65392163065978421831697 65147363131125821854612 65083463196209121877561 64938763261147921900459 65004663326152421923356 64759363390911821946223 58050663448962421967294 66130063515092421990216 66282763581375122013080 66250863647625922035933 66169763713795622058758 66013563779809222081537 66105163845914222104324 66021463911935622127090 65850163977785722149844 65919464043705122172567 65802564109507622195281 65629064175136622217990 65449564240586122240684 


\begin{tabular}{|c|c|c|c|c|c|c|c|c|c|c|c|c|c|c|c|c|c|}
\hline & \multirow[t]{2}{*}{ Date } & \multicolumn{3}{|c|}{$\begin{array}{l}\text { 1st Stage } \\
\text { Separator }\end{array}$} & \multicolumn{2}{|c|}{$\begin{array}{l}\text { 2nd Stage } \\
\text { Separator }\end{array}$} & \multirow{2}{*}{\begin{tabular}{c} 
Sales \\
Gas \\
\hdashline (scf/d)
\end{tabular}} & \multicolumn{2}{|c|}{$\begin{array}{c}\text { Max Surface } \\
\text { Pressure }\end{array}$} & \multirow{2}{*}{$\begin{array}{c}\text { Brine } \\
\text { Rate }\end{array}$} & \multicolumn{3}{|c|}{$\begin{array}{c}\text { Cum Gas/Brine } \\
\text { Ratios }\end{array}$} & \multirow{2}{*}{\begin{tabular}{c} 
Calc \\
BHP \\
\hdashline$-\cdots$ \\
(psia)
\end{tabular}} & \multirow{2}{*}{\begin{tabular}{c}
$\begin{array}{c}\text { Perf } \\
\text { Gas }\end{array}$ \\
\hdashline (scf/d)
\end{tabular}} & \multirow{2}{*}{$\begin{array}{l}\text { Cum } \\
\text { Gas } \\
\text { (scf) }\end{array}$} & \multirow{2}{*}{$\begin{array}{r}\text { Cum } \\
\text { Brine } \\
\text { (stb) }\end{array}$} \\
\hline & & $\begin{array}{l}\text { Press } \\
\text { (psig) }\end{array}$ & $\begin{array}{r}\text { Brine } \\
\text { Rate } \\
\text { (RB/d) }\end{array}$ & $\begin{array}{r}\text { Gas } \\
\text { Rate } \\
\text { (scf/d) }\end{array}$ & $\begin{array}{c}\text { Press } \\
\text { (psig) }\end{array}$ & $\begin{array}{r}\text { Gas } \\
\text { Rate } \\
\text { (scf/d) }\end{array}$ & & $\begin{array}{l}\text { Prod } \\
\text { Well } \\
\text { (psig) }\end{array}$ & $\begin{array}{l}\text { Disp } \\
\text { Well } \\
\text { (psig) }\end{array}$ & & $\begin{array}{r}\text { 1st } \\
\text { Stage } \\
(\mathrm{scf} / \mathrm{stb})(\end{array}$ & $\begin{array}{r}\text { 2nd } \\
\text { Stg } \\
\text { (scf/stb) }\end{array}$ & $\begin{array}{l}\text { Disp } \\
\text { Well } \\
\text { (scf/stb) }\end{array}$ & & & & \\
\hline & $\begin{array}{l}\text { 1-Mar-87 } \\
\text { 2-Mar-87 } \\
\text { 3-Mar-87 } \\
\text { 4-Mar-87 } \\
\text { 5-Mar-87 } \\
\text { 6-Mar-87 } \\
\text { 7-Mar-87 } \\
\text { 8-Mar-87 } \\
\text { 9-Mar-87 } \\
\text { 10-Mar-87 } \\
\text { 11-Mar-87 } \\
\text { 12-Mar-87 } \\
\text { 13-Mar-87 } \\
\text { 14-Mar-87 } \\
\text { 15-Mar-87 } \\
\text { 16-Mar-87 } \\
\text { 17-Mar-87 } \\
\text { 18-Mar-87 } \\
\text { 19-Mar-87 } \\
\text { 20-Mar-87 } \\
\text { 21-Mar-87 } \\
\text { 22-Mar-87 } \\
\text { 23-Mar-87 } \\
\text { 24-Mar-87 } \\
\text { 25-Mar-87 } \\
\text { 26-Mar-87 } \\
\text { 27-Mar-87 } \\
\text { 28-Mar-87 } \\
\text { 29-Mar-87 } \\
\text { 30-Mar-87 } \\
\text { 31-Mar-87 }\end{array}$ & $\begin{array}{l}1000 \\
1001 \\
1000 \\
1001 \\
1000 \\
1000 \\
1000 \\
1000 \\
1001 \\
1000 \\
1000 \\
1000 \\
1001 \\
1000 \\
1000 \\
1001 \\
1001 \\
1001 \\
1001 \\
1001 \\
1001 \\
1002 \\
1001 \\
1001 \\
1001 \\
1001 \\
1002 \\
1007 \\
1002 \\
1000 \\
1000\end{array}$ & $\begin{array}{l}24176 \\
24166 \\
24154 \\
24134 \\
24133 \\
24105 \\
19541 \\
24218 \\
24180 \\
24152 \\
24126 \\
24104 \\
24078 \\
24068 \\
24049 \\
24037 \\
24016 \\
24007 \\
24010 \\
23989 \\
23973 \\
23958 \\
23934 \\
23925 \\
23921 \\
23903 \\
23882 \\
23862 \\
23857 \\
23821 \\
23804\end{array}$ & $\begin{array}{l}517166 \\
517048 \\
517363 \\
516879 \\
517469 \\
518171 \\
416815 \\
520150 \\
518428 \\
516971 \\
516128 \\
517987 \\
516767 \\
514472 \\
515384 \\
514802 \\
514325 \\
513868 \\
512366 \\
512361 \\
511541 \\
511325 \\
511642 \\
511112 \\
510743 \\
509843 \\
510010 \\
510150 \\
509477 \\
509888 \\
510016\end{array}$ & $\begin{array}{l}2861 \\
2861 \\
2851 \\
2821 \\
2811 \\
2811 \\
404 \\
396 \\
398 \\
395 \\
395 \\
408 \\
414 \\
416 \\
416 \\
415 \\
404 \\
413 \\
410 \\
407 \\
409 \\
403 \\
407 \\
410 \\
405 \\
400 \\
407 \\
415 \\
398 \\
406 \\
405\end{array}$ & $\begin{array}{r}100499 \\
103061 \\
101592 \\
100937 \\
101370 \\
102591 \\
76288 \\
76761 \\
76540 \\
76930 \\
76798 \\
76807 \\
75238 \\
75132 \\
74891 \\
74891 \\
74490 \\
74223 \\
74020 \\
75484 \\
75022 \\
75119 \\
744445 \\
74533 \\
74719 \\
74502 \\
73895 \\
73856 \\
74060 \\
72608\end{array}$ & $\begin{array}{l}604088 \\
601904 \\
603168 \\
601299 \\
595309 \\
598609 \\
488868 \\
580193 \\
581269 \\
579071 \\
579349 \\
581292 \\
577722 \\
578555 \\
578944 \\
578949 \\
578571 \\
577710 \\
576094 \\
577520 \\
572129 \\
575625 \\
574092 \\
572830 \\
572896 \\
576320 \\
574636 \\
573023 \\
572912 \\
574428 \\
574033\end{array}$ & $\begin{array}{l}1150 \\
1153 \\
1151 \\
1151 \\
1148 \\
1148 \\
1150 \\
1151 \\
1148 \\
1149 \\
1151 \\
1150 \\
1154 \\
1150 \\
1145 \\
1142 \\
1142 \\
1143 \\
1146 \\
1148 \\
1144 \\
1141 \\
1139 \\
1144 \\
1145 \\
1144 \\
1144 \\
1145 \\
1142 \\
1147 \\
1147\end{array}$ & $\begin{array}{ll}0 & 147 \\
3 & 147 \\
1 & 148 \\
1 & 147 \\
8 & 149 \\
8 & 149 \\
0 & 320 \\
1 & 320 \\
8 & 318 \\
9 & 317 \\
1 & 316 \\
0 & 319 \\
4 & 329 \\
0 & 333 \\
5 & 333 \\
2 & 332 \\
2 & 329 \\
3 & 332 \\
6 & 333 \\
8 & 325 \\
4 & 326 \\
1 & 324 \\
9 & 323 \\
4 & 325 \\
5 & 324 \\
4 & 324 \\
4 & 323 \\
5 & 324 \\
2 & 321 \\
7 & 320 \\
7 & 322\end{array}$ & $\begin{array}{l}22668 \\
22659 \\
22647 \\
22629 \\
22628 \\
22602 \\
18322 \\
22707 \\
22672 \\
22646 \\
22621 \\
22601 \\
22576 \\
22567 \\
22549 \\
22538 \\
22518 \\
22510 \\
22513 \\
22493 \\
22478 \\
22464 \\
22441 \\
22433 \\
22429 \\
22412 \\
22393 \\
22374 \\
22369 \\
22335 \\
22319\end{array}$ & $\begin{array}{l}22.81 \\
22.82 \\
22.84 \\
22.84 \\
22.87 \\
22.93 \\
22.75 \\
22.91 \\
22.87 \\
22.83 \\
22.82 \\
22.92 \\
22.89 \\
22.80 \\
22.86 \\
22.84 \\
22.84 \\
22.83 \\
22.76 \\
22.78 \\
22.76 \\
22.76 \\
22.80 \\
22.78 \\
22.77 \\
22.75 \\
22.78 \\
22.80 \\
22.78 \\
22.83 \\
22.85\end{array}$ & $\begin{array}{l}27.25 \\
27.37 \\
27.33 \\
27.30 \\
27.35 \\
27.47 \\
26.91 \\
26.29 \\
26.24 \\
26.23 \\
26.21 \\
26.32 \\
26.22 \\
26.13 \\
26.18 \\
26.16 \\
26.15 \\
26.13 \\
26.05 \\
26.13 \\
26.10 \\
26.11 \\
26.12 \\
26.11 \\
26.10 \\
26.07 \\
26.08 \\
26.10 \\
26.09 \\
26.08 \\
26.09\end{array}$ & $\begin{array}{l}28.85 \\
28.97 \\
28.93 \\
28.89 \\
28.93 \\
29.04 \\
29.13 \\
28.46 \\
28.43 \\
28.4 \\
28.38 \\
28.55 \\
28.49 \\
28.41 \\
28.46 \\
28.44 \\
28.36 \\
28.39 \\
28.29 \\
28.37 \\
28.34 \\
28.32 \\
28.35 \\
28.35 \\
28.32 \\
28.27 \\
28.31 \\
28.37 \\
28.27 \\
28.31 \\
28.31\end{array}$ & $\begin{array}{l}8651 \\
8653 \\
8651 \\
8649 \\
8646 \\
8643 \\
8333 \\
8657 \\
8651 \\
8650 \\
8650 \\
8647 \\
8650 \\
8645 \\
8638 \\
8634 \\
8633 \\
8633 \\
8637 \\
8637 \\
8632 \\
8627 \\
8623 \\
8628 \\
8629 \\
8627 \\
8625 \\
8624 \\
8621 \\
8624 \\
8622\end{array}$ & $\begin{array}{l}653972 \\
656431 \\
655178 \\
653752 \\
654628 \\
656362 \\
533720 \\
646241 \\
644565 \\
643146 \\
641984 \\
645259 \\
643190 \\
641128 \\
641745 \\
640981 \\
638610 \\
639059 \\
636893 \\
638126\end{array}$ & 662190215 & $\begin{array}{l}22263352 \\
22286011 \\
22308658 \\
22331287 \\
22353915 \\
22376517 \\
22394839 \\
22417546 \\
22440218 \\
22462864 \\
22485485 \\
22508086 \\
22530662 \\
22553229 \\
22575778 \\
22598316 \\
22620834 \\
22643344 \\
22665857 \\
22688350 \\
22710828 \\
22733292 \\
22755733 \\
22778166 \\
22800595 \\
22823007 \\
22845400 \\
22867774 \\
22890143 \\
22912478 \\
22934797\end{array}$ \\
\hline
\end{tabular}




\begin{tabular}{|c|c|c|}
\hline & \multicolumn{2}{|c|}{$\begin{array}{l}\text { 1st Stage } \\
\text { Separator }\end{array}$} \\
\hline & $\begin{array}{l}\text { Press } \\
\text { (psig) }\end{array}$ & $\begin{array}{l}\text { Brine } \\
\text { Rate } \\
\text { (RB/d) }\end{array}$ \\
\hline
\end{tabular}

$\begin{array}{llll}1-A p r-87 & 1001 & 23806 & 509762\end{array}$ 2-Apr-87 $\quad 1000 \quad 23795 \quad 509254$ 3-Apr-87 $1002 \quad 23776 \quad 508976$ $\begin{array}{lllll}4-A p r-87 & 1000 & 23781 & 509512\end{array}$ $\begin{array}{llll}5-A p r-87 & 1000 & 22738 & 488424\end{array}$ $\begin{array}{llllll}6-A p r-87 & 1000 & 23733 & 508290\end{array}$ $\begin{array}{lllll}7-A p r-87 & 1000 & 23730 & 507739\end{array}$ $\begin{array}{llllll}8 \text { 8-Apr-87 } & 1000 & 23727 & 506981\end{array}$ $\begin{array}{lllll}9-A p r-87 & 1001 & 23721 & 507120\end{array}$ $\begin{array}{lllll}10-A p r-87 & 1000 & 23705 & 506891\end{array}$ 11-Apr-87 $1001 \quad 23696 \quad 506572$ 12-Apr-87 $1001 \quad 23684 \quad 506385$ 13-Apr-87 $1002 \quad 23672 \quad 506387$ $\begin{array}{llll}14-A p r-87 & 503 & 23596 & 605888\end{array}$ $\begin{array}{lllll}15-A p r-87 & 505 & 26364 & 654408\end{array}$ 16-Apr-87 $1002 \quad 12756 \quad 186540$ 17-Apr-87 $1000 \quad 23930 \quad 513645$ 18-Apr-87 $1001 \quad 23868 \quad 510356$ 19-Apr-87 $1000 \quad 23830 \quad 511404$ 20-Apr-87 $1000 \quad 23801 \quad 508690$ 21-Apr-87 $1000 \quad 23764 \quad 507637$ 22-Apr-87 $1000 \quad 21257 \quad 459135$ 23-Apr-87 $1000 \quad 19036 \quad 408137$ 24-Apr-87 $1000 \quad 19054 \quad 408822$ 25-Apr-87 $\quad 1000 \quad 19070 \quad 408873$ 26-Apr-87 $1000 \quad 19088 \quad 408916$ 27-Apr-87 $1002 \quad 19104 \quad 408516$ 28-Apr-87 $1000 \quad 15818 \quad 357883$ 29-Apr-87 $1002 \quad 14097 \quad 300150$ 30-Apr-87 $1000 \quad 13943 \quad 298487$

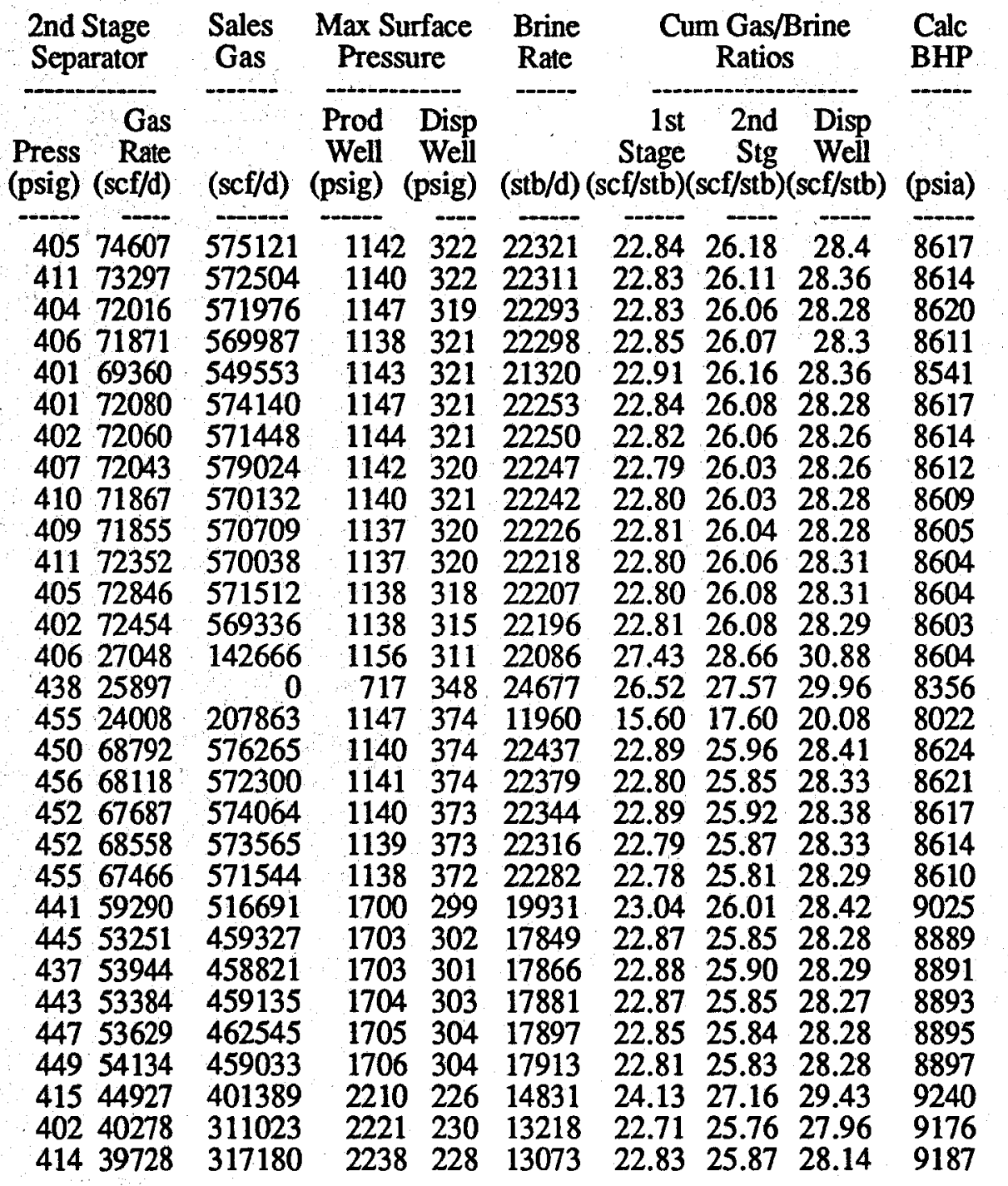

(scf/d)

(scf)

(stb)

63391666282413222957118 63274066345687222979429 63044666408731823001722 63103366471835123024020 60463566532298623045340 62931566595230123067593 62878566658108623089843 62870066720978623112090 62900466783879023134332 62855166846734123156558 62899266909633323178776 62868066972501323200983 62792567035293823223179 68201667103495423245265 73932367177427723269942 24015767201443323281902 63743567265186923304339 63399767328586623326718 63412367391998823349062 63221267455220123371378 63035867518255823393660 56643967574899723413591 $504770676253767 \quad 23431440$ 50542967675919623449306 50549667726469223467187 50612767777081923485084 50658067827739923502997 43647667871387523517828 36957567908345123531046 36787467945132523544119 


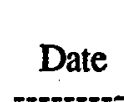

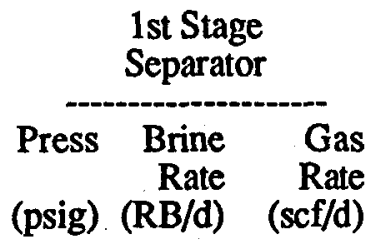

\begin{tabular}{llll}
\hline $1-M a y-87$ & $\overline{1001}$ & $\overline{13981}$ & $\mathbf{2 9 9 1 2 5}$
\end{tabular} 2-May-87 $1000 \quad 14002 \quad 299181$ 3-May-87 $1000 \quad 14025 \quad 299243$ 4-May-87 100014044299984 5-May-87 $1001 \quad 10781 \quad 230757$ 6-May-87 $999 \quad 9027 \quad 195485$ 7-May-87 $1002 \quad 9047 \quad 196065$ 8-May-87 $1001 \quad 9068196215$ 9-May-87 $999 \quad 9093 \quad 196863$ 10-May-87 10019093196783 11-May-87 $1002 \quad 8967194741$ 12-May-87 $1001 \quad 5563 \quad 131571$ 13-May-87 $1002 \quad 4512 \quad 97785$ 14-May-87 $1000 \quad 4470 \quad 97262$ 15-May-87 $1000 \quad 4455 \quad 93350$ 16-May-87 $1001 \quad 4531 \quad 98194$ 17-May-87 $1000 \quad 4525 \quad 97930$ 18-May-87 $1001 \quad 4529 \quad 96641$ 19-May-87 $998 \quad 8215 \quad 174966$ 20-May-87 $1001 \quad 10051217510$ 21-May-87 $1002 \quad 10088 \quad 218595$ 22-May-87 $1004 \quad 10092218498$ 23-May-87 $1000 \quad 9799 \quad 212348$ 24-May-87 $999 \quad 9955214990$ 25-May-87 1001 9953215078 26-May-87 $1000 \quad 9981215867$ 27-May-87 $1002 \quad 9965215932$ 28-May-87 $1002 \quad 9939215217$ 29-May-87 $1002 \quad 9992 \quad 216512$ 30-May-87 $1001 \quad 10006216845$ 31-May-87 $1000 \quad 10029217237$ \begin{tabular}{cccc} 
2nd Stage & $\begin{array}{c}\text { Sales } \\
\text { Separator }\end{array}$ & $\begin{array}{c}\text { Mas Surface } \\
\text { Pressure }\end{array}$ & $\begin{array}{c}\text { Brine } \\
\text { Rate }\end{array}$ \\
\hline Gas & & $\begin{array}{c}\text { Prod Disp } \\
\text { Prod }\end{array}$ & \\
\hline & &..--
\end{tabular}

Cum Gas/Brine Ratios

1st 2nd Disp

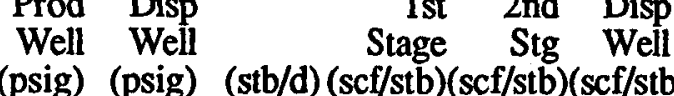
Press Rate (psig) (scf/d)

40240426 40440281 40140167 40040052 40131241 39923313 39826609 40424604 40224049 40227783 40027133 40120193 39816273 40016530 39915733 $401 \quad 15717$ 40015916 $400 \quad 16040$ 39831246 40234906 40735183 40634151 40533252 40235094 40633971 40133480 40030504 40224353 39829170 40229295 39929674 (scf/d) (stb/d) (sct/ 328852 331224 327031 252677 214919 214323 213431 214381 214917 213986 143770 101342 105944

104608 105182 104391 103994 186507 236541 236382 252649 231843 235019 230839 235947 235079 242161 240874 239789 240646 $\begin{array}{llll}2249 & 229 & 13109 & 22 \\ 2248 & 229 & 13129 & 22\end{array}$ $\begin{array}{lll}2253 & 229 & 13150\end{array}$ $\begin{array}{lll}2258 & 227 & 13168\end{array}$ $\begin{array}{lll}2651 & 150 & 10109\end{array}$ $\begin{array}{lll}2659 & 152 & 8464\end{array}$ $\begin{array}{lll}2667 & 152 & 8483\end{array}$ $\begin{array}{lll}2676 & 154 & 8502\end{array}$ 2684156 2694155 $2711 \quad 150$ 8939 2946 $\begin{array}{lll}2960 & 89 & 4191\end{array}$ $\begin{array}{lll}2972 & 91 & 4177\end{array}$ $\begin{array}{lll}2981 & 91 & 4248\end{array}$ $\begin{array}{lll}2996 & 91 & 4243\end{array}$ $\begin{array}{lll}3004 & 92 & 4247\end{array}$ $\begin{array}{lll}2746 & 173 & 7703\end{array}$ $2751 \quad 174$ $2751 \quad 175$ $2762 \quad 175$ $2771 \quad 174$ $2776 \quad 175$ $2780 \quad 175$ $2782 \quad 176$ $2788 \quad 175$ $2792 \quad 176$ $2797 \quad 176$ $2805 \quad 177$ $2810 \quad 178$ (scf/stb)(scf/stb)(scf/stb) (psia)

$\begin{array}{lll}22.82 & 25.90 & 28.11\end{array}$ $\begin{array}{lll}22.79 & 25.86 & 28.07\end{array}$ $\begin{array}{lll}22.76 & 25.81 & 28.01\end{array}$ $\begin{array}{lll}22.78 & 25.82 & 28.02\end{array}$ $\begin{array}{lll}22.83 & 25.92 & 28.12\end{array}$ $23.10 \quad 25.85 \quad 28.04$ $\begin{array}{lll}23.11 & 26.25 & 28.44\end{array}$ $23.08 \quad 25.97 \quad 28.19$ $23.0925 .91 \quad 28.12$ $\begin{array}{llll}23.08 & 26.34 & 28.55\end{array}$ $\begin{array}{llll}23.16 & 26.39 & 28.59\end{array}$ $\begin{array}{llll}25.22 & 29.10 & 31.3\end{array}$ $\begin{array}{lll}23.11 & 26.96 & 29.15\end{array}$ $23.2127 .15 \quad 29.35$ $22.35 \quad 26.1128 .31$ $\begin{array}{lll}23.11 & 26.81 & 29.01\end{array}$ $\begin{array}{lll}23.08 & 26.83 & 29.03\end{array}$ $\begin{array}{lll}22.76 & 26.53 & 28.73\end{array}$ $\begin{array}{lll}22.72 & 26.77 & 28.96\end{array}$ $\begin{array}{lll}23.08 & 26.78 & 28.99\end{array}$ $\begin{array}{lll}23.11 & 26.83 & 29.06\end{array}$ $\begin{array}{lllll}9463 & 23.09 & 26.70 & 28.93\end{array}$ $\begin{array}{llll}9188 & 23.11 & 26.73 & 28.95\end{array}$ $\begin{array}{llll}9334 & 23.03 & 26.79 & 29\end{array}$ $\begin{array}{lllll}9332 & 23.05 & 26.69 & 28.91\end{array}$ $\begin{array}{lllll}9358 & 23.07 & 26.64 & 28.85\end{array}$ $\begin{array}{llll}9344 & 23.11 & 26.38 & 28.57\end{array}$ $\begin{array}{lllll}9319 & 23.09 & 25.71 & 27.91\end{array}$ $\begin{array}{llll}9369 & 23.11 & 26.22 & 28.41\end{array}$ $\begin{array}{lllll}9382 & 23.11 & 26.24 & 28.44\end{array}$ $\begin{array}{llll}9403 & 23.10 & 26.26 & 28.45\end{array}$ $\begin{array}{cccc}\text { Calc } & \text { Perf } & \text { Cum } & \text { Cum } \\ \text { BHP } & \text { Gas } & \text { Gas } & \text { Brine }\end{array}$ (scf/d) (scf) (stb) 36849467981981923557228 36853168018835023570357 36833268055668123583507 36896768092564923596675 28426568120991423606784 23733168144724423615248 24125768168850123623731 23967168192817223632233 23975168216792323640759 24341768241134123649285 24038568265172523657693 16326168281498623662909 12333468293832023667140 12300668306132623671331 11825168317957623675508 12323468330281123679756 12317468342598523683999 12201668354800223688246 22307968377108023695949 27320268404428223705373 27487968431916123714832 27376568459292523724295 26599368485891823733483 27068668512960423742817 26978868539939223752149 26997868566937023761507 26695868593632823770851 26009368619642223780170 26617368646259523789539 26682468672941923798921 26751568699693423808324 
\begin{tabular}{cccc}
$\begin{array}{c}\text { 2nd Stage } \\
\text { Separator }\end{array}$ & $\begin{array}{c}\text { Sales } \\
\text { Gas }\end{array}$ & $\begin{array}{c}\text { Max Surface } \\
\text { Pressure }\end{array}$ & $\begin{array}{l}\text { Brine } \\
\text { Rate }\end{array}$ \\
\hline Gas & & Prod Disp &
\end{tabular}

Prod Disp

Press Rate

(scf/d) (psig) (psig) (psig) (RB/d) (scf/d)

$\begin{array}{llll}1-J u n-87 & 1001 & 10040 & 217358\end{array}$ $\begin{array}{llll}2-J u n-87 & 1001 & 10062 & 217965\end{array}$

3-Jun-87 $\quad 1002 \quad 10068 \quad 217938$

4-Jun-87 $1000 \quad 10091 \quad 218029$

$\begin{array}{lllll}5-J u n-87 & 1002 & 10042 & 217367\end{array}$

$\begin{array}{llll}6-J u n-87 & 1002 & 9959 & 216227\end{array}$

$\begin{array}{llll}7-J u n-87 & 1002 & 9981 & 215954\end{array}$

$\begin{array}{lllll}8-J u n-87 & 1000 & 9983 & 215977\end{array}$

$\begin{array}{llll}9-J u n-87 & 1001 & 10001 & 216980\end{array}$

10-Jun-87 $1000 \quad 9985 \quad 216683$

11-Jun-87 $999 \quad 10014 \quad 216931$

12-Jun-87 $1001 \quad 10032 \quad 217398$

13-Jun-87 $1002 \quad 10062 \quad 217616$

14-Jun-87 $1001 \quad 10082 \quad 218104$

15-Jun-87 $\quad 1000 \quad 10043 \quad 217669$

$\begin{array}{lllll}16-J u n-87 & 998 & 10010 & 217682\end{array}$

17-Jun-87 $999 \quad 10019 \quad 218185$

18-Jun-87 $1001 \quad 10021 \quad 217828$

19-Jun-87 $1002 \quad 10027 \quad 217159$ 20-Jun-87 $1000 \quad 10043 \quad 217334$ 21-Jun-87 $999 \quad 10054 \quad 217304$ 22-Jun-87 $1000,10080 \quad 217718$ 23-Jun-87 $1002 \quad 10083 \quad 219339$ 24-Jun-87 $1002 \quad 10088 \quad 218403$ 25-Jun-87 $1002 \quad 9935 \quad 215541$ 26-Jun-87 $1001 \quad 9909 \quad 214493$ 27-Jun-87 $1000 \quad 9915 \quad 214970$ 28-Jun-87 $1002 \quad 9927 \quad 215394$ 29-Jun-87 $1002 \quad 9941 \quad 214998$ 30-Jun-87 $1000 \quad 9948 \quad 215325$ $\begin{array}{lllll}401 & 29710 & 240905 & 2809 & 179\end{array}$

$\begin{array}{lllll}402 & 28947 & 240940 & 2812 & 178\end{array}$

$\begin{array}{lllll}399 & 28948 & 241079 & 2826 & 172\end{array}$

$40030597 \quad 242325$

$\begin{array}{lll}395 & 30423 & 244437\end{array}$

$402 \quad 29414 \quad 241644$

$40129773 \quad 240207$

$40030401 \quad 240094$

$39931096 \quad 240729$

$40230827 \quad 240833$

$39931656 \quad 241640$

$40230805 \quad 241828$

$40031165 \quad 240656$

$39930852 \quad 241244$

$402 \quad 30892 \quad 240379$

$40131180 \quad 241683$

$40228967 \quad 237739$

$40329504 \quad 239589$

$40127635 \quad 239850$

$40227983 \quad 238693$

$40727408 \quad 240363$

$40028004 \quad 236924$

$40227917 \quad 241699$

$40529515 \quad 238965$

$\begin{array}{lll}395 & 30598 & 240114\end{array}$

$\begin{array}{lll}396 & 30552 & 240187\end{array}$

$40030965 \quad 238674$

$39830621 \quad 239682$ $\begin{array}{ll}2826 & 172 \\ 2823 & 174\end{array}$

$2836 \quad 173$

$2834 \quad 175$

$2848 \quad 175$

$2851 \quad 177$

$2856 \quad 177$

$2859 \quad 178$

$2860 \cdot 176$

$2867 \quad 179$

$2870 \quad 178$

$2874 \quad 179$

$2887 \quad 178$

$2898 \cdot 179$

2895180

$2903 \quad 179$

$2907 \quad 172$

2912177

2913177

2920178

$2938 \quad 179$

2939173

2944172

2952174

$2955 \quad 175$

$2961 \quad 175$

2966177

2961176
$40030816 \quad 239831$

$40328834 \quad 239501$ $\begin{array}{lllll}9414 & 23.09 & 26.25 & 28.45\end{array}$

$\begin{array}{lllll}9434 & 23.10 & 26.17 & 28.38\end{array}$

$\begin{array}{lllll}9440 & 23.09 & 26.15 & 28.34\end{array}$

$\begin{array}{lllll}9462 & 23.04 & 26.28 & 28.47\end{array}$

$\begin{array}{llll}9416 & 23.09 & 26.32 & 28.49\end{array}$

$\begin{array}{lllll}9338 & 23.16 & 26.31 & 28.51\end{array}$

$\begin{array}{lllll}9359 & 23.08 & 26.26 & 28.46\end{array}$

$\begin{array}{lllll}9360 & 23.07 & 26.32 & 28.52\end{array}$

$\begin{array}{lllll}9377 & 23.14 & 26.46 & 28.65\end{array}$

$\begin{array}{lllll}9362 & 23.14 & 26.44 & 28.64\end{array}$

$\begin{array}{lllll}9389 & 23.10 & 26.48 & 28.67\end{array}$

$\begin{array}{llllll}9406 & 23.11 & 26.39 & 28.59\end{array}$

$\begin{array}{lllll}9434 & 23.07 & 26.37 & 28.57\end{array}$

$\begin{array}{llllll}9453 & 23.07 & 26.34 & 28.53\end{array}$

$\begin{array}{llll}9417 & 23.12 & 26.40 & 28.6\end{array}$

$\begin{array}{llll}9386 & 23.19 & 26.52 & 28.72\end{array}$

$\begin{array}{lllll}9394 & 23.23 & 26.51 & 28.7\end{array}$

$\begin{array}{llllll}9396 & 23.18 & 26.27 & 28.47\end{array}$

$9402 \quad 23.10 \quad 26.24 \quad 28.45$

$9417 \quad 23.08 \quad 26.14 \quad 28.35$

$\begin{array}{llll}23.05 & 25.98 & 28.18\end{array}$

$\begin{array}{llll}9451 & 23.04 & 26.00 & 28.2\end{array}$

$\begin{array}{lllll}9454 & 23.20 & 26.10 & 28.33\end{array}$

$\begin{array}{lllll}9459 & 23.09 & 26.05 & 28.25\end{array}$

$\begin{array}{lllll}9315 & 23.14 & 26.14 & 28.34\end{array}$

$9291 \quad 23.09 \quad 26.26 \quad 28.48$

$\begin{array}{lllll}9297 & 23.12 & 26.41 & 28.58\end{array}$

$\begin{array}{llll}9308 & 23.14 & 26.42 & 28.6\end{array}$

$\begin{array}{lllll}9321 & 23.07 & 26.39 & 28.58\end{array}$

$\begin{array}{lllll}9328 & 23.08 & 26.37 & 28.55\end{array}$ \begin{tabular}{llcc} 
Calc & Perf & Cum & Cum \\
BHP & Gas & Gas & Brine \\
\hdashline & - & -
\end{tabular}

(scf/d)

(scf)

(stb)

26782868726476323817738 26773768753250023827172 26753068780002923836612 26938368806941223846074 26826268833767423855490 26622668860390123864828 26635768887025823874187 26694768913720523883547 26865168940585623892924 26812868967398423902286 26918368994316623911675 26891869021208423921081 26952969048161323930515 26969469075130723939968 26932669102063423949385 26956669129019923958771 26960869155980723968165 26750469182731123977561

$\begin{array}{lllll}9728 & 267504 & 691827311 & 23977561 \\ 9732 & 267487 & 692094798 & 23986963\end{array}$

$\begin{array}{llll}9732 & 267487692094798 & 23986963\end{array}$

974026565369262742324005807

$9748 \quad 26651869289394124015258$

$9766 \quad 26783269316177324024712$

$9768 \quad 26721769342899024034171$

$9768 \quad 26398769369297724043486$

$9775 \quad 26460869395758524052777$

$\begin{array}{llll}9778 & 265708694223293 & 24062074\end{array}$

$9784266209694489502 \quad 24071382$

$9790 \quad 26639469475589624080703$

978526631469502221024090031 
1-Jul-87

2-Jul-87

3-Jul-87

4-Jul-87

5-Jul-87

6-Jul-87

7-Jul-87

8-Jul-87

9-Jul-87

10-Jul-87

13-Jul-87

\begin{tabular}{ll}
+ & $14-J u l-87$ \\
\hline & $15-J u l-87$
\end{tabular}

16-Jul-87

17-Jul-87

18-Jul-87

19-Jul-87

20-Jul-87

21-Jul-87

22-Jul-87

23-Jul-87

24-Jul-87

25-Jul-87.

26-Jul-87

27-Jul-87

28-Jul-87

30-Jul-87

\begin{tabular}{ccc}
\multicolumn{3}{c}{ 1st Stage } \\
Separator \\
Press & $\begin{array}{c}\text { Brine } \\
\text { Rate }\end{array}$ & $\begin{array}{c}\text { Gas } \\
\text { Rate }\end{array}$ \\
(psig) & $(\mathrm{RB} / \mathrm{d})$ & (scf/d)
\end{tabular}

Separator

\begin{tabular}{c} 
Sales \\
Gas \\
\hdashline$-\cdots$
\end{tabular}

$\begin{array}{lll}1001 & 9958 & 216029\end{array}$

$\begin{array}{lll}1001 & 9970 & 216132\end{array}$

$1002 \quad 9982 \quad 216034$

$\begin{array}{lll}1000 & 9991 & 216792\end{array}$

$1000 \quad 9999216328$

$1001 \quad 10015216657$

$\begin{array}{lll}1000 & 10015 & 217024\end{array}$

$\begin{array}{lll}999 & 10028 & 217538\end{array}$

$\begin{array}{lll}1000 & 10043 & 217931\end{array}$

100010056218102

100010065218146

$1002 \quad 10073 \quad 218267$

$\begin{array}{lll}1002 & 10084 & 218391\end{array}$

$999 \quad 10093 \quad 218002$

$100010054 \quad 217564$

$\begin{array}{lll}1001 & 9921 & 217452\end{array}$

$\begin{array}{lll}1002 & 9895 & 215270\end{array}$

9944215523

$\begin{array}{lll}1001 \quad 9981 & 216159\end{array}$

$\begin{array}{lll}1001 & 9984 & 216937\end{array}$

$\begin{array}{lll}1000 \quad 9991 & 216543\end{array}$

$\begin{array}{llll}1001 & 10003 & 216967\end{array}$

$\begin{array}{llll}1002 & 10021 & 217323\end{array}$

$1002 \quad 10030 \quad 217413$

$\begin{array}{lll}1001 & 10037 & 217530\end{array}$

$\begin{array}{llll}1001 & 10040 & 217597\end{array}$

$1001 \quad 10046217596$

100110062218195

$\begin{array}{lll}1001 & 10069 & 217753 \\ 1001 & 10064 & 217855\end{array}$

Press Rate

(psig) (scf/d)

40030331

$39629797 \quad 239732$

$\begin{array}{lll}401 & 29454 & 237918\end{array}$

$39830092 \quad 237998$

$40829475 \quad 238538$

40729181239095

$40429663 \quad 238403$

$40130288 \quad 239327$

$40030617 \quad 241505$

$40130925 \quad 241758$

$40031548 \quad 240656$

$40231674 \quad 240484$

$40131573 \quad 241191$

$40230886 \quad 241008$

$40431723 \quad 242025$

$\begin{array}{lll}420 & 29717 & 241051\end{array}$

41229056239680

$40329449 \quad 238637$

$\begin{array}{lll}399 & 29797 & 238874\end{array}$

$39229588 \quad 236252$

$\begin{array}{llll}408 & 29552 & 238047\end{array}$

$41130130 \quad 237620$

$39920556 \quad 240537$

$39930018 \quad 240758$

$\begin{array}{lll}401 & 29507 & 240726\end{array}$

$\begin{array}{lll}398 & 29690 & 240468\end{array}$

$40229966 \quad 240152$

40029910240188

39730181241011

$40130383 \quad 241311$

$40230860 \quad 241748$

Max Surface Brine

Well Well

(psig) (psig) (stb

$2964 \overline{177}$

$2980 \quad 176$

$2982 \quad 178$

$2977 \quad 177$

$2982 \quad 176$

$2987 \quad 179$

$2991 \quad 179$

$2996 \quad 179$

$3007 \quad 178$

3006181

$3015 \quad 180$

3008181

$3004 \quad 180$

$3014 \quad 180$

$3016 \quad 182$

$3045 \quad 178$

$3039 \quad 177$

3046178

3041180

$3040 \quad 174$

3046173

$3051 \quad 176$

$3057 \quad 178$

3058179

$3058 \quad 178$

$3058 \quad 180$

3060181

$3061 \quad 181$

3062181

Brine
Rate

Cum Gas/Brine Ratios

1st 2nd Disp

Stage Stg Well

$(\mathrm{stb} / \mathrm{d})(\mathrm{scf} / \mathrm{stb})(\mathrm{scf} / \mathrm{stb})(\mathrm{scf} / \mathrm{stb})$ (psia)

$\begin{array}{lllll}9337 & 23.14 & 26.39 & 28.58\end{array}$

$\begin{array}{llll}9348 & 23.12 & 26.31 & 28.48\end{array}$

$\begin{array}{lllll}9359 & 23.08 & 26.23 & 28.43\end{array}$

$\begin{array}{llll}9368 & 23.14 & 26.35 & 28.54\end{array}$

$\begin{array}{llll}9375 & 23.07 & 26.22 & 28.46\end{array}$

$\begin{array}{llll}9390 & 23.07 & 26.18 & 28.41\end{array}$

$\begin{array}{lllll}9390 & 23.11 & 26.27 & 28.49\end{array}$

$\begin{array}{llll}9403 & 23.14 & 26.36 & 28.56\end{array}$

$\begin{array}{lllll}9417 & 23.14 & 26.39 & 28.59\end{array}$

$\begin{array}{lllll}9429 & 23.13 & 26.41 & 28.61\end{array}$

$\begin{array}{llll}9437 & 23.12 & 26.46 & 28.65\end{array}$

$\begin{array}{lllll}9445 & 23.11 & 26.46 & 28.67\end{array}$

$\begin{array}{lllll}9455 & 23.10 & 26.44 & 28.64\end{array}$

$\begin{array}{lllll}9463 & 23.04 & 26.30 & 28.51\end{array}$

$\begin{array}{lllll}9427 & 23.08 & 26.44 & 28.66\end{array}$

$\begin{array}{lllll}9302 & 23.38 & 26.57 & 28.87\end{array}$

$\begin{array}{llll}9278 & 23.20 & 26.33 & 28.59\end{array}$

$\begin{array}{llll}9324 & 23.12 & 26.27 & 28.49\end{array}$

$\begin{array}{llll}9358 & 23.10 & 26.28 & 28.47\end{array}$

$\begin{array}{llll}9361 & 23.17 & 26.33 & 28.49\end{array}$

$\begin{array}{lllll}9368 & 23.12 & 26.27 & 28.51\end{array}$

$\begin{array}{llll}9379 & 23.13 & 26.35 & 28.6\end{array}$

$\begin{array}{lllll}9396 & 23.13 & 25.32 & 27.51\end{array}$

$\begin{array}{lllll}9404 & 23.12 & 26.31 & 28.5\end{array}$

$\begin{array}{llll}9411 & 23.11 & 26.25 & 28.45\end{array}$

$\begin{array}{lllll}9414 & 23.11 & 26.27 & 28.45\end{array}$

$\begin{array}{lllll}9419 & 23.10 & 26.28 & 28.49\end{array}$

$\begin{array}{llll}9429 & 23.08 & 26.25 & 28.45\end{array}$

$\begin{array}{lllll}9434 & 23.13 & 26.33 & 28.51\end{array}$

$\begin{array}{lllll}9441 & 23.06 & 26.28 & 28.48\end{array}$

$3072 \quad 182$ $\begin{array}{lllll}9436 & 23.09 & 26.36 & 28.56\end{array}$ $\begin{array}{llll}\text { Calc } & \text { Perf } & \text { Cum } & \text { Cum } \\ \text { BHP } & \text { Gas } & \text { Gas } & \text { Brine }\end{array}$

(scf/d)

(scf)

(stb)

26685169528906224099368

26623169555529324108716

26607669582136924118075

26736369608873224127443

26681369635554424136818

26677069662231424146208

26752169688983524155598

26855069715838524165001

26923269742761724174418

26976469769738124183847

27037069796775124193284

27078869823853924202729

27079169850933024212184

26979069877912024221647

27017869904929824231074

26854969931784724240376

26525869958310524249654

26564169984874624258978

26642270011516824268336

26669570038186324277697

26708270064894424287065

26823970091718424296444

25848470117566824305840

26801470144368224315244

26774370171142524324655

26782870197925324334069

26834770224760024343488

26825570251585524352917

26896370278481924362351

26888070305369824371792

26949270332319124381228 


\begin{tabular}{ll} 
Date & $\begin{array}{c}\text { 1st Stage } \\
\text { Separator }\end{array}$ \\
\hdashline Press & $\begin{array}{c}\text { Brine } \text { Gas } \\
\text { Rate } \\
\text { Rate }\end{array}$ \\
(psig) (RB/d) (scf/d)
\end{tabular}

$\begin{array}{llll}1 \text {-Aug-87 } & 1001 & 10041 \quad 218192\end{array}$ 2-Aug-87 $\quad 1003 \quad 10074 \quad 218376$

3-Aug-87 $1001 \quad 10085 \quad 218140$

4-Aug-87 $1001 \quad 9995 \quad 217066$

5-Aug-87 $1000 \quad 10005 \quad 217270$

6-Aug-87 $1000 \quad 10014 \quad 217181$

7-Aug-87 $1000 \quad 10021 \quad 217008$

8-Aug-87 $1001 \quad 10039 \quad 217489$

9-Aug-87 $\quad 999 \quad 10050 \quad 217385$

10-Aug-87 $1002 \quad 10035 \quad 217367$

11-Aug-87 $1000 \quad 10054 \quad 217607$

12-Aug-87 $1001 \quad 10062 \quad 217522$

13-Aug-87 $1002 \quad 10064 \quad 217926$

14-Aug-87 $1002 \quad 10074 \quad 218344$

15-Aug-87 $1001 \quad 10085 \quad 218629$

16-Aug-87 $1002 \quad 10087 \quad 218052$

17-Aug-87 1001 $10034 \quad 217840$

18-Aug-87 $1000 \quad 9976 \quad 216529$

19-Aug-87 1001 $9997 \quad 216863$

20-Aug-87 $1000 \quad 10010 \quad 217103$

21-Aug-87 $1000 \quad 10015 \quad 217015$

22-Aug-87 $1000 \quad 10016 \quad 216907$

23-Aug-87 $1001 \quad 10017 \quad 216937$

24-Aug-87 $1000 \quad 10031 \quad 217189$

25-Aug-87 $1000 \quad 10033 \quad 217048$

26-Aug-87 $998 \quad 10034 \quad 217320$

27-Aug-87 $999 \quad 10057 \quad 217513$

28-Aug-87 1001 10031217359

29-Aug-87 $1002 \quad 10041217343$

30-Aug-87 $999 \quad 10042 \quad 217813$

31-Aug-87 $1000 \quad 10036 \quad 217451$ \begin{tabular}{cccc}
$\begin{array}{c}\text { 2nd Stage } \\
\text { Separator }\end{array}$ & $\begin{array}{c}\text { Sales } \\
\text { Gas }\end{array}$ & $\begin{array}{c}\text { Max Surface } \\
\text { Pressure }\end{array}$ & $\begin{array}{c}\text { Brine } \\
\text { Rate }\end{array}$ \\
\hline Gas & & $\begin{array}{c}\text { Prod Disp } \\
\text { Press Rate }\end{array}$ & Well Well
\end{tabular}

Cum Gas/Brine Ratios

$\begin{array}{cccc}\text { Calc } & \text { Perf } & \text { Cum } & \text { Cum } \\ \text { BHP } & \text { Gas } & \text { Gas } & \text { Brine }\end{array}$

1st 2nd Disp Stage Stg Well (psig) (scf/d)

(scf/d) (psig) (psig)

39930636 242229

40330627

39930036

40130340

40130258

39629989

39930640

40830469

41030282

39830011

40929022

39729260

40029595

40629323

39529317

39529206

40029146

40429423

40229710

40131426

40230234

39930080

40029605

40130199

40429821

40328637

40329225

40429858

$\begin{array}{llll}243929 & 3075 & 182\end{array}$

$(\mathrm{stb} / \mathrm{d})(\mathrm{scf} / \mathrm{stb})(\mathrm{scf} / \mathrm{stb})(\mathrm{scf} / \mathrm{stb}) \quad$ (psia)

(scf/d)

(scf)

(stb)

26945770359264824390643

27006170386270924400089

$\begin{array}{lllllllll}9456 & 23.07 & 26.31 & 28.52 & 9917 & 269685 & 704132394 & 24409545\end{array}$

$\begin{array}{lllllllllll}242782 & 3088 & 181 & 9372 & 23.16 & 26.37 & 28.56 & 9918 & 267664 & 704400059 & 24418917\end{array}$

$\begin{array}{lllllllllll}242958 & 3091 & 181 & 9381 & 23.16 & 26.39 & 28.6 & 9921 & 268297 & 704668355 & 24428298\end{array}$

$\begin{array}{llllllllllll}241381 & 3093 & 181 & 9389 & 23.13 & 26.35 & 28.55 & 9924 & 268056 & 704936411 & 24437687\end{array}$

$\begin{array}{llllllllllll}241208 & 3102 & 182 & 9396 & 23.10 & 26.29 & 28.46 & 9933 & 267410 & 705203821 & 24447083\end{array}$

$\begin{array}{lllllllllll}241580 & 3110 & 183 & 9413 & 23.11 & 26.36 & 28.55 & 9942 & 268741 & 705472562 & 24456496\end{array}$

$\begin{array}{llllllllllll}241196 & 3109 & 183 & 9423 & 23.07 & 26.30 & 28.54 & 9941 & 268932 & 705741495 & 24465919\end{array}$

$\begin{array}{llllllllllll}242169 & 3103 & 179 & 9409 & 23.10 & 26.32 & 28.57 & 9935 & 268815 & 706010310 & 24475328\end{array}$

$\begin{array}{llllllllllll}241557 & 3108 & 180 & 9427 & 23.08 & 26.27 & 28.45 & 9941 & 268198 & 706278508 & 24484755\end{array}$

$\begin{array}{lllllllllll}241509 & 3110 & 181 & 9434 & 23.06 & 26.13 & 28.37 & 9943 & 267643 & 706546151 & 24494189\end{array}$

$\begin{array}{lllllllllll}243253 & 3114 & 182 & 9436 & 23.09 & 26.20 & 28.38 & 9947 & 267794 & 706813944 & 24503625\end{array}$

$\begin{array}{lllllllllll}242406 & 3117 & 179 & 9446 & 23.12 & 26.25 & 28.44 & 9951 & 268644 & 707082589 & 24513071\end{array}$

$\begin{array}{lllllllllll}242741 & 3125 & 182 & 9456 & 23.12 & 26.22 & 28.45 & 9959 & 269023 & 707351612 & 24522527\end{array}$

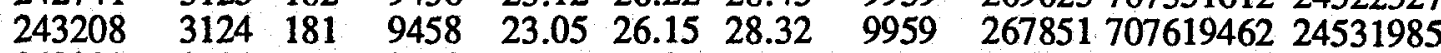

$\begin{array}{lllllllllll}242328 & 3134 & 178 & 9408 & 23.15 & 26.26 & 28.43 & 9967 & 267469 & 707886932 & 24541393\end{array}$

$\begin{array}{lllllllllll}241918 & 3137 & 181 & 9354 & 23.15 & 26.26 & 28.46 & 9968 & 266215 & 708153147 & 24550747\end{array}$

$\begin{array}{llllllllllll}241850 & 3147 & 182 & 9374 & 23.14 & 26.27 & 28.49 & 9979 & 267065 & 708420212 & 24560121\end{array}$

$\begin{array}{lllllllllllll}240853 & 3155 & 182 & 9386 & 23.13 & 26.30 & 28.5 & 9988 & 267501 & 708687713 & 24569507\end{array}$

$\begin{array}{llllllllllll}241030 & 3157 & 183 & 9390 & 23.11 & 26.46 & 28.66 & 9989 & 269117 & 708956830 & 24578897\end{array}$

$\begin{array}{lllllllllll}241795 & 3154 & 180 & 9391 & 23.10 & 26.32 & 28.52 & 9987 & 267831 & 709224662 & 24588288\end{array}$

$\begin{array}{llllllllllll}241168 & 3158 & 181 & 9392 & 23.10 & 26.30 & 28.49 & 9991 & 267578 & 709492240 & 24597680\end{array}$

$\begin{array}{lllllllllll}240784 & 3158 & 182 & 9405 & 23.09 & 26.24 & 28.44 & 9992 & 267478 & 709759718 & 24607085\end{array}$

$\begin{array}{llllllllllll}240694 & 3160 & 183 & 9407 & 23.07 & 26.28 & 28.48 & 9994 & 267911 & 710027629 & 24616492\end{array}$

$\begin{array}{llllllll}9408 & 23.10 & 26.27 & 28.49 & 9986 & 268034 & 710295663 & 24625900\end{array}$

$\begin{array}{llllllllllll}241684 & 3153 & 183 & 9430 & 23.07 & 26.10 & 28.32 & 9988 & 267058 & 710562721 & 24635330\end{array}$

$\begin{array}{lllllllllll}241729 & 3158 & 193 & 9405 & 23.11 & 26.22 & 28.43 & 9992 & 267384 & 710830105 & 24644735\end{array}$

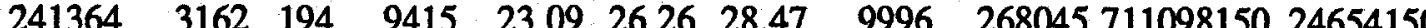

$\begin{array}{llllllllll}397 & 29841 & 242108 & 3161 & 193 & 9416 & 23.13 & 26.30 & 28.48\end{array}$

$40130091 \quad 241941$
$3167 \quad 194$ 


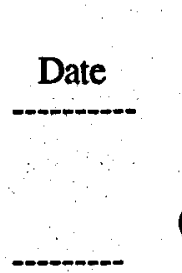

1-Oct-87

2-Oct-87

3-Oct-87

4-Oct-87

5-Oct-87

6-Oct-87

7-Oct-87

8-Oct-87

9-Oct-87

10-Oct-87

11-Oct-87

12-Oct-87

15-Oct-87 $999 \quad 10061 \quad 217192$

16-Oct-87 $1000 \quad 10068 \quad 217505$

17-Oct-87 $1011 \quad 10088 \quad 218025$

$\begin{array}{lllll}18-O c t-87 & 1018 & 10069 & 217872\end{array}$

19-Oct-87 $1014 \quad 10077 \quad 217774$

20-Oct-87 $1008 \quad 9951215563$

21-Oct-87 $1001 \quad 9937 \quad 215846$

22-Oct-87 $1006 \quad 9922 \quad 215714$

23-Oct-87 $1001 \quad 9935215097$

24-Oct-87 $1022 \quad 9948 \quad 216044$

$\begin{array}{lllll}25-O c t-87 & 1001 & 11438 & 241031\end{array}$

26-Oct-87 $1002 \quad 12074 \quad 264283$

27-Oct-87 $1004 \quad 9955 \quad 215383$

28-Oct-87 $1010 \quad 9950 \quad 215649$

29-Oct-87 $1003 \quad 9952 \quad 215396$

$\begin{array}{lllll}30-\text { Oct-87 } & 1003 \quad 4988 & 116874\end{array}$

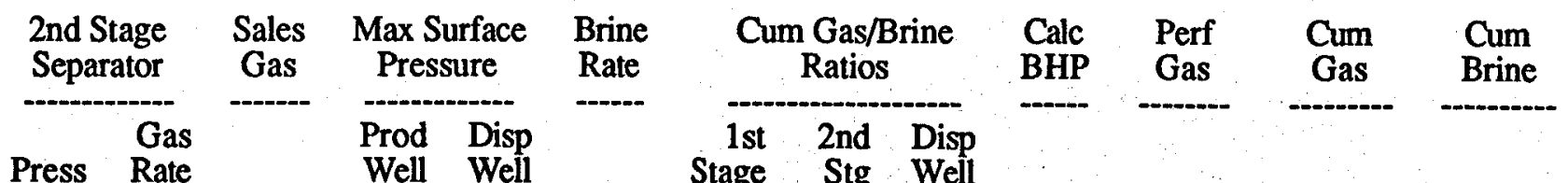
(scf/d) (psig) (psig) (stb/d) (scf/stb)(scf/stb)(scf/stb) (psia)

(scf/d)

(scf)

(stb)

$\begin{array}{llllllllll}402 & 30549 & 241996 & 3245 & 186 & 9368 & 23.09 & 26.35 & 28.55 & 10080\end{array}$ $\begin{array}{llllllllll}400 & 30205 & 242554 & 3252 & 189 & 9369 & 23.10 & 26.32 & 28.52 & 10087\end{array}$

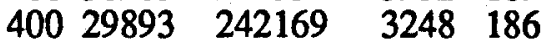
$\begin{array}{lllll}403 & 29416 & 242427 & 3255 & 192\end{array}$ $\begin{array}{lllll}400 & 29535 & 241921 & 3254 & 189\end{array}$ $\begin{array}{lllll}400 & 30236 & 241516 & 3252 & 190\end{array}$ $\begin{array}{lllll}401 & 29983 & 241885 & 3259 & 192\end{array}$ $\begin{array}{lllll}405 & 29746 & 241248 & 3260 & 192\end{array}$ $\begin{array}{lllll}405 & 30646 & 241919 & 3285 & 193\end{array}$ $\begin{array}{lllll}398 & 30124 & 242833 & 3259 & 195\end{array}$ $\begin{array}{lllll}400 & 29609 & 242441 & 3263 & 194\end{array}$ $\begin{array}{lllll}402 & 30295 & 241057 & 3269 & 193\end{array}$ $\begin{array}{lllll}402 & 29626 & 241954 & 3269 & 191\end{array}$ $\begin{array}{lllll}409 & 29475 & 242420 & 3269 & 192\end{array}$ $\begin{array}{lllll}404 & 29715 & 243105 & 3265 & 193\end{array}$ $\begin{array}{lllll}402 & 29617 & 242699 & 3269 & 193\end{array}$ $\begin{array}{lllll}400 & 29796 & 243274 & 3269 & 192\end{array}$ $\begin{array}{llllll}401 & 30504 & 242956 & 3273 & 193\end{array}$ $\begin{array}{lllll}398 & 30579 & 242587 & 3276 & 192\end{array}$ $\begin{array}{lllll}402 & 29879 & 240851 & 3284 & 192\end{array}$ $\begin{array}{lllll}403 & 30498 & 241311 & 3289 & 190\end{array}$ $\begin{array}{lllll}409 & 29775 & 242284 & 3293 & 194\end{array}$ $\begin{array}{lllll}405 & 30984 & 241030 & 3289 & 193\end{array}$ $\begin{array}{lllll}399 & 31765 & 242615 & 3292 & 195\end{array}$ $40736701 \quad 272736$ $40240698 \quad 287846$ 39741669238665 $40031529 \quad 241581$ $40031529 \quad 241827$ $400 \quad 16513 \quad 131317$ $\begin{array}{llllll}9383 & 23.08 & 26.27 & 28.46 & 10084\end{array}$ $\begin{array}{llllll}9398 & 23.08 & 26.21 & 28.42 & 10091\end{array}$ $\begin{array}{lllll}9405 & 23.13 & 26.27 & 28.46 & 10091\end{array}$ $\begin{array}{llllll}9402 & 23.07 & 26.29 & 28.48 & 10088\end{array}$ $\begin{array}{llllll}9413 & 23.06 & 26.25 & 28.45 & 10096\end{array}$ $\begin{array}{lllll}9391 & 23.12 & 26.29 & 28.51 & 10096\end{array}$ $\begin{array}{llllll}9384 & 22.99 & 26.26 & 28.48 & 10122\end{array}$ $\begin{array}{lllll}9421 & 23.02 & 26.22 & 28.4 & 10096\end{array}$ $\begin{array}{lllll}9422 & 23.07 & 26.21 & 28.41 & 10100\end{array}$ $\begin{array}{lllll}9420 & 23.08 & 26.29 & 28.5 & 10106\end{array}$ $\begin{array}{lllll}9428 & 23.04 & 26.19 & 28.39 & 10107\end{array}$ $\begin{array}{llllll}9426 & 23.03 & 26.15 & 28.4 & 10107\end{array}$ $\begin{array}{llllll}9433 & 23.02 & 26.17 & 28.39 & 10103\end{array}$ $\begin{array}{llllll}9440 & 23.04 & 26.18 & 28.38 & 10107\end{array}$ $\begin{array}{lllll}9459 & 23.05 & 26.20 & 28.39 & 10108\end{array}$ $\begin{array}{llllll}9442 & 23.08 & 26.31 & 28.51 & 10111\end{array}$ $\begin{array}{lllll}9449 & 23.05 & 26.28 & 28.47 & 10115\end{array}$ $\begin{array}{llllll}9331 & 23.10 & 26.31 & 28.51 & 10119\end{array}$ $\begin{array}{llllll}9317 & 23.17 & 26.44 & 28.65 & 10123\end{array}$ $\begin{array}{lllll}9303 & 23.19 & 26.39 & 28.63 & 10127\end{array}$ $\begin{array}{lllll}9315 & 23.09 & 26.42 & 28.64 & 10123\end{array}$ $\begin{array}{lllllll}9328 & 23.16 & 26.57 & 28.76 & 10126\end{array}$ $\begin{array}{lllllll}2928 & 252 & 10725 & 22.47 & 25.90 & 28.13 & 9802\end{array}$ $\begin{array}{llllllll}3281 & 402 & 11321 & 23.34 & 26.94 & 29.15 & 10187\end{array}$ $\begin{array}{llllllll}3288 & 191 & 9334 & 23.07 & 27.54 & 29.72 & 10120\end{array}$ $\begin{array}{lllllll}3295 & 192 & 9330 & 23.11 & 26.49 & 28.69 & 10130\end{array}$ $\begin{array}{llllllll}3289 & 192 & 9331 & 23.08 & 26.46 & 28.66 & 10124\end{array}$ $\begin{array}{lllllll}3584 & 192 & 4677 & 24.99 & 28.52 & 30.72 & 10303\end{array}$
26745671975425924960128 26720472002146324969497 26704072028850324978880 26709172055559424988278 26766672082326124997683 26776972109103025007085 26780072135882925016498 26773772162656725025889 26725672189382325035273 26755672216137925044694 26767972242905925054116 26847072269752925063536 26766172296518925072964 $267698723232888 \quad 25082390$ 26780372350069125091823 26790772376859825101263 26854172403713925110722 26919172430633025120164 26901372457534325129613 26602772484137025138944 26693272510830225148261 26634572537464725157564 26678272564142925166879 26827372590970225176207 30169472621139625186932 33000772654140325198253 27740672681881025207587 26767872708648825216917 26742672735391425226248 14367772749759125230925 
$-$

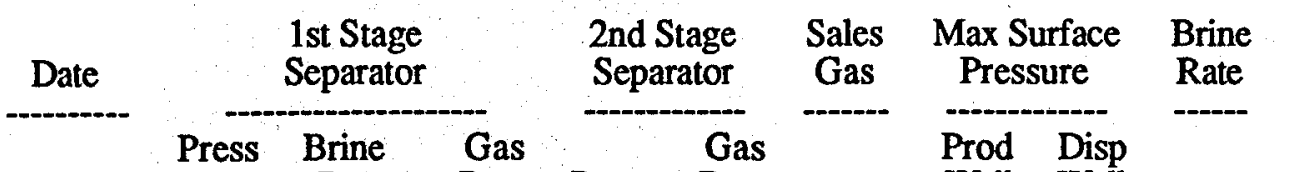

$\begin{array}{llll}1-S e p-87 & 1001 & 10037 & 217437\end{array}$ 2-Sep-87 $1001 \quad 10040 \quad 217808$ $3-$ Sep-87 $1000 \quad 8220 \quad 180385$ 4-Sep-87 $\quad 1000 \quad 9434 \quad 203115$ 5-Sep-87 $1000 \quad 7956 \quad 176683$ 6-Sep-87 $1009 \quad 10092 \quad 219259$ 7-Sep-87 $1000 \quad 10072 \quad 218533$ $\begin{array}{lllll}8-\text { Sep-87 } & 1000 & 9985 & 216350\end{array}$ $\begin{array}{lllll}9-S e p-87 & 998 & 9990 & 216626\end{array}$ 10-Sep-87 $1012 \quad 10011217068$ 11-Sep-87 $1008 \quad 10002 \quad 217234$ $\begin{array}{lllll}12-S e p-87 & 1005 & 10044 \quad 218150\end{array}$ $\begin{array}{lllll}13-S e p-87 & 1014 \quad 10041 \quad 127950\end{array}$ $\begin{array}{lllll}14-S e p-87 & 1005 & 10058 & 218009\end{array}$ 15-Sep-87 $1001 \quad 10056 \quad 218065$ $\begin{array}{llll}16-S e p-87 & 999 & 10081 & 218444\end{array}$ $\begin{array}{llll}17-S e p-87 & 1000 & 10088 & 218534\end{array}$ 18-Sep-87 $1019 \quad 10081 \quad 218483$ 19-Sep-87 $1009 \quad 10069218293$ 20-Sep-87 $999 \quad 10075 \quad 218323$ 21-Sep-87 $1000 \quad 9988 \quad 216851$ 22-Sep-87 $1006 \quad 9967 \quad 216012$ 23-Sep-87 $999 \quad 9970216059$ 24-Sep-87 $1001 \quad 9983 \quad 217155$ 25-Sep-87 $1001 \quad 9986216908$ 26-Sep-87 $1001 \quad 9995 \quad 216987$ 27-Sep-87 $\quad 1002 \quad 9972 \quad 216994$ 28-Sep-87 $1001 \quad 9984 \quad 216960$ 29-Sep-87 $1011 \quad 9990 \quad 217058$ 30-Sep-87 $1020 \quad 9990 \quad 217294$
Press Rate Well Well $\quad$ Stage 2 Stg Well

(psig) (scf/d) (scf/d) (psig) (psig) (stb/d) (scf/stb)(scf/stb)(scf/stb) (psia)

$\begin{array}{llllllllll}397 & 30157 & 242677 & 3165 & \overline{188} & \overline{9411} & \mathbf{2 3 . 1 0} & \mathbf{2 6 . 3 1} & \mathbf{2 8 . 4 9} & \overline{9999}\end{array}$ $\begin{array}{llllllllll}403 & 30154 & 241855 & 3166 & 191 & 9414 & 23.14 & 26.34 & 28.55 & 10000\end{array}$ $\begin{array}{lllllllllll}402 & 19021 & 196388 & 3322 & 143 & 7707 & 23.40 & 25.87 & 28.08 & 10109\end{array}$ $\begin{array}{lllll}400 & 26537 & 222524 & 3173 & 185\end{array}$

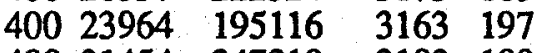
$\begin{array}{lllll}400 & 31454 & 247210 & 3183 & 189\end{array}$ $\begin{array}{lllll}400 & 31398 & 243074 & 3190 & 189\end{array}$ $\begin{array}{lllll}400 & 30966 & 242438 & 3193 & 191\end{array}$ $\begin{array}{lllll}402 & 30925 & 242840 & 3193 & 191\end{array}$ $\begin{array}{lllll}408 & 30292 & 243774 & 3194 & 192\end{array}$ $\begin{array}{lllll}407 & 30525 & 243984 & 3197 & 190\end{array}$ $\begin{array}{lllll}40830348 & 243170 & 3205 & 193\end{array}$ $\begin{array}{lllll}406 & 29951 & 242841 & 3203 & 192\end{array}$ $\begin{array}{lllll}403 & 30465 & 242257 & 3208 & 192\end{array}$ $\begin{array}{lllll}400 & 30378 & 241849 & 3204 & 192\end{array}$ $\begin{array}{lllll}406 & 30027 & 242086 & 3205 & 191\end{array}$ $\begin{array}{lllll}399 & 30118 & 243734 & 3209 & 191\end{array}$ $\begin{array}{lllll}405 & 29823 & 242293 & 3213 & 192\end{array}$ $\begin{array}{lllll}402 & 30506 & 242239 & 3213 & 192\end{array}$ $\begin{array}{lllll}399 & 30704 & 243193 & 3215 & 192\end{array}$ $\begin{array}{lllll}398 & 30227 & 242300 & 3226 & 191\end{array}$ $\begin{array}{lllll}402 & 29995 & 241024 & 3228 & 191\end{array}$ $\begin{array}{lllll}402 & 30447 & 241208 & 3229 & 188\end{array}$ $\begin{array}{lllll}407 & 30574 & 242833 & 3231 & 191\end{array}$ $\begin{array}{lllll}402 & 30826 & 242330 & 3235 & 189\end{array}$ $\begin{array}{lllll}402 & 31093 & 242504 & 3239 & 188\end{array}$ $\begin{array}{lllll}405 & 31541 & 242482 & 3241 & 188\end{array}$ $\begin{array}{lllll}404 & 31214 & 242466 & 3242 & 188\end{array}$ $\begin{array}{lllll}403 & 31183 & 242827 & 3244 & 188\end{array}$ $\begin{array}{lllll}408 & 30513 & 242864 & 3242 & 190\end{array}$ $\begin{array}{llllll}8846 & 22.96 & 25.96 & 28.16 & 9989\end{array}$

$\begin{array}{lllll}7460 & 23.68 & 26.90 & 29.09 & 9936\end{array}$ $\begin{array}{llllll}9463 & 23.17 & 26.49 & 28.69 & 10019\end{array}$

$\begin{array}{llllll}9444 & 23.14 & 26.47 & 28.66 & 10025\end{array}$

$\begin{array}{lllll}9362 & 23.11 & 26.42 & 28.61 & 10026\end{array}$

$\begin{array}{lllll}9367 & 23.13 & 26.43 & 28.63 & 10026\end{array}$

$\begin{array}{llllll}9387 & 23.12 & 26.35 & 28.59 & 10028\end{array}$

$\begin{array}{llllll}9378 & 23.16 & 26.42 & 28.65 & 10030\end{array}$

$\begin{array}{llllll}9418 & 23.16 & 26.39 & 28.62 & 10040\end{array}$

$\begin{array}{lllll}9415 & 13.59 & 16.77 & 19 & 10053\end{array}$

$\begin{array}{lllll}9431 & 23.12 & 26.35 & 28.56 & 10044\end{array}$

$\begin{array}{llllll}9429 & 23.13 & 26.35 & 28.55 & 10040\end{array}$

$\begin{array}{llllll}9452 & 23.11 & 26.29 & 28.51 & 10041\end{array}$

$\begin{array}{llllll}9453 & 23.11 & 26.27 & 28.49 & 10050\end{array}$

$\begin{array}{llllll}9441 & 23.12 & 26.35 & 28.56 & 10049\end{array}$

$\begin{array}{lllll}9447 & 23.11 & 26.36 & 28.55 & 10051\end{array}$

$\begin{array}{llllll}9365 & 23.16 & 26.38 & 28.57 & 10060\end{array}$

$\begin{array}{lllll}9346 & 23.11 & 26.32 & 28.53 & 10062\end{array}$ $\begin{array}{lllll}9348 & 23.11 & 26.37 & 28.58 & 10063\end{array}$ $\begin{array}{llllll}9360 & 23.20 & 26.47 & 28.7 & 10065\end{array}$ $\begin{array}{lllll}9363 & 23.17 & 26.46 & 28.66 & 10069\end{array}$ $\begin{array}{llllll}9372 & 23.15 & 26.47 & 28.68 & 10073\end{array}$ $\begin{array}{llllll}9350 & 23.21 & 26.58 & 28.8 & 10074\end{array}$ $\begin{array}{lllll}9361 & 23.18 & 26.51 & 28.73 & 10076\end{array}$ $\begin{array}{llllll}9367 & 23.17 & 26.50 & 28.71 & 10078\end{array}$ $\begin{array}{lllll}9368 & 23.20 & 26.45 & 28.69 & 10076\end{array}$ $\begin{array}{llllll}9459 & 23.10 & 26.29 & 28.48 & 10046\end{array}$ (scf/d) (scf) (stb)

26811971190271624682387 26877071217148624691801 21641371238789824699508 24910371263700224708354 21701171285401324715814 27149371312550724725277 27066571339617224734721 26784771366401824744083 26817771393219624753450 $268374714200570 \quad 24762837$ 26868071446925024772215 26954371473879324781633 17888571491767824791048 26934971518702724800479 26919871545622524809908 26947771572570224819360 26939271599509424828819 26931671626441024838272 26963571653404524847713 26971271680375724857160 26755871707131524866525 26664171733795624875871 26716671760512224885219 26863271787375424894579 26834471814209824903942 26878971841088724913314 26928071868016724922664 26894271894910824932025 26892771921803524941392 26876871948680324950760 
Flow Tests of the Gladys MCCall Well Through October 1990

\section{APPENDIX D}

Sand 8 Graphical Production Data

D-1 

Flow Tests of the Gladys MCCall Well Through OCtober 1990

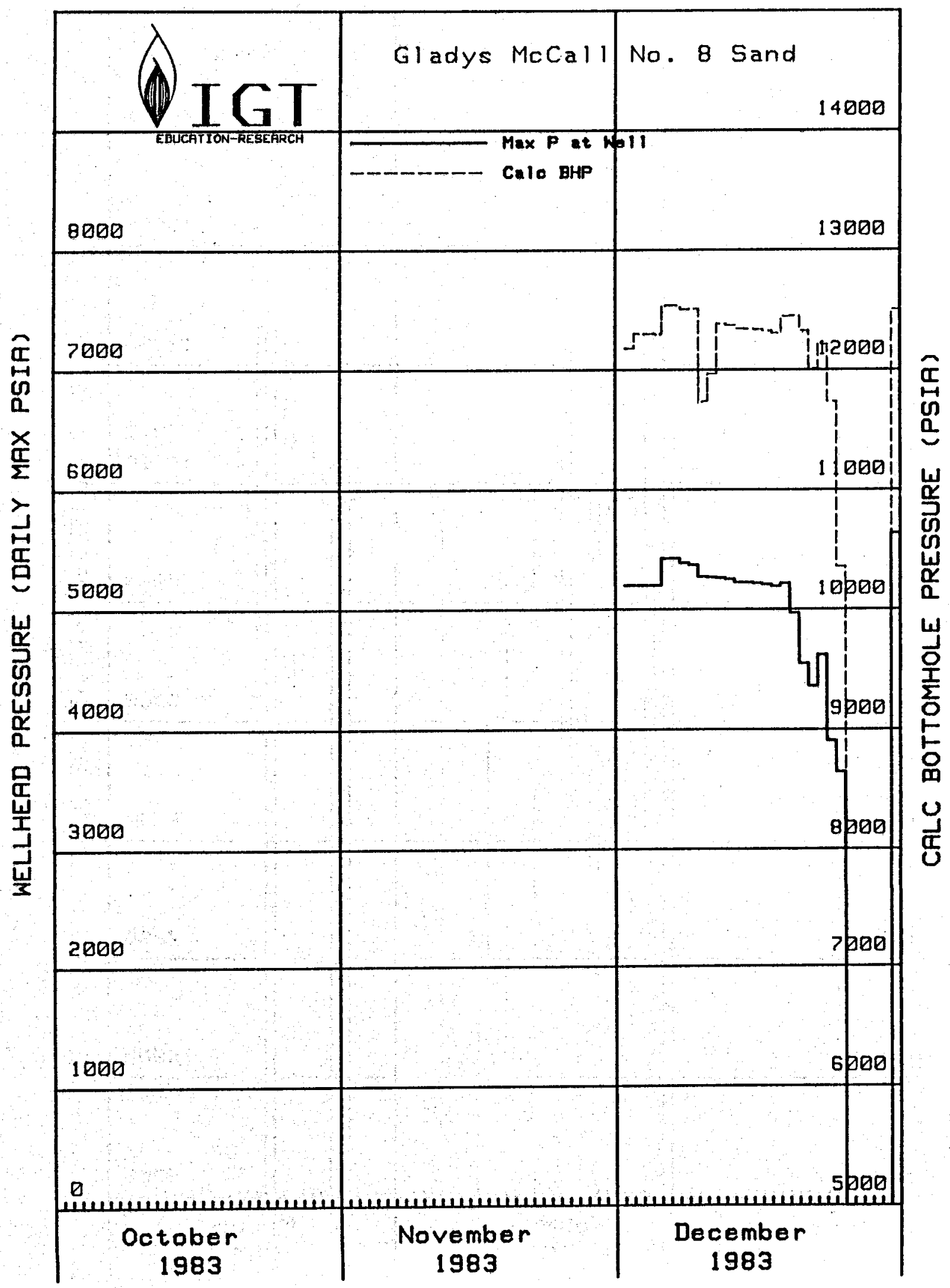

D-3
I N S T I T U T E
O F
G A S
T E C H N O L O G Y 


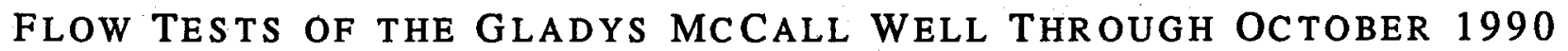

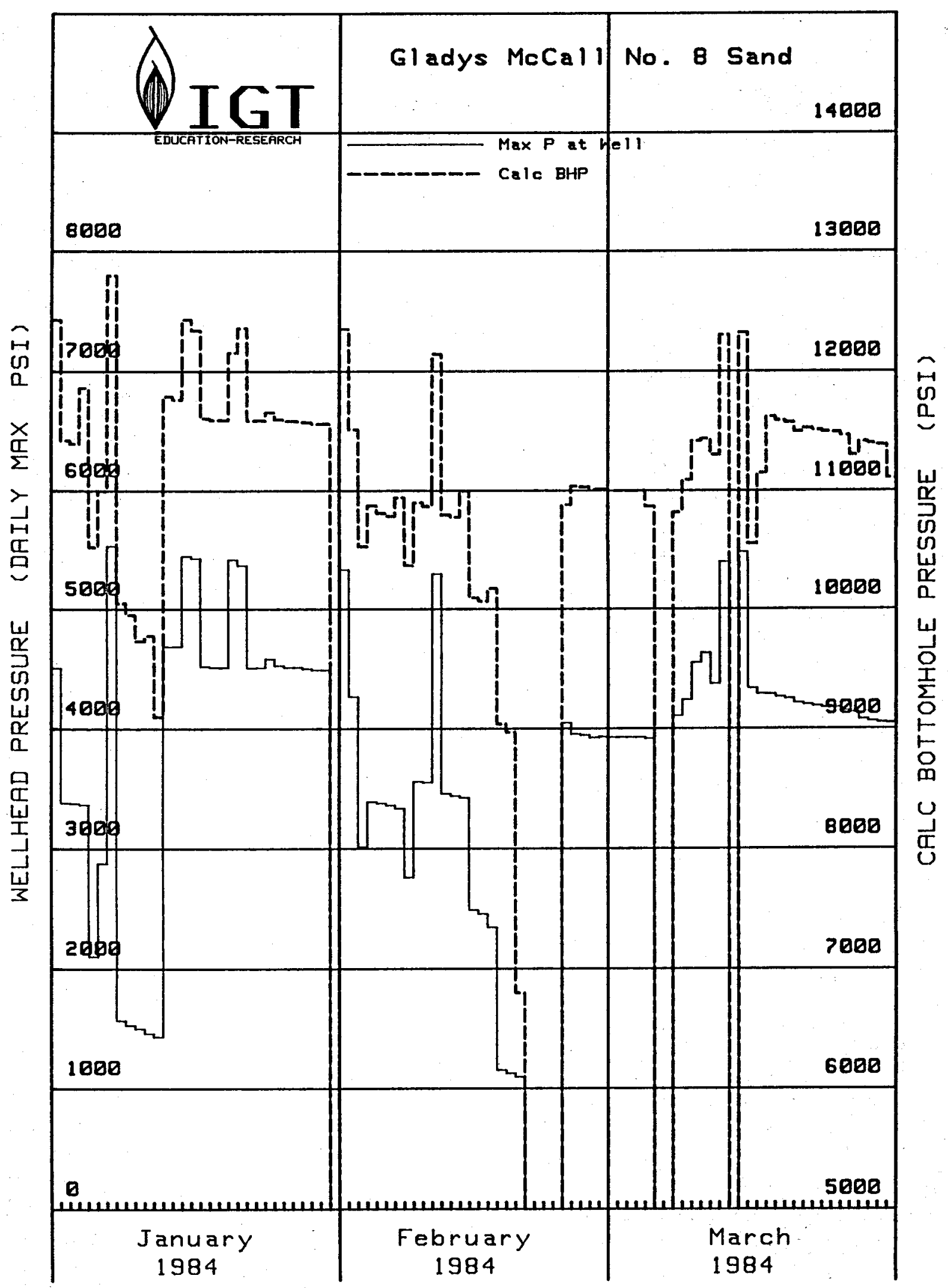

D-4
I N S T I T U T E
O F
G A S
T E C C H 
FLOW TESTS OF THE GLAdys MCCALl Well THROUgh OCtober 1990

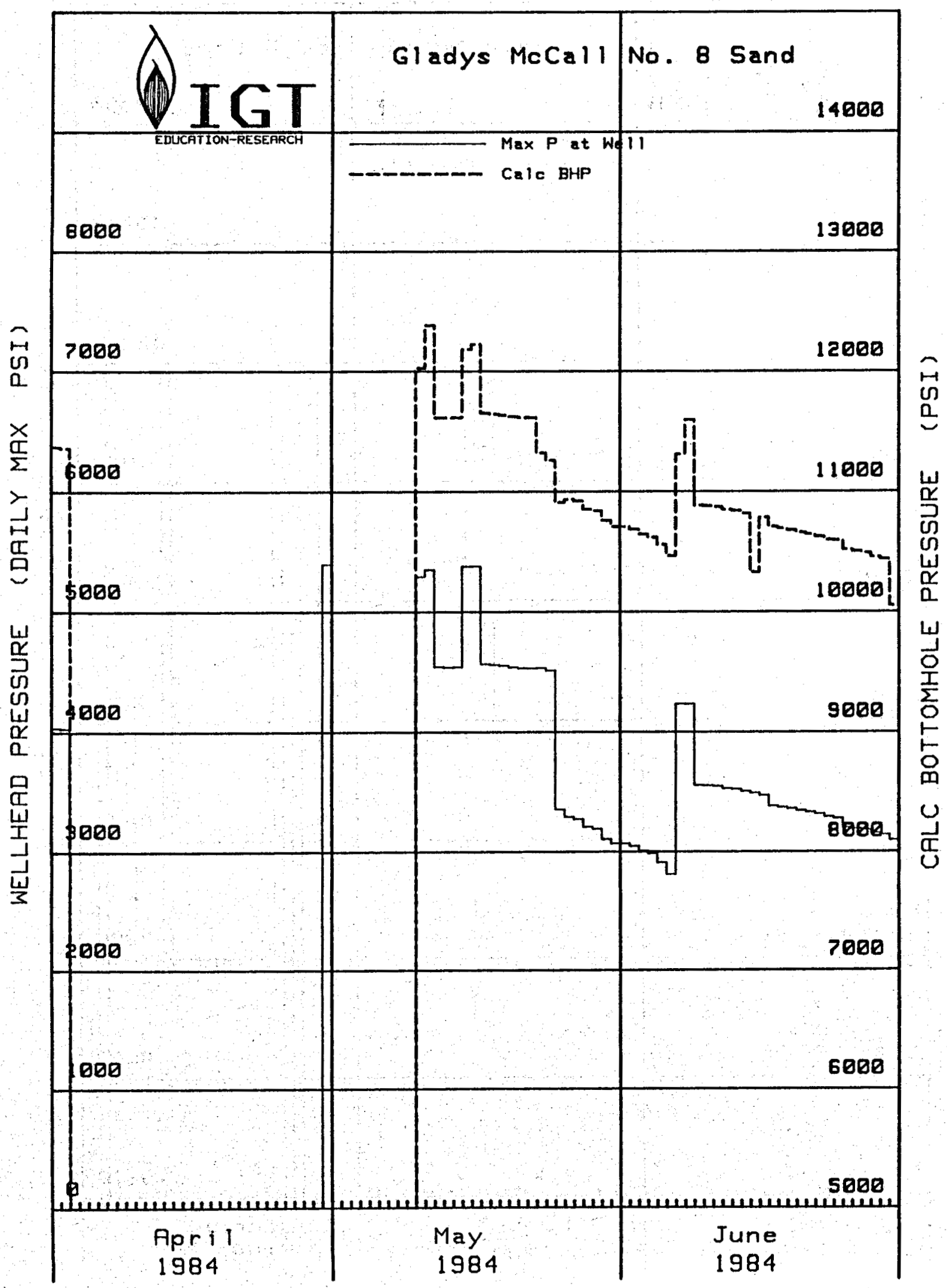

D-5
I NST IT U T E
o. $F$
G A S
T E CH N O L O G Y 
Flow tests of the Gladys MCCall Well Through OCtober 1990

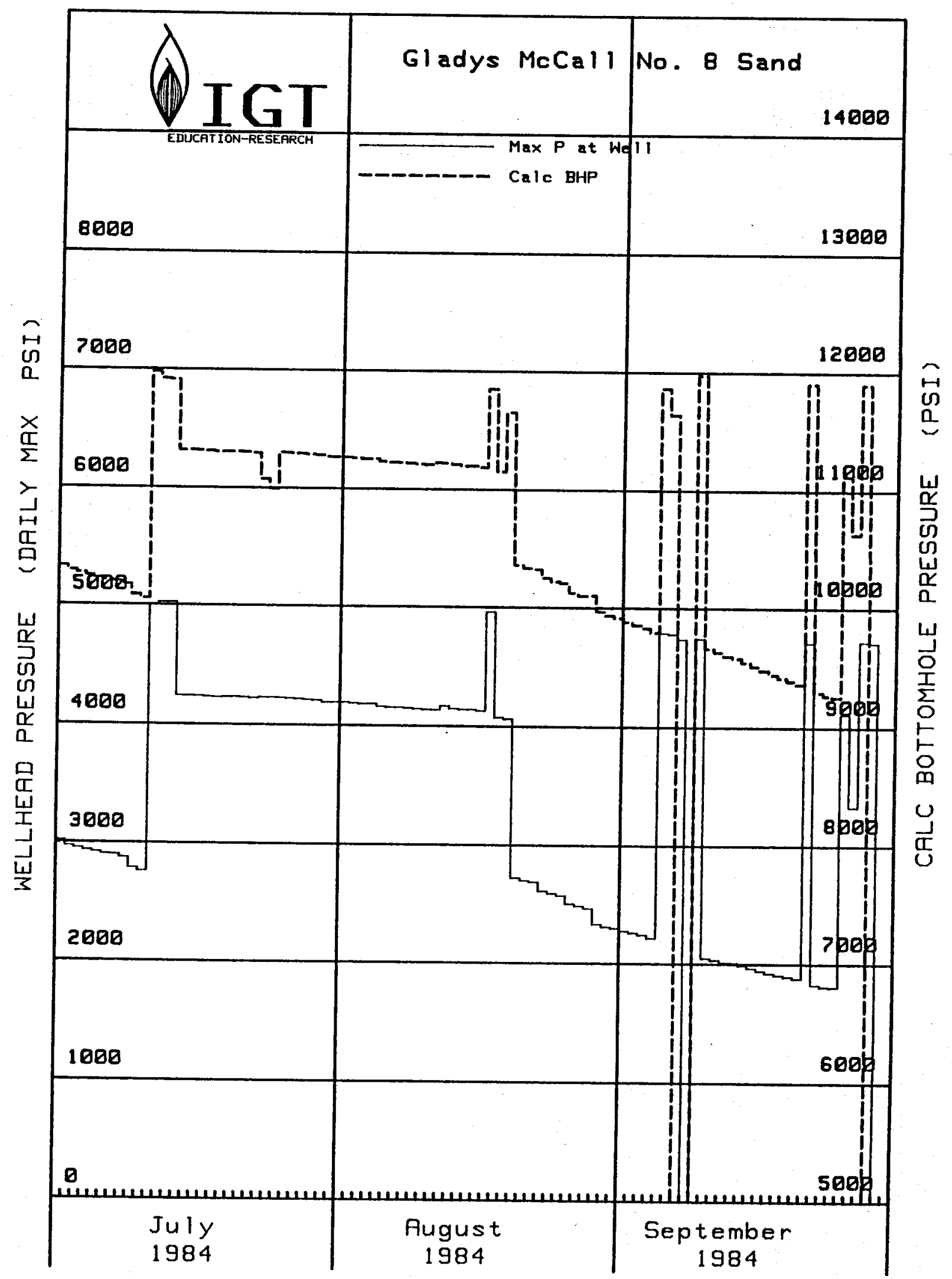

D-6

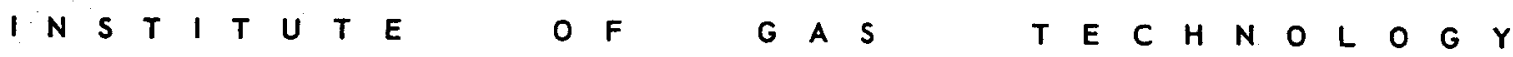


Flow TESTS OF THE GLADYS MCCALL WELl THROUgh OCtOBER 1990

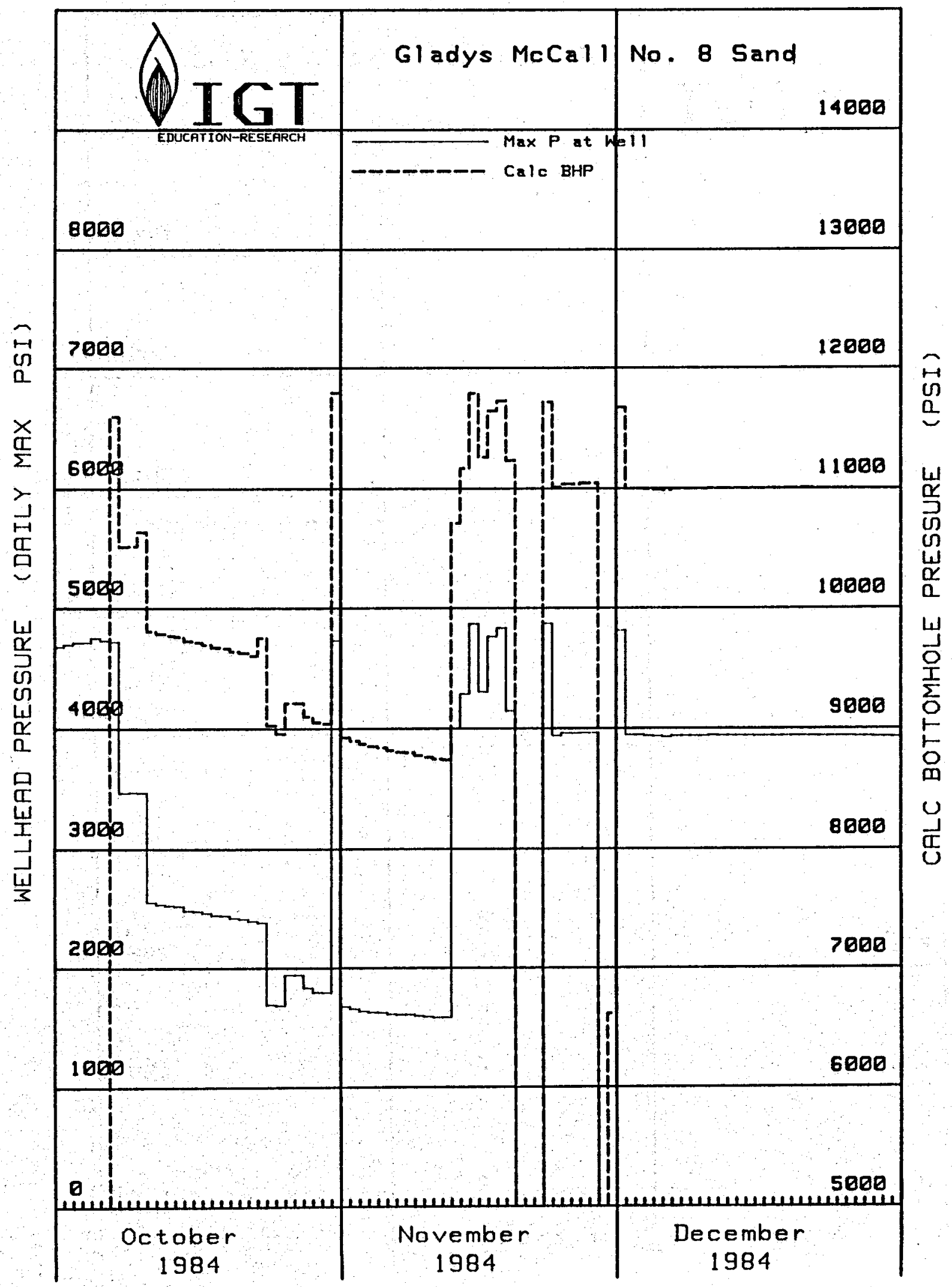

D-7
I N S T I T U T E
o $F$
G A S
T E C H N O L O G Y 
Flow Tests of the Gladys MCCall Well Through OCtober 1990

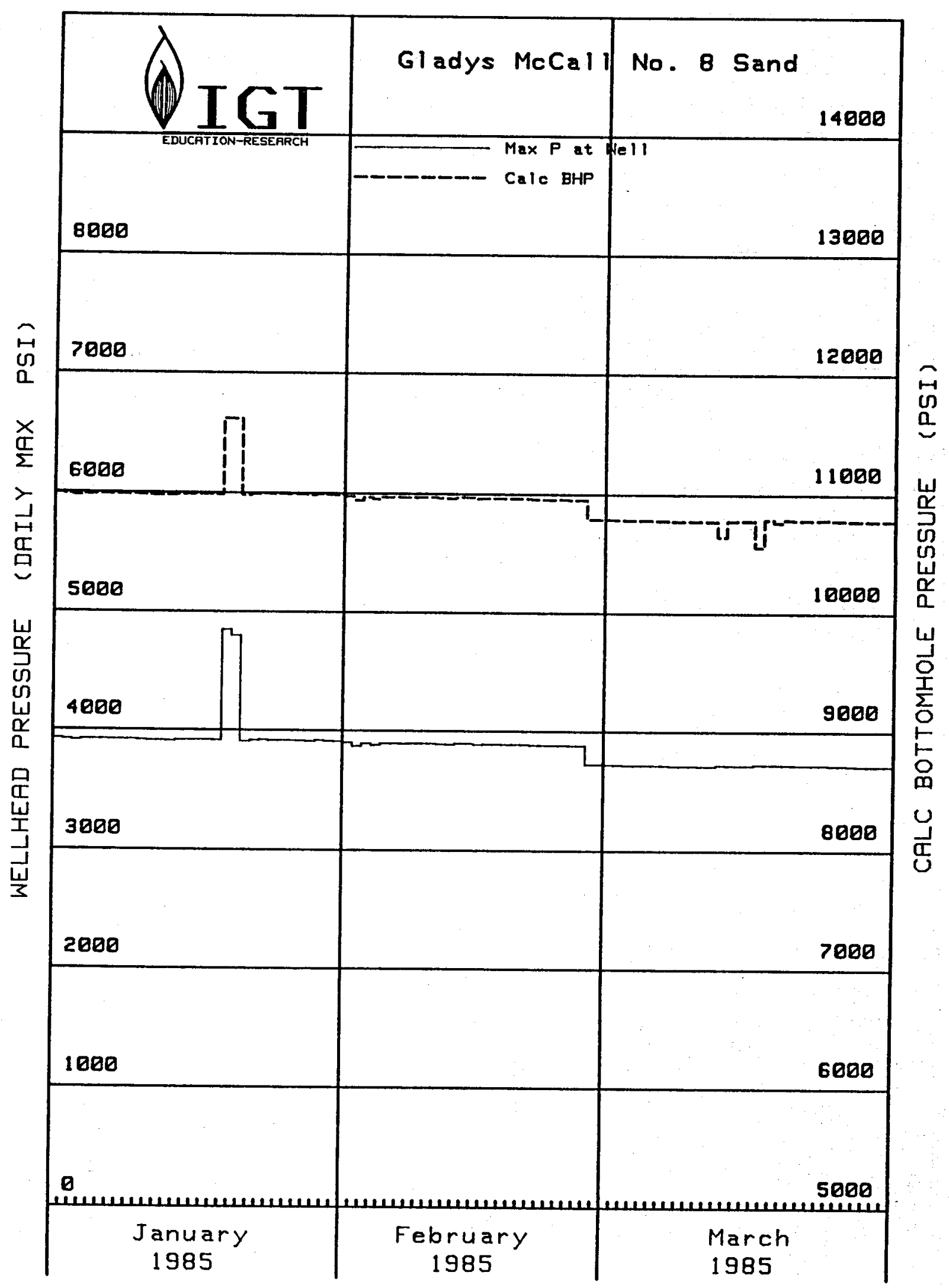

D-8
I NSTIT U T E
O F
G A S
T E C H N O L O G Y 
Flow Tests of the Gladys MCCall Well Through OCtober 1990

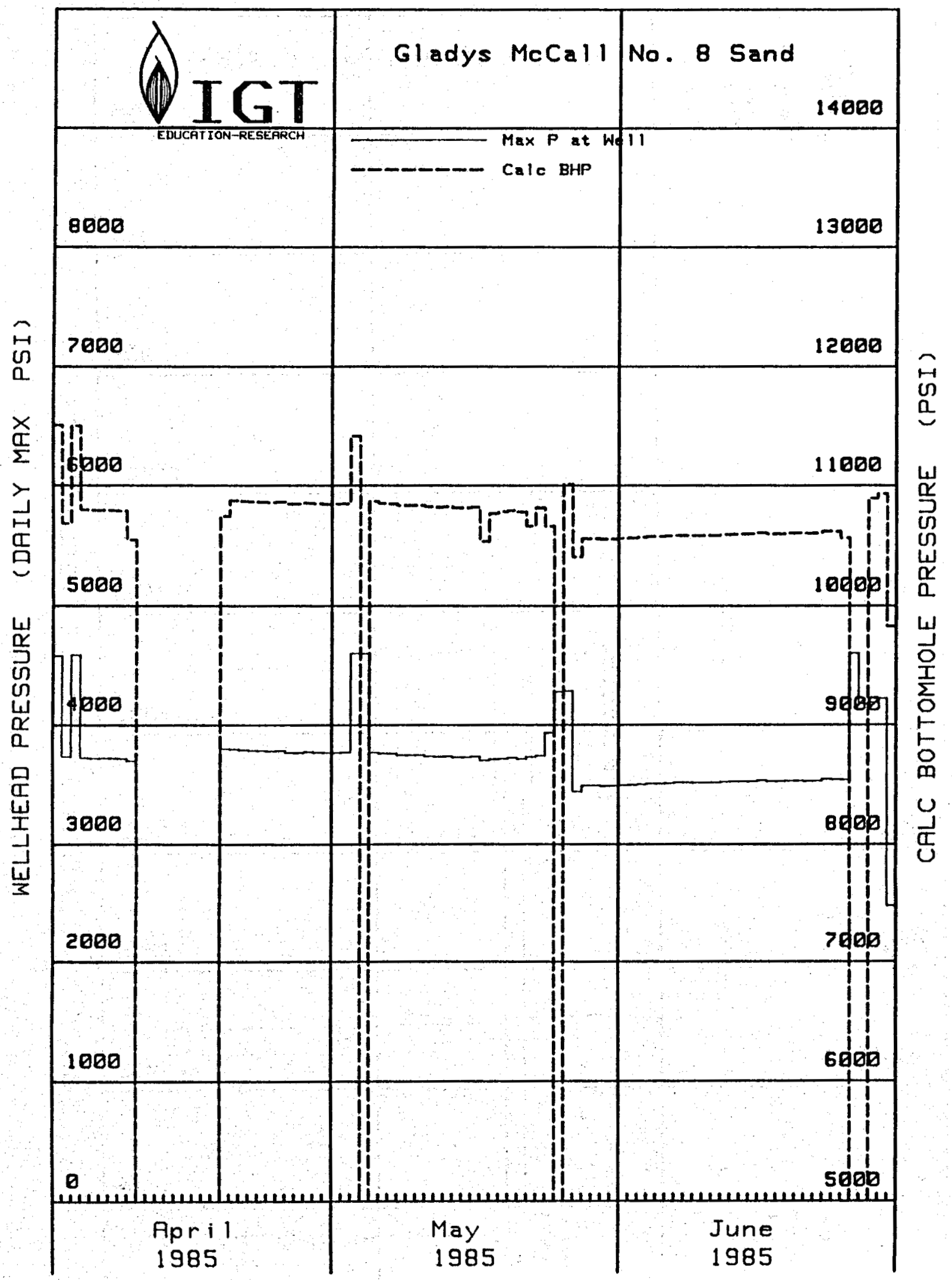

D-9
I NST T T U T
O. $F$
G A S
T E C H N O L O G Y 
Flow Tests of the Gladys MCCALl Well Through OCtober 1990

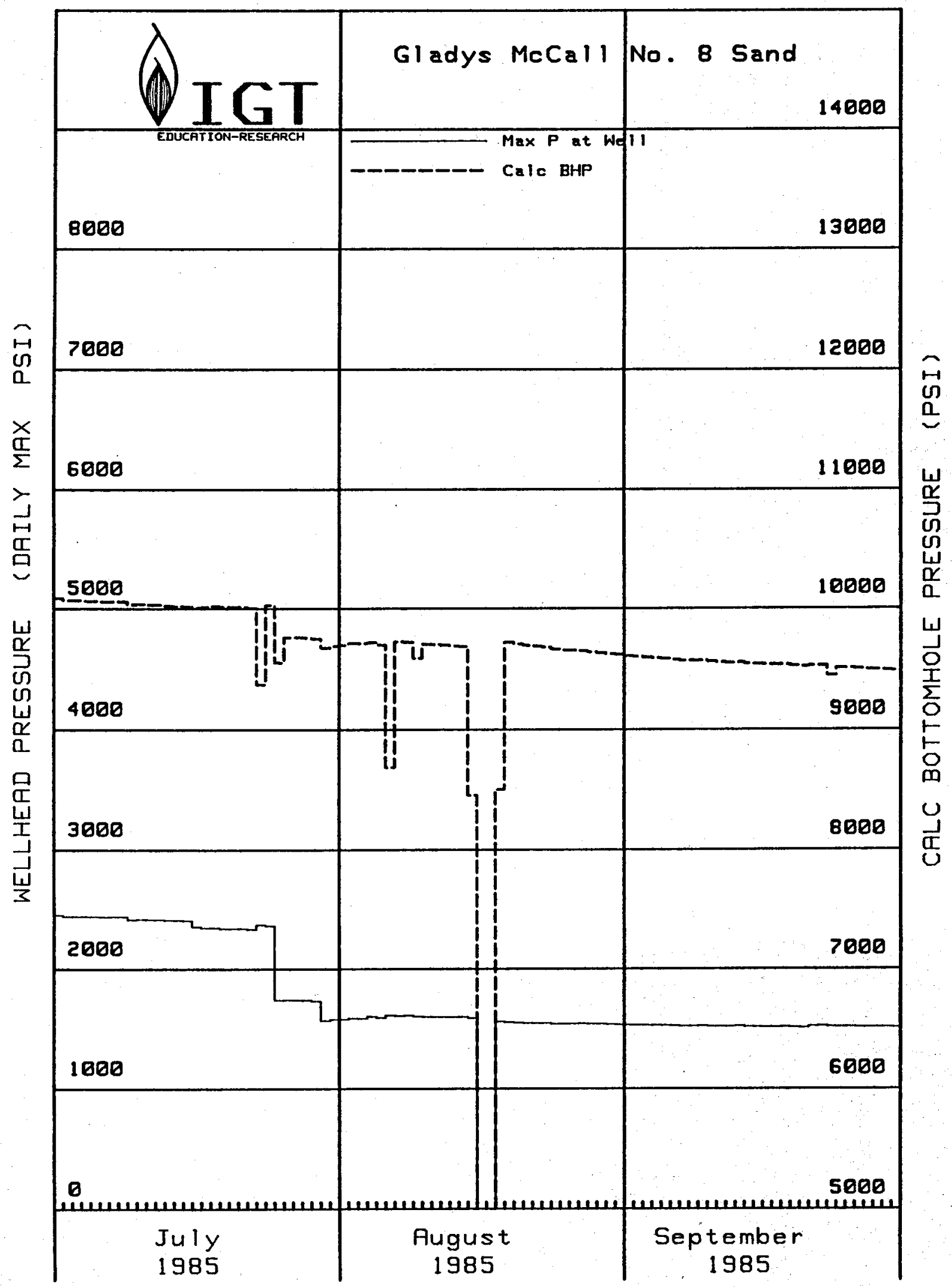

D-10 
Flow Tests of the Gladys MCCALl Well Through OCtober 1990

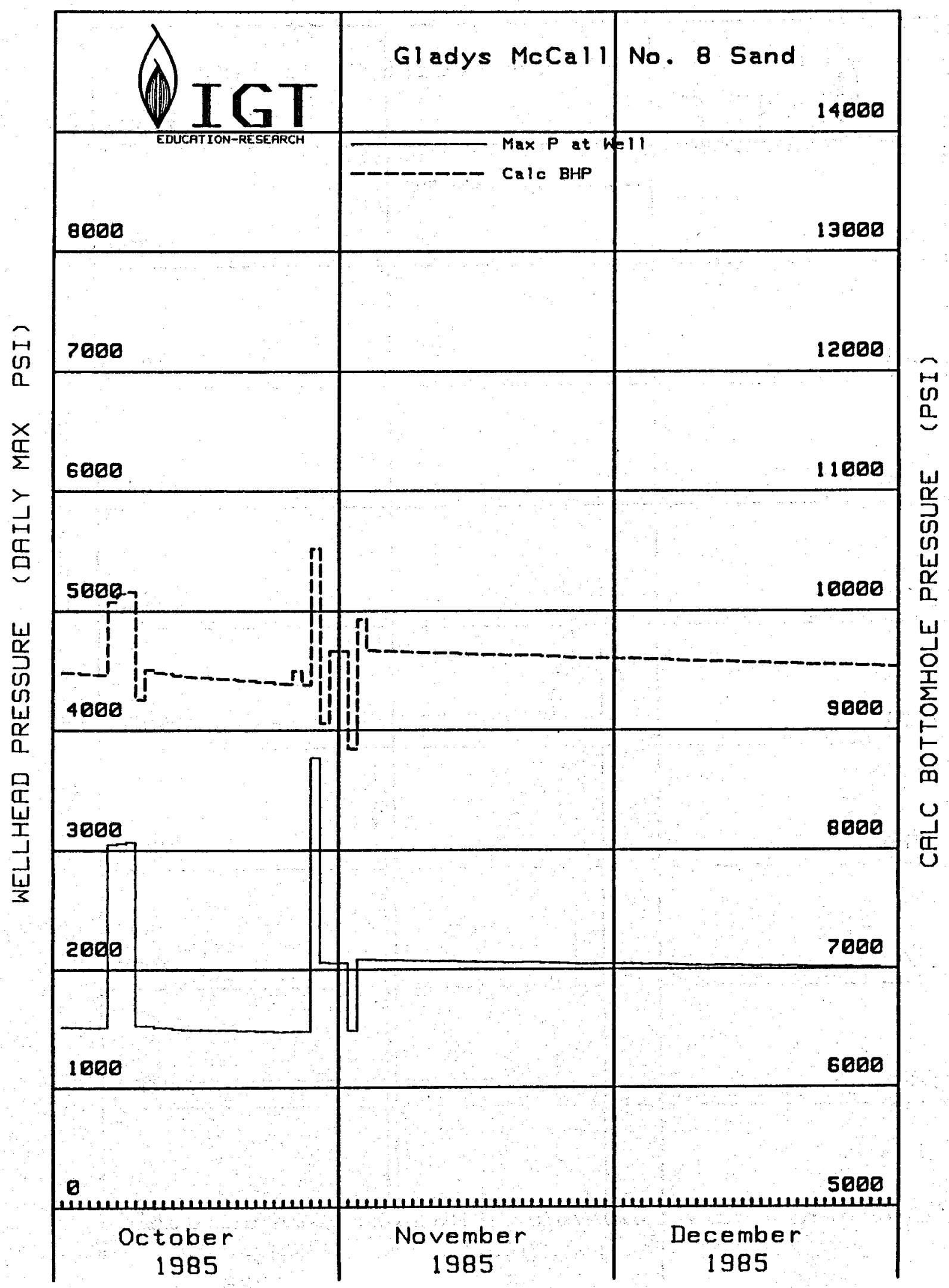

D-11
I N S T I T U T E
O F
G A. 5
TECHNO
L O G Y 
Flow TESTS OF the Gladys MCCall Well Through OCtOBer 1990

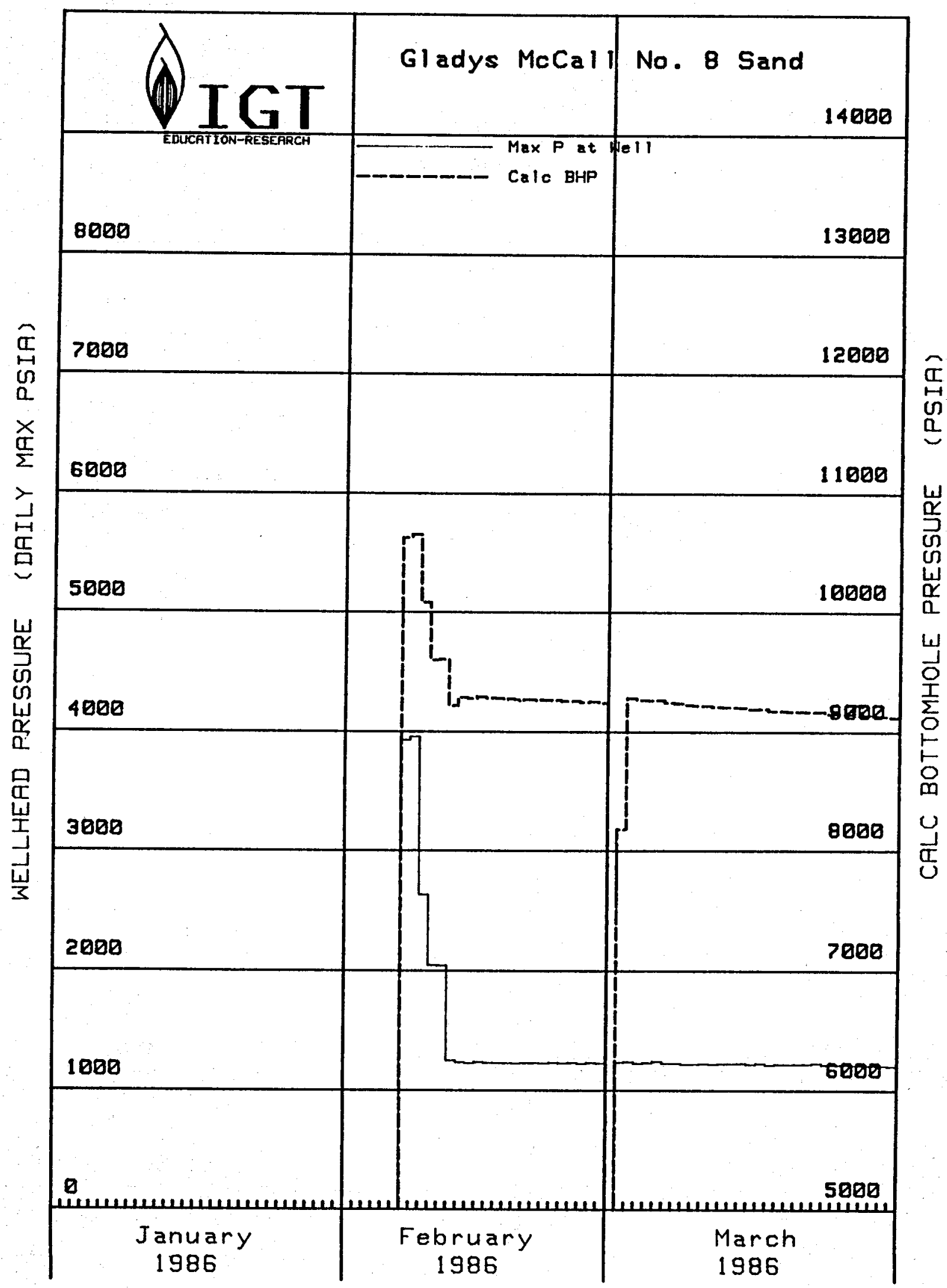

D-12

IN S T I T U T E $O$ OF G G A S T E C H N O L O G Y


Flow Tests of the Gladys MCCALl Well Through OCtober 1990

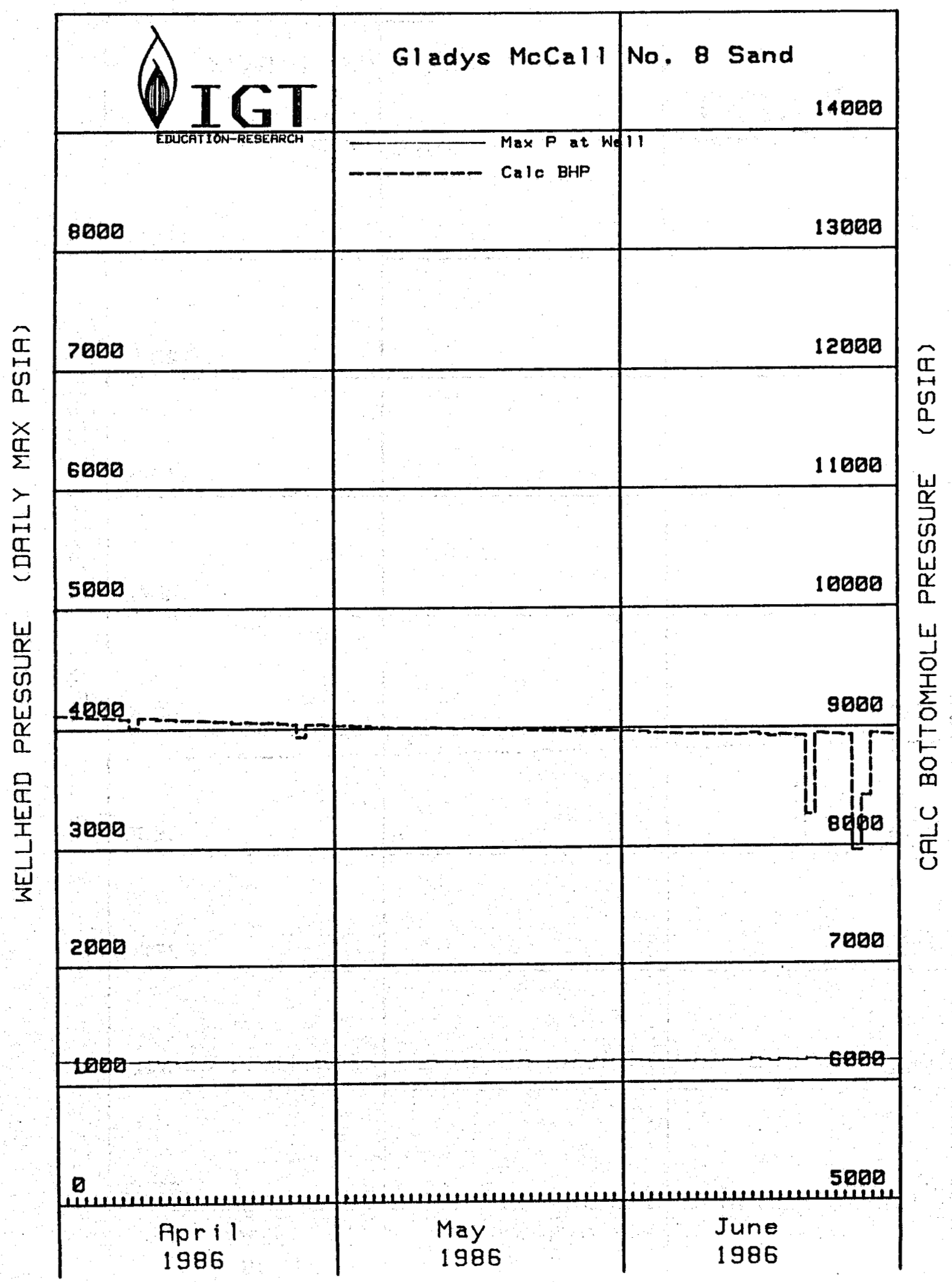

D-13
I N S T I T U T E
O F
G A S
T. E C H N O L O 
Flow Tests of the Gladys MCCALl Well Through OCtober 1990

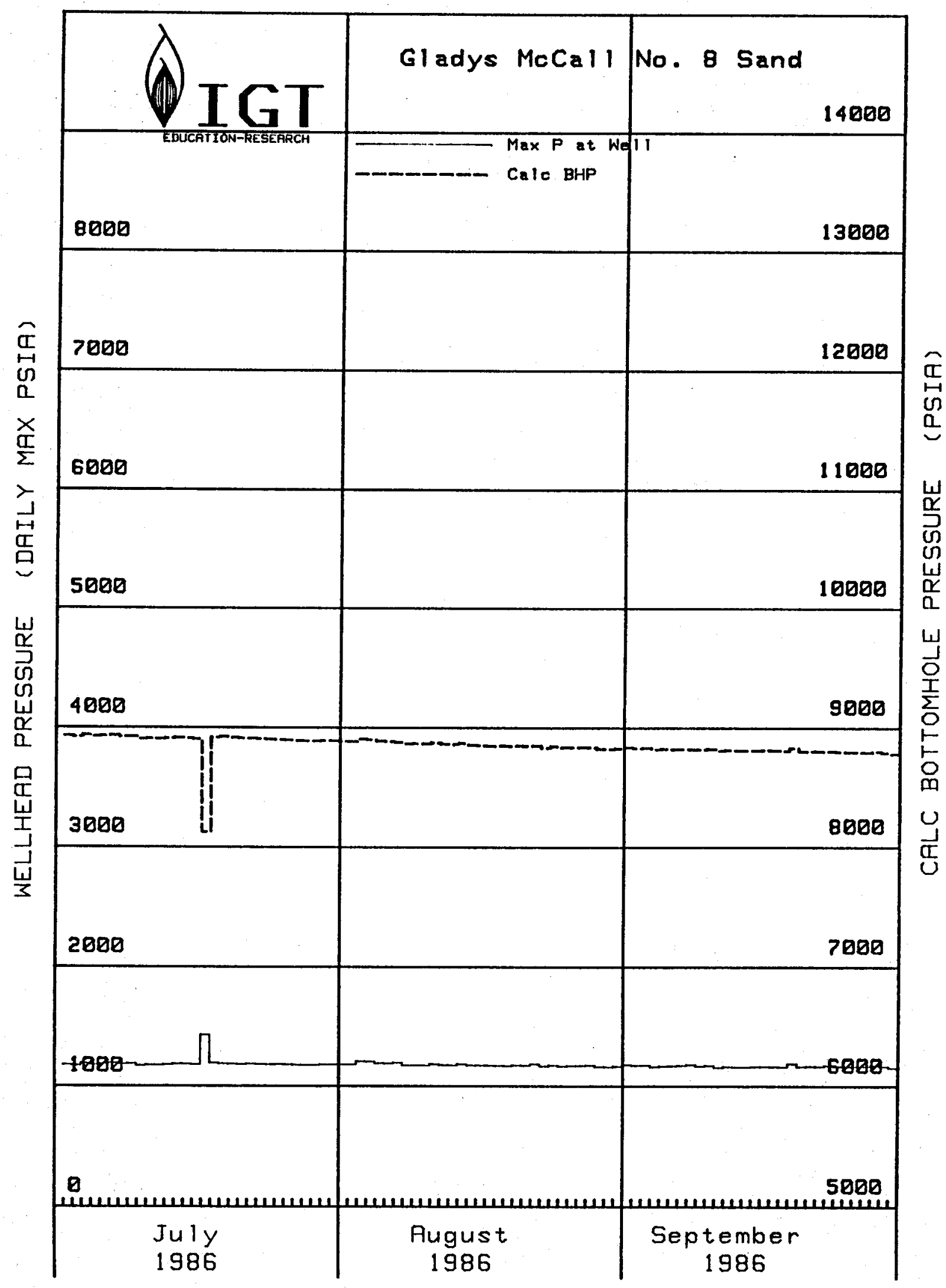

D-14
I N S T I T U T
$0 \mathrm{~F}$
G A S
T E C H N O
L O G Y 
Flow TESTS OF THE GLAdys MCCALL Well THROUgh OCTOBER 1990

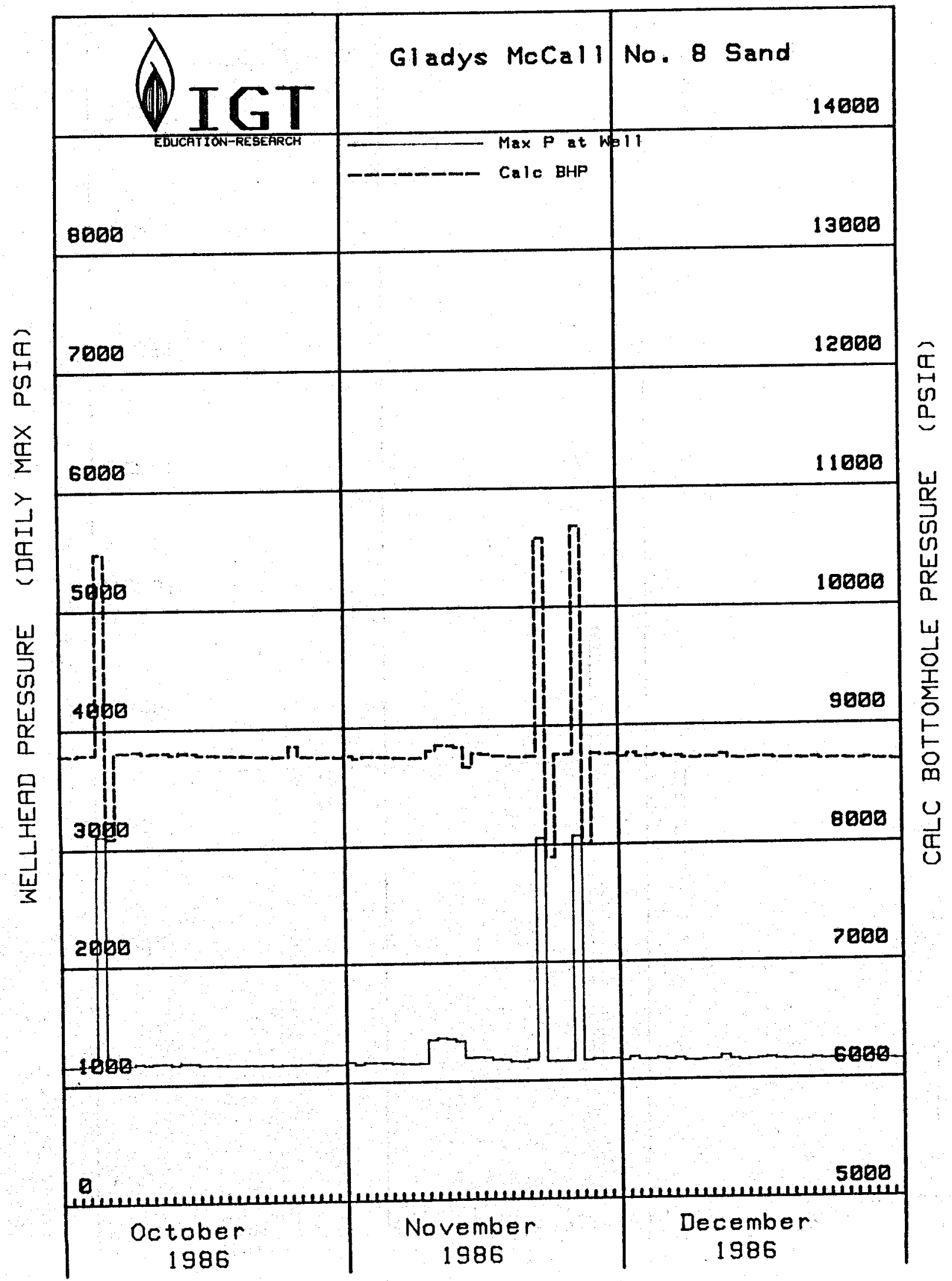

D-15
O F
G A S
T E C H N O L O G Y 
Flow tests of the Gladys MCCall Well Through OCtober 1990

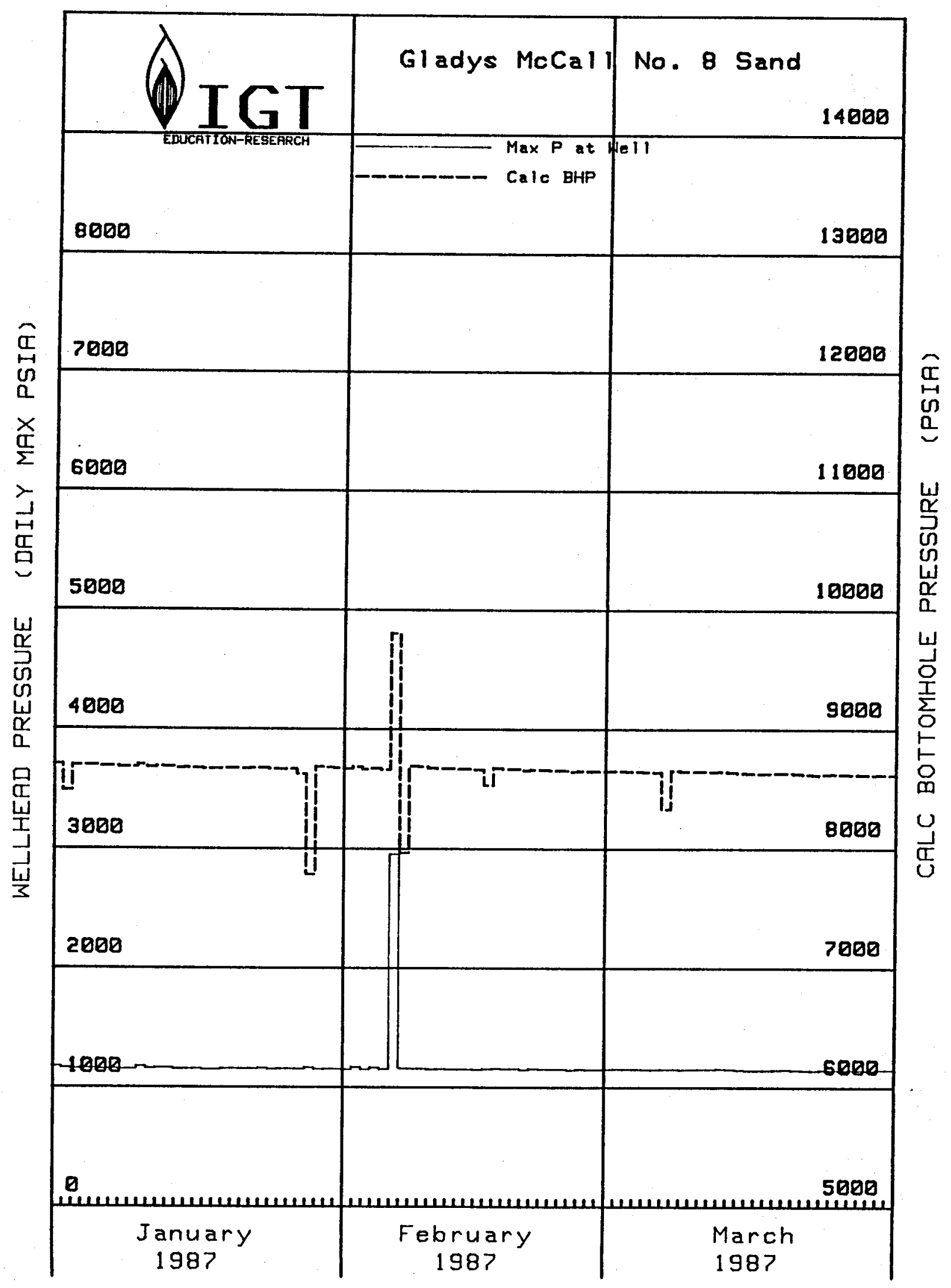

D-16
I N S T I T U T E
O F
G A S
T E C H N O L O G 
FLOW TESTS OF THE GLAdYS MCCALL Well THROUGH OCTOBER 1990

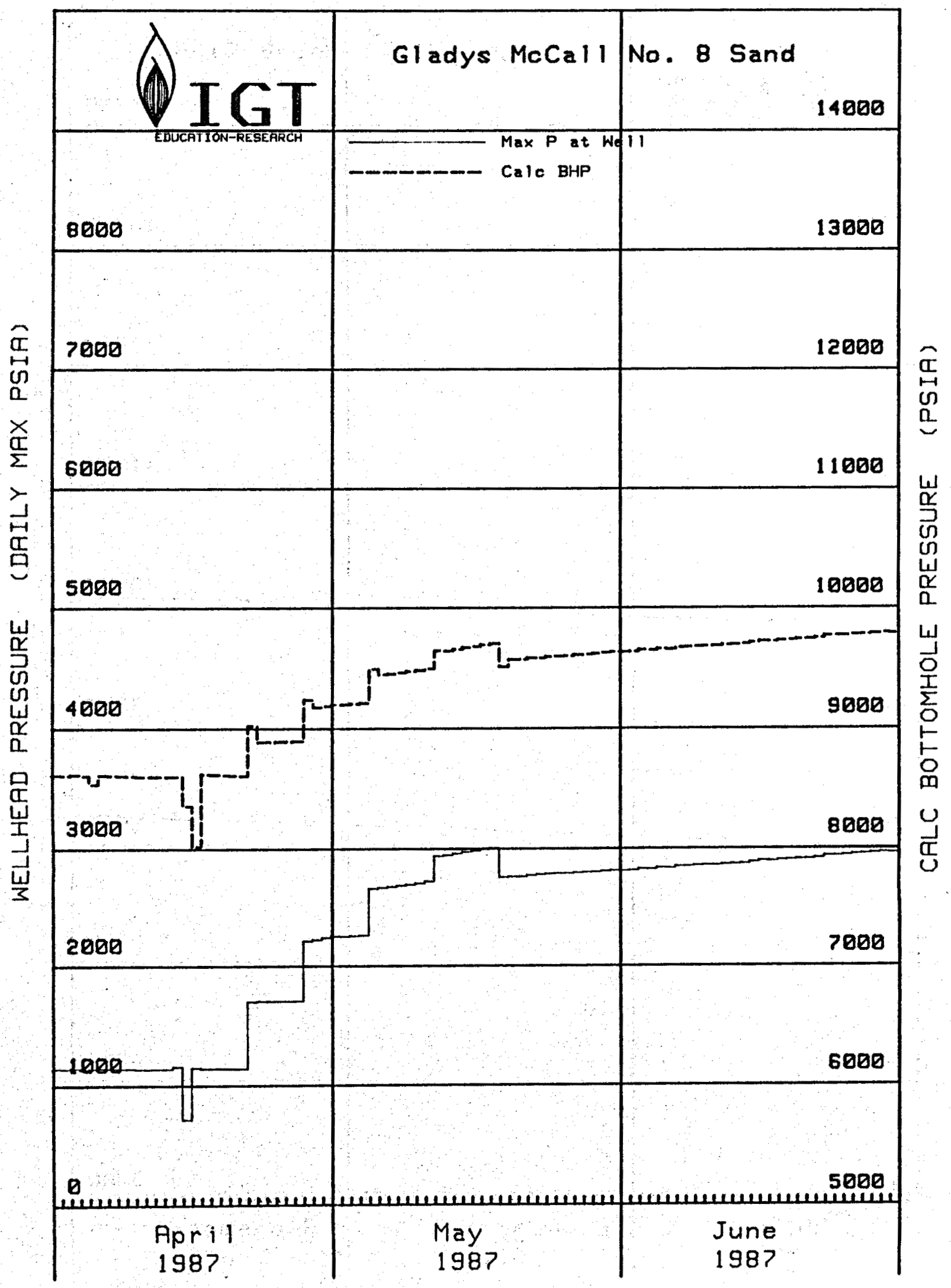

D-17
INST I T U T E
o $F$
G A S
T E C H N O L O G Y 
Flow Tests of the Gladys MCCall Well Through OCtober 1990

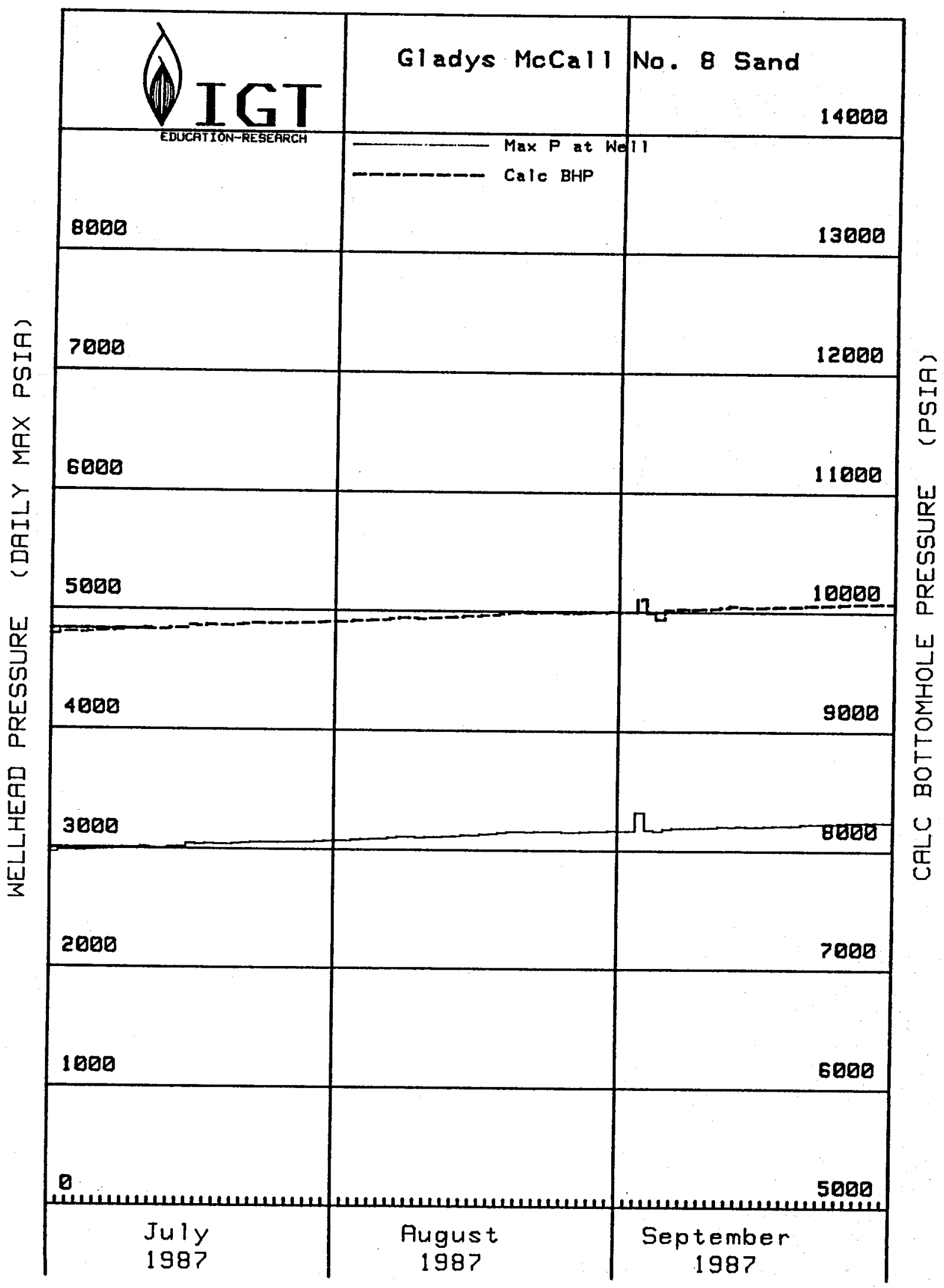

D-18

I NS T I T U TE OF G A S T T C H N O L O G Y 
FLOW TESTS OF THE GLADYS MCCALL Well THROUgh OCTOBER 1990

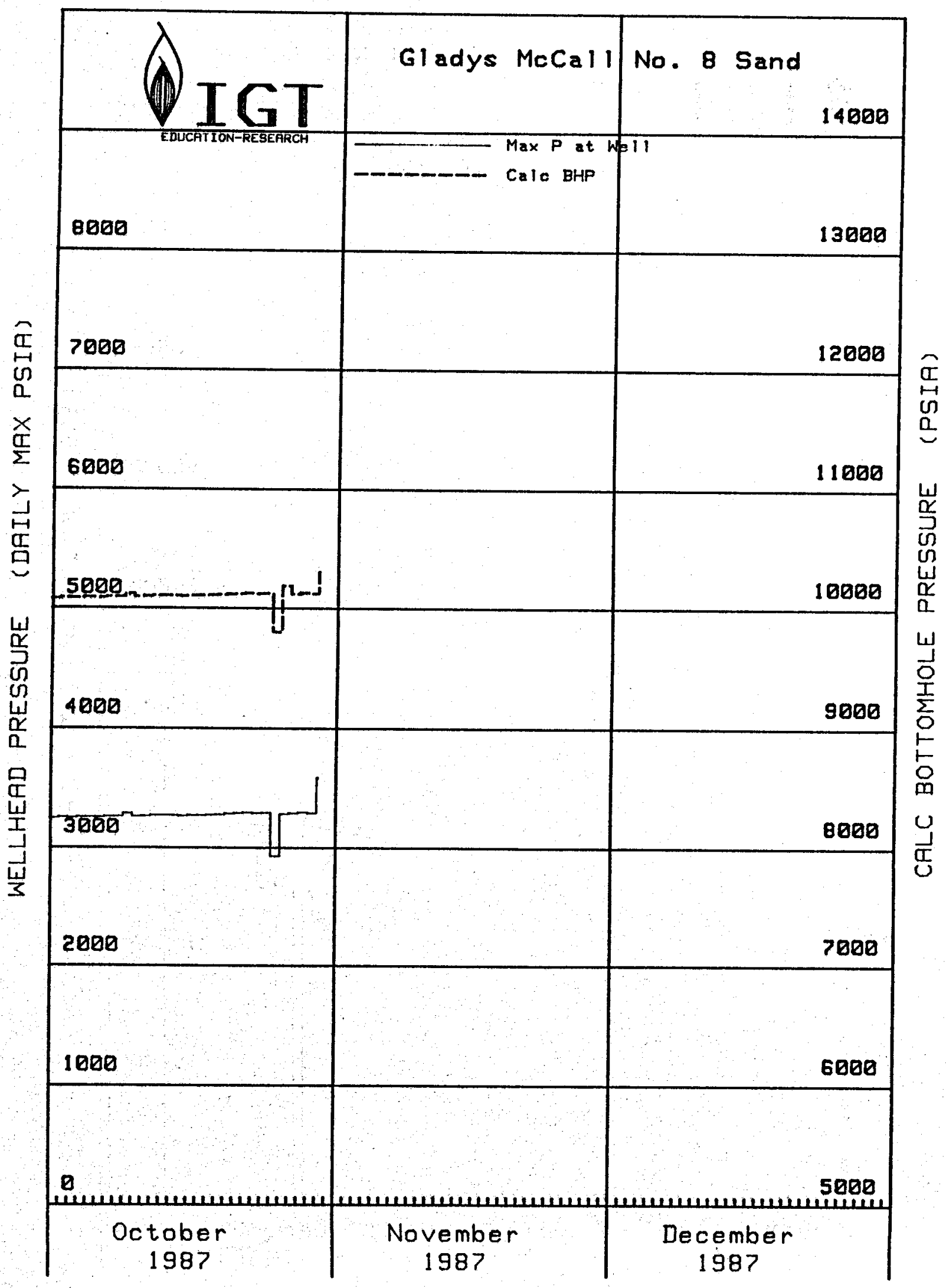

D-19
INSTITUTE
O F
G. A S
TECHNOLOG Y 
Flow Tests of the Gladys MCCall Well Through OCtober 1990

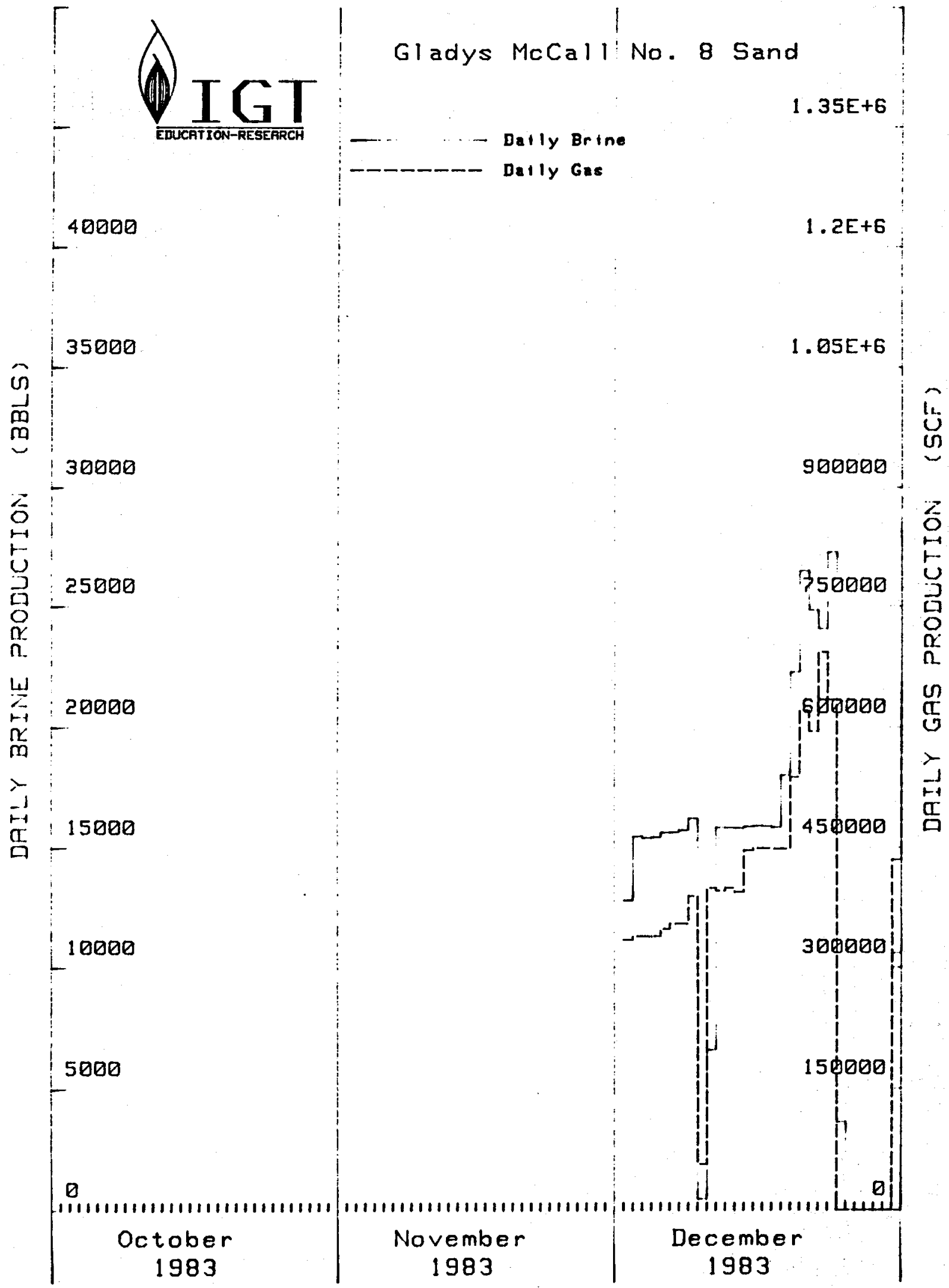

D-20 
FLOW TESTS OF THE GLADYS MCCALL WELL THROUGH OCTOBER 1990

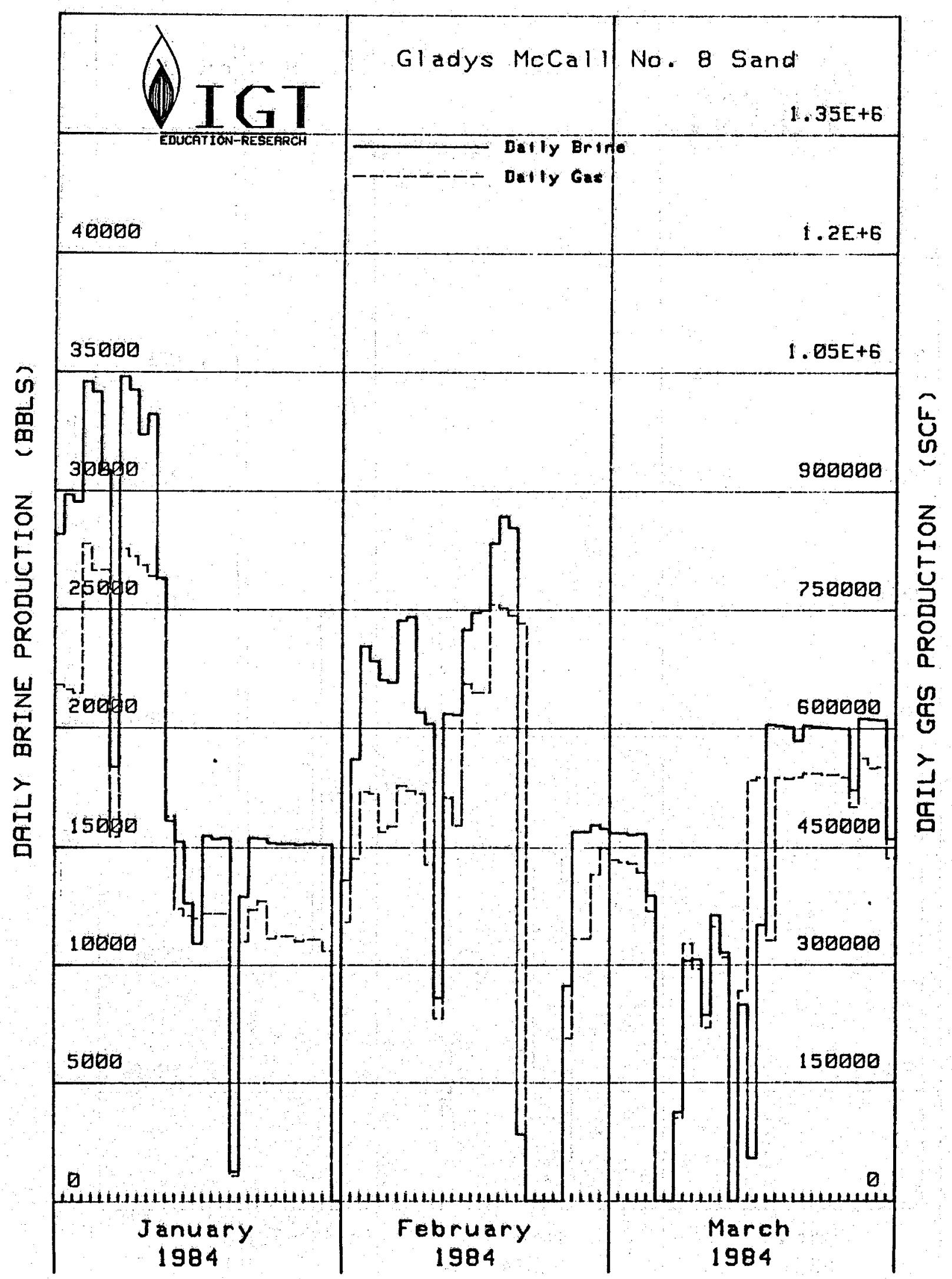

D-21
I N S T I T U T E
O F
G A S
TE C H N O L O G Y 
Flow TeStS OF THE Gladys MCCALl Well THROUgh OCTOBER 1990

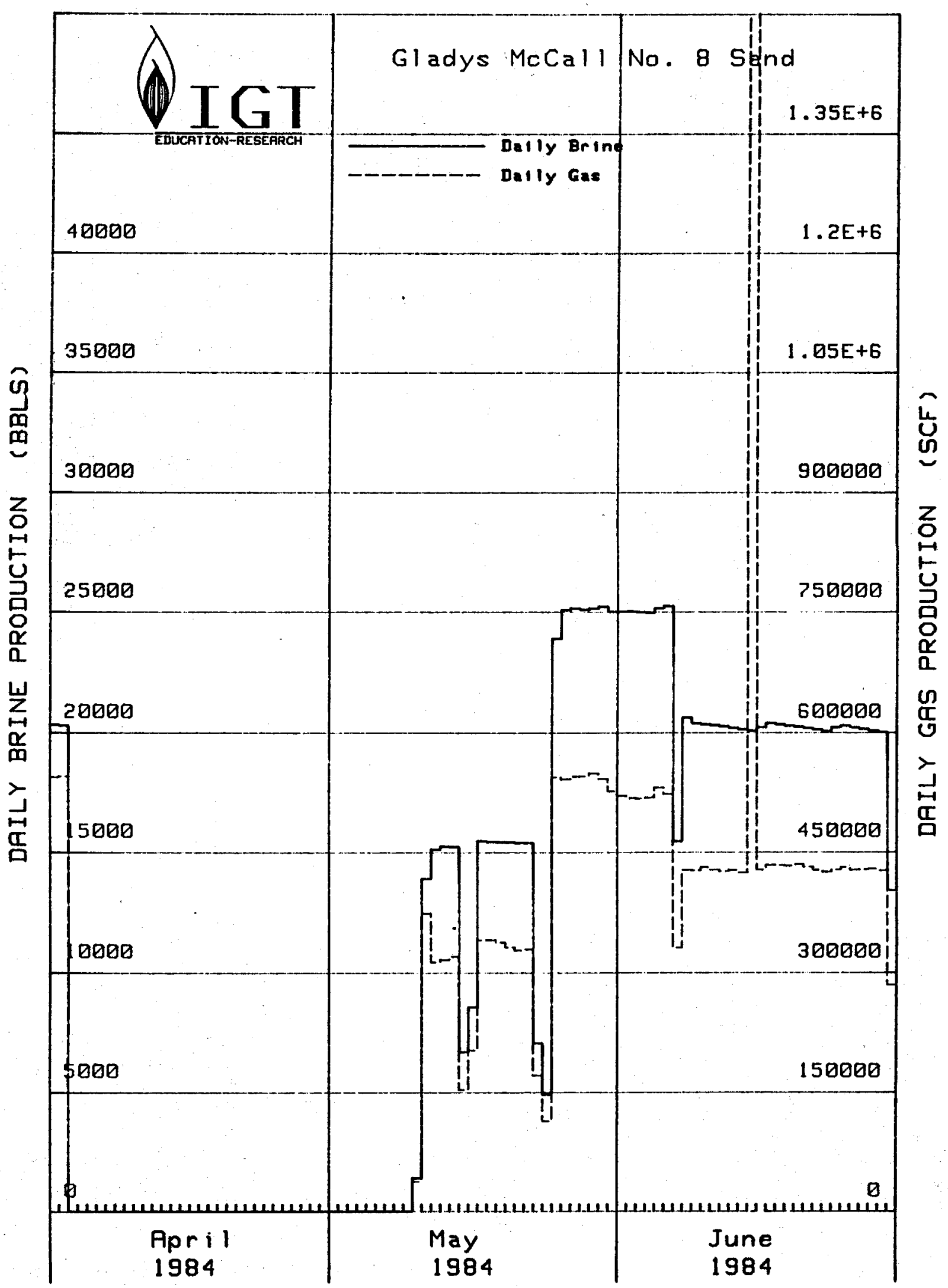

D-22

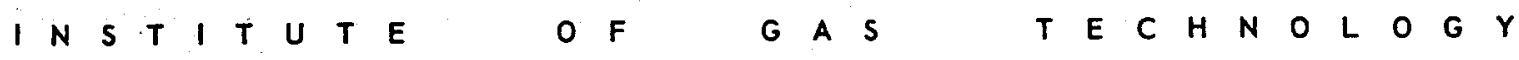


Flow Tests of the Gladys McCall Well Through OCtober 1990

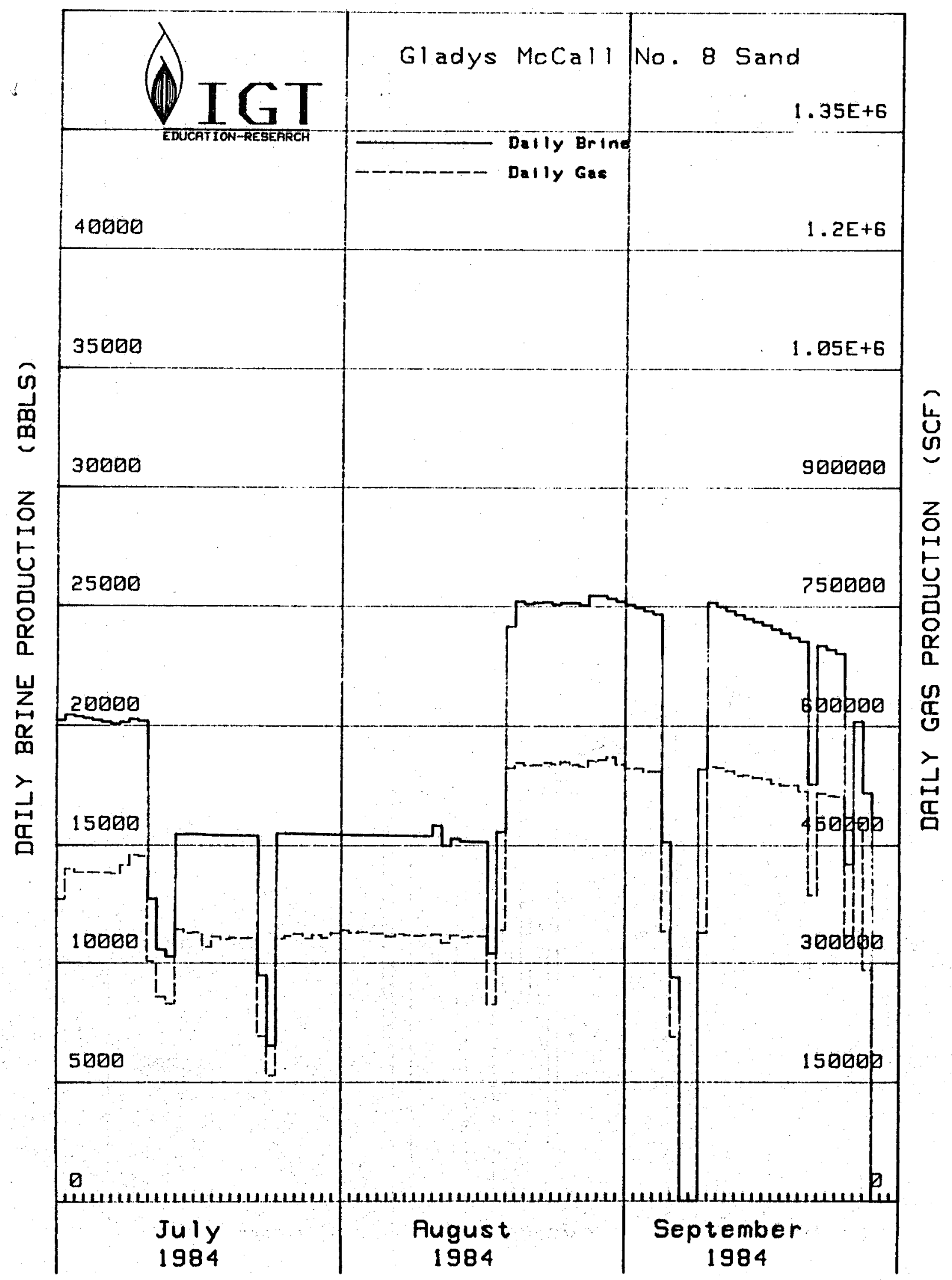

D-23
$\begin{array}{llllllllll}\text { I } & N & S & T & \text { I } & \text { T } & \text { U } & \text { T } & E\end{array}$
OF G A S
T E C H N O L O G Y 
Flow tests of the Gladys MCCall Well Through OCtober 1990

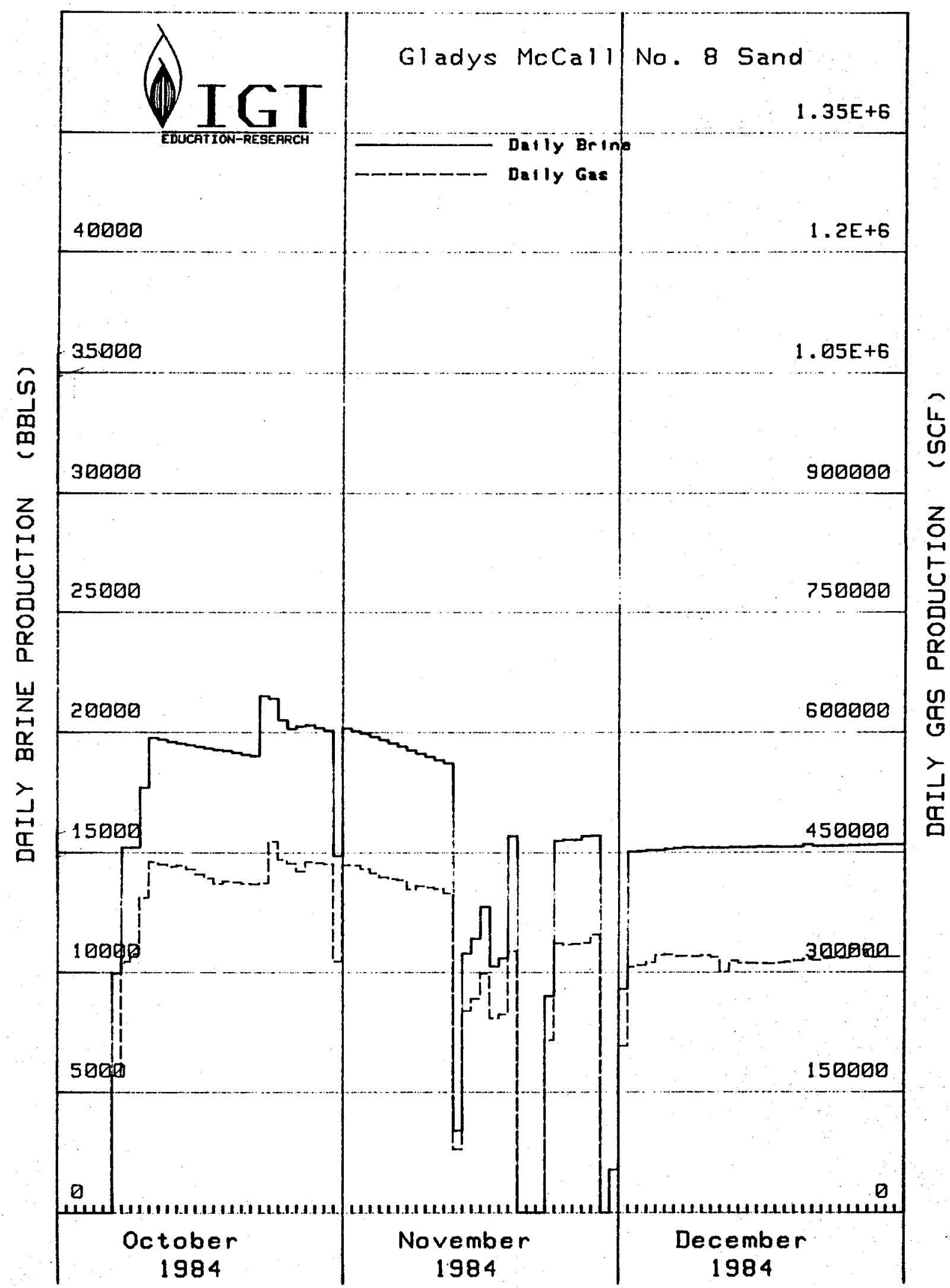

D-24

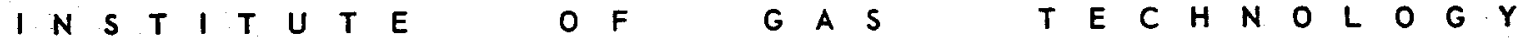




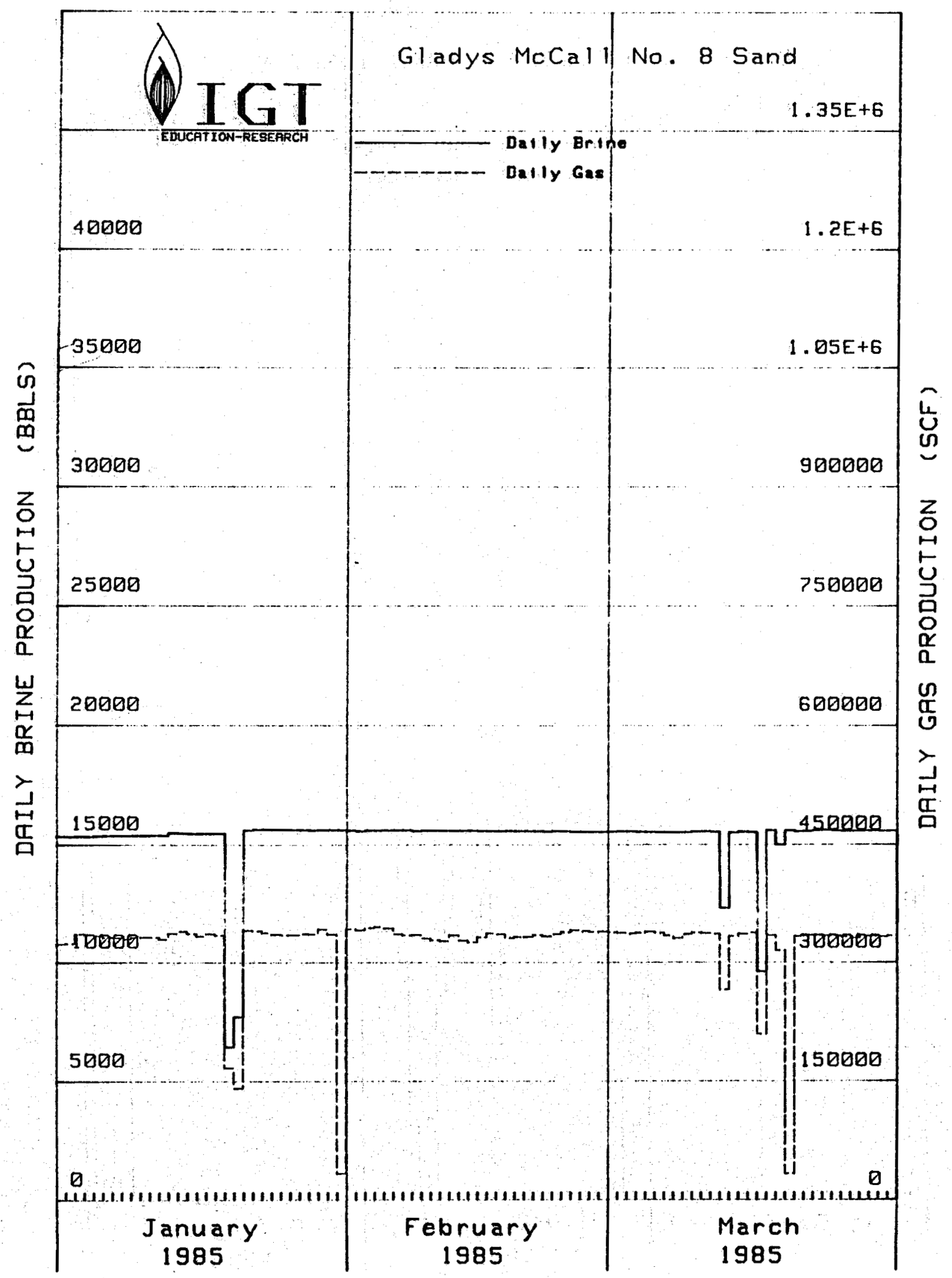

D-25
I N S T I T U T E
O F
G A S
T E C H N O L O G Y 
Flow Tests of the Gladys MCCall Well Through OCtober 1990

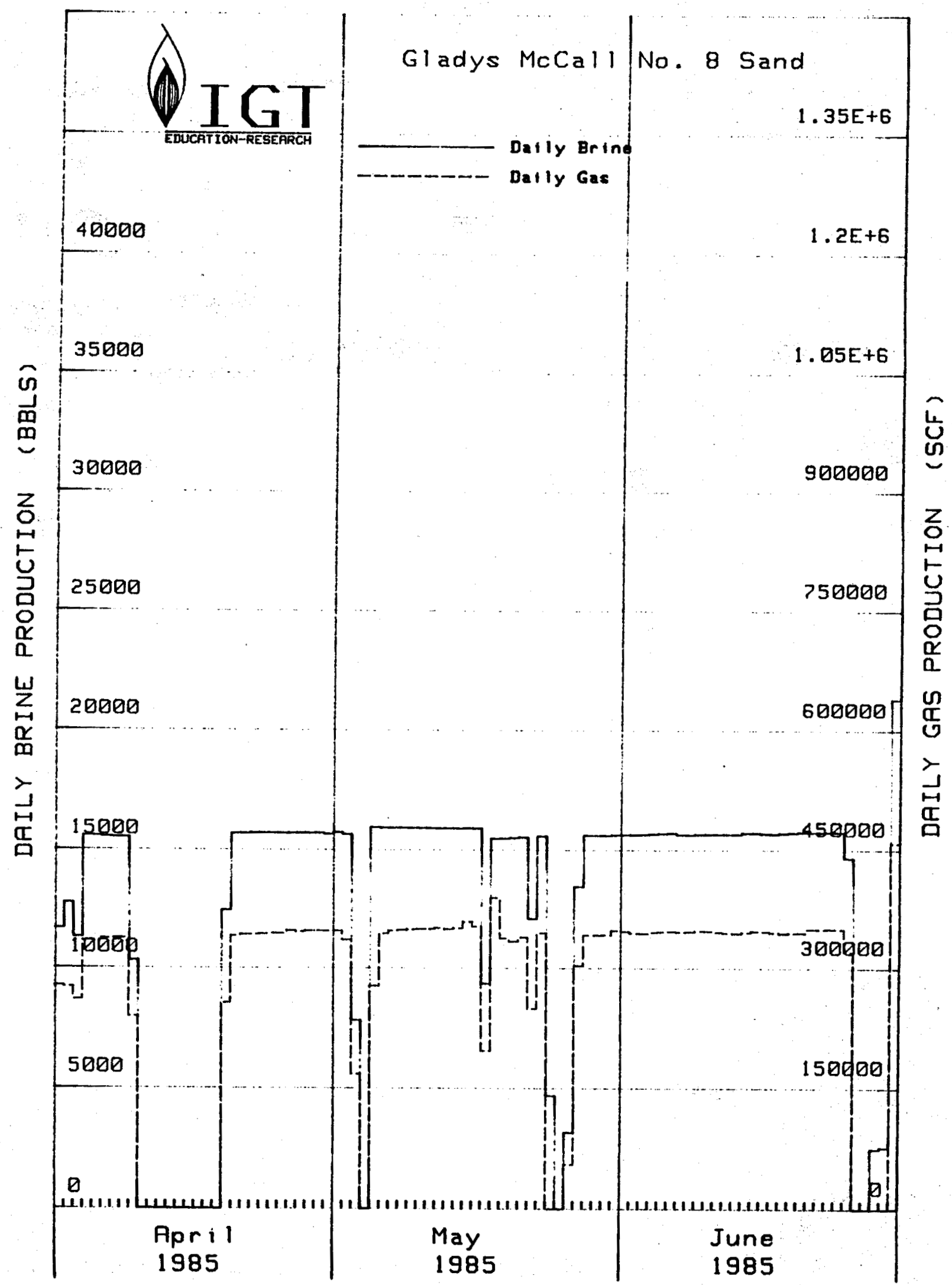

D-26

INSTITUTE G G A S TECHNOLOG Y 
FLOW TESTS OF THE GLADYS MCCALL WELL THROUgh OCTOBER 1990

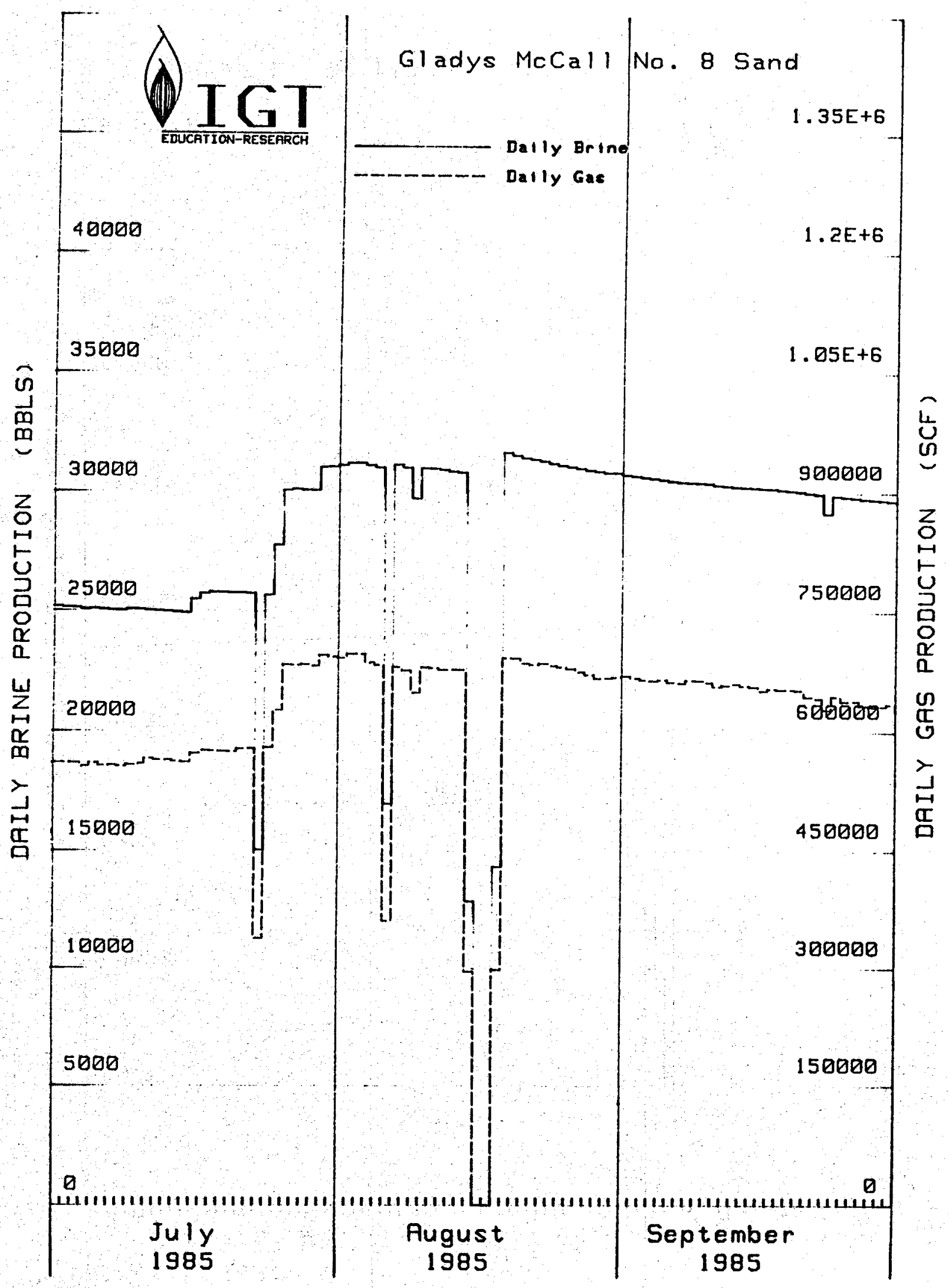

D-27
INST ITUTE
$0 \mathrm{~F}$
G A S
TE CHN O LO G Y 


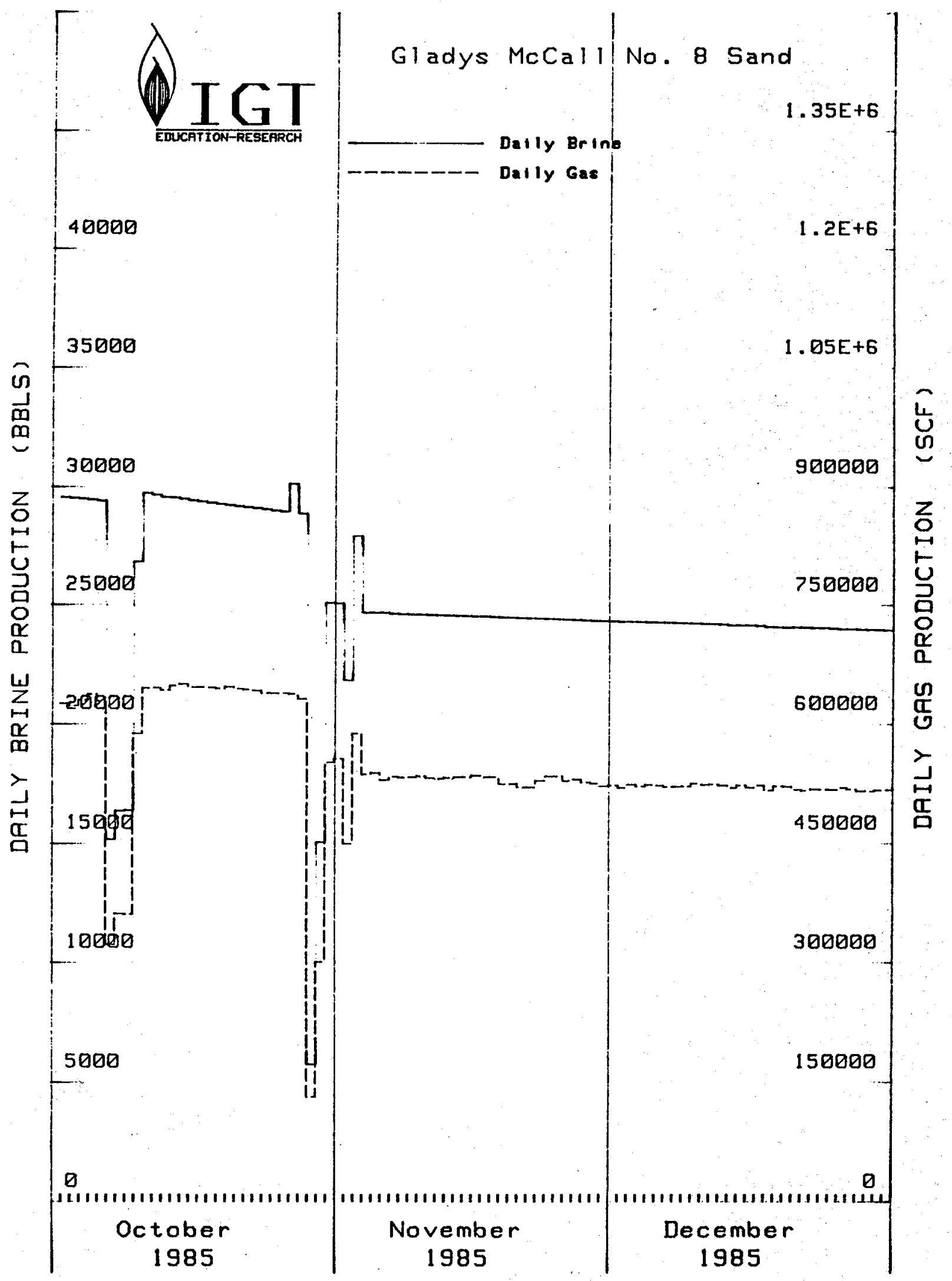

D-28 
Flow Tests of the Gladys MCCALL Well Through OCtober 1990

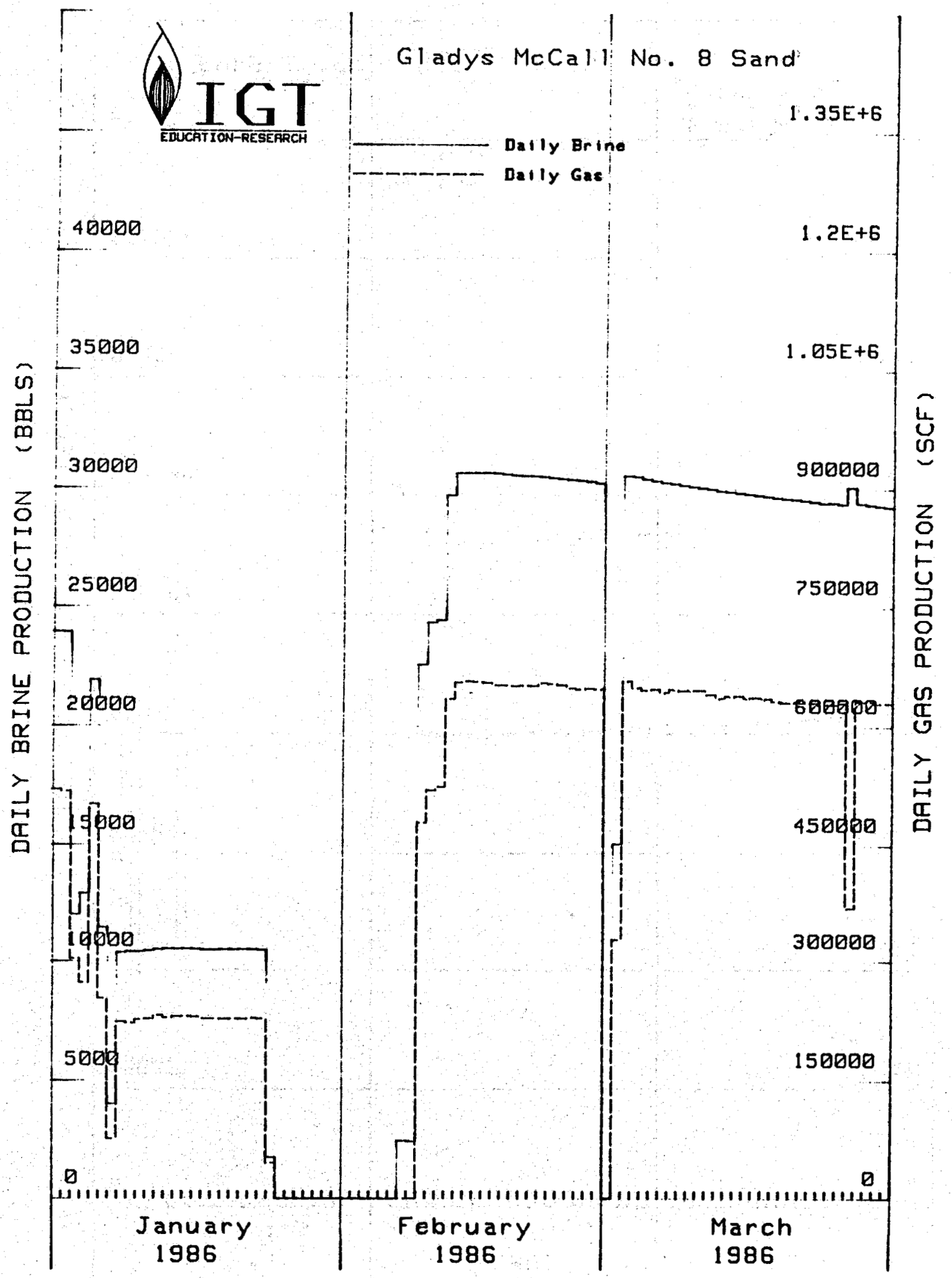

D-29
IN S T I U T E
O F
G A S
T E C H N O L O G Y 
Flow Tests of the Gladys MCCALl Well Through OCtober 1990

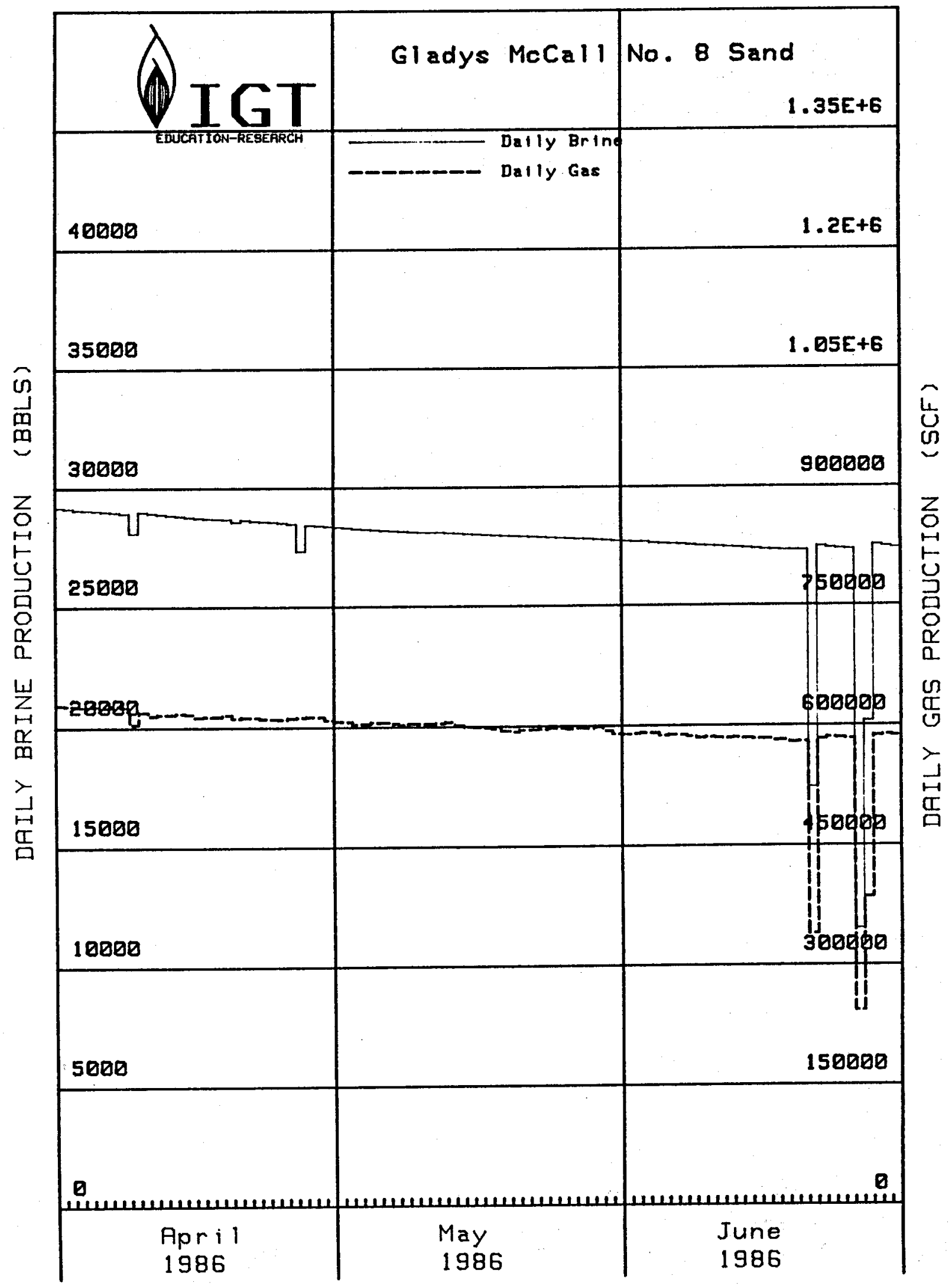

D-30
I N S T I T U T E
O $F$
G A S
T E C H 
FLOW TESTS OF THE GLADYs MCCALl Well Through OCTOBER 1990

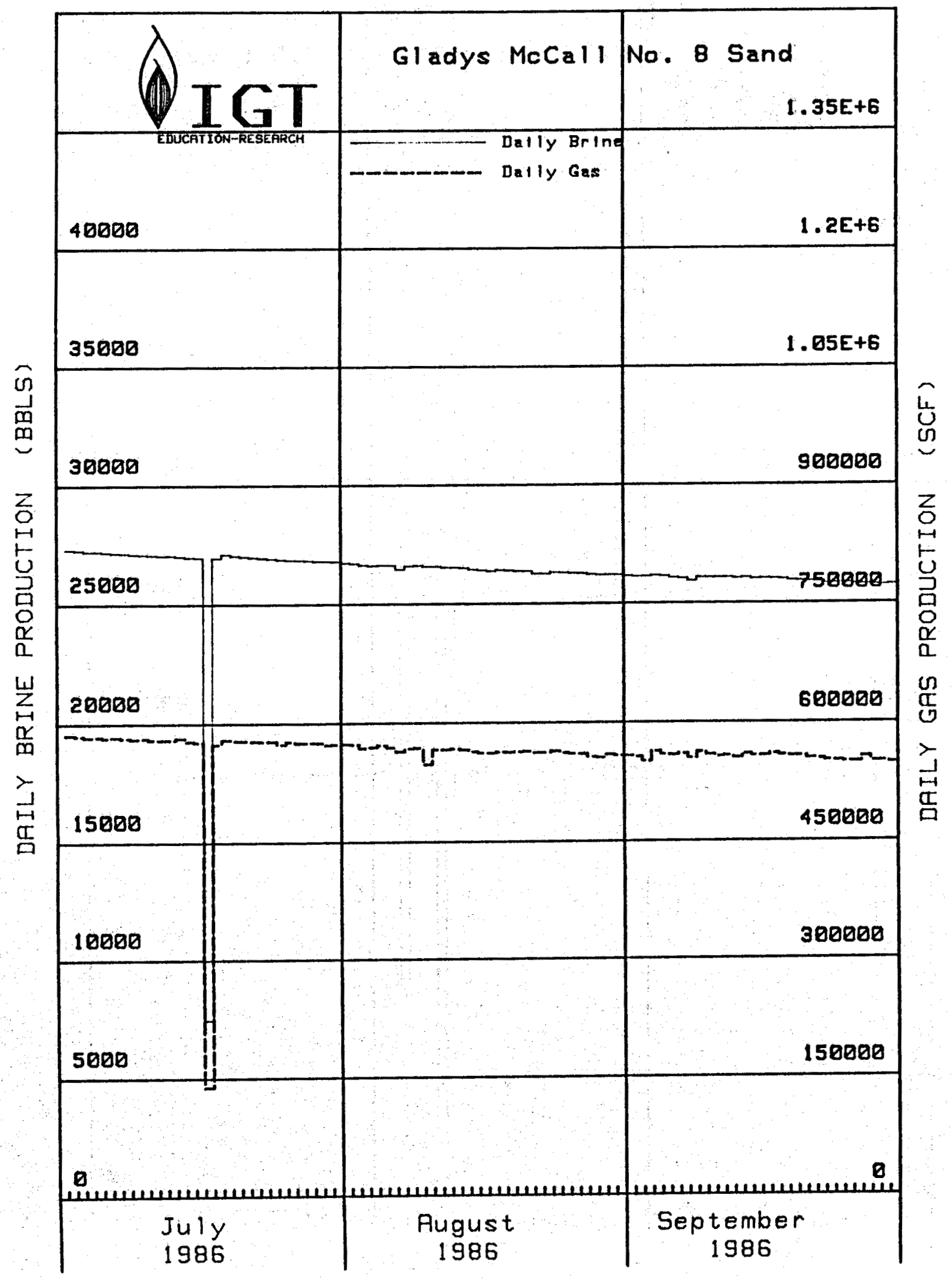

D-31
INSTITUTE
o $F$
G A S
TECH NOLOG Y 
Flow Tests of the Gladys MCCall Well Through OCtober 1990

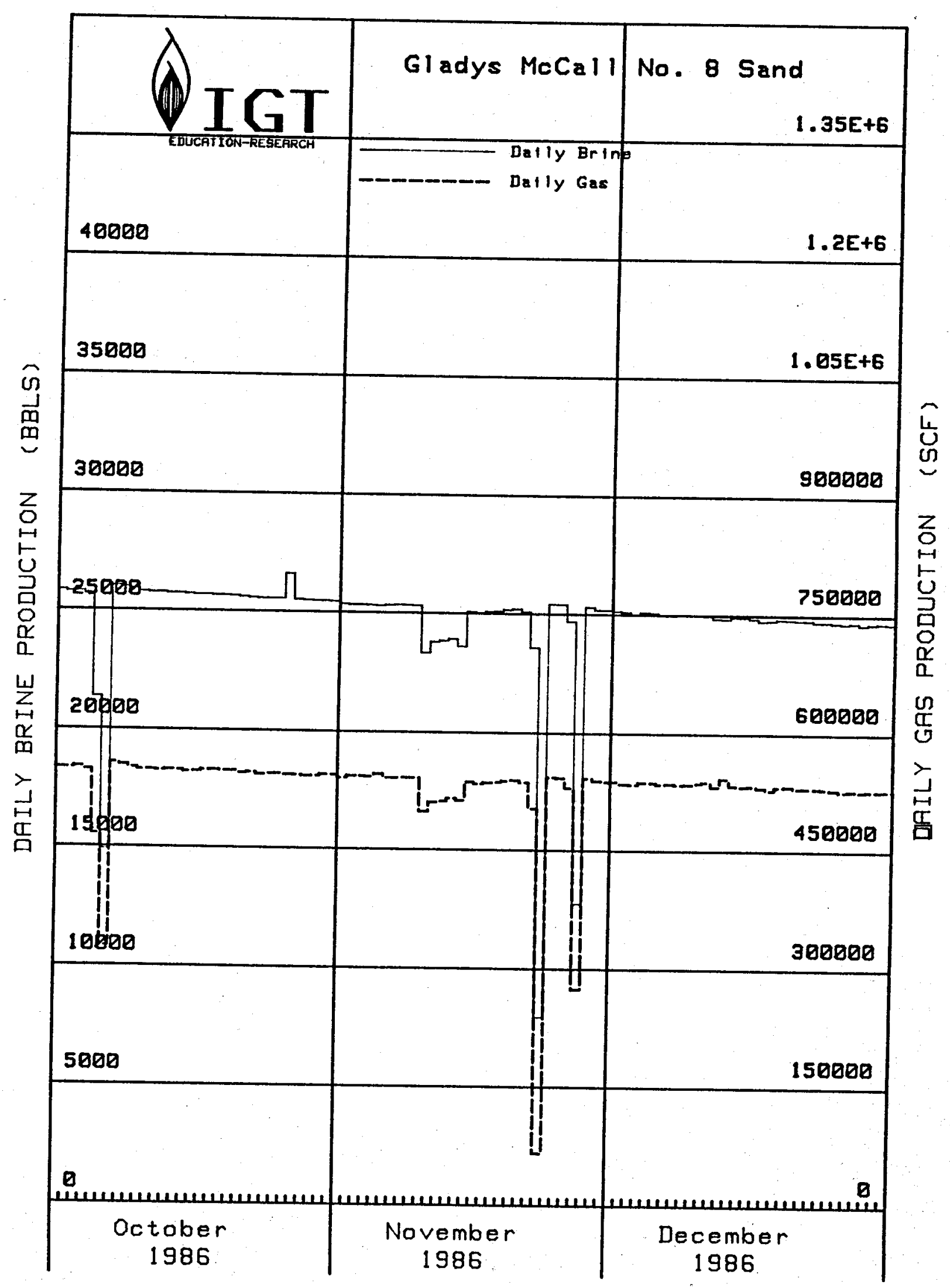

D-32
I NS T I T U T E
O F
G A $S$
T E C H N 
FLOW TESTS OF THE GLADYS MCCALL Well THROUGH OCTOBER 1990

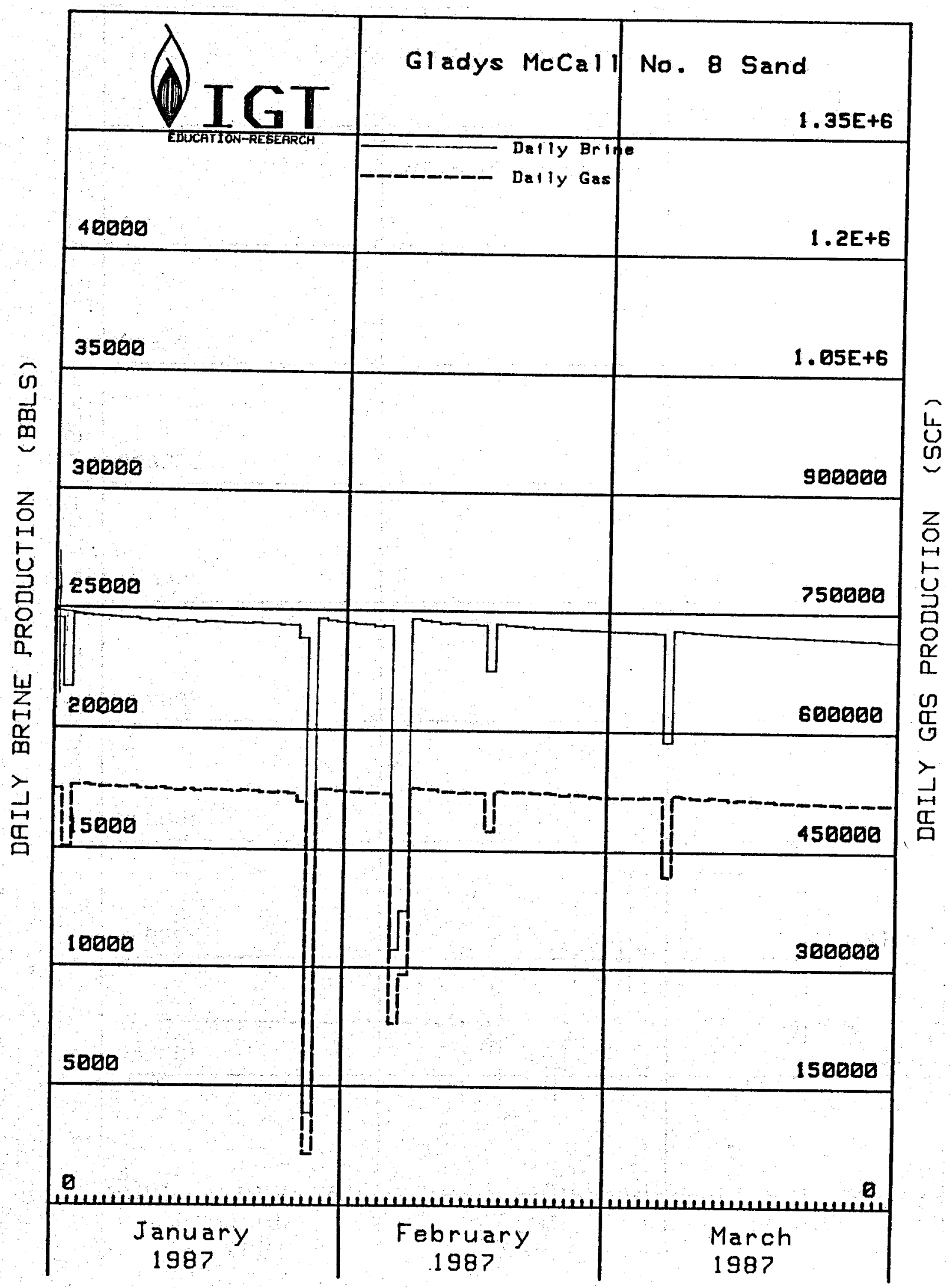

D-33

INSTITUTE OF GAS TECHNOLOG Y 
Flow TESTS OF THE Gladys MCCALL Well Through OCTOBER 1990

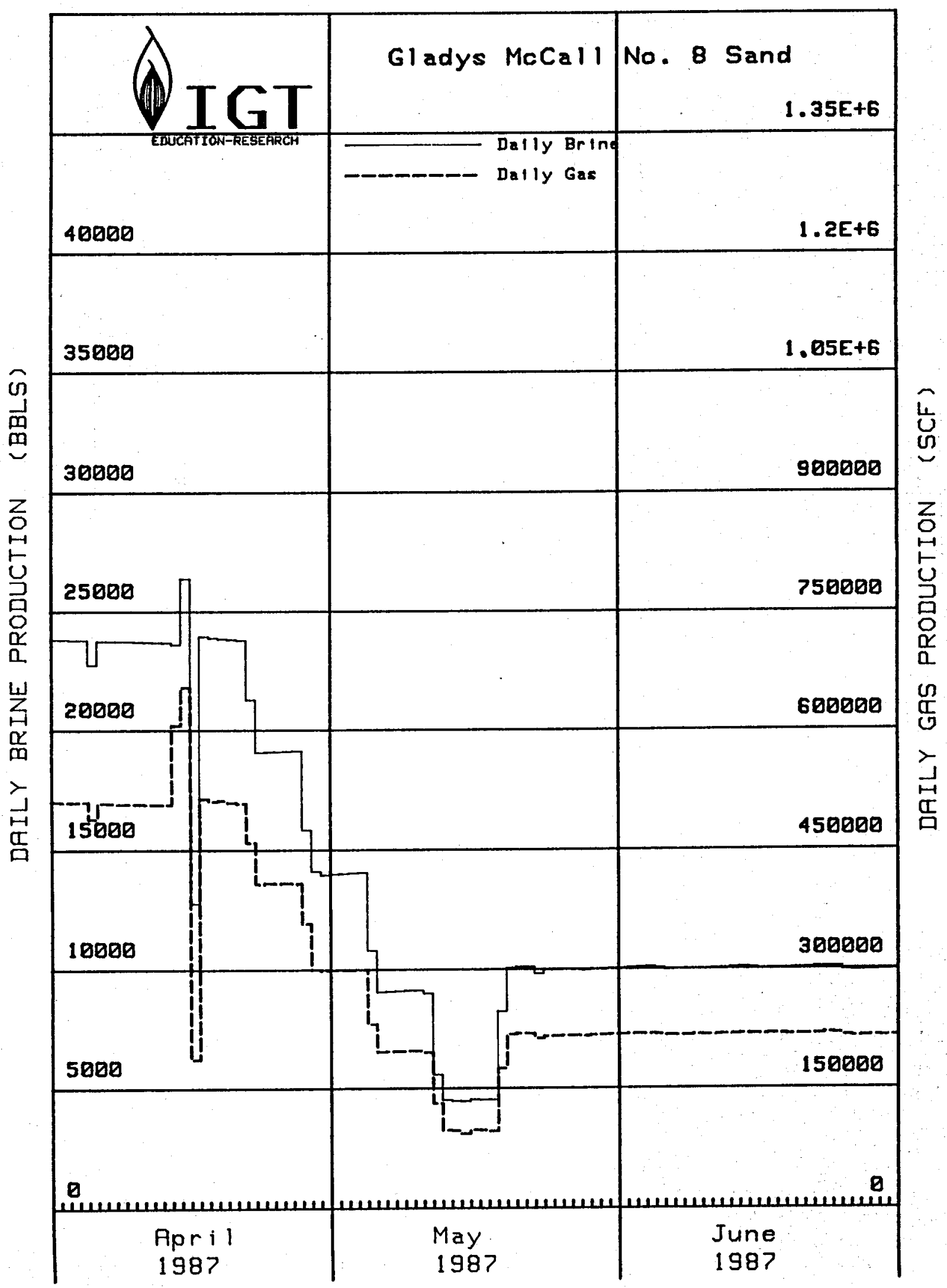

D-34 
FLow TESTS OF THE GLADYS MCCALL Well Through OCTOBER 1990

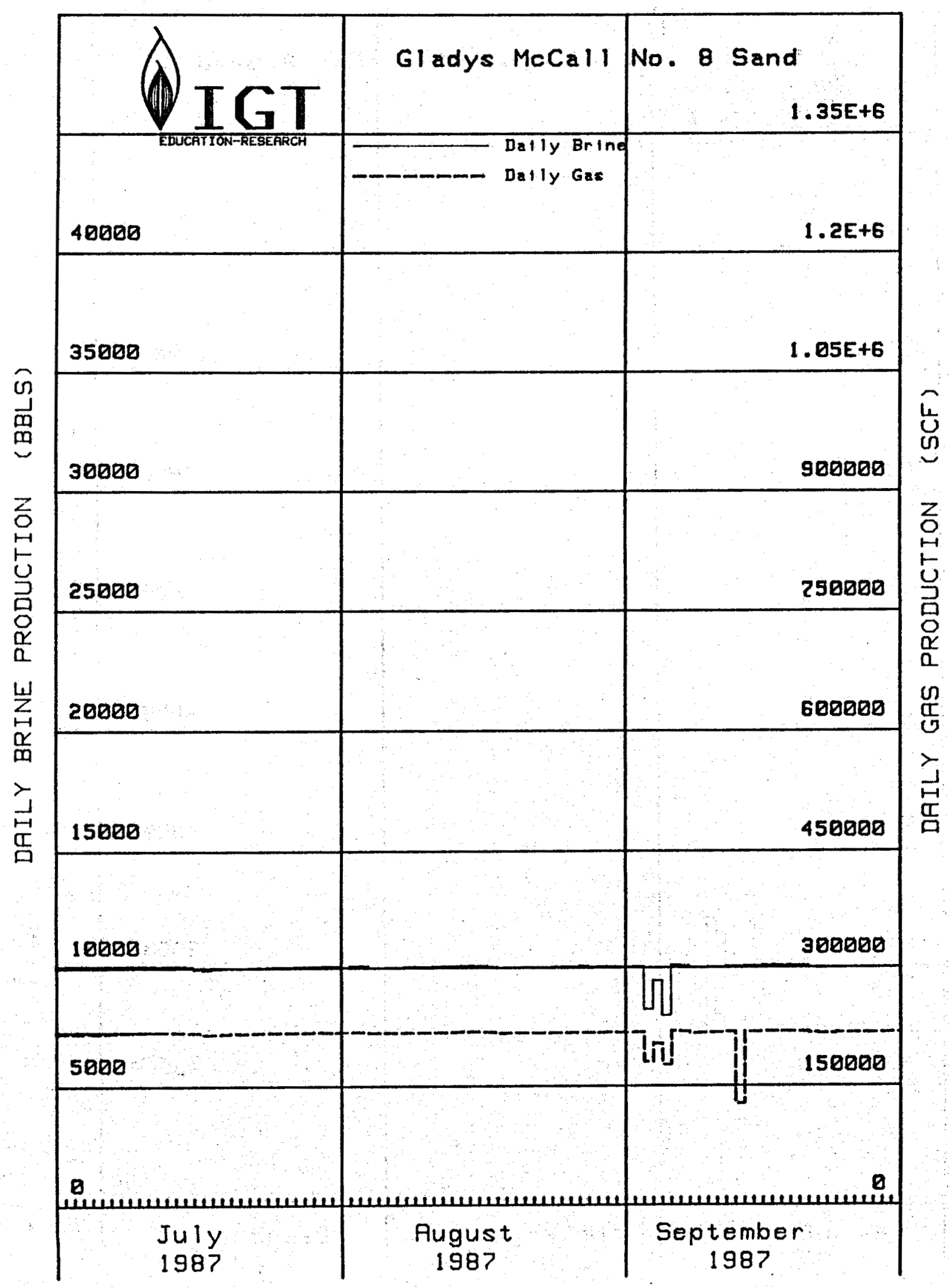

D-35
I N S T I T U T E
$0 \quad F$
G A S
T E C H N O L O G Y 
Flow Tests of the Gladys MCCALL Well Through OCtober 1990

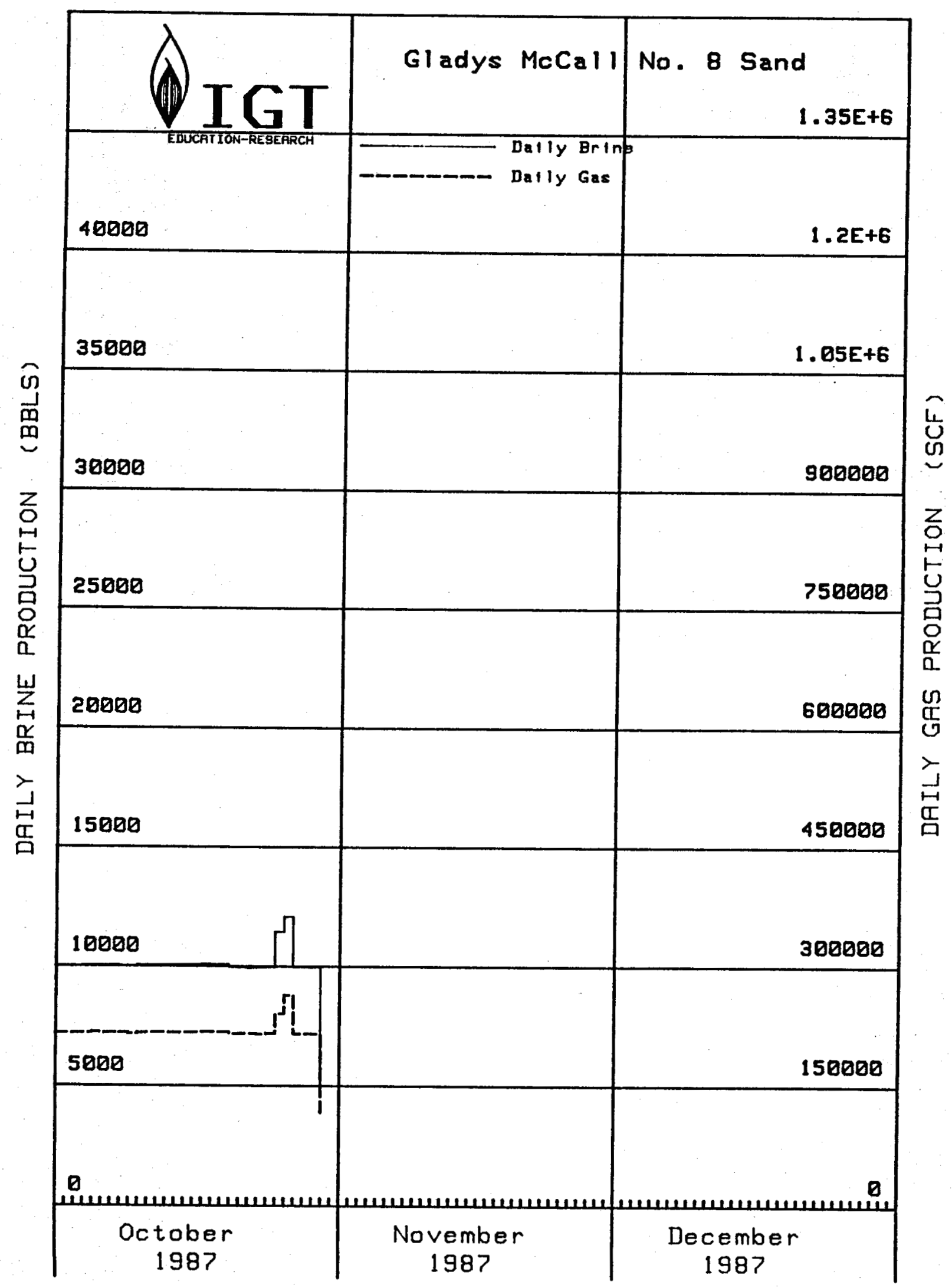

D-36
I N S T I T U T E
O F G A S
T E C H N O
L O G Y 
Flow Tests of the Gladys MCCall Well Through OCtober 1990

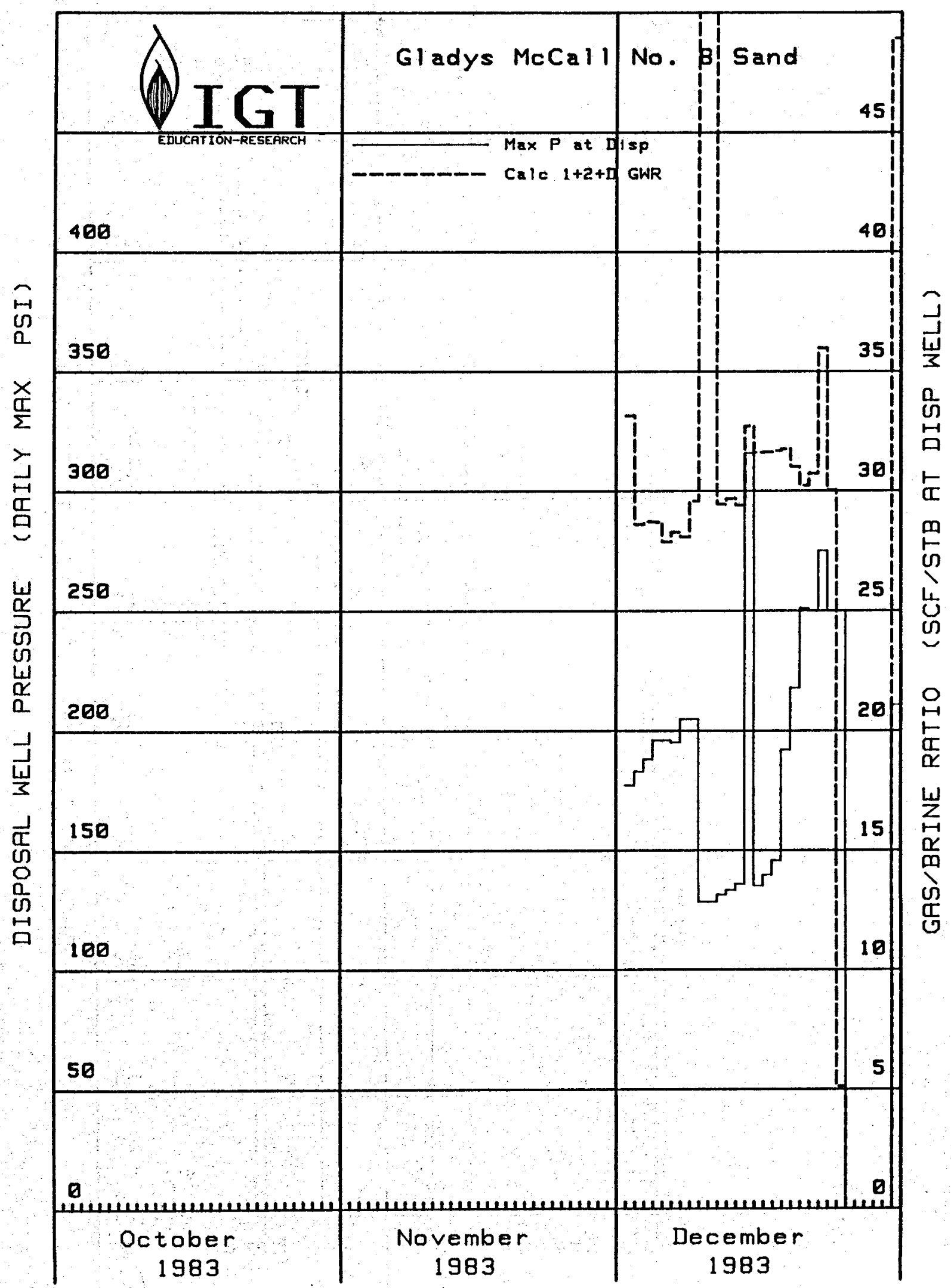

D-37

INSTITUTE O T F G A T T C H NOLOG Y 


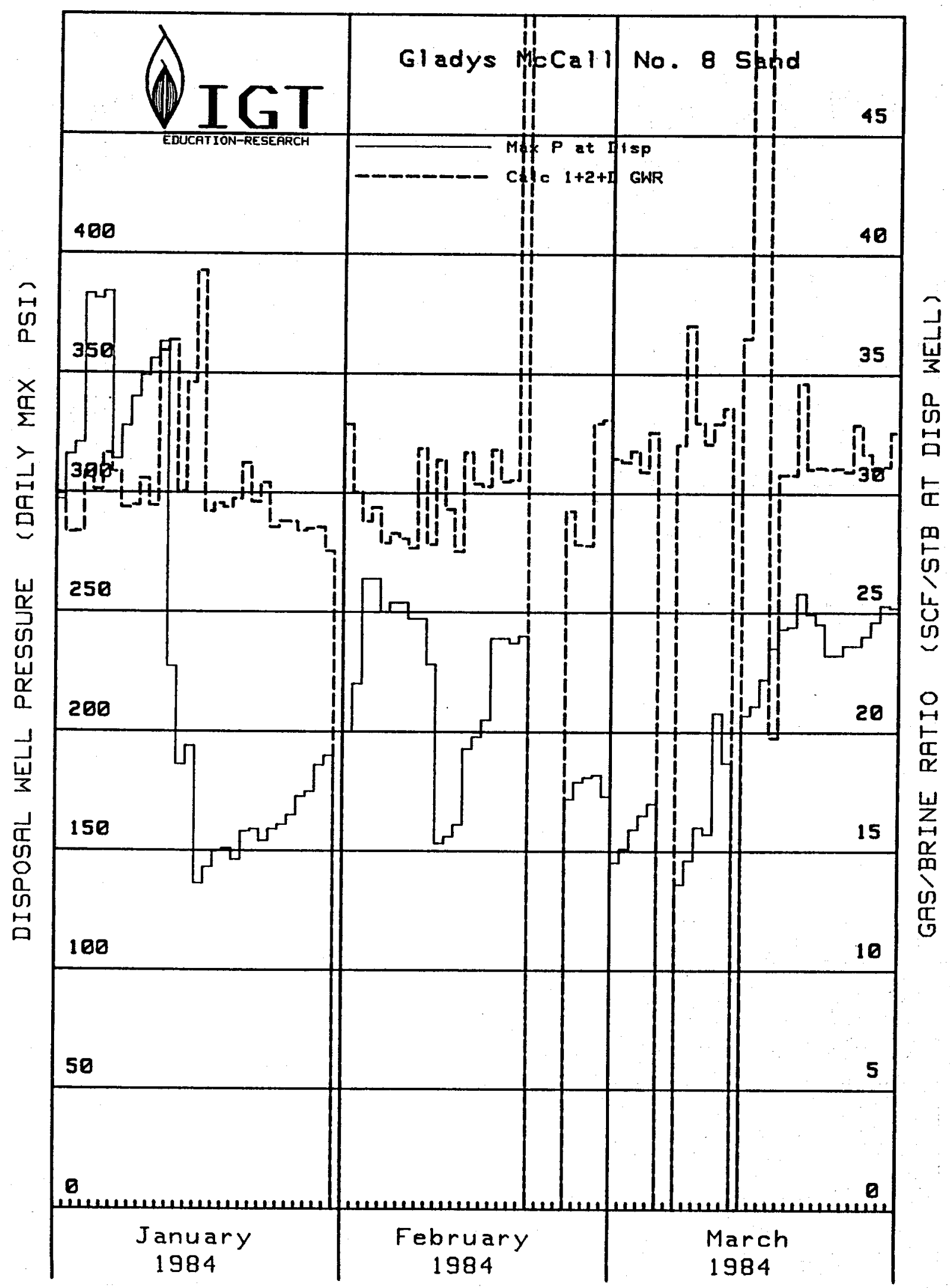

D-38

I NST I T U TE 
FLOW TESTS OF THE GLADYS MCCALL WeLl THROUgh OCTOBER 1990

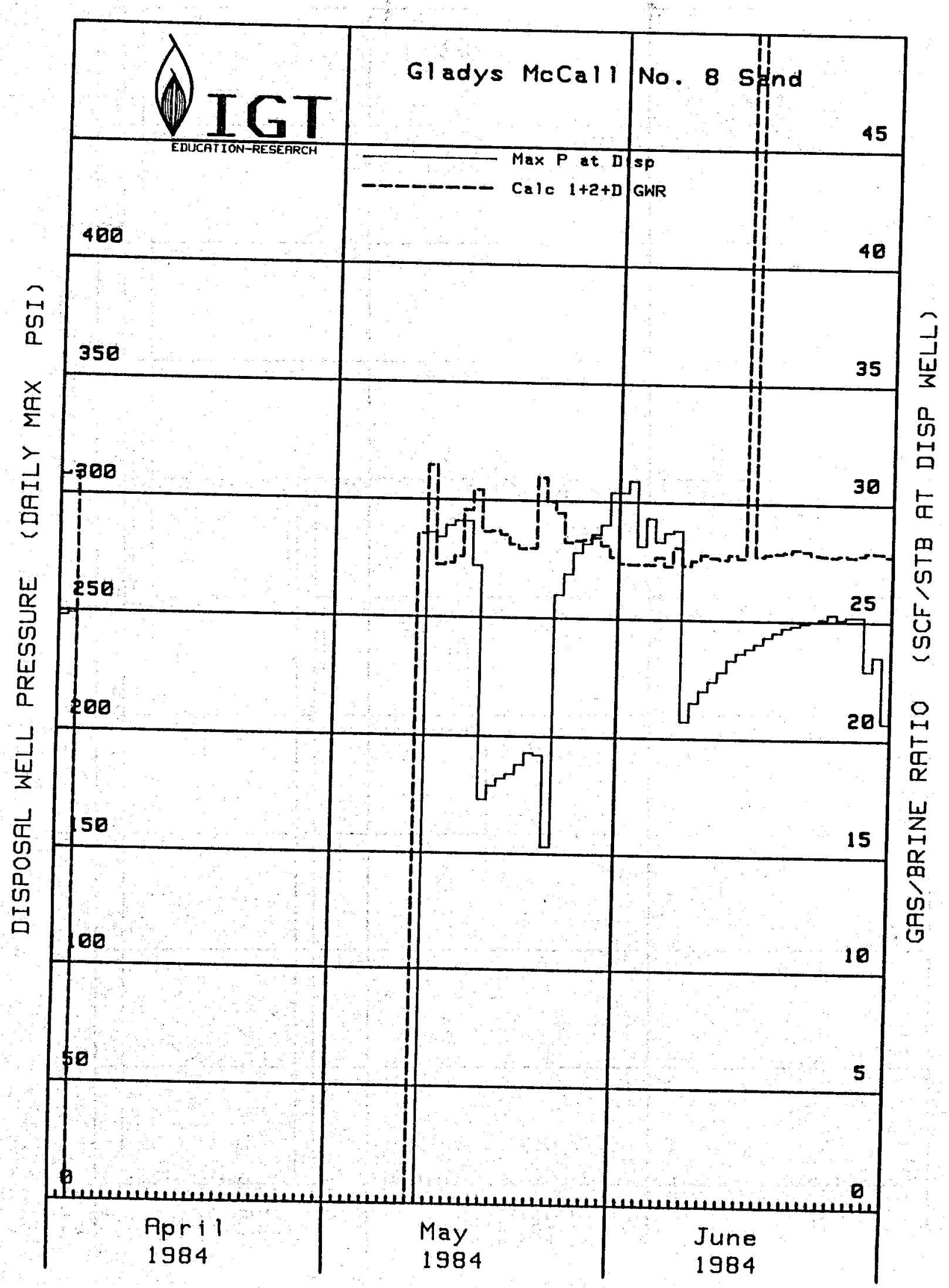

D-39
INST T U T E
$0 \mathrm{~F}$
G A S
TECHNOLOG Y 
Flow Tests of the Gladys MCCall Well Through OCtober 1990

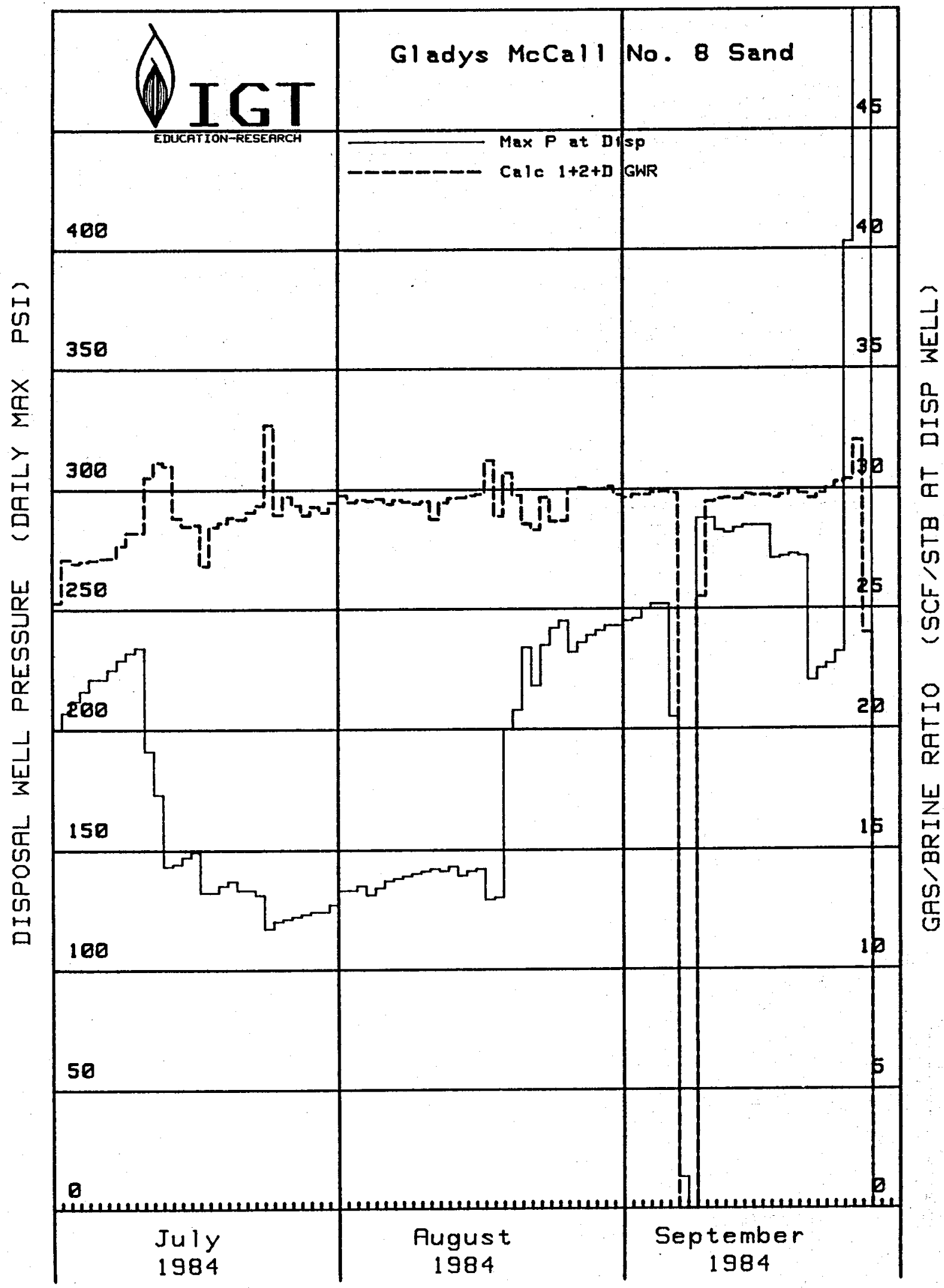

D-40

I NST T T U T E O F G A S T T C H N O L O G Y 
Flow Tests of the Gladys McCall Well Through OCtober 1990

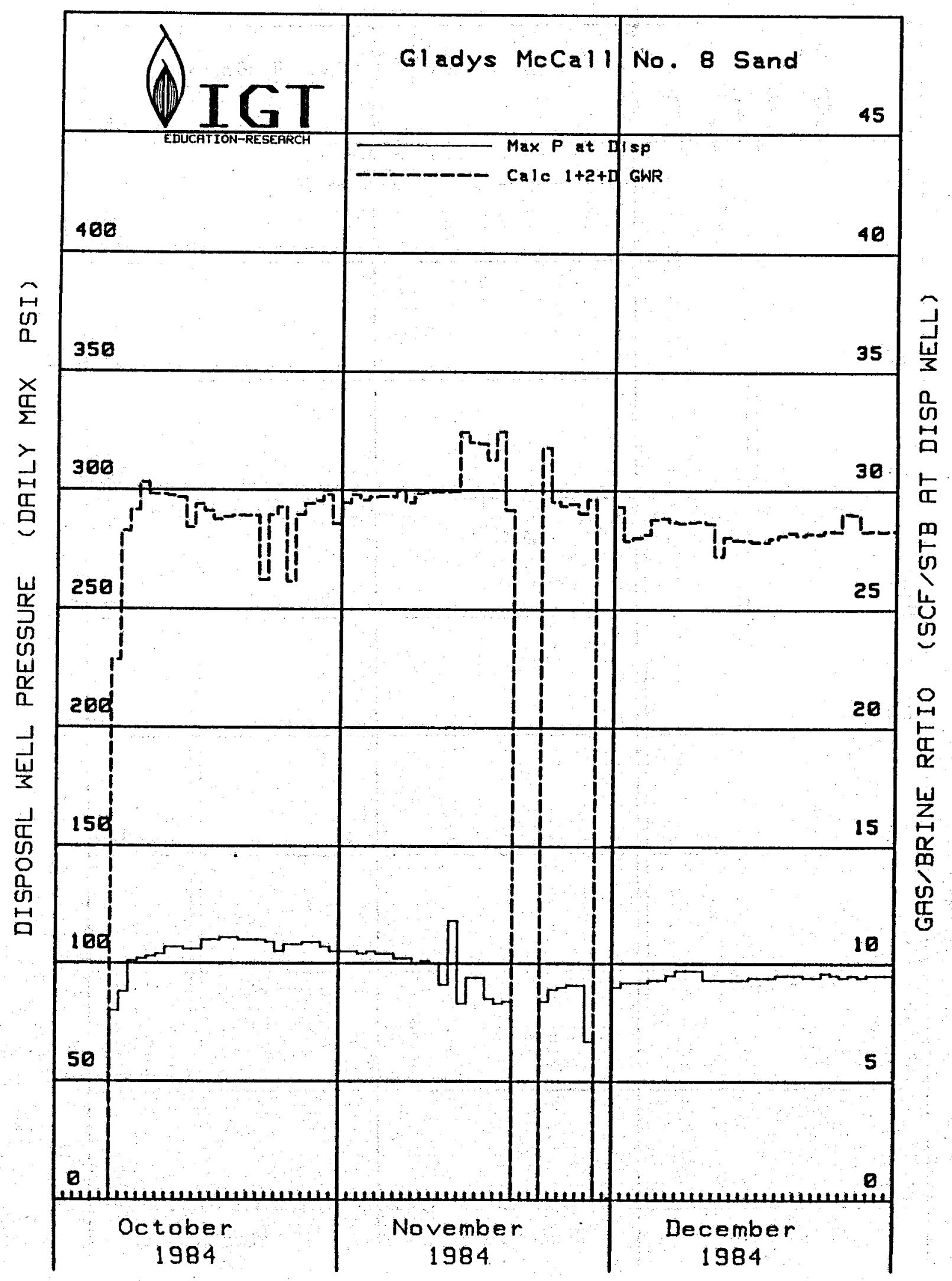

D-41
INSTITUTE
O F
G A S
TECH NOL.O G Y 


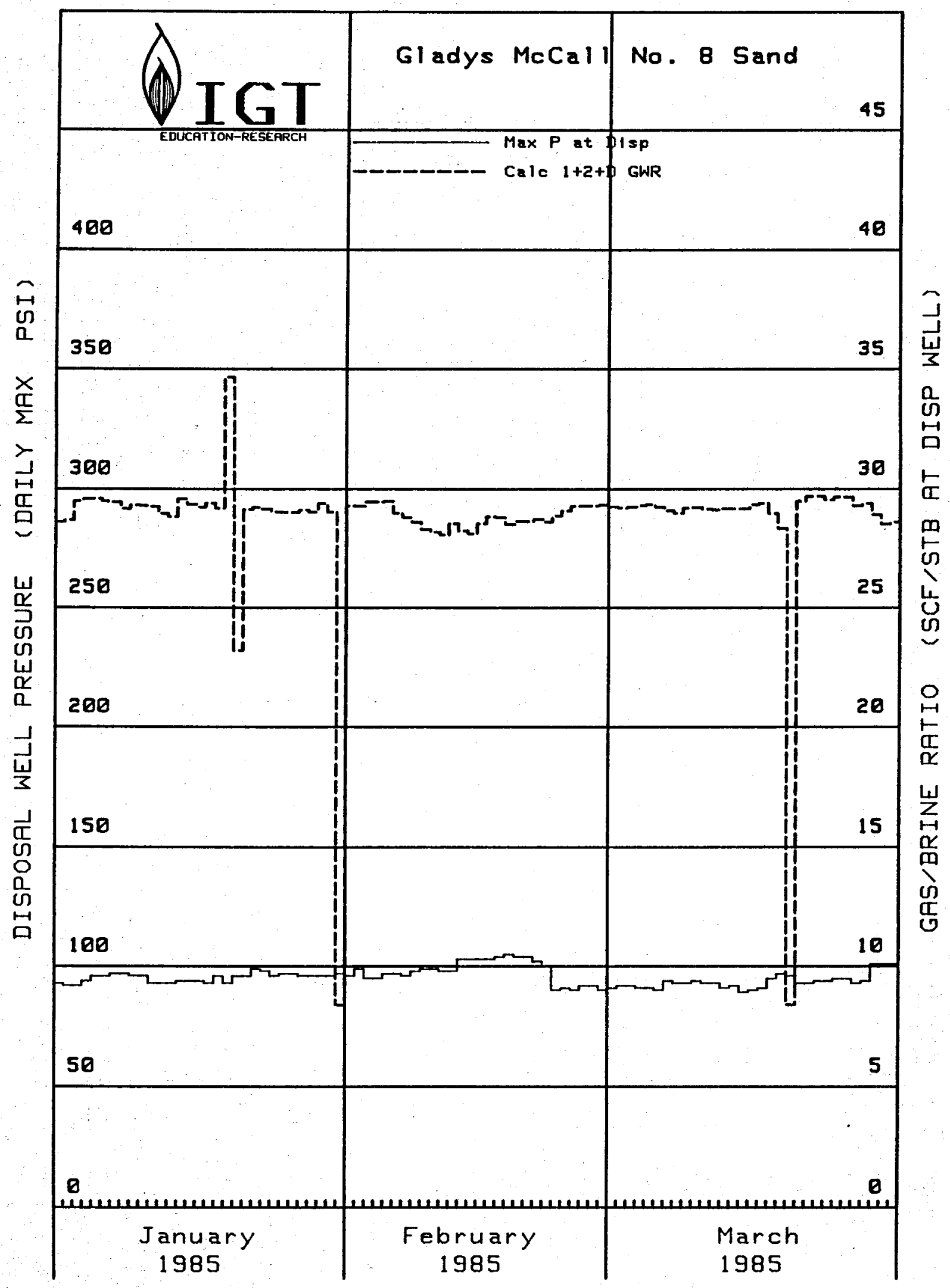

D-42 
Flow tests of the Gladys MCCall Well Through OCtober 1990

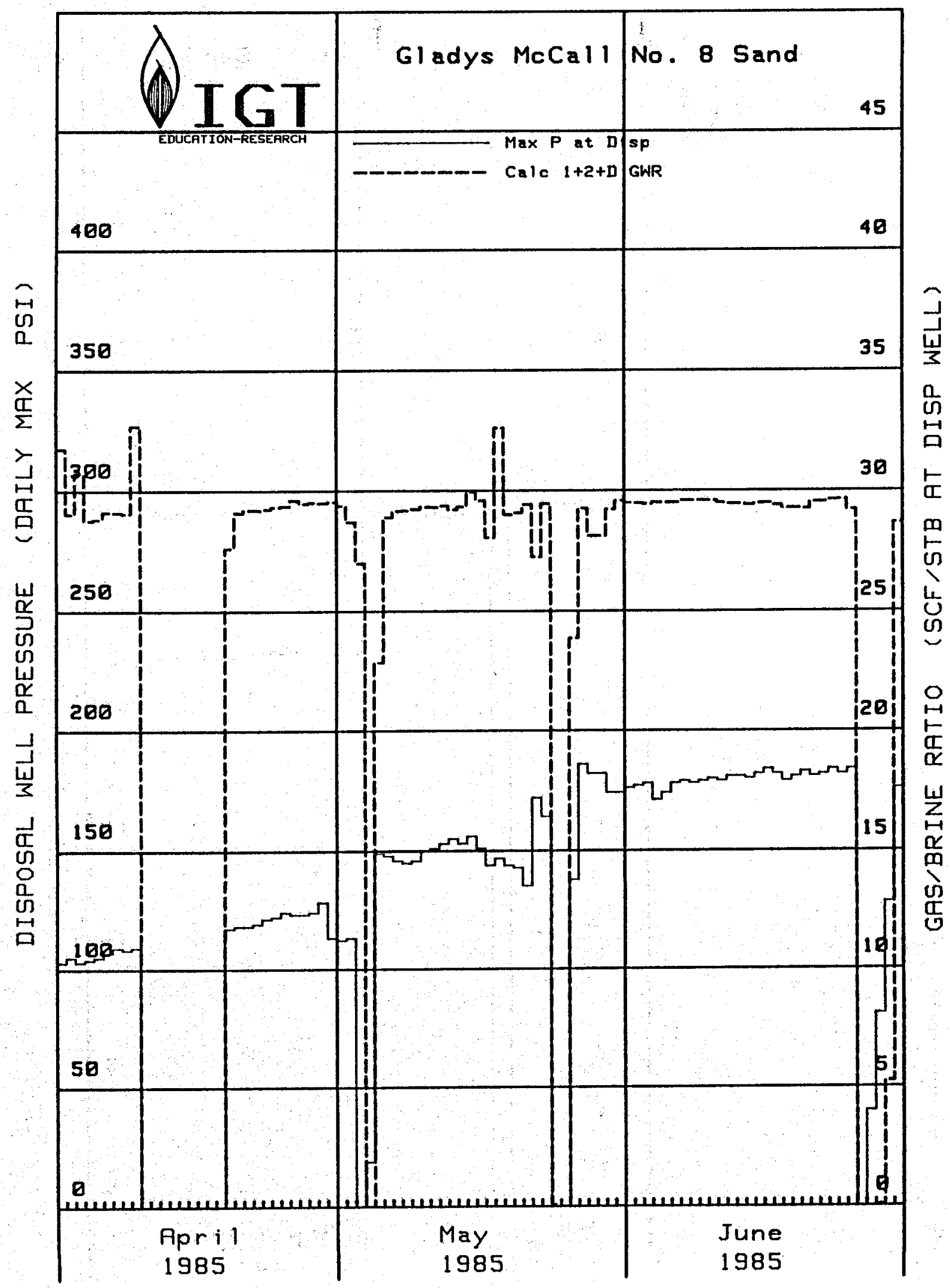

D-43 
Flow Tests of the Gladys McCall Well Through October 1990

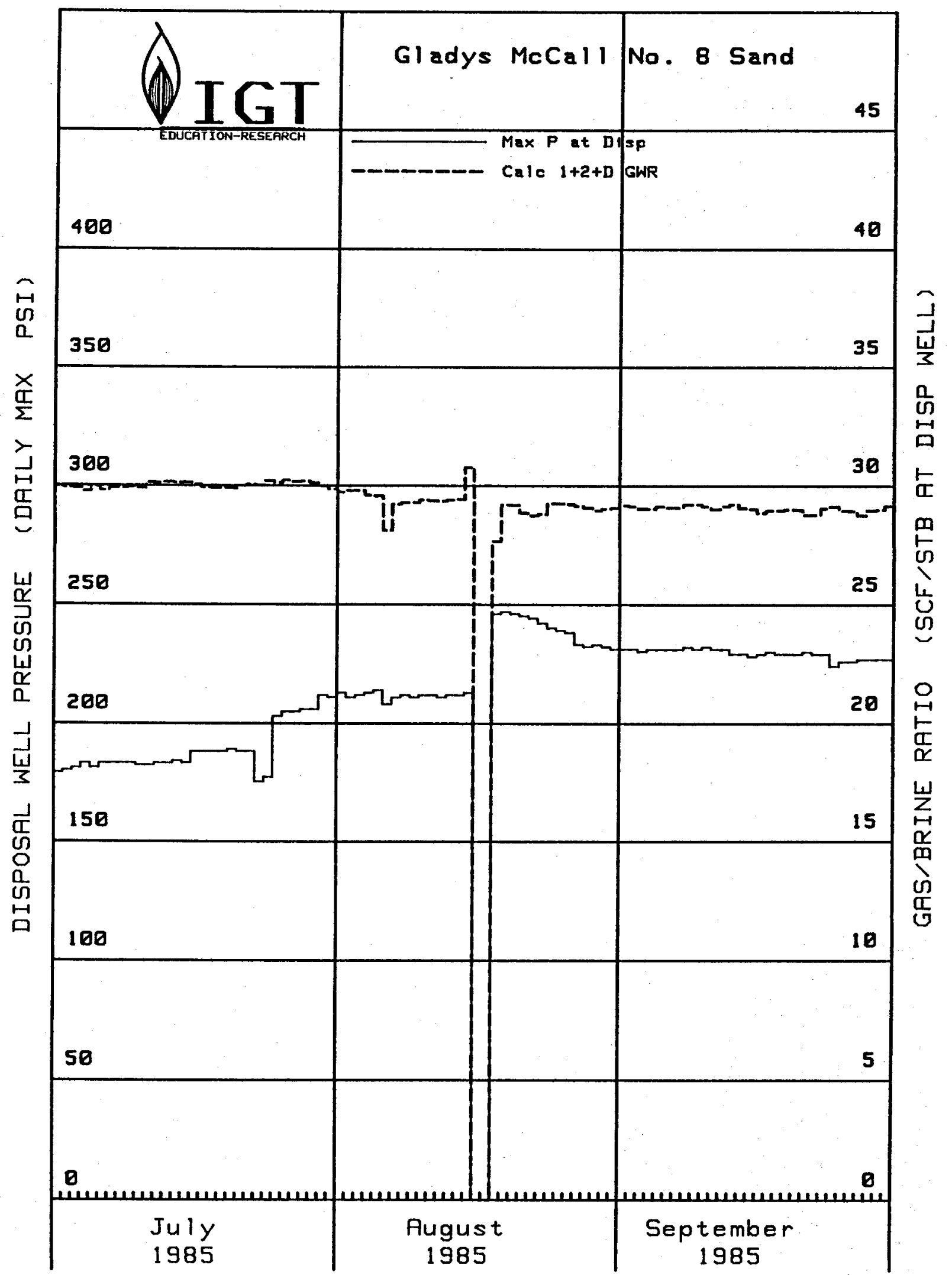

D-44

INSTITUTE OF GAS TE C H N O L O G Y 
FLOW TESTS OF THE GLADYS MCCALL Well Through OCTOBER 1990

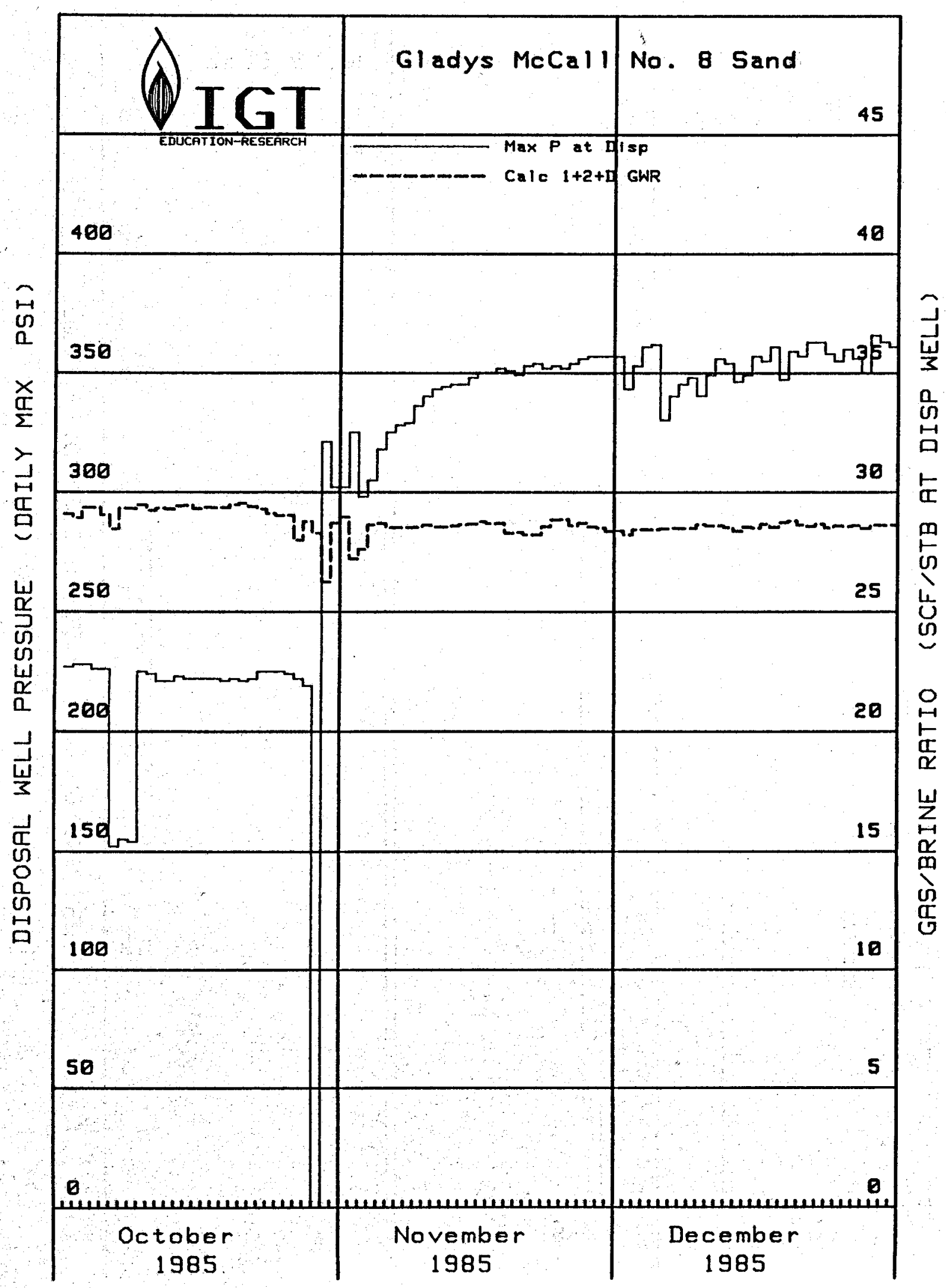

D-45
I N S T I T U T E
o $F$
G A S
T E C H N O L O G Y 
Flow Tests of the Gladys MCCall Well Through OCtober 1990

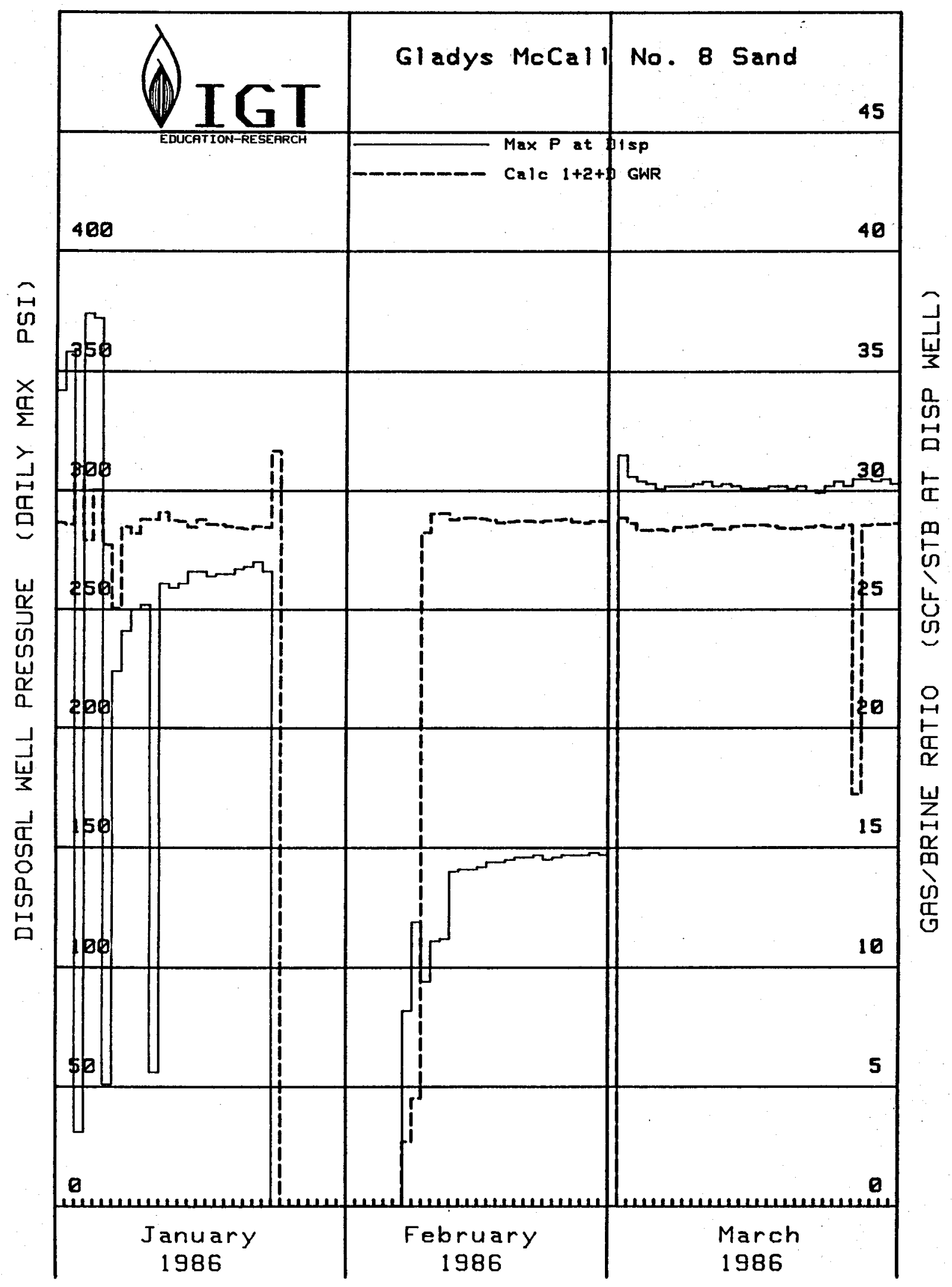

D-46

INSTITUTE T T OF GAS T T E C H O O L O G Y 
Flow tests of the Gladys MCCall Well Through OCtober 1990

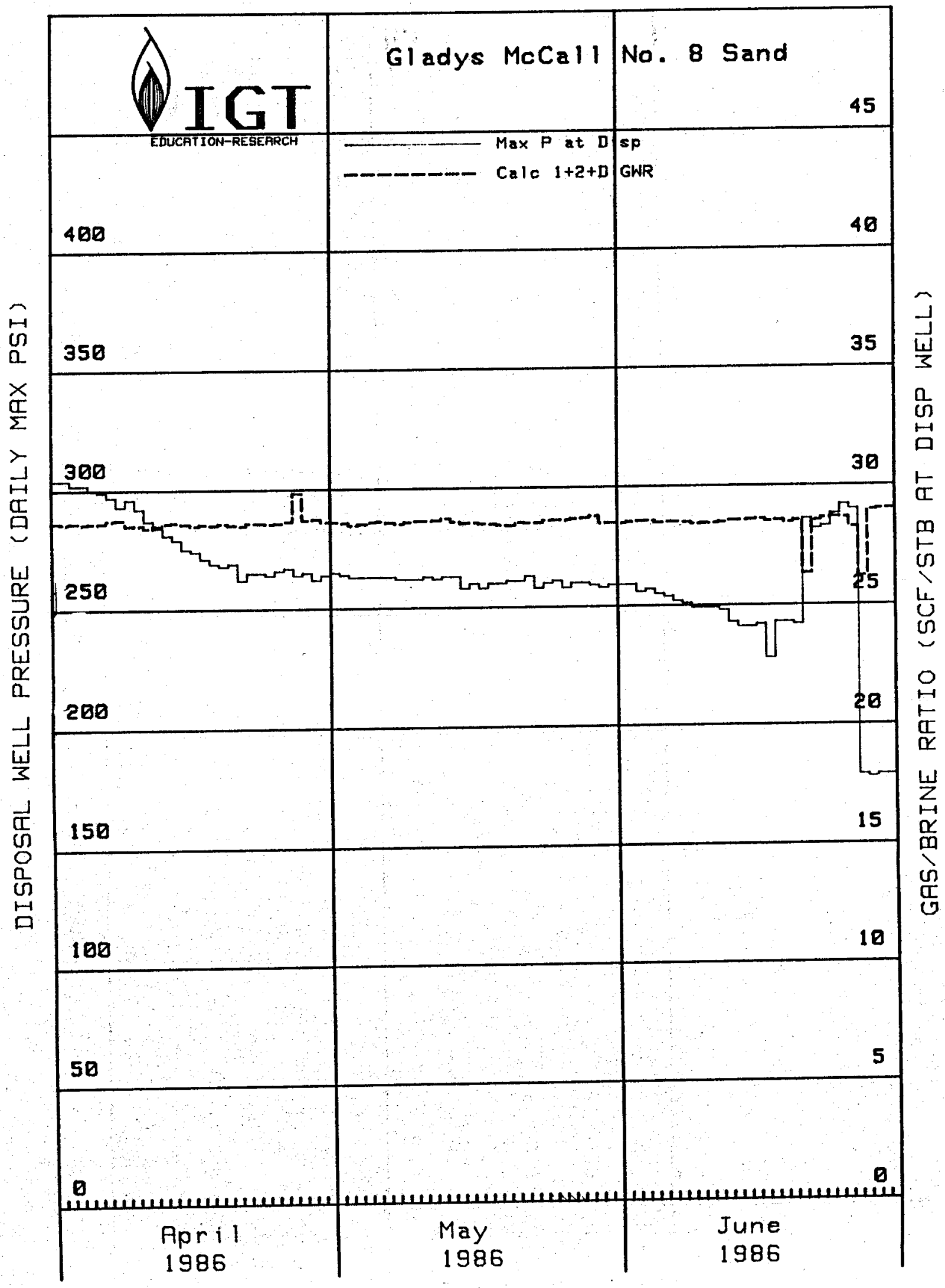

D-47
INST I T UTE
O F
G A S
TE C H NOLO G Y 
FLOW TESTS OF THE GLAdYS MCCALL WeLl THROUgh OCTOBER 1990

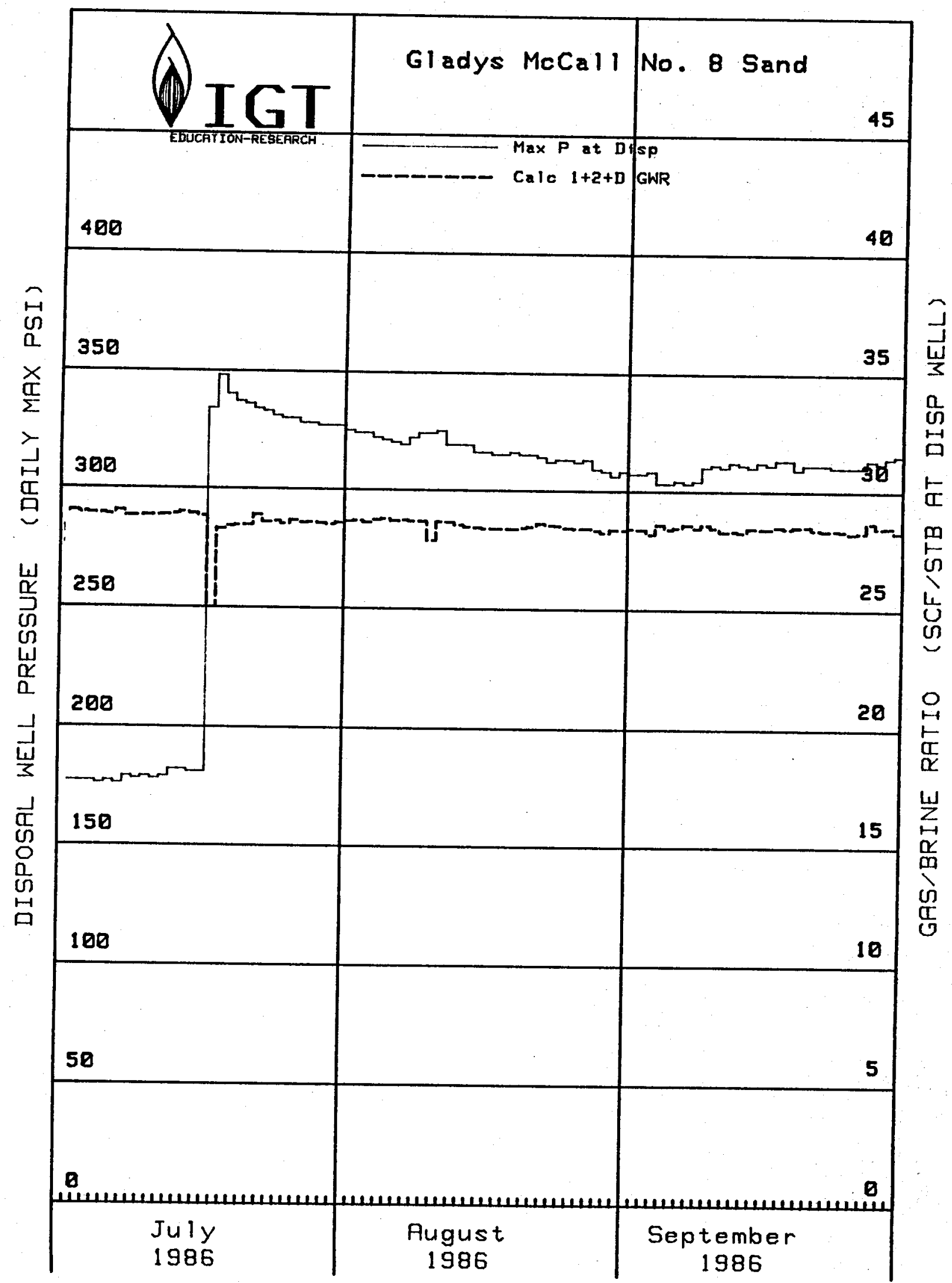

D-48
I N S T I T U T E
O F G A S
T E C H N O L O G Y 
FLOW TESTS OF THE GLAdYS MCCALL Well THROUgh OCTOBER 1990

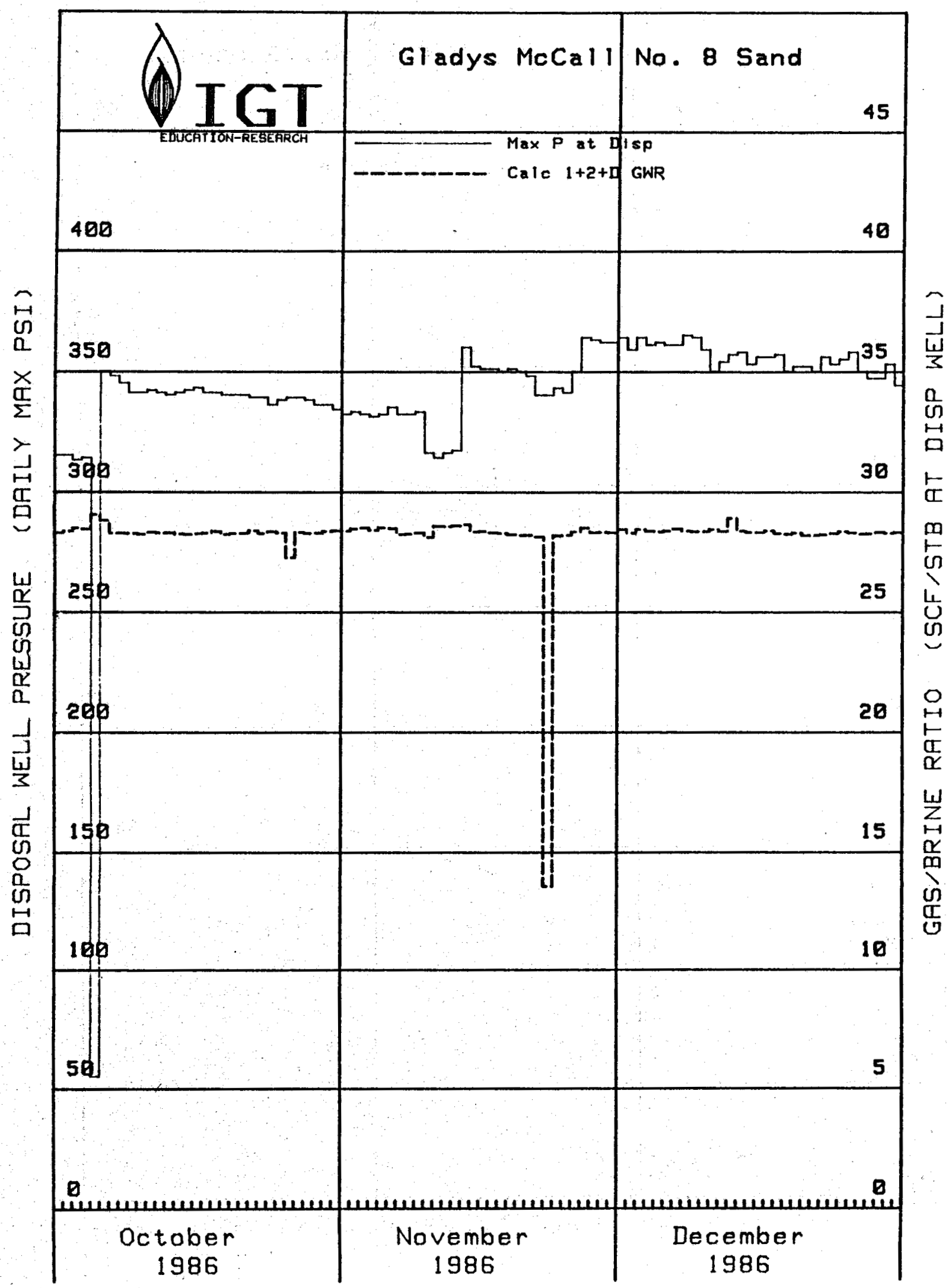

D-49
I N S T T U TE
O F
G A S
T E C H N O L O G Y 
FLOW TESTS OF THE GLAdys MCCALL Well THROUgh OCtOBER 1990

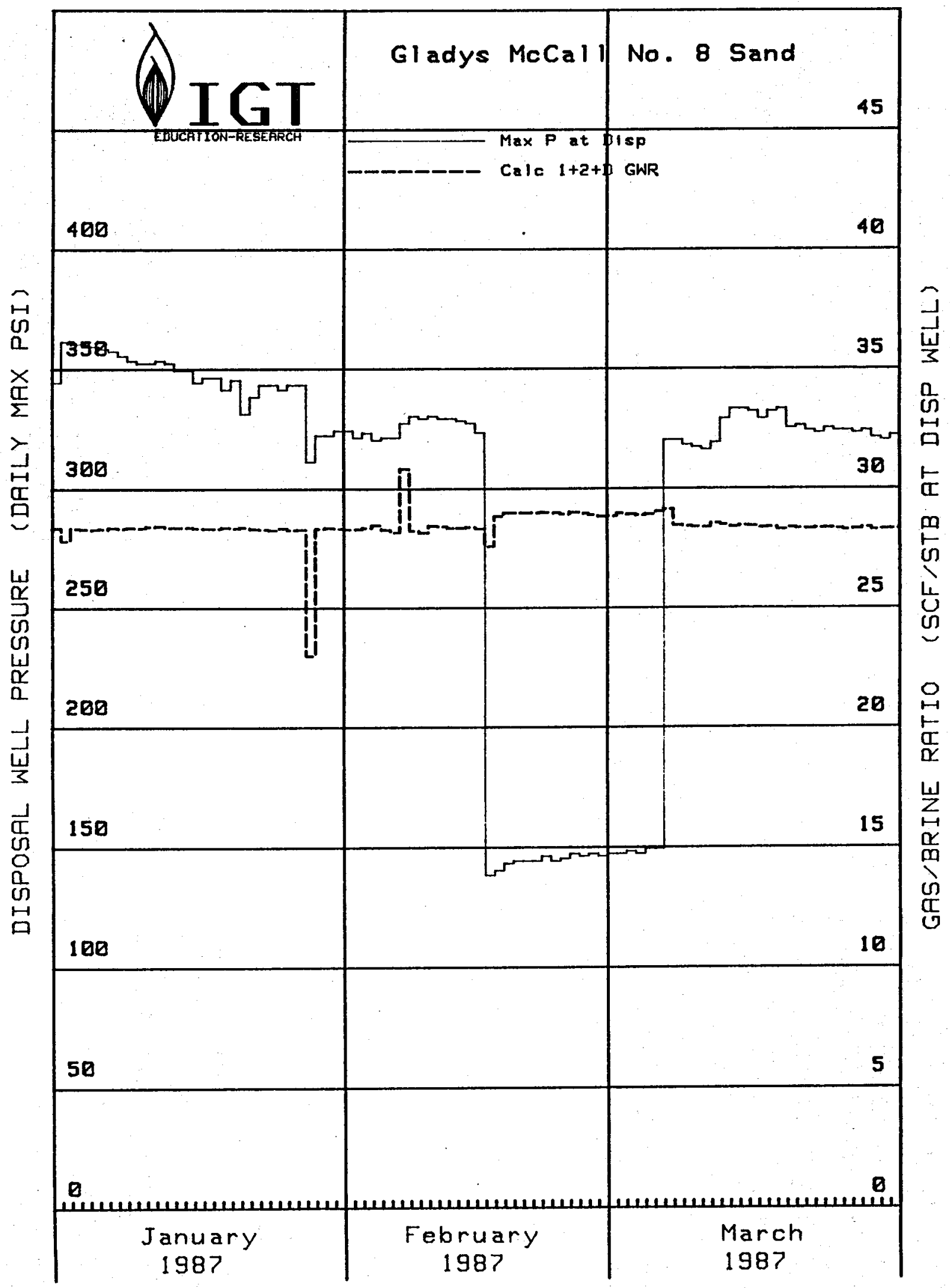

D-50

INSTITUTE OF GAS TE T C H NOL O G Y 
FLOW TESTS OF THE GLADYS MCCALL Well THROUgh OCTOBER 1990

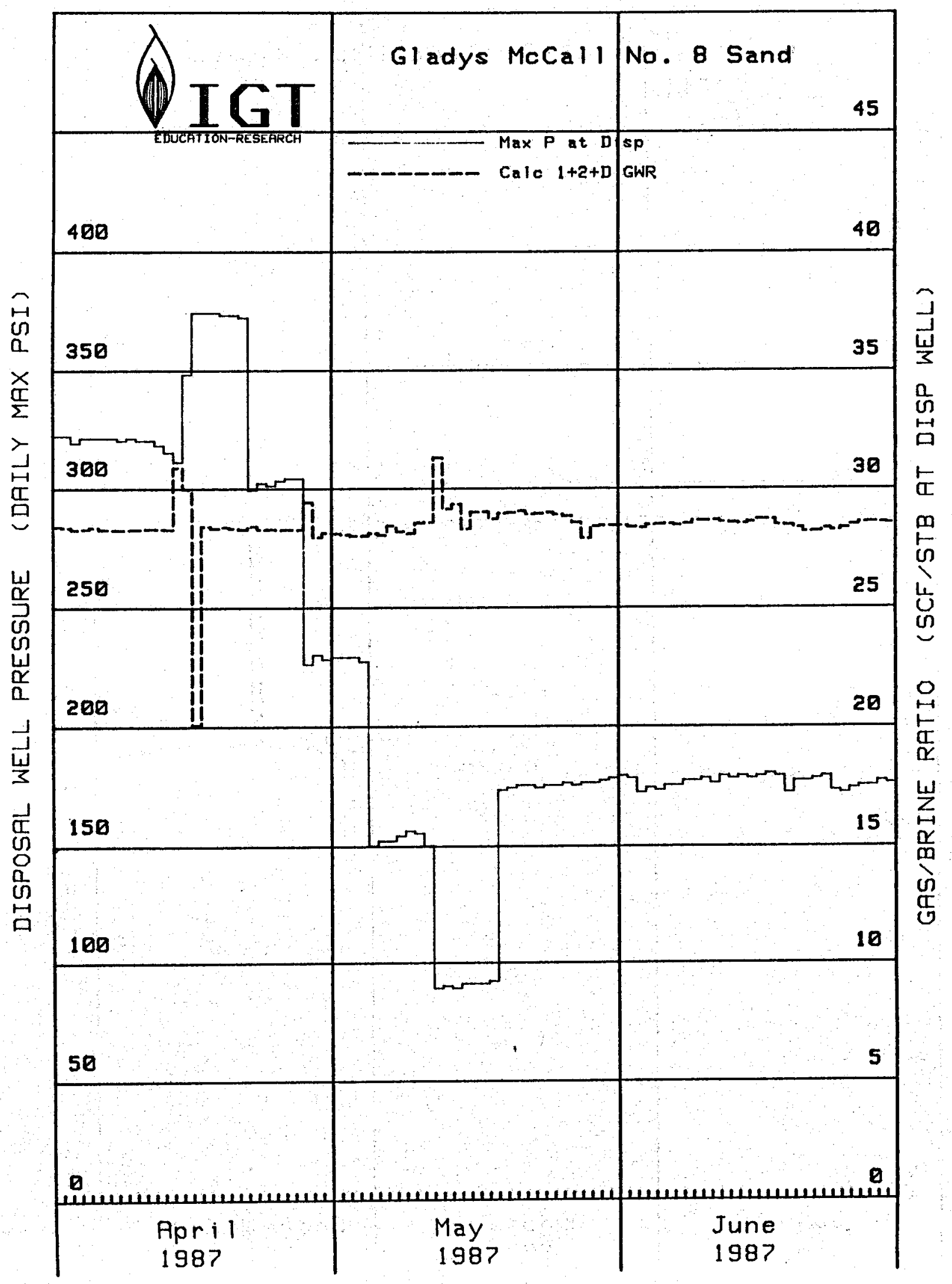

D-51

INSTITUTE OF GAS TECHNOLOGY 
FLOW TESTS OF THE GLAdy MCCALL WELL THROUgh OCTOBER 1990

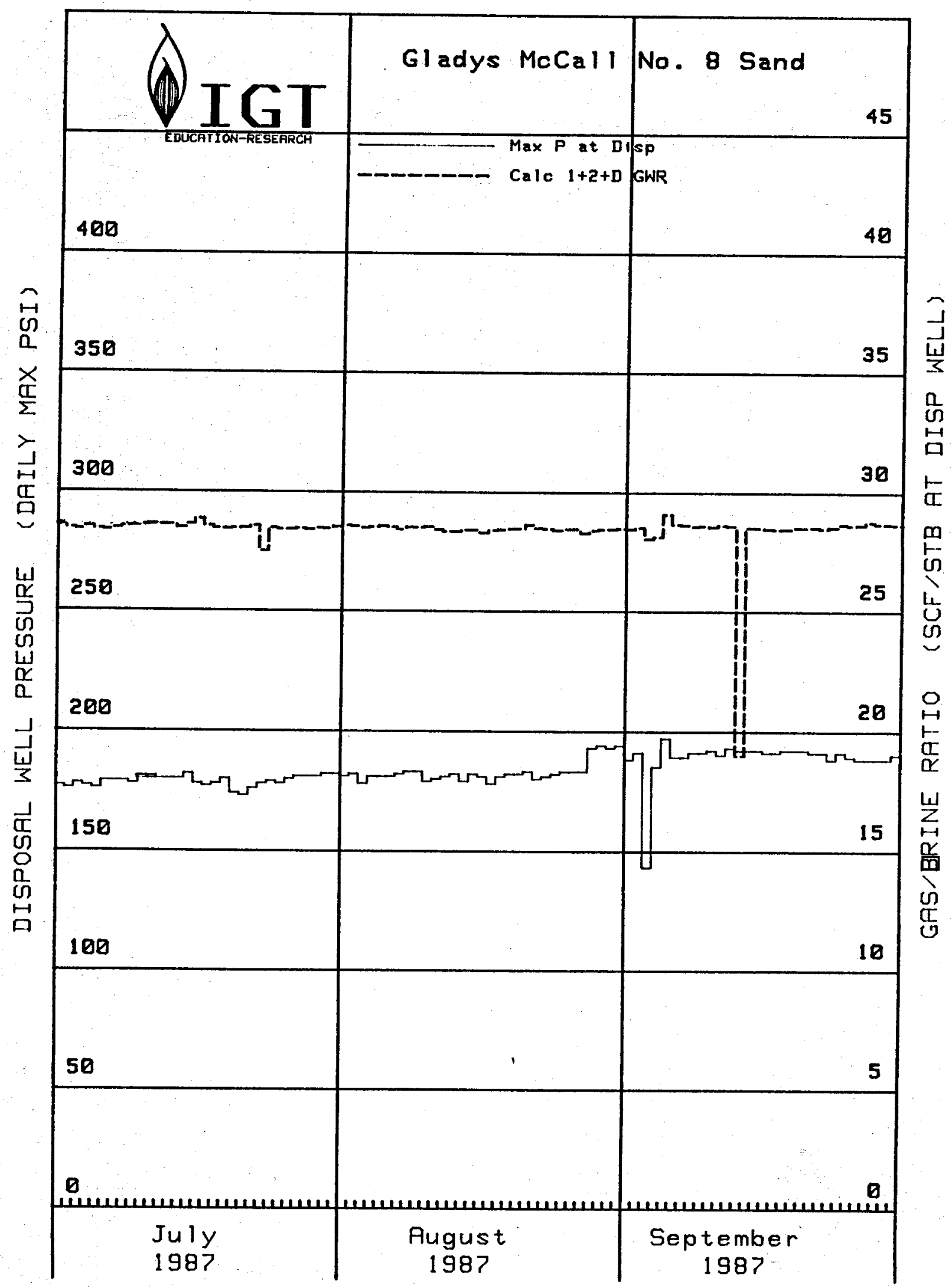

D-52

INST IT T T E


Flow TESTS OF THE Gladys MCCall Well THROUgh OCtOBER 1990

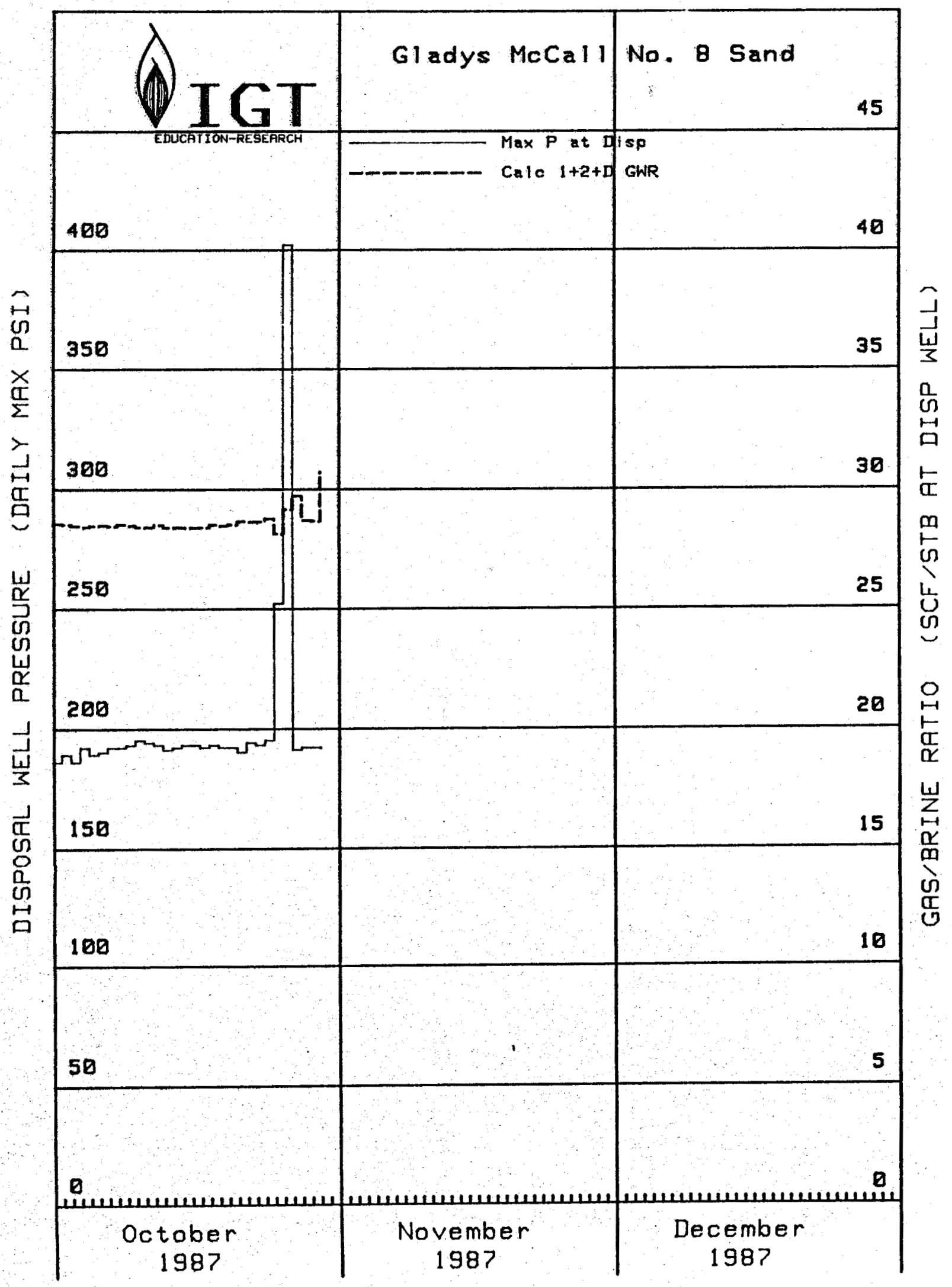

D-53 
Flow TESTS OF THE GLADYS MCCALL WeLl THROUGH OCTOBER 1990

\section{APPENDIX E}

\section{Sand 8 Gas Rate Measurements.}

E-1 
There were several inconsistencies in the gas rate calculations reported from the site. Some, although not all, of the sources of error were eliminated and gas rates were recalculated for this report. The field procedure for calculating gas production assumed that the only variables in the orifice equation were the pressure, differential pressure, and temperature. It ignored the effects of the water-vapor content of the gas and changing gas composition, both of which had a significant effect on the reported flow rates. The following subsections document these problems and the corrections made.

\section{Loss of Accuracy at Lower Flow Rates}

The measurements of gas production rates from the two separators and of the commingled gas to sales were made with orifice meters. Each separator was equipped with separate orifice plates for gas flow to sales and for gas flow to flare. Portions of gas from each separator could be simultaneously sold and flared. The orifices were not equipped with block valves and bypasses. Thus, shut-in of production was required to change orifice plates. In practice, rather than shut in the production, the sensitivity of the differential-pressure transmitter was changed, with the inherent degrading of resolution, temperature sensitivity, and accuracy during periods of low flow rates.

\section{Water-Vapor Content of Measured Gas}

Gas rates reported herein are corrected for the water-vapor content of the gas. Correction of metered gas rates for water vapor was particularly significant for the meter runs on the lowpressure separator. At a temperature of $260^{\circ} \mathrm{F}$, the vapor pressure of water is $35.4 \mathrm{psia}$. The water-vapor content of the gas was $35.4 / 400$ psia at a separator pressure of 400 psia. In this representative case, roughly $9 \%$ of the gas passing through the orifice plate was water vapor that was condensed and removed from the stream before the gas was sold. Field gas rate calculations treated this water vapor as produced gas.

\section{Factors Used in Gas Rate Calculations}

The gas production rates reported from the Gladys McCall location were calculated manually by the operators using orifice factor conversion tables for each meter run. The orifice factors were tabulated for various pressures and temperatures such that multiplying the value obtained by interpolation of the tables by the square root of the differential pressure yielded the gas flow rate. These tables were provided to the operator by a consultant during 1984 . Although the details on how these orifice factors were derived were not included in the records, notations on the tables revealed a few of the values listed in Exhibit E-1 that were used to calculate them. 
FLOW TESTS OF THE GLADYS MCCALL Well ThROUgh OCTOBER 1990

Exhibit E-1. APPARENT FACTORS FOR MANUAL GAS RATE CALCULATIONS

$\begin{array}{lccc} & \text { HP Sep } & \text { LP Sep } & \text { Sales } \\ \text { Pipe ID, in. } & 2.626 & 2.626 & 2.067 \\ \text { Orifice bore, in. } & 0.75 & 0.375 & 0.625 \\ \text { Molecular Weight } & 18.957 & 22.832 & 19.407 \\ \text { Specific Heat Ratio } & 1.3 & 1.3 & 1.3 \\ \text { Viscosity, cP } & 0.015 & 0.015 & 0.015\end{array}$

Back-calculation by IGT to obtain the dry gas gravity from the above parameters and orifice factors gave the values $0.6545,0.7883$, and 0.6701 , respectively, for the three orifice meters. When IGT installed the computer data acquisition system on the Gladys McCall site in 1986, the real dry gas gravities selected in an effort to match operator-reported rates were $0.6562,0.727$, and 0.670 for the high-pressure separator, low-pressure separator, and sales-gas meter runs, respectively. Subsequent resolution of differences (up to a few percent) between operator-reported rates and rates from the digital system was not practicable because of the lack of details on the calculations used to produce the tables used by the operators.

The gas rates presented herein were not corrected for changes in gas composition and the associated change in gas gravity. The actual dry gas gravity depended primarily on the pressure of the separators. The higher the separator pressure, the lower the gas gravity. This function is clearly shown in Exhibits E-2 and E-3, which present the gas gravity calculated from analyses of gas samples collected at the orifice meters on the high- and low-pressure separators (Locations 4 and 7) at various times over the life of the test.

The dry gas gravity was also affected by the brine temperature and, for the low-pressure separator, by the operating pressure of the high-pressure separator. During normal operation these are secondary effects because these values were essentially constant for most of the test. On April $13-14,1987$, when the high-pressure separator was at 515 psia and the low-pressure separator was at 400 to 450 psia, the low-pressure separator gas gravity was lower than would be expected at that pressure. These data points are blackened in Exhibit E-2 to differentiate them from the remaining samples. The extent to which the lower gravities are caused by undocumented transfers of gas from the high-pressure separator to the low-pressure separator through a bypass line is not clear. These gas transfers were occasionally needed to maintain control of the brine level in the low-pressure separator. 
FLOW TESTS OF THE Gladys MCCALl Well THROUgh OCTOBER 1990

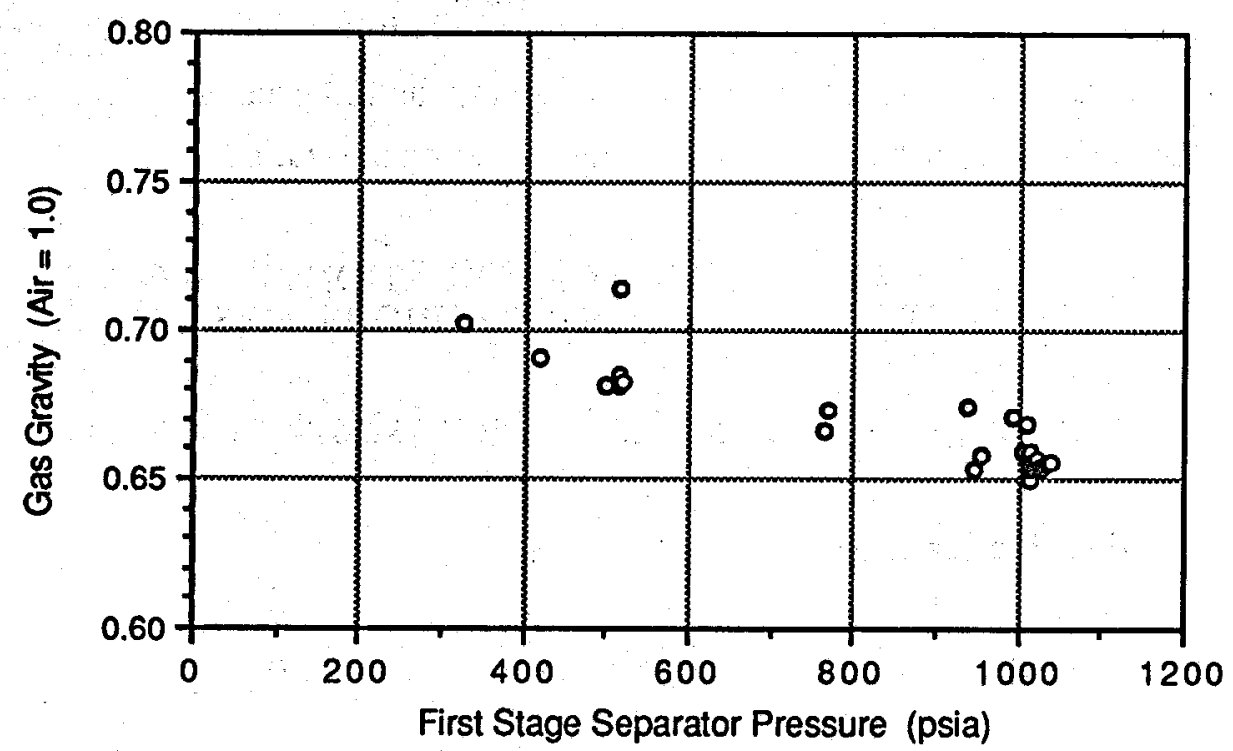

Exhibit E-2. GAS GRAVITY VERSUS FIRST-STAGE SEPARATOR PRESSURE

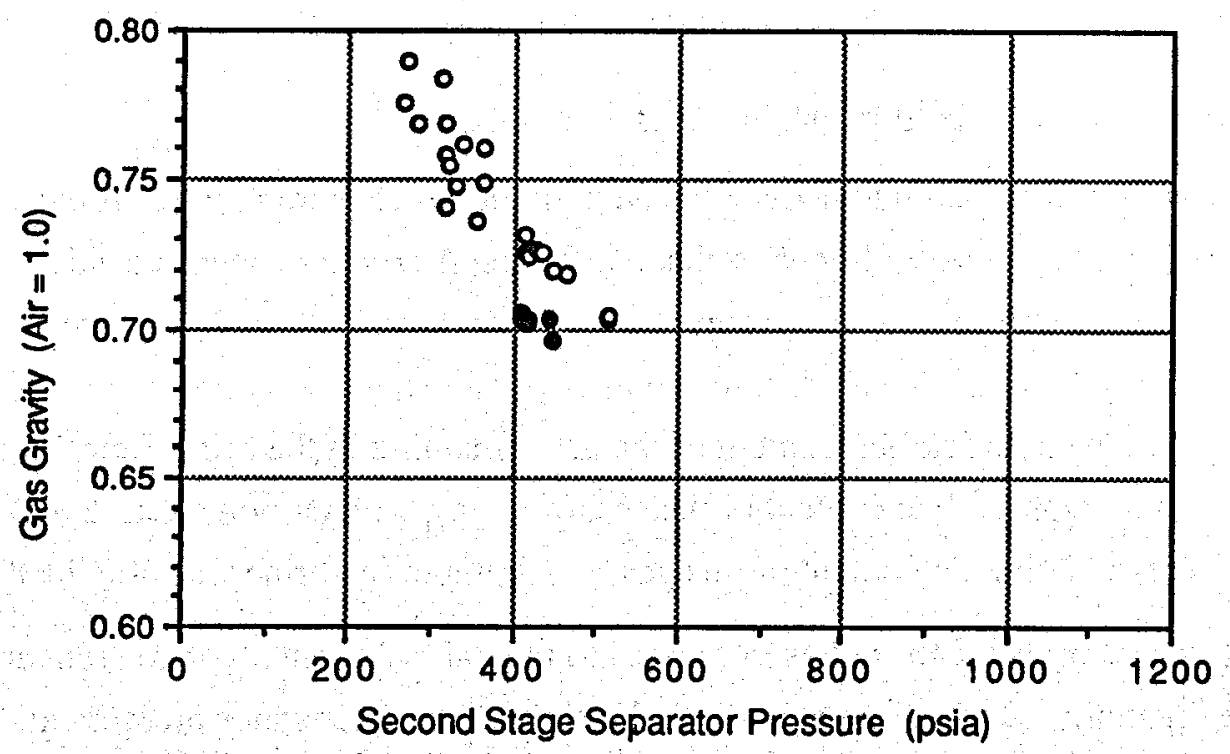

Exhibit E-3. GAS GRAVITY VERSUS SECOND-STAGE SEPARATOR PRESSURE 
With the actual gas gravities differing from the assumed gas gravity, the calculated gas flow rates were slightly in error. The gravities would be correct only if the high-pressure separator was operated at 1000 psia and the low-pressure separator was kept at 420 psia. Exhibit E-4 shows how much the reported gas rates are in error at several operating pressures.

\section{Exhibit E-4. ERROR IN GAS RATE CALCULATIONS BASED ON THE DIFFERENT GAS GRAVITIES AT VARIOUS PRESSURES}

Pressure Gas Gravity Error in Calculated Gas Rate

High-Pressure Separator

$\begin{array}{lll}750 \text { psia } & 0.669 & 1.0 \\ 1015 \text { psia } & 0.656 & 0.0\end{array}$

Low-Pressure Separator (HP Sep at $1000 \mathrm{psi}$ )

$\begin{array}{llr}300 \text { psia } & 0.775 & 3.2 \\ 400 \text { psia } & 0.732 & 0.3 \\ 500 \text { psia } & 0.708 & -1.0\end{array}$

\section{Corrections for Gas Remaining in Brine After the Separator}

IGT developed a correlation to deduce the quantity of gas remaining in the brine. This correlation was based on the solubility of methane in brine. A comparison of the calculated values versus actual measurements of the gas content of brine after the separator were made in Exhibit 7.1.2-1 of this report. The algorithm accurately calculates the hydrocarbon gas content of this dissolved gas. The hydrocarbon content of the gas remaining in the brine after the separator is much lower than the hydrocarbon content of the separator gas, with carbon dioxide making up the difference. The carbon dioxide content of this gas remaining in the brine was $40 \% \pm 10 \%$.

The IGT algorithm is therefore low compared to the total gas content of gas remaining in the brine after the separator. During operation with the, second-stage separator pressure at 420 psia, the measured total gas value averaged 2.8 SCF/STB while the IGT algorithm calculated a value of 2.2 SCF/STB. The perforation gas rate reported in Appendix C during this time would be low by about $0.6 \mathrm{SCF} / \mathrm{STB}$. This algorithm more nearly represents the marketable gas and ignores the large quantity of carbon dioxide that flashes off the brine as the pressure is lowered to atmospheric. 
Flow TESTS OF THE Gladys MCCall Well Through OCtober 1990

APPENDIX F

Long-Term Horner Plot

F-1 
The Horner plot provides a mechanism to predict the final pressure that the reservoir will build up to following the production. This value is found where the extrapolation of the buildup curve intersects the $(T+\Delta t) / \Delta t=1$ axis.

The final pressure was calculated from the material-balance equation --

$$
\mathrm{C}_{\mathrm{T}} \mathrm{V}_{\mathrm{o}}\left[\mathrm{P}_{\mathrm{O}}-\mathrm{P}_{\mathrm{f}}\right]=\mathrm{V}_{\mathrm{p}} \mathrm{B}
$$

where -- $\quad C_{T}=$ Brine + Reservoir Compressibility $=6.27 \times 10^{-6}[1 / \mathrm{psi}]$

$\mathrm{V}_{\mathrm{o}}=$ Initial Reservoir Volume [bbls]

$P_{\mathrm{O}}=$ Initial Reservoir Pressure $=12,811 \mathrm{psi}$, at $15,150 \mathrm{ft}$

$\mathrm{P}_{\mathbf{f}}=$ Final Reservoir Pressure [psi, at time $=\infty$ ]

$\mathrm{V}_{\mathrm{p}}=$ Volume of Produced Brine $=25.54 \times 10^{6}[\mathrm{bbls}]$

$\mathrm{B}=$ Formation Volume Factor $=0.984[\mathrm{bbl} / \mathrm{bbl}]$

Values for $\mathrm{C}_{\mathrm{T}}$ and $\mathrm{B}$ are those used by $\mathrm{S}-\mathrm{Cubed}$. The point marked $\mathrm{P}_{\mathrm{f}}$ in Exhibit 6.3.2-1 is the end point that should be reached for the S-Cubed model with 7.8 billion barrels in the reservoir.

The Horner plots of the bottomhole pressure versus $\Delta t /(T+\Delta t)$, where $T$ is the flow time before shut-in and $\Delta t$ is the time increment since shut-in. The early-time part of the plot reflects the transients of shutting in the well. Following the transient period is the semi-steady-state period characterized by a straight-line segment in the plot. This portion of the plot is useful for determining the flow capacity, or transmissibility ( $\mathrm{kh}=$ permeability times thickness) of the reservoir. The last part of the plot is the final adjustment phase of the reservoir seeking its new equilibrium and is characterized by the plot curving away from the straight line of the semi-steadystate stage. Where the extrapolated plot intersects the $\Delta t /(T+\Delta t)=1$ axis (when $\Delta t=\infty$ ) is the new equilibrium pressure that will be reached with the remaining brine left in the reservoir. The exact curvature of the final segment of the plot depends on the shape of the reservoir and where the well is located in the reservoir. For a circular reservoir with the well in the center, the plot simply bends downward as it extends to the $\Delta t(T+\Delta t)=1$ axis. When the reservoir is long and skinny, and has the well way off center, the plot takes on an "S" shape as it is extrapolated to the $\Delta t /(T+\Delta t)=1$ axis. (For examples, see Reference 15.)

The common assumption for geopressured reservoirs is that they are hydraulically sealed and not in communication with adjacent reservoirs. The wisdom being that, if they were not sealed, their pressures would be hydrostatic rather than geopressured. This is the theoretical mathematical case of a reservoir with no-flow boundaries that is fully saturated with a slightly compressible fluid. For sealed reservoirs, the late-time portion of the Horner buildup plot will roll over to a final 
pressure lower than the initial pressure at the $\Delta t /(T+\Delta t)=1$ axis as the result of removing the fluid from a sealed system. This is shown in Exhibit 6.3.2-1 by the dotted line extrapolation to the value $P_{f}$ on the $\Delta t /(T+\Delta t)=1$ axis.

Visual examination of Exhibit 6.3.2-1 reveals that the pressure buildup of the McCall reservoir has an upward curvature, indicating the buildup has passed the initial semi-steady-state stage and is in the phase characterized by an "S"-shaped curvature to the plot. The plot is still on the upward curvature and has not yet turned over as expected to a downward curvature so that the extrapolation of the plot will intersect the $\Delta t /(T+\Delta t)=1$ axis at a point below the initial pressure. Straight-line extrapolation of the data intersects the $\Delta t /(T+\Delta t)=1$ axis close to the initial pressure. This extrapolation would indicate that the reservoir is either infinite in size, has water influx, porevolume creep, or some other mechanism adequate to reestablish the original pressure. The steep slope of the late-time buildup data ( $1900 \mathrm{psi} / \mathrm{cycle})$ may be indicative of a huge low-permeability region away from the well. 
Flow TESTS OF THE GLAdYS MCCALL WELl ThROUGH OCTOBER $1990^{\circ}$

\section{APPENDIX G}

Gas Sampling and Analysis

G-1 
The gas analyses were performed by IGT, Weatherly Laboratories, or Petroleum Analyst, Inc. Petroleum Analyst, Inc., was the laboratory used by the gas buyer (Louisiana Resources, Inc.). The natural gas liquids content, gravity, and heating value for all samples were recalculated on a common basis because the basis for calculating the heating values used by different laboratories was not consistent. Note that heating value is tabulated for a base pressure of 14.73 psia, whereas the natural gas liquids are reported on the Louisiana pressure base of $15.025 \mathrm{psia}$. The following table shows the Sand 8 gas analyses performed for each sample location. Each sample location described below is identified by its location number on Exhibit 4.0-1.

Location 1 is a gas sampling point at the top of the high-pressure separator. This gas is sampled at the high-pressure separator pressure and brine temperature. This gas is at equilibrium with the brine. This gas is most representative of what is being produced at a given moment from the well, because most of the gas produced is first available at that sample point.

Location 2 is a gas sampling point in the gas line between the high-pressure separator and the gas cooler. Gas from this location is almost indistinguishable from gas sampled at Location 1 in that some cooling of the gas has occurred in the piping, resulting in associated condensation of water vapor and natural gas liquids. This location is where the University of Southwest Louisiana (Keeley and Meriwether) collected "cryocondensate" samples from the gas stream.

Location 3 is a gas sampling point just ahead of the gas cooler. Gas from this location is almost indistinguishable from Location 2.

Location 4 is a gas sampling point at the first separator orifice meter run after the gas has been cooled to near-ambient conditions and condensed liquids have been removed. These gas analyses should be used in the flow-rate calculation for that orifice meter. Gas samples obtained from the high-pressure separator $\mathrm{H}_{2} \mathrm{~S}$ sample point is indistinguishable from gas obtained at the meter run.

Location 5 is a sampling point in the brine flow line on the high-pressure separator immediately ahead of the dump valves. Brine with its dissolved gas is collected at the highpressure separator pressure and temperature in steel cylinders. The brine sample cylinder is cooled and the pressure reduced to atmospheric pressure in a volumetric cylinder. The gas exsolved from the brine is then analyzed. The gas remaining in the brine at this point is carried to the lowpressure separator. 
Location 6 is a sampling point located on top of the low-pressure separator. Gas from this location is almost indistinguishable from Location 7.

Location 7 is a gas sample point in the line between the low-pressure separator and the sales orifice meter. This gas is at the low pressure and at a temperature usually near that of the brine. Analyses of this gas should be used in the flow-rate calculations for that orifice meter. Gas samples obtained at the low-pressure separator $\mathrm{H}_{2} \mathrm{~S}$ sample point are similar to gas obtained at the orifice plate.

Location 8 is a brine sampling point in the brine flow line from the low-pressure separator temperature and pressure measurement locations. Brine with its dissolved gas is collected at the low-pressure separator pressure and temperature in steel cylinders. The brine sample cylinder is cooled and the pressure reduced to atmospheric pressure in a volumetric cylinder. The gas exsolved from the brine is then analyzed. The gas remaining in the brine at this point is carried down the disposal well with the brine.

Location 9 is a gas sampling point in the gas line after the high-pressure and low-pressure gases have been cooled, had the water removed with a glycol unit, and brought to sales-line pressure. The sample location is near the sales-gas orifice meter.

Location 10 is a gas sampling point at the custody transfer point near Highway 82, roughly 2.4 miles from the Gladys McCall location. This gas should be the same as gas at Location 9, but analyses of samples from this point by the buyer, Louisiana Resources, Inc., are used for custody transfer considerations. These include verification that the gas meets contract specifications (such as water, hydrogen sulfide, and carbon dioxide content) and determination of its heating value. 
DOE Gladys McCall Well No. 1 Well - Sand 8

Analysis of Gas Samples Taken During Flow Test

Sample Analysis Sample Sample Temp Press CO2 N2 C1 C2 C3 iC4 nC4 iC5 nC5 C6+ Liquids Gravity Heat Value Point Lab Date Time ( ${ }^{\circ}$ ) (psig) (Mol \%) (Mol \%) (Mol \%) (Mol \%) (Mol \%) (Mol \%) (Mol \%) (Mol \%) (Mol \%) (Mol \%) GAL/MCF (Air=1.0) (BTU/SCF)

\begin{tabular}{|c|c|c|c|c|c|}
\hline & & & & & \\
\hline I.G.T. & 9-Feb-86 & 2:45 PM & 285 & 1024 & 7.75 \\
\hline I.G.T. & 9-Feb-86 & 7:15 PM & 285 & 1025 & 7.68 \\
\hline I.G.T. & 10-Feb-86 & 1:05 PM & 294 & 1015 & 7.74 \\
\hline I.G.T. & 11-Feb-86 & 10:31 AM & 306 & 1020 & 7.78 \\
\hline I.G.T. & $11-\mathrm{Feb}-86$ & 11:11 AM & 289 & 1022 & 8.00 \\
\hline I.G.T. & 11-Feb-86 & 11:32 AM & 291 & 1019 & 8.01 \\
\hline I.G.T. & 11-Feb-86 & 12:21 PM & 294 & 1020 & 7.91 \\
\hline I.G.T. & 11-Feb-86 & $2: 25 \mathrm{PM}$ & 302 & 1018 & 7.81 \\
\hline I.G.T. & 13-Apr-87 & 8:43 AM & 284 & 1013 & 8.07 \\
\hline I.G.T. & 13-Apr-87 & 4:00 PM & 284 & 515 & 11.31 \\
\hline I.G.T. & 14-Арт-87 & 7:50 AM & 280 & 515 & 10.99 \\
\hline I.G.T. & 14-Apr-87 & $12: 30 \mathrm{PM}$ & 280 & 515 & 11.05 \\
\hline I.G.T. & 14-Apr-87 & 12:40 PM & 280 & 515 & 10.97 \\
\hline I.G.T. & 14-Apr-87 & 1:35 PM & 280 & 516 & 11.19 \\
\hline I.G.T. & 17-Dec-85 & 5:10 PM & 91 & 1019 & 7.88 \\
\hline I.G.T. & 18-Dec-85 & 9:30 AM & 90 & 1018 & 8.00 \\
\hline I.G.T. & 15-Jan-86 & 7:00 AM & 225 & 1015 & 7.86 \\
\hline I.G.T. & $7-\mathrm{Feb}-86$ & 9:15 PM & 208 & 518 & 9.11 \\
\hline I.G.T. & 7-Feb-86 & 9:15 PM & 208 & 518 & 9.14 \\
\hline I.G.T. & 8-Feb-86 & $8: 45 \mathrm{AM}$ & 260 & 1024 & 7.39 \\
\hline I.G.T. & 8-Feb-86 & $12: 44 \mathrm{PM}$ & 280 & 1021 & 7.79 \\
\hline I.G.T. & 10-Feb-86 & 1:10 PM & 294 & 1015 & 7.75 \\
\hline I.G.T. & 12-Feb-86 & 3:05 PM & 297 & 1020 & 7.88 \\
\hline I.G.T. & 12-Feb-86 & 7:00 PM & 298 & 1024 & 7.77 \\
\hline atherly & 8-Oct-83 & $12: 00 \mathrm{PM}$ & 97 & 500 & 10.63 \\
\hline eatherly & 28-Oct-83 & 12:00 PM & 275 & 515 & 10.31 \\
\hline Veatherly & 14-Jan-84 & $12: 00 \mathrm{PM}$ & 227 & 769 & 9.09 \\
\hline Veatherly & 18-Jan-84 & 2:00 PM & 100 & 765 & 6.80 \\
\hline Neatherly & 24-Jan-84 & $12: 00 \mathrm{PM}$ & 110 & 1015 & 7.89 \\
\hline therly & 26-Jan-84 & $12: 00 \mathrm{PM}$ & 100 & 1021 & 7.81 \\
\hline atherly & 27-Jan-84 & 12:00 PM & 245 & 1016 & 7.83 \\
\hline Veather & 7-Feb-84 & 12:00 PM & 88 & 1015 & 7.77 \\
\hline Veathe & 9-Feb-84 & $12: 00 \mathrm{PM}$ & 93 & 1015 & 7.29 \\
\hline Neather & 29-Feb-84 & 11:00 AM & 88 & 324 & 12.74 \\
\hline
\end{tabular}

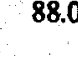


DOE Gladys McCall Well No. 1 Well -- Sand 8

Analysis of Gas Samples Taken During Flow Test

(Cont.)

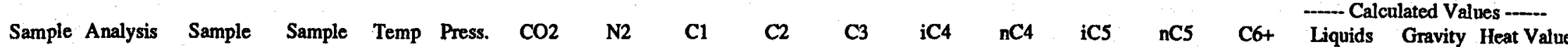
Point Lab Date Time ( ${ }^{\circ}$ F) (psig) (Mol \%) (Mol \%) (Mol \%) (Mol \%) (Mol \%) (Mol \%) (Mol \%) (Mol \%) (Mol \%) (Mol \%) GAL/MCF (Air=1.0) (BTU/SCF)

\begin{tabular}{|c|c|c|c|c|c|c|c|c|c|c|c|c|c|c|c|c|c|}
\hline & & & & & & & & & & & & & & & & & \\
\hline 4 & Weatherly & 3-Mar-84 & 10:00 AM & 92 & 419 & 11.61 & 0.24 & 85.03 & 2.27 & 0.50 & 0.08 & 0.07 & 0.02 & 0.01 & 0.17 & 0.89 & 0.691 \\
\hline 4 & Weatherly & 4-Jun-84 & $12: 00 \mathrm{PM}$ & 102 & 1005 & 8.15 & 0.27 & 88.20 & 2.44 & 0.56 & 0.10 & 0.08 & 0.03 & 0.02 & 0.15 & 0.96 & 0.659 \\
\hline 4 & Weatherly & 29-Jun-84 & $12: 00 \mathrm{PM}$ & 78 & 945 & 7.82 & 0.26 & 88.66 & 2.45 & 0.56 & 0.10 & 0.08 & 0.02 & 0.01 & 0.04 & 0.91 & 0.653 \\
\hline 4 & Weatherly & 4-Jun-84 & $12: 00 \mathrm{PM}$ & 105 & 957 & 8.14 & 0.27 & 88.23 & 2.46 & 0.57 & 0.10 & 0.08 & 0.02 & 0.01 & 0.12 & 0.95 & 0.658 \\
\hline 4 & Weatherly & 18-Jul-84 & 2:00 PM & 97 & 1015 & 7.80 & 0.25 & 88.59 & 2.46 & 0.56 & 0.10 & 0.08 & 0.02 & 0.01 & 0.13 & 0.95 & 0.655 \\
\hline 4 & Weatherly & 20-Jul-84 & 12:00 PM & 95 & 1015 & 7.83 & 0.26 & 88.57 & 2.46 & 0.56 & 0.10 & 0.08 & 0.02 & 0.01 & 0.11 & 0.94 & 0.655 \\
\hline 4 & Weatherly & 22-Jul-84 & $12: 00 \mathrm{PM}$ & 101 & 995 & 9.31 & 0.69 & 86.70 & 2.45 & 0.53 & 0.09 & 0.07 & 0.02 & 0.01 & 0.13 & 0.93 & 0.671 \\
\hline 4 & Weatherly & 24-Jul-84 & $12: 00 \mathrm{PM}$ & 94 & 1018 & 7.82 & 0.27 & 88.53 & 2.46 & 0.56 & 0.10 & 0.08 & 0.02 & 0.01 & 0.15 & 0.96 & 0.656 \\
\hline 4 & Weatherly & 26-Jul-84 & 12:00 PM & 82 & 1020 & 7.88 & 0.26 & 88.50 & 2.46 & 0.56 & 0.10 & 0.08 & 0.02 & 0.01 & 0.13 & 0.95 & 0.656 \\
\hline 4 & Weatherly & 22-Aug-84 & $12: 00 \mathrm{PM}$ & 87 & 940 & 9.99 & 0.30 & 86.56 & 2.33 & 0.52 & 0.09 & 0.07 & 0.02 & 0.01 & 0.11 & 0.89 & 0.675 \\
\hline 4 & Weatherly & 12-Oct-84 & 12:10 PM & 87 & 1039 & 7.89 & 0.31 & 88.44 & 2.47 & 0.56 & 0.10 & 0.08 & 0.02 & 0.01 & 0.12 & 0.95 & 0.656 \\
\hline 4 & Weatherly & 6-Dec-84 & 12:00 PM & 210 & 1031 & 7.54 & 0.28 & 88.71 & 2.48 & 0.57 & 0.10 & 0.08 & 0.02 & 0.01 & 0.21 & 0.99 & 0.655 \\
\hline 4 & Weatherly & 6-Dec-84 & 12:00 PM & 72 & 1010 & 9.24 & 0.27 & 87.34 & 2.28 & 0.51 & 0.08 & 0.07 & 0.03 & 0.02 & 0.16 & 0.90 & 0.669 \\
\hline 4 & Weatheriy & 28-Feb-85 & 12:00 PM & 80 & 1024 & 7.81 & 0.27 & 88.46 & 2.49 & 0.59 & 0.11 & 0.09 & 0.02 & 0.02 & 0.14 & 0.98 & 0.657 \\
\hline 4 & I.G.T. & 15-Jan-86 & $6: 00 \mathrm{AM}$ & 88 & 1015 & 7.42 & 0.27 & 89.07 & 2.41 & 0.55 & 0.09 & 0.07 & 0.01 & 0.01 & 0.10 & 0.91 & 0.650 \\
\hline 4 & I.G.T. & 9-Feb-86 & 2.50 PM & 285 & 1025 & 7.70 & 0.21 & 88.84 & 2.40 & 0.54 & 0.10 & 0.08 & 0.00 & 0.00 & 0.13 & 0.92 & 0.653 \\
\hline 4 & I.G.T. & 9-Feb-86 & 7:21 PM & 285 & 1025 & 7.73 & 0.24 & 88.70 & 242 & 0.57 & 0.10 & 0.08 & 0.01 & 0.00 & 0.15 & 0.95 & 0.655 \\
\hline 4 & I.G.T. & 10-Feb-86 & 1:18 PM & 293 & 1016 & 7.80 & 0.23 & 88.52 & 2.47 & 0.60 & 0.11 & 0.09 & 0.03 & 0.02 & 0.13 & 0.98 & 0.656 \\
\hline 4 & I.G.T. & 12-Feb-86 & 11:10 AM & 295 & 1035 & 7.88 & 0.26 & 88.55 & 2.43 & 0.55 & 0.09 & 0.08 & 0.02 & 0.01 & 0.13 & 0.94 & 0.656 \\
\hline 4 & I.G.T. & 19-Feb-87 & $10: 50 \mathrm{AM}$ & 90 & 1015 & 7.91 & 0.25 & 88.57 & 2.40 & 0.53 & 0.08 & 0.07 & 0.02 & 0.02 & 0.15 & 0.93 & 0.656 \\
\hline 4 & I.G.T. & 13-Apr-87 & 12:30 PM & 95 & 1013 & 8.17 & 0.25 & 88.36 & 2.44 & 0.54 & 0.08 & 0.07 & 0.02 & 0.01 & 0.06 & 0.90 & 0.656 \\
\hline 4 & I.G.T. & 13-Apr-87 & 5:10 PM & 83 & 514 & 11.06 & 0.23 & 85.75 & 2.26 & 0.48 & 0.07 & 0.06 & 0.01 & 0.02 & 0.06 & 0.83 & 0.682 \\
\hline 4 & I.G.T. & 13-Apr-87 & $6: 20 \mathrm{PM}$ & 79 & 515 & 11.11 & 0.23 & 85.69 & 2.28 & 0.49 & 0.07 & 0.03 & 0.02 & 0.01 & 0.07 & 0.83 & 0.683 \\
\hline 4 & I.G.T. & 14-Apr-87 & 7:25 AM & 80 & 515 & 10.87 & 0.22 & 85.95 & 2.23 & 0.47 & 0.07 & 0.08 & 0.02 & 0.01 & 0.08 & 0.83 & 0.681 \\
\hline 4 & I.G.T. & 14-Apr-87 & $2: 50 \mathrm{PM}$ & 91 & 517 & 11.17 & 0.23 & 85.55 & 2.30 & 0.49 & 0.07 & 0.07 & 0.02 & 0.01 & 0.09 & 0.86 & 0.685 \\
\hline 4 & I.G.T. & 14-Apr-87 & 10:00 PM & 85 & 519 & 11.01 & 0.25 & 85.75 & 2.27 & 0.48 & 0.07 & 0.06 & 0.02 & 0.02 & 0.07 & 0.84 & 0.683 \\
\hline 4 & I.G.T. & 15-Apr-87 & $6: 25 \mathrm{AM}$ & 73 & 515 & 11.09 & 0.22 & 85.70 & 2.29 & 0.49 & 0.07 & 0.06 & 0.00 & 0.00 & 0.08 & 0.84 & 0.683 \\
\hline 4 & I.G.T. & 20-Apr-87 & 4:50 PM & 78 & 1015 & 8.07 & 0.25 & 88.47 & 2,42 & 0.54 & 0.08 & 0.08 & 0.02 & 0.02 & 0.05 & 0.90 & 0.655 \\
\hline 4 & I.G.T. & 27-Apr-87 & 9:45 AM & 100 & 1020 & 8.09 & 0.24 & 88.42 & 2.44 & 0.55 & 0.08 & 0.07 & 0.02 & 0.02 & 0.07 & 0.91 & 0.656 \\
\hline 5 & Weatherly & 8-Oct-83 & 12:00 PM & 97 & 500 & 39.89 & 0.00 & 57.73 & 1.39 & 0.19 & 0.02 & 0.02 & 0.00 & 0.00 & 0.76 & 0.76 & 0.969 \\
\hline 5 & Weatherly & 28-Oct-83 & $12: 00 \mathrm{PM}$ & 275 & 515 & 40.74 & 0.00 & 57.21 & 1.35 & 0.19 & 0.02 & 0.02 & 0.00 & 0.00 & 0.47 & 0.63 & 0.970 \\
\hline 5 & Weatherly & 14-Jan-84 & $12: 00 \mathrm{PM}$ & 227 & 769 & 34.05 & 0.00 & 63.44 & 1.62 & 0.46 & 0.07 & 0.03 & 0.04 & 0.00 & 0.29 & 0.74 & 0.906 \\
\hline 5 & Weatherly & 18-Jan-84 & $2: 00 \mathrm{PM}$ & 275 & 765 & 32.79 & 0.00 & 65.18 & 1.51 & 0.29 & 0.04 & 0.03 & 0.01 & 0.01 & 0.14 & 0.58 & 0.887 \\
\hline 5 & Weatherly & 24-Jan-84 & $12: 00 \mathrm{PM}$ & 275 & 1015 & 25.53 & 0.00 & 72.62 & 1.52 & 0.19 & 0.02 & 0.02 & 0.00 & 0.00 & 0.10 & 0.52 & 0.814 \\
\hline
\end{tabular}


Sample Analysis Sample Sample Temp Press. $\mathrm{CO} 2 \quad \mathrm{~N} 2 \quad \mathrm{C1} \quad \mathrm{C2} \quad \mathrm{C3}$ iC4 nC4 iC5 nC5 C6+ Liquids Gravity Heat Value

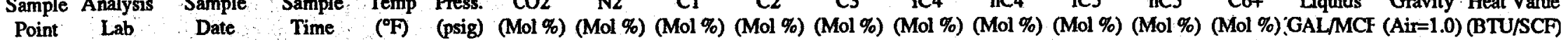

Point Lab Date Time (

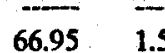

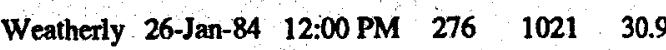

Weatherly 27-Jan-84 $12: 00$ PM $276,1016 \quad 30.87$

Weatherly 7-Feb-84 10:30 AM $282 \quad 1015 \quad 34.30$

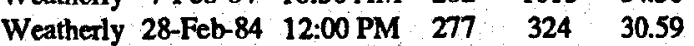

Weatherly 3-Mar-84 10:00 AM 277

Weatherly $18-\mathrm{Jul}-84 \quad 12: 00 \mathrm{PM} \quad 97$

Weatherly 24-Jul-84 12:00 PM $94 \quad 1018 \quad 34.76$

Weatherly 26-Jul-84 12.00 PM 82

I.G.T. 7-Feb-86 9:10 PM 208

I.G.T. $\quad 8$-Feb-86 $8: 54$ AM $264 \quad 1031 \quad 28.47$

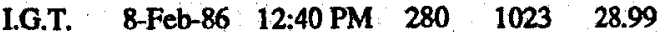

IGT 10-Feb-86 1.25 PM $295 \quad 1017 \quad 23.50$

$\begin{array}{llllll}\text { I.G.T. 10-Feb-86 } & 4: 00 \text { PM } & 298 & 1014 & 25.00\end{array}$

I.G.T. 11-Feb-86 10:34 AM $306 \quad 1020 \quad 27.98$

IG.T $\quad 11$-Feb-86 1114 AM $289 \quad 1022 \quad 25.98$

I.G.T. 11-Feb-86 11:38 AM $291 \quad 1019 \quad 25.87$

I.G.T. 11-Feb-86 12.24 PM $294 \quad 1020 \quad 26.04$

IGT $11-\mathrm{Feb}-86 \quad 2: 30 \mathrm{PM} \quad 302 \quad 1018 \quad 27.31$

I.G.T. 14-Apr-87 10:30 AM 280 515 30.46

I.G.T. 14-Apr-87 $3: 20$ PM $280 \quad 516 \quad 28.90$

I.G.T. 14-Apr-87 10:30 PM 285 519 28.36

IGT 15-Apr-87 7:10 AM 285 $515 \quad 29.34$

I.G.T 20-Apr-87 5:40 PM $284 \quad 1015 \quad 31.01$

Weatherly 14-Jan-84 4:00 PM 226

Weatherty 24-Jan-84 12:00 PM 220

Weatherly 26-Jan-84,12:00 PM 230

Wenty 27-Jan-84 $12: 00$ PM $250 \quad 319 \quad 18.95$

Weatherly 9-Feb-84 12.00 PM 252

$\begin{array}{llll}\text { Weatherly } & 18-J u l-84 & 2: 00 \text { PM } & 223 \\ \text { Weatherly } & 20-J u l-84 & 12.00 ~ P M & 225\end{array}$

Weatherly 24-Jul-84 1:00 PM 22

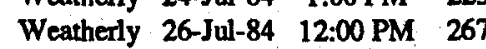

0.00

$0.00 \quad 67.36$

$\begin{array}{lll}0.00 & 63.94 & 1.36\end{array}$

$\begin{array}{lll}0.00 & 67.53 & 1.49\end{array}$

0.00

0.00

0.00

0.00

0.00

\subsection{0}

0.00
0.00

0.00

0.00

0.00

1.02

0.66
0.50
0.70

0.50

0.70
0.50

0.16

0.19

0.18

0.16

0.18

0.19

41515.98

$318 \quad 19.63$

$269 \quad 22.24$ $\begin{array}{lll}72.58 & 1.59 & 0.23\end{array}$

$\begin{array}{lll}65.78 & 0.22 & 0.02\end{array}$

$\begin{array}{lll}65.25 & 1.55 & 0.18\end{array}$

$63.66 \quad 1.29$

$65.60 \quad 139$

$\begin{array}{llll}69.85 & 1.38 & 0.18\end{array}$

$69.31 \quad 1.38$

$74.69 \quad 1.49$

$73.20 \quad 1.47$

$\begin{array}{lll}70.27 & 1.40 & 0.20\end{array}$

$72.25 \quad 1.43$

$72.36 \quad 1.43$

$72.19 \quad 1.43$

$\begin{array}{llll}68.58 & 1.49 & 0.22\end{array}$

$69.36 \quad 1.46$

$68.20 \quad 1.43$

$66.79: \quad 1.38$

$78.33 \quad 1.81$

$83.74 \quad 1.94$

$81.61 \quad 1.85$

$78.55 \quad 1.75$

$81.88 \quad 1.78$

$80.23 \quad 1.7$

$81.54 \quad 1.83$

$77.60 \quad 1.68$

$\begin{array}{ll}75.30 & 1.63\end{array}$

\begin{tabular}{|l|l|}
\hline 0.05 & 0.02 \\
\hline 0.02 & 0.02 \\
\hline 0.02 & 0.02 \\
\hline 0.03 & 0.03 \\
0.02 & 0.02 \\
\hline & \\
\hline 0.00 & 0.00 \\
0.01 & 0.01 \\
\hline 0.01 & 0.02 \\
0.02 & 0.02 \\
0.01 & 0.01 \\
\hline 0.02 & 0.01 \\
\hline 0.02 & 0.02 \\
0.02 & 0.02 \\
\hline 0.02 & 0.02 \\
0.02 & 0.02 \\
\hline 0.02 & 0.02 \\
\hline 0.02 & 0.02 \\
\hline 0.02 & 0.02 \\
\hline 0.02 & 0.02 \\
\hline 0.02 & 0.02 \\
\hline 0.02 & 0.02 \\
\hline 0.02 & 0.02 \\
\hline 0.02 & 0.02 \\
\hline 0.01 & 0.01 \\
\hline 0.03 & 0.03 \\
\hline 0.04 & 0.03 \\
\hline 0.03 & 0.03 \\
\hline 0.03 & 0.02 \\
\hline 0.03 & 0.03 \\
\hline 0.03 & 0.02 \\
\hline 0.03 & 0.03 \\
0.03 & 0.03 \\
0.03 & 0.03 \\
0.02 & 0.02 \\
\hline & \\
\hline
\end{tabular}

$\begin{array}{ll}0.00 & 0.11 \\ 0.00 & 0.13 \\ 0.00 & 0 . \\ 0.01 & 0.0\end{array}$

$0.00 \quad 0.09$

$0.08 \quad 0.02$

0.00

0.01

0.01

$0.00 \quad 0.09$

$0.00 \quad 0.10$

$0.00 \quad 0.07$

$0.00 \quad 0.09$
0.00

$0.00 \quad 0.12$

$0.00 \quad 0.11$

$0.00 \quad 0.11$

$0.00 \quad 0.11$

$\begin{array}{ll}0.00 & 0.12 \\ 0.00 & 0.10\end{array}$

$0.00 \quad 0.11$

$0.00 \quad 0.08$

$0.00 \quad 0.10$

0.00

$0.01 \quad 0.43$

$0.00 \quad 0.21$

$0.00 \quad 0.27$

$0.00 \quad 0.28$

0.02

0.00

0.01

0.00

\begin{tabular}{|c|c|c|}
\hline & & \\
\hline 0.60 & 0.869 & 724 \\
\hline 0.51 & 0.866 & 721 \\
\hline 0.51 & 0.900 & 687 \\
\hline 0.53 & 0.864 & 724 \\
\hline 0.55 & 0.814 & 776 \\
\hline 0.10 & 0.886 & 676 \\
\hline 0.49 & 0.884 & 696 \\
\hline 0.45 & 0.902 & 679 \\
\hline 0.55 & 0.885 & 708 \\
\hline 0.46 & 0.856 & 727 \\
\hline 0.47 & 0.842 & 743 \\
\hline 0.48 & 0.847 & 738 \\
\hline 0.51 & 0.794 & 794 \\
\hline 0.51 & 0.809 & 779 \\
\hline 0.50 & 0.838 & 750 \\
\hline 0.50 & 0.818 & 770 \\
\hline 0.50 & 0.817 & 771 \\
\hline 0.50 & 0.819 & 769 \\
\hline 0.50 & 0.832 & 757 \\
\hline 0.51 & 0.866 & 714 \\
\hline 0.53 & 0.850 & 734 \\
\hline 0.50 & 0.843 & 740 \\
\hline 0.50 & 0.854 & 728 \\
\hline 0.48 & 0.868 & 712 \\
\hline 0.79 & 0.762 & 858 \\
\hline 0.73 & 0.705 & 904 \\
\hline 0.72 & 0.727 & 884 \\
\hline 0.68 & 0.758 & 849 \\
\hline 0.67 . & 0.724 & 881 \\
\hline 0.68 & 0.741 & 866 \\
\hline 0.71 & 0.703 & 905 \\
\hline 0.66 & 0.726 & 875 \\
\hline 0.74 & 0.769 & 847 \\
\hline 0.63 & 0.789 & 813 \\
\hline
\end{tabular}


DOE Gladys McCall Well No. 1 Well -- Sand 8

Analysis of Gas Samples Taken During Flow Test

(Cont.)

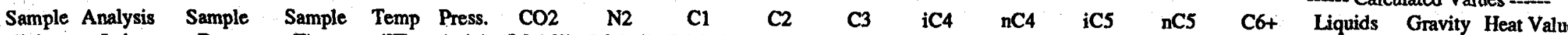
Point Lab Date Time ( ${ }^{\circ} \mathrm{F}$ (psig) (Mol \%) (Mol \%) (Mol \%) (Mol \%) (Mol \%) (Mol \%) (Mol \%) (Mol \%) (Mol \%) (Mol \%) GAI MCF (Ais=1 (O) (BTU/SC)

$\begin{array}{lll}0.81 & 60.25 & 1.05 \\ 0.97 & 58.81 & 1.06\end{array}$

0.02

0.00

0.00
0.02
0.00

0.13

\subsection{2}

\subsection{6}

827

891

0.731

864

$\begin{array}{lll}0.00 & 0.07 & 0.61 \\ 0.00 & 0.05 & 0.69\end{array}$

$\begin{array}{llllllllll}83.73 & 2.01 & 0.35 & 0.04 & 0.03 & 0.01 & 0.00 & 0.05 & 0.69 \\ 83.35 & 2.06 & 0.36 & 0.04 & 0.04 & 0.00 & 0.00 & 0.07 & 0.72\end{array}$

\subsection{3}

$\begin{array}{lllll}0.01 & 0.00 & 0.00 & 0.12 & 0.36\end{array}$

0.36

0.980

0.954

0.946

$1.007 \quad 565$

$0.986 \quad 582$

$\begin{array}{lllllllllll}54.52 & 1.00 & 0.10 & 0.01 & 0.01 & 0.00 & 0.00 & 0.11 & 0.35 & 0.992 & 580\end{array}$

$\begin{array}{lllllllllll}57.81 & 1.03 & 0.10 & 0.01 & 0.01 & 0.00 & 0.00 & 0.09 & 0.35 & 0.960 & 612\end{array}$

$\begin{array}{lllllllll}0.11 & 0.01 & 0.01 & 0.00 & 0.00 & 0.11 & 0.38 & 0.978 & 596\end{array}$

$\begin{array}{ll}0.978 & 596 \\ 0.995 & 575\end{array}$

$\begin{array}{ll}0.995 & 575 \\ 1.016 & 559\end{array}$

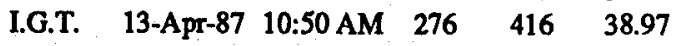

0.01
0.01
0.00
0.01
0.01

$\begin{array}{ll}0.01 & 0.00 \\ 0.01 & 0.00 \\ 0.01 & 0.00 \\ 0.00 & 0.00\end{array}$

$0.00 \quad 0.07$

\section{$0.00 \quad 0.06$}

$\begin{array}{ll}0.00 & 0.09 \\ 0.00 & 0.13\end{array}$

$\begin{array}{ll}0.00 & 0.13 \\ 0.00 & 0.08\end{array}$

0.01

0.00

$0.00 \quad 0.07$ 
DOE Gladys McCall Well No. 1 Well -- Sand 8

Analysis of Gas Samples Taken During Flow Test

(Cont.)

Sample Analysis Sample Sample Temp Press. $\mathrm{CO} 2$ N2 C1 C2 C3 iC4 nC4 iC5 nC5 C6+ Liquids Gravity Heat Value

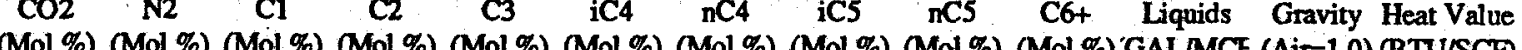

8

418

I.G.T. 14-Apr-87 9:00 AM 280

IG.T 14-Apr-87 4:00 PM 275

LG.T, 14-Apr-87 9:15 PM 280

I.G.T. 27-Apr-87 10:00 AM 274

Weatherty 12-Oct-84 12:42 PM 98

Weatherly 28-Feb-85 12.00 PM 67

Weatherly 28-Feb-85 12:00 PM 62

I.G.T. 15-Jan-86 8:55 AM

I.G.T. 11-Feb-86 9:50 AM 65

I.G.T. 11-Feb-86 11:33 PM 62

L.G.T. 12-Feb-86 10:55 AM

I.G.T. 19-Feb-87 9:15 AM 69

I.G.T. 19-Feb-87 11:10 AM 72

I.G.T. 13-Apr-87 10:15 AM 88

I.G.T. 27-Apr-87 11:35 AM 92

La Res. 29-May-84 12:00 PM 76

La. Res. 29-Jun-84 12:00 PM 78

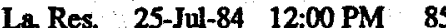

La Res: 24-Aug-84 12:00 PM 81

La Res 24-Sep-84 12:00 PM 84

La. Res. 22-Oct-84 12:00 PM 78

La Res. 22-Oct-84 12:00 PM 78

La Res. 28-Nov-84 12:00 PM 60

La. Res. 21-Dec-84 12:00 PM

La. Res. 22-Jan-85 12:00 PM

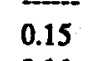

0.01

0.01

0.00

0.00

$\overline{0.07}$

0.42

0.894

679

0.78
0.70

$70.52 \quad 1.43$

0.18

$\begin{array}{lll}0.18 & 0.01 & 0.01\end{array}$

0.00

0.00

0.10

0.45

0.48
0.47

0.35

0.886

0.830

0.935

735

749

$\begin{array}{llllll}1015 & 10.15 & 0.26 & 86.52 & 2.32\end{array}$

$1024 \quad 9.15$

$1019 \quad 8.93$

$\begin{array}{lll}0.27 & 87.32 & 239\end{array}$

$0.50 \quad 0.08$

0.54

0.10

0.07

0.02

0.01

0.86

0.92
0.93

0.675

0.668

0.668

941

955

956

$1015 \quad 9.96$

$1019 \quad 9.45$

$\begin{array}{ll}1020 & 9.36 \\ 1040 & 9.49\end{array}$

$\begin{array}{lll}0.21 & 86.88 & 2.26\end{array}$

0.21
0.24

87.31

0.5

$\begin{array}{lll}0.02 & 0.01 & 0.15 \\ 0.00 & 0.00 & 0.04\end{array}$

0.8

0.671

0.49

0.08

0.08
0.08

0.07

0.07

0.01
0.02

0.02

$0.00 \quad 0.04$
0.01

$0.01 \quad 0.05$

0.82
0.84

0.86

0.667

0.668

941

949

$985 \quad 9.88$

$990 \quad 9.81$

$\begin{array}{lll}0.24 & 86.91 \quad 2.28\end{array}$

0.48

0.07

0.06

0.02

0.01

$1010 \quad 8.91$

$\begin{array}{lll}0.23 & 87.64 & 234\end{array}$

0.49

$0.07 \quad 0.06$

$927 \quad 9.04$

935.8 .49

$\begin{array}{lll}0.25 & 87.55 \quad 2.33\end{array}$

0.5

$\begin{array}{llllll}825 & 8.42 & 0.25 & 88.10 & 2.38\end{array}$

$\begin{array}{llllll}970 & 8.06 & 0.26 & 88.43 & 2.40\end{array}$

$215 \quad 7.83$

0.32

$250 \quad 9.76$

$170 \quad 9.64$

$\begin{array}{lll}0.25 & 87.09 & 2.21\end{array}$

$\begin{array}{lll}0.24 & 88.75 & 2.25\end{array}$

$0.26 \quad 86.92$

$86.02 \quad 2.27$

L. Res. 22-Jan-85 12:00 PM 30

La. Res. 21-Feb-85 12:00 PM 67

La. Res. 21-Feb-85 12:00 PM

$975 \quad 9.60$

$0.25 \quad 87.02$

$210 . \quad 9.50$

La. Res. 22-Mar-85 12:00 PM 66

$960 \quad 10.39$

$\begin{array}{lll}0.27 & 86.92 & 2.40 \\ 0.25 & 87.18 & 2.24\end{array}$

$87.18 \quad 2.24$

$87.01 \quad 2.25$

La. Res. 22-Mar-85 12:00 PM

$205 \quad 9.71$
$0.55 \quad 0.09$

0.56

0.55
0.56

0.51

0.57

0.47

$0.49 \quad 0.09$

$\begin{array}{lll}0.53 & 0.09 & 0.07\end{array}$

$\begin{array}{lll}0.54 & 0.10 & 0.08\end{array}$

$\begin{array}{lll}0.52 & 0.09 & 0.08 \\ 0.52 & 0.08 & 0.07\end{array}$ $\begin{array}{lll}0.02 & 0.01 & 0.04 \\ 0.00 & 0.01 & 0.01\end{array}$

0.02

$0.01 \quad 0.01$

$\begin{array}{lll}0.02 & 0.01 & 0.11\end{array}$

0.02

0.01

0.01
0.02

0.01

0.0

0.02

$\begin{array}{lll}0.02 & 0.01 & 0.13\end{array}$

$\begin{array}{lll}0.06 & 0.02 & 0.18\end{array}$

$\begin{array}{lll}0.02 & 0.01 & 0.05 \\ 0.01 & 0.01 & 0.04\end{array}$ $\begin{array}{lll}0.01 & 0.01 & 0.03\end{array}$

\begin{tabular}{|c|c|c|c|c|c|c|c|c|}
\hline 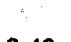 & 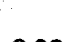 & 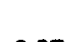 & 0 & ( & . & 2 & 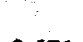 & $\therefore$ \\
\hline 0.49 & 0.08 & 0.07 & 0.01 & 0.00 & 0.04 & 0.82 & 0.671 & 941 \\
\hline 0.49 & 0.08 & 0.07 & 0.02 & 0.01 & 0.05 & 0.84 & 0.667 & 947 \\
\hline 0.51 & 0.08 & 0.07 & 0.02 & 0.01 & 0.06 & 0.86 & 0.667 & 949 \\
\hline$\therefore$ & 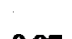 & 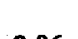 & 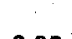 & $\therefore$ & 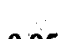 & $\therefore$ & $\therefore$ & $\therefore$ \\
\hline 0.48 & 0.07 & 0.06 & 0.02 & 0.01 & 0.05 & 0.83 & 0.671 & 942 \\
\hline 0.50 & 0.07 & 0.06 & 0.02 & 0.01 & 0.04 & 0.84 & 0.670 & 943 \\
\hline 0.49 & 0.07 & 0.07 & 0.00 & 0.01 & 0.01 & 0.83 & 0.663 & 948 \\
\hline $0=8$ & $m$ & n & PM & 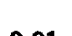 & 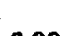 & 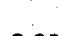 & S & $\cdots$ \\
\hline 0.55 & 0.09 & 0.08 & 0.02 & 0.01 & 0.08 & 0.89 & 0.665 & 954 \\
\hline 0.55 & 0.09 & 0.07 & 0.01 & 0.01 & 0.03 & 0.86 & 0.658 & 957 \\
\hline 0.56 & 0.09 & 0.08 & 0.02 & 0.01 & 0.09 & 0.91 & 0.660 & 961 \\
\hline 0.55 & 0.09 & 0.07 & 0.02 & 0.01 & 0.11 & 0.92 & 0.657 & 965 \\
\hline 08 & 00 & 307 & 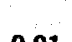 & 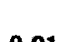 & 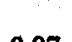 & 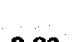 & 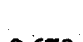 & 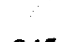 \\
\hline 0.31 & 0.08 & 0.07 & 0.01 & 0.01 & 0.07 & 0.83 & 0.670 & 945 \\
\hline 0.37 & 0.11 & 0.09 & 0.02 & 0.01 & 0.06 & 0.88 & 0.654 & 965 \\
\hline 0.47 & 0.07 & 0.06 & 0.01 & 0.01 & 0.07 & 0.86 & 0.670 & 944 \\
\hline 0.52 & 0.08 & 0.07 & 0.01 & 0.00 & 0.03 & 0.83 & 0.669 & 943 \\
\hline 0 & 0 & $\mathrm{~m}$ & 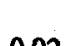 & 001 & 12 & Oas & $0<7$ & 0 \\
\hline 0.49 & 0.09 & 0.07 & 0.02 & 0.01 & 0.13 & 0.91 & 0.671 & 949 \\
\hline 0.33 & 0.09 & 0.01 & 0.02 & 0.01 & 0.05 & 0.84 & 0.669 & 946 \\
\hline 0.34 & 0.10 & 0.08 & 0.06 & 0.02 & 0.18 & 0.93 & 0.673 & 954 \\
\hline 0.32 & 0.09 & 0.08 & 0.02 & 0.01 & 0.05 & 0.83 & 0.676 & 938 \\
\hline
\end{tabular}


DOE Gladys McCall Well No. 1 Well -- Sand 8

Analysis of Gas Samples Taken During Flow Test

(Cont.)

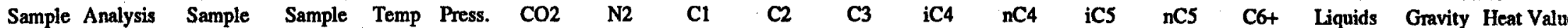
(

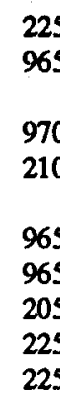

10 La. Res. 22-Aug-85 12:00 PM 87

10 La. Res. 19-Sep-85 12:00 PM 83

La. Res. 19-Sep-85 12:00 PM 83

25-Sep-85 $12.00 \mathrm{PM} 83$

10 La. Res. 22-Oct-85 12:00 PM 80

10 Weatherly 26-Oct-85 12:00 PM 85

10 Weatherl

Weatherly 21-Nov-85 12:00 PM

L.a. Res. 21-Nov-85 12:00 PM

La. Res. 24-Jan-86 12:00 PM 63

I.G.T. 12-Feb-86 10:46 AM 72

La. Res. 24-Mar-86 12:00 PM 66

La. Res. 19-Jun-86 12:00 PM 81

$\begin{array}{llll}\text { La. Res. } & 22-J u l-86 & 12: 00 ~ P M & 80\end{array}$

$\begin{array}{llll}\text { La. Res. } & \text { 21-Aug-86 } & 12 ; 00 \text { PM } 84\end{array}$

10 La. Res. 5-Sep-86 12:00 PM 86

10 La.Res. 23-Sep-86 12:00 PM 85

10 La Res. 21-Oct-86 12:00 PM 85

10 La. Res. 21-Nov-86 12:00 PM 70

10 La. Res. 17-Dec-86 12:00 PM 5

10 La. Res. 16-Jan-87 12:00 PM 5

$\begin{array}{lllll}10 & \text { La. Res. } & 23-F e b-87 & 12: 00 ~ P M & 60 \\ 10 & \text { La. Res. } & 24-M a r-87 & 12: 00 ~ P M & 85\end{array}$

$\begin{array}{llll}10 & \text { La. Res. } & \text { 21-Apr-87 } & \text { 12:00 PM }\end{array}$

\begin{tabular}{cccc}
\hline 225 & 9.33 & 0.20 & 87.4 \\
965 & 9.44 & 0.26 & 87.08 \\
& 10.64 & 0.25 & 86.1 \\
970 & 10.64 & 0.25 & 86.13 \\
210 & 10.00 & 0.25 & 86.81 \\
& & & \\
965 & 9.94 & 0.82 & 86.23 \\
965 & 10.27 & 0.24 & 86.4 \\
205 & 10.34 & 0.25 & 86.42 \\
225 & 9.80 & 0.25 & 86.7 \\
225 & 9.81 & 0.29 & 86.66 \\
& & & \\
925 & 9.99 & 0.30 & 86.56 \\
990 & 10.15 & 0.25 & 86.5 \\
200 & 10.18 & 0.27 & 86.57 \\
990 & 10.11 & 0.30 & 86.35 \\
205 & 9.96 & 0.26 & 86.70 \\
& & & \\
985 & 10.00 & 0.29 & 86.55 \\
965 & 7.33 & 0.26 & 89.22 \\
200 & 9.90 & 0.25 & 86.84 \\
975 & 8.67 & 0.26 & 87.89 \\
205 & 9.51 & 0.27 & 87.18 \\
& & & \\
1052 & 9.41 & 0.23 & 87.28 \\
195 & 9.72 & 0.26 & 86.98 \\
985 & 10.02 & 0.27 & 86.74 \\
900 & 10.21 & 0.26 & 86.56 \\
995 & 9.72 & 0.28 & 87.00 \\
& & & \\
1020 & 9.60 & 0.31 & 87.11 \\
800 & 9.66 & 0.27 & 87.00 \\
750 & 9.77 & 0.25 & 86.94 \\
900 & 9.45 & 0.23 & 87.31 \\
1030 & 9.42 & 0.29 & 87.22 \\
& & & \\
1025 & 9.56 & 0.23 & 87.19 \\
650 & 10.02 & 0.24 & 86.78 \\
645 & 9.94 & 0.23 & 86.84 \\
780 & 9.62 & 0.24 & 87.14 \\
& & &
\end{tabular}

87.46

$87.08 \quad 2.38$

$87.08 \quad 2.38$

$86.13 \quad 2.24$

$86.81 \quad 2.25$

$86.23 \quad 2.24$

$86.40 \quad 2.28$

$86.42 \quad 2.27$

$86.77 \quad 2.35$

$86.66 \quad 2.38$

$86.56 \quad 2.33$

$86.52 \quad 2.26$

$86.57 \quad 2.26$

$86.35 \quad 2.32$

$86.70 \quad 2.29$

$\begin{array}{ll}86.55 & 2.32 \\ 89.22 & 2.41\end{array}$

$86.84 \quad 2.26$

$87.89 \quad 239$

$87.18 \quad 2.29$

$87.28 \quad 2.32$

$86.98 \quad 2.28$

$86.56 \quad 2.23$

$87.00 \quad 2.26$

$87.11 \quad 2.26$

$87.00 \quad 2.31$

$86.94 \quad 2.27$

$87.31 \quad 2.26 \quad 0.49$

$\begin{array}{lll}87.22 & 2.27 & 0.53\end{array}$

$\begin{array}{lll}87.19 & 2.27 & 0.5\end{array}$

$\begin{array}{lll}86.78 & 2.23 & 0.50\end{array}$

$\begin{array}{lll}87.14 & 2.25 & 0.49\end{array}$

\begin{tabular}{ll}
\hline 0.53 & 0.10 \\
0.55 & 0.09 \\
0.51 & 0.09 \\
0.50 & 0.08 \\
0.50 & 0.08 \\
& \\
0.50 & 0.08 \\
0.51 & 0.08 \\
0.50 & 0.08 \\
0.54 & 0.09 \\
0.55 & 0.10 \\
& \\
0.52 & 0.09 \\
0.51 & 0.08 \\
0.50 & 0.09 \\
0.52 & 0.09 \\
0.51 & 0.08 \\
& \\
0.52 & 0.08 \\
0.53 & 0.09 \\
0.51 & 0.08 \\
0.52 & 0.09 \\
0.50 & 0.08 \\
& \\
0.50 & 0.08 \\
0.50 & 0.08 \\
0.48 & 0.08 \\
0.48 & 0.08 \\
0.49 & 0.08 \\
0.49 & 0.08 \\
0.49 & 0.08 \\
0.49 & 0.09 \\
0.49 & 0.07 \\
0.53 & 0.07 \\
& \\
0.51 & 0.07 \\
0.50 & 0.07 \\
0.49 & 0.07 \\
0.49 & 0.07 \\
& \\
\hline
\end{tabular}

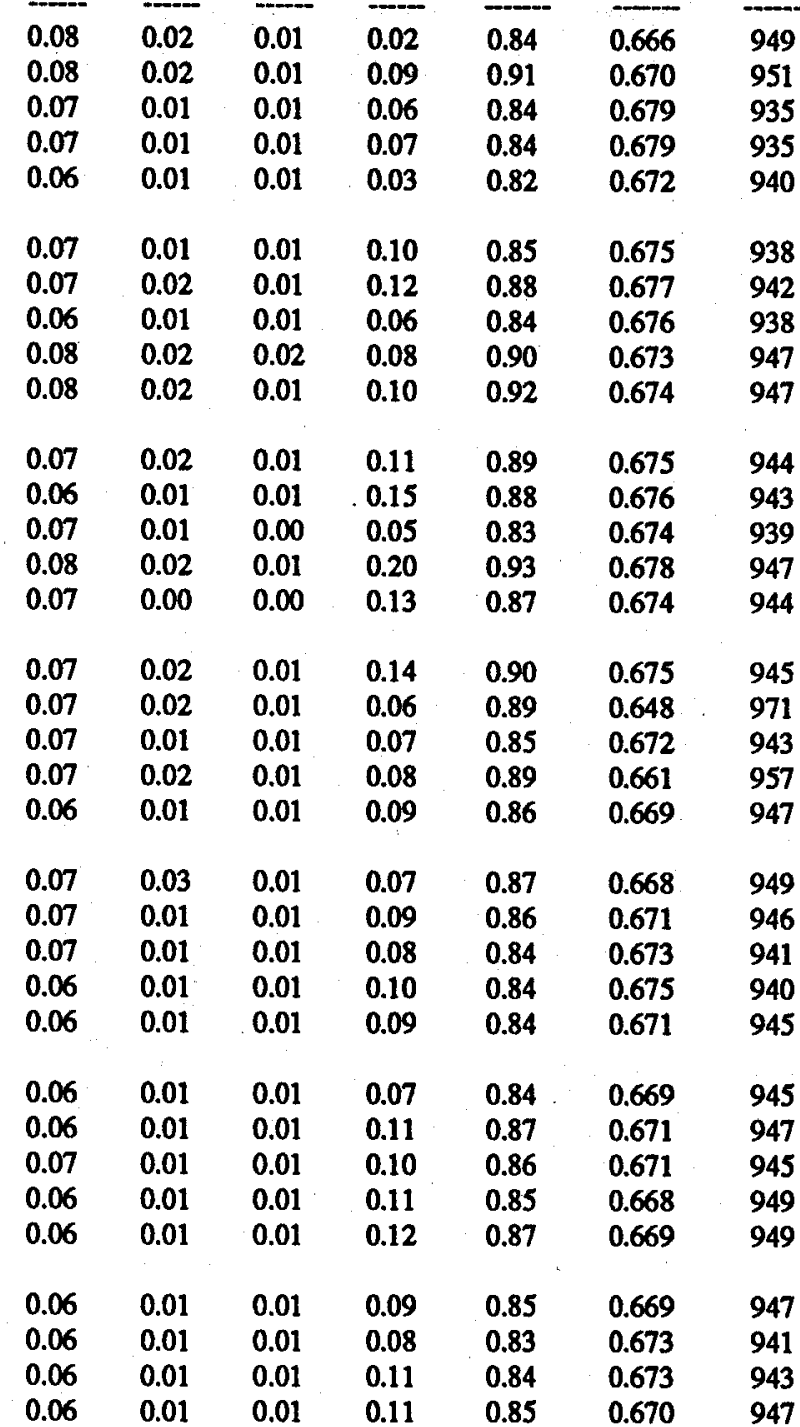


DOE Gladys McCall Well No. 1 Well -- Sand 8

Sample Analysis Sample Sample Temp Press. $\mathrm{CO} 2$ N2 $\mathrm{C1}$ C2 C3 iC4 nC4 iC5 nC5 C6+ Liquids Gravity Heat Value -

(-)

$\begin{array}{ll}-0.50 & 0.07 \\ 0.50 & 0.0 \\ 0.50 & 0.07 \\ 0.51 & 0.08 \\ 0.53 & 0.1 \\ 0.50 & 0.0\end{array}$

\begin{tabular}{ll}
\hline $\mathbf{0 . 0 7}$ & 0.06 \\
$\mathbf{0 . 0 7}$ & 0.06 \\
0.07 & 0 \\
$\mathbf{0 . 0 8}$ & 0.06 \\
0.10 & 0.03 \\
0.09 & 0.07
\end{tabular}

\begin{tabular}{ll}
\hline 0.06 & 0. \\
0.06 & 0.01 \\
0.06 & 0. \\
0.06 & 0. \\
0.03 & 0.03 \\
0.07 & 0.01
\end{tabular}

0.01
0.01
0.01
0.01
0.03
0.01

0.01
0.01
0.01
0.01
0.02
0.01

0.11

$0.11 \quad 0.85$

0.85

$\begin{array}{ll}0.06 & 0.83 \\ 0.05 & 0.83\end{array}$

0.667

0.665 $\begin{array}{llllll}\text { La. Res. } & \text { 24-Jun-87 } & 12: 00 \text { PM } & 85 & 750 & 9.30 \\ \text { La. Res. } 21-J u l-87 & 12: 00 \text { PM } & 85 & 751 & 9.27\end{array}$

\begin{tabular}{llllll} 
La. Res. & $13-A u g-87$ & $12: 00$ PM & 80 & 990 & 9.21 \\
\hline La Res & $28-S e p-87$ & $12: 00$ PM & 85 & 810 & 9.06
\end{tabular}

0.665

0.664

0.667 
Flow tests of the Gladys McCall Well Through OCtober 1990

\section{APPENDIX $\mathrm{H}$}

Calculation of Total Produced Gas

$\mathrm{H}-1$ 

The separator gas combination and the amount of gas recovered from the separators was found to be a function of the separator pressure. Hayden and Randolph (Reference 7 in text) showed that, in the range of separator pressures typically encountered, the hydrocarbon gas solubilities obeyed simple Henry's Law relationships. The Henry's Law constants, however, are different for each hydrocarbon species. The end result is that the concentration of ethane, propane, butanes, etc., to methane in the dissolved gas and with the gas in equilibrium with the brine changes with pressure. The solubility behavior of carbon dioxide is even more complex due to the carbonic acid and bicarbonate ions in solution. Because the quantity and composition of recovered gas varies with separator pressure, a sampling and analysis methodology to quantify total produced gas was followed.

The method of measuring total gas composition used in this study was to mathematically combine the separator gases and gas left in the brine after the separator, using the gas/brine ratio to appropriately weight each fraction. For instance, a typical value for the high-pressure separator gas/brine ratio was 24 SCF/STB. The gas/brine ratio from the low-pressure separator was 3 SCF/STB, and the amount of gas left in the brine after the low-pressure separator was also about 3 SCF/STB. The total gas composition for this hypothetical case would be $80 \%$ of the high-pressure separator gas composition and $10 \%$ each of the lowpressure gas composition and of the composition of gas left in the brine after the low-pressure separator, In cases where the quantity and composition of gas left in the brine after the large separator was determined directly, the composition and quantity of the low-pressure separator gas would not be needed to calculate a total gas composition. It should be noted that the recombination method used herein and described by Hayden and Randolph does not include carbon dioxide remaining in the brine after flashing to atmospheric pressure. There is about $1 \mathrm{SCF} / \mathrm{STB}$ of carbon dioxide that is left out of this calculation. This value was determined on numerous samples by the acid liberation-nitrogen purge technique and an alkalinity titration to determine the quantity of carbon dioxide tied up as bicarbonate.

Sample locations are designated by a sample-point code that is explained on the last page of the table. A default time of 12:00 was entered if no time was recorded. The composition of the total gas is about $84 \%$ methane, $13 \%$ carbon dioxide, $2.2 \%$ ethane, $0.46 \%$ propane, and lesser amounts of nitrogen and heavier hydrocarbons. 
Gladys McCall Sand 8 Total Gas Study

$-1$
GWR

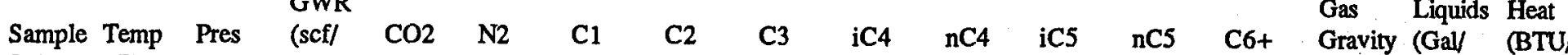

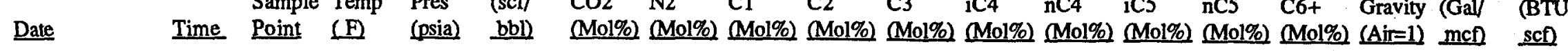

8-Oct-83 8-Oct-83 $\begin{array}{llllllllll}12: 00 & 4 & 97 & 500 & 26.50 & 10.63 & 0.25 & 85.96 & 2.34 & 0.52\end{array}$ Calculated Total Gas

28-Oct-83 28-Oct-83

$12: 00 \quad 4 \quad 27$ $\begin{array}{lll}12: 00 & 5 & 275 \\ \text { Calculated Total Gas }\end{array}$

$\begin{array}{lll}12: 00 & 4 & 227 \\ 16: 00 & 7 & 226\end{array}$

14-Jan-84 14-Jan-84 14-Jan-84 $\begin{array}{lll}16: 00 & 8 & 226\end{array}$

Calculated Total Gas

18-Jan-84

18-Jan-84 I

24-Jan-84

24-Jan-84

24-Jan-84

26-Jan-84

26-Jan-84

26-Jan-84

27-Jan-84

27-Jan-84

27-Jan-84

14:00 $\quad 4 \quad 100$

$\begin{array}{lll}14: 00 & 5 & 275\end{array}$

Calculated Total Gas

$12: 00 \quad 4 \quad-110 \quad 1015$

$\begin{array}{rrrr}12: 00 & 7 & 220 & 515 \\ 12.00 & 8 & 267 & 515\end{array}$

Calculated Total Gas

$\begin{array}{llll}12: 00 & 4 & 100 & 102\end{array}$

$\begin{array}{rrrr}12: 00 & 4 & 100 & 1021 \\ 12: 00 & 7 & 230 & 425 \\ 12: 00 & 8 & 276 & 425\end{array}$

Calculated Total Gas

$\begin{array}{rrrr}12: 00 & 4 & 245 & 1016 \\ 12: 00 & 7 & 250 & 319 \\ 12: 00 & 8 & 267 & 319\end{array}$

Calculated Total Gas

7-Feb-84

7-Feb-84

$\begin{array}{rrr}12: 00 & 4 & 88\end{array}$

$12: 30 \quad 8 \quad 166 \quad 418$

Calculated Total Gas $\begin{array}{lll}30.25 & 14.26 & 0.22\end{array}$

$82.46 \quad 2.22$

$\begin{array}{llll}0.19 & 0.02 & 0.02 & 0.00\end{array}$

$0.48 \quad 0.08$

$\begin{array}{lllll}26.50 & 10.31 & 0.24 & 84.85 & 2.31\end{array}$

$\begin{array}{lllll}3.85 & 40.74 & 0.00 & 57.21 & 1.35\end{array}$

$\begin{array}{lll}30.35 & 14.17 & 0.21\end{array}$

$\begin{array}{lll}24.96 & 9.09 & 0.25\end{array}$

$\begin{array}{lllll}3.05 & 18.89 & 0.16 & 78.14 & 2.41\end{array}$

$\begin{array}{lll}2.33 & 42.66 & 0.00\end{array}$

$\begin{array}{ll}55.89 & 1.09\end{array}$

25.20

$\begin{array}{rrr}25.20 & 6.80 & 0.26 \\ 6.03 & 32.79 & 0.00\end{array}$

$\begin{array}{lll}31.23 & 11.82 & 0.21\end{array}$

$88.76 \quad 2.44$

$65.18 \cdot 1.51$

$84.21 \quad 2.26$

$\begin{array}{ll}88.35 & 2.48\end{array}$

$\begin{array}{llllll}2.49 & 13.54 & 0.19 & 83.74 & 1.94\end{array}$

$\begin{array}{lll}4.22 & 40.25 & 0.00\end{array}$

$\begin{array}{lll}29.61 & 12.98 & 0.22\end{array}$

1.10

$83.70 \quad 2.24$

22.36

$\begin{array}{lll}3.20 & 15.73 & 0.18\end{array}$

$88.52 \quad 2.48$

$\begin{array}{ll}81.61 & 1.85 \\ 59.29 & 1.09\end{array}$

$59.29 \quad 1.09$

22.5

$\begin{array}{lll}2.55 & 7.83 & 0.27\end{array}$

$88.51 \quad 2.47$

$\begin{array}{rrrrr}2.60 & 45.73 & 0.00 & 53.03 & 1.00\end{array}$

$\begin{array}{lll}83.84 & 2.23 & 0.47\end{array}$

22.80

$\begin{array}{rrrrrr}1.68 & 15.67 & 0.12 & 81.88 & 1.78\end{array}$

$\begin{array}{rrr}3.34 & 43.76 & 0.00 \\ 27.82 & 12.57 & 0.24\end{array}$ $\begin{array}{lll}3.19 & 39.40 & 0.00\end{array}$

$84.12 \quad 2.25$ $\begin{array}{lll}0.51 & 0.09 & 0.08\end{array}$

0.55

0.12

0.03

0.010 .01

0.03

0.010 .0

$\begin{array}{lll}0.03 & 0.01 & 0.43\end{array}$

0.55

$\begin{array}{ll}0.50 & 0.09\end{array}$

$0.57 \quad 0.10$

0.31

0.04
0.01

0.10

$0.28 \quad 0.03$

0.03
0.01
0.08

0.03

0.03
0.01

0.49

$0.56 \quad 0.10$

$\begin{array}{lll}26 & 0.03 & 0.08\end{array}$

$0.10 \quad 0.01$

0.01

0.01

$\begin{array}{llll}0.56 & 0.10 & 0.08\end{array}$

$\begin{array}{llll}28 & 0.03 & 0.03 & 0.00\end{array}$

$\begin{array}{llll}0.09 & 0.01 & 0.01 & 0.00 \\ 0.49 & 0.08 & 0.07 & 0.02\end{array}$
$0.19 \quad 0.02 \quad 0.02$ $\begin{array}{lllllll}0.01 & 0.11 & 0.681 & 0.89 & 938\end{array}$

$\begin{array}{llllll}0.00 & 0.76 & 0.969 & 0.76 & 653\end{array}$

$\begin{array}{lll}0.717 & 0.88 & 903\end{array}$

$\begin{array}{lll}0.714 & 1.50 & 997\end{array}$

$\begin{array}{lll}0.970 & 0.63 & 633\end{array}$

$\begin{array}{lll}0.746 & 1.39 & 951\end{array}$

0.673 $1.03 \quad 965$

$\begin{array}{llll}0.762 & 0.79 & 858\end{array}$

$0.980 \quad 0.43 \quad 600$

$\begin{array}{lll}0.705 & 0.96 \quad 926\end{array}$

$\begin{array}{lll}0.666 & 1.30 & 1012\end{array}$

$\begin{array}{lll}0.887 & 0.58 & 705\end{array}$

$0.709 \quad 1.16 \quad 952$

$\begin{array}{lll}0.659 & 1.01 \quad 973\end{array}$

$\begin{array}{lll}0.705 & 0.73 & 904\end{array}$

$\begin{array}{lll}0.954 & 0.38 & 621\end{array}$

$\begin{array}{lll}0.705 & 0.89 & 917\end{array}$

$\begin{array}{lll}0.656 & 0.97 & 970\end{array}$

$\begin{array}{lll}0.727 & 0.72 & 884\end{array}$

$\begin{array}{llll}0.946 & 0.37 & 629\end{array}$

$\begin{array}{lll}0.696 & 0.87 & 923\end{array}$

$\begin{array}{lll}0.656 & 0.96 & 970\end{array}$

$\begin{array}{lll}0.758 & 0.68 & 849\end{array}$

$\begin{array}{lllllll}.00 & 0.00 & 0.12 & 1.007 & 0.36 & 565 \\ .02 & 0.01 & 0.17 & 0.703 & 0.87 & 916\end{array}$

$\begin{array}{lllllll}.00 & 0.00 & 0.12 & 1.007 & 0.36 & 565 \\ .02 & 0.01 & 0.17 & 0.703 & 0.87 & 916\end{array}$

$\begin{array}{llllll}02 & 0.01 & 0.17 & 0.656 & 0.97 & 971\end{array}$

$\begin{array}{lllllll}0.00 & 0.00 & 0.21 & 0.724 & 0.67 & 881\end{array}$

$\begin{array}{llllllll}0.02 & 0.01 & 0.16 & 0.700 & 0.88 & 919\end{array}$ 
Sample Temp Pres (scf/ $\mathrm{CO} 2 \mathrm{N2} \quad \mathrm{C} 1 \quad \mathrm{C} 2 \quad \mathrm{C} 3 \quad$ iC4 4 nC4 iC5 nC5 C6+ Gravity (Gal (BTU/

9-Feb-84 12:00

9-Feb-84

\begin{tabular}{rrrrrrrrr}
4 & 93 & 1015 & 22.80 & 7.29 & 0.27 & 88.95 & 2.48 \\
\hline & 252 & 315 & 4.20 & 17.26 & 0.18 & 80.23 & 1.74
\end{tabular}

9-Feb-84

12:00

$\begin{array}{lllll}4.20 & 17.26 & 0.18 & 80.23 & 1.74\end{array}$

0.57

0.10

0.08

0.02

$\begin{array}{lllll}2.60 & 44.25 & 0.00 & 54.52 & 1.00\end{array}$

$\begin{array}{lllllllll}0.57 & 0.10 & 0.08 & 0.02 & 0.02 & 0.22 & 0.653 & 1.00 & 979 \\ 0.26 & 0.03 & 0.02 & 0.00 & 0.00 & 0.28 & 0.741 & 0.68 & 866 \\ 0.10 & 0.01 & 0.01 & 0.00 & 0.00 & 0.11 & 0.992 & 0.35 & 580\end{array}$

Calculated Total Gas

$\begin{array}{lllll}29.60 & 11.95 & 0.23 & 84.69 & 2.25\end{array}$

0.10

$0.01 \quad 0.01$

$\begin{array}{lllllllll}11.00 & 4 & 88 & 324 & 28.30 & 12.74 & 0.24 & 83.92 & 2.25\end{array}$

29-Feb-84

$\begin{array}{lllll}12: 00 & 5 & 277 & 324\end{array}$

$\begin{array}{rrrrr}2.31 & 30.59 & 0.00 & 67.53 & 1.49\end{array}$

0.49

0.08

0.07

0.02

0.02

$\begin{array}{lllll}30.61 & 14.09 & 0.22 & 82.68 & 2.19\end{array}$

0.47

0.03
0.08

0.07

$\begin{array}{lll}0.02 & 0.01 & 0.18\end{array}$

$10: 00 \quad 4 \quad 92$

3-Mar-84

$\begin{array}{lll}10: 00 & 5 & 277 \\ \text { Calculated Total Gas }\end{array}$

419
419

$\begin{array}{llllll}28.10 & 11.61 & 0.24 & 85.03 & 2.27\end{array}$

0.50

0.08

$0.07 \quad 0.02$

$12: 00$

$\begin{array}{cccccc}30.72 & 12.79 & 0.22 & 83.97 & 2.21\end{array}$

0.23

0.02

$0.07 \quad 0.02$

$0.02 \quad 0.01$

$\begin{array}{llllllllll}12: 00 & 8 & 223 & 515 & 4.42 & 40.95 & 0.00 & 57.81 & 1.03\end{array}$

$\begin{array}{llllllllll}14: 00 & 4 & 97 & 1015 & 22.30 & 7.80 & 0.25 & 88.59 & 2.46\end{array}$

0.10

0.07

0.02

0.020 .01

0.01

18-Jul-84

18-Jul-84

$\begin{array}{llll}14: 00 & 7 & 223 & 515\end{array}$

$\begin{array}{llllll}3.30 & 13.40 & 0.19 & 83.93 & 1.91\end{array}$

Calculated Total Gas

$\begin{array}{lllll}30.02 & 13.30 & 0.21 & 83.55 & 2.19\end{array}$

20-Jul-84

20-Jul-84

$\begin{array}{lllll}12: 00 & 4 & 95 & 1015\end{array}$

$\begin{array}{llllll}23.10 & 7.83 & 0.26 & 88.57 & 2.46\end{array}$

$\begin{array}{lllllllll}12: 00 & 7 & 225 & 415 & 3.60 & 15.98 & 0.17 & 81.54 & 1.83\end{array}$

$12: 00 \quad 8 \quad 225$

Calculated Total Gas

$\begin{array}{llllll}3.76 & 42.74 & 0.00 & 55.94 & 1.08\end{array}$

$\begin{array}{lllll}30.46 & 13.10 & 0.22 & 83.71 & 2.22\end{array}$

$0.31 \quad 0.03$

0.01

0.02

0.01

$\begin{array}{llll}0.174 & 0.691 & 0.89 & 930\end{array}$

12:00 $4 \quad 94$

24-Jul-84

$\begin{array}{lllll}23.00 & 7.82 & 0.27 & 88.53 & 2.46\end{array}$

$\begin{array}{lllllllll}12: 00 & 8 & 225 & 318 & 2.80 & 44.60 & 0.00 & 54.21 & 0.99\end{array}$

$\begin{array}{llll}13: 00 & 7 & 225 & 318\end{array}$

$\begin{array}{rrrrr}4.80 & 19.63 & 0.32 & 77.60 & 1.68\end{array}$

$\begin{array}{lll}30.60 & 13.04 & 0.25\end{array}$

0.56

$0.03 \quad 0.03$

$\begin{array}{lllll}0.00 & 0.00 & 0.09 & 0.960 & 0.35\end{array}$

$\begin{array}{lllll}0.02 & 0.01 & 0.13 & 0.655 & 0.95 \\ 0.00 & 0.02 & 0.18 & 0.703 & 0.71\end{array}$

0.10

Calculated Total Gas

26-Jul-84

$\begin{array}{llll}12: 00 & 4 & 82 & 1020\end{array}$

$\begin{array}{lllllllll}12: 00 & 4 & 82 & 1020 & 23.40 & 7.88 & 0.26 & 88.50 & 2.46\end{array}$

$\begin{array}{lllllllll}12.00 & 7 & 267 & 269 & 4.67 & 22.24 & 0.29 & 75.30 & 1.63\end{array}$

$\begin{array}{l:lll}12: 00 & 8 & 267 & 269\end{array}$

$\begin{array}{llllll}4.67 & 22.24 & 0.29 & 75.30 & 1.63 \\ 2.31 & 46.50 & 0.00 & 52.31 & 0.88\end{array}$

$\begin{array}{lllll}30.38 & 13.02 & 0.24 & 83.72 & 2.21\end{array}$

$0.28-0.03$

$0.11 \quad 0.01$

$\begin{array}{llllll}0.06 & 0.01 & 0.01 & 0.13 & 0.705 & 0.84\end{array}$

Calculated Total Gas

17-Dec-85

17-Dec-85

\begin{tabular}{rrrr}
$17: 10$ & 2 & 91 & 1019 \\
$17: 20$ & 7 & 270 & 430 \\
$22: 15$ & 8 & 273 & 430 \\
\multicolumn{4}{l}{ Calculated Total Gas }
\end{tabular}

$\begin{array}{lllll}23.41 & 7.88 & 0.25 & 88.60 & 2.42\end{array}$

$81.55 \quad 1.81$

0.28

$\begin{array}{rrrrrrr}2.85 & 26.11 & 0.00 & 72.38 & 1.30 & 0.13 \\ 29.59 & 10.55 & 0.22 & 86.24 & 2.24 & 0.48\end{array}$

$0.56 \quad 0.10$

0.11

0.01

0.03

$\begin{array}{llllll}0.08 & 0.02 & 0.01 & 0.11 & 0.655 & 0.94\end{array}$

0.03

0.00

0.00

$\begin{array}{lll}0.14 & 0.726 & 0.66\end{array}$

$\begin{array}{lllllll}0.00 & 0.00 & 0.11 & 0.978 & 0.38 & 596\end{array}$

17-Dec-85

$$
29 .
$$

$\begin{array}{ll}0.56 & 0.10 \\ 0.23 & 0.02 \\ 0.08 & 0.01 \\ 0.47 & 0.08 \\ & \\ 0.55 & 0.09 \\ 0.28 & 0.03 \\ 0.13 & 0.01 \\ 0.48 & 0.08\end{array}$

$\begin{array}{lllllll}0.08 & 0.02 & 0.01 & 0.15 & 0.656 & 0.96 & 970 \\ 0.01 & 0.00 & 0.00 & 0.07 & 0.995 & 0.34 & 575 \\ 0.03 & 0.01 & 0.01 & 0.44 & 0.769 & 0.74 & 847 \\ 0.07 & 0.02 & 0.01 & 0.19 & 0.705 & 0.87 & 915 \\ & & & & & & \\ 0.08 & 0.02 & 0.01 & 0.13 & 0.656 & 0.95 & 969 \\ 0.02 & 0.01 & 0.00 & 0.26 & 0.789 & 0.63 & 813 \\ 0.01 & 0.01 & 0.00 & 0.20 & 1.016 & 0.36 & 559 \\ 0.07 & 0.02 & 0.01 & 0.16 & 0.704 & 0.86 & 914 \\ & & & & & & \\ 0.07 & 0.01 & 0.02 & 0.11 & 0.655 & 0.92 & 967 \\ 0.03 & 0.00 & 0.00 & 0.13 & 0.726 & 0.65 & 875 \\ 0.01 & 0.00 & 0.00 & 0.06 & 0.817 & 0.42 & 764 \\ 0.06 & 0.01 & 0.02 & 0.11 & 0.679 & 0.84 & 937\end{array}$


Gladys McCall Sand 8 Total Gas Study

GWR

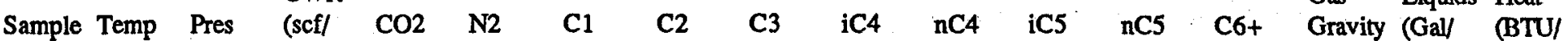

\section{Date}

18-Dec-85

18-Dec-85

18-Dec-85

15-Jan-86

15-Jan-86

15-Jan-86

\section{8-Feb-86}

8-Feb-86

8-Feb-86

가 8-Feb-86

a

10-Feb-86

10-Feb-86

11-Feb-86

11-Feb-86

11-Feb-86

11-Feb-86

11-Feb-86

11-Feb-86

11-Feb-86 11-Feb-86
Time Point (F)

$\begin{array}{rrrr}9: 15 & 8 & 274 & 435 \\ 9: 30 & 2 & 90 & 1018 \\ 9: 44 & 7 & 270 & 435\end{array}$

Calculated Total Gas

bbl) (Mol\%) (Mol\%)

$$
\begin{array}{rrr}
2.66 & 33.59 & 0.00
\end{array}
$$$$
3.49 \quad 16.04
$$$$
\begin{array}{rrr}
3.49 & 16.04 & 0.10 \\
29.39 & 11.27 & 0.15
\end{array}
$$$$
88.592 .43
$$$$
\begin{array}{ll}
81.57 & 1.81
\end{array}
$$$$
\text { 7:00 }
$$$$
\begin{array}{llll}
7: 00 & 2 & 225 & 1015 \\
8: 15 & 7 & 245 & 356
\end{array}
$$$$
\begin{array}{rrrrrr}
7 & 245 & 356 & 3.00 & 17.10 & 0.27
\end{array}
$$$$
\begin{array}{llll}
9: 30 & 8 & 245 & 356
\end{array}
$$

Calculated Total Gas

$\begin{array}{llll}8: 45 & 2 & 260 & 1024\end{array}$

$\begin{array}{lllllll}8: 54 & 5 & 264 & 1031 & 6.60 & 7.39 & 0.23\end{array}$

Calculated Total Gas

$12: 40 \quad 5 \quad 280 \quad 1023$

$\begin{array}{lrrr}12: 40 & 5 & 280 & 1023 \\ 12: 44 & 2 & 280 & 1021 \\ \text { Calculated Total Gas } & \end{array}$

$\begin{array}{llll}13: 05 & 1 & 294 & 1015 \\ 13.25 & 5 & 295 & 1017\end{array}$

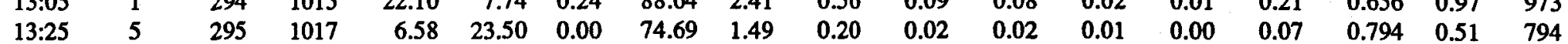

Calculated Total Gas

$\begin{array}{llll}28.68 & 11.36 & 0.18\end{array}$

$10: 31 \quad 1 \quad 306 \quad 1020$

$\begin{array}{llrl}10: 31 & 1 & 306 & 1020 \\ 10: 34 & 5 & 306 & 1020 \\ \text { Calculated } & \text { Total } & \text { Gas }\end{array}$

$11: 11 \quad 1 \quad 289 \quad 1022$

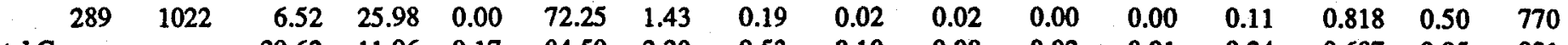

Calculated Total Gas

$\begin{array}{lll}29.62 & 11.96 & 0.17\end{array}$

$11: 32 \quad 1 \quad 291 \quad 1019$

$\begin{array}{llrl}11: 32 & 1 & 291 & 1019 \\ 11: 38 & 5 & 291 & 1019 \\ \text { Calculated } & \text { Total Gas }\end{array}$

$\begin{array}{lllll}019 & 23.20 & 8.01 & 0.23 & 88 .\end{array}$

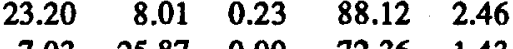

$\begin{array}{lll}30.23 & 12.16 & 0.18\end{array}$

$\begin{array}{lllllllllllll}12: 21 & 1 & 294 & 1020 & 22.70 & 7.91 & 0.22 & 88.37 & 2.48 & 0.60 & 0.11 & 0.09 & 0.03\end{array}$

$\begin{array}{lllllllllllll}12: 24 & 5 & 294 & 1020 & 6.69 & 26.04 & 0.00 & 72.19 & 1.43 & 0.19 & 0.02 & 0.02 & 0.00\end{array}$

Calculated Total Gas $\begin{array}{lllllllll}29.39 & 12.04 & 0.17 & 84.69 & 2.24 & 0.51 & 0.09 & 0.07 & 0.02\end{array}$ 
GWR

$\begin{array}{llllllllllllll}\text { Sample Temp } & \text { Pres } & \text { (scf/ } & \mathrm{CO} 2 & \mathrm{~N} 2 & \mathrm{C} 1 & \mathrm{C} 2 & \mathrm{C} 3 & \mathrm{iC} 4 & \mathrm{nC} 4 & \mathrm{iC} 5 & \mathrm{nC} 5 & \mathrm{C} 6+ & \begin{array}{l}\text { Gas } \\ \text { Gravity }\end{array} \text { (Giquids Heat } \\ \text { (BTU/ }\end{array}$

Date Time Point (F) (psia) bb

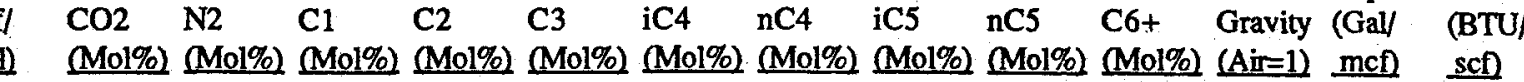

-1 $11-$ Feb-86

11-Feb-86

$\begin{array}{llll}14: 25 & 1 & 302 & 1018 \\ 14: 30 & 5 & 302 & 1018\end{array}$

Calculated Total Gas

$\begin{array}{llllll}23.10 & 7.81 & 0.22 & 88.74 & 2.40 & 0.54\end{array}$

0.09

0.07

$\begin{array}{llllll}0.02 & 0.01 & 0.10 & 0.654 & 0.91 & 968 \\ 0.00 & 0.00 & 0.12 & 0.832 & 0.50 & 757\end{array}$

$\begin{array}{lllllll}6.81 & 27.31 & 0.00 & 70.92 & 1.41 & 0.20\end{array}$

0.07

0.06

0.02

$0.832 \quad 0.50$

$\begin{array}{lllllll}4.44 & 20.52 & 0.16 & 77.22 & 1.64 & 0.24\end{array}$

0.02

$\begin{array}{lllllllllll}0.02 & 0.01 & 0.00 & 0.17 & 0.769 & 0.60 & 828\end{array}$

19-Feb-87
19-Feb-87

19-Feb-87

$\begin{array}{lllll}9: 40 & 7 & 280 & 285\end{array}$

$\begin{array}{rrrr}10: 50 & 4 & 90 & 1015 \\ 11: 00 & 8 & 280 & 285\end{array}$

Calculated Total Gas

$\begin{array}{lll}22.86 & 7.91 & 0.25\end{array}$

0.53

$29.05 \quad 11.61$

$\begin{array}{ll}60.25 & 1.05\end{array}$

$\begin{array}{ll}0.10 & 0.01\end{array}$

0.07

0.00

0.00

$9.30 \quad 7 \quad 276$

13-Apr-87

9:30

$\begin{array}{llll}90.50 & 7 & 276 & 415\end{array}$

$12: 30 \quad 4 \quad 95 \quad 1013$

Calculated Total Gas

$\begin{array}{llllll}3.34 & 16.71 & 0.22 & 80.90 & 1.81 & 0.26\end{array}$

0.02

0.01

0.02

$17: 40 \quad 7 \quad 250$

\begin{tabular}{lllllllll}
$17: 40$ & 7 & 250 & 410 & 1.20 & 13.89 & 0.19 & 83.35 & 2.06 \\
\hline
\end{tabular}

$\begin{array}{llllllllll}17820 & 4 & 79 & 515 & 27.27 & 11.11 & 0.23 & 85.69 & 2.28\end{array}$

$\begin{array}{llllllllll}19: 00 & 8 & 253 & 418 & 2.91 & 33.59 & 0.96 & 63.95 & 1.26\end{array}$

Calculated Total Gas

$\begin{array}{lllll}31.38 & 13.30 & 0.30 & 83.58 & 2.18\end{array}$

0.10

0.01
0.08

$\begin{array}{ll}0.01 & 0.00 \\ 0.01 & 0.00\end{array}$

$\begin{array}{lllll}0.00 & 0.17 & 0.769 & 0.60 & 828 \\ 0.02 & 0.15 & 0.656 & 0.93 & 968\end{array}$

25

$\begin{array}{llllll}515 & 27.21 & 10.87 & 0.22 & 85.95 & 2.23\end{array}$

$\begin{array}{llllll}1.18 & 13.43 & 0.19 & 83.71 & 2.08\end{array}$

$\begin{array}{llllll}2.88 & 32.70 & 1.03 & 64.68 & 1.31\end{array}$

$\begin{array}{rrrrr}2.88 & 32.70 & 1.03 & 64.68 & 1.31 \\ 31.27 & 12.98 & 0.29 & 83.91 & 2.14\end{array}$

$0.46 \quad 0.07$

$0.07 \quad 0.02$

$\begin{array}{lll}8: 30 & 7 & 280\end{array}$

$\begin{array}{lll}9: 00 & 8 & 280 \\ \text { Calculated Total Gas }\end{array}$

$\begin{array}{llll}7: 50 & 1 & 280 & 515\end{array}$

14-Apr-87

$7: 50$
$10: 30$

Calculated Total Gas

$\begin{array}{lll}27.21 & 10.99 & 0.27\end{array}$

$\begin{array}{ll}0.36 & 0.04\end{array}$

$\begin{array}{ll}0.49 & 0.07\end{array}$

0.15

0.01
0.06

$0.04 \quad 0.00$

$0.03 \quad 0.02$

0.0

$\begin{array}{lll}0.47 & 0.07 & 0.08\end{array}$

0.02

0.38

0.05

0.05

$\begin{array}{ll}0.02 & 0.01 \\ 0.01 & 0.00\end{array}$

$\begin{array}{llllll}0.00 & 0.08 & 0.927 & 0.35 & 637\end{array}$

$\begin{array}{lllll}0.02 & 0.15 & 0.690 & 0.85 & 927\end{array}$

$$
\begin{aligned}
& \text { 14-Apr-87 } \\
& \text { 14-Apr-87 } \\
& \\
& \text { 14-Apr-87 } \\
& \text { 14-Apr-87 } \\
& \text { 14-Apr-87 }
\end{aligned}
$$

$14: 50$

$15: 20$
Calculated

Calculated Total Gas

14:50

$14: 00 \quad 7 \quad 270$

$\begin{array}{lll}16: 00 & 8 & 275\end{array}$

Calculated Total Gas

515
517
516

517
442
445

\begin{tabular}{rllllll}
27.21 & 10.99 & 0.27 & 85.77 & 2.26 & 0.47 \\
\hline 4.31 & 30.46 & 1.02 & 66.72 & 1.45 & 0.21
\end{tabular}

\begin{tabular}{llllllll}
30.46 & 1.02 & 66.72 & 1.45 & 0.21 & 0.02 \\
\hline
\end{tabular}

$0.07 \quad 0.06$

0.07

0.00

$\begin{array}{llllll}0.00 & 0.07 & 0.731 & 0.61 & 864\end{array}$

$\begin{array}{lllllll}0.02 & 0.01 & 0.06 & 0.656 & 0.90 & 962\end{array}$

$0.81 \quad 914$

$\begin{array}{llllll}0.00 & 0.07 & 0.706 & 0.72 & 897\end{array}$

$\begin{array}{lllllll} & 0.01 & 0.07 & 0.683 & 0.83 & 930\end{array}$

$\begin{array}{llllll} & \\ 0.00 & 0.00 & 0.07 & 0.894 & 0.42 & 679\end{array}$

r

$\begin{array}{llllll}27.47 & 11.17 & 0.23 & 85.55 & 2.30 & 0.49\end{array}$

$0.06 \quad 0.05$

$\begin{array}{llllll}0.02 & 0.02 & 0.07 & 0.682 & 0.83 & 931 \\ 0.00 & 0.00 & 0.10 & 0.866 & 0.51 & 714\end{array}$

$\begin{array}{llllll}0.00 & 0.00 & 0.10 & 0.866 & 0.51 & 714\end{array}$

$\begin{array}{llllll}0.02 & 0.02 & 0.07 & 0.707 & 0.79 & 902\end{array}$

$\begin{array}{llllllll}0.07 & 0.07 & 0.02 & 0.01 & 0.09 & 0.685 & 0.86 & 931\end{array}$ $\begin{array}{llllllllllllll}3.90 & 28.90 & 0.66 & 68.58 & 1.49 & 0.22 & 0.02 & 0.02 & 0.00 & 0.00 & 0.11 & 0.850 & 0.53 & 734\end{array}$ $\begin{array}{llllllllllllll}31.37 & 13.37 & 0.28 & 83.44 & 2.20 & 0.46 & 0.06 & 0.06 & 0.02 & 0.01 & 0.09 & 0.705 & 0.82 & 907\end{array}$

$\begin{array}{lllllll}27.47 & 11.17 & 0.23 & 85.55 & 2.30 & 0.49\end{array}$

$\begin{array}{llllllll}0.07 & 0.07 & 0.02 & 0.01 & 0.09 & 0.685 & 0.86 & 931\end{array}$

$\begin{array}{llllllll}0.04 & 0.04 & 0.01 & 0.01 & 0.09 & 0.704 & 0.76 & 904\end{array}$

$\begin{array}{llllllllllllll}2.82 & 28.56 & 0.61 & 69.12 & 1.43 & 0.18 & 0.01 & 0.03 & 0.00 & 0.00 & 0.06 & 0.845 & 0.48 & 735\end{array}$

$\begin{array}{llllllllllllll}31.36 & 12.81 & 0.26 & 84.01 & 2.22 & 0.46 & 0.06 & 0.07 & 0.02 & 0.01 & 0.09 & 0.700 & 0.82 & 913\end{array}$ 
Gladys McCall Sand 8 Total Gas Study

$\begin{array}{llllllllllllll}\text { Sample Temp } & \text { Pres } & \begin{array}{l}\text { GWR } \\ (\mathrm{scf} /\end{array} & \mathrm{CO} 2 & \mathrm{~N} 2 & \mathrm{Cl} & \mathrm{C} 2 & \mathrm{C} 3 & \mathrm{iC} 4 & \mathrm{nC} 4 & \mathrm{iC} 5 & \mathrm{nC5} & \mathrm{C} 6+ & \begin{array}{l}\text { Gas } \\ \text { Gravity }\end{array} \text { (Giquids Heat } \\ \text { (BTU/ }\end{array}$

Date

14-Apr-87

14-Apr-87

14-Apr-87

14-Apr-87

14-Apr-87

15-Apr-87

15-Apr-87

21-Apr-87

21-Apr-87

๑

$>$

27-Apr-87
27-Apr-87
27-Apr-87

4-May-87

4-May-87

4-May-87

m

ก

I

$z$

0

$r$

0

11-May-87

11-May-87

18-May-87

18-May-87 Time Point (F) (psia)

bbl) (Mol\%) $\mathrm{Mo}$

$$
\begin{aligned}
& 22: 00 \\
& \text { 22:30 }
\end{aligned}
$$
Calculated Total Gas

22:00

$21: 00 \quad 4 \quad 85$

$21: 15 \quad 8 \quad 280$

Calculated Total Gas

$6: 25 \quad 4 \quad 73$

$\begin{array}{ll}7: 10 & 5 \\ \text { Calculated Total Gas }\end{array}$

$\begin{array}{rrrrrrr}16: 50 & 4 & 78 & 1015 & 21.66 & 8.07 & 0.25 \\ 17: 40 & 5 & 284 & 1015 & 8.97 & 30.95 & 0.71\end{array}$

Calculated Total Gas

$9: 45 \quad 4-100 \quad 1020$

$\begin{array}{lllll}9: 45 & 4 & - & 100 & 1020 \\ 10: 00 & 8 & 274 & 463\end{array}$

10:14 $7 \quad 27$

Calculated Total Gas

$\begin{array}{rrrr}9: 45 & 4 & 79 & 1006 \\ 8: 00 & 7 & 266 & 4\end{array}$

$\begin{array}{llll}8: 15 & 8 & 266 & 423\end{array}$

Calculated Total Gas

$\begin{array}{rrr}7: 15 & 4 & 80 \\ 7.55 & 7 & 258\end{array}$

$\begin{array}{rrrr}7: 55 & 7 & 258 & 418 \\ 9: 10 & 8 & 258 & 418\end{array}$

Calculated Total Gas

$\begin{array}{cccc}10: 55 & 4 & 93 & 1017\end{array}$

18-May-87

$\begin{array}{llll}11.55 & 7 & 231 & 408 \\ 12: 00 & 8 & 253 & 408\end{array}$

Calculated Total Gas

$\begin{array}{lll}30.63 & 14.77 & 0.38\end{array}$

$\begin{array}{lll}3.36 & 38.17 & 0.70\end{array}$

$\begin{array}{lll}4.24 & 15.41 & 0.17\end{array}$

$30.24 \quad 12.46 \quad 0.28$

$\begin{array}{lll}85.75 & 2.27 & 0.48\end{array}$

$\begin{array}{lll}69.36 & 1.46 & 0.20\end{array}$

$\begin{array}{lll}83.92 & 2.18 & 0.45\end{array}$

$\begin{array}{ll}85.75 & 2.27\end{array}$

$84.35 \quad 2.15$

$\begin{array}{ll}70.52 & 1.43\end{array}$

$84.40 \quad 2.19$

$68.20 \quad 1.43$

$83.72 \quad 2.19$

$\begin{array}{lll}88.47 & 2.42 & 0.54\end{array}$

$66.64 \quad 1.38$

$\begin{array}{lll}82.08 & 2.12 & 0.45\end{array}$

$\begin{array}{ll}88.42 & 2.44\end{array}$

$\begin{array}{lll}82.15 & 1.86 & 0.28\end{array}$

$84.37 \quad 2.21$

$88.62 \quad 2.41$

$\begin{array}{lll}3.77 & 16.14 & 0.16\end{array}$

$\begin{array}{lll}3.18 & 43.05 & 0.40\end{array}$

$\begin{array}{lll}29.73 & 12.76 & 0.25\end{array}$

$\begin{array}{ll}55.34 & 0.99 \\ 84.16 & 2.18\end{array}$

0.10
0.45

$\begin{array}{ll}0.07 \quad 0.06 \\ 0.02 & 0.02\end{array}$

$\begin{array}{lll}0.07 & 0.06 & 0.02\end{array}$

$\begin{array}{ll}0.06 & 0.06\end{array}$

0.07

0.050 .05

0.0

$\begin{array}{lll}0.45 & 0.06 & 0.06\end{array}$

$0.49 \quad 0.07$

$\begin{array}{lll}0.07 & 0.06 & 0.00\end{array}$

0.02
0.06

0.02
0.06

0.08

0.0

0.06

$\begin{array}{lll}23.16 & 7.84 & 0.40\end{array}$

$\begin{array}{lll}3.23 & 15.93 & 0.38\end{array}$

$\begin{array}{lll}88.63 & 2.40 & 0.53\end{array}$

$81.57 \quad 1.76 \quad 0.26$

$\begin{array}{rrr}3.07 & 44.50 & 0.50 \\ 29.46 & 12.55 & 0.41\end{array}$

$\begin{array}{lll}53.86 & 0.94 & 0.09\end{array}$

$84.23 \cdot 2.18$

0.45

$\begin{array}{llllll}22.76 & 7.74 & 0.22 & 88.88 & 2.43 & 0.55\end{array}$

$\begin{array}{llllll}3.77 & 15.68 & 0.14 & 82.04 & 1.77 & 0.27\end{array}$

$\begin{array}{lll}3.33 & 44.76 & 0.50\end{array}$

$\begin{array}{lll}29.86 & 12.87 & 0.24\end{array}$
$53.64 \quad 0.91$

$84.09 \quad 2.18$

\section{$\begin{array}{llllllll}0.08 & 0.07 & 0.02 & 0.02 & 0.07 & 0.656 & 0.91 & 964\end{array}$}

$\begin{array}{llllllll}0.02 & 0.02 & 0.00 & 0.00 & 0.09 & 0.719 & 0.64 & 879\end{array}$

$\begin{array}{llllllll}0.08 & 0.06 & 0.02 & 0.02 & 0.05 & 0.654 & 0.89 & 964\end{array}$

$\begin{array}{llllllll}0.02 & 0.02 & 0.01 & 0.00 & 0.09 & 0.726 & 0.61 & 871\end{array}$

$\begin{array}{lllllllll}0.01 & 0.00 & 0.00 & 0.00 & 0.11 & 0.982 & 0.35 & 587\end{array}$

$\begin{array}{llllllll}0.06 & 0.05 & 0.02 & 0.02 & 0.06 & 0.698 & 0.79 & 912\end{array}$

$\begin{array}{llllllll}0.08 & 0.05 & 0.02 & 0.01 & 0.04 & 0.653 & 0.87 & 962\end{array}$

$\begin{array}{llllllll}0.02 & 0.02 & 0.00 & 0.00 & 0.06 & 0.724 & 0.59 & 869\end{array}$

$\begin{array}{lllllllll}0.07 & 0.04 & 0.02 & 0.01 & 0.05 & 0.696 & 0.79 & 911\end{array}$

$\begin{array}{llllllll}0.08 & 0.06 & 0.01 & 0.00 & 0.03 & 0.651 & 0.88 & 965\end{array}$

$\begin{array}{lllllllll}0.02 & 0.02 & 0.00 & 0.00 & 0.06 & 0.720 & 0.60 & 875\end{array}$

$\begin{array}{llllll}0.46 & 0.06 & 0.05 & 0.01 & 0.00 & 0.04\end{array}$

$\begin{array}{lll}0.998 & 0.32 & 568 \\ 0.698 & 0.78 & 909\end{array}$ 
Gladys McCall Sand 8 Total Gas Study

GWR

Gas Liquids Heat

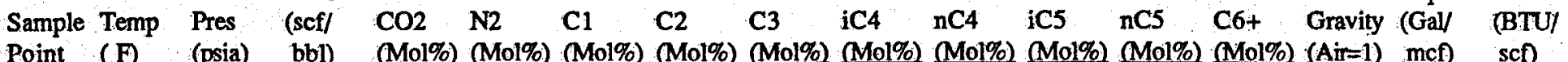

(Mol\%) (Air=1) (Gen

\begin{tabular}{|c|c|c|c|c|c|c|c|c|c|c|c|c|c|c|c|c|c|c|}
\hline -Oct-87 & $18: 30$ & 4 & 92 & 1015 & 24.84 & 7.92 & 0.16 & 88.62 & 2.48 & 0.58 & 0.09 & 0.06 & 0.01 & 0.01 & 0.07 & 0.654 & 0.92 & 967 \\
\hline $20-0 \mathrm{ct}-8$ & $19: 05$ & 7 & 261 & 416 & 2.66 & 15.60 & 0.13 & 82.03 & 1.81 & 0.28 & 0.03 & 0.02 & 0.01 & 0.01 & 0.08 & 0.721 & 0.63 & 878 \\
\hline \multirow{2}{*}{$20-0 c t-87$} & $19: 20$ & 8 & 261 & 416 & 3.34 & 41.51 & 0.40 & 56.80 & 1.03 & 0.11 & 0.01 & 0.01 & 0.01 & 0.01 & .11 & .968 & 0.37 & 604 \\
\hline & \multicolumn{3}{|c|}{ Calculated Total Gas } & & 30.84 & 12.22 & 0.18 & 84.61 & 2.27 & 0.50 & 0.08 & 0.05 & 0.01 & 0.01 & 0.08 & 0.694 & 0.84 & 920 \\
\hline$t-8$ & $10: 20$ & 5 & 263 & 1013 & 7.22 & 30.26 & 0.40 & 67.56 & 1.4 & & 0.02 & 0.02 & 0.0 & 0.01 & & & & \\
\hline \multirow[t]{2}{*}{ 21-Oct-87 } & $8: 50$ & 4 & 82 & 1014 & 25.85 & 7.98 & 0.12 & 88.49 & 2.53 & 0.58 & 0.09 & 0.08 & 0.03 & 0.01 & 0.09 & 56 & 0.96 & 969 \\
\hline & \multicolumn{3}{|c|}{ Calculated Total Gas } & & 33.07 & 12.84 & 0.18 & 83.92 & 2.29 & 0.50 & 0.07 & 0.07 & 0.03 & 0.01 & 0.09 & 0.701 & 0.86 & 915 \\
\hline & & 4 & 82 & 1014 & 25.85 & 7.98 & 0.12 & 88.49 & 2.5 & 0.5 & 0.09 & $0 . C$ & & 0.0 & 0.09 & & 0.96 & \\
\hline & $9: 25$ & 7 & 263 & 417 & 2.22 & 15.63 & 0.12 & 81.98 & 1.81 & 0.28 & 0.03 & 0.01 & 0.01 & 0.01 & 0.12 & 0.722 & 0.64 & 79 \\
\hline \multirow{2}{*}{ 21-Oct-87 } & & & 263 & 417 & 3.03 & 39.11 & 0.41 & 9.16 & 1.08 & & 0.01 & 0.01 & 0.01 & 0.01 & 0.10 & 0.945 & 0.38 & 28 \\
\hline & \multicolumn{4}{|c|}{ Calculated Total Gas } & 31.10 & 11.56 & 0.15 & 85.17 & 2.34 & 0.51 & 0.08 & 0.07 & 0.03 & 0.01 & 0.09 & 0.689 & 0.88 & 22 \\
\hline
\end{tabular}

\section{LOCATION:}

Directly from top of first separator

From tubing connected to horizontal num between first stage separator and gas cooler.

From either the Drager sample point or the meter nun after the gas cooler.

Gas released from brine taken from first stage separator. Pressure reduced to atmospheric pressure.

From Drager sample point on top of second separator.

Gas released from brine taken from second separator. Pressure reduced to atmospheric pressure. 
Flow Tests of the Gladys MCCall Well Through OCtober 1990

\section{APPENDIX I}

Liquid Hydrocarbon Production

I-1 
$$
-
$$ 
A few hundred barrels of two distinctly different liquid hydrocarbons, a heavy aliphatic oil and an aromatic condensate, were recovered during the production of over 25 million barrels of brine and 700 million standard cubic feet of gas. The liquid hydrocarbons generated considerable interest because 1) the possibility of the fraction of liquid hydrocarbons increasing to the point where oil sales may become a significant source of revenue was not known, 2) the mechanism of transport of this oil to the wellbore is not understood, and 3) production of heavy oil at the Sweezey well was quickly followed by the well sanding up and loss of the well.

A measurement technique was employed to try to measure the amount of liquid hydrocarbons produced. Concentrations and compositions were monitored by the University of Southwestern Louisiana, who coined the term "cryocondensates" after the method of collecting the samples. This method found a small quantity, roughly $35 \mathrm{ppm}$, of primarily aromatic hydrocarbons produced with the brine. The separation and recovery of most of these dissolved hydrocarbons was not economically feasible, although a small fraction of this $35 \mathrm{ppm}$ of condensible/extractable hydrocarbons made up the condensate mentioned above.

Compositions of the hydrocarbon fractions and methods of transport to the wellbore are discussed in subsections below.

Heavy Aliphatic Oil -- During January 1985, after production of approximately 6 million barrels of brine, a heavy oil was found floating at the gas/brine interface in the separators. This oil was bled from the separators daily and the volumes were recorded. The quantity of oil recovered versus cumulative brine production is reproduced here as Exhibit I-1. The recovered oil averaged about 7 parts per million in the produced brine.

There was some question about whether heavy oil production began at an earlier date but was not noticed until January 1985 . There was an increase in the alkane fraction of the predominantly aromatic cryocondensate that coincided with the onset of production of heavy oil. The increase in alkanes appeared in the cryocondensate sample of December 28, 1 month before the production of heavy oil was noted, but was not observed in earlier samples. This is strong evidence that no heavy oil was produced prior to December 1984.

The composition of the heavy oil was clearly different from the cryocondensate and the condensate that condensed from the gas stream. Several samples of the heavy oil were analyzed by gas chromatography. Only a portion of each sample was recovered from the chromatograph. Very heavy ends, such as asphaltenes and tar, were irreversibly adsorbed onto the chromatographic column and did not reach the detector. The distribution of the eluted portion of the samples is presented versus carbon number in Exhibit I-2. The fraction of each sample that was not recovered 


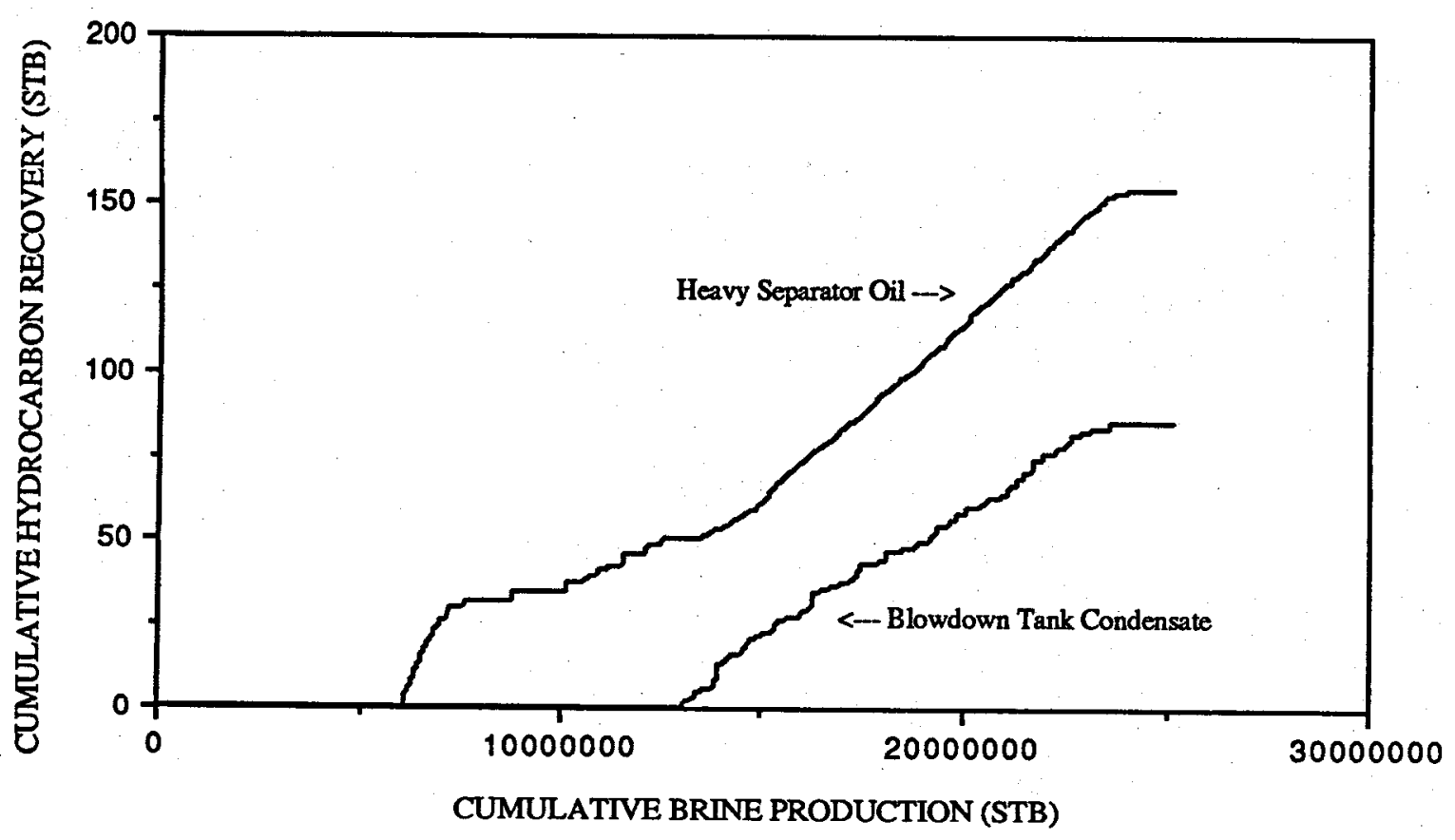

Exhibit I-1. LIQUID HYDROCARBON RECOVERY

was the fraction higher than the highest carbon number in the table. Representative chromatograms are presented in Exhibit I-3 and I-4. The normal alkane backbone, clearly apparent in most samples, is labeled.in Exhibit I-4.

The samples were also analyzed on shorter simulated distillation gas chromatography columns that provide less resolution but greater recovery of the heavy ends. These data are presented in Exhibits I-5 and I-6. The initial boiling point of the heavy oil samples are close to $400^{\circ} \mathrm{F}$. It is probable that the lighter ends of this heavy oil were cooked off (distilled) during the time the oil resided in the large separator. The light ends were transported out of the separator in the gas stream, and these lighter hydrocarbons were then observed as an increase in the alkane portion in the condensate samples.

There was some question about how the oil was transported to the well. Conventional theory states that the oil saturation must be above some minimum value, generally $20 \%$ to $30 \%$ of the pore volume, before oil will flow. There was no evidence of an oil phase in the core or the log interpretations obtained from this well. Alternate hypotheses for transport of oil to the wellbore are 1) that the heavy oil was dissolved in the brine, much like the aromatics that were found in the 
FLOW TESTS OF THE GLADys MCCALl Well Through OCTOBER 1990

Exhibit I-2, Part 1. HIGH-PRESSURE SEPARATOR OIL CARBON NUMBER DISTRIBUTION

Carbon No. 19Feb 87 13 Apr 87 14 Apr 87 15Apr87 21 Apr 87 27 Apr 87

\begin{tabular}{|c|c|c|c|c|c|c|}
\hline 9 & 0.04 & -- & $\cdots$ & - - & $\cdots$ & - \\
\hline$o$-Xylene & 0.06 & -- & - & -- & $\cdots$ & \\
\hline 10 & 0.13 & $<0.01$ & $<0.01$ & 0.18 & 0.31 & 0.19 \\
\hline 11 & 0.24 & 0.44 & 0.30 & 0.26 & 0.23 & 0.17 \\
\hline 12 & 0.29 & 0.52 & 0.37 & 0.31 & 0.44 & 0.38 \\
\hline 13 & 0.63 & 0.59 & 0.43 & 0.54 & 0.71 & 0.46 \\
\hline 14 & 1.12 & 1.11 & 0.79 & 1.20 & 0.71 & 0.83 \\
\hline 15 & 1.67 & 1.40 & 1.13 & 1.86 & 1.31 & 1.18 \\
\hline 16 & 2.06 & 1.80 & 1.52 & 2.35 & 1.67 & 1.55 \\
\hline 17 & 2.90 & 2.75 & 2.41 & 3.28 & 2.51 & 2.34 \\
\hline 18 & 4.09 & 3.19 & 2.83 & 3.53 & 1.12 & 2.75 \\
\hline 19 & 4.73 & 3.81 & 3.50 & 3.91 & 5.29 & 3.25 \\
\hline 20 & 5.19 & 4.24 & 4.02 & 4.23 & 3.93 & 3.64 \\
\hline 21 & 5.17 & 4.78 & 4.56 & 4.60 & 4.39 & 4.13 \\
\hline 22 & 5.17 & 4.99 & 4.84 & 4.96 & 5.08 & 4.63 \\
\hline 23 & 4.53 & 4.63 & 5.14 & 4.58 & 4.55 & 4.18 \\
\hline 24 & 3.32 & 4.58 & 3.75 & 3.59 & 3.60 & 3.39 \\
\hline 25 & 3.29 & 4.27 & 4.22 & 3.87 & 3.92 & 3.59 \\
\hline 26 & 2.37 & 4.19 & 4.10 & 3.87 & 3.93 & 4.21 \\
\hline 27 & 1.83 & 4.64 & 4.57 & 4.34 & 4.42 & 3.59 \\
\hline 28 & 1.24 & 3.57 & 3.56 & 3.38 & 3.40 & 3.17 \\
\hline 29 & 0.65 & 4.38 & 4.39 & 4.20 . & 4.24 & 3.89 \\
\hline 30 & & 2.20 & 1.92 & 1.84 & 1.87 & 1.79 \\
\hline 31 & & 2.77 & 2.72 & 2.56 & 2.57 & 2.43 \\
\hline 32 & & 2.99 & 2.99 & 2.87 & 2.88 & 2.67 \\
\hline 33 & & 3.31 & 3.19 & 3.08 & 2.39 & 2.80 \\
\hline 34 & & 1.27 & 1.28 & 2.03 & 1.88 & 1.61 \\
\hline 35 & & 2.14 & 2.07 & 1.20 & 1.64 & 1.43 \\
\hline 36 & & 1.72 & 1.58 & 1.34 & 1.18 & 1.30 \\
\hline 37 & & 1.18 & 1.18 & 1.32 & 1.77 & 1.20 \\
\hline 38 & & 1.17 & 1.12 & 1.09 & 1.09 & 1.04 \\
\hline 39 & & 1.06 & 1.05 & 1.01 & 1.02 & 0.93 \\
\hline 40 & & 0.96 & 0.93 & 0.90 & 0.88 & 0.85 \\
\hline 41 & & 0.86 & 0.80 & 0.79 & 0.82 & 0.75 \\
\hline 42 & & 0.74 & 0.76 & 0.73 & 0.73 & 0.70 \\
\hline 43 & & 0.72 & 0.69 & 0.67 & 0.66 & 0.63 \\
\hline 44 & & 1.31 & 1.32 & 1.20 & 1.29 & 1.22 \\
\hline
\end{tabular}

$\%$ of Sample

Recovered

50.90

83.99

80.00

81.64

78.43

72.83 
Flow Tests of the Gladys MCCALl Well THROUgh OCTOBER 1990

Exhibit I-2, Part 2. HIGH-PRESSURE SEPARATOR OIL CARBON NUMBER DISTRIBUTION

Carbon No. 4May 87 11 May 87 18 May 87 16 Jul 87 21 Oct 87

9

o-Xylene

10

11

12

13

14

15

16

17

18

19

20

21

22

23

24

25

26

27

28

29

30

31

32

33

34

35

36

37

38

39

40

41

42

43

44

$\%$ of Sample

Recovered

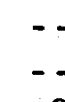

0.15

0.10

0.27

0.51

0.42

0.93

1.24

1.88

2.37

3.03

3.63

4.27

5.15

4.12

4.55

4.34

3.17

3.11

4.06

3.80

3.82

3.65

3.20

2.71

2.31

2.33

2.37

1.96

1.25

1.16

1.04

0.89

0.87

0.75

1.48

80.87

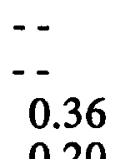

0.20

0.43

0.29

0.52

0.62

0.66

0.83

1.08

1.28

1.72

2.35

3.09

3.39

3.60

3.09

3.91

4.66

3.77

4.02

3.44

3.06

3.77

4.04

1.65

1.38

2.03

2.52

1.41

1.32

1.18

1.04

0.97

0.86

1.52

70.00

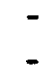

4.78

2.53

5.09

7.31

4.66

7.33

6.01

5.64

4.75

3.98

3.49

3.34

3.13

2.65

2.42

1.80

3.00

1.51

1.80

2.34

1.84

1.59

1.35

1.27

0.94

0.78

0.71

0.73

0.68

0.68

0.56

0.59

0.38

$0.33^{\prime}$

0.25

90.23

41.71

0.83

2.12
-

$--$

0.06

0.19

0.34

0.34

0.52

0.36

0.45

0.29

0.68

0.61

0.73

0.75

1.12

1.31

1.78

2.20

2.81

3.33

4.38

4.57

5.54

3.73

2.20

4.69

3.27

2.47

2.53

3.60

1.66

2.67

1.69

1.10

1.36

0.83

64.00 
Flow tests of the Gladys MCCall Well Through OCtober 1990

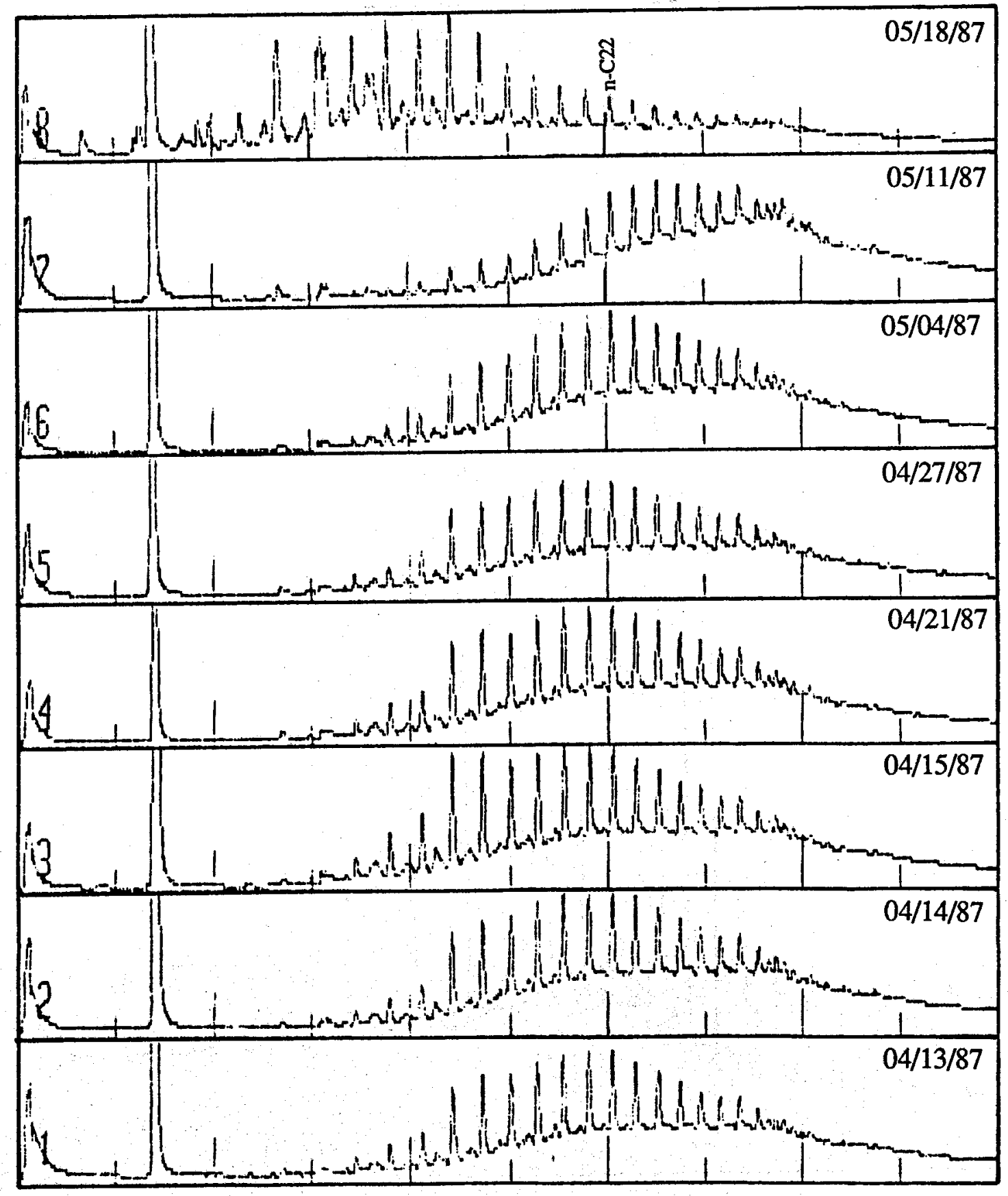

Exhibit I-3. HIGH-PRESSURE SEPARATOR OIL CHROMATOGRAMS 
Flow Tests of the Gladys MCCall Well Through OCtober 1990

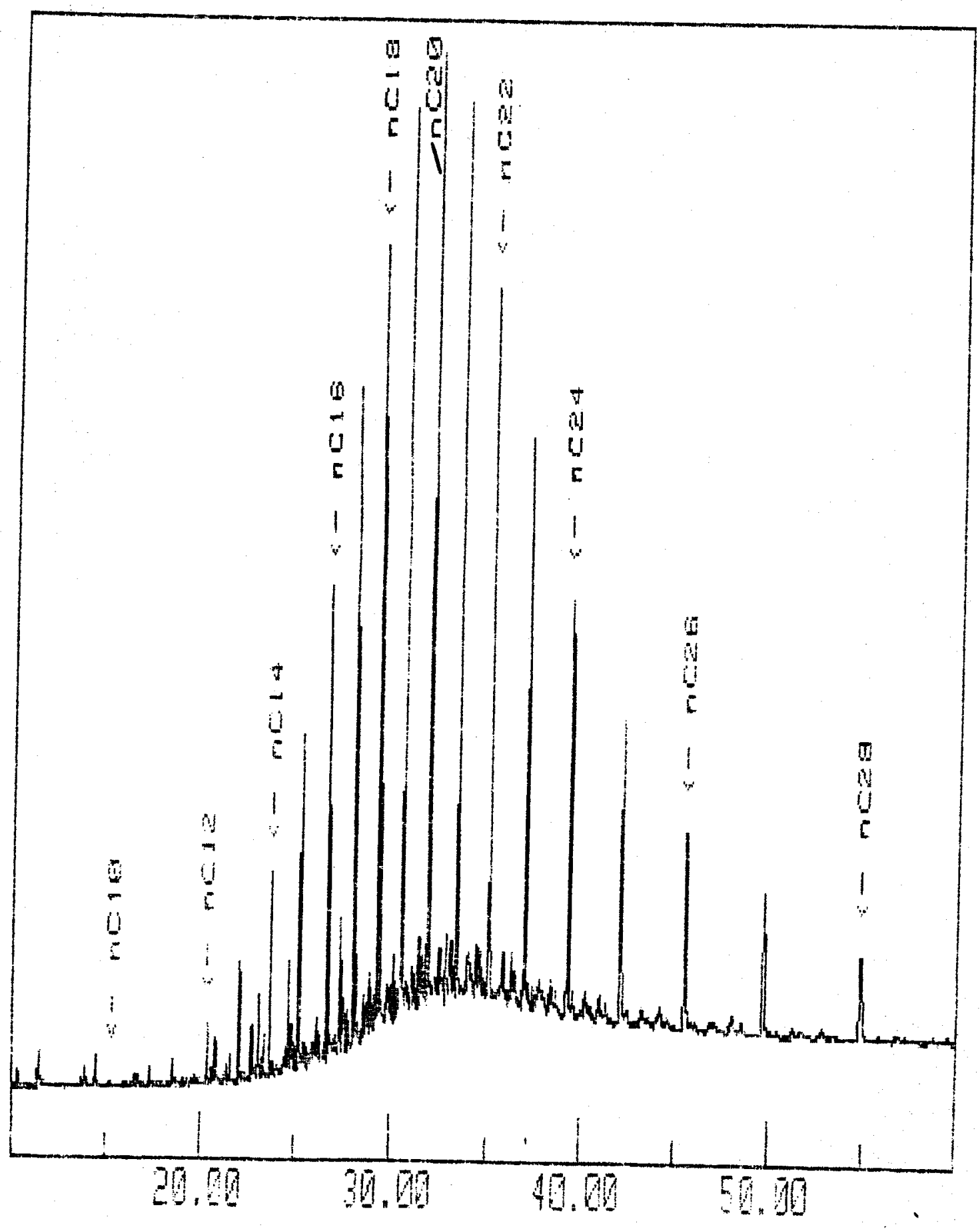

Exhibit I-4. HIGH-PRESSURE SEPARATOR OIL CHROMATOGRAM 
Flow TeStS OF the Gladys MCCALL Well Through OCtober 1990

Exhibit I-5. HEAVY OIL SIMULATED DISTILLATION BY GAS CHROMATOGRAPHY

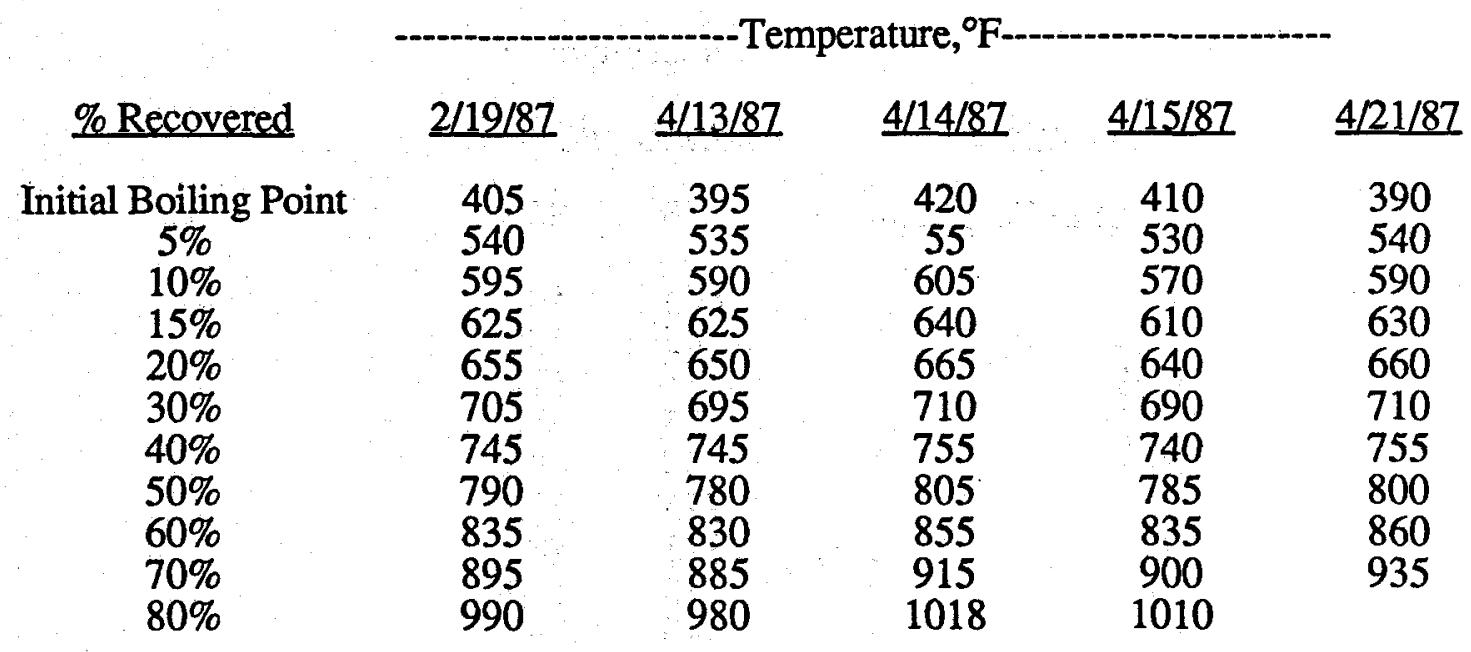

\begin{tabular}{cccccc} 
& & & & & \\
\% Recovered & $4 / 27 / 87$ & $5 / 04 / 87$ & $5 / 11 / 87$ & $5 / 18 / 87$ & $7 / 16 / 87$ \\
\hline Initial Boiling Point & 410 & 420 & 390 & $<200$ & 390 \\
$5 \%$ & 550 & 570 & 600 & 350 & 710 \\
$10 \%$ & 600 & 620 & 670 & 410 & 795 \\
$15 \%$ & 640 & 655 & 710 & 450 & 840 \\
$20 \%$ & 670 & 680 & 735 & 470 & 860 \\
$30 \%$ & 715 & 725 & 780 & 505 & 920 \\
$40 \%$ & 770 & 770 & 830 & 560 & 1010 \\
$50 \%$ & 820 & 805 & 875 & 615 & \\
$60 \%$ & 885 & 860 & 940 & 685 & \\
$70 \%$ & 995 & 920 & 1018 & 765 & \\
$80 \%$ & & 1018 & & 860 & \\
$90 \%$ & & & & 1018 & \\
& & & & &
\end{tabular}

cryocondensate; 2) that the oil was dispersed in the reservoir in discrete, immobile accumulations that were transported to the wellbore through a free gas phase; and 3) that a small quantity of oil was being coned in from a nearby pool of oil. Each mechanism is supported by some data, although no proposed method had a clear advantage over the others. Each mechanism is discussed briefly in the following paragraphs.

The quantity of oil that is being produced, 5 to $9 \mathrm{ppm}$ by weight, is consistent with laboratory data on the solubility of oil in water. Exhibit I-7 is reproduced from J. P. Price's "Aqueous Solubility of Crude Oil" (1981). This study involved distilling a crude oil, similar to the 


\section{Exhibit I-6. LOW-PRESSURE SEPARATOR SIMULATED DISTILLATION BY GAS CHROMATOGRAPHY}

\begin{tabular}{lcc} 
& \multicolumn{2}{c}{ Temperature, ${ }^{\circ} \mathrm{F}$} \\
\% Recovered & $2 / 19 / 91$ & $4 / 13 / 87$ \\
\cline { 1 - 2 } Initial Boiling Point & 440 & 360 \\
$5 \%$ & 605 & 540 \\
$10 \%$ & 645 & 585 \\
$15 \%$ & 675 & 615 \\
$20 \%$ & 695 & 645 \\
$30 \%$ & 745 & 695 \\
$40 \%$ & 775 & 735 \\
$50 \%$ & 825 & 785 \\
$60 \%$ & 875 & 830 \\
$70 \%$ & 940 & 895 \\
$80 \%$ & & 1010
\end{tabular}

oil produced at the Gladys McCall well, into carbon-number fractions and determining the solubility of each fraction in water. The pressure was approximately 10,875 psia in this study. At $140^{\circ} \mathrm{C}$-- the temperature of the Sand 8 -- the solubility of the oil fractions reported by Price are as follows:

$\begin{array}{lr}\text { C6 to } \mathrm{C} 10 & 130 \mathrm{ppm} \text { by weight } \\ \mathrm{C} 12 \text { to } \mathrm{C} 15 & 55 \mathrm{ppm} \text { by weight } \\ \mathrm{C} 14 \text { to } \mathrm{C} 20 & 19 \mathrm{ppm} \text { by weight } \\ \mathrm{C} 19 \text { to } \mathrm{C} 25 & 6 \mathrm{ppm} \text { by weight } \\ \mathrm{C} 24 \text { to } \mathrm{C} 34 & 2 \mathrm{ppm} \text { by weight }\end{array}$

Price found that these solubilities were not additive and there was interference between ranges. He also noted that salt, at $10 \%$ by weight, decreased the solubility of the $\mathrm{C} 10$ to $\mathrm{C15}$ fraction by about $75 \%$. Nevertheless, the data suggest that the 7 parts per million of oil produced could have been dissolved in the brine at reservoir conditions.

Weres (1985) suggested the produced oil was in a gas phase in the reservoir. The scenario calls for an oil phase to exist in the reservoir, but the oil saturation is too small for the oil phase to 


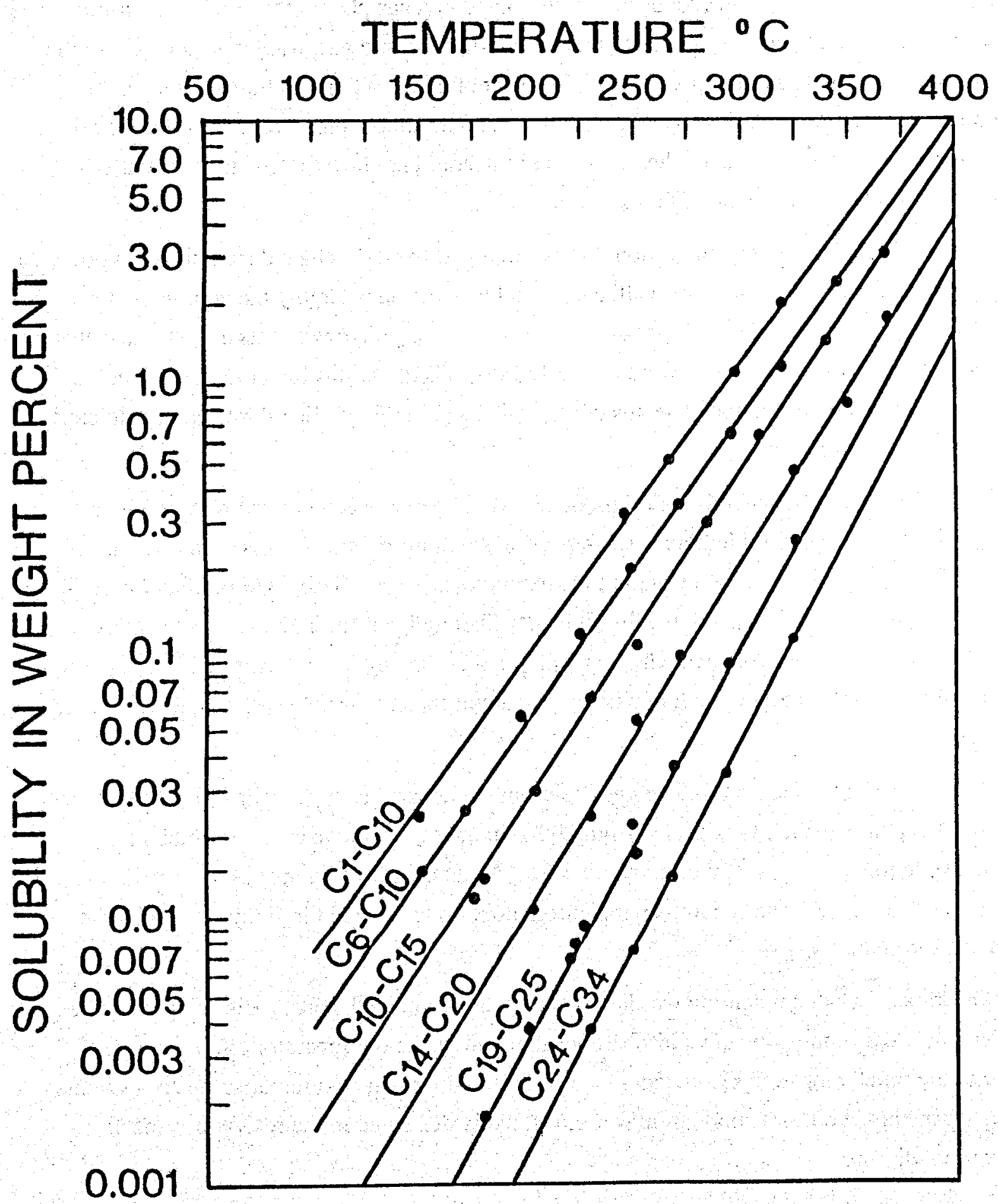

Aqueous solubility of six petroleum distillation fractions in ppm (by weight) as a function of temperature at a constant pressure of 750 bars. Carbon number range shown for each curve.

Exhibit I-7. AQUEOUS SOLUBILITY OF CRUDE OIL [From J. P. Price's "Aqueous Solubility of Crude Oil" (1981)] 
migrate as such. The heavy oil produced was dissolved in a gas phase that formed down-hole after reservoir pressure declined in response to production of brine and gas. He cites increases in the $\mathrm{C7}$ to $\mathrm{C} 13$-alkanes production just prior to the onset of heavy oil production to support this hypothesis. A problem with this hypothesis is that the bottomhole pressure at the onset of oil production was over 10,700 psia, whereas a gas phase could not be expected to form until the bubble-point pressure of around 9200 psia was reached.

Finally, there has been a suggestion that oil migrated from the shale during the drawdown, or was present at this interface near the well, and the oil production is largely the coning in of a very thin oil accumulation from the shale/sandstone interface. A problem with this hypothesis is that oil production began while brine rates were below $15,000 \mathrm{STB} / \mathrm{d}$. At this lower rate, particularly following higher rate production, it seems unlikely that a pressure gradient large enough to cause oil coning could be present.

It is unlikely that the quantity of oil produced would become economical with continued production. If the original oil in place was trapped in small immobile pockets in the Number 8 Sand and is being transported to the well in the newly formed gas phase, then production of this oil will be dependent on production of the differentially liberated gas out in the reservoir. In the Gas Section of this report, we explained why this will not occur to any large extent. Oil production from the Gladys McCall Sand 8 will remain only at a nuisance level of a few parts per million in the brine.

Knockout-Pot Condensate -- The knockout-pot condensate is those hydrocarbons that drop out of the gas phase as the gas is cooled from $290^{\circ} \mathrm{F}$ in the separators to the near-ambient temperature required for gas dehydration and sales. An analysis of a sample of the knockout pot is provided in Exhibit I-8. The accompanying chromatogram is provided in Exhibit I-9 with the normal alkane chain labeled.

The knockout-pot condensate was largely aromatic (contained benzene-like ring structures) and contained less of the aliphatic hydrocarbons than did the heavy separator oil. Because aromatics are much more soluble in water than their straight-chain counterparts, the components making up the knockout-pot condensate were most likely dissolved in the reservoir brine at reservoir conditions.

The knockout-pot condensate was disposed of without measuring volumes for the first half of the test. Volumes were first measured in 1985. The sudden appearance of knockout-pot condensate at 13 million barrels of brine produced should not be construed to mean this hydrocarbon liquid was not being produced before this time, as was the case for the heavy oil production. 
FLOW TESTS OF THE GLADYS MCCALL WELL THROUgh OCTOBER 1990

Exhibit I-8. GAS COOLER CONDENSATE COMPOSITION

Carbon No.

1
2
3
4
5
6

Benzene

7 Toluene

8

Ethylbenzene

$m, p$-Xylene

Styrene

9

o-Xylene

C3-Benzene

10

11

12

Naphthalene

C1-Naphthalene

14

C2-Naphthalene

15

16

C3-Naphthalene

17

18

19

20

21

22

23

24

25

26

27

28
19 Feb 87 04 May $87 \quad 11$ May $87 \quad 18$ May $87 \quad 16 \mathrm{Jul} 87 \quad 21$ Oct 87

\begin{tabular}{|c|c|c|c|c|c|}
\hline$<0.01$ & $\cdots$ & & -- & -- & 0.01 \\
\hline 0.01 & $<0.01$ & $<0.01$ & 0.01 & 0.01 & 0.02 \\
\hline 0.07 & $<0.01$ & 0.05 & 0.06 & 0.02 & 0.08 \\
\hline 0.17 & $<0.01$ & 0.13 & 0.11 & 0.06 & 0.15 \\
\hline 0.19 & $<0.01$ & 0.13 & 0.12 & 0.06 & 0.13 \\
\hline 0.27 & $<0.01$ & 0.34 & 0.30 & 0.18 & 0.20 \\
\hline 4.01 & $<0.01$ & 3.05 & 3.26 & 2.57 & 5.10 \\
\hline 0.60 & $<0.01$ & 0.56 & 0.52 & 0.32 & 0.29 \\
\hline 4.07 & $<0.01$ & 3.16 & 3.54 & 2.86 & 5.24 \\
\hline 1.26 & $<0.01$ & 0.31 & 0.36 & 0.14 & 0.56 \\
\hline 1.00 & $<0.01$ & 0.83 & 0.94 & 0.80 & 1.25 \\
\hline 1.91 & $<0.01$ & 1.67 & 1.94 & 1.69 & 2.63 \\
\hline$\cdots$ & $\cdots$ & $\cdots$ & - & - & 0.02 \\
\hline $\begin{array}{r}1.44 \\
1.66\end{array}$ & 0.01 & 1.01 & 1.79 & 0.95 & $\begin{array}{l}0.24 \\
2.37\end{array}$ \\
\hline 1.00 & $<0.01$ & 1.12 & 0.95 & 0.95 & $\begin{array}{l}2.37 \\
3.56\end{array}$ \\
\hline 3.97 & 0.09 & 3.44 & 3.61 & 4.55 & 0.39 \\
\hline 6.16 & 0.39 & 3.88 & 3.34 & 1.94 & 4.12 \\
\hline 6.16 & 2.17 & 4.76 & 4.58 & 1.86 & 2.77 \\
\hline & 0.38 & 3.08 & 4.18 & 6.36 & 6.79 \\
\hline 9.85 & 5.75 & 6.22 & 5.34 & 3.48 & 1.53 \\
\hline$\because \pi$ & 2.46 & 5.38 & 7.81 & 13.07 & 12.94 \\
\hline 11.07 & 9.63 & 7.46 & 5.75 & 3.57 & 2.80 \\
\hline & $=$ & $\overline{i i}$ & & & 8.78 \\
\hline $\begin{array}{r}10.49 \\
7.54\end{array}$ & $\begin{array}{l}16.91 \\
12.47\end{array}$ & $\begin{array}{r}11.70 \\
9.00\end{array}$ & $\begin{array}{r}11.81 \\
8.57\end{array}$ & $\begin{array}{l}11.34 \\
10.21\end{array}$ & $\begin{array}{l}4.27 \\
7.57\end{array}$ \\
\hline$\cdots$ & & $\ldots$ & & -. & 3.94 \\
\hline 6.99 & 14.50 & 10.07 & 7.89 & 10.50 & 1.64 \\
\hline 6.97 & 9.24 & 5.91 & 6.82 & 5.25 & 4.18 \\
\hline 5.08 & 8.29 & 5.20 & 4.86 & 3.30 & 3.54 \\
\hline 3.36 & 5.18 & 3.62 & 3.27 & 3.12 & 2.29 \\
\hline 2.31 & 4.14 & 3.22 & 2.70 & 2.89 & 2.27 \\
\hline 1.47 & 2.47 & 1.92 & 1.94 & 2.36 & 1.91 \\
\hline 0.89 & 1.96 & 1.15 & 1.46 & 2.10 & 1.73 \\
\hline 0.54 & 2.87 & 0.74 & 1.37 & 1.69 & 1.83 \\
\hline 0.29 & 1.09 & 0.89 & 0.80 & 1.80 & 1.17 \\
\hline 0.14 & -- & & & & 1.16 \\
\hline 0.05 & - & $\cdots$ & & & 0.39 \\
\hline$<0.01$ & $-\cdots$ & $\cdots$ & $\therefore$ & $\ldots$ & 0.11 \\
\hline
\end{tabular}

I-13 
Flow Tests of the Gladys MCCall Well Through OCtober 1990

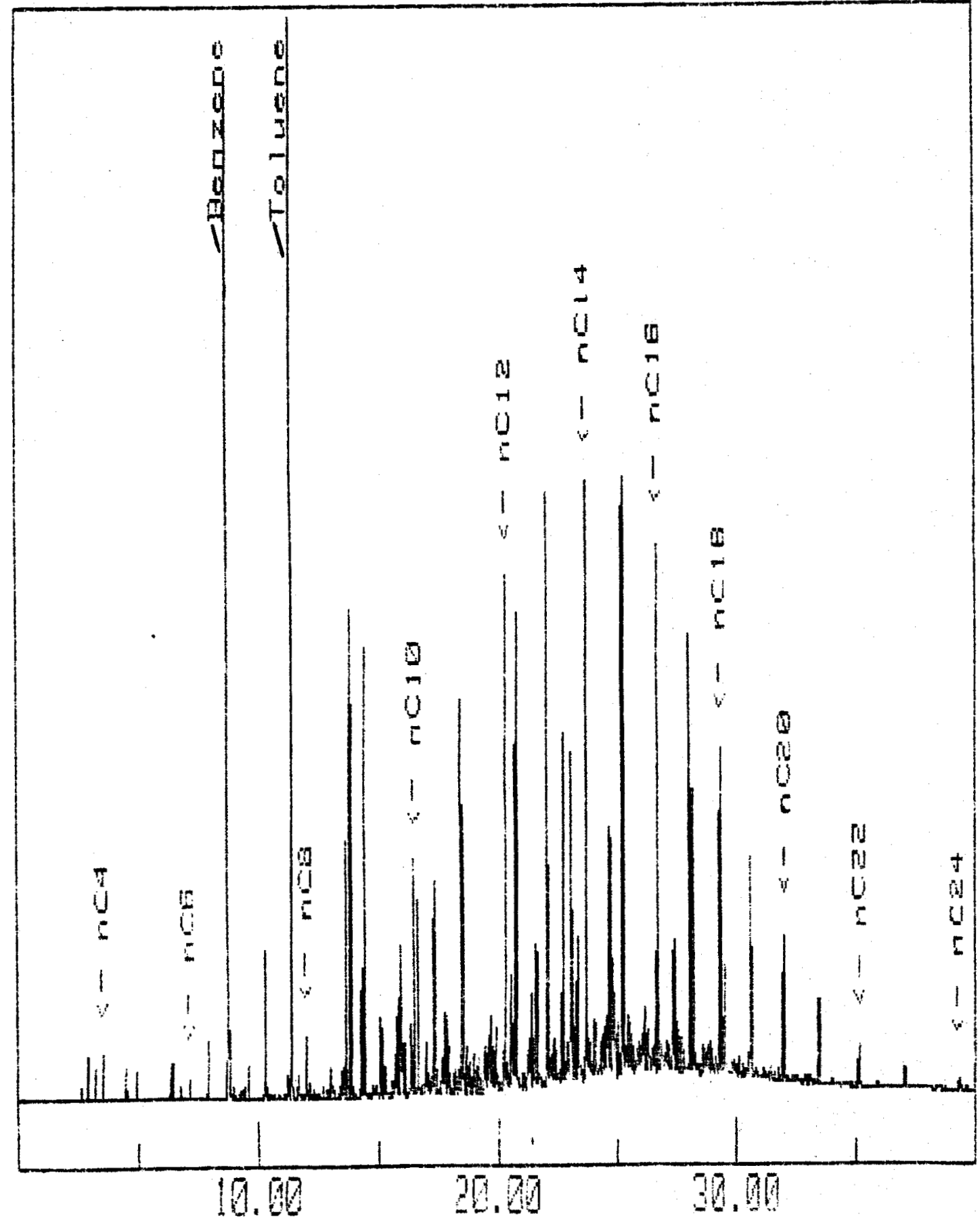

Exhibit I-9. KNOCKOUT-POT CONDENSATE CHROMATOGRAM 
Cryocondensates -- The term "cryocondensates" is used to describe most of the heavy, predominantly aromatic, hydrocarbons produced. These hydrocarbons were collected and analyzed by Drs. J. Meriwether and D. Keeley of the University of Southwestern Louisiana, and most of the data incorporated herein is taken from their reports. The cryocondensates include all hydrocarbons that condense from the gas at about $-60^{\circ} \mathrm{F}$, plus those hydrocarbons that remain in brine that has been cooled to below ambient temperature and flashed to 1 atmosphere pressure. The cryocondensates contain numerous aromatic hydrocarbons, including benzene, naphthalene, indene, phenyl and biphenyl, benzofurans, anthracene, phenanthrene, and their derivatives. There are only minor amounts of alkanes present.

Much like the knockout-pot condensate described above, these hydrocarbons are believed to be dissolved in the brine at reservoir conditions. Because aromatics are much more soluble in water than their straight-chain counterparts, the components making up the knockout-pot condensate were most likely dissolved in the reservoir brine at reservoir conditions. Indeed, almost half of these hydrocarbons remain dissolved in the brine at separator conditions, whereas the remainder flashes into the gas phase.

Changes in the cryocondensate concentrations have been speculated to portend the production of oil. Zarrella et al. (1967) reported that the concentration of benzene decreased with distance from an oil deposit. These observations were based on hydropressured, not geopressured, reservoirs. The brine in hydropressured reservoirs where commercial accumulations of hydrocarbons exist tends to be more mobile over geologic time than the brine trapped in geopressured aquifers. The oil source would constantly replenish the aromatics in the brine as fresh brine is introduced to the system. In geopressured reservoirs, the aquifer is bound by shale and fault barriers. Brine flow into the system is very limited. We therefore would not expect the relationship between the benzene concentration gradients to be as related to an oil deposit in a geopressured reservoir as in a conventionally pressured reservoir.

Zarrella also noted that brines in contact with gas fields did not contain benzene. Again, this is probably not applicable to geopressured-geothermal reservoirs. This lack of benzene is consistent with the above scenario whereby benzene' in the brine is continually replenished by an oil phase in the reservoir. Benzene and other aromatics are produced by the diagenesis of kerogen and large organic molecules. Both are stable molecules that do not tend to readily degrade into smaller molecules at the pressure and temperature found in this aquifer. Indeed, methane and benzene have been found in all geopressured-geothermal wells and also in the much hotter geothermal wells. 
Flow Tests of the Gladys McCall Well Through OCtober 1990

\section{APPENDIX $\mathbf{J}$}

PVT Analysis for Sand 8 by Weatherly Laboratories, Inc.

$\mathrm{J}-1$ 
FLOW TESTS OF THE GLADYS MCCALL WELL THROUGH OCTOBER 1990

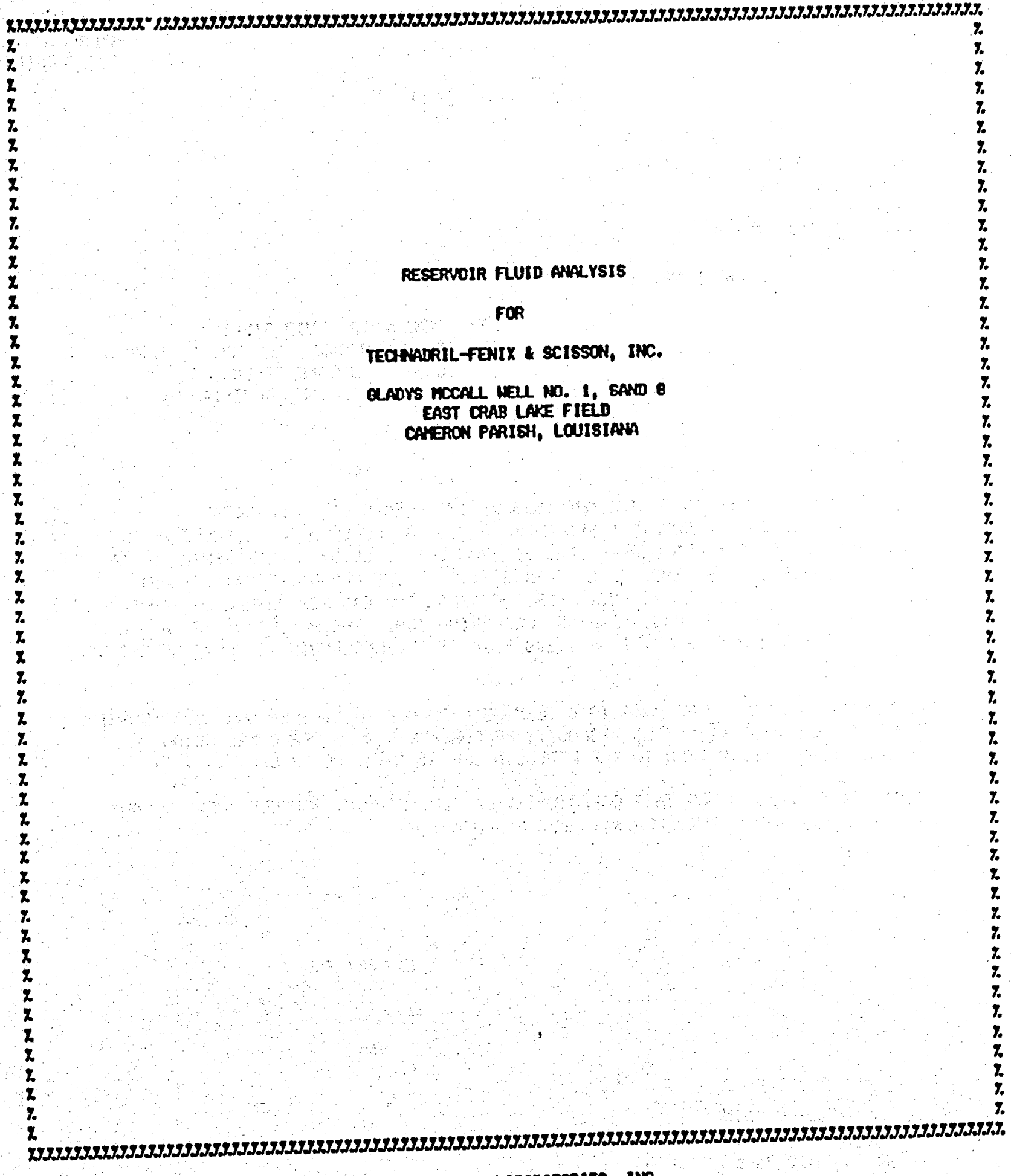

IJATHERLY LABORATORIES, INC.

$\mathrm{J}-3$

I. NST I T U T E 
MEATIERLY LABRRATORIES, INC. J. E. WEATHERLY, UR.

\author{
223 CEOROETTE LAFAYETTE, LA 70506 \\ PtDre (318) 232-4877
}

\section{OCTOBER 24, 1983}

JOW D. NEAL PRESIDENT BRYAN SONWIER VICE PRESIDENT

\begin{abstract}
TECHADRIL-FENIX \& SCISSON, IMC. 3 MORTHPOINT DRIVE SUITE 200 HOUSTON, TEXAS 77060

ATIENTION: HR. LARPY DURRETT
\end{abstract}

\author{
RE: RESERVOIR FLUID STUDY \\ GLADYS MOCALL WELL NO. 1, SAND 8 \\ EAST CRAB LAKE FIELD \\ CAMERON PARISH, LOUISIANA
}

\title{
GENTLEREN
}

ATTACHED ARE THE PESULTS OF THE ANALYSES OF THE CHEMICAL AND PHYSICAL CHARACTERISTICS OF A RECOMBINED REEERNOIR FUUID SALYPLE FROM THE SUBJECT WELL. SURFACE SEPARATOR SAMPLES WERE COLLECTED FROM THIS WELL BY A REPRESENTATIVE OF MEATHERR Y LABORATORIES, INC. ON OCTOBER 8, 1983. THE GAS-HATER RATIO (GLR) MEASURED ON THIS TEST, 25.01 CUBIC FEET OF SEPARATOR GAS PER BARREL OF SEPARATOR LIOUID, WAS USED AS THE BASIS FOR ONE RECOMBINATION. THE RESULTANT RESERVOIR FLUID EXHIBITED A BUBBLE POINT OF 9,200 PSIA AT THE RESERVOIR TERPERATURE 290 DEGREES FAHREMHEIT.

OTIER RECOMBINATIONS MERE DONE TO DETERMINE A BUBBLE POINT -VS- GRR RELATIONSHIP. A DIFFERENTIAL LIBERATION AND VISCOSITY MEASUREMENTS NERE PERFOPOTED USING RESERVOIR FLUID RECOMBINED TO THE PRODUCED GHR AT THE TIME OF SAMPLING.

WE HISH TO THANK YOU FOR THIS OPPORTUNITY OF SERVING YOU. SHOU.D THERE BE ANY QLESTIONS CONCERIINO THIS REPORT, PLEASE CONTACT US.

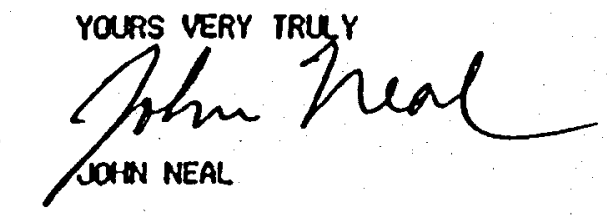

CC: M. JOWHE BERING

TECHADRIL FENIX \& SCISSCN, INC.

RT. 1, BOX 36-B

GRAND CHENIER, LA 70643

LAB. NO. N2106-10457 
TECHNADRIL-FENIX \& SCISSON, INC. GLADYS MCCALL WELL NO. 1, SAND 8 EAST CRAB LAKE FIELD

\section{CEOPRESSURE/CEOTHERWAL PROVECT SAMPLIMO AND LABORATORY PROCEDURE}

1) LaTER VAPOR CONTENT OF SEPARATOR Gas UAS DETERMINED BY FLOHING GaS fROM A METERING VALVE ON THE SEPARATOR GAS METER RUN THROUGH A WEIGHINO TUBE (INDICATCR LRIERITE (CASO4) MEIOHED TO 0.1 MILLIORAM) TO A RUSKA GASONETER. SEPARATOR GAS SAMPLES WERE TAKEN FROM THE SAME PLACE INTO I GALLON STAIMLESS STEEL (S:S.) CYLINDERS AFTER THOROLIGH PURGINO. SEPARATOR LIQUID SAYPLE CYLINDERS (1000 M. S.S.) WERE FIRST CHARGED WITH SEPARATOR GAS TO FULL SEPARATOR PRESSURE. THE LIQUID CYLINDERS WERE THEN CONWECTEU TO THE SEPARATOR WATER SAMPLINO POINT BY A S.S. TUBE LONG ENOUGH TO LOOP THROUGH A COOL ING BATH. THE HATER TRANSFER LINE HAS THEN SLOHLY AND THOROUOIRY PURGED AT THE CYLINDER. SEPARATCR HATER HAS LET INTO THE CYL INDER BY SLOWY BLEEDINGS OAS FROM THE TOP VALVE. AT NO TIHE HAS THE WATER CAUGHT IN THE CYLINDER ALLOWED TO DROP BELON SEPARATOR PRESSTRE.

2) FLASH LIBERATION OF GAS FROM SEPARATOR NATER HAS ACCOHPLISHED BY USING A WEIGHEI SEPARATOR FLASK. THIS SEPARATOR FLASK WAS COANECTEO TO THE OUTLET OF A SEPARATOR WATER CYLINDER BY A SHDRT CAPILLARY LINE. GAS FROM THE SEPARATOR FLASK PASSED THROUGH A IEIGHED DRYING TUBE THFOUGH A OLASS CYLINDER ( 300 ML.) TO A RUSKA GASOMETER. A VACUUM VALVE AND A MERCURY MANOHETER WAS COMMECTED TO IHE GAS MANIFOLD BETLEEN THE DRYING TUBE AND THE GASOMETER. BEFORE COUHENCING THE FLASH, THE ENTIRE FLASH GAS MANIFOLD HAS EVACUATED AND THEN FILLED HITH IELIUM TO ATMOSPHERIC PRESSLFE. A KNOWN VOLUTE OF SEPARATOR WATER HAS PUSHED OUT OF THE SAMPLE CYLINDER AT A PRESSURE OLICHTLY ABOVE FIELD SEPARATOR PRESSURE BY USE OF A CALIBRATED MERCURY PUIP. TIE VOLUEE OF STOCK TANK WATER PRODUCED WAS DETERMINED BY ITS HEIGHT AND DENSITY. THE VOLUME OF DRY GAS EVOLVED WAS DETERTIINED WITH THE GASOKETER. THIS CAS VOLUME WAS SUBJECT TO \& 2\%. ERROR DUE TO THE VERY SHALL AMOUNTS MEASURED. THE GAS WAS CMARGED TO A CAROTOTOGRAPH FOR ANALYSIS FROH THE GLASS CYLINDER.

3) PHIYSICAL RECOMBINATION OF SEPARATOR EFFLLENTS:

SEPARATCR GAS MAS CHARGED INTO A TEMPERATURE CONTROLLED CELL. THE VOLUME OF THIS WINDOWED CELL IS KNOWN FOR ANY PRESSURE AND TEMPERATURE. THE PRESSURE OF TIEE GAS IN THE CELL WAS MEASURED HITH A MEROURY MANOTETER AND A BRROHETER. THIS CALCLLATEI GAS VOUUATE HAS SUBJECT TO A \pm 1 T ERROR DUE TO THE STRLL ATOUNT CHARGED TO THE CELL. A VOUUME OF SEFARATOR HATER UAS CHARCED INTO THE NINDOHED CELL BY USE OF A CALIBRATED HERCURY PUMP. THE MATER WAS METERED AND MEASURED AT A PRESSURE SLIGHTLY ABOVE FIELD SEPARATOR PFESSURE. FOUR RECOHBINATIONS WERE DONE IN ORDER TO PRODUCE A SATUKATION PRESSURE-VS-GAS WATER RATIO CURVE. RESERNOIR FLUID RESULTING FROM RECUMBINATIOHI OF THE PRODUCED GWR (FIFTH RECOMBINATION) WAS USED TO PERFORM A DIFFERENTIAL LIBERATION AND. VISCOSITY MEASUREHENT. 
TECHNADRIL-FENIX \& SCISSON, INC. QLADYS MCCALL WELL NO. 1, SAND B EAST CRAB LAKE FIELD

1) PRESSURE-VOLUTE RELATIONS OF RECOMBIMED RESERWIR FLUID AT RESERVOIR TEHPERATURE, EACH DATUH OF PRESSURE-VOLURE RELATIONS HAS CORRECTED FOR MERCURY PUIP CALIBRATION, MANIFOLD EXPANSION, CZLL EXPANSION, MERCURY COHPRESSIBILITY AND MERCURY THERTAL EXPANSIOW. LIQUID VOLLME PERCENT IAS TETERMINED BY CAL IBRATED CATHETCHETER AND BY DATA INTERPRETATION.

5) DIFFERENTIAL LIBERATION OF RESERVIR FLUID AT RESERVOIR TEMPERATLRE: GAS FRON EACH PRESSURE DECREHENT OF THE DIFFERENTIAL LIBERATION HAS ANALLYED IN THE SAIE MANER AS DESCRIBED IN 21, (FLASH LIBERATION). DIFFERENTIAL LIQUID CHANGES MERE NOTED.

6) VISCOSITY OF RESERUOIR FLUID WAS HEASURED BY MR. J. R. COMEAU OF WEATHERLY LABORATCRIES. A DESCRIPTION OF MR. COHEAU'S EXFERIMENTAL PROCEDURES IS OIVEN BELOW:

GEOTHEPAHA HATER VISCOSITIES MERE REASURED USING A RUSKA ROLLING BALL VISCOKETER HITH AN ELECTRONIC DETECTION SYSTEM TO PREVENT ELECTROLYSIS. THE DETECTION SYSTEM CONSISTS OF A SENSITIVE AUDIO ANPLIFIER WITH POSITIVE FEEDBACK ADUUSTED JUST BELOU OSCILLATION. THE BALL IS HED BY AN ELECTROMAGETT. WHEN CURPENT TO THE MAGNET IS. TUPAED OFF, A PULSE IS PRODUCTED WHICH STARTS A DIOITAL TIMER. WHEN THE BALL STRIKES THE CONTACT AT THE OTHER END OF THE VISCOAKTER THE ELECTRICAL DISTURBANCE PRODUCED IS CENERALY ANTLLIFIED AND TURNS THE TIMER OFF. TIMES WERE REASURED TO 1/100TH OF A SECCIND AND AVERACED. THE VISCONETER LAS CALIBRATED AT EACH OF TWO ANGLES USINO DISTILLED MATER AT SEVERAL TERPERATURES. THESE RESULTS WERE USED ALONO WITH PREVIOUS RESLLTS TO OBTAIA NEN CAL IBRATION CURVES. $t$ P VERSUS U WERE PLOTTED TO OBTAIN CALIBRATION.

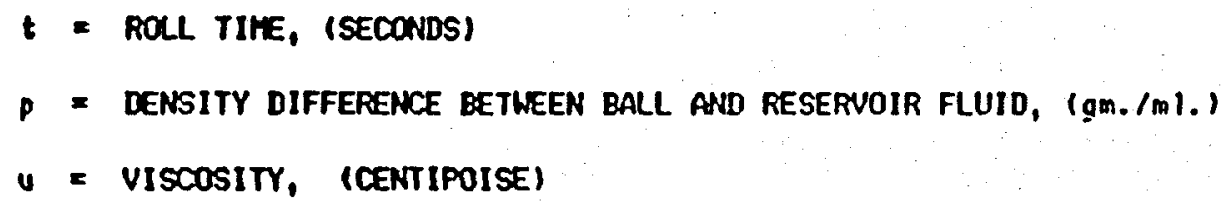

THE VISCOMETER WAS CHAROED MITH RESERNOIR FLUID AND RUN AT 299 'F AT 1090 LB. INTERVALS. THE VISCOSITIES HAD A PROBABLE ERROR OF \pm 0.01 CENTIPOISE.

NOTEI ALL DATA FOR PRESSURES GREATER THAN 11,000 PSI MERE DBTAINED BY EXTRAPOLATION. THE VISCOSITY DATA ARE ABOUT 0.1 CENTIPOISE LOWER THAN THE PREVIOUS REPORT (N1901. 10224 OF APRIL 1983). WE BELIEVE THAT THIS IS DUE TO A FILM BUILDUP IN THE 404 S.S. BARREL OF THE OD E.L.I. VISCOHETER. THIS FILM DID NOT FOFH IN THE 316 S.S. BARREL OF THE RUSKA VISCOMETER. 
FIEL DATA FOR LEATHERTY LABORATORY INVESTIGATION

WELl RECORD

CorpanY

Wall

FIELD

PARISH AND STATE
TECHMADRIL-FENIX \& SCISSON, INC. GLADYS MCCALL NO. 1

EAST CRAB LAKE

CAHERON, LOUISIANA

FIED CHARACTERISTICS

FORTATION NATE

SAND NAME AND DESIGNATION

DATE COHPLETED

8

ORIGINAL RESERUOIR PRESSURE

WEL CHARACTERISTICS

ORIGINAL PROQUCED GAS-LIQUID RATIO

PERFORATIONS

ELVATIONS

TOTAL DEPTH

LAST RESERWIR PRESSURE

RESERUDIR TEYPERATURE

$\begin{aligned} 12,783 & \text { PSIA } \\ 290 & \text { DEGRES F }\end{aligned}$

SAMPLINO CONDITIONS

DATE SAHPLED

TUBINO PREESSURE, FLOWING

PRIMARY SEPARATCR TEMPERATURE

PRIMARY SEPARATOR PRESSURE

PRIMARY SEPARATOR GAS RATE

SEPARATOR LIQUID RATE

GAS-LIOUID RATIO (SEPARATOR)

SHINKACE FACTOR (VO, S.T.HATER $60^{\circ} \mathrm{F} / \mathrm{WO}$. SEP, HATER)

OAS-LIQUID RATIO (STOCK TANK)

PRESSURE BASE

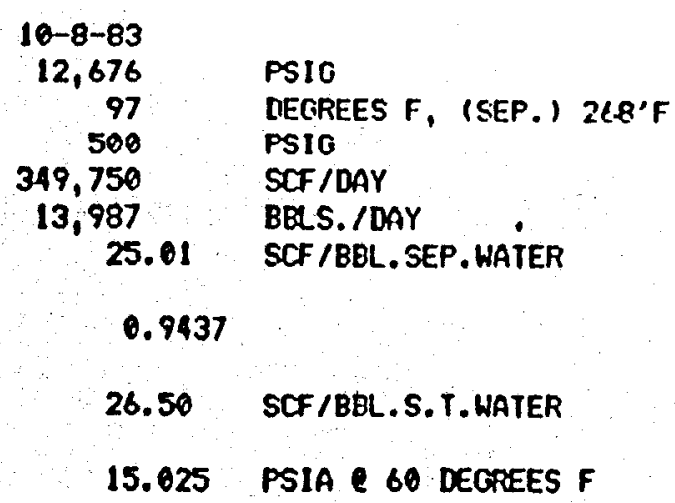

NOTE: FOR DRY GAS, 24.95 SCF/BBL. SEP. WATER E SEP, CONDITIONS.

26.44 SCF/BBL. S.T. HATER 60 'F.

LAB. ND. N2106-10457

PACE 4 OF 25

$\mathrm{J}-7$
INSTITUTE
O F
G A 5
T E C H N
O L O G Y 
TECWNADRIL-FENIX \& SCISSON, INC. GLADYS MCCALL WELL NO. 1, SAND 8 EAST CRAB LAKE FIELD

CALCLLATION OF bAS RATE, 10-8-83 TEST

(Factors fros CPSA Engineering Data Book)

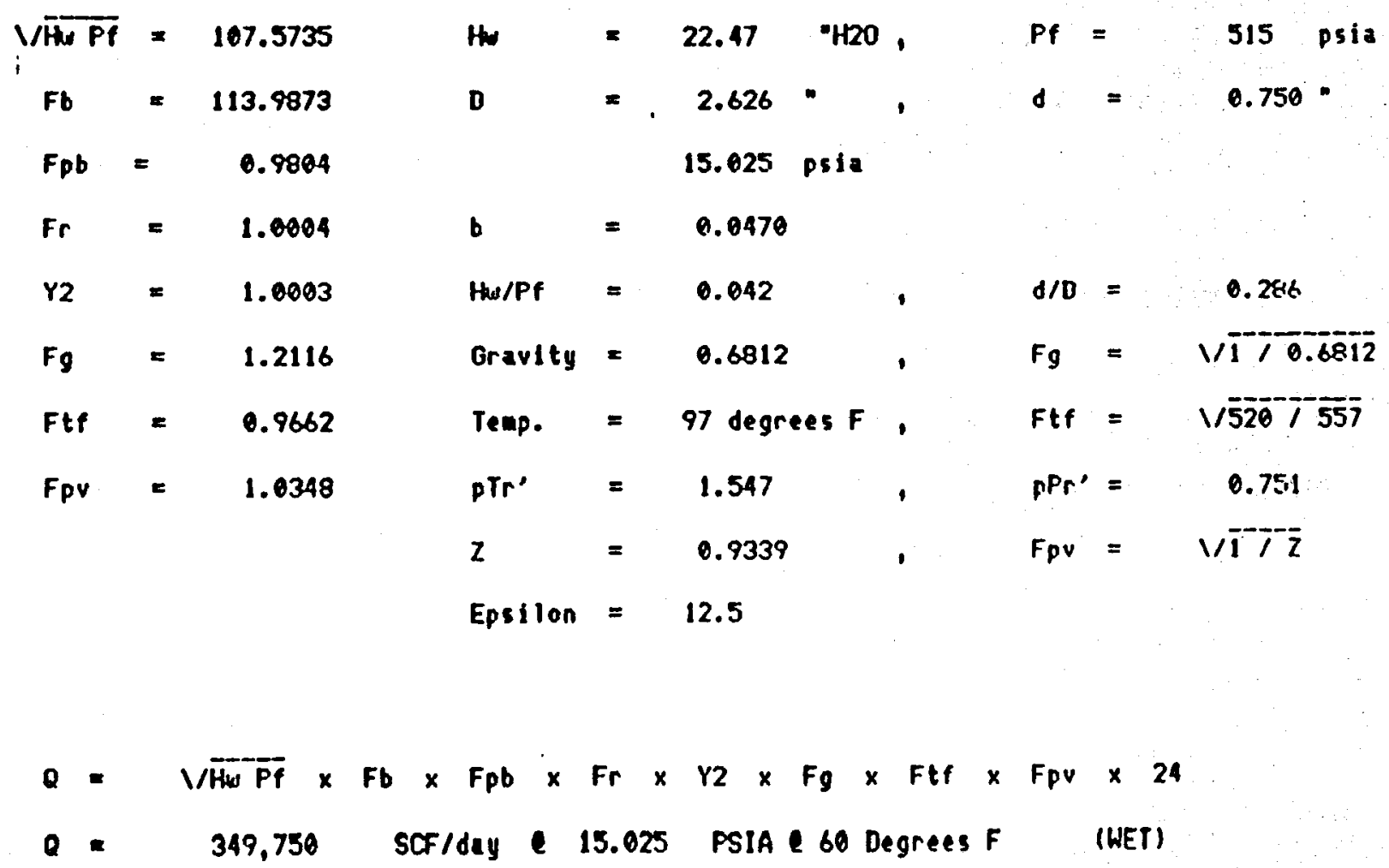

LAB ND. N2106-10457

PAGE 5 OF 25 
TECHNABRIL-FENIX \& SCISSON, INC. QLADYS HCCALL HELL NO. I, SAND 8 EAST CRAB LAKE FIELD

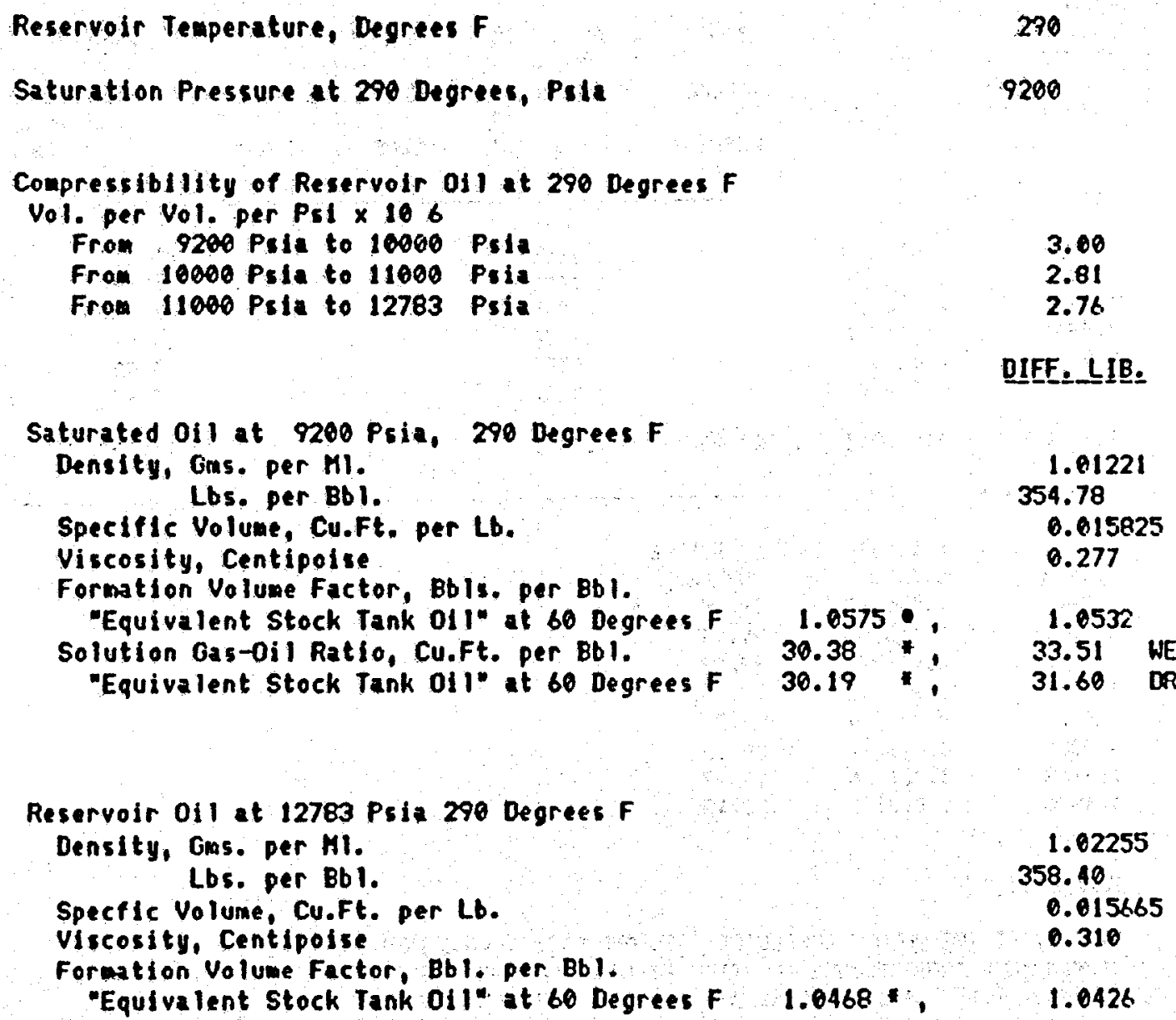

NOTE; REFERENCES TO 'OIL' ABOVE SHOLD READ 'WATER'.

- based on separator later flash. 
TECIWALRIL-FENIX : SCISSON, INC. QLADYS MDCALL HELL NO. 1, SAND 8 EAST CRAB LAKE FIELD

COMPOSITE LABCRATORY DATA 290 DEOPEES F

RECONBINATION (II) 20.00 SOF SEP. GAS 15.025 PSIA $60^{\circ}$ F/BRL. SEP. WATER C SEP. CONDITIONS.

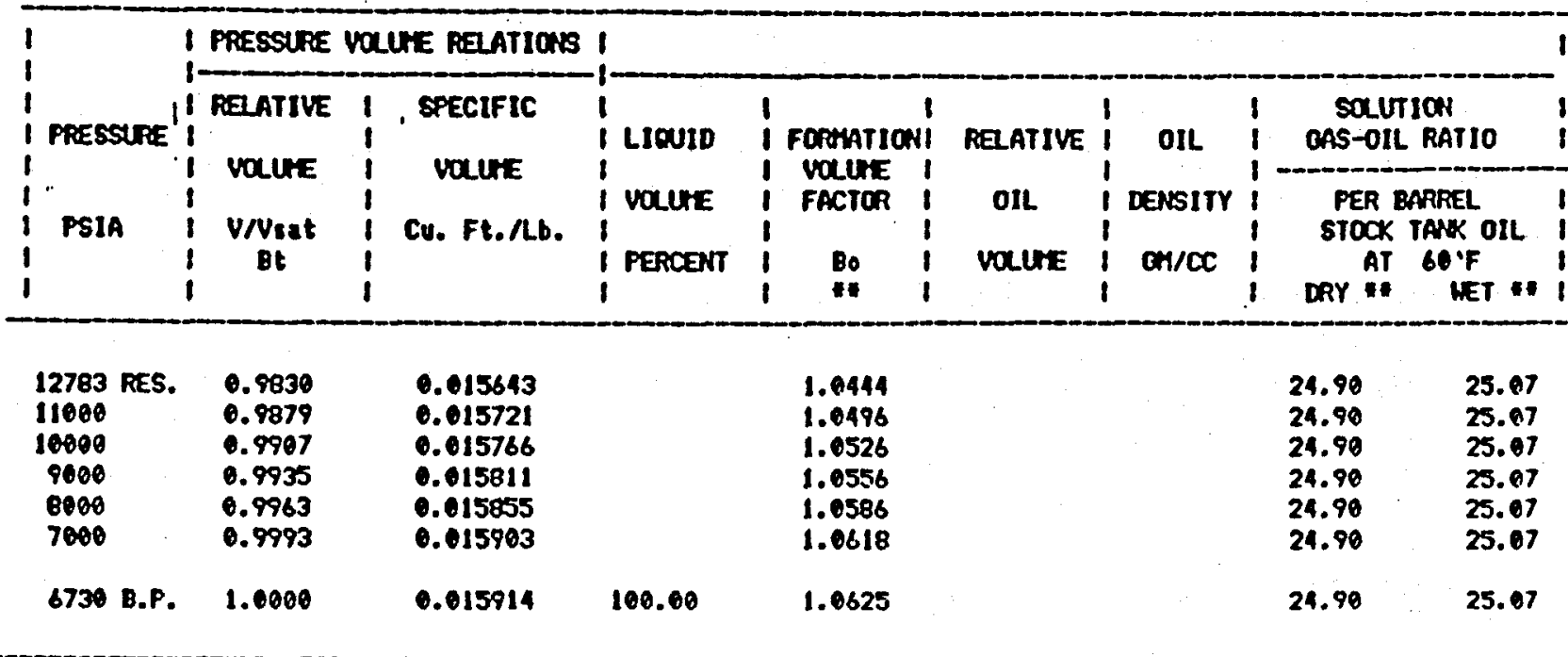

$\begin{array}{rrrr}6707 & 1.0001 & 0.015916 & \text { TIKY BUBBLE } \\ 6605 & 1.0004 & 0.015920 & \text { BUBBLE } \\ 6501 & 1.0008 & 0.015927 & 99.99 \\ 6009 & 1.0027 & 0.015957 & 99.94 \\ 5000 & 1.0068 & 0.016022 & 99.83 \\ 1000 & 1.0112 & 0.016092 & 99.68 \\ 3000 & 1.0191 & 0.016218 & 99.20 \\ 2004 & 1.0331 & 0.016411 & 98.13 \\ 1000 & 1.0768 & 0.017136 & 94.12 \\ 71 & 4.1075 & 0.070111 & 23.13\end{array}$

NOREMCLATLRE:

V/USAT. IS THE VOLUIE OF FLUIDS (OIL AND OASI AT THE INDICATED TEMPERATURE AND PRESSURE RELATIVE TO THE WOLUHE OF SATURATED OIL AT GUEBLE-POINT PRESSTRE AND INDICATED TEHPERATURE.

Bo IS THE VOLUNE OF OIL AT RESERWIR TEWPERATURE AND INDICATED PRESSURE RELATIVE TO THE VOLUNE OF EQUIVALENT STOCK TANK OIL MEASURED AT 60 BECTEES F.

CAS-OIL RATIO, IS CUBIC FEET OF GAS AT 15.025 PSIA AND 60

DEOREES F, PER BARREL OF STOCK TANK OIL AT 60 DEGREES F.

MTE: *: BASED ON SEPARATOR MATER FLASH.

REF. TO 'OIL' ABOVE SHOLLD READ 'WATER'. 
TECINAORIL-FENIX \& SCISSDN, INC. gladYs HCCALL WELL No. 1, SAND 8 EAST CRAB LA:E FIELD

COHOSITE LABORATORY DATA 29 DECREES F

RECORBINATION (2) 10.00 8CF 6EP. OAS \& 15. 225 PSIA \& 60'F/BEL. SEP. HATER E SEP. CONDITIONS.

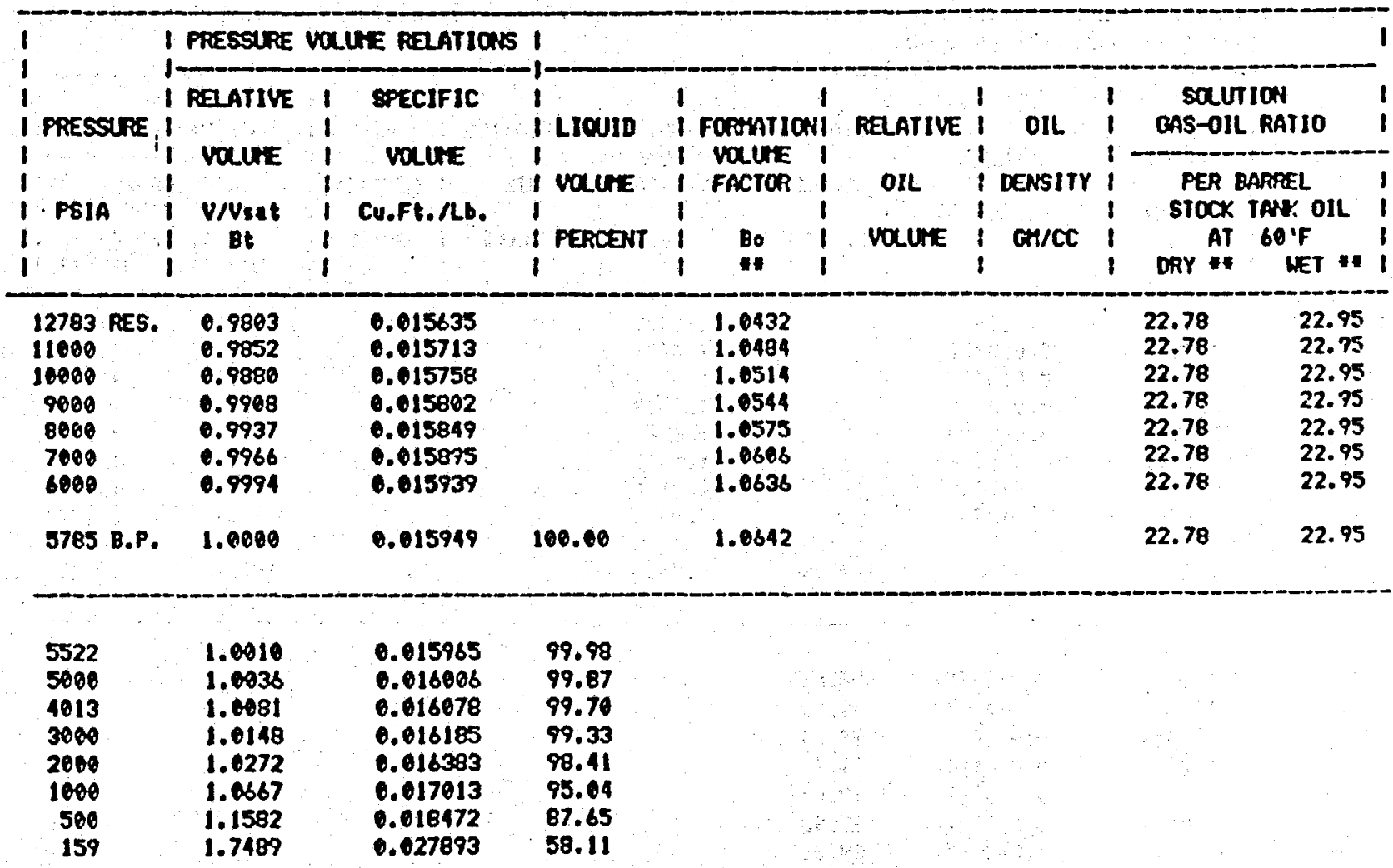

\section{MOTENCLATURE:}

V/USAT. IS THE VOLUTE OF FLUIOS (OIL AND GASI AT THE INDICATED TEMPERATURE AND PRESSURE RELATIVE TO THE VOLUTE OF SATURATED OIL AT BUBBLE-POINT PRESSTRE AND INDICATED TEMERATURE.

Bo IS THE VOLUHE OF OIL AT RESERVIR TEMPERATUFE AND INDICATEO PRESSURE RELATIVE TO THE VCLLIE OF EQUIVALENT STOCK TANK OIL. MEASURED AT 60 DEGREES F.

GAS-OIL RATIO, IS CURIC FEET OF GAS AT 15.025 PSIA AND 60 DEGREES F, PER BARREL OF STOCK TANK OIL AT 60 DECREES $F$.

NOTE:

* Based on separator water flash. REF. TO 'OIL' ABOVE SHOULD READ 'WATER'. 
TECINADRIL-FENIX SCISSON, INC. GLADYS MCCALL WELL NO. 1, SAND 8 EAST CRAB LAKE FIELD

CORPOSITE LABORATORY DATA 290 DECREES F

RECOHBINATION (3) 15.00 SCF SEP. OAS 15.025 PSIA \& $60^{\circ}$ F/BEL. SEP. WATER 2 SEP. CONOITIONS.

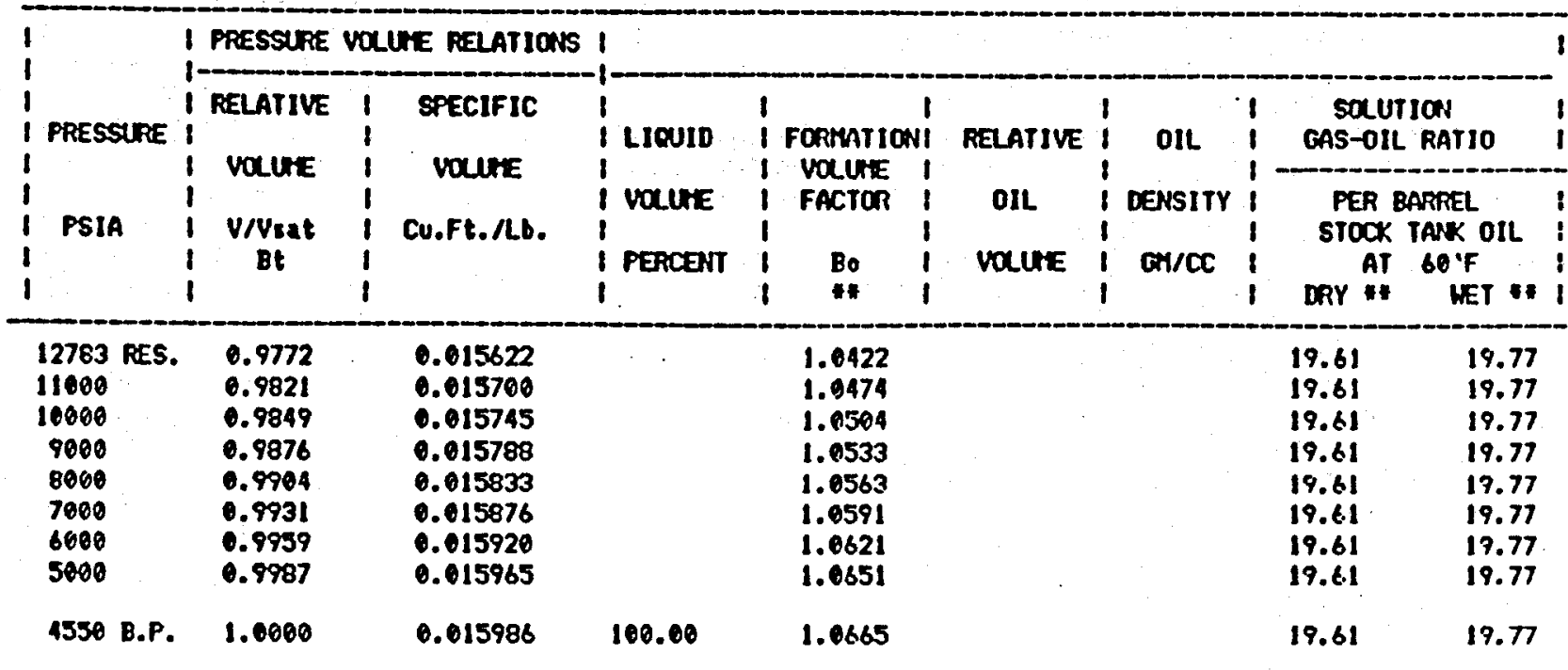

$\begin{array}{rrrr}4500 & 1.0002 & 0.015989 & \text { BUBBLE } \\ 4000 & 1.0022 & 0.016021 & 99.93 \\ 3500 & 1.0046 & 0.016060 & 99.84 \\ 3000 & 1.0090 & 0.016114 & 99.64 \\ 2000 & 1.0189 & 0.016287 & 98.86 \\ 1000 & 1.0526 & 0.016827 & 95.95 \\ 500 & 1.1318 & 0.018093 & 89.36 \\ 197 & 1.4605 & 0.023348 & 69.31\end{array}$

MORENCLATURE:

V/USAT. IS TIE VOLUE OF FLUIDS (OIL AND GASI AT THE INMICATED TEMPERATURE AND PRESSURE RELATIVE TO THE VOLLHE OF SATURATED OIL AT BUEBLE-POINT PRESSURE AND INDICATED TEMPERATURE.

Bo Is THE VOCUNE OF OIL AT RESERVOIR TEMPERATURE AND INDICATED PRESSURE RELATIVE TO THE VOLUNE OF EOUIVALENT STOCK TANK OIL MEASURED AT 60 DEGREES F.

CAS-OIL RATIO, IS CUBIC FEET OF CAS AT 15.025 PSIA AND 60 DEGREES F, PER BARREL OF STOCK TANK OIL AT 60 DEGREES F.

NOTE: * BASED ON SEPARATOR HATER FLASH. REF. TO 'OIL' ABOVE SHOLLD READ 'WATER'. 
TECHNADRIL-FENIX \& SCISSON, INC. QLADYS MCCALL WELL NO. 1, SAND 8 EAST CRAB LAKE FIELD

COHPSITE LABORATORY DATA 290 DEOREES F

PECOKBIMATION (4) 10.00 SCF SEP. BAS 15.025 PSIA \& 60!F/BB. SEP. NATER Q SEP, CONDITIONS.

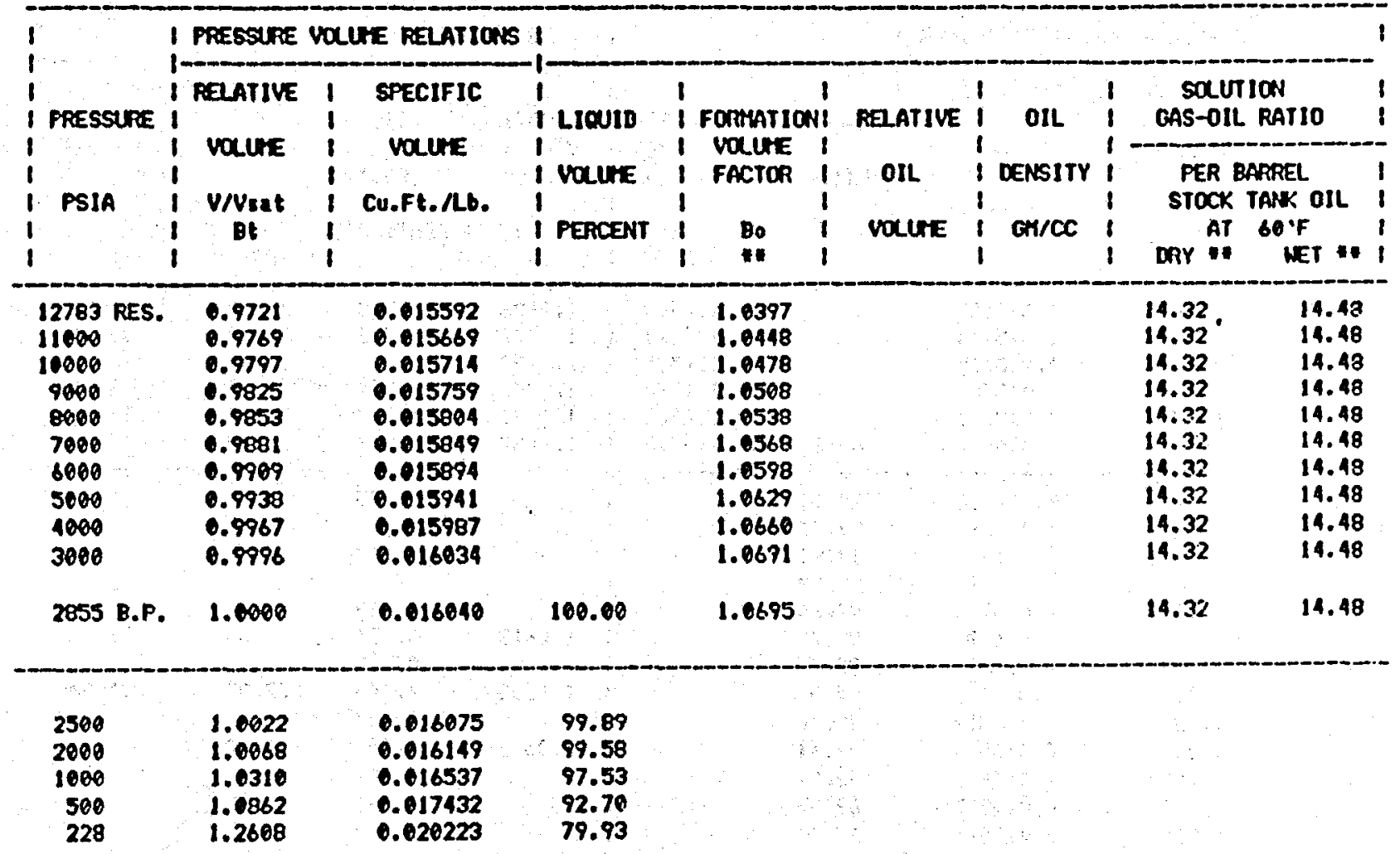

\section{NOKENCLATURE:}

V/VSAT. IS THE VOCUNE OF FLUIDS (OIL ANI GASI AT THE INOICATEL TERPEATURE AND PRESSURE RELATIVE TO THE VOLUTE OF SATURATED OIL AT BUBBLE-POINT PRESSURE AND INDICATED TEMPERATURE.

Bo IS THE VOLUHE OF OIL AT RESERVOIR TEMEERATURE AND INDICATED PRESSLRE RELATIVE TO THE VOLUE OF EWUIVALENT STOCK TANK OIL MEASURED AT 60 DEGREES F.

GAS-0IL RATIO, IS CUEIC FEET OF GAS AT 15.025 PSIA AND 60 DEGREES F, PER BAFREL OF STOCK TANK OIL AT 60 DEGREES F.

NOTE: BASED ON SEPARATOR WATER FLASH. REF. TO 'OIL' ABOVE SHOURO READ 'WATER'. 
TECWNADRIL-FENIX \& SCISSON, INC. gladYS MCCALL WELL NO. 1, SAND 8 EAST CRAB LAKE FIELD

COMPOSITE LABORATORY DATA 290 DECREES F

RECOMBINATION (5) 25.01 SCF SEP. CAS Q 15.025 PSIA \& 60 F/BBL. SEP. WATER Q SEP. COND. - PRODUCED CHR

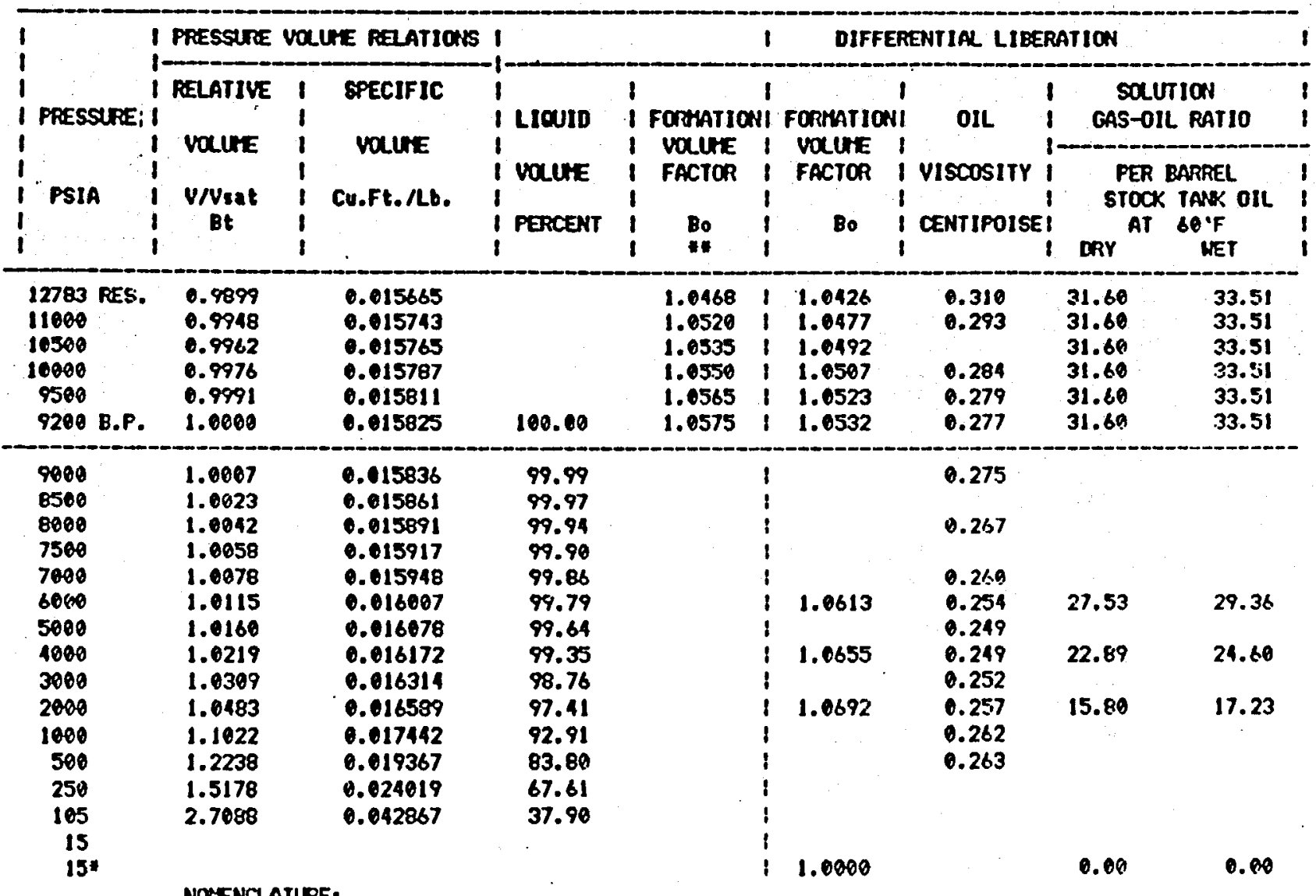

V/USAT. IS THE VOLUE OF FLUIDS (OIL AND GASI AT THE INDICATED TEMPERATURE AND PRESSURE RELATIVE TO THE VOLUHE OF SATURATED OIL AT BUBBLE-FOINT PRESSURE AND INDICATED IEMPERATURE.

Bo IS THE VOLUHE OF OIL AT RESERVOIR TEKPERATURE AND INDICATED PRESSURE RELATIVE TO THE VOLUTE OF EQUIVALENT STOCK TANK. OIL. MEASTRED AT 60 DEOREES F.

CAS-OIL RATIO, IS CUBIC FEET OF BAS AT 15.025 PSIA ANO 6 A DEGREES F, PER BARREL OF STOCK TANK OIL AT 60 DEGREES F.

Note: - INDICaTes Valle reasUREd 60'F

* BASED ON SEPARATOR WATER FLASH

ALSO BASED ON SEP. WATER FLASH: SOLUTION OAS IN RES. FLD. IS

30.19 SCF ORY GAS/BR. S.T. WATER E 60'F 30.39 SCF WET CAS/BBL. S.T. WATER Q 60'F

REF. TO "OIL" ABOVE SHOUCD READ "WATER"

LAB. NO. N2106-10457

PAGE 11 OF 25 
FLOW TESTS OF THE GLAdys MCCALL Well ThROUGH OCTOBER 1990 TECINAURIL-FENIX \& $\cong$ CISSUN, INC. GLAOYS MCCALL HELL NO. 1, SAND 8 EAST CRAB LAKE FIELD

EFFECT OF BAS-HATER RATIO UPON BUBBLE POINT PRESSRRES Q 290'F

GAS-WATER RATIO

BUBBLE POINT

(SCF SEP. OAS 15.025 PSIA 7 60'F)

(BBL. SEP. WATER E 506 PSIG \& 268)

(PSIA)

31.9 EXTRAPOLATED

12783 RES. PRESSURE

25.01 (PRODUCED)

9200

20.00

6730

18.00

5785

15.00

4550

10.60

2855 
Flow tests of the Gladys MCCall Well Through OCtober 1990

TECINUDRIL-FENIX \& SCISSON, INC. GLADYS MOCALL WELL NO. 1, SAND 8 EAST CRAB LAKE FIELD

\section{SEPARATOR HATER FLASH TO O PSIO \& 78'F}

SQUTION GAS-WATER RATIO, DRY $=\mathbf{3 . 7 5}$

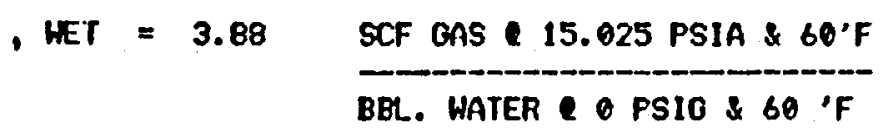

SHRINKAGE

$=0.9437$

VOL. S.T. HATER $Q$ 69'F

WOL. SEP. H2O 500 PSICi $\$ 260^{\circ} \mathrm{F}$

STOCK TARK HATER DENSITY

$=1.0656 \mathrm{Om} / \mathrm{HI} .60^{\circ} \mathrm{F}$

GAS GRAVITY

$$
\begin{aligned}
& \text { 1 DRY }=0.9729 \text { (SEE ANALYSIS ON PAGE 15) } \\
& \text {, HET }=0.9590
\end{aligned}
$$

PRODUCED OCTOBER 8, 1983:

$$
\begin{aligned}
& \text { GWR }=26.44+3.75=30.19 \text { SCF TOTAL DRY GAS 15.025 PSIA \& 60' F } \\
& \text { BBL. STOCK. TANH WAIER } 60^{\prime} \mathrm{F}
\end{aligned}
$$

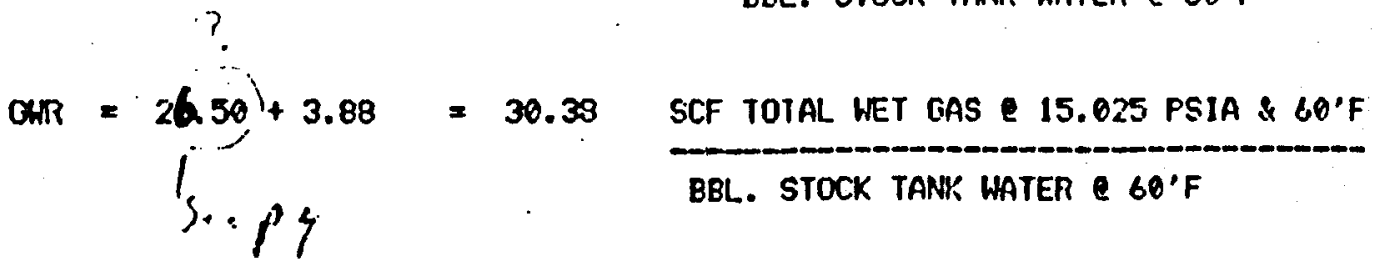

LAB. ND. N2106-10457 
FLOW TESTS OF THE GLADYS MCCALL WELL THROUGH OCTOBER 1990

TECINADRIL-FENIX \& SCISSON, INC.

CLADYS MCCALL WELL NO. 1, SAND 8 EAST CRAB LAKE FIELD

\section{SEPARATOR CAS SATPLED: \\ OCTOBER 8, 1983 Q \\ SOA PSIG \& 97 '}

ChROATOORAPHIC AMULYSIS

DRY HET

MOLE ?.

WATER

CARBON DIOXIDE

NITROGEN

Methiane

ETHANE

PROPANE

ISO-BUTANE

N-BUTANE

I50-fEnTANE

N-PENTANE

HEXANES

HEPTANES PLUS

TOTAL

GRAVITY (AIR $=1.00$ )

NOTEi HATER VAPOR MEASURED ON SITE, AVERAGE 5 RUNS.
$0.22 \pm .04$

10.63

10.61

0.25

0.25

85.96

85.77

2.34

2.33

0.52

0.52

0.09

0.69

0.07

0.07

0.02

0.02

0.01

0.01

0.00

0.00

0.11

0.11

100.00

100.08

0.6813

0.6812

LAB. NO. N2106-10457

PAGE 14 OF 25 
Flow TESTS OF THE GLAdys MCCALl WELl ThROUGh OCTOBER 1990

TECHNUDRIL-FENIX \& SCISSON, IMC. GLADYS MCCALL HELL NO. 1, SAND 8 EAST CRAB LAKE F IELD

\section{SOLUTION OAS FROH SEFARAIOR HATER FLASH \\ - PSIG \& 78'F (CALCULATED NITROGEN FREE)}

CRROHATOORAPHIC ANRE YSIS
MAIER

CARBUN DIOXIDE

NITROLEN

RETHANE

ETHWNE

PRCPANE

ISO-BUTANE

N-BUTANE

ISO-PENTANE

N-PENTANE

HEXANES

HEPTANES PLUS

TOIAL

GRAVITY (AIR $=1.00)$
ORY

MET

MOLE Y.

\begin{tabular}{ll} 
& 3.24 \\
39.89 & 38.60 \\
\hdashline 57.73 & -1.0 \\
1.39 & 55.86 \\
0.19 & 1.34 \\
0.02 & 0.18 \\
0.02 & 0.02 \\
0.00 & 0.02 \\
0.00 & 0.00 \\
0.00 & 0.00 \\
0.76 & 0.00 \\
\hline 0 & 0.74 \\
\hline
\end{tabular}

100.00

100.00

0.9729

0.8570 
Flow Tests of the Gladys MCCall Well Through OCtober 1990

TECINADRIL-FENIX \& SCISSON, INC. GLADYS MCCALL WELL NO. 1, SAND 8 EAST CRAB LAKE FIELD

SOCUTION OAS FROM

6000 PSIA SNTILE -

DIFFERENITAL LIBERATION

(CALCULATED MITROCEN FREE)

CRTOHATOCRAPHIC ANALYSIS

WATER

CARBON DIOXIDE

NITROGEN

METHANE

ETHANE

PROPANE

ISO-BUTANE

N-BUTANE

ISO-PENTANE

N-PENTANE

HEXANES

HEPTANES PLUS

TOTAL

CRAVITY (AIR $=1.00)$
DRY

NET

MOLE Y.

89.03

87.37

4.34

4.26

1.53

1.50

0.22

0.22

0.18

0.18

0.08

0.08

0.04

0.04

0.00

0.00

0.38

0. 37

100.00

100.00

0.6513

0.6507

GAS DEVIATION FACTOR $(Z)=1.109$ Q 6000 PSIA \& 290'F

BELS. GAS IN RES./MSCF $(B g)=713$ e 6000 PSIA 290'F

LAB. NO. N2106-10457

PASE 16 of 25 
Flow TeStS OF the Gladys MCCall Well Through OCtober 1990 TECH NADRIL-FENIX * SCISSON, INC. GLADYS MOCALL HELL NO. 1, SAND 8 EAST CRAB LAKE FIELD

SQCUTION OAS FROH 1000 PSIA SATPLE DIFFERENITAR LIBERATION (CPLCLLATED NITROOEN FREE)

CIROHATOGRAPHIC ANRLYSIS

DRY

WET

MOLE \%

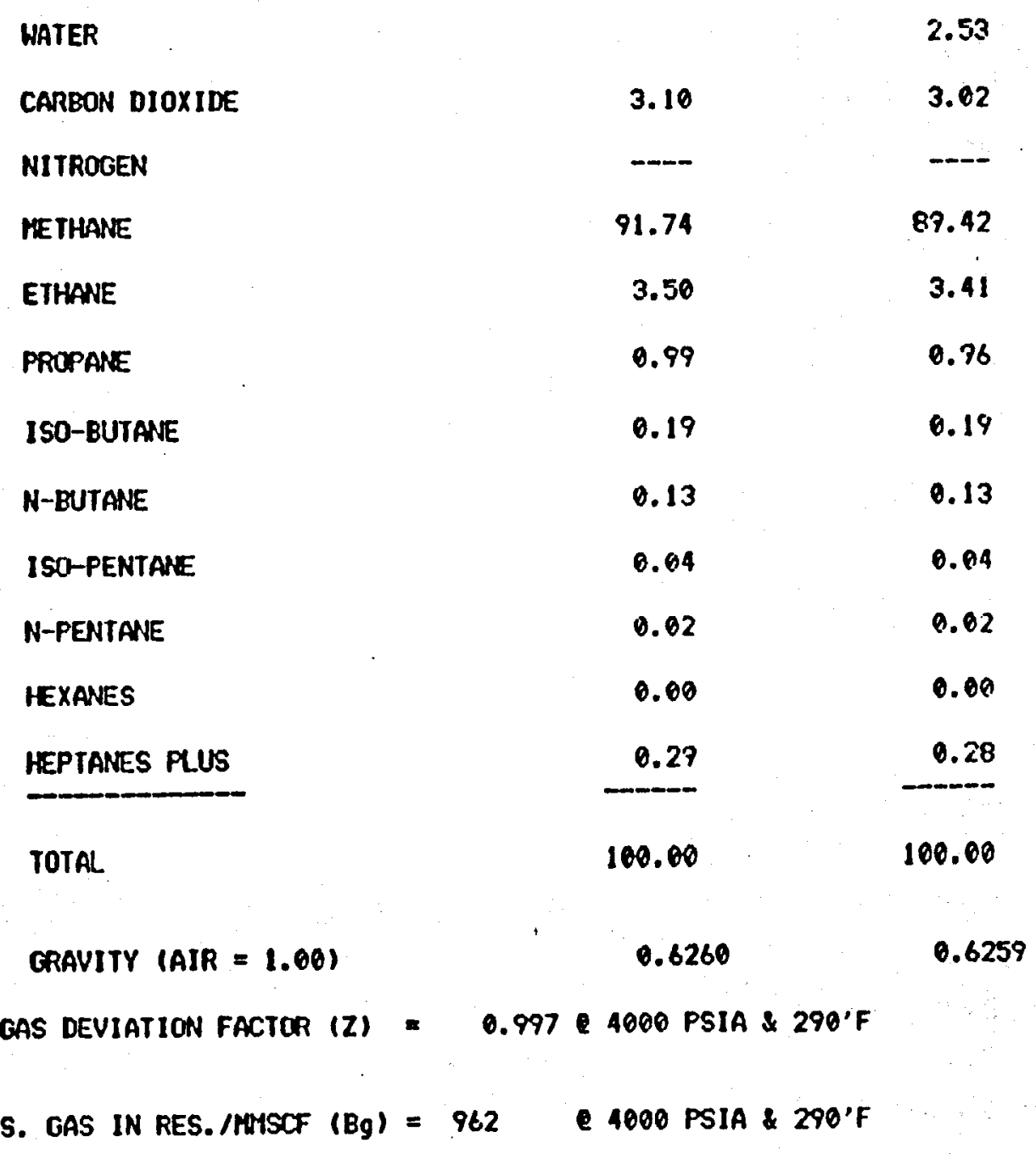

LAB. 10. 12106-10457

PAGE 17 of 25

$\mathrm{J}-20$

INST ITUTE OF G G A S TE CH NOL O G G 
Flow tests of the Gladys McCall Well Through October 1990 IECAHMDPIL-FENIX \& SCISSON, INC:
GLADYS MCCALL WELL NO. I, SAND \&
EAST CRAB LAKE FIELD

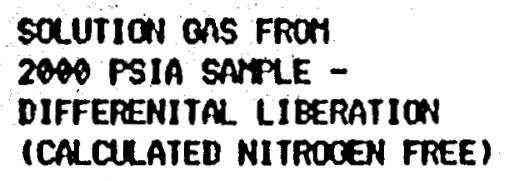

CKROKATOORAPHIC ANALYYSIS

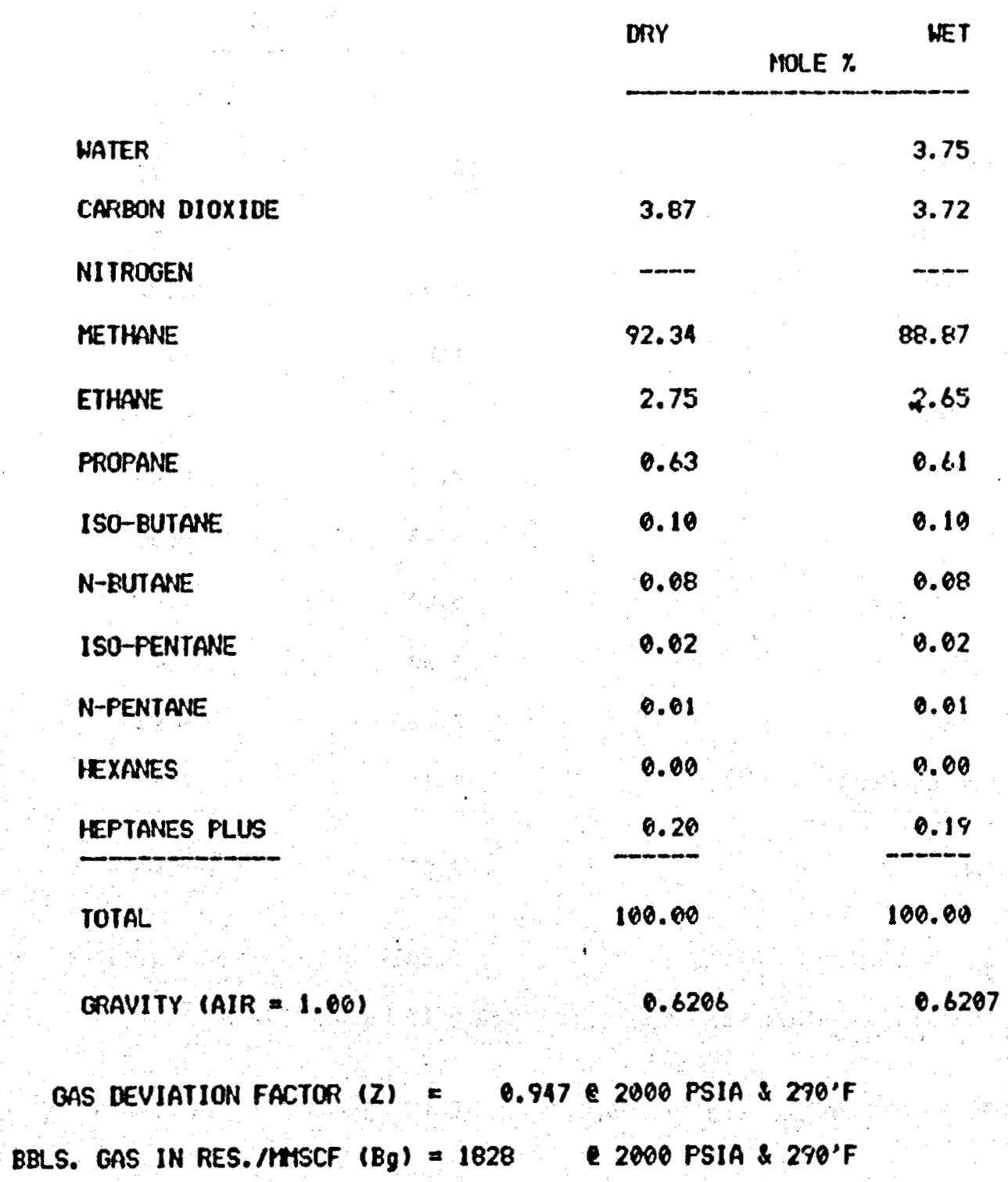

LAB. NO. N2106-10457

PASE 18 OF 15 
Flow Tests of the Gladys MCCall Well Through OCtober 1990 TECINARRIL-FENIX \& SCISSON, INC. OLADYS MOCALL WELL NO. 1, SAND 8 EAST CRAB LAKE FIELD

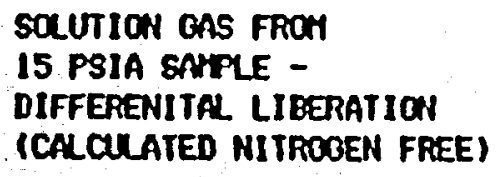

CHROHATOCRAPHIC ANALYSIS

\begin{tabular}{|c|c|c|}
\hline & DRY & WET \\
\hline WATER & & 8.32 \\
\hline CAREXN DIOXIDE & 24.79 & 22.73 \\
\hline HITROGEN & -- & $-\cdots$ \\
\hline METHANE & 73.93 & 67.78 \\
\hline ETHANE & 1.06 & 0.97 \\
\hline PROPANE & 0.11 & 0.10 \\
\hline ISO-EUTANE & 0.00 & 0.09 \\
\hline N-BUTANE & 0.00 & 0.00 \\
\hline ISO-PENTANE & 0.00 & 0.00 \\
\hline N-PENTANE & 0.00 & 0.00 \\
\hline MEXANES & 0.00 & 0.00 \\
\hline HEPTANES PLUS & 0.11 & 0.10 \\
\hline TOTAL & 100.00 & 100.00 \\
\hline GRAVITY (AIR $=1.00)$ & 0.8032 & 0.7881 \\
\hline
\end{tabular}

BBLS. CAS IN RES. /

C 15.025 PSIA \& 290'F

LAB. NO. N2106-10457

PAGE 19 OF 25

$\mathrm{J}-22$
I NST I T U T E
O F
G A S
T E C H N O L O G Y 
Flow TESTS OF THE GLAdys MCCALl Well Through OCtober 1990

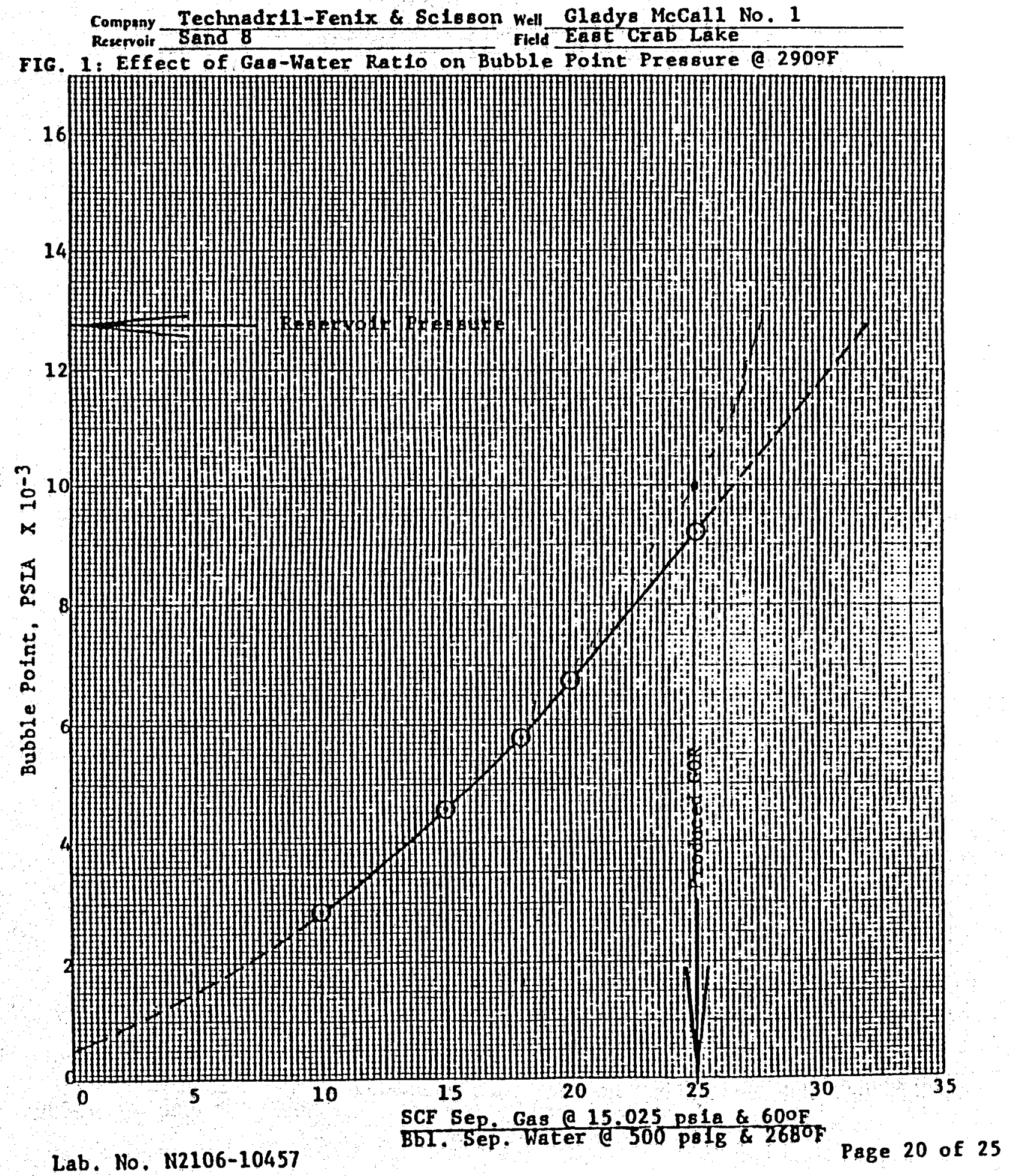


FLOW TESTS OF THE GLADYS MCCALl Well Through OCTOBER 1990

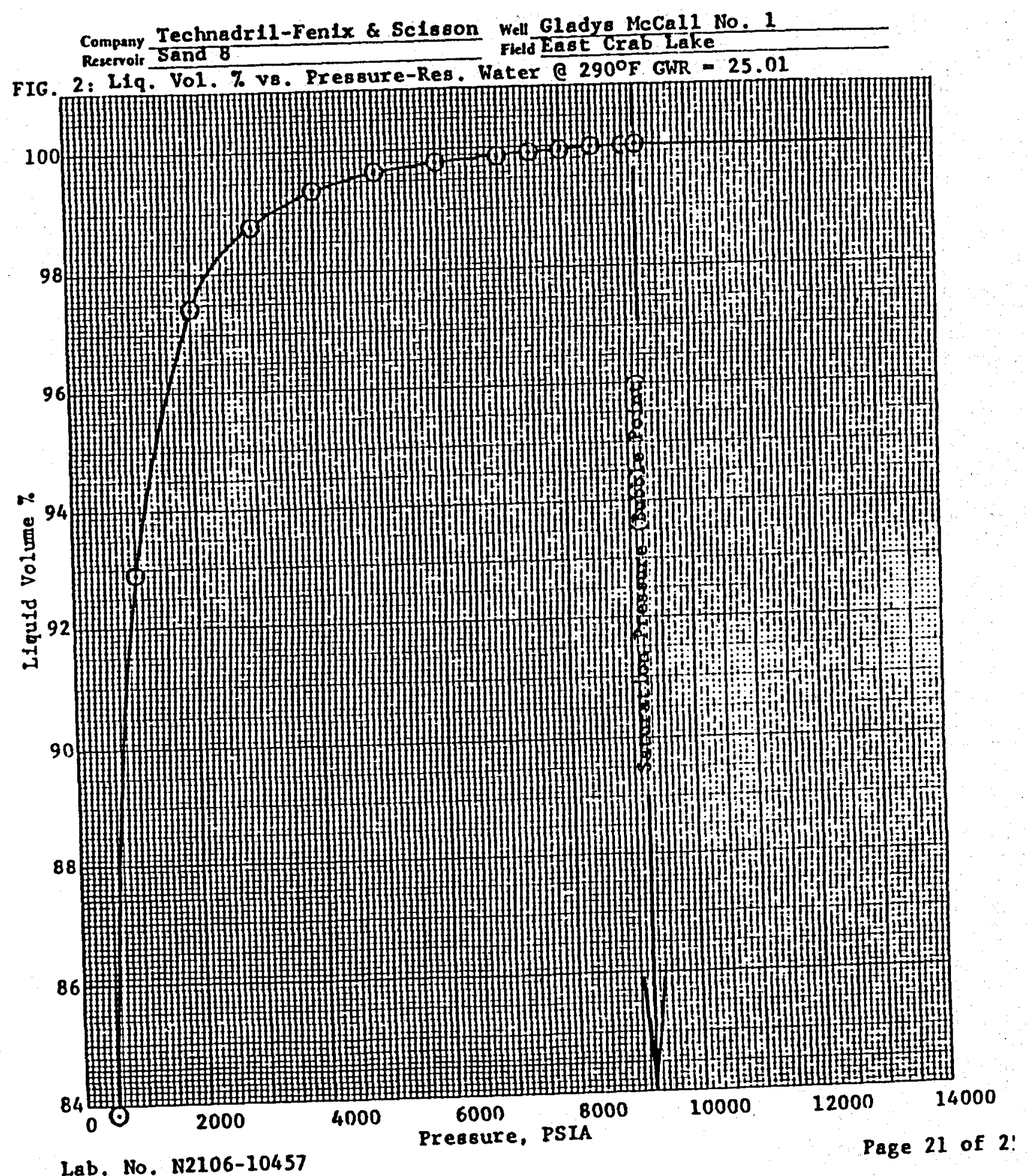

J-24

$\begin{array}{lllllllll}\text { I } & N & S & T & \text { I } & T & \text { U } & T & E\end{array}$

O F G A S

T E C H N O 
FLOW TESTS OF THE Gladys MCCALL Well Through OCTOBER 1990 TESTS OP THE GLADYS MCCALL WELL THR

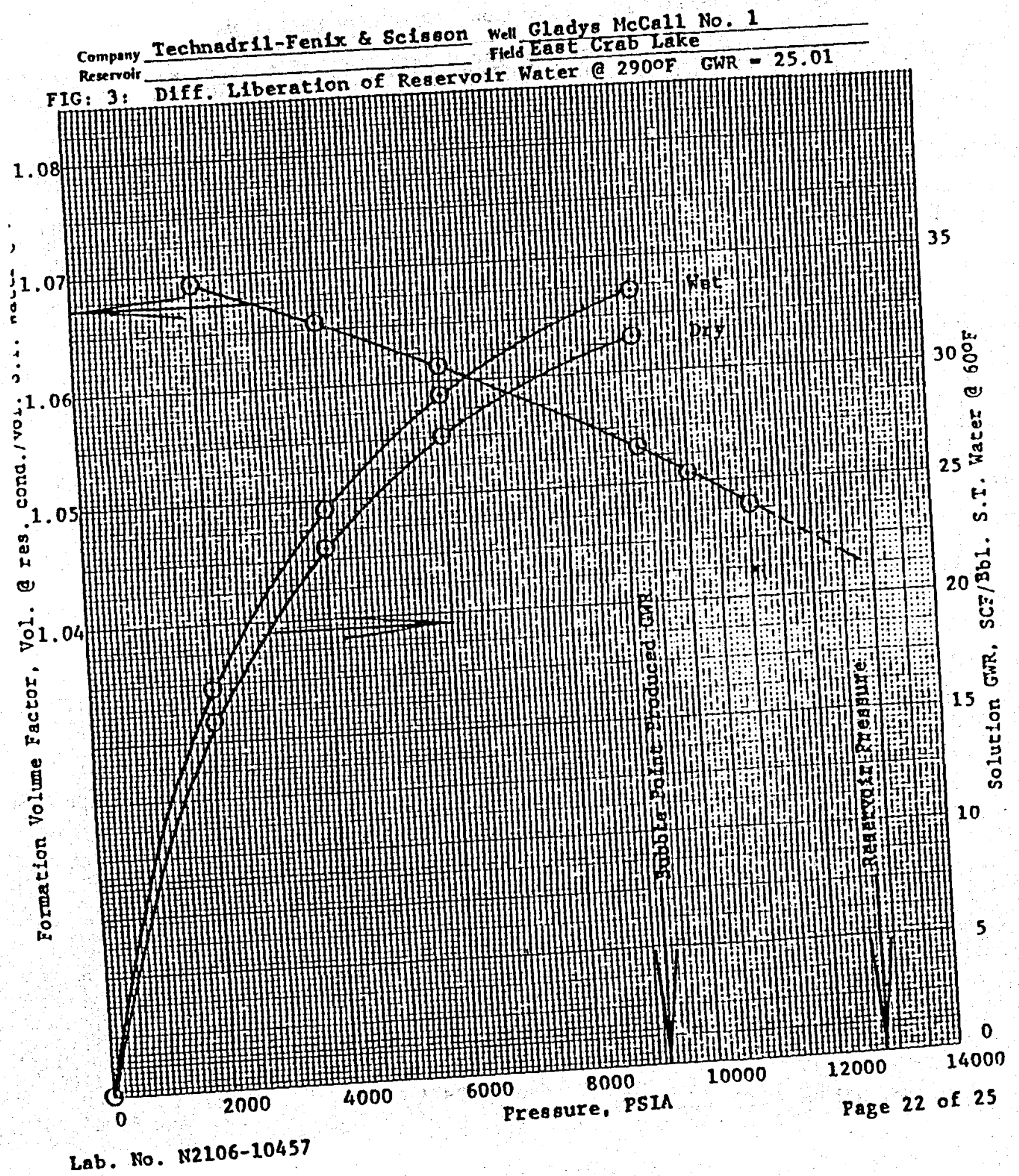


FLOW TESTS OF THE GLADYS MCCALL WELL THROUGH OCTOBER 1990

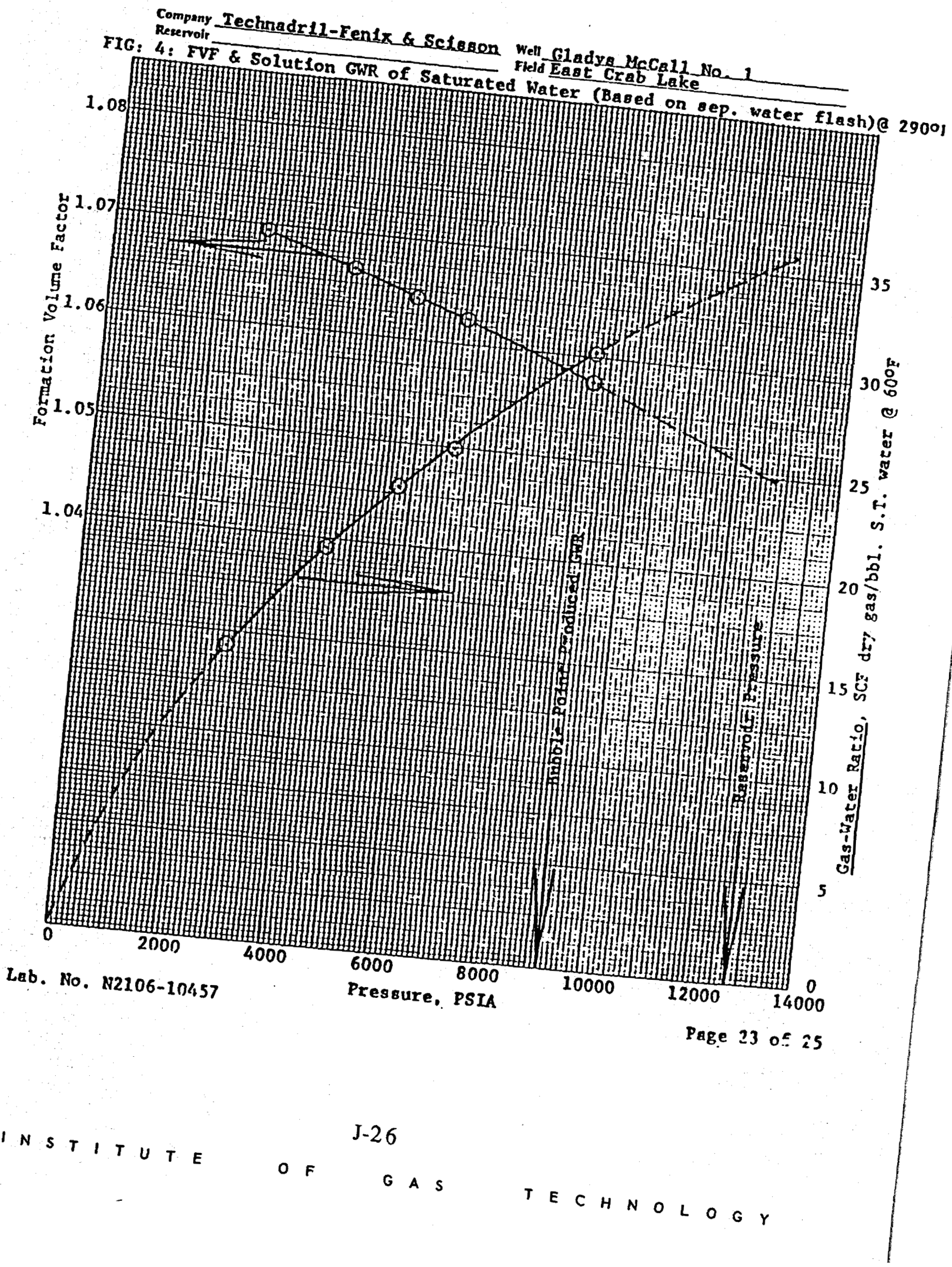


FLOW TESTS OF THE GLADYS MCCALL WELL THROUGH OCTOBER 1990

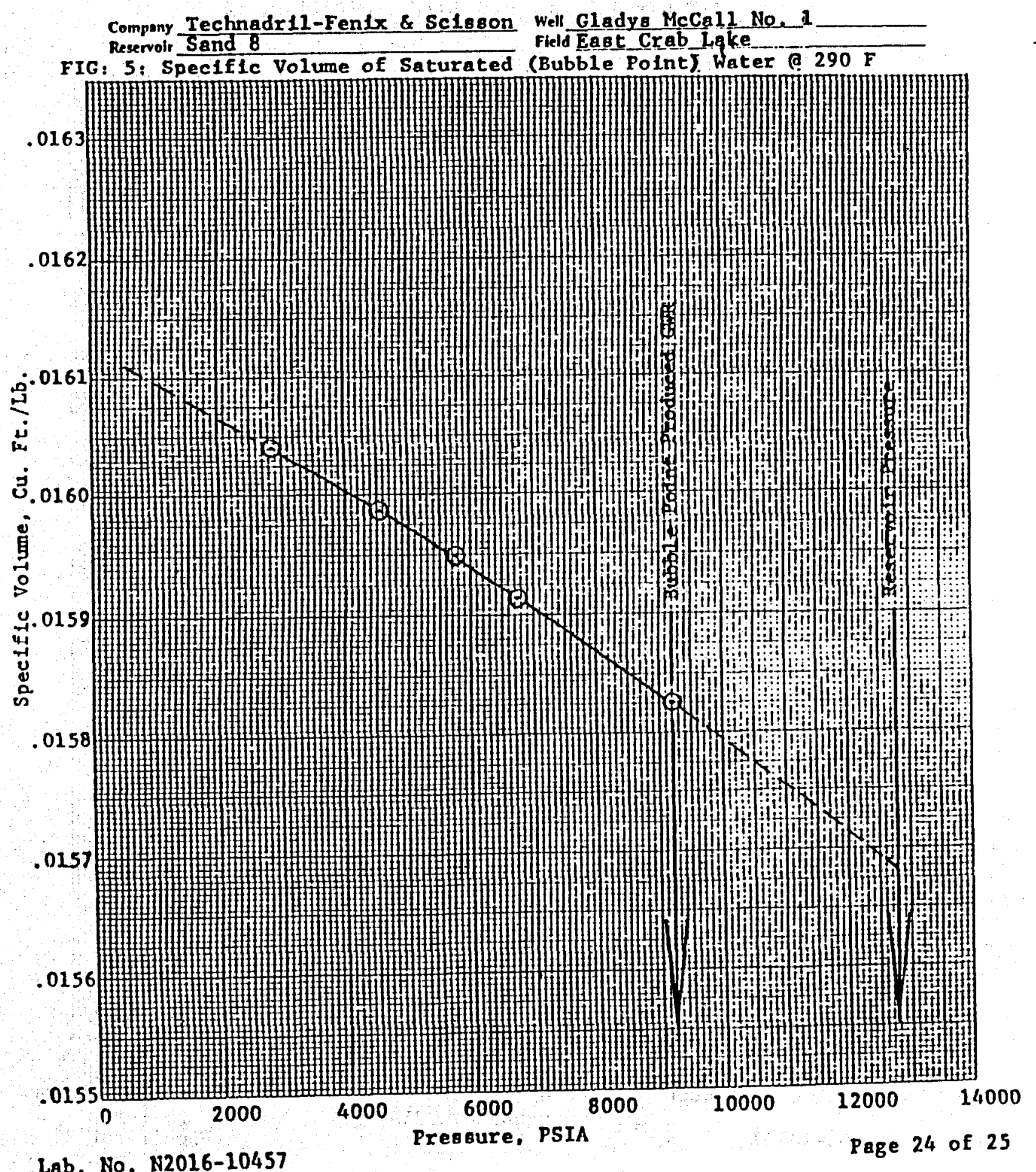

INSTITUTE OF GAS TECHNOLOG Y


FLOW TES TS OF THE GLADYS MCCALL Well ThROUGH OCTOBER 1990

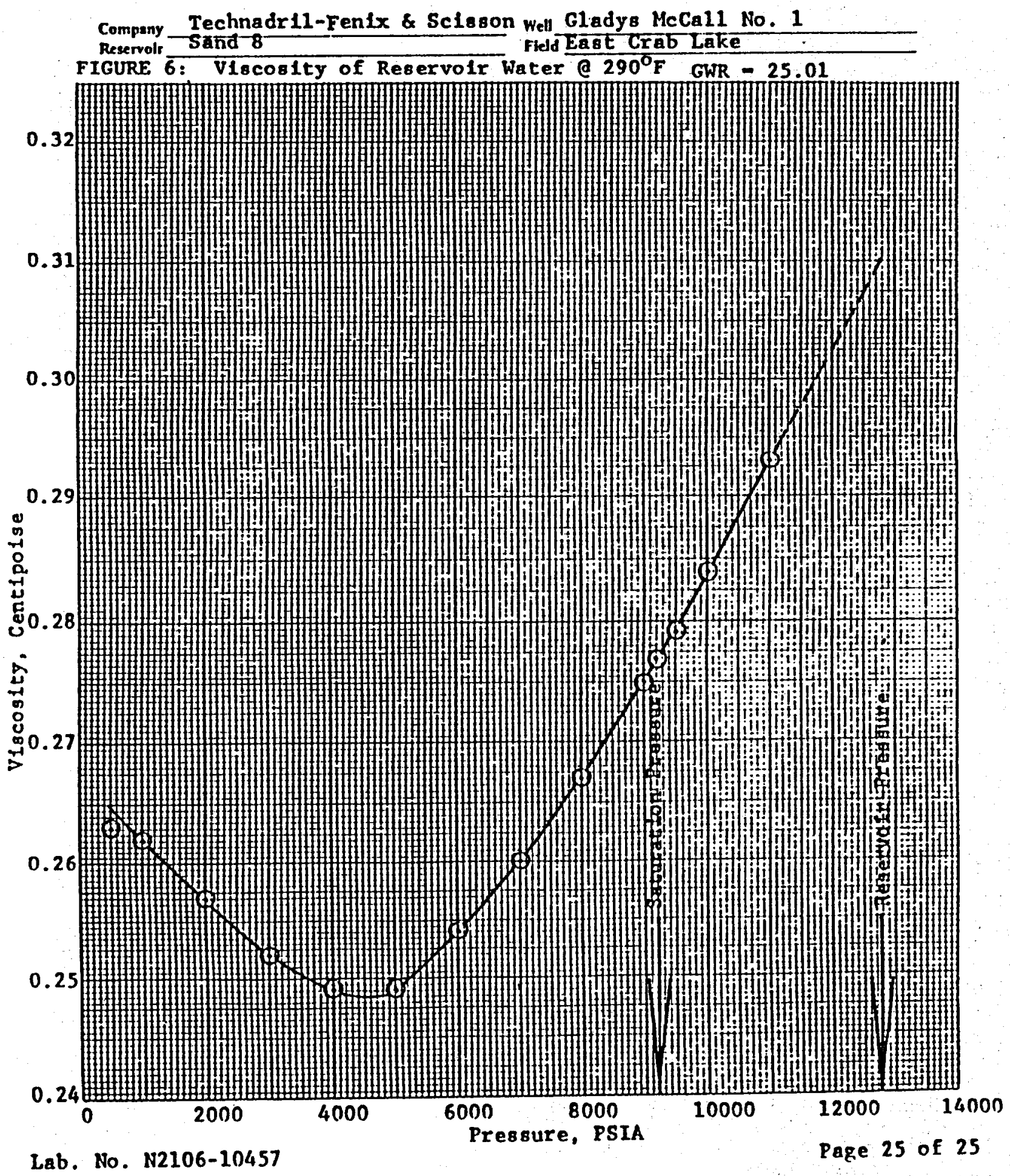


Flow Tests of the Gladys MCCall Well Through OCtober 1990

\section{APPENDIX K}

Reservoir Bubble Tests

$\mathrm{K}-1$

G A S

TE CHNOOLOG Y 
During tests of Wells of Opportunity that produced gas-saturated brine (G.M. Koelemay, Riddle-Saldana, and Prairie Canal wells), IGT observed that sudden increases in production rate were accompanied by a transient "bubble" of natural gas having a duration of 10 's of minutes. During the "bubble," produced gas/brine ratio was higher, natural gas liquid (NGL) content of the gas was higher, and carbon dioxide content was unchanged relative to steady-state production of gas-saturated brine. Understanding of the bubble was found in the phenomena described below.

IGT adopted the procedure of carefully monitoring gas rates and composition following a step increase in drawdown as a "bubble test" to determine whether the flowing bottomhole pressure was below the bubble-point pressure of reservoir brine -- or, in other words, to determine whether free gas was in pores of the reservoir rock near the wellbore.

As brine pressure in the reservoir drops below the bubble-point pressure, a portion of the gas is exsolved. This gas is much richer in heavy hydrocarbons than the gas remaining in solution. Furthermore, this gas is trapped in the reservoir until the gas phase is continuous. The gas saturation needed to form a continuous gas phase is termed the "critical gas saturation." There is little data available on critical gas saturation, but the value is assumed to be about $3 \%$ of the total pore volume (National Petroleum Council, 1980). Data from the PVT study indicate that the Gladys McCall reservoir pressure would have to drop to below 2000 psia before gas would occupy $3 \%$ of the pore volume in the entire reservoir. But in the area immediately surrounding the wellbore, brine being produced experiences large differential-pressure gradients associated with brine converging on the wellbore and perforations.

As the bottomhole pressure drops below the bubble-point pressure; gas exsolves near the wellbore. Gas saturation near the wellbore increases as fresh brine sweeps through the high pressure-gradient region, leaving its small gas-phase contribution. The gas saturation will increase until the critical gas saturation is reached. Thereafter, any gas exsolving from solution will raise the saturation above critical and result in an equally small amount of free-gas production up the wellbore. The reservoir volume at the critical gas saturation will increase as the pressure declines, but it will always be a very small fraction of the total reservoir volume under any reasonable production scenario. Production of free gas from the high pressure-gradient region near the wellbore will be hidden by exsolution of gas further out in the reservoir.

One condition wherein production of previously trapped free gas will be noticed is temporary in nature and constitutes IGT's "bubble test." If the well had been flowing at a steady rate and had built up critical gas saturation near the wellbore, a sudden drop in the bottomhole pressure would cause the gas to expand. The amount of expansion will depend on the drop in the bottomhole pressure. For example, if the bottomhole pressure drops from 9500 to 9300 psia, the gas will 
expand approximately $2 \%$. This small portion of the gas in near wellbore pore space that is at critical gas saturation will become mobile and will be produced.

The amount of mobilized gas will be small, but its composition will be markedly different from the composition of the dissolved gas that is normally produced. Although small gas composition changes over long periods may be attributed to many factors, these same small changes over a period of a few hours needed to perform a bubble test are conclusive. If the ethane/methane and propane/methane ratios increase after "bottoms-up" during a bubble test, free gas is being produced.

Two bubble tests were performed at the Gladys McCall well. The first was on February 12, 1986, and the second was on April 14, 1987.

On February 11, 1986, the brine rate was increased from about 23,000 to about $28,500 \mathrm{STB} / \mathrm{d}$. IGT collected gas samples and analyzed them onsite. Exhibit K-1 presents the relevant data. As the brine rate increased, the bottomhole pressure dropped from 9580 to $9250 \mathrm{psia}$. The ratios of ethane/methane and propane/methane changed significantly, as shown graphically in Exhibit K-2.

\section{Exhibit K-1. TOTAL GAS HYDROCARBON RATIO CHANGES DURING THE FEBRUARY 11,1986 , BUBBLE TEST}

Time In Test

Before Rate Increase

After Rate Increase,

Before Bottoms-Up

About 15 Minutes After Bottoms-Up

About 30 Minutes After Bottoms-Up

About 80 Minutes After Bottom-Up

About 3.5 Hours After Bottoms-Up

About 8 Days After Bottoms-Up
Ethane/Methane

0.0257

0.0259

0.0271

0.0263

0.0265

0.0257

0.0259
Propane/Methane

0.0056

0.0056

0.0063

0.0061

0.0060

0.0055

0.0054

The increase in the hydrocarbon ratios after the slow (about 1-hour) increase in brine rate was obvious in Exhibit K-1. But examination of Exhibit K-2 reveals no obvious increase in the gas/brine ratio. The increase, if any, was less than 1 SCF/STB. The gas composition data reveals that the maximum amount of time that free gas may have been produced was 4 hours. This leads us to conclude that free-gas production was less than $5000 \mathrm{SCF}$.

At bottomhole pressure and temperature, 5000 SCF of gas would occupy less than 12 cubic feet of reservoir pore volume. Adjusting for porosity (16\%) and the assumed water saturation (97\%), this is equivalent to the gas content of 2500 cubic feet of reservoir rock. As the fraction of 
gas produced would be proportional to the drop in the bottomhole pressure, which declined from 9580 to 9250 psia (only $3.6 \%$ of the free gas could flow), the free-gas phase at the critical gas saturation necessary to produce 5000 SCF of gas should occupy 70,000 cubic feet of reservoir rock. Assuming a pay thickness of 300 feet, this volume would be a cylinder with a radius of 8.6 feet. This is an upper limit because an upper limit for free-gas production (1 SCF/STB for 4 hours) was used in these calculations.

The buildup of free gas to critical gas saturation would have occurred over a time of weeks or months before the "bubble test." Review of the history of calculated flowing bottomhole pressure suggests that this may have occurred during the fourth quarter of 1985 at a pressure of roughly 9500 psi.

During April 1987 the bubble test was repeated. Long-term production had reduced the bottomhole pressure to about 8600 psia. Flow rates had been controlled by the first-stage separator pressure, and the chokes were fully open. It was recognized that increasing the flow rate required lowering the separator pressure. If this occurred during the bubble test, changing inventories of gas in the separator volume would make it difficult to quantize any change in the gas to brine ratio.

On April 13, 1987, the first-stage separator pressure was lowered from 1010 to 515 psia, a minimum pressure needed to maintain control of the levels in the separators and drive brine into the disposal well. At the same time, the chokes were adjusted so that the wellhead pressure remained constant at about 1150 psia and the brine-flow rate remained constant at slightly above 20,000 STB. The well was then allowed to run overnight so that the gas compositions in the separators would equilibrate at the lower separator pressure and good baseline data could be obtained.

The chokes were then opened all the way at 12:00 hours on April 14. The brine rate jumped from 22,050 to $25,300 \mathrm{STB} / \mathrm{d}$, the wellhead pressure dropped from 1150 to $710 \mathrm{psia}$, and the calculated bottomhole pressure dropped from 8590 to 8395 psia. Exhibit K-3 presents the changes in the gas/brine ratio, the brine flow rate, and the hydrocarbon ratios during the test. Pertinent data is plotted in Exhibit $\mathrm{K}-4$. 


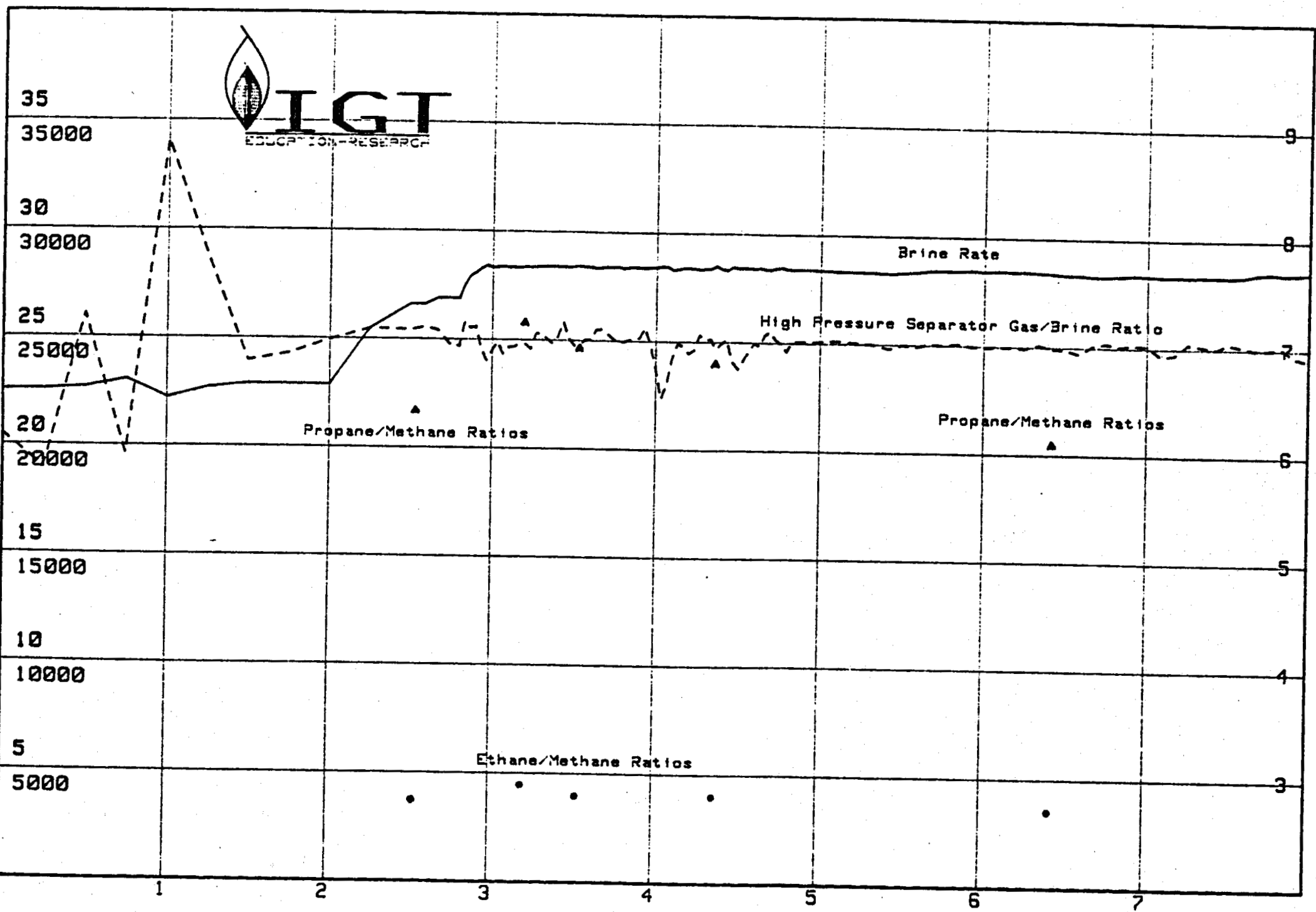

Gladys McCall Bubble Test - Hours Rfter 88:00 on 11 FEB 1986

Exhibit K-2. BRINE RATE, FIRST-STAGE SEPARATOR GAS/BRINE RATIO AND HYDROCARBON RATIOS DURING FEBRUARY 11, 1986, RESERVOIR BUBBLE TEST 
Although the changes in the hydrocarbon ratios are not as clear during this test as in the February 1986 test, an increase in the hydrocarbon ratios is evident. In Exhibit K-4 it is also clear that the production of free gas was at most trivial. The bubble, if it could be called such, consisted of less than 1000 SCF of gas.

\section{Exhibit K-3. FIRST-STAGE SEPARATOR GAS HYDROCARBON RATIO CHANGES DURING THE APRIL 14, 1987, BUBBLE TEST}

Time in Test

Before Rate Increase

About 25 Minutes After Bottoms-Up

About 80 Minutes After Bottoms-Up

About 2.5 Hours After Bottoms-Up

About 10 Hours After Bottoms-Up

About 18 Hours After Bottoms-Up

\section{Ethane/Methane Propane/Methane}

$\begin{array}{ll}0.0264 & 0.0055 \\ 0.0266 & 0.0058 \\ 0.0269 & 0.0057 \\ 0.0269 & 0.0057 \\ 0.0265 & 0.0056 \\ 0.0267 & 0.0057\end{array}$

This is only about 2.5 cubic feet of gas at bottomhole pressure and temperature. Adjusting for porosity (16\%) and the assumed water saturation $(97 \%)$, this is equivalent to the gas content of 500 cubic feet of reservoir. The fraction of free gas that would be produced is proportional to the drop in the bottomhole pressure and the resultant gas expansion (about $195 \mathrm{psi} / 8395 \mathrm{psia}$, or 2.3\%). Thus, 1000 SCF of gas is estimated to have come from a reservoir volume of about 20,000 cubic feet. Assuming a thickness of $300 \mathrm{feet}$, this volume would be in a cylinder with a radius of 4.5 feet.

This data is not inconsistent with the February 1986 test, which concluded that any free gas production had to come from a cylinder with a radius less than 7.7 feet.

The mathematical model that provides insight consists of examining a right circular cylinder in the reservoir that is concentric with the wellbore and has a radial thickness $\Delta r$. Brine that is below its bubble-point pressure and is radially flowing through this cylinder of reservoir rock liberates about 0.002 SCF/STB of gas per psi of pressure drop across the radial thickness $\Delta r$. But that flowing pressure drop is related to the dimensions of the cylinder and brine rate by Darcy's Law. Equating the pressure drops from the equations for these two phenomena makes possible solving for the time required to achieve critical gas saturation as a function of radial distance from the wellbore, brine rate, and reservoir parameters. In conventional oil field units, the resultant equation is -- 
Exhibit K-4. BRINE RATE, FIRST-STAGE SEPARATOR GAS/BRINE RATIO AND HYDROCARBON RATIOS DURING THE APRIL 14, 1987,RESERVOIR BUBBLE TEST 


$$
t=\left(4.59 \pi^{2} \mathrm{P} \mathrm{T}_{\mathrm{b}} \varnothing \mathrm{S}_{\mathrm{gc}} \mathrm{Kh} \mathrm{h}^{2} \mathrm{r}^{2}\right) /\left(\mathrm{E}_{\mathrm{X}} \mathrm{Pb} \mathrm{T} \mu \mathrm{Q}^{2}\right)
$$

$$
\begin{aligned}
& \text { Where }-t=\text { Time, days } \\
& \mathbf{P}=\text { Pressure, psia } \\
& \mathrm{T}_{\mathrm{b}}=\text { Temperature Base, Deg. } \mathrm{K} \text {. } \\
& \varnothing=\text { Porosity, fraction } \\
& S_{\mathrm{gc}}=\text { Critical Gas Saturation, fraction } \\
& \mathrm{K} \text { = Permeability, Darcies } \\
& \text { h = Pay Zone Thickness, } \mathrm{ft} \\
& r=\text { Radius, } f t \\
& E_{X}=\text { Gas Exsolved for a Pressure Drop of } 1 \mathrm{psi},=0.002 \text { SCF/STB } \\
& \mathbf{P}_{\mathrm{b}}=\text { Pressure Base, psia } \\
& T=\text { Temperature, Deg. } K \text {. } \\
& \mu \quad=\text { Brine Viscosity, } \mathrm{cP} \\
& \mathbf{Q}=\text { Brine Rate, STB } / \mathrm{d}
\end{aligned}
$$

Solving this equation for the Gladys McCall well for a flow rate of $25,000 \mathrm{STB} / \mathrm{d}$ and for a radius of 10 feet reveals that about 277 days or 9 months would be required to achieve critical gas saturation. In contrast, for the Wells of Opportunity where the bubbles were observed, permeability and thickness were both about an order of magnitude smaller than for the Gladys $\mathrm{McCall}$ well. For a brine rate of $5000 \mathrm{STB} / \mathrm{d}$, such a well would achieve critical gas saturation 10 feet from the wellbore in the much shorter time of about a week.

This very slow buildup of the critical gas saturation in the reservoir, coupled with not being able to change the bottomhole pressure more than a few percent, led to the conclusion that there is no reasonable engineering basis to support expectations of a large bubble of free gas being produced during April 1987. The bubble test was successful in that it did provide a qualitative indication of whether or not the reservoir was saturated. The second test supports the conclusions reached on the first bubble test; that is, the bottomhole pressure was below the bubble-point pressure of the brine.

The produced gas/brine ratio appeared to start a very slow decline in the third or fourth quarter of 1985. The bottomhole pressure at this time ranged from 9400 to 10,000 psia. These were the lowest bottomhole pressures experienced to date. The decline in the produced gas/brine ratio is assumed to be caused by gas being liberated in the reservoir because of the bottomhole pressure falling below the bubble-point pressure. Small but apparent changes in the produced brine composition and the characteristics of the produced hydrocarbons (oil production was first noticed during January 1985) must be considered. There remains a possibility that the changes in the gas/brine ratio reflect previously isolated brine production. 
The produced gas composition changed slightly between April and December 1985. The change, a slight reduction in the ethane/methane and propane/methane ratios, is consistent with gas being liberated from the brine in the reservoir. The bottomhole pressure ranged from 9400 to 10,800 psia. There were no gas analyses during this period that could narrow the extensive range in pressure. Again, there remains a possibility that a previously isolated brine started being produced during this time frame as discussed above.

The January 11, 1986, bubble test provided conclusive evidence that the bottomhole pressure was below the bubble-point pressure prior to January 1986. The lowest bottomhole pressure experienced before the test was 9400 psia in October 1985. The bubble-point pressure was above 9400 psia.

The April 14, 1986, bubble test provided conclusive evidence that the bubble-point pressure was above 8600 psia. Obviously the result was redundant after the 1986 test, but the 1987 bubble test also provided additional insight into interpretation of the results of a bubble test. 
Flow Tests of The Gladys MCCALl Well Through OCtober 1990

\section{APPENDIX L}

Procedures Manual for Geopressured Fluids

L-1 

Flow Tests of the Gladys MCCall Well Through october 1990

\section{STANDARD SAMPLING AND ANALYTICAL}

\section{METHODS}

FOR

\section{GEOPRESSURED FLUIDS}

Prepared For

DEPARTMENT OF ENERGY

by

McNeese State University

Lake Charles, Louisiana 70609

September 1980

B. E. Hankins, Editor

GAS RESEARCH INSTITUTE CONTRACT NO. 5080-321-0301

L-3 


\section{FOREWORD}

This manual was produced in conjunction with a committee formed by the Department of Energy for the expressed purpose of writing a set of standards to be used for sampling and analyzing geopressured fluids. Each procedure is the result of a consensus of the committee. The name of each committee member, together with the mailing address and the telephone number, is listed below for the convenience of the reader. Many of the references listed in the procedures sections were authored by one or more of the committee members. Individual members of the committee will welcome the opportunity to provide additional information to interested parties.

\section{GEOPRESSURE STANDARDS COMMITTEE}

\author{
Name \\ Dr. Robert A. Morton, \\ Chairman
}

Dr. B. E. Hankins,

Editor

Dr. Don Bebout

Dr. Fred Goldsberry

Dr. O.C. Karkalits

Dr. Yousif Kharaka

\section{Represenfing}

The University of Texas

McNeese State University

Louisiana Geological

Survey

Department of Energy

McNeese State University

U.S. Geological Survey

\author{
Address and Telephone \\ Dr. Robert A. Morton \\ The University of Texas \\ Bureau of Economic Geology \\ University Station, Box $X$ \\ Austin, Texas 78712 \\ 512/474-5994
}

Dr. B.E. Hankins, Dean

College of Science.

McNeese State University

Lake Charles, LA 70609

318/477-2520, Ext. 428

Dr. Don Bebout

Louisiana Geological

Survey

Box G

Baton Rouge, LA 70893

504/34,2-6754

Dr. Fred Goldsberry

Department of Energy

Geopressure Projects

Office

Suite 8620, Federal BIdg.

515 Rusk Street

Houston, Texas 77002

713/226-5511

Dr. O.C. Karkalits, Dean

College of Engineering and

Technology

McNeese State University

Lake Charles, LA 70609

318/478-8070

Dr. Yousif Kharaka U.S. Geological Survey Water Resources Division 345 Middlefield Road Menlo Park, CA 94025

415/323-8111, Ext. 2144 
FLOW TESTS OF THE GLADYS MCCALl Well THROUGH OCTOBER 1990

\section{Name}

Dr. Tom Kraemer

Dr. Jack V. Matson

Mr. John Sharer

Dr. Mason Tomson

Mr. Keith Westhusing

\section{Representing}

U.S. Geological Survey

University of Houston

Gas Research Institute

Rice University

Department of Energy

\section{Address and Telephone}

Dr. Tom Kraemer

U.S. Geological Survey

NSTL Station, Miss. 39529

601/688-3136

Dr. Jack V. Matson

Department of Civil Engineering University of Houston

Central Campus

Houston, Texas 77004

713/749-1348

Mr. John Sharer, Asst. Dir. Unconventional Natural Gas

Gas Research Institute 10 West 35 th Street

Chicago, Illinois 60616 312/567-6600

Dr. Mason Tomson

Environmental Science

Rice University

Box 1892

Houston, Texas 77001

713/527-8101 Ext. 2392

Mr. Keith Westhusing, Director Department of Energy

Geopressure Projects Office

Suite 8620 , Federal Bldg.

515 Rusk Street

Houston, Texas 77002

713/226-5511 
Flow Tests of the Gladys MCCall Well Through october 1990

\section{TABLE OF CONTENTS}

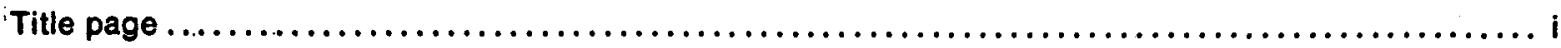

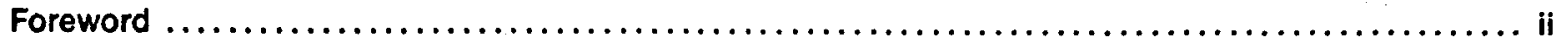

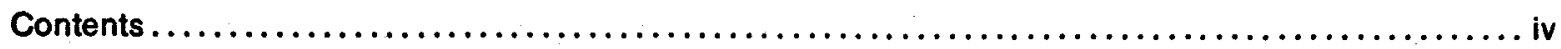

I. INTRODUCTION..................................... 1

A. Determinations to be performed on Water Samples.........1

B. Determinations to be performed on Gas Samples ..........1

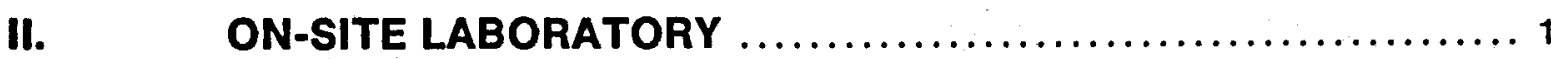

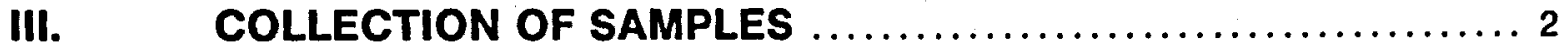

A. Gas Samples .............................. 2

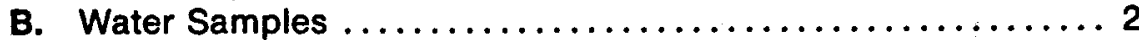

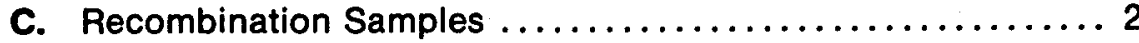

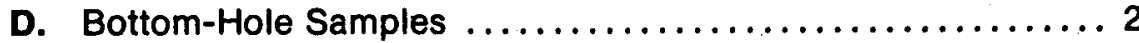

IV. EVALUATION OF GAS/WATER RATIO DATA $\ldots \ldots \ldots \ldots \ldots 5$

A. From Bottom-Hole Samples .................... 5

B. From Surface Measurements .................... 5

C. From Recombination-Differential Liberation measurements ...5

D. Relationship Between Gas/Water Ratio measurements ......5

v. TREATMENT OF WATER SAMPLES $\ldots \ldots \ldots \ldots \ldots \ldots \ldots \ldots \ldots \ldots, 6 \ldots \ldots$

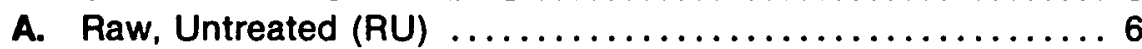

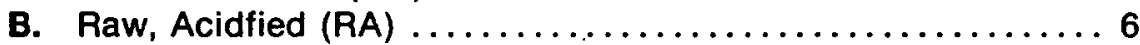

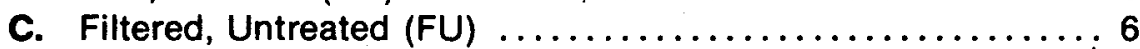

D. Filtered, Acidfied $\left(F A-\mathrm{HNO}_{3}\right) \ldots \ldots \ldots \ldots \ldots \ldots \ldots \ldots \ldots \ldots \ldots \ldots \ldots \ldots \ldots$

E. Filtered, Acidfied (FA-HCI) $\ldots \ldots \ldots \ldots \ldots \ldots \ldots \ldots \ldots \ldots \ldots$

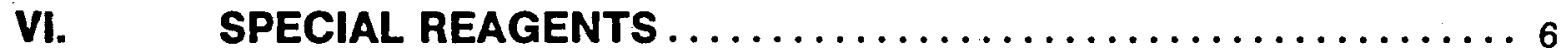

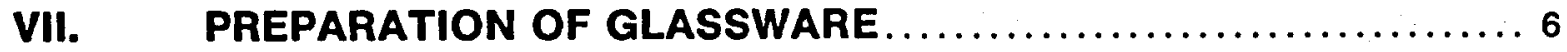

VIII. CONTAINER PREPARATION $\ldots \ldots \ldots \ldots \ldots \ldots \ldots \ldots \ldots \ldots \ldots \ldots$

A. Stainless Steel Cylinders $\ldots \ldots \ldots \ldots \ldots \ldots \ldots \ldots \ldots \ldots \ldots$

B. Plastic Containers ............................ 7

IX. SAMPLING FREQUENCY $\ldots \ldots \ldots \ldots \ldots \ldots \ldots \ldots \ldots \ldots \ldots \ldots, \ldots \ldots \ldots, \ldots \ldots \ldots$

X. SAMPLES TO BE ANALYZED $\ldots \ldots \ldots \ldots \ldots \ldots \ldots \ldots \ldots \ldots \ldots$

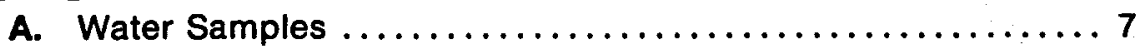

B. Gas Samples ........................... 7

C. Suspended Solids $\ldots \ldots \ldots \ldots \ldots \ldots \ldots \ldots \ldots \ldots, \ldots \ldots \ldots$ 
XI. DETERMINATIONS THAT REQUIRE SPECIAL EQUIPMENT ....7

A. Determinations in Water Samples $\ldots \ldots \ldots \ldots \ldots \ldots \ldots \ldots 7$

B. Determinations in Gas Samples .................. 8

XII. SCALE AND CORROSION INHIBITORS $\ldots \ldots \ldots \ldots \ldots \ldots \ldots \ldots$

XIII. PROCEDURES: DETERMINATIONS IN WATER SAMPLES .....9

XIV. PROCEDURES: DETERMINATIONS IN GAS SAMPLES ........35

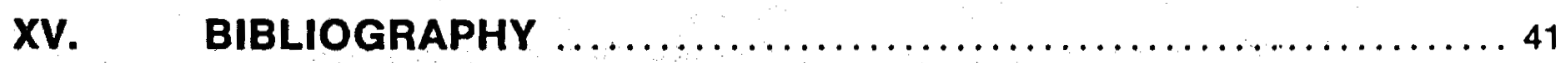

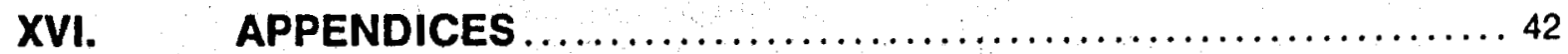

A. Calculation of Gas/Water Ratio from Surface Measurements 43

B. Condensed On-site Procedures $\ldots \ldots \ldots \ldots \ldots \ldots \ldots \ldots . \ldots \ldots$

C. Alphabetical Listing of Procedures (water) $\ldots \ldots \ldots \ldots \ldots 46$

D. Alphabetical Listing of Procedures (gas) $\ldots \ldots \ldots \ldots \ldots \ldots 48$ 


\section{SAMPLING AND ANALYSIS OF GEOPRESSURED FLUIDS}

\section{INTRODUCTION}

Fluids from most geopressured-geothermal wells contain a high concentration of dissolved solids, principally sodium chloride. The fluids, under several thousand psig pressure and at elevated temperature, also contain large amounts of natural gas. Furthermore, samples from these wells usually are collected at the surface where the pressure is lower than that found in the reservoir; thus, equilibrium conditions between gas and liquid phases have been disturbed. These samples are unique, therefore, and often require special procedures and special conditions for their analyses.

The Department of Energy and the Gas Research Institute recognized that a set of standard sampling and analytical procedures for geopressured-geothermal fluids should be published: DOE established an 11member board (see Foreword) to study the problem and GRI provided the funds for writing and publishing the material. Members of the DOE-appointed board will be happy to discuss the procedures with others or to provide additional information.

The sampling and analytical procedures outlined in this manual are the result of a consensus of the 11member board established by DOE; these procedures should be followed when analyzing fluids from geopressured-geothermal wells. Analyses of water samples (Section XIII) and gas samples (Section XIV) are included. A condensed set of on- site procedures may be found in Appendix $B$.

Most commercial laboratories have the equipment necessary to carry out the majority of the determinations listed in this manual; however, some determinations require special equipment which many commercial installations lack. The determinations that require special equipment are listed in Section $\mathrm{XI}$; it may be necessary to contact a university laboratory for these. Also, it may be necessary to subcontract some other determinations to laboratories having special equipment.

References are listed with each determination. Methods for the collection and analysis of surface and ground waters have been published by the U.S. Geological Survey (8). Many of these procedures have been modified for application to oil field and geopressured waters (6). Some of these procedures, and others, have been adapted further by chemists at McNeese State University, Lake Charles, LA $(3,4)$.

\section{A. DETERMINATIONS TO BE PERFORMED ON WATER SAMPLES}

$\mathrm{pH}, \mathrm{T}$, specific conductance, dissolved solids, suspended solids, $\mathrm{Na}, \mathrm{K}, \mathrm{Ca}, \mathrm{Mg}, \mathrm{Sr}, \mathrm{Ba}$, $\mathrm{HCO}_{3}, \mathrm{CO}_{3}{ }^{\circ}, \mathrm{Cl}^{-}, \mathrm{SO}_{4}{ }^{=}, \mathrm{SiO}_{2}, \mathrm{Mn}, \mathrm{Fe}_{1} \mathrm{~S}^{=}, \mathrm{B}, \mathrm{Cd}, \mathrm{Hg}, \mathrm{Zn}$. As, $\mathrm{Cr}, \mathrm{Cu}, \mathrm{Pb}, \mathrm{F}^{-}, \mathrm{NH}_{3}, \mathrm{Ra}-226$, gross $\alpha$, aross $\beta$, gross $\gamma$, identification of metals in dissolved solids by emission spectrography, identification of clays and minerals in suspended solids by $x$-ray diffractometry (or equivalent method).

\section{B. DETERMINATIONS TO BE PERFORMED ON GAS SAMPLES}

Standard hydrocarbon analysis $\left(\mathrm{C}_{1}-\mathrm{C}_{6}\right.$ and $\mathrm{C}_{6^{+}}$), $\mathrm{H}_{2} \mathrm{~S}, \mathrm{He}, \mathrm{Rn}-222, \mathrm{CO}_{2}, \mathrm{~N}_{2}, \mathrm{NH}_{3}, \mathrm{O}_{2}, \mathrm{H}_{2}$, identification of other gases from $Z=1$ to $Z \cong 400$ by mass spectrometry, the gas/water ratio from recombination-differential liberation studies or zero-flashed bottom-hole samples and the gas/water ratio from surface measurements at the gas/water separator.

\section{ON-SITE LABORATORY}

The following determinations must be made at an on-site laboratory before precipitation occurs in the sample (within $\mathbf{3 0}$ minutes of the time the sample is collected): $\mathrm{pH}, \mathrm{T}$, specific conductance, dissolved solids (gravimetric), suspended solids, alkalinity (including organic acid anions). alkalinity ( $\left(\mathrm{CO}_{2}^{\prime}\right), \mathrm{Cl}^{-}$(filtered, untreated (FU) samples), $\mathrm{S}^{*}, \mathrm{NH}_{3}, \mathrm{SiO}_{2}$,(FU samples not diluted). Other determinations may be made later and in more conventional facilities. Hydrogen and helium must be determined as soon as possible because they diffuse through the sample containers rapidly. If $\mathrm{SiO}_{2}$. is to be determined later, dilute one FU sample 1:2 with deionized water and dilute another FU sample 1:4 with deionized water Determine $\mathrm{SiO}_{2}$ on both samples. Collect individual samples for the on-site determination of $\mathrm{S}^{\mathbf{A}}$ and $\mathrm{NH}_{3}$. 


\section{II!. COLLECTION OF SAMPLES}

\section{A. GAS SAMPLES}

The on-site equipment must be provided with certain take-off accessories. (Figures I ano 2) The nigh-pressure separator must be fitted with a valve at the top of the unit (gas take-off point) so that the now uf the gas can be controlled. The valve must contain a 14 " NPT female connection. Collect gas samples from the gas take-off point of the high-pressure separator in 75 cc. teflon-lined stainless steel containers fitted with Whitey valves containing $1 / 4$ "ID NPT male connectors.

\section{B. WATER SAMPLES}

Collect water samples as close to the well-head as possible. A water take-off point must be installed after the high-pressure choke but before the high-pressure separator (Figures 1 and 2 ) A valve must be provided to control the flow of fluid. The assembly is completed by attaching a pressure gauge and a 20-foot length of stainless steel tubing (teflon-lined if possible). A section of the tubing should be colled and placed inside a 55-gallon drum, which has been filled with chilled water. Terminate the tubing with a $1 / 4$ "NPT stainless steel cross. Attach a valve to one port of the cross and plug the remaining two ports with stainless steel threaded plugs. These plugs can be removed to attach filters.

Small amounts of water samples may be collected and stored in $4 \mathrm{oz}$. flint glass bottles fitted with polyseal caps. These are avallable from most chemical supply houses. Larger amounts of water samples may be collected and stored in plastic containers; see Sections VII and VIII for special cleansing instructions. Samples to be used for boron or sillcon determinations should not be collected or stored in glass bottles.

\section{RECOMBINATION SAMPLES}

Gas samples for determining the solubility of natural gas in brine (gas/water ratio) by racombination-differential liberation studies shoula ve cullected at the gas sampling port uescribeo earlier (Section III-A and Figure 1). Water samples to be used in recombination studies should be collected from a point on the high-pressure separator that represents the low-pressure side such that stock-tank water samples are available. A control valve with $1 / 4$ "NPT female threads shouid be installed at the stock-tank water port to control the flow of fluid (Figure 1).

\section{BOTTOM-HOLE SAMPLES}

Several commercial companies market devices designed to collect bottom-hole samples at in-sltu temperatures and pressures. The operation is simple in theory but difficult in practice, especially when applied to geopressured wells. None of the gejopressured-geothermal wells tested to date have yielded reliable data from bottom-hole samples collected under in-altu conditions, when these samples were transferred to high-pressure containers prior to determining the gas/water ratio.

The following procedures for collecting and transferring bottom-hole samples are idealistic in concept. Equipment for performing these operations under ideal conditions does not exist at this time because sultable bottom-hole samplers are not fitted with heating devices and the temperature of the fluid within the samplers cannot be maintained at In-eltu conditions.

To cöllect à bottom-hỏle sample from a geopressuréd-geothermal well, a téflon-lined sampler containing a heated jacket that is thermostatically controlled should be used. The diameter of this unit is dictated by the diameter of the well-bore and the length of the unit is dictated by the volume of the sample required. Using a wire-line, lower the unit to the depth from which samples are desired. One standard device is a flow-through unit that has both upper and lower valves open when the unit is inserted into the well-bore. When the unit is located at the desired depth, the valves can be clpsed with a clock-timer mechanism, a shear-pin mechanism, or a pressure-actuated mechanism. Another unit has a chamber with one valve only. In practice, the sample chamber in this unit is evacuated before inserting the sampler into the well-bore. The sampler is lowered to the required depth using a wire-line, the valve is opened mechanically or electrically to admit fluid, then closed, then the entire sampler is retrieved with the wire-line.

A single sampler may be used to collect several samples by transferring the contents of the sampler after each collection to a high-pressure container. The high-pressure containers may be transported to a laboratory where the gas/water ratlo can be determined.

Standard "oll patch" technology for transferring geopressured-geothermal samples from bottom-hole devices has relled on the use of a hydraullc device to pressure-up the high-pressure contalner töln-altu conditions; the single-phase fluld then flows from the bottom-hole sampler to the high-pressure container. Commercial hydraulic units have used mercurv for the confining liquid but another fluid would be better to 


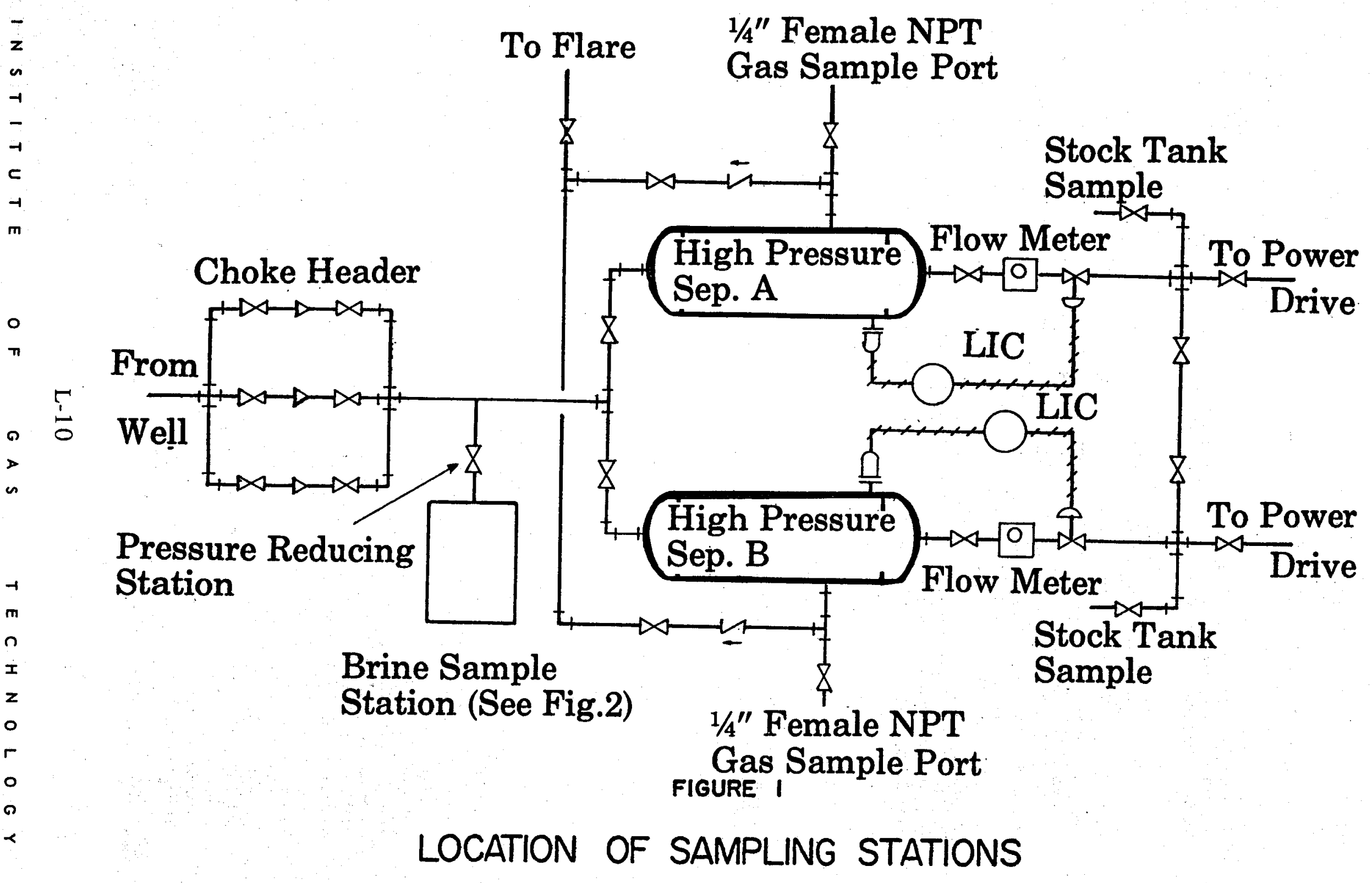




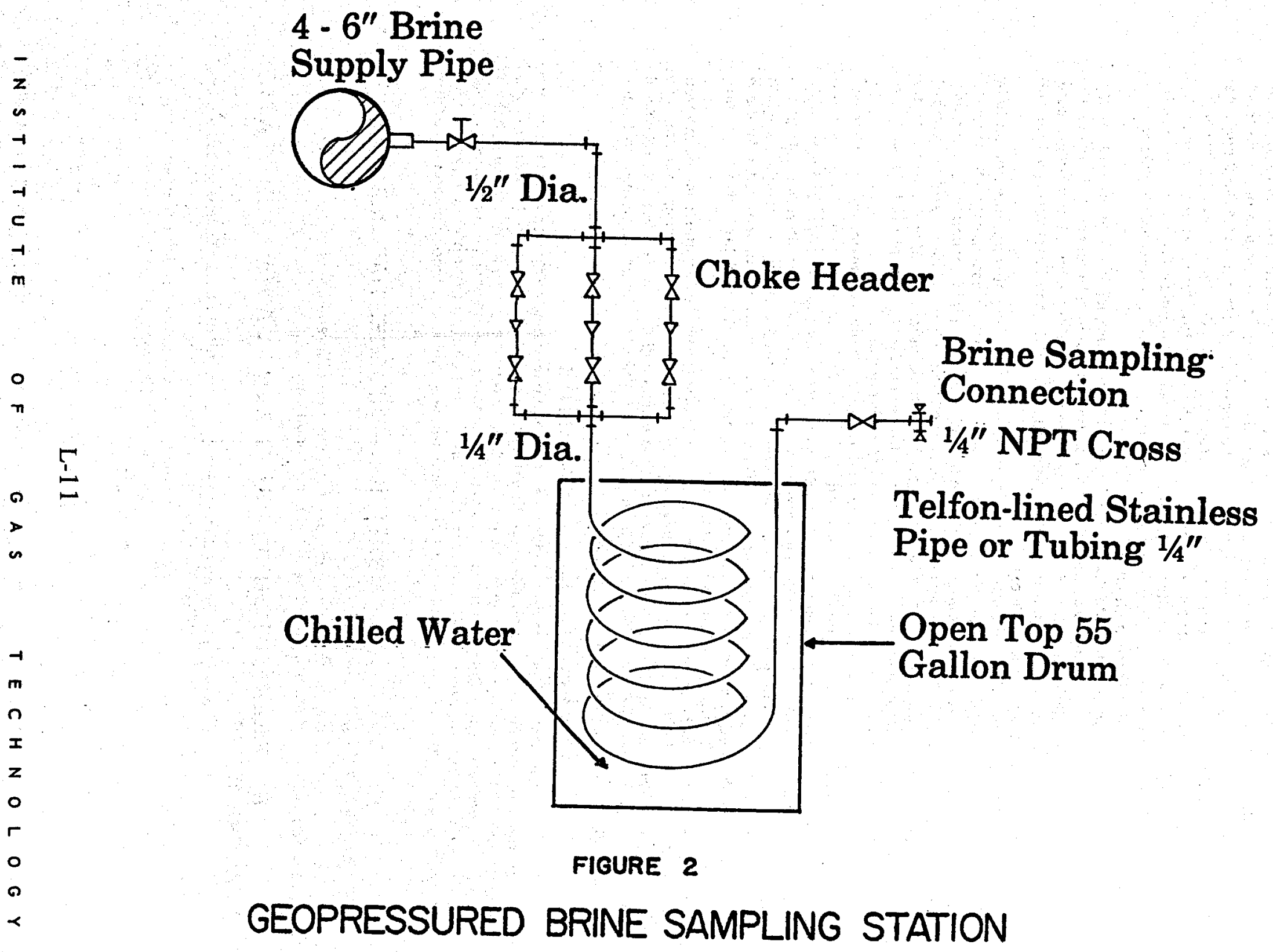


avold contaminating the sample with mercury and other metals. Transfer of the single-phase fluid from the bottom-hole sampler to the high-pressure contalner must be made at pressures no lower than reservoir pressure.

\section{EVALUATION OF GAS/WATER RATIO DATA}

\section{A. FROM BOTTOM-HOLE SAMPLES}

Commercial bottom-hole sampling devices used to date do not have heaters and the Insltu temperature of the fluid within the sampler cannot be maintained; therefore, the bottom-hole fluid cools as it is brought to the surface, the pressure decreases, and a two-phase system forms. Even though the sample is subjected to the correct in-eltu pressure and vigorous agitation later, the operator never can be positive that the system has returned to a single phase. It is best, therefore, to determine the gas/water ratio directly on the sample contained in the bottom-hole device. If the seals of the bottom-hole device hold and if the integrity of the sample is maintained, the gas/water ratio data obtained from zero-flashing the sample directly from the bottom-hole sampler should be rellable.

The problem with gas/water ratio data collected from bottom-hole samples is encountered because bottom-hole samplers are expensive and operators wish to use the same sampler to collect severat samples; therefore, the samples usually are transferred to high-pressure containers. If either temperature or pressure falls below reservoir conditions before the sample is transferred, some of the gas dissolved in the brinewill be exsolved and a two-phase system will exist.

The standard transfer procedure involves pressuring-up the transfer apparatus and the bottom-hole sampler to in-silu pressure, then agitating the fluids contained in the bottom-holesampler to return them to a single-phase system. However, experience has shown that it is very difficult, if not impossible, to return the system to a single phase. The gas may be redissolved in the brine only after vigorous and prolonged agitation, conditions that are difficult to achieve in the field. Even then, without a window in the sampler for observing the condition of the fluids, there is uncertainty as to the number of phases present. Furthermore. some operators have transferred the fluids at less than reservoir pressure.

With the hydraulic transfer system currently in use, and for reasons outlined previously, there is some question concerning the complete transfer of gas and brine from the bottom-hole sampler to the highpressure container; therefore, the gas/water ratio data from these measurements are suspect. If the temperatureof the bottom-hole fluid could be maintained in the sampler (with a heater), a single-phase system would remain and a properly designed transfer system pressured-up to in-situ conditions would allow all of the sample to be transferred from the sampler to the high-pressure containers. Under these conditions, data obtained from the transferred samples would be as reliable as the data obtained from zeroflashing samples directly from the bottom-hole sampler.

Teflon-lined bottom-hole samplers are not necessary to determine the gas/water ratio reliably; however. the use of the teflon-lined equipment would allow fluids uncontaminated with the sampler metal to be collected and the chemical analysis of the brine would be more meaningful. Likewise, chemical analysis of the bottom-hole fluid would be more meaningful if some fluid other than mercury were used for the confining fluid in the hydraulic pump.

\section{B. FROM SURFACE MEASUREMENTS}

Gas/water ratio data obtained from surface equipment may be skewed high because the surface equipment measures the steam as well as the natural gas from the llashed fluid. Also, any free gas from gas-pockets in the producing zone will be measured along with the gas from the brine and that will increase the gas/water ratio. Calculations can correct for the amount of additional gas measured as steam (see Appendix A), but no correction can be made for the intrusion of free gas into the producing zone unless reliable gas/water ratios have been obtained from bottom-hole samples and recombination-differential liberation studies.

\section{MEASUREMENTS}

\section{FROM RECOMBINATION-DIFFERENTIAL LIBERATION}

The gas/water ratio obtained from recombination-differential liberation measurements is the saturation value of the gas in the brine at reservoir conditions.

\section{MEASUREMENTS}

\section{RELATIONSHIP \\ BETWEEN \\ GAS/WATER \\ RATIO}

The gas/water ratio obtained from recombination-differential liberation measurements assumes saturation of the brine with natural gas in the producing zone.

The gas/water ratio obtained from a bottom-hole sample whose integrity has been maintained may be less than the saturation value; this is the best method of measuring the extent to which these geopressuredgeothermal fluids approach saturation with natural gas.

\section{L-1 2}


The gas/water ratio obtained from surface measurements may be high; l.e., higher than the saturation value, due to free gas entering the well-bore along with the geopressured brine. If there is no gas cap, and if the brine is not saturated with gas, then the ratio obtained from both surface equipment and bottom-hole samples will be less than that obtained from recombination-differential ilberation measurements.

\section{TREATMENT OF WATER SAMPLES}

Note: Water from geopressured-geothermal wells often contains crude petroleum which interferes with various analytical procedures. Most of this oil may be removed by allowing the water sample to flow through a loose plug of glass wool during the collection process.

\section{A. RAW, UNTREATED (RU)}

Collect a water sample in a previously cleaned bottle and stopper the bottle tightly. Label the bottle "RU." The following determinations are to be made on RU water: pH, T, specific conductance. suspended solids, alkalinity, and $S^{*}$.

\section{B. RAW, ACIDIFIED (RA)}

Collect a water sample in a previously cleaned bottle and add enough $1: 1 \mathrm{HNO}_{3}$ to make the $\mathrm{pH}$ of the solution $1.5 \pm 0.5$ as measured with $\mathrm{pH}$ paper or a $\mathrm{pH}$ meter. Mix the contents thoroughly, stopper the bottle tightly, and label the bottle "RA." The following determinations are to be made on RA samples: Ra-226, gross $\alpha$, gross $\beta$, and gross $\gamma$.

\section{FILTERED, UNTREATED (FU)}

Collect a sample of water that has been filtered through a $0.45-\mathrm{m}$ membrane filter. Stopper the container tightly and label it "FU." The following determinations should be made on FU samples: dissolved solids (on-site), $\mathrm{Cl}^{-}$, (on-site), $\mathrm{SiO}_{2}, \mathrm{~B}, \mathrm{~F}$, and $\mathrm{NH}_{3}$.

\section{FILTERED ACIDIFIED (FA- $\mathrm{HNO}_{3}$ )}

Collect a measured amount of water as specified in Section $\mathrm{V}-\mathrm{C}$ and add $1: 1 \mathrm{HNO}_{3}$ with a calibrated pipet until the $\mathrm{pH}$ is -1.5 (pH meter). Discard the solution. Collect an additionat sample of water as specified in Section V-C. Using the information obtained from the $\mathrm{pH}$ adjustment of the discarded solution, add an appropriate amount of $1: 1 \mathrm{HNO}$ to the new sample to produce a $\mathrm{pH}$ of 1.5 . mix ine contents thoroughly, and label "FA-HNO3." Test a portion of the acidified solution to confirm that the pH of the new sample is $1.5 \pm 0.5$, then discard the portion tested. Stopper the container tightly. Make a notation of the amount of acid used in the $\mathrm{pH}$ adjustment. The following determinations are to be made on $\mathrm{FA}_{-}-\mathrm{HNO}_{3}$ samples: $\mathrm{Cu}, \mathrm{As}, \mathrm{Cr}, \mathrm{Pb}, \mathrm{Cl}^{-}$(not on-site). $\mathrm{Mn}$. Fe, $\mathrm{Cd}, \mathrm{Hg}$, and $\mathrm{Zn}$.

\section{E. FILTERED, ACIDIFIED (FA-HCI)}

Collect a measured amount of water as specified in Section $V-C$ and add $1: 1 \mathrm{HCl}$ with a calibrated pipet until the $\mathrm{pH}=3.0$ ( $\mathrm{pH}$ meter). Discard the solution. Collect an additional sample of water as specified in Section $V-C$. Using the information obtained from the pHadjustment of the discarded solution, add an appropriate volume of $1: 1 \mathrm{HCl}$ to the new sample to adjust the pH to 3.0 , mix the contents thoroughly, and label "FA-HCl." Test a portion of the acidified solution to confirm that the pHof the analytical sample is 3.0 \pm 0.5 , then discard the portion tested. Stopper the container tightly. Make a notation of the amount of acid used in the pH adjustment. The following determinations are to be made on $\mathrm{FA}-\mathrm{HCl}$ samples: Ba, $\mathrm{Sr}$, $\mathrm{Na}, \mathrm{K}, \mathrm{Ca}, \mathrm{Mg}$, and SO.".

\section{SPECIAL REAGENTS}

All $\mathrm{HCl}, \mathrm{HNO}_{3}, \mathrm{H}_{2} \mathrm{SO}_{4}$, and $\mathrm{NH}_{4} \mathrm{OH}$ used must be ultra-pure. Ultrex reagents have been found to be suitable as have the ultra-pure reagents from G.F. Smith Chemical Company, but equivalent grades are available from most commercial chemicall suppliers. Other reagents used for the various determinations should be "analytical" grade.

\section{PREPARATION OF GLASSSWARE}

The glassware used in procedures for determining trace elements must be cleaned scrupulously. Follow the procedure outlined in Section VIII-B, but adjust the amounts proportionately.

\section{CONTAINER PREPARATION}

\section{A. STAINLESS STEEL CYLINDERS (TEFLON-LINED)}

Check the cylinders to see that no grease or loose solid material is present. Remove any L-13 
grease by rinsing with an organic solvent such as petroleum ether. Be sure to remove the last traces of the organic solvent; passing dry nitrogen through the container usually will remove all of the solvent from the cylinder.

Install valves on the cylinder with teflon tape. Pressure-test each cylinder by filling it with nitrogen 10300 psig and immersing the cylinder in a water bath for $1 / 2$ hour.

\section{B. PLASTIC CONTAINERS}

Rinse with two $250-\mathrm{mL}$ portions of $6 \mathrm{M} \mathrm{HCl}$. Remove the $\mathrm{HCl}$ by rinsing with $300-\mathrm{mL}$ portions of deionized water until the rinse water gives no test with $\mathrm{AgNO}_{3}$, then rinse with a final $300-\mathrm{mL}$ portion of deionized water. The fourth rinse usually is free of chloride when cleaning five-gallon plastic containers and the third rinse usually is free of chloride when cleaning one-gallon containers.

\section{SAMPLING FREQUENCY}

Sampling frequency depends upon how long the well flows. Consult the following table to determine how often samples should be collected.

$\begin{array}{lll}\text { Flow Tlme } & \text { Nampling Time } & \text { of Samples } \\ 1 \text { week } & \text { Day 1,3,5 } & 3 \\ 2 \text { weeks } & \text { Day } 12 & 1 \text { (total of 4) } \\ 3 \text { weeks } & \text { Day 19 } & 1 \text { (total of 5) } \\ 4 \text { weeks } & \text { Day } 26 & 1 \text { (total of 6) } \\ >4 \text { weeks } & \text { Sample once each month } & \text { (1 per month) }\end{array}$

\section{SAMPLES TO BE ANALYZED}

\section{A. WATER SAMPLES}

The following determinations should be made on each water sample collected according to the above schedule: $\mathrm{pH}, \mathrm{T}$, specific conductance, dissolved solids, suspended solids, $\mathrm{Na}, \mathrm{K}, \mathrm{Ca}, \mathrm{Mg}$. Sr. alkalinity (including organic acid anions), alkalinity $\left(\mathrm{CO}_{2}\right), \mathrm{Cl}^{-}, \mathrm{F}^{-}, \mathrm{SiO}_{2}, \mathrm{Fe}, \mathrm{S}^{*}, \mathrm{Cd}$, $\mathrm{Zn}$, and $\mathrm{NH}_{3}$.

The following determinations should be made on the water samples collected on day 1 , day 12 , day 26 , and on every third water sample collected monthly after day 26 ; i.e., quarterly: $\mathrm{Ba}, \mathrm{SO}_{4}{ }^{2}, \mathrm{Mn}, \mathrm{B}, \mathrm{Hg}, \mathrm{As}, \mathrm{Cr}$. $\mathrm{Cu}, \mathrm{Pb}, \mathrm{Ra}-226$, gross $\alpha$, gross $\beta$, gross $\gamma$. identification of metals in dissolved solids by emission spectrography. These determinations should be repeated on the first and second samples collected monthly after day 26 if the quarterly determinations show irends.

\section{B. GAS SAMPLES}

The following determinations should be made on the gas samples collected on day 1 . day 12, day 26 and on every third gas sample collected monthly after day 26; i.e., quarterly: standard hydrocarbon analysis $\left(\mathrm{C}_{1}-\mathrm{C}_{6}\right.$ and $\left.\mathrm{C}_{8_{+}}\right), \mathrm{H}_{2} \dot{\mathrm{S}}, \mathrm{He}, \mathrm{An}-222, \mathrm{CO}_{2}, \mathrm{~N}_{2}, \mathrm{NH}_{3}, \mathrm{O}_{2}, \mathrm{H}_{2}$. . These determinations should be repeated on the first and second samples collected monthly after day 26 if the quarterly determinations show trends.

The identification of gases other than those listed above should be made on one sample only using mass spectrometry. Gases from $Z=1$ to $Z \cong 400$ should be sought. The one sample chosen for this determination should be obtained from the middle of the test period.

The amount of natural gas dissolved in the brine (gas/water ratio) should be delermined on at least one set of gas and water samples from the separator and from bottom-hole samples when available.

\section{SUSPENDED SOLIDS}

The clays and minerals in the suspended solids collected on days $1,3,5$, and 12 should be determined by $x$-ray diffractometry (or equivalent method). Save the remaining suspended solids samples for the identification of clays and minerals if that becomes necessary.

\section{DETERMINATIONS THAT REQUIRE SPECIAL EQUIPMENT}

\section{A. DETERMINATIONS IN WATER SAMPLES}

Special equipment is needed to determine Ra-226, gross $\alpha$, gross $\beta$, gross $\gamma$,metais in dissolved solids by emission spectrography and clays and minerals in suspended solids by $x$-ray diffraction. Many university laboratories have the equipment necessary to make these determinations $(3,4)$.

$$
\text { L-14 }
$$


Some oll service testing companies that perform core analyses have $x$-ray diffraction equipment and the expertise to identify clays and minerals.

Procedures for determining $\mathrm{Ba}, \mathrm{Mn}, \mathrm{As}, \mathrm{Cu}, \mathrm{Cr}, \mathrm{Pb}$, and $\mathrm{Hg}$ use neutron activation analysis as an analytical tool; thus, a neutron'generator or a nuclear reactor is required to perform these determinations by neutron activation analysis. Again, some university laboratories have this equipment $(3,4)$. Alternate procedures for these metals are listed, however, using atomic absorption spectrometry.

\section{B. DETERMINATIONS IN GAS SAMPLES}

Special equipment is needed to determine $\mathrm{An}-222$ and to identify the components of a gas from $Z=1$ to $Z \cong 400$ by mass spectromeiry as explained in Section XI-A.

\section{SCALE AND CORROSION INHIBITORS}

Records must be kept for any chemical added to the system to inhibit corrosion or scaling. Information stiould include the following:

Type and chemical description; molecular weight range and charge density (for polymers): cost; reasons for choice; alternatives; dosage level; point of addition to the system, reasons for this choice, and alternatives; time of addition; dosage versus time curves; method of monitoring the dosage; effectiveness of the chemical; description of the problem; and quantitative information on changes in scaling or corrosion characteristics and locations. In addition, a method of obtaining inhibitor-free water samples should be provided. 
Flow TESTS OF THE GLAdys MCCALL Well THROUgh OCTOBER 1990

XIII. PROCEDURES:

DETERMINATIONS IN WATER SAMPLES

L-16 


\section{ALKALINITY \\ INCLUDES ORGANIC ACID ANIONS \\ AN ON-SITE DETERMINATION} INTRODUCTION This procedure determines the total alkalinity, including the portion attributable to
organic acid anions.

METHOD

SAMPLING

PROCEDURE

RESULTS

AEFERENCE
Volumetric.

Use a raw, untreated sample. See Section V-A for special instructions.

Allow the sample to cool somewhat before an aliquot is taken. Pipet $50.00 \mathrm{~mL}$ of the cooled sample into a $250-\mathrm{mL}$ beaker. Place the electrodes of a calibrated $\mathrm{pH}$ meter into the sample and titrate with $0.02 \mathrm{~N} \mathrm{H}_{2} \mathrm{SO}_{4}$. Add the standard acid in increments of $1-2 \mathrm{~mL}$ at the beginning of the titration and change the increments to $0.25-0.5 \mathrm{~mL}$ at $\mathrm{pH}=5.0$. The incremental volumes should be determined by the actual titration and the speed with which the $\mathrm{pH}$ is changing. Titrate the solution until the $\mathrm{pH}$ is 2.0 . Tabulate values of $\mathrm{pH}$ and $\mathrm{mL}$ and determine the end point graphically from a plot of pH vs. $\mathrm{mL}$.

\section{Report alkalinity as $\mathrm{mg} \mathrm{HCO}_{3}{ }^{-} / \mathrm{L}$.}

6 


\section{ALKALINITY \\ TOTAL CARBON DIOXIDE AN ON-SITE DETERMINATION}

INTRODUCTION

METHOD

SAMPLING

PROCEDURE

RESULTS

REFERENCE

ALTERNATE PROCEDURE

REFERENCE
This method determines the alkalinity due to the carbonate type species in the sample.

Gravimetric (loss of carbon dioxide)

Use a raw, untreated sample. See Section V-A for special instructions.

Loss of carbon dioxide may be obtained by using an alkalimeter (unit-weight model). Allow the sample to cool somewhat betore an aliquot is taken. Pipet a portion of the cooled sample into the alkalimeter and fill the reservoir of the alkalimeter with dilute $\mathrm{H}_{2} \mathrm{SO}_{4}$. The sample and acid are weighed, the stopcock is opened to admit the $\mathrm{H}_{2} \mathrm{SO}_{4}$ to the sample (slowly), the mixture is heated gently (being careful not to lose water vapor) to expel any dissolved carbon dioxide, and the alkalimeter is weighed again. The loss in weight is the amount of carbon dioxide.

Report as $\mathrm{mg} \mathrm{HCO}_{3}{ }^{-} / \mathrm{L}$.

9

The Knorr $\left(\mathrm{CO}_{2}\right.$-weight model) type alkalimeter may be used also.

5 


\section{GROSS ALPHA, GROSS BETA, GROSS GAMMA}

\section{METHOD \\ SAMPLING \\ PROCEDURE}

RESULTS

REFERENCE

\section{Radioassay}

Use a raw, acidified sample. See Section V-B for special instructions.

Gross Alpha: Evaporate a small amount of the water sample and count the alpha radiation in an evacuated chamber.

Gross Beta: Evaporate a portion of the water sample and count total beta activity with a $\mathrm{G}-\mathrm{M}$ beta detector.

Gross Gamma: Evaporate a portion of the water sample (or use the portion prepared for the gross beta) and count gross gamma with a Ge (Li) detector.

Report gross alpha as $\mu \mathrm{g} \mathrm{U} / \mathrm{L}$.

Report gross beta as $\mathrm{pCi}{ }^{137} \mathrm{Cs} / \mathrm{L}$.

Report gross gamma as pCi total gamma radiation.

3 


\section{AMMONIA, FLUORIDE, SULFIDE}

METHOD

SAMPLING

PROCEDURE

RESULTS lon-specific electrode

Ammonia: Collect a separate filtered, untreated sample for ammonia. This is an on-site determination.

Sulfide: Collect a separate raw, untreated sample for sulfide. If the solution is turbid, filter it through glass wool. This is an on-site determination.

Fluoride: Use a filtered, untreated sample. See Section V-C for special instructions.

Use the appropriate specific ion electrode and follow the manufacturer's instructions. Measure the ammonia, fluoride, or sulfide content.

Report ammonia as $\mathrm{mg} \mathrm{N} \mathrm{NH}_{3} / \mathrm{L}$.

Report fluoride as $\mathrm{mg} \mathrm{F}^{-} \mathrm{L}$.

Report sulfide as $\mathrm{mg} \mathrm{S}^{*} / \mathrm{L}$. 
MÉTHOD

SAMPLING

PROCEDURE

RESULTS

REFERENCES

ALTERNATE PROCEDURE

REFERENCE

\section{ARSENIC}

Neutron activation analysis

Use a filtered, acidified $\left(\mathrm{HNO}_{3}\right)$ sample. See Section V-D for special instructions.

Prepare arsenic-free $\mathrm{HCl}$ by adding $500 \mathrm{~mL}$ of benzene to $-1500 \mathrm{~mL}$ of concentrated $\mathrm{HCl}$. Shake thoroughly, allow the two layers to separate, and discard the benzene layer. Repeat the extraction with an additional $500 \mathrm{~mL}$ of benzene and discard the benzene.

Place $100.00 \mathrm{~mL}$ of the sample in a $500-\mathrm{mL}$ separatory funnel, add $10 \mathrm{~mL}$ of arsenicfree $\mathrm{HCl}$ and $10.00 \mathrm{~mL}$ of benzene. Shake for two minutes, remove $5.00 \mathrm{~mL}$ of benzene, and place the benzene in a $10-\mathrm{mL}$ rabbit. Evaporate the benzene in a vacuum oven $\left(<40^{\circ} \mathrm{C}\right)$, seal the rabbit, and irradiate the contents of the rabbit with $\sim 10^{13} \mathrm{n} / \mathrm{cm}^{2}-s$ for two hours. Count arsenic as As-76 (26.3 hours). The sensitivity is affected by the presence of bromine and the two peaks must not be confused.

Report as mg As/L.

Preparation of arsenic-free $\mathrm{HCl}: 7$

Activation procedure: 3

Arsenic may be determined by atomic absorption spectrometry either directly or after converting the metal to arsine. Care should be exercised to prevent the absorption of radiation by organic vapors (e.g., acetylene) at the arsenic wavelengths.

8 


\section{BARIUM}

METHOD

SAMPLING

PROCEDURE

RESULTS

REFERENCE

ALTERNATE

PROCEDURE.

REFERENCE
Neutron activation analysis

Use a filtered, acidified $(\mathrm{HCl})$ sample. See Section V-E for special instructions.

Irradiate $2.00 \mathrm{~mL}$ of the sample and an appropriate standard for two minutes at $\sim 10^{13}$ $\mathrm{n} / \mathrm{cm}^{2}-\mathrm{s}$. Post irradiation chemistry is necessary. Add $20 \mathrm{mg}$ of $\mathrm{Ba}^{++}$and $10 \mathrm{mg}$ of $\mathrm{Fe}^{+++}$to the irradiated water sample and standard. Precipitate $\mathrm{Fe}^{+++}$as the hydroxide with ammonium hydroxide, then precipitate $\mathrm{Ba}^{++}$with $\left(\mathrm{NH}_{4}\right)_{2} \mathrm{CO}_{3}$. Filter, dissolve the precipitate in dilute $\mathrm{HCl}$, reprecipitate $\mathrm{Fe}^{+++f}$ as the hydroxide and $\mathrm{Ba}^{\text {t+ }}$ as the carbonate, filter, dry, weigh for the determination of recovery efficiency, and count Ba-139 (83 min.).

Report as $\mathrm{mg} \mathrm{Ba/L}$.

3

Barium may be determined in a nitrous oxide-acetylene flame by atomic absorption spectrometry.

8 


\section{BORON}

INTRODUCTION Use Teflon or plastic beakers for collection and analysis.

METHOD Carmine-spectrometric.

SAMPLING Use a filtered, untreated sample. See Section V-C for special instructions.

PROCEDURE If precipitation has occurred in the filtered, untreated sample, shake the solution thoroughly and allow it to settle somewhat. Pipet $2.00 \mathrm{~mL}$ of the sample into a $30-\mathrm{mL}$ Tefion beaker. Prepare a blank by pipetting $1.8 \mathrm{~mL}$ of deionized water into a Teflon beaker. Pipet $1.8 \mathrm{~mL}$ of standard boron solutions $(0.01$ and $0.025 \mathrm{mg} \mathrm{B} / \mathrm{L}$ ) into a Teflon beaker. To blank and standard solutions, add $0.2 \mathrm{~mL}$ of silica standard. The concentration of silica in the $2.00 \mathrm{~mL}$ volumes of samples, blank. and standards should be the same. Adjust the volume of the standards to $2.00 \mathrm{~mL}$. To blank, standards, and samples, add two drops of concentrated $\mathrm{HCl}$ and two drops of concentrated $\mathrm{H}_{2} \mathrm{SO}_{4}$. Allow to cool, add $10.00 \mathrm{~mL}$ of carmine solution $(0.5 \mathrm{~g}$ of carmine/liter of concentrated $\mathrm{H}_{2} \mathrm{SO}_{4}$ ) to blank, standards, and sample. Allow to stand for 1 hour. Set the spectrophotometer to $600 \mathrm{~nm}$ and use the blue sensitive phototube. Use a 1-inch cell and read the absorbance of each sample against the blank as a reference. Determine the amount of boron graphically.

RESULTS

Report as $\mathrm{mg} \mathrm{B/L}$.

REFERENCE 


\section{CADMIUM, IRON, ZINC}

METHOD

SAMPLING

PROCEDURE

RESULTS

REFERENCE
Atomic absorption spectrometry.

Use a filtered, acldified (HNO $)$ sample. See Section V-D for special instructions.

Determine cadmium, iron, or zine directly by atomlc absorption spectrometry.

Report cadmium as $\mathrm{mg} \mathrm{Cd/L}$.

Report iron as $\mathrm{mg} \mathrm{Fe} / \mathrm{L}$.

Report zinc as $\mathrm{mg} \mathrm{Zn/L}$. 


\section{CALCIUM, MAGNESIUM}

INTRODUCTION Lanthanum chloride must be added to mask interferences.

METHOD Atomic absorption spectrometry.

SAMPLING Use a filtered, acidified $(\mathrm{HCl})$ sample. See Section V-E for special instructions.

PROCEDURE Determine calcium or magnesium directly by atomic absorption spectrometry. Use $1.00 \mathrm{~mL}$ of $\mathrm{La}_{2} \mathrm{O}_{3}$ solution $\left(29 \mathrm{~g}\right.$ of $\mathrm{La}_{2} \mathrm{O}_{3}$ dissolved in small portions in $250 \mathrm{~mL}$ of concentrated $\mathrm{HCl}$ (CAUTIONI) and dilute to $500 \mathrm{~mL}$ with deionized water) for each $10.00 \mathrm{~mL}$ of sample or standard.

RESULTS Report calcium as $\mathrm{mg} \mathrm{Ca/L}$.

Report magnesium as $\mathrm{mg} \mathrm{Mg} / \mathrm{L}$.

REFERENCE $\quad 8$ 


\section{CHLORIDE}

INTRODUCTION If this determination is performed on-site, allow the sample to cool somewhat before an aliquot is taken; otherwise, a volume error will be made during the pipetting step.

METHOD

Mohr titration.

SAMPLING

Use a filtered, untreated sample for on-site analysis or a filtered, acidified. ( $\left.\mathrm{HNO}_{3}\right)$ sample for analysis at a later time. See Sections $V-C$ and $V-D$ for special instructions.

PROCEDURE

RESULTS

Report as $\mathrm{mg} \mathrm{Cl}^{-} / \mathrm{L}$.

REFERENCE

8 


\section{CHROMIUM, COPPER, LEAD}

INTRODUCTION

METHOD

SAMPLING

PROCEDURE

RESULTS

REFERENCES

ALTERNATE PROCEDURE

\section{REFERENCE}

Chromium, copper, or lead may be extracted with ammonium pyrollidine dithiocarbamate in methyl isobutyl ketone. The three metals are extracted simultaneously and each may be determined by subjecting the extract to atomic absorption spectrometry or to neutron activation analysis.

Atomic absorption spectrometry.

Use a filtered, acidified $\left(\mathrm{HNO}_{3}\right)$ sample. See Section $\mathrm{V}-\mathrm{D}$ for special instructions.

Pipet a $100.00-\mathrm{mL}$ sample into a $250-\mathrm{mL}$ volumetric flask. Prepare a blank and a standard containing $0.1 \mathrm{mg} \mathrm{M}^{+n} / \mathrm{L}$ in the extracted medium similarly. Add two drops of bromphenol blue solution $(0.1 \mathrm{~g}$ of bromphenol blue dissolved in $100 \mathrm{~mL}$ of $50 \%$ ethanol) to each flask. Adjust the pH by adding $2.5 \mathrm{M} \mathrm{NaOH}(10 \mathrm{~g}$ of NaOH in $1 \mathrm{~L}$ of solution) dropwise until the blue color persists, then add $0.3 \mathrm{M} \mathrm{HCl}(25 \mathrm{~mL}$ of concentrated $\mathrm{HCl}$ in deionized water dilutegd to $1 \mathrm{~L}$ ) until the blue color just disappears. Add $2.00 \mathrm{~mL}$ of $0.3 \mathrm{M} \mathrm{HCl}$ in excess. Add $5.00 \mathrm{~mL}$ of APDC solution $11 \mathrm{~g}$ of ammonium pyrrolidine dithiocarbamate in deionized water diluted to $100 \mathrm{~mL}$. Prepare fresh daily.) and mix. Add $10.00 \mathrm{~mL}$ of MIBK (methyl isobutyl ketone) and shake the flask and contents for three minutes. Allow the layers to separate and add deionized water until the MIBK layer is in the neck of the flask. Determine $\mathrm{Cu}, \mathrm{Cr}$, or $\mathrm{Pb}$ in the MIBK extract by atomic absorption spectrometry.

Report chromium as $\mathrm{mg} \mathrm{Cr} / \mathrm{L}$.

Report copper as $\mathrm{mg}$ Cu/L.

Report lead as $\mathrm{mg} \mathrm{Pb/L}$.

Extraction procedure: 4

Atomic absorption spectrometry: 8

Remove $5.00 \mathrm{~mL}$ of the MIBK extract from the neck of the volumetric flask. place the extract in a $10-m L$ rabbit, evaporate the MIBK in a vacuum oven $\left(<35^{\circ} \mathrm{C}\right)$, seal the rabbit, and irradiate with $5 \times 10^{12} \mathrm{n} / \mathrm{cm}^{2}-\mathrm{s}$ in a pneumatic system for $10-15 \mathrm{~s}$ Copper is counted as Cu-66 (5.1 minutes). Irradiate for one hour. Chromium is counted as Cr-51 (27.7 days). Irradiate with $14.8 \mathrm{Mev}$ neutrons. Count, using a pneumatic system, the $0.8 \mathrm{~s}$ activity of ${ }^{207} \mathrm{~m} \mathrm{~Pb}$ produced from the ${ }^{208} \mathrm{~Pb}(n, 2 n)$ reaction. 


\section{CLAYS AND MINERALS}

INTRODUCTION The composition of the suspended solids, with regard to clays and minerals, may be determined by $\mathrm{x}$-ray diffraction.

METHOD X-ray diffractometry.

SAMPLING Use the solid material from the suspended. solids determination.

PROCEDURE The suspended solids collected on the filter should be subjected to $x$-ray diffraction techniques such that clays and minerals will be identified. A semi-quantitative determination of each mineral identified is desirable.

RESULTS Report the identities of the clays or minerals present. 


\section{DISSOLVED SOLIDS}

\section{AN ON-SITE DETERMINATION}

METHOD

SAMPLING

PROCEDURE

RESULTS

REFERENCE

ALTERNATE

PROCEDURE

REFERENCE
Gravimetric.

Use a filtered, untreated sample. See Section V-C for special instructions.

Pipet a volume of sample containing $<200 \mathrm{mg}$ of dissolved solids into a pre-weighed container. Evaporate the liquid over a steam bath or in an oven $\left(-80^{\circ} \mathrm{C}\right)$, then dry at $180^{\circ} \mathrm{C}$ for two hours or until constant weight is attained. Save the dried material for possible analysis by emission spectrography.

\section{Report as mg dissolved solids/L.}

4

Alternatively, the dissolved solids content may be calculated by adding the concentrations found for the cations and the anions. Convert $\left(\mathrm{HCO}_{3}{ }^{-}\right)$to $\left(\mathrm{CO}_{3}{ }^{\circ}\right)$ for this calculation.

8 


\section{MANGANESE}

INTRODUCTION

METHOD

SAMPLING

PROCEDURE

RESULTS

REFERENCE

ALTERNATE PROCEDURE

REFERENCE
Large amounits of manganese may be determined directly by atomic absorption spectrometry ( see CADMIUM, IRON, ZINC). Trace amounts may be determined directly by neutron activation analysis. Alternatively, trace amounts of manganese may be determined by atomic absorption spectrometry following an extraction procedure. Iron and magnesium interfere in the extraction step, however, and the neutron activation procedure is preferred.

Neutron activation analysis.

Use a filtered, acidified $\left(\mathrm{HNO}_{3}\right)$ sample. See Section V-D for special instructions.

Irradiate $1.00 \mathrm{~mL}$ of the sample for 30 minutes at $-10^{13} \mathrm{n} / \mathrm{cm}^{2}-\mathrm{s}$. Precipitate the Inanganese as the hydroxide with ammonium hydroxide, centrifuge, dissolve the precipitate with dilute $\mathrm{HCl}$, then precipitate $\mathrm{MnO}_{2}$ by adding (carefully!) $100 \mathrm{mg}$ of $\mathrm{KBrO}_{3}$. Count as $\mathrm{Mn}-56$ (2.6 hours).

Report as $\mathrm{mg} \mathrm{Mn/L}$.

3

Pipet a $100.00 \mathrm{~mL}$ sample into a $250-\mathrm{mL}$ volumetric flask. Prepare a blank and a standard containing $0.1 \mathrm{mg} \mathrm{Mn} / \mathrm{L}$ in the extracted medium similarly. Add two drops of bromcresol green solution $(0.1 \mathrm{~g}$ of bromcresol green dissolved in $100 \mathrm{~mL}$ of $20 \%$ ethanol) to each flask. Adjust the $\mathrm{pH}$ by adding $0.3 \mathrm{M} \mathrm{HCl}(25 \mathrm{~mL}$ of concentrated $\mathrm{HCl}$ in deionized water diluted to $1 \mathrm{~L}$ ) dropwise until a light olive-green color is attained. Add $5.00 \mathrm{~mL}$ of APDC solution $4 \mathrm{~g}$ of ammonium pyrrolidine dithiocarbamate in deionized water diluted to $100 \mathrm{~mL}$. Prepare fresh daily.) and mix. Add $5.00 \mathrm{~mL}$ of MIBK (methyl isobutyl ketone) and shake the flask and contents for two minutes. Allow the layers to separate and add deionized water until the MIBK layer is in the neck of the flask. Determine manganese in the MIBK layer by atomic absorption spectrometry.

8 


\section{MERCURY}

INTRODUCTION Special procedures for cleaning the glassware are necessary when determining very low levels of mercury. Soak borosilicate glass bottles with chromic acid overnight, rinse five times with deionized water, and oven dry $>200^{\circ} \mathrm{C}$ for two hours.

METHOD Neutron activation analysis.

SAMPLING Use a filtered, acidified $\left(\mathrm{HNO}_{3}\right)$ sample. See Section V-D for special instructions.

PROCEDURE Irradiate $10.00 \mathrm{~mL}$ of the sample at $-10^{13} \mathrm{n} / \mathrm{cm}^{2}-\mathrm{s}$ for 14 hours. Allow to decay for $\sim$ two months before counting $\mathrm{Hg}-203$ ( 46.6 days).

RESULTS Report as $\mathrm{mg} \mathrm{Hg} / \mathrm{L}$

REFERENCES Special cleaning procedure: 1

Analytical procedure: 3

ALTERNATE PROCEDURE

Alternatively, mercury may be determined by flameless atomic absorption spectrometry.

REFERENCE

8 


\section{METALS \\ QUALITATIVE OR SEMI-QUANTITATIVE \\ IN SUSPENDED SOLIDS AND DISSOLVED SOLIDS}
INTRODUCTION Metals in the suspended solids or metals in the water may be identified quickly and easily by emission spectrography.
METHOD Emission spectrography.
SAMPLING
For the identification of metals in solution, use the dried material collected from the dissolved solids determination. Metals in the suspended solids may be identified by removing some of the solid material from the $0.45-\mu \mathrm{m}$ filter used in the suspended solids determination.

PROCEDURE

Use an instrument with a plate factor of at least $3.5 \mathrm{~A} / \mathrm{mm}$ and photograph the ultraviolet part of the spectrum. Sample dilution with graphite, sample and counter electrodes used, exposure time, current, developing conditions, etc. are left to the discretion of the laboratory involved. An overall good sensitivity for qualitative analysis is required. Examine the plates for the presence of metals not specifically requested in Section I-A. These metals may then be determined by the appropriate analytical procedure. 


\section{AN ON-SITE DETERMINATION}

METHOD

SAMPLING

PROCEDURE

RESULTS

ALTERNATE PROCEDURE

REFERENCE

\section{Electrometric.}

Use a raw, untreated sample. See Section V-A for special instructions.

Use a pH meter with automatic temperature compensation. Calibrate the $\mathrm{pH}$ meter with buffers of $\mathrm{pH}=7.0$ and $\mathrm{pH}=4.0$ immediately prior to collecting the sample. Measure the $\mathrm{pH}$ of the water sample as soon as possible after collection. Do not stir the sample. The readings of some samples drift downscale when the electrodes are inserted in the sample, then drift upscale as the $\mathrm{CO}_{2}$ is exsolved from solution. Report the lowest reading. A stable $\mathrm{pH}$ reading will not be available until all of the $\mathrm{CO}_{2}$ has been removed from the sample and the stable reading is not the true $\mathrm{pH}$ of the original sample.

Report acidity in $\mathrm{pH}$ units.

A more rigorous method for $\mathrm{pH}$ measurement is as follows: Calibration of the $\mathrm{pH}$ meter with the appropriate buffer should be carried out at the same temperature at which the geopressured fluid was collected. Completely fill a $4 \mathrm{oz}$. glass bottle (polyseal cap) with a sample collected at the well-head. Stopper the sample bottle immediately and measure the $\mathrm{pH}$ as soon as possible. The pH electrodes should be fitted with a plastic sleeve which fits tightly into the mouth of the glass bottle containing the sample to be measured. This procedure is essential to minimize loss of $\mathrm{CO}_{2}$ during the $\mathrm{pH}$ measurement. Record the temperature at which the sample is collected as well as the temperature at which the $\mathrm{pH}$ is measured. 


\section{POTASSIUM}

METHOD

SAMPLING

PROCEDURE

RESULTS

REFERENCES

ALTERNATE

PROCEDURE

REFERENCE
Flame emission or atomic absorption spectrometry.

Use a filtered, acidified $(\mathrm{HCl})$ sample. See Section V-E for special instructions.

Determine potassium directly by flame emission or atomic absorption spectrometry. Sodium interference may be compensated for by preparing potassium standards containing the same concentration of sodium found in the samples.

Report as $\mathrm{mg} \mathrm{K/L}$.

Flame emission spectrometry: 4

Atomic absorption spectrometry: 6

Sodium interference may be masked by adding sodium equivalent to $2000 \mathrm{mg} \mathrm{Na} / \mathrm{L}$ to the potassium samples and standards aspirated into the flame.

6 


\section{RADIUM}

INTRODUCTION

METHOD

SAMPLING

PAOCEDURE
RESULTS

REFERENCE
This procedure determines Ra-226, Ra-228, and other radium isotopes electroplated on platinum foil. A multi-channel analyzer is useful for separating the energy levels.

\section{Radioassay.}

Use a raw, acidified sample. See Section V-B for special instructions.

To $100.00 \mathrm{~mL}$ of the sample, add $50 \mathrm{mg}$ of $\mathrm{Ba}^{++}$(as $\mathrm{BaCl}_{2}$ ) and $20 \mathrm{mg}$ of $\mathrm{Fe}^{+++}$(as $\mathrm{FeCl}_{3}$ ) to act as a carrier. Make the solution basic with $\mathrm{NH}_{4} \mathrm{OH}$, digest at $80-90^{\circ} \mathrm{C}$. filter, and discard the $\mathrm{Fe}(\mathrm{OH})_{3}$. Precipitate $\mathrm{Ba}(\mathrm{Ra}) \mathrm{CO}_{3}$ with $\left(\mathrm{NH}_{4}\right)_{2} \mathrm{CO}_{3}$. Filter and retain the precipitate. Dissolve the precipitate in $6 \mathrm{M} \mathrm{HNO}$. and precipitate $\mathrm{Ba}(\mathrm{Ra})\left(\mathrm{NO}_{3}\right)_{2}$ by adding $20 \mathrm{~mL}$ of fuming nitric acid. Filter and retain the precipitate. Add $10 \mathrm{~mL}$ of absolute ethanol to the precipitate, cool in an ice bath, add $10 \mathrm{~mL}$ of ether, and stir thoroughly. This last step dissolves $\mathrm{Ca}\left(\mathrm{NO}_{3}\right)_{2}$. Filter. Dissolve the remaining precipitate in water, make the solution basic with $\mathrm{NH}_{4} \mathrm{OH}$, and precipitate $\mathrm{Ba}(\mathrm{Ra}) \mathrm{CO}_{3}$ with $\left(\mathrm{NH}_{4}\right)_{2} \mathrm{CO}_{3}$., Filter. Dissolve the precipitate with $0.2 \mathrm{M} \mathrm{HNO}_{3}$ and use the resulting solution to load a Dowe $50 \times 8$ ion exchange column. "Separate the $\mathrm{Ba}$ and $\mathrm{Ra}$ by eluting with $0.32 \mathrm{M}$ ammonium citrate solution adjusted to $\mathrm{pH}=5.6$ with dilute ammonium hydroxide or dilute hydrochloric acid. To the Ra fraction (second fraction eluted), add $2 \mathrm{mg}$ of $\mathrm{Ba}^{++}$carrier, adjust the $\mathrm{pH}$ to 8.0 with dilute $\mathrm{NH}_{4} \mathrm{OH}$, precipitate $\mathrm{Ba}(\mathrm{Ra}) \mathrm{CO}_{3}$ with $\left(\mathrm{NH}_{4}\right)_{2} \mathrm{CO}_{3}$. Dissolve the $\mathrm{Ba}(\mathrm{Ra}) \mathrm{CO}_{3}$ in the minimum amount of $0.5 \mathrm{M} \mathrm{HN} \mathrm{HNO}_{3}^{-}$. Place the nitric acid solution in an electroplating cell and electroplate the metal onto platinum foil at $20 \mathrm{~mA}$ for 6 hours. Place the electroplated sample in an alpha chamber to determine Ra-226. Place the electroplated sample in a beta detection system to determine Ra-228.

"Prepare the Dowex ion exchange resin column as follows: Remove organic material by washing the column with several column volumes of $95 \%$ ethyl alcohol, followed by two or more column volumes successively of $0.6 \mathrm{M}$ ammonium citrate $(\mathrm{pH}=5.6)$ and $1.5 \mathrm{M} \mathrm{NH}_{4} \mathrm{OH}$.

Report as pCi Ra-226 or pCi Ra-228/L. 


\section{SILICA}

INTRODUCTION

METHOD

SAMPLING

PROCEDURE

RESULTS

REFERENCE

ALTERNATE

PROCEDURE

REFERENCE
Silica may be determined directly in FU samples on-site if the determination is made immediately after sample collection; otherwise, field dilutions will be necessary since some precipitation of silica may occur if too much time elapses between sample collection and analysis. Use Teflon or plastic beakers for collection and analysis.

Molydenum blue-spectrometric.

Use a filtered: untreated sample for on-site analysis. See Section V-C for special instructions.

Allow the FU sample to cool somewhat. (1) Pipet $1.00 \mathrm{~mL}$ of the sample into a beaker. Add $10.00 \mathrm{~mL}$ of deionized water. (2) Pipet $1.00 \mathrm{~mL}$ of each standard into separate beakers. Add $10.00 \mathrm{~mL}$ of $\mathrm{NaCl}$ solution (containing 1/10 the concentration of chloride found in the sample) to each beaker containing standards. (3) Prepare a blank by adding $1.00 \mathrm{~mL}$ of deionized water and $10.00 \mathrm{~mL}$ of $\mathrm{NaCl}$ solution (same concentration as in step 2) to a beaker. (4) Pipet into each of the beakers in steps 1-3: (a) $5.00 \mathrm{~mL}$ of $1.0 \mathrm{~N} \mathrm{HCl}$, (b) $5.00 \mathrm{~mL}$ of $\mathrm{Na}_{2}$ EDTA solution $(10 \mathrm{~g} / \mathrm{L})$, and (c) $5.00 \mathrm{~mL}$ of ammonium molybdate solution $\left(52 \mathrm{~g}\right.$ of $\left(\mathrm{NH}_{4}\right)_{6} \mathrm{MO}_{7} \mathrm{O}_{24} \cdot 4 \mathrm{H}_{2} \mathrm{O}$ in deionized water, adjust the pH to 7-8 with $10 \mathrm{M} \mathrm{NaOH}$, and dilute to $1 \mathrm{~L}$ with deionized water. Filter through $0.45-\mu \mathrm{m}$ membrane filter if necessary.) (5) Wait 5 minutes and add $5.00 \mathrm{~mL}$ of $\mathrm{H}_{2} \mathrm{C}_{4} \mathrm{H}_{4} \mathrm{O}_{6}$ (tartaric acid) solution $(100 \mathrm{~g} / \mathrm{L}$ ) to each beaker. Mix. (6) Wait 2 minutes and add $10.00 \mathrm{~mL}$ of $\mathrm{Na}_{2} \mathrm{SO}_{3}$ solution $(170 \mathrm{~g} / \mathrm{L})$ to each beaker. Mix. (7) Wait 30 minutes. Use $1 \mathrm{~cm}$ cells and measure the absorbance of each sample and standard at $700 \mathrm{~nm}$ (red filter, red sensitive phototube) against the blank as a reference. Plot the data and graphically determine the $\mathrm{SiO}_{2}$ concentration.

Report as $\mathrm{mg} \mathrm{SiO} / \mathrm{L}$.

4

To prevent the possible precipitation of silica in samples not intended for on-site analysis, collect two FU samples and dilute them 1:2 and 1:4, respectively, with distilled water. The amount of silica should be determined in both dilutions; agreement between the two dilutions is evidence that no precipitation of silica occurred. To determine silica, follow the procedure outlined above. Some volume adjustments must be made for the diluted samples.

8. 
Flow Tests of the Gladys MCCall Well Through OCtober 1990

\section{SODIUM}

METHOD

SAMPLING

PROCEDURE

RESULTS

REFERENCE

ALTERNATE

PROCEDURE

REFERENCE
Flame emisșion spectrometry

Use a filtered, acidified $(\mathrm{HCl})$ sample. See Section $\mathrm{V}-\mathrm{E}$ for special instructions.

Determine sodium directly by flame emission spectrometry. Potassium does not interfere at levels up to $1 \mathrm{mg} \mathrm{K/L}$ in the aspirated solution. At $5 \mathrm{mg} \mathrm{K} / \mathrm{L}$ in the aspirated solution, an enhancement of $4-6 \%$ in the measured sodium concentration is observed. Most geopressured-geothermal samples contain high $\mathrm{Na} / \mathrm{K}$ ratios and the samples must be diluted several thousand-fold in order to place the level of sodium in the proper analytical range. At these dilutions, the potassium concentration rarely exceeds $1 \mathrm{mg} \mathrm{K/L}$.

Report as $\mathrm{mg} \mathrm{Na} / \mathrm{L}$.

3

Determine sodium directly by atomic absorption spectrometry. Mask potassium interference by adding potassium equivalent to $1000 \mathrm{mg} \mathrm{K} / \mathrm{L}$ to the sodium samples and standards aspirated into the flame.

6 


\section{SPECIFIC CONDUCTANCE}

\section{AN ON-SITE DETERMINATION}

METHOD

SAMPLING

PROCEDURE

RESULTS

REFERENCE
Electrometric.

Use a raw, untreated sample. See Section V-A for special instructions.

Tn determine specific conductance, use a commercial instrument that has been calibrated with $\mathrm{KCl}$ at various temperatures.

Report specific conductance in $\mu \mathrm{mhos} / \mathrm{cm}$ or $\mu \mathrm{S} / \mathrm{cm}$ (microsiemens $/ \mathrm{cm}$ ) at $25^{\circ} \mathrm{C}$.

8 
FLOW TESTS OF THE GLADYS MCCALL WELL THROUGH OCTOBER 1990

\section{STRONTIUM}

METHOD

SAMPLING

PROCEDURE

RESULTS

REFERENCE
Atomic absorption spectrometry.

Use a filtered, acidified $(\mathrm{HCl})$ sample. See Section V-E for special instructions.

Use $1.00 \mathrm{~mL}$ of a $\mathrm{La}_{2} \mathrm{O}_{3}-\mathrm{KCl}$ mixture (Dissolve $117.3 \mathrm{~g}$ of $\mathrm{La}_{2} \mathrm{O}_{3}$ in the minimum amount of dilute $\mathrm{HCl}+19.1 \mathrm{~g}$ of $\mathrm{KCl}$, then add deionized water to $1000 \mathrm{~mL}$ ) for each $10.00 \mathrm{~mL}$ of sample or standard.

Report as $\mathrm{mg} \mathrm{Sr} / \mathrm{L}$.

8 


\section{SULFATE}

METHOD

SAMPLING

PROCEDURE

RESULTS

REFERENCES

ALTERNATE

PROCEDURE

REFERENCE
Gravimetric.

Use a filtered, acidified $(\mathrm{HCl})$ sample. See Section V-E for special instructions.

Prepare a chromatographic column as follows: Wash 80-200 mesh chromatographic grade alumina with deionized water. Allow the alumina to settle, decant the supernatant liquid, and repeat the washing procedure untit the supernatant liquid is clear. Transfer the alumina to a chromatographic column, wash with $50 \mathrm{~mL}$ of $1 \mathrm{M}$ ammonium hydroxide, several $5-\mathrm{mL}$ portions of $0.1 \mathrm{Mammonium}$ hydroxide, and 50 $\mathrm{mL}$ of deionized water. Wash with $10 \mathrm{~mL}$ of $1 \mathrm{M} \mathrm{HCl}$ for the final wash.

Acidify the sample with $30 \% \mathrm{HCl}$ to $\mathrm{pH}=0.5-1.0$. Introduce the sample onto the previously prepared chromatographic column, wasn with $10 \mathrm{~mL}$ of $1 \mathrm{M} \mathrm{HCl} \mathrm{followed}$ with a total of $25 \mathrm{~mL}$ of deionized water added in several portions. Elute the sulfate from the column by adding $5 \mathrm{~mL}$ of $1 \mathrm{M}$ ammonium hydroxide followed by $20 \mathrm{~mL}$ of $0.1 \mathrm{M}$ ammonium hydroxide. Add an additional $20 \mathrm{~mL}$ of $0.1 \mathrm{M}$ ammonium hydroxide in $5-\mathrm{mL}$ portions. Wash with $25 \mathrm{~mL}$ of deionized water. Do not allow the column to become dry.

Neutralize the eluted sample with dilute $\mathrm{HCl}$ and add $1 \mathrm{~mL}$ of dilute $\mathrm{HCl}$ in excess, then dilute to approximately $200 \mathrm{~mL}$ with deionized water. Treat with $0.25 \mathrm{M} \mathrm{BaCl}_{2}$ solution. Digest the precipitate for two hours at $80-90^{\circ} \mathrm{C}, \mathrm{cool}$, filter, wash the paper, and heat the residue in a muffle furnace $\left(\sim 1000^{\circ} \mathrm{C}\right)$ until constant weight is attained.

Report as $\mathrm{mg} \mathrm{SO}_{4}{ }^{2} / \mathrm{L}$.

Preparation of chromatographic column: 2

Adsorption of sample on, and elution from, the column: 2

Precipitation of sulfate: any standard text.

Alternatively, sulfate may be determined by ion chromatography.

6 


\section{SUSPENDED SOLIDS}

\section{AN ON-SITE DETERMINATION}

\section{METHOD}

SAMPLING

PROCEDURE

RESULTS

REFERENCE

\section{Gravimetric.}

Collect the suspended solids residue during the filtration step for filtered, untreated or filtered, acidified samples.

Weigh a piece of $0.45-\mu \mathrm{m}$ membrane filter, then filter a measured volume of sample through the membrane. Remove soluble salts by washing the membrane with deionized water. Remove oil and grease by washing the membrane with petroleum ether. Dry the filter at $110^{\circ} \mathrm{C}$ and reweigh it. Save the dried material for possible $x$-ray diffraction or emission spectrographic analysis.

\section{Report suspended solids in $\mathrm{mg} / \mathrm{L}$.}

3 
Flow Tests of the Gladys MCCALL Well Through OCtOBer 1990

XIV. PROCEDURES:

DETERMINATIONS IN GAS SAMPLES 


\section{AMMONIA, HELIUM, HYDROGEN, HYDROGEN SULFIDE}

INTRODUCTION

METHOD

SAMPLING

PROCEDUAE

RESULTS
Hydrogen and helium diffuse through most sample containers quickly; therefore, these gases must be determined as soon as possible after collection.

Gas chromatography.

Use a sample collected from the separator or the sample remaining from previous gas analyses. See Section III-A for special instructions. Save the sample for the possible determination of other gases.

These gases should be determined by standard gas chromatography. Use the proper column, carrier gas, etc. to obtain the correct determination.

Report as mole per-cent of each element or compound. 


\title{
COMPOSITION OF GASES
}

\author{
QUALITATIVE
}

INTRODUCTION The composition of gases, as determined by procedures listed in this manual, is reported in mole-percent. This reporting procedure is a method for normalizing the reported components of a gas to $100 \%$; however, other components may be present but go undetected. To guard against this possibility, at least one gas sample should be subjected to a mass spectrometric analysis.

\section{METHOD \\ PROCEDURE}

RESULTS
Mass spectrometry.

Follow the standard procedure for detecting gases from $Z-1$ to $Z \cong 400$. A semiquantitative determination is desirable.

Report the identity of the gases present and the semi-quantitative results if possible. 


\section{GAS/WATER RATIO}

INTRODUCTION

METHOD

SAMPLING

PROCEDURE

\section{RESULTS}

ALTERNATE

PROCEDURE

REFERENCE
The solubility of natural gas in brine is determined at reservoir conditions of temperature and pressure. Record the bottom-hole temperature and the bottomhole pressure.

Recombination-Differential Liberation.

Collect a gas sample at the high-pressure separator in a one-gallon teflon-lined stainless steel container after the container has been flushed with at least five volumes of separator gas. Collect the gas under the pressure of the system by closing the exit valve of the sample container before closing the inlet valve.

Collect a sample of water at the low-pressure side of the high-pressure separator in a $500-\mathrm{mL}$ teflon-lined stainless steel container. Collect the water sample under equilibrium conditions as follows: Fill the container with gas from the separator. Attach the container (in a vertical position) to the water collection port and completely open the valve from the separator. Completely open the inlet valve of the sample container, but open the exit valve of the sample container only slightly. Under these conditions, the fluid will displace the gas in the container very slowly, and the equilibrium conditions will be maintained as nearly as possible. The $500-\mathrm{mL}$ container should be filled in about 20 minutes. Close the exit valve, close the inlet valve of the sample container, then close the separator valve. The water and gas samples should be collected as close to the same time as possible.

Perform a recombination and differential liberation study on the gas-water system at reservoir temperature and pressure. Use a windowed equilibrium cell such that saturation can be observed visually. The details of this procedure are rather standard in petroleum service testing laboratories. Weatherly Labs (Lafayette, La.), PVT Labs (Houston, TX.), and Core Labs (Dallas, Tx.) are three such service laboratories in the Louisiana-Texas area.

Report SCF gas $\left(60^{\circ} \mathrm{F}\right) / \mathrm{Bb}$ brine $\left(60^{\circ} \mathrm{F}\right)$.

The gas/water ratio may be determined from surface measurements at the separator or from battom-hole samples.

See Sections III-C and III-D.

See the discussion in Section IV and Appendix A. 


\section{HYDROCARBONS}

\section{INCLUDES CARBON DIOXIDE, NITROGEN AND OXYGEN}

METHOD

SAMPLING

PROCEDURE

RESULTS
Gas chromatography.

Use a sample collected from the separator or the sample remaining from previous gas analyses. See Section III-A for special instructions. Save the sample for the possible determination of other gases.

Use a gas chromatograph to determine $C_{1}-C_{6}$ and $C_{6+}$. The standard analysis usually determines $\mathrm{CO}_{2}, \mathrm{~N}_{2}$ and $\mathrm{O}_{2}$ simultaneously.

Report as mole per-cent of each element or compound. 


\section{RADON-222}

INTRODUCTION Record the date and time of sampling.

METHOD Radioassay.

SAMPLING

Use a sample collected from the separator or the sample remaining from previous gas analyses. See Section III-A for special instructions. Save the sample for the possible determination of other gases.

PROCEDURE

Evacuate the alpha counting chamber and admit a known amount of the gas sample into the chamber. Count the Rn-222.

RESULTS

Report as $\mathrm{pCi}{ }^{222} \mathrm{Rn} / \mathrm{L}$. Results must be corrected to the time of sampling because of the short half-life $(\sim 3$ days $)$ of $R n-222$.

REFERENCE

3 


\section{BIBLIOGRAPHY}

1. James W. Ball, Everett A. Jenne, and J.M. Burchard, Proceedings of the First Workshop on

Sampling Geothermal Effluents, Las Vegas, Nevada, October 20-21, 1975; U.S. Environmental Protection Agency, EPA-600/9-76-011, May 1976; p. 227.

2. James Fritz, Stanley S. Yamamura, and Marlene Johnson, Anal. Chem, 29, 158, (1957).

3. B. E. Hankins, unpublished procedures developed by McNeese State University personnel, Chemistry Department, Lake Charles, La. 70609.

4. B. E. Hankins, unpublished modification of U.S.G.S. procedures developed by McNeese State University personnel, Chemistry Department, Lake Charles, La. 70609.

5. W. Horwitz, Ed., Official Methods of Analysis of the Association of Official Analytical Chemists; 12th Ed.; Association of Official Analytical Chemists: Washington, D.C.. 1975; p. 3.

6. Michael S. Lico, Yousif K. Kharaka, William W. Carothers, and Victoria A. Wright, "Methods for Collection and Analysis of Geopressured-Geothermal and Oil Field Waters"; U.S. Geological Survey open file report, Menlo Park, CA, 1980.

7. G. H. Morrison and Henry Freiser,. "Solvent Extraction in Analytical Chemistry"; Wiley and Sons, N.Y., 1957; p. 127-131.

8. M. W. Skougstad, M. J. Fishman, Linda C. Friedman, David D. Erdmann, and Saundra S. Duncan, "Methods for Determination of Inorganic Substances in Water and Fluvial Sediments"; U.S. Geological Survey; U.S. Government Printing Office, Washington, D.C., 1979; Book 5, Chapter A 1, 626 pages.

9. G. L. Spencer and G. P. Meade, "Cane Sugar Handbook"; 8th Ed.; Wiley and Sons, N.Y., 1945; p. 664. 
FLOW TESTS OF THE GLADYS MCCALL WeLl THROUgh OCTOBER 1990 


\section{APPENDIX A}

\section{CALCULATION OF GAS/WATER RATIO FROM SURFACE MEASUREMENTS}

The gas/water ratio can be calculated readily from temperature, pressure, and flow rate data taken at the gas/water separator of the surface equipment immediately downstream of the well-head.

Figure 3 represents the flow conditions at the separator. Symbols are defined below and used in the sample calculations which follow.

Figure 3.

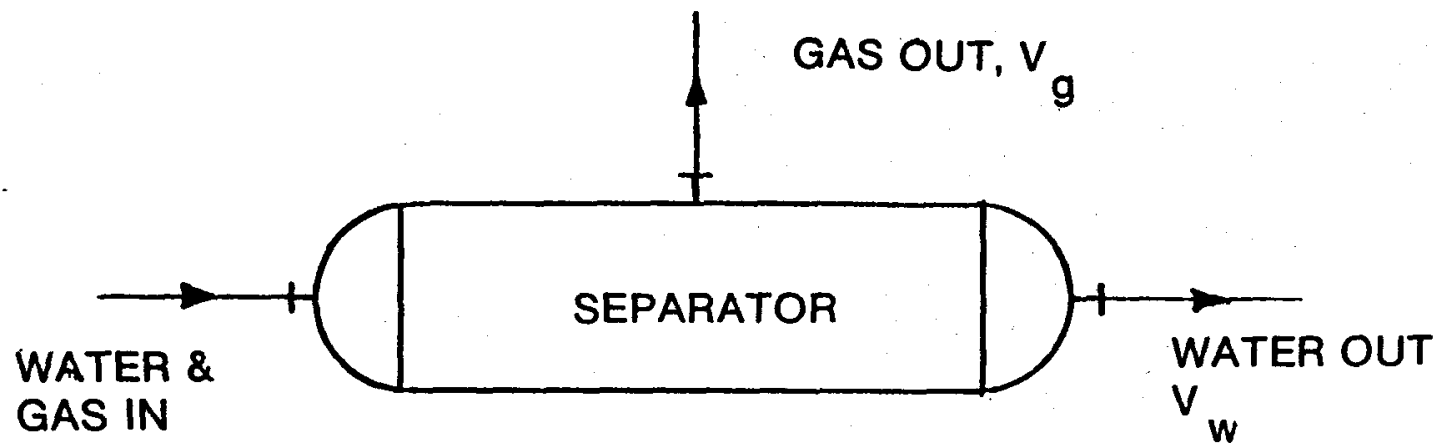

Symbols

$V_{0} \quad=$ Volume of gas leaving separator, cu.ft./hour @ $t_{\mathbf{a}}, P_{\mathbf{s}}$.

$t_{\text {. }}=$ Temperature of separator, ${ }^{\circ} \mathrm{F}$.

$P_{\mathbf{B}} \quad=$ Pressure of separatore, psig.

$V_{w}=$ Volume of water leaving separator, Bbls./hour.

SCF $=$ Standard cubic feet .

SCFH $=$ Standard cubic feet/hour.

Bbls $=$ Barrels .

Standard conditions for the gas $=60^{\circ} \mathrm{F}, 14.7$ psia.

Assumptlons

1 Gas and water are in equilibrium as they leave the separator.

2. Gas and water leave the separator at $t_{8}$ and $P_{3}$. 


\section{SAMPLE CALCULATION}

$$
\begin{aligned}
& P_{s}=300 \text { psig. } \\
& t_{s}=250^{\circ} \mathrm{F} . \\
& V_{w}=625 \text { Bbls/hour. } \\
& V_{0}=823,000 \text { cu.ft./hour@t, } P_{s} .
\end{aligned}
$$

The gas leaving the separator is, therefore, saturated with water vapor (as steam) at $t_{8}, P_{8}$.

\section{The Calculation of Gas/Water Ratlo for "Wet" Gas}

Gas volume at standard conditions is:

$$
823,000 \times \frac{460+60}{460+250} \times \frac{14.7}{300+14.7}
$$

$823,000 \times 0.7324 \times 0.0467=28,156 \mathrm{SCF}$

Rate of flow $=28,156 \mathrm{SCFH}$

$$
\text { Gas } / \text { Water Ratio }=\frac{28,156}{625}=45.0 \text { SCF/Bbl (wet) }
$$

\section{The Calculation of Gas/Water Ratio for "Dry" Gas}

The partial pressure of water (steam) in the gas is read from any compilation of the properties of water, usually referred to as "Steam Tables." From the table headed "saturation temperatures,". observe that the pressure of water at $250^{\circ} \mathrm{F}$ is $29.8 \mathrm{psia}$. This value is the partial pressure of steam in the separator of Figure 3. The total pressure is 314.7 psia. The percent of the pressure due to water is $29.8 / 314.7=0.0947$, or $9.47 \%$. Since volume percent is equal to pressure percent, it is apparent that $9.47 \%$ of the gas leaving the separator is water. The volume of dry gas leaving the separator is

$(1-0.0947) 28,156=0.9053 \times 28,156=25,490$ SCF

The gas/water ratio is, therefore, $25,490=40.8 \mathrm{SCF} / \mathrm{Bbl}$ (dry). 


\section{APPENDIX B}

\section{CONDENSED ON-SITE PROCEDURES AND CHECKLIST}

1.Collect a raw, untreated sample of the water, filter through a loose plug of glass wool and perform the following determinations: $\mathrm{pH}, \mathrm{T}$, specitic conductance, alkalinity. (including organic acid anions), alkalinity (total $\mathrm{CO}_{2}$ ) $\mathrm{S}^{\mathbf{2}}$

2.Filter a measured portion (about one gallon) of the water through a $0.45 \mu \mathrm{m}$ membrane filter and perform the following determinations: suspended solids, dissolved solids, $\mathrm{Cl}^{-}, \mathrm{SiO}_{2}, \mathrm{~B}, \mathrm{~F}, \mathrm{NH}_{3}$.

Note:Dissolved sollds, $\mathrm{Cl}^{-}, \mathrm{B}$, and $\mathrm{F}^{-}$ineed not be determined on-site. Dilute a separate sample 1:2 and another 1:4 with distilled water if $\mathrm{SiO}_{2}$ is to be determined later and not on-site.

3.Collect a filtered sample using a $0.45 \mathrm{um}$ membrane filter, adjust the $\mathrm{DH}$ to $1.5 \pm 0.5$. with $1: 1 \mathrm{HNO}_{3}$ (Section V-D ). No on-site determinations are made using this solution. Section V-D lists the ions to be determined with $\mathrm{FA}-\mathrm{HNO}_{3}$ solution.

4.Collect a filtered sample using a $0.45 \mu \mathrm{m}$ membrane filter. adjust the pH to $3.0 \pm 0.5$ with $1: 1 \mathrm{HCl}$ (Section V-E ) No on-site determinations are made using this solution. Section V-E: lists the ions to be determined with $\mathrm{FA}-\mathrm{HCl}$ solution.

5.Collect a raw, untreated sample of the water and adjust the $\mathrm{pH}$ to $1.5 \pm 0.5$ with $1: 1 \mathrm{HNO}_{3}$ (Section $\mathrm{V}$ $B$ ). No on-site determinations are made using this solution. Section $V-B$ lists the determinations to be made with RA solution.

6.Collect a gas sample in a $75 \mathrm{cc}$ teflon-lined stainless steel container (Section III-A). Note separator gas pressure and temperature.

7.Collect gas and water samples for recombination-differential liberation studies (Section Iil-C) as needed.

8.Collect bottom-hole samples (Section III-D) as needed. 
FLOW TESTS OF THE GLADYS MCCALL WELL THROUGH OCTOBER 1990

\section{APPENDIX C}

\section{ALPHABETICAL LISTING OF PROCEDURES (WATER)}

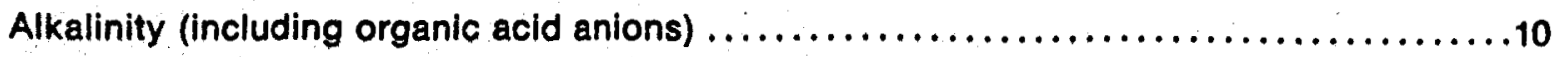

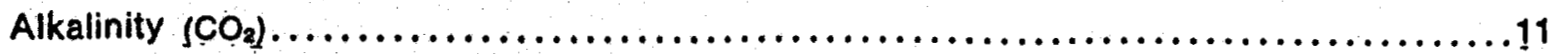

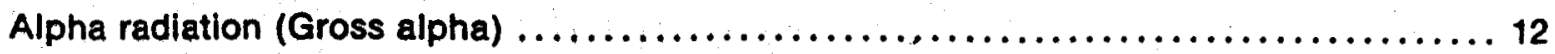

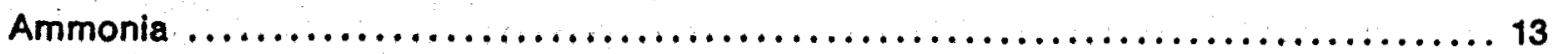

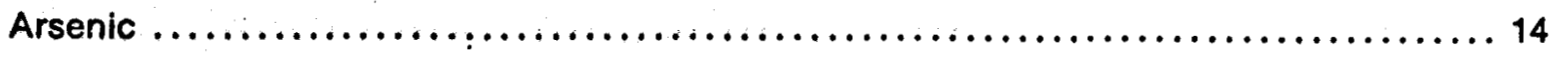

Barium...................................................... 15

Beta radiation (Gross beta) $\ldots \ldots \ldots \ldots \ldots \ldots \ldots \ldots \ldots \ldots \ldots \ldots \ldots \ldots \ldots \ldots \ldots \ldots \ldots \ldots$

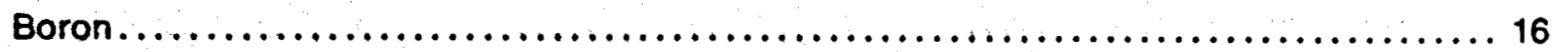

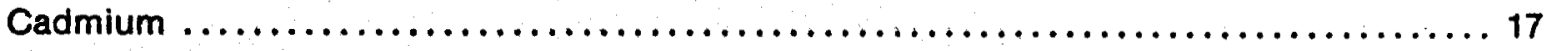

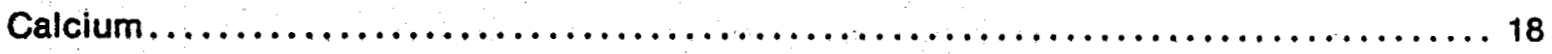

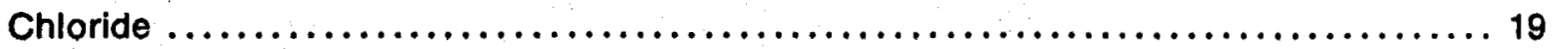

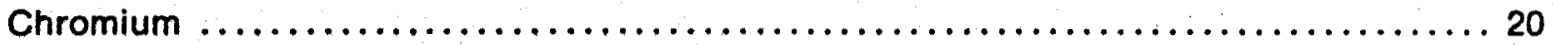

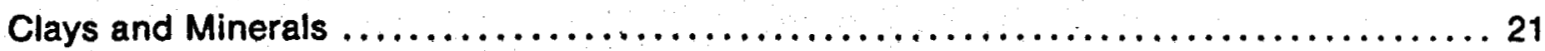

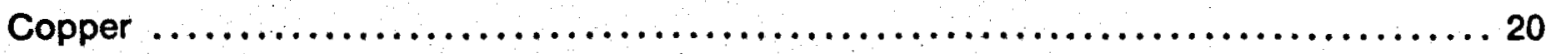

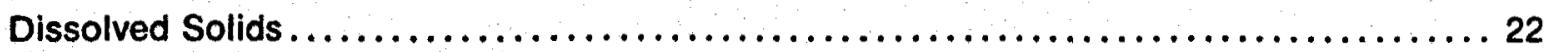

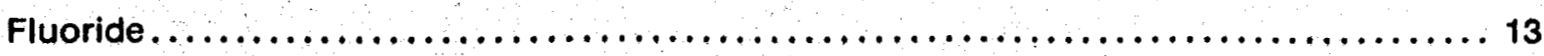

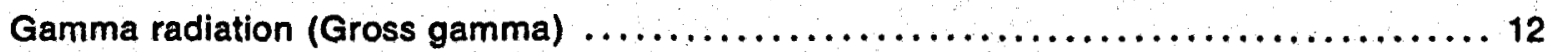

Iron $. . \ldots \ldots \ldots \ldots \ldots \ldots \ldots \ldots \ldots \ldots \ldots \ldots \ldots \ldots \ldots \ldots \ldots \ldots \ldots \ldots \ldots \ldots \ldots, 17$

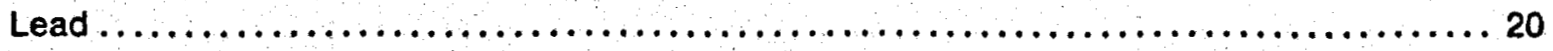

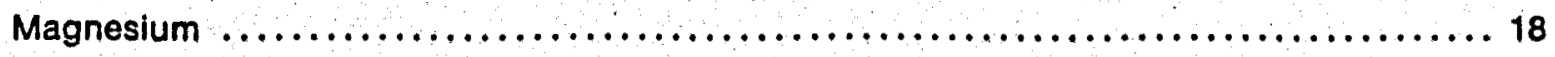

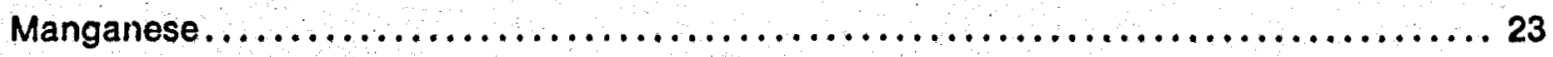

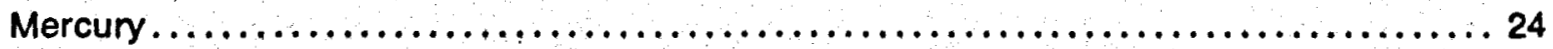


Flow Tests of the Gladys MCCall Well Through october 1990

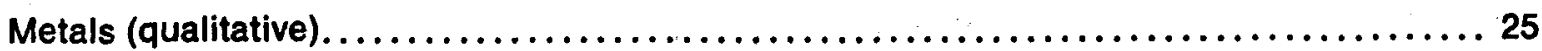

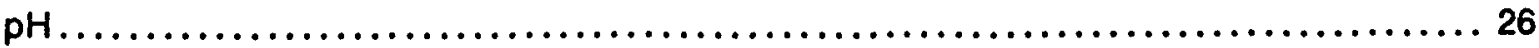

Potassium.......................................................... 27

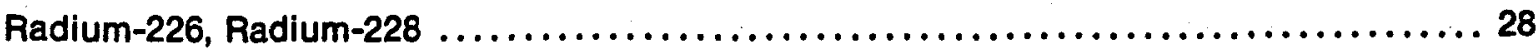

Silica $\ldots \ldots \ldots \ldots \ldots \ldots \ldots \ldots \ldots \ldots \ldots \ldots \ldots \ldots \ldots \ldots \ldots \ldots \ldots \ldots \ldots \ldots \ldots \ldots \ldots \ldots, 29$

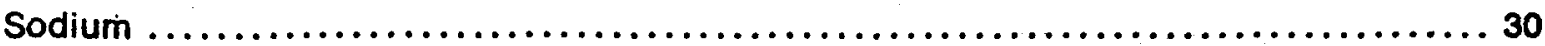

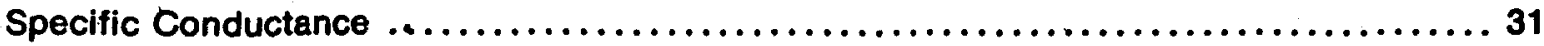

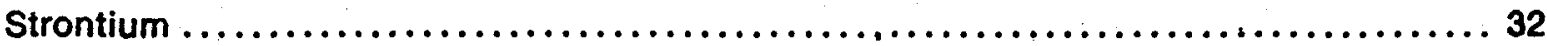

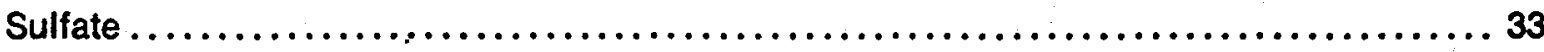

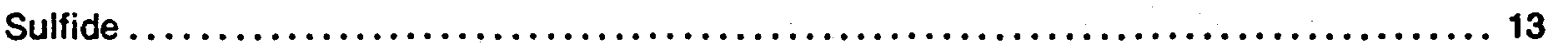

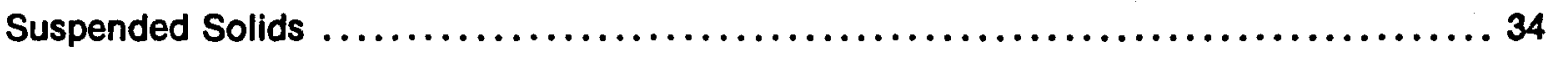

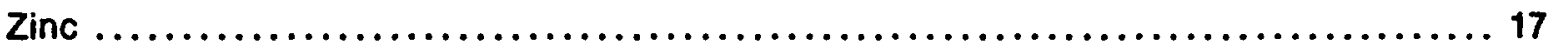


Flow tests of the Gladys MCCall Well Through october 1990

\section{APPENDIX D}

\section{ALPHABETICAL LISTING OF PROCEDURES (GAS)}

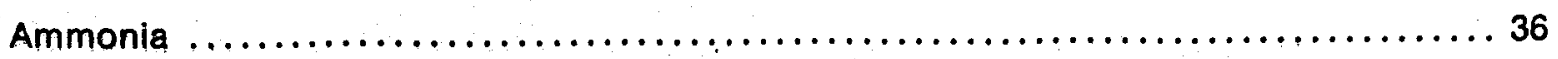

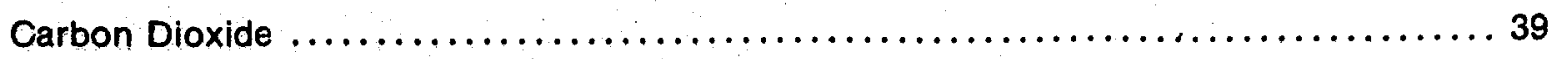

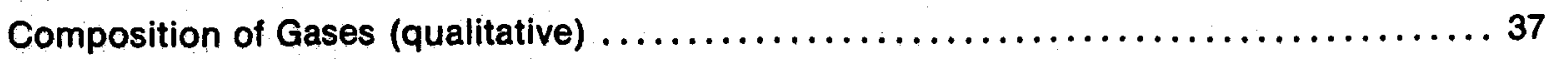

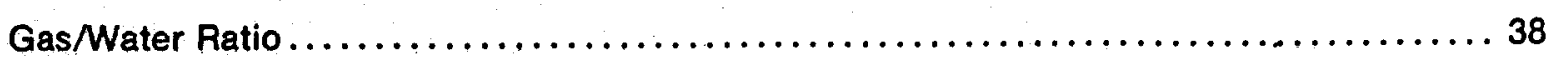

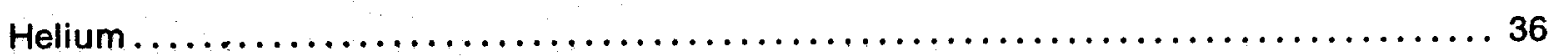

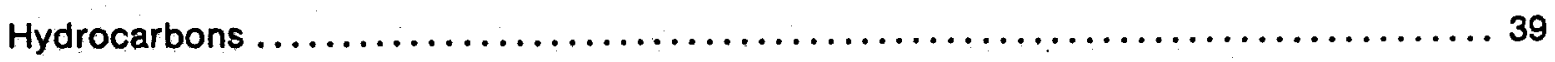

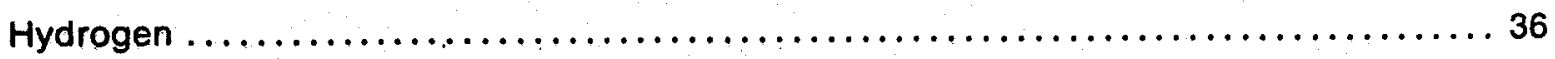

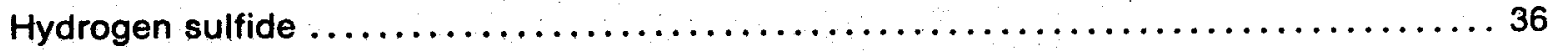

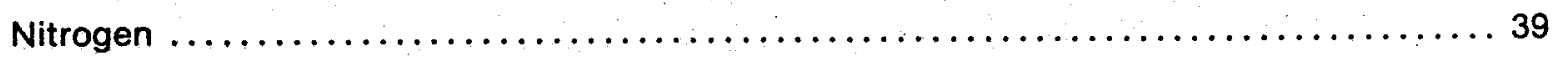

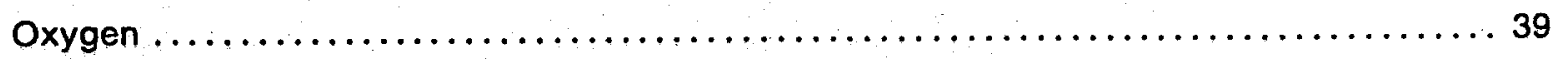

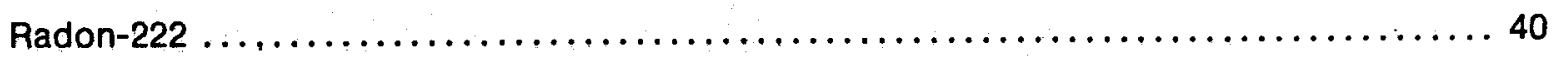


Flow Tests Of The Gladys MCCall Well Through october 1990

\title{
STANDARD SAMPLING AND ANALYTICAL
}

\author{
METHODS
}

FOR

\section{GEOPRESSURED FLUIDS}

\author{
Prepared For \\ DEPARTMENT OF ENERGY \\ by \\ McNeese State University \\ Lake Charles, Louisiana 70609
}

September 1980

B. E. Hankins, Editor

GAS RESEARCH INSTITUTE CONTRACT NO. 5080-321-0301 
avold contaminating the sample with mercury and other metals. Tranofer of the single-phase fluld from the bottom-hole sampler to the high-pressure contalner must be made at pressures no lower than reservoir pressure.

\section{EVALUATION OF GAS/WATER RATIO DATA}

\section{A. FROM BOTTOM-HOLE SAMPLES}

Commerclal bottom-hole sampling devices used to date do not have heaters and the insllu temperature of the fluid within the eampler cannot be maintalned; therefore, the bottom-hole fluid cools as it is brought to the surfece, the pressure decreases, and.a two-phase system forms. Even though the sample is subjected to the correct in-altu pressure and vigorous agitation later, the operator never can be positive that the system has returned to a single phase. It is test, therefore, to determine the gas/water ratio directly on the sample contalned in the bottom-hole device. If the seals of the bottom-hole device hold and if the integrity of the sample is maintained, the gas/water ratio data obtained from zero-flashing the sample directly from the bottom-hole sampler should be rellable.

The problem with gas/water ratio data collected from bottom-hole samples is encountered because bottom-hole samplets are expensive and operators wish to use the same sampler to collect several samples: therefore, the samples usually are transferred to high-pressure containers. If either temperature or pressure falls below reservoir conditlons before the sample is transferred, some of the gas dissolved in the brinewill be exsolved and a two-phase system will exist.

The standard transfer procedure involves pressuring-up the transfer apparatus and the bottom-hole sampler to in-eltu pressure, then agltating the fluids contalned in the bottom-holesampler to refurn them to a single-phase system. However, experience has shown that it is very difficult. if not impossible, to return the system to a single phase. The gas may be redissolved in the brine only after vigorous and prolonged agitation, conditions that are difficult to achieve in the lield. Even then, without a window in the sampler for observing the condition of the fluids, there is uncertainty as to the number of phases present. Furthermore. some operators have transferred the fluids at less than reservoir pressure.

With the hydraulic transfer system currently in use, and for reasons outlined previously, there is some question concerning the complete transler of gas and brine from the bottom-hole sampler to the highpressure container; therefore, the gas/water ratio data from these measurements are suspect. If the temperatureof the bottom-hole fluid could be maintained in the sampler (with a heater), a single-phase system would remain and a properly designed transfer system pressured-up to in-situ conditions would allow all of the sample to be transferred from the sampler to the high-pressure containers. Under these conditions, data obtained from the transferred samples would be as reliable as the data obtained from zeroflashing samples directly from the bottom-hole sampler.

Teflon-lined bottom-hole samplers are not necessary to determine the gas/water ratio reliably: however. the use of the teflon-lined equipment would allow fluids uncontaminated with the sampler metal to be collected and the chemical analysis of the brine would be more meaningful. Likewise, chemical analysis of the bottom-hole fluid would be more meaningful if some fluid other than mercury were used for the confining fluid in the hydraulic pump.

\section{B. FROM SURFACE MEASUREMENTS}

Gas/water ratio data obtained from surface equipment may be skewed high because the surface equipment measures the steam as well as the natural gas from the flashed fluid. Also, any free gas from gas-pockets in the producing zone will be measured along with the gas from the brine and that will increase the gas/water ratio. Calculations can correct for the amount of additional gas measured as steam (see Appendix A), but no correction can be made for the intrusion of free gas into the producing zone unless reliable gas/water ratios have been obtained from bottom-hole samples and recombination-differential liberation studies.

\section{MEASUREMENTS}

\section{FROM RECOMBINATION-DIFFERENTIAL LIBERATION}

The gas/water ratio obtained from recombination-differential liberation measurements is the saturation value of the gas in the brine at reservoir conditions.

\section{MEASUREMENTS}

\section{RELATIONSHIP BETWEEN GAS/WATER RATIO}

The gas/water ratlo obtained from recombination-differential liberation measurements assumes saturation of the brine with natural gas in the producing zone.

The gas/water ratio obtained from a bottom-hole sample whose integrity has been malntained may be less than the saturation velue; this is the best method of measuring the extent to which these geopressuredgeothermal flulds epproach saturation with natural gas.

\section{L-58}


The gas/water ratio obtained from surface measuremeits may be high; 1.e., higher than the saturation value, due to free gas entering the well-bore along with the geopressured brine. If there is no gas cap, and if the brine is not saturated with gas, then the ratio obtained from both surface equipment and bottom-hole samples will be less than that obtained from recombination-differential liberation messurements.

\section{TREATMENT OF WATER SAMPLES}

Note: Water from geopressured-geothermal wells often contains crude petroleum which interferes with various analytical procedures. Most of this oll may be removed by allowing the water sample to flow through a loose plug of glass wool during the collection process.

\section{A. RAW, UNTREATED (RU)}

Collect a water sample In a prevlously cleaned bottle and stopper the bottle tightly. Label the bottle "RU." The following determinations are to be made on RU water: $\mathrm{pH}, T$, specific conductance, suspended solids, alkalinity, and $\mathrm{S}^{*}$.

\section{B. RAW, ACIDIFIED (RA)}

Collect a water sample in a previously cleaned bottle and add enough 1:1 $\mathrm{HNO}_{3}$ to make the $\mathrm{pH}$ of the solution $1.5 \pm 0.5$ as measured with $\mathrm{pH}$ paper or a $\mathrm{pH}$ meter. Mix the contents thoroughly. stopper the bottle tightly, and label the bottle "RA." The following determinations are to be made on RA samples: Ra-226, gross $\alpha$, gross $\beta$, and gross $\gamma$.

\section{FILTERED, UNTREATED (FU)}

Collect a sample of water that has been filtered through a $0.45-\mathrm{m}$ membrane filter. Stopper the container tightly and label it "FU." The following determinations should be made on FU samples: dissolved solids (on-site), $\mathrm{Cl}^{-}$, (on-site), $\mathrm{SiO}_{2}, \mathrm{~B}, \mathrm{~F}^{-}$, and $\mathrm{NH}_{3}$.

\section{FILTERED ACIDIFIED (FA- $\mathrm{HNO}_{3}$ )}

Collect a measured amount of water as specified in Section $\mathrm{V}-\mathrm{C}$ and add 1:1 $\mathrm{HNO}_{3}$ with a calibrated pipet until the $\mathrm{pH}$ is $\sim 1.5$ (pH meter). Discard the solution. Collect an additional sample of water as specified in Section V-C. Using the information obtained from the pH adjustment of the discarded solution, add an appropriate amount of 1:1 $\mathrm{HNO}_{3}$ to the new sample to produce a pH of 1.5. mix the contents thoroughly, and label "FA-HNO." Test a portion of the acidified solution to confirm that the pH of the new sample is $1.5 \pm 0.5$, then discard the portion tested. Stopper the container tightly. Make a notation of the amount of acid used in the $\mathrm{pH}$ adjustment. The following determinations are to be made on FA-HNO, samples: $\mathrm{Cu}, \mathrm{As}, \mathrm{Cr}, \mathrm{Pb}, \mathrm{Cl}^{-}$(not on-site). $\mathrm{Mn}, \mathrm{Fe}, \mathrm{Cd}, \mathrm{Hg}$, and $\mathrm{Zn}$.

\section{E. FILTERED, ACIDIFIED (FA-HCI)}

Collect a measured amount of water as specified in Section $\mathrm{V}-\mathrm{C}$ and add $1: 1 \mathrm{HCl}$ with a calibrated pipet until the $\mathrm{pH}=3.0$ ( $\mathrm{pH}$ meter). Discard the solution. Collect an additional sample of water as specified in Section $\mathrm{V}-\mathrm{C}$. Using the information obtained from the pH adjustment of the discarded solution. add an appropriate volume of $1: 1 \mathrm{HCl}$ to the new sample to adjust the pH to $3.0, \mathrm{mlx}$ the contents thoroughly, and label "FA-HCl." Test a portion of the acidified solution to confirm that the pH of the analytical sample is $3.0 \pm 0.5$, then discard the portion tested. Stopper the container tightly. Make notation of the amount of acid used in the $\mathrm{pH}$ adjustment. The following determinations are to be made on FA-HCl samples: Ba, Sr. Na, K, Ca, Mg, and So,:

\section{SPECIAL REAGENTS}

All $\mathrm{HCl}_{1} \mathrm{HNO}_{3}, \mathrm{H}_{2} \mathrm{SO}_{4}$ and $\mathrm{NH}_{4} \mathrm{OH}$ used must be ultra-pure. Ultrex reagents have been found to be suitable as have the ultra-pure reagents from G.F. Smith Chemlcal Company, but equivalent grades are available from most commercial chemlcall suppliers. Other reagents used for the various determinations should be "analytical" grade.

\section{PREPARATION OF GLASSWARE}

The glassware used in procedures for determining trace elements must be cleaned scrupulously. Follow the procedure outlined In Section VIII-B, but adjust the amounts proportionately.

\section{CONTAINER PREPARATION}

\section{A. STAINLESS STEEL CYLINDERS (TEFLON-LINED)}

Check the cylinders to see that no grease or loose solid material is present. Remova any 
grease by rinsing with an organic solvent such as petroleum ether. Be sure to remove the last traces of the organic solvent; passing dry nitrogen through the container usually will remove all of the solvent from the cylinder.

Install valves on the cyllinder with tellon tape. Pressure-test each cylinder by filling It with nitrogen to 300 psig and immersing the cylinder in a water bath for $1 / 2$ hour.

\section{B. PLASTIC CONTAINERS}

Rinse with two $250-\mathrm{mL}$ portions of $6 \mathrm{M} \mathrm{HCl}$. Remove the $\mathrm{HCl}$ by rinsing with $300-\mathrm{mL}$ portions of deionized water until the rinse water gives no test with $\mathrm{AgNO}_{3}$, then rinse with a final $300-\mathrm{mL}$ portion of deionized water. The fourth rinse usually is free of chloride when cleaning five-gallon plastic containers and the third rinse usually is free of chloride when cleaning one-gallon containers.

\section{SAMPLING FREQUENCY}

Sampling frequency depends upon how long the well flows. Consult the following table to determine how often samples should be collected.

$\begin{array}{lll}\text { Flow Time } & \text { Samplling Tlme } & \text { No. of Samples } \\ 1 \text { week } & \text { Day } 1,3.5 & 3 \\ 2 \text { weeks } & \text { Day } 12 & 1 \text { (total of } 4) \\ 3 \text { weeks } & \text { Day } 19 & 1 \text { (total of } 5) \\ 4 \text { weeks } & \text { Day } 26 & 1 \text { (total of } 6) \\ >4 \text { weeks } & \text { Sample once each month } & \text { (1 per month) }\end{array}$

\section{SAMPLES TO BE ANALYZED}

\section{A. WATER SAMPLES}

The following determinations should be made on each water sample collected according to the above schedule: $\mathrm{pH}$. T, specific conductance, dissolved solids, suspended solids, $\mathrm{Na}, \mathrm{K}, \mathrm{Ca}, \mathrm{Mg}, \mathrm{Sr}$, alkalinity (including organic acid anions), alkalinity $\left(\mathrm{CO}_{2}\right), \mathrm{Cl}^{*}, \mathrm{~F}^{-}, \mathrm{SiO}_{2}, \mathrm{Fe}, \mathrm{S}^{\prime \prime}, \mathrm{Cd}, \mathrm{Zn}$, and $\mathrm{NH}_{3}$.

The following determinations should be made on the water samples collected on day 1, day 12, day 26. and on every third water sample collected monthly after day 26 ; i.e., quarterly: $\mathrm{Ba}, \mathrm{SO},=\mathrm{Mn}, \mathrm{B}, \mathrm{Hg}, \mathrm{As}, \mathrm{Cr}$. $\mathrm{Cu}, \mathrm{Pb}, \mathrm{Ra}-226$, gross $\alpha$, gross $\beta$. gross $\gamma$, identification of metals in dissolved solids by emission spectrography. These determinations should be repeated on the first and second samples collected monthly after day $\mathbf{2 6}$ if the quarterly determinations show trends.

\section{B. GAS SAMPLES}

The following determinations should be made on the gas samples collected on day 1 . day 12, day 26 and on every third gas sample collected monthly after day 26; i.e., quarterly: standard hydrocarbon analysis $\left(\mathrm{C}_{1}-\mathrm{C}_{6}\right.$ and $\left.\mathrm{C}_{6+}\right), \mathrm{H} \mathrm{S}$. He, Rn-222, $\mathrm{CO}_{2}, \mathrm{~N}_{2}, \mathrm{NH}_{3}, \mathrm{O}_{2}, \mathrm{H}_{2}$. . These determinations should be repeated on the first and second samples collected monthly after day 26 if the quarterly determinations show trends.

The identification of gases other than those listed above should be made on one sample only using mass spectrometry. Gases from $Z=1$ to $Z \cong 400$ should be sought. The one sample chosen for this determination should be obtained from the middle of the test period.

The amount of natural gas dissolved in the brine (gas/water ratio) should be determined on at least one set of gas and water samples from the separator and from bottom-hole samples when available.

\section{SUSPENDED SOLIDS}

The clays and minerals in the suspended solids collected on days $1,3,5$, and 12 should be determined by $x$-ray diffractometry (or equivalent method). Save the remaining suspended solids samples for the Identification of clays and minerals if that becomes necessary.

\section{DETERMINATIONS THAT REQUIRE SPECIAL EQUIPMENT}

\section{A. DETERMINATIONS IN WATER SAMPLES}

Special equipment is needed to determine Ra-226, gross $\alpha$, gross $\beta$, gross $\gamma$.metals in dissolved solids by emission spectrography and clays and minerals in suspended solids by $x$-ray diffraction. Many university laboratories have the equipment necessary to make these determinations $(3,4)$. 
Some oll service testing companies that perform core analyses have $x$-ray diffraction equipment and the expertise to identlfy clays and minerals.

Procedures for determining $\mathrm{Ba}, \mathrm{Mn}, \mathrm{As}, \mathrm{Cu}, \mathrm{Cr}, \mathrm{Pb}$, and $\mathrm{Hg}$ use neutron activation analysis as an analytical tool; thus, a neutron'generator or a nuclear reactor is required to perform these determinations by neutron activation analysis. Again, some university laboratories have this equipment $(3,4)$. Alternate procedures for these metals are listed, however, using atomic absorption spectrometry.

\section{B. DETERMINATIONS IN GAS SAMPLES}

Special equipment is needed to determine Rn-222 and to identify the components of a gas from $Z=1$ to $Z \simeq 400$ by mass spectrometry as explained in Section $X I-A$.

\section{SCALE AND CORROSION INHIBITORS}

Records must be kept for any chemical added to the system to inhibit corrosion or scaling. Information stiould include the following:

Type and chemical description; molecular weight range and charge density (for polymers); cost; reasons for choice; alternatives; dosage level; point of addition to the system, reasons for this cholce, and alternatives; time of addition; dosage versus time curves; method of monitoring the dosage; effectiveness of the chemical; description of the problem; and quantitative information on changes in scaling or corrosion characteristics and locations. In addition, method of obtaining inhibitor-free water samples should be provided. 
FLow TESTS OF THE GLAdys MCCALL Well Through OCtober 1990

\section{APPENDIX M}

Sand 8 Brine Analyses by Rice University

M-1 

This appendix presents the results of analyses performed on produced brine. The brine contained about $100,000 \mathrm{mg} / \mathrm{L}$ of dissolved solids. The composition of the produced brine was typical of oil field brines and contained primarily sodium chloride. The data suggest the brine was getting fresher with time, although that conclusion is tenuous.

There were ten brine analyses performed, with the majority performed by SCAI before 1986. Average analyses are provided in Exhibit M-1. The SCAI data in Exhibit M-1 is the average brine composition for seven samples analyzed by SCAI between 1983 and 1985. Also included are the results of a December 17, 1985, sample analyzed by IGT, a September 4, 1986, sample collected by IGT and analyzed at the University of Texas Bureau of Economic Geology, and an average of four June 5,1987, samples analyzed by Rice University. Finally, the last column is an average of the four values presented on this page, with no weighting factors such as the number of samples analyzed or the number of duplicate analyses performed on a sample. The individual analyses are presented in Exhibit M-2.

There was also an overall decline in calcium, chloride, and sodium over the life of this test. These three elements constitute $98 \%$ of the total dissolved solids present in the brine, so the data suggest the brine was getting less saline as the test proceeded. This change my be interpretted as evidence of shale de-watering or possible communication with a fresher zone. To determine whether this change is statistically significant is difficult, given the small number of brine analyses performed, the number of laboratories involved, and possible differences in sample collection and handling. Some values, such as a $38,400 \mathrm{mg} / \mathrm{L}$ sodium reported by SCAI for the August 7, 1984, sample, are believed to be erroneous simply because they are far outside the range of other analyses. Low barium concentrations reported by SCAI for samples collected from 1984 to February 1985 are also believed to be erroneous. Samples from that period that were archived were analyzed by Rice University in 1987 and were found to have close to $500 \mathrm{mg} / \mathrm{L}$ barium, rather than the 50 to $100 \mathrm{mg} / \mathrm{L}$ reported. Nevertheless, most errors are in the range of a few percent, and the average composition is a fair indication of the composition of the produced brine.

It is clear from the data that the SCAI samples were more saline than the samples collected by IGT and Rice. This is equivalent to stating that the samples analyzed during the first half of the flow test were more saline than samples analyzed during the second half of the flow test. IGT and Rice cool the brine prior to exposing the brine to atmospheric pressure. If the brine is not cooled prior to releasing pressure during sample collection, the water flashing off the $290^{\circ} \mathrm{F}$ brine will concentrate the remaining salts by about $6 \%$. Whether the observed salinity change is a function of sampling procedures or of the produced brine becoming less saline is not known. 


\section{Exhibit M-1. AVERAGE BRINE COMPOSITION}

\begin{tabular}{|c|c|c|c|c|c|}
\hline & $\begin{array}{c}\text { SCAIb } \\
11 / 83-5 / 85 \\
\end{array}$ & $\begin{array}{c}\text { IGT } \\
17 / 12 / 85 \\
\end{array}$ & $\begin{array}{l}\text { BEG } \\
2 / 9 / 86 \\
\end{array}$ & $\begin{array}{c}\text { Rice } \\
5 / 6 / 87 \\
\end{array}$ & Average $^{c}$ \\
\hline Alkalinity (HCO3) & 285 & 488 & 306 & 477 & 389 \\
\hline Ammonia & 118 & 72 & - & . - & 95 \\
\hline Arsenic & 0.007 & - & $<2.5$ & - & 0.007 \\
\hline Barium & 185 & 576 & 536 & 468 & 441 \\
\hline Boron & 40 & - & 33 & 39 & 37 \\
\hline Bromide & - & & - & - & 25 \\
\hline Cadmium & 0.02 & 0.11 & $<0.5$ & 0.12 & 0.1 \\
\hline Calcium & 3,872 & 3,900 & 3,760 & 3,574 & 3,777 \\
\hline Chloride & 57,100 & 55,200 & 55,770 & 55,000 & 55,768 \\
\hline Chromium & 0.04 & 0.06 & $<0.5$ & 0.03 & 0.04 \\
\hline Copper & 0.03 & 0.14 & $<0.5$ & 0.02 & 0.06 \\
\hline Dissolved Solids & 94,000 & 96,500 & - & - & 95,250 \\
\hline Fluoride & 0.22 & - & 0.5 & - & 0.4 \\
\hline Iodide & - & 44 & - & - & 44 \\
\hline Iron & 31 & 27 & 28 & 31 & 29 \\
\hline Lead & 0.07 & $<0.2$ & - & $<1$ & 0.07 \\
\hline Lithium & - & 25 & 25 & 29 & 26 \\
\hline Magnesium & 329 & 280 & 300 & 256 & 291 \\
\hline Manganese & 2.1 & 1.9 & 2.0 & 2.1 & 2.0 \\
\hline Mercury & $<0.001$ & $<0.005$ & - & - & $<0.05$ \\
\hline $\mathrm{pH}$ (pH units) & 6.6 & 6.8 & - & - & 6.7 \\
\hline Potassium & 757 & 788 & 862 & 749 & 789 \\
\hline Silica $\left(\mathrm{SiO}_{2}\right)$ & 125 & 149 & 101 & 151 & 132 \\
\hline Sodium & 31,700 & 34,000 & 31,930 & 29,560 & 31,798 \\
\hline Strontium & 448 & 324 & 336 & 381 & 372 \\
\hline Sulfate & 1.7 & $<2$ & $<10$ & - & $<2$ \\
\hline Zinc & 0.28 & 0.11 & $<0.5$ & 0.16 & 0.2 \\
\hline $\begin{array}{l}\text { Spec. Grav. } \\
\text { Conductivity }\end{array}$ & 1.064 & - & - & - & 1.07 \\
\hline$\mu \mathrm{mho} / \mathrm{cm}$ & 111,200 & - & - & - & 111,200 \\
\hline
\end{tabular}

a All results in $\mathrm{mg} / \mathrm{L}$ unless otherwise specified.

b SCAI data are mean value of seven analyses. Chloride value for August 7, 1984, sample was deleted from the data set.

c Average is mean of the analyses presented in this table. No weighting factors were used to account for the fact the SCAI data are an average of seven samples collected between November 1983 and May 1985. The Rice data was an average of four samples collected on June 5, 1987.

There was an extensive study of the brine chemistry performed by Cuddihee et al. of Rice University in 1987. This included the analysis presented in Exhibit M-1 plus numerous other analyses. Roughly sixty samples were analyzed for $\mathrm{pH}$, alkalinity, hardness, iron, silica, chloride, and some trace metals. Most of the samples analyzed were collected between April 1986 and June 
and some trace metals. Most of the samples analyzed were collected between April 1986 and June 1986, although some archived samples were also analyzed. Cuddihee found a relationship between brine rates and iron concentration and also noted the decrease in chloride over an 18-month period that suggested the brine was getting fresher. He also noted a fluctuation in chloride concentration that had a range of about $3000 \mathrm{mg} / \mathrm{L}$ ( $5 \%$ of the total) with a periodicity of 30 to 60 days. The report is included herewith. 


\section{Exhibit M-2. GLADYS McCALL SAND 8 BRINE ANALYSES}

\section{Analysis for \\ Units}

Alkalinity ( $\mathrm{HCO} 3)$

Alpha (gross)

Ammonia

Arsenic

Barium

Beta(gross)

Boron

Cadmium

Calcium

Chloride

Chromium

Conductivity

Copper

Dissolved Solids

Fluoride

Gamma(gross)

Harness (CaCO3)$$
\begin{aligned}
& \text { lodide } \\
& \text { Iron }
\end{aligned}
$$

Lithium

Magnesium

Manganese

Mercury

$\mathrm{pH}$

Potassium

Radium

Radon(gas)

Silica(SiO2)

Sodium

Specific Gravity

Strontium

Sulfate

Sulfide

Zinc

Laboratory

$\mathrm{mg} / \mathrm{l}$

$\mathrm{pCi} / \mathrm{l}$

$\mathrm{mg} / \mathrm{l}$

$\mathrm{mg} / \mathrm{I}$

$\mathrm{mg} / \mathrm{l}$

pCi/I

$\mathrm{mg} / \mathrm{l}$

$\mathrm{mg} / \mathrm{l}$

$\mathrm{mg} / 1$

$m g / l$

$\mathrm{mg} / \mathrm{l}$

$\mathrm{mg} / \mathrm{l}$

$\mathrm{mg} / \mathrm{l}$

$\mathrm{mg} / \mathrm{l}$

pCi/I

$\mathrm{mg} / \mathrm{l}$

$\mathrm{mg} / \mathrm{I}$

$\mathrm{mg} / \mathrm{l}$

$\mathrm{mg} / \mathrm{l}$

$\mathrm{mg} / \mathrm{l}$

$\mathrm{mg} / \mathrm{l}$

$\mathrm{mg} / \mathrm{l}$

$\mathrm{mg} / \mathrm{I}$

$\mathrm{mg} / 1$

pCi/l

$\mathrm{pCi} / \mathrm{l}$

$\mathrm{mg} / \mathrm{l}$

$\mathrm{mg} / 1$

$g / m l$

$m g / l$

$m g / l$

$\mathrm{mg} / \mathrm{l}$

$\mathrm{mg} / \mathrm{l}$ $\mu \mathrm{mho} / \mathrm{cm}$

SCAI SCAI SCA

Scientific Consulting and Analysis, Inc.

IGT = Institute of Gas Technology

$M S L=$ Mineral Studies Laboratory, University of Texas, Bureau of Economic Geology

RICE = Rice University

$\begin{array}{lll}\text { NA } & 232 & 288 \\ 40 & 1570 & 72 \\ \text { NA } & 280 & 135 \\ 0.013 & 0.004 & <0.005 \\ 420 & 60 & 80\end{array}$

$\begin{array}{lllll}420 & 60 & 80 & 44 & 125\end{array}$

38.5

40.8

$$
0.005
$$

345

40.6

0.020

3830

3643

57750

$56300 \quad 55200$

$<0.02$

0.11

111800

$<0.02$

117800
0.035

$0.020 \quad 0.020$

91700

0.17

$\begin{array}{ll}93600 & 91700 \\ 150 & 0.16\end{array}$

150

NA

NA

NA

290

NA

$14.0 \quad 18.6$

$<0.05<0.05$

NA NA

$354 \quad 318$

$2.1 \quad 1.4$

$0.001<0.001$

$730 \quad 7.2$

$17 \quad 33$

NA. $\quad 49.3$

$100 \quad 127$

$29750 \quad 30200$

1.06391 .0637

540

473

NA

23.6

$<0.05$

NA

370

1.6

$<0.001$

8.9

72

26

129

NA

NA

230

NA

$<0.05$

NA

$348 \quad 300$

1.7

300

$<0.001$

3.1

$6.18 \quad 6.34$

825

41

20

130

807

807
45

30

128

1.0626

$\begin{array}{ll}1.0610 & 1.0632\end{array}$

440

$$
427
$$

$<1$

$<0.5$

2.0

$0.24<0.5$

0.21

SCA

SCAI

Nov 83 07 Feb $84 \quad 07$ Aug $84 \quad 12$ Oct 84 01 Dec 8428 Feb 85 01 May 85 17 Dec 85 04 Sep 86 06 May 87

337

56

60

$<0.005$

95

470
40.3

0.015

3730

56600

0.040

107200

0.035

93500
0.20

180

NA

NA

25.6

$<0.05$

NA

305

2.4

$<0.001$

6.56

810

47

33

128

31700
1.0666

400

1.1

$<0.5$

0.28

SCAI

SCAI

0.030

0.035

91600
0.19

250

NA

26.5

0.08

NA

2.1

6.30

817

53
36

132

32550

1.0627

433

3.3

$<0.5$

0.37

281
35
81
0.015
470
510
40.4
0.015
3690
56100

110000

$<0.001$

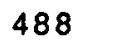

306 .

$\begin{array}{ll}N A & N A \\ 72 & N A\end{array}$

NA NA

$576 \quad 522$

$\mathrm{NA} \quad \mathrm{NA}$

$\mathrm{NA}<0.2$

0.11

3900

0.06

NA

0.14

96500

NA

NA

11200

44

26.6

$<0.20$

24.8

280

1.9

$<0.005$

6.8
788

NA

NA

149

34000

N

324

$<2.0$

N.11

IGT

T

MSL

3680

$55770 \quad 55000$

$\mathrm{NA} \mathrm{NA}$

NA $\quad 0.02$

$93000 \quad N$

NA NA

NA NA

NA NA

$N A \quad N A$

31.0

$<1$

$23.7 \quad 29.0$

256

$1.9 \quad 2.1$

NA NA

$858 \quad N 4$

NA NA

$133 \quad 151$

$31200 \quad 29560$ 
Flow TESTS OF the Gladys MCCALL Well Through OCtOBER 1990

\title{
MITIGATION OF ADVERSE BRINE CHEMISTRY ASSOCIATED WITH GEOPRESSURED ENERGY PRODUCTION
}

by
J. Cuddihee
M. H. Salimi
E. H. Street
M. B. Tomson

FINAL REPORT

to

Institute of Gas Technology

\begin{abstract}
Department of Environmental Science and Engineering Rice University

Houston, Texas 77251
\end{abstract}

October, 1987

M-7 
Flow tests of the Gladys McCall Well through OCtober 1990

TABLE OF CONTENTS*

Section

ABSTRACT. . . . . . . . . . . . . . . . . . . . . . 1

BACKGROUND AND SUMMARY OF RESULTS . . . . . . . . . . . . . . . . I I

SAMPLING AND ANALYTICAL PRECISION . . . . . . . . . . . . . . . . II

BULK PARAMETER ANALYSES . . . . . . . . . . . . . . . . . . . . . . III

ICP RESULTS . . . . . . . . . . . . . . . . . . . . . . . IV

DATA COMPARISONS: Concentration vs. Time, Flow, ect. . . . . . . . . v

ChLORIDE RESULTS. . . . . . . . . . . . . . . . . . . . . . . vi

SCALE ANALYSES. . . . . . . . . . . . . . . . . . . . . . . . viI

S.P.E. PAPER SURMARY OF WELL AND OVERALL APPROACH . . . . . . . . . . . . VIII

*Tables, Figures, and Appendices are at the end of each section.

M-8
I N S S T I T
O F
G A S
T E C H N O L O G Y 


\section{ABSTRACT}

Geopressured reservoirs in the Gulf Coast area are potential sources of vast quantities of energy in the form of thermal and mechanical energy and dissolved natural gas. As the brine is produced from these reservoirs the pressure reduces. This drop in pressure causes scale formation. In addition, the hot brines are often quite corrosive due to dissolved carbon dioxide.

In order to understand the brine chemistry of these produced fluids and to mitigate the adverse effects of scale and corrosion it was proposed to measure the concentration of brine components as a function of time and flow rate. About sixty different samples were measured for common bulk parameters and for trace metals. Bulk parameters such as $\mathrm{pH}$, alakalinity, hardness, total dissolved solids, silicon, and iron were measured by conventional "wet" methods in the laboratory. Trace elements were measured by inductively coupled plesma arc (ICP) spectroscopy. The ICP results required two runs on each sample, one run for the higher concentration elements and one run for the element present at lower concentrations. Considerable attention was given to sample collection methods and to documenting reproducibility of each measurement procedure; this greatly facilitated intersample comparisons and trend detection.

Samples dating from March, 1983 to July, 1987, were analyzed, with emphases on samples collected during 1987. Most elements showed no statistically significant change in concentration during the study period, when appropriate corrections were made for sampling methods. The concentration of chloride seemed to decrease about $4 \%$ from 1985 to 1987 with a secondary periodicity of about sixty days, although these effects are just in the range of the overall confidence of the experiments and collection procedures. Iron exhibited the most striking change with flow rate. The concentration of iron was inversely related to flow rate to the 0.30 -power with a correlation coefficient of 0.94. This strongly suggests that the steel pipe is slowly corroding at a constant rate and that as the flow increases the concentration decreases. The concentration of phosphonate remained constant at $0.15 \mathrm{mg} / 1$ during the study period. Finally, some scale did form in the surface equipment during the drawdown tests. This scale analyzed to be conventional "oil field" calcite containing about five mole percent iron. 


\section{BACKGROUND AND SUMMARY OF RESULTS}

Vast quantities of recoverable natural gas may exist in deep geopresured formations along the Gulf Coast area. Initial results suggest that the produced brines are probably saturated with methane, natural gas, and carbon dioxide. These brines also contain large quantities of inorganic materials such as calcium, chloride, sodium, and bicarbonate. As the brines are produced, the pressure decreases. As the pressure drops, carbon dioxide and methane escape from solution into the gas phase. The release of carbon dioxide causes the $\mathrm{pH}$ to increase which increases the amount of ionic carbonate $\left(\mathrm{CO}_{3}^{2-}\right)$ in water. The increased concentration of ionic carbonate causes calcium carbonate (calcite) scale to form. Also, pressure and temperature affect the equilibrium constants of the calcite system; a drop in temperature reduces the calcite scale formation tendency and a drop in pressure increases the scale formation tendency. Generally, scale formation is controlled by the use of threshold inhibitors which interact with groffing nuclei to prevent the formation of stable scale crystals. Threshold scale inhibitors include, phosphonates, polyacrylate and polymaleate.

Corrosion is generally expected to be a problem in produced hot brine with substantial carbon dioxide. Less is known about corrosion formation and control than about scalc. More needs to be known about corrosion formation and the relationship of scale formation to corrosion control.

The overall objective of this project has been to perform analytical chemistry tests to better understand the constituative nature of produced geopressured fluids from the DOE Gladys McCall well. Several bulk parameters were analyzed by conventional laboratory procedures, whereas, the 
concentrations of motals and trace elements were determined by the newer procedures of inductively coupled plasma arc (ICP) spectroscopy. Considerable attention was given to sampling procedures and to analytical procedure statistics.

To summarize, the following conclusions have been reached relative to the composition of Gladys McCall brine. Some tests were performed on samples dating back to 31 March 1983.

1. Most elements showed no statistical change in concentration.

2. The concentration of chloride $\left(\mathrm{Cl}^{-}\right)$appears to have decreased about $4 \%$ from 1985 to present. In addition, the chloride data shows a 30 to 60 day periodicity. The periodicity swing is about five times larger than the experimental precision.

3. The concentration of iron is inversely related to the flow rate:

$$
\text { Fe } \propto \frac{1}{\text { Flow } 0.301}
$$

This is about what would be expected if corrosion were occurring at a mass transport controlled rate, as is probably the case.

4. When appropriate controls and standards are run, there appears to be 1ittle systematic variation between the concentration results obtained using conventional laboratory "wet" methods and the newer ICP methods. Note: "wet" methods measure Ca+Sr+Ba+Hg as "hardness" and Ca+Sr+Ba as "calcium."

5. No change in phosphonate concentration $(\sim 0.15 \mathrm{mg} / 1)$ in the produced brine was detected during the study period. 
Flow TESTS OF the Gladys MCCall Well Through OCtober 1990

6. There is a significant concentration of strontium, $\operatorname{Sr}(\sim 390 \mathrm{mg} / 1)$ and barium Ba $(\sim 460 \mathrm{mg} / 1)$ in the produced brine. Neither element showed any significant variation during the study period.

7. Occasional scale which formed in the surface equipment during the study period had the average composition:

$$
\mathrm{Ca}_{0.92}{ }^{\mathrm{Fe}}{ }_{0.05^{\mathrm{Kg}}}{ }_{0.02} \mathrm{Sr}_{0.007^{\mathrm{Ba}}}{ }_{0.002}^{\mathrm{CO}_{3}}
$$

This is a conventional oil or gas well calcite material. 


\section{BRINE SAMPLING AND ANALYTICAL PRECISION}

On June 5, 1987 four consecutive one liter brine samples were collected under $\mathrm{CO}_{2}$ for the purposes of messuring the reproducibility of the sampling procedure. Wellhead samples $\# 1$ - \#4 were collected from approximately 1:45 p.m to $2: 15 \mathrm{p} . \mathrm{m}$. by the usual procedure of slowly circulating the brine through a coil of stainless steel tubing imersed in an ice bath and bubbling $100 \% \mathrm{CO}_{2}$ through the sample as the sample bottle filled.

One large bag of ice was used in collecting all four samples. The collection temperature of the first sample varied from an initial $20^{\circ} \mathrm{C}$ to a final temperature of $30^{\circ} \mathrm{C}$. The temperature of the second sample was not measured but the final temperature of the third sample was a tepid $48^{\circ} \mathrm{C}$. The temperature of the fourth sample was not measured but was assumed to be greater than $48^{\circ} \mathrm{C}$. There was no ice remaining in the immersion bath at the conclusion of sampling. Samples $1-3$ were collected in glass bottles while sample 4 was collected in the usual narrow-necked nalgene bottle.

The results of the wet chemical analyses are included in Table II-1. Table II-2 includes the results of the ICP analyses. The tables also include the results of the $6 / 5 / 87$ sample collected by well site personnel (E.0.C.) earlier in the day. This sample was also collected in a $\mathrm{CO}_{2}$ atmosphere while circualting through an ice bath. The reproducibility results are summarized graphica1ly in Figures 1a-f.

For "wet" chemical methods the overall precisions vary from $0.4 \%$ for hardness to $5.5 \%$ for iron. There is no detectable difference between glass or nalgene collection bottles or between EOC and Rice University staff. In the following paragraphs "wet" chemical methods are compared with ICP analyses. 
Comparison of ICP vs, Wet Method

June 5, 1987 Samples

Iron - In general there is excellent agreement between the Hach colorimetric method and the ICP method. Both methods measured the average of all $6 / 5$ samples to be equal to $31.4 \mathrm{mg} / 1$. It was observed that complete color development occasionally would take as long as 10 to 15 minutes. This could account for an occasional low value measured by the wet method.

Silicon - In general the colorimetric Hack method is about $15 \%$ lower than the ICP analyses. This could be due to suppressed color development in the Hach method due to "molybdate - unreactive" forms of silica in the brines. However, careful calibration of the sodium metasilicate ICP standard by the technique of known addition is also suggested to assure that emission is truly linear over the range concentrations between the standard and the samples.

Calcium - The Hach method utilizes an EDTA titration method at $13 \mathrm{pH}$ to prevent interference from magnesium. However, barium and strontium are titrated along with calcium. In order to compare the two methods, the equivalent weights as calcium of barium and strontium determined by the ICP must be added to the ICP calcium measurements .

M-14 
Flow Tests of the Gladys MCCall Well Through OCtober 1990

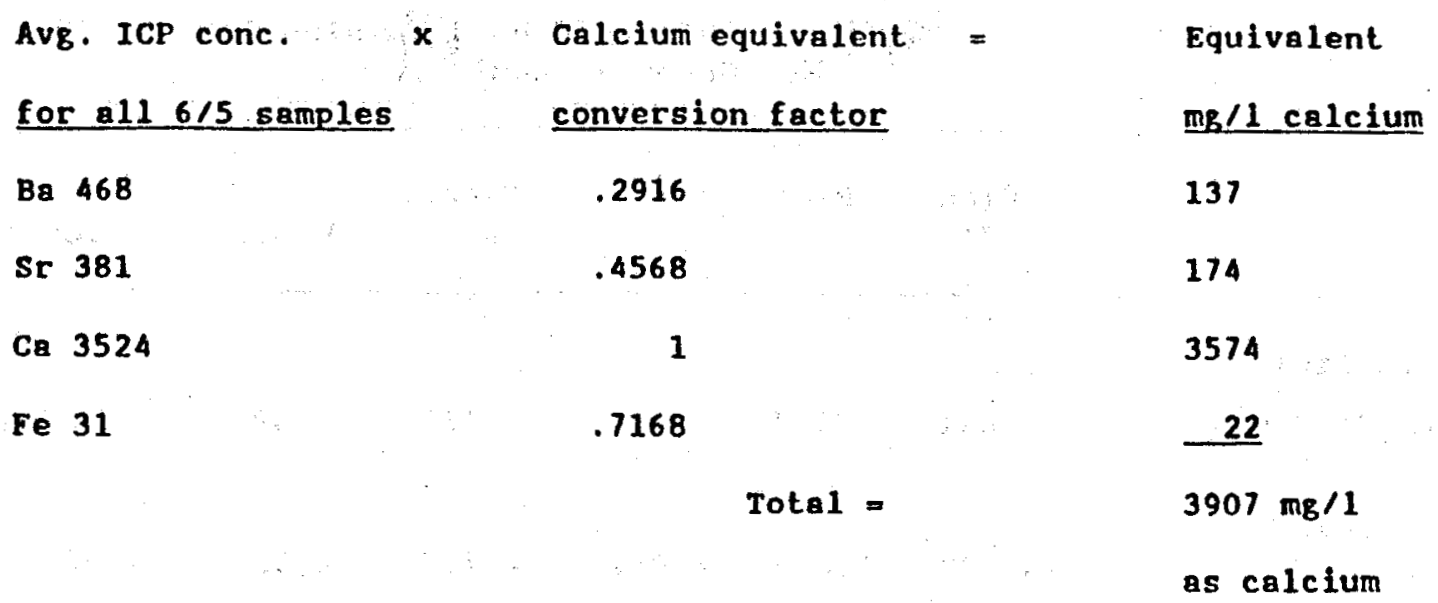

The wet method measured $4064 \mathrm{mg} / 1$ as calcium which is $3.8 \%$ higher than

the $3907 \mathrm{mg} / \mathrm{l}$ value calculated from ICP analyses.

Hardness - The hardness titration is performed at $10 \mathrm{pH}$ to enable all divalent cations (including magnesium) to be measured. The calcium equivalent of the magnesium concentration is calculated as above:
Avg. ICP conc.
for all $6 / 5$ samples
Calcium equivalent conversion factor
Equivalent ms/1 calcium
Hg 256
$\mathbf{x}$
1.648
$422 \mathrm{mg} / 1$
os calcium

The wet method measured total hardness equal to $4510 \mathrm{mg} / 1$ as calcium which is $4.0 \%$ higher than the calculated ICP value of 4329 . 
Flow TESTS OF the Gladys MCCall Well Through OCtober 1990

Table II-1. Gladys McCall Well Head Samples June 5, 1987 Wet Chemical Analysis

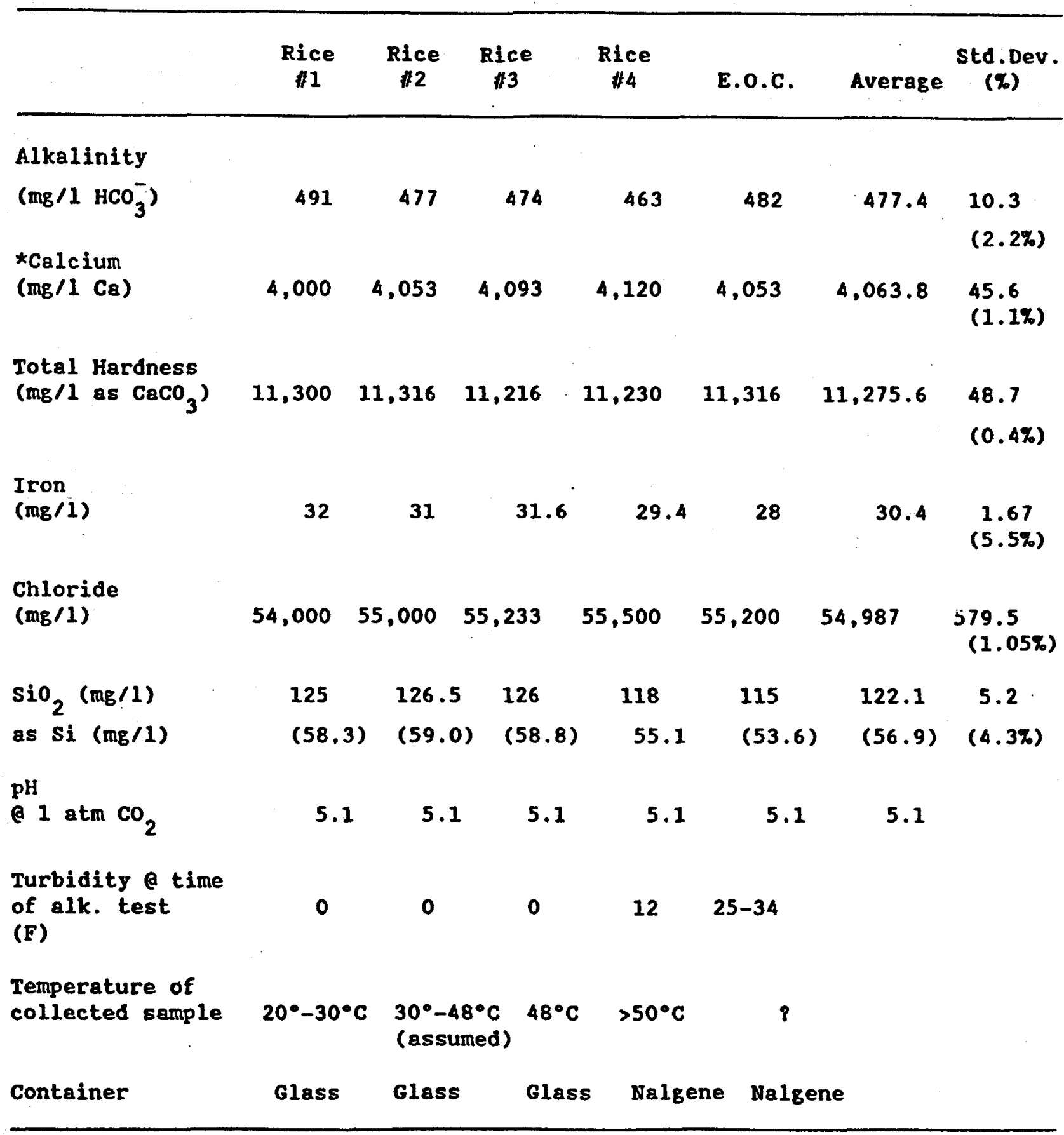

*Reported calcium values include barium and strontium since these elements titrate as a calcium in the EDTA titration method.

M-16

INST ITU TE OF GAS TECHNOL O G Y 
Flow tests of the Gladys MCCall Well Through OCtober 1990

Table II-2. Gladys McCall Well Head Samples June 5, 1987 ICP Analysis (mg/1)

\begin{tabular}{|c|c|c|c|c|c|c|c|c|}
\hline & $\begin{array}{c}\text { Rice } \\
\# 1\end{array}$ & $\begin{array}{c}\text { Rice } \\
\# 2\end{array}$ & $\begin{array}{c}\text { Rice } \\
\# 3\end{array}$ & $\underset{\mathbb{R}}{\text { Rice }}$ & E.O.C. & Avg. & $\begin{array}{l}\text { std.Dev. } \\
\mathrm{mg} / 1\end{array}$ & $\stackrel{\%}{R S D}$ \\
\hline Iron & 32.0 & 31.2 & 31.1 & 31.8 & 31.1 & 31.44 & .43 & $1 \%$ \\
\hline Boron & 39.2 & 37.7 & 38.2 & 39.4 & 39.6 & 38.82 & .83 & $2.1 \%$ \\
\hline silicon & 71 & 80 & 72 & 73 & 57 & 70.6 & 8.38 & $11.8 \%$ \\
\hline Magnesium & 257 & 251 & 251 & 258 & 263 & 256 & 5.09 & $1.99 \%$ \\
\hline strontium & 381 & 377 & 380 & 376 & 391 & 381 & 5.96 & $1.56 \%$ \\
\hline Calcium & 3571 & 3479 & 3535 & 3584 & 3701 & 3574 & 81.83 & $2.29 \%$ \\
\hline Barium & 467 & 460 & 458 & 470 & 487 & 468.4 & 11.50 & $2.46 \%$ \\
\hline Sodium & 29835 & 28915 & 28961 & 29615 & 30459 & 29557 & 644.5 & $2.18 \%$ \\
\hline Lithium & 32.9 & 28.8 & 26.2 & 28.6 & 27.9 & 28.88 & 2.47 & $8.55 \%$ \\
\hline Potassium & 935 & 705 & 775 & 663 . & 669 & 749.4 & 112.9 & $15.1 \%$ \\
\hline Chromium & ND & ND & WD & 0.03 & 0.03 & 0.03 & $-0-$ & $-0-$ \\
\hline Manganese & 2.06 & 2.20 & 2.01 & 2.04 & 1.94 & 2.05 & 0.09 & $4.65 \%$ \\
\hline Cadmiun & 0.11 & 0.15 & 0.11 & 0.10 & 0.14 & 0.122 & 0.02 & $17.7 \%$ \\
\hline Copper & 0.02 & 0.01 & 0.02 & 0.02 & 0.01 & 0.016 & 0.0055 & $34 \%$ \\
\hline Lead & ND & WD & ND & IND & ND & $-0-$ & $-0-$ & $-0-$ \\
\hline Zinc & 0.22 & 0.13 & 0.16 & 0.13 & 0.14 & 0.156 & 0.0378 & $24 \%$ \\
\hline
\end{tabular}

M-17 
Flow tests of the Gladys MCCall Well Through OCtober 1990

Figure II-1.a-f. Graphical comparison of sampling procedures and ICP vs. wet analyses.

M-18 
FLOW TESTS OF THE Gladys MCCALl Well Through OCTOBER 1990

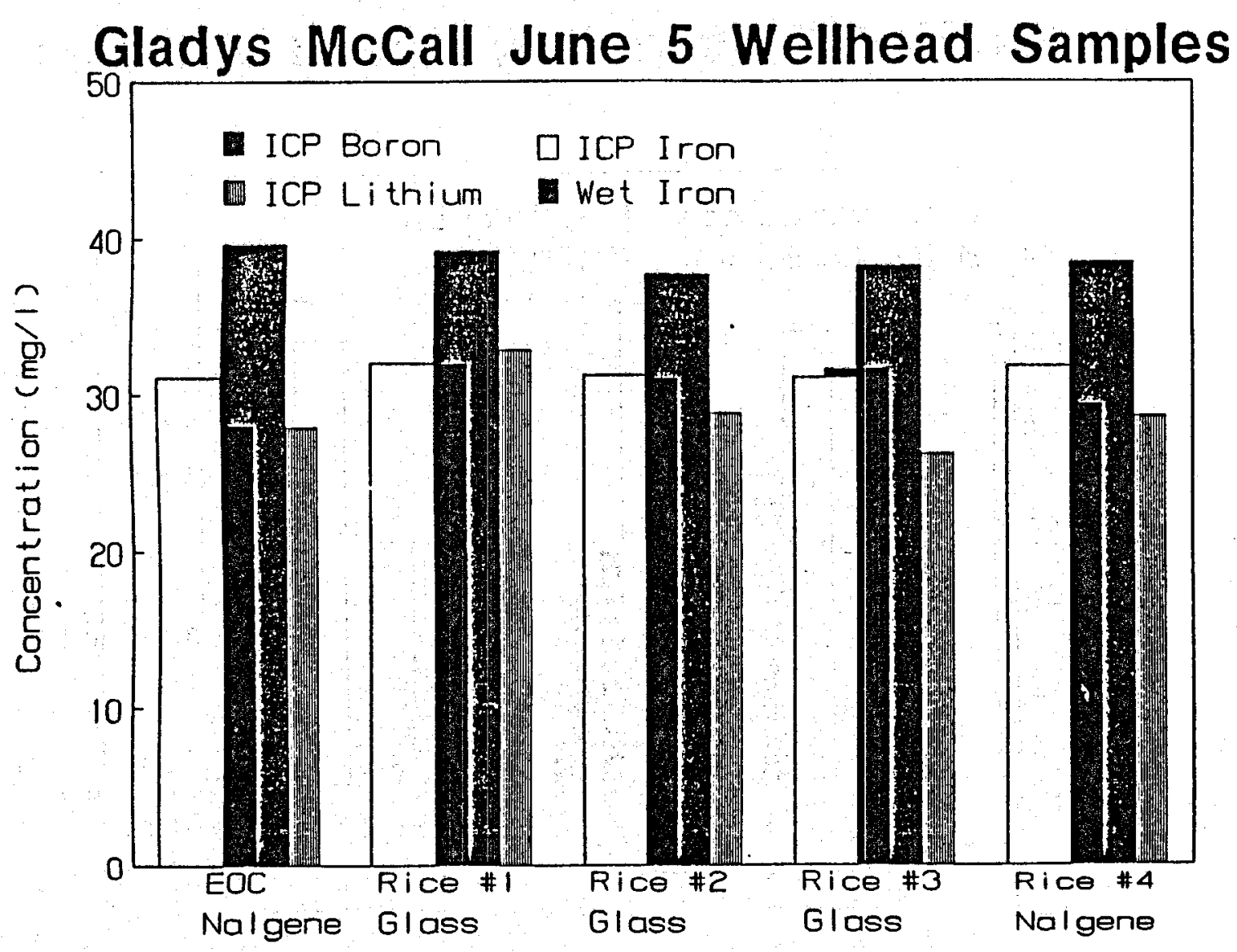

Figure II-1a. 
Gladys McCall June 5 Wellhead Samples

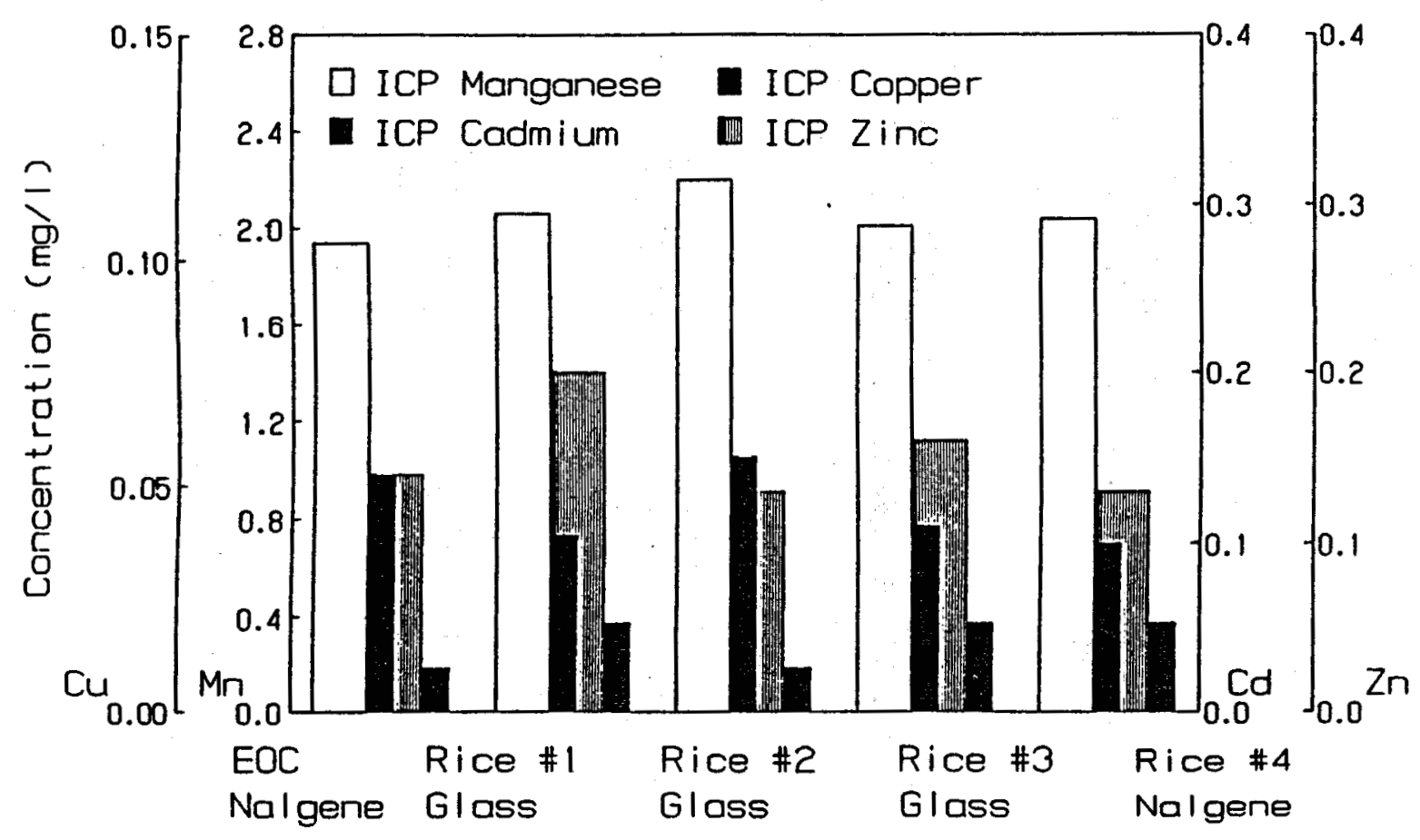

Figure II-Ib. 
FLOW TESTS OF THE GLAdys MCCALl Well Through OCTOBER 1990

\section{Gladys McCall June 5 Wellhead Samples}

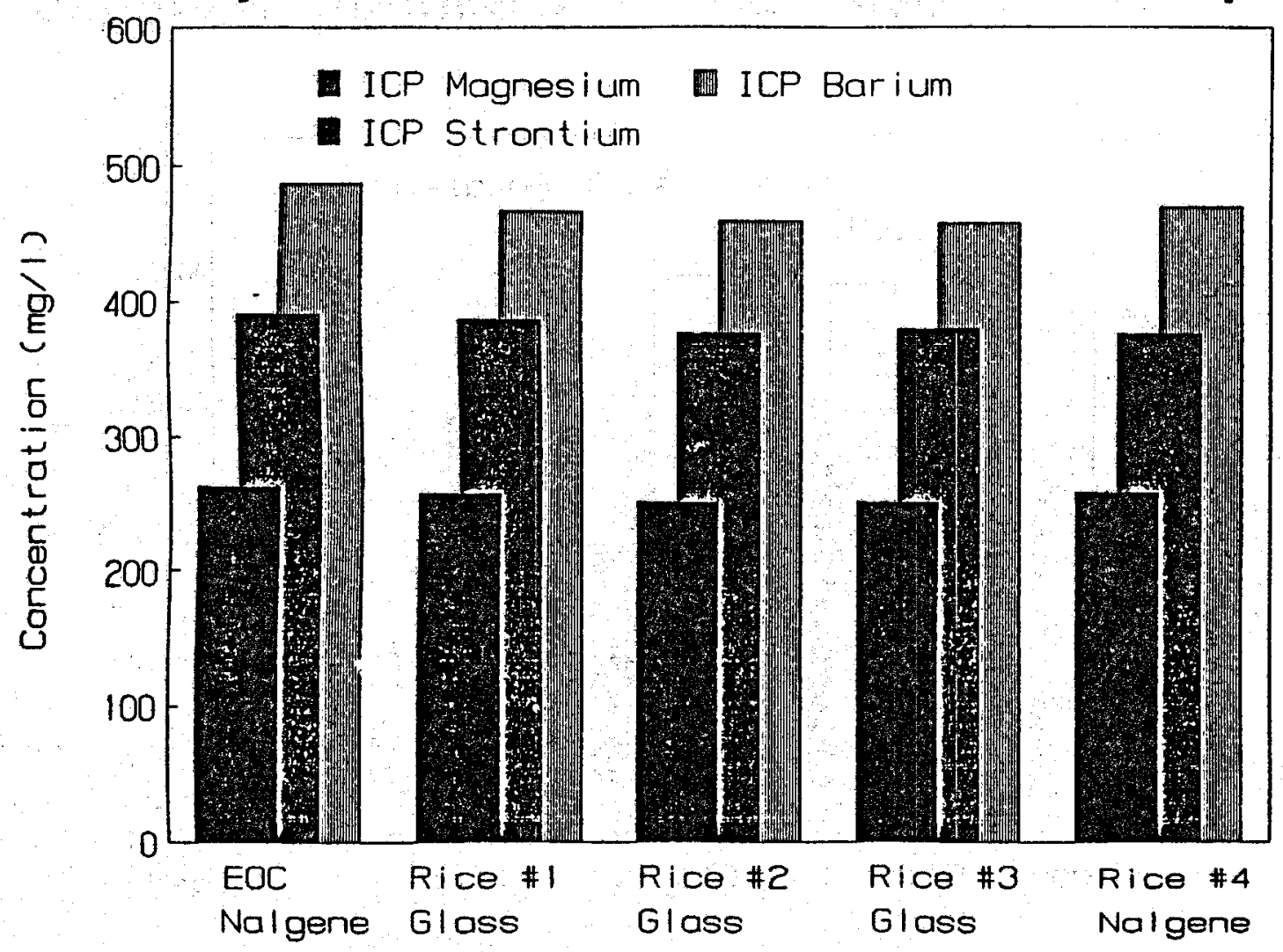

Figure II-1c. 
Flow Tests of the Gladys MCCALl Well Through OCtober 1990

\section{Gladys McCall June 5 Wellhead Samples}

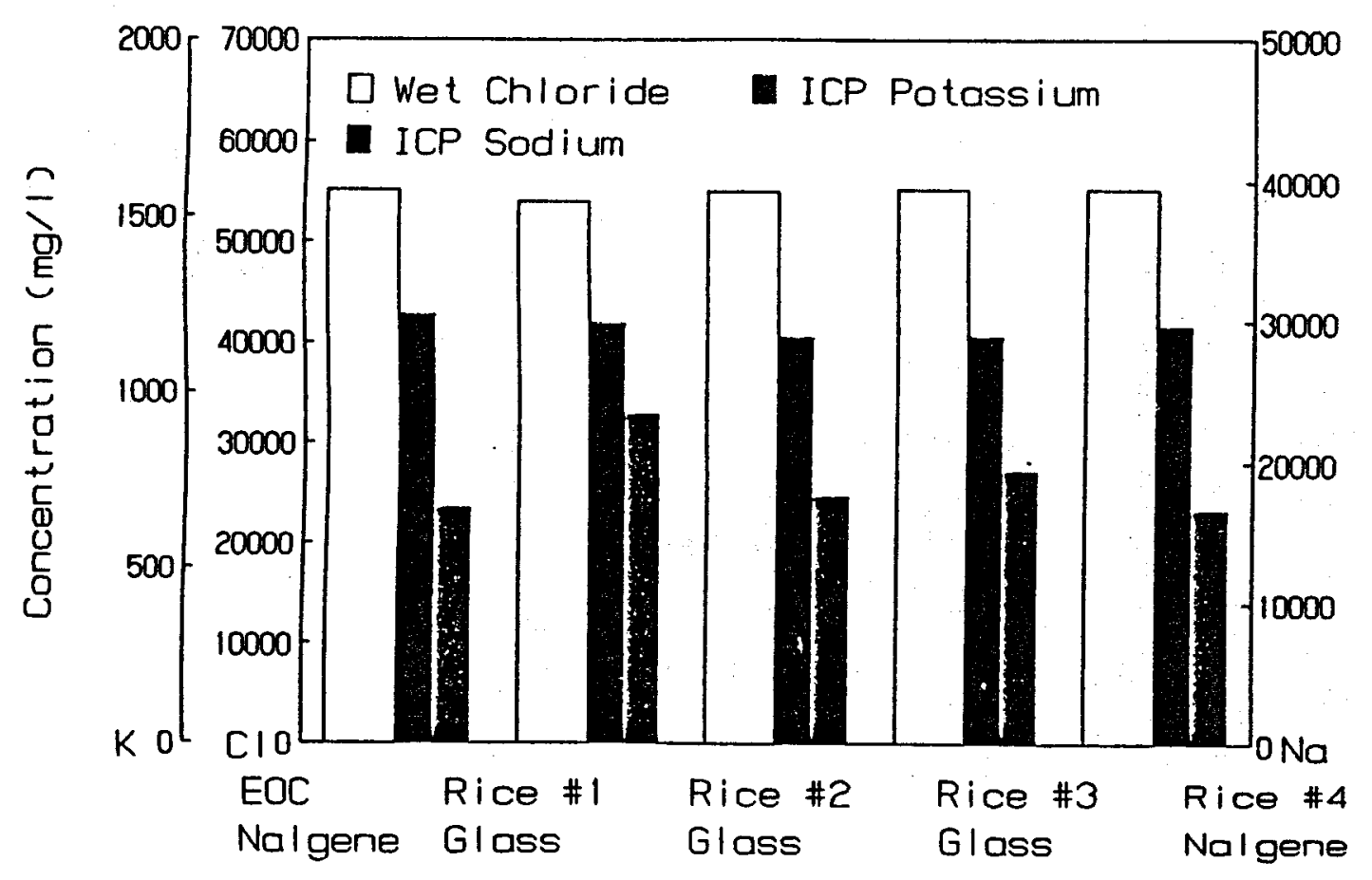

F1gure II-1d. 
Flow Tests of the Gladys MCCall Well Through OCtober 1990

\section{Gladys McCall June 5 Wellhead Samples}

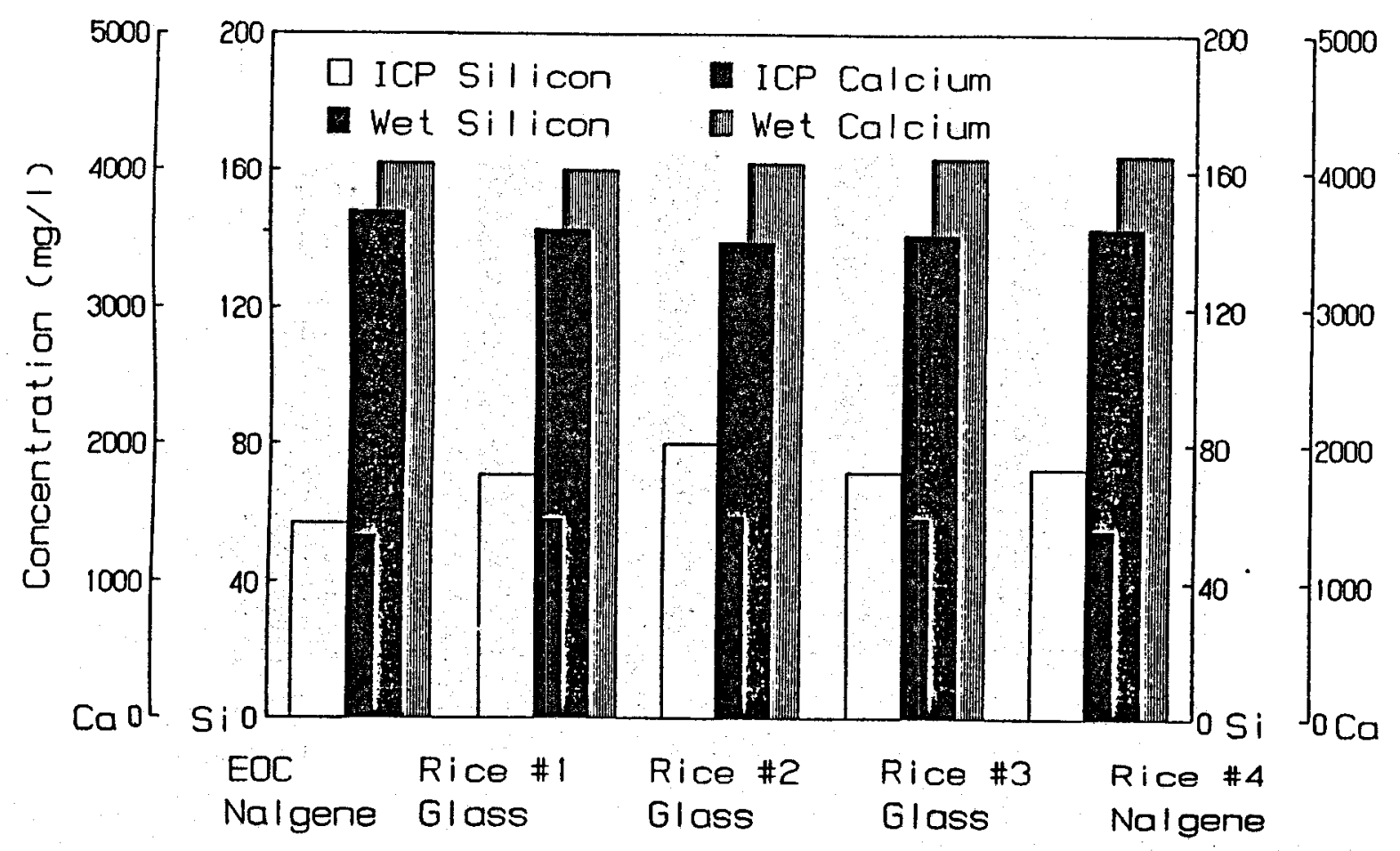

Figure II-le. 
Flow Tests of the Gladys MCCall Well Through OCtober 1990

\section{Gladys McCall June 5 Wellhead Samples}

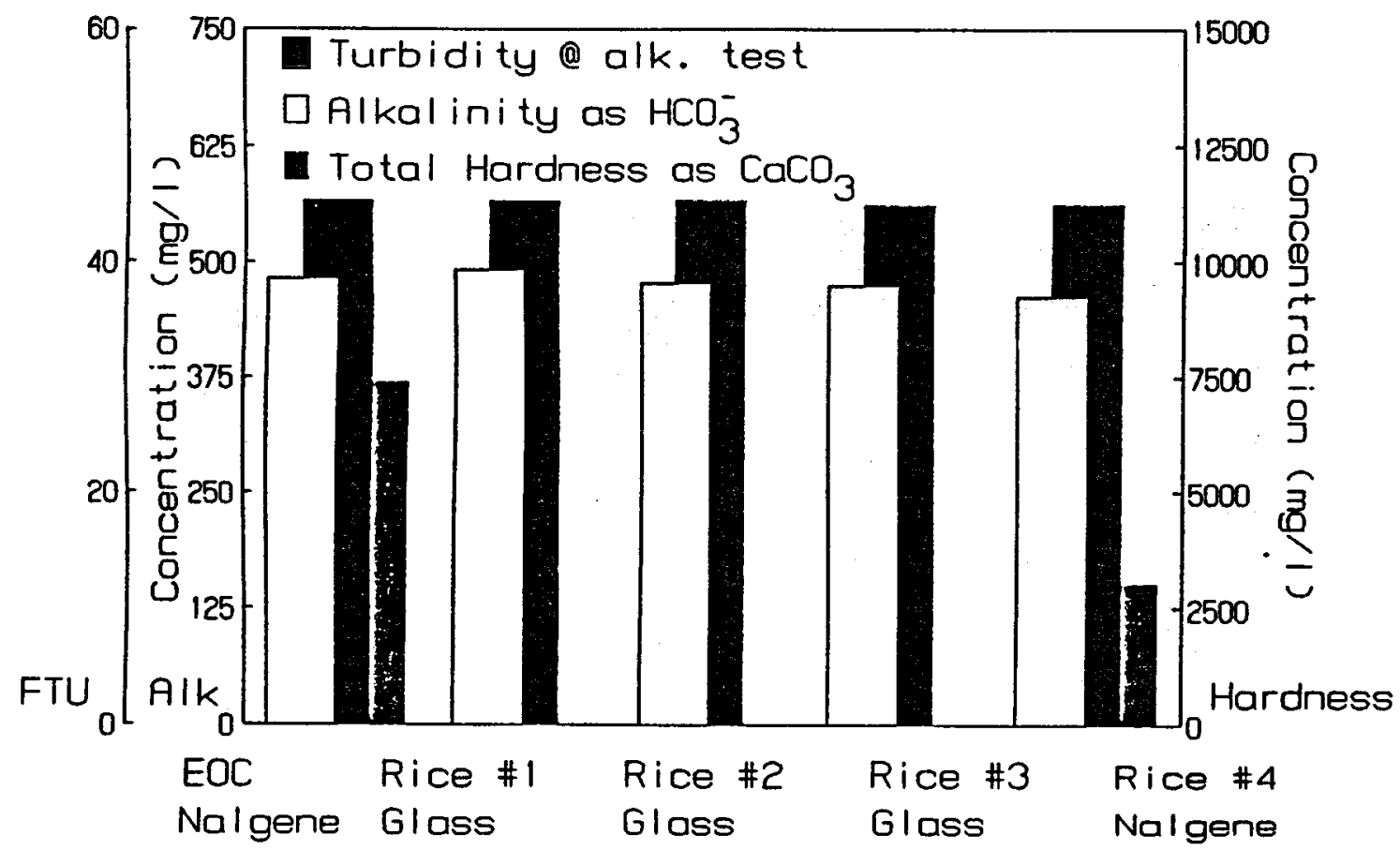

Figure II-1f. 


\section{BULK PARAMETER ANALYSES}

Sumnary

The results of wet chemical analyses on Gladys McCall brine samples from April 13 through May 11 are presented in Tables III-1 and III-2. There does not appear to be a significant discernable change in the major element composition of the brine over the time period studied. However, the alkalinity does exhibit statistically significant changes in certain samples. The observed decrease in alkalinity $(15 \mathrm{mg} / 1)$ following the April 13/14 flow test may be interpreted in terms of calcium carbonate scale formation. The weight of scale expected ( 88 lbs.) from the measured decreased in alkalinity is reasonably consistent with the reported occurrence in the field. (It should also be noted that the associated decrease in $\mathrm{Ca}^{2+}$ for this amount of scale would be too small to be detected given the precision of our calcium analysis). The observed location of scale downstream of the choke is also expected from the saturation index equation (Appendix III-1).

However, examination of the data over the entire 4 week period creates a more complicated picture. In the 3 weeks following the initial flow test, flow conditions were not conducive for scaling at the well head, yet two well head samples had appreciably lower alkalinities than had previously been measured ( $400 \mathrm{mg} / 1$ ). Also, the variation in alkallnity between daily samples during periods of stabilized flow exceeded the variation previously discussed for the April 13/14 flow test. Therefore, the possibility that the variation in measured alkalinity is not related to scale formation in the well or surface equipment should be considered. One possibility is that the variation is related to the sample collection process. Another possibility is that the alkalinity of the produced formation brine is actually variable due to complex

INSTITUTE O T T G G S T C H N O L O G Y


geochemical or reservoir processes not yet understood. Otherwise, if one adopts the notion that all significantly large changes in alkalinity are the result of $\mathrm{CaCO}_{3}$ scaling, then the data presented here would imply that the scaling process may be episodic.

$4 / 13 / 87$ to $4 / 14 / 87$ Flow Test

The 4/13/87 12:50 p.m. pre-test samples were taken while the well was producing at an approximate rate of 23,000 barrels per day. Well head pressure was approximately 1140 psia* and the low-pressure separator was at approximately $400 \mathrm{psi}$. Immediately after sampling at 1:20 p.m. the temperature of the brine was $284^{\circ} \mathrm{F}$ (with an ambient temperature of $77^{\circ} \mathrm{F}$ ) and the calculated bottom hole pressure was 8590 psia.

At noon on $4 / 14 / 87$ the choke was opened to reduce well head pressure. By 12:30 p.m. the well head pressure had decreased to $710 \mathrm{psi}$ and the first and second stage separators were at 502 and $432 \mathrm{psi}$, respectively. The brine production rate was about 27,000 barrels per day. The well flowed for four hours at these conditions until post-test samples were taken from 4:30-5:00 p.m. when the well head, low-pressure separator and disposal well were at epproximately 709,435 and $345 \mathrm{psi}$, respectively. Prior to the 4:30 p.m. brine sampling, no evidence of scale was detected by wellsite personnel on visual examination of coupons in the surface equipment at approximately 3 p.m. In addition, there was no discernable change in the differential pressure across the disposal well filters. A change in pressure would be expected if calcite nuclei suspended in the brine were large enough to be trapped by the filters.

*Production rates, pressures, and temperatures were taken from J.L.C.'s field notes and do not represent "of $\mathrm{ficial}$ " conditions. 
The well continued to flow for approximately one day until it was shut-in to repair the surface equipment. While the well was shut-in, a visual examination of the choke showed that scale was indeed present at the choke and immediately downstream of the choke. Scale formation downstream of the choke was expected considering the decrease in pressure. of $643 \mathrm{psi}$ across the choke during the flaring operation. At 2:04 p.m. on 4/13/87 a wellhead pressure of $1150 \mathrm{psi}$ was recorded and a first stage separator pressure of $507 \mathrm{psi}$ (The original first stage separator pressure was approximately 950 psi prior to flaring al:15 p.m.).

The change in the saturation index due to pressure effects from bottomhole to wellhead before the test was $\Delta S I=1.427$. Following the choke adjustment, $\Delta S I$ increased to 1.644 (Appendix). Previous experience with the Gladys McCa11 \#1 well showed that scale formed when $\triangle$ SI exceeded 1.30 (GRI Annual Report, 1985 p. 3-9). Therefore, in the absence of inhibitors, downhole scale formation would be expected.

\section{Brine Chemistry}

Analyses of subsequent samples are sumarized in Table III-2. These data are also displayed in figures III-1a-1, III-a,b, for the purpose of comparing the changes that were measured in the following four weeks. This discussion will focus on those species related to calcium carbonate scale formation.

The alkalinity was determind by potentiometric titration and reported as mg/l bicarbonate ion ( $\mathrm{HCO}_{3}^{-}$). Calcium was measured by the Hach method involving an EDTA titration at a pH of 13 to remove magnesium interference. Preliminary ICP ans lysis of the Gladys HCCall brine messured the barium and strontium concentretion at approximately 500 and $400 \mathrm{mg} / 1$ respectively, indicating that calcium is by far the major divalent cation. 
Calcium carbonate scale formation can be thought of as an equal number of calcium cations and bicarbonate anions combining to produce the same number of insoluble calcium carbonate species and hydrogen ions:

$$
\mathrm{Ca}^{2+}+\mathrm{HCO}_{3}^{-} \longrightarrow \mathrm{CaCO}_{3(\mathrm{~s})}+\mathrm{H}^{+}
$$

Since the scaling reaction occurs on a molecule for molecule basis, the relative weight loss of $\mathrm{Ca}^{2+}$ and $\mathrm{HCO}_{3}^{-}$will be proportional to their molecular weights. Therefore, only 40 grams of calcium will react with 61 grams of bicarbonate in the formation of $100 \mathrm{grams}$ of $\mathrm{CaCO}_{3}$. The released proton, $\mathrm{H}^{+}$, will neutralize one additional bicarbonate ion.

The measured decrease in the system's alkalinity following the flow test of approximately $15 \mathrm{mg} / 1$ as bicarbonate would only result in a decrease of 5 mg/1 of calcium. The analytical precision of the alkalinity titration is \pm 5 $\mathrm{mg} / 1$ while the precision of the calcium test is $\pm 50 \mathrm{mg} / 1$. Hence, the formation of small amounts of scale ( $100 \mathrm{lbs.}$ ) could be measured by a decrease is alkalinity ( $15 \mathrm{mg} / 1$ ) but would probably not be detected by the calcium method (10 mg/1). The calcium and alkalinity are plotted on the same scale in Figure III-1i.

The decrease in alkalinity can be interpreted in terms of the weight of $\mathrm{CaCO}_{3}$ that would be necessary to produce the observed change in alkalinity. Applying the saturation index equation at various points and times in the flow stream predicts the greatest tendency for scaling would have occurred downstream of the choke during the flaring operation (Appendix III-1). since these flow conditions continued for 22 hours, a calculated weight of 88 pounds of scale was expected. 
Flow Tests of the Gladys MCCall Well Through OCtober 1990

The apparent agreement between the measured chemistry and the actual observed scale, lends credence to the notion that alkalinity is a sensitive indicator of scale in the Gladys $\mathrm{McCa} 11$ well. However, the wellhead data from April 20-kay 11 show much larger variation in bicarbonate alkalinity than had been measured in the April 13/14 flow test. The question then becomes, are these variations due to a scaling phenomenon or are they related to other processes?

$4 / 20 / 87$ through $5 / 11 / 87$ Well Head Samples (Table 2)

Figure III-2a shows the production rate and Figure III-2b shows well head pressure through May 11. The flow rate was steadily decreased from 24,000 BPD to 9,000 BPD in three weekly increments of 5,000 BPD. The corresponding well head pressure increased from approximately 1100 psia to 2700 psia over the same time period. It is generally accepted that these flow conditions are not conducive to scaling relative to the $4 / 14$ conditions. Nevertheless, the $4 / 27$ and 5/11 well head samples had significantly lower alkalinities than all other samples. The decrease of $85 \mathrm{mg} \mathrm{HCO}_{3} / 1$ between $4 / 20$ and the $4 / 27$ samples could be the result of scaling in either of two places; 1) the formation of about 250 lbs of scale in the downhole production tubing or 2) the precipitation of only 35 milligrams of $\mathrm{CaCO}_{3}$ in the sample collection line during the course of collecting a one liter sample. The most likely location would be that portion of the stainless steel coil tubing between the ice bath and the sampling port. Note that calcium decreased by $180 \mathrm{mg} / 1$ when only a $28 \mathrm{mg} / \mathrm{l}$ loss would have been expected. Alternatively, this reduction could be due to inherent variation in the produced brine due to reservoir or non-scaling geochemical processes. 
Probably the most perplexing aspect of the alkalinity data is the return to "baseline" levels of $475-500 \mathrm{mg} / 1$ in the May 4 th sample following the low value of April 27th. Significant daily fluctuation can also be seen for the week of May 4 through Hay 11. If we accept scaling as the operative process to account for this variation, it is logical to conclude that scale formation is intermittent (either in the down-hole tubing, or in the sample collection tubing).

Finally a brief discussion of the remaining measurements is presented:

Chloride

Total Hardness

Total Iron and Silica

Sulfate

$\mathrm{pH}$
Chloride is clearly the dominant anion present averaging $54,400 \mathrm{mg} / 1 \pm 1 \%$.

The total hardness test is very similar to the calcium test but includes a measurement of magnesium plus strontium, plus barium. The end-point is much sharper than the calcium test and is therefore considered to be more reliable. Both measurements are colorimetric and both elements are subject to post-sampling precipitation; silica due to temperature effects and iron due to oxidation. The variation of iron with flow rate will be discussed later. The Gladys HcCall brine contains only 2-4 mg/1 sulfate or less. The detection limit is in this range.

The pH was measured prior to the alkalinity titrations when the sample was equilibrated with 1 atmosphere of $\mathrm{CO}_{2}$ by bubbling $\mathrm{CO}_{2}$ through 
Flow Tests of the Gladys MCCall Well Through OCtober 1990

the sample for approximately 30 minutes. The excellent agreement between $\mathrm{pH}$ and alkalinity (Figures III-1a and III-1b) would be expected if scaling were taking place either in the system or during sampling. The correlation coefficient between alkalinity and $\mathrm{pH}$ is $r=0.86$, or $r^{2}=0.74$ (i.e., 74\% of the variation in $\mathrm{pH}$ can be accounted for by a linear variation in alkalinty). 
Table III-1. 4-13-87 to 4-14-87 Gladys McCall Flow Test

Potentiometric

titration under

Mkalinity mos/1

$( \pm 5 \mathrm{mg} / 1$ )

497

85

479

3,880

EDTA titration

at $\mathrm{pH} 13 *$

\section{Total Hardness}

$\mathrm{mg} / 1$ as $\mathrm{CaCO}_{3}$

$( \pm 100 \mathrm{mg} / 1)^{3}$

11,200

11,325

$\star *$

11,025

10,730

54,100

( $\pm 300 \mathrm{mg} / 1$ )

Iron $\mathrm{mg} / 1$

$\mathrm{s}_{\mathrm{i}} \mathrm{O}_{2} \mathrm{mg} / \mathrm{l}$

( $\pm 2 \mathrm{mg} / \mathrm{l}$ )

Sulfate mg/1

( $1 \mathrm{mg} / 1$ )

3

111,000

(rmhos/cm)

925 $\mathrm{C}$

0.13

0.11

pH (under $1 \mathrm{~atm}$.

5.20

5.17

5.19

5.19

$920^{\circ} \mathrm{C}$
BDTA titration

at $\mathrm{pH} 10$

Mercuric Nitrate

titration

Colorimetric

method

Colorimetric

method

Turbidimetric

method

Complexametric method utilizing an isobutanol extraction

Measured under 1 atmosphere $\mathrm{CO}_{2}$ 
Table III-2. Gladys McCall Well Head Samples 4-20-87 through 5-11-87

\begin{tabular}{|c|c|c|c|c|c|c|c|c|c|c|}
\hline 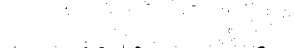 & $4 / 20$ & $4 / 27$ & $5 / 4$ & $5 / 5$ & $5 / 6$ & $5 / 7$ & $5 / 8$ & $5 / 9$ & $5 / 10$ & $5 / 11$ \\
\hline $\begin{array}{l}\text { Alkalinity mg/l } \\
\text { as } \mathrm{HCO}_{\overline{3}} \\
( \pm 5 \mathrm{mg} / 1)\end{array}$ & 475 & 390 & 494 & 476 & 464 & 457 & 482 & 457 & 506 & 415 \\
\hline $\begin{array}{l}\text { Calcium mg/1 } \\
( \pm 50 \mathrm{mg} / 1)\end{array}$ & $4,120 *$ & 3,940 & 3,960 & 3,920 & 3,860 & 3,850 & 3,950 & 3,960 & 3,890 & 3.988 \\
\hline $\begin{array}{l}\mathrm{mg} / 1 \text { as } \mathrm{CaCO}_{3} \\
( \pm 100 \mathrm{mg} / \mathrm{l})\end{array}$ & 11,375 & 11,000 & 11,000 & 10,950 & 11,133 & 11,150 & 11,067 & 11,083 & 10,900 & 11,083 \\
\hline $\begin{array}{l}\text { Chloride mg/l } \\
( \pm 300 \mathrm{mg} / 1)\end{array}$ & 54,575 & 54,300 & 54,800 & 53,800 & 53,900 & 54,725 & 54,800 & 54,500 & 54,300 & 55.000 \\
\hline $\begin{array}{l}\text { Iron mg/l } \\
( \pm 2 \mathrm{mg} / 1)\end{array}$ & 24.5 & 26 & 27 & 30.5 & 31.8 & 31.5 & 32.5 & 33.3 & 35.3 & 31.5 \\
\hline $\begin{array}{l}\mathrm{SiO}_{2} \mathrm{mg} / 1 \\
( \pm 2 \mathrm{mg} / 1)\end{array}$ & 122.5 & 123.5 & 112.3 & 117.3 & 124.5 & 115 & 120.5 & 122 & 125 & 122 \\
\hline $\begin{array}{l}\text { Sulfate } m g / 1 \\
( \pm 1 \mathrm{mg} / 1)\end{array}$ & & 4 & & & 3.5 & & 2.5 & & 2 & \\
\hline $\begin{array}{l}\mathrm{pH} \text { (under I atm } \\
\mathrm{CO}_{2} \text { ) }\end{array}$ & $\begin{array}{l}5.12 \\
023^{\circ} \mathrm{C}\end{array}$ & $\begin{array}{r}5.00 \\
924^{\circ} \mathrm{C}\end{array}$ & $\begin{array}{r}5.13 \\
023^{\circ} \mathrm{C}\end{array}$ & $\begin{array}{r}5.14 \\
924^{\circ} \mathrm{C}\end{array}$ & $\begin{array}{r}5.07 \\
022^{\circ} \mathrm{C}\end{array}$ & $\begin{array}{r}5.12 \\
922^{\circ} \mathrm{C}\end{array}$ & $\begin{array}{l}5.11 \\
0211^{\circ} \mathrm{C}\end{array}$ & $\begin{array}{r}5.10 \\
921^{\circ} \mathrm{C}\end{array}$ & $\begin{array}{r}5.17 \\
921^{\circ} \mathrm{C}\end{array}$ & $\begin{array}{r}4.98^{\circ} \\
620^{\circ} \mathrm{C}\end{array}$ \\
\hline
\end{tabular}

*Barium and strontium are titrated as calcium in this method. 
FLow TESTS OF THE GLAdys MCCALL Well Through OCtober 1990

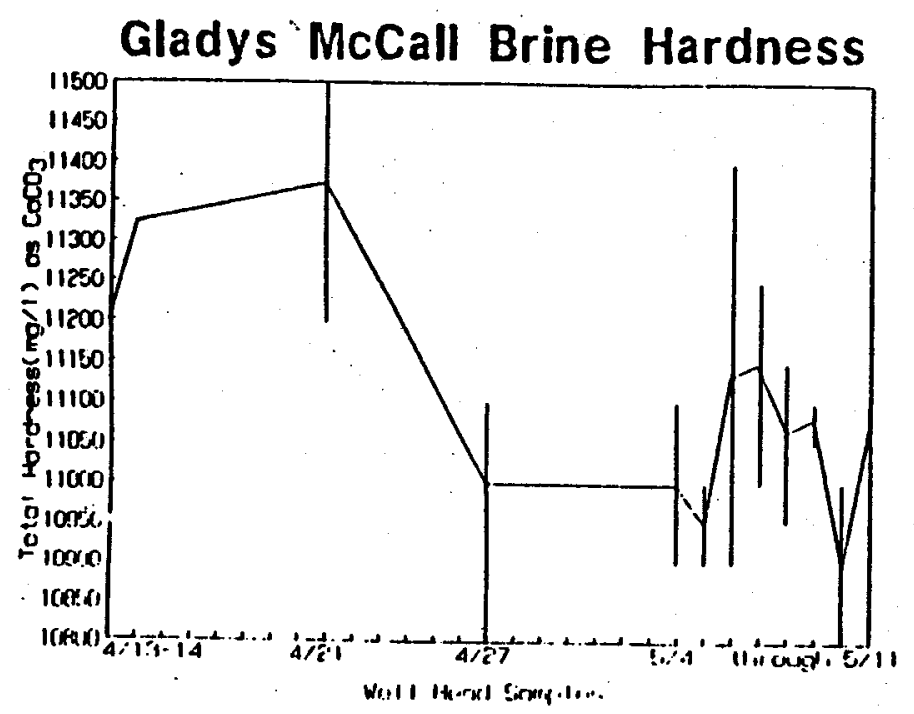

Figure III-1d.
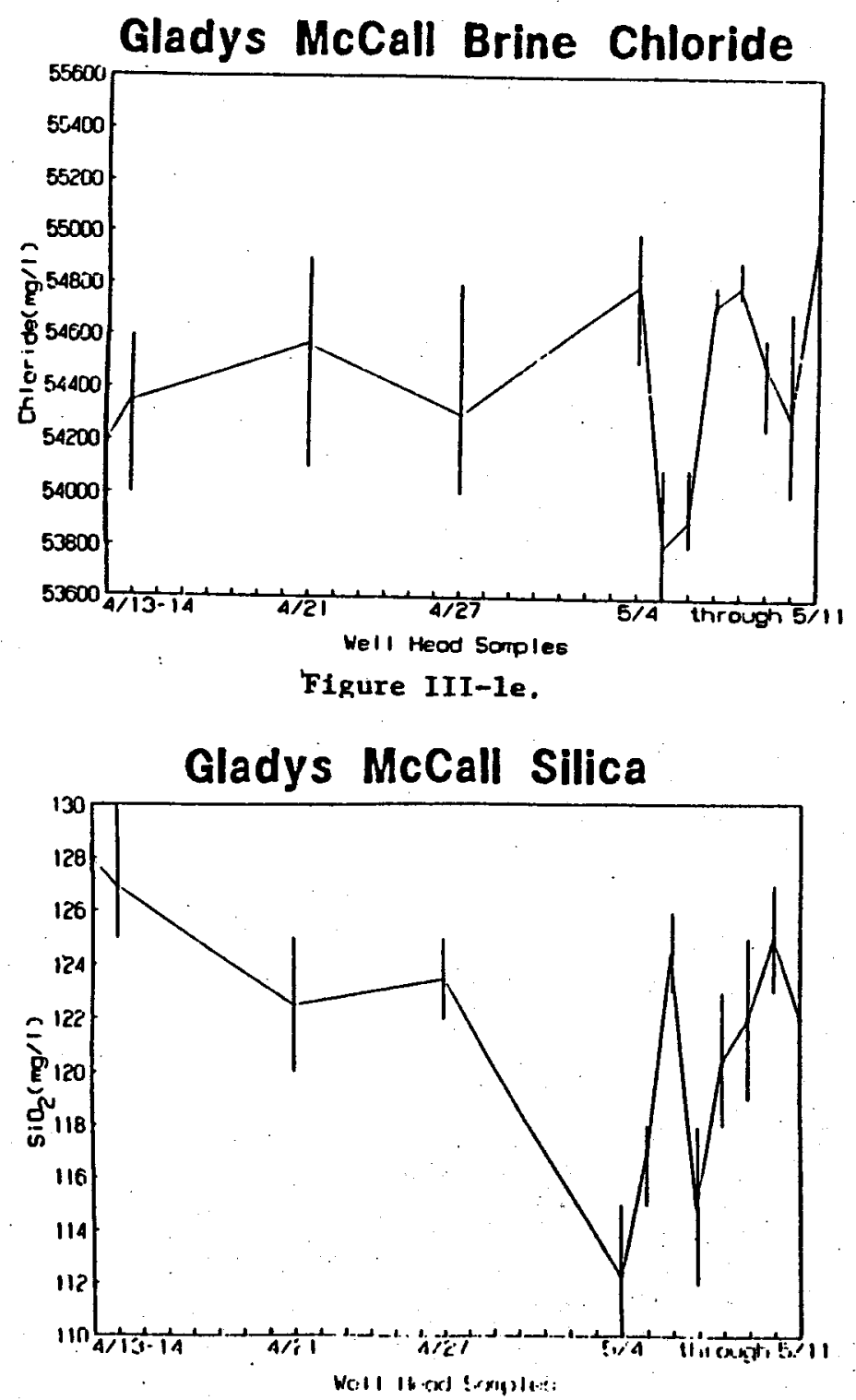

Figure III-1f.

$$
\text { M-34 }
$$


Flow tests of The Gladys MCCALl Well Through OCtober 1990

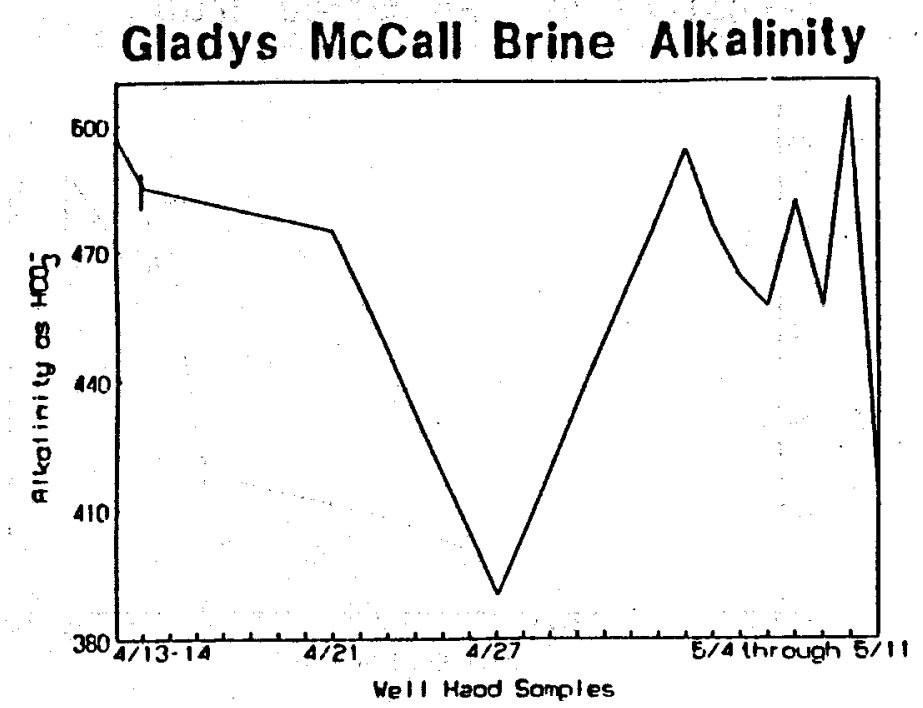

FIgure III-1a.

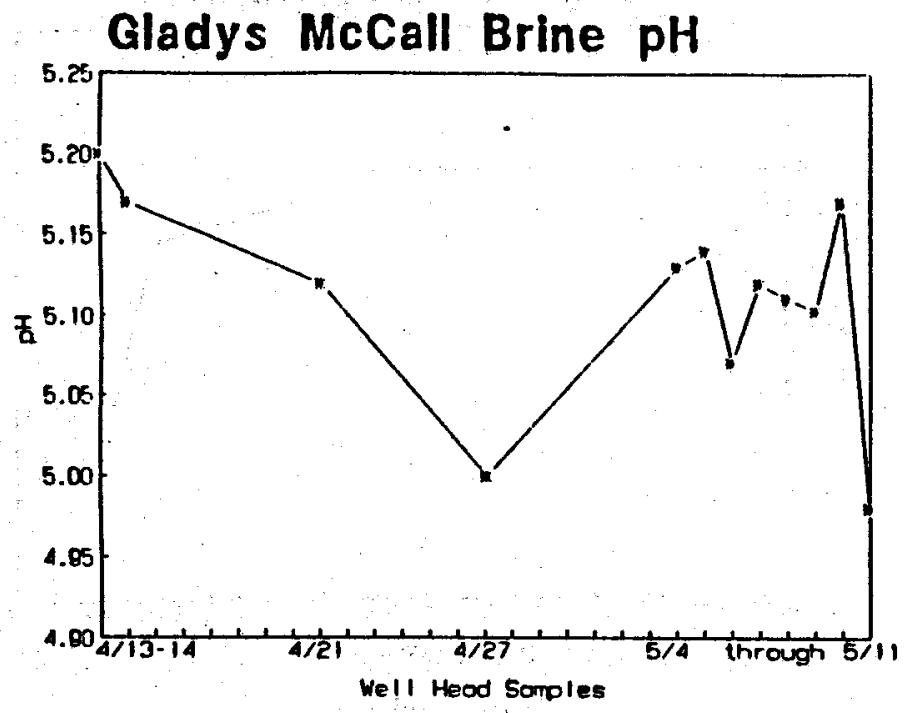

Figure III-1b.

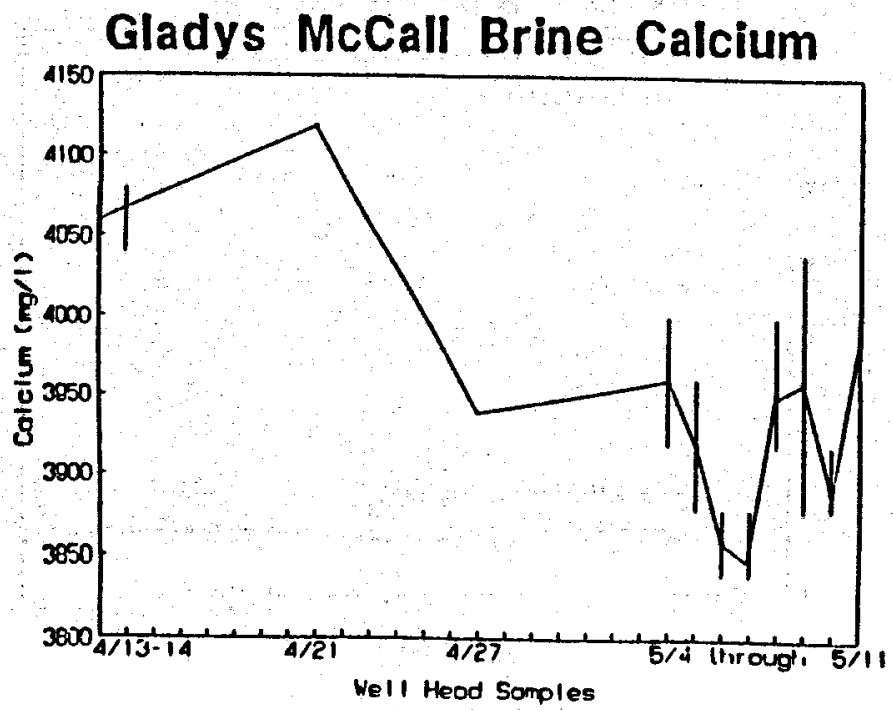

M-35

INST T TUTE O O T G A S T T C H N O L O G Y 
FLOW TESTS OF THE GLADYS MCCALL WELL THROUGH OCTOBER 1990

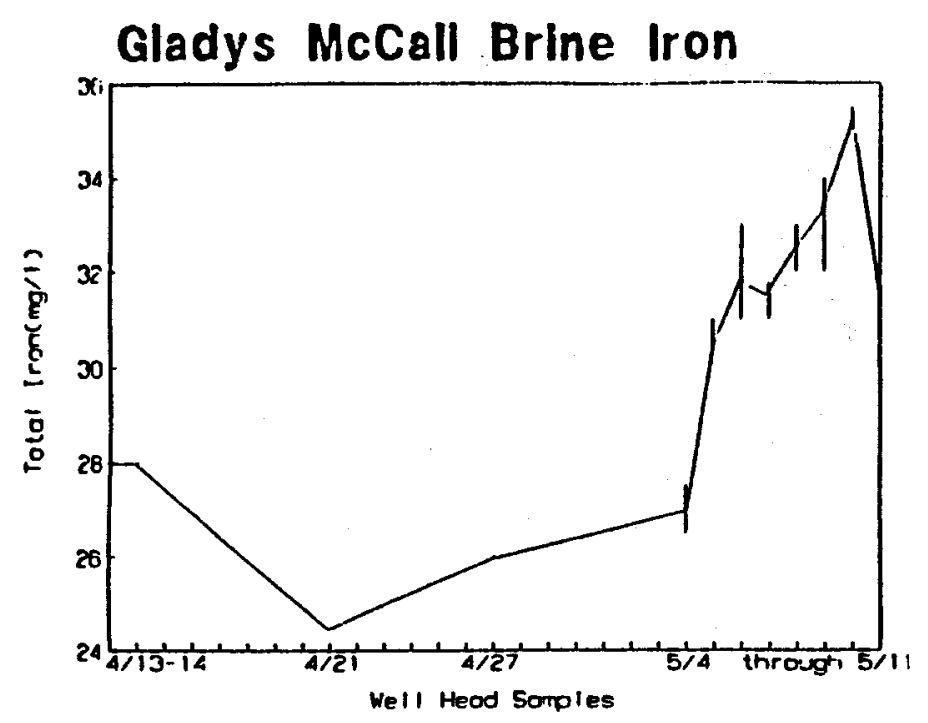

Figure III-1g.

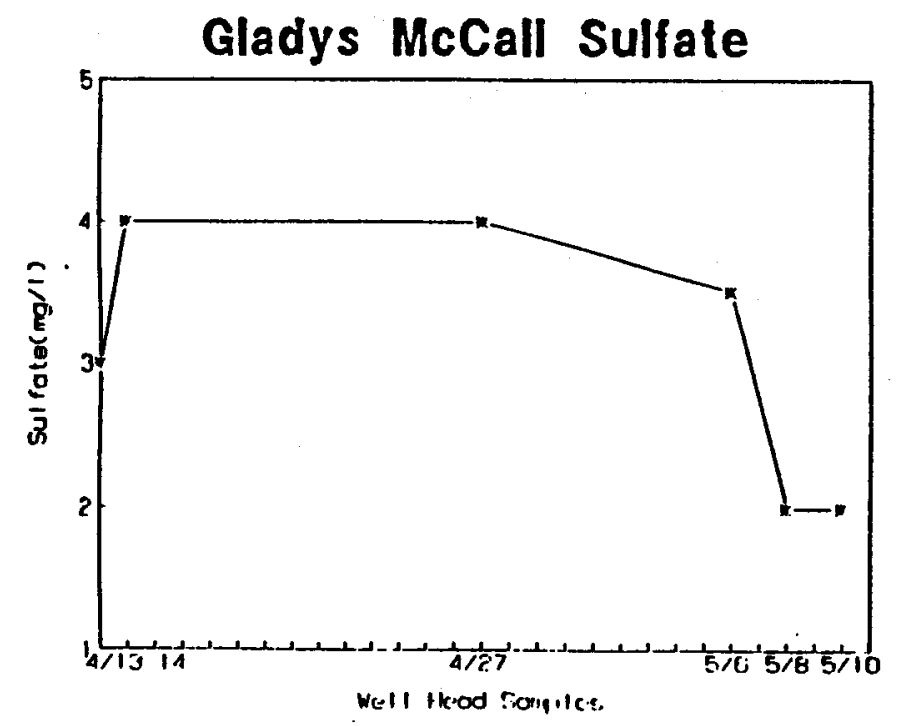

Figure -1h.

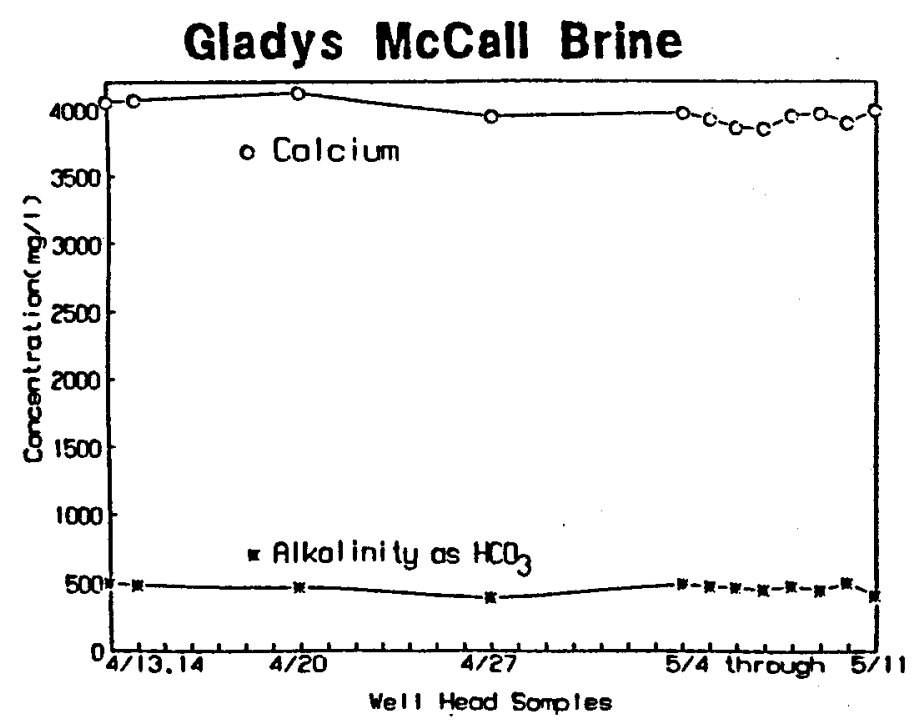

Fieure III-11.

M-36 
Flow TESTS OF THE GLADYS MCCALL Well THROUgh OCtOBER 1990

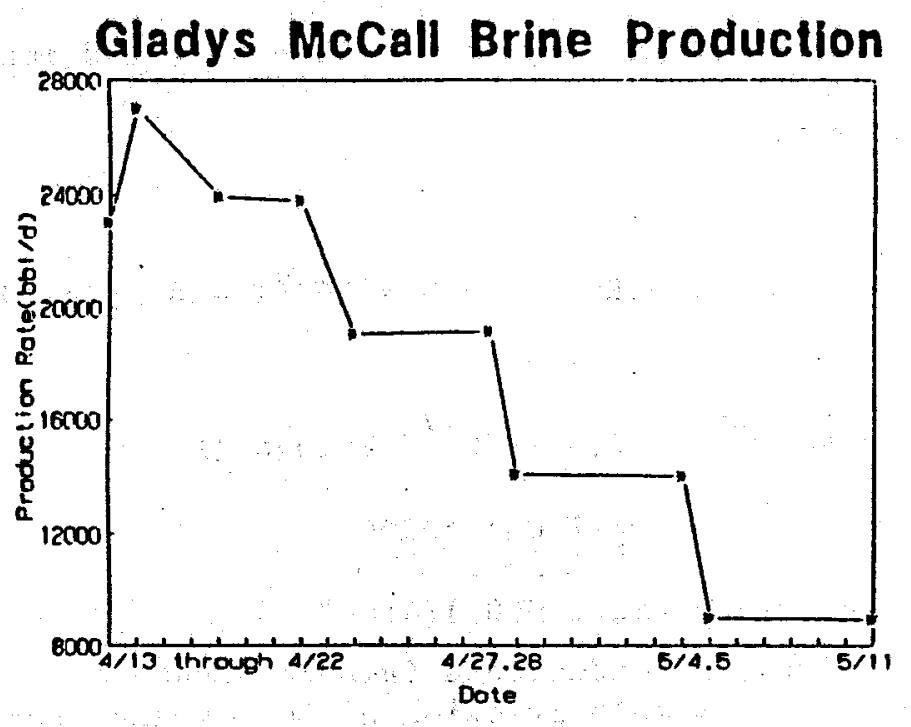

F1gure III-2a.

Gladys McCall Brine Well Head Pressure

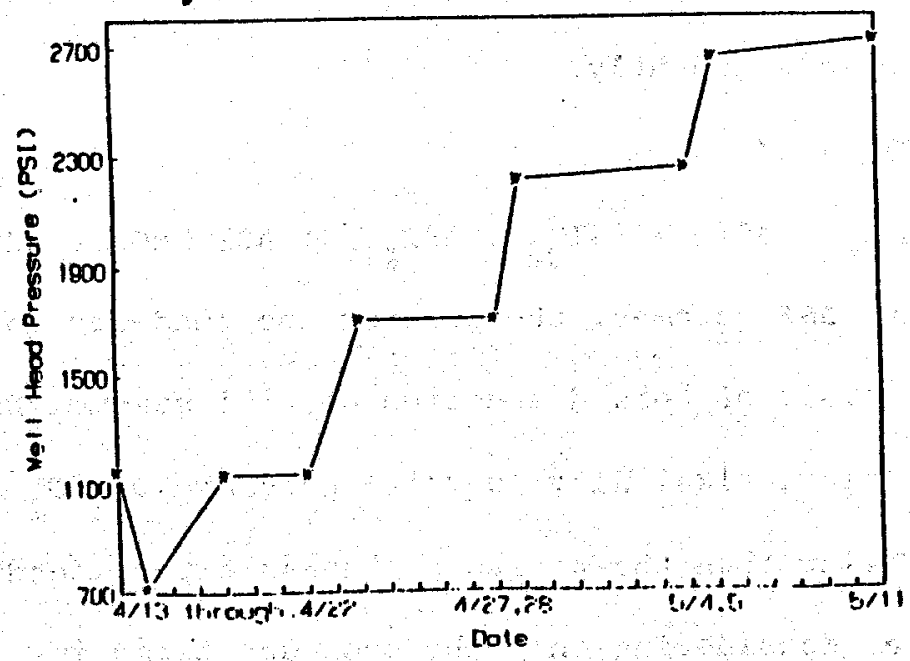

F1gure III-2b. 


\section{Appendix III-1}

Oddo and Tomson's least squares approximation of the saturation index equation takes into account temperature, pressure and ionic strength effects on $\mathrm{CaCO}_{3}$ solubility:

$$
\begin{aligned}
& S I=\log _{8} \frac{\mathrm{T}_{\mathrm{Ca}^{A} \mathrm{Ak}}{ }^{2}}{\mathrm{PX}_{\mathrm{CO}_{2}}}+5.89+1.549 \times 10^{-2} \mathrm{~T}-4.26 \times 10^{-6} \mathrm{~T}^{2} \\
& -7.44 \times 10^{-5} \mathrm{P}-2.526 \mathrm{IS}^{1 / 2}+.920 \mathrm{IS} \\
& \text { where } \mathrm{TCa}(\mathrm{molar})=(\mathrm{mg} / 1 \mathrm{Ca}) / 40000 \\
& \text { Alk (molar) }=\left(\mathrm{mg} / 1 \mathrm{KCO}_{3}\right) / 61000 \\
& \text { IS (molar) = Conductance ( } \mu \text { mho/ } \mathrm{cm} \text { ) } / 66667 \\
& \mathrm{XCO}_{2} \quad=\text { mole fraction of } \mathrm{CO}_{2} \text { in gas phase } \\
& P \quad=\text { pressure in psia } \\
& \text { T } \quad=\text { temperature in } \cdot F
\end{aligned}
$$

The total change in the saturation index, $\Delta S I$, between any two points in the brine stream is defined as the sums of the changes resulting from $P, T, C a$, Alk, $\mathrm{P}_{\mathrm{CO}_{2}}$ and IS independently:

$$
\begin{aligned}
\Delta S I & =S I_{2}-S I_{1} \\
& =\Delta S I_{p}+\Delta S I_{T}+\Delta S I_{C a}+\Delta S I_{A l k}+\Delta S I P_{2}+\Delta S T_{T D S}
\end{aligned}
$$

The more positive $\Delta S I$ becomes, the greater the tendency to scale.

For the purposes of this discussion we will assume that changes in temperature, calcium, alkalinity, partial pressure of $\mathrm{CO}_{2}$ and ionic strength will be much smaller than the pressure changes experienced during the flow test. Therefore, considering only the pressure terms in the above equation:

$$
\Delta S I=S I_{P_{2}}-S I_{P_{1}}
$$




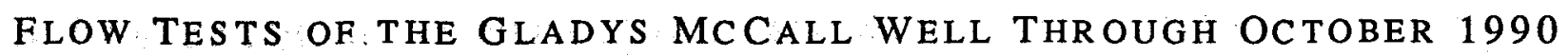

where $S I_{P_{2}}$ and $S I_{P_{2}}$ are the pressure constributions to the saturation indices at points 2 and 1 in the flow stream:

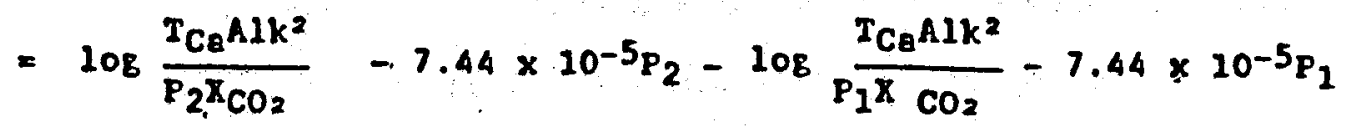

Assuming the following average parameters for sand zone $\# \mathrm{~B}$ :

$$
\begin{aligned}
& I_{C a}(\operatorname{molar})=(4,000 \mathrm{mg} / 1 \mathrm{Ca}) / 40000=.1000 \\
& \text { Alk (molar) }=(485 \mathrm{mg} / 1 \mathrm{HCO}) / 61000=.0079 \\
& \text { IS }(\text { molar })=(110,000 \mu \text { mho/ } \mathrm{cm}) / 66667=1.6499 \\
& \mathrm{X}_{\mathrm{CO}_{2}}{ }^{(\mathrm{molar})}=0.09
\end{aligned}
$$

We can rewrite the above equation as:

$$
\Delta S I=108 \frac{7.024 \times 10^{-5}}{P_{2}}-7.44 \times 10^{-5} P_{2}-108 \frac{7.024 \times 10^{-5}}{P_{1}}-7.44 \times 10^{-5} P_{1}
$$

Cancelling and rearranging:

$$
\begin{aligned}
& =-108 P_{2}+108 P_{1}+7.44 \times 10^{-5}\left(P_{1}-P_{2}\right) \\
\Delta S I & =\log \frac{P_{1}}{P_{2}}+7.44 \times 10^{-5}\left(P_{1}-P_{2}\right)
\end{aligned}
$$


Flow Tests of the Gladys MCCall Well Through OCtober 1990

Note that the resulting equation is independent of brine chemistry. Applying the same $\Delta S I$ equation over the flow stream from the bottom-hole to the well head at various times gives:

1. Before flaring (1 p.m. 4/13/87):

Bottom-hole $\left(P_{1}\right)$ to well head $\left(P_{2}\right)$

$$
\begin{aligned}
& P_{1}=8590 \mathrm{psi} \\
& P_{2}=1150 \mathrm{psi}
\end{aligned}
$$

$\Delta S I_{\text {before }}$ flare $=\log \frac{8590}{1150}+7.44 \times 10^{-5}(8590-1150)=1.427$

2. After choke adjustment (noon 4/14/87)

Bottom-hole $\left(P_{1}\right)$ to wellhead $\left(P_{2}\right)$

$$
\begin{aligned}
& P_{1}=8395 \mathrm{psi} \\
& P_{2}=710 \mathrm{psi}
\end{aligned}
$$

$\Delta S I_{\text {after choke adjustment }}=\log \frac{8395}{710}+7.44 \times 10^{-5}(8395-710)=1.644$ 
Flow tests of the gladys McCall Well Through OCtober 1990

IV. ICP ANALYTICAL RESULTS FOR METALS AND TRACE ELEMENTS Inductively coupled plasma (ICP) arc spectroscopic results for 16 metals and trace elements are presented in Table IV-1. From preliminary screening the elements in Table IV-1 were grouped into two groups based upon concentration. These two Broups were run separately, each along with appropriate standards in a matrix matched solution. Graphical data comparisons and discussion are presented in Section $v$. 
Table IV-1. ICP Analytical Results for Motals and Irace Elements

\begin{tabular}{|c|c|c|c|c|c|c|c|c|c|c|c|c|}
\hline $\begin{array}{l}\text { Sample: } \\
\text { (ppa) }\end{array}$ & $3 / 31 / 83$ & $\begin{array}{l}10.27 / 83 \\
\text { sep/flltered }\end{array}$ & $\begin{array}{c}3 / 6 / 85 \\
\text { of }\end{array}$ & $\underset{H}{2 / 27 / 87}$ & $\begin{array}{c}2 / 27 / 87 \\
z\end{array}$ & $4 / 23 / 87$ & 1/14/87 & $4 / 20 / 87$ & $\frac{1 / 27 / 87}{4}$ & B & Ars. & \\
\hline \multirow[t]{2}{*}{78} & 29.1 & 18.3 & 37.0 & 34.3 & 23.7 & 25.5 & 26.2 & 25.8 & 23.9 & 23.1 & & \\
\hline & 28.7 & & & & 24.5 & 23.2 & 25.3 & & 24.0 & 23.2 & & \\
\hline \multirow[t]{2}{*}{ B } & 35.2 & 60.9 & 31.5 & 40.0 & 40.1 & 39.5 & 40.9 & 42.3 & 38.9 & 39.1 & & \\
\hline & 32.7 & & & & 39.8 & 39.9 & 10.4 & & 10.2 & 39.8 & 39.5 & \\
\hline \multirow[t]{2}{*}{ si } & 49 & 49 & 53 & 61 & & 61 & 59 & 57 & 51 & & & \\
\hline & 45 & & 68 & & 67 & 66 & 53 & & 64 & 60 & 58 & \\
\hline Ms & 205 & 288 & 193 & 257 & 255 & 253 & 261 & 259 & 252 & 253 & & \\
\hline sr & 301 & $A 15$ & 284 & 390 & 380 & 389 & 396 & 389 & 382 & & & \\
\hline $\mathbf{C a}$ & 3035 & 4753 & 2739 & 3557 & 3576 & 3587 & 3600 & 3593 & 3492 & 3508 & & \\
\hline $\mathrm{Ba}$ & 355 & 503 & 334 & 468 & 464 & 463 & 174 & 465 & 456 & 462 & & \\
\hline Ha & 21654 & 32875 & 1394 & 29449 & 29364 & & 29783 & 30156 & $302 q 4$ & 29665 & 29697 & 29682 \\
\hline $\mathbf{L i}$ & 23.8 & 37.2 & 21.3 & 29.5 & 36.9 & 31.7 & 32.5 & 30.0 & 31.4 & 31.7 & & \\
\hline $\mathbf{x}$ & 698 & 953 & 557 & 868 & 2193 & 848 & 882 & 593 & 843 & 760 & 802 & \\
\hline Cr & & 0.05 & 0.07 & 0.03 & & 0.02 & sD & $m$ & 0.03 & & & \\
\hline th & & 1.93 & 2.01 & 1.87 & & 1.84 & 1.90 & 1.88 & 3.71 & & & \\
\hline cd & & 0.15 & 0.11 & 0.13 & & 0.14 & 0.14 & 0.12 & 0.13 & & & \\
\hline $\mathrm{Cu}$ & & 0.03 & 0.03 & 0.04 & & 0.03 & 0.01 & 0.03 & 0.02 & & & \\
\hline $\mathrm{Pb}$ & & $\mathbb{W}$ & ED & $D D$ & & $\mathbb{D D}$ & 20 & $m$ & wo & & & \\
\hline $2 n$ & & 1.82 & 0.15 & 0.19 & & 0.17 & 0.09 & 0.13 & 0.13 & & & \\
\hline Alkalinity & & & & & & 497 & 485 & 475 & 390 & & & \\
\hline $\mathbf{P H}$ & & & . & & & & & & & & & \\
\hline Flow cate & & & & & . & 23.5 & 23.5 & 24 & & & & \\
\hline
\end{tabular}


Iable IV-I (cont'd)

\begin{tabular}{|c|c|c|c|c|c|c|c|c|c|c|c|}
\hline $\begin{array}{l}\text { Sample: } \\
\text { (ppm) }\end{array}$ & $5 / 4 / 87$ & $5 / 5 / 87$ & $5 / 6 / 87$ & $5 / 7 / 87$ & $5 / 8 / 87$ & $5 / 9 / 87$ & $5 / 10 / 87$ & $5 / 21 / 87$ & $5 / 12 / 87$ & $5 / 13 / 87$ & $5 / 14 / 87$ \\
\hline \multirow[t]{2}{*}{ Fe } & 28.4 & 32.5 & 31.3 & 31.5 & 30.8 & 33.4 & 32.6 & 28.0 & 11.1 & 40.6 & 42.3 \\
\hline & & & & 31.4 & & 32.1 & & 27.5 & & & \\
\hline \multirow[t]{3}{*}{ B } & 40.5 & 40.3 & 39.4 & 39.7 & 39.7 & 12.1 & 39.7 & 12.0 & 40.9 & 39.6 & 39.7 \\
\hline & & $\cdots$ & & 10.4 & $\cdots$ & $3 / 8$ & & 39.7 & & & \\
\hline & & & & 40.4 & & 40.9 & $\because$ & 10.5 & & & \\
\hline \multirow[t]{2}{*}{$\mathbf{s i}$} & 32 & & 60 & 66 & & 62 & & 60 & & 39 & \\
\hline & & & & 68 & 67 & & 65 & & & & $\because$ \\
\hline $\mathrm{M}_{8}$ & 261 & 256 & 259 & 255 & 255 & 255 & 252 & 259 & 259 & 250 & 255 \\
\hline se & 391 & 380 & 386 & 388 & 374 & 386 & 380 & 390 & 385 & 388 & 380 \\
\hline$C_{2}$ & 3594 & 3599 & 3575 & 3491 & 3491 & 3612 & 3582 & 36.26 & 3564 & 3561 & 3529 \\
\hline Ba & 471 & 469 & 465 & 457 & 456 & 464 & 464 & 477 & 471. & 476 & 465 \\
\hline Ma & 29452 & 29668 & 29842 & 29765 & 28606 & 29874 & 29122 & 29581 & 30096 & 29667 & 29281 \\
\hline $\mathbf{L i}$ & 33.4 & 30.6 & 34.0 & 32.5 & 32.7 & 31.9 & 32.7 & $\quad 32.2$ & 31.6 & 31.4 & 30.9 \\
\hline $\mathbf{x}$ & 928 & 594 & 851 & 824 & 2164 & 900 & 962 & 952 & 917 & 1130 & 747 \\
\hline cr & 0.05 & & 0.05 & & 2.02 & $\because$ & 0.01 & 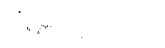 & mo & & 0.04 \\
\hline $\ln$ & 2.88 & & 1.95 & & 2.00 & & 2.01 & & 2.07 & & 2.06 \\
\hline cd & 0.15 & & 0.16 & & 0.13 & & 0.13 & & 0.12 & & 0.17 \\
\hline cu & 0.01 & & 0.02 & & 0.02 & & 0.02 & 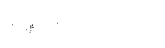 & 0.01 & & 0.01 \\
\hline $\mathbf{P b}$ & $\infty$ & & $\mathbf{m}$ & & 10 & & ro & & DD & & $m$ \\
\hline $2 n$ & 0.14 & & 0.16 & & 0.12 & & 0.15 & & 0.16 & & 0.13 \\
\hline Alkalinity & 194 & 476 & 164 & 457 & 482 & 457 & 506 & 415 & 497 & 458 & \\
\hline ph & & & & & & & & & 5.17 & & \\
\hline Flow rate & 14 & 9 & 9 & 9 & 9 & 9 & 9 & 9 & 4.5 & 4.5 & \\
\hline
\end{tabular}




\begin{tabular}{|c|c|c|c|c|c|c|c|c|c|c|c|}
\hline $\begin{array}{l}\text { Sample: } \\
\text { (ppa) }\end{array}$ & $5 / 15 / 87$ & $5 / 26 / 87$ & $5 / 17 / 87$ & $5 / 18 / 87$ & $5 / 29 / 87$ & $5 / 20 / 87$ & $5 / 21 / 87$ & $5 / 22 / 87$ & $\begin{array}{c}5 / 23 / 87 \\
G 00\end{array}$ & ErrvI & Avg \\
\hline \multirow[t]{3}{*}{ fe } & 39.5 & 43.0 & 37.4 & 40.9 & 30.3 & 30.4 & 31.2 & 32.2 & 31.0 & 38.4 & \\
\hline & & & 39.1 & & 30.0 & . & 31.3 & 32.6 & & & \\
\hline & & & 38.3 & & & & & & & & \\
\hline \multirow[t]{3}{*}{ B } & 39.6 & 39.5 & 38.9 & 38.9 & 42.8 & 38.9 & 39.5 & 40.8 & 38.0 & 38.7 & \\
\hline & & & 4.0 & & 40.0 & & 10.7 & 10.6 & & & \\
\hline & & & 39.5 & & 40.9 & & 40.1 & & & & \\
\hline \multirow[t]{2}{*}{$\mathbf{s i}$} & & 64 & 63 & 63 & 65 & 63 & 12 & 70 & & 66 & \\
\hline & & & 68 & & 67 & & 69 & 70 & & & \\
\hline$n_{8}$ & 258 & 254 & 255 & 252 & 256 & 252 & 250 & 256 & 249 & 256 & \\
\hline se & 385 & 383 & 387 & 385 & 384 & 380 & 385 & 386 & 375 & 378 & \\
\hline $\mathrm{ca}$ & 3591 & 3563 & 3495 & 3566 & 3636 & 3512 & 3568 & 3522 & 3506 & 3568 & 3537 \\
\hline Ba & 465 & 469 & 461 & 460 & 468 & 169 & 469 & 460 & 451 & 464 & 458 \\
\hline Ha & 29810 & 29316 & 29137 & 29526 & 29741 & 29763 & 28929 & 29787 & 29106 & 29682 & 29394 \\
\hline Li & 29.7 & 36.7 & 32.2 & 30.5 & 31.5 & 27.9 & 30.6 & 31.6 & 31.6 & 29.2 & 30.4 \\
\hline$x$ & 615 & 835 & 835 & 733 & 921 & 646. & 788 & 900 & 842 & 904 & 873 \\
\hline Cr & & 0.05 & 0.03 & 0.13 & 0.02 & 0.03 & 0.04 & 0.04 & & 0.11 & \\
\hline min & & 2.14 & 2.19 & 2.16 & 1.98 & 2.06 & 2.13 & 2.08 & & 2.02 & \\
\hline cd & & 0.12 & 0.06 & 0.05 & 0.13 & 0.10 & 0.11 & 0.14 & & 0.11 & \\
\hline ou & & 0.02 & 0.02 & 0.03 & 0.01 & 0.02 & 0.02 & 0.03 & & 0.02 & \\
\hline $\mathbf{P b}$ & & $M$ & $\mathrm{WD}$ & ND & AD & $\mathbf{s 0}$ & wD & MD & & $\mathbf{x D}$ & \\
\hline $2 n$ & & 0.10 & 0.09 & 0.25 & 0.11 & 0.25 & 0.23 & 0.11 & & 0.09 & \\
\hline Alkalinity & & 470 & 503 & 470 & & 472 & 505 & 482 & & & \\
\hline pH & & & 5.14 & & & $\cdot$ & & 3.18 & & & \\
\hline Ilow rate & 4.5 & 4.5 & 4.5 & 4.5 & 10 & 10 & 10 & 10 & 10 & & \\
\hline
\end{tabular}


Table IV-1 (cont d)

\begin{tabular}{|c|c|c|c|c|c|c|c|c|c|c|c|}
\hline $\begin{array}{l}\text { Sample: } \\
\text { (ppa) }\end{array}$ & $5724 / 87$ & $5 / 25 / 87$ & $5 / 26 / 87$ & $\begin{array}{c}5 / 27 / 87 \\
680\end{array}$ & Envi & AVB 87 & $5 / 28 / 87$ & $5 / 29 / 87$ & $5 / 30 / 87$ & $5 / 31 / 87$ & $\therefore 6 / 1 / 87$ \\
\hline Fe & 30.2 & 32.7 & $\begin{array}{l}33.3 \\
32.9\end{array}$ & 32.4 & 31.7 & & 31.6 & 31.6 & 32.3 & $\begin{array}{l}32.3 \\
32.4\end{array}$ & 33.6 \\
\hline a & 38.9 & 38.9 & $\begin{array}{l}40.4 \\
39.0 \\
39.7\end{array}$ & 10.4 & 39:1 & 39.8 & 39.9 & 39.4 & $\begin{array}{l}39.6 \\
\end{array}$ & $\begin{array}{r}40.4 \\
39.6\end{array}$ & 39.1 \\
\hline si & 67 & 68 & $\begin{array}{l}66 \\
70\end{array}$ & & 68 & $\because$ & 59 & 68 & 72 & $\begin{array}{l}\quad 66 \\
69\end{array}$ & $\begin{array}{c}11 \\
\vdots\end{array}$ \\
\hline $\mathrm{HB}$ & 253 & 253 & 259 & 260 & 255 & & 254 & 256 & 256 & 257 & 253 \\
\hline se & 382 & 378 & 384 & 389 & 382 & & 382 & 388 & 380 & 385 & 380 \\
\hline $\mathbf{C a}$ & 3531 & 3452 & 3597 & 3626 & 3577 & 3602 & 3557 & 3538 & 3555 & 3555 & 3532 \\
\hline Ba & 462 & 459 & 463 & 472 & 462 & .67 & 164 & 459 & 459 & 169 & 454 \\
\hline עa & 29485 & 29089 & 29717 & 29995 & 29798 & 29897 & 29200 & 29596 & 29337 & 39703 & 30275 \\
\hline Li & 26.6 & 26.5 & 30.9 & 33.0 & 27.1 & 30.1 & 29.6 & 33.5 & 38.0 & 30.9 & 32.1 \\
\hline $\mathbf{k}$ & 711 & 1114 & 770 & 1165 & 762 & 964 & 1072 & 1175 & 1363 & 822 & 778 \\
\hline CE & 0.03 & 0.05 & 0.07 & & 0.02 & & 0.01 & 20.01 & Do & 0.05 & 20.01 \\
\hline m & 1.99 & 2.06 & 2.03 & & 2.02 & & 2.09 & 1.98 & 2.09 & 2.05 & 2.06 \\
\hline Cd & 0.17 & 0.13 & 0.10 & & 0.13 & & 0.11 & 0.09 & 0.17 & 0.12 & 0.16 \\
\hline cu & 0.01 & 0.02 & $\therefore 0.02$ & & 0.01 & & 0.02 & 0.03 & 0.01 & 0.03 & 0.01 \\
\hline Pb & 80 & $\mathbf{8 0}$ & $\infty 0$ & & mo & & so & $\mathbf{T}$ & $D$ & 10 & 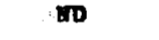 \\
\hline $2 \mathbf{n}$ & 0.15 & 0.12 & 0.23 & & 0.12 & & 0.14 & 0.11 & 0.14 & 0.15 & 0.13 \\
\hline Akalinity & & 464 & 294 & & & & & 476 & & 506 & \\
\hline pH & & & 3.19 & & & & & & & 5.15 & \\
\hline Flow rate & 10 & 10 & 10 & 10 & & & 10 & 10 & 20 & 10 & 10 \\
\hline
\end{tabular}


Table IV-L (cont'd)

\begin{tabular}{|c|c|c|c|c|c|c|c|c|c|}
\hline $\begin{array}{l}\text { Sample: } \\
6 / 5-1 \\
\text { (ppm) }\end{array}$ & $6 / 2 / 87$ & $\begin{array}{c}6 / 3 / 87 \\
0 \\
\end{array}$ & $6 / 4 / 87$ & $\begin{array}{l}6 / 5 / 87 \\
\text { EOC }\end{array}$ & $\begin{array}{c}6 / 5-1 \\
620\end{array}$ & Envi & $6 / 5-2$ & $6 / 5-3$ & $6 / 5-4$ \\
\hline \multirow[t]{2}{*}{$\mathrm{Fe}$} & 31.0 & 7.88 & 32.5 & 31.1 & 31.1 & 32.0 & 31.0 & 31.1 & 31.8 \\
\hline & & 1.77 & & & & & 31.5 & & . \\
\hline \multirow[t]{2}{*}{$\mathbf{B}$} & 38.8 & 40.6 & 38.7 & 39.6 & 36.7 & 39.2 & 37.4 & 38.2 & 39.4 \\
\hline & & 40.6 & & & & & & & \\
\hline \multirow[t]{2}{*}{ si } & 66 & 70 & 69 & 57 & & 72 & 80 & 72 & 73 \\
\hline & & 76 & & & & 70 & & & \\
\hline $\mathrm{Hg}_{\mathbf{g}}$ & 247 & 260 & 255 & 263 & 244 & 257 & 252 & 251 & 258 \\
\hline Sr & 371 & 386 & 381 & 391 & 364 & 381 & 375 & 380 & 376 \\
\hline \multirow[t]{2}{*}{$\mathrm{Ca}_{3}$} & 3422 & 3636 & 3553 & 3701 & 3392 & 3571 & 3473 & 3535 & 3584 \\
\hline & & & & & & & 3484 & & \\
\hline $\mathbf{B a}$ & 446 & 469 & 463 & 487 & 444 & 467 & 460 & 458 & 470 \\
\hline $\mathrm{Ma}$ & 28826 & 29960 & 29407 & 30459 & 28054 & 29835 & 28966 & 28961 & 29615 \\
\hline $\mathrm{Li}$ & 26.1 & 32.6 & 30.4 & 27.9 & 29.8 & 32.9 & 28.8 & 26.2 & 28.6 \\
\hline$k$ & 724 & 980 & 768 & 669 & 843 & 935 & 819 & 775 & 663 \\
\hline Cr & 0.08 & 0.08 & 0.02 & 0.03 & & $\mathrm{ID}$ & ID & $\mathbf{a n}$ & 0.03 \\
\hline Mn & 1.99 & 2.09 & 2.07 & 1.94 & & 2.04 & 2.20 & 2.01 & 2.04 \\
\hline \multirow[t]{2}{*}{ cd } & 0.12 & 0.11 & 0.14 & 0.14 & & 0.11 & 0.15 & 0.11 & 0.10 \\
\hline & & & & & & & & 0.10 & \\
\hline Cu & 0.02 & 0.02 & 0.01 & 0.01 & & 0.02 & 0.01 & 0.02 & 0.02 \\
\hline $\mathbf{P b}$ & DD & $\mathbf{D D}$ & DD & vD & & WD & ID & no & ND \\
\hline \multirow[t]{2}{*}{$2 n$} & 0.12 & 0.15 & 0.12 & 0.14 & & 0.22 & 0.13 & 0.16 & 0.13 \\
\hline & & & & & & 0.18 & & & \\
\hline Akalinity & & 497 & & 482 & & & & & \\
\hline $\mathrm{pH}$ & & 5.18 & & 5.14 & & & & & \\
\hline Plow rate & 10 & 10 & 1010 & 10 & & & & & \\
\hline
\end{tabular}


FLOW TESTS OF THE GLAdys MCCALL Well ThROUgh OCTOBER 1990

v. GRAPHICAL DATA PRESENTATION ANU DISCUSSION

In order to facilitate examination of various trends in the reported data several plots are included in this section. In Figures $v-1 a-j$, flow rate, Fe, $\mathrm{Alk}, \mathrm{Mn}, \mathrm{Na}, \mathrm{Ca}, \mathrm{Si}, \mathrm{Mg}, \mathrm{Ba}, \mathrm{Sr}, \mathrm{Li}, \mathrm{Mg}, \mathrm{B}$, and $\mathrm{K}$ are plotted vs, time of sampling. In Figures $v-2 a-j, 2 a-h$ various parameters are plotted against flow rate. Finally, in Figures $V-3 a-e, 3 z-g$ various parameters are plotted against each other to discuss potential trends. The scale has been magnified in all cases and as a consequence small percent variations may appear significant.

The most significant correlation appears between iron (Fe) and flow rate in Figures $v-1 a$ and $v-2 b$ :

$$
\mathrm{Fe}(\mathrm{mg} / 1)=62.92 \mathrm{FLOW}(\mathrm{tbpd})-0.301 \Omega(4)=0.94
$$

Qualitatively, this equation suggests that some process is taking place such that the faster the flow rate the lower the iron concentration. A similar but less pronounced relationship exists between in and flow rate, Figure V-2i. Yet, no such a correlation exists between any of the remaining composition variables. It is therefore probably not a property of the production reservoir chemistry. Rather, it is probabiy a consequence of corrosion of the steel pipe at approximately a mass transport limited rate. Similar exponential dependence follows from an analysis of dimensionless mass transport groups, but more modeling on this well brine is needed to confirm the mechanism.

Few of the remaining parameters vary over sufficient a range to warrant interpreting any trend results. 
Flow TeStS OF THE Gladys MCCall Well Through OCtOber 1990

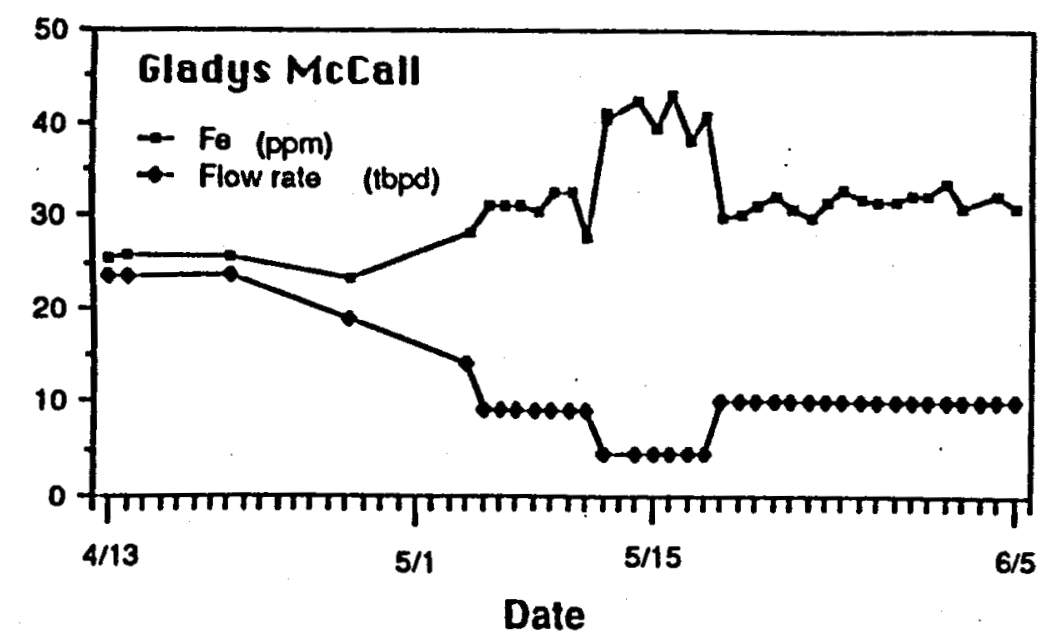

Figure V-1a.

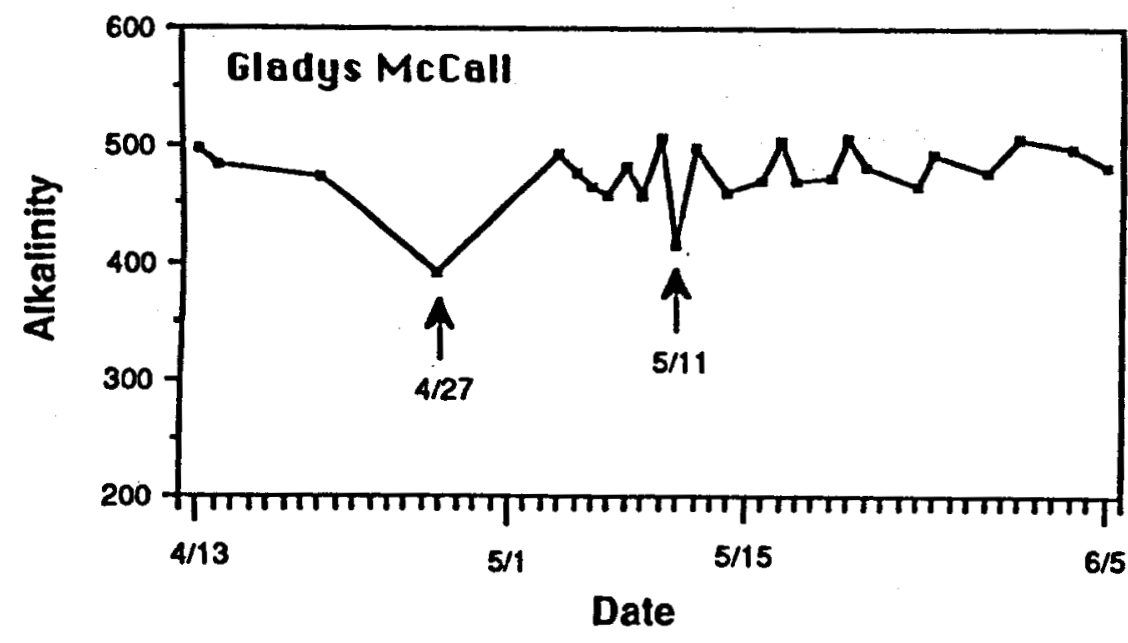

Figure V-1b.

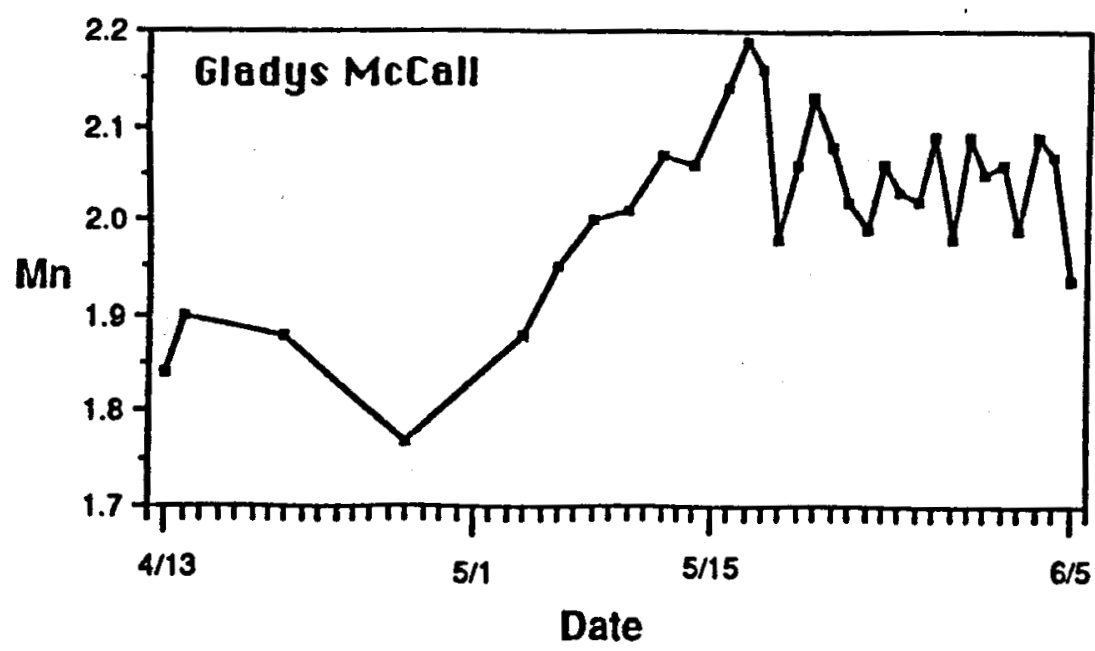

Figure V-1c.

$\mathrm{M}-48$

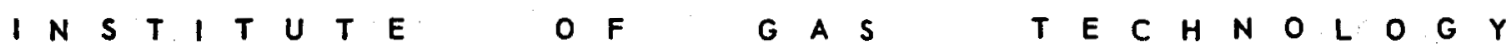


FLOW TES TS OF THE GLADYS MCCALL WELl Through OCTOBER 1990

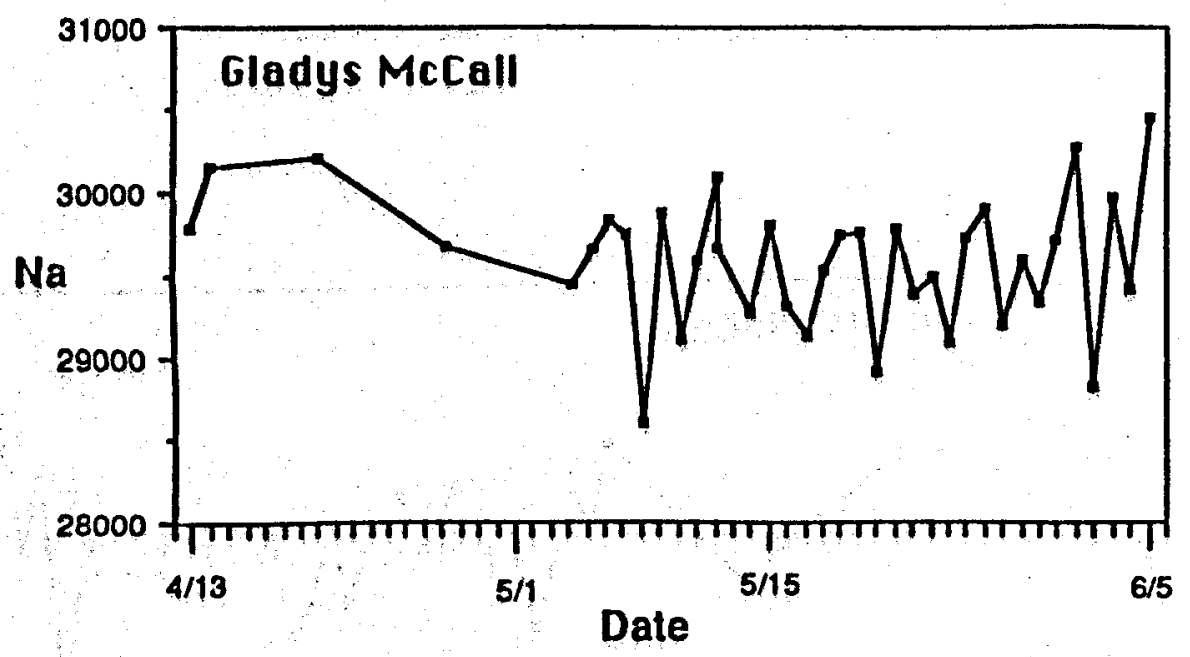

Figure V-1d.
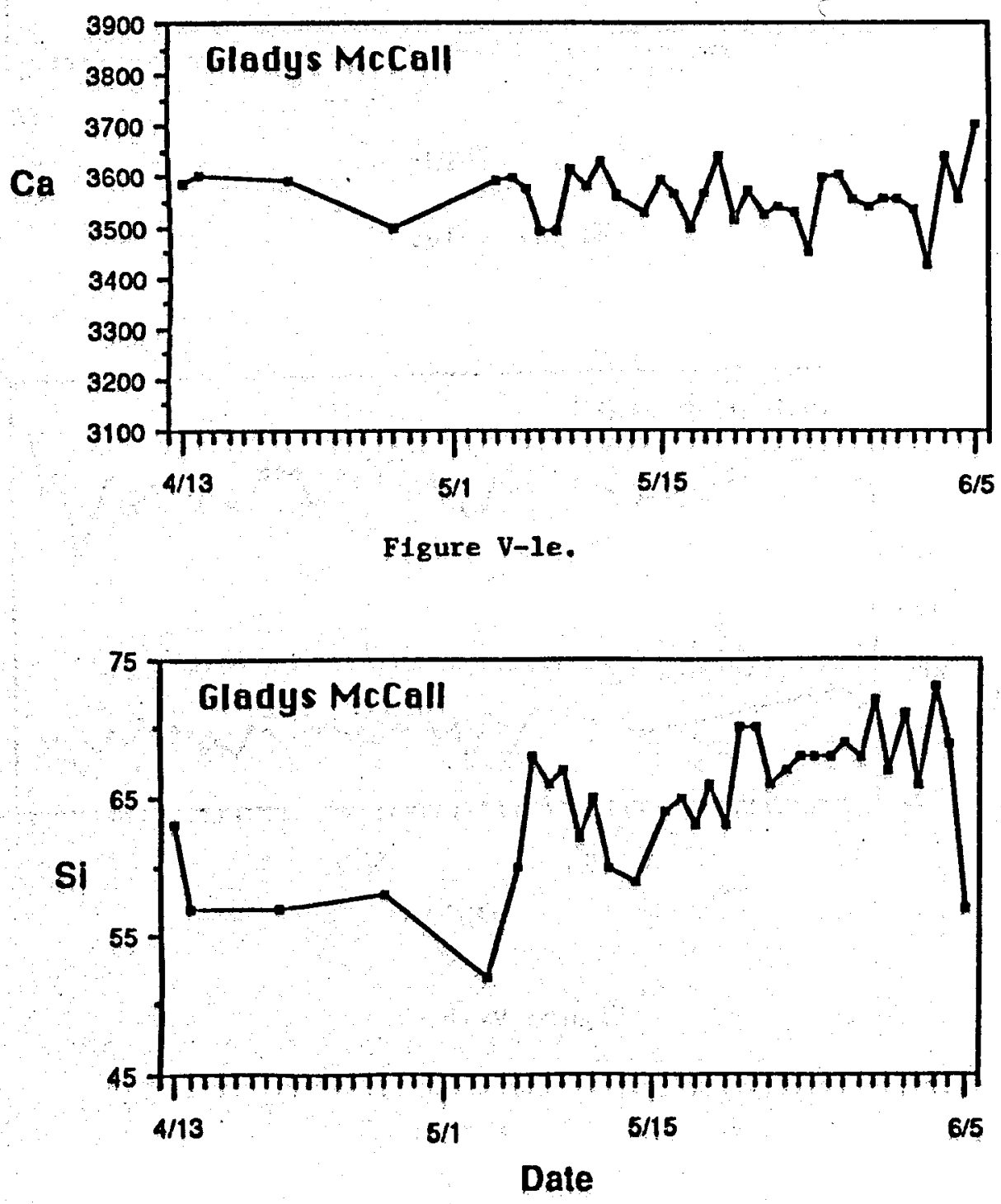

Figure V-1f,

$$
\text { M-49 }
$$


FLOW TESTS OF THE GLADYS MCCALL WELL THROUGH OCTOBER 1990

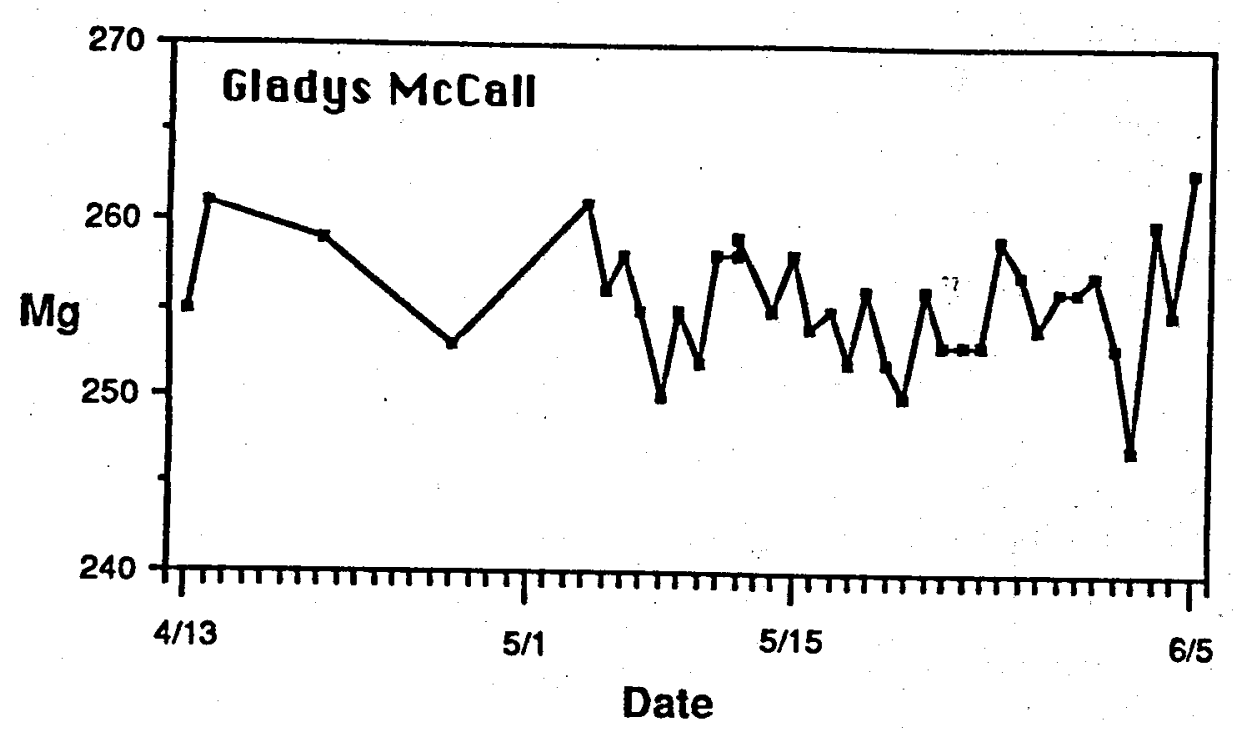

Figure V-1g.

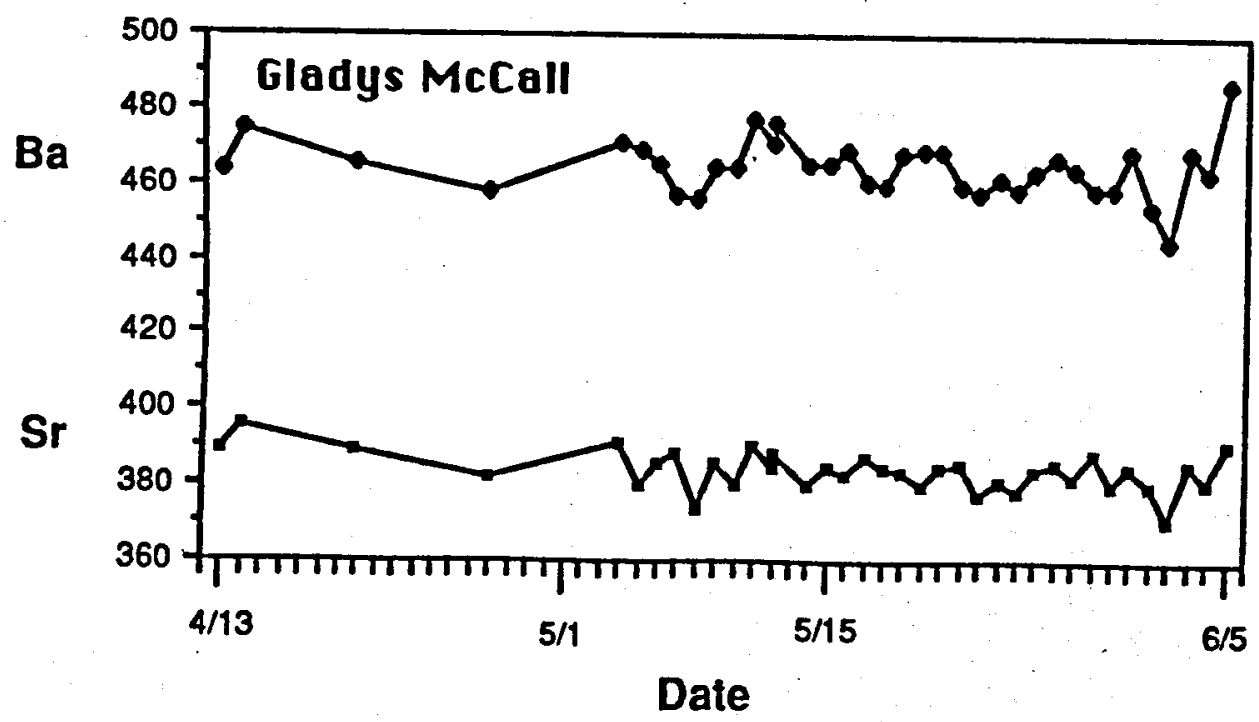

Figure V-1h.

M-50

INSTITUTE OF GAS TECHNOLOGY 
FLOW TESTS OF THE GLADYS MCCALL WELL THROUGH OCTOBÉR 1990

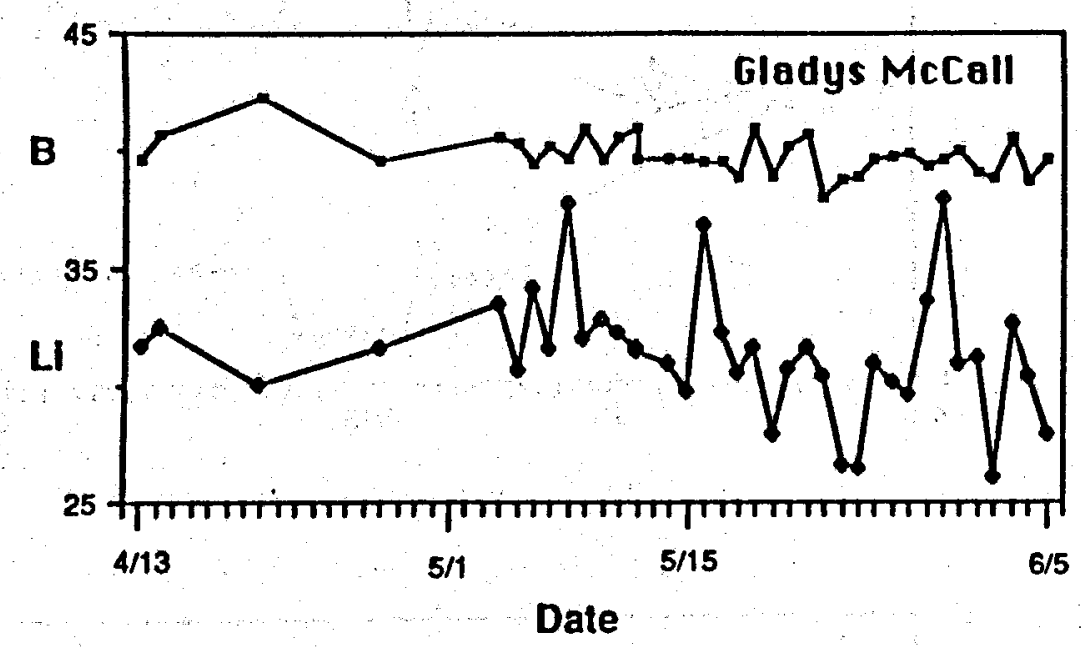

Figure $v-11$

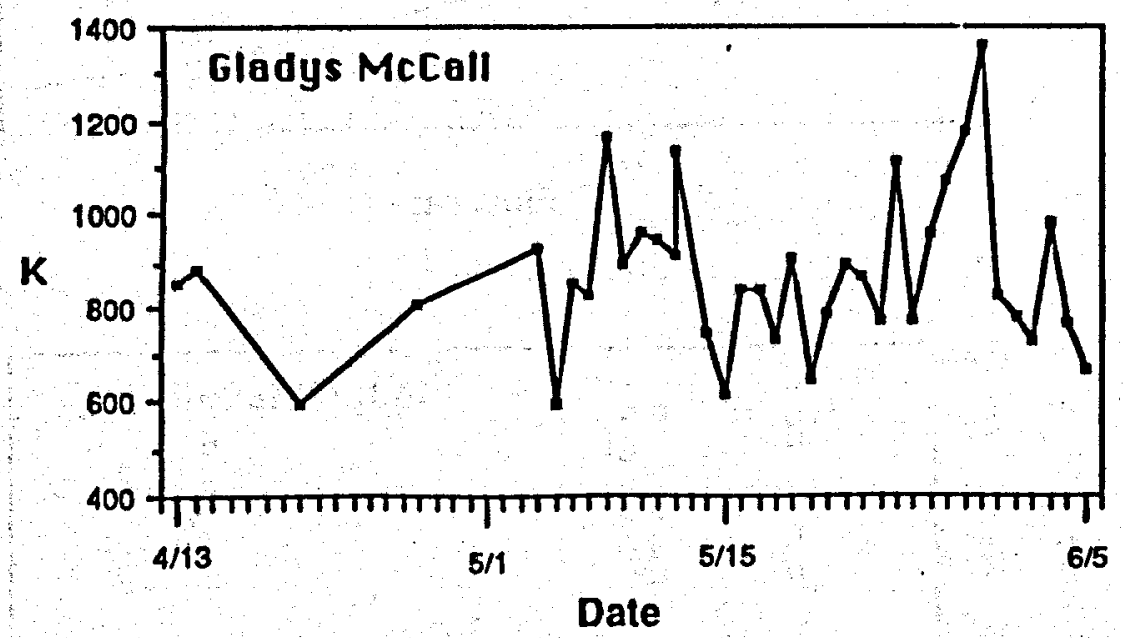

Figure V-1j.

M-51 
Flow tests of the Gladys MCCALl Well Through OCtober 1990
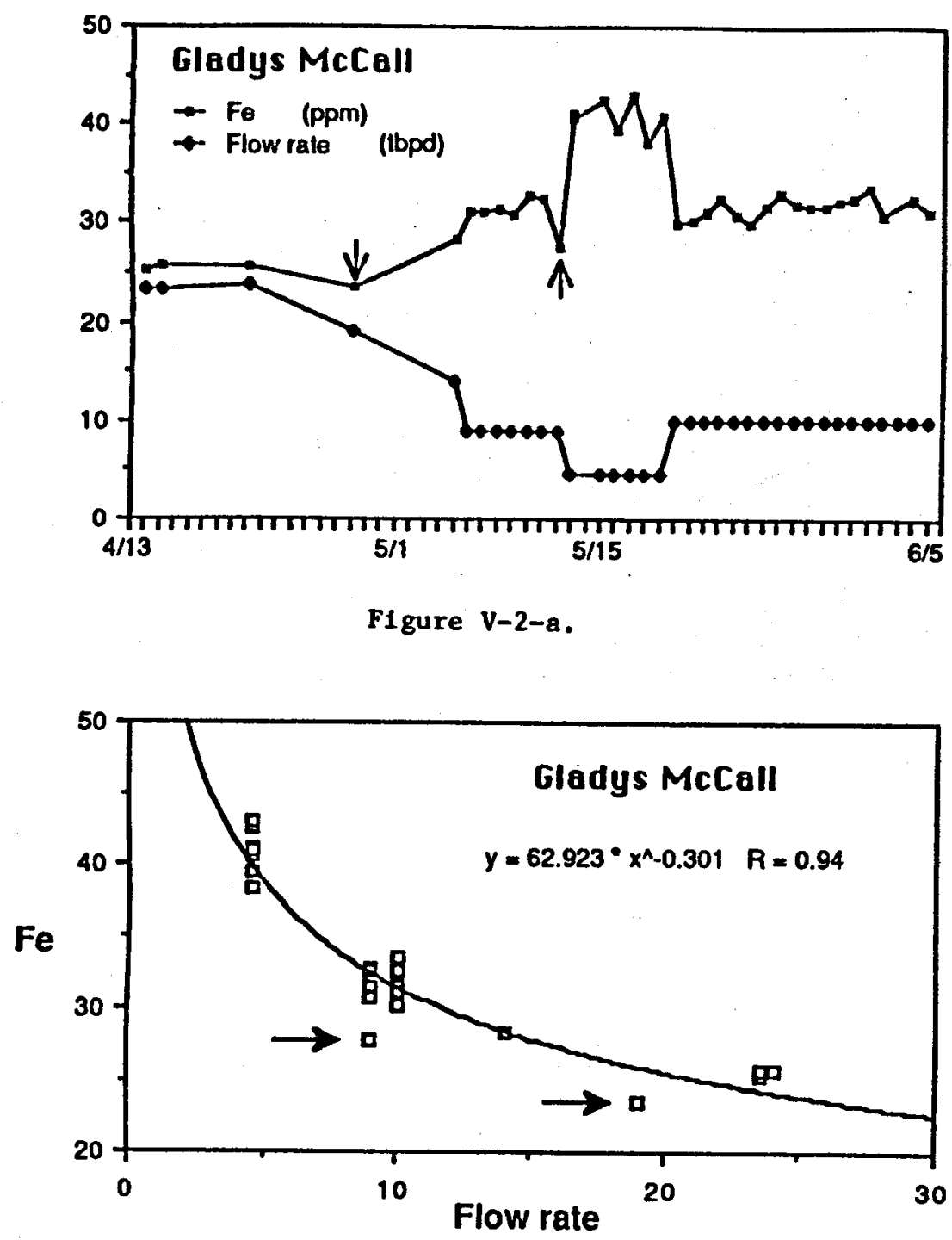

Figure v-2b.

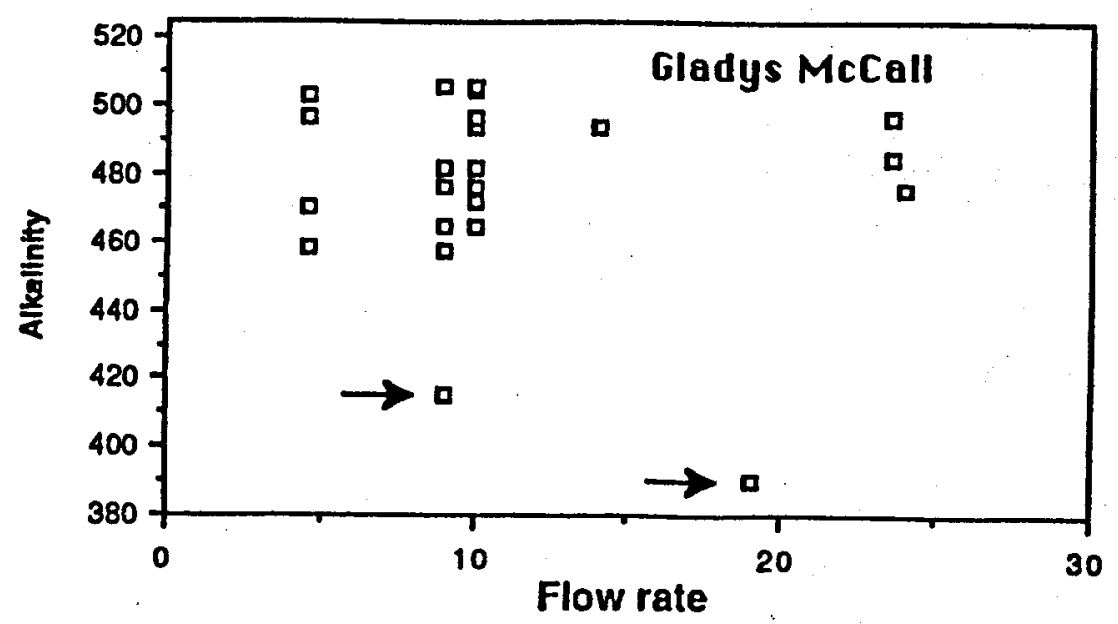

Figure V-2c.

M-52 
FLOW TESTS OF THE GLADYS MCCALL WeLl THROUgh OCTOBER 1990
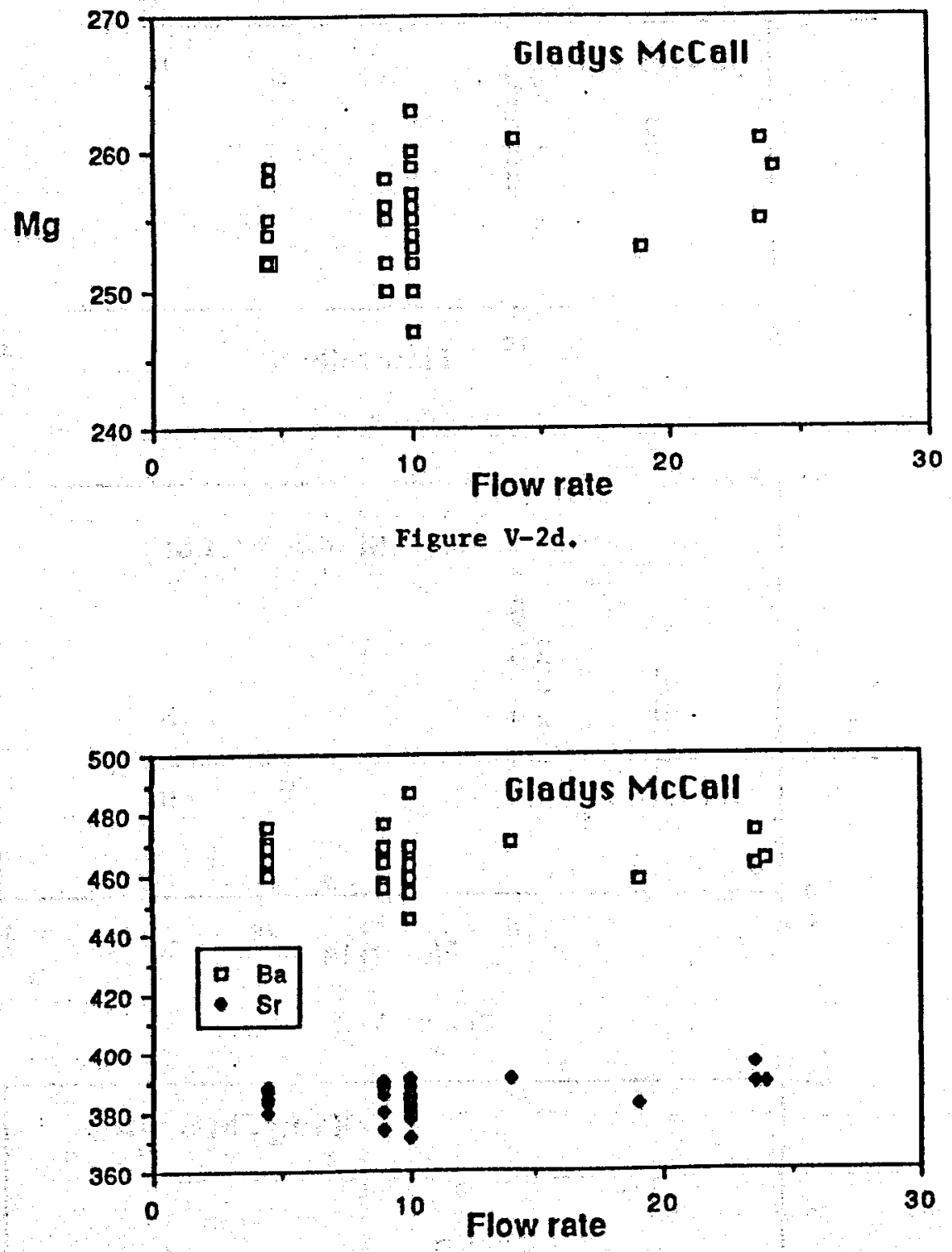

Figure V-2e.

M-53 
Flow Tests of the Gladys MCCall Well Through OCtober 1990
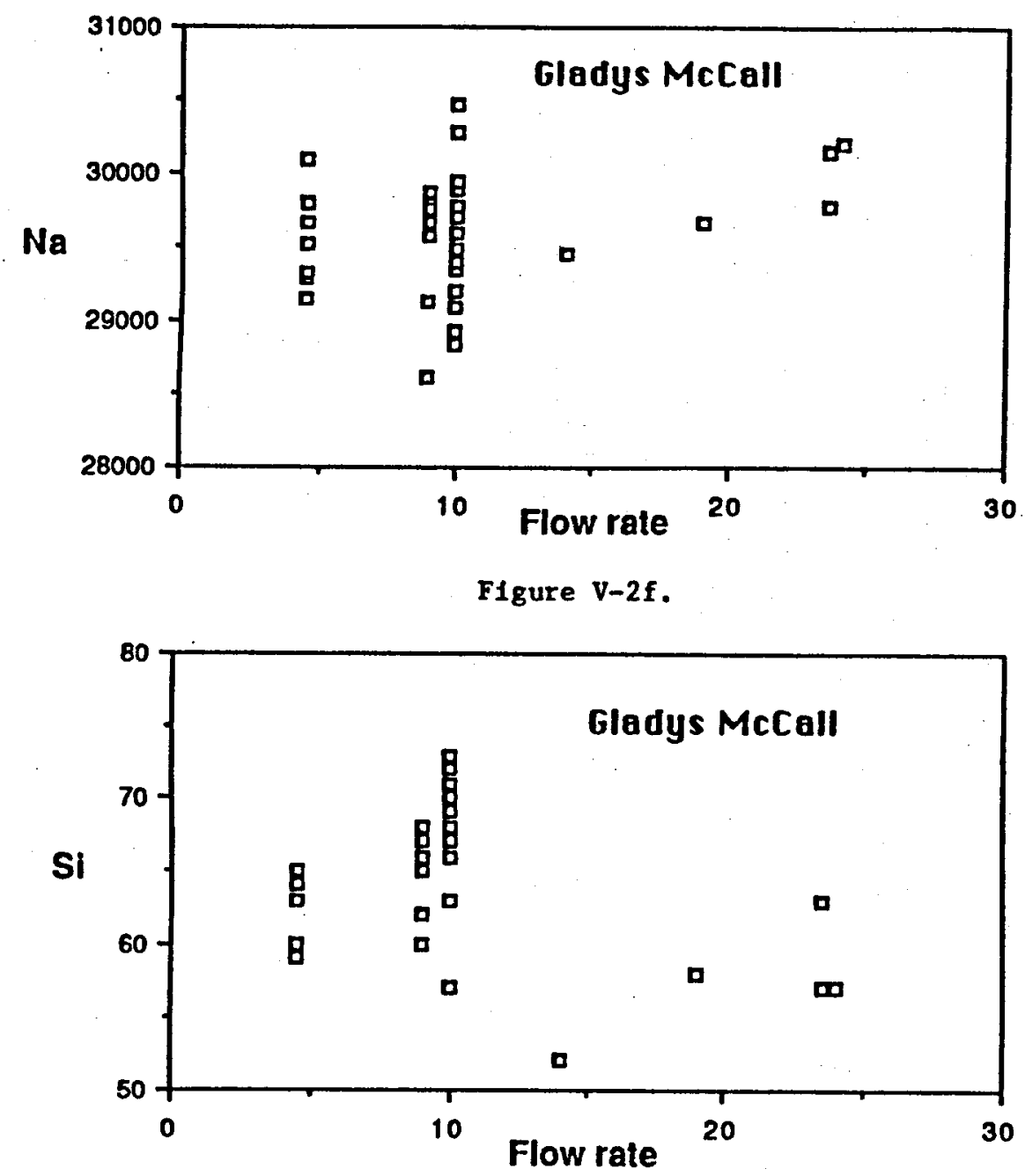

Figure v-2g.

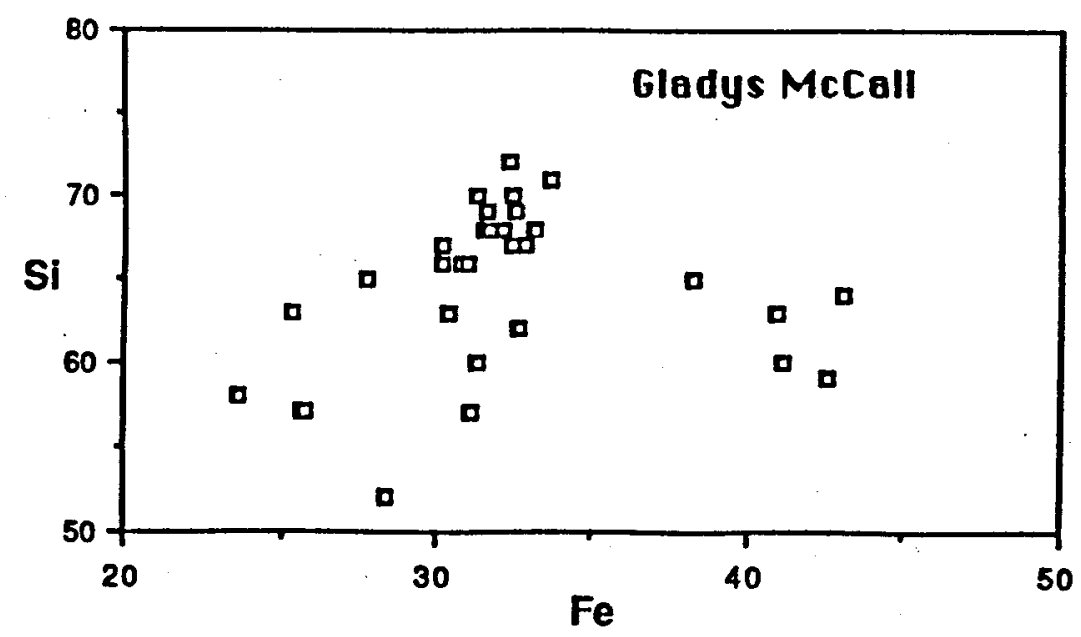

Figure V-2h.

M-54 
Flow Tests of the Gladys MCCALl Well Through OCtober 1990

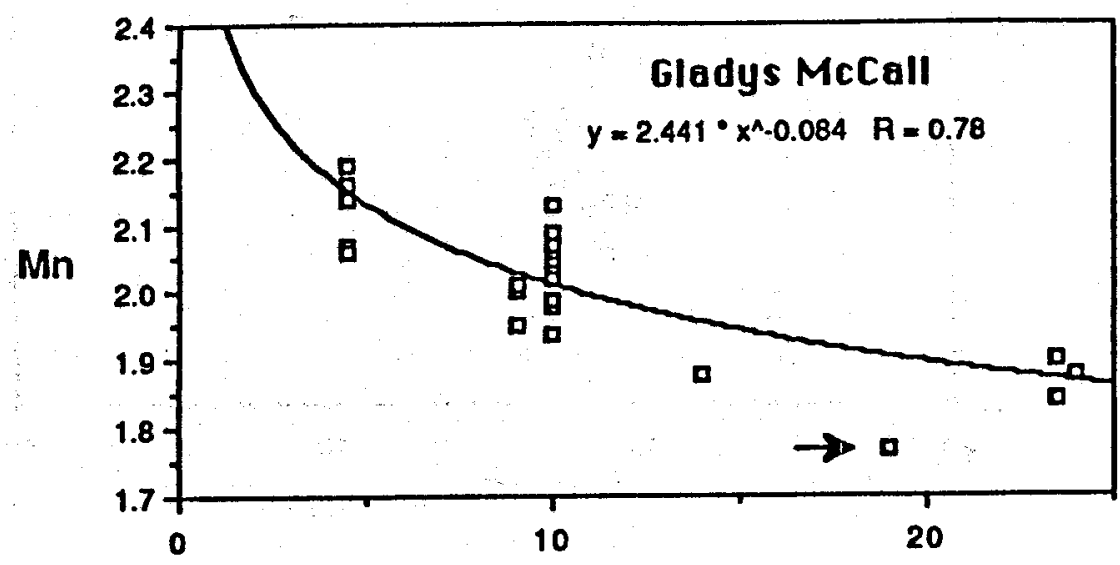

Flow rate

Figure V-21.

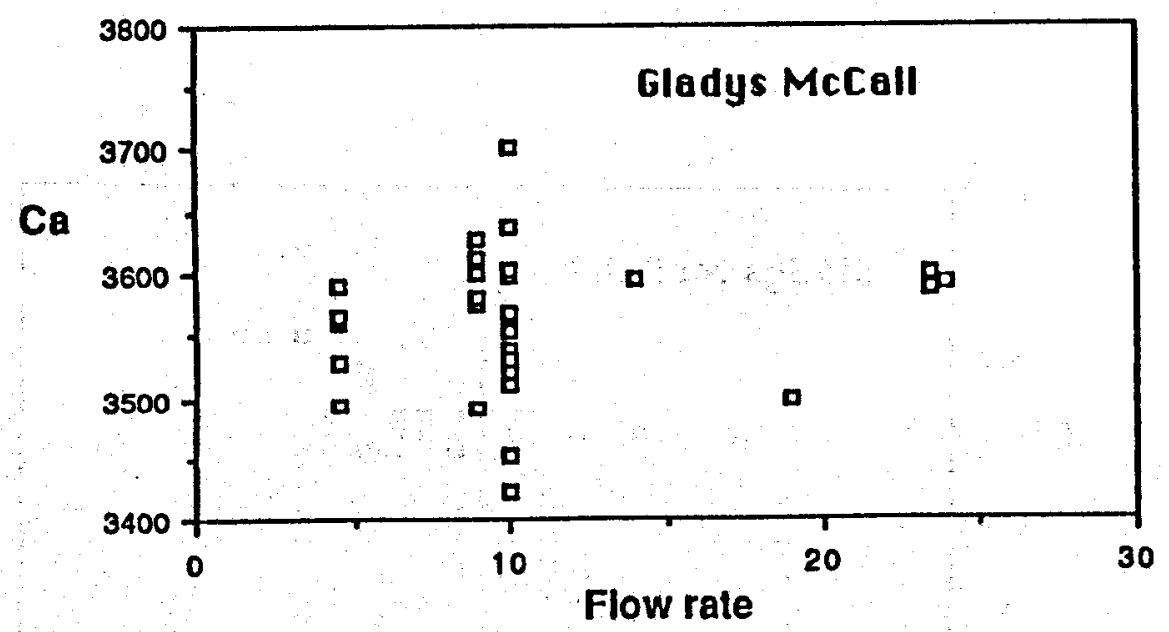

Figure V-2j, 
Flow Tests of the Gladys MCCALl Well THRough OCtober 1990

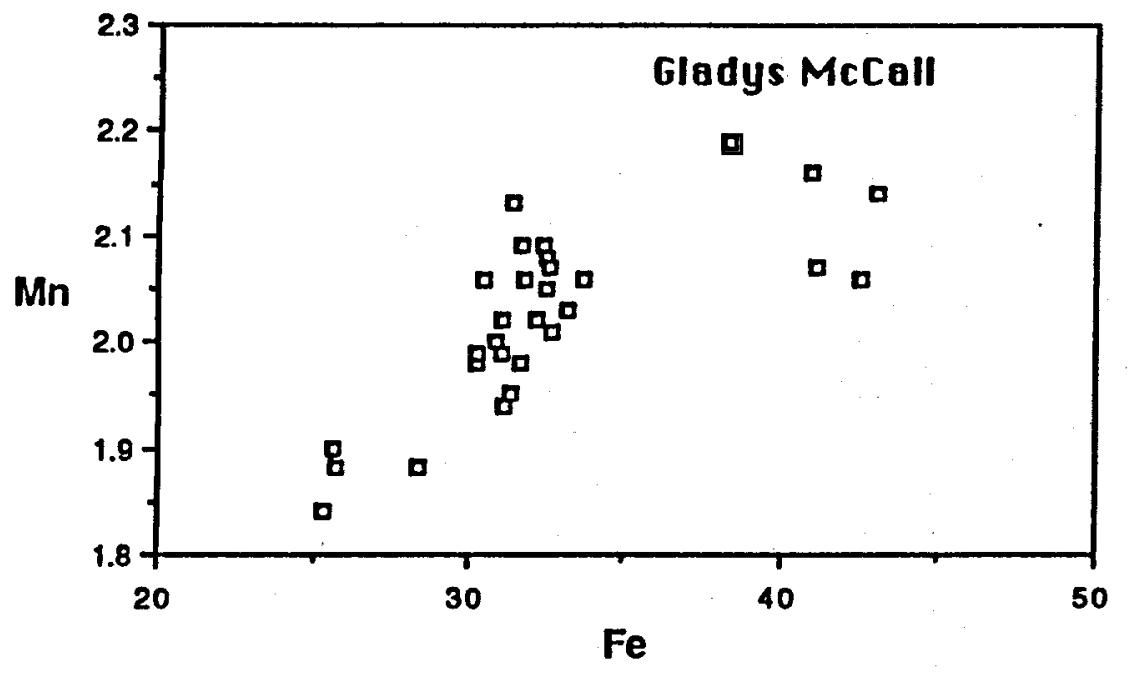

Figure v-3a.

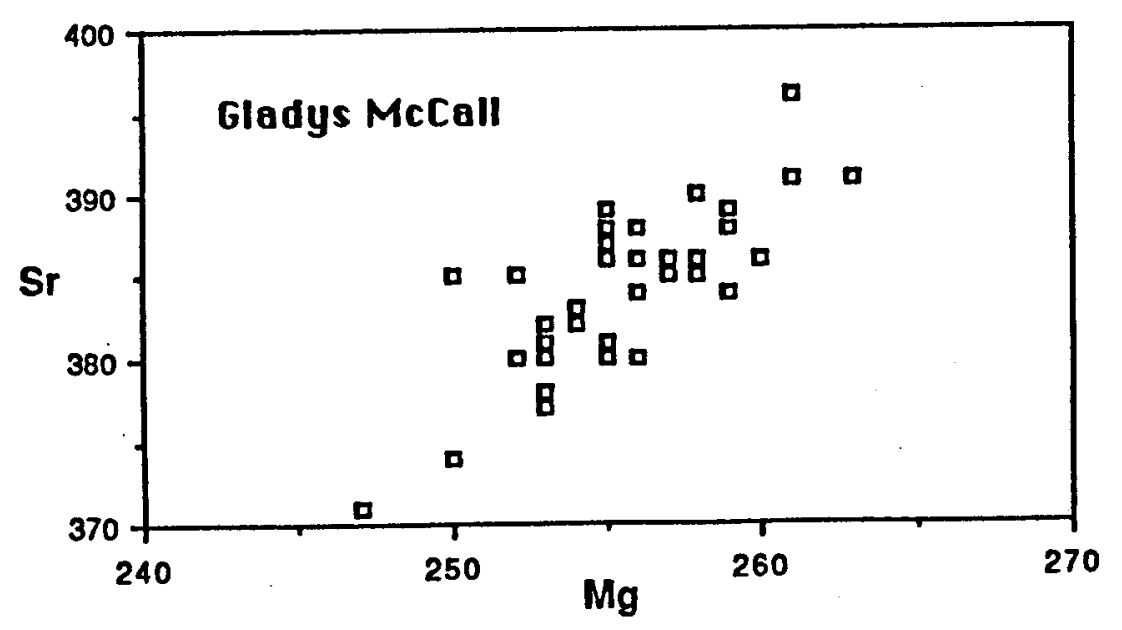

Figure v-3b.

M-56 
FLOW TESTS OF THE GLADYS MCCALL WELL THROUGH OCTOBER 1990

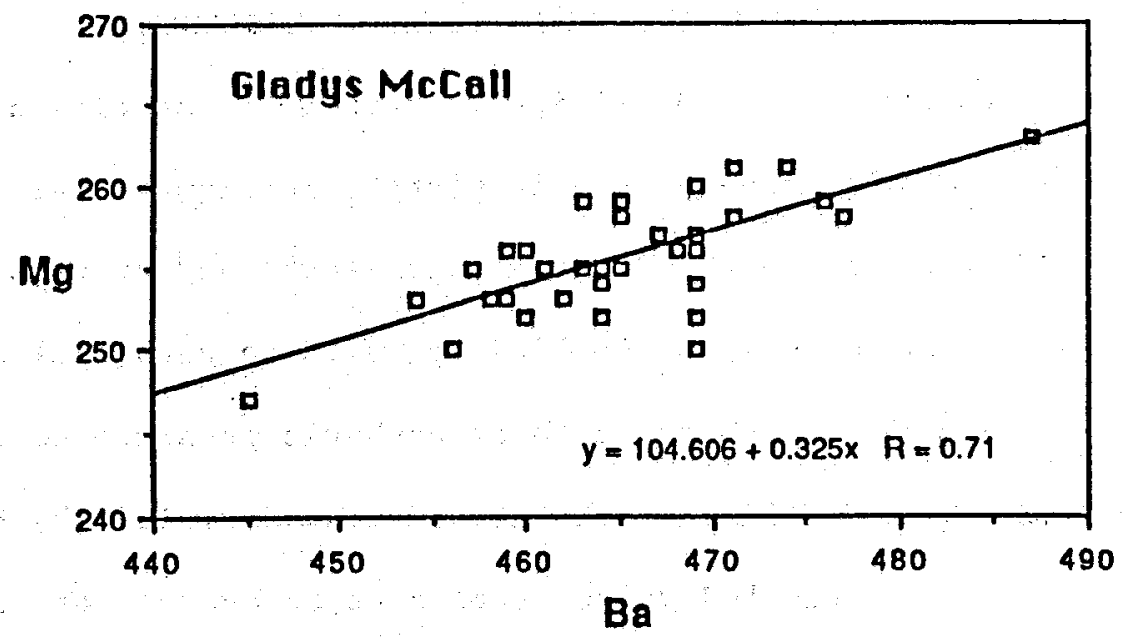

Figure $v-3 c$.

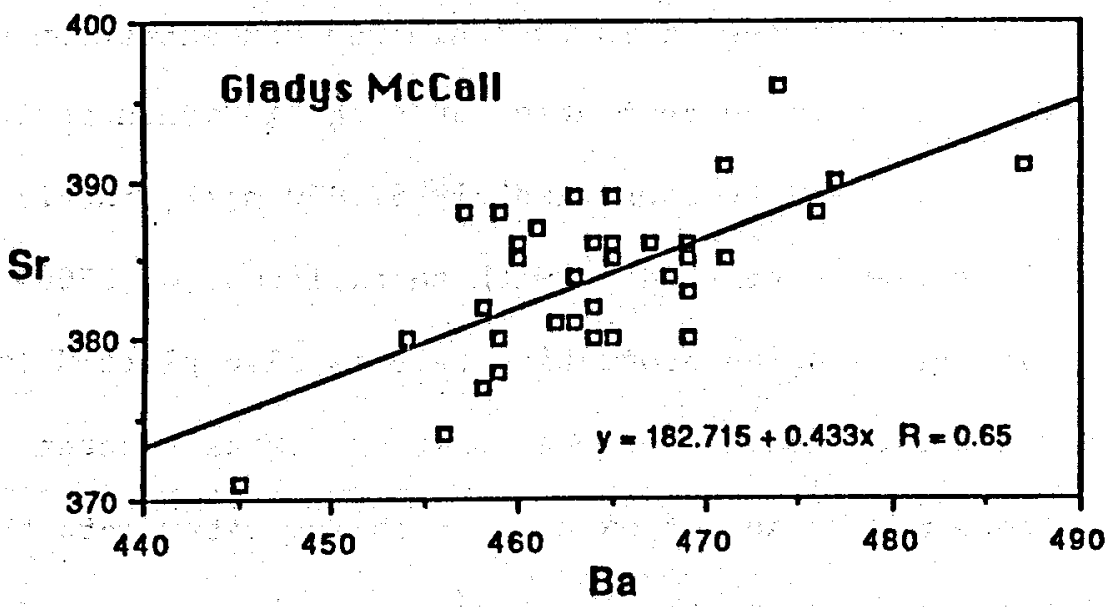

F1gure v-3d.

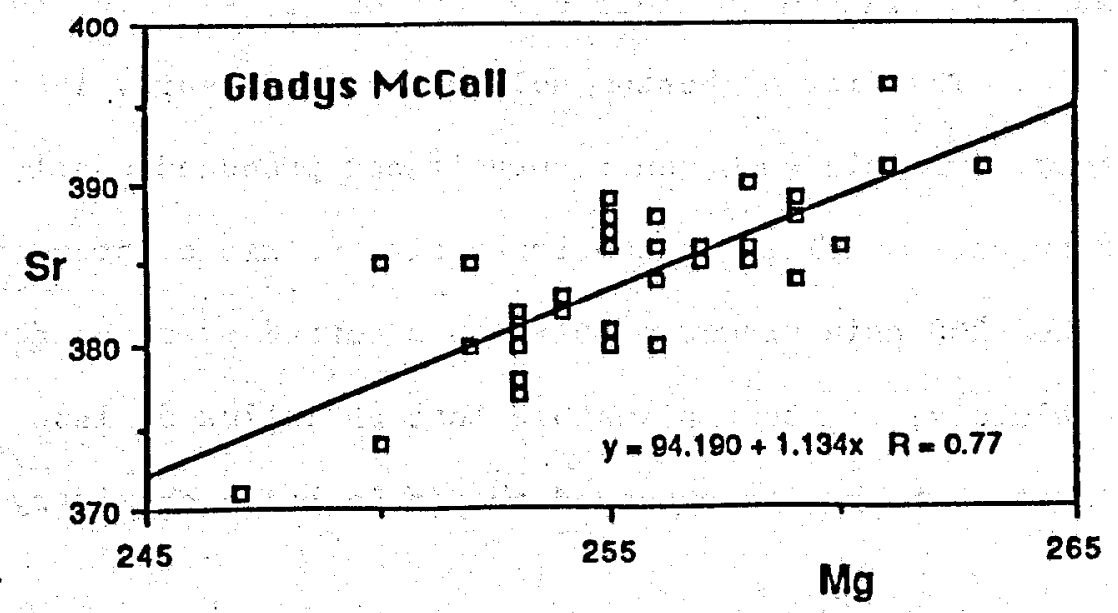

Figure $V-3 e$.

M-57 


\section{vi. GLADYS MCCALL CHLORIDE RESULTS}

The chloride concentration of eighty-three brine samples during the period from July 1985 - January 1987 is plotted in Figure VI-1. The data represent an analysis for approximately every sixth day of flow. The samples were collected in $500 \mathrm{ml}$ Nalgene bottles by wellsite personnel with no attempt to cool the brine prior to exposure to atmospheric pressure during sampling. The samples were analyzed in the laboratory in January 1987 by titration with mercuric nitrate. The plotted values represent an average of three to four measurements per sample with an analytical precision of $\pm 0.5 \%$ ( $\pm 300 \mathrm{mg}$ ).

Two phenomena are observed in the chloride concentration with time; 1) an overall decrease of $4 \%$ in concentration over the 18 month period from approximately $59,500 \mathrm{mg} / 1$ to approximately $57,000 \mathrm{mg} / 1$, and 2) an apparent periodicity of thirty to sixty days with an amplitude of $1500-4500 \mathrm{mg} / 1$ $(2.5-7.5 \%)$. The daily brine production rate is also plotted in Figure 1 . Several factors could account for the observed overall decrease in salinity with time. There may be an influx of less saline water into the produced zone from adjacent formations as the long term reservoir pressure declines. Sand zone \#8 had an initial bottom hole pressure of 12,783 psia when production began in 1983. The flowing bottom hole pressure in early 1987 was approximately 8600 psia when the reservoir had produced nearly 25 million barrels of brine. Considering the impressive volume of produced formation water and the 4200 psia drawdown that has occurred over the four year production history, it seems plausible that an influx of less saline formation water could account for the observed change in brine chemistry. 
However, it should be noted that variation in measured brine salinity could arise from both the brine sampling procedure (flashing of the brine on exposure to atmospheric pressure) and the eighteen month lag before analyzing the 1985 samples (potential for water loss through the nalgene bottle). This study clearly points out the need for timely analysis of samples and a sampling procedure designed to eliminate adverse chemical reactions.

The second phenomenon of the apparent periodicity of the fluctuation in chloride content is admittedly more dubious and difficult to explain. Once again, it could simply be an artifact of the sampling process. Alternatively, it may be related to complex reservoir mechanisms not yet understood.

The oscillations are not immediately related to the flow rate. However, it is interesting to note that the brine chemistry is relatively stable during the initial months following the shut-in period for both inhibitor squeezes, and that the oscillations appear to increase in both amplitude and period as time increases. Perhaps a limiting volume of brine must be produced following a shut-in period before the phenomenon is observed. Once again, additional long-term study is needed in other large volume reservoirs to verify the observed trend.

Finally, the measured chloride content of Gladys HcCall brines (Table III-2) sampled by slowly circulating the brine through coiled stainless steel tubing immersed in an ice bath, are typically $4-7 \%$ less concentrated than samples collected in open bottles without previous cooling of the brine. This is most easily explained by the uncontrolled water loss due to vaporization. The observed change is in excellent agreement with the water loss calculated by Chris Hayden (personal communication 1/16/87). 


\section{Gladys McCall Chloride}

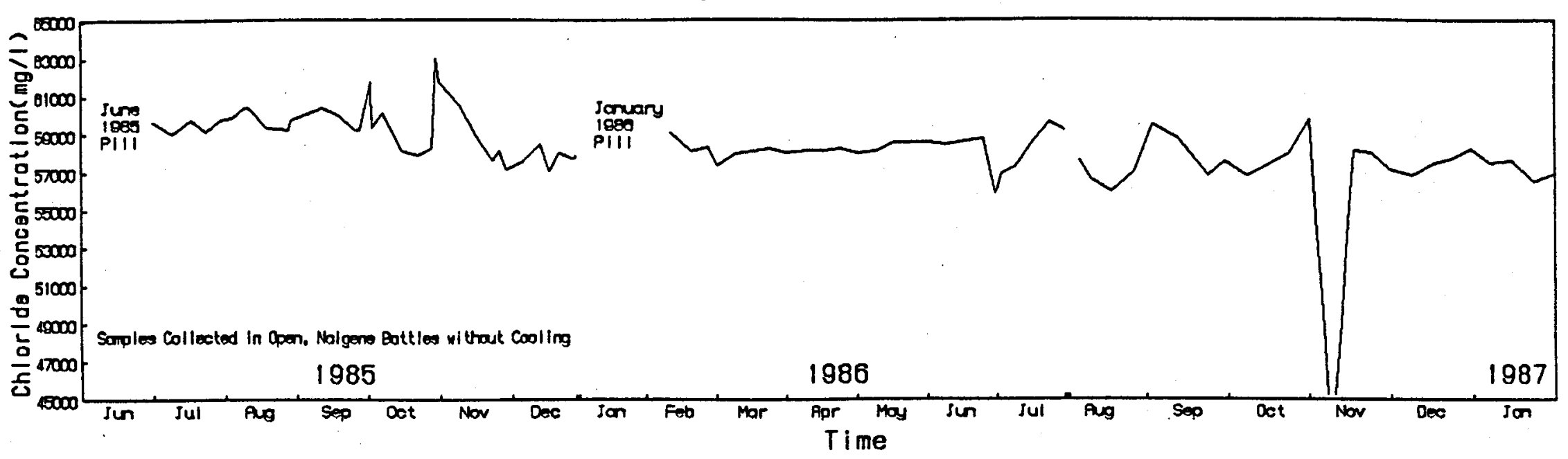

Figure VI-1. 
Flow TESTS OF THE GLAdys MCCALL Well THROUgh OCTOBER 1990

VII. COMPOSITION OF GLADYS MCCALL CARBONATE SCALE SAMPLES COLLECTED APRIL 1987

The flow rate was $\approx 24-27,000 \mathrm{BPD}$. The Scale 1 and Scale 2 samples are referred to as "soft" scale that was found downstream of the willis choke but upstream of the surface inhibitor injection point (Table vII-1). Scale 3 is a much "harder" scale that was found at the Willis choke. The scale cyrstals exhibit a very pronounced orientation.

The weighed samples were dissolved in dilute $\mathrm{HCl}$ and diluted to a final concentration near that of our major element ICP standard.

From the ICP results in Table VII-1 the composition of the scale was determined to be:

$$
\left[\mathrm{Ca} .92^{\mathrm{Fe}} .05^{\mathrm{Kg}} .02^{\mathrm{Sr}} .007^{\mathrm{Ba}} .002^{\mathrm{CO}_{3}}\right.
$$

This scale composition is typical of calcite materials from gas and oil field scales. Although the texture was observably different, the chemical analysis is quite similar. This suggests that the texture of scale is related to physical process and not a chemical composition. 
Flow Tests of the Gladys MCCall Well Through OCtober 1990

Table VII-1. Composition of Scale from Gladys McCall Well, April, 1987

\begin{tabular}{lccrrrr}
\hline & \multicolumn{2}{c}{ Scale-1 } & \multicolumn{2}{c}{ Scale -2} & & Scale -3 \\
\cline { 2 - 5 } & & & & \\
$\mathrm{Ca}$ & $380.0 \mathrm{ppm}(90.0 \%)$ & $373.5(90.2 \%)$ & 379.5 & $(89.9 \%)$ \\
$\mathrm{Fe}$ & 27.85 & $(6.6 \%)$ & 26.8 & $(6.5 \%)$ & 27.5 & $(6.5 \%)$ \\
$\mathrm{HB}$ & 6.15 & $(1.5 \%)$ & 6.0 & $(1.4 \%)$ & 5.8 & $(1.4 \%)$ \\
$\mathrm{Sr}$ & 5.6 & $(1.3 \%)$ & 5.5 & $(1.3 \%)$ & 6.2 & $(1.5 \%)$ \\
$\mathrm{Ba}$ & $\frac{2.6}{422.2}$ & $\frac{(0.6 \%)}{100 \%}$ & $\frac{2.5}{414.3} \frac{(0.6 \%)}{100 \%}$ & $\frac{3.15}{422.2} \frac{(0.7 \%)}{100 \%}$
\end{tabular}

Avg Composition of typical Gladys Scale:

Wt\%

Calcium

Iron

Magnesium

Strontium

Barium
90.1

6.5

6.0

5.8

0.6
Ho1\%

.0094

.0005

.0002

.00007

.00002
Relative Molz

$92.3 \%$

$4.9 \%$

$1.9 \%$

$0.7 \%$

$0.2 \%$ 
FLOW TESTS OF THE GLAdys MCCALL Well THROUgh OCTOBER 1990

\section{APPENDIX N}

Corrosion Coupon Data

N-1 

Corrosion coupons were checked with a frequency of daily to weekly for much of the test. A few coupons were left in place for as long as several months between checking. The corrosion coupon data are presented in Exhibits $\mathrm{N}-1$ through $\mathrm{N}-6$. The entries in this exhibit are in chronological order with the exception that the entries are grouped by step in the testing sequence and by coupon location.

Corrosion in the surface facilities was noted early in the flow test. The October 27, 1983, Daily Testing Report stated that a coupon had lost 2 grams of weight ( $20 \%$ of its total weight) during a 1-week interval. The coupons had an area of about 2.5 square inches exposed to the brine. This weight loss corresponds to a corrosion rate of about $\mathbf{4 0 0}$ mils per year. High corrosion rates for coupons continued to be observed. The November 1, 1984, Daily Testing Report stated that another coupon lost $25 \%$ of its weight in 3 days, with an inferred corrosion rate of about 1000 mils per year.

The high coupon corrosion rates were observed in the coupons through much of the flow test. However, the data must be used with caution for several reasons as listed below:

- The coupons were fabricated from $1 / 8$-inch "mild steel" plate in a local machine shop. The metallurgy and coupon fabrication procedures are not known and it is possible that there are metallurgical differences between coupons.

- The coupons were not electrically isolated from the pipe, which leaves open the possibility that corrosion may have been accelerated or inhibited by an electric potential set up between dissimilar metals.

- The corrosion coupon installation and data collection procedures changed over time. Interpretation of corrosion data is difficult without a thorough understanding of corrosion coupon locations and data collection practices.

Some of the important changes in coupon procedure are summarized in the paragraphs below,

The early tests of the well had a first coupon station between the choke and the separator and second coupon station in the brine line between the separator dump valve and the filter skid. After the second separator was installed in series, a new upstream coupon station was built into the brine line between the high-pressure separator dump valve and the inlet to the low-pressure separator. The downstream station remained between the low-pressure separator dump valve and the filter skid.

The initial coupon station between the choke and the first separator differed from the other two in that it involved a small-diameter pipe in parallel with the main flow line. Thus, only a small 
fraction of the flowing brine passed through the pipe that contained the coupon. In contrast, the full stream passed by the coupons in the other two stations

Initially, there were three coupon holders at each location for daily, weekly, and monthly samples. The extent to which weekly or monthly coupons were used is apparent from the tabulated "Time In" in Exhibits N-1 through N-6.

The most comprehensive coupon data were collected in January 1985. Coupons located in a 6-inch-diameter brine line between the high-pressure separator dump valve and the low-pressure separator were inspected daily. There was considerable variability day by day, but the average weight loss was over 0.5 grams per day. This corresponds to an average corrosion rate of about 700 mils per year. The flow rate during this period was just over 15,000 barrels per day, and the brine velocity in the 6-inch line would have been about 6 feet per second. At the same time, coupons installed in a 6-inch line after the low-pressure separator had a corrosion rate orders of magnitude lower than the coupons located between the separators. It is hypothesized that this was caused by scale formation on the downstream coupons.

The same coupon was often re-installed after being inspected. This is apparent from the numerous entries in Exhibit N-1 wherein the "Weight In" is equal to the "Weight Out" for the prior time interval. This was the case despite recorded weight loss, signifying corrosion, or weight gain, signifying scale deposition. As a result, much of the data, especially after April 1985, are of marginal value. The coupon between the separators was installed on October 9, 1985, and used through the end of the test on October 1987. The coupon was removed every 3 to 7 days during periods when the well was flowing but was not replaced. The original weight of the coupon was 9.14 grams. As shown in the table below, it was higher than the initial value for most of the time. This indicates a coating on the coupon that may well have precluded corrosion.

Date

October 9, 1985

February 15, 1986

March 3, 1986

April 8, 1986

June 23, 1986

June 23, 1986 a

October 8, 1986

April 7, 1987

July 31, 1987

July $31,1987^{a}$

October 26, 1987
Weight

9.14 grams

9.08 grams

9.14 grams

9.20 grams

9.454 grams

9.367 grams

9.40 grams

9.381 grams

9.38 grams

9.26 grams

9.328 grams
Difference From Initial Weight

-0.06 grams

0.00 grams

0.06 grams

0.314 grams

0.227 grams

0.26 grams

0.241 grams

0.24 grams

0.12 grams

0.188 grams

a Signifies the coupon was washed in acid prior to reinsertion. 
Corrosion data for the location after the low-pressure separator had a few valid data points. Corrosion was high enough that coupons were changed with more regularity, generally once every few months. Corrosion rates for new coupons would usually range from 10 to 100 mils per year for a week or so. After a week or two of service, however, the weight of the corrosion coupon would stabilize and usually slowly increase. For instance, a coupon installed on August 19, 1985, had corrosion rates than averaged over 10 mils per year over the next 13 days. Then, weight loss stopped and the average corrosion rate over the following 4 months was a negative value. The coupon was changed on December 27, 1985, and corrosion over the next 12 days averaged over 30 mils per year. Then, the coupon weight changes again showed a negative value over the next few months.

The corrosion data for those periods just after changing coupons was probably the most realistic data available. Large variability in corrosion rates may have been caused by the conflicting processes of scaling and corrosion. 
Flow Tests of the Gladys MCCall Well Through OCtober 1990

Exhibit N-1. CORROSION COUPON DATA FOR THE 24-DAY FLOW TEST OF SAND 9

Before Separator

Date In Date Out Weight In Weight Out Weight Loss Time In Loss Rate

\begin{tabular}{|c|c|c|c|c|c|c|}
\hline & & (grams) & (grams) & (grams) & (Days) & (mils/yr) \\
\hline $3 / 25 / 83$ & $3 / 28 / 83$ & 10.430 & 10.448 & -0.018 & 3 & -6.77 \\
\hline $3 / 28 / 83$ & $3 / 29 / 83$ & 10.465 & 10.458 & 0.007 & 1 & 7.90 \\
\hline $3 / 29 / 83$ & $3 / 30 / 83$ & 10.244 & 10.255 & -0.011 & 1 & -12.41 \\
\hline $3 / 30 / 83$ & $4 / 1 / 83$ & 10.226 & 10.243 & -0.017 & 2 & -9.59 \\
\hline $4 / 1 / 83$ & $4 / 2 / 83$ & 10.347 & 10.365 & -0.018 & 1 & -20.30 \\
\hline $4 / 2 / 83$ & $4 / 3 / 83$ & 10.449 & 10.465 & -0.016 & 1 & -18.05 \\
\hline $4 / 3 / 83$ & $4 / 4 / 83$ & 10.458 & 10.460 & -0.002 & 1 & -2.26 \\
\hline $4 / 4 / 83$ & $4 / 5 / 83$ & 10.313 & 10.314 & -0.001 & 1 & -1.13 \\
\hline $4 / 5 / 83$ & $4 / 6 / 83$ & 10.227 & 10.189 & 0.038 & 1 & 42.86 \\
\hline $4 / 6 / 83$ & $4 / 7 / 83$ & 10.282 & 10.297 & -0.015 & 1 & -16.92 \\
\hline $4 / 7 / 83$ & $4 / 8 / 83$ & 10.295 & 10.314 & -0.019 & 1 & -21.43 \\
\hline $4 / 8 / 83$ & $4 / 9 / 83$ & 10.274 & 10.310 & -0.036 & 1 & -40.61 \\
\hline 4/9/83 & $4 / 10 / 83$ & 10.347 & 10.381 & -0.034 & 1 & -38.35 \\
\hline $4 / 10 / 83$ & $4 / 11 / 83$ & 10.271 & 10.283 & -0.012 & 1 & -13.54 \\
\hline $4 / 11 / 83$ & $4 / 12 / 83$ & 10.370 & 10.382 & -0.012 & 1 & -13.54 \\
\hline $4 / 12 / 83$ & $4 / 13 / 83$ & 10.197 & 10.207 & -0.010 & 1 & -11.28 \\
\hline
\end{tabular}

Disposal Well Line After Separator

$\begin{array}{ccccccr}\text { Date In } & \text { Date Out } & \begin{array}{c}\text { Weight In } \\ \text { (grams) }\end{array} & \begin{array}{c}\text { Weight Out } \\ \text { (grams) }\end{array} & \begin{array}{c}\text { Weight Loss } \\ \text { (grams) }\end{array} & \begin{array}{c}\text { Time In } \\ \text { (Days) }\end{array} & \begin{array}{c}\text { Loss Rate } \\ \text { (mils/yr) }\end{array} \\ 3 / 25 / 83 & 3 / 28 / 83 & 10.317 & 10.330 & -0.013 & 3 & -4.89 \\ 3 / 28 / 83 & 3 / 29 / 83 & 10.000 & 10.034 & -0.034 & 1 & -38.35 \\ 3 / 29 / 83 & 3 / 30 / 83 & 10.220 & 10.249 & -0.029 & 1 & -32.71 \\ 3 / 30 / 83 & 4 / 1 / 83 & 10.301 & 10.323 & -0.022 & 2 & -12.41 \\ 4 / 1 / 83 & 4 / 2 / 83 & 10.416 & 10.440 & -0.024 & 1 & -27.07 \\ 4 / 2 / 83 & 4 / 3 / 83 & 10.400 & 10.426 & -0.026 & 1 & -29.33 \\ 4 / 3 / 83 & 4 / 4 / 83 & 10.228 & 10.239 & -0.011 & 1 & -12.41 \\ 4 / 4 / 83 & 4 / 5 / 83 & 10.327 & 10.360 & -0.033 & 1 & -37.22 \\ 4 / 5 / 83 & 4 / 6 / 83 & 10.458 & 10.461 & -0.003 & 1 & -3.38 \\ 4 / 6 / 83 & 4 / 7 / 83 & 10.239 & 10.245 & -0.006 & 1 & -6.77 \\ 3 / 29 / 83 & 4 / 6 / 83 & 10.465 & 10.476 & -0.011 & 8 & -1.55 \\ 4 / 7 / 83 & 4 / 8 / 83 & 10.019 & 10.112 & -0.093 & 1 & -104.90 \\ 4 / 8 / 83 & 4 / 9 / 83 & 10.314 & 10.231 & 0.083 & 1 & 93.62 \\ 4 / 9 / 83 & 4 / 10 / 83 & 10.034 & 9.998 & 0.036 & 1 & 40.61 \\ 4 / 10 / 83 & 4 / 11 / 83 & 9.677 & 9.696 & -0.019 & 1 & -21.43 \\ 4 / 11 / 83 & 4 / 12 / 83 & 9.986 & 9.981 & 0.005 & 1 & 5.64 \\ 4 / 12 / 83 & 4 / 13 / 83 & 10.223 & 10.256 & -0.033 & 1 & -37.22 \\ 4 / 6 / 83 & 4 / 13 / 83 & 10.281 & 10.300 & -0.019 & 7 & -3.06\end{array}$

N-6 
Flow TESTS OF The GLAdys MCCALL Well Through OCTOBER 1990

Exhibit N-2. CORROSION COUPON DATA FOR THE 21-DAY FLOW TEST OF SAND 8

Before Separator (Flow was 9 Hours on 9/16/83, From 10/7 to 28/83, and Starting 12/2/83)

$\begin{array}{ccccccc}\text { Date In } & \text { Date Out } & \begin{array}{c}\text { Weight In } \\ \text { (grams) }\end{array} & \begin{array}{c}\text { Weight Out } \\ \text { (grams) }\end{array} & \begin{array}{c}\text { Weight Loss } \\ \text { (grams) }\end{array} & \begin{array}{c}\text { Time in } \\ \text { (Days) }\end{array} & \begin{array}{c}\text { Loss Rate } \\ \text { (mils/yr) }\end{array} \\ 9 / 16 / 83 & 10 / 19 / 83 & 10.426 & 10.558 & -0.132 & 33 & -4.51 \\ 10 / 19 / 83 & 12 / 5 / 83 & 10.110 & 10.025 & 0.085 & 47 & 2.04\end{array}$

Disposal Well Line After Separator (Flow was 9 hours on 9/16/83 and From $10 / 7$ to 28/83)

\begin{tabular}{rrrrrrr} 
Date In & Date Out & $\begin{array}{c}\text { Weight In } \\
\text { (grams) }\end{array}$ & $\begin{array}{r}\text { Weight Out } \\
\text { (grams) }\end{array}$ & $\begin{array}{r}\text { Weight Loss } \\
\text { (grams) }\end{array}$ & $\begin{array}{r}\text { Time in } \\
\text { (Days) }\end{array}$ & $\begin{array}{r}\text { Loss Rate } \\
\text { (mils/yr) }\end{array}$ \\
$9 / 16 / 83$ & $10 / 8 / 83$ & 10.269 & 10.435 & -0.166 & 22 & -8.51 \\
$9 / 16 / 83$ & $10 / 8 / 83$ & 10.216 & 9.991 & 0.225 & 22 & 11.54 \\
$9 / 16 / 83$ & $10 / 8 / 83$ & 10.463 & 10.558 & -0.095 & 22 & -4.87 \\
$10 / 8 / 83$ & $10 / 9 / 83$ & 10.422 & 10.391 & 0.031 & 1 & 34.97 \\
$10 / 9 / 83$ & $10 / 10 / 83$ & 10.360 & 10.365 & -0.005 & 1 & -5.64 \\
$10 / 10 / 83$ & $10 / 11 / 83$ & 10.284 & 10.239 & 0.045 & 1 & 50.76 \\
$10 / 11 / 83$ & $10 / 12 / 83$ & 10.206 & 10.157 & 0.049 & 1 & 55.27 \\
$10 / 11 / 83$ & $10 / 19 / 83$ & 9.920 & 9.833 & 0.087 & 8 & 12.27 \\
$10 / 11 / 83$ & $10 / 31 / 83$ & 10.338 & 10.297 & 0.041 & 20 & 2.31 \\
$10 / 12 / 83$ & $10 / 13 / 83$ & 9.820 & 9.423 & 0.397 & 1 & 447.82 \\
$10 / 13 / 83$ & $10 / 14 / 83$ & 10.217 & 9.900 & 0.317 & 1 & 357.58 \\
$10 / 14 / 83$ & $10 / 15 / 83$ & 10.122 & 9.951 & 0.171 & 1 & 192.89 \\
$10 / 15 / 83$ & $10 / 16 / 83$ & 10.217 & 10.087 & 0.130 & 1 & 146.64 \\
$10 / 16 / 83$ & $10 / 17 / 83$ & 10.460 & 10.021 & 0.439 & 1 & 495.19 \\
$10 / 17 / 83$ & $10 / 18 / 83$ & 10.331 & 10.117 & 0.214 & 1 & 241.39 \\
$10 / 18 / 83$ & $10 / 19 / 83$ & 9.767 & 9.700 & 0.067 & 1 & 75.58 \\
$10 / 19 / 83$ & $10 / 20 / 83$ & 10.150 & 10.122 & 0.028 & 1 & 31.58 \\
$10 / 19 / 83$ & $10 / 26 / 83$ & 10.350 & 8.926 & 1.424 & 7 & 229.47 \\
$10 / 20 / 83$ & $10 / 21 / 83$ & 10.260 & 9.930 & 0.330 & 1 & 372.24 \\
$10 / 21 / 83$ & $10 / 22 / 83$ & 9.850 & 9.770 & 0.080 & 1 & 90.24 \\
$10 / 22 / 83$ & $10 / 23 / 83$ & 10.160 & 9.890 & 0.270 & 1 & 304.56 \\
$10 / 23 / 83$ & $10 / 24 / 83$ & 10.210 & 9.770 & 0.440 & 1 & 496.32 \\
$10 / 24 / 83$ & $10 / 25 / 83$ & 10.140 & 9.930 & 0.210 & 1 & 236.88 \\
$10 / 25 / 83$ & $10 / 26 / 83$ & 10.260 & 10.229 & 0.031 & 1 & 34.97 \\
$10 / 26 / 83$ & $10 / 27 / 83$ & 10.144 & 10.045 & 0.099 & 1 & 111.67 \\
$10 / 26 / 83$ & $11 / 1 / 83$ & 10.222 & 10.165 & 0.057 & 6 & 10.72 \\
$10 / 27 / 83$ & $10 / 28 / 83$ & 10.235 & 10.163 & 0.072 & 1 & 81.22 \\
\hline & & & & & &
\end{tabular}


FLOW TESTS OF THE GLAdys MCCALl Well THROUgh OCTOBER 1990

Exhibit N-3. CORROSION COUPON DATA FOR THE LONG-TERM FLOW TEST -- ONE SEPARATOR FROM 12/2/83.THROUGH 1/14/84

Before Separator (Well was Shut in From 10/28/83 Through 12/2/83)

$\begin{array}{ccccccc}\text { Date In } & \text { Date Out } & \begin{array}{c}\text { Weight In } \\ \text { (grams) }\end{array} & \begin{array}{c}\text { Weight Out } \\ \text { (grams) }\end{array} & \begin{array}{c}\text { Weight Loss } \\ \text { (grams) }\end{array} & \begin{array}{c}\text { Time in } \\ \text { (Days) }\end{array} & \begin{array}{c}\text { Loss Rate } \\ \text { (mils/yr) }\end{array} \\ 10 / 19 / 83 & 12 / 5 / 83 & 10.110 & 10.025 & 0.085 & 47 & 2.04 \\ 12 / 5 / 83 & 12 / 8 / 83 & 9.972 & 9.980 & -0.008 & 3 & -3.01\end{array}$

Disposal Well Line After Separator

$\begin{array}{ccccccr}\text { Date In } & \text { Date Out } & \begin{array}{c}\text { Weight In } \\ \text { (grams) }\end{array} & \begin{array}{c}\text { Weight Out } \\ \text { (grams) }\end{array} & \begin{array}{c}\text { Weight Loss } \\ \text { (grams) }\end{array} & \begin{array}{c}\text { Time in } \\ \text { (Days) }\end{array} & \begin{array}{r}\text { Loss Rate } \\ \text { (mils/yr) }\end{array} \\ 12 / 1 / 83 & 12 / 3 / 83 & 10.548 & 10.470 & 0.078 & 2 & 43.99 \\ 12 / 1 / 83 & 12 / 5 / 83 & 10.478 & 10.540 & -0.062 & 4 & -17.48 \\ 12 / 3 / 83 & 12 / 4 / 83 & 10.040 & 9.875 & 0.165 & 1 & 186.12 \\ 12 / 4 / 83 & 12 / 5 / 83 & 10.047 & 9.670 & 0.377 & 1 & 425.26 \\ 12 / 5 / 83 & 12 / 6 / 83 & 10.040 & 10.000 & 0.040 & 1 & 45.12 \\ 12 / 6 / 83 & 12 / 7 / 83 & 9.860 & 9.811 & 0.049 & 1 & 55.27 \\ 12 / 7 / 83 & 12 / 9 / 83 & 9.950 & 9.725 & 0.225 & 2 & 126.90 \\ 12 / 9 / 83 & 12 / 10 / 83 & 10.414 & 10.244 & 0.170 & 1 & 191.76 \\ 12 / 9 / 83 & 12 / 16 / 83 & 10.099 & 9.950 & 0.149 & 7 & 24.01 \\ 12 / 10 / 83 & 12 / 11 / 83 & 10.327 & 10.150 & 0.177 & 1 & 199.66 \\ 12 / 11 / 83 & 12 / 12 / 83 & 10.374 & 10.159 & 0.215 & 1 & 242.52 \\ 12 / 12 / 83 & 12 / 13 / 83 & 10.202 & 9.803 & 0.399 & 1 & 450.07 \\ 12 / 13 / 83 & 12 / 14 / 83 & 10.399 & 10.150 & 0.249 & 1 & 280.87 \\ 12 / 14 / 83 & 12 / 15 / 83 & 10.350 & 10.120 & 0.230 & 1 & 259.44 \\ 12 / 15 / 83 & 12 / 16 / 83 & 10.470 & 10.540 & -0.070 & 1 & -78.96 \\ 12 / 16 / 83 & 12 / 17 / 83 & 10.430 & 10.380 & 0.050 & 1 & 56.40 \\ 12 / 17 / 83 & 12 / 18 / 83 & 10.190 & 10.150 & 0.040 & 1 & 45.12 \\ 12 / 18 / 83 & 12 / 19 / 83 & 10.990 & 10.030 & 0.960 & 1 & 1082.88 \\ 12 / 19 / 83 & 12 / 20 / 83 & 10.230 & 9.810 & 0.420 & 1 & 473.76 \\ 12 / 20 / 83 & 12 / 21 / 83 & 10.470 & 10.566 & -0.096 & 1 & -108.29 \\ 12 / 21 / 83 & 12 / 22 / 83 & 10.385 & 10.321 & 0.064 & 1 & 72.19 \\ 12 / 22 / 83 & 12 / 29 / 83 & 10.088 & 9.894 & 0.194 & 7 & 31.26 \\ 12 / 29 / 83 & 12 / 31 / 83 & 10.328 & 10.005 & 0.323 & 2 & 182.17 \\ 12 / 31 / 83 & 1 / 1 / 84 & 10.267 & 9.638 & 0.629 & 1 & 709.51 \\ 1 / 1 / 84 & 1 / 2 / 84 & 10.320 & 9.560 & 0.760 & 1 & 857.28 \\ 1 / 2 / 84 & 1 / 3 / 84 & 10.183 & 9.458 & 0.725 & 1 & 817.80 \\ 1 / 3 / 84 & 1 / 4 / 84 & 10.578 & 9.714 & 0.864 & 1 & 974.59 \\ 1 / 4 / 84 & 1 / 5 / 84 & 10.203 & 10.200 & 0.003 & 1 & 3.38 \\ 1 / 5 / 84 & 1 / 7 / 84 & 10.317 & 8.833 & 1.484 & 2 & 836.98 \\ 1 / 7 / 84 & 1 / 8 / 84 & 10.169 & 9.473 & 0.696 & 1 & 785.09 \\ 1 / 8 / 84 & 1 / 10 / 84 & 10.153 & 9.930 & 0.223 & 2 & 125.77 \\ 1 / 10 / 84 & 1 / 11 / 84 & 10.490 & 9.830 & 0.660 & 1 & 744.48 \\ 1 / 11 / 84 & 1 / 12 / 84 & 10.400 & 10.370 & 0.030 & 1 & 33.84 \\ 1 / 12 / 84 & 1 / 13 / 84 & 10.300 & 10.180 & 0.120 & 1 & 135.36 \\ 1 / 13 / 84 & 1 / 14 / 84 & 10.140 & 9.920 & 0.220 & 1 & 248.16\end{array}$

$\mathrm{N}-8$ 
Flow tests of the Gladys McCall Well Through OCtober 1990

Exhibit N-4, Part 1. CORROSION COUPON DATA FOR THE LONG TERM-FLOW TEST - TWO SEPARATORS FROM 1/14/84 THROUGH 2/29/84

Between Separators

$\begin{array}{lcrrrrr}\text { Date In } & \text { Date Out } & \begin{array}{c}\text { Weight In } \\ \text { (grams) }\end{array} & \begin{array}{c}\text { Weight Out } \\ \text { (grams) }\end{array} & \begin{array}{c}\text { Weight Loss } \\ \text { (grams) }\end{array} & \begin{array}{c}\text { Time In } \\ \text { (Days) }\end{array} & \begin{array}{c}\text { Loss Rate } \\ \text { (mils/yr) }\end{array} \\ 1 / 14 / 84 & 1 / 16 / 84 & 10.102 & 10.080 & 0.022 & 2 & 12.41 \\ 1 / 16 / 84 & 1 / 17 / 84 & 10.220 & 10.210 & 0.010 & 1 & 11.28 \\ 1 / 17 / 84 & 1 / 20 / 84 & 9.974 & 9.978 & -0.004 & 3 & -1.50 \\ 1 / 20 / 84 & 1 / 21 / 84 & 10.197 & 10.200 & -0.003 & 1 & -3.38 \\ 1 / 21 / 84 & 1 / 22 / 84 & 10.258 & 10.262 & -0.004 & 1 & -4.51 \\ 1 / 22 / 84 & 1 / 23 / 84 & 10.484 & 10.480 & 0.004 & 1 & 4.51 \\ 1 / 23 / 84 & 1 / 24 / 84 & 10.311 & 10.315 & -0.004 & 1 & -4.51 \\ 1 / 24 / 84 & 1 / 25 / 84 & 10.411 & 10.450 & -0.039 & 1 & -43.99 \\ 1 / 25 / 84 & 1 / 26 / 84 & 10.080 & 10.080 & 0.000 & 1 & 0.00 \\ 1 / 26 / 84 & 1 / 28 / 84 & 10.000 & 10.002 & -0.002 & 2 & -1.13 \\ 1 / 28 / 84 & 1 / 29 / 84 & 10.419 & 10.422 & -0.003 & 1 & -3.38 \\ 1 / 29 / 84 & 2 / 2 / 84 & 10.323 & 10.115 & 0.208 & 4 & 58.66 \\ 2 / 2 / 84 & 2 / 3 / 84 & 10.170 & 10.170 & 0.000 & 1 & 0.00 \\ 2 / 3 / 84 & 2 / 4 / 84 & 10.100 & 10.091 & 0.009 & 1 & 10.15 \\ 2 / 4 / 84 & 2 / 5 / 84 & 10.330 & 10.300 & 0.030 & 1 & 33.84 \\ 2 / 5 / 84 & 2 / 6 / 84 & 10.310 & 10.300 & 0.010 & 1 & 11.28 \\ 2 / 6 / 84 & 2 / 7 / 84 & 10.370 & 10.340 & 0.030 & 1 & 33.84 \\ 2 / 7 / 84 & 2 / 8 / 84 & 10.360 & 10.353 & 0.007 & 1 & 7.90 \\ 2 / 8 / 84 & 2 / 9 / 84 & 10.330 & 10.310 & 0.020 & 1 & 22.56 \\ 2 / 9 / 84 & 2 / 10 / 84 & 10.470 & 10.430 & 0.040 & 1 & 45.12 \\ 2 / 10 / 84 & 2 / 29 / 84 & 10.240 & 10.220 & 0.020 & 19 & 1.19\end{array}$


Flow Tests of the Gladys mcCall Well Through October 1990

Exhibit N-4, Part 2. CORROSION COUPON DATA FOR THE LONG-TERM FLOW TEST - TWO SEPARATORS FROM 1/14/84 THROUGH 2/29/84

Disposal Well Line After Separator

$\begin{array}{ccccccc}\text { Date In } & \text { Date Out } & \begin{array}{c}\text { Weight In } \\ \text { (grams) }\end{array} & \begin{array}{c}\text { Weight Out } \\ \text { (grams) }\end{array} & \begin{array}{c}\text { Weight Loss } \\ \text { (grams) }\end{array} & \begin{array}{c}\text { Time In } \\ \text { (Days) }\end{array} & \begin{array}{c}\text { Loss Rate } \\ \text { (mils/yr) }\end{array} \\ 1 / 14 / 84 & 1 / 15 / 84 & 10.280 & 10.260 & 0.020 & 1 & 22.56 \\ 1 / 15 / 84 & 1 / 16 / 84 & 10.620 & 10.620 & 0.000 & 1 & 0.00 \\ 1 / 16 / 84 & 1 / 17 / 84 & 10.360 & 9.155 & 1.205 & 1 & 1359.24 \\ 1 / 17 / 84 & 1 / 21 / 84 & 9.854 & 9.861 & -0.007 & 4 & -1.97 \\ 1 / 21 / 84 & 1 / 22 / 84 & 9.894 & 8.922 & 0.972 & 1 & 1096.42 \\ 1 / 22 / 84 & 1 / 23 / 84 & 10.407 & 9.606 & 0.801 & 1 & 903.53 \\ 1 / 23 / 84 & 1 / 24 / 84 & 10.379 & 9.928 & 0.451 & 1 & 508.73 \\ 1 / 24 / 84 & 1 / 25 / 84 & 10.469 & 9.490 & 0.979 & 1 & 1104.31 \\ 1 / 25 / 84 & 1 / 26 / 84 & 10.540 & 9.574 & 0.966 & 1 & 1089.65 \\ 1 / 26 / 84 & 1 / 28 / 84 & 10.230 & 8.037 & 2.193 & 2 & 1236.85 \\ 1 / 28 / 84 & 1 / 29 / 84 & 10.544 & 9.627 & 0.917 & 1 & 1034.38 \\ 1 / 29 / 84 & 2 / 2 / 84 & 10.051 & 10.322 & -0.271 & 4 & -76.42 \\ 2 / 2 / 84 & 2 / 3 / 84 & 10.260 & 10.095 & 0.165 & 1 & 186.12 \\ 2 / 3 / 84 & 2 / 5 / 84 & 10.010 & 9.040 & 0.970 & 2 & 547.08 \\ 2 / 5 / 84 & 2 / 8 / 84 & 9.840 & 9.800 & 0.040 & 3 & 15.04 \\ 2 / 8 / 84 & 2 / 11 / 84 & 10.140 & 9.030 & 1.110 & 3 & 417.36 \\ 2 / 11 / 84 & 2 / 12 / 84 & 10.340 & 9.223 & 1.117 & 1 & 1259.98 \\ 2 / 12 / 84 & 2 / 13 / 84 & 10.395 & 10.090 & 0.305 & 1 & 344.04 \\ 2 / 13 / 84 & 2 / 15 / 84 & 10.394 & 8.518 & 1.876 & 2 & 1058.06 \\ 2 / 15 / 84 & 2 / 18 / 84 & 10.303 & 6.572 & 3.731 & 3 & 1402.86 \\ 2 / 18 / 84 & 2 / 24 / 84 & 10.257 & 7.680 & 2.577 & 6 & 484.48\end{array}$

N-10 
FLOW TESTS OF THE Gladys MCCALl Well Through OCtober 1990

Exhibit N-5. CORROSION COUPON DATA FOR THE LONG-TERM FLOW TEST -- ONE SEPARATOR FROM 2/21/84 THROUGH 7/17/84

Disposal Well Line After Separator

\begin{tabular}{|c|c|c|c|c|c|c|}
\hline Date In & Date Out & $\begin{array}{l}\text { Weight In } \\
\text { (grams) }\end{array}$ & $\begin{array}{l}\text { Weight Out } \\
\text { (grams) }\end{array}$ & $\begin{array}{l}\text { Weight Loss } \\
\text { (grams) }\end{array}$ & $\begin{array}{l}\text { Time In } \\
\text { (Days) }\end{array}$ & $\begin{array}{l}\text { Loss Rate } \\
\text { (mils/yr) }\end{array}$ \\
\hline $2 / 24 / 84$ & $2 / 27 / 84$ & 10.395 & 10.319 & 0.076 & 3 & 28.58 \\
\hline $2 / 27 / 84$ & $2 / 29 / 84$ & 10.280 & 10.220 & 0.060 & 2 & 33.84 \\
\hline $2 / 29 / 84$ & $3 / 2 / 84$ & 10.020 & 8.508 & 1.512 & 2 & 852.77 \\
\hline $3 / 2 / 84$ & $3 / 15 / 84$ & 10.447 & 10.087 & 0.360 & 13 & 31.24 \\
\hline $3 / 15 / 84$ & $3 / 20 / 84$ & 10.294 & 9.592 & 0.702 & 5 & 158.37 \\
\hline $3 / 20 / 84$ & $3 / 23 / 84$ & 10.159 & 9.692 & 0.467 & 3 & 175.59 \\
\hline $3 / 23 / 84$ & $3 / 27 / 84$ & 10.170 & 9.646 & 0.524 & 4 & 147.77 \\
\hline $3 / 27 / 84$ & $3 / 30 / 84$ & 10.095 & 10.078 & 0.017 & 3 & 6.39 \\
\hline $3 / 30 / 84$ & $5 / 11 / 84$ & 10.161 & 7.373 & 2.788 & 42 & 74.88 \\
\hline $5 / 11 / 84$ & $5 / 16 / 84$ & 10.219 & 10.185 & 0.034 & 5 & 7.67 \\
\hline $5 / 16 / 84$ & $5 / 17 / 84$ & 10.290 & 10.280 & 0.010 & 1 & 11.28 \\
\hline $5 / 17 / 84$ & $5 / 18 / 84$ & 10.162 & 9.376 & 0.786 & 1 & 886.61 \\
\hline $5 / 18 / 84$ & $5 / 19 / 84$ & 10.360 & 9.890 & 0.470 & 1 & 530.16 \\
\hline $5 / 19 / 84$ & $5 / 20 / 84$ & 10.375 & 10.080 & 0.295 & 1 & 332.76 \\
\hline $5 / 20 / 84$ & $5 / 21 / 84$ & 10.270 & 9.580 & 0.690 & 1 & 778.32 \\
\hline $5 / 21 / 84$ & $5 / 22 / 84$ & 10.560 & 9.785 & 0.775 & 1 & 874.20 . \\
\hline $5 / 22 / 84$ & $5 / 25 / 84$ & 10.450 & 10.016 & 0.434 & 3 & 163.18 \\
\hline $5 / 25 / 84$ & $5 / 26 / 84$ & 10.310 & 10.280 & 0.030 & 1 & 33.84 \\
\hline $5 / 26 / 84$ & $5 / 27 / 84$ & 10.212 & 10.185 & 0.027 & 1 & 30.46 \\
\hline $5 / 27 / 84$ & $5 / 28 / 84$ & 10.051 & 9.803 & 0.248 & 1 & 279.74 \\
\hline $5 / 28 / 84$ & $5 / 29 / 84$ & 10.436 & 9.705 & 0.731 & 1 & 824.57 \\
\hline $5 / 29 / 84$ & $6 / 1 / 84$ & 9.820 & 8.630 & 1.190 & 3 & 447.44 \\
\hline $6 / 1 / 84$ & $6 / 2 / 84$ & 10.280 & 9.260 & 1.020 & 1 & 1150.56 \\
\hline $6 / 2 / 84$ & $6 / 3 / 84$ & 9.380 & 8.420 & 0.960 & 1 & 1082.88 \\
\hline $6 / 3 / 84$ & $6 / 4 / 84$ & 10.560 & 10.420 & 0.140 & 1 & 157.92 \\
\hline $6 / 4 / 84$ & $6 / 5 / 84$ & 10.000 & 9.970 & 0.030 & 1 & 33.84 \\
\hline $6 / 5 / 84$ & $6 / 8 / 84$ & 10.160 & 10.154 & 0.006 & 3 & 2.26 \\
\hline $6 / 8 / 84$ & $6 / 12 / 84$ & 10.010 & 9.946 & 0.064 & 4 & 18.05 \\
\hline $6 / 12 / 84$ & $6 / 15 / 84$ & 10.520 & 7.630 & 2.890 & 3 & 1086.64 \\
\hline $6 / 15 / 84$ & $6 / 18 / 84$ & 10.190 & 9.380 & 0.810 & 3 & 304.56 \\
\hline $6 / 18 / 84$ & $6 / 21 / 84$ & 10.360 & 9.529 & 0.831 & 3 & 312.46 \\
\hline $6 / 21 / 84$ & $6 / 24 / 84$ & 9.950 & 7.941 & 2.009 & 3 & 755.38 \\
\hline $6 / 24 / 84$ & $6 / 27 / 84$ & 10.199 & 9.960 & 0.239 & 3 & 89.86 \\
\hline $6 / 27 / 84$ & $6 / 30 / 84$ & 10.400 & 9.990 & 0.410 & 3 & 154.16 \\
\hline $6 / 30 / 84$ & $7 / 3 / 84$ & 10.100 & 9.800 & 0.300 & 3 & 112.80 \\
\hline $7 / 3 / 84$ & $7 / 6 / 84$ & 9.680 & 7.860 & 1.820 & 3 & 684.32 \\
\hline $7 / 6 / 84$ & $7 / 10 / 84$ & 10.080 & 8.230 & 1.850 & 4 & 521.70 \\
\hline $7 / 10 / 84$ & $7 / 13 / 84$ & 9.984 & 9.994 & -0.010 & 3 & -3.76 \\
\hline $7 / 13 / 84$ & $7 / 16 / 84$ & 6,830 & 6.810 & 0.020 & 3 & 7.52 \\
\hline
\end{tabular}


Flow TESTS OF THE GLAdys MCCALL Well THROUGH OCTOBER 1990

Exhibit N-6, Part 1. CORROSION COUPON DATA FOR THE LONG-TERM FLOW TEST -- TWO SEPARATORS FROM 7/17/84 THROUGH 10/27/87

Between Separators

\begin{tabular}{|c|c|c|c|c|c|c|}
\hline Date In & Date Out & $\begin{array}{l}\text { Weight In } \\
\text { (grams) }\end{array}$ & $\begin{array}{l}\text { Weight Out } \\
\text { (grams) }\end{array}$ & $\begin{array}{l}\text { Weight Loss } \\
\text { (grams) }\end{array}$ & $\begin{array}{l}\text { Time In } \\
\text { (Days) }\end{array}$ & $\begin{array}{c}\text { Loss Rate } \\
\text { (mils/yr) }\end{array}$ \\
\hline $7 / 17 / 84$ & $7 / 20 / 84$ & 10.460 & 9.550 & 0.910 & 3 & 342.16 \\
\hline $7 / 20 / 84$ & $7 / 24 / 84$ & 10.200 & 8.876 & 1.324 & 4 & 373.37 \\
\hline $7 / 24 / 84$ & $7 / 27 / 84$ & 11.400 & 10.950 & 0.450 & 3 & 169.20 \\
\hline $7 / 27 / 84$ & $7 / 29 / 84$ & 10.310 & 9.620 & 0.690 & 2 & 389.16 \\
\hline $7 / 29 / 84$ & $8 / 1 / 84$ & 9.630 & 9.850 & -0.220 & 3 & -82.72 \\
\hline $8 / 1 / 84$ & $8 / 4 / 84$ & 10.210 & 8.887 & 1.323 & 3 & 497.45 \\
\hline $8 / 4 / 84$ & $8 / 7 / 84$ & 10.020 & 9.420 & 0.600 & 3 & 225.60 \\
\hline $8 / 7 / 84$ & $8 / 10 / 84$ & 10.194 & 8.013 & 2.181 & 3 & 820.06 \\
\hline $8 / 10 / 84$ & $8 / 11 / 84$ & 10.270 & 9.110 & 1.160 & 1 & 1308.48 \\
\hline $8 / 11 / 84$ & $8 / 14 / 84$ & 10.290 & 7.900 & 2.390 & 3 & 898.64 \\
\hline $8 / 14 / 84$ & $8 / 17 / 84$ & 10.240 & 7.701 & 2.539 & 3 & 954.66 \\
\hline $8 / 17 / 84$ & $8 / 20 / 84$ & 10.390 & 9.280 & 1.110 & 3 & 417.36 \\
\hline $8 / 20 / 84$ & $8 / 23 / 84$ & 10.104 & 9.890 & 0.214 & 3 & 80.46 \\
\hline $8 / 23 / 84$ & $8 / 26 / 84$ & 9.200 & 8.850 & 0.350 & 3 & 131.60 \\
\hline $8 / 26 / 84$ & $8 / 29 / 84$ & 10.180 & 9.020 & 1.160 & 3 & 436.16 \\
\hline $8 / 29 / 84$ & $9 / 2 / 84$ & 10.391 & 9.065 & 1.326 & 4 & 373.93 \\
\hline $9 / 2 / 84$ & $9 / 5 / 84$ & 10.063 & 8.293 & 1.770 & 3 & 665.52 \\
\hline $9 / 5 / 84$ & $9 / 7 / 84$ & 10.070 & 9.762 & 0.308 & 2 & 173.71 \\
\hline $9 / 7 / 84$ & $9 / 11 / 84$ & 10.440 & 8.706 & 1.734 & 4 & 488.99 \\
\hline $9 / 11 / 84$ & $9 / 13 / 84$ & 10.280 & 8.061 & 2.219 & 2 & 1251.52 \\
\hline $9 / 13 / 84$ & $9 / 16 / 84$ & 10.053 & 7.274 & 2.779 & 3 & 1044.90 \\
\hline $9 / 16 / 84$ & $10 / 7 / 84$ & 10.340 & 9.220 & 1.120 & 21 & 60.16 \\
\hline $10 / 7 / 84$ & $10 / 10 / 84$ & 9.320 & 7.087 & 2.233 & 3 & 839.61 \\
\hline $10 / 10 / 84$ & $10 / 13 / 84$ & 10.010 & 7.510 & 2.500 & 3 & 940.00 \\
\hline $10 / 13 / 84$ & $10 / 18 / 84$ & 10.090 & 9.010 & 1.080 & 5 & 243.65 \\
\hline $10 / 18 / 84$ & $10 / 21 / 84$ & 10.270 & 10.070 & 0.200 & 3 & 75.20 \\
\hline $10 / 21 / 84$ & $10 / 24 / 84$ & 10.030 & 9.850 & 0.180 & 3 & 67.68 \\
\hline $10 / 24 / 84$ & $10 / 28 / 84$ & 9.880 & 7.872 & 2.008 & 4 & 566.26 \\
\hline $10 / 28 / 84$ & $11 / 2 / 84$ & 9.710 & 7.240 & 2.470 & 5 & 557.23 \\
\hline $11 / 2 / 84$ & $11 / 5 / 84$ & 10.510 & 10.030 & 0.480 & 3 & 180.48 \\
\hline $11 / 5 / 84$ & $11 / 8 / 84$ & 10.200 & 9.811 & 0.389 & 3 & 146.26 \\
\hline $11 / 8 / 84$ & $11 / 11 / 84$ & 9.560 & 8.469 & 1.091 & 3 & 410.22 \\
\hline $11 / 11 / 84$ & $12 / 2 / 84$ & 10.270 & 9.400 & 0.870 & 21 & 46.73 \\
\hline $12 / 2 / 84$ & $12 / 6 / 84$ & 9.570 & 9.050 & 0.520 & 4 & 146.64 \\
\hline $12 / 6 / 84$ & $12 / 9 / 84$ & 10.430 & 8.263 & 2.167 & 3 & 814.79 \\
\hline $12 / 9 / 84$ & $12 / 12 / 84$ & 10.100 & 9.950 & 0.150 & 3 & 56.40 \\
\hline $12 / 12 / 84$ & $12 / 15 / 84$ & 10.250 & 9.860 & 0.390 & 3 & 146.64 \\
\hline $12 / 15 / 84$ & $12 / 18 / 84$ & 10.300 & 9.960 & 0.340 & 3 & 127.84 \\
\hline
\end{tabular}

$\mathrm{N}-12$ 
Flow Tests of the Gladys MCCALl Well Through OCTOBER 1990

Exhibit N-6, Part 2. CORROSION COUPON DATA FOR THE LONG-TERM FLOW TEST -- TWO SEPARATORS FROM 7/17/84 THROUGH 10/27/87

Between Separators

Date In Date Out Weight In Weight Out Weight Loss Time In Loss Rate

\begin{tabular}{ccccccr} 
& & (grams) & (grams) & (grams) & (Days) & (mils/yr) \\
$12 / 18 / 84$ & $12 / 22 / 84$ & 10.280 & 7.077 & 3.203 & 4 & 903.25 \\
$12 / 22 / 84$ & $12 / 26 / 84$ & 10.280 & 6.056 & 4.224 & 4 & 1191.17 \\
$12 / 26 / 84$ & $12 / 30 / 84$ & 10.440 & 7.254 & 3.186 & 4 & 898.45 \\
$12 / 30 / 84$ & $1 / 3 / 85$ & 10.250 & 5.360 & 4.890 & 4 & 1378.98 \\
$1 / 3 / 85$ & $1 / 6 / 85$ & 10.210 & 6.280 & 3.930 & 3 & 1477.68 \\
$1 / 6 / 85$ & $1 / 9 / 85$ & 9.719 & 8.210 & 1.509 & 3 & 567.38 \\
$1 / 9 / 85$ & $1 / 12 / 85$ & 9.960 & 7.990 & 1.970 & 3 & 740.72 \\
$1 / 12 / 85$ & $1 / 15 / 85$ & 10.310 & 4.020 & 6.290 & 3 & 2365.04 \\
$1 / 15 / 85$ & $1 / 18 / 85$ & 10.490 & 10.100 & 0.390 & 3 & 146.64 \\
$1 / 18 / 85$ & $1 / 22 / 85$ & 9.860 & 6.820 & 3.040 & 4 & 857.28 \\
$1 / 22 / 85$ & $1 / 25 / 85$ & 10.200 & 8.714 & 1.486 & 3 & 558.74 \\
$1 / 25 / 85$ & $1 / 28 / 85$ & 10.310 & 9.676 & 0.634 & 3 & 238.38 \\
$1 / 28 / 85$ & $1 / 31 / 85$ & 10.240 & 8.150 & 2.090 & 3 & 785.84 \\
$1 / 31 / 85$ & $2 / 4 / 85$ & 10.070 & 9.000 & 1.070 & 4 & 301.74 \\
$2 / 4 / 85$ & $2 / 7 / 85$ & 9.000 & 8.750 & 0.250 & 3 & 94.00 \\
$2 / 185$ & $2 / 13 / 85$ & 10.090 & 7.801 & 2.289 & 6 & 430.33 \\
$2 / 13 / 85$ & $2 / 17 / 85$ & 10.410 & 9.230 & 1.180 & 4 & 332.76 \\
$2 / 17 / 85$ & $2 / 21 / 85$ & 10.140 & 7.337 & 2.803 & 4 & 790.45 \\
$2 / 21 / 85$ & $2 / 25 / 85$ & 9.760 & 7.010 & 2.750 & 4 & 775.50 \\
$2 / 25 / 85$ & $2 / 28 / 85$ & 10.360 & 7.670 & 2.690 & 3 & 1011.44 \\
$2 / 28 / 85$ & $3 / 3 / 85$ & 9.990 & 8.920 & 1.070 & 3 & 402.32 \\
$3 / 3 / 85$ & $3 / 6 / 85$ & 8.920 & 7.620 & 1.300 & 3 & 488.80 \\
$3 / 6 / 85$ & $3 / 9 / 85$ & 7.620 & 7.000 & 0.620 & 3 & 233.12 \\
$3 / 9 / 85$ & $3 / 11 / 85$ & 7.000 & 6.890 & 0.110 & 2 & 62.04 \\
$3 / 11 / 85$ & $3 / 14 / 85$ & 10.180 & 10.000 & 0.180 & 3 & 67.68 \\
$3 / 14 / 85$ & $3 / 18 / 85$ & 9.990 & 9.810 & 0.180 & 4 & 50.76 \\
$3 / 18 / 85$ & $3 / 22 / 85$ & 9.810 & 9.493 & 0.317 & 4 & 89.39 \\
$3 / 22 / 85$ & $3 / 26 / 85$ & 10.300 & 6.370 & 3.930 & 4 & 1108.26 \\
$3 / 26 / 85$ & $3 / 29 / 85$ & 6.370 & 6.213 & 0.157 & 3 & 59.03 \\
$3 / 29 / 85$ & $4 / 2 / 85$ & 6.214 & 3.850 & 2.364 & 4 & 666.65 \\
$4 / 2 / 85$ & $4 / 18 / 85$ & 7.750 & 7.692 & 0.058 & 16 & 4.09 \\
$4 / 18 / 85$ & $4 / 22 / 85$ & 7.692 & 6.270 & 1.422 & 4 & 401.00 \\
$4 / 22 / 85$ & $4 / 26 / 85$ & 8.700 & 8.382 & 0.318 & 4 & 89.68 \\
$4 / 26 / 85$ & $4 / 30 / 85$ & 8.382 & 8.324 & 0.058 & 4 & 16.36 \\
$4 / 30 / 85$ & $5 / 9 / 85$ & 8.324 & 8.375 & -0.051 & 9 & -6.39 \\
$5 / 9 / 85$ & $5 / 13 / 85$ & 8.375 & 8.400 & -0.025 & 4 & -7.05 \\
$5 / 13 / 85$ & $5 / 18 / 85$ & 8.400 & 8.280 & 0.120 & 5 & 27.07 \\
$5 / 18 / 85$ & $5 / 28 / 85$ & 8.280 & 8.170 & 0.110 & 10 & 12.41 \\
$5 / 28 / 85$ & $6 / 7 / 85$ & 8.170 & 8.143 & 0.027 & 10 & 3.05 \\
$6 / 7 / 85$ & $6 / 13 / 85$ & 8.143 & 8.164 & -0.021 & 6 & -3.95 \\
& & & & & & \\
\hline
\end{tabular}

$\mathrm{N}-13$ 
Flow Tests of The Gladys MCCALL Well Through OCtober 1990

Exhibit N-6, Part 3. CORROSION COUPON DATA FOR THE LONG-TERM FLOW TEST -- TWO SEPARATORS FROM 7/17/84 THROUGH 10/27/87

Between Separators

\begin{tabular}{|c|c|c|c|c|c|c|}
\hline Date In & Date Out & $\begin{array}{l}\text { Weight In } \\
\text { (grams) }\end{array}$ & $\begin{array}{l}\text { Weight Out } \\
\text { (grams) }\end{array}$ & $\begin{array}{l}\text { Weight Loss } \\
\text { (grams) }\end{array}$ & $\begin{array}{l}\text { Time In } \\
\text { (Days) }\end{array}$ & $\begin{array}{l}\text { Loss Rate } \\
\text { (mils/yr) }\end{array}$ \\
\hline $6 / 13 / 85$ & $6 / 17 / 85$ & 8.164 & 8.160 & 0.004 & 4 & 1.13 \\
\hline $6 / 17 / 85$ & $6 / 21 / 85$ & 8.160 & 8.174 & -0.014 & 4 & -3.95 \\
\hline $6 / 21 / 85$ & $7 / 15 / 85$ & 8.174 & 8.052 & 0.122 & 24 & 5.73 \\
\hline $7 / 15 / 85$ & $7 / 18 / 85$ & 8.052 & 8.050 & 0.002 & 3 & 0.75 \\
\hline $7 / 18 / 85$ & $7 / 21 / 85$ & 8.050 & 8.033 & 0.017 & 3 & 6.39 \\
\hline $7 / 21 / 85$ & $7 / 24 / 85$ & 8.033 & 8.023 & 0.010 & 3 & 3.76 \\
\hline $7 / 24 / 85$ & $7 / 27 / 85$ & 8.220 & 8.030 & 0.190 & 3 & 71.44 \\
\hline $7 / 27 / 85$ & $7 / 30 / 85$ & 8.300 & 8.320 & -0.020 & 3 & -7.52 \\
\hline $7 / 30 / 85$ & $8 / 2 / 85$ & 8.300 & 8.000 & 0.300 & 3 & 112.80 \\
\hline $8 / 2 / 85$ & $8 / 5 / 85$ & 8.000 & 7.940 & 0.060 & 3 & 22.56 \\
\hline $8 / 5 / 85$ & $8 / 8 / 85$ & 7.940 & 7.943 & -0.003 & 3 & -1.13 \\
\hline $8 / 8 / 85$ & $8 / 22 / 85$ & 7.943 & 7.000 & 0.943 & 14 & 75.98 \\
\hline $8 / 22 / 85$ & $8 / 30 / 85$ & 7.000 & 7.950 & -0.950 & 8 & -133.95 \\
\hline $8 / 30 / 85$ & $9 / 3 / 85$ & 7.950 & 7.950 & 0.000 & 4 & 0.00 \\
\hline $9 / 3 / 85$ & $9 / 7 / 85$ & 7.950 & 7.960 & -0.010 & 4 & -2.82 \\
\hline $9 / 7 / 85$ & $9 / 10 / 85$ & 7.960 & 7.960 & 0.000 & 3 & 0.00 \\
\hline $9 / 10 / 85$ & $9 / 13 / 85$ & 7.960 & 7.960 & 0.000 & 3 & 0.00 \\
\hline $9 / 13 / 85$ & $9 / 16 / 85$ & 7.960 & 7.970 & -0.010 & 3 & -3.76 \\
\hline $9 / 16 / 85$ & $9 / 19 / 85$ & 7.970 & 7.960 & 0.010 & 3 & 3.76 \\
\hline $9 / 19 / 85$ & $9 / 22 / 85$ & 7.960 & 7.950 & 0.010 & 3 & 3.76 \\
\hline $9 / 22 / 85$ & $9 / 25 / 85$ & 7.950 & 7.940 & 0.010 & 3 & 3.76 \\
\hline $9 / 25 / 85$ & $9 / 30 / 85$ & 7.940 & 7.990 & -0.050 & 5 & -11.28 \\
\hline $9 / 30 / 85$ & $10 / 3 / 85$ & 7.990 & 8.000 & -0.010 & 3 & -3.76 \\
\hline $10 / 3 / 85$ & $10 / 9 / 85$ & 8.000 & 7.990 & 0.010 & 6 & 1.88 \\
\hline $10 / 9 / 85$ & $10 / 12 / 85$ & 9.140 & 9.137 & 0.003 & 3 & 1.13 \\
\hline $10 / 12 / 85$ & $10 / 15 / 85$ & 9.137 & 9.125 & 0.012 & 3 & 4.51 \\
\hline $10 / 15 / 85$ & $10 / 18 / 85$ & 9.125 & 9.120 & 0.005 & 3 & 1.88 \\
\hline $10 / 18 / 85$ & $10 / 23 / 85$ & 9.120 & 9.130 & -0.010 & 5 & -2.26 \\
\hline $10 / 23 / 85$ & $10 / 27 / 85$ & 9.130 & 9.130 & 0.000 & 4 & 0.00 \\
\hline $10 / 27 / 85$ & $11 / 3 / 85$ & 9.130 & 9.123 & 0.007 & 7 & 1.13 \\
\hline $11 / 3 / 85$ & $11 / 6 / 85$ & 9.123 & 9.120 & 0.003 & 3 & 1.13 \\
\hline $11 / 6 / 85$ & $11 / 9 / 85$ & 9.120 & 9.129 & -0.009 & 3 & -3.38 \\
\hline $11 / 9 / 85$ & $11 / 12 / 85$ & 9.129 & 9.130 & -0.001 & 3 & -0.38 \\
\hline $11 / 12 / 85$ & $11 / 15 / 85$ & 9.130 & 9.127 & 0.003 & 3 & 1.13 \\
\hline $11 / 15 / 85$ & $11 / 18 / 85$ & 9.127 & 9.120 & 0.007 & 3 & 2.63 \\
\hline $11 / 18 / 85$ & $11 / 22 / 85$ & 9.120 & 9.130 & -0.010 & 4 & -2.82 \\
\hline $11 / 22 / 85$ & $11 / 25 / 85$ & 9.130 & 9.140 & -0.010 & 3 & -3.76 \\
\hline $11 / 25 / 85$ & $11 / 29 / 85$ & 9.140 & 9.137 & 0.003 & 4 & 0.85 \\
\hline $11 / 29 / 85$ & $12 / 2 / 85$ & 9.137 & 9.135 & 0.002 & 3 & 0.75 \\
\hline
\end{tabular}

N-14 
Flow TestS OF THE Gladys MCCALL Well Through OCTOBER 1990

Exhibit N-6, Part 4. CORROSION COUPON DATA FOR THE LONG-TERM FLOW TEST -- TWO SEPARATORS FROM 7/17/84 THROUGH 10/27/87

Between Separators

\begin{tabular}{|c|c|c|c|c|c|c|}
\hline Date In & Date Out & $\begin{array}{c}\text { Weight In } \\
\text { (grams) }\end{array}$ & $\begin{array}{l}\text { Weight Out } \\
\text { (grams) }\end{array}$ & $\begin{array}{l}\text { Weight Loss } \\
\text { (grams) }\end{array}$ & $\begin{array}{l}\text { Time In } \\
\text { (Days) }\end{array}$ & $\begin{array}{c}\text { Loss Rate } \\
\text { (mils/yr) }\end{array}$ \\
\hline $12 / 2 / 85$ & $12 / 5 / 85$ & 9.135 & 9.141 & -0.006 & 3 & -2.26 \\
\hline $12 / 5 / 85$ & $12 / 8 / 85$ & 9.141 & 9.138 & 0.003 & 3 & 1.13 \\
\hline $12 / 8 / 85$ & $12 / 11 / 85$ & 9.138 & 9.136 & 0.002 & 3 & 0.75 \\
\hline $12 / 11 / 85$ & $12 / 14 / 85$ & 9.136 & 9.139 & -0.003 & 3 & -1.13 \\
\hline $12 / 14 / 85$ & $12 / 17 / 85$ & 9.139 & 9.137 & 0.002 & 3 & 0.75 \\
\hline $12 / 17 / 85$ & $12 / 20 / 85$ & 9.137 & 9.130 & 0.007 & 3 & 2.63 \\
\hline $12 / 20 / 85$ & $12 / 23 / 85$ & 9.130 & 9.158 & -0.028 & 3 & -10.53 \\
\hline $12 / 23 / 85$ & $12 / 27 / 85$ & 9.158 & 9.160 & -0.002 & 4 & -0.56 \\
\hline $12 / 27 / 85$ & $12 / 30 / 85$ & 9.160 & 9.160 & 0.000 & 3 & 0.00 \\
\hline $12 / 30 / 85$ & $1 / 2 / 86$ & 9.160 & 9.151 & 0.009 & 3 & 3.38 \\
\hline $1 / 2 / 86$ & $1 / 5 / 86$ & 9.151 & 9.146 & 0.005 & 3 & 1.88 \\
\hline $1 / 5 / 86$ & $1 / 8 / 86$ & 9.146 & 9.140 & 0.006 & 3 & 2.26 \\
\hline $1 / 8 / 86$ & $1 / 11 / 86$ & 9.140 & 9.146 & -0.006 & 3 & -2.26 \\
\hline $1 / 11 / 86$ & $1 / 14 / 86$ & 9.146 & 9.139 & 0.007 & 3 & 2.63 \\
\hline $1 / 14 / 86$ & $1 / 17 / 86$ & 9.139 & 9.113 & 0.026 & 3 & 9.78 \\
\hline $1 / 17 / 86$ & $2 / 8 / 86$ & 9.113 & 9.113 & 0.000 & 22 & 0.00 \\
\hline $2 / 8 / 86$ & $2 / 12 / 86$ & 9.100 & 9.090 & 0.010 & 4 & 2.82 \\
\hline $2 / 12 / 86$ & $2 / 15 / 86$ & 9.090 & 9.080 & 0.010 & 3 & 3.76 \\
\hline $2 / 15 / 86$ & $2 / 18 / 86$ & 9.080 & 9.110 & -0.030 & 3 & -11.28 \\
\hline $2 / 18 / 86$ & $2 / 21 / 86$ & 9.110 & 9.120 & -0.010 & 3 & -3.76 \\
\hline $2 / 21 / 86$ & $2 / 25 / 86$ & 9.120 & 9.130 & -0.010 & 4 & -2.82 \\
\hline $2 / 25 / 86$ & $2 / 28 / 86$ & 9.130 & 9.136 & -0.006 & 3 & -2.26 \\
\hline $2 / 28 / 86$ & $3 / 3 / 86$ & 9.136 & 9.140 & -0.004 & 3 & -1.50 \\
\hline $3 / 3 / 86$ & $3 / 6 / 86$ & 9.140 & 9.143 & -0.003 & 3 & -1.13 \\
\hline $3 / 6 / 86$ & $3 / 9 / 86$ & 9.143 & 9.146 & -0.003 & 3 & -1.13 \\
\hline $3 / 9 / 86$ & $3 / 12 / 86$ & 9.146 & 9.160 & -0.014 & 3 & -5.26 \\
\hline $3 / 12 / 86$ & $3 / 16 / 86$ & 9.160 & 9.162 & -0.002 & 4 & -0.56 \\
\hline $3 / 16 / 86$ & $3 / 20 / 86$ & 9.162 & 9.160 & 0.002 & 4 & 0.56 \\
\hline $3 / 20 / 86$ & $3 / 24 / 86$ & 9.160 & 9.170 & -0.010 & 4 & -2.82 \\
\hline $3 / 24 / 86$ & $3 / 27 / 86$ & 9.170 & 9.189 & -0.019 & 3 & -7.14 \\
\hline $3 / 27 / 86$ & $3 / 30 / 86$ & 9.189 & 9.190 & -0.001 & 3 & -0.38 \\
\hline $3 / 30 / 86$ & $4 / 2 / 86$ & 9.190 & 9.188 & 0.002 & 3 & 0.75 \\
\hline $4 / 2 / 86$ & $4 / 5 / 86$ & 9.188 & 9.194 & -0.006 & 3 & -2.26 \\
\hline $4 / 5 / 86$ & $4 / 11 / 86$ & 9.194 & 9.200 & -0.006 & 6 & -1.13 \\
\hline $4 / 11 / 86$ & $4 / 14 / 86$ & 9.200 & 9.230 & -0.030 & 3 & -11.28 \\
\hline $4 / 14 / 86$ & $4 / 17 / 86$ & 9.230 & 9.230 & 0.000 & 3 & 0.00 \\
\hline $4 / 17 / 86$ & $4 / 20 / 86$ & 9.230 & 9.240 & -0.010 & 3 & -3.76 \\
\hline $4 / 20 / 86$ & $4 / 23 / 86$ & 9.240 & 9.242 & -0.002 & 3 & -0.75 \\
\hline $4 / 23 / 86$ & $4 / 26 / 86$ & 9.242 & 9.248 & -0.006 & 3 & -2.26 \\
\hline
\end{tabular}


Flow Tests of The Gladys MCCall Well Through OCtober 1990

Exhibit N-6, Part 5. CORROSION COUPON DATA FOR THE LONG-TERM FLOW TEST -- TWO SEPARATORS FROM 7/17/84 THROUGH 10/27/87

Between Separators

\begin{tabular}{|c|c|c|c|c|c|c|}
\hline Date In & Date Out & $\begin{array}{l}\text { Weight In } \\
\text { (grams) }\end{array}$ & $\begin{array}{l}\text { Weight Out } \\
\text { (grams) }\end{array}$ & $\begin{array}{l}\text { Weight Loss } \\
\text { (grams) }\end{array}$ & $\begin{array}{l}\text { Time In } \\
\text { (Days) }\end{array}$ & $\begin{array}{c}\text { Loss Rate } \\
\text { (mils/yr) }\end{array}$ \\
\hline $4 / 26 / 86$ & $4 / 29 / 86$ & 9.248 & 9.245 & 0.003 & 3 & 1.13 \\
\hline $4 / 29 / 86$ & $5 / 2 / 86$ & 9.245 & 9.246 & -0.001 & 3 & -0.38 \\
\hline $5 / 2 / 86$ & $5 / 5 / 86$ & 9.246 & 9.250 & -0.004 & 3 & -1.50 \\
\hline $5 / 5 / 86$ & $5 / 8 / 86$ & 9.250 & 9.263 & -0.013 & 3 & -4.89 \\
\hline $5 / 8 / 86$ & $5 / 12 / 86$ & 9.263 & 9.271 & -0.008 & 4 & -2.26 \\
\hline $5 / 12 / 86$ & $5 / 15 / 86$ & 9.271 & 9.277 & -0.006 & 3 & -2.26 \\
\hline $5 / 15 / 86$ & $5 / 18 / 86$ & 9.277 & 9.280 & -0.003 & 3 & -1.13 \\
\hline $5 / 18 / 86$ & $5 / 21 / 86$ & 9.280 & 9.290 & -0.010 & 3 & -3.76 \\
\hline $5 / 21 / 86$ & $5 / 25 / 86$ & 9.290 & 9.303 & -0.013 & 4 & -3.67 \\
\hline $5 / 25 / 86$ & $5 / 28 / 86$ & 9.303 & 9.314 & -0.011 & 3 & -4.14 \\
\hline $5 / 28 / 86$ & $5 / 31 / 86$ & 9.314 & 9.326 & -0.012 & 3 & -4.51 \\
\hline $5 / 31 / 86$ & $6 / 4 / 86$ & 9.326 & 9.340 & -0.014 & 4 & -3.95 \\
\hline $6 / 4 / 86$ & $6 / 8 / 86$ & 9.340 & 9.348 & -0.008 & 4 & -2.26 \\
\hline $6 / 8 / 86$ & $6 / 11 / 86$ & 9.348 & 9.343 & 0.005 & 3 & 1.88 \\
\hline $6 / 11 / 86$ & $6 / 14 / 86$ & 9.343 & 9.340 & 0.003 & 3 & 1.13 \\
\hline $6 / 14 / 86$ & $6 / 17 / 86$ & 9.340 & 9.346 & -0.006 & 3 & -2.26 \\
\hline $6 / 17 / 86$ & $6 / 20 / 86$ & 9.346 & 9.450 & -0.104 & 3 & -39.10 \\
\hline $6 / 20 / 86$ & $6 / 23 / 86$ & 9.450 & 9.454 & -0.004 & 3 & -1.50 \\
\hline $6 / 23 / 86$ & $6 / 25 / 86$ & 9.367 & 9.373 & -0.006 & 2 & -3.38 \\
\hline $6 / 25 / 86$ & $6 / 28 / 86$ & 9.373 & 9.385 & -0.012 & 3 & -4.51 \\
\hline $6 / 28 / 86$ & $7 / 2 / 86$ & 9.385 & 9.386 & -0.001 & 4 & -0.28 \\
\hline $7 / 2 / 86$ & $7 / 5 / 86$ & 9.386 & 9.380 & 0.006 & 3 & 2.26 \\
\hline $7 / 5 / 86$ & $7 / 8 / 86$ & 9.380 & 9.392 & -0.012 & 3 & -4.51 \\
\hline $7 / 8 / 86$ & $7 / 11 / 86$ & 9.392 & 9.388 & 0.004 & 3 & 1.50 \\
\hline $7 / 11 / 86$ & $7 / 14 / 86$ & 9.388 & 9.396 & -0.008 & 3 & -3.01 \\
\hline $7 / 14 / 86$ & $7 / 17 / 86$ & 9.396 & 9.399 & -0.003 & 3 & -1.13 \\
\hline $7 / 17 / 86$ & $7 / 20 / 86$ & 9.399 & 9.410 & -0.011 & 3 & -4.14 \\
\hline $7 / 20 / 86$ & $7 / 23 / 86$ & 9.410 & 9.410 & 0.000 & 3 & 0.00 \\
\hline $7 / 23 / 86$ & $7 / 26 / 86$ & 9.410 & 9.410 & 0.000 & 3 & 0.00 \\
\hline $7 / 26 / 86$ & $7 / 30 / 86$ & 9.410 & 9.404 & 0.006 & 4 & 1.69 \\
\hline $7 / 30 / 86$ & $8 / 3 / 86$ & 9.404 & 9.400 & 0.004 & 4 & 1.13 \\
\hline $8 / 3 / 86$ & $8 / 6 / 86$ & 9.400 & 9.410 & -0.010 & 3 & -3.76 \\
\hline $8 / 6 / 86$ & $8 / 15 / 86$ & 9.410 & 9.399 & 0.011 & 9 & 1.38 \\
\hline $8 / 15 / 86$ & $8 / 18 / 86$ & 9.399 & 9.400 & -0.001 & 3 & -0.38 \\
\hline $8 / 18 / 86$ & $8 / 21 / 86$ & 9.400 & 9.411 & -0.011 & 3 & -4.14 \\
\hline $8 / 21 / 86$ & $8 / 24 / 86$ & 9.411 & 9.419 & -0.008 & 3 & -3.01 \\
\hline $8 / 24 / 86$ & $8 / 28 / 86$ & 9.419 & 9.415 & 0.004 & 4 & 1.13 \\
\hline $8 / 28 / 86$ & $9 / 1 / 86$ & 9.415 & 9.417 & -0.002 & 4 & -0.56 \\
\hline
\end{tabular}

N-16 
FLOW TESTS OF THE GLADYS MCCALL WELL THROUGH OCTOBER 1990

Exhibit N-6, Part 6. CORROSION COUPON DATA FOR THE LONG-TERM FLOW TEST - TWO SEPARATORS FROM 7/17/84 THROUGH 10/27/87

Between Separators

$\begin{array}{ccccccc}\text { Date In } & \text { Date Out } & \begin{array}{c}\text { Weight In } \\ \text { (grams) }\end{array} & \begin{array}{c}\text { Weight Out } \\ \text { (grams) }\end{array} & \begin{array}{c}\text { Weight Loss } \\ \text { (grams) }\end{array} & \begin{array}{c}\text { Time In } \\ \text { (Days) }\end{array} & \begin{array}{c}\text { Loss Rate } \\ \text { (mils/yr) }\end{array} \\ 9 / 1 / 86 & 9 / 4 / 86 & 9.417 & 9.415 & 0.002 & 3 & 0.75 \\ 9 / 4 / 86 & 9 / 7 / 86 & 9.415 & 9.414 & 0.001 & 3 & 0.38 \\ 9 / 86 & 9 / 10 / 86 & 9.414 & 9.400 & 0.014 & 3 & 5.26 \\ 9 / 10 / 86 & 9 / 13 / 86 & 9.400 & 9.398 & 0.002 & 3 & 0.75 \\ 9 / 13 / 86 & 9 / 17 / 86 & 9.398 & 9.411 & -0.013 & 4 & -3.67 \\ 9 / 17 / 86 & 9 / 20 / 86 & 9.411 & 9.417 & -0.006 & 3 & -2.26 \\ 9 / 20 / 86 & 9 / 23 / 86 & 9.417 & 9.421 & -0.004 & 3 & -1.50 \\ 9 / 23 / 86 & 9 / 26 / 86 & 9.421 & 9.401 & 0.020 & 3 & 7.52 \\ 9 / 26 / 86 & 9 / 29 / 86 & 9.401 & 9.400 & 0.001 & 3 & 0.38 \\ 9 / 29 / 86 & 10 / 2 / 86 & 9.400 & 9.399 & 0.001 & 3 & 0.38 \\ 10 / 2 / 86 & 10 / 5 / 86 & 9.399 & 9.390 & 0.009 & 3 & 3.38 \\ 10 / 5 / 86 & 10 / 8 / 86 & 9.390 & 9.400 & -0.010 & 3 & -3.76 \\ 10 / 8 / 86 & 10 / 11 / 86 & 9.400 & 9.425 & -0.025 & 3 & -9.40 \\ 10 / 11 / 86 & 10 / 14 / 86 & 9.425 & 9.410 & 0.015 & 3 & 5.64 \\ 10 / 14 / 86 & 10 / 17 / 86 & 9.410 & 9.417 & -0.007 & 3 & -2.63\end{array}$


Flow Tests of The GLadys MCCALL Well Through OCtober 1990

Exhibit N-6, Part 7. CORROSION COUPON DATA FOR THE LONG-TERM FLOW TEST -- TWO SEPARATORS FROM 7/17/84 THROUGH 10/27/87

Between Separators

\begin{tabular}{|c|c|c|c|c|c|c|}
\hline Date In & Date Out & $\begin{array}{l}\text { Weight In } \\
\text { (grams) }\end{array}$ & $\begin{array}{l}\text { Weight Out } \\
\text { (grams) }\end{array}$ & $\begin{array}{l}\text { Weight Loss } \\
\text { (grams) }\end{array}$ & $\begin{array}{l}\text { Time In } \\
\text { (Days) }\end{array}$ & $\begin{array}{l}\text { Loss Rate } \\
\text { (mils/yr) }\end{array}$ \\
\hline $10 / 17 / 86$ & $10 / 20 / 86$ & 9.417 & 9.421 & -0.004 & 3 & -1.50 \\
\hline $10 / 20 / 86$ & $10 / 23 / 86$ & 9.421 & 9.422 & -0.001 & 3 & -0.38 \\
\hline $10 / 23 / 86$ & $10 / 26 / 86$ & 9.422 & 9.437 & -0.015 & 3 & -5.64 \\
\hline $10 / 26 / 86$ & $10 / 29 / 86$ & 9.437 & 9.430 & 0.007 & 3 & 2.63 \\
\hline $10 / 29 / 86$ & $11 / 1 / 86$ & 9.430 & 9.432 & -0.002 & 3 & -0.75 \\
\hline $11 / 1 / 86$ & $11 / 4 / 86$ & 9.432 & 9.435 & -0.003 & 3 & -1.13 \\
\hline $11 / 4 / 86$ & $11 / 7 / 86$ & 9.435 & 9.433 & 0.002 & 3 & 0.75 \\
\hline $11 / 7 / 86$ & $11 / 10 / 86$ & 9.433 & 9.440 & -0.007 & 3 & -2.63 \\
\hline $11 / 10 / 86$ & $11 / 13 / 86$ & 9.440 & 9.459 & -0.019 & 3 & -7.14 \\
\hline $11 / 13 / 86$ & $11 / 16 / 86$ & 9.459 & 9.455 & 0.004 & 3 & 1.50 \\
\hline $11 / 16 / 86$ & $11 / 19 / 86$ & 9.455 & 9.446 & 0.009 & 3 & 3.38 \\
\hline $11 / 19 / 86$ & $11 / 24 / 86$ & 9.446 & 9.435 & 0.011 & 5 & 2.48 \\
\hline $11 / 24 / 86$ & $11 / 27 / 86$ & 9.435 & 9.430 & 0.005 & 3 & 1.88 \\
\hline $11 / 27 / 86$ & $11 / 30 / 86$ & 9.430 & 9.427 & 0.003 & 3 & 1.13 \\
\hline $11 / 30 / 86$ & $12 / 3 / 86$ & 9.427 & 9.430 & -0.003 & 3 & -1.13 \\
\hline $12 / 3 / 86$ & $12 / 6 / 86$ & 9.430 & 9.452 & -0.022 & 3 & -8.27 \\
\hline $12 / 6 / 86$ & $12 / 10 / 86$ & 9.452 & 9.427 & 0.025 & 4 & 7.05 \\
\hline $12 / 10 / 86$ & $12 / 13 / 86$ & 9.427 & 9.430 & -0.003 & 3 & -1.13 \\
\hline $12 / 13 / 86$ & $12 / 17 / 86$ & 9.430 & 9.446 & -0.016 & 4 & -4.51 \\
\hline $12 / 17 / 86$ & $12 / 20 / 86$ & 9.442 & 9.440 & 0.002 & 3 & 0.75 \\
\hline $12 / 20 / 86$ & $12 / 23 / 86$ & 9.440 & 9.441 & -0.001 & 3 & -0.38 \\
\hline $12 / 23 / 86$ & $1 / 1 / 87$ & 9.441 & 9.438 & 0.003 & 9 & 0.38 \\
\hline 1/1/87 & $1 / 4 / 87$ & 9.438 & 9.430 & 0.008 & 3 & 3.01 \\
\hline $1 / 4 / 87$ & $1 / 7 / 87$ & 9.430 & 9.430 & 0.000 & 3 & 0.00 \\
\hline $1 / 7 / 87$ & $1 / 10 / 87$ & 9.430 & 9.434 & -0.004 & 3 & -1.50 \\
\hline $1 / 10 / 87$ & $1 / 13 / 87$ & 9.434 & 9.429 & 0.005 & 3 & 1.88 \\
\hline $1 / 13 / 87$ & $1 / 16 / 87$ & 9.429 & 9.430 & -0.001 & 3 & -0.38 \\
\hline $1 / 16 / 87$ & $1 / 19 / 87$ & 9.430 & 9.434 & -0.004 & 3 & -1.50 \\
\hline $1 / 19 / 87$ & $1 / 22 / 87$ & 9.434 & 9.433 & 0.001 & 3 & 0.38 \\
\hline $1 / 22 / 87$ & $1 / 25 / 87$ & 9.433 & 9.432 & 0.001 & 3 & 0.38 \\
\hline $1 / 25 / 87$ & $1 / 28 / 87$ & 9.432 & 9.426 & 0.006 & 3 & 2.26 \\
\hline $1 / 28 / 87$ & $1 / 31 / 87$ & 9.426 & 9.400 & 0.026 & 3 & 9.78 \\
\hline $1 / 31 / 87$ & $2 / 3 / 87$ & 9.400 & 9.394 & 0.006 & 3 & 2.26 \\
\hline $2 / 3 / 87$ & $2 / 6 / 87$ & 9.394 & 9.376 & 0.018 & 3 & 6.77 \\
\hline $2 / 6 / 87$ & $2 / 9 / 87$ & 9.376 & 9.374 & 0.002 & 3 & 0.75 \\
\hline 2/9/87 & $2 / 12 / 87$ & 9.374 & 9.372 & 0.002 & 3 & 0.75 \\
\hline $2 / 12 / 87$ & $2 / 14 / 87$ & 9.372 & 9.372 & 0.000 & 2 & 0.00 \\
\hline $2 / 14 / 87$ & $2 / 16 / 87$ & 9.372 & 9.370 & 0.002 & 2 & 1.13 \\
\hline
\end{tabular}

N-18 
Flow TESTS OF THE Gladys MCCall Well THROUgh OCtober 1990

Exhibit N-6, Part 8. CORROSION COUPON DATA FOR THE LONG-TERM FLOW TEST -- TWO SEPARATORS FROM 7/17/84 THROUGH 10/27/87

Between Separators

$\begin{array}{ccccccc}\text { Date In } & \text { Date Out } & \begin{array}{c}\text { Weight In } \\ \text { (grams) }\end{array} & \begin{array}{c}\text { Weight Out } \\ \text { (grams) }\end{array} & \begin{array}{c}\text { Weight Loss } \\ \text { (grams) }\end{array} & \begin{array}{c}\text { Time In } \\ \text { (Days) }\end{array} & \begin{array}{r}\text { Loss Rate } \\ \text { (mils/yr) }\end{array} \\ 2 / 16 / 87 & 2 / 19 / 87 & 9.370 & 9.369 & 0.001 & 3 & 0.38 \\ 2 / 19 / 87 & 2 / 22 / 87 & 9.369 & 9.360 & 0.009 & 3 & 3.38 \\ 2 / 22 / 87 & 2 / 25 / 87 & 9.360 & 9.345 & 0.015 & 3 & 5.64 \\ 2 / 25 / 87 & 2 / 28 / 87 & 9.345 & 9.374 & -0.029 & 3 & -10.90 \\ 2 / 28 / 87 & 3 / 3 / 87 & 9.374 & 9.377 & -0.003 & 3 & -1.13 \\ 3 / 3 / 87 & 3 / 6 / 87 & 9.377 & 9.371 & 0.006 & 3 & 2.26 \\ 3 / 6 / 87 & 3 / 9 / 87 & 9.371 & 9.372 & -0.001 & 3 & -0.38 \\ 3 / 9 / 87 & 3 / 12 / 87 & 9.372 & 9.378 & -0.006 & 3 & -2.26 \\ 3 / 12 / 87 & 3 / 14 / 87 & 9.378 & 9.377 & 0.001 & 2 & 0.56 \\ 3 / 14 / 87 & 3 / 17 / 87 & 9.377 & 9.380 & -0.003 & 3 & -1.13 \\ 3 / 17 / 87 & 3 / 20 / 87 & 9.378 & 9.360 & 0.018 & 3 & 6.77 \\ 3 / 20 / 87 & 3 / 23 / 87 & 9.360 & 9.370 & -0.010 & 3 & -3.76 \\ 3 / 23 / 87 & 3 / 26 / 87 & 9.370 & 9.370 & 0.000 & 3 & 0.00 \\ 3 / 26 / 87 & 3 / 29 / 87 & 9.370 & 9.377 & -0.007 & 3 & -2.63 \\ 3 / 29 / 87 & 4 / 1 / 87 & 9.377 & 9.384 & -0.007 & 3 & -2.63 \\ 4 / 1 / 87 & 4 / 4 / 87 & 9.384 & 9.383 & 0.001 & 3 & 0.38 \\ 4 / 4 / 87 & 4 / 7 / 87 & 9.383 & 9.381 & 0.002 & 3 & 0.75 \\ 4 / 7 / 87 & 4 / 10 / 87 & 9.381 & 9.373 & 0.008 & 3 & 3.01 \\ 4 / 10 / 87 & 4 / 12 / 87 & 9.373 & 9.375 & -0.002 & 2 & -1.13 \\ 4 / 12 / 87 & 4 / 15 / 87 & 9.375 & 9.379 & -0.004 & 3 & -1.50 \\ 4 / 15 / 87 & 4 / 18 / 87 & 9.379 & 9.376 & 0.003 & 3 & 1.13 \\ 4 / 18 / 87 & 4 / 22 / 87 & 9.376 & 9.363 & 0.013 & 4 & 3.67 \\ 4 / 22 / 87 & 4 / 25 / 87 & 9.363 & 9.360 & 0.003 & 3 & 1.13 \\ 4 / 25 / 87 & 4 / 28 / 87 & 9.360 & 9.352 & 0.008 & 3 & 3.01 \\ 4 / 28 / 87 & 5 / 1 / 87 & 9.352 & 9.349 & 0.003 & 3 & 1.13 \\ 5 / 1 / 87 & 5 / 4 / 87 & 9.349 & 9.345 & 0.004 & 3 & 1.50 \\ 5 / 4 / 87 & 5 / 187 & 9.345 & 9.346 & -0.001 & 3 & -0.38 \\ 5 / / 87 & 5 / 10 / 87 & 9.346 & 9.344 & 0.002 & 3 & 0.75 \\ 5 / 10 / 87 & 5 / 13 / 87 & 9.344 & 9.340 & 0.004 & 3 & 1.50 \\ 5 / 13 / 87 & 5 / 16 / 87 & 9.340 & 9.342 & -0.002 & 3 & -0.75 \\ 5 / 16 / 87 & 5 / 19 / 87 & 9.342 & 9.340 & 0.002 & 3 & 0.75 \\ 5 / 19 / 87 & 5 / 22 / 87 & 9.340 & 9.350 & -0.010 & 3 & -3.76 \\ 5 / 22 / 87 & 5 / 25 / 87 & 9.350 & 9.350 & 0.000 & 3 & 0.00 \\ 5 / 25 / 87 & 5 / 28 / 87 & 9.350 & 9.350 & 0.000 & 3 & 0.00 \\ 5 / 28 / 87 & 5 / 31 / 87 & 9.350 & 9.354 & -0.004 & 3 & -1.50 \\ 5 / 31 / 87 & 6 / 4 / 87 & 9.354 & 9.353 & 0.001 & 4 & 0.28 \\ & & & & & & \\ & & & 3 & 3 \\ \end{array}$


Flow Tests of the Gladys MCCall Well Through OCtober 1990

Exhibit N-6, Part 9. CORROSION COUPON DATA FOR THE LONG-TERM FLOW TEST -- TWO SEPARATORS FROM 7/17/84 THROUGH 10/27/87

Between Separators

\begin{tabular}{|c|c|c|c|c|c|c|}
\hline Date In & Date Out & $\begin{array}{c}\text { Weight In } \\
\text { (grams) }\end{array}$ & $\begin{array}{l}\text { Weight Out } \\
\text { (grams) }\end{array}$ & $\begin{array}{l}\text { Weight Loss } \\
\text { (grams) }\end{array}$ & $\begin{array}{l}\text { Time In } \\
\text { (Days) }\end{array}$ & $\begin{array}{l}\text { Loss Rate } \\
\text { (mils/yr) }\end{array}$ \\
\hline $6 / 4 / 87$ & $6 / 7 / 87$ & 9.353 & 9.353 & 0.000 & 3 & 0.00 \\
\hline $6 / 7 / 87$ & $6 / 10 / 87$ & 9.353 & 9.353 & 0.000 & 3 & 0.00 \\
\hline $6 / 10 / 87$ & $6 / 13 / 87$ & 9.353 & 9.350 & 0.003 & 3 & 1.13 \\
\hline $6 / 13 / 87$ & $6 / 16 / 87$ & 9.350 & 9.344 & 0.006 & 3 & 2.26 \\
\hline $6 / 16 / 87$ & $6 / 19 / 87$ & 9.344 & 9.379 & -0.035 & 3 & -13.16 \\
\hline $6 / 19 / 87$ & $6 / 22 / 87$ & 9.379 & 9.375 & 0.004 & 3 & 1.50 \\
\hline $6 / 22 / 87$ & $6 / 25 / 87$ & 9.375 & 9.371 & 0.004 & 3 & 1.50 \\
\hline $6 / 25 / 87$ & $6 / 28 / 87$ & 9.371 & 9.371 & 0.000 & 3 & 0.00 \\
\hline $6 / 28 / 87$ & $7 / 1 / 87$ & 9.371 & 9.383 & -0.012 & 3 & -4.51 \\
\hline $7 / 1 / 87$ & $7 / 4 / 87$ & 9.383 & 9.374 & 0.009 & 3 & 3.38 \\
\hline $7 / 4 / 87$ & $7 / 7 / 87$ & 9.374 & 9.374 & 0.000 & 3 & 0.00 \\
\hline $7 / 7 / 87$ & $7 / 10 / 87$ & 9.374 & 9.370 & 0.004 & 3 & 1.50 \\
\hline $7 / 10 / 87$ & $7 / 13 / 87$ & 9.370 & 9.372 & -0.002 & 3 & -0.75 \\
\hline $7 / 13 / 87$ & $7 / 16 / 87$ & 9.372 & 9.383 & -0.011 & 3 & -4.14 \\
\hline $7 / 16 / 87$ & $7 / 19 / 87$ & 9.383 & 9.370 & 0.013 & 3 & 4.89 \\
\hline $7 / 19 / 87$ & $7 / 22 / 87$ & 9.370 & 9.371 & -0.001 & 3 & -0.38 \\
\hline $7 / 22 / 87$ & $7 / 25 / 87$ & 9.371 & 9.378 & -0.007 & 3 & -2.63 \\
\hline $7 / 25 / 87$ & $7 / 28 / 87$ & 9.378 & 9.375 & 0.003 & 3 & 1.13 \\
\hline $7 / 28 / 87$ & $7 / 31 / 87$ & 9.375 & 9.380 & -0.005 & 3 & -1.88 \\
\hline $7 / 31 / 87$ & $8 / 3 / 87$ & 9.260 & 9.260 & 0.000 & 3 & 0.00 \\
\hline $8 / 3 / 87$ & $8 / 6 / 87$ & 9.260 & 9.259 & 0.001 & 3 & 0.38 \\
\hline $8 / 6 / 87$ & $8 / 9 / 87$ & 9.259 & 9.257 & 0.002 & 3 & 0.75 \\
\hline $8 / 9 / 87$ & $8 / 12 / 87$ & 9.257 & 9.264 & -0.007 & 3 & -2.63 \\
\hline $8 / 12 / 87$ & $8 / 15 / 87$ & 9.264 & 9.267 & -0.003 & 3 & -1.13 \\
\hline $8 / 15 / 87$ & $8 / 18 / 87$ & 9.267 & 9.270 & -0.003 & 3 & -1.13 \\
\hline $8 / 18 / 87$ & $8 / 21 / 87$ & 9.270 & 9.271 & -0.001 & 3 & -0.38 \\
\hline $8 / 21 / 87$ & $8 / 24 / 87$ & 9.271 & 9.272 & -0.001 & 3 & -0.38 \\
\hline $8 / 24 / 87$ & $8 / 28 / 87$ & 9.272 & 9.282 & -0.010 & 4 & -2.82 \\
\hline $8 / 28 / 87$ & $8 / 30 / 87$ & 9.282 & 9.285 & -0.003 & 2 & -1.69 \\
\hline $8 / 30 / 87$ & $9 / 2 / 87$ & 9.285 & 9.280 & 0.005 & 3 & 1.88 \\
\hline $9 / 2 / 87$ & $9 / 5 / 87$ & 9.280 & 9.283 & -0.003 & 3 & -1.13 \\
\hline $9 / 5 / 87$ & $9 / 8 / 87$ & 9.283 & 9.286 & -0.003 & 3 & -1.13 \\
\hline $9 / 8 / 87$ & $9 / 11 / 87$ & 9.286 & 9.292 & -0.006 & 3 & -2.26 \\
\hline $9 / 11 / 87$ & $9 / 14 / 87$ & 9.292 & 9.299 & -0.007 & 3 & -2.63 \\
\hline $9 / 14 / 87$ & $9 / 17 / 87$ & 9.299 & 9.299 & 0.000 & 3 & 0.00 \\
\hline $9 / 17 / 87$ & $9 / 20 / 87$ & 9.299 & 9.303 & -0.004 & 3 & -1.50 \\
\hline $9 / 20 / 87$ & $9 / 23 / 87$ & 9.303 & 9.370 & -0.067 & 3 & -25.19 \\
\hline $9 / 23 / 87$ & $9 / 27 / 87$ & 9.370 & 9.305 & 0.065 & 4 & 18.33 \\
\hline
\end{tabular}


Flow Tests of THE Gladys MCCALL Well Through OCTOBER 1990

Exhibit N-6, Part 10. CORROSION COUPON DATA FOR THE LONG-TERM FLOW TEST -- TWO SEPARATORS FROM 7/17/84 THROUGH 10/27/87

Between Separators

$\begin{array}{ccccccc}\text { Date In } & \text { Date Out } & \begin{array}{c}\text { Weight In } \\ \text { (grams) }\end{array} & \begin{array}{c}\text { Weight Out } \\ \text { (grams) }\end{array} & \begin{array}{c}\text { Weight Loss } \\ \text { (grams) }\end{array} & \begin{array}{c}\text { Time In } \\ \text { (Days) }\end{array} & \begin{array}{c}\text { Loss Rate } \\ \text { (mils/yr) }\end{array} \\ 9 / 27 / 87 & 9 / 30 / 87 & 9.305 & 9.300 & 0.005 & 3 & 1.88 \\ 9 / 30 / 87 & 10 / 7 / 87 & 9.300 & 9.314 & -0.014 & 7 & -2.26 \\ 10 / 7 / 87 & 10 / 11 / 87 & 9.314 & 9.320 & -0.006 & 4 & -1.69 \\ 10 / 11 / 87 & 10 / 14 / 87 & 9.320 & 9.262 & 0.058 & 3 & 21.81 \\ 10 / 14 / 87 & 10 / 17 / 87 & 9.262 & 9.291 & -0.029 & 3 & -10.90 \\ 10 / 17 / 87 & 10 / 20 / 87 & 9.291 & 9.316 & -0.025 & 3 & -9.40 \\ 10 / 20 / 87 & 10 / 23 / 87 & 9.316 & 9.318 & -0.002 & 3 & -0.75 \\ 10 / 23 / 87 & 10 / 26 / 87 & 9.318 & 9.328 & -0.010 & 3 & -3.76\end{array}$


Flow TES TS OF THE GLAdys MCCALL WELl Through OCTOBER 1990

Exhibit N-6, Part 11. CORROSION COUPON DATA FOR THE LONGTERM FLOW TEST -- TWO SEPARATORS FROM 7/17/84 THROUGH 10/27/87

Disposal Well Line After Separator

\begin{tabular}{|c|c|c|c|c|c|c|}
\hline Date In & Date Out & $\begin{array}{l}\text { Weight In } \\
\text { (grams) }\end{array}$ & $\begin{array}{l}\text { Weight Out } \\
\text { (grams) }\end{array}$ & $\begin{array}{l}\text { Weight Loss } \\
\text { (grams) }\end{array}$ & $\begin{array}{l}\text { Time In } \\
\text { (Days) }\end{array}$ & $\begin{array}{c}\text { Loss Rate } \\
\text { (mils/yr) }\end{array}$ \\
\hline $7 / 16 / 84$ & $7 / 20 / 84$ & 10.260 & 10.237 & 0.023 & 4 & 6.49 \\
\hline $7 / 20 / 84$ & $7 / 24 / 84$ & 10.065 & 10.052 & 0.013 & 4 & 3.67 \\
\hline $7 / 24 / 84$ & $7 / 27 / 84$ & 10.342 & 9.890 & 0.452 & 3 & 169.95 \\
\hline $7 / 27 / 84$ & $7 / 29 / 84$ & 10.430 & 10.300 & 0.130 & 2 & 73.32 \\
\hline $7 / 29 / 84$ & $8 / 1 / 84$ & 9.980 & 9.440 & $\ldots .540$ & 3 & 203.04 \\
\hline $8 / 1 / 84$ & $8 / 4 / 84$ & 10.250 & 9.070 & 1.180 & 3 & 443.68 \\
\hline $8 / 4 / 84$ & $8 / 7 / 84$ & 10.180 & 10.010 & 0.170 & 3 & 63.92 \\
\hline $8 / 7 / 84$ & $8 / 10 / 84$ & 10.273 & 8.950 & 1.323 & 3 & 497.45 \\
\hline $8 / 10 / 84$ & $8 / 11 / 84$ & 9.810 & 8.490 & 1.320 & 1 & 1488.96 \\
\hline $8 / 11 / 84$ & $8 / 14 / 84$ & 10.270 & 9.000 & 1.270 & 3 & 477.52 \\
\hline $8 / 14 / 84$ & $8 / 17 / 84$ & 10.340 & 9.090 & 1.250 & 3 & 470.00 \\
\hline $8 / 17 / 84$ & $8 / 20 / 84$ & 10.520 & 9.250 & 1.270 & 3 & 477.52 \\
\hline $8 / 20 / 84$ & $8 / 23 / 84$ & 10.268 & 9.000 & 1.268 & 3 & 476.77 \\
\hline $8 / 23 / 84$ & $8 / 26 / 84$ & 9.600 & 9.200 & 0.400 & 3 & 150.40 \\
\hline $8 / 26 / 84$ & $8 / 29 / 84$ & 10.240 & 9.856 & 0.384 & 3 & 144.38 \\
\hline $8 / 29 / 84$ & $9 / 2 / 84$ & 10.221 & 9.917 & 0.304 & 4 & 85.73 \\
\hline $9 / 2 / 84$ & $9 / 5 / 84$ & 9.882 & 8.370 & 1.512 & 3 & 568.51 \\
\hline $9 / 5 / 84$ & $9 / 7 / 84$ & 10.140 & 9.960 & 0.180 & 2 & 101.52 \\
\hline 9/7/84 & $9 / 11 / 84$ & 10.460 & 8.700 & 1.760 & 4 & 496.32 \\
\hline $9 / 11 / 84$ & $9 / 13 / 84$ & 9.420 & 8.882 & 0.538 & 2 & 303.43 \\
\hline $9 / 13 / 84$ & $9 / 16 / 84$ & 10.030 & 8.160 & 1.870 & 3 & 703.12 \\
\hline $9 / 16 / 84$ & $10 / 7 / 84$ & 10.408 & 9.310 & 1.098 & 21 & 58.98 \\
\hline $10 / 7 / 84$ & $10 / 10 / 84$ & 9.580 & 9.201 & 0.379 & 3 & 142.50 \\
\hline $10 / 10 / 84$ & $10 / 13 / 84$ & 9.201 & 8.861 & 0.340 & 3 & 127.84 \\
\hline $10 / 13 / 84$ & $10 / 18 / 84$ & 8.861 & 8.660 & 0.201 & 5 & 45.35 \\
\hline $10 / 18 / 84$ & $10 / 24 / 84$ & 8.660 & 8.600 & 0.060 & 6 & 11.28 \\
\hline $10 / 24 / 84$ & $10 / 28 / 84$ & 9.640 & 9.410 & 0.230 & 4 & 64.86 \\
\hline $10 / 28 / 84$ & $11 / 2 / 84$ & 9.410 & 9.420 & -0.010 & 5 & -2.26 \\
\hline $11 / 2 / 84$ & $11 / 5 / 84$ & 9.420 & 9.419 & 0.001 & 3 & 0.38 \\
\hline $11 / 5 / 84$ & $11 / 8 / 84$ & 9.370 & 8.780 & 0.590 & 3 & 221.84 \\
\hline $11 / 8 / 84$ & $11 / 11 / 84$ & 8.780 & 8.770 & 0.010 & 3 & 3.76 \\
\hline $11 / 11 / 84$ & $12 / 2 / 84$ & 8.770 & 8.288 & 0.482 & 21 & 25.89 \\
\hline $12 / 2 / 84$ & $12 / 6 / 84$ & 9.340 & 9.342 & -0.002 & 4 & -0.56 \\
\hline $12 / 6 / 84$ & $12 / 9 / 84$ & 9.342 & 9.350 & -0.008 & 3 & -3.01 \\
\hline $12 / 9 / 84$ & $12 / 12 / 84$ & 9.350 & 9.348 & 0.002 & 3 & 0.75 \\
\hline $12 / 12 / 84$ & $12 / 15 / 84$ & 9.348 & 9.346 & 0.002 & 3 & 0.75 \\
\hline $12 / 15 / 84$ & $12 / 18 / 84$ & 9.346 & 9.347 & -0.001 & 3 & -0.38 \\
\hline $12 / 18 / 84$ & $12 / 22 / 84$ & 9.347 & 9.345 & 0.002 & 4 & 0.56 \\
\hline
\end{tabular}


FLOW TESTS OF THE GLADYS MCCALL WELl THROUGH OCTOBER 1990

Exhibit N-6, Part 12. CORROSION COUPON DATA FOR THE LONGTERM FLOW TEST - TWO SEPARATORS FROM 7/17/84 THROUGH 10/27/87

Disposal Well Line After Separator

\begin{tabular}{|c|c|c|c|c|c|c|}
\hline Date In & Date Out & $\begin{array}{l}\text { Weight In } \\
\text { (grams) }\end{array}$ & $\begin{array}{l}\text { Weight Out } \\
\text { (grams) }\end{array}$ & $\begin{array}{c}\text { Weight Loss } \\
\text { (grams) }\end{array}$ & $\begin{array}{l}\text { Time'In } \\
\text { (Days) }\end{array}$ & $\begin{array}{c}\text { Loss Rate } \\
\text { (mils/yr) }\end{array}$ \\
\hline $12 / 22 / 84$ & $12 / 26 / 84$ & 9.345 & 9.340 & 0.005 & 4 & 1.41 \\
\hline $12 / 26 / 84$ & $12 / 30 / 84$ & 9.340 & 9.350 & -0.010 & 4 & -2.82 \\
\hline $12 / 30 / 84$ & $1 / 3 / 85$ & 9.350 & 9.350 & 0.000 & 4 & 0.00 \\
\hline $1 / 3 / 85$ & $1 / 6 / 85$ & 9.350 & 9.364 & -0.014 & 3 & -5.26 \\
\hline $1 / 6 / 85$ & $1 / 9 / 85$ & 9.364 & 9.350 & 0.014 & 3 & 5.26 \\
\hline $1 / 9 / 85$ & $1 / 12 / 85$ & 9.350 & 9.360 & -0.010 & 3 & -3.76 \\
\hline $1 / 12 / 85$ & $1 / 15 / 85$ & 9.360 & 9.370 & -0.010 & 3 & -3.76 \\
\hline $1 / 15 / 85$ & $1 / 18 / 85$ & 9.370 & 9.370 & 0.000 & 3 & 0.00 \\
\hline $1 / 18 / 85$ & $1 / 22 / 85$ & 9.370 & 9.370 & 0.000 & 4 & 0.00 \\
\hline $1 / 22 / 85$ & $1 / 25 / 85$ & 9.370 & 9.390 & -0.020 & 3 & -7.52 \\
\hline $1 / 25 / 85$ & $1 / 28 / 85$ & 9.390 & 9.390 & 0.000 & 3 & 0.00 \\
\hline $1 / 28 / 85$ & $1 / 31 / 85$ & 9.390 & $9: 390$ & 0.000 & 3 & 0.00 \\
\hline $1 / 31 / 85$ & $2 / 4 / 85$ & 9.390 & 9.420 & -0.030 & 4 & -8.46 \\
\hline $2 / 4 / 85$ & $2 / 7 / 85$ & 9.420 & 9.430 & -0.010 & 3 & -3.76 \\
\hline $2 / 7 / 85$ & $2 / 13 / 85$ & 9.430 & 9.420 & 0.010 & 6 & 1.88 \\
\hline $2 / 13 / 85$ & $2 / 17 / 85$ & 9.420 & 9.420 & 0.000 & 4 & 0.00 \\
\hline $2 / 17 / 85$ & $2 / 21 / 85$ & 9.420 & 9.450 & -0.030 & 4 & -8.46 \\
\hline $2 / 21 / 85$ & $2 / 25 / 85$ & 9.450 & 9.430 & 0.020 & 4 & 5.64 \\
\hline $2 / 25 / 85$ & $2 / 28 / 85$ & 9.430 & 9.428 & 0.002 & 3 & 0.75 \\
\hline $2 / 28 / 85$ & $3 / 3 / 85$ & 9.428 & 9.420 & 0.008 & 3 & 3.01 \\
\hline $3 / 3 / 85$ & $3 / 6 / 85$ & 9.420 & 9.400 & 0.020 & 3 & 7.52 \\
\hline $3 / 6 / 85$ & $3 / 9 / 85$ & 9.400 & 9.410 & -0.010 & 3 & -3.76 \\
\hline $3 / 9 / 85$ & $3 / 11 / 85$ & 9.410 & 9.450 & -0.040 & 2 & -22.56 \\
\hline $3 / 11 / 85$ & $3 / 14 / 85$ & 9.450 & 9.470 & -0.020 & 3 & -7.52 \\
\hline $3 / 14 / 85$ & $3 / 18 / 85$ & 9.470 & 9.470 & 0.000 & 4 & 0.00 \\
\hline $3 / 18 / 85$ & $3 / 22 / 85$ & 9.470 & 9.490 & -0.020 & 4 & -5.64 \\
\hline $3 / 22 / 85$ & $3 / 26 / 85$ & 9.490 & 9.500 & -0.010 & 4 & -2.82 \\
\hline $3 / 26 / 85$ & $3 / 29 / 85$ & 9.500 & 9.510 & -0.010 & 3 & -3.76 \\
\hline $3 / 29 / 85$ & $4 / 2 / 85$ & 9.510 & 9.500 & 0.010 & 4 & 2.82 \\
\hline $4 / 2 / 85$ & $4 / 18 / 85$ & 9.500 & 9.510 & -0.010 & 16 & -0.70 \\
\hline $4 / 18 / 85$ & $4 / 22 / 85$ & 9.510 & 9.498 & 0.012 & 4 & 3.38 \\
\hline $4 / 22 / 85$ & $4 / 26 / 85$ & 9.498 & 9.500 & -0.002 & 4 & -0.56 \\
\hline $4 / 26 / 85$ & $4 / 30 / 85$ & 9.500 & 9.530 & -0.030 & 4 & -8.46 \\
\hline 4/30/85 & $5 / 9 / 85$ & 9.530 & 9.510 & 0.020 & 9 & 2.51 \\
\hline $5 / 9 / 85$ & $5 / 13 / 85$ & 9.510 & 9.520 & -0.010 & 4 & -2.82 \\
\hline $5 / 13 / 85$ & $5 / 18 / 85$ & 9.520 & 9.300 & 0.220 & 5 & 49.63 \\
\hline $5 / 18 / 85$ & $5 / 28 / 85$ & 9.300 & 9.301 & -0.001 & 10 & -0.11 \\
\hline $5 / 28 / 85$ & $6 / 7 / 85$ & 9.301 & 9.300 & 0.001 & 10 & 0.11 \\
\hline
\end{tabular}


Flow Tests of the Gladys McCall Well Through OCtober 1990

Exhibit N-6, Part 13. CORROSION COUPON DATA FOR THE LONGTERM FLOW TEST -- TWO SEPARATORS FROM 7/17/84 THROUGH 10/27/87

Disposal Well Line After Separator

$\begin{array}{ccccccr}\text { Date In } & \text { Date Out } & \begin{array}{c}\text { Weight In } \\ \text { (grams) }\end{array} & \begin{array}{c}\text { Weight Out } \\ \text { (grams) }\end{array} & \begin{array}{c}\text { Weight Loss } \\ \text { (grams) }\end{array} & \begin{array}{c}\text { Time In } \\ \text { (Days) }\end{array} & \begin{array}{r}\text { Loss Rate } \\ \text { (mils/yr) }\end{array} \\ 6 / 7 / 85 & 6 / 13 / 85 & 9.300 & 9.320 & -0.020 & 6 & -3.76 \\ 6 / 13 / 85 & 6 / 17 / 85 & 9.320 & 9.319 & 0.001 & 4 & 0.28 \\ 6 / 17 / 85 & 6 / 21 / 85 & 9.319 & 9.338 & -0.019 & 4 & -5.36 \\ 6 / 21 / 85 & 6 / 7 / 85 & 9.338 & 9.361 & -0.023 & -14 & 1.85 \\ 6 / 7 / 85 & 7 / 5 / 85 & 9.361 & 9.290 & 0.071 & 28 & 2.86 \\ 7 / 5 / 85 & 7 / 6 / 85 & 8.500 & 8.300 & 0.200 & 1 & 225.60 \\ 7 / 6 / 85 & 7 / 7 / 85 & 8.300 & 8.280 & 0.020 & 1 & 22.56 \\ 7 / 7 / 85 & 7 / 12 / 85 & 8.280 & 8.304 & -0.024 & 5 & -5.41 \\ 7 / 12 / 85 & 7 / 15 / 85 & 8.304 & 8.300 & 0.004 & 3 & 1.50 \\ 7 / 15 / 85 & 7 / 18 / 85 & 8.300 & 8.225 & 0.075 & 3 & 28.20 \\ 7 / 18 / 85 & 7 / 21 / 85 & 8.225 & 8.210 & 0.015 & 3 & 5.64 \\ 7 / 21 / 85 & 7 / 24 / 85 & 8.210 & 8.110 & 0.100 & 3 & 37.60 \\ 7 / 24 / 85 & 7 / 27 / 85 & 8.110 & 8.090 & 0.020 & 3 & 7.52 \\ 7 / 27 / 85 & 7 / 30 / 85 & 8.090 & 8.050 & 0.040 & 3 & 15.04 \\ 7 / 30 / 85 & 8 / 2 / 85 & 8.050 & 7.990 & 0.060 & 3 & 22.56 \\ 8 / 2 / 85 & 8 / 5 / 85 & 7.990 & 7.990 & 0.000 & 3 & 0.00 \\ 8 / 5 / 85 & 8 / 8 / 85 & 7.990 & 7.980 & 0.010 & 3 & 3.76 \\ 8 / 8 / 85 & 8 / 19 / 85 & 7.980 & 7.972 & 0.008 & 11 & 0.82 \\ 8 / 19 / 85 & 8 / 22 / 85 & 8.608 & 8.506 & 0.102 & 3 & 38.35 \\ 8 / 22 / 85 & 8 / 30 / 85 & 8.506 & 8.450 & 0.056 & 8 & 7.90 \\ 8 / 30 / 85 & 9 / 3 / 85 & 8.450 & 8.450 & 0.000 & 4 & 0.00 \\ 9 / 3 / 85 & 9 / 7 / 85 & 8.450 & 8.412 & 0.038 & 4 & 10.72 \\ 9 / 7 / 85 & 9 / 10 / 85 & 8.412 & 8.410 & 0.002 & 3 & 0.75 \\ 9 / 10 / 85 & 9 / 13 / 85 & 8.410 & 8.399 & 0.011 & 3 & 4.14 \\ 9 / 13 / 85 & 9 / 16 / 85 & 8.399 & 8.399 & 0.000 & 3 & 0.00 \\ 9 / 16 / 85 & 9 / 19 / 85 & 8.399 & 8.390 & 0.009 & 3 & 3.38 \\ 9 / 19 / 85 & 9 / 22 / 85 & 8.390 & 8.370 & 0.020 & 3 & 7.52 \\ 9 / 22 / 85 & 9 / 25 / 85 & 8.370 & 8.360 & 0.010 & 3 & 3.76 \\ 9 / 25 / 85 & 9 / 30 / 85 & 8.360 & 8.410 & -0.050 & 5 & -11.28 \\ 9 / 30 / 85 & 10 / 3 / 85 & 8.410 & 8.420 & -0.010 & 3 & -3.76 \\ 10 / 3 / 85 & 10 / 6 / 85 & 8.420 & 8.419 & 0.001 & 3 & 0.38 \\ 10 / 6 / 85 & 10 / 9 / 85 & 8.419 & 8.420 & -0.001 & 3 & -0.38 \\ 10 / 9 / 85 & 10 / 12 / 85 & 8.420 & 8.443 & -0.023 & 3 & -8.65 \\ 10 / 12 / 85 & 10 / 15 / 85 & 8.443 & 8.430 & 0.013 & 3 & 4.89 \\ 10 / 15 / 85 & 10 / 18 / 85 & 8.430 & 8.436 & -0.006 & 3 & -2.26 \\ 10 / 18 / 85 & 10 / 23 / 85 & 8.436 & 8.450 & -0.014 & 5 & -3.16 \\ 10 / 23 / 85 & 10 / 27 / 85 & 8.450 & 8.460 & -0.010 & 4 & -2.82 \\ 10 / 27 / 85 & 11 / 3 / 85 & 8.460 & 8.460 & 0.000 & 7 & 0.00 \\ & & & & & & \end{array}$


FLow TES TS OF THE GLADYS MCCALL WELL THROUGH OCTOBER 1990

Exhibit N-6, Part 14. CORROSION COUPON DATA FOR THE LONGTERM FLOW TEST - TWO SEPARATORS FROM 7/17/84 THROUGH 10/27/87

Disposal Well Line After Separator

\begin{tabular}{|c|c|c|c|c|c|c|}
\hline Date In & Date Out & $\begin{array}{l}\text { Weight In } \\
\text { (grams) }\end{array}$ & $\begin{array}{l}\text { Weight Out } \\
\text { (grams) }\end{array}$ & $\begin{array}{l}\text { Weight Loss } \\
\text { (grams) }\end{array}$ & $\begin{array}{l}\text { Time In } \\
\text { (Days) }\end{array}$ & $\begin{array}{c}\text { Loss Rate } \\
\text { (mils/yr) }\end{array}$ \\
\hline $11 / 3 / 85$ & $11 / 6 / 85$ & 8.460 & 8.452 & 0.008 & 3 & 3.01 \\
\hline $11 / 6 / 85$ & $11 / 9 / 85$ & 8.452 & 8.458 & -0.006 & 3 & -2.26 \\
\hline $11 / 9 / 85$ & $11 / 12 / 85$ & 8.458 & 8.466 & -0.008 & 3 & -3.01 \\
\hline $11 / 12 / 85$ & $11 / 15 / 85$ & 8.466 & 8.460 & 0.006 & 3 & 2.26 \\
\hline $11 / 15 / 85$ & $11 / 18 / 85$ & 8.460 & 8.465 & -0.005 & 3 & -1.88 \\
\hline $11 / 18 / 85$ & $11 / 22 / 85$ & 8.465 & 8.460 & 0.005 & 4 & 1.41 \\
\hline $11 / 22 / 85$ & $11 / 25 / 85$ & 8.460 & 8.470 & -0.010 & 3 & -3.76 \\
\hline $11 / 25 / 85$ & $11 / 29 / 85$ & 8.470 & 8.470 & 0.000 & 4 & 0.00 \\
\hline $11 / 29 / 85$ & $12 / 2 / 85$ & 8.470 & 8.475 & -0.005 & 3 & -1.88 \\
\hline $12 / 2 / 85$ & $12 / 5 / 85$ & 8.475 & 8.468 & 0.007 & 3 & 2.63 \\
\hline $12 / 5 / 85$ & $12 / 8 / 85$ & 8.468 & 8.466 & 0.002 & 3 & 0.75 \\
\hline $12 / 8 / 85$ & $12 / 11 / 85$ & 8.466 & 8.464 & 0.002 & 3 & 0.75 \\
\hline $12 / 11 / 85$ & $12 / 14 / 85$ & 8.464 & 8.460 & 0.004 & 3 & 1.50 \\
\hline $12 / 14 / 85$ & $12 / 17 / 85$ & 8.460 & 8.460 & 0.000 & 3 & 0.00 \\
\hline $12 / 17 / 85$ & $12 / 20 / 85$ & $8: 460$ & 8.460 & 0.000 & 3 & 0.00 \\
\hline $12 / 20 / 85$ & $12 / 23 / 85$ & 8.460 & 8.486 & -0.026 & 3 & -9.78 \\
\hline $12 / 23 / 85$ & $12 / 27 / 85$ & 8.486 & 8.480 & 0.006 & 4 & 1.69 \\
\hline $12 / 27 / 85$ & $12 / 30 / 85$ & 8.917 & 8.890 & 0.027 & 3 & 10.15 \\
\hline $12 / 30 / 85$ & $1 / 2 / 86$ & 8.890 & 8.571 & 0.319 & 3 & 119.94 \\
\hline $1 / 2 / 86$ & $1 / 5 / 86$ & 8.571 & 8.560 & 0.011 & 3 & 4.14 \\
\hline $1 / 5 / 86$ & $1 / 8 / 86$ & 8.560 & 8.557 & 0.003 & 3 & 1.13 \\
\hline $1 / 8 / 86$ & $1 / 11 / 86$ & 8.557 & 8.554 & 0.003 & 3 & 1.13 \\
\hline $1 / 11 / 86$ & $1 / 14 / 86$ & 8.554 & 8.550 & 0.004 & 3 & 1.50 \\
\hline $1 / 14 / 86$ & $1 / 17 / 86$ & 8.550 & 8.538 & 0.012 & 3 & 4.51 \\
\hline $1 / 17 / 86$ & $2 / 8 / 86$ & 8.538 & 8.531 & 0.007 & 22 & 0.36 \\
\hline $2 / 8 / 86$ & $2 / 12 / 86$ & 8.530 & 8.490 & 0.040 & 4 & 11.28 \\
\hline $2 / 12 / 86$ & $2 / 15 / 86$ & 8.490 & 8.400 & 0.090 & 3 & 33.84 \\
\hline $2 / 15 / 86$ & $2 / 18 / 86$ & 8.400 & 8.510 & -0.110 & 3 & -41.36 \\
\hline $2 / 18 / 86$ & $2 / 21 / 86$ & 8.510 & 8.520 & -0.010 & 3 & -3.76 \\
\hline $2 / 21 / 86$ & $2 / 25 / 86$ & 8.520 & 8.530 & -0.010 & 4 & -2.82 \\
\hline $2 / 25 / 86$ & $2 / 28 / 86$ & 8.530 & 8.533 & -0.003 & 3 & -1.13 \\
\hline $2 / 28 / 86$ & $3 / 3 / 86$ & 8.533 & 8.540 & -0.007 & 3 & -2.63 \\
\hline $3 / 3 / 86$ & $3 / 6 / 86$ & 8.540 & 8.539 & 0.001 & 3 & 0.38 \\
\hline $3 / 6 / 86$ & $3 / 9 / 86$ & 8.539 & 8.543 & -0.004 & 3 & -1.50 \\
\hline $3 / 9 / 86$ & $3 / 12 / 86$ & 8.543 & 8.560 & -0.017 & 3 & -6.39 \\
\hline $3 / 12 / 86$ & $3 / 16 / 86$ & 8.560 & 8.565 & -0.005 & 4 & -1.41 \\
\hline $3 / 16 / 86$ & $3 / 20 / 86$ & 8.565 & 8.560 & 0.005 & 4 & 1.41 \\
\hline $3 / 20 / 86$ & $3 / 24 / 86$ & 8.560 & 8.590 & -0.030 & 4 & -8.46 \\
\hline
\end{tabular}


Flow tests of the Gladys mCCall Well Through OCtober 1990

Exhibit N-6, Part 15. CORROSION COUPON DATA FOR THE LONGTERM FLOW TEST -- TWO SEPARATORS FROM 7/17/84 THROUGH 10/27/87

Disposal Well Line After Separator

\begin{tabular}{|c|c|c|c|c|c|c|}
\hline Date In & Date Out & $\begin{array}{l}\text { Weight In } \\
\text { (grams) }\end{array}$ & $\begin{array}{l}\text { Weight Out } \\
\text { (grams) }\end{array}$ & $\begin{array}{l}\text { Weight Loss } \\
\text { (grams) }\end{array}$ & $\begin{array}{l}\text { Time In } \\
\text { (Days) }\end{array}$ & $\begin{array}{l}\text { Loss Rate } \\
\text { (mils/yr) }\end{array}$ \\
\hline $3 / 24 / 86$ & $3 / 27 / 86$ & 8.590 & 8.600 & -0.010 & 3 & -3.76 \\
\hline $3 / 27 / 86$ & $3 / 30 / 86$ & 8.600 & 8.605 & -0.005 & 3 & -1.88 \\
\hline $3 / 30 / 86$ & $4 / 2 / 86$ & 8.605 & 8.600 & 0.005 & 3 & 1.88 \\
\hline $4 / 2 / 86$ & $4 / 5 / 86$ & 8.600 & 8.680 & -0.080 & 3 & -30.08 \\
\hline $4 / 5 / 86$ & $4 / 8 / 86$ & 8.680 & 8.690 & -0.010 & 3 & -3.76 \\
\hline $4 / 8 / 86$ & $4 / 11 / 86$ & 8.690 & 8.680 & 0.010 & 3 & 3.76 \\
\hline $4 / 11 / 86$ & $4 / 14 / 86$ & 8.680 & 8.635 & 0.045 & 3 & 16.92 \\
\hline $4 / 14 / 86$ & $4 / 17 / 86$ & 8.635 & 8.642 & -0.007 & 3 & -2.63 \\
\hline $4 / 17 / 86$ & $4 / 20 / 86$ & 8.642 & 8.650 & -0.008 & 3 & -3.01 \\
\hline $4 / 20 / 86$ & $4 / 23 / 86$ & 8.650 & 8.680 & -0.030 & 3 & -11.28 \\
\hline $4 / 23 / 86$ & $4 / 26 / 86$ & 8.680 & 8.710 & -0.030 & 3 & -11.28 \\
\hline $4 / 26 / 86$ & $4 / 29 / 86$ & 8.710 & 8.660 & 0.050 & 3 & 18.80 \\
\hline $4 / 29 / 86$ & $5 / 2 / 86$ & 8.660 & 8.670 & -0.010 & 3 & -3.76 \\
\hline $5 / 2 / 86$ & $5 / 5 / 86$ & 8.670 & 8.680 & -0.010 & 3 & -3.76 \\
\hline $5 / 5 / 86$ & $5 / 8 / 86$ & 8.680 & 8.681 & -0.001 & 3 & -0.38 \\
\hline $5 / 8 / 86$ & $5 / 12 / 86$ & 8.681 & 8.702 & -0.021 & 4 & -5.92 \\
\hline $5 / 12 / 86$ & $5 / 15 / 86$ & 8.702 & 8.710 & -0.008 & 3 & -3.01 \\
\hline $5 / 15 / 86$ & $5 / 18 / 86$ & 8.710 & 8.717 & -0.007 & 3 & -2.63 \\
\hline $5 / 18 / 86$ & $5 / 21 / 86$ & 8.717 & 8.730 & -0.013 & 3 & -4.89 \\
\hline $5 / 21 / 86$ & $5 / 25 / 86$ & 8.730 & 8.737 & -0.007 & 4 & -1.97 \\
\hline $5 / 25 / 86$ & $5 / 28 / 86$ & 8.737 & 8.743 & -0.006 & 3 & -2.26 \\
\hline $5 / 28 / 86$ & $5 / 31 / 86$ & 8.743 & 8.750 & -0.007 & 3 & -2.63 \\
\hline $5 / 31 / 86$ & $6 / 4 / 86$ & 8.750 & 8.766 & -0.016 & 4 & -4.51 \\
\hline $6 / 4 / 86$ & $6 / 8 / 86$ & 8.766 & 8.770 & -0.004 & 4 & -1.13 \\
\hline $6 / 8 / 86$ & $6 / 11 / 86$ & 8.770 & 8.789 & -0.019 & 3 & -7.14 \\
\hline $6 / 11 / 86$ & $6 / 14 / 86$ & 8.789 & 8.800 & -0.011 & 3 & -4.14 \\
\hline $6 / 14 / 86$ & $6 / 17 / 86$ & 8.800 & 8.840 & -0.040 & 3 & -15.04 \\
\hline $6 / 17 / 86$ & $6 / 20 / 86$ & 8.840 & 8.790 & 0.050 & 3 & 18.80 \\
\hline $6 / 20 / 86$ & $6 / 23 / 86$ & 8.790 & 8.793 & -0.003 & 3 & -1.13 \\
\hline $6 / 23 / 86$ & $6 / 25 / 86$ & 8.793 & 8.795 & -0.002 & 2 & -1.13 \\
\hline $6 / 25 / 86$ & $6 / 28 / 86$ & 8.795 & 8.811 & -0.016 & 3 & -6.02 \\
\hline $6 / 28 / 86$ & $7 / 2 / 86$ & 8.811 & 8.813 & -0.002 & 4 & -0.56 \\
\hline $7 / 2 / 86$ & $7 / 5 / 86$ & 8.813 & 8.816 & -0.003 & 3 & -1.13 \\
\hline $7 / 5 / 86$ & $7 / 8 / 86$ & 8.816 & 8.818 & -0.002 & 3 & -0.75 \\
\hline $7 / 8 / 86$ & $7 / 11 / 86$ & 8.818 & 8.817 & 0.001 & 3 & 0.38 \\
\hline $7 / 11 / 86$ & $7 / 14 / 86$ & 8.817 & 8.819 & -0.002 & 3 & -0.75 \\
\hline $7 / 14 / 86$ & $7 / 17 / 86$ & 8.819 & 8.830 & -0.011 & 3 & -4.14 \\
\hline $7 / 17 / 86$ & $7 / 20 / 86$ & 8.830 & 8.841 & -0.011 & $\cdot 3$ & -4.14 \\
\hline
\end{tabular}

N-26 
FLOW TESTS OF THE GLADYS MCCALL WELL THROUGH OCTOBER 1990

Exhibit N-6, Part 16. CORROSION COUPON DATA FOR THE LONGTERM FLOW TEST - TWO SEPARATORS FROM 7/17/84 THROUGH 10/27/87

Disposal Well Line After Separator

\begin{tabular}{ccccccc} 
Date In & Date Out & $\begin{array}{c}\text { Weight In } \\
\text { (grams) }\end{array}$ & $\begin{array}{c}\text { Weight Out } \\
\text { (grams) }\end{array}$ & $\begin{array}{c}\text { Weight Loss } \\
\text { (grams) }\end{array}$ & $\begin{array}{c}\text { Time In } \\
\text { (Days) }\end{array}$ & $\begin{array}{c}\text { Loss Rate } \\
\text { (mils/yr) }\end{array}$ \\
$7 / 20 / 86$ & $7 / 23 / 86$ & 8.841 & 8.845 & -0.004 & 3 & -1.50 \\
$7 / 23 / 86$ & $7 / 26 / 86$ & 8.845 & 8.844 & 0.001 & 3 & 0.38 \\
$7 / 26 / 86$ & $7 / 30 / 86$ & 8.844 & 8.836 & 0.008 & 4 & 2.26 \\
$7 / 30 / 86$ & $8 / 3 / 86$ & 8.836 & 8.834 & 0.002 & 4 & 0.56 \\
$8 / 3 / 86$ & $8 / 6 / 86$ & 8.834 & 8.835 & -0.001 & 3 & -0.38 \\
$8 / 6 / 86$ & $8 / 15 / 86$ & 8.835 & 8.850 & -0.015 & 9 & -1.88 \\
$8 / 15 / 86$ & $8 / 18 / 86$ & 8.850 & 8.853 & -0.003 & 3 & -1.13 \\
$8 / 18 / 86$ & $8 / 21 / 86$ & 8.853 & 8.852 & 0.001 & 3 & 0.38 \\
$8 / 21 / 86$ & $8 / 24 / 86$ & 8.852 & 8.860 & -0.008 & 3 & -3.01 \\
$8 / 24 / 86$ & $8 / 25 / 86$ & 8.860 & 8.861 & -0.001 & 1 & -1.13 \\
$8 / 25 / 86$ & $9 / 1 / 86$ & 8.861 & 8.860 & 0.001 & 7 & 0.16 \\
$9 / 1 / 86$ & $9 / 4 / 86$ & 8.860 & 8.858 & 0.002 & 3 & 0.75 \\
$9 / 4 / 86$ & $9 / 7 / 86$ & 8.858 & 8.856 & 0.002 & 3 & 0.75 \\
$9 / 7 / 86$ & $9 / 10 / 86$ & 8.856 & 8.871 & -0.015 & 3 & -5.64 \\
$9 / 10 / 86$ & $9 / 13 / 86$ & 8.871 & 8.866 & 0.005 & 3 & 1.88 \\
$9 / 13 / 86$ & $9 / 17 / 86$ & 8.866 & 8.873 & -0.007 & 4 & -1.97 \\
$9 / 17 / 86$ & $9 / 20 / 86$ & 8.873 & 8.882 & -0.009 & 3 & -3.38 \\
$9 / 20 / 86$ & $9 / 23 / 86$ & 8.882 & 8.887 & -0.005 & 3 & -1.88 \\
$9 / 23 / 86$ & $9 / 26 / 86$ & 8.887 & 8.882 & 0.005 & 3 & 1.88 \\
$9 / 26 / 86$ & $9 / 29 / 86$ & 8.882 & 8.880 & 0.002 & 3 & 0.75 \\
$9 / 29 / 86$ & $10 / 2 / 86$ & 8.880 & 8.877 & 0.003 & 3 & 1.13 \\
$10 / 2 / 86$ & $10 / 5 / 86$ & 8.877 & 8.874 & 0.003 & 3 & 1.13 \\
$10 / 5 / 86$ & $10 / 8 / 86$ & 8.874 & 8.900 & -0.026 & 3 & -9.78 \\
$10 / 8 / 86$ & $10 / 11 / 86$ & 8.900 & 8.918 & -0.018 & 3 & -6.77 \\
$10 / 11 / 86$ & $10 / 14 / 86$ & 8.918 & 8.913 & 0.005 & 3 & 1.88 \\
$10 / 14 / 86$ & $10 / 17 / 86$ & 8.913 & 8.915 & -0.002 & 3 & -0.75 \\
$10 / 17 / 86$ & $10 / 20 / 86$ & 8.915 & 8.917 & -0.002 & 3 & -0.75 \\
$10 / 20 / 86$ & $10 / 23 / 86$ & 8.917 & 8.917 & 0.000 & 3 & 0.00 \\
$10 / 23 / 86$ & $10 / 26 / 86$ & 8.917 & 8.933 & -0.016 & 3 & -6.02 \\
$10 / 26 / 86$ & $10 / 29 / 86$ & 8.933 & 8.928 & 0.005 & 3 & 1.88 \\
$10 / 29 / 86$ & $11 / 1 / 86$ & 8.928 & 8.934 & -0.006 & 3 & -2.26 \\
$11 / 1 / 86$ & $11 / 4 / 86$ & 8.934 & 8.940 & -0.006 & 3 & -2.26 \\
$11 / 4 / 86$ & $11 / 7 / 86$ & 8.940 & 8.944 & -0.004 & 3 & -1.50 \\
$11 / 7 / 86$ & $11 / 10 / 86$ & 8.944 & 8.948 & -0.004 & 3 & -1.50 \\
$11 / 10 / 86$ & $11 / 13 / 86$ & 8.948 & 8.951 & -0.003 & 3 & -1.13 \\
$11 / 13 / 86$ & $11 / 16 / 86$ & 8.951 & 8.948 & 0.003 & 3 & 1.13 \\
$11 / 16 / 86$ & $11 / 24 / 86$ & 8.948 & 8.933 & 0.015 & 8 & 2.12 \\
$11 / 24 / 86$ & $11 / 27 / 86$ & 10.238 & 10.210 & 0.028 & 3 & 10.53 \\
& & & & & & \\
\hline
\end{tabular}


Flow tests of the gladys mCCall Well Through OCtober 1990

Exhibit N-6, Part 17. CORROSION COUPON DATA FOR THE LONGTERM FLOW TEST -- TWO SEPARATORS FROM 7/17/84 THROUGH 10/27/87

Disposal Well Line After Separator

\begin{tabular}{|c|c|c|c|c|c|c|}
\hline Date In & Date Out & $\begin{array}{l}\text { Weight In } \\
\text { (grams) }\end{array}$ & $\begin{array}{l}\text { Weight Out } \\
\text { (grams) }\end{array}$ & $\begin{array}{l}\text { Weight Loss } \\
\text { (grams) }\end{array}$ & $\begin{array}{l}\text { Time In } \\
\text { (Days) }\end{array}$ & $\begin{array}{l}\text { Loss Rate } \\
\text { (mils/yr) }\end{array}$ \\
\hline $11 / 27 / 86$ & $11 / 30 / 86$ & 10.210 & 10.200 & 0.010 & 3 & 3.76 \\
\hline $11 / 30 / 86$ & $12 / 3 / 86$ & 10.200 & 10.183 & 0.017 & 3 & 6.39 \\
\hline $12 / 3 / 86$ & $12 / 10 / 86$ & 10.183 & 9.980 & 0.203 & 7 & 32.71 \\
\hline $12 / 10 / 86$ & $12 / 13 / 86$ & 10.388 & 8.322 & 2.066 & 3 & 776.82 \\
\hline $12 / 13 / 86$ & $12 / 17 / 86$ & 10.240 & 8.712 & 1.528 & 4 & 430.90 \\
\hline 12/17/86 & $12 / 20 / 86$ & 8.712 & 3.300 & 5.412 & 3 & 2034.91 \\
\hline $12 / 20 / 86$ & $12 / 23 / 86$ & 10.158 & 7.571 & 2.587 & 3 & 972.71 \\
\hline $12 / 23 / 86$ & $1 / 1 / 87$ & 10.400 & 2.100 & 8.300 & 9 & 1040.27 \\
\hline $1 / 1 / 87$ & $1 / 4 / 87$ & 10.435 & 9.337 & 1.098 & 3 & 412.85 \\
\hline $1 / 4 / 87$ & $1 / 7 / 87$ & 9.337 & 3.853 & 5.484 & 3 & 2061.98 \\
\hline $1 / 7 / 87$ & $1 / 10 / 87$ & 10.355 & 5.240 & 5.115 & 3 & 1923.24 \\
\hline $1 / 10 / 87$ & $1 / 13 / 87$ & 10.266 & 9.787 & 0.479 & 3 & 180.10 \\
\hline $1 / 13 / 87$ & $1 / 22 / 87$ & 9.787 & 8.731 & 1.056 & 9 & 132.35 \\
\hline $1 / 22 / 87$ & $1 / 25 / 87$ & 10.600 & 6.210 & 4.390 & 3 & 1650.64 \\
\hline $1 / 25 / 87$ & $1 / 28 / 87$ & 9.787 & 5.010 & 4.777 & 3 & 1796.15 \\
\hline $1 / 28 / 87$ & $1 / 31 / 87$ & 9.880 & 6.399 & 3.481 & 3 & 1308.86 \\
\hline $1 / 31 / 87$ & $2 / 3 / 87$ & 6.399 & 3.090 & 3.309 & 3 & 1244.18 \\
\hline 2/3/87 & $2 / 6 / 87$ & 10.040 & 9.835 & 0.205 & 3 & 77.08 \\
\hline $2 / 6 / 87$ & $2 / 9 / 87$ & 9.835 & 9.522 & 0.313 & 3 & 117.69 \\
\hline 2/9/87 & $2 / 12 / 87$ & 9.522 & 9.375 & 0.147 & 3 & 55.27 \\
\hline $2 / 12 / 87$ & $2 / 14 / 87$ & 9.375 & 9.245 & 0.130 & 2 & 73.32 \\
\hline $2 / 14 / 87$ & $2 / 16 / 87$ & 10.345 & 8.036 & 2.309 & 2 & 1302.28 \\
\hline $2 / 16 / 87$ & $2 / 19 / 87$ & 9.925 & 9.365 & 0.560 & 3 & 210.56 \\
\hline 2/19/87 & 2/22/87 & 9.365 & 9.018 & 0.347 & 3 & 130.47 \\
\hline $2 / 22 / 87$ & $2 / 25 / 87$ & 9.018 & 8.760 & 0.258 & 3 & 97.01 \\
\hline $2 / 25 / 87$ & $2 / 28 / 87$ & 8.760 & 5.542 & 3.218 & 3 & 1209.97 \\
\hline $2 / 28 / 87$ & $3 / 3 / 87$ & 10.070 & 8.960 & 1.110 & 3 & 417.36 \\
\hline $3 / 3 / 87$ & $3 / 6 / 87$ & 8.960 & 5.972 & 2.988 & 3 & 1123.49 \\
\hline $3 / 6 / 87$ & 3/9/87 & 10.286 & 3.662 & 6.624 & 3 & 2490.62 \\
\hline 3/9/87 & $3 / 12 / 87$ & 10.117 & 7.127 & 2.990 & 3 & 1124.24 \\
\hline $3 / 12 / 87$ & $3 / 14 / 87$ & 9.681 & 5.767 & 3.914 & 2 & 2207.50 \\
\hline $3 / 14 / 87$ & 3/17/87 & 10.000 & 6.271 & 3.729 & 3 & 1402.10 \\
\hline 3/17/87 & $3 / 20 / 87$ & 9.908 & 7.650 & 2.258 & 3 & 849.01 \\
\hline $3 / 20 / 87$ & $3 / 23 / 87$ & 10.320 & 8.650 & 1.670 & 3 & 627.92 \\
\hline $3 / 23 / 87$ & $3 / 26 / 87$ & 8.650 & 8.996 & -0.346 & 3 & -130.10 \\
\hline $3 / 26 / 87$ & $3 / 29 / 87$ & 8.996 & 8.650 & 0.346 & 3 & 130.10 \\
\hline $3 / 29 / 87$ & $4 / 1 / 87$ & 8.650 & 7.517 & 1.133 & 3 & 426.01 \\
\hline $4 / 1 / 87$ & $4 / 4 / 87$ & 7.517 & 6.771 & 0.746 & 3 & 280.50 \\
\hline
\end{tabular}


Flow TESTS OF THE GLADYS MCCALl Well THROUgh OCTOBER 1990

Exhibit N-6, Part 18. CORROSION COUPON DATA FOR THE LONGTERM FLOW TEST - TWO SEPARATORS FROM 7/17/84 THROUGH 10/27/87

Disposal Well Line After Separator

\begin{tabular}{|c|c|c|c|c|c|c|}
\hline Date In & Date Out & $\begin{array}{l}\text { Weight In } \\
\text { (grams) }\end{array}$ & $\begin{array}{l}\text { Weight Out } \\
\text { (grams) }\end{array}$ & $\begin{array}{l}\text { Weight Loss } \\
\text { (grams) }\end{array}$ & $\begin{array}{l}\text { Time In } \\
\text { (Days) }\end{array}$ & $\begin{array}{c}\text { Loss Rate } \\
\text { (mils/yr) }\end{array}$ \\
\hline $4 / 4 / 87$ & $4 / 7 / 87$ & 10.333 & 9.850 & 0.483 & 3 & 181.61 \\
\hline $4 / / / 87$ & $4 / 10 / 87$ & 9.850 & 9.492 & 0.358 & 3 & 134.61 \\
\hline $4 / 10 / 87$ & $4 / 12 / 87$ & 9.492 & 6.883 & 2.609 & 2 & 1471.48 \\
\hline $4 / 12 / 87$ & $4 / 15 / 87$ & 10.250 & 8.786 & 1.464 & 3 & 550.46 \\
\hline $4 / 15 / 87$ & $4 / 18 / 87$ & 9.950 & 8.340 & 1.610 & 3 & 605.36 \\
\hline $4 / 18 / 87$ & $4 / 22 / 87$ & 9.650 & 6.728 & 2.922 & 4 & 824.00 \\
\hline $4 / 22 / 87$ & $4 / 25 / 87$ & 9.236 & 7.933 & 1.303 & 3 & 489.93 \\
\hline $4 / 25 / 87$ & $4 / 28 / 87$ & 7.933 & 7.092 & 0.841 & 3 & 316.22 \\
\hline $4 / 28 / 87$ & $5 / 1 / 87$ & 7.092 & 4.924 & 2.168 & 3 & 815.17 \\
\hline $5 / 1 / 87$ & $5 / 4 / 87$ & 10.191 & 10.002 & 0.189 & 3 & 71.06 \\
\hline $5 / 4 / 87$ & $5 / / 87$ & 10.002 & 9.855 & 0.147 & 3 & 55.27 \\
\hline $5 / 7 / 87$ & $5 / 10 / 87$ & 9.855 & 9.465 & 0.390 & 3 & 146.64 \\
\hline $5 / 10 / 87$ & $5 / 13 / 87$ & 9.465 & 9.200 & 0.265 & 3 & 99.64 \\
\hline $5 / 13 / 87$ & $5 / 16 / 87$ & 9.200 & 7.340 & 1.860 & 3 & 699.36 \\
\hline $5 / 16 / 87$ & $5 / 19 / 87$ & 10.620 & 10.400 & 0.220 & 3 & 82.72 \\
\hline $5 / 19 / 87$ & $5 / 22 / 87$ & 10.400 & 9.375 & 1.025 & 3 & 385.40 \\
\hline $5 / 22 / 87$ & $5 / 25 / 87$ & 9.375 & 9.237 & 0.138 & 3 & 51.89 \\
\hline $5 / 25 / 87$ & $5 / 28 / 87$ & 9.237 & 7.786 & 1.451 & 3 & 545.58 \\
\hline $5 / 28 / 87$ & $5 / 31 / 87$ & 7.786 & 7.690 & 0.096 & 3 & 36.10 \\
\hline $5 / 31 / 87$ & $6 / 4 / 87$ & 7.690 & 7.585 & 0.105 & 4 & 29.61 \\
\hline $6 / 4 / 87$ & $6 / 7 / 87$ & 10.180 & 10.090 & 0.090 & 3 & $33: 84$ \\
\hline $6 / 7 / 87$ & $6 / 10 / 87$ & 10.090 & 8.734 & 1.356 & 3 & 509.86 \\
\hline $6 / 10 / 87$ & $6 / 13 / 87$ & 10.145 & 10.140 & 0.005 & 3 & 1.88 \\
\hline $6 / 13 / 87$ & $6 / 16 / 87$ & 10.140 & 8.620 & 1.520 & 3 & 571.52 \\
\hline $6 / 16 / 87$ & $6 / 19 / 87$ & 8.620 & 4.880 & 3.740 & 3 & 1406.24 \\
\hline $6 / 19 / 87$ & $6 / 22 / 87$ & 8.455 & 6.380 & 2.075 & 3 & 780.20 \\
\hline $6 / 22 / 87$ & $6 / 25 / 87$ & 6.380 & 6.330 & 0.050 & 3 & 18.80 \\
\hline $6 / 25 / 87$ & $6 / 28 / 87$ & 6.330 & 4.074 & 2.256 & 3 & 848.26 \\
\hline $6 / 28 / 87$ & $7 / 1 / 87$ & 9.808 & 9.808 & 0.000 & 3 & 0.00 \\
\hline 7/1/87 & $7 / 4 / 87$ & 9.808 & 9.807 & 0.001 & 3 & 0.38 \\
\hline $7 / 4 / 87$ & $7 / / 87$ & 9.807 & 9.806 & 0.001 & 3 & 0.38 \\
\hline $7 / 7 / 87$ & $7 / 10 / 87$ & 9.806 & 9.804 & 0.002 & 3 & 0.75 \\
\hline $7 / 10 / 87$ & $7 / 13 / 87$ & 9.804 & 9.800 & 0.004 & 3 & 1.50 \\
\hline $7 / 13 / 87$ & $7 / 16 / 87$ & 9.800 & 9.800 & 0.000 & 3 & 0.00 \\
\hline $7 / 16 / 87$ & $7 / 19 / 87$ & 9.800 & 9.810 & -0.010 & 3 & -3.76 \\
\hline $7 / 19 / 87$ & $7 / 22 / 87$ & 9.810 & 9.810 & 0.000 & 3 & 0.00 \\
\hline $7 / 22 / 87$ & $7 / 25 / 87$ & 9.810 & 9.810 & 0.000 & 3 & 0.00 \\
\hline $7 / 25 / 87$ & $7 / 28 / 87$ & 9.810 & 9.810 & 0.000 & 3 & 0.00 \\
\hline
\end{tabular}


FLOW TESTS OF THE GLADYS MCCALL Well THROUgh OCTOBER 1990

Exhibit N-6, Part 19. CORROSION COUPON DATA FOR THE LONGTERM FLOW TEST -- TWO SEPARATORS FROM 7/17/84 THROUGH 10/27/87

Disposal Well Line After Separator

$\begin{array}{ccccccc}\text { Date In } & \text { Date Out } & \begin{array}{c}\text { Weight In } \\ \text { (grams) }\end{array} & \begin{array}{c}\text { Weight Out } \\ \text { (grams) }\end{array} & \begin{array}{c}\text { Weight Loss } \\ \text { (grams) }\end{array} & \begin{array}{c}\text { Time In } \\ \text { (Days) }\end{array} & \begin{array}{c}\text { Loss Rate } \\ \text { (mils/yr) }\end{array} \\ 7 / 28 / 87 & 7 / 31 / 87 & 9.810 & 9.807 & 0.003 & 3 & 1.13 \\ 7 / 31 / 87 & 8 / 3 / 87 & 9.790 & 9.783 & 0.007 & 3 & 2.63 \\ 8 / 3 / 87 & 8 / 6 / 87 & 9.783 & 9.763 & 0.020 & 3 & 7.52 \\ 8 / 6 / 87 & 8 / 9 / 87 & 9.763 & 9.757 & 0.006 & 3 & 2.26 \\ 8 / 9 / 87 & 8 / 12 / 87 & 9.757 & 9.755 & 0.002 & 3 & 0.75 \\ 8 / 12 / 87 & 8 / 15 / 87 & 9.755 & 9.721 & 0.034 & 3 & 12.78 \\ 8 / 15 / 87 & 8 / 18 / 87 & 9.721 & 9.660 & 0.061 & 3 & 22.94 \\ 8 / 18 / 87 & 8 / 21 / 87 & 9.660 & 9.650 & 0.010 & 3 & 3.76 \\ 8 / 21 / 87 & 8 / 24 / 87 & 9.650 & 9.640 & 0.010 & 3 & 3.76 \\ 8 / 24 / 87 & 8 / 27 / 87 & 9.640 & 9.576 & 0.064 & 3 & 24.06 \\ 8 / 27 / 87 & 9 / 2 / 87 & 9.576 & 9.460 & 0.116 & 6 & 21.81 \\ 9 / 2 / 87 & 9 / 5 / 87 & 9.460 & 9.400 & 0.060 & 3 & 22.56 \\ 9 / 5 / 87 & 9 / 8 / 87 & 9.400 & 9.340 & 0.060 & 3 & 22.56 \\ 9 / 8 / 87 & 9 / 11 / 87 & 9.340 & 9.180 & 0.160 & 3 & 60.16 \\ 9 / 11 / 87 & 9 / 14 / 87 & 7.221 & 7.102 & 0.119 & 3 & 44.74 \\ 9 / 14 / 87 & 9 / 17 / 87 & 7.102 & 6.919 & 0.183 & 3 & 68.81 \\ 9 / 17 / 87 & 9 / 20 / 87 & 6.919 & 6.802 & 0.117 & 3 & 43.99 \\ 9 / 20 / 87 & 9 / 23 / 87 & 6.802 & 6.836 & -0.034 & 3 & -12.78 \\ 9 / 23 / 87 & 9 / 27 / 87 & 6.836 & 6.668 & 0.168 & 4 & 47.38 \\ 9 / 27 / 87 & 9 / 30 / 87 & 6.668 & 6.666 & 0.002 & 3 & 0.75 \\ 9 / 30 / 87 & 10 / 8 / 87 & 6.660 & 4.208 & 2.452 & 8 & 345.73 \\ 10 / 8 / 87 & 10 / 11 / 87 & 10.359 & 8.498 & 1.861 & 3 & 699.74 \\ 10 / 11 / 87 & 10 / 14 / 87 & 8.498 & 8.110 & 0.388 & 3 & 145.89 \\ 10 / 14 / 87 & 10 / 17 / 87 & 8.110 & 6.055 & 2.055 & 3 & 772.68 \\ 10 / 17 / 87 & 10 / 20 / 87 & 10.582 & 10.410 & 0.172 & 3 & 64.67 \\ 10 / 20 / 87 & 10 / 23 / 87 & 10.410 & 10.370 & 0.040 & 3 & 15.04 \\ 10 / 23 / 87 & 10 / 26 / 87 & 10.370 & 10.000 & 0.370 & 4 & 104.34\end{array}$

